\title{
HEAd 15
}

$1^{\text {st International Conference }}$ on Higher Education Advances

\section{June 24-26, 2015 Valencia, Spain}

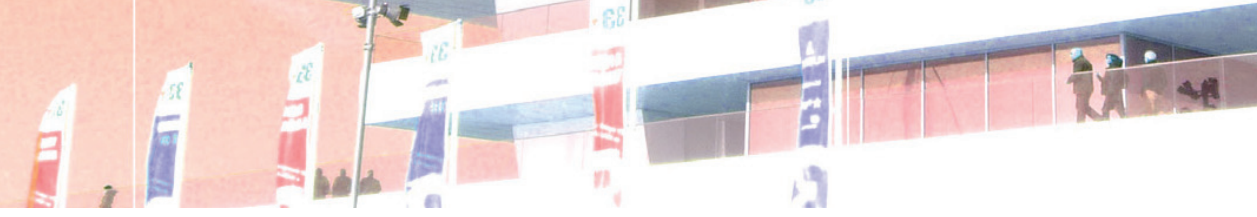




\section{Colección Congresos UPV}

Los contenidos de esta publicación han sido evaluados por el Comité Científico que en ella se relaciona y según el procedimiento que se recoge en http://www.headconf.org/

\section{Editores}

Elena de la Poza

Josep Domènech

Jaime Lloret

M. Cinta Vincent Vela

Elena Zuriaga Agustí

\section{Editado por}

Editorial Universitat Politècnica de València, 2015

www.lalibreria.upv.es / Ref.: 2106_04_01_01

ISBN: 978-84-9048-340-4

DOI: http://dx.doi.org/10.4995/HEAD15.2015.1522

\section{(c)}

HEAd'15. Conference on Higher Education Advances.

Se distribuye bajo una Licencia Creative Commons Atribución-NoComercial-NoDerivada 4.0 Internacional. Basada en una obra en http://ocs.editorial.upv.es/index.php/HEAD/HEAD15 


\section{Preface}

This volume contains the proceedings of the First International Conference on Higher Education Advances (HEAd'15), which was held in Valencia, Spain during 24-26 June 2015. HEAd aims to become a forum for researchers and practitioners to exchange ideas, experiences, opinions and research results relating to the preparation of students and the organization of educational systems. The conference was hosted by the Faculty of Business Administration and Management of the Universitat Politècncia de València.

The conference featured three invited speakers who overviewed important and actual topics: John Kalu Osiri (Washington State University) delivered the presentation on the indispensable role of educators in shaping a nation, Ana Muñoz-Miquel (Universitat Jaume I) on how to bridge the gap between professional practice and university education, and José V. Benlloch-Dualde (Universitat Politècnica de València) on effective ways to enhance collaboration in the classroom.

Following the call for papers, HEAd'15 received 165 submissions with authors representing 41 different countries. Papers went through a rigorous review process. Each paper was reviewed by at least two program committee members. Finally, 50 submissions were selected as full papers (representing an acceptance rate of 30\%) and 22 submissions were selected as short papers. Additionally, 20 papers were selected to be presented as posters.

I would like to thank all the people and institutions who contributed to the success of the HEAd'15 conference: the authors, the members of the program committee as well as the additional reviewers, the invited speakers, the members of the organizing committee, and the sponsors. I am also grateful to the Faculty of Business Administration and Management and the Universitat Politècnica de València for supporting this conference 


\section{Organizing Committee}

\section{General chair}

Josep Domènech, Universitat Politècnica de València, Spain

Program chair

Jaime Lloret, Universitat Politècnica de València, Spain

Workshops chair

Habib M. Ammari, University of Michigan-Dearborn, USA

Sponsorship \& Exhibits chair

Milos Stojmenovic, Singidunum University, Serbia

\section{Publication chairs}

M. Cinta Vincent Vela, Universitat Politècnica de València, Spain

Elena Zuriaga Agustí, Universitat Politècnica de València, Spain

\section{Arrangements chair}

Elena de la Poza, Universitat Politècnica de València, Spain

\section{Publicity co-chairs}

Sandra Sendra, Universitat Politècnica de València, Spain

Kayhan Zrar Ghafoor, University of Koya, Iraq

\section{Industry chair}

Francisco Javier Sanchez Bolumar, Centro de Formación Tecnológica de ADIF, Spain

\section{Sponsors \& Supporters}

Universitat Politècnica de València

Facultad de Administración y Dirección de Empresas

Departamento de Eocnomía y Ciencias Sociales

Nievina

Renfe

Iberia

IGIC

Univerzitet Singidunum

Campus ADIF-FFE 


\section{Local organization}

Silvia Álvarez Blanco

Desamparados Blazquez

Vicent Caballer Tarazona

Kapil M. Ingole

Jose Miguel Jimenez Herranz

Jose Antonio Mendoza Roca

Olga Moreno-Pérez

Lorena Parra

\section{Program committee}

Javier Aguiar, University of Valladolid, Spain

Patrícia Albergaria-Almeida, University of Aveiro, Portugal

Peter Albion, University Of Southern Queensland, Australia

Jose Alcaraz-Calero, University of the West of Scotland, UK

Gabriella Aleandri, University of Macerata, Italy

Karmela Aleksic-Maslac, Zagreb School of Economics and Management, Croatia

Francisco Alvarez, Universidad Autonoma de Aguascalientes, Mexico

Asier Aranzabal, University of the Basque Country, Spain

Ketil Arnesen, Sør-Trøndelag University College, Norway

Roni Aviram, Ben-Gurion University, Israel

Vicki L. Baker, Albion College, USA

Matt Bamber, Bristol University, UK

Virginia Barba Sanchez, University of Castilla-La Mancha, Spain

Danuse Bauerova, VSB - Technical University, Ostrava, Czech Republic

Victoria Beck, University of Wisconsin Oshkosh, USA

Kim Blackmore, Australian National University, Australia

Ignacio Bosch Roig, Universitat Politècnica de València, Spain

Mark Bullen, University of British Columbia, Canada

Marina Buzzi, IIT-CNR, Italy

Chris Campbell, University Of Queensland, Australia

Giovanna Carloni, Università degli Studi di Urbino “Carlo Bo”, Italy

Gail Casey, Deakin University, Australia

Roberto Cervelló-Royo, Universitat Politècnica de València, Spain 
Roberto Cippitani, Università degli Studi di Perugia, Italy

Linda Corrin, University Of Melbourne, Australia

Clara Coutinho, Minho University, Portugal

John Cowan, Edinburgh Napier University, UK

Barney Dalgarno, Charles Sturt University, Australia

Giuliana Dettori, Istituto per le Tecnologie Didattiche, Italy

Eimear Dolan, Robert Gordon University, UK

Marilyn Dono-Koulouris, St. John’s University, USA

Jacqueline Douglas, Liverpool John Moores University, UK

Jure Erjavec, University of Ljubjana, Slovenia

Mostafa Ezziyyani, Abdelmalek Essaadi University, Morocco

Paula Figas, University of Applied Sciences Kempten, Germany

Silvia Florea, Lucian Blaga University of Sibiu, Romania

Mark E. Frydenberg, Bentley University, USA

Pedro Fuentes Durá, Universitat Politècnica de València, Spain

Chin Lay Gan, Multimedia Univeristy, Malaysia

Miguel García Pineda, Universitat de València, Spain

$M^{\text {a }}$ de Fátima Goulão, Universidade Aberta, Portugal

Gabriela Grosseck, West University of Timisoara, Romania

Wolfgang A. Halang, FernUniversität in Hagen, Germany

John Hannon, La Trobe University, Australia

Christopher Hill, University of Nottingham Malaysia Campus, Malaysia

Peter Hockicko, University of Zilina, Slovakia

Šárka Hubáčková, University of Hradec Králové, Czech Republic

Srećko Joksimović, Simon Fraser University, Canada

Min Jou, National Taiwan Normal University, Taiwan

Markku Karhu, Helsinki Metropolia University of Applied Sciences, Finland

Blanka Klímová, Univerzita Hradec Králové, Czech Republic

Hasso Kukemelk, University of Tartu, Estonia

Ida Kukliansky, Ruppin Academic Center, Israel

Aleksandra Kulpa-Puczyńska, Cardinal Stefan Wyszyński University in Warsaw, Poland

A. V. Senthil Kumar, Hindusthan College of Arts and Science, India

Katarzyna Anna Kuzmicz, Bialystok University of Technology, Poland

Raquel Lacuesta, Universidad San Jorge, Spain 
Natalia Lajara Camilleri, Universitat Politècnica de València, Spain

Sawsen Lakhal, Sherbrooke University, Canada

Maciej Laskowski, Lublin University of Technology, Poland

Ho Keat Leng, National Institute of Education, Singapur

Carlos Lerma Elvira, Universitat Politècnica de València, Spain

Maria Limniou, University of Liverpool, UK

Pascal Lorenz, University of Haute Alsace, France

Elsa M. Macías López, University of Las Palmas de Gran Canaria, Spain

Brenda Mallinson, Rhodes University, Republic of South Africa

Yuxin Mao, Zhejiang Gongshang University, China

Laura Marquez, Universitat Jaume I, Spain

Maria Luisa Martí Selva, Universitat Politècnica de València, Spain

J. Reinaldo Martínez-Fernández, Universitat Autònoma de Barcelona, Spain

Víctor Martínez-Gómez, Universitat Politècnica de València, Spain

Alicia Mas Tur, Universitat de València, Spain

Anne Matthew, Queensland University of Technology, Australia

Óscar Mealha, University of Aveiro, Portugal

David Menendez Alvarez Hevia, Manchester Metropolitan University, UK

Antonio Moreira Teixeira, Universidade Aberta, Portugal

Ana Muñoz-Miquel, Universitat Jaume I, Spain

Mihaela Muresan, Dimitrie Cantemir Christian University, Romania

Fabio Nascimbeni, MENON Network, Belgium

Fezile Özdaml, Near East University, Cyprus

Gonzalo Pajares, Universidad de Castilla la Mancha, Spain

Desislava Paneva-Marinova, Bulgarian Academy of Sciences, Bulgaria

Belinda Pastrana, Instituto Tecnológico de Minatitlán, Mexico

Elena Paunova, Bulgarian Academy of Sciences, Bulgary

María L. Pertegal Felices, University of Alicante, Spain

Soner Polat, Kocaeli University, Turkey

Julie Prescott, University of Bolton, UK

Robert Pucher, Fachhochschule Technikum Wien, Austria

Ali Rahimi, Bangkok University, Thailand

Patient Rambe, Central University of Technology, Republic of South Africa

Timothy Read, UNED, Spain

Miroslav Rebernik, University of Maribor, Slovenia 
Norat Roig, Universidad Europea de Valencia, Spain

Esther Sanabria Codesal, Universitat Politècnica de València, Spain

Sebastian Scherr, LMU Munich, Germany

Elies Seguí-Mas, Universitat Politècnica de València, Spain

Sandra Sendra Compte, Universitat Politècnica de València, Spain

Li-Jen Yu Shannon, Sam Houston State University, USA

Lei Shu, Osaka University, Japan

Niwat Srisawasdi, Khon Kaen University, Thailand

Álvaro Suárez Sarmiento, University of Las Palmas de Gran Canaria, Spain

Paul Sudnik, Munich University of Applied Sciences, Germany

Sabu M. Tahmpi, IIITM-K, India

Cesar Eduardo Velázquez Amador, Universidad Autónoma de Aguascalientes, Mexico

Philips Wang, Caritas Insitute of Higher Education, Hong Kong

Georgios K. Zarifis, Aristotle University of Thessaloniki, Greece

Jiabin Zhu, Shanghai Jiao Tong University, China

Imran A. Zualkernan, American University of Sharjah, UAE

\section{External reviewers}

Raman Kumar Agrawalla

José Roberto Sanz Ponce

Lucía Aguirre

Natalia Alexandrovna Serdyukova

Galina Georgievna Artyushina

Zachary Simpson

Jessica Badillo Guzmán

Snejina Sonina

Jennifer Anne Banks

Iman Tohidian

Nadia Charalambous

Cristina Vilaplana-Prieto

Naina Garg

Daniel J Wong

Tom Gedeon

Mohammad H Yarmohammadian

Ana Hirsch Adler

Dorin Isoc

Robin J. Jacobs

Insu Kim

Ignacio Laiton

María Teresa Lozano Albalate

Daniel Moise

Cecilia Salomé Navia Antezana

Antonio Pinto 


\section{SESSIONS}

$\checkmark$ Session 1a. Assessment

$\checkmark$ Session 1b. Competences

$\checkmark$ Session 1c. Innovative Teaching Methods (I)

$\checkmark$ Session 2a. Emerging technology practices

$\checkmark$ Session 2b. Linguistics

$\checkmark$ Session 2c. Media

$\checkmark$ Session 3a. Economics

$\checkmark$ Session 3b. Engineering

$\checkmark$ Session 3c. Ethics and Culture

$\checkmark$ Session 4a. Health

$\checkmark$ Session 4b. Problem-based Learning

$\checkmark$ Session 4c. Innovative Teaching Methods (II)

$\checkmark$ Session 5a. Entrepreneurship

$\checkmark$ Session 5b. Teacher Education

$\checkmark$ Session 5c. Misc

$\checkmark$ Session 6a. Scientific and Research Education

$\checkmark$ Session 6b. Mobile Learning

$\checkmark$ Session 6c. Planning and Organization

$\checkmark$ Session 7a. Computer-based Learning

$\checkmark$ Session 7b. Internships

$\checkmark$ Session 7c. Teaching and Learning Experiences

$\checkmark$ Posters 
HEAd'15

SeSSION 1A

ASSESSMENT 


\title{
Assessment of oral and written communication competences in the European Higher Education Area: a proposal of evaluation methodologies
}

\author{
A. Sonseca, O. Sahuquillo, J. Martínez-Casas, J. Carballeira, F. D. Denia, J. J. Ródenas
}

Departamento de Ingeniería Mecánica y de Materiales, Universitat Politècnica de València (UPV), Camino de Vera s/n, 46022 Valencia (Spain)

\begin{abstract}
The international accreditation for the Master and Bachelor degrees offered at our university, together with the demands of the employers, have made it clear that the students' curricula should specify not only what they have studied, but also what they are actually able to do. Although the competence based curricula approach has been used in the development of the new programmes for the Master and Bachelor degrees within the European Higher Education Area in recent years, the assessment of these competences is still a pending task. This work presents an 'outcomes' approach for the assessment of the oral and written communication skills within subjects related to mechanical and materials engineering. In particular, this paper proposes some rubrics developed in order to quantify the level of achievement. These rubrics are based on the evaluation of some learning outcomes that can be observed by using different strategies during the course. Conclusions about preliminary results and the difficulties found in order to create these tools are also described here.
\end{abstract}

Keywords: competence assessment; learning outcomes; oral and written competence; rubrics

\section{Introduction}

The Bachelor and Master degree programmes developed at our university within the frame of the European Higher Education Area follow a competence based approach (A. Sursock, 2010; Murias, de Miguel, \& Rodríguez, 2007; Rieckmann, 2012). These programmes clearly define the specific and generic competences to be worked in each degree, and also, the particular subjects along the degree. The assessment of the specific competences continues to be reflected on the students' curricula by using numerical qualifications, but the assessment of the generic competences has been passed over somehow. It has been understood that the students would have acquired these capacities and skills at the end of the studies. The international accreditation of these programmes, together with the requirements of the employers to have better information on the students' competences, have put the university to work on this issue (Andrews \& Higson, 2008; Entwistle \& Peterson, 2004).

This paper presents some results obtained in the frame of an innovative project (PIME program) on the evaluation of three generic competences that have been traditionally worked within subjects of mechanical and materials engineering: capacity for problem analysis; capacity for applying knowledge in practice; and communication skills, using name convention from Tuning (2014) (http://www.unideusto.org/tuningeu/). In particular, in this work some methodologies for the analysis of the skills in oral and written communication have been developed (Sparks, Song, Brantley, \& Liu, 2014; Dunbar, Brooks, \& Kibicka-Miller, 2006). The aim is to obtain reliable information in order to evaluate strengths and weaknesses of the students in the communication competences (Jonsson \& Svingby, 2007). Furthermore, these methodologies of evaluation try to encourage students to participate and to be focused during lessons, as they will have to explain the key information in public to their classmates, in case of oral competence, and to develop a technical report dealing with the solution of a problem, in case of the written competence. 
Some quantitative results are presented using data collected from two subjects: lab works on Materials Science, from the Bachelor degree in Chemistry Engineering, and Mechanical Vibrations, from the Master degree in Aeronautical Engineering, both offered at the Technical University of Valencia (UPV).

In the case of the oral competence, students were divided into work groups of 4-5 people for the Bachelor degree, while for the Master degree they worked individually. Students had to work during the time between lessons (1-2 weeks) to maximize their selflearning, so that they could expose the lesson in the best way to their classmates. Students were expected to interact, sharing concepts and strategies assuming responsibility for their self-learning and that of the other members of the class that were evaluating their work. It sought not only to develop public communication skills but also, to improve autonomous learning skills, critical thinking, synthesis capacity and responsibility to search for, analyse and verify main information to explain it to their mates. In the case of the written competence, students worked individually. Students were proposed to develop a pair of open case studies related to a specific subject. They were expected to be involved in a real problem in which, with all the acquired knowledge during the lessons, they had to decide a strategy, a method to apply, and to take decisions to solve the problem by explaining the plan and steps followed to achieve the solution. The method tries not only to develop the written communication skills, also to offer the students an active learning method as a challenge and an opportunity to deal with a real problem, that is, they have to plan hypotheses and make diagnosis of the chosen situation to find the best solution using their individual knowledge.

\section{Methods}

For the evaluation of the oral communication skills, students were asked to prepare oral presentations ranging from 10 to 15 minutes to explain some topics taught in the previous lesson to the class. The oral presentation was individual, but for the Bachelor students the work was team-based developed (4-5 people). To ensure that each member participates in a significant manner, at the beginning of each lesson the teacher would randomly choose a student to make the oral presentation of the group. The rest of the students and two teachers evaluated the presentation using the rubric below (Table 1; Rubric 1). The students' presentations were evaluated considering eleven different items. The first four items were mainly related to the organization, structure and content of the whole presentation, that is, they correspond to the same dimension (content). The fifth item concerned the effectiveness into the interpretation and justification of the information presented and the sixth item evaluated how clearly the student structured and communicated the topic to the audience. The seventh item evaluated the technical language usage, and the eighth item was related to the use of additional resources (board, objects, examples...) that can ensure better effectiveness on delivery the information to the audience. The ninth and the tenth items were related to the temporal planning, and to how well the speaker explained to the audience in terms of diction, corporal position, tone of voice and visual contact, respectively. Finally, to evaluate the analytical capacity, the audience (teachers or students) made questions to value the eleventh item.

Written communication skills were only evaluated for Master students. They had to formulate and solve two different problems explaining all the solution process in a written report to demonstrate and apply the acquired knowledge during the lessons. 
Rubric 2 (Table 2) was developed to be applied on the students' reports with a view to evaluating the level of achievement on the written communication competence.

Similarly to the oral communication evaluation, the students' written reports were evaluated also along ten different items. The first four items were about the content (introduction, objectives, results and conclusions). The fifth item dealt with the structure and formal coherence of the information, while the sixth item evaluated the quality in terms of style and format of the report. The seventh item was related to the presence of grammar and orthography mistakes, and the eighth item valued the appropriated use of technical language. The ninth and the tenth items evaluated the achievement of a professional and high quality report through the argumentation and justification of the information presented, as well as through the use of graphical resources to emphasize the most relevant results.

For both oral and written skills evaluation, each of the items was assigned a scale ranging from 0 to 5 , representing an increasing level of development. As described before, first to fourth items corresponded to the same dimension, while for the rest, fifth to eleventh (tenth in case of written skills), one item corresponded to one dimension. It means that, for oral communication, there were eleven items to quantify and eight different dimensions of the competence, while for written communication there were ten items to quantify and seven dimensions. The overall score was assigned by simply adding the marks corresponding to all the items. Finally, to evaluate the level of achievement of the competences, an assessment scale was developed. The total value range obtained from the rubrics ( 0 to 55 points for oral communication and 0 to 50 points for written communication) were split up into six different ranges (Table 3) from low to master level. These scales allowed to obtain comparable values of the overall communication competence. Ranges were delimited as logical as it was possible, taking into account that most of the students would have to achieve a medium level in the development of the evaluated competence. That is, lower and higher levels value ranges were shorter than medium. Applying the same logic, higher levels of achievement were the most difficult to reach, and so they had the shortest range.

This evaluation methodology (rubric based), helped the authors not only to evaluate the oral, written and the whole communication skills of the students, but also to know to what extent the lessons had been understood (critical thinking), providing a valuable feedback about students' knowledge. 
Table 1. Rubric 1; Oral communication skills

\begin{tabular}{|c|c|c|c|c|c|c|c|}
\hline & Item & $\begin{array}{l}\text { 0-Does not } \\
\text { archieve }\end{array}$ & 1-Deficient & 2-Regular & 3-Good & 4-Verygood & 5-Excelent \\
\hline 1 & Effective introduction & Not introduced & $\begin{array}{l}\text { Introduced but } \\
\text { mostly incomplete }\end{array}$ & $\begin{array}{l}\text { Introduced but } \\
\text { undeveloped and } \\
\text { incomplete }\end{array}$ & Introduced to the audience & $\begin{array}{l}\text { Clearly introduced and } \\
\text { audience put in } \\
\text { situation }\end{array}$ & $\begin{array}{l}\text { Clearly introduced and } \\
\text { audience put in situation } \\
\text { plus interesting examples }\end{array}$ \\
\hline 2 & Main objectives and ideas & $\begin{array}{l}\text { Objectives not } \\
\text { presented }\end{array}$ & Very few objectives & $\begin{array}{l}\text { Most of the } \\
\text { objectives still } \\
\text { undeveloped and } \\
\text { incomplete }\end{array}$ & All the objectives & $\begin{array}{l}\text { All the objectives } \\
\text { organized and concise }\end{array}$ & $\begin{array}{l}\text { All the objectives organized } \\
\text { and concise with student } \\
\text { own perspective }\end{array}$ \\
\hline 3 & $\begin{array}{l}\text { The student presents and } \\
\text { properly argue the results }\end{array}$ & $\begin{array}{l}\text { Results not } \\
\text { presented }\end{array}$ & Very few results & $\begin{array}{l}\text { Most of the results } \\
\text { still undeveloped } \\
\text { and incomplete }\end{array}$ & All results & Main results & $\begin{array}{l}\text { Main results and well } \\
\text { discussed }\end{array}$ \\
\hline 4 & $\begin{array}{l}\text { Conclusions appropriated } \\
\text { and concise }\end{array}$ & $\begin{array}{l}\text { Conclusions not } \\
\text { presented }\end{array}$ & Very few conclusions & $\begin{array}{l}\text { Most of the } \\
\text { conclusions still } \\
\text { undeveloped and } \\
\text { incomplete }\end{array}$ & All conclusions & $\begin{array}{l}\text { Main conclusions } \\
\text { organized and concise }\end{array}$ & $\begin{array}{l}\text { Main conclusions organized } \\
\text { and concise and the } \\
\text { student evaluates them }\end{array}$ \\
\hline 5 & $\begin{array}{l}\text { Discuss and justifies the } \\
\text { information presented }\end{array}$ & Not done & $\begin{array}{l}\text { Done with lots of } \\
\text { mistakes }\end{array}$ & $\begin{array}{l}\text { Done with some } \\
\text { mistakes }\end{array}$ & Well done but incomplete & Well done & $\begin{array}{l}\text { Well done emphasizing the } \\
\text { relevant aspects }\end{array}$ \\
\hline 6 & $\begin{array}{l}\text { Structured, clear, } \\
\text { effective and consistent }\end{array}$ & Not done & Partly structured & Structured & At least structured and clear & $\begin{array}{l}\text { Structured, clear and } \\
\text { consistent }\end{array}$ & $\begin{array}{l}\text { Structured, clear, } \\
\text { consistent and effective }\end{array}$ \\
\hline 7 & $\begin{array}{l}\text { Appropriate technical } \\
\text { language }\end{array}$ & Not done & With lots of mistakes & $\begin{array}{l}\text { With some } \\
\text { mistakes }\end{array}$ & Occasionally and correctly & $\begin{array}{l}\text { Frequently and } \\
\text { correctly }\end{array}$ & $\begin{array}{l}\text { Frequently, correctly and } \\
\text { introduce new concepts }\end{array}$ \\
\hline 8 & $\begin{array}{l}\text { Available resources for a } \\
\text { more efficient } \\
\text { communication }\end{array}$ & Not done & $\begin{array}{l}\text { Used but when not } \\
\text { really necessary }\end{array}$ & Used to clarify ideas & Clarify some main ideas & $\begin{array}{l}\text { Frequently clarify main } \\
\text { ideas }\end{array}$ & $\begin{array}{l}\text { Frequently clarify main } \\
\text { ideas and use new } \\
\text { resources }\end{array}$ \\
\hline 9 & Adjust to time available & $\begin{array}{l}\text { No timing } \\
\text { control }\end{array}$ & Too long or too short & $\begin{array}{l}\text { Approximately time } \\
\text { available }\end{array}$ & Adjusts into time available & $\begin{array}{l}\text { Adjusts into time } \\
\text { available } \\
\text { and spends proper time } \\
\text { in each part }\end{array}$ & $\begin{array}{l}\text { Adjusts into time available } \\
\text { and spends proper time in } \\
\text { each part and redistribute } \\
\text { time if needed. }\end{array}$ \\
\hline 10 & $\begin{array}{l}\text { Clear voice, right tone, } \\
\text { proper corporal posture } \\
\text { and eye contact with the } \\
\text { audience }\end{array}$ & None & $\begin{array}{l}\text { At least makes one } \\
\text { correctly }\end{array}$ & $\begin{array}{l}\text { Voice clear but tone } \\
\text { boring }\end{array}$ & $\begin{array}{l}\text { Voice clear and right } \\
\text { corporal posture }\end{array}$ & $\begin{array}{l}\text { Voice clear, right tone } \\
\text { and corporal posture }\end{array}$ & $\begin{array}{l}\text { Voice clear, right tone and } \\
\text { corporal posture and eye } \\
\text { contact with audience }\end{array}$ \\
\hline 11 & $\begin{array}{l}\text { Analyse, evaluate and } \\
\text { answer the audience } \\
\text { questions }\end{array}$ & None & $\begin{array}{l}\text { Analyse but not to } \\
\text { evaluate or answer } \\
\text { questions }\end{array}$ & $\begin{array}{l}\text { Analyse and } \\
\text { evaluate but not to } \\
\text { answer questions }\end{array}$ & $\begin{array}{l}\text { Analyse and evaluate but } \\
\text { not to answer questions } \\
\text { with the help of the teacher }\end{array}$ & $\begin{array}{l}\text { Analyse and evaluate } \\
\text { answering questions } \\
\text { with own perspective }\end{array}$ & $\begin{array}{l}\text { Analyse and evaluate } \\
\text { answering questions } \\
\text { Proposing questions and } \\
\text { creating debate }\end{array}$ \\
\hline
\end{tabular}

Table 2. Rubric 2; Written communication skills

\begin{tabular}{|c|c|c|c|c|c|c|c|}
\hline & Item & $\begin{array}{l}\text { 0-Does not } \\
\text { archieve }\end{array}$ & 1-Deficient & 2-Regular & 3-Good & 4-Verygood & 5-Excelent \\
\hline 1 & Effective introduction & Not introduced & $\begin{array}{l}\text { Introduced but } \\
\text { mostly incomplete }\end{array}$ & $\begin{array}{l}\text { Introduced but } \\
\text { undeveloped and } \\
\text { incomplete }\end{array}$ & $\begin{array}{l}\text { Introduced to the } \\
\text { audience }\end{array}$ & $\begin{array}{l}\text { Clearly introduced } \\
\text { and audience put in } \\
\text { situation }\end{array}$ & $\begin{array}{l}\text { Clearly introduced and audience } \\
\text { put in situation } \\
\text { plus interesting examples }\end{array}$ \\
\hline 2 & $\begin{array}{l}\text { Main objectives and } \\
\text { ideas }\end{array}$ & $\begin{array}{l}\text { Objectives not } \\
\text { presented }\end{array}$ & Very few objectives & $\begin{array}{l}\text { Most of the } \\
\text { objectives still } \\
\text { undeveloped and } \\
\text { incomplete }\end{array}$ & All the objectives & $\begin{array}{l}\text { All the objectives } \\
\text { organized and concise }\end{array}$ & $\begin{array}{l}\text { All the objectives organized, } \\
\text { concise and student relates } \\
\text { them with real situations }\end{array}$ \\
\hline 3 & $\begin{array}{l}\text { Student presents results } \\
\text { and well founded }\end{array}$ & $\begin{array}{l}\text { Results not } \\
\text { presented }\end{array}$ & Very few results & $\begin{array}{l}\text { Most of the results } \\
\text { still undeveloped } \\
\text { and incomplete }\end{array}$ & All the results & Most relevant results & $\begin{array}{l}\text { Most relevant results } \\
\text { well founded }\end{array}$ \\
\hline 4 & $\begin{array}{l}\text { Conclusions appropriated } \\
\text { and concise }\end{array}$ & $\begin{array}{l}\text { Conclusions not } \\
\text { presented }\end{array}$ & Very few conclusions & $\begin{array}{l}\text { Most of the } \\
\text { conclusions still } \\
\text { undeveloped and } \\
\text { incomplete }\end{array}$ & All conclusions & $\begin{array}{l}\text { Main conclusions } \\
\text { organized and concise }\end{array}$ & $\begin{array}{l}\text { Main conclusions organized and } \\
\text { concise and evaluates their } \\
\text { consequences }\end{array}$ \\
\hline 5 & $\begin{array}{l}\text { Report clear structured } \\
\text { and coherent }\end{array}$ & Not structured & $\begin{array}{l}\text { Report's structure } \\
\text { have lack of } \\
\text { coherence }\end{array}$ & $\begin{array}{l}\text { Report structure } \\
\text { partially } \\
\text { inconsistent }\end{array}$ & Structure coherent & $\begin{array}{l}\text { Structure coherent } \\
\text { and all sections } \\
\text { related and connected }\end{array}$ & $\begin{array}{l}\text { Structure coherent and sections } \\
\text { related, connected and } \\
\text { information order is grounded in } \\
\text { communication efficiency }\end{array}$ \\
\hline 6 & Formal style and format & $\begin{array}{l}\text { Not formal } \\
\text { manner }\end{array}$ & $\begin{array}{l}\text { Illogical style and } \\
\text { format }\end{array}$ & $\begin{array}{l}\text { Logical style } \text { and } \\
\text { format but still } \\
\text { weak }\end{array}$ & $\begin{array}{l}\text { Correct format and } \\
\text { style }\end{array}$ & $\begin{array}{l}\text { Advanced format and } \\
\text { style }\end{array}$ & Formal format and style \\
\hline 7 & Grammar (orthography) & $\begin{array}{l}\text { Completely lack } \\
\text { of grammar / } \\
\text { orthography }\end{array}$ & $\begin{array}{l}\text { High content in } \\
\text { grammar/ } \\
\text { orthography mistakes }\end{array}$ & $\begin{array}{l}\text { Some grammar / } \\
\text { orthography } \\
\text { mistakes }\end{array}$ & $\begin{array}{l}\text { Writing without } \\
\text { grammar / orthography } \\
\text { mistakes }\end{array}$ & $\begin{array}{l}\text { Correct and technical } \\
\text { use of grammar / } \\
\text { orthography }\end{array}$ & $\begin{array}{l}\text { Correct and technical use of } \\
\text { grammar / orthography with } \\
\text { high content in synonyms }\end{array}$ \\
\hline 8 & $\begin{array}{l}\text { Appropriate technical } \\
\text { language }\end{array}$ & Not done & With lots of mistakes & $\begin{array}{l}\text { With some } \\
\text { mistakes }\end{array}$ & Occasionally done & $\begin{array}{l}\text { Frequently and } \\
\text { correctly }\end{array}$ & $\begin{array}{l}\text { Frequently, correctly and } \\
\text { introduce new concepts }\end{array}$ \\
\hline 9 & $\begin{array}{l}\text { Discuss and justifies the } \\
\text { information presented }\end{array}$ & Not done & Done with mistakes & $\begin{array}{l}\text { Well done but } \\
\text { limited }\end{array}$ & $\begin{array}{l}\text { Well done but } \\
\text { incomplete }\end{array}$ & Well done & $\begin{array}{l}\text { Well done emphasizing the } \\
\text { relevant aspects }\end{array}$ \\
\hline 10 & $\begin{array}{l}\text { Uses graphical resources } \\
\text { in effective way giving } \\
\text { quality to the report }\end{array}$ & Not used & Inappropriate use & $\begin{array}{l}\text { Used but not } \\
\text { increase the quality }\end{array}$ & $\begin{array}{l}\text { Used and increase the } \\
\text { quality but still in weak } \\
\text { way }\end{array}$ & $\begin{array}{l}\text { Graphical resources } \\
\text { are used increasing } \\
\text { the report quality }\end{array}$ & $\begin{array}{l}\text { Common graphical used. } \\
\text { Introduces new achieving a high } \\
\text { quality (professional) report }\end{array}$ \\
\hline
\end{tabular}


Table 3. Range values to obtain the achievement level of the oral and written communication competence

\begin{tabular}{cccccc}
\hline \multicolumn{5}{c}{ ORAL COMMUNICATION SCALE } \\
\hline LOW & LOW-MEDIUM & MEDIUM & MEDIUM-HIGH & HIGH & MASTER \\
From 0 to $<9$ & From 9 to $<17$ & From 17 to $<35$ & From 35 to $<44$ & From 44 to $<50$ & From 50 to $<55$ \\
\hline \multicolumn{7}{c}{ WRITTEN COMMUNICATION SCALE } \\
\hline LOW & LOW-MEDIUM & MEDIUM & MEDIUM-HIGH & HIGH & MASTER \\
From 0 to $<8$ & From 8 to $<15$ & From 15 to $<33$ & From 33 to $<40$ & From 40 to $<46$ & From 46 to $<50$ \\
\hline
\end{tabular}

\section{Results and Discussion}

Among the objectives of the presented work, one is to evaluate the differences between data collected by the different teachers and the data collected by the teachers and students. These results are directly related to the efficacy and reliability of the evaluation methods developed. Figure 1 and Figure 2 show a comparison of the average data collected on Bachelor and Master courses, respectively, to evaluate oral communication competence. Figures 1a/2a compare the average marks from studentsteachers evaluations and Figures 1c/2c compare marks from teacher-teacher evaluations. Radial direction represents the marks obtained from the evaluation using the rubric 1 , the minimum value being zero and the maximum 55 . Each point in the graph represents one single evaluation act. Figures $\mathbf{1 b} / \mathbf{2} \mathbf{b}$ show the students' standard deviations of each evaluation act, and Figures 1d/2d are the teachers' standard deviations. These data has been ordered from lower to higher values for better understanding.

As it was expected, teachers' scoring was slightly lower to that of the students; however, small differences between students and teachers evaluations occur resulting in a relatively good correlation (Figures 1a and 2a). Regarding the standard deviation between the students marks for each presentation (Figure 1b), variation in Bachelor values is also low, $42 \%$ of the values having $\boldsymbol{S D} \leq \pm 3$, while $63 \%$ yielding $\boldsymbol{S D} \leq \pm 5$. Comparing teachers' evaluations (Figure 1d), a still lower dispersion of the data was obtained, $74 \%$ of the values having $\boldsymbol{S D} \leq \pm 3$, while $95 \%$ of the data delivering $\boldsymbol{S D} \leq$ \pm 5 . In case of the Master values, a similar picture is obtained. Taking into account teachers and students' evaluations (Figure 2b), $60 \%$ and $80 \%$ of the data provide $\boldsymbol{S D}$ $\leq \pm 3$ and $\boldsymbol{S D} \leq \pm 5$, respectively, while for teachers' evaluation (Figure 2d) $100 \%$ of the values present $\boldsymbol{S D} \leq \pm 5$. Thus, considering the influence of standard deviation in the final marks of the students, these only vary $5 \%$ or $9 \%$ taking into account $\boldsymbol{S D} \leq \pm 3$ or $\boldsymbol{S D} \leq \pm 5$ respectively. The Figures 1a/1c and Figures 2a/2c show a fine correlation between evaluations made by different evaluators, this has been confirmed by means of statistic analysis based on t-Student's test. Commonly, it is used to decide if it could consider means difference statistically significant. In teacher's evaluations for Bachelor and Master, p-value obtained 0.33 and 0.83 respectively, are higher than 0.05 which indicates lack of difference. In case of students versus teacher marks in Bachelor degree, $53 \%$ of evaluation acts showed no mean differences between students and teachers. This value became higher for Master degree, reaching up to $80 \%$ of agreement. The increase may be caused by further extended formation of Master students and also by more objective student evaluations. 
a)

b)
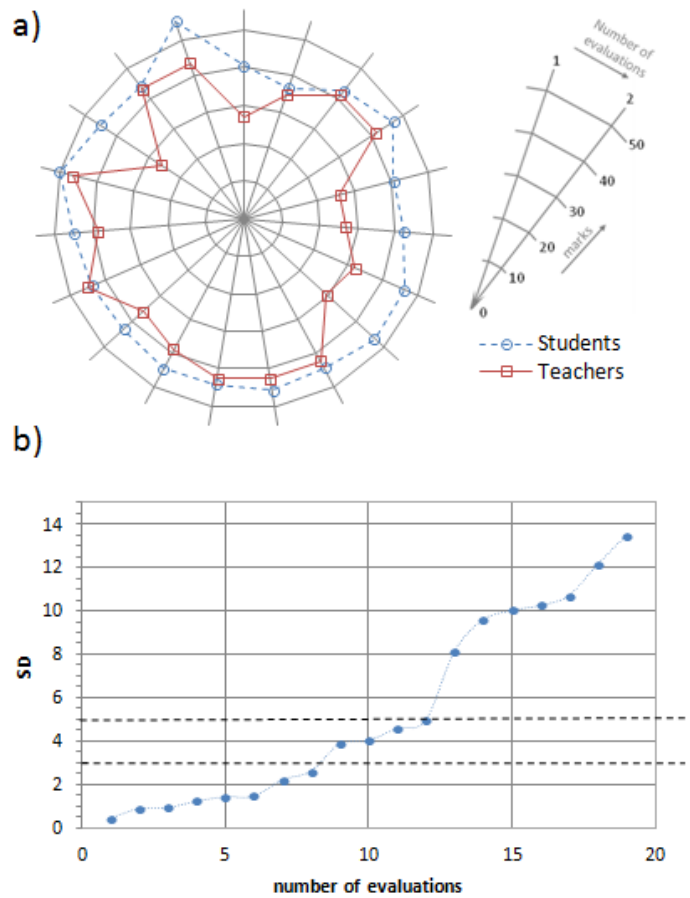

c)

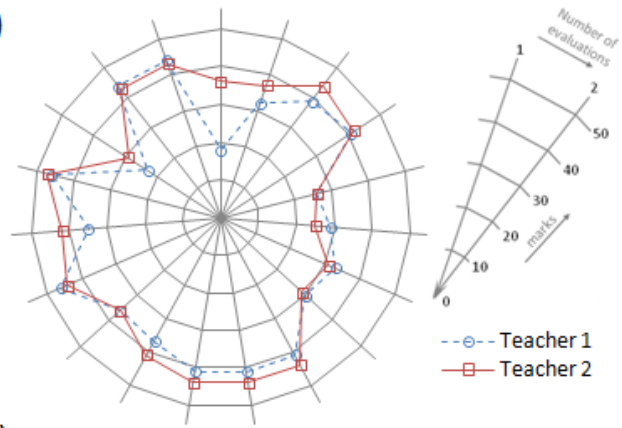

d)

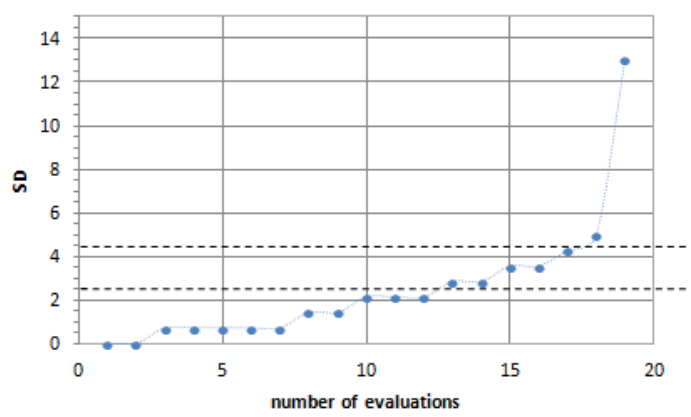

Figure 1. Comparative evaluation results in oral communication skills (rubric 1 ) from teachers and Bachelor degree students. (a) Average values of students and teachers evaluations and (b) students standard deviation. (c) Teachers' evaluations and (d) their standard deviation.

a)

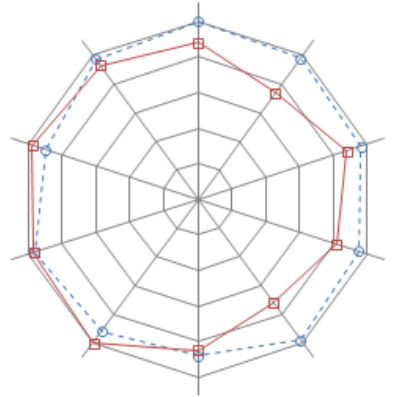

b)

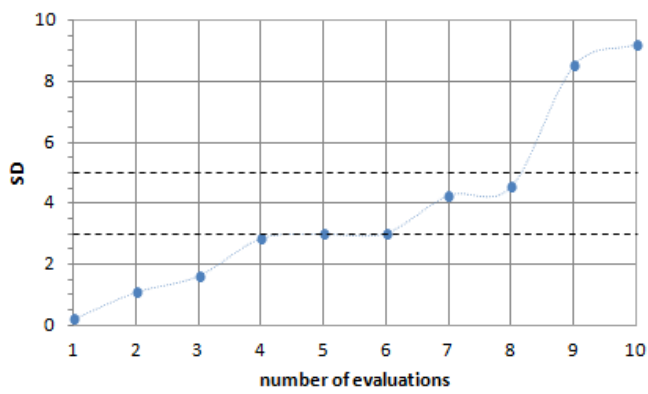

c)
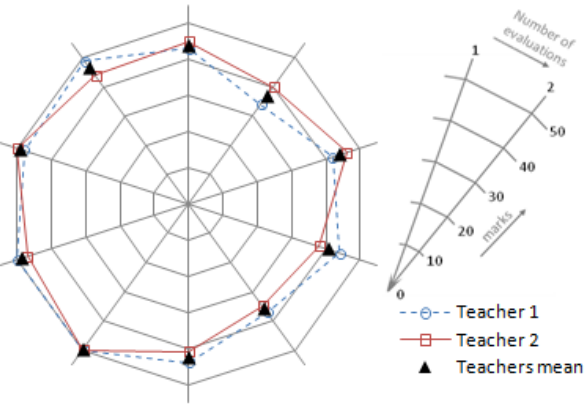

d)

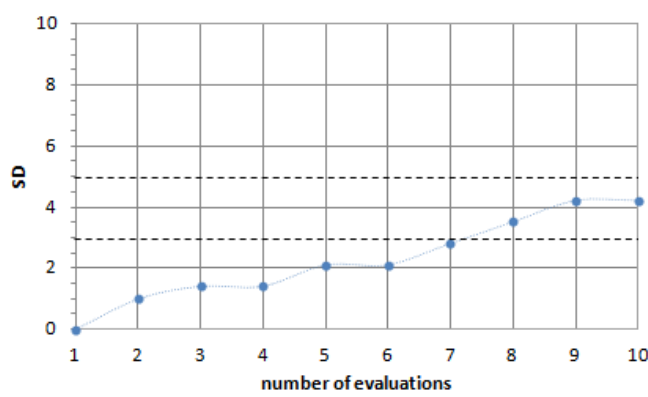

Figure 2. Comparative evaluation results in oral communication skills (rubric 1 ) from teachers and master students. (a) Average values of students and teachers evaluations and (b) students standard deviation. (c) Teachers' evaluations and (d) their standard deviation.

The use of rubrics has proved to be very beneficial for the students' learning and motivation. Figure 3 shows the assessment of the written communication skills (Master students) from the beginning to the end of the course. The general trend in the global final marks (Figure 3a) obtained from Rubric 2, is an improvement along the course. Analyzing each individual item, it also results in higher marks for all the students at the 
end of educational program, pointing to a better development of the command task with the time.

a)

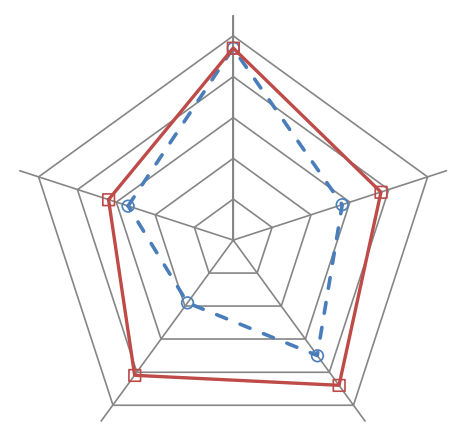

b)

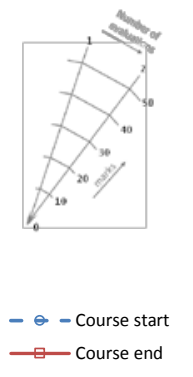

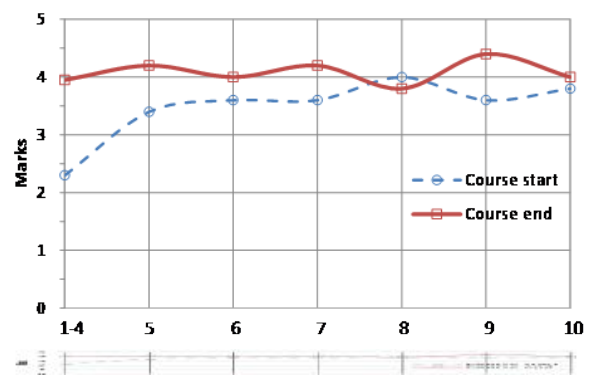

Figure 3. Evolution of the marks obtained at the beginning and end of the course for Master students.

(a) Total marks of each student at the beginning and end of the course. (b) Average of the marks obtained by individual item at the beginning and end of the course.

With the purpose to evaluate the flexibility of the methodology proposed, Figure 4 shows a comparison between the data obtained from oral communication evaluation of Bachelor degree and Master students. As it was expected, maximum total results are higher for Master students compared with Bachelor degree students. Distributing the data according to the developed scale of achievement (Table 3; Oral communication scale), $37 \%$ of the Bachelor degree students' marks are in a medium level, while most of the students (53\%) are in a medium-high level and only $10 \%$ of the marks achieve high level in the development of this competence. In case of Master students' marks, $40 \%$ are in a medium-high level, $50 \%$ in a high level and $10 \%$ of students achieve Master level. Results are in accordance with the students' level, reflecting good connection between the method developed and the feedback obtained.

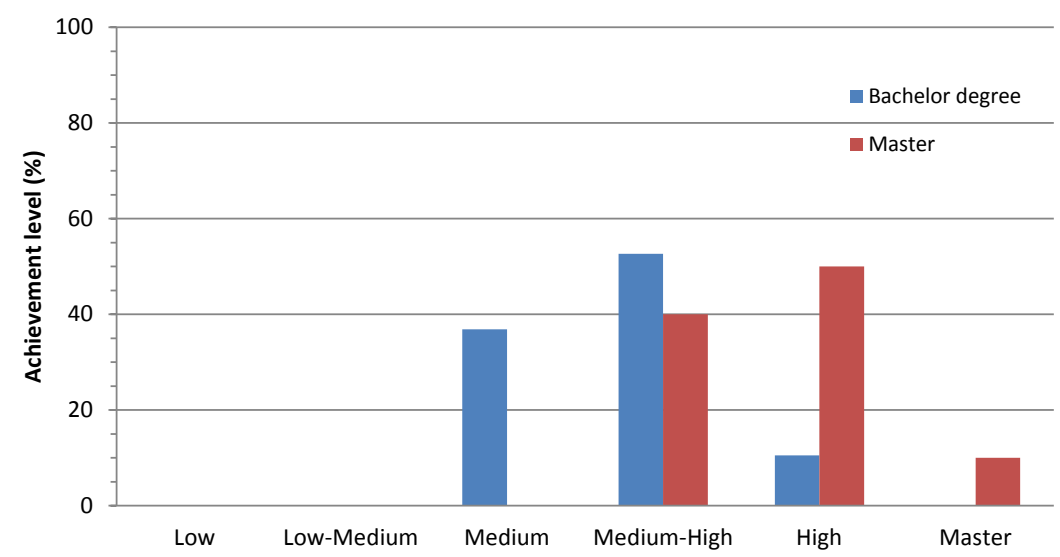

Figure 4. Comparison of oral communication competence achievement levels for master and Bachelor degree students taking into account teacher's evaluations.

\section{Conclusions}

The aim of this paper is to present a rubric-based method developed for the evaluation of the oral and written communication skills of Bachelor and Master students. The results obtained were analysed to test the reliability and validity of the methods proposed. Low differences between students judgments were obtained, meaning a good understanding of the criteria used for evaluation. That is, a good correlation between 
data collected by students and teachers indicates that the criteria proposed are easy to understand, clear and transparent for different kinds of people (teachers, Master and Bachelor students). Thus, the proposed methodology can be used with independence of the framework of the subject (in technical subjects) and/or the degree of the students. This methodology presents a good correlation between teachers' evaluations and between teachers and Master students. Differences between Bachelor students' and teachers' evaluations could be caused by students inexperience in peer review evaluation and in some cases due to a doubtful objectivity. The reason for the assessment of the competences to improve in time is that, through this evaluation method, students know what they have to do, what it is important and why they are doing it, making the method meaningful for them and so promoting their learning. Furthermore, by applying the final scales developed to qualify the students in the achievement level of the competence, the flexibility of the method is demonstrated, as results obtained from students of different technical subjects and levels can be successfully "standardise" and compared. Based on the evidences found, rubrics seem to promote learning and to improve teachers' instruction as their use provides teachersstudents feedback in both directions. They also provide self-assessment to the students, what makes them an effective and reliable tool to evaluate students' performance.

\section{Acknowledgements}

The authors acknowledge the financial contribution of Universitat Politècnica de València through the project PIME/2014/A/012/B.

\section{References}

A. Sursock, H. S. (2010). Trends 2010: A decade of change in european higher education. Brussels: European University Association.

Andrews, J., \& Higson, H. (2008). Graduate employability, 'Soft skills' versus 'Hard' business knowledge: A european study. Higher Education in Europe, 33, 411-422.

Dunbar, N. E., Brooks, C. F., \& Kibicka-Miller, T. (2006). Oral communication skills in higher education: Using a performance-based evaluation rubric to asses communication skills. Innovative Higher Education, 31, 115-128.

Entwistle, N. J., \& Peterson, E. R. (2004). Conceptions of learning and knowledge in higher education: Relationships with study behaviour and influences of learning environments. International Journal of Educational Research, 41, 407-428.

Jonsson, A., \& Svingby, G. (2007). The use of scoring rubrics: Reliability, validity and educational consequences. Educational Research Review, 2, 130-144.

Murias, P., de Miguel, J. C., \& Rodríguez, D. (2007). A composite indicator for university quality assesment: The case of Spanish higher education system. Social Indicators research, 89, 129-146.

Rieckmann, M. (2012). Future-oriented higher education: Which key competencies should be fostered through university teaching and learning? Futures, 44, 127-135.

Sparks, J. R., Song, Y., Brantley, W., \& Liu, O. L. (2014). Assessing written communication in higher education: Review and recommendations for nextgeneration assessment. ETS Research Report Series, 2014, 1-52.

Tuning project. (2014). Approaches to teaching, learning and assessment in competences based degree programmes. (Retrieved July 22, 2014). 


\title{
Mixed-format exams in higher education: Assessment of internal consistency reliability
}

\author{
N. Garg*, E. S. Lee* \\ *Sobey School of Business, Saint Mary’s University, Halifax, NS, Canada B3H 3C3
}

\begin{abstract}
In higher education courses, instructors often use mixed-format exams composed of several types of questions such as essays, short-answer, problem-solving, and multiple-choice to evaluate student performance. It is important to discriminate reliably among students according to their performance on final examinations. The lower the reliability of student exam scores, the greater the error associated with making decisions based on them. Why then have we found no previous studies of reliability for this, one of the most common types of exam? We investigated the reliability of student scores on 12 official mixed-format final exams used in 22 classes with 1012 students in six undergraduate courses taught by five professors in three fields of business (finance, accounting, and statistics). We focussed on estimating internal consistency reliability, which is essentially a measure of the reproducibility of test scores. Using coefficient omega, the most appropriate measure for assessing reliability for mixed-format exams, we found that in these 22 classes reliability averaged .85, with over $90 \%$ of the classes with reliabilities exceeding .80 . These reliabilities are very high, comparable with those reported for professionally developed standardized tests and better than those reported recently for single-format, multiple-choice exams in higher education.
\end{abstract}

Keywords: Reliability; mixed-format exams; coefficient alpha; coefficient omega; higher education; internal consistency reliability

\section{Introduction}

Professors in higher education employ a variety of different types of exams. Three of the most common types - essay only, multiple-choice questions (MCQ) only, and problem-solving only - are single-format exams with only one type of question on an exam and each question allotted the same number of marks. However, one of the most commonly used types in many academic disciplines is arguably the mixed-format exam, composed of a mixture of question types (such as short answer, multiple choice, problem solving, and essays) and with varying mark values assigned to each question (Qualls, 1995). Mixed-format exams are becoming increasingly popular even on standardized tests (Cao, 2008, p.18). These exams have the singular disadvantage of requiring an excessively long time to mark as do essay and problem solving exams (Lee et al., 2104). Nevertheless, they offer distinct advantages including ease of construction and reputedly high content validity. Given their importance in determining student success or failure, examining the reliability of student scores on examinations is of great importance.

However, "examination marks are not perfectly reliable, that is to say that if the assessment is repeated in some way, the candidate will generally receive a second mark which is different from the first" (Hill, 1978, p. 186). In higher education, it is important to discriminate reliably between students according to their final examination marks (Dracup, 1997). The lower the reliability of student exam scores, the greater the error associated with making decisions based on those scores (Crocker \& Algina, 2008; Nunnally \& Bernstein, 1994). Furthermore, reliability of test scores, in general, is of central importance (Henchy, 2013). Wilkinson and the APA Task Force on Statistical Inference (1999) criticized researchers for not assessing the reliability of the test scores used in their studies. Editors of many journals have argued 
in a similar vein (Fan \& Thompson, 2001). The same criticism can be made of classroom exams.

Reliability is generally assessed in three forms: stability over time, inter-marker reliability, and internal consistency reliability (Henson, 2001; Nunnally \& Bernstein, 1994). For stability over time (Crocker \& Algina, 2008, pp. 133-134), the focus is usually on assessing how student scores on an exam change over some period of time, primarily because of temporary changes in the student. Stability over time is typically estimated by test-retest reliability, the correlation between student scores on the same exam administered twice. However, test-retest reliability is of little concern here given that student exam scores on any repeated administrations of exactly the same exam would have to be suspect. Moreover, the recognition of test-retest reliability as a weak form of reliability is widespread (Morley, 2014, p. 130; Nunnally \& Bernstein, 1994, p. 255). Consequently, we are not concerned with this form of reliability.

Inter-marker reliability is typically estimated by the correlation among markers in the grades awarded to students for a common exam. Various measures of inter-rater reliability have been explored by Krippendorff (2004) and Morley (2014). This form of reliability is focussed primarily on the error introduced into assessments of student exam performance by variation in how different markers score the same student exams (Crocker \& Algina, 2008, p. 143). Many researchers have investigated the inter-marker reliability of classroom exams in higher education (e.g., Dracup, 1997; Hill, 1978; Newstead, 2002). In many higher education institutions, having multiple markers mark each exam in a course is economically impractical given large class sizes (e.g., in North America). More importantly, however, Morley (2014, p. 128-129) convincingly makes the case that "internal consistency is appropriate when we want to make statements about the respondent" (the student, in our case) whereas other types of reliability are appropriate for other purposes (Ebel, 1965).

Internal consistency reliability "estimates the correlation between a test and an alternative version of the same test of the same length, having randomly selected questions." Many methods have been used to estimate internal consistency reliability. However, coefficient alpha $(\alpha)$, which is based on the tau-equivalent measurement model (Graham 2006; Lord \& Novick, 1968; Sijtsma, 2009), is the most commonly reported measure of internal-consistency reliability (Padilla et al., 2012). However, it is often an underestimation of the actual reliability because the assumptions underlying the use of coefficient alpha are frequently violated in mixed-format exams (Miller, 1995; Qualls, 1995). We argue that coefficient omega, which is based on the congeneric measurement model, provides a more accurate and more appropriate estimate of actual reliability for mixed-format exams (Dunn et al., 2014; Feldt \& Charter, 2003; Schmitt, 1996). Hence, coefficient omega should be used for tests that use multiple-item formats or when the range of possible score values vary across different exam questions, as they do for the mixed-format exams in the present study (Dunn et al., 2014; Padilla \& Divers, 2013a, 2013b; Qualls, 1995).

The internal consistency reliability of exams in higher education has, somewhat surprisingly, rarely been reported in the literature (Jensen et al., 2013, Cox, 1967). More recently, Jensen et al. (2013), in a quasi-experimental study of two introductory biology classes with 155 students in total, reported the internal consistency reliability of their MCQ exam to be quite poor, $\alpha=.66$. Although some professors have resorted to the use of MCQ tests in response to dramatic rises in class sizes, many eschew the use of such exams. Instead, many administer exams composed of several types of 
questions (such as a mixture of short-answer, problem-solving, and essay questions) with different values assigned to each question. Yet, we could find no previous assessments of the reliability of mixed-format exams. Perhaps this is not surprising given that techniques for accurately estimating the reliability of student scores for such exams have been developed only recently (Qualls, 1995). As well, Cox (1967) noted that "although examining is an important and time-consuming occupation, very few of those who are actively engaged in it regard it as a field for experiment and research, or if they do, they keep their findings very much to themselves”.

The focus of the present paper is on estimating the internal consistency reliability of mixed-format exams in a variety of classes, courses, and subject areas as well as with different professors, students, and final exams. We focused on estimating only this type of reliability, first, because it can be estimated with the single administration of a test. Second, being the most commonly reported measure of reliability (Hogan et al., 2000; Padilla et. al., 2012; Thompson, 1999), it is easily understood. Third, the other two reliability estimates, inter-marker and test-retest, were of little importance in our present studies, test-retest because it is widely recognized as a weak form of reliability (Krippendorff, 2004, p. 216) and inter-marker because in many institutions only a single individual marks each final exam. Furthermore, as Morley (2014, p. 128) pointed out "The critical difference between internal consistency reliability and interrater reliability is that, with the former, one is attempting to make a statement about the test-taker, and, with the latter, one is attempting to make a statement about some object of judgement such as a professor.”

\section{Method}

In our study, we investigated six undergraduate courses offered at a Canadian university from three different fields in business: statistics $(S)$, finance $(F)$, and accounting (A). All classes were one-term 39 lecture-hour courses (see Table 1). In these six undergraduate courses, classes S1 to S15, F1, and F2 were taught in the 2nd year; F2, F3, A1, and A2 were taught in the 3rd year; and A3 was taught to graduating students in their 4th and final year of studies. The statistics and finance courses were introductory whereas in accounting the courses were either at the intermediate or advanced levels. Student performance on all exams was graded out of $100 \%$. Each student exam was marked by a single marker (customary in many institutions) who was in all cases the course instructor. In all these courses, professors administered mixed-format exams that varied between 2.0 and 3.0 hrs in length. In these 22 classes, there were 1012 students in total. Roughly 55\% were females and $45 \%$ males. One male and four female instructors, ranging from lecturers to full professors, took part in our study. A total of 12 different exams were used. For each exam, student scores on each part of each question that had been separately marked on the original exam were entered in an SPSS spreadsheet. Reliabilities were then computed for each class.

We used the MBESS program (Dunn et al., 2014; Revelle \& Zinbarg, 2009; Kelley, 2007) written for the $R$ platform for statistical computing (Field et al., 2012) to estimate reliability coefficients alpha and omega. We used the normal bootstrapping method of estimating reliabilities, as it is known to be appropriate for small sample sizes (Padilla \& Divers, 2013a, 2013b).

To average our reliabilities, we used two of the methods described by Feldt and Charter (2006). In their Monte Carlo study, they examined six different approaches to 
averaging internal consistency reliabilities that had been used by previous researchers. In their study, all approaches generated virtually identical averages. To be conservative, we used their approaches \#1 (the simple weighted average) and \#3 (the rto-z and z-to-r transformations weighted by sample size) to average reliabilities but expected no differences between them for our data.

\section{Results}

Results of student performance in our 22 classes as estimated by reliability coefficients alpha and omega are displayed in Table 1. Both approaches to averaging reliabilities produced virtually identical values and will, therefore, not be discussed further (approaches \#1 and \#3 in Feldt \& Charter, 2006).

Table 1. Reliability estimates for 22 classes in three higher education subjects

\begin{tabular}{cccccccccc}
\hline & & & \multicolumn{3}{c}{ Exam length } & \multicolumn{2}{c}{ Exam marks (\%) } & \multicolumn{2}{c}{ Reliability } \\
Class & Course & Prof & Exam & $\mathbf{n}$ & $\mathbf{t}$ & $\mathbf{k}$ & Mean (SD) & $\boldsymbol{\alpha}$ & $\boldsymbol{\omega}_{\mathbf{M}}$ \\
\hline F1 & Finance I & $\mathrm{a}$ & 1 & 60 & 3.0 & 37 & $63.3(16.9)$ & .85 & .87 \\
F2 & Finance I & $\mathrm{a}$ & 1 & 57 & 3.0 & 37 & $67.2(19.2)$ & .86 & .91 \\
F3 & Finance II & $\mathrm{a}$ & 2 & 52 & 3.0 & 47 & $67.7(14.9)$ & .85 & .85 \\
F4 & Finance II & $\mathrm{a}$ & 2 & 55 & 3.0 & 47 & $67.9(17.2)$ & .88 & .89 \\
A1 & Acct Int I & $\mathrm{b}$ & 3 & 37 & 3.0 & 36 & $57.8(14.0)$ & .86 & .89 \\
A2 & Acct Int II & $\mathrm{b}$ & 4 & 22 & 3.0 & 33 & $50.9(11.4)$ & .67 & .73 \\
A3 & Acct Topics & $\mathrm{b}$ & 5 & 35 & 2.5 & 20 & $61.8(15.2)$ & .86 & .88 \\
S1 & Statistics & $\mathrm{c}$ & 6 & 25 & 3.0 & 15 & $64.8(23.8)$ & .83 & .90 \\
S2 & Statistics & $\mathrm{c}$ & 6 & 63 & 3.0 & 15 & $71.2(22.4)$ & .82 & .86 \\
S3 & Statistics & $\mathrm{c}$ & 6 & 61 & 3.0 & 15 & $67.4(23.1)$ & .82 & .87 \\
S4 & Statistics & $\mathrm{d}$ & 6 & 23 & 3.0 & 15 & $77.5(14.5)$ & .79 & .84 \\
S5 & Statistics & $\mathrm{d}$ & 7 & 46 & 3.0 & 21 & $66.7(19.7)$ & .74 & .81 \\
S6 & Statistics & $\mathrm{d}$ & 8 & 38 & 3.0 & 27 & $68.8(15.3)$ & .71 & .74 \\
S7 & Statistics & $\mathrm{e}$ & 9 & 40 & 2.5 & 31 & $47.8(15.7)$ & .84 & .84 \\
S8 & Statistics & $\mathrm{e}$ & 9 & 48 & 2.5 & 31 & $45.5(19.0)$ & .88 & .90 \\
S9 & Statistics & $\mathrm{c}$ & 10 & 36 & 2.0 & 13 & $67.6(19.2)$ & .81 & .84 \\
S10 & Statistics & $\mathrm{c}$ & 10 & 66 & 2.0 & 13 & $70.9(20.6)$ & .80 & .83 \\
S11 & Statistics & $\mathrm{c}$ & 10 & 59 & 2.0 & 13 & $65.1(21.0)$ & .79 & .83 \\
S12 & Statistics & $\mathrm{c}$ & 11 & 22 & 2.0 & 12 & $66.5(26.0)$ & .87 & .91 \\
S13 & Statistics & $\mathrm{c}$ & 11 & 65 & 2.0 & 12 & $58.2(23.0)$ & .80 & .84 \\
S14 & Statistics & $\mathrm{c}$ & 11 & 59 & 2.0 & 12 & $62.8(22.2)$ & .79 & .83 \\
S15 & Statistics & $\mathrm{e}$ & 12 & 43 & 2.0 & 30 & $50.0(19.0)$ & .83 & .86 \\
\hline
\end{tabular}

Note: Student marks $=\%$; Acct Int I = Accounting Intermediate I; Acct Int II = Accounting Intermediate II; Acct Topics = Accounting Special Topics; Prof = class professor or instructor; $n=$ number of students in class; $t=$ maximum time allowed for exam completion (hrs); $k=$ number of separately marked questions or parts of questions on exam; SD = standard deviation (\%); $\alpha=$ coefficient alpha and $\omega_{M}=$ coefficient omega: estimated by MBESS software.

Coefficient omega averaged .85 across the 22 classes, with class reliabilities ranging between .73 and .91. The median was marginally higher at .86. Over $90 \%$ of the classes tested (20 out of 22) had reliabilities greater than .80. Average alpha equalled .82 (alphas for these classes ranged between .67 and .88). However, our empirical results confirmed the theoretical prediction that coefficient alpha underestimates actual reliability for mixed-format exams (underestimates ranged from 0 to .07). On average, coefficient alpha underestimated reliability by .035 , a rather large and significant difference (sign test, 2 ties, 20/20 classes in predicted direction, $p<.0001$ ).

Though there appear to be some differences in the reliability of exam scores across different professors, exams, courses, and fields of study, these differences are all relatively small and inconsequential. However, we do not believe our present study 
permits statistical assessments of these issues. One issue that we did address was whether student scores of shorter examinations would have significantly lower reliabilities. Professor "e" examined students using both 3.0-and 2.0-hr final exams for the same course (see Table 1). There was no significant difference between short and long exams given by this professor in this course (independent-groups $t(\mathrm{df}=7)=1.47$, $p=.09$ ). We must caution the reader, however, of the unacceptably small sample size of only nine classes used for this test and the lack of independence of some reliability estimates (which are based on the same exam albeit for different classes).

\section{Discussion}

Professors in higher education often use exams composed of more than one type of question with variable marks assigned to each question on the exam. Many professors (mistakenly) believe that such mixed-format exams are relatively unreliable and especially poor when compared with the reliability of so-called objective MCQ exams (e.g., Cao, 2008, pp. 1 and 13). Yet we could find no reports of score reliabilities for mixed-format exams in higher education. Our study examined the reliability of student exam performance on mixed-format exams in many classes, in different courses and fields in business, and with different exams, students, and professors.

The most appropriate measure of reliability when one's focus is on decisions affecting students, as it is in our case, is unquestionably internal consistency (Morley, 2014). The most commonly reported measure of this type of reliability is coefficient alpha, but this estimate is known to underestimate the true reliability of exams composed of more than one type of question or with questions of unequal value (Dunn et al., 2014). Instead we estimated congeneric reliability using coefficient omega that is most appropriate for use with such tests as ours (Feldt \& Charter, 2003; Qualls, 1995).

Reliability of exam scores was very high with coefficient omega averaging .85 in the 22 classes in our study. Moreover, the reliabilities were remarkably consistent from class to class (ranging from .73 to .91) despite variation in students, professors, exams, fields of study courses, and classes taught. Scores on the exams in over $90 \%$ of the 22 classes tested in our study had reliabilities exceeding .80. Practically speaking, these reliabilities imply that error is relatively small, and decisions based on student performance on this type of exam in the courses tested are well founded.

However, decisions on students are often based not just on their performance on a single final exam but on assignments, midterms, projects, and presentations in the same course as well. Such additional measures of student performance generally increase reliability (Nunnally \& Bernstein, 1994). Thus, reliability of student scores on a single final exam undoubtedly underestimates the reliability of student grades assigned for all aspects of a course. Furthermore, decisions about students are often made on the basis of performance in many different courses with different professors, fields, class sizes, and time periods. As Dracup (1997) has shown, reliability based on student performance on essay-only exams in many courses can be exceptionally high $(\alpha=.95)$ even when the (inter-marker) reliability of most courses is very poor (median intermarker reliability $=.64$ with some reliabilities as low as -.28 ).

Previous studies of reliability are relatively rare in higher education (Cox, 1967; Jensen et al., 2013). Recently, however, Jensen et al. (2013) reported $\alpha=.66$ for the internal consistency reliability for student scores on a single MCQ exam in two introductory biology classes taught by one instructor. Such poor reliability implies that error is 
relatively high and that decisions based on the results of such MCQ exams could be somewhat compromised. The reliability for all 22 of the classes in our study exceeded that for their MCQ exam scores. The reliabilities we have found for mixed-format scores compare favourably with those found by others for MCQ and other types of exam scores in higher education. In fact, the reliabilities in Table 1 are comparable with those reported for costly, professionally-developed standardized clinical and psychological tests. Yet, classroom exams, such as ours, are normally intended for onetime use (Nunnally \& Bernstein, 1994, p. 295).

Several limitations should be stressed. First, in this paper we focussed exclusively on investigating internal consistency reliability to the exclusion of other forms such as inter-marker reliability, which explore different sources of error (Crocker \& Algina, 2008). However, as Morley (2014, p. 128) so clearly affirms, internal consistency reliability is useful for making judgments about students while inter-marker reliability is useful for making judgments about professors. Given our focus on the importance of marks or grades on exams when making decisions about students, internal consistency reliability is unquestionably most appropriate. Similarly, the issues of moderation, a method for improving marker consistency in which several markers meet to iron out differences, and calibration, in which markers learn to mark more consistently by working with other markers, are both concerned with inter-marker reliability (Sadler, 2013), and therefore, while important issues in their own right, are not the focus here.

Second, our interpretation of the present results must be tempered somewhat by the relatively small number of exams, instructors, classes, courses, and subject fields tested in the present study. Nevertheless, we surveyed 1012 students, 12 exams, 5 instructors, 22 classes, 6 courses, and 3 subject fields. In forthcoming studies, our objective is to cover more subject areas, courses, classes and students, exams, and professors.

Third, we studied only mixed-format exams. Nevertheless, these are among the most commonly used types of exams in higher education. Others have reported reliabilities for essay-only exams in psychology (e.g., Dracup, 1997), problem-solving-only exams in engineering (e.g., Hill, 1978), and MCQ exams in biology (e.g., Jensen et al., 2013). Those interested in these other types of exams should consult the references cited.

Fourth, are the exams in these 3 disciplines really comparable? This is an important issue which cannot be addressed in appropriate depth here given space constraints. Nevertheless, several arguments can be advanced for believing that at least some of the exams are comparable. All courses examined in our study are, for example, in applied disciplines (e.g., accounting). All exams included both strong quantitative and strong non-quantitative or narrative components. Each mixed-format exam also included many problem-solving and narrative short-answer questions. Nevertheless, another response to this question is that they are certainly not. Questions on finance exams bear little resemblance to those on statistics exams. Even within a discipline, exams on introductory courses can differ radically from those on more advanced courses. However, readers will certainly differ in what they believe constitutes exam comparability. This is why the reliabilities are provided for each exam in each of the classes, courses, and disciplines studied (see Table 1). Finally, one must consider that, despite these manifold differences, reliabilities for these widely divergent exams were uniformly high in our study (more that $90 \%$ had reliabilities exceeding .80).

In our forthcoming studies, our objective is to cover more subject areas, courses, classes and students, exams, and professors. The present studies were restricted to an exploration of internal consistency reliability only. Other estimates of reliability such 
as inter-marker reliability, which explore other sources of error, were not addressed (Crocker \& Algina, 2008). While we have explored reliability for classes in three areas of business, other areas such as economics were not examined in our study. Similarly, we did not investigate courses in arts, sciences, or engineering. Additionally, we have not studied single-format exams such as those consisting of only essay questions.

\section{References}

Cao, Y. (2008). Mixed-format test equating: Effects of test dimensionality and common-item sets. (Doctoral dissertation, Department of Measurement, Statistics and Evaluation, University of Maryland, 2008).

Cox, R. (1967). Examinations and higher education: A survey of the literature. Higher Education Quarterly, 21, 292-340.

Crocker, L., \& Algina, J. (2008). Introduction to classical and modern test theory. Fort Worth: Harcourt, Brace and Jovanovich.

Dracup, C. (1997). The reliability of marking on a psychology degree. British Journal of Psychology, 88, 691-708.

Dunn, T., Baguley, T. \& Brunsden, V. (2014). From alpha to omega: a practical solution to the pervasive problem of internal consistency estimation. British Journal of Psychology, 105, 399-412.

Ebel, R. L. (1965). Measuring educational achievement. Englewood Cliffs, NJ: Prentice-Hall.

Fan, X. \& Thompson, B. (2001). Confidence intervals about score reliability coefficients, please: An EPM guidelines editorial. Educational and Psychological Measurement, 61, 517-531.

Feldt, L. S., \& Charter, R. A. (2003). Estimating the reliability of a test split into two parts of equal or unequal length. Psychological Methods, 8(1), 102.

Feldt, L. S., \& Charter, R. A. (2006). Averaging internal consistency reliability coefficients. Educational and Psychological Measurement, 66(2), 215-227.

Field, A., Miles, J., \& Field, J. (2012). Discovering statistics using R. London: Sage Publications, Ltd.

Graham, J. M. (2006). Congeneric and (essentially) tau-equivalent estimates of score reliability what they are and how to use them. Educational and Psychological Measurement, 66(6), 930-944.

Henchy, A. M. (2013). Review and evaluation of reliability generalization research. (Doctoral dissertation, Educational, School, and Counseling Psychology, University of Kentucky, 2013).

Henson, R. (2001). Understanding internal consistency reliability estimates: A conceptual primer on coefficient alpha. Measurement and Evaluation in Counseling and Development, 34, 177- 189.

Hill, B. J. (1978). Examination paper length: How many questions? British Journal of Educational Psychology, 48, 186-195.

Hogan, T. P., Benjamin, A., \& Brezinski, K. L. (2000). Reliability methods: A note on the frequency of use of various types. Educational and Psychological Measurement, 60(4), 523-531. 
Jensen, J., Berry, D., \& Kummer, T. (2013). Investigating the effects of exam length on performance and cognitive fatigue. PLOS ONE, 8(8), 1-9, e70270.

Kelley, K. (2007). Methods for the behavioral, educational, and social sciences: An R package. Behavior Research Methods, 39(4), 979-984.

Krippendorff, K. (2004). Reliability in content analysis: Some common misconceptions and recommendations. Communications Research, 30(3),411-433.

Lee, E., Bygrave, C., Mahar, J., Garg, N. and Cottreau, S. (2014) "Can exams be shortened? Using a new empirical approach to test in finance courses", International Conference on Higher Education and Management (ICHEM 2014), London, UK, January 2014.

Lord, F. M., \& Novick, M. R. (1968). Statistical theories of mental test scores. Reading, MA: Addison-Wesley.

Miller, M. (1995). Coefficient alpha: A basic introduction from the perspectives of classical test theory and structural equation modelling. Structural Equation Modeling, 2, 255-273.

Morley, D. (2014). Assessing the reliability of student evaluations of teaching: Choosing the right coefficient. Assessment \& Evaluation in Higher Education, $39(2), 127-139$.

Newstead, S. (2002). Examining the examiners: Why are we so bad at assessing students? Psychology Learning and Teaching, 2(2), 70-75.

Nunnally, J., \& Bernstein, I. (1994). Psychometric theory. 3rd edition, Toronto: McGraw-Hill.

Padilla, M. A., Divers, J., \& Newton, M. (2012). Coefficient alpha bootstrap confidence interval under nonnormality. Applied Psychological Measurement, 36(5), 331-348.

Padilla, M. A., \& Divers, J. (2013a). Coefficient omega bootstrap confidence intervals: Nonnormal distributions. Educational \&Psychological Measurement, 73, 956-972.

Padilla, M. A., \& Divers, J. (2013b). Bootstrap interval estimation of reliability via coefficient omega. Journal of Modern Applied Statistical Methods, 12, 78-89.

Qualls, A. L. (1995). Estimating the reliability of a test containing multiple item formats. Applied Measurement in Education, 8, 111-120.

Revelle, W., \& Zinbarg, R. E. (2009). Coefficients alpha, beta, omega, and the glb: Comments on Sijtsma. Psychometrika, 74(1), 145-154.

Sadler, R. (2013). Assuring academic achievement standards: from moderation to calibration. Assessment in Education: Principles, Policy and Practice, 20(1), 5-19.

Schmitt, N. (1996). Uses and abuses of coefficient alpha. Psychological Assessment, 8, 350-353.

Sijtsma, K. (2009) On the use, misuse, and the very limited usefulness of Cronbach's alpha. Psychometrika, 74, 107-120.

Thompson, B. (1999). If statistical significance tests are broken/misused, what practices should supplement or replace them? Theory and Psychology, 9, 165-181.

Wilkinson, L., \& the APA Task Force on Statistical Inference (1999). Statistical methods in psychology journals. American Psychologist, 54, 594-604. 


\title{
The role of self-monitoring in adult learning in online context
}

\author{
$M^{\text {a }}$ de Fátima Goulão*, Rebeca Cerezo Menedez ** \\ * UIEDF-UL / Universidade Aberta, Portugal \\ ** University of Oviedo, Department of Psychology, Spain
}

\begin{abstract}
This paper examines the reflexions made by a set of online students regarding the results obtained in an assessment task and its consequences for the future. The sample included 43 students in continuous assessment, from both sexes. After knowing the results they were asked to indicate the implications of this exercise to their future studies. The content analysis revealed the existence of two categories - Causality (intrinsic / extrinsic) and Influence (Generics/Specifics/No consequences) - regardless of the approach to real evaluation. The reflection that students can make about their learning process and the difficulties in developing their tasks is of great relevance to achieve success. This was evident in the analysis that our students made on the completion of the assessment work, as well as the consequences for their future study. This process of reflection and awareness in the teaching learning process is particularly relevant in online education where the role of metacognitive monitoring and control system gains a prominent role. Allowing students to reflect on these issues permits them to be more effective learners.
\end{abstract}

Keywords: metacognition; adult learning; online learning

\section{Introduction}

Technological advances have been giving a new face to distance learning systems. ICTs open new perspectives to facilitate learning. They work as tools that complement and are a real and basic support to the training system. Through the features of virtual learning environments, virtuality - eliminating barriers of time and space -, globality and the ubiquity - the campus is always with us.

This new format implies methodological, pedagogical, psychological and even emotional changes with consequent modifications in roles and functions of the actors involved in it. These new learning scenarios lead to a change of attitude and posture relative to this whole process. This change should be taken into account on both sides - learners and teachers.

Students in eLearning require greater self-direction and self-regulation to achieve their academic goals (Bol \& Garner, 2011). To lead the students to reflect on their learning strategy and tailor their metacognitive strategies to achieve success in the task is of great relevance. This means that the incorporation of ICT in the educational context, using the virtual spaces, allows a more effective response to the educational challenges by allowing using strategies and tools that best fit to the real needs of their learners. The research work of Azevedo and Cromley (2004) points to the implications that the design of virtual learning environments have on the acquisition of knowledge.

Learners who know, more appropriately, how to study and how learning occurs, i.e., have better metacognitive knowledge and learn better, when compared with those who have less metacognitive knowledge. It is therefore essential to teach learners about how they learn and identify themselves with the most effective learning strategies, so that they can improve their metacognitive judgments, as well as the selfregulation of their learning. 
Leclercq and Denis (1995) defined a good learner as a person who solves learning problems (p.155); that is a good regulator of their own learning. For them learning is a regulated process of problem solving (p.155). This process can be decomposed into six major phases and a good learner is one who can manage well each one. This process requires analyzing needs, setting goals, planning of learning strategies, executing, observing and ultimately deciding.

Hacker et al (2009) refer that learners can be agents of their own thoughts and behaviors, can monitor their knowledge or skills, establish their learning objectives, outline and control strategies / plan to achieve them, monitor progress for their possible adjustments and, finally, assess whether the objectives were achieved. All this translates into what Zimmerman (2000) calls self-regulation of behavior. According to this author the concept of self-regulation can be defined as selfgenerated thoughts, feelings and actions for attaining academics goals (Zimmerman, 1998). The key element of self-regulation is self-monitoring that involves the observation and monitoring of the performance itself, as well as its results. This in order to understand their learning process and apply these strategies in future situations, where they will prove to be adequate.

According to Serra and Metcalfe (2007) the following aspects have been associated to the concept of metacognition - knowledge about the process, about their monitoring and their control. The learning process leads to a continuous self-evaluation and a consequent decision on what to do with the information collected: What's next? What do I need to study more? Have I study this content? What strategies will be used? (Goulão, 2009).

According to Bjork, Dunlosky and Kornell (2013) for learners to become effective in the learning process, they should not only be able to assess accurately the states of their own learning, but also be able to manage it and the activities in response to such monitoring (pág.422).

By monitoring, the learner can check how his plans become actions and through the introspection, made about their achievements, learners can perceive discrepancies between what were their goals and what actually exists. The learner can thereby exercise metacognitive control, reviewing goals, plans to adapt or operations of change (Winne \& Nesbit, 2009).

According to Blakey and Spence (2000) the basic metacognitive strategies are a) to know how to relate new information with existing one, b) to know how to select the appropriate thinking strategies and c) to learn to plan, monitor and evaluate the thought processes. The reflection, in a conscious way, about the processes of learning is therefore an essential element to the development of increasingly efficient learners.

To Ertmer and Newby (1996) the expert learner is one who is aware of the specific knowledge to reactivate, the goals they have to achieve, the strategies they need to achieve them, as well as this whole process - Figure 1 .

Expert Learning

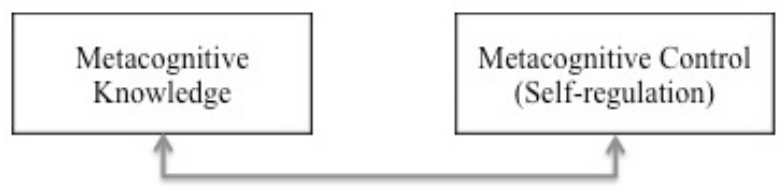

Figure1. Major components of expert learning (Ertmer \& Newby, 1996, pág. 7) 
Those learners are considered experts due to the fact that they can incorporate and implement different knowledge to improve their performance.

In online distance education, learners found more flexibility, allowing them to achieve goals that otherwise were unachievable. The acquisitions are located at different levels: concerning their formal knowledge and at the personal level, with the development of their autonomy, their critical thinking and collaborative work. This flexibility of time and space allows better management of their education formation according to their needs. In online distance education environments one of the most important roles of the teacher is as the mediator / facilitator of learning. This means that you as the teacher should aim to provide appropriate educational aid for students to develop their autonomy and their learning construction - Figure 2.

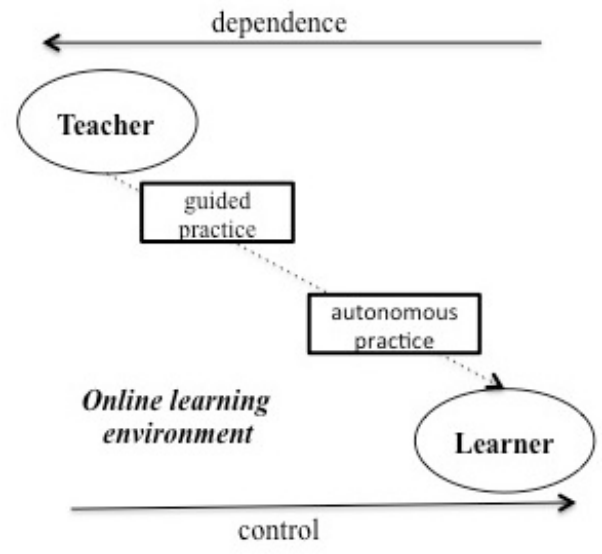

Figure 2. Methodological scenario

Thus, these new learning scenarios lead to a change of attitude and posture relative to this whole process. This change should be taken into account on both sides learners and teachers.

Learners who know, more appropriately, how to study and how learning occurs, i.e., have better metacognitive knowledge and learn better, when compared with those who have less metacognitive knowledge. It is therefore essential to teach learners about how they learn and identify themselves with the most effective learning strategies, so that they can improve their metacognitive judgments, as well as the selfregulation of their learning.

\section{Material and Methods}

\section{Objectives}

This study aims to analyze the reflexions made by a set of online students regarding the results obtained in an assessment task and its consequences for the future.

\section{Design and participants}

Data collection was made through the answers students gave to a question made after the results of their assessment were disclosure. A total of 43 students, in continuous assessment, answered the question, as volunteers.14\% were males and $86 \%$ were females. The average age of the participants was 41, ranging from 26 and 57 years old (see Table 1) one student was in his 20s, 21 students were in their 30s, 11 students were in their 40s and 9 students were in their 50s. The median age was 42. 
Table 1. Descriptive statistics of participansts’ age

\begin{tabular}{llllll}
\hline Variable & $\mathrm{N}$ & MIN & MAX & AVG & SD \\
\hline Age & 43 & 25 & 60 & 42.17 & 8.82 \\
\hline
\end{tabular}

\section{Material and procedure}

The data was collected in one curricular unit from to the first year, second semester of the degree course in Education. We have three moments of continuous assessment. Our analysis will be made only to the results obtained in the first moment.

Before starting, a message was placed in the "News" forum about the purpose of the research and requesting the participation of the students. Whenever a questionnaire was available for collecting data another message was placed in the forum requesting the response of students.

The data collection was done in three stages. Before completing their assessment test, students were asked to indicate what grade they expected to obtain (Predicted scores). Immediately after finishing their test, they were asked again to indicate the grade they expected to obtain (Postdicted Score). Finally, after the results came out students were asked to indicate whether their real grades, were higher, lower or equal compared with their prediction. Furthermore, they were asked about this and what would be the implications for their study method. Our analysis focus was on this last phase.

\section{Data analyses}

We proceeded to the analysis of participants' responses according to how the questions were asked. It was the purpose of this research to examine the justifications given by this online students regarding the results obtained in the first continuos assessment task and how this fact will affect their study process in the future. To analyse their responses, we used content analysis. In the answers given by the students could be found more than one category or sub-category. For this reason the number of occurrences by category be more than the number of participants in the study.

\section{Results and Discussion}

The content analysis of the answers given by the students to the question after the results came out (real grades) allowed us to establish the following categories and sub-categories, regardless of the dimension in question - Table 2

Table 2. Content analysis results: Categories and sub-categories

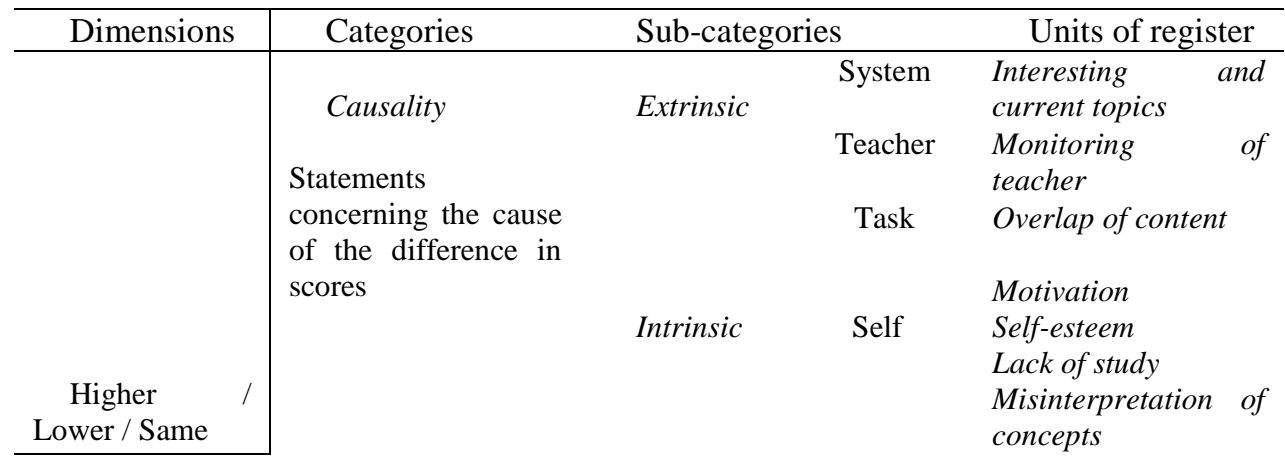




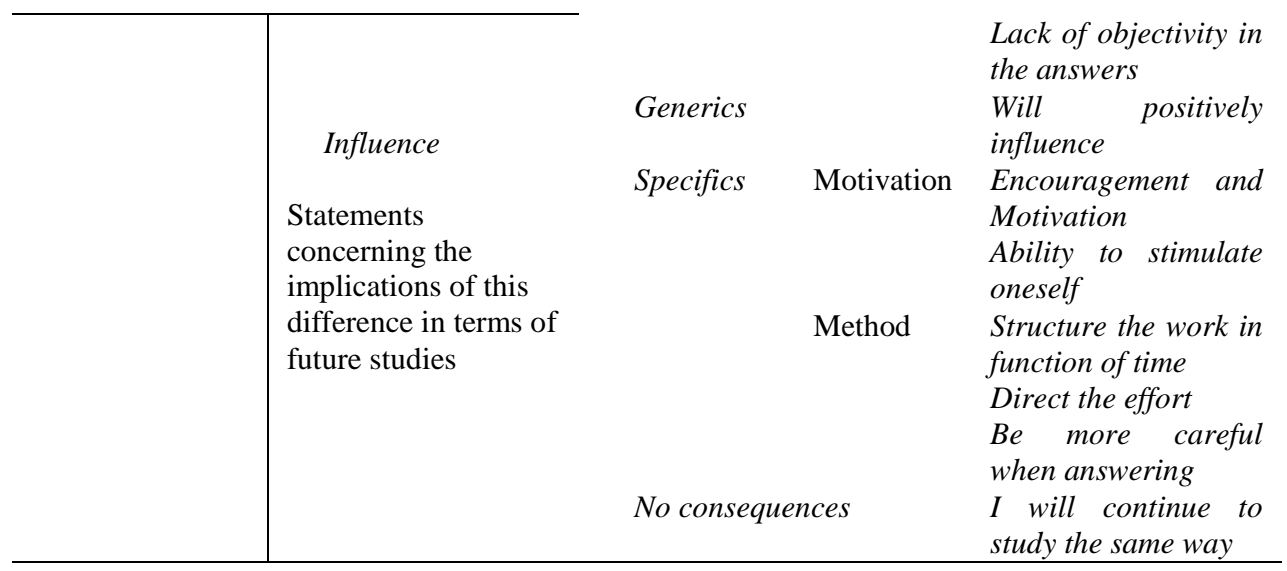

The indication of a Higher, Lower or Same classification, comparing the scores obtained with the ones predicted was not clear. For that reason, the content analysis presented in this paper includes the responses in global terms. The Dimension has not proved to be a suitable descriptor. The following results refer to the analysis of frequency distribution taking into account the categories and sub-categories. Table 3 shows the results found in the category Causality.

Table 3. Categorie Causality: Number of occurrences of sub-categories

\begin{tabular}{|c|c|c|c|c|c|}
\hline & \multicolumn{4}{|c|}{ Sub-categories } & $\mathbf{N}$ \\
\hline \multirow{8}{*}{ 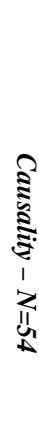 } & & System & & & 2 \\
\hline & Extrinsic & Teacher & & & 2 \\
\hline & Total $=6$ & Task & & & 2 \\
\hline & \multicolumn{4}{|c|}{ Individual characteristics } & 12 \\
\hline & \multirow{4}{*}{$\begin{array}{l}\text { Intrinsic } \\
\text { Total = } \\
\mathbf{4 8}\end{array}$} & \multirow[t]{4}{*}{ Self } & \multirow{2}{*}{$\begin{array}{l}\text { Performance } \\
\text { (Total = 19) }\end{array}$} & Positive nature & 6 \\
\hline & & & & Negative nature & 13 \\
\hline & & & \multirow{2}{*}{$\begin{array}{l}\text { Organization } \\
\text { / Planning } \\
(\text { Total }=16)\end{array}$} & Positive nature & 10 \\
\hline & & & & Negative nature & 6 \\
\hline
\end{tabular}

As it can be seen in Table 3, the highest number of occurrences that justify the classifications obtained is at the level of the subject himself. These may refer to more individual characteristics, such as motivation, self-esteem and lack of confidence in the competencies, but also on aspects that may be more controllable by the student. This level involves the way the subject feels within the assessment task, such as an incorrect interpretation of questions, a difficulty in understanding some questions. Finally, we find the issues related to the preparation for the assessment task. These refer to the organization and planning of the study itself.

We turn now to the presentation of the results concerning the influence for future study situations. - Table 4 
Table 4. Categories Influence: $\mathrm{N}^{\mathrm{o}}$ of occurrences of sub-categories

\begin{tabular}{|c|c|c|c|c|}
\hline \multirow{6}{*}{ 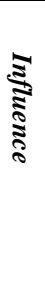 } & \multicolumn{3}{|l|}{ Sub-categories } & \multirow[t]{2}{*}{$\mathbf{N}$} \\
\hline & Generics & & & \\
\hline & & Motivation & & 10 \\
\hline & Specifics & Method & Performance & 8 \\
\hline & & (Total=17) & Organization & 9 \\
\hline & No consequences & & & 1 \\
\hline
\end{tabular}

The largest number of occurrences indicates that the influence will be felt more deeply at the level of motivation and method of work. This is particularly true in regards to issues relating to the method of organizing tasks in either study, or in they performance in the next assessment task.

\section{Conclusions}

In this paper, we set out to find out and work on the reflections that of a group of online learning students has made about their performance in a very specific assessment task. In a first analysis of the responses we observed that these reflections involve mainly factors related to the students or factors that they can control.

The analysis of the answers seems to indicate an emphasis on the concern with issues related to organization and planning of the study. This is evident in both the causes and the conditions to be considered in a future study. However, reading these results should be done in a careful manner and taking into account that the students participated in this study voluntarily and that the majority considered to have a good rating taking as reference the statement given in the previous phase of the study.

From our point of view is important to know the aspects that are taken into account and valued by students to have a good performance. These elements allow us to organize tasks and outline strategies to help students find their own strategies for monitoring and self-regulation of learning, becoming increasingly autonomous and thereby achieving a deeper level of learning. The knowledge that each person has in dealing with learning activities, becomes a powerful tool nowadays (Bjork, Dunlosky \& Kornell, 2013). The understanding of learning activities and associated processes promotes understanding, retention and transfer of learning.

From the point of view of Goulão and Cerezo (2015) to develop self-regulatory competence of students is not only very important to help them achieve success now, but also to ensure future successes. Actions relating to the control of performance have a critical role in the self-regulatory process leading to a monitoring process of learning by the students. This action control allows them to not only detect the weaknesses of the learning process, but also alert to the effectiveness of learning strategies that are being used. (p. 1907).

According to Ertmer and Newby (1996) reflection on the learning process is considered as an essential ingredient to develop more effective learners. In this sense we believe it is important to find strategies that help students monitor their own learning process. This monitoring is a complex process that involves understanding what you're doing, where does that fit into the sequence of the task and also the anticipation and planning of steps to follow. All this happens during the actual act of learning. For Phelp, Hase and Ellis (2001) in the context of rapid transformation, with 'capable' learners, metacognitive strategies provide great advantages and can be 
considered more important than some skills. In this sense the teacher should provide strategies to help the learner become an "expert learner".

Self-regulation plays an extremely relevant role in the learning process of students in general. With regard to distance learning online these processes retains relevance. The self-regulatory capacity of learning is an important factor to overcome procrastination. This importance is increased when we are in online contexts, to provide information to teachers to seek to develop strategies that help reduce procrastination and thus make them more self-regulated learners. Moreover, in the online distance education, with adult learners, when placing the emphasis on the autonomy of the same is necessary they are holders to these competencies to enable them to analyze and understand their learning processes with a view to meaningful learning.

\section{References}

Azevedo,R. \& Cromley, J.G., (2004). Does training on self-regulated learning facilitate student's learning with hypermedia?.Journal of Educational Psychology, 96(3), 523-535

Bjork, R.A., Dunlosky,J. \& Kornell,N. (2013). Self-Regulated Learning: Beliefs, Techniques and Illusions. Annual Review of Psychology, 64,417-444

Blakey, E., \& Spence, S. (2000). Developing metacognition. Syracuse, NY: ERIC Clearinghouse on Information Resources. Retrieved from http://ericae.net/edo/ED327218.htm

Bol,L \& Garner,J.K. (2011). Challenges in supporting self-regulation in distance education environments. Journal Computer High Education, 23, $104-123$

Ertmer, P. A., \& Newby, T. J. (1996). The expert learner: Strategic, self-regulated and reflective. Instructional Science, 24, 1-24.

Goulão, $M^{a}$ F. (2009). Metacognition, Learning Styles and Distance Education. In Subhi-Yamin,T.(Eds), Excellence in Education 2008: Future Minds and Creativity. Proceedings of the Annual Conference of the International Centre for Innovation in Education (pp.224 - 232). ICIE: Ulm- Germany

Goulão, M ${ }^{\mathrm{a} F}$. \& Cerezo, R. (2015). Learner autonomy and self-regulation in eLearning. Procedia - Social and Behavioral Sciences, 174, 1900 - 1907

Hacker, D.J. et al (2009). Metacognition in Education: A focus on Calibration. In Dunlosky,J. \& Bjork,R. (Eds.), Handbook of Memory and Metacognition (pp.149). Mahwah, NJ: Lawrence Erlbaum Associates.

Leclercq, D. \& Denis,B. (1995).Autoformation \& Hypermédias: Qu'est-ce qu'un bon auto-apprenant ?. in Pratiques d'autoformation et d'aide à l'autoformation, Actas do Deuxième colloque européen sur l'autoformation, USTL / CUEEP, pp.155 161

Phelp,R., Ellis,A. \& Hase,S. (2001, December). The role of metacognitive and reflective learning process in developing capable computer users. In in $G$ Kennedy, M Keppell, C McNaught \& $\mathrm{T}$ Petrovic (Eds), Meeting at the crossroads: proceedings of the 18th Annual Conference of the Australasian Society for Computers in Learning in Tertiary Education (ASCILITE) (pp. 481490). University of Melbourne, Biomedical Multimedia Unit, University of Melbourne, Melbourne, Vic. 
Serra, M.J. \& Metalfe,J. (2009). Effective Implementation of Metacognition. In Hacker,D.J. Dunlosky,J. \& Graesser, A.C. (Eds.). Handbook of Metacognition in Education (pp.278-298). New York: Routledge.

Winne,P.H. \& Nesbit,J.C.(2009). Supporting Self-Regulated Learning with Cognitive Tools. In Hacker, D., Dunlosky,J. \& Graesser, A. (Eds). Handbook of Metacognition in Education (pp.259-277). New Yok: Routledge

Zimmerman (2000). Attaining self-regulation: A social cognitive perspective. In Boekaerts,M., Pintrich, P.R. \& Zinder, M. (Eds), Handbook of Sel-Regulation (pp.13-29). San Diego, CA:Academic Press

Zimmerman, B. (1998). Academic studying and the development of personal skill: a self-regulatory perspective. Educational Psychologist, 33(2/3), 73-86 


\title{
The Rubric: An Assessment Tool to Guide Students and Markers
}

\author{
G C Cox*, J Morrison**, B H Brathwaite*** \\ *Senior Lecturer, Middlesex University \\ **Lecturer, Middlesex University \\ ***Senior Lecturer, Hertfordshire University
}

\begin{abstract}
The changing environment for both students and lecturers dictates the requirement for giving feedback on assessment activities rapidly. In order to close this cycle of learning for the student and facilitate the feed-forward process, the development of rubrics has become an essential part of the workload. The rubric tool needs to have clearly stated performance indicators and criteria so that both student and lecturer have the same expectations of the assessment activity. The rubric must be robust enough to be able to capture the balance of being both an easy tool for marking but also detailed enough to give constructive feedback reflecting the learning outcomes. The rubric development, given its complexity, when constructing this tool, can be time consuming but eventually becomes time saving. Thereby reducing the grading workload effort of the lecturer while maintaining the knowledge gained by the students through the assessment activity.
\end{abstract}

Key words: Rubric; VLE; Performance Criteria; Feedback; Feedforward

\section{Introduction}

For the teaching and learning cycle, the word 'rubric' is understood generally to connote a simple assessment tool that describes levels of performance on a particular task and is used to assess outcomes in a variety of performance-based contexts' (Hafner and Hafner, 2003 p, 1509). The rubric as a marking tool and the virtual learning environment (VLE) have both worked their way into nursing education as 'new' way of teaching, learning and assessing students (Lai and Ng 2011). This allows both lecturer and student to develop as the facilitator and interpreter of knowledge and permitting clear ideas of what is expected from the assessment and what is achievable by the student. The rubric, unlike a marking template, is not only focused on giving guidance to marker but includes the student. With the marking templates there is greater capacity for and moreover, an inherent lack of uniformity and parity between markers, born out of each markers interpretation of the marking template. With the requirement of rapid turnaround times, transparent feedback to the student, combined with the ease of access via the VLE and the moderation process to be considered, a clear need has arisen to facilitate the marking process. The progressive movement of the use of technology and the easy access provided by online learning platforms, has created learning conditions where different aspects of feedback can be used (group, individual, audio), to ensure that the students learning is fluent and allows progression of the learning cycle.

Combine the introduction of a new degree nursing curriculum in England (Nursing and Midwifery Council 2010), with the university's e-assessment strategy, and this brought an opportunity to review models of learning and teaching focussing on:-

1. How the student could engage in different ways of learning (e.g. Discussion boards, the flipped classroom, digital stories)

2. The capabilities of VLE (does it do what the lecturer wants?)

3. How best to facilitate submission and feedback within this environment. 
The ideology behind the VLE is to create an engaging learning environment in which students can participate, while they are effectively developing 'clear thinking' and promoting an interactive learning experience (Lewis et al., 2012). Therefore it is of paramount importance to give clear concise performance criteria and provide a forum in which students can create their own learning opportunities. Thus enabling the learner to build a genuine comprehension of the subject matter so they can foster confidence and research skills when conveying their ideas and opinions on a topic, (Pucer et al., 2014). Given these criteria, it becomes imperative that both the lecturer and student have a clear understanding of the performance indicators, hence why the rubric was considered important tool.

\section{The Advantages and Disadvantages of Rubrics}

Andrade and Du (2005) advocate that a rubric as an assessment tool should be used by the student and assessor to give both parties clear understanding of what is expected by either doing task or grading the assessment. This aims to ensure achieving learning outcomes and activating a feed forward mechanism through concise information on how to improve performance whilst enabling student's time to reflect on their work (Truemper 2005).This reflective ethos on work produced, fosters communication and the learning cycle to be completed.

There are many different debates surrounding the use of the rubric tool as an assessment and communication tool, as the themes become clear with the use of parity and gives guidance this is evident from school age to higher education nursing and non-nursing education (Andrade and Du 2005; Caulfield-Sloan and Ruzcika; Hafner and Hafner 2003; Truemper 2004). Mandills et al (2009) support the use of rubrics in primary, secondary, further and higher education context as the grading is seen to be fairer and more consistent. While Beaglehole (2014) focuses on students of school age children in Australia and encourages that clear and specific goals for writing are highly effective.

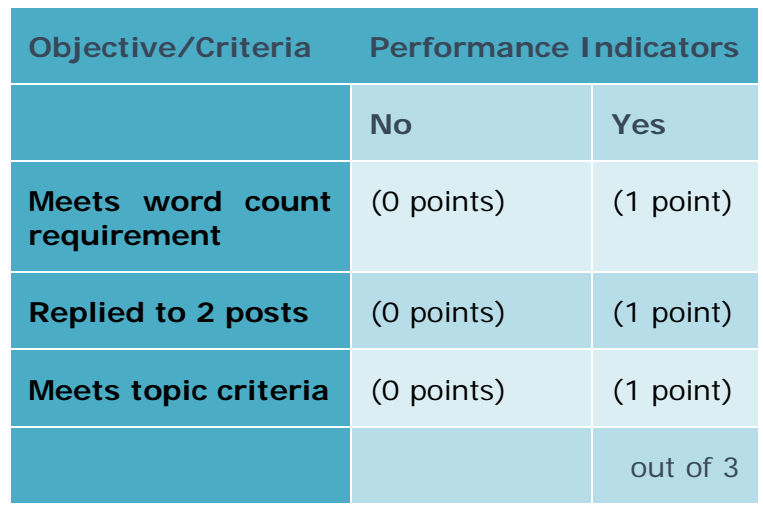

Figure 1 Rubric 1

The rubric as an assessment tool can be either presented as a simple Rubric [yes /no performance indicators Figure1], as was adopted, for example for a non-graded formative discussion board or as a complex Rubric [descriptive banded performance indicators: unsatisfactory, pass, good, very good \& excellent, Figure 2], as it should reflect the assessment learning outcomes (Popham 1997) and should be presented with no confusion of the learning opportunity that needs to be taking place for the student (Vallino 2008). Oppositely, for the marker the rubric should be a tool that is ultimately relies on the ability, knowledge and preparation of the assessor this will be enhanced with the familiarity of the performance criteria.

The other advantage of the rubric when marking is its focus on the specific criteria that the students have to attain for the module (Truemper 2003). Fors and Gunning (2014) 
suggests that the Rubric needs to present a clear set of assignment descriptions/categories and have levels of performance indicators that are the evaluation dimension which may or may not hold a numerical value to them. The

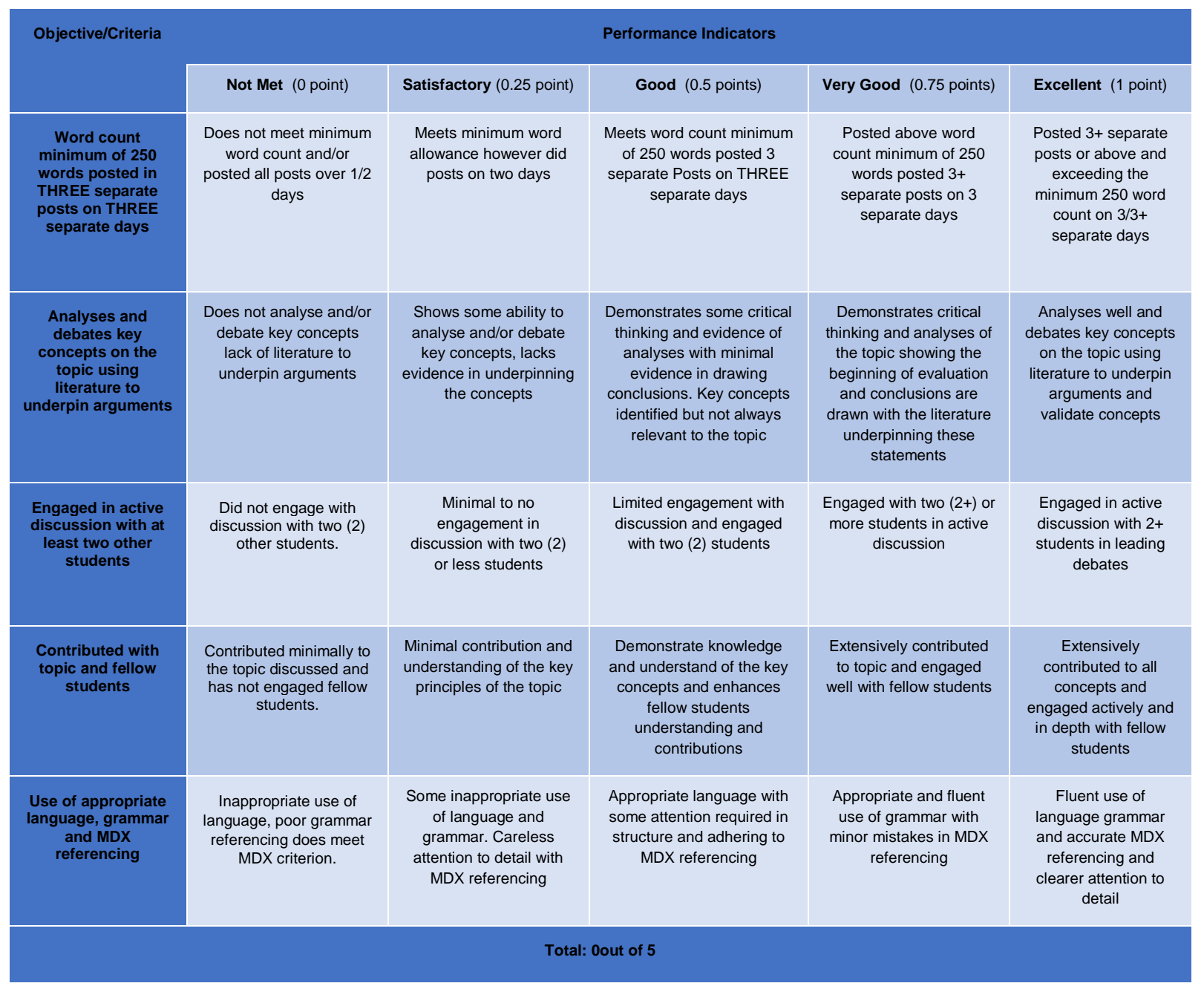

Figure 2 Rubric 2 Complex

indicators are the different categories that the students are required to meet and the performance indicators represent how well these have been achieved.

Rubrics fall into two categories, either 'analytical or multiple trait consisting of multiple, separate scales and therefore provides a set of scores' (Rezaei and Lovorn 2010 p19; Dunbar et al 2006). This loans itself to different types of teaching and assessment strategies enabling use of different tools to assess different aspects of what is required from the student. A holistic rubric will look at the elements combined and give an overall impression of the learning to be achieved, (Dunbar et al 2006; Truemper 2004). It has been agreed that rubric is not simply a checklist or just a checklist (Andrade 2005; Petkov and Petkov 2006). A rubric is only as good as its design, support and explanation in its use and conversely the expectations from the use of the rubric should enhance the learning outcomes for the students. Without this, a rubric can lead to promotion of shallow learning whilst producing conformity and standardisation in the VLE, (Mandills et al 2009). In turn this can create missed learning opportunities for the student as they are only working towards the rubric criteria. There are some criticisms of the use of rubrics in regards to 'validity, reliability and fairness' particularly in relation to students in view of a lack of empirical evidence to support 
effective use of a rubric, (Andrade and Du 2005 p 29). Jonsson and Svingby (2007) propose that effectiveness of rubrics can be examined based on literature at the time of writing. Despite these on-going issues there is growing confidence about the effectiveness of rubrics (Rezaei and Lovorn 2010)

When developing a rubric the lecturer needs to consider the type of assessment being designed eg essay, learning log, discussion board, poster, and whether there is already a marking guide on which to base the rubric. Hence in development of the rubric, Nicol and Mcfarlen-Dick's (2006) seven principles of good feedback should implemented:-

1. Clarify what good performance is

2. Facilitate reflection and self-assessment in learning

3. Deliver high-quality feedback information that helps learners self-correct

4. Encourage teacher-learner and peer dialogue

5. Encourage positive motivational beliefs and self-esteem

6. Provide opportunities to act on feedback

It should be simple to use and the language of the performance indicators should be easily understood by both the lecturers and students (Whittaker, Salend and Duhaney 2001; Wilson and Fairchild 2011). To promote this effect it is critical that the language used in the performance indicators and the categories is transparent and there is no misconception of what is expected from the learning outcomes (Lasater, 2006). Other contributing factors to consider is how the rubric is intended to be used as a feedback mechanism for students, and thereby to continue to improve their comprehension and expectation of the assessment activity (Morgaine, 2010; Frances 2010). When using the rubric as a grading tool and to elicit the engagement of the students through understanding the assessment activity requirements, the main reference to the rubrics for both parties are the differing criteria for each of the performance indicators. These categories have to be accurately represented and achievable. The communication that the rubric gives, enables the students to engage in assessment activity. Hence the use of the language within the rubric must foster a dialogue that works in partnership with the feedback and promotes discussion between the lecturer and the student. Stevens and Levi (2005) sees the rubric as a translator device to gain a level playing field in the learning activity.

The goal of the developing rubric, is to create equal opportunities for the students when engaging with the assessment process and receiving feedback from the lecturer. A result of the changed the learning environment via the VLE for students is to have a constructive influence on student engagement. The VLE gives easy student home-based access with the benefits of developing critical thinking with socialised interaction with others in a learning space (Buckley, et al 2005). A key positive outcome for the lecturers when using the rubric is that the tool being user friendly, it becomes easy to identify the different grading scales that correlate with the performance indicators. This simplifies the marking experience speeding up the process whilst enabling the giving constructive feedback in a timely fashion. It also minimizes the inconsistencies between lecturers and gaining parity in the assessment process. 


\section{Conclusion}

In today's educational environment, the student wants clear guidance and direction to "how is this assessment being graded?" and "what is it that the assessment is asking for?" In return there is increasingly more expectations on the lecturer to engage with a variety of different modes of assessment and to enhance the learning experience of the student. In real terms this means rapid marking and feedback to be ready in a short time frame, therefore the use of a rubric for this purpose is a tool that can facilitate this. However to design an effective rubric requires time and revaluation after each usage. Each rubric should be designed individually to reflect the assessment activity. When starting out it is easier to start simple rather than complex as the road travelled for the rubric is about meeting the needs of the lecturer and the student. The rubric is a grading tool that should communicate the expectation of the assessment activity and used as constructive feedback for the student to feed-forward with the learning concepts obtained from the assessment task.

The performance levels indicators must enable both the lecturer and student to differentiate between levels. Hence the description of these levels needs to be clearly defined and logically sequenced. It should promote recognition of varying levels of performance and encouraging the student to improve and drive own learning to enhance their depth of knowledge. This can be further achieved through the ability to discriminate between performance levels via the use of a range of subjective words in defining these differences. The specificity of the performance indicators needs to demonstrate usefulness, and allow enhanced analysis of the given task.

The development [see Figures 1 and 2] of this rubric was to facilitate fast and effective feedback to feed forward for an online discussion board. It was a way of ensuring that both lecturer and student understood what was required of them. This style of analytic rubric provided the potential for the student to take accountability for their own learning through clear performance criteria. By combining the assessment outcomes with the performance indicators the rubric has been able to provide the students with information regarding what is most important to focus on and where their level and depth of knowledge is in relation to the given assessment. Through reviewing students work and the original rubric against the developing rubric other additional criteria are generated or deleted. This therefore triggered another revision of the rubric which will concentrate on the finer differentiation of levels. How the rubric continues to develop will be dictated by its usage and the revision/evaluation process. In conclusion it be seen that the rubric is not a static thing but a tool that is continually evolving and enhancing the learning process.

\section{References}

Andrade, H., (2005). Teaching with rubrics the good, the bad, and the ugly. College Teaching, 53(1), 27-30.

Andrade, H., Du, Y., (2005). Student perspectives on rubric-referenced assessment. Practical Assessment Research and Evaluation, 10(3), 1-11

Beaglehole, V. (2014) Assessing Writing Using rubrics. Practically Primary. Practically Primary, 19(2), 13-15.

Buckley, K.M., Benya, B., Dudley-Brown, S., (2005). Promoting active learning through on-line discussion board. Nurse Educator, 30(1), 35-36. 
Caulfield-Sloan, M.B., Ruzicka M.F., (2005). The Effect of teachers’ staff development in the use of higher-order questioning strategies on third grade students' rubric science assessment performance. Planning and Changes, 36(3-4), 157 - 175.

Dunbar, N, E., Brooks, C.F., Kubicka-Miller, T., (2006). Oral communication skills in higher education: Using a performance-based Evaluation Rubric to assess communication skills. Innovation Higher Education, 23(2), 115-127.

Fors, U.G.H., Gunning, W.T., (2014). The impact of different scoring rubrics for grading virtual patient -based exams. Journal Education Computing Research, 50(1), 97-119.

Hafner, J., Hafner, P., (2003). Quantitative analysis of the rubric as an assessment tool: an empirical study of student peer-group rating. International Journal of Science Education, 25(12), 1509-1528.

Jonsson, A., Svingby., (2007). The use of scoring rubrics: Reliability, validity and educational consequences. Educational Research Review, 2, 130-144.

Lai, Y.C., Ng, E,M,W., (2012). Using Wikis to develop students teachers' learning, teaching and assessment capabilities. Internet and Higher Education, 14, 15 - 26.

Lasater, K., (2007). Clinical Judgment Development: Using Simulation to Create an Assessment Rubric. Journal of Nursing Education, 46(11), 496 - 503.

Mansilla, V.B., Duraisingh, E.D., Wofle, C.R., and Haynes, C., (2009). Targeted assessment rubric: An empirically grounded rubric for interdisciplinary writing. The Journal of Higher Education, 80(3), 334-353.

Morgaine, W., (2010). Developing Rubrics: lessons learned; Assessing Outcomes and Improving: Tips and tools for Using Rubrics , 11-13. Chicago.

Nicol, D.J., Macfarlane-Dick, D., (2006). 'Formative assessment and self-regulated learning: A model and seven principles of good feedback practice', Studies in Higher Education, 31(2), 199-218.

Nursing and Midwifery Council. (2010). Standards for pre-registration education.

Petkov, D., Petkova, O., (2006). Development of Scoring Rubrics for IS projects as an assessment tool. Information Science and Technology 3, 500 - 509.

Popham, W.J., (1997). What's Wrong - and What's Right- With Rubrics Educational Leadership, 55, 72- 75.

Pucer, P., Trobec, C.I., Zvanut, B., (2014). An information on communication. Technology based approach for acquisition of critical thinking skills. Nursing Education Today, 34 (6) 964-970.

Reddy, Y.M., Andrade, H., (2009). A review of rubric in higher education. Assessment and Evaluation in Higher Education, 35 (4) 435-448.

Rezaei, A.R., Lovorn, M., (2010). Reliability and validity if rubric for assessment through writing. Assessing Writing, 15, 18 -39.

Sadler, B., Andrade, H., (2004). The Writing Rubric. Educational Leadership, 62 (2), 48-52

Song, L., McNary, S.W., (2011). Understanding Students' Online Interaction: Analysis of Discussion Board Postings. Journal of Interactive Online Learning 10 (1) 114.

Stevens, D.D., Levi, A., (2005). Introduction to Rubrics. An assessment tool to save grading time, convey effective feedback and promote student learning. Stylus Publishing, LLC . Virginia 
Truemper, C.M., (2004). Using scoring rubrics to facilitate assessment and evaluation of graduate level nursing students. Journal of Nursing Education, 43, (12) 562-4.

Vallino, J., (2008). Workshop- Rubrics : Start to Finish. Proceedings of 2008 Frontiers in Education Conference, Saratoga Springs, NY.

Whittaker, C.R., Salend, S.J., Duhaney, D., (2001). Creating instructional rubrics for inclusive classrooms. Teaching Exceptional Children, 34(2), 8-13.

Wilson, M., Fairchild, C., (2011). Collaborative learning and the importance of the discussion board. Journal of Diagnostic Medical Sonography, 27(1), 45-51. 
HEAd'15

SESSION 1B COMPETENCES 


\title{
Students' perception of competences development in an undergraduate university environment
}

\author{
R. Gallo-Martínez*, M.C. Alarcón-del-Amo* \\ * Universitat Autònoma de Barcelona, Barcelona, Spain
}

\begin{abstract}
The pressure for universities to generate employable graduates requires the implementation of different ways of managing the learning process. Course programmes have thus been adapted to the new framework where skills and competences development are to be the resulting outcomes of students' stay at university. On-going evaluation systems, in combination with the selection of specific activities, help professors plan for the achievement of this objective. The study carried out in a group of $3^{\text {rd }}$ year Marketing students of Business and Management shows that students identify different activities as both adequate for and effective in competences development. The authors conclude that embedding competences development in course programming is a useful and helpful tool for course management that is well accepted and valued by students.
\end{abstract}

Keywords: Learning process; competences development; course programming

\section{Introduction}

Professionals at all levels of education, whether primary, secondary or terciary (higher) education, living in increasingly knowledge-based societies such as the European Union member countries, do not question the need to help students develop skills and competences allowing them to adequately enter the labor market (EACEA, 2014), which is to say, education, specially higher education, should increase graduates employability (EACEA, 2012).

However, employability is not only a necessary goal of higher education; it is also a “complex concept encompassing many definitions and approaches" (EACEA, 2014, p. 61). In fact, there seem to be two main approaches to help graduates achieve the adequate degree of employability: the employment-centred approach, which is related to increasing "graduates chances of finding employment soon after graduation" (EACEA, 2014, p. 63). Universities develop and implement programmes addressed towards helping students entry into the labor market; including practical training in study programmes, developing seminars about specific issues such as preparing C.V. and job interviews, creating placement offices, etc. (EACEA, 2014).

The other approach is the competences-centred one, where the role of higher education is "to develop the skills and competences of graduates necessary to find a job" (EACEA, 2014, p. 64), furthermore, "students' knowledge, skills and competences are expressed as the learning outcomes of the education process" (EACEA, 2010, p. 22). A learning outcome is understood to be a statement "of what a learner is expected to know, understand and/or be able to demonstrate at the end of a period of learning" (Adam, 2006), learning outcomes "chief advantage is the clarity and precision they bring to any curriculum development process” (Adam, 2006).

The competences-centred approach requires that education professionals, in this case higher/terciary education professors, understand their job to be student centred. Not a small challenge. According to the Eurydice Report: The European Higher Education Area in 2012 "genuine student-centred learning is (...) difficult to integrate into everyday higher education reality. It should comprise actions that ensure that students learn how to think critically, participate in all kinds of academic life and are given more 
independence and responsibility.” (EACEA, 2010, p. 25). The approach that can be found in Spain is this second one, the competences-centred approach. Although many Spanish Universities also implement employment-centred activities.

This article focuses on the analysis of students' perception of competences development and the adequacy of the tools used to help them develop these competences. This analysis was performed within a third year (junior) marketing course: Marketing I (Course 102353_04 Facultat d'Economia I Empresa, Universitat Autònoma de Barcelona -UAB).

The course program is designed according to an UAB model that is built on several assumptions, being one of them the fact that "competencies needed to be effective can be developed" (Boyatzis, 2008). Another one is that the "development of competencies needed to be effective managers and leaders require program design and teaching methods focused on learning” (Boyatzis, 2008).

\section{Course Programing}

The Marketing I course program includes, therefore, a list of 17 learning outcomes that can be organized into two categories, course specific and transversal learning outcomes, but can also be organized in the three categories established by Katz in 1974; technical skills, human skills and conceptual skills (Katz ,1974; Parente, 2012). These skills include analysis, critical thinking and problem solving (hard skills according to different authors (Parente, 2012)) as well as soft skills, related to dealing with others, such as communication skills and team work, information and knowledge sharing (Parente, 2012), as well as related to dealing with one-self, such as being able to organize one's learning process, time management, and information selection and generation among others.

Marketing I sessions were programed by the author-teacher with a "co-responsibitily" framework of mind. Both the professor and the student are responsible of the outcome of their interaction in Marketing I. The professor is to organize sessions' contents and activities in order to help students develop the learning outcomes of the course, and students are to invest the time, effort, as well as willingness and enthusiasm required for these learning outcomes to come true.

With this objective in mind both contents and activities were programmed. Activities include exercises, cases, articles and readings, oral presentations, and mind maps generation. Activities may be individual or in group, in order to help students develop competences related to dealing with others. Each type of activity is intended to help students develop specific competences, and may be to related more than one competence. Table 2 shows which competences are related to each type of activity.

Each activity was programmed at least twice during the course (15 weeks) in order for the learning process, usually cumulative, to take place. In that way students could incorporate the learning $s$ of the first time each activity was performed and see their own improvement the second time each activity was carried out.

\section{Methods}

The sample was composed by students enrolled on Marketing I UAB -ADE, English track $3^{\text {rd }}$ year. A total of 52 students were studied). Most of them were students from 
20 to 22 years old (82.7\%), 69.2\% female and 30.8\% male, both local (36.5\%) and Erasmus students (63.5\%).

The research instrument used in this research was a questionnaire that included personal characteristics, opinions, satisfaction and recommendation. Specifically a two-wave cross-section was conducted during the second semester of the academic course 201314.

The first wave was conducted at the beginning of the course asking questions about their expectations with regard the different activities that they will develop during the course and the objectives that they thought these activities would help achieve. Selfreport indicators of these expectations were measured by the items "Do you think these activities can help students achieve the objectives related to them?", to each activity and each objective. The questions had to be answered on a Liker scale ranging from strongly disagree (1) to strongly agree (5).

The second wave was conducted at the end of the semester, after completing the course, asking about their opinion with regard to the different activities and the objectives/capabilities that they had helped improve. This second questionnaire contained items similar to the previous questionnaire, but the general question was "Do you think these activities have helped you develop or improve your capabilities?”, to each activity and each capability. The questions had to be answered also on a 5-point Likert scale. In addition, in this questionnaire questions regarding the general satisfaction with the course and the intention to recommend it were included. The level of satisfaction was assessed by one item "What is your degree of satisfaction with the course?”, a 5-point Likert-scale was used. In addition, recommendation was also measured by one item "Would you recommend other students to take this course?", measured with a 5-point Likert scale.

The data collected were computed and analysed using the SPSS 19. The frequency and percentages of the responses to the specific questions were calculated. We used chisquared analysis to analyse whether the personal characteristics of the students influenced some of their responses. Spearman's rho rank-order correlations, which is a non-parametric test that is used to measure the degree of association between two ranked variables (Myers et al., 2010), were used to investigate any significant correlations between the ordinal scales, that is, those which were measured by 5-point Likert scales. The correlations were measured between the objectives that they thought they could achieve developing the different activities, and the capabilities they thought that they had improved with these activities, the general satisfaction of the course and the possibility of recommendation. 


\section{Results and Discussion}

\section{Descriptive analysis}

Table 1 presents the different activities, the objectives assigned to each activity and the degree of opinion about whether these activities can help achieve these objectives ("Can help" column) and if have finally helped to achieve them ("Have helped" column). Students understand activities programmed to be adequate tools for competences development, and they acknowledge these activities have been effective in developing and/or improving the specified competences.

Table 1. Objectives and capabilities that students thought that the activities could help to acquire and which have finally have help to acquire

\begin{tabular}{|c|c|c|c|c|}
\hline Activity & Objectives & Opinion categories & Can help & Have helped \\
\hline \multirow{4}{*}{ Exercises } & \multirow{4}{*}{$\begin{array}{l}\text { Illustrate specific concepts related } \\
\text { to a given topic }\end{array}$} & 2 - Disagree & $1.9 \%$ & $5.8 \%$ \\
\hline & & 3 - Neutral & $11.5 \%$ & $21.2 \%$ \\
\hline & & 4 - Agree & $69.2 \%$ & $61.5 \%$ \\
\hline & & 5 - Strongly agree & $17.3 \%$ & $11.5 \%$ \\
\hline \multirow{12}{*}{ Cases } & \multirow{4}{*}{$\begin{array}{l}\text { Illustrate. Use and apply models of } \\
\text { analysis studied in class }\end{array}$} & 2 - Disagree & $0.0 \%$ & $1.9 \%$ \\
\hline & & 3 - Neutral & $5.8 \%$ & $21.2 \%$ \\
\hline & & 4 - Agree & $65.4 \%$ & $59.6 \%$ \\
\hline & & 5 - Strongly agree & $28.8 \%$ & $17.3 \%$ \\
\hline & \multirow{4}{*}{$\begin{array}{l}\text { Models. Develop diagnosis } \\
\text { capabilities }\end{array}$} & 2 - Disagree & $1.9 \%$ & $3.8 \%$ \\
\hline & & 3 - Neutral & $28.8 \%$ & $30.8 \%$ \\
\hline & & 4 - Agree & $48.1 \%$ & $50.0 \%$ \\
\hline & & 5 - Strongly agree & $21.2 \%$ & $15.4 \%$ \\
\hline & \multirow{4}{*}{$\begin{array}{l}\text { Diagnosis. Develop a systemic } \\
\text { understanding of a given business } \\
\text { situation }\end{array}$} & 2 - Disagree & $5.9 \%$ & $5.8 \%$ \\
\hline & & 3 - Neutral & $21.6 \%$ & $25.0 \%$ \\
\hline & & 4 - Agree & $49.0 \%$ & $48.1 \%$ \\
\hline & & 5 - Strongly agree & $23.5 \%$ & $21.2 \%$ \\
\hline \multirow{8}{*}{$\begin{array}{l}\text { Articles } \\
\text { and } \\
\text { readings }\end{array}$} & \multirow{4}{*}{$\begin{array}{l}\text { Knowledge. Acquire } \\
\text { complementary knowledge about a } \\
\text { given topic }\end{array}$} & 2 - Disagree & $7.7 \%$ & $7.7 \%$ \\
\hline & & 3 - Neutral & $25.0 \%$ & $21.2 \%$ \\
\hline & & 4 - Agree & $44.2 \%$ & $53.8 \%$ \\
\hline & & 5 - Strongly agree & $23.1 \%$ & $17.3 \%$ \\
\hline & \multirow{4}{*}{$\begin{array}{l}\text { Analytical. Develop analytical } \\
\text { capabilities }\end{array}$} & 2 - Disagree & $3.8 \%$ & $3.8 \%$ \\
\hline & & 3 - Neutral & $34.6 \%$ & $46.2 \%$ \\
\hline & & 4 - Agree & $53.8 \%$ & $36.5 \%$ \\
\hline & & 5 - Strongly agree & $7.7 \%$ & $13.5 \%$ \\
\hline \multirow{9}{*}{$\begin{array}{l}\text { Oral } \\
\text { presentati } \\
\text { ons }\end{array}$} & \multirow{5}{*}{$\begin{array}{l}\text { Group work. Be able to work in } \\
\text { work (negotiation, job } \\
\text { coordination) }\end{array}$} & 1 - Strongly disagree & $0.0 \%$ & $1.9 \%$ \\
\hline & & 2 - Disagree & $7.7 \%$ & $9.6 \%$ \\
\hline & & 3 - Neutral & $21.2 \%$ & $19.2 \%$ \\
\hline & & 4 - Agree & $40.4 \%$ & $48.1 \%$ \\
\hline & & 5 - Strongly agree & $30.8 \%$ & $21.2 \%$ \\
\hline & \multirow{4}{*}{$\begin{array}{l}\text { Present Orally. Be able to present } \\
\text { orally to an audience the results of } \\
\text { your work }\end{array}$} & 2 - Disagree & $7.7 \%$ & $5.8 \%$ \\
\hline & & 3 - Neutral & $9.6 \%$ & $25.0 \%$ \\
\hline & & 4 - Agree & $50.0 \%$ & $40.4 \%$ \\
\hline & & 5 - Strongly agree & $32.7 \%$ & $28.8 \%$ \\
\hline \multirow{5}{*}{$\begin{array}{l}\text { Individua } \\
1 \text { mind } \\
\text { map }\end{array}$} & \multirow{5}{*}{$\begin{array}{l}\text { Develop a global understanding of } \\
\text { a specific issue, and the relations } \\
\text { between topics }\end{array}$} & 1 - Strongly disagree & $0.0 \%$ & $9.6 \%$ \\
\hline & & 2 - Disagree & $23.1 \%$ & $15.4 \%$ \\
\hline & & 3 - Neutral & $23.1 \%$ & $21.2 \%$ \\
\hline & & 4 - Agree & $34.6 \%$ & $34.6 \%$ \\
\hline & & 5 - Strongly agree & $19.2 \%$ & $19.2 \%$ \\
\hline
\end{tabular}


Regarding satisfaction and recommendation, which is also other way to measure the satisfaction (Keiningham et al., 2007), in general, students are satisfied (55.8\% satisfied and $25 \%$ strongly satisfied) and will recommend other students to take this course (38.5\% agree and 38.5\% strongly agree). It is worth noting that no student was strongly dissatisfied or strongly disagreed.

\section{Chi-square test for independence}

Given two categorical variables, the chi-squared test of independence determines whether or not there exists a statistical dependence between them, that is, whether the proportions for one variable are different among values of the other variable.

In our case, we analyse whether or not there is an association between sociodemographic characteristics (gender, age, Erasmus or not and student characteristics) and opinion about the objectives that can or have helped achieve each activity.

We conclude that there is no association between the variables under consideration (pvalue $>0.05$ ), except for gender and the opinion that "Articles and readings" can help to achieve the objective "Acquire complementary knowledge about a given topic" (ChiSquare=10.969; Sig. $=0.012$ ). Most women do agree that articles and readings can help increase knowledge (52.8\% do agree and $22.2 \%$ do strongly agree) and a minor percentage is neutral (25\%). However, men's opinion is equally distributed from disagree to strongly agree ( $25 \%$ in each category)

\section{Correlation analysis: Spearman's rho test}

Correlation is a bivariate analysis that measures the strengths of association between two variables. The value of the correlation coefficient varies between +1 and -1 . Specifically, coefficients between 0.10 and 0.29 represent a small association; coefficients between 0.30 and 0.49 represent a medium association; and coefficients above 0.50 represent a large association or relationship (Corder and Formena, 2014). We will focus on Spearm rank correlation. This test does not make any assumptions about data distribution and is the appropriate correlation analysis when the variables are measured on a scale that is at least ordinal (Lehman, 2005; Spearman, 1904).

We will analyse the correlation between the opinion about whether the activities under consideration can help develop or improve certain capabilities before and after carrying them out, and the perception of whether they have finally helped achieve the objectives, and the general satisfaction level and recommendation intentions.

Table 2 shows Rho test for all the variables under consideration. It is worth noting that, regardless of significance, all Rho test values are positive (Rho $>0$ ), indicating a direct positive relationship between variables, that is, they move in the same direction.

Regarding the opinions about whether the different activities have helped achieve the objectives under consideration, significant correlations were found with the opinions they had at the beginning of the course regarding whether they thought they could help $(p<0.05)$. The Rho test shows a large association or relationship for each variable (Rho>0.50), except for "Exercises" can and have helped illustrate specific concepts and "Cases" can and have helped develop diagnosis capabilities, which represent a medium association (Rho between 0.30 and 0.49 ).

In the second block of variables listed in Table 5, the relationship between the opinion about the objectives that the different activities have helped achieve and the satisfaction of the course are presented. We can observed that there is not significative correlation between the general satisfaction of the course and the opinion about whether the 
"Cases" have helped develop diagnosis capabilities, "Articles and readings" have helped develop analytical capabilities and "Oral presentations" have helped being able to work in work (negotiation, job coordination) and being able to present orally to an audience the results of your work ( $p>0.05)$. However, there is a medium association between the level of satisfaction and the opinion about the "Exercises" have helped illustrate specific concepts related to a given topic, "Cases" have helped use and apply models of analysis studied in class", "Articles and readings" have helped acquire complementary knowledge about a given topic, and "Mind map" has helped develop a global understanding of a specific issue, and the relations between topics (Rho between 0.30 and $0.49 ; \mathrm{p}<0.05$ ). Finally, there is a small association between satisfaction and opinion about "Cases" have helped develop diagnosis capabilities (Rho=0.296; $\mathrm{p}<0.05)$.

In the third block of variables in Table 2, the relationship between the opinion about the objectives that the different activities have helped achieve and the probability of recommending other students to take this course are presented. It is worth noting that there is not significative correlation between the possibility of recommending the course and the opinion about whether the "Exercises" have helped illustrate specific concepts related to a given topic, "Articles and readings" have helped develop analytical capabilities, and "Oral presentations" have helped being able to work in work and to present orally to an audience the results of your work ( $>0.05$ ). However, there is a large association between the possibility of recommendation and the opinion of "Articles and readings" have helped acquire complementary knowledge about a given topic (Rho=0.518; $\mathrm{p}<0.05$ ). Oh the other hand, there is a medium association between the possibility of recommendation and the opinion that "Cases" have helped use and apply models of analysis studied in class, develop diagnosis capabilities and develop a systemic understanding of a given business situation, and "Mind maps" have helped develop a global understanding of a specific issue, and the relations between topics (Rho between 0.30 and $0.49 ; \mathrm{p}<0.05$ ).

Finally, it is worth noting that there is a positive and large association between the satisfaction with the course and the probability of recommending it $(\mathrm{Rho}=0.715 ; \mathrm{p}<0$ 005). If a student is satisfied with the course, there would be a high probability of recommending other students to take this course. 
Table 5. Spearman's Rho test

\begin{tabular}{|c|c|c|c|}
\hline & & Rho & $\begin{array}{l}\text { Sig. (2- } \\
\text { tailed) }\end{array}$ \\
\hline Have helped: EXERCISES concepts & Can help: EXERCISES & 0.493 & $0.000 * *$ \\
\hline Have helped: CASES_Illustrate & Can help: CASES Illustrate & 0.601 & $0.000 * *$ \\
\hline Have helped: CASES_models & Can help: CASES models & 0.545 & $0.000 * *$ \\
\hline Have helped: CASES_diagnosis & Can help: CASES diagnosis & 0.401 & $0.004 * *$ \\
\hline $\begin{array}{l}\text { Have helped: ARTICLES AND } \\
\text { READINGS Knowledge }\end{array}$ & $\begin{array}{l}\text { Can help: ARTICLES AND } \\
\text { READINGS Knowledge }\end{array}$ & 0.803 & $0.000 * *$ \\
\hline $\begin{array}{l}\text { Have helped: ARTICLES AND } \\
\text { READINGS_Analytical }\end{array}$ & $\begin{array}{l}\text { Can help: ARTICLES AND } \\
\text { READINGS Analytical }\end{array}$ & 0.600 & $0.000 * *$ \\
\hline Have helped: ORAL PRES_Group work & Can help: ORAL PRES Group work & 0.714 & $0.000 * *$ \\
\hline Have helped: ORAL PRES_oral pres & Can help: ORAL PRES oral pres & 0.663 & $0.000 * *$ \\
\hline Have helped: MIND MAP & Can help: MIND MAP & 0.651 & $0.000 * *$ \\
\hline Have helped: EXERCISES concepts & Satisfaction & 0.364 & $0.008 * *$ \\
\hline Have helped: CASES_Ilustrate & Satisfaction & 0.336 & $0.015^{*}$ \\
\hline Have helped: CASES_models & Satisfaction & 0.296 & $0.033 *$ \\
\hline Have helped: CASES_diagnosis & Satisfaction & 0.263 & 0.060 \\
\hline $\begin{array}{l}\text { Have helped: ARTICLES AND } \\
\text { READINGS Knowledge }\end{array}$ & Satisfaction & 0.438 & $0.001 * *$ \\
\hline $\begin{array}{l}\text { Have helped: ARTICLES } \\
\text { READINGS_Analytical }\end{array}$ & Satisfaction & 0.196 & 0.164 \\
\hline Have helped: ORAL PRES_Group work & Satisfaction & 0.235 & 0.093 \\
\hline Have helped: ORAL PRES_oral pres & Satisfaction & 0.103 & 0.468 \\
\hline Have helped: MIND MAP & Satisfaction & 0.426 & $0.002 * *$ \\
\hline Have helped: EXERCISES concepts & Recommendation & 0.262 & 0.060 \\
\hline Have helped: CASES_Ilustrate & Recommendation & 0.464 & $0.001 * *$ \\
\hline Have helped: CASES_models & Recommendation & 0.307 & $0.027 *$ \\
\hline Have helped: CASES_diagnosis & Recommendation & 0.399 & $0.003 * *$ \\
\hline $\begin{array}{l}\text { Have helped: ARTICLES AND } \\
\text { READINGS_Knowledge }\end{array}$ & Recommendation & 0.518 & $0.000 * *$ \\
\hline $\begin{array}{l}\text { Have helped: ARTICLES AND } \\
\text { READINGS_Analytical }\end{array}$ & Recommendation & 0.259 & 0.064 \\
\hline Have helped: ORAL PRES_Group work & Recommendation & 0.168 & 0.234 \\
\hline Have helped: ORAL PRES_oral pres & Recommendation & 0.027 & 0.851 \\
\hline Have helped: MIND MAP & Recommendation & 0.346 & $0.012 * *$ \\
\hline Satisfaction & Recommendation & 0.715 & $0.000 * *$ \\
\hline
\end{tabular}

*Sig. $<0.05$ (2-tailed)

$* *$ Sig. $<0.01$ (2-tailed)

\section{Conclusions}

As suggested by different authors (Andrews et al., 2012; Boyatzis et al., 2008), embedding competences development in different courses is possible provided it is taken into account when programming the course. Our research shows students agree with this and acknowledge their having generated and/or improved the sought after competences. We conclude that when both professor and students involvement is high, results and satisfaction are positive.

Students understand their investment in the course has effectively helped them grow not only in knowledge, but also in competences development (students think activities can help, they acknowledge activities have helped, they are satisfied). Therefore, probably, one of the reasons for the high degree of satisfaction is the professor's practical approach and students' involvement required for this course. 
This research also suggests female students, prefer reading as a learning strategy for the acquisition of complementary knowledge. In spite of the chi-square test being adequate for this size sample, a future research line could be to analyze a bigger sample and find out whether male or female students show different preferred learning strategies. Another future research line is related to the optimum combination of activities required for the development of specific competences.

\section{References}

Adam, S. (2006). An introduction to learning outcomes: A consideration of the nature, function and position of learning outcomes in the creation of the European Higher Education Area. In E. Froment, J. Kohler, L. Purser, \& L. Wilson (Eds.), EUA Bologna Handbook - Making Bologna Work. Berlin: Raabe Verlag.

Andrews, G., \& Russell, M. (2012). Employability skills development Higher Education. Skills and Work Based Knowledge, 2(1), 33-44.

Boyatzis, R., \& Saatcioglu, A. (2008). A 20-year view of trying to develop emotional, socialand cognitive intelligence competencies in graduate management education. Journal of Management Development, 27(1), 92-108.

Corder, G. W., \& Foreman, D. I. (2014). Nonparametric Statistics: A Step-by-Step Approach. John Wiley \& Sons.

EACEA/Eurydice (2010). New Skills for New Jobs. Policy initiative in the field of education: Short Overview of the current situation in Europe. Bruselas: Eurydice p9.

EACEA/Eurydice (2012). The European Higher Education Area in (2012): Bologna process Implementation Report. Bruselas: P9 Eurydice.

EACEA/Eurydice (2014). Modernisation of Higher Education in Europe: Access, Retention and Employability 2014. Eurydice Report. Luxemburg Publications Office.

Katz, R. L. (1974). Skills of an effective administrator. Harvard Business Review, 51(5), 90-102.

Keiningham, T. L., Cooil, B., Andreassen, T. W., \& Aksoy, L. (2007). A longitudinal examination of net promoter and firm revenue growth. Journal of Marketing, 71(3), 39-51.

Lehman, A. (2005). JMP for basic univariate and multivariate statistics: a step-by-step guide. Cary, NC: SAS Institute.

Myers, J. L., Well, A., \& Lorch, R. F. (2010). Research design and statistical analysis. New York: Routledge.

Parente, D. H., Stephan. J. D., \& Brown. R. C. (2012). Facilitating the acquisition of strategic skills Management Research Review, 35(11), 1004-1028.

Spearman, C. (1904). The proof and measurement of association between two things. The American journal of psychology, 15(1), 72-101. 


\title{
Teamwork competence assessment
}

\author{
E Viles*, C Jaca*, M Zárraga-Rodríguez** \\ * Tecnun (University of Navarra) \\ ** ISSA (University of Navarra)
}

\begin{abstract}
Teamwork is an important competence to be developed among students and this paper presents a case study related with teamwork competence assessment and development. Several processes take place during team assignment among students. We consider that the development of teamwork competence is related with being efficient in those processes. From a literature review of the processes that arise during teamwork, we present a evaluation tool which includes formative feedback in order to help students to target their own teamwork competence development. By providing students with guidelines for improvement, it seems reasonable to expect a better performance in subsequent experiences and thus it is also reasonable to assume the progressive competence development. A total of 58 teams from a Bachelor's Degree Programme in Industrial Engineering have been evaluated with this tool and therefore some conclusions are presented.
\end{abstract}

Keywords: Teamwork, competences, higher education

\section{Introduction}

Under the new European Higher Education Area it has been necessary to design learning and evaluation models in accordance with the Bologna guidelines which imply moving from acquiring knowledge to developing competences. In particular, in this paper, we are focused on teamwork competence and its development.

Students' teamwork competence is not developed just by working together on an assignment and involves the acquisition of different skills. Moreover, teamwork competence is obtained through a process that is difficult to tackle if students do not receive justified feedback on their performance as part of work teams (Marin-Garcia et al., 2008, Martinez-Gomez \& Marin-Garcia, 2009). This feedback will help the students to improve their performance in next team assignments. Students' acquisition of teamwork competence is a continuous and progressive process. Teachers should monitor this process and, in order to assess teamwork competence development, evidences regarding students' performance during their learning experiences need to be collected and analyzed.

During a team assignment among students several processes take place. According to the literature review, those processes are participation, conflict management, problem solving, internal communication / mutual respect / trust, external communication / feedback, collaboration / cooperation and leadership. We consider that to the extent that the students are efficient in relation to those processes, their teamwork competence development is enabled. There already exists a tool for assessing the performance of the team regarding those processes (Viles et al., 2013). In this work we are focused on the assessment of the individual performance of each student.

Usually, the teacher tries to assess the individual performance of each student; however nobody argues today about the need of finding new ways to assess competences taking into account not only the teachers' perceptions but also the perceptions of the others agents involved in teamwork, i.e., the students. In order to evaluate students' performance the use of peer ratings and self-evaluations are evidenced to be useful techniques that will help students to improve their individual performance. In this context the paper present a case study related with the assessment of teamwork 
competence among students. We present a tool that allows self-assessment and peer evaluation of students' performance during a team assignment. It also allows giving formative feedback to the students on their performance as part of work teams. By providing students with this formative evaluation, it seems reasonable to expect a better performance in subsequent experiences and thus it is also reasonable to expect the progressive competence development.

A total of 224 students involved in 58 teams from a Bachelor's Degree Programme in Industrial Engineering participated in the case study and some conclusions from this experience are presented.

\section{Conceptual framework}

\section{Self-assessment and peer review}

Self-assessment and peer review have been deployed in some areas of education for many years. The disciplines areas where this type of assessment is used are varied and it is used across a very wide range of educational stages, from school to higher education and even in professional post courses. While some authors discuss about the lack of reliability or validity of this type of assessments, in contrast, others mention that formative assessment can help students to plan their own learning, identifying their own strengths and weaknesses, in order to direct their efforts to specific areas for improvement actions and to develop other personal and professional skills (Boud et al., 1990; Boud \& Fachikov, 2006; Falchikov \& Goldfinch, 2000; Brown \& Knight, 2004; Topping, 2003).

Regarding teamwork, some authors have provided valuable research on the assessment of team members (Chalupa,Chen \& Sormunen-Jones, 2000; Gueldenzoph \& May, 2002). Specifically, Gueldenzoph and May (2002) mention some best practices in order to achieve and effective evaluation process. Creating an effective evaluation tool and implementing formative feedback are some critical aspects which have to be taken into account. Crews and North (2000) suggest that formative evaluation should be conducted throughout collaborative experience. Peer ratings help students to develop teamwork competence (Oakley eta al., 2004) and anonymous peer feedback is recommended as a way to shape members' teamwork skills (Parratt et al.,2014). If students can receive continual feedback on their team performance, group members could modify their behavior as necessary to assure the correct acquisition of the competence.

\section{Processes that arise during teamwork}

Several processes occur during teamworking and affect the team performance and its effectiveness. These processes are divided into two groups: operational processes and emergent states (Markset al., 2001). Operational processes are included in the different models of teamwork (Cohen \& Bailey, 1997; Kozlowski \& Ilgen, 2006; Mathieu, Heffner, Goodwin, Cannon-Bowers, \& Salas, 2008, McGrath, 1964). These processes describe functions and interactions that occur during teamwork and how they are managed in order to perform team tasks (OP1-OP7). Emerging states consist of motivational processes that capture trends, relationships between team members and affective reactions (ES1-ES4). These processes involve a dynamic display, which tends to be stable over time (Kozlowski \& Ilgen, 2006). Our understanding of these processes is consistent with the proposals of different authors as shown below. 
OP1: Participation - refers to the extent to which team members have an active role in the development of the work and how decisions are made. (DeDreu \& West, 2001; Sheppard et al., 2004)

OP2: Conflict management - refers to how conflicts are valued in the team and if they are properly managed. (Bolton, 1999; Kozlowski \& Ilgen, 2006; Oakley et al., 2007; Sheppard et al., 2004).

OP3: Problem solving - refers to the ability to solve problems, which is related to the team's goal of improving. (Sheppard et al., 2004; Thylefors et al., 2005).

OP4: Internal communication / mutual respect / trust - is in relation with proper and effective communication. (Brooks \& Ammons, 2003; Delson, 2001; Oakley et al., 2007; Sheppard et al., 2004; Zander, 1994).

OP5: External communication and feedback - refers to the extent to which the team has access to information and is duly listened to by the organization. (Delson, 2001; Oakley et al., 2007; Seat \& Lord, 1999).

OP6: Collaboration and cooperation - refers to the extent to which team members work on a voluntary basis to achieve the objectives that have been established. (Gratton \& Erickson, 2007; Lopez-Paniagua et al., 2011.).

OP7: Leadership - refers to the internal team leader ( Zaccaro et al., 2001).

ES1: Team Learning. This learning refers to knowledge embedded within the team (Edmondson, 1999). The capabilities accumulate and improve as team members accrue experiences and learn how to work together better (Kozlowski \& Ilgen; 2006).

ES2: Team climate. Climate refers to "the set of norms, attitudes and expectations that individuals perceive to operate in a specific social context.” (Pirola-Merlo et al., 2002). Creating a positive team climate implies creating conditions and an atmosphere in which individuals can speak up and express concerns (Leonard et al., 2004).

ES3: Mutual trust. Trust in a team is the shared belief that team members will perform their roles and protect the interests of their teammates (Salas et al., 2005).

ES4: Motivation. Motivation is related with the sense of collective confidence and taskbased cohesion with regard to mission accomplishment (Marks et al., 2001). This includes encouraging team members to perform better or to maintain high levels of performance by communicating their beliefs about team ability, competence in particular tasks and being leaders involved with the development of the project. (Guzzo \& Dickinson, 1996).

\section{Case study}

The case study presented in this paper was designed to assist the development of students' teamwork competence. For this purpose we both measured students' individual performance and provided such information to students involved. Moreover, a proposal of actions leading to improve that performance was also provided to the students.

A total of 224 students were involved in the experience, who were attending at the firstyear subject of a Bachelor's Degree Programme in Industrial Engineering. In this subject, students had to do an assignment in groups of 4 members and therefore a total of 58 teams took part in the case study. 
Once students had completed the assignment each student was asked to individually rate their own performance and the performance of each of his teammates. Items in the questionnaire used to collect the data were defined taking into account several proposals (Viles et al., 2013; Oakley et al., 2007; Gueldezoph \& May, 2002 among others). The questionnaire was developed in a web platform and the link to the questionnaire was sent to the students via mail. The aim of the questionnaire and how to answer it (instructions and dates) were also explained in the mail. As a condition to know the final mark of the assignment, each student had to respond to the questionnaire.

\section{The Tool}

To measure student performance, we elaborated an evaluation tool based on a questionnaire which evaluates the student performance within the team from both their own point of view and the point of view of the other team components. From data collected in the questionnaires we draw a individual student performance radar graph. To provide adequate feedback to the student, each student received an evaluation file with his or her individual radar graph together with a set of guidelines for teamwork competence improvement.

The questionnaire was designed to assess the operational processes that arise once a team is working on an assignment. Although the analysis of the teamwork emerging states would be also interesting, it is quite difficult to evaluate. On one hand, the establishment of scales in this case is more complex. On the other hand, the literature indicates that emerging states tend to stabilize over time as the teams remain (Ilgen et al., 2005; Mathieu et al., 2008), and this characteristic hardly occurs in a degree or teaching cycle where the teams often are exclusively formed for a particular assignment. Therefore, the questionnaire measures only the operational processes, not the emerging states.

Table 1 presents the specific items in the questionnaire related with the operational processes they aimed to assets using a scale from 1(never) to 5 (always).

Table 1. Operational processes and items in the questionnaire

\begin{tabular}{|c|c|}
\hline Process & Items in the questionnaire \\
\hline \multirow{3}{*}{ OP1: Participation } & The student has attended team meetings punctually. \\
\hline & $\begin{array}{l}\text { The student has assumed and performed the role and the tasks that } \\
\text { have been assigned to him. }\end{array}$ \\
\hline & The student has actively participated in decision making. \\
\hline OP2: Conflict management & $\begin{array}{l}\text { The student has exposed his opinion in an impartial and constructive } \\
\text { way }\end{array}$ \\
\hline OP3: Problem solving & $\begin{array}{l}\text { The student has analyzed problem information and has proposed } \\
\text { solutions }\end{array}$ \\
\hline \multirow{2}{*}{$\begin{array}{l}\text { OP4: Internal } \\
\text { communication / mutual } \\
\text { respect / trust }\end{array}$} & $\begin{array}{l}\text { The student has paid attention to the opinion of his teammates with } \\
\text { respect for them }\end{array}$ \\
\hline & $\begin{array}{l}\text { The student has been open-minded to different ways of thinking and } \\
\text { working }\end{array}$ \\
\hline $\begin{array}{l}\text { OP5: External } \\
\text { communication and } \\
\text { feedback }\end{array}$ & The student is aware of external factors that may affect the teamwork \\
\hline
\end{tabular}




\begin{tabular}{ll}
\hline Process & Items in the questionnaire \\
\hline $\begin{array}{l}\text { OP6: Collaboration and } \\
\text { cooperation }\end{array}$ & $\begin{array}{l}\text { The student has made contributions in team meetings } \\
\text { The student has cooperated with the overall team effort (analysis, } \\
\text { resolution and completion of the report) }\end{array}$ \\
\hline OP7: Leadership & The student has been the leader planning and organizing the team
\end{tabular}

Once the questionnaires were fulfilled, data collected were processed in order to obtain for each student and for each process the following information: auto-assigned score and an average of the scores given by his teammates. This information was summarized using individual radar graphs which were delivered to students in a document or file. The radar graph allowed the student to compare his own perception with the perceptions of his teammates about his performance. Every student knows the average of the scores assigned by their peers; therefore, anonymity in response is guaranteed.

Figure 1 shows an example of an individual radar graph together with some guidelines for teamwork competence improvement.

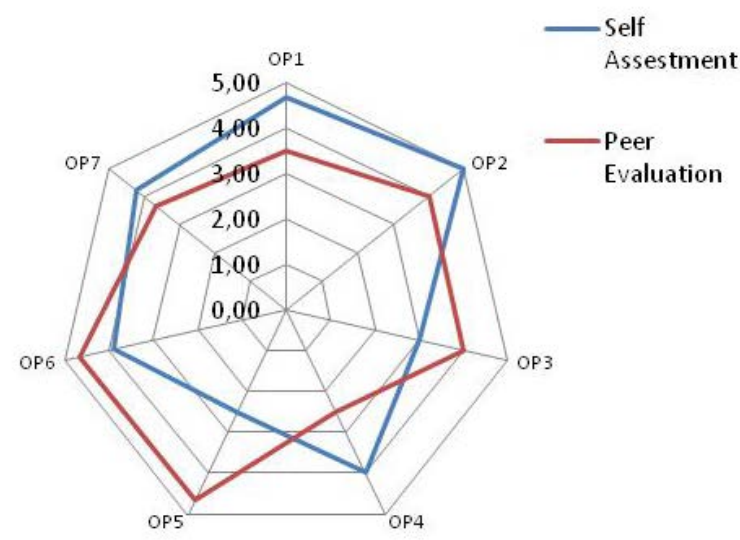

\section{Guidelines for teamwork competence improvement}

OP4: Give your opinion respecting others turns.

OP5: look for dialogue with the teacher in order to receive feedback about the work.

Figure 1. Individual radar graph and guidelines

\section{Results}

To assess the students' opinion about the new evaluation tool, we asked them about its usefulness.

They were asked about the feedback they had received (understandability and usefulness of the evaluation file). They were also asked whether they considered the information provided useful guide for improving their individual teamwork competence in future team assignments that they will have to face with throughout the degree. Both questions should be rated between 1 (very unclear / useless) to 5 (very light / useful). At the same time, they could make any comment about the effectiveness of the evaluation process. 
Table 2. Data collected

\begin{tabular}{lcccccccc}
\hline Variable & $\mathrm{n}$ & Mean & StDev & Minimun & Q1 & Median & Q3 & Maximun \\
\hline Understandably & $81(35 \%)$ & 3,81 & 0,85 & 1 & 3 & 4 & 4 & 5 \\
Usefulness & $77(33 \%)$ & 4,17 & 0,7 & 3 & 4 & 4 & 5 & 5 \\
\hline
\end{tabular}

The 34\% of students who participated in this study answered to this survey. Table 2 summarizes collected information. From these data we can observe that students scored high both understandably and usefulness. It should also be noted the broad acceptance among students this information has had. The students received as something positive the result of their assessment and their comments were in general that the feedback received could help them to improve. The majority of comments referred to the importance of having information from their peer teammates. As opposed to other authors we have not detect rejection towards this type of assessment.

\section{Conclusions}

The new educational models aimed at developing competencies also lead to the need to assess the degree of acquisition of them. Therefore, for competences development it is necessary to provide supervised learning experiences to the students throughout the degree. These learning experiences have to be monitored and students have to receive feedback that leads them to achieve better performance in the following experience which they face with. Giving each student their individual radar graph along with a list of guidelines for teamwork competence improvement can facilitate understanding, monitoring and improving the individual performance in team projects/assignments and it can lead to a progressive acquisition of teamwork competence by each student.

To the extent that this method is used in others team projects/assignments throughout the degree it will allow student to collect evidences of their teamwork competence development along the whole degree.

Future studies could pass the questionnaire during the course in order to analyse the impact of the feedback on their team learning experiences.

\section{References}

Bolton, M. K. (1999). The role of coaching in student teams: A "just-in-time" approach to learning. Journal of Management Education, 23(5), 467-488.

Boud D., Cohen R. \& Sampson J. (1999) Peer Learning and Assessment. Assessment \& Evaluation in Higher Education, 24(4), 413-426.

Boud D. \& Falchikov N. (2006) Aligning assessment with long-term learning. Assessment \& Evaluation in Higher Education. 31 (4), 399-413.

Brooks, C. M., \& Ammons, J. L. (2003). Free riding in group projects and the effects oftiming, frequency, and specificity of criteria in peer assessments. Journal of Education for Business, 78(5), 268-272.

Brown S. \& Knight P. (2004) Assessing Learners in Higher Education. Teaching and Learning in Higher Education Series. Series Editor: John Stephenson. British Library. ISBN 0749411139

Chalupa, M. R.; Chen, C. S. \& Sormunen-Jones, C. (2000). Reliability and Validity of the Group Member Rating Form. Delta Pi Epsilon Journal, 42 (4), 235-245. 
Cohen, S. G., \& Bailey, D. E. (1997). What makes teams work: Group effectiveness research from the shop floor to the executive suite. Journal of Management, 23(3), 239-290.

Crews and North (2000) Team evaluation (Part2 of 2). Instructional Strategies, 16 (2), 1-4.

Dedreu, C. K. W., \& West, M. A. (2001). Minority dissent and team innovation: The importance of participation in decision making. Journal of Applied Psychology, 86(6), 1191-1201.

Delson, N. (2001). Increasing team motivation in engineering design courses. International Journal of Engineering Education, 17(4-5), 359-366.

Edmondson, A. (1999). Psychological safety and learning behavior in work teams. Administrative Science Quarterly, 44(2), 350-383.

Falchikov, N. \& Goldfinch, J. (2000) Student Peer Assessment in Higher Education: A Meta-Analysis Comparing Peer and Teacher Marks. Review of Educational research, 70 (3), 287-322.

Gratton, L. \& Erickson, T. J. (2007). Eight ways to build collaborative teams. Harvard Business Review, vol.85, núm11: 100-109.

Gueldenzoph, L.E. \& May G.L. (2002). Collaborative Peer Evaluation: Best Practices for Group Member Assessments. Business Communication Quarterly, 65(1), 9-20.

Guzzo, R. A. \& Dickinson, M. W. (1996). Teams in organizations: Recent research on performance and effectiveness. Annual Review of Psychology, 47, 307-338.

Ilgen, D. R., Hollenbeck, J. R., Johnson, M., \& Jundt, D. (2005). Team in organizations: From inputprocess-output models to IMOI models. Annual Revision Psychologist, 56, 517-543.

Kozlowski, S. W. J., \& Ilgen, D. R. (2006). Enhancing the effectiveness of work groups and teams. Psychological Science in the Public Interest, 7(3), 77-124.

Leonard, M., Graham, S., \& Bonacum, D. (2004). The human factor: The critical importance of effective teamwork and communication in providing safe care. Quality Safety in Health Care, 13, I85-I90.

Lopez-Paniagua, I., Nieto-Carlier, R., Rodriguez-Martin, J., Gonzalez-Fernandez, C., \& Jimenez-Alvaro, A. (2011). Practical sessions: A key tool for teaching in the European higher education area framework. Dyna, 86(5), 523-530.

Marin-Garcia, J. A., Miralles-Insa, C., García-Sabater, J. J., \& Vidal-Carreras, P., I. (2008). Enseñando administración de empresas con docencia basada en el trabajo en equipo de los estudiantes: Ventajas, inconvenientes y propuestas de actuación. Intangible Capital, 4(2), 143-165.

Marin-Garcia, J. A., Garcia-Sabater, J. P., Perello-Marin, M. R., \& Canos-Daros, L. (2009). Propuesta de competencias para el ingeniero de organización en el contexto de los nuevos planes de estudio. Intangible Capital, 5(4), 387-406.

Marks, M., Mathieu, J. E., \& Zaccaro, S. (2001). A temporally based framework and taxonomy of team processes. The Academy of Management Review, 26(3), 356-376.

Mathieu, J. E., Maynard, M. T., Rapp, T., \& Gilson, L. (2008). Team effectiveness 1997-2007: A review of recent advancements and a glimpse into the future. Journal of Management, 34(3), 410-476.

Mathieu, J. E., Heffner, T. S., Goodwin, G. F., Salas, E., \& Cannon-Bowers, J. A. (2000). The influence of shared mental models on team process and performance. Journal of Applied Psychology, 85, 273-283

Mcgrath, J. E. (1964). Social psychology: A brief introduction. New York: Holt, Rinehart \& Winston.

Mickan, S., \& Rodger, S. (2000). Characteristics of effective teams: A literature review. Australian Health Review, 23(3), 201-208.

Oakley, B. A., Hanna, D. M., Kuzmyn, Z., \& Felder, R. M. (2007). Best practices involving teamwork in the classroom: Results from a survey of 6435 engineering, student respondents. IEEE Transactions on Education, 50(3), 266-272.

Parratt, J. A.; Fahy, K. M.; Hastie, C. R.(2014). Midwifery students' evaluation of team-based academic assignments involving peer-marking. Women and Birth, 27(1), 58-63. 
Pirola-Merlo, A., Härtel, C., Mann, L., \& Hirst, G. (2002). How leaders influence the impact of affective events on team climate and performance in R\&D teams. The Leadership Quarterly, 13(5), 561-581.

Salas, E., Sims, D. E., \& Burke, C. S. (2005). Is there a "big five" in teamwork? Small Group Research, 36(5), 555-599.

Seat, E., \& Lord, S. M. (1999). Enabling effective engineering teams: A program for teaching interaction skills. Journal of Engineering Education, 88(4), 385-390.

Sheppard, K., Dominick, P., \& Aronson, Z. (2004). Preparing engineering students for the new business paradigm of international teamwork and global orientation. International Journal of Engineering Education, 20(3), 475-483.

Steiner, M., Kanai, J., Hsu, C., Alben, R., \& Gerhardt, L. (2011). Holistic assessment of student performance in multidisciplinary engineering capstone design projects. International Journal of Engineering Education, 27(6), 1259-1272.

Thylefors, I., Persson, O., \& Hellström, D. (2005). Team types, perceived efficiency and team climate in swedish cross-professional teamwork. Journal of Interprofessional Care, 19(2), 102-114.

Topping, K. (2003) Self and Peer Assessment in School and University: reliability, Validity and Utility. Optimising New Modes of Assessment: In Search of Qualities and Standards. Innovation and Change in Professional Education, 1, 55-87.

Viles, E., Zárraga-Rodríguez, M. \& Jaca, C. (2013) Herramienta para evaluar el funcionamiento de los equipos de trabajo en entornos docentes . Intangible Capital, 9(1): 281-304.

Zaccaro, S. J., Rittman, A. L., \& Marks, M. A. (2001). Team leadership. The Leadership Quarterly, 12(4), 451-483.

Zander, A. (1994). Making Groups Effective. San Francisco: Oxford: Ed.Jossey-Bass. 


\title{
Use of scoring rubrics for evaluating oral presentations in aerospace engineering education
}

\author{
A. Tiseira*, P. Martí-Aldaraví*, R. Navarro*, M. Carreres* \\ * CMT-Motores Térmicos, Universitat Politècnica de València
}

\begin{abstract}
Under the frame of Bologna system, alternative assessment methodologies gain significance in the evaluation process of the students. This article analyses the use of scoring rubrics for evaluating oral presentations of two different courses in aerospace engineering education, namely Aircraft Design and Aerodynamics II, at Universitat Politècnica de València. The score obtained at the presentation represents a significant percentage of the final grade for both courses. It has been observed that the students find difficulties to keep timing limitations overall. In addition, rubrics have proved to be a powerful tool to enhance some skills of the students, such as critical thinking and selfevaluation, although they may lead to unfairly high grades nonetheless.
\end{abstract}

Keywords: scoring rubrics; aerospace education; oral presentation; evaluation

\section{Introduction}

UNESCO (Delors, 1996), through the International Commission on Education for the XXI century, points out that the main theme of any educational project should be 'teach to know to do, to educate'. In other words, the students should learn by applying the knowledge, but also determining under which conditions they have the capability to apply it, for instance, enclosed and summarized in a single assignment. Therefore, education must not allow to comprise the understanding just from one point of view.

Engineering education in Europe is nowadays experiencing important changes (Joshi (2009)). In particular, aerospace engineering education is being affected by two main reasons. Firstly, the problem of educating aerospace engineers is worldwide, given the strong competition that USA is facing from Europe and Japan nowadays in this industry (Niosi and Zhegu, 2005). Secondly, the Bologna declaration and the European Higher Education Area (UK HE Educational Unit, 2015) make it necessary to improve the teaching-learning process. Assessments become more dynamic and short-term based. Therefore the students need to mature the knowledge in a faster way, which is not possible only through exams. New initiatives, projects and methodologies are needed in order to provide the future engineers with a comprehensive view of the practical aspects of engineering, forming not just scientists and designers, but professionals that could deal with multidisciplinary problems including design, manufacturing, finances and business plans, among others. At this point, teaching activities and facilities that bring the students closer to real life situations in aerospace systems are essential in order to progress in the teachinglearning procedure and contribute to stimulate the student to acquire knowledge.

As pointed out above, aerospace is one of the most dynamic and competitive of the technical fields (Lapins, 1997). Therefore, it is important to determine whether the students have acquired critical knowledge and skills. With this purpose, it is convenient to stimulate the self-evaluation when the students perform an engineering work and focus a portion of their thinking to a critical process through an objective foundation represented by a professional character. Exams are the most common way to evaluate the students. They are a good instrument when the evaluation is individual 
and its purpose is to make the student demonstrate his knowledge (Crooks, 1988). Through this action however, the students do not get the capability to determine their capacity and demonstrate their attitudes to carry out engineering work by themselves. In other words, they do not develop critical knowledge. New approaches to assessment, often known as "authentic" or "performance" assessment, are needed to make the students develop important transversal skills like public speaking or the aforementioned self-evaluation. Project courses and oral presentations, in combination with others, are good evaluation methodologies for doing so (Palomba, 1999). Nonetheless, the information interchange between the professors and the students has a strong impact on the success of these methodologies. On one side, the students autoevaluate the information and they can improve the theoretical lessons offered by the professor, and on the other side the professors are responsible for improving the critical spirit created in the student.

Courses in topics such as aircraft design or aerodynamics play an essential role in any Aerospace Engineering Degree. Their contents are fundamental to reach further detailed knowledge of aircraft systems. Hence, it is needed to provide the students with a suitable balance between conceptual and real world background, so that a successful future professional career can be ensured. In that sense, integration of theoretical and practical work is desirable. Theoretical concepts are necessary in topics such as design, in which complex morphology (airfoil, engine location, pressure distribution, fuselage shape, etc.) is found in real systems. To accomplish these goals, Aircraft Design and Aerodynamics II courses at Universitat Politècnica de València include a public oral defense of the course projects as part of their evaluation process. In these projects, which are described in the next section, the students put into practice the theory explained during the theoretical and practical classes and compare their results with real aerospace vehicles that fly or flew on the skies.

\section{Methods}

\section{Evaluation of oral presentations}

The common way to evaluate the quality of an oral presentation is to employ a scoring rubric. In education terminology, this means "a standard of performance for a defined population” (NCSESA, 1996). Rubrics are standardized ratings linked to learning objectives which theoretically support student self-reflection and selfassessment as well as communication between an assessor (the professor) and those being assessed (the students). They also allow professors, in combination with students, to review the employed criteria, which can be complex and subjective.

Since more than 30 years ago, many scoring rubrics have been presented in a graphic format, mainly as tables, by many universities, associations and companies. According to Herman et al. (1992), all of them present the same elements:

- One or more traits of dimensions that serve as the basis for judging the student response.

- Definitions and examples to clarify the meaning of each trait or dimension.

- A scale of values on which to rate each dimension.

- Standards of excellence for specified performance levels accompanied by models or examples of each level. 
One of the main advantages of this type of evaluation is that the criteria employed to prove the quality of the performance (what in real worlds may be a product, process, etc.) can be known beforehand by the student. Nonetheless, this feature may imply a negative effect on the overall performance. The students, obviously, focus on the traits which are evaluated and forget other aspects of an oral presentation that, although not evaluated, may be relevant (for example, the dressing code). This work analyzes the students' outcome with and without knowing in advance the assessment criteria.

Another issue of scoring rubrics is that each level of fulfillment covers a wide range of marks. In addition, a small change in the evaluation on the rubric may lead to an unfair change in the numerical grade. Therefore, one of the subjects presents numerical scoring determined by ranges according to levels of fulfillment.

Multidimensional rubrics allow students to hide and compensate for a lack of ability in one trait by improving another one. However, if the traits are weighted properly, rubrics are a very effective way to improve the student weaknesses.

\section{Description of the courses}

Aircraft Design and Aerodynamics II courses are taught simultaneously during the first semester of the $4^{\text {th }}$ year of the Aerospace Engineering Bachelor Degree at Universitat Politècnica de València. At that point, the students already have the basic foundations in Mathematics, Physics, Structures and Loads, Solid Mechanics, Fluid Mechanics, Aerodynamics, Control Systems and Aerospace Technology. The teaching-learning methodology is similar for both courses. In both evaluation methodologies, a significant percentage of the total grade of the course is obtained through the assessment of an oral public presentation. The presentation deals with the defense of their ideas and the work performed during the semester. With this kind of system, not only knowledge and critical thinking are evaluated, but also transversal skills such as teamwork and communication.

\section{Aircraft Design}

The Aircraft Design course is structured as a project-based course in which the students are required to apply their knowledge of different topics in order to perform a course project about the conceptual and preliminary design of an aircraft that fulfils the requirements in all different areas, taking into account general requirements such as performance, applications, green design, sustainability and economy.

Its evaluation is divided in three different parts: the evaluation of the course project, a oral defense of it, and a traditional exam. The project accounts for the $50 \%$ of the student grade, while the oral exposition and the exam weight $25 \%$ each. The course project consists in pre-designing an aircraft following certain specifications given by the professors, such as maximum cruise speed, range or propulsion technology. This project is carried out by groups of 3-4 students.

In this course, the scoring rubric of the oral exposition (see Table 1) is not known in advance by the students. Thus, they must use their general knowledge (or personal research) to figure out which abilities are ranked in the evaluation process. Professors who form the evaluating tribunal are also asked to give a global mark to the presentation without taking into account the traits of the rubric, just by their general opinion. 
Table 1. Scoring rubric employed in the Aircraft Design course

\begin{tabular}{|c|l|c|}
\hline Criterion & Description & Score \\
\cline { 3 - 3 } Contents & $\begin{array}{l}\text { Aircraft design final results, } \\
\text { marketing, and mission definition. }\end{array}$ & \\
\hline Answers & $\begin{array}{l}\text { Critical judgments, defense of their } \\
\text { design. }\end{array}$ & \\
\hline Time & $\begin{array}{l}\text { Fluency of the presentation, use of a } \\
\text { given time. }\end{array}$ & \\
\hline Resources & $\begin{array}{l}\text { Organization, presentation, posture, } \\
\text { speaking skills... }\end{array}$ & \\
\hline Innovation & $\begin{array}{l}\text { Morphology, new applications, } \\
\text { versatility, operation... }\end{array}$ & \\
\hline
\end{tabular}

Table 1 shows that each criterions is qualified with a score from 0 to 10 . As previously said, different levels of fulfilment determine scoring ranges, providing clear and uniform criteria for the different professors. Due to manuscript length limitations, the levels of fulfilment for each dimension are not included.

\section{Aerodynamics II}

The Aerodynamics II course is a traditional lecture-based course with several computational laboratory sessions. The main topic of this course is fundamentals of high speed aerodynamics, for example potential flow over supersonic wings or lift force of slender bodies.

The global evaluation of this course consists of three exams, a course project and an oral presentation of the project. Exams represent $70 \%$ of the grade, the course project $20 \%$ and the presentation $10 \%$. The course project and also the oral presentation comprises four laboratory sessions in which the students analyze different aircraft geometries (a missile, a slender wing...) under different high speed (subsonic and supersonic) flight conditions. In this case, the students know the scoring rubric of the presentation (shown in Table 2) since the beginning of the course. In addition, they are provided with a brief guide about "how to" perform an oral presentation. This rubric could be used by the students to guess the aspects evaluated in the Aircraft Design course, but the tribunal is not the same. For this reason rubrics and mainly rank criteria are quite different.

Table 2. Scoring rubric employed in the Aerodynamics II course

\begin{tabular}{|c|l|c|c|c|c|c|}
\hline \multirow{2}{*}{ Criterion } & \multirow{2}{*}{ Description } & \multicolumn{5}{|c|}{ Score } \\
\cline { 3 - 7 } Contents & $\begin{array}{l}\text { Clear communication, critic judgment, } \\
\text { answers. }\end{array}$ & & & & & $\mathbf{0 . 5}$ \\
\hline Organization & $\begin{array}{l}\text { Order of topics, connection between } \\
\text { sections. }\end{array}$ & & & & & \\
\hline Time & $\begin{array}{l}\text { Fluency of the presentation, use of a } \\
\text { given time. }\end{array}$ & & & & & \\
\hline Resources & $\begin{array}{l}\text { Graphics and animations, creativity, } \\
\text { quality and utility. }\end{array}$ & & & & & \\
\hline $\begin{array}{c}\text { Scenic } \\
\text { performance }\end{array}$ & $\begin{array}{l}\text { Posture, confidence, eye contact, voice } \\
\text { volume. }\end{array}$ & & & & & \\
\hline
\end{tabular}


In this course, the score for each dimension can only present 5 different values, from 0 to 2.5 points (see table 2), corresponding to the different levels of fulfilment. Again, for the sake of brevity, descriptors are omitted for the scoring rubric described in Table 2.

\section{Results and Discussion}

In this section, the scores obtained by the students as well as the personal opinion of professors and students alike are analyzed. In order to simplify and extract general trends, averaged values and standard deviations are given. The same 40 students (academic year 2014-2015) were ranked in both courses to minimize uncertainties. The time gap between the two evaluation events is less than two weeks, so the experience of the students in oral presentations is more or less the same.

\section{Case 1: Aircraft Design}

Table 3 shows the Aircraft Design presentation score. Relatively high scores were obtained by all the students. The low standard deviation found in each item remarks that the groups performed in a quite homogeneous way. The highest average grade was obtained for the "Time" criterion, i.e., the ability of the students to defend their project in no more nor less than a predefined time (in this case, 15 minutes). However, it has the highest standard deviation. This is due to the fact that a couple of groups exceeded the time limitations in a really important way.

On the other side, the "Innovation" dimension was the aspect in which the students performed in a poorer way. This criterion awards the groups of students which design an innovative aircraft in terms of aerodynamics, operability, target mission... instead of a straightforward one. The authors noticed that this is a trend that changes over the years in the Aircraft Design course: when students from one year really try to innovate in their design in order to improve their marks in this sense, the students from following years show a lack in innovation in order to enhance other aspects of the project and go further in their calculations. The authors suspect that this is due to the fact that older students prevent the next generation ones from introducing complicated innovations in their designs due to the added difficulty.

Another important result is that the global marks given by the professors without considering the scoring rubric matches almost perfectly the average of the scoring rubric criteria, with just a slightly higher standard deviation. This could be explained since the evaluators' experience probably leads them to assess a global mark based on the same items considered in the rubric in an unconscious way. What is more, the marks they globally give to the presentations might be inferred by the marks they just gave to each of the criteria, since the professors internally try to respect these marks.

Table 3. Grade obtained by the students in the oral presentation of the Aircraft Design course

\begin{tabular}{|c|c|c|}
\hline Criterion & Average grade [\%] & Standard deviation [\%] \\
\hline Contents & 76.17 & 5.67 \\
\hline Answers & 77.5 & 5.94 \\
\hline Time & 83.0 & 11.57 \\
\hline Resources & 81.33 & 8.74 \\
\hline Innovation & 72.33 & 8.02 \\
\hline Total score & $\mathbf{7 8 . 0 7}$ & $\mathbf{4 . 6 6}$ \\
\hline Global mark & $\mathbf{7 8 . 8 3}$ & $\mathbf{7 . 6 6}$ \\
\hline
\end{tabular}




\section{Case 2: Aerodynamics II}

Table 4 presents the Aerodynamics II course presentation marks. Generally, high scores were obtained with high difference between teams. Low homogeneity is observed in the group of students. Some of them took profit of the documentation given to them and performed very well with oral presentations, whilst some other did not defend their work in a proper manner. It is interesting to see that "Organization" is the aspect with the highest average score and lowest deviation. This means that Aerodynamics II students are able to sort the data correctly and logically. Again, "Time" is the criterion with the the highest deviations. However, in this subject this dimension presents the lowest average mark. Students find it very hard to stick to a given time when they feel that they have done a high amount of work and want to present all of it. This means that they have to improve the transversal competence related to summarization of information.

Table 4. Grade obtained by the students in the oral presentation of the Aerodynamics II course

\begin{tabular}{|c|c|c|}
\hline Criterion & Average grade [\%] & Standard deviation [\%] \\
\hline Contents & 80.68 & 15.30 \\
\hline Organization & 95.45 & 12.53 \\
\hline Time & 75.00 & 28.87 \\
\hline Resources & 82.95 & 19.50 \\
\hline Scenic performance & 89.77 & 14.76 \\
\hline Total score & $\mathbf{8 4 . 7 7}$ & $\mathbf{1 3 . 9 2}$ \\
\hline
\end{tabular}

\section{General results}

Score of presentations is generally high. In fact, no one (out of 40) failed. In average, there is a difference of about 15 points when this score is compared to the mark obtained in other evaluation activities, i.e. exams. As stated in the "Methods" section, rubrics allow the students to hide some of their weaknesses. This does not mean rubrics are not useful. The students are aware of their downsides and that is why they are able to hide them. Thus, the auto-evaluation skill has been enhanced indeed. Nevertheless, score presentations then seem kind of unfair.

When both studied cases are compared, it is noted that the influence of knowing in advance the scoring rubrics leads the student to perform better in the different items that are evaluated, obtaining scores about 6 points higher than the ones obtained without this information. When preparing their presentation, students tend to focus on the particular items that will be assessed, rather than trying to introduce additional features to their presentation. For instance, it was noticed by the professors that most students stuck to a formal dress code in the Aircraft Design presentations, whereas they did not give any importance to this fact in the Aerodynamics II ones.

\section{Conclusions}

The use of scoring rubrics for the evaluation of oral presentations in an Aerospace Engineering Degree has been analyzed. Their advantages and drawbacks are well known by the community, and they have also been observed in this work. However, interesting results have been obtained. 
Overall, the students find difficulties to keep timing limitations even when they are warned to do so by giving them the information about the scoring rubric in advance. Given the relevance of timing in engineering projects, exercises to improve the summarizing skill should be proposed to the students. The use of scoring rubrics is hence a good tool to identify the performance of the students in this transverse competences.

In addition, this work pointed out that the fact that the students know the scoring rubric in advance leads them to focus exclusively in the stipulated criteria, forgetting about other features that could also improve the overall quality of their presentations. In order to get the best of both worlds, the criteria might be given in advance, but an additional "overall impression" dimension should be included.

However, in general terms, the objective of enhancing self-evaluation and critical thinking is fulfilled with the methodology proposed in this paper. Thus, it is recommended to keep the use of scoring rubrics for the evaluation of next generations.

\section{References}

Crooks, T. J. (1988), The impact of classroom evaluation practices on students, Review of Educational Research, 58, 438-481.

Herman, J. L., Aschbacher, P. R., Winters, L. (1992). A practical guide to alternative assessment. Washington D. C: Association for Supervision and Curriculum Development.

Joshi, D. S. (2009), Viewpoint: Aerospace education for 2000 and beyond, International Journal of Engineering Education, 13, 138-142.

Lapins, M. (1997), Aerospace engineering education: An industry view from a preliminary design perspective, International Journal of Engineering Eduation, 13, 376-379.

National Committee of Science Education Standards and Assessment (1996). National Science Education Standards. Washington D. C.: National Research Council.

Niosi, J., \& Zhegu, M. (2005). Aerospace clusters: local or global knowledge spillovers?. Industry \& Innovation, 12(1), 5-29.

Palomba, C., Banta, T. W. (1999). Assessment Essentials: Planning, Implementing, and Improving Assessment in Higher Education. Hihger and Adult Education Series. San Francisco: Jossey-Bass, Inc. Publishers.

Torrance, H. (1995). Evaluating Authentic Assessment: Problems and Possibilities in New Approaches to Assessment (Assessing Assessment). Buckingham: Open University Press.

Delors, J. et al. (1996). Learning: the treasure within. Paris: United Nations Educational, Scientific and Cultural Organization.

UK HE Educational Unit (last accessed on January, 2015). Guide to the Bologna Process. Editions 1\&2, on-line. Website: www.international.ac.uk 


\title{
Instructional factors and over-education of university graduates over time
}

\author{
V. González-Romá ${ }^{1,2}$, A. Hernández ${ }^{1,2}$, J.P. Gamboa ${ }^{2}$ \\ IDOCAL $^{1}$, OPAL ${ }^{2}$, University of Valencia
}

\begin{abstract}
The aim of this study is to test the role of the level of generic competences developed during University studies and the professional and practice orientation of instruction (PPOI) in the prediction of graduates' initial vertical fit and change in vertical fit over an 8-year period. The study sample comprised 334 graduates who finished their degrees two years before they were interviewed for the first time (Time 1). Four and eight years later they were interviewed again (Times 2 and 3, respectively). All of them were employed at Times 1, 2 and 3. Hypotheses were tested by means of Latent Growth Curve Analysis. The results showed that only PPOI was positively and significantly related to graduates' rate of change in vertical fit over time, meaning that the rate of change of graduates who received a more professional and practice-oriented instruction was faster than the rate of change of graduates who received a less professional and practice-oriented instruction.
\end{abstract}

Keywords: generic competences; professional orientation of instruction; vertical fit; over-education

\section{Introduction}

Over-education is an important issue among Spanish graduates (García-Montalvo \& Peiró, 2009). It means that many graduates have jobs that require lower educational levels than the level they actually have.

Taking into account the negative consequences of over-education (i.e. it has been negatively related to salaries, job and life satisfaction, well-being, etc.) (McKee-Ryan \& Harvey, 2011), it is important to know what kinds of factors prevent young people from starting their professional careers as over-educated employees and/or mitigate this situation over time. In the context of Higher Education Institutions, some instructional factors may be especially relevant because they could become routes to prevent graduates' over-education and reduce it over time. There is some evidence that the quality of training and the orientation of teaching toward labour market demands have a positive effect on educational fit (Verhaest \& van der Velden, 2013). However, empirical evidence in this area is still quite scarce.

With this in mind, we expect that teaching focused on the development of key job competences and abilities, on the one hand, and instruction oriented toward professional practice (PPOI), on the other, will allow graduates to obtain jobs that fit their educational levels better. Thus, we propose the following hypotheses:

Hypothesis 1: Higher levels of generic competences acquired during university studies will be positively related to initial levels of graduates' vertical fit and its rate of change over an 8-year period.

Hypothesis 2: Professional and practice orientation of instruction (PPOI) will be positively related to initial levels of graduates' vertical fit and its rate of change over an 8-year period. 


\section{Method}

\section{Sample and procedure}

To test the study hypotheses, we used longitudinal data from a representative sample of university graduates who obtained their degrees in 2002 and 2003. The sample was surveyed two (Time 1), six (Time 2) and ten years after graduation (Time 3). The final sample comprised 334 graduates who were employed at Times 1, 2 and 3 . The average age of respondents was $27.4(\mathrm{SD}=4.3)$ at Time 1 . Regarding sex, $63.8 \%$ were female. In terms of their fields of study, respondents were distributed as follows: Engineering (6\%), Natural Sciences and Mathematics (11.4\%), Humanities (13.2\%), Health Sciences (17.4\%), Educational Sciences (18.9\%), and Social Sciences (33.2\%).

\section{Measures}

To measure the study variables, we used a number of scales and items included in the questionnaire administered to the surveyed graduates.

Development of generic competences at Time 1 was assessed by the following question with 9 items, "To what extent has the training received at the university contributed to the development of each of the following competences and abilities?: 1. social skills, 2. time and resources planning and management, 3. problem solving, 4. decision making, 5. creativity, 6. management, 7. team work, 8. critical thinking, 9. oral and written communication. Respondents answered by using a response scale that ranged from 0 (It has not contributed at all) to 10 (It has contributed a lot).

A global competence score was calculated by averaging the ratings provided for the nine competences mentioned above. The scale reliability (Cronbach's coefficient alpha $=.91$ ) was satisfactory.

Professional and practice orientation of instruction (PPOI). This variable was measured at Time 1 by means of a 4-item scale (e.g., "Teaching methods facilitate the acquisition of professional abilities and skills"). The response scale ranged from 0 (strongly disagree) to 10 (strongly agree). The scale reliability (Cronbach's coefficient alpha $=.81$ ) was satisfactory.

Vertical fit. The dependent variable was operationalized as the ratio between the educational level required by the job and the graduate's attained educational level. Graduates were asked to indicate the educational level required by their current job. The response options were as follows: 1 . None, 2. Compulsory education, 3. Vocational education-1st level, 4. Vocational education-2nd level, 5. High school, 6. A 3-year university degree, and 7. A 5-year university degree. Graduates' attained educational level only presented two values (6. A 3-year university degree or 7. A 5-year university degree). Therefore, values less than one $(<1)$ indicate over-education (graduate has a higher level of studies than what is required by the job). Values equalling one (1) indicate vertical fit. Graduates’ vertical fit was calculated at T1, T2 and T3.

\section{Analysis}

We tested our hypotheses by means of Latent Growth Curve Analysis. The analyses were conducted with MPlus using Maximum Likelihood estimation methods. Apart from our two independent variables (competences acquired and PPOI), we controlled for a number of variables: academic performance (average degree mark), sex, age, social class, and field of study (basic, technical, health, social, humanities, and educational sciences). For the field of study, 5 dummy variables were created, using 
humanities as the reference category. All the variables were introduced as predictors of initial vertical-fit (intercepts) and fit change over time (slopes).

\section{Results and Discussion}

Regarding our hypotheses, the tested model was satisfactory in terms of fit $\left(\chi^{2}=24.06\right.$, $\mathrm{df}=13 ; \mathrm{p}<.05$; RMSEA=.05; CFI=.96; TLI=.89; SRMSR=.02). The results are shown in Tables 1 and 2. The professional and practice orientation of the instruction received at the University was positively and significantly related to graduates' rate of change in vertical fit over time (estimate $=.01$; standardized estimate $=.25 \mathrm{p}<.05$ ). In other words, the rate of positive change toward better fitting jobs in graduates who received a more professional and practice-oriented instruction was faster than the rate of change in graduates who received a less professional and practice-oriented instruction. Contrary to our expectations, the level of competence developed during the studies did not significantly predict the initial levels of vertical fit or the rate of change in fit.

Table 1. Results of the Latent Growth Curve Analysis to estimate the relationship between the predictors and graduates' initial vertical fit

\begin{tabular}{|c|c|c|c|}
\hline & Estimate & $\mathrm{SE}$ & $\mathrm{p}^{\mathrm{b}}$ \\
\hline Age & -0.007 & 0.003 & 0.017 \\
\hline Sex & 0.028 & 0.026 & 0.291 \\
\hline Social class & 0.016 & 0.009 & 0.077 \\
\hline Average mark & 0.019 & 0.030 & 0.516 \\
\hline Dummy Basics & 0.013 & 0.048 & 0.788 \\
\hline Dummy Technical & 0.045 & 0.060 & 0.452 \\
\hline Dummy Social & -0.020 & 0.039 & 0.603 \\
\hline Dummy Education & -0.029 & 0.043 & 0.496 \\
\hline Dummy Health & 0.079 & 0.043 & 0.068 \\
\hline Competences development $^{\text {Dem }}$ & 0.006 & 0.010 & 0.516 \\
\hline PPOI & -0.008 & 0.009 & 0.363 \\
\hline
\end{tabular}

${ }^{\text {a }}$ Professional and Practice Orientation Instruction

b Unstandardized Coefficients. Two-tail p-values

Table 2. Results of the Latent Growth Curve Analysis to estimate the relationship between the predictors and the rate of change in vertical fit over time

\begin{tabular}{|c|c|c|c|}
\hline & Estimate & $\mathrm{SE}$ & $\mathrm{p}^{\mathrm{b}}$ \\
\hline Age & -0.001 & 0.002 & 0.452 \\
\hline Sex & 0.014 & 0.015 & 0.355 \\
\hline Social class & 0.004 & 0.005 & 0.398 \\
\hline Average mark & 0.005 & 0.017 & 0.742 \\
\hline Dummy Basics & 0.002 & 0.027 & 0.941 \\
\hline Dummy Technical & -0.023 & 0.034 & 0.491 \\
\hline Dummy Social & 0.010 & 0.022 & 0.637 \\
\hline Dummy Education & 0.033 & 0.024 & 0.168 \\
\hline Dummy Health & -0.005 & 0.024 & 0.849 \\
\hline Competences development $^{\text {PPOI }}$ & 0.002 & 0.005 & 0.731 \\
\hline Pomp & 0.010 & 0.005 & 0.046 \\
\hline
\end{tabular}

\footnotetext{
${ }^{a}$ Professional and Practice Orientation Instruction
}

${ }^{\mathrm{b}}$ Unstandardized Coefficients. Two-tail p-values 


\section{Conclusions}

The results show that universities should consider increasing the professional and practice orientation of the instruction (PPOI) they provide because it may help to reduce graduates' over-education over time. This could be mainly due to the fact that PPOI can affect graduates' job search process. Specifically, PPOI can give graduates a broader knowledge of the labour market, which, in turn, can help them to avoid experiencing career indecision (Zikic \& Hall, 2009) and ending up in mismatched jobs.

In addition, an education oriented toward professional practice, which clearly shows professional paths and relates theory to practice, is likely to be a facilitator of career exploration, and this may also contribute to improving fit over time (Zikic \& Hall, 2009). Finally, a professionally oriented education can also contribute to higher job search clarity in graduates, which has shown positive effects on job search intensity and outcomes (Côté, Saks \& Zikic, 2006).

\section{References}

Boudarbat, B., \& Chernoff, V. (2010). The Determinants of Education-Job Match among Canadian University Graduates. Scientific Series, 2010s-14. Montreal: Cirano.

Côté, S., Saks, A. M., \& Zikic, J. (2006). Trait affect and job search outcomes. Journal of Vocational Behavior, 68, 233-252.

Feldman, D.C. (1996). The nature, antecedents, and consequences of underemployment. Journal of Management, 22, 385-407.

Grayson, J.P. (2004). Social dynamics, university experiences, and graduates' job outcomes. British Journal of Sociology of Education, 25, 609-627.

García-Montalvo, J., \& Peiró, J.M. (2009). Análisis de la sobrecualificación y de la flexibilidad laboral. Observatorio de Inserción Laboral de los Jóvenes 2008. Valencia: Fundación Bancaja-IVIE.

Kanfer, R., Wanberg, C. R., \& Kantrowitz, T. M. (2001). Job search and employment: A personality-motivational analysis and meta-analytic review. Journal of Applied Psychology, 86, 837-855.

McKee-Ryan, F. M., \& Harvey, J. (2011). “I Have a Job, But...”: A Review of Underemployment. Journal of Management, 37, 962-996.

Saks, A.M., \& Ashforth, B.E. (2002). Is Job Search Related to Employment Quality? It All Depends on the Fit. Journal of Applied Psychology, 87, 646-654.

Valls, V., González-Romá, V. Hernández, A., Yeves, J., \& Gamboa, J.P. (2013) Quality of Education and New Entrants' Job Search Intensity: The Mediating Role of General Self-efficacy. 16th EAWOP congress. Munster (Germany).

Verhaest, D., \& van der Velden, R. (2013). Cross-country Differences in Graduate Overeducation. European Sociological Review, 29, 642-653.

Zikic, J., \& Hall, D.T. (2009). Toward a More Complex View of Career Exploration. The Career Development Quarterly, 58, 181-191. 


\title{
Some aspects of the Formation in Engineering: the Curriculum by Competitions and the Curriculum Socio-Critic
}

\author{
Jaime Espinoza Oyarzún \\ Group of Investigation in New Technologies \\ Technological Faculty, University of Santiago of Chile (USACH), jaime.espinoza@usach.cl
}

\begin{abstract}
This paper discusses some aspects of the training of engineers, showing two different approaches, the skills approach and socio-critical approach and how they are possible to be integrated in such a way to bring their potential to the formation of this professional, considering the challenges the future.
\end{abstract}

Keywords: engineer, competitions, socio-critical.

\section{Introduction}

Science and technology have had a steady and sustained progress in the past five decades, causing a strong impact on human activities.

In turn, the work field has felt the impact as education; it has been forced to introduce major changes to meet the needs of companies to have qualified human resources and advanced.

UNESCO, through the Delors (Delors, 1994) Report and other documents (Magendzo, 2006), (Faure, 1973), (UNESCO, 1990), (UNESCO, 2000) and others (Prelac, 2002), (CRES, 2008) have introduced the concept of lifelong learning and have added that education is a highly relevant and inalienable right, whose purpose is the integral development of individuals.

Skills training have been one of the ways in which education has faced the needs of the workplace. This stems from the world of work and has been adopted by many institutions of higher education as a model for engineering education.

Skills training are a curricular approach among its qualities shows job training, based on a look at the productive sectors resulting in the relevance of the curriculum, but relativizing humanist education. (Ibid) (Schink and Ormeño, 2006), which has preoccupied the academic world by the emergence of neoliberal thinking, leading to other more humanistic approaches.

In this context, the socio-critic curriculum appears as opposed to curriculum competencies, which promotes the transformation of society through a reflective-critical transformation, humanizing, which gives an emphasis on the role of education and curriculum content, attaches importance to the student as an agent of change and shows a social vision of the school.

\section{Methodology}

From Engineering Congress 2014, held in Buenos Aires in which UNESCO guidelines for engineering education arise from the concern arises 2015 by entering into this topic. Starts collecting information, interviews with professionals from the University of Santiago De Chile, curriculum specialists and engineering review of official electronic 
information from some universities. Then, analyzed and studied the information is applicable to the preparation of this work, including its conclusions.

\section{Objectives}

Demonstrate the possibility to apply the socio-critic curriculum in training engineer. Analyze the advantages and disadvantages of both approaches in engineering training.

\section{Antecedents}

The University of Santiago, Chile (USACH) is a state institution of higher education and public which, among its many degrees, dictates Engineering with two different approaches: competency in the Faculty of Engineering (Letelier et al, 2005) and linear curriculum Faculty of Technology.

Currently, the skills approach is recurrent in the current training of engineers, paradigmatic in many universities. The reference document presents a sustainable system for engineering skills training; only mentions training for work and not considered an important aspect as the integral formation that allows the student to be a critical professional and dutiful to society.

\section{The Curriculum}

Within the curricular concepts, one of the most important approaches has raised Shirley Grundy (Grundy, 1992). It argues that the curriculum is a cultural concept that reflects what society tries to reproduce in the new generations. In this conception the skills approach corresponds to a technical curriculum characterized in that the objectives are predefined by the company; the idea of curriculum, reflected in the plans and programs of study, before the educational activity; the organization, based on the ability of the teacher and the teaching action as a product giving searched learning in students. In this approach the task of theory serves the efficient achievement of operational objectives; practice only exists in relation to compliance with certain plans.

Today, the conceptualizations of competencies point to perform the action, experience and performance context as key in such conceptualizations. The trend is that the powers integrate theory and practice that it solves everyday problems but as well how emergent problems, atypical or rare in the engineer applies a repertoire of knowledge and skills that allow you to be smart against a given situation. This concept involves a concatenation of knowledge that not only articulates a conception of being, knowledge, know-how and knowledge to live, or put another way, involves pragmatic knowledge and knowledge production oriented.

In relation to engineering education, this approach allows the engineer is able to solve problems in different contexts, whether professional or cultural; combining training and work cycles; self-learning; ability to respond quickly to new everyday problems; integrate and reconvert skills; jeopardize the capabilities of mathematical-abstract and reflection to develop initiative, creativity, innovation and decision-making ability logical thinking.

On the other hand, advantages of this approach are the effective linkage between business and universities, training in various sociocultural contexts, continuous updating of curricula and study programs, learning through electronic media, facilitating the integration and better learning assessment.

This approach is also possible to mention disadvantages. Including interference neoliberal economic model that prioritizes the needs of the companies of the country, there is a limitation of control and autonomy of teachers in the development and 
implementation of learning, poor training in the social and human level, creates unmet demands on workers.

\section{Curriculum Socio-Critic}

Socio-Critical Theory meets a set of theories from different fields of thought whose purpose is to look at reality from a revolutionary and transformative view, for it seeks to transform the world. Within this concept USACH motto is inscribed, "Educating people to transform the country".

Curricularly, postulates that the basic values to develop are the shared values, cooperative, shared in common and liberating. The contents must be socially meaningful and the constructive activities and shared learning activities. The relation between theory and practice is inseparable from this contradiction in the facts and situations; practice is the theory in action. The fixation of objectives is made through dialogue and discussion among students. It considers that the official curriculum is an instrument of reproduction of power. Primacy of teamwork within the school and its environment. The teacher's role should be considered reflective, critical, transformative agent of social change, a researcher in the classroom, committed to the education of students and the socio-political situation.

\section{Analysis}

Perform a curriculum redesign involves a profound changes; especially if it is passed from a still persistent, a curriculum by competencies and even more if it is a sociocritical curriculum, somewhat unknown linear curriculum.

In engineering, it is very important training in basics science; they provide solid and broad foundation for the basic technological development of professional performance. The formation in basic science, based on the transmission of knowledge, is shaped suitably in the linear curriculum, then the formation in sciences of engineering and specific technologies can be developed according to various curricular approaches.

It is necessary to mention that the engineer can perform in varied professional and cultural contexts, different areas of performance and complex situations, dysfunctional situations and emerging contexts. This means that a curriculum hardly can shape the variety of skills that the professional can develop. All the engineering competitions essentially point at the technology, relativizing the integral formation, which is the ultimate goal of education.

In a curriculum which foster the integral development engineer taking skills training as an axis, it would be advisable to exercise gradually, through the hidden curriculum, introducing elements of socio-critical curriculum, integrating the qualities of both approaches. Incorporate skills for development of critical thinking, related to moral discernment, to live and understand, to issue ethical and aesthetic judgments and to express himself adequately in their mother tongue. In this regard, the prominent educator Ms. Viola Soto (Soto, 2004) believes that educational policy should advocate training that "on the one hand, a caring man looking in continuing cooperation with others, with a story based on which builds its vision and its entry into the planetary civilization; otherwise, a competitor individual, able to deny the presence of others or separate their benefit, whose north is the future of techno-scientific "globalization".

The success in the implementation of a curriculum as the indicated will be difficult and slow, have a natural resistance to change; teachers with initial training that does not comply with the principle of "reflective practitioner" (Schön, 1992); guide training in the learning-development axis; to approach the theory and the daily practice, 
incorporating service-learning methodology; joint training levels that enable effective training itinerary; universities should provide quality education with an innovative multidisciplinary management by incorporating a culture of change and continuous quality improvement; sufficient for the associated costs of the student practice financial resources.

These concepts are shaped the recommendations of UNESCO (Brito, 2014) in the Agenda for the Development after 2015.

In Chile, some universities declare skills training, including, secondarily, social skills, but a simple analysis of information on the official websites of these schools, enough to realize that the stated curriculum is linear, ie, traditional no indication of socio-critical curriculum. (U de Chile, 20015), (U of Talca, 2015), (U de la Frontera, 2015). They all agree on issues such as ethics, social responsibility, oral and written communication incorporated as subjects with no more than 2 hours a week. Moreover, a study conducted at the National Technological University of Argentina shows the difficulty of incorporating, as elements of social skills and personal development. The authors, among its recommendations point to the increase in social science subjects. (Ferrando, Karina and Páez, Olga, 2009)

\section{Conclusions}

The competency-based approach has gained ground in engineering education with the strong support of the prevailing neoliberal system and international organizations, but it should be stressed that the linear engineering, traditional approach still remains and, in some colleges the approach competences not pass rather than being a statement. If deemed central to the curriculum competency axis, facing a socio-critical approach, it is advisable to integrate the best of both concepts in order to develop and implement a curriculum that ensures competency-based training, which is Based on the engineering training that will lead to a comprehensive education, implying an engineer with technological and scientific training at the highest level, with a high sense of social responsibility and a marked development of critical and reflective thinking and skills issue argued and ethical judgments, that places engineering in central finding solutions for sustainable development and promote a more integrated and collaborative research. (Ibídem)

\section{References}

Brito, L (2014). Ciencia y sustentabilidad global. Desafíos para la educación Superior. Ingeniería 2014, Latinoamérica y Caribe. Congreso y Exposición. Buenos Aires. www.cai.org.ar/index.php/biblioteca-Ing2014/ponencias

Cres (2008). Declaración de la Conferencia Regional de la Educación Superior en América Latina y el Caribe. www.cres2008.org/es/index.php

Delors, J (1994). La Educación Encierra un Tesoro. Informe a la Unesco de la Comisión Internacional sobre Educación para el Siglo XXI. UNESCO.

Fauré, E (1973). Aprender a Ser; la Educación del Futuro. Comisión Internacional sobre el Desarrollo de la Educación, UNESCO. 
Ferrando, Karina Cecilia y Páez, Olga Haydée: Formación de Ingenieros: un análisis reflexivo desde los estudios sociales de la Ciencia y la Tecnología. Facultad Regional Avellaneda, Universidad Tecnológica Nacional, 2009.

www.coini.com.ar/COINI2009/contenidos/FORMACION_DE_INGENIEROS.pdf

Grundy, S (1992): Producto o praxis del currículum. Editorial Morata.

Letelier, Mario et al (2005). Sistema de Competencias Sustentables para el Desempeño Profesional en Ingeniería. CICES, USACH. Revista de la Facultad de Ingeniería Universidad de Tarapacá. Vol. 13, Nº 2.

Magendzo, A (2006). El Derecho a una Educación, a una Educación de Calidad con Equidad para Todos: el Ejercicio de un Derecho Humano. Diario de la Sociedad Civil.

Prelac (2002). Un Trayecto Regional hacia la Educación para Todos. La Habana.

Cres (2008). Declaración de la Conferencia Regional de la Educación Superior en América Latina y el Caribe.

Schink, H y Ormeño, E (2006). Hacia un concepto de formación de personas competentes. Revista Intramuros, $N^{\circ} 17$. Universidad Metropolitana de Ciencias de la Educación.

Schön, D (1992). La formación de profesionales reflexivos. Paidós

Soto, V (2004). Políticas, acciones curriculares y reforma de la educación en Chile. Universidad Metropolitana de Ciencias de la Educación.

www.colegiodeprofesores.cl/congreso/viola_soto.htm

UNESCO (1990). Declaración Mundial sobre Educación para Todos y Marco de Acción para Satisfacer las Necesidades Básicas de Aprendizaje. Jomtien, Tailandia.

UNESCO (2000). Educación para Todos: Cumplir Nuestros Compromisos Comunes. Foro Mundial sobre Educación para Todos. Dakar, Senegal.

U DE Chile (2015) www.ingenieria.udechile.cl/carreras

U de la Frontera (2015) www.admision.ufro.cl/index.php/ver-carreras

U de Talca (2015) www.udetalca.cl/link.cgi/carreraspregrado 
HEAd'15

\section{SESSION 1C}

\section{INNOVATIVE TEACHING}

METHODS (I) 


\title{
A Software Interface as a Teaching Tool for Analysing Conformal Antenna Arrays
}

\author{
J. P. González-Coma, R. Maneiro-Catoira, P. M. Castro, J. Brégains
}

*Department of Electronics and Systems, Universidade da Coruña (Spain)

\begin{abstract}
Electromagnetic laboratory teaching activities greatly benefit from utilizing Information and Communication Technologies (ICTs), due to the fact that the understanding of concepts that are difficult to be communicated using traditional approaches becomes easier. We have developed a graphical interface, designed with MATLAB ${ }^{\circledR}$, that represents a very useful tool to convey concepts related to configuration and radiation of conformal antennas to students that are not experts in that particular field.
\end{abstract}

Keywords: Conformal antenna arrays, ICTs, MATLAB, software interface, teaching tool.

\section{Introduction}

Previous researches have shown that students learn and retain much more when they directly experiment in the laboratory, as opposed to when they only listen or see concepts in traditional classroom lectures, as explained in works by Shyr (2010), Bonwell (1991) and McKeachie (1994). Learning is a dynamic activity, and the process of comprehension and understanding of a set of interrelated concepts is greatly enhanced if the student takes an active part in such an assimilation process. In the case of proactive students, the aforementioned dynamism practically does not depend on their teachers, as they march at almost self-taught pace. But for less determined students, any external supplementary tool can help to fill the motivational gaps. It is clear that the number and nature of the variables that modify motivation conform a complex topic that deserves a separate research -see for example Christensen (2010), Hanrahan (1998) and Henning (2007)-, but no doubt the nearer the learning tools to amusing activities, the higher the enthusiasm that will catalyse the learning process towards successful outcomes. The tremendous ubiquity of computer systems nowadays allows teachers to reach this purpose by focusing the design of learning activities on software tools that result to be entertaining for the students, in some cases up to the limit of creating videogames, Mitchell (2004). Under these views it is of no surprise that the European Higher Education Area -EHEA, see Declaración de Soborna (1998) and Declaración de Bolonia (1999)- promotes, among other things, the utilization of Information and Communication Technologies (ICTs) in order to reinforce the self-based learning of students. As nowadays students are totally familiarized with ICTs, it is easy for them to learn the use of new software tools without complex memorization requirements; this feature, together with the fact that most of them play or have played videogames on a regular basis, deepens the justification of professors to design new computer applications that facilitate the learning process. Moreover, as the combination of visual with conceptual learnings is much more effective than conceptual learning alone -widely employed by traditional methodologies-, graphic-based teaching tools are particularly useful for handling those concepts that sometimes are hidden by abstract ideas, or even in cases where the ideas are simple, but the mathematical language used to describe them is so entangled that such ideas easily become obscured. This latter is the case of, for example, antenna theory, whose conceptual modelling has easy-to-follow concepts, but whose mathematics require from the students additional efforts, compensated by necessary, and sometimes tiresome, training sessions. 
In agreement with the abovementioned perspectives, we have designed a teaching tool that makes use of ICTs and that allows the teacher to facilitate the students' understanding of the subject of antenna radiation patterns, successfully included in the syllabus of the Master's course program "Information Technologies and Communications in Mobile Networks (ITCRM)", and in the subject "Mobile and Wireless Networks (RM)" corresponding to the fourth year of the Degree in Computer Science at the University of A Coruña (Spain). The tool, described in this paper, consists of a novel graphical interface, designed with MATLAB ${ }^{\circledR}$, and intended to be used to convey concepts related to antenna radiation. Such an interface is capable of representing both the spatial and electrical configurations of a conformal antenna array, as well as the different patterns radiated by it. Thanks to this computerassisted learning, students are able to perform, at will, instructive experiments to further understand the theoretical concepts given previously in the traditional classroom lectures. The utility of the tool is illustrated with a sample lesson.

\section{Material and Methods}

An arrangement of single electromagnetic radiating elements is called an antenna array. According to their spatial distribution, they are called linear -when the elements are aligned along a straight line, planar -when arranged on a plane, or conformal -if distributed on a specific three-dimensional surface. Antenna arrays are designed in order to radiate electromagnetic energy towards desired spatial locations, focusing on desired regions. Another important feature of antenna arrays is related to their electromagnetic feeding distribution, which, basically, represents the amount of energy used to supply each element. Each element of an array has its own radiation diagram, and also a feature called polarization, which represents the spatial direction of the oscillation of the radiated field. The proper combination of both the spatial and feeding configurations, taking also into account the polarization arrangement, allows the designer to obtain the required radiated energy spatial distribution.

Conformal antennas are especially difficult to characterize, since the polarizations of their elements are usually not aligned among themselves, a feature that considerably increases the design complexity. In spite of the fact that they nowadays constitute a well-studied subject, as seen in Josefsson (2006), surprisingly it is not easy to find any freely-distributed software tool capable of representing visual information about the spatial distributions of both their physical configuration and their electromagnetic radiation. The currently available tools correspond to either commercial electromagnetic simulators that make use of well-known numerical techniques, such as Finite Difference Time Domain (FDTD), Method of Moments (MM), etc., see Davidson (2010), or a recent MATLAB ${ }^{\circledR}$ toolbox called "Phased Array System Toolbox" -The Matlab Group (2011)-, neither of them freely available. Normally, those tools are expensive, and, which is also important, their handling entails considerable technical knowledge from the users. The latter drawback is remarkably important when the tools are required to be used with learning purposes, since students usually have a limited amount of time to acquire the necessary, and complex, handling skills.

The designed software tool described here deals efficiently with the abovementioned problems: it requires little previous knowledge from the user and its source code can be freely obtained, provided he/she has MATLAB at his/her disposal -as happens with the students of our courses. Such a free tool developed by the authors is also relevant in the sense of strengthening the homework of students without the need of being 
present in a traditional lecture, thus ensuring two basic principles of the EHEA: firstly, by promoting the Student-Centred Learning (SCL), since it increases the active learning with a major motivation in the students, Alonso (1998) and Colas (2009), and secondly, by exploiting a new relationship between them and the teacher, given that the traditional way of teaching and learning is substituted or complemented by the employment of ICTs that simulate the real environment. Thus, they can empirically test different configurations with several parameters that would not be approached using the traditional oral questions addressed to the professor for solving doubts. This tool is also intended to reinforce the interaction teacher-student, as represented in Figure 1, and it is exclusively oriented to university studies due to the high technical knowledge required to the students when they are bound to justify the presented results, which also contributes to promote their criticism, in order to avoid automatic behaviours that most of the time obstructs the reasoning process.

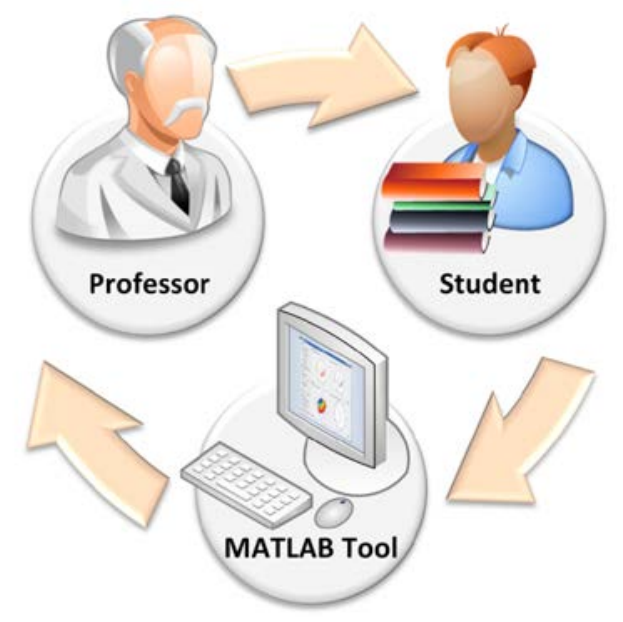

Figure 1. Interaction between student and professor using the teaching tool presented in this work. Source of the icons: www.iconarchive.com

\section{Description of the Tool: Example and Discussion}

During the course, the students are given, through regular lectures, the mathematical description of the physical models that represent conformal array antennas. Part of the mathematical description related with the presented tool can be found in the papers by Brégains et al. (2004, 2010, and 2011).

We proceed now to briefly describe the proposed tool, including an example.

By typing the sentence (The MATLAB Group, 2008) >> guide ConfPolPow3D.fig in the MATLAB ${ }^{\circledR}$ command line, the MATLAB GUI compiler will be opened. In this case, the designed ConfPolPow3D program will not run immediately, and just its interface will appear on the main window. In this manner, the user is able to edit both the outer aspect of the interface (add buttons, text boxes, etcetera), and the source code that will follow the commands actions that such an interface will receive from the user.

After having finished its edition, the program will be executed by using the Ctrl+T shortcut, for example. Afterwards its main interface will appear, see Figure 2. As it can be seen, there are separate frames corresponding to: Array Configuration (for both the spatial and the electrical configuration of the array), Pattern Options (2D and 3D features for the field spatial distribution) and Visualization Space (four sub-frames within which there will appear, on the one hand, the visual representation of the array 
spatial and electrical distribution, and, on the other hand, the plots corresponding to the field radiated by it).

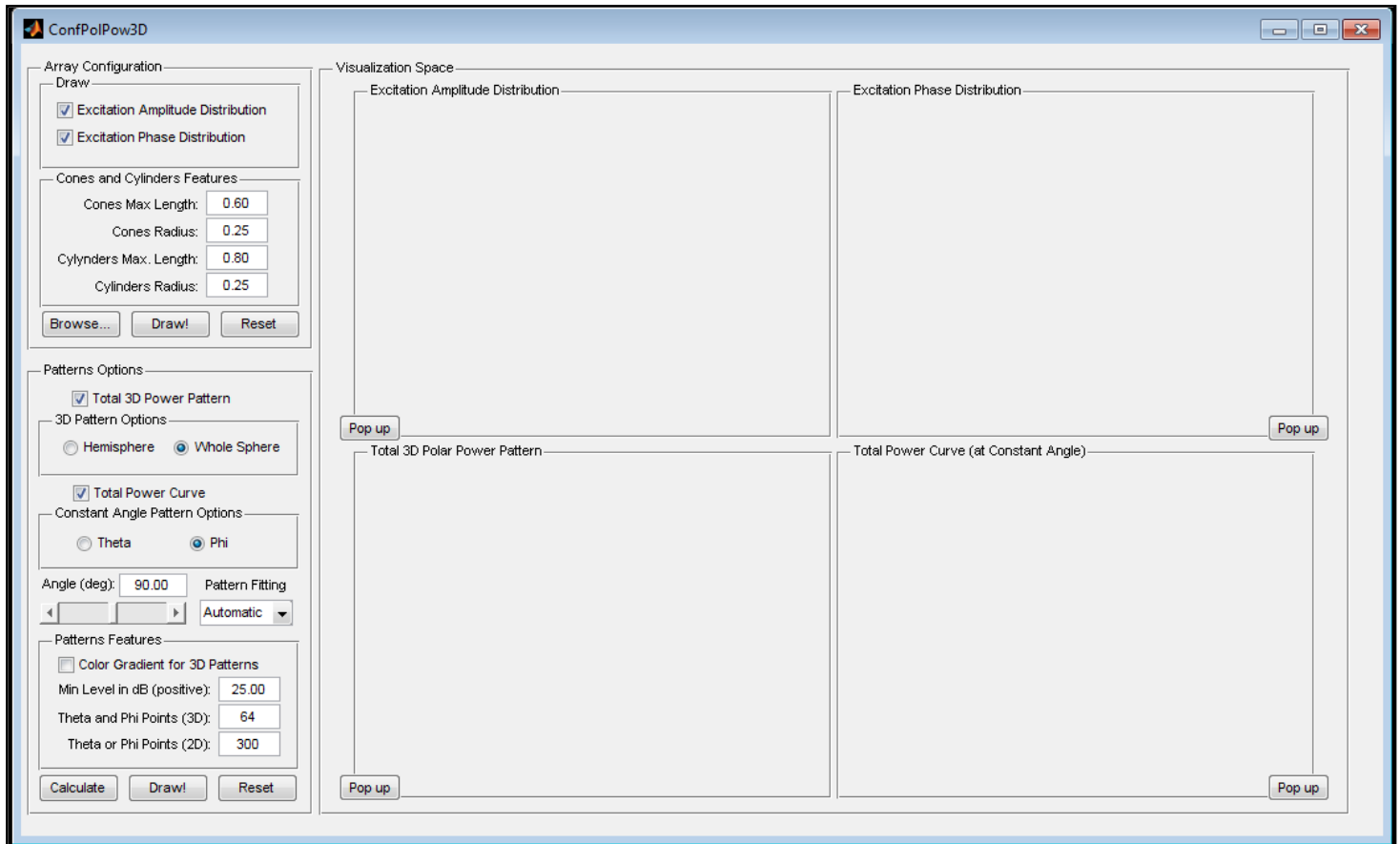

Figure 2. Main interface of the described tool.

When the student clicks on the "Browse..." button from the Array Configuration frame, see Figure 2, the program proceeds to load into memory the conformal array configuration. This is done by reading a selected text file (.dat extension). The data corresponding to each radiating element must have been previously introduced by the student into such a text file. After having selected the configuration file, the program will load the data and run some previous calculations, informing, by means of a window message if there have been any errors when accessing the file. If the data have been correctly loaded, then both the number and type of elements (patches, dipoles, or isotropic elements, see Balanis, 2005, and Brégains, 2003 and 2005) will be shown to the student, indicating also that both the electrical and spatial configurations of the array are ready to be visualized (see Figure 3). Figure 4 shows an example when an array composed of eleven dipoles arranged on a cylinder has been successfully loaded.

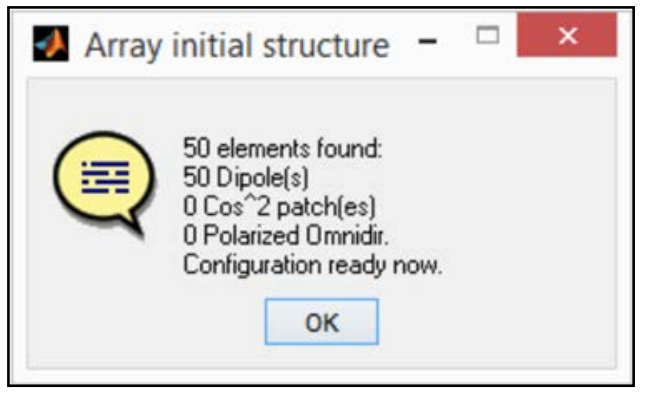

Figure 3. Message box indicating that the program successfully loaded an array configuration composed of fifty dipoles (Brégains, 2003 and 2005).

Before proceeding to plot such configurations, the student will be able to establish the relative size, given in $\lambda$ units, of the maximum amplitude and phases (feeding of the elements), represented by oriented cones and non-oriented cylinders, respectively. The orientation of each cone represents the $z_{n}$ direction of the local coordinate system of 
each element (Brégains et al., 2011). The heights and radius of those geometric figures representing amplitudes and phases can be configured by the controls gathered on panel Cones and Cylinders Features, see Figure 3.

Once the configuration is loaded, by clicking on Draw! button from the Array Configuration frame, the program will proceed to plot the array relative amplitude and/or phase distributions, according to the selections performed within the Draw panel (at least one of the Excitation Amplitude Distribution and Excitation Phase Distribution checkboxes must be selected, see Figure 2). The corresponding plots will appear on the upper half of the Visualization Space, see Figure 4. The student will have then at his/her disposal the option of erasing the graphics by clicking on Reset button in the Array Configuration panel, or of obtaining detached figures, capable of being adequately edited, by clicking on any of the Popup buttons, located on the bottom vertex of the given plots on the Excitation Amplitude Distribution or Excitation Phase Distribution frames, see Figure 2.

Once the array configuration has been loaded, it will be necessary to set the power pattern parameters to be further calculated and visualized: on the one hand, it will be necessary to indicate if the 3D pattern is requested to be calculated (Total 3D Power Pattern at the top of the Patterns Options panel, see Figure 2), over the whole space (Whole Space) or the southern hemisphere (Hemisphere), and, on the other hand, the student will have to specify a 2D pattern by setting either $\theta$ =constant or $\varphi=$ constant (which are the usual spherical coordinates), at an angle specified by the Angle (deg) edit text box, this latter having the option of being selected with the help of a slider located below it. In Figure 3, for example, within the Constant Pattern Options panel, there has been selected the Phi radio button option, considering Angle (deg): 90.00. This means that the power radiated pattern is calculated by taking $\varphi=90^{\circ}$, with $\theta \in(0$, $\left.180^{\circ}\right)$.

The Pattern Fitting options list will set the type of limit adjustment of the axis box containing the 3D pattern. The student will be able to select the more adequate solution according to his/her: Automatic, corresponding to the axis auto MATLAB ${ }^{\circledR}$ option; Packed, setting axis fill, or Level, establishing the box limits (i.e., the limits of the box enclosing the coordinate axes of the visualized power patterns) between $-l e v_{\min }$ and $l e v_{\min }$, being $l e v_{\min }$ the value indicated on Min Level in $d B$ (Positive) text box, from the Patterns Features panel.

The Theta and Phi Points (3D) text will indicate the program the number of points selected for sweeping the $\theta$ and $\varphi$ angles on the 3D plot: in other words, the number of $\varphi$ points taken from 0 to $360^{\circ}$, and the number of $\theta$ points taken from 0 to $180^{\circ}$ (in case of whole space) or from 0 to $90^{\circ}$ (in case of hemisphere) on which the radiated power pattern is calculated to be finally represented. The same is applicable for the Theta or Phi Points (2D) edit text, that indicates the number of points for sweeping the $\varphi$ (for $\theta=$ constant ) or the $\theta$ (for $\varphi=$ constant) angles on the planar patterns.

The Color Gradient for 3D Patterns option will set a colour map on the 3D power surfaces, with corresponding colour bars that will inform the student about the concerned levels (unless the field is null, in which case those bars will be omitted). If such an option is not selected, then the 3D patterns will be drawn with uniform colours and no level bar. In both cases, the axis box will be given with ticks and labels on the $x, y$, and $z$ axes. 
When clicking the Calculate button, the program will perform the computations of all the fields (total, and a few components, Brégains et al. 2011) specified by the student (3D and/or 2D patterns). Figure 4 shows the 3D patterns obtained for the array configuration presented above, after the corresponding Calculate and Draw! buttons have been clicked.

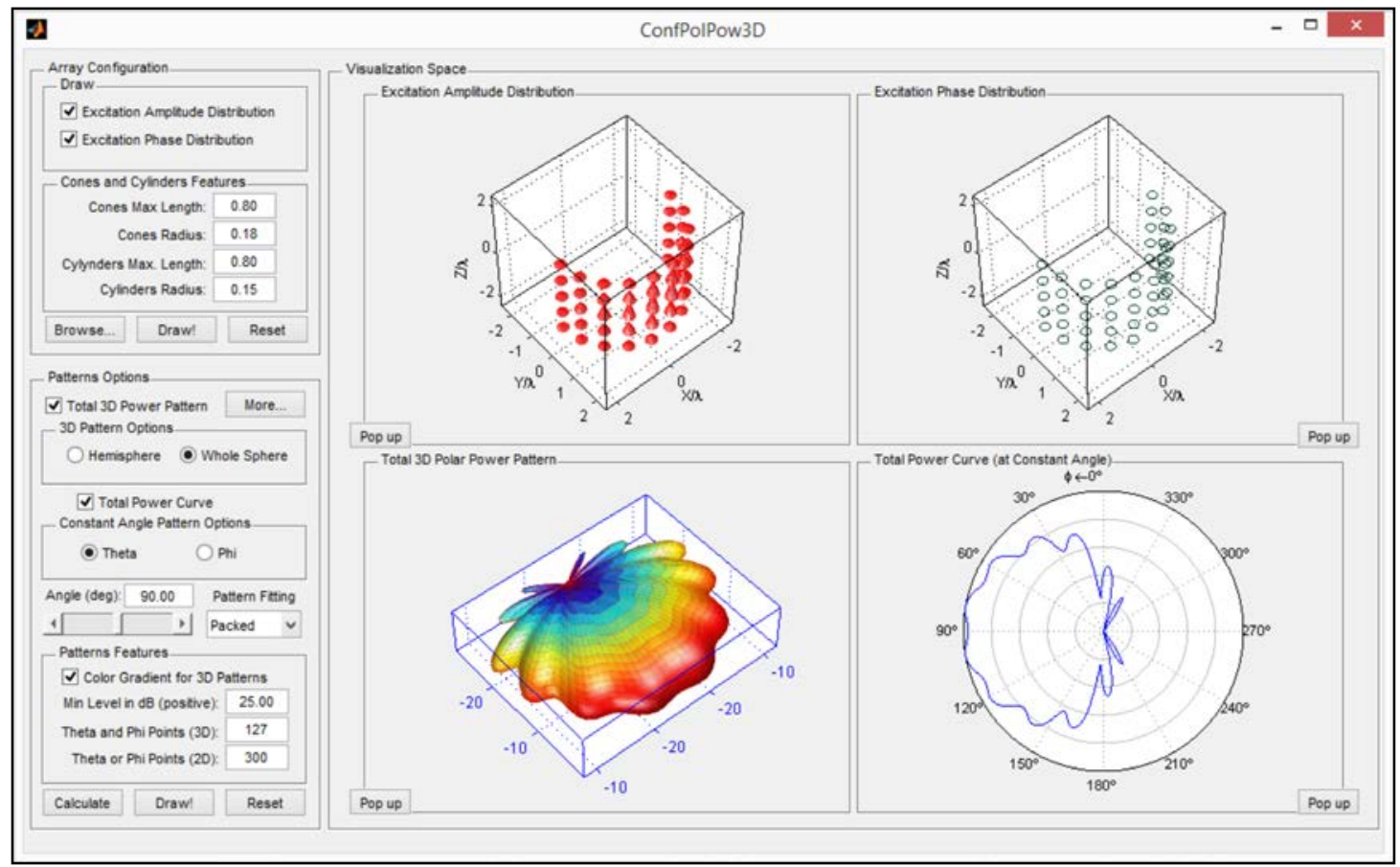

Figure 4. Outward appearance of the main interface of the tool once the spatial and electrical configuration of the array, as well as its radiated patterns, have been plotted. Plots correspond to a semicylindrical array of 50 dipoles (Brégains, 2003 and 2005) backed by a ground plane. Top: electrical and spatial array configuration. Bottom: Total power (3D and 2D) patterns.

The source code is performed so as to give the students the possibility of having at their disposal the use of several options of the array elements. In the first attempt of our code we have considered three options: a half-wavelength dipole, a circular patch and finally an (unrealistic, but useful for further testing the program) omnidirectional element.

With the "Popup" button of the 3D diagram the program will plot, in separate windows, the graphics corresponding to three different components of the field. There is also a corresponding Pop up button for 2D plots, see Total Power Curve (at Constant Angle) panel in Figure 4. In all these cases, including the plot belonging to such a panel, we have used a function that performs planar polar plots.

\section{Conclusions}

This tool has been used as a test in the lectures corresponding to the Master's course program "Information Technologies and Communications in Mobile Networks (ITCRM)" during the academic year 2011/12 and in the lectures of "Mobile and Wireless Networks (RM)" introduced in 2013/2014 according to the new studies plan designed in the context of EHEA up to now. This optional subject corresponds to the fourth year of the Degree in Computer Science at the University of A Coruña (Spain). We have used this tool in conjunction with standard graphical tools in the area of antenna radiation and signal propagation, although as a further line work we are 
currently seeking the development of a unique and integrated software, thus avoiding the utilization of multiple software (neither always free nor easily available for the students). The tool was welcomed by the students, and although we did not gather yet the required information to quantitatively evaluate the impact of the use of this program on their performance, we have found a significant improvement on the quality of the management of the concepts they have to acquire since the tool was introduced.

For the visual representation of the fields generated by conformal arrays composed of elements whose patterns are well studied, and with configurations where the mutual coupling can be neglected, the presented tool constitutes a reliable alternative to the commercial programs based on known numerical techniques. The students have also the option of modifying at will the source code, which remarkably increases the utility of the tool.

In spite of the completeness of the tool, some improvements could be suggested. The possibility of writing an output file containing any of the calculated patterns is a possibly useful feature. The three components of the field for the constant $\theta$ (or $\varphi$ ) polar cuts could be represented within a single figure. Sometimes would be preferable to draw Cartesian planar plots instead of polar ones. Additional pattern attributes could be controlled by the inclusion of further controls (buttons, check boxes, etcetera), but at the price of needing more space to locate them.

Finally, it is important to remark that several results obtained with the proposed tool were successfully validated -taking into account that the negligibility of the mutual coupling between elements would cause apparent differences with respect to the more realistic results- with a commercial software tool (based on the FDTD technique). In this sense, it would be also possible, in a future work, to compare the performance of the tool introduced here with that of MATLAB -Phased Array System Toolbox, mentioned previously (MATLAB, 2011)-, something that was not performed here because our research group does not hold the corresponding tool license yet.

The source code is freely available on request to one the authors of this work (julio.bregains@udc.es). The zipped file containing the code also includes several antenna configurations, such as the one given here as example, together with a brief tutorial that would help the interested user to quickly grasp the program handling.

\section{Acknowledgements}

The authors thanks Xunta de Galicia and Ministerio de Economía y Competitividad of Spain for its financial support under grants number 2012/287 and TEC2013-47141C4-1-R.

\section{References}

Alonso Tapia, J. (1998) ¿Qué podemos hacer los profesores universitarios para mejorar el interés y el esfuerzo de nuestros alumnos por aprender? Ministerio de Educación y Cultura (Ed), Madrid: Premios Nacionales de Investigación Educativa, 151-187.

Bonwell, C.C. \& Eison, J.A. (1991). Active learning: Creating excitement in the classroom, Washington C. C. George Washington University.

Balanis, C.A. (2005). Antenna Theory. Analysis and design, 3r edition, New Jersey: Wiley-Interscience 
Brégains, J. C., Ares, F. \& Moreno, E. (2004). Visualizing the 3D Polar Power Patterns and Excitations of Planar Arrays with MATLAB, IEEE Antennas and Propagation Magazine, 46, 2004, 108-112.

Brégains, J.C. \& Ares. F. (2003). Variation in Bandwidths of Pattern Quality Parameters and Maximum Embedded Impedance Among the Solutions to Shaped Beam Synthesis Problems for Collinear Dipole Arrays, IEEE Antennas and Wireless Propagation Letters, 2, 267-268.

Brégains, J.C. \& Ares, F. (2005). Variation in Bandwidths among Solutions to Shaped Beam Synthesis Problems Concerning Linear Arrays of Parallel Dipoles, IEEE Transactions on Antennas and Propagation, 53, 563-564.

Brégains, J.C. García-Naya, J.A., Dapena, A \& González-López, M. (2010) A MATLAB Tool for Visualizing The 3D Polar Power Patterns and Excitations of Conformal Arrays, IEEE Antennas and Propagation Magazine, 52, 127-133.

Brégains, J.C., García-Naya, J.A., González-López, M. A., Castedo, L. (2011). A MATLAB Interface for Analyzing Conformal Arrays Composed of Polarized Heterogeneous Elements, IEEE Antennas and Propagation Magazine, 53, 136144.

Christensen, C.M., Horn, M.B. \& Johnson, C.W. (2010). Rethinking student motivation: Why understanding the 'job' is crucial for improving education, Boston: Innosight Institute.

Colas, P. \& De Pablos, J. (2009). La universidad en la Unión Europea. El Espacio Europeo de Educación Superior y su impacto en la docencia. Archidona: Aljibe.

Davidson, D.B. (2010). Computational Electromagnetics for RF and Microwave Engineering (2nd edition), New York: Cambridge University Press.

Declaración De Bolonia. (1999). Online: http://www.universia.es/contenidos/universidades/documentos/Universidades_do cum_bolonia.htm, Paris.

Declaración De Sorbona. (1998). Online: http://www.universia.es/contenidos/universidades/documentos/Universidades_do cum_sorbona.htm, Paris.

Hanrahan, M. (1998). The Effect of Learning Environment Factors on Students' Motivation and Learning, International Journal of Science Education, 20, 737753.

Henning, M. (2007). Students' Motivation to Learn, Academic Achievement, and Academic Advising (PhD Thesis), New Zealand: AUT University.

Josefsson, L. \& Persson, P. (2006). Conformal Array Antenna Theory and Design, New York: IEEE Press/John Wiley.

Mckeachie, W.J. (1994). Teaching Tips: Strategies, Research, and Theory for College and University Teachers, 9th ed. Lexington, MA: Cengage Learning.

Mitchell, A. \& Savill-Smith, C. (2004).The Use of Computer and Video Games for Learning, London: Learning and Skills Development Agency.

Shyr, J. W. (2010). Integrating laboratory activity into a junior high school classroom, IEEE Transactions on Education, 53, 32-37.

The Matlab Group, Inc. (2008). Matlab Function Reference: Volumes 1, 2, 3, (printed version of the corresponding MATLAB Help menu).

The Matlab Group, Inc. (2011). Online: www.mathworks.com/products/phased-array. 


\title{
Development of an online platform for experimental teaching in microeconomics
}

\author{
I. Barreda Tarrazona*; E. Camacho Cuena*, A. García Gallego*, M. Ginés Vilar*, A. \\ Jaramillo Gutiérrez*, S. López Ovejero*, S. Behnk*, A. Morone*, J. C. Pernías \\ Cerrillo*, G. Sabater Grande*, T. Jaber López*
}

* LEE \& Economics Department, Universitat Jaume I, Av. Vicente Sos Baynat, s/n, Castellón, España

\begin{abstract}
The instructors of the microeconomics courses at the University Jaume I in Castellón, Spain have created a group for educational innovation in microeconomics devoted to the introduction of experiment-based learning in the economics domain. The main goals of this project are to facilitate and to enrich student learning and to provide microeconomics teachers with useful materials to introduce experiment-based activities in their classroom. The methodology used is that of experimental economics: students participate in laboratory sessions where a computer program reproduces the main characteristics of the market structures studied in introductory and intermediate microeconomics. After the students interactions determine the outcome for each participant, the underlying theoretical model is solved and presented. Finally, observed and predicted outcomes are graphically compared and discussed. In order to facilitate this process, we developed a webpage in 2013 on which students and teachers can freely download instructions, software, theoretical solutions and data analysis examples corresponding to each experiment. Afterwards, we conducted a survey in order to evaluate the effectiveness of the classroom experiments in combination with the online platform. The results obtained from the questionnaire data show the effectiveness of our project. More than two thirds of the students considered these practices to be helpful for a better understanding of the course and confirmed a high demand for the online platform. 90\% stated that they would recommend the experimental lectures approach. We would like to share our materials with other universities that are considering these practices as part of their teaching processes so that they can benefit from our experience.
\end{abstract}

Keywords: Classroom Experiments; Microeconomics; Information Technologies

\section{Introduction}

During the academic course 2011-2012, the new degrees in Economics, Finance and Accounting as well as Business Administration were implemented at the University Jaume I in Castellón, Spain, and adapted to the European Higher Education Area. At the same time, a Group of Educational Innovation (GIE) in microeconomics was created that received funding and official recognition from the university to carry out educational innovation projects for the classroom. The first project promoted by the GIE was the implementation of experimental lessons in a computer laboratory in the modules related to the microeconomics field.

The main goal of this project is to facilitate and to improve the students' learning process by letting them explore and experience economic concepts on their own, so that they develop new skills and reach new learning objectives which were never systematically developed in previous programs. Moreover, lecturers are provided with guidance and tools for implementing this innovation in the classroom which can easily be used without previous experience in running didactical experiments.

\section{Laboratory classes}

The teaching methodology used is based on economic classes in the computer laboratory. These exercises are underpinned by the constructivist and interactive experimental approach and go back to Chamberlin (1948) and Smith (1962). By now, a variety of experiments have been developed regarding many aspects of economic settings, for instance regarding information cascades (Holt and Anderson, 1996), public good contributions (Holt and Laury, 1997) or monopolies (Oxoby, 2001). 
A limited variety of studies has investigated the effect of specific economic experiments on students' performance in particular tasks. For instance, the study of Frank (1997) found that participating in an experiment helped the students to better understand many aspects of the underlying problem but not all of them. Dickie (2006) also finds a positive effect of economic experiments in class. In his study, participation in several experiments was especially effective for the performance of top students. Durham et al. (2007) also confirm the positive effect of experiments on the students' performance and find different effects according to individual learning styles.

Students are active builders of their own knowledge during these classes, undertaking the role of a dynamic agent and being totally aware and responsible for their actions and their learning. On the other hand, most of the students still do not know the microeconomic theories which can predict their behaviour in the experiments before running them. This approach goes far beyond the classical learning-by-doing. In this way, they can build their own theories based on their decisions and observations of the experimental outcomes. After that, the students test the validity of their self-constructed concepts by comparing them with the formal mathematical theories which are presented in the module under different market conditions and explained later on.

The lessons start with a presentation of the market structures and the experimental rules followed by the preparation of the respective programs in the laboratory. Slides are used in order to organize all this information. Students have to get the program started on their own in order to become familiar with the software. The session continues with the participation of the students in an experimental market including the features of the market structures studied in the introductory modules of microeconomics (Pindyck \& Rubinfeld, 2009), for instance perfect competition, monopoly or duopoly. The markets are simulated with symmetric or asymmetric cost, with homogeneous or heterogeneous products. There are no explicit rules for the students about colluding or not with others during the experiment. Students are only informed that their main goal is to maximise their benefits and that they make their decisions on their own. During a pre-defined sequence of rounds, students make decisions about prices or quantities simultaneously or sequentially, depending on the market structure, for instance in the common Cournot, Bertrand or Stackelberg settings.

After finishing all market stages, the experiment ends and the lecturer solves the theoretical model of the market used in the experiment in front of the class. This part is particularly useful for the students as they acquire new theoretical and practical knowledge and combine this knowledge with what they learned before. At the end, the data obtained during the experiment is presented in the classroom using graphs. The students' aggregated decisions are compared with the previously calculated equilibrium magnitudes. In this way, the students can see the suitability of a particular theory for explaining a market situation they have just created.

Besides these learning advantages, carrying out the laboratory experiments is a challenge for the coordination of the course because it requires preparing many experiments with the corresponding instructions, theoretical solutions and experimental software including the coordination and monitoring of the students in the computer laboratory. Therefore, lecturers must be instructed to use Z-tree (Fischbacher, 2007), the software with which the market simulations were developed and programmed by the innovation group director, Iván Barreda Tarrazona. The lessons also require the lecturers' ability to react to differences in the convergence of the data to the theoretical predictions, an uncertainty that is unavoidable when using individual decision-making. 
Furthermore, it is a methodology which gives rise to questions and comments from the students which cannot always be predicted.

A challenge for students is that it requires their presence in the classroom in order to participate in the experiment. In order to motivate students to attend these classes, they are given the opportunity to solve a questionnaire regarding the observations they made during the experiments and the underlying theory, which accounts for $20 \%$ of the students' final mark in the course.

\section{Development of an online platform}

Information technologies are an efficient enhancement to the classical economic experiments (see, for instance, Cheung, 2008). In order to help with the coordination of the experimental lectures and to provide an easy access to material online for students and lecturers we developed a website, where instructions, software and examples of data analyses for a variety of classroom experiments can be found for downloading. The material is fully and freely accessible online after registration at "www.experimentosdeclase.com" and "www.lee.uji.es/experimentosdeclase". We use a creative commons license in terms of an equal share and not for commercial use. Thus, both students and lecturers are provided with an updated source to obtain all needed materials for the laboratory classes.

The website is a teaching tool designed to facilitate the teaching-learning process using new technologies. The attraction of new technologies and interactive environments in addition to the innovative methodology of didactic experiments are a promising motivation for students to participate actively in the course.

On the website we have taken into account the technical and visual requirements for an easy navigation, for instance the presence of the navigation menus, a clear design and the use of multimedia elements in order to motivate the reader. Furthermore, we implemented a frequently asked questions (FAQ) section so that students are able to find answers to the most common questions regarding the content of the website.

Moreover, we have considered didactic and pedagogical aspects (Cabero \& Gisbert, 2002), for instance the exposure to information by a brief and clear introduction, giving an idea of the topic, as well as the incorporation of conceptual maps to organise the contents, which gives the user the advantage of having all information summarized on a single page.

As a measure of the website's success we use a visit and download counter. A statistical service for websites is used to obtain reports regarding this data. Besides, we aim to create a list of lecturers who are using these programmes in their classes at different universities.

\section{Methods}

During the 2013-2014 academic year, we used four experimental practice groups in the Introduction to Microeconomics module (first year) and seven practice groups in the Microeconomics module (second year) at the University Jaume I. Altogether, this approach enabled over 3000 strategic behaviour experiences in different market settings during the academic year. In order to evaluate the use of the experimental practices and the online material as well as the students' satisfaction with this teaching methodology, 
they were given an anonymous questionnaire for evaluating their experience in these classes.

We have chosen the questionnaire as the most suitable evaluation method for the use of the online platform and the students' satisfaction, taking into account the main advantages pointed out by McKernan (1999) in relation with other information gathering methods. Some of these advantages are: the facility of evaluation and implementation, the opportunity to compare groups and individuals and the behaviour feedback, adequacy of resources, preparation of future sessions and quantifiable data.

We developed the questionnaire by firstly deciding on the information we wanted to obtain, evaluating the personal and temporary resources that we had, selecting the sample, using an appropriate wording for the questions and designing the questionnaire structure. Once the questionnaire was ready, it was handed out anonymously to 148 students who attended the experimental classes on a regular basis in different groups and with different lecturers, both in classes that took place in the morning and in the afternoon.

\section{Results}

Below, we describe the questions and the answer possibilities that were used in the questionnaire, combined with the graphical presentation of the obtained results. A summary of the aggregated results is presented at the end of this section.

In QUESTION 1 we asked: Considering what you have learned in the lectures and classes, how much did the laboratory classes help you in understanding the course? The possible answers to this question were: a lot, quite a lot, indifferent, a bit and nothing.

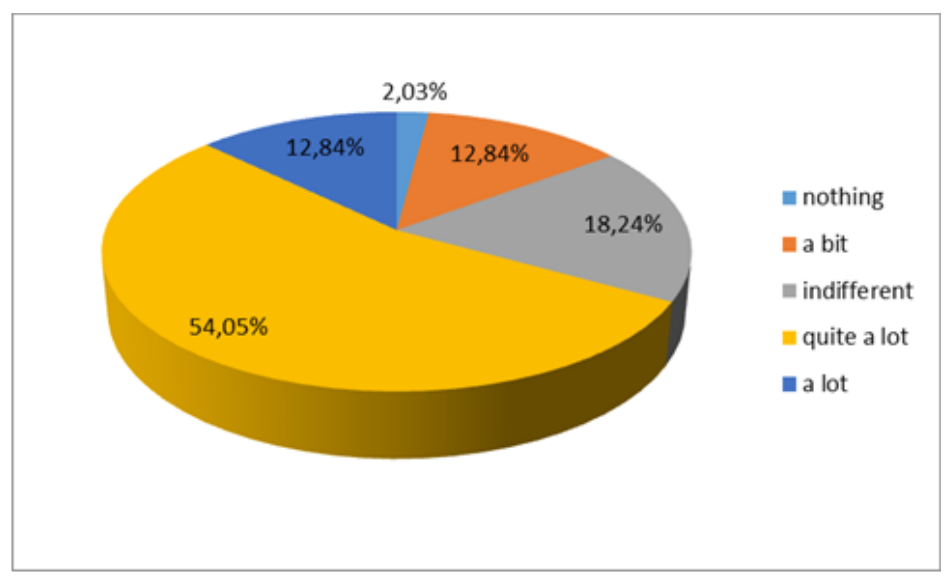

Figure 1. Understanding

QUESTION 2: Was it difficult for you to create a direct access to the program and to use it? The possible answers were: a lot, quite a lot, indifferent, a bit and nothing. 


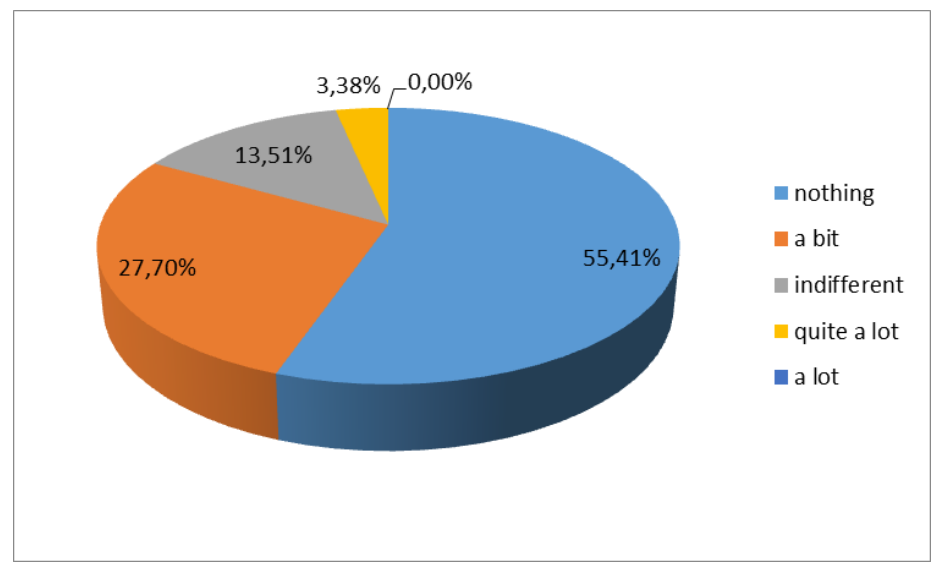

Figure 2. Usability of the program

QUESTION 3: Do the dynamics of the experiments motivate you to participate again? The possible answers were: a lot, quite a lot, indifferent, a bit and nothing.

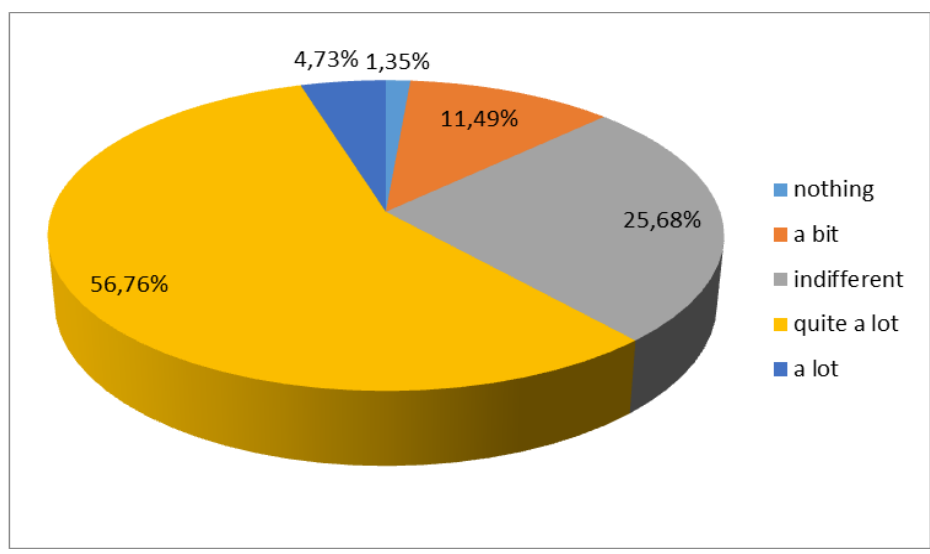

Figure 3. Motivation for participation

QUESTION 4: What do you think about the time you dedicated to the experimental decision-making in each session? The possible answers were: too much, adequate, insufficient.

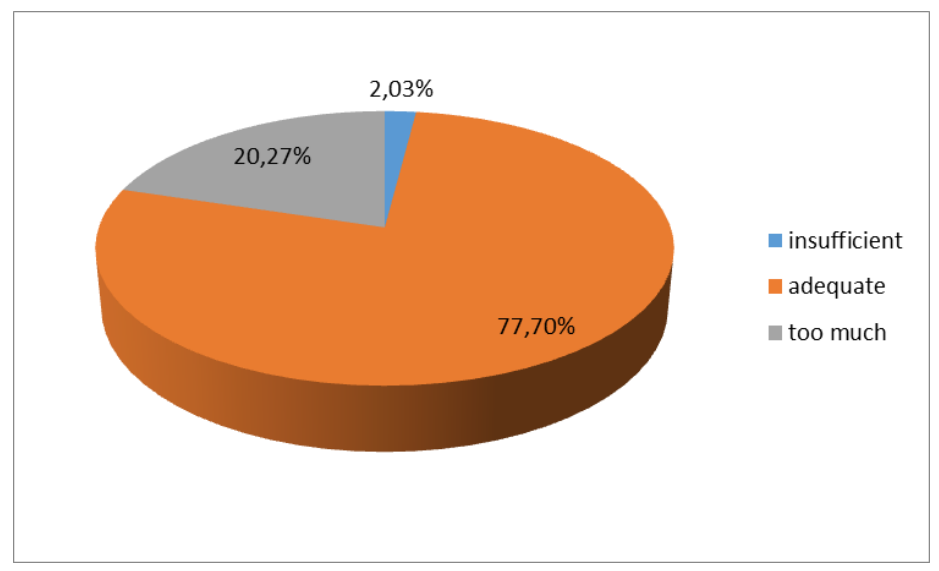

Figure 4. Dedicated time

QUESTION 5: Would you have found it useful to have access to a website during the course where you can view the various experiments that you participated in, in addition to the theoretical solutions and sample data? The possible answers were: a lot, quite a lot, indifferent, a bit and nothing. 


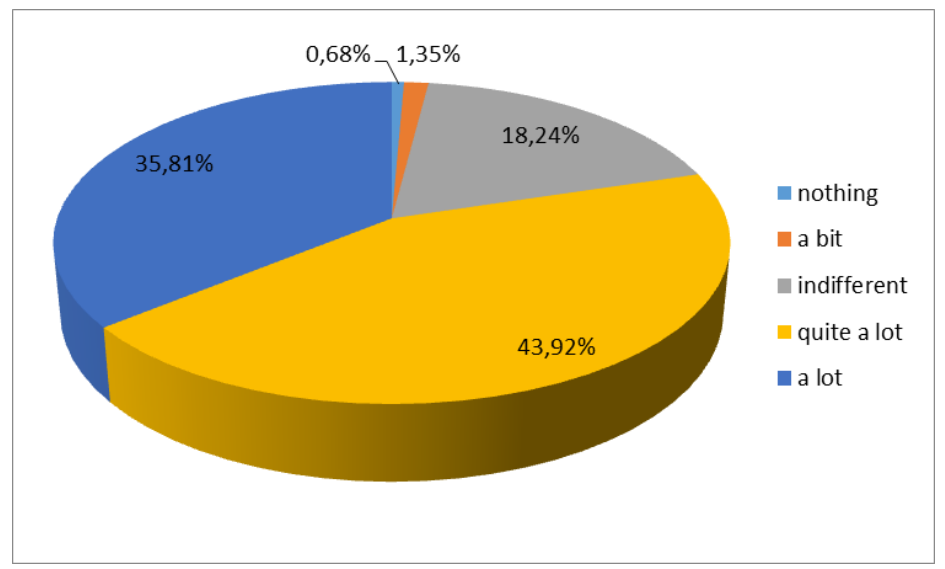

Figure 5. Usefulness of the website

QUESTION 6: Would you recommend to assist in the laboratory classes in the following course to a colleague? The possible answers were: yes and no.

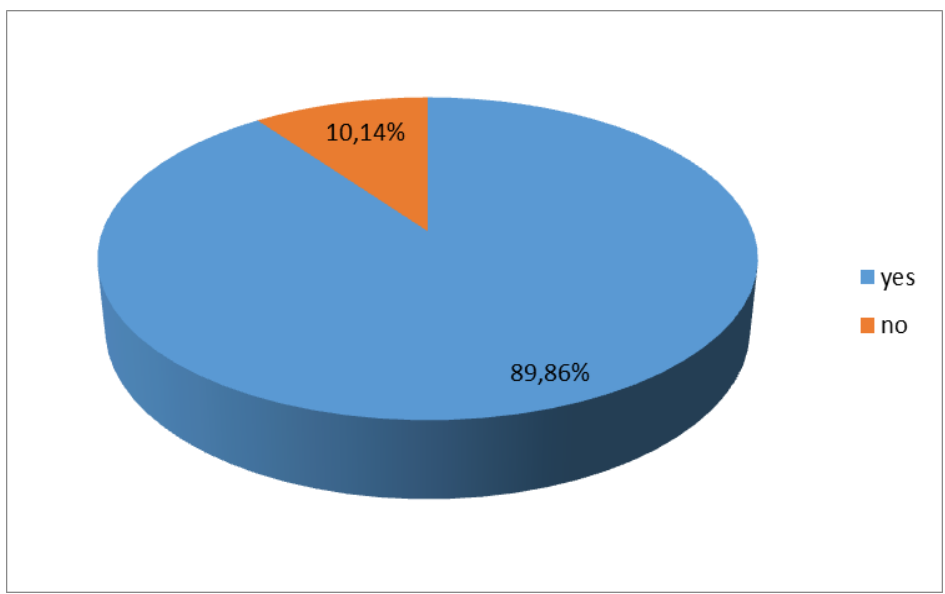

Figure 6. Recommendation

QUESTION 7: Do you think what you have learned in these classes will be useful in the future? The possible answers were: a lot, quite a lot, indifferent, a bit and nothing.

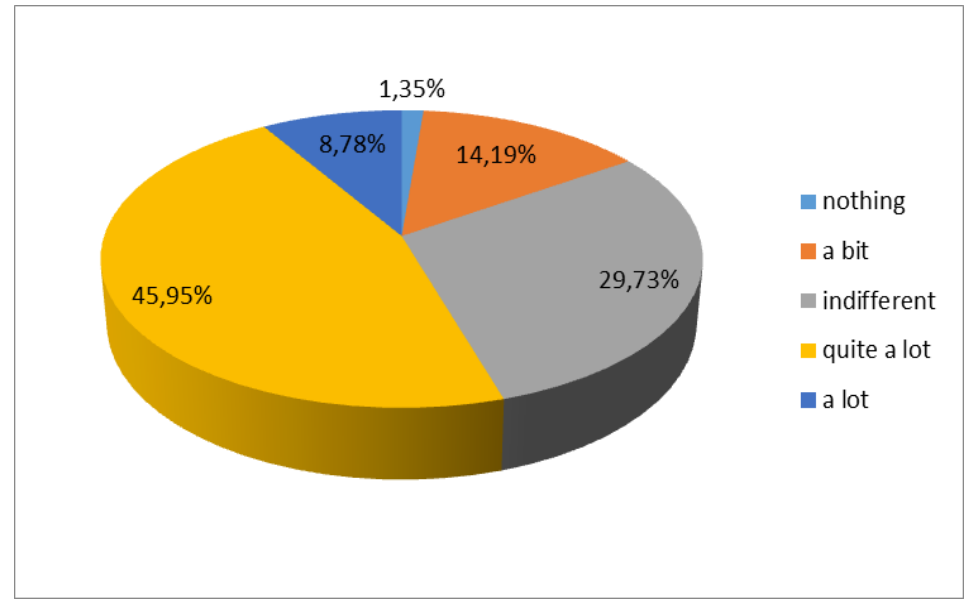

Figure 7. Usefulness of the classes 


\section{Discussion}

The results obtained from the questionnaire data show the effectiveness of our project. Altogether, more than two thirds of the participants stated that the laboratory classes helped them quite a lot and, respectively, a lot to understand the microeconomics courses in a better way using experiments. Their experience in the experimental practices encouraged the vast majority of the students to take an active part in future classes, thus the methodology used seems to motivate the students sufficiently. As a consequence, 9 out of 10 students would recommend the classes to their peers.

Their answers also confirmed the high demand for an online platform providing information and supplementary material regarding the experiments used in class. Regarding the question about the usefulness of a specific website for the experiment, $80 \%$ of the students think it would have helped "a lot" or "quite a lot", compared with another $18 \%$ who think it is indifferent and the other $2 \%$ who think it is not very useful. This indicates the importance of such an online platform and confirms again the success of the experimental classes. Lastly, more than half of the students in the survey stated that what they learned in these sessions is going to be useful in the future, which means that with this project we are enhancing some of the skills they think will allow them to better off their performances in the future.

Most of the students agreed with the available time to make decisions during the experiments and also with the balance between time dedicated to the game with the software, the mathematical solutions of the theoretical models and the descriptive analysis of data. But although almost $80 \%$ of the participants stated that the time they dedicated to the classes was adequate, still one fifth of them had the impression that the classes were too time-consuming. This can probably be due to the fact that the preparation of the computers and the programs for the market simulations are more time-consuming than the procedures in the standard microeconomic classes. Hence, although only $4 \%$ of the students declared that they had difficulties using the software, one aspect of future improvements of computer-based classroom experiments is the development of efficient processes to prepare the respective programs before and during the class.

\section{Conclusions}

We developed an online platform for classroom experiments in microeconomics, where instructions, software and examples of data analyses for a variety of experiments can be found for downloading. The material is fully accessible online after free registration at "www.experimentosdeclase.com" and "www.lee.uji.es/experimentosdeclase". It helps in understanding many subtle economic aspects which only a theoretical and expositive point of view could not do. After we started to run the experiments in the classroom and after we obtained the results from our survey, we have seen that the project achieves our objectives since it motivates students and facilitates the learning process. Particularly, more than two thirds of the students considered these practices to be helpful for a better understanding of the course and confirmed a high demand for the online platform. The vast majority stated that they would recommend the experimental lectures approach. This study sheds further light on the perception und effectiveness of classroom experiments and the respective platform in qualitative terms, but we do not compare the students' quantitative performance in terms of marks with and without the 
use of experiments and the online material. Another aspect of potential interest for future studies is how different student characteristics, such as personality traits or gender, interact with the efficacy of our approach in the individual learning process, based on the study of Durham et al. (2007). Finally, one of our main goals is to extend this tool to all Spanish-speaking lecturers who would like to offer this opportunity to their students. Our intention is to enhance all materials and to translate them into English in the near future.

\section{References}

Cabero, J. \& Gisbert, M. (2002). Materiales formativos multimedia en la red. Guía práctica para su diseño. Sevilla: Secretariado de Recursos Audiovisuales y Nuevas Tecnologías de la Universidad de Sevilla.

Chamberlin, E.H. (1948). An experimental imperfect market. Journal of Political Economy 56, 95-108.

Cheung, S.L. (2008). Using mobile phone messaging as a response medium in classroom experiments. Journal of Economic Education 39, 51-67.

Dickie, M. (2006). Do Classroom Experiments Increase Learning in Introductory Microeconomics? The Journal of Economic Education 37(3), 267-288.

Durham, Y., McKinnon, T. \& Schulman, C. (2007). Classroom experiments: not just fun and games. Economic Inquiry 45, 162-178.

Fischbacher, U. (2007). z-Tree: Zurich toolbox for ready-made economic experiments. Experimental Economics 10, 171-178.

Frank, B. (1997). The impact of classroom experiments on the learning of economics: an empirical investigation. Economic Inquiry 35(4), 763-769.

Holt, C.A. \& Anderson, L.R. (1996). Classroom games: Information cascades. Journal of Economic Perspectives 10(4), 187-193.

Holt, C.A. \& Laury, S.K. (1997). Classroom Games: Voluntary Provision of a Public Good. Journal of Economic Perspectives 11(4), 209-215.

McKernan, J. (1999). Investigación-acción y curriculum. Madrid: Morata.

Oxoby, R. (2001). A Monopoly Classroom Experiment. The Journal of Economic Education 32(2), 160-168.

Pindyck, R. S. \& Rubinfeld, D. L. (2009). Microeconomía. $7^{\text {a }}$ Edición, Madrid: Editorial Prentice Hall.

Smith, V.L. (1962). An experimental study of competitive market behavior. Journal of Political Economy 70, 111-137. 


\title{
From a research project to an Information System course: a professional approach
}

\author{
M. Lozano*, R. Trillo-Lado** \\ Red EULES \\ *Centro Universitario de la Defensa, Universidad de Zaragoza, Mayte.Lozano@unizar.es \\ **Escuela de Ingeniería y Arquitectura, Universidad de Zaragoza, raqueltl@unizar.es
}

\begin{abstract}
Nowadays, new business models are arising thanks to the development of ICT. In this context, the law is constantly being adapted to guarantee the rights of individuals. Studying topics related to legislation without considering its relation with a particular project is unattractive and generally it does not motivate computer science students. However, according to reports by the Instituto Nacional de Tecnologías de la Comunicación (INTECO), a high percentage of Small and Medium Enterprises (SMEs) does not consider current legislation on issues related to ICT. For these reasons, we develop a series of guides defining behaviour protocols, based on an active computer research project oriented to SMEs; and, at the same time, we decided to try to engage computer science students of the need to respect the regulations for the development of any software project (part of their next career future) making clear the relation between their tasks in any project of this kind and the laws and norms that should be respected during this process by the practical use and respect of these laws, in an Information Systems course. This last part is the work we present here.
\end{abstract}

Keywords: project based learning; problem based learning; professional approach; active learning

\section{Introduction}

During the last decades there has been a huge increase in the amount of digitized data available to be processed, thanks to the development of Information and Communications Technology (ICT). This has led to new business models and applications in many areas and sectors. In particular, in the health scope has emerged the area of bioinformatics. According to the definition available in Wikipedia (accessed on October the $1^{\text {st }} 2014$ ), bioinformatics is the application of ICT to the management and analysis of biological data. Furthermore, in recent years, there has been an increase in Small and Medium Enterprises (SMEs), and emerging research groups that thanks to the popularization of biomedical sensors, develop management and processing systems of biomedical signals (signals originated by the human body, used in diagnosis or medical research) with different objectives: improving cognitive development, Escolano et al. (2013), determining the level of stress, Dranca et al. (2013), development of neuromarketing applications, Javor et al. (2013), etc.

At the same time, the development of ICT has generated the need to create and adapt the legislation to guarantee people rights and duties in the context of the so-called Information Society; some concrete examples in the Spanish scope are the Ley Orgánica 15/1999, de 13 de diciembre, de Protección de Datos de Carácter Personal (LOPD) and the Real Decreto 1720/2007, de 21 de diciembre, de aprobación del Reglamento de desarrollo de la LOPD (RLOPD). However, according to data provided by the Instituto Nacional de Tecnologías de la Comunicación (INTECO), a high percentage of SMEs are not aware of being subjected to these laws, Pérez San-José et al. (2012), despite of the work that some institutions such as the Agencia Española de Protección de Datos (AEPD) have already done.

In this context, we decide to tackle the challenge of the development of an information system to manage data and information from the research project Identificación de Situaciones de Disminución del Rendimiento del Militar, basado en la Relación de la 
Variabilidad del Ritmo Cardiaco con el estrés y la Privación de sueño, Dranca et al. (2013), Peláez Coca (2014) and describe lessons learned during its development.

Starting from this environment, the objective of this work is that the students of Computer Science and Engineering live an experience where they develop an application similar to the ones that they will find in their professional career when they finish their studies. Thus, they have been responsible of specific tasks to be performed within a technological innovation project that is already being developed, with the aim of motivating them in the study of existing legislation on issues related to ICT and Information Systems.

Extracted from the professional reality, the activities were introduced in different sessions of problems and practices in the Information Systems course, with the main objective of helping students to better assume the concepts, the techniques and the technologies used to develop an information system, while involving students of the need to respect the regulations and norms for the development of any software project or information system in general. Moreover, special emphasis was done explaining the concept Normalization. Normalization is the process of developing, implementing and improving the rules that apply to different scientific, industrial or economic activities in order to arrange and improve them. Broadly, the normalization essentially pursues these three objectives:

1. Simplification: to reduce the number of models to work with and to keep only the more necessary information.

2. Unification: to allow international exchange of different methods, concepts and tools.

3. Specification: to avoid errors in identification and interpretation, creating a clear and precise language.

Thus, for the aspects of analysis, design, development, implementation and maintenance of the information system to support CUD2013-11 project, Peláez Coca (2014), we have taken into account the guidelines of the Asociación Española de Normalización y Certificación (AENOR) and the standards established by the International Standard Organization (ISO) for the government and the administration of the technologies and information systems. Furthermore, as shown in the different guidelines and standards, we have considered the study of current legislation. So, it is shown to the students in this way.

In the project that concerns us we firstly studied the family of ISO standards 20000 and 27000 (see Figure 1), considering them more relevant than others when starting the development of hardware and software infrastructure to support the information systems required.

The ISO 20000 series deals with aspects related to the management of ICT services and is based on an oriented process to provide users with services that meet the requirements established and a continuous improvement through the PDCA (Plan, Do, Check, Act) model. The ISO 27000 series focuses on information security, that is, the preservation of the confidentiality, integrity and availability of data and information. Security information can also include other properties such as authenticity (assurance that an entity is who it is said to be or that an entity guarantees the source from which the data comes from) and traceability (ensuring that at any time it will be able to determine who did what and when). 


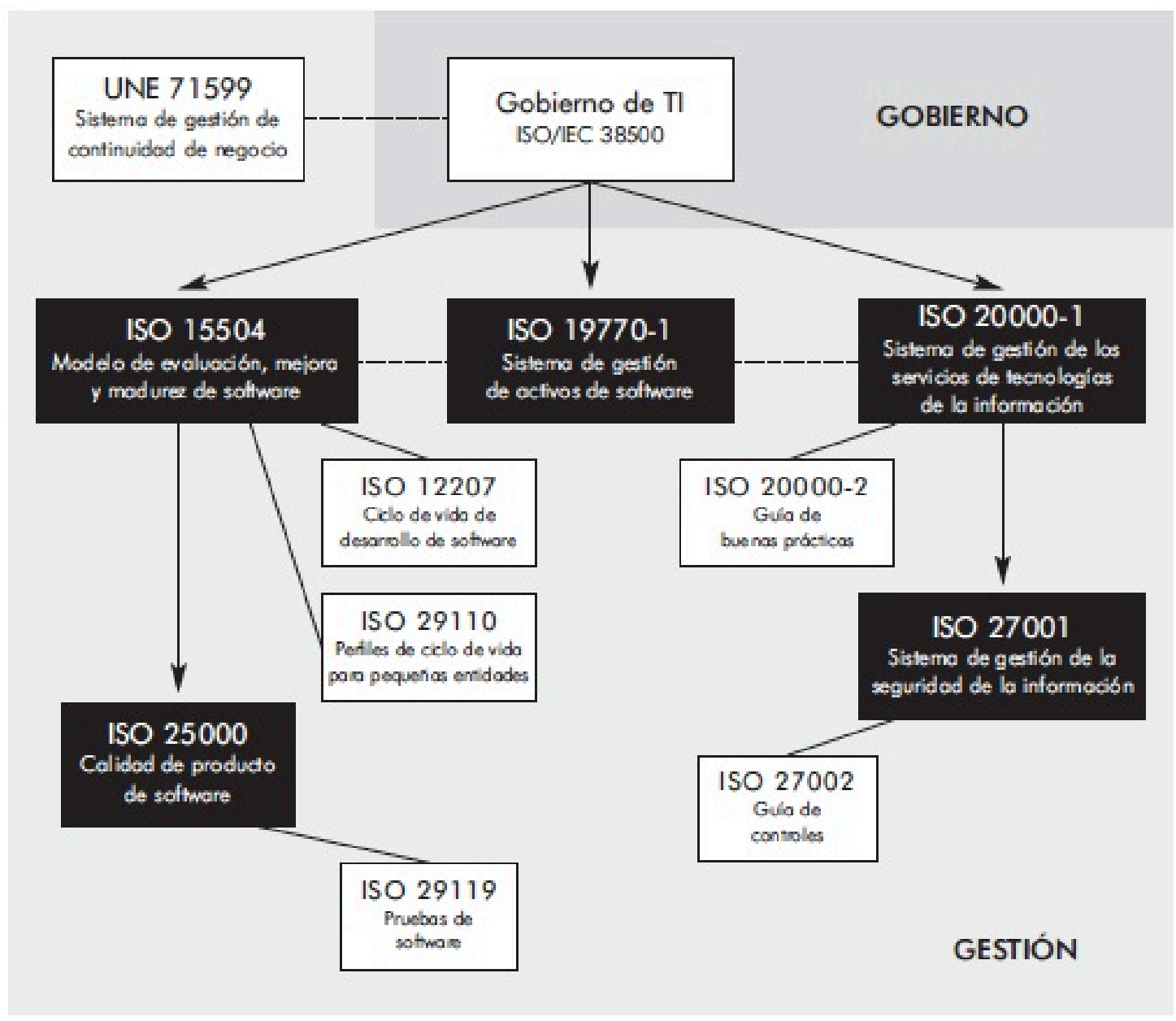

Figure 1. Expanded AENOR model for ICT. Source: Fernándes Sánchez and Piattini Velthius (2012)

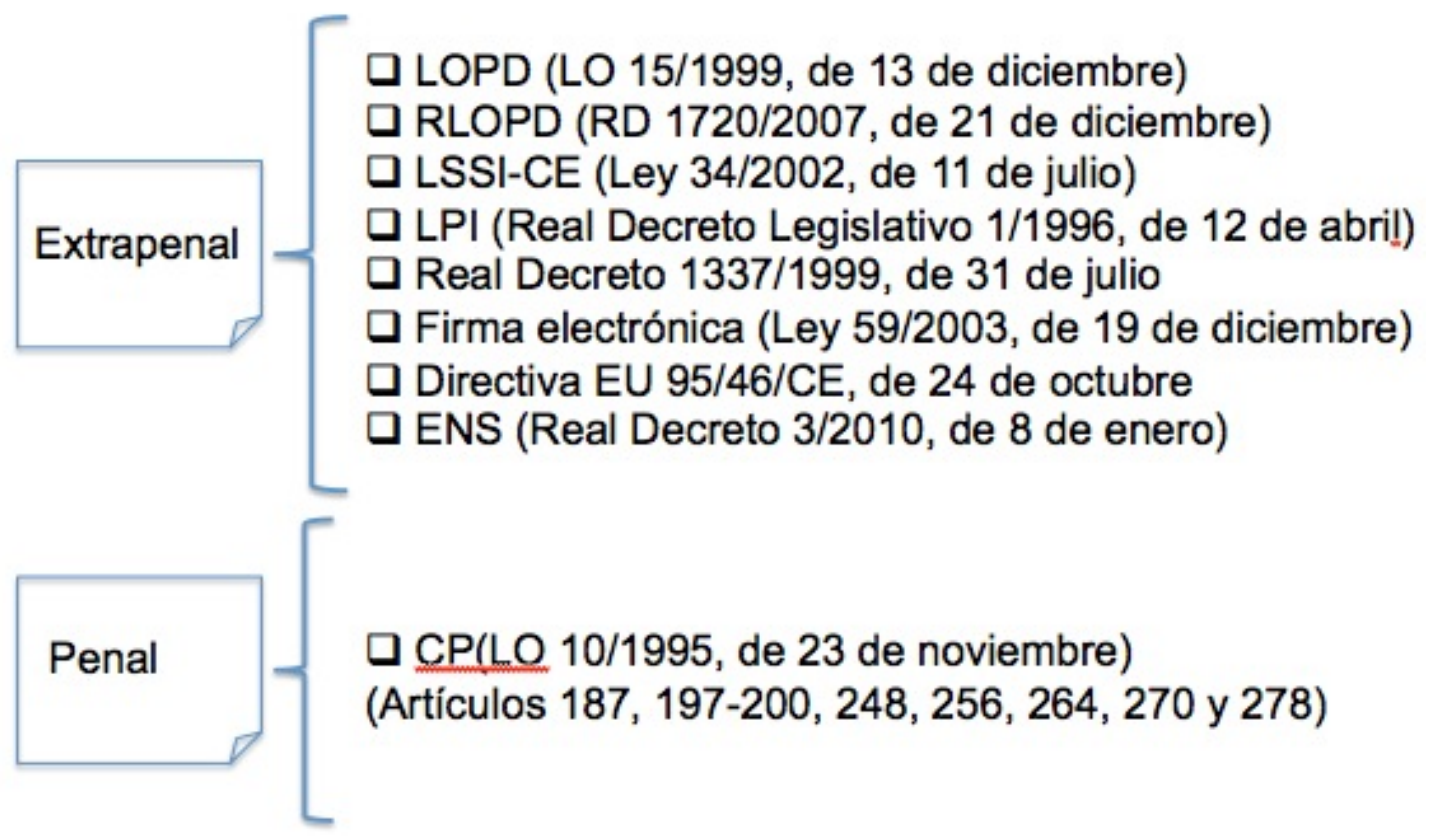

Figure 2. Existing legislation related to Information Systems. Source: Lozano and Trillo-Lado (2014).

Regarding the legislation, the main aspects of the legal framework on the Information Society are considered in relation to the management of safety systems and 
technologies of information (see Figure 2). Specifically, we initially focused in the study and analysis of the LOPD and RLOPD. In addition, the current regulations proposal related to data protection in the European Union (EU), European Union (2012) has been taken into account.

\section{Methods}

The target audience of this experience of professional approach are the students of the Information Systems course, which belongs to the Computer Science and Engineering Degree taught at the Escuela de Ingeniería y Arquitectura, Universidad de Zaragoza. In general, during the development of practices and problems of the course, students often work with simple examples that do not motivate them. Besides, aspects of legislation in the field of ICT in a Computer Science and Engineering degree do not usually appeal to students. Therefore, in this work we propose that students work and develop their practice in a research project of the Centro Universitario de la Defensa: Identificación de Situaciones de Disminución del Rendimiento del Militar, basado en la Relación de la Variabilidad del Ritmo Cardiaco con el estrés y la Privación de sueño, Dranca et al. (2013), Peláez Coca (2014).

The main innovation introduced by this work is, therefore, the use of a real development and technological innovation project, in order to motivate students to study existing legislation and norms on issues related to ICT and Information Systems (Project Based Learning, PBL). Activities are introduced in different kinds of problems and practices of the subject involved. With these activities is intended to get the students close to the professional reality in relation to the subject. The main objective, so, is that this professional experience could help students to better assume the concepts, the techniques, and the technologies used for the development of an information system, from the knowledge and fulfilment of the law, principally, and also the norms.

No set of standards, methodologies and laws can guarantee the full success of the development, implementation and maintenance of an information system. However, considering national and international standards, and the use of standard methodologies, they:

1. facilitate the management of the project (the system does not depend only on the point of view of a particular person),

2. save time (no need to reinvent something already used by others) and

3. facilitate communication among different team members.

Apart from the fulfilment of the law, one of the main ideas to be conveyed to students is that it is necessary to consider the security aspects of the storage, processing and transmission of data and information from the beginning of the project; and not only when implementing and parameterizing specific software.

For the development of this experience the following main activities have been planned:

1. initial development and approach to the foundations of the computer project to approach;

2. based on the previous expertise, designing and setting of the practices and problems to be solved in the classroom, in relation to the various tasks to be performed on the computer project (Problem Based Learning and Project Based Learning);

3. estimating of the workload of the practices assessment proposed to students; 
4. development of the practice and problems sessions;

5. evaluating the development of the practices and the final result of them;

6. satisfaction survey designing and evaluation of the activity, to be completed by students;

7. designing of the interviews to be conducted to students of current and previous year;

8. a final evaluation of the experience, so that the strengths and weaknesses of it are obtained, taking into account:

- $\quad$ survey results

- information obtained from interviews,

- as well as comments and opinions of the teachers of the course,

- $\quad$ and the time taken for the development of this educational project, both by teachers and students.

The students organized themselves in groups of 5 persons to develop a Web application to register, consult and update the information related to the volunteers (patients) of the Identificación de Situaciones de Disminución del Rendimiento del Militar project. Moreover, some one-hour seminars to which the groups of students could optionally attend were developed. In more detail, three seminars were held:

1) spanish Legislation about personal data: LOPD and RLOPD,

2) cloud computing and their implications, and

3) methodology to analyze and manage risks: MAGERIT methodology.

After that, the groups of students were asked to write a report where the risks of the Web application that they have previously developed were analyzed. Moreover, some extra time (two weeks) was provided to the students to allow them to improve the implementation of their Web Application.

In relation to the technologies used to develop those activities, several web technologies were explained and proposed to develop the Web Applications: HTML, CSS, ApacheTomcat, relational and object-relational databases (Oracle, PostgreSQL, Cache, MySQL), middleware mapping object-relational (Hibernate with JPA), Java, JDBC and J2EE. Nevertheless, students could select other technologies and frameworks to develop their information systems. Thus, some of them selected NoSQL database technologies such as MongoDB, scripting languages such as Node.js, etc.

\section{Results and Discussion}

In general, during the development of current practices and problems students often work with simple examples that do not motivate them. Besides, topics related to legislation and ICT in a Computer Science and Engineering degree do not usually appeal to students. So, through this experience students increased their knowledge of the subject, Information Systems, and especially the expertise and know how, as it is a real professional approach that which the students practice with. In addition, they learn it in a more entertaining way, thanks to the motivation of students, because the obtained result is to be applied on a project that is already ongoing. Thus, teachers observed that during the course students were more aware of the need to accomplish with the legal issues than in the previous courses. Moreover, students considered that taking into account the legal issues improved the security and maintenance of their systems. 
After the extra time given to the students to refine their systems, the most common improvements of the systems designed and developed by the students that attended the seminars (described in the previous section) were:

1) encrypting the passwords of the users of the web application stored in the databases,

2) establishing politics to force the users of the Web applications to update their passwords after a period of time, and

3) performing backups of the databases of the system.

On the other hand, groups of students who did not attend to the seminars improved the web interfaces of the systems and solved some bugs related to the connections to the databases to allow concurrency. Besides, students who attend to the seminars got better marks in the questions related to legislation issues in the final exams (a test and some short questions).

After the final evaluation results were published, teachers of the subject also interviewed four students (two from the current course and two from the previous one, in order to compare the assimilation of the concepts). The students of the previous year did not remember basic concepts such as the different security levels or the different user roles defined in the LOPD. Besides, they said that legal issues were not important for them and that they did not like them. In contrast, students of the current course claimed that they would like to know more issues related to methodologies and legal issues.

Regarding to sustainability, this experience would be repeated in subsequent years in the same subject, using as a basis new projects that would be useful for the implementation of the tasks that are part of the course, so that it will facilitate the learning of those tasks. Regarding to transferability, the idea of approaching reality through professional learning in a professional development project to an academic degree course could be exported to other related subjects. In fact, it is planned to export this experience to other subjects that the authors would teach in the future.

\section{Conclusions}

The feedback provided by the students and teachers involved in this project indicate that legal concepts are better understood when students are involved in a real project. Besides, the results indicate that the students involved in this project obtained higher marks than students that did not participate. Moreover, students were motivated to consider legal issues on their applications, as they appreciated that this leads to improve the security and maintenance of their systems. We think that the main point is that students are motivated due to the relation of the activities they do with something real.

\section{Acknowledgements}

This work has been supported by the Red EULES, from the Universidad de Zaragoza, the project PIIDUZ_14_529 from the Universidad de Zaragoza, the project CUD201311 from the Centro Universitario de la Defensa de Zaragoza, the project TEC201454143-P from the Ministerio de Economía y Competitividad and the action COST Keystone IC1302. 


\section{References}

Escolano, C., Navarro-Gil, M., Garcia-Campayo, J., Mínguez, J. (2013). EEG-based Upper-Alpha Neurofeedback for Cognitive Enhancement in Major Depressive Disorder: A preliminary, Uncontrolled Study. International Conference of the IEEE Engineering in Medicine and Biology Society, Osaka (Japón).

Dranca, L., Lozano, M., Martínez Cantín, R., Pastor, J.J., Peláez Coca, M.D., Sancho, J.J., ... Buatas, M. (2013). Identificación de situaciones de estrés, privación de sueño y sobreentrenamiento mediante alteraciones en la variabilidad del ritmo cardiaco. In González-Marcos, A.P. (coord.) Actas: Congreso Nacional de I+D en Defensa y Seguridad-DESEi+d (pp. 535-542). Madrid: E.T.S.I. Telecomunicación, UPM.

Javor, A., Koller, M., Lee, N., Chamberlain, L., Ransmayr, G. (2013). Neuromarketing and consumer neuroscience: contributions to neurology. In BMC Neurology, 13:13 doi:10.1186/1471-2377-13-13.

Lozano, M., Trillo Lado, R. (2014). Experiencia en el desarrollo de un sistema de información para la gestión de señales biomédicas en PYMES y grupos de investigación emergentes. In A. Dena Arto, M.T. Sánchez Rúa, \& J. Martínez Torres (Eds.) Actas: II Congreso Nacional de $i+d$ en Defensa y Seguridad DESEi+d 2014 (pp. 637-644). Zaragoza: Centro Universitario de la Defensa Zaragoza.

Peláez Coca, M.D. (I.P.) Identificación de Situaciones de Disminución del Rendimiento del Militar, basado en la Relación de la Variabilidad del Ritmo Cardiaco con el Estrés y la Privación de Sueño, CUD2013-11. 1/1/2014-31/12/2016.

Pérez San-José, P., Gutiérrez Borge, C., Álvarez Alonso, E., García Pérez, L., de la Fuente Rodríguez, S. (2012). Estudio sobre seguridad de la información y continuidad de negocio en las PYMES españolas. Informe Instituto Nacional de Tecnologías de la Información.

Fernándes Sánchez, C.M., Piattini Velthius, L. (2012). Modelo para el gobierno de las TIC basado en normas ISO. AENOR Ediciones.

European Union. (2012). Proposal for a Regulation of the European Parliament and of the Council on the protection of individuals with regard to the processing of personal data and on the free movement of such data (General Data Protection Regulation). Brussels, 25/1/2012. 


\title{
eCity: Virtual City Environment for Engineering Problem Based Learning
}

\author{
P. Lahuerta*, A. Cháfer** \\ *Department of Inorganic Chemistry, **Department of Chemical Engineering \\ University of Valencia, Dr. Moliner 50, 46100 Burjassot-Valencia, Spain
}

\begin{abstract}
The main objective of the eCITY project is to design, develop and validate a pedagogical methodology, supported by an online, collaborative, city-development simulation engine (Simcity like) that stimulates the integration and continuous exploitation of Problem-Based Learning (PBL) in engineering and science schools but, at the same time, fostering the interest for these orientations in secondary school students.
\end{abstract}

Keywords: eCITY project; city-development simulation engine; Problem-Based Learning; secondary school students.

\section{Introduction}

The difficulty that secondary education students have with Mathematics and other Science topics is a widespread problem in Europe as stated by several international comparative studies like PISA or TIMMS. This prevents these students to follow a technical academic path like Engineering or Sciences. This generation is the "netgeneration" or "digital natives": they quickly absorb information in shorter chunks, they expect instant responses and feedback and they want to be active in their learning.

Problem-based learning (PBL) is a learner-centered educational pedagogy in which students develop their ability to go through a problem solving process, usually based on real-life situations. Engineering is one of the areas where PBL is a valid learning alternative/complement to the traditional learning methods. Several authors ( Tree (2007); Lacuesta (2009) ; Felder et al (2000) ; Kolmos et al. (2004) ; Woods (1994) Kolmos (2011)) have reported benefits for engineering students considerable improvements in critical, lateral and creative thinking, problem solving skills, group collaboration and communication skills.

In a convergent path, games and simulations can be instantiated for learning as they involve mental and physical stimulation and develop practical skills as they force the player to decide, choose, to define priorities, solve problems, etc. One of the main reasons for the increased research and development interest in computer games for learning purposes is that those games are believed to have the potential to support innovative constructivist-inspired models of learning, such as learning-by-doing, exploratory learning, situate learning and learning through participation in communities of practice (Facer (2003); Shaffer et al. (2004)). It, thus, seems that computer games offer a powerful new medium to support learning in the information age (Kirriemuir et al. (2004)). This assertion holds especially true for educational online games, which, relying on the inherent capabilities for communication, interaction, and resource sharing provided by the Internet and the Web. Can offer increased opportunities for collaborative learning an knowledge construction through social interaction. Papastergiou (2008) in a review about the use of computer games for educational proposes, conclude that educational online games should constitute engaging virtual environments that offer students authentic, goaloriented, challenging, exploratory, experiential, collaborative problem-solving learning 
experiences that reflect real-life situations that scientists or professional of the respective field encounter in their everyday practice. This overviewed study show that student's response to the educational online games were very positive. Students clearly enjoyed the games and found them interesting, motivational, immersive, beneficial and worthwhile. They felt that such games offer a realistic and useful way to learn.

\section{Methods}

The main objective of the eCITY project is to design, develop and validate a pedagogical methodology, supported by an online, collaborative, city-development simulation engine (Simcity like) that stimulates the integration and continuous exploitation of Problem Based Learning in engineering schools but at the same time, fostering the interest in Engineering in secondary school students.

ECity's PBL virtual learning environment (VLE) is expected to be a general and stimulating context especially due to the nature and complexity of the range of problems that will be available in the virtual city. The platform will also promote a sense of belonging to a community, peer support and an additional rewarding system that includes reputation points for problem solving, allowing the establishment of rankings (promoting an healthy competition).

The platform is integrated in a clear pedagogical methodology, PBL-oriented, to ensure that the upmost relevance is given to the learning process.

New problems or challenges can be fed into the platform as homework, teamwork, curricular activities, extra-curricular competition, big or small projects, etc.

PBL can be incorporated within the existing structures with little disruption as it can be implemented in a variety of forms. Therefore it is not necessary to change the curricular organization problems can be formatted to different time and work schemes.

Many PBL courses and activities still rely mainly on traditional face-to-face activities. Nevertheless it has been suggested that Virtual Learning Environments (VLE) enhance the PBL experience and effectiveness (Tree (2007); Lacuesta (2009); Felder et al (2000) ; Kolmos et al. (2004) ; Woods (1994) Kolmos (2011)).

A VLE is an online (frequently Web 2.0 based) education platform that models conventional real-world education by integrating a set of equivalent virtual concepts for contents, lectures, tests, assignments, classes, classrooms and other academic resources. These tools have the potential to increase the communication between a larger number of educational actors (VLEs4VET project (2007); Pot (2004); Miao et al. (1999)). The definition of VLE encompasses a large number of different types of learning platforms:

In some cases to follow the games, the academic knowledge is used as a tool to achieve goals. This means that to play the user will need to have some previous knowledge and, in addition, such knowledge must be expanded to move forward in the game itself. There is therefore a kind of binomial fun / knowledge. Knowledge becomes a necessity to succeed in the game, which will motivate the learning of it by students.

However in some cases it is not necessary to have a certain initial knowledge, just enough student's curiosity or intuition, and the game itself would be enough to provide or promote additional knowledge. 


\section{Results}

The simulation engine is now developed and students can access to it through the following web: http://ecity-project.eu/es/game/

Here is a list of the problems selected by for implementation in eCity platform with a brief description of the context, goals and expected results of each problem.

\section{Cloud Infrastructure for Whatsapp Servers}

Facebook wants to extend the whatsapp functionalities in our city. The company wants to improve their functionalities trying to provide a good response-time taking into account the number of present and future clients and also the increase in service needs. They need to decide how many servers to deploy, where these servers (memory, computing) are going to be located, the links and capacity among the servers, the energy sources, the needs for redundant systems, backup issues, wifi connections, wireless communications, antennas distribution, etc. Previous knowledge of Physics and Mathematics will be required

\section{Purification of a natural gas field}

The city needs a supply of energy from different sources. The recent prospections in the area have found a natural gas deposit that might provide enough energy to cover up to $20 \%$ of the city regular consumption. The analysis reflects a measurable content of pollutants-containing compounds, mainly $\mathrm{SH}_{2}$ and $\mathrm{CO}_{2}$, that makes the natural gas unsuitable in the present conditions. Gas purification involves the removal of the impurities from the gas streams. Information about the primary operation of gas purification processes will be provided to the students. This problem will include the treatment of the separated residues and the possible transformation in products with commercial application. Previews knowledge of basic chemistry will be required.

\section{Creating an earthquake-resistant city}

The city is located near a fault zone. The player will select the correct place by evaluating various factors like the expected earthquake gratitude, history of earthquakes in the area, soil types and combinations, nearness to the fault zone and decide on the type of construction, materials to be used for construction, maybe even the type of concrete to be used, cost of construction, number of floors etc. At the end of the given time there will be an earthquake simulation to show success of the player.

The aim is to provide the correct balance between an economic and social development of a city and the life guarantee of its inhabitants. The background knowledge depends on the target players of the game. If it is being played for secondary school students, the teacher will assign simpler factors.

\section{MyMVNO's Access Network deployment}

MyMVNO is a Mobile Virtual Network Operator company that has experienced a large increase of customers in recent years. Being a virtual operator, the company lacks any access infrastructure. In other words, the company does not have its own Access Network (AN) and it has to pay to other providers for using their infrastructure. Therefore, MYMVNO intends to deploy its own infrastructure and it wants to perform some simulations. The objective of the simulations is to verify that the company can deploy its 
own infrastructure while maintaining service quality (i.e. increasing operator's revenue) and reduce their operation costs. The learning goal of this game is to provide a view of how a mobile network works. This is addressed to engineering students with knowledge in telecommunications (signal, channel access methods, mobile network architecture), Energy, Cost Management Skills and Physics.

\section{Operation of industrial activities.}

The community needs to have an industrial base to generate jobs and provide needed consumer goods. This includes installations of various types of industries, such as bakery, slaughter of animals, paint factory, winery, manufacture of ceramic products, vegetable processing plants, dairies, etc. The student will find the most suitable method to reduce the residues generated by the industry, so that they meet the environmental requirements of the community. At an elementary level of the problem, a list with the nature of the waste generated by the industry as well as the properties and hazards will be provided.

\section{Code-Living City}

The game presents a future city as a living entity that is able to control some of its public services. Particularly, streets are journeyed by automatic buses, taxis and other vehicles that are driven by automatic systems. Students will be required to program these systems, so the vehicles move around the city according to their planned routes to serve the city inhabitants. Students must model these active elements by using programming sentences. This will bring them the opportunity to experiment with programming elements. For example, students will model a bus journeying its route; or will create algorithms to make taxis to offer their services to the inhabitants of the city, etc.

The game can be composed by many stages. The goal of the game is to fulfil the requirements of each stage until all stages are done. As long as the stages are completed, students will learn basic concepts of programming languages oriented to Object-Oriented Programming languages (OOP). So, it is expected that students will be able to learn programming basics while competing against their peers.

\section{Building, setting up and testing a Local Area Network}

The fundamental proposal's goal is the development of a serious allow students to acquire skills and competencies in the informatics sector to be applied in the real world. By playing real-life situations students have to build a Local Network Area (LAN), set it up and test it using specific knowledge inside a simulated and protected work environment. Thank to this proposal the game will consent students to select at least 5 problems where different type, dimension of net subnet, and device have to functioning in a Local Network Area. Furthermore students will have the opportunity to set up new problems by themselves and then try to solve them.

\section{Busses to the University and Beyond}

The problem involves the need to provide bus services to attend university students, and other users: K-12, high school students and public in general. Each one of these users has different timetables and travels. The objective of the problem is to optimize the use of buses, supporting all people with the minimum number of buses and drivers. We want to reduce the carbon footprint also: if not enough buses are provided, the people will use their own cars and the pollution will increase. The game/simulation application will show a particular city with some schools and roads. Students need to decide the routes, the 
number of buses, the timetables, etc. The application will calculate the number of cars needed, the pollution produced, etc.

\section{Energy supply to the city}

The city needs energy supply that can be obtained from different sources, coal, nuclear plant, wind farms or solar energy plants. When selecting a new energy source for the city the student should take into account different aspects: building cost, maintenance cost, sourcing capacity and environmental impact.

Figure 1 show a scenario when most of the city has received electricity supply from different sources.

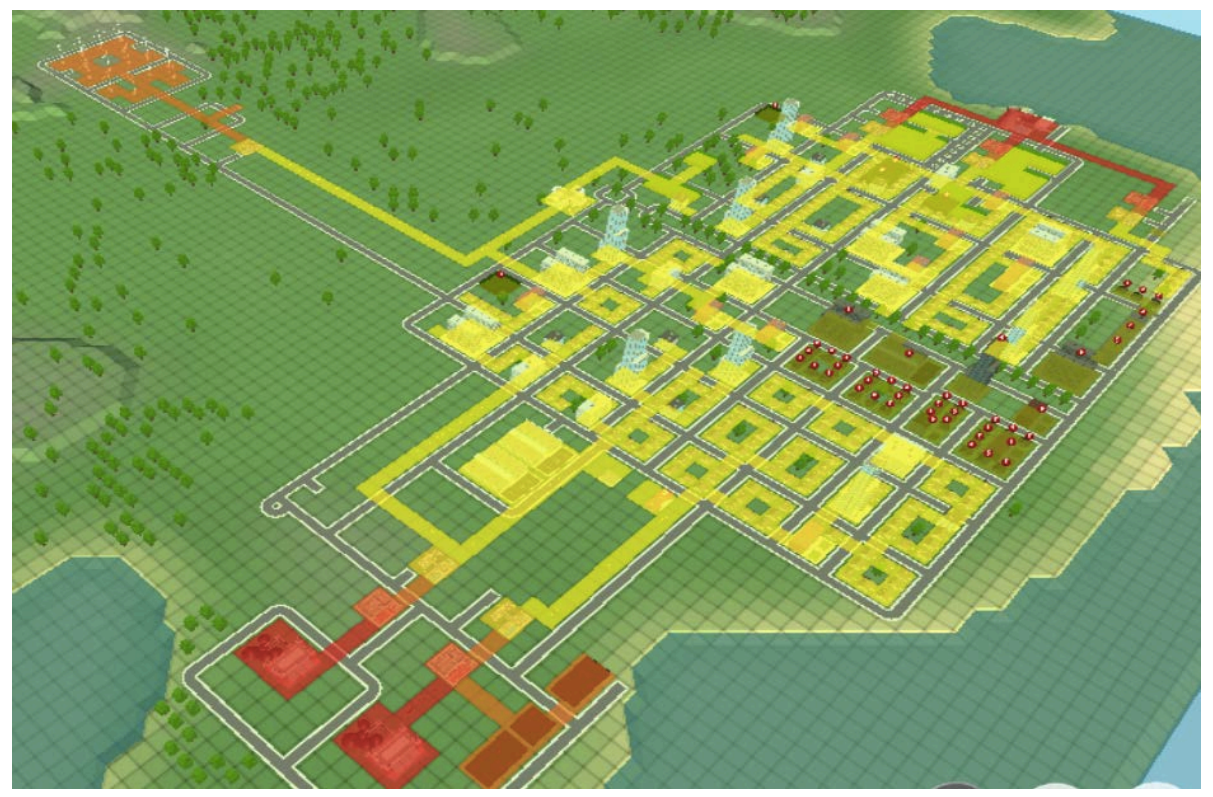

Figure 1. A view of a scenario of the city when most of the buildings has received electricity supply form different sources.

\section{Conclusions}

At this moment, the simulation engine is finished in English and it is being traduced to different languages as Spanish, Italian, Greek, etc.

The project will continue the activity until the end of 2015. Now we are broadcasting the simulator eCity between the Secondary educational community, so that this tool could be apply in their classes the next course. Considering that some of the problems will be also oriented to secondary school students, the participation of schoolteachers in the project will be highly beneficial. 


\section{References}

Facer, K. (2003) Computer games and learning. Last access April 16, 2015, from http://www2.futurelab.org.uk/resources/documents/discussion_papers/Computer_G ames_and_Learning_discpaper.pdf

Felder, A., Woods, R., Stice, M., Rugacia, J., (2000) The future of engineering education ii. Teaching methods that work, Chem. Eng. Educ. 34, vol. no. 1,

Kirriemuir, J. McFarlane, A. (2004) Literature review in games and learning: A report for NESTA Futurelab. Last access April 16, 2015, from https://hal.archives-ouvertes.fr/hal-00190453/document

Kolmos, A. (2011) New trends in engineering education: Mega projects and globalization, Proceedings of the 1st EUCEET Association Conference, Patras, Greece.

Kolmos, A., Gynnild V. and Roxå T. (2004): The Organisational Aspect of Faculty Development, in Anette Kolmos, Ole Vinther, Pernille Andersson, Lauri Malmi and Margrete Fuglem, eds: Faculty Development in Nordic Engineering Education, Aalborg University Press, 2004.

Lacuesta, R. (2009) Active learning through problem based learning methodology in engineering education. Proc. 39th IEEE Int. Conf. Front. Educ. Conf., pp. 530-535.

Miao, Y.; Fleschutz, M. and Zentel, P. (1999) Learning contexts to support communities of practice. Proc. CSCL, pp. 391-397.

Papastergiou, M. (2008), Online computer games as collaborative learning environments: prospects and challenges for tertiary education. J. Educational Technology Systems, 37, 19-38.

Pot, W. (2004) Means to improve social interaction in virtual learning environments. 1st Twente Caput \& Referaat Conference, Enschede, Netherlands.

Shaffer, D.; Squire, K.; Halverson, R.; Gee, J. (2004) Video games and the future of learning. University of Wisconsin-Madison and Academic Advanced Distributed Learning Co-Laboratory. Last access April 16, 2015, from http://www.academiccolab.org/resources/gappspaper1.pdf

TREE - (2007) Teaching and Research in Engineering in Europe Special, 20th Conference on Software Engineering Education \& Training, Dublin, Ireland.

VLEs4VET project, (2011). Reflecting on the implementation of the virtual learning environments in education across europe. Last access April 16, 2015, from http://www.adameurope.eu/prj/6441/prd/4/1/Reflecting\%20on\%20VLE\%20implementation.pdf

Woods, D. (1994) Problem based learning: How to get the most from PBL, McMaster University. 


\title{
Here a Game, There a Game: classification, gamification, and retrieval learning
}

\author{
O. Borchert, G. Hokanson, A. Peruri, B.M. Slator
}

Department of Computer Science, North Dakota State University

\begin{abstract}
A multi-user classification system is used in a classroom setting. Groups of students take samples, then collaborate on conducting experiments and building classification trees. Students are motivated by a point scoring system as they build the trees: formative gamification. Once the trees are completed they are exchanged between groups. The trees are constructed with structural commonality enabling them to act as content for template-based identification games: summative gamification.
\end{abstract}

Keywords: innovative materials, teaching and learning experiences, emerging technology practices, gamification

\section{Introduction}

CIRCLE (Collaborative Identification, Retrieval, and Classification Learning Environment) uses mobile technology to support teams of students who gather content for classroom projects that identify and classify real world objects such as plants and animals or rocks and minerals. The classification trees produced are used to populate identification and classification game templates that students can then play to rehearse through practiced retrieval. Retrieval learning postulates the act of retrieving knowledge in multiple different ways leads to better learning outcomes (Karpicke, 2012).

In decades past, identification and classification learning took place through the use of flash cards. These paper-based practices evolved into identification and classification games during the Internet age (Kids Know It Network 2013; Crimson Trails 2013; Jensen 2013; Kinder Web Games 2013). There are two primary drawbacks to these methods. While they have been studied extensively (Nist \& Joseph 2008; Kornell 2009), they are not informed by modern educational practice. It has been shown that students are not simply empty vessels, meant to be filled, but actively construct their knowledge (Richardson 2003; Bransford et al. 2000). In addition, these games are fairly static and designed completely by their developers.

Game templates offer an avenue for improvement on these static games. An example of a game with a template is GeoGuessr (Coldwell 2013). In this game, students see a Google Street View image and get points for identifying where on the world they are located. Less technological game template solutions include trivia games and typing tutors.

While these pre-defined templates are entertaining, user generated content provides a unique method of motivating individuals. Studies identifying motivations of individuals creating user generated content show a variety of reasons for its development (Daugherty et al. 2008; Leung 2009). Rather than using content developed by instructors, we place content gathering into user hands. We harness this motivation to teach students the identification and classification task. 


\section{Methods}

CIRCLE implements retrieval learning through the use of games in two primary ways. First, students gather content, identify specimens, and build classification structures. Students score points in this phase by contributing to the content structures. We call this formative gamification. Second, game templates are created by developers. These templates specify the rules for a particular game, while remaining context independent. Students reinforce their learning by playing these games which are generated by integrating specific content into the game template. We call this summative gamification.

\begin{tabular}{|c|c|c|c|c|c|c|}
\hline POINTS & Gathered & Elaborated & Identified & Constructed & Played & Total \\
\hline & 1 & 4 & 0 & 1 & 3 & 9 \\
\hline & 4 & 5 & 1 & 0 & 1 & 11 \\
\hline
\end{tabular}

Figure 1: Students score points which provide motivation and individual accountability. The player in the fourth row has not gathered any specimens, but has 12 points, the most on the team.

\section{Implementing Classification Acquisition}

There are five primary student activities in CIRCLE. Content acquisition, trait elaboration, hypothesis formation, and tree construction are independent activities while game play is part of all the others. The system tracks students and records their use of the system, time on task during each activity, and interactions with each other. Students are assigned collaborative roles according to the activities. Throughout each of these stages, points associated with these activities are kept as a running score, see figure 1 . We call this formative gamification.

\section{Content Acquisition}

Gatherers primarily collect photographs that are uploaded to a central server for inspection by the team. Camera phones with GPS are preferred, since this simplifies logging the time and place the specimens are collected.

\section{Trait Elaboration}

Elaborators suggest traits to observe or experiments to conduct as a means towards identification. Gatherers perform these experiments and observations, returning to the logged location if necessary. The team can also vote on experiments they feel are most important to completing the identification.

\section{Tree Construction}

Classification trees are constructed where traits and experiments are shown as branches of the tree, and specimens are the leaves. Students in the role of 'constructors' take suggestions from team members on how to arrange the structure leading to a dichotomous key. 


\section{Hypothesis Formation}

Hypotheses are offered by team members in the 'identifier' role as to the general classification or precise identity of the specimens. In the absence of an expert, such as a classroom teacher, hypotheses are voted on in a parimutuel-like system, where a probability of identification is associated with each competing classification.

\section{Game Play}

A knowledge base of logging data is collected during the four phases, see table 1 . This data is used to populate game templates, described below. Players select a game to play and their collected content is used to create a game unique to their information, including all experiments and observations suggested and performed, all results of these experiments and observations, the moderation scores of the elaborations, all hypotheses suggested whether correct or not, the identification of each individual specimen, and the specific set of tests required to identify the specimens.

Table 1. Data gathered in CIRCLE by stage

\begin{tabular}{|c|c|}
\hline Stage & Data Gathered \\
\hline Gathering & $\begin{array}{l}\text { - Text description of the specimen } \\
\text { - Multimedia artifacts of the specimen (ie audio, video, and images) } \\
\text { - Text description of the location of the specimen } \\
\text { - GPS coordinates of the specimen (if available) }\end{array}$ \\
\hline Elaborating & $\begin{array}{l}\text { - Name of the elaboration } \\
\text { - } \text { Instructions for how to perform the elaboration } \\
\text { - } \text { Basic description of the elaboration. } \\
\text { - Results of the elaboration (i.e. Number, text, picture, audio clip, } \\
\text { and/or video) }\end{array}$ \\
\hline Classifying & $\begin{array}{l}\text { - Paths of elaborations and results that lead to particular specimens } \\
\text { - All individual actions taken to construct the tree }\end{array}$ \\
\hline Identifying & $\begin{array}{l}\text { - } \text { Correct and incorrect hypotheses suggested by players } \\
\text { - Reasons for choosing a particular hypothesis } \\
\text { - Votes indicating which hypothesis players feel is the correct one }\end{array}$ \\
\hline Other & $\begin{array}{l}\text { - Real-time conversations though a chat interface } \\
\text { - Asynchronous communication through a bulletin board system } \\
\text { - Client-side actions that players have taken (e.g. mouse clicks, } \\
\text { buttons pressed) }\end{array}$ \\
\hline
\end{tabular}

\section{Example}

After a gatherer has submitted photographs of a rocky outcrop, an elaborator might suggest a 'hardness' experiment using a 'glass plate' to classify a mineral. Team members moderate the experiments and voting takes place to reach team consensus on the important trait elaborations, such as an acid test be performed on a neighboring rock. The constructors take these pieces and interactively shape them into a classification tree. Then student identifiers suggest "Limestone" for a particular node 
of the tree as a hypothesis based on the experimental results. The combination of these efforts represents the learning outcomes of the team

\section{Select Experiments Game}

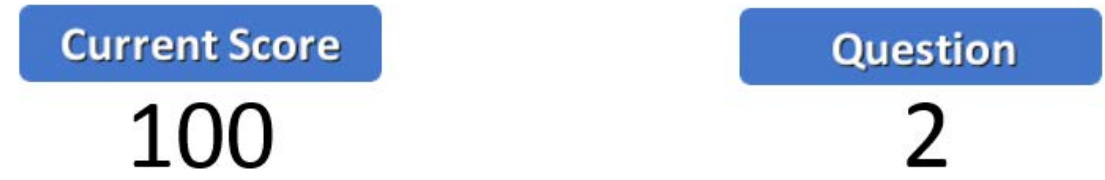

\section{Name}

Flowering Dogwood

\section{Multimedia}

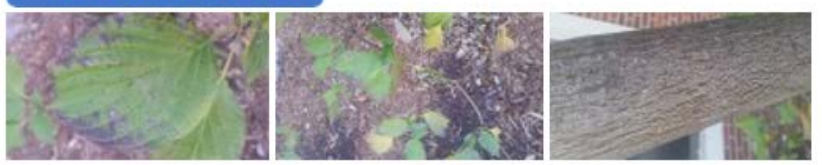

\section{Description}

short, small trunk, small leaves

\section{Select Experiments}

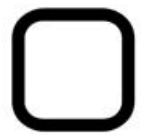

Branching Pattern

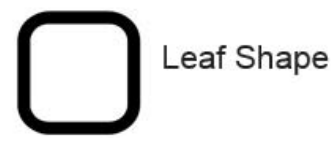

Figure 2: A mock-up of the Select Experiments Game. The name, multimedia, description, and experiments to select are changed for each question and match specific specimens the group has identified. In this example, a player must click the empty boxes, selecting whether they feel that leaf shape or branching pattern is more important to identifying Flowering Dogwood.

\section{Implementing Gaming Templates}

When classification trees are completed and validated they become input to game templates. These templates are essentially a system of game rules as predetermined by developers. Context is then applied to these templates based on the knowledge base developed during formative gamification.

The "Select Experiments" game and the "Identification" game are two template examples. During the "Select Experiments" game (see figure 2), students are given a description, name, and multimedia artifacts related to a previously identified specimen. They gain and lose points based on their selection of appropriate experiments and observations to identify that specimen. In the identification game, students are given the description, location, multimedia artifacts, and relevant experimental and observational results and receive points for each correctly identified specimen.

\section{Results and Discussion}

CIRCLE holds great promise at improving student understanding of the classification and identification tasks. Future development will focus on the creation of more game 
templates. In addition to the "Select Experiments" game and the "Identification" game many more opportunities for game templates exist. Some ideas include:

- Multiplayer - Players take turns selecting experiments or identifying specimens.

- Timed - Players are timed while they select experiments and identify specimens. The fastest time with the highest accuracy gets the most points.

- Memory Game - The system places gathered multimedia specimens onto cards with two of each specimen face down. Players need to find the two cards that contained the same specimen. The fewest number of moves would receive the most points. This could be combined with a multiplayer template such that the individual who found the most pairs wins.

- Classi-Caching - (see Geocaching) - Users attempt to find other examples of the same specimen out in the real world. If they find an example, they mark the location in the game. Other players need to go to that location and either agree or disagree that it is the same as the original specimen. Points are given for the number of matching specimens found and level of agreement on whether the specimen matches the in-game specimen.

- Audio hide and seek - In this audio-only template, students would search for a sound that was similar to a specimen that was already collected. Players receive points for how close the sounds matched.

\section{Conclusions and Future Work}

CIRCLE was used by both STEM experts and undergraduate ecology students in 2014 (Borchert et al. 2015). The actions of each participant was logged to accurately capture their sequence. In addition, the participants were observed and formative feedback was solicited. Finally, a 10-item System Usability Scale (SUS 1986) and 4item open ended questionnaire was administered as a means of gathering information about the ease of use of CIRCLE.

The open ended questions included "What things were good about CIRCLE? Why?", "What was bad about CIRCLE? Why?", "What should be changed about CIRCLE?”, and included an area to add additional comments. In the SUS instrument, users expressed an opinion on a five point Likert scale from Strongly Agree to Strongly Disagree. The responses to the open ended questions were then correlated with individual SUS questions. For example, SUS question \#5 is " 9 . I found the various functions in CIRCLE were well integrated" and user comments included (referring to using the color red as a visual cue in CIRCLE) "Red prompts for what to do next"

By contrast, SUS question \#6 is "I thought there was too much inconsistency in CIRCLE" which prompted one user to add "Unable to go back and change things", and another to suggest "add home button". A total of about 20 concrete and implementable suggestions were provided.

The next version of CIRCLE will address many of the 20 suggestions offered by the pilot study group, and our next experiment will administer another SUS questionnaire, with the responses tracked by SUS question number. In this way, we can methodically track and measure the improvements in the next version using changes in SUS scores.

Future development will focus on improving usability, so that players learn to love this innovative approach towards retrieval learning. 


\section{References}

Borchert, O., Slator, B. M., \& Hokanson, G. (2015). Lessons Learned in the Development of a Collaborative Learning Environment Designed to Educate Students on the Creation of User-generated Classification Structures. Proceedings of the Eighth International Conference on e-Learning and Innovative Pedagogies. Common Ground Publishing: Santa Cruz, CA. November 2-3.

Bransford, J. D., Brown, A. L., \& Cocking, R. R. (2000). How People Learn: Brain, Mind, Experience, and School. National Academy Press: Washington, DC.

Coldwell, W. (2013). Where in the world am I? The addictive mapping game that is GeoGuessr. The Independent. Retrieved from http://www.independent.co.uk/lifestyle/gadgets-and-tech/features/where-in-the-world-am-i-the-addictive-mappinggame-that-is-geoguessr-8641265.html on January 26, 2015.

Crimson Trails (2013). Geobirds. Retrieved from http://geobirds.com/play on September 9, 2013.

Daugherty, T., Eastin, M., \& Bright, L. (2008). Exploring Consumer Motivations for Creating User-Generated Content. Journal of Interactive Advertising, 8(2).

Geocaching (2000). http://en.wikipedia.org/wiki/Geocaching. Accessed 30 January 2015

Jensen, M. (2013). The Anatomy Game (Web Anatomy II). Retrieved from http://msjensen.cehd.umn.edu/webanatomy_archive/game/ on September 9, 2013.

Karpicke, J. D. (2012). Retrieval-Based Learning: Active Retrieval Promotes Meaningful Learning. Current Directions in Psychological Science, 21(3), 157163. doi: $10.1177 / 0963721412443552$

Kids Know It Network (2013). Identify Rock Types Game. Retrieved from http://www.kidsgeo.com/geology-games/rocks-game.php on August 26, 2013.

Kinder Web Games (2013). Letter Learning Game. Retrieved from http://kinderwebgames.com/a.html on September 9, 2013.

Kornell, N. (2009). Optimising learning using flashcards: Spacing is more effective than cramming. Applied Cognitive Psychology, 23(9), 1297-1317.

Leung, L. (2009). User-generated content on the internet: an examination of gratifications, civic engagement and psychological empowerment. New Media \& Society, 11(8), 1327-1347. doi: 10.1177/1461444809341264

Fielding, R. (2000). Architectural Styles and the Design of Network-based Software Architectures (Doctoral Dissertation). Retrieved from: http://www.ics.uci.edu/ fielding/pubs/dissertation/top.htm

Nist, L., \& Joseph, L. M. (2008). Effectiveness and Efficiency of Flashcard Drill Instructional Methods on Urban First-Graders' Word Recognition, Acquisition, Maintenance, and Generalization. School Psychology Review, 37(3), 294-308.

Richardson, V. (2003). Constructivist Pedagogy. Teachers College Record, 105(9), 1623-1640. doi: 10.1046/j.1467-9620.2003.00303.x

SUS (1986). System Usability Scale. Retrieved from http://www.usability.gov/howto-and-tools/methods/system-usability-scale.html on January 28, 2015. 


\section{HEAd'15}

\section{SESSION 2A}

EMERGING TECHNOLOGY PRACTICES 


\title{
Digitech, Remix and Design Research for course /program-wide thinking and enhancement
}

\author{
Gail Casey and Annemieke Craig
}

Deakin University

\begin{abstract}
This paper describes the initial stage of an exploratory investigation in which the authors aim to build course/program-wide thinking into a process aimed at supporting, documenting and sharing technology-rich practices, innovative teaching and active student learning. The investigation uses a remix lens, in an attempt to creatively consider the manipulation of resources and approaches for reuse, while supporting consistency across subjects/units within a course. The authors are working within Deakin University's Course Enhancement Process, which is a major universitywide initiative that includes a framework of collaborative teams comprising academic and resourcing specialists working with faculty academic leaders. The Course Enhancement Process is flexible in its implementation and the authors aim to use the process to build a sustainable course-wide sharing and thinking approach within the Business and Law faculty at Deakin University, Australia.
\end{abstract}

Keywords: Course Thinking; Learning Design; Design Research, Remix, Active learning

\section{Introduction}

Universities face substantial change in a rapidly evolving global context. Boud and Associates (2009) argue that the challenges of meeting new expectations about academic standards, in the next decade and beyond, mean that assessment will need to be rethought and renewed. In considering many of these complexities, including quality standards and measures, Deakin University has implemented a process called 'Course Enhancement' (see, http://www.deakin.edu.au/learning/designing-assessing-andevaluating/enhancing-courses). This is a university-wide major initiative and one that also considers new age learning, diverse cohorts of students along with increasing multicultural needs for students.

Undergraduate courses, at Deakin, are usually of three years duration; some universities may call these 'programs'. Author 1 in her role as Course Enhancer, at Deakin, is involved in learning and assessment design while focusing on course-wide inputs and outputs of curriculum standards; she is supported by a resource team and works closely with course directors and subject/unit heads. Her role also aims to build teaching staff capacity and implement course enhancement processes and to provide tools that assist staff. Author 2 is the course director for Work Integrated Learning (WIL) in the faculty of Business and Law and has a focus on authentic and active learning with technology (Coldwell, Craig, \& Goold, 2011) and (Coldwell-Neilson, Beekhuyen, \& Craig, 2012).

In 2014, Author 1 was responsible for leading course enhancement with more than ten Business and Law courses and in 2015 this number has increased significantly. Author 1, as an experienced action researcher (Casey, 2013a, 2013b, 2013c; Casey \& Evans, 2011), considers, informally, that each of her courses is one action research cycle involving planning, acting, observing and reflecting. This cyclic approach is aimed at the continuous improvement of her own practice.

Designing a course at a university, as argued by Bahr and Lloyd (2011), is the easy part. They explain that this component can be exciting, creative and collegiate as well as providing opportunities for faculty members to work together in genuinely collaborative ways. However, they argue that after the first year or so of 
implementation, almost inevitably, the initial design starts to come unstuck, for many reasons including staffing changes, subtle and incremental migration of course resources, opportunistic inclusions of 'off the shelf' or subject/unit-based innovative teaching and learning approaches, and perhaps generally poor attention to detail with regard to the impact of new introductions and electives. They describe (p. 21) this effect as the 'parts' become more important than the 'whole' and faculty lose sight of course outcomes. The authors have seen this occur many times and, hence, aim to embed a course-wide thinking approach within their study.

This paper discusses the initial stages of the authors' exploratory study aimed at designing and testing of a course-wide thinking approach. It uses WIL, from within the course enhancement process, as an example of their approach.

\section{DigiTech and Remix}

The failure to embrace emerging technologies in higher education courses can lead to pedagogies that risk alienating a generation of learners (Herrington \& Parker, 2013). Coldwell et al. (2011) argue that the judicious use of appropriate technologies support the diverse needs of students. At Deakin University, it is expected that all subjects/units within a course (whether online, blended or face-to-face) develop their own online learning environment, as part of what is known as CloudDeakin (see, http://www.deakin.edu.au/students/clouddeakin). This aims to use located and cloud learning to provide accessible media-rich, interactive and active educational experiences (Deakin University, 2014b).

The authors use the word digitech to encapsulate the use of rich media and technologies. As part of Course Enhancement, course and subject/unit information is gathered and a document known as a 'Course Evidence Portfolio' (Deakin University, 2014a) is generated. This data is organised in a way that provides a starting point for course-wide thinking (see, http://www.deakin.edu.au/learning/designing-assessing-andevaluating/enhancing-courses). Author 1 then spends time with course directors and course teams to develop a clear and concise set of course priorities, learning outcomes and minimum standards. The faculty helps to ensure that these align with Deakin Graduate Learning Outcomes, accreditation requirements (where applicable) and the Australian Qualifications Framework (Deakin University, 2014c).

Author 1 finds the role of course enhancer a very challenging role, but one that continually offers snippets of excellent innovative teaching practice along with opportunities to gain insider knowledge from some of the most successful lecturers at the university. Being privileged to these resources comes with the responsibility to share insights to help build staff capacity. However, such resources rarely come packaged in a perfect bundle ready to embed in different subjects or courses; hence, this leads the authors to consider Markham's (2013) notion of remix. As a brief caveat, Markham (2013, p. 66) describes remix as a 'generative tool for thinking creatively'. The authors aim to use the concept of remix (generating, playing, borrowing, moving and interrogating) as a way of thinking about the reuse of resources; in particular, digital resources. 


\section{The Study: Course thinking using Educational Design Research}

In considering the complex demands surrounding higher education, the authors have aligned their study with Deakin's 'LIVE the future agenda 2020' (Deakin University, 2014b) and searched for a research methodology that includes improvement cycles of planning, acting and reflection in order to cater for the changing nature of higher education.

Herrington, Reeves, and Oliver (2010) argue that it is almost impossible to conceive of any authentic learning endeavour, in higher education today, that does not take advantages of the affordances of computers and the Internet. They promote an educational design research (also known as design-based or design research) method when integrating an authentic e-learning approach and this uses iterative cycles; although this requires teachers to take risks and authentic tasks must be well supported with guidance and resources.

Design-based research evolved near the beginning of the $21^{\text {st }}$ century and was heralded as a practical research methodology that could effectively bridge the chasm between research and practice in formal education (Anderson \& Shattuck, 2012). In educational design research it is common practice to develop and implement curriculum materials in order to address a particular educational problem (Tolboom \& Kuiper, 2014). One of the main criticisms of educational design research is that the report of the evaluation is qualitative and, as Tolboom and Kuiper (2014) point out, this could lead to conclusions which are very dependent on the conditions in a specific part of the sample. Educational design research was chosen for this study because it is a methodology designed by and for educators that seeks to increase the impact, transfer and translation of education research into improved practice (Anderson \& Shattuck, 2012). It also, as explained by Anderson and Shattuck (2012), stresses the need for theory building and the development of design principles that guide, inform and improve both practice and research in educational contexts.

In considering the suitability of design research within the Course Enhancement Process, it is useful to understand the four stages of Course Enhancement at Deakin (see, $\quad$ http://www.deakin.edu.au/learning/designing-assessing-andevaluating/enhancing-courses). These stages are also outlined in the Course Evidence Portfolio, mentioned earlier. Such a document highlights how curriculum standards are designed to guide course development and enhancement. It also provides a document that helps to understand the importance of course-wide thinking and why the authors aim to investigate ways to integrate a course-wide thinking approach within their WIL study.

The authors are guided by Herrington et al. (2010) and Reeves (2006, p. 59) 'design research approaches in educational technology' combined with approaches from Anderson and Shattuck (2012). The following four elements describe the initial thoughts and research planning by the Authors for Work Integrated Learning research using a design research approach.

\section{Analysis of practical problems by researchers and practitioners in collaboration}

Work Integrated Learning (see, http://www.deakin.edu.au/buslaw/enhancestudy/work-integrated-learning), is a series of ten subjects/units that are integrated into a range of Business and Law core, co-core and elective courses. Some can also be 
incorporated as electives in undergraduate courses across Deakin. More information on these subjects/units can be found on the Work Integrated information flyer at http://www.deakin.edu.au/_data/assets/pdf_file/0009/236079/WIL-web.pdf.

All ten subjects/units are fully online and available during any study period (Deakin courses run over three trimesters in a twelve month period-rather than the usual semester approach at most universities). All ten WIL subjects/units are aimed at maximising the employability of students within Business and Law.

As part of an increased emphasis on employability of graduates, at Deakin, Author 2, as course director of WIL, needs to ensure that Work Integrated learning can be scaled up as more courses seek to integrate opportunities for student employability. Work Integrated learning must now be scalable to cater for an increasing demand. This includes upgrading the WIL online learning environment to support increased dissemination of information as well as building shared student knowledge banks to support peer-to-peer learning and revisiting assessment tasks to ensure consistency and clarity as the number of required assessors increases. A collaborative team of staff is being constructed including experts in digital literacies and language skills to support issues surrounding the large international student cohort. For strength and consistency, it is important that the thinking and approaches taken by this team are course-wide.

\section{Development of solutions - authentic eLearning design and effective assessment}

All ten subjects/units within Work Integrated Learning are fully online and, therefore, the authors aim to take advantage of the characteristics of the Internet and its capacity to allow for a worldwide community to exchange ideas and to learn from each other (Davidson \& Goldberg, 2009).

In developing a solution for the Work Integrated Learning problems discussed, Deakin's Graduate learning Outcomes (see, http://www.deakin.edu.au/learning/designing-assessing-and-evaluating/graduatelearning-outcomes) provide the theoretical underpinning for the capabilities that graduates acquire and demonstrate at the completion of any course. Also, the following nine points, in italic, outline Herrington et al. (2010) characteristics of authentic learning. Each of these are followed by the Authors' attempt to align these with the planning for Work Integrated Learning.

\section{Elements of Authentic Learning:}

1. Provide authentic contexts that reflect the way the knowledge will be used in real life - structure lectures, tutorials and online examples around real people involved in real-life business problems as well as solutions.

2. Provide authentic tasks - use Work Integrated learning and simulations wherever possible. When designing assessment, carefully consider what the graduate, in the specific area, will be doing and how they will be evaluated in the work-place setting.

3. Provide access to expert performances and the modelling of processes - where possible, provide students with annotated samples of students' past assessment of a pass and credit standard.

4. Provide multiple roles and perspectives - use peer-to-peer online discussion and sharing to generate a knowledge bank of experiences and perspectives.

5. Support collaborative construction of knowledge - as in point 4. 
6. Promote reflection to enable abstractions to be formed - provide opportunities for students to give serious thought and consideration to the way they are thinking, acting and/or reacting.

7. Promote articulation to enable tacit knowledge to be made explicit - as in point 4.

8. Provide coaching and scaffolding by the teacher at critical times - use the library staff and language and literacy staff as collaborators for scaffolding assessment design.

9. Provide for authentic assessment of learning within the tasks - as in point 2.

In adding further context for effective learning, the authors see the need to identify how effective learning takes place and, therefore, there is a need to carefully consider aspects of assessment. In considering the demands and changes within higher education, Boud and Associates (2009) provide seven propositions for assessment reform in higher education developed. These were developed by a team of experienced assessment researchers, academic development practitioners and senior academic managers aimed at identifying current best thinking about the ways assessment will need to address immediate and future demands. These propositions are:

1. Assessment is used to engage students in learning that is productive.

2. Feedback is used to actively improve student learning.

3. Students and teachers become responsible partners in learning and assessment.

4. Students are inducted into the assessment practices and cultures of higher education.

5. Assessment for learning is placed at the centre of subject and program design.

6. Assessment for learning is a focus for staff and institutional development.

7. Assessment provides inclusive and trustworthy representation of student achievement.

“Assessment is the making of judgements about how students' work meets appropriate standards" (Boud \& Associates, 2009, p. 1). As discussed by Boud and Associates (2009), students themselves need to develop the capacity to make judgements about both their own work and that of others in order to become effective continuing learners and practitioners. These seven points, combined with Herrington et al. (2010) nine characteristics of authentic learning make sixteen elements that the authors aim to use as the foundations of theory for this design research study.

\section{Iterative Cycles}

The iterative cycles, when implementing design research, need to involve testing and refinement, but underlying each cycle, for the authors, is a drive for sustainable improvement involving course-wide thinking. Lecturers and academics are, in many cases, time poor. With this in mind, Herrington et al. (2010, p. 22) propose the following questions to ask when 'developing guidelines for developing authentic tasks'. These are very helpful to revisit after during each cycle. Their foci help to drive the development of the solution.

1. What kinds of activities are conducted, in the real world, that use the knowledge, skills and attitudes that are the focus of the course?

2. How is this knowledge applied to answer real-world questions and solve realworld problems? 
In returning to our study involving Work Integrated Learning, an iterative cycle would occur in a trimester. The aim is, initially, to trial and test ideas, collaboratively devised, within one subject/unit. After reflection and further planning, a broader course-wide approach would occur after each cycle.

\section{Reflection to produce 'Design Principles'}

With the approach discussed, reflection, including further planning is paramount for the successful integration of other WIL units into the design research study. Design principles are needed in order to effectively build course-wide thinking.

\section{Discussion and conclusion}

In this early stage of the study, this paper describes the need for course wide thinking in higher education. The approach taken and the reasons behind this has been discussed. A number of further documents and resources can also be made available. In the authors' search for a methodology that has the potential to deal with complex learning environments and best practice, Design Research is showing excellent potential through its ability to integrate the development of solutions to practical problems in learning environments, while identifying reusable design principles (Reeves, 2006).

The concept of reuse is ideal for Author 1's role as course enhancer. It also aligns well with the notion of remix while helping to think more creatively in the way the different elements are reused, manipulated and redesigned.

In meeting Reeves' (2006) call for the educational technology research community to adopt design research methods more widely, the authors aim to use the iterative cycles within the process to develop 'rapid prototyping with on-going improvement and redesign’ (Herrington \& Teras, 2014, p. 232) for Work Integrated Learning.

This initial stage of this exploratory study has moved past what could be called a 'good idea' and into systematic and pedagogically sound research. It is an approach that has the potential to offer a 'best practice' approach (Anderson \& Shattuck, 2012, p. 24) while taking into account complex learning environments. This paper has used Work Integrated Learning as the focus of this study. The Authors' longer-term goal is to expand this research into further courses and use the Work Integrated learning study to inform the development of other courses. The ultimate goal is to work towards a sustainable approach to course enhancement that involves self-generating iterative cycles of reflection, analysis and redevelopment of solutions: an approach that we hope will lead to engaging, effective and efficient courses with a shared understanding of graduate learning outcomes.

\section{References}

Anderson, T., \& Shattuck, J. (2012). Design-based research: A decade of progress in education research. Educational Researcher, 41(1), 16-25.

Bahr, N., \& Lloyd, M. (2011). Course Cohesion: An elusive goal for tertiary education. Journal of Learning Design, 4(4), 21-30. 
Boud, D., \& Associates. (2009). Assessment 2020: Seven propositions for assessment reform in higher education. http://www.uts.edu.au/sites/default/files/Assessment2020_propositions_final.pdf

Casey, G. (2013a). Building a student-centred Learning framework using social software in the middle years classroom: An action research study. Journal of Information Technology Education: Research, 12, 159-189. http://www.jite.org/documents/Vol12/JITEv12ResearchP159-189Casey1186.pdf

Casey, G. (2013b). Interdisciplinary Literacy through Social Media in the Mathematics Classroom: an Action Research Study. Journal of Adolescent and Adult Literacy, 57(1), 58-69. doi: 10,1002

Casey, G. (2013c). Social media in the classroom: a simple yet complex hybrid environment for students. Journal of Educational Multimedia and Hypermedia, 22(1), 5-24.

Casey, G., \& Evans, T. (2011). Designing for learning: Online social networks as a classroom environment. The International Review of Research in Open and Distance Learning, 12(7), 1-26. http://www.irrodl.org/index.php/irrodl/article/view/1011 and ( published in Spanish) http://bdistancia.ecoesad.org.mx/contenido/numeros/numero7/presencia_01.html.

Coldwell, J., Craig, A., \& Goold, A. (2011). Using e Technogies for active learning. Interdisciplinary Journal of Information, Knowledge, and Management, 6, 1-12.

Coldwell-Neilson, J., Beekhuyen, J., \& Craig, A. (2012). Which e-learning technolgy is right for me? International journal of emerging technogies in learning, 7(2), 1321.

Davidson, C., \& Goldberg, D. (2009). The Future of Learning Institutions in a Digital Age: Massachusetts Institute of Technology.

Deakin University. (2014a). Course evidence portfolio. http://www.deakin.edu.au/_data/assets/pdf_file/0018/229140/Course-evidenceportfolio-2014.pdf

Deakin University. (2014b). LIVE the future agenda 2020. http://www.deakin.edu.au/_data/assets/pdf_file/0004/6961/strategic-planbooklet-print.pdf

Deakin University. (2014c). Stage 2: Assessment and learning design. from http://www.deakin.edu.au/learning/designing-assessing-andevaluating/enhancing-courses/stage-2

Herrington, J., \& Parker, J. (2013). Emerging technologies as cognitive tools for authentic learning. British Journal of Educational Technology, 44(4), 607-615. doi: 10.1111/bjet.12048

Herrington, J., Reeves, T., \& Oliver, R. (2010). A guide to authentic e-learning. New York and London: Routledge.

Herrington, J., \& Teras, H. (2014). Neither the frying pan nor the fire: In search of a balanced authentic e-Learning design through an educationla design research process. International Review of Research in Open \& Distance Learning, 15(2), 232-253.

Markham, A. (2013). Remix culture, remix methods: Reframing qualitative inquiry for social media contexts. In M. Giardiana \& N. Denzin (Eds.), Global Dimensions of Qualitative Inquiry (pp. 63-81). Walnut Creek, CA: Left Coast Press. 
Reeves, T. (2006). Design research from a technolgy perspective. In J. Van Den Akker, K. Gravemeijer, S. McKenney, \& N. Nieveen (Eds.), Educational Design Research (pp. 52-66). London: Routledge.

Tolboom, J., \& Kuiper, W. (2014). Quantifying correspondence between the intended and the implemented intervention in educational design research. Studies in Educational Evaluation, 43(0), 160-168. doi: http://dx.doi.org/10.1016/j.stueduc.2014.09.001 


\title{
MOOCs as a tool to connect higher education and professional experience? Experiences from a student-made MOOC on E-Learning
}

\author{
J. Griesbaum*, M. Görtz** \\ * University of Hildesheim, Institute of Information Science and Language Technology \\ ** Accenture Strategy, Talent \& Organization
}

\begin{abstract}
This paper describes results from a student-made MOOC (Massive Open Online Course) on E-Learning. The main focus of interest lies on two aspects. Firstly, to explore the potential of using the process of creating a MOOC as a teaching method and secondly, to get insights into the affordances and outcomes linked to a cooperation with a knowledge-based company during the course of events of the MOOC. Both concepts aim for an improvement of quality in higher education by combining the concept of "learning by doing" with the initiation of communication between students and professionals in the field. On the one hand, the data shows that employing the task of building a MOOC as a teaching method is a very worthwhile didactic approach to initiate a complex and authentic learning scenario. On the other hand, the outcome indicates that the realized level of participation is expandable.
\end{abstract}

Keywords: Collaborative E-Learning, MOOC, Higher Education, Professional Experience

\section{Introduction}

The diffusion of MOOCs and the corresponding public and scientific discussion on the topic sparks the field of E-Learning in many ways and with great impact. It is therefore not surprising that MOOC research encompasses a wide span of topics. The Department for Business Innovation \& Skills (Haggard, Gore, Inkelaar, Lawton \& Katsomitros, 2013) and the Norwegian MOOC Commission sub-report (Time for MOOCs, 2013) provide an overview and a review of the literature used in this field of study. According to that, the didactic configuration of learning processes in MOOCs can be seen as an important field of research. The most prominent debate on this subject is probably on the differences of cMOOCs vs. xMOOCs. MOOCs originated as learning environments that correspond to and realize connectivist ideas of (cooperative) learning (cMOOCs). In contrast, the rising popularity and media presence of MOOCs are the result of the success and large audiences of courses offered on platforms like Edx, Udacity and Coursera that predominately follow a docent-centric knowledge distribution metaphor (xMOOCs) (Blom, Verma, Li, Skevi \& Dillenbourg, 2013). One may argue that this kind of "massification of learning" (Yuan \& Powell, 2013) comes with a price: a rather low level of didactic quality and learning scenarios which can often barely claim to address the higher levels of learning goals as described by different taxonomies, e. g. synthesis, evaluation, or metacognitive knowledge (Krathwohl, 2002). Hence, at present, learning experiences in MOOCs are often far-flung from the quality of discourse and interaction based learning processes as argued by theoretical approaches that aim beyond a knowledge acquisition metaphor, e.g. O'Donnel (2006), Scardamalia and Bereiter (1994), Slavin (1996), Siemens (2005). But the current debate on learning in MOOCs should not be restricted to a rather dichotomic discourse on "antiquated" and "up-to-date" views on learning. The concept and diffusion of MOOCs is directly connected to the idea and the adaption of socially unlimited communication. Seen from 
this point of view, MOOCs are an opportunity and playground to think of learning as an interaction of different people and groups in new ways.

This is the starting point of our work. We aim to explore the potentials of MOOCs for enhanced in-class learning and to connect stakeholder groups which were usually separated in learning. The first goal is to explore the concept of MOOCs as an in-class teaching method in which students are given the task to draft, implement, execute and evaluate a MOOC. Such a didactic setting can be seen as a complex and authentic task to initiate and foster self-initiated and autonomous learning on part of the students. The second goal is to link theory and practice by connecting students with practitioners. Students should elaborate basic concepts and theories for practitioners of the profession. In turn, practitioners should provide feedback with regard to the needs and experiences of practitioners daily work life, thus enriching the learning experiences of the students. In the following, the configuration and results of an exploratory case study are described. The paper starts with theoretical considerations about the learningrelated added values of this MOOC scenario. Then, the configuration of the MOOC and its execution are delineated. Following that, the outcomes are analyzed. The paper closes with an estimation of the added values and the limitations of this concept.

\section{Approach and Concept}

Figure 1 gives an overview of the structure of the MOOC and the stakeholders' interaction in this case study to illustrate the following argumentation.

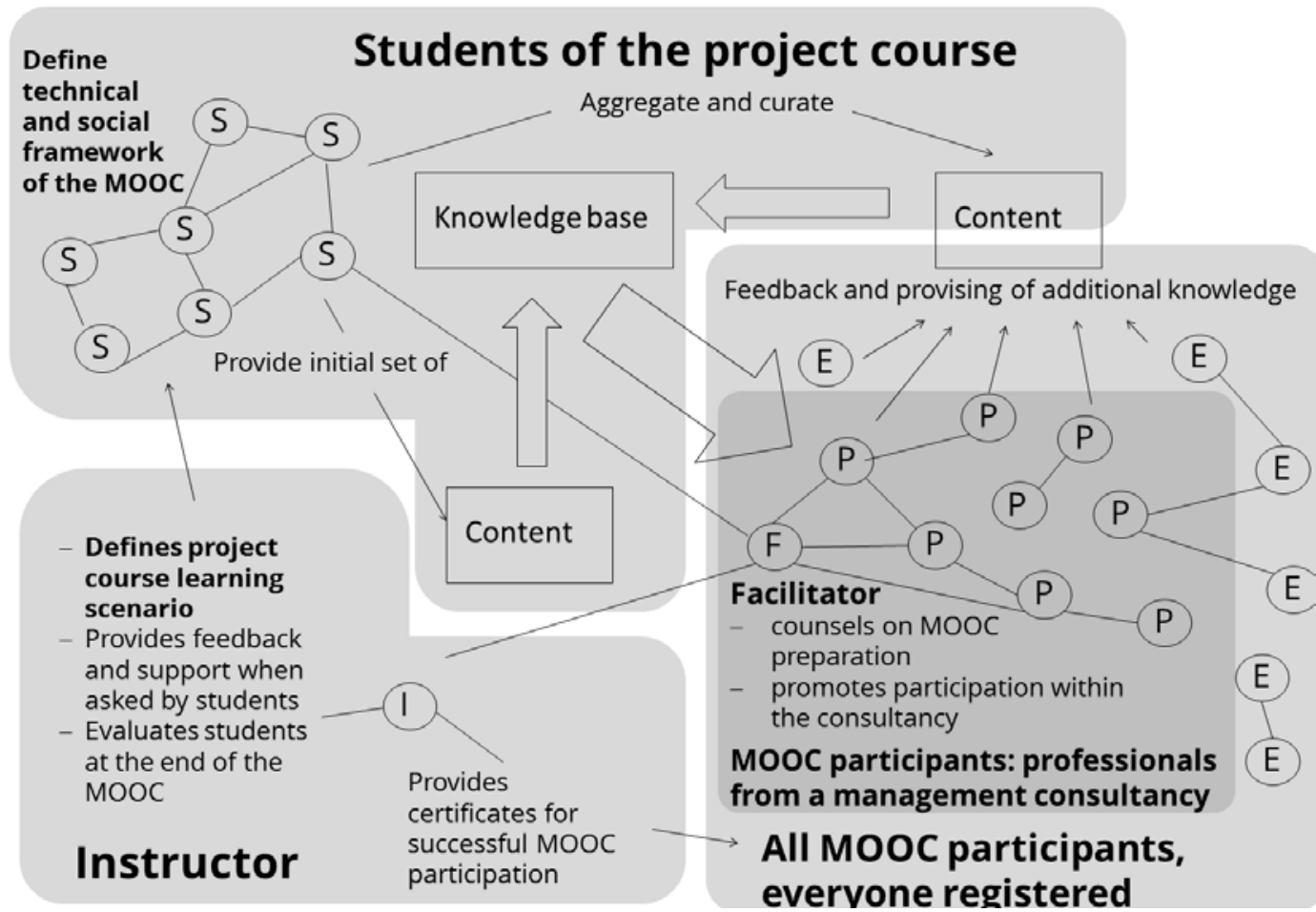

Figure 1. MOOC structure: interaction of stakeholders 


\section{Organizational context of this MOOC}

Our didactic scenario is complex. It encompasses a regular project course as an internal learning scenario at the university and a MOOC which originated as a result of students learning activities within the project course. The course in which the MOOC is developed and executed is a project course and part of the module "e-learning", in which advanced students of the master programs "International Information Management" and "Information Management and Information Technology" at the University of Hildesheim collectively acquire practical skills and knowledge. During the winter term of 2013 and 2014, the learning task of the project course was to build up and execute a MOOC on the topic "Collaborative E-Learning". The basic layout of this learning scenario was defined by the instructor of the project course, who is also the first author of this paper. To alleviate differentiation between the two courses within the didactic scenario, we refer to the project course of the students of the master programs as PC-EL and to the MOOC on the topic collaborative learning (which is developed in PC-EL) as MOOC-CL.

\section{Actor group and roles}

The following table gives an overview of stakeholders and their roles in this learning scenario as defined by the instructor at the start of the project course.

Table 1. Stakeholders and their roles in the learning scenario

\begin{tabular}{|l|l|l|}
\hline Stakeholder & PC-EL & MOOC-CL \\
\hline Students of the project course & Learners & Instructors and learners \\
\hline University instructor & Instructor & Quality manager, recipient \\
\hline $\begin{array}{l}\text { Facilitator from a management } \\
\text { consultancy }\end{array}$ & Advisor & Promoter, Learner \\
\hline $\begin{array}{l}\text { Professionals from } \\
\text { management consultancy }\end{array}$ & - & Learners \\
\hline Everyone interested & - & Learners \\
\hline
\end{tabular}

There are five stakeholder groups. Three of them are active both in the project course the PC-EL and the MOOC-CL. The role of these actor groups is different in the two courses. In the project course, students are learners. They learn about e-learning and knowledge management by developing an open learning scenario with regard to these topics, the MOOC-CL. Then, during the execution of the MOOC-CL, they act as instructors, providing the initial MOOC content. In addition, students initiate and moderate the learning process of the MOOC participants. The university instructor defines the learning scenario of the project course PC-EL. He is not actively involved in the execution of the MOOC-CL, but serves as a kind of quality manager with respect to the content provided by the students. Else, he is a passive recipient of the MOOC, 
not interfering with the course of events to maximize autonomous MOOC control on part of the project course students. The third actor is the facilitator from a management consultancy who is also the second author of this paper. Whereas the instructor defined and controlled the learning scenario of the PC-EL, the task of the facilitator was to announce and promote the MOOC-CL within the cooperating management consultancy. During the MOOC development, he additionally gave advice to students concerning learning related information needs of the professionals in the consultancy.

The last two actor groups correspond to that kind of participants which could be addressed as MOOC learners. In our scenario, the core target group were professionals in the field, that means knowledge workers professionally counseling customers with regard to knowledge related activities to foster information management and knowledge management in middle to large sized companies. Still, the MOOC-CL follows the "open paradigm" and is not restricted to a certain audience. Hence, the MOOC-CL is open for everyone interested.

\section{Conceptual considerations on learning related advantages of the learning scenario}

Why could it be worthwhile to employ the task of building up and executing a MOOC as an in-class teaching method? Why to connect higher education and professional experience in a MOOC based learning scenario? In short, such a scenario realizes a "learning by doing" approach and tries to initiate exchange between theory and practice by an ongoing dialog between students and professionals in the field.

For the students of PC-EL three core advantages can be stated: A) the learning scenario of PC-EL realizes an authentic and complex learning task. B) The MOOC-CL creates a space for discourse and feedback from the community. C) The MOOC-CL provides a room to build up online identity and reputation.

With respect to the management consultancy and its professional workforce and all learners in the MOOC-CL further advantages can be argued. D) The MOOC provides a free course to a topic which is relevant for professionals in the field. And finally, E) the MOOC offers businesses (especially the directly involved consultancy company) new options to get in direct contact with potential candidates for open positions.

\section{MOOC configuration and execution}

To give an orientation, the following figure provides an overview of the course of events of the PC-EL and the MOOC-CL. 


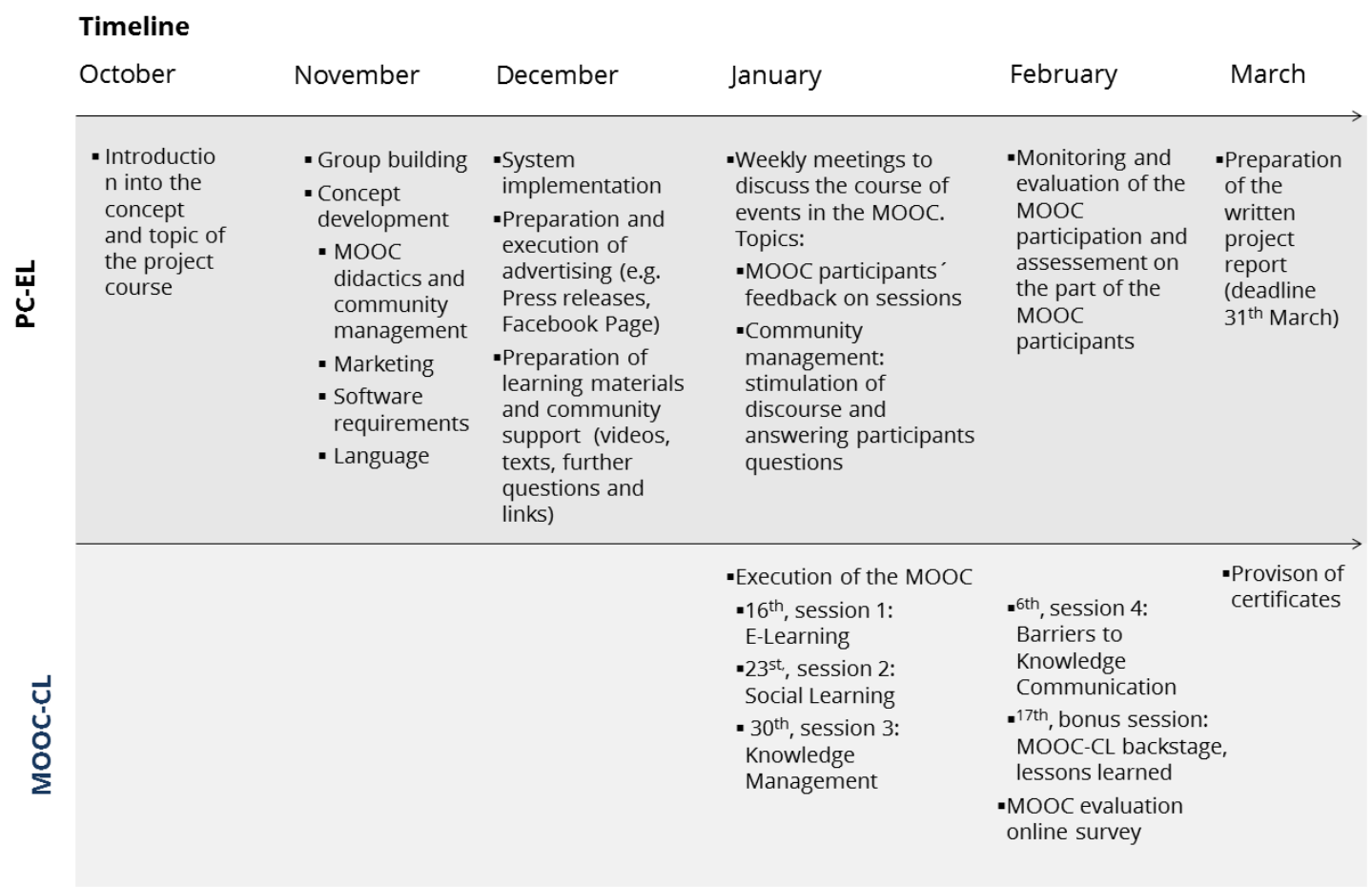

Figure 2. Course of events of PC-EL and MOOC-CL

At the start of the project course, the instructor introduced the students to the concept of the course and provided some basic suggestions concerning self-organization, group coordination, and work packages.

After that, the students took over the management of the course. The instructor restricted himself on a guide role, giving feedback only when explicitly asked for and providing infrastructural services, like preparing and handing out certificates to MOOC participants. From that date on, the students realized a truly self-controlled constructivist learning scenario. First, students determined basic aspects of selforganization and the MOOC-CL. As a starting point, it was decided to follow a connectivist paradigm in MOOC development. Hence, MOOC-CL should rather correspond to a cMOOC than a xMOOC. Group formation resulted in different groups: project management, content development, community management, controlling, software configuration and support, and marketing. Next, the content of the MOOCCL, the time schedule and the number of MOOC sessions were decided. Every session was prepared and executed by a specific session or content group.

After these basic aspects were determined, the MOOC-CL was prepared. CourseSites, a free MOOC software by Blackboard, was chosen as the software infrastructure. The choice was not without problems. On the one hand, the system provided the necessary technical features and was easy to setup and configurate. On the other hand, there were login and content submission related problems with Internet Explorer 9, the standard browser used by the participants of the management consultancy.

The marketing team decided on a broad range of advertising measures, including online as well as classic marketing channels. For content development a storytelling concept was worked out, telling the story of a student who faces different learning and 
knowledge management related problems as a recurrent theme throughout all four MOOC sessions. Videos (with a length of a few minutes) and photo stories were prepared as the primary format for knowledge transfer. External experts were also included in the videos. For visualization, the software tools Videoscribe, PowToon, and ComicLife 3 were employed. All videos produced for the MOOC can be found at https://www.youtube.com/channel/UCH0mIduX62yZTNUWKhe0svw.

In addition, to initiate and support knowledge development within the MOOC community, a specific community management concept was developed. Firstly, discussions for each session were prepared and initiated. During the sequence of the four sessions, a successively larger variety of communication and knowledge generation tools was provided. For each of the tools an initial inventory of content was prepared. Finally, students prepared questionnaires for an evaluation and to give the participants an opportunity to post requests for following sessions.

\section{Results and Discussion}

The analysis is structured with regard to the different stakeholder groups in the two courses forming the whole learning scenario. First, learning processes and outcome for students in PC-EL are evaluated. Following that, MOOC-CL related values for the learners in the MOOC are discussed. Finally, both perspectives are brought together.

\section{Learning success of students in PC-EL}

The analysis of students' learning success is based on the assessment of the participants' learning processes and outcome on part of the instructor and on the students' selfestimation captured by a survey at the end of PC-EL. According to the estimation of the instructor, the course of events as described in section 3 strongly indicates that the learning scenario successfully evoked a widely self-directed and self-controlled learning process on part of the students. In PC-EL, students were very active and highly involved. After the introduction in the course, which was given by the instructor, the students organized in-class and virtual learning activities autonomously. During the active phase of the MOOC-CL sessions, the students often decided to have additional face-to-face project course meetings.

As the preparation and execution of the MOOC-CL was well-founded and clearly presented in the final in-class presentation and elaborately described and argued in the project report, the group work was rated with the best grade, which can be seen as a direct measurement of learning success. This corresponds with the students' selfevaluation of their learning success. All 14 students took part in the final course evaluation. Table 2 shows the results. 
Table 2. Results of the final course evaluation in PC-EL

\begin{tabular}{|l|c|}
\hline Question & Mean Value (SD) \\
\hline q.1) Workload & $1.64(0.48)$ \\
\hline $\begin{array}{l}\text { q.2) Learning success with regard to the content related aspects of the } \\
\text { course }\end{array}$ & $1.36(0.72)$ \\
\hline q.3) Learning success with regard to the project management & $1.71(0.59)$ \\
\hline q.4) Charateristics of team work & $1.21(0.94)$ \\
\hline q.5) Motivational effect of team work & $0.86(0.83)$ \\
\hline
\end{tabular}

$\mathrm{N}=14$, measured on a 5-stage scale ranging from -2 (q.1, q.2, q.3 and q.5="very low", q.4="cooperative") to +2 (q.1, q.2, q.3 and q.5="very high", q.4="collaborative")

Learning success was assessed as high with a mean value higher than 1 (q.2 and q.3). Workload (q.1) was also assessed as high, indicating that students were highly involved. Motivation can also be interpreted as positive (q.5). The characteristics of group work can be estimated as very positive because the group process was judged as rather collaborative (q.4). Seen from socio-genetic and socio-cultural perspectives of learning, real collaboration has to be seen as a prerequisite for the occurrence of processes like cognitive conflicts, externalization of knowledge, and consensus building. Such processes in turn are causative for enhanced learning success in group learning. In sum, with a positive motivation, strong immersion and high learning success, students assessed their learning success very positively. Overall, both from the instructor's perspective and students' view on their learning, results with regard to learning success are very encouraging.

\section{MOOC-CL values}

To determine the value of the MOOC-CL, audience reach, participation and MOOC participant evaluation are analyzed.

\section{Audience reach}

Audience reach is captured with data provided by CourseSites which is further refined and aggregated. All data provided encompasses user actions between January 16th and February 28th. Overall, till the end of February, 277 participants registered on MOOCCL. Audience reach is operationalized as the number of unique users per MOOC session.

MOOC-CL started with 200 users in session 1. Thus, the MOOC can be assessed as rather small with regard to the number of participants. Nevertheless, a number of 200 users is not insignificant. It shows that the MOOC still reached an audience size corresponding to a multitude of standard courses. In the following sessions the number of users declined. This is a pattern typical for MOOCs (Koller, 2012). The different 
elements of the four sessions were used to a different degree. On the due date of 12th of February (one week after the fourth session) the number of total requests in forums $(n=17,657)$ more than doubles the amount of request of provided learning materials $(n=8,115)$. This indicates that discourse and collaborative knowledge production formed a central part of the learning experience of all MOOC participants.

\section{Knowledge generation and participation}

Resources prepared by the students of PC-EL formed the core and bulk of the knowledge which was created in MOOC-CL. Students prepared 11 videos, 5 photo stories, 9 forums, 6 blogs and 9 wikis. Collaborative knowledge generation primarily focused on the discussions in the forums. 308 forum posts were written, roughly half of them by the students of PC-EL (147 posts) and half of them by the MOOC-CL participants (161 posts). Thus, knowledge generation in forums can be assessed as successful. In contrast to that, participative knowledge generation in other tools (blogs, wikis) was rather sparse.

\section{Estimation of the participants of MOOC-CL}

At the end of session 4, a final questionnaire was prepared for the MOOC-CL participants to enable them to provide feedback with respect to the quality of the MOOC. 19 participants took part in the survey. 95\% rated the quality of the MOOC as high or very high. With regard to learning, nearly $50 \%$ of the participants rated the videos as the primary means for knowledge acquisition. $85 \%$ of the participants assessed the forums as their preferred tool for interaction. Furthermore, users provided feedback with regard to their motivation for MOOC-CL participation and the learnings achieved. Data denotes two different motivations for MOOC participation. First, a MOOC format specific perspective. Participants took part because they were interested in MOOCs as a new "tool" for learning. The second motivation is content related. Participants took also part in MOOC-CL because they were interested in the topic of the MOOC “collaborative learning”. According to the survey data, learnings achieved with respect to learning format related goals focused on aspects of MOOC organization and tools for video production. Feedback on content related learning goals indicates a consolidation of already available knowledge which was deepened in the forum discourse.

In sum, this chapter indicates manifold values of MOOC-CL for the professionals of the management consultant agency and the open web public. The number of participants shows a certain amount of interest and demand on the MOOC-CL. In addition, real discourse and collaborative knowledge generation can be observed. Finally, learning and learning outcomes are assessed as positive and of high knowledge value. On the one hand, these results sound encouraging. On the other hand, they need to be put in perspective. As a whole, audience reach is of a rather low level and therefore, the knowledge related values for the professionals of the management consultant agency and the open web public remain of limited magnitude. 


\section{Success of connecting higher education with professional experience}

Finally, was the learning scenario able to invoke a connection between higher education and professional experience?

In sum, we can conclude that the cooperation was basically successful. At the same time, we see that success of this cooperation strongly relates to the amount of participation of the management consultancy professionals. Regarding to this, the success rate was rather basic as only $10 \%$ of the target group took part in MOOC-CL. Two kinds of hurdles for participation were identified, organizational and technical factors. Both pointing to requirements which should be considered in further experiments. Firstly and probably most important, the effort taken in participating a MOOCshould be accounted for in the work schedule. Secondly, the compatibility between the MOOC software and the technical infrastructure of the company needs to be assured beforehand.

\section{Conclusions}

As an overall estimation, the conclusion here is that employing a MOOC as an in-class teaching method in the sense of a "students teaches the web community" approach can be seen as worthwhile. However, it is a teaching method, which deserves further exploration. The case study shows the limits of this concept but also indicates positive learning effects on part of the students and manifold values for the web community. At the same, it turns out that a stronger and explicit connection to professional experience is not achievable that easily. At least, the configuration tested in this case study shows room for improvement.

\section{References}

Blom, J., Verma, H., Li, N., Skevi, A. \& Dillenbourg, P. (2013). MOOCs are More Social than You Believe. eLearning Papers, 33. Retrieved from https://oerknowledgecloud.org/sites/oerknowledgecloud.org/files/Fromfield_33_1.pdf

Cress, U. \& Kloos, D. C. (2014). Proceedings EMOOCs 2014, the Second MOOC European Stakeholders Summit, Feb. 10-12, Lausanne (Switzerland).

Fournier, H., Kop, R. \& Durand, G. (2014). Challenges to Research in MOOCs. MERLOT Journal of Online Learning and Teaching, 10(1), Retrieved from http://jolt.merlot.org/vol10no1/fournier_0314.pdf

Griesbaum, J. (2014). Students as teachers in MOOCs: The double gain of MOOCs as an in-class teaching method experiences from a student-made MOOC" Online Data Privacy. International Journal of Information and Education Technology, 4(1), 2934.

Haggard, S., Gore, T., Inkelaar, T., Lawton, W. \& Katsomitros, A. (2013). The Maturing of the MOOC. Literature review of Massive Open Online Courses and 
other forms of Online Distance Learning (BIS Research Paper Number 130). London: Department for Business Innovation \& Skills. Retrieved from https://www.gov.uk/government/uploads/system/uploads/attachment_data/file/24 0193/13-1173-maturing-of-the-mooc.pdf.

Ingham, A. G., Levinger, G., Graves, J. \& Peckham, V. (1974). The Ringelmann effect: Studies of group size and group performance. Journal of Experimental Social Psychology, 10(4), 371-384.

Johnson, D.W., Johnson, R.T. \& Holubec, E.J. (1998). Cooperation in the classroom. Edina: Interaction Book.

Koller, D. (2012). MOOCs on the move: How coursera is disrupting the traditional classroom [Podcast]. In Knowledge Wharton (2012), Retrieved Sep. 9, 2014 from http://knowledge.wharton.upenn.edu/article/moocs-on-the-move-how-courserais-disrupting-the-traditional-classroom/

Kop, R. \& Hill, A. (2008). Connectivism: Learning theory of the future or vestige of the past? The International Review of Research in Open and Distance Learning. 9(3). Retrieved from http://www.irrodl.org/index.php/irrodl/article/view/523/1103

Krathwohl, D.R. (2002), A Revision of Bloom's Taxonomy: An Overview. Theory into Practice, 41, pp. 212-218.

N.A. (2013), Time for MOOCs, Norwegian MOOC Commission sub-report. Retrieved May 5, 2014 http://www.regjeringen.no/upload/KD/Time_for_MOOCs.pdf

O'Donnel, A. M. (2006). The role of peers and group learning. In Alexander, P. A. \& Winnie, P. H. (Eds.), Handbook of educational psychology (pp. 781-802). $2^{\text {nd }}$ ed. Lawrence Erlbaum Associates.

Scardamalia, M. \& Bereiter, C. (1994). Computer support for knowledge building communities. Journal of the Learning Sciences, 3, 265-283.

Siemens, G. (2005). Connectivism: A Learning Theory for the Digital Age. International Journal of Instructional Technology and Distance Learning. Retrieved from http://www.itdl.org/journal/jan_05/article01.htm

Slavin, R.E. (1996). Research for the future. Research on Cooperative Learning and Achievement: What We Know, What We Need to Know. Contemporay Educational Psychology, 21, 43-69.

Yuan, L. \& Powell, S. (2013). MOOCs and disruptive innovation: Implications for higher education. eLearning Papers, 33. Retrieved from http://www.openeducationeuropa.eu/en/download/file/fid/27007 


\title{
Learning Analytics for E-Learning Content Recommendations
}

\author{
A. S. Perera*, S. Tharsan* \\ *Dept. of Computer Science and Engineering, \\ University of Moratuwa, Moratuwa 10400, Sri Lanka.
}

\begin{abstract}
E-Learning systems have caused a rapid increase to the amount of learning content available on the web. It has become a time consuming and a daunting task for e-learners to find the relevant content that they should study. Existing e-learning technology lacks the automated capability to provide guidance for students to prioritize and engage in the most vital course content. The students who are unable to find out the most suitable resources, for their studies and the assignments, may waste most of their time on browsing and searching. Some of the "good-students" can indirectly act as good guides to other students. Average learners could follow the content adopted by good students in the process of learning. It is possible to capture the behaviour of "good-students" and expose it as a form of automated guiding. For this to work it is important to be able to predict students who are going to be successful at the end of the course based on their performance during the early part of the course. This work demonstrates the use of data mining techniques on e-Learning data to enable "Good-students” to indirectly guide “Average-Students" to find the most relevant content on an e-Learning environment.
\end{abstract}

Keywords: e-Learning; Learning Analytics; recommender systems; data mining;

\section{Introduction}

The popularity of e-learning has created a huge amount of educational resources and as a result locating suitable learning references is a formidable challenge (Lauria \& Baron, 2011). In a typical University e-learning environment, students are expected to follow all the course material that is available in the e-learning systems like Moodle and Sakai (Lauria \& Baron, 2011). But, when the time is limited for each course and with the availability of a large number of learning material they need to prioritize the items to maximize on the learning process. Excess amount of material lead the students to spend more time on browsing and filtering to identify information that suits their needs better, rather than on actually spending time on the content. If they are guided to select the most suitable learning material among all of the existing ones, they could spend more time in learning, than in browsing. Ability to identify "good learning material" is not easy for all the students. But it would not be a hard task for "good learners/good students" to choose "good learning material”. Hence, suggesting the "highly accessed materials" by the "good students" to the average students would help average students to get involved in studies rather than wasting time on searching. This work therefore aims to propose an intelligent recommender system that is based on the artificial intelligence gained from the access patterns of "good learners" to the students who are not capable of identifying relevant learning material that are suitable for their studies. The idea of learning from best students or good learners is also strongly supported by the Social Learning Theory, that states that people can learn by observing the behaviour of others and the outcome of their behaviour (Ghauth \& Abdullah, 2011).

This work used the weblog data generated by the Moodle learning management system which is installed at the Department of Computer Science and Engineering, University of Moratuwa, Sri Lanka, to analyse and build the prediction and recommender models. The Moodle log contains a rich set of data that can help to design and construct models for the recommendation system. 
Identifying the good students and recommending learning resources are two key problems dealt within the methodological framework. The quality of the learning material recommendations has an important effect on a student's future learning behaviour (Lu, 2004).

\section{Learning Analytics and Recommender Systems}

E-learning has been used for more than a decade. But recently learning analytics has received considerable attention in higher education (Lauria \& Baron, 2011). The continuous stream of weblog data being collected and stored in course management systems can be used as input to build the predictive models that can be used to implement data driven decision making systems. Despite the identification of the vast potential, learning analytics remains as an immature field that is yet to be explored broadly across a range of higher educational institutions, student populations and learning technologies (Lauria \& Baron, 2011 ; Monk, 2005; Castro, 2007). All access to a learning management system can be tracked. Course access logs contain all the student interactions in a chronological order, indicating when a given URL was requested by a particular client (Zaïane, 2001). Log files generally has the login name of the user who generated the request, the date and time of the request, the method of the request, the name of the requested file, the result of the request (success, failure, error, etc.), the size of the data sent, the URL of the page, data about the application and some information about the data exchanged between the client and the server. These log entries are not in a format that is usable for data mining. Data mining applications require reformatting and clean-up of data in order to identify the necessary information to build up the predictive models (Spiliopoulou, Faulstich, \& Winkler, 1999).

The Signals project at Purdue University, which applied the principles of business intelligence analytics to academia, facilitates to improve student success, retention, and graduation rates (Mazza \& Milani, 2005). The project mines a large dataset continuously and applies statistical techniques to predict which students might be falling behind. The warnings provided by the Purdue Early Warning System (PAWS) tend to be general in nature and does not include the resources available for a specific course. These warnings alert the students, but do not provide any learning material recommendations. Different technologies can be used to build recommender systems. Technologies in the area of data mining such as collaborative filtering, content based filtering, rule based expert system, artificial network and fuzzy logic can be used for this purpose (Ghauth \& Abdullah, 2011; Govaerts, et al., 2012; Lu, 2004). The recommender systems in (Ghauth \& Abdullah, 2011) suggests learning materials based on the average ratings given by good learners. Though it outperforms with respect to the accuracy of recommendations when compared with other frameworks, the drawback of this framework is, it requires explicit rating of learning material. It would be very hard to get the majority of the students to rate the learning material when they are hard pressed to complete the assigned work. In order to address the issue of explicitly collecting rating information automatic recommendation could be more atractive based on browsing patterns of other successful learners (Zaiane, 2002). The successful learners' have the capability to discriminate the relevant materials from a large collection of resources. Hence, if the access pattern of the good students is identified, based on that, the resources that are used by the good students can be recommended to the average students. 
The personalized recommendation approaches were first proposed and applied to ecommerce applications like many big web retailers, including Amazon.com and CDNow.com when the customers buy products. Providing personalized product recommendations would help the customers, to find products that they would like to purchase, by producing a list of recommended products for each given customer. Such recommendations are generated by the recommender systems, based on the analysis done, on the past transactions made by each customer (Lu, 2004). The content-based recommender systems has a common problem which requires a large set of key attributes. If the dataset is too small, obviously there is insufficient information to learn about the customer profile. Hence, if a customer visits the site, but has not made any purchase and the customer wants to buy a product which is not frequently purchased. In this case, what products need to be suggested, This is called a cold start problem(Ghauth \& Abdullah, 2011). (Lu, 2004) proposes a framework called PLRS for recommending learning materials to students who may have different backgrounds, learning styles and learning needs. The PLRS tries to identify a student's need, and how to accurately find the learning materials which match the student's need. The framework comprises four components, each with different purposes. 'Getting student information', 'Identifying student requirements', 'Learning material matching analysis and 'Generating recommendations' are the main four components of the PLRS.

It has also been suggested that e-learning environments have a psychological and physical cost, as it "may affect student performance due to cognitive overload caused by too much information to process multiple resources in a very short time and because of vision problems caused by spending long time to read the materials off computer screens (Monk, 2005).

Based on the literature review, this work attempts to build a resource recommendation framework based on access behaviour of good learners. Though recommendation based on good learners' rating is the ideal solution, it cannot be implemented in most of the current LMSs at the moment as this requires explicitly getting the rating feedback from the good learners.

\section{Methodology}

The objective of this research is to build e-Learning resource recommender system based on the behaviour of the "good-students" in a particular course. This requires two prediction systems. One system to predict the "good-students" based on the initial activities carried out by the students during the first few weeks of the course. And the other system is to be able to recommend suitable e-Learning content to be able to succeed in the course. Both systems are modelled using available data mining techniques by extracting patterns from completed e-Learning courses. Predictive analytics model development from data mining requires the data extraction, transformation, loading, training, and validation. In addition to the above data privacy also needs to be assured when building the model using actual data from completed courses.

\section{Dataset}

The dataset was extracted from a Moodle course management system used at the University of Moratuwa, Sri Lanka. Ten courses were selected in the area of computer 
science for the study and some characterisation information on the data is given in Table 1. Only a selected set of attributes from a total of 84 attributes are indicated in the table. In order to address the issue of privacy preservation the data was anonymized to avoid disclosure of sensitive data without removing the important patterns in the data based on (Zhang, et al, 2006). The input data was normalized using standard normalization techniques. And also the data was cleaned and integrated into a database based on a standard data warehousing schema that contains all the extracted data for the purpose of building the predictive models.

Standard data mining pre-processing steps were carried out to identify the impact of each of the attributes towards building the prediction model and a reduced set of attributes were selected out of the original 84 attributes for the respective prediction models. These attributes contained direct attributes and also derived attributes. For the student performance prediction model the selected most predictively influential attributes included the grade obtained by students for assignments, number of forum discussions, number of wiki entries made by the student, number of completed assignments, number of visits to the course page, number of resources accessed by the student, and the number of resources accessed by the students close to deadlines. For the resource recommendation model attributes such as the file size of the resource, location of the resource with respect to the other resources within the week, week on which the resources was made available for students, and resources accessed by the good students were some of the attributes that were predictively influential. The input dataset was also appropriately split into a training and validation set.

Table 1 Descriptive Characterization of Input data

\begin{tabular}{|c|c|c|c|c|c|c|}
\hline $\begin{array}{c}\text { Course Code and } \\
\text { Year }\end{array}$ & $\begin{array}{c}\text { No of } \\
\text { Students }\end{array}$ & $\begin{array}{c}\text { Average } \\
\text { Final } \\
\text { Grade }\end{array}$ & $\begin{array}{c}\text { No of Open } \\
\text { Discussions }\end{array}$ & $\begin{array}{c}\text { No of } \\
\text { Discussion } \\
\text { Replies }\end{array}$ & $\begin{array}{c}\text { No of Wiki } \\
\text { Entries }\end{array}$ & $\begin{array}{c}\text { No of } \\
\text { Assignments }\end{array}$ \\
\hline CS5105ISec-2008 & 42 & 78.32 & 99 & 56 & 164 & 5 \\
\hline CS5105ISec-2009 & 40 & 79.14 & 7 & 189 & 214 & 4 \\
\hline CS5404CNS-2010 & 32 & 75.07 & 110 & 71 & 252 & 5 \\
\hline CS5105ISec-2010 & 31 & 76.41 & 19 & 97 & 127 & 4 \\
\hline CS5401SND-2011 & 29 & 46.95 & 44 & 34 & 81 & 2 \\
\hline CS5404CNS-2011 & 29 & 71.85 & 37 & 45 & 196 & 6 \\
\hline CS5105ISec-2011 & 23 & 76.19 & 12 & 56 & 98 & 3 \\
\hline CS5404CNS-2012 & 31 & 72.65 & 73 & 80 & 204 & 6 \\
\hline CS5105ISec-2012 & 24 & 78.59 & 22 & 72 & 90 & 5 \\
\hline CS5404CNS-2009 & 33 & 76.90 & 133 & 47 & 451 & 5 \\
\hline
\end{tabular}

\section{Data Mining for Predictive Models}

In the process of data mining for predictive models it is important to evaluate multiple techniques to identify the most appropriate technique (Han, et al, 2012). This work evaluated Decision Tree, Neural Networks, SVM, k-NN, Naive Basis, Rule Induction, Perceptron, Linear Regression, Polynomial Regression, Vector Linear Regression, and Gaussian Process in standard forms as available in literature (Han, et al, 2012).

The respective accuracy values for the predictive models are shown in Figure 1. As indicated by the figure most of the classification techniques are providing a significantly high accuracy. All the classification techniques were executed multiple times with different settings to obtain the maximum possible accuracy. Also this shows that the data pre-processing steps carried out on the input data have been successful in extracting the most relevant data for the purpose of building the classification model. 


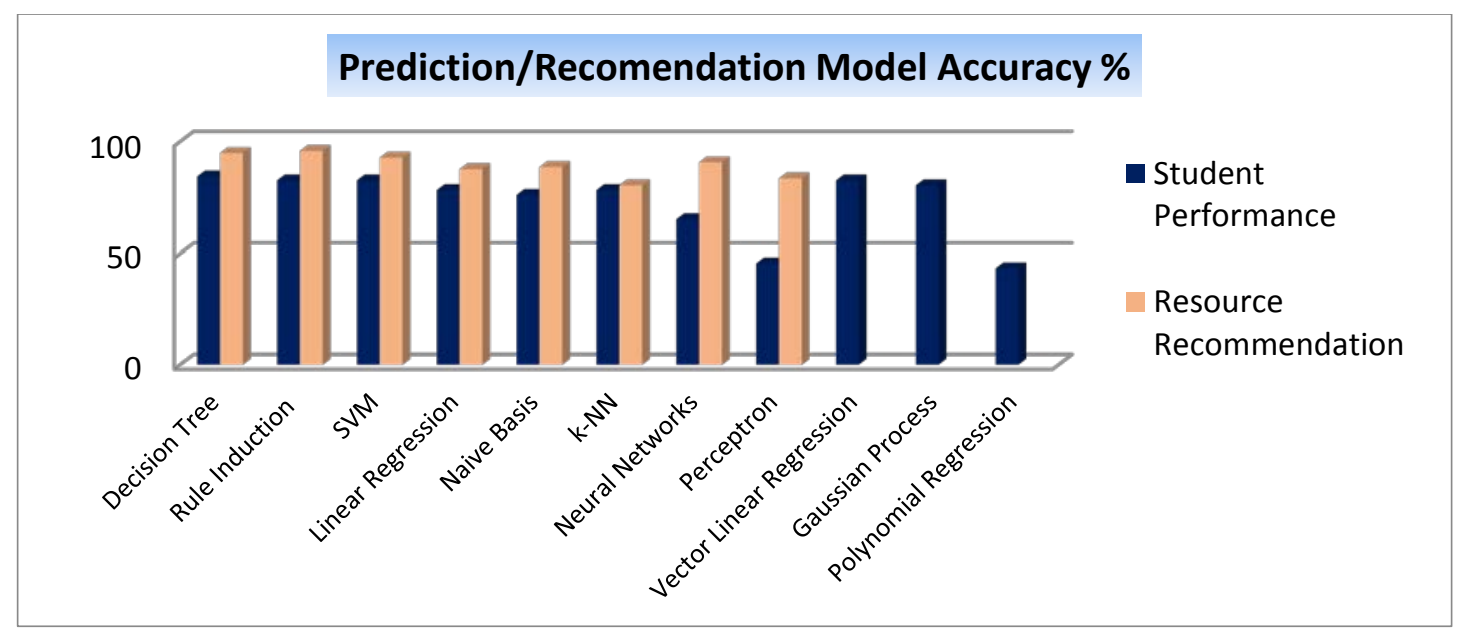

Figure 1 Prediction Model Accuracy

\section{Results and Discussion}

High accuracy levels indicated on figure 1 clearly indicates the ability to use data mining techniques for the purpose of building a recommender system for students engaged in eLearning courses. Out of the Data Mining techniques carried out Decision Trees shows the highest overall accuracy for both predictive models and can be suggested as the technique to be used for a future recommendation application to be built based on the work presented on this paper. Decision Tree algorithm extracts rules based on the patterns in the data in the process of building the predictive model. One major advantage of Decision Tree approach is that human domain experts can look at the rules and formulate an interpretation of the rules to further validate the predictive models. Also these rules can be very easily implemented on the e-Learning platform to execute on the existing database to perform the recommendation tasks. It is very important to have light weight predicative technique to reduce the workload on the e-Learning computing environment.

The predictive models described in this work could be implemented as a plugin for the Moodle that would recommend the resources to the students who require assistance to identify the most relevant materials. It is also possible to use the student performance classification model as a standalone application with some slight modifications as an early warning system to identify the students who are at a risk of failing, so that they can be monitored with close surveillance. Same ideas can also be extended to Massive Online Open Courses (MOOCS) as an additional feature to recommend resources based on other users. One minor drawback of the application of the system would be the loss of opportunities for students to gain experience in searching for content. Applicability of the proposed learning analytics to other subject areas other than computer science needs to be also evaluated as future work.

\section{Conclusions}

An additional benefit that can be provided for students in an eLearning environment is ability to recommend the most appropriate resource for the learning process. All academics expect all students to go through all the learning material given on course webpages. But in practice most of the time students do not have sufficient time to go through all the resources and would be at an advantage if the student has some from 
of guidance to identify the most appropriate resource from the list of resource available on the course page. The proposed solution has the capability to provide individualised automated feedback and guidance for students to prioritize and engage in the required course content. This will allow students who do not have knowledge to find out the most suitable resources, links and references for their studies and the assignments, without wasting time. The proposed solution captures the behaviour of "good-students" to indirectly act as "good" guides to their fellow students. The process and the data mining models described in this work can be used to identify "good-students" in a class before the final exam and use their access pattern as a guide and a recommender with high accuracy. The student performance prediction has an accuracy of $85 \%$ and the recommendation system has an accuracy of $95 \%$ based on the validation conducted on the input data. It is important to note that the high accuracies are obtained through a process of a rigorous data pre-processing based on the dataset available for this study. The pre-processing process and the predicative models can be implemented on any e-Learning environment that produces similar data.

\section{References}

Castro, F., Vellido, A., Nebot, À., \& Mugica, F. (2007). Applying Data Mining Techniques to e-Learning Problems., Evolution of Teaching and Learning Paradigms in Intelligent Environment, 183-221.

Ghauth, K. I., \& Abdullah, N. A. (2011). The Effect of Incorporating Good Learners' Ratings in e-Learning Content-based Recommender System, Educational Technology \& Society, 14(2), 248-257.

Govaerts, Verbert, Duval, \& Pardo S., "The student activity meter for awareness and self-reflection," in CHI '12 Extended Abstracts on Human Factors in Computing Systems, ACM, New York, NY, USA, 869-884.

Han J., Kamber. \& Pei, j. (2012). Data Mining: Concepts and Techniques (3rd ed.). Morgan Kaufmann Publishers.

Lauria, E. J. M., \& Baron, J. (2011). Mining Sakai to Measure Student Performance, Opportunities and Challenges in Academic Analytics.

Lu, J. (2004). Personalized e-learning material recommender system. In In: Proc. of the Int. Conf. on Information Technology for Application 374-379.

Mazza, R., \& Milani, C. (2005). Exploring Usage Analysis in Learning Systems: Gaining Insights from Visualisations, AIED Workshops (AIED'05), 65-72.

Monk, D. (2005). Using data mining for e-learning decision making. Electronic Journal of E-Learning, 3, 41-54.

Spiliopoulou, M., Faulstich, L. C., \& Winkler, K. (1999). A Data Miner analyzing the Navigational Behaviour of Web Users. Proc. of the Workshop on Machine Learning in User Modelling of the ACAI99.

Zaiane, O. R. (2002). Building a recommender agent for e-learning systems. International Conference on Computers in Education, 2002. Proceedings vol.1, 55-59. 


\section{HEAd'15}

\section{SESSION 2B}

\section{LINGUISTICS}




\title{
E-learning methodology in English language courses for employed adult learners in Slovakia
}

\author{
Valéria Medárová \\ School of Management / City University of Seattle, Bratislava, Slovakia, vmedarova@vsm.sk
}

\begin{abstract}
The paper analyses e-learning methodology in language education in the specific category of Slovak adult learners with work experience. The current labor market situation in Slovakia puts pressure on employees to develop their language skills, mainly in the English language. The research focuses on application of adaptive e-learning methodology for this specific learner category. A studied group of learners took part in a free pilot course of the English language for intermediate learners, which was designed as an on-line course in the learning management system Moodle. The outcomes of the pilot course and the following learner feedback showed many interesting learning tendencies and motivational backgrounds of adult language learners. The research has revealed various challenges of online language courses, such as high drop-out rate, lack of human contact, poor time management and others. In summary, if properly designed and managed, online language courses for adult learners have a great potential in career development.
\end{abstract}

Keywords: e-learning; language learning; course design; adult learner; employee education; Moodle

\section{Introduction}

E-learning in the workplace has great potential since development of the knowledge society is unimaginable without life-long learning. In Slovakia, employee training using e-learning technology is still not widespread or fully developed. This limitation is even more obvious in language learning with the use of e-learning technology and methodology.

The author of the paper analyzes conditions of effective employee training using elearning technologies and the most common obstacles that hinder the education process in the workplace. The area of the author's research is the possibility of effective introduction of e-learning in language education in the specific category of Slovak adult learners with full-time employment. This category of learners has been selected due to their specific learning needs and limitations. As fully-employed adults, they do not have easy access to language education in the traditional format of language courses. However, the current job market and the overall economic situation in Slovakia put pressure on Slovak employees to develop their language skills, mainly in the English language. The language learning system in Slovakia has still not sufficiently met those learning needs.

The research focuses on application of adaptive e-learning methodology for this specific learner category. The goal is to propose a set of efficient learning tools that can provide the right content to the right person at the right time.

\section{Methods}

We have developed an online English language course, which serves as a testing environment for various e-learning tools and linguistic methodologies. Participants of the course represented a sample group of Slovak adult learners with full-time employment or work experience. They had various career backgrounds and levels of experience with language learning. We observed their learning process, learning styles, frequency of study, study results, and other factors. The observed factors lead to the 
hypothesis that the right combination of computer technology and human element in teaching languages is justifiable and effective.

\section{Design of the Pilot Online Course of English for Intermediate Learners}

The pilot online course of English was created to verify effectiveness of various elearning tools and their adaptability to individual learner needs. It was conducted on the online learning portal Moodle, as an unofficial language course of the School of Management. The course was divided into 6 weeks - 6 modules. Each module contained a set of various learning activities focused on several language skills and language components, including grammar explanation, vocabulary on specific topics, reading passages, interactive listening activities, and video files. Grammar explanation files consisted of pdf files with explanation created by the course instructor, as well as video explanation of grammar elements and interactive grammar exercises available on various free online educational portals. Reading passages were selected from various available online and textbook sources. Vocabulary lists were either created by the course instructor or adopted from textbook sources. Listening exercises and video files with recorded real-life conversations were selected from several available language learning websites. Variety of learning tools is crucial. Using many methods of explanation that match learners' needs can solve the problem of low motivation and difficulties with understanding study topics (Melicheríková \& Bušíková, 2012).

To stimulate learners' interaction, we created a discussion activity in the form of online chat forum enabled by Moodle, where the contributors could give their opinions on topics of the week. Also, the learners had a possibility to practice their speaking skills in Skype interviews with the instructor once a week, during a 15-minute conversation, which was adjusted to individual speaking skills and vocabulary of each learner. Each week/module was concluded by a short online quiz/exercise designed by the course instructor. Every end-of-week test contained 20 grammar and vocabulary questions related to the topics of the previous week. It was possible to do each quiz 3 times, at any time before Week 6 of the course, giving a learner a chance to test his/her gained knowledge repeatedly.

Course participants were selected from a pool of interested people who took a simple grammar/vocabulary test for pre-intermediate learners. All the participants were adults, employed in various companies in Slovakia or having work experience in a company in Slovakia. The course was very open and user-friendly (the pilot course was completely for free), which means the learners could choose their pace and frequency of study - which activities they will do, how many times they will do them, and when they will do them. For example, a learner could choose to do all the activities for the given week in the proposed order or do only some of them in random order. Also, a learner could choose to be passive for several weeks and then catch up with the missed course material later on. This rather open and flexible approach to individual learning progress is justified by the belief of many researchers. For example, Sanchez-Villalon et al. (2010) state that learners should become developers of their own learning path, while tutors should act as their guides and help them develop their critical thinking. 


\section{Results and Discussion}

\section{Outcomes of the Pilot English Course}

The first pilot course of English in the online format was running in July - August 2014, with 15 participants. The second pilot course, with 20 participants, lasted from October to November 2014. The content, assignments, and schedule (distribution of learning activities within 6 week-modules) of both courses was exactly the same. In the first pilot course, 9 out of 15 participants completed the course and took the final online test. In the second course, 7 out of 20 participants completed the course, including the final test. The final test contained 50 multiple-choice questions related to vocabulary and grammar covered in the course. The questions were a selection and mix of questions taken from 6 previous end-of-week tests, which concluded each particular course module (course week). Individual grades for the final tests were calculated immediately after completion and they ranged from $60 \%$ to $98 \%$, the average grade being $87.0 \%$. We can consider it a high success rate.

The course participants used the possibility to select learning activities and do them repeatedly as they wished. Also, they took the chance to skip some of the activities if they did not feel they were interesting for them. For example, only a few learners participated in online discussions and only a limited number of them used the opportunity to conduct an interview with the instructor via Skype.

Also, some of the students did not follow through to the last $\left(6^{\text {th }}\right)$ week of the course and interrupted their study after a few weeks. The main reason, as stated in a learner feedback survey, was lack of time for study caused by work duties and various personal issues. The first pilot course was organized in the summer season; therefore, some of the participants could not finish it or complete all the activities due to their summer travel plans. Table 1 shows the drop-out rate of the participants during the 6-week course.

Table 1. Drop-out rate during two 6-week pilot courses.

\begin{tabular}{|c|c|c|}
\hline & $\begin{array}{c}\text { Remaining number } \\
\text { of active participants }\end{array}$ & $\begin{array}{c}\text { Remaining } \\
\text { active participants in \% }\end{array}$ \\
\hline after Week 1 & 26 & 74.2 \\
\hline after Week 2 & 23 & 65.7 \\
\hline after Week 3 & 21 & 60.0 \\
\hline after Week 4 & 20 & 57.1 \\
\hline after Week 5 & 19 & 54.2 \\
\hline
\end{tabular}

Despite these facts, we consider the number of participating students (16 out of 35 completed the course) and their final course results as success, taking into consideration the fact that the student sample was very varied and randomly chosen.

The purpose of end-of-week tests was to give learners an opportunity to practice grammar and vocabulary topics covered in the given week and, at the same time, to verify their acquired knowledge. In design of both end-of-week tests and the final (end- 
of-course) test, we used a test-design tool of the Moodle system, which automatically evaluates students' responses. The learners could take each end-of-week test repeatedly, up to 3 times, at any time during the course. Thus, they could "learn on their mistakes" and improve their test results. As Yousefzadeh (2010) states in analysis of computer-based feedback in language learning courses, the most beneficial feedback for language learners is feedback provided immediately, which is especially challenging in a big student group with various ability levels. In this aspect, learning management systems prove to be very efficient.

Table 2 shows actual participation rate in specific online activities of the course. The learners were mostly interested in grammar explanation, reading passages, and grammar exercises. In addition, many of the learners "clicked on" the relevant links more than once and went back to them if they found them very useful. On the other hand, class discussions and video links were the least popular in the observed group of learners. Low participation in discussion may be caused by lack of time or human factors, such as fear of making mistakes in English and "losing face" in front of other participants. Low interest in video links is rather surprising. We suppose one of the reasons could also be psychological - fear of not being able to follow "real life" conversation in the English language. Also, since the number of "clicks" on video files started dropping after Week 3, we can assume that the learners gradually lost interest in the topics of the recorded conversations.

Table 2. Participation in online course activities and assignments in two pilot courses.

\begin{tabular}{|l|c|}
\hline \multicolumn{1}{|c|}{ Activities and Assignments } & Participation of students in \% \\
\hline Reading Passages & 62.3 \\
\hline Vocabulary Lists & 57.7 \\
\hline Grammar Explanation & 67.6 \\
\hline Grammar Exercises & 58.0 \\
\hline Listening Activities & 55.2 \\
\hline Videos with Conversations & 36.1 \\
\hline Class Discussions & 25.2 \\
\hline End-of-week Tests & 40.0 \\
\hline End-of-course Test & 45.7 \\
\hline
\end{tabular}

\section{Learner Feedback on the Pilot English Course}

After each of the two pilot courses, we conducted a feedback survey in which the participants evaluated effectiveness of various learning tools and the overall quality of the course. The questions concerned individual types of activities related to: grammar explanation and exercises, reading passages, listening skills, comprehension of videos, 
vocabulary lists, online quizzes at the end of each module, online discussions, and Skype interviews. Most questions required response in the form of the Likert scale (from 1 to 5), while some were open questions, such as naming 3 most effective and 3 least effective learning activities.

We received 7 filled-out questionnaires from the participants of the first pilot course (the pool of 15 learners) and 8 responses (the pool of 25 learners) after the second course. In addition, we obtained comments in a form of e-mail reaction from 3 more course participants. As we expected, the responses reflected various personal learning styles, preferences, time constraints, work duties, and other limitations the learners were dealing with during the course. For example, when asked to choose 3 most effective and 3 least effective learning activities, the respondents gave overlapping answers, that is activities like videos and discussions were judged as productive by some learners and as unproductive by others. However, all the respondents agreed that the course contributed to improving their English speaking skills, and that Moodle portal is a suitable environment for a language course.

Most verbal comments on the pilot course were very positive:

"Some of the articles were interesting, bringing new information."

"I liked that I could test my knowledge in online quizzes."

"All the activities seemed very useful. We could practice everything because there were so many possibilities."

"I like discussions, where I could write my opinions."

"It was a demanding course, but I reviewed a lot of my knowledge and I learned a lot of new things... That was possible thanks to a variety of activities."

"One of the advantages was that I could study at home. I didn't need to go anywhere."

"I liked the fact that I was not limited by time. I could do the activities when I had time

- in the morning, in the afternoon, or late at night."

On the other hand, some negative comments referred to the following issues:

"Participation in online discussion was very low, and students' contributions were too short."

"A disadvantage was a missing contact with classmates. There was an online discussion forum where we could contribute, but the learners did not use it much."

"I didn't find videos with conversations very meaningful."

"I didn't have time to do the last two online quizzes while they were open, which is my fault... I am sorry there was no chance to do them later."

The final question in the survey focused on the preferred form of studying the English language. There were three choices:

1. in-class course with a teacher and classmates

2. individual (face-to-face) classes with a teacher

3. purely online course

4. online course with Skype interviews

5. online course combined with face-to-face consultations with a teacher (blended course) 
The responses varied here, too. Some respondents picked more than one choice. As a result, the most attractive choices proved to be the possibilities \# 4 (6 votes) and \# 5 (6 votes) - an online course with Skype interviews and a combination of online course and consultations with a teacher, followed by the possibility \# 1 - a traditional in-class course with a teacher and classmates (4 votes).

In summary, the survey of user satisfaction gave us an interesting picture of effectiveness of the applied e-learning tools. The learners appreciated the flexibility of the online study format as well as the opportunity to choose from a wide selection of learning tools and match them conveniently with their specific learning styles.

A significant number of survey respondents would welcome learning the English language in the online or blended format in the workplace. This research outcome proves a big potential of e-learning and adaptive learning methodology in foreign language education in Slovakia.

\section{Implications for e-learning in the Workplace in Slovakia}

Application of e-learning tools in education in Slovakia is not common practice in corporations and organizations. Therefore, e-learning has not fully fulfilled its potential yet. Small and medium-sized organizations all over the world face similar obstacles to implementation of effective e-learning programs in the workplace. Our research of this topic has led to realizing 4 main categories of barriers to implementation of e-learning in SMEs. These are: conceptual barriers, organizational barriers, technology, and the human factor. The conceptual barriers are related to definition of the purpose of elearning in the organization and its alignment with the organization's needs. The organizational barriers include planning, communication, funding, control and improvement, and application of skills. Technological barriers are related to quality, support, and update of information and communication technology (ICT) and communication media. Last but not least, individual and social factors play a significant role in application of e-learning in the organization (Medárová et al, 2012).

The learner feedback of the pilot online English courses showed the human factor as an even more significant issue or barrier to learning than we had expected. It was reflected in lack of time devoted to study and early drop-out rate (as shown in Table 1).

\section{Conclusions}

Based on the pilot course outcomes and feedback responses, we can conclude that the online format has a great potential and offers many promising opportunities for learning a foreign language, especially for working (and busy) adults. However, there still is a significant need of personal communication and contact with people, whether it takes places online or in real life.

Our study is limited by a small sample of learners and a relatively short period of observation of the learning process (the course took place two times). Further research is needed to clarify motivations and fears of adult learners as participants of online language courses.

Successful design and application of online language courses for working adults requires suitable criteria for selection of learners (pre-tests), appropriately designed 
course content (a balanced selection of various skill-oriented learning tasks and feasible amount of workload in a limited time - weekly modules), and more opportunities to provide individualized feedback to learners. Also, it is necessary to find ways to motivate adult learners to work consistently and avoid early drop-outs or interruption of study.

To sum up, there are still many challenges ahead of us if we want to improve the quality level and efficiency of e-learning in language education. In this effort, we should take into consideration a complex of linguistic, pedagogical, technical, organizational, and psychological factors, which can present both benefits and obstacles to online learning.

\section{References}

Medárová, V., Bureš, V., \& Otčenášková, T. (2012). A review of obstacles to successful e-learning deployment in SMEs. Journal of Innovation Management in Small \& Medium Enterprises, Vol. 2012, 9 pps. Available at http://www.ibimapublishing.com/journals/JIMSME/2012/715039/a715039.html

Melicheríková, Z. \& Bušíková, A. (2012). Adaptive e-learning - a tool to overcome disadvantages of e-learning. In Emerging eLearning Technologies \& Applications (ICETA), 10th International IEEE Conference. IEEE, Stará Lesná, 263-266. ISBN: 978-1-4673-5120-1.

Sanchez-Villalon, P.P., Ortega, M., \& Sanchez-Villalon, A. (2010). Multimedia integration for language e-learning: Content, context and the e-dossier. US-China Education Review, (7)8, 1-10.

Yousefzadeh, M. (2010). Computer-based feedback vs. instructor-provided feedback and second language learners' reading comprehension. International Journal of Instructional Technology and Distance Learning. (7)7. Available at: http://itdl.org/Journal/Jul_10/article03.htm 


\title{
Linguistics in Fashion: Explaining Concepts with Visual Metaphors
}

\author{
S. Sonina \\ University of Toronto Scarborough
}

\begin{abstract}
This empirical project, a study of the effect of metaphors and games on the learning process, is related to my research on fashion terminology but focuses on student-professor or student-computer interactions. The project emphasises similarities between fashion and language systems and explores the effect of comparisons between grammar and fashion, as well as associated play activities, on the learning process. This article gives a few examples of visual metaphors used for teaching different aspects of linguistics and explains how they work to facilitate the -learning process and to capture students' attention. Applied to linguistics, these empirical findings will hopefully provide inspiring examples and serve as models for exploring visual metaphors in the teaching of other disciplines.
\end{abstract}

Keywords: innovative materials; new teaching/learning models

\section{Introduction}

For at least a century, research in psychology has proven that human memory works better with the aid of pictures than with that of words or numbers (Ozick, 1989), and yet textbooks for higher education rarely provide pictures to illustrate difficult concepts. Linguistics textbooks practically never do so. Fortunately, PowerPoint presentations allow teachers to bring images to the classroom, thus making the process of instruction and learning both more engaging and more memorable. In my teaching practice, I have developed a format that not only uses separate images but that also combines them into rather elaborate visual metaphors to help illustrate and explain complex linguistic concepts.

My interest in metaphor and ludolinguistics (Mollica, 2010) is rooted in my education in a school of fine arts and in my experience teaching students of the "Net Generation" (Tapscott, 1998). To understand my students better, I have often analysed my own learning experiences and come to the conclusion that the most memorable courses of my life were the ones in the art school. These courses differed from other classes in two key ways: there was a sense of aesthetic involved, and the classes were interactive. According to Don Tapscott, the new generation prefers interactive entertainment (video games and web surfing) to passive entertainment (television). My teaching experience confirms that our students prefer interactive exercises and enjoy playing games or matching pictures with concepts. But do they in fact learn the grammar better when I use visual metaphors, games, and give them interactive and creative exercises as homework?

In this article I will briefly describe my own experience of using visual metaphors in French linguistics courses. The main goal of this undertaking is to encourage teachers in higher education to use metaphors by showing that a little extra work is worth the effort here. My secondary objective is to contribute to the discussion about the use of PowerPoint in the classroom by forwarding a few arguments in its favour.

\section{Methods}

The methods used for the evaluation of the effect of visual metaphors on students' understanding and memory include specific questions added to customary course evaluations, 
simple surveys, and an analysis of students' success on tests and, especially, on quizzes designed specifically to check the understanding of the concept explained.

The creation of metaphors themselves technically requires only basic skills in working with PowerPoint presentations, mainly copy-paste or enlarge-minimize, as well as the ability to search the Internet and choose pictures that lend themselves to being combined into complex images. By way of basic advice for the choice of pictures: high-resolution images with a good colour contrast usually prove the best.

\section{Results and Discussion}

The importance of visual representations became apparent to me when I began working as a lecturer of French after the completion of my thesis on the process of denomination in fashion terminology. While participating in teaching and learning seminars, I was taken by by the idea of incorporating research into teaching, but linguistic material seemed too complicated to present to students in a general language course. Thus I had the idea of using fashion concepts and pictures to illustrate grammatical notions. To my own surprise, this process worked extremely well: not only did the students show greater interest in grammar; they also seemed to better comprehend it when I employed fashion illustrations as metaphors for style or syntactic structures. Later on, these metaphors proved invaluable for the teaching of linguistics.

\section{Fashion metaphors in the presentation of language structure}

To define the object of study in a linguistics course - Phonology, Morphology, or Syntax - it is necessary to give students an idea about its place within the field of study. It is not difficult to describe language studies in words, but outlining the whole picture of the discipline takes time if a teacher uses comprehensive examples, and it can become boring and insufficient if, on the other hand, a teacher does not take the time to provide proper examples for claims. Comparing language and fashion as two semiotic systems can prove quite convenient for the first presentation of the course. I, for example, use pictures representing clothing and linguistic terms to describe the branches of linguistic science.

The slide below (Figure 1) introduces the object of study in the course FREB45, French Morphology and Syntax, and requires only a brief explanation and appeal to students' imagination to compare the two systems: just imagine that the sounds of the languagephonemes-represent fabric; then we can from that cut out significant parts of words, morphemes, which, in turn, can be put together into words, just like items of clothing are sewn together. The words can subsequently form phrases and sentences, just like clothing items will constitute an outfit, and phrases can be organised into a speech, just like costumes can be assorted for a show. These few words, accompanied by pictures gradually appearing on the screen, suffice to introduce the course and give a clear image of its place within linguistics: morphology and syntax occupy its very core and help examine the structure of its main units, words and sentences.

Fashion pictures prove even more illustrative for the representation of stylistic levels of speech. 


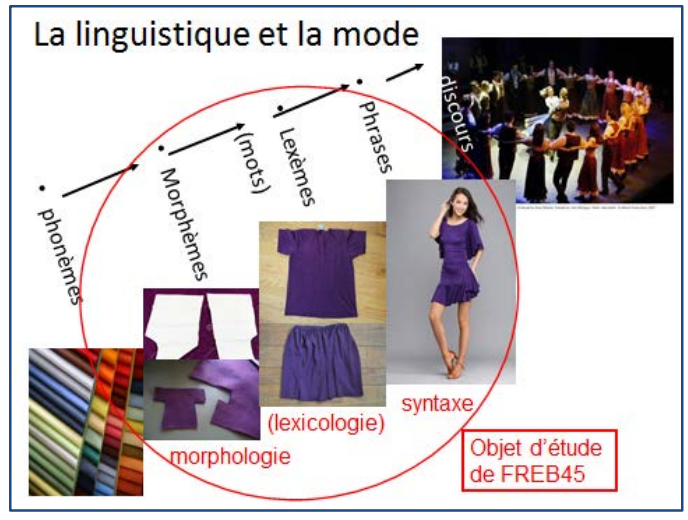

Figure 1. Branches of linguistic science

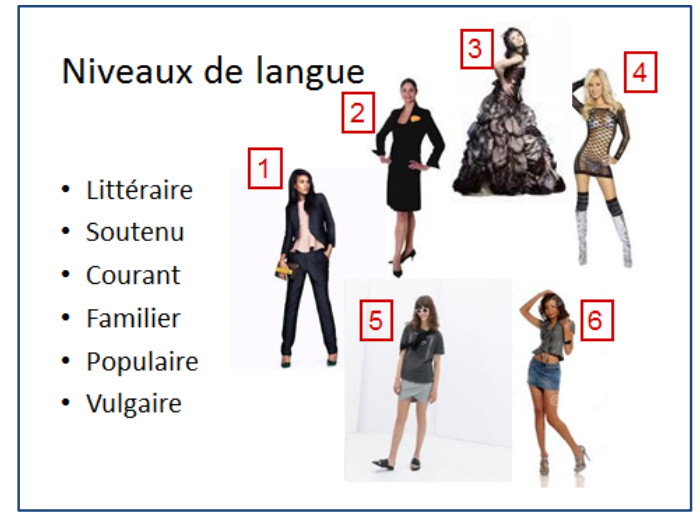

Figure 2. Stylistic levels in language and clothing

The comparison in Figure 2 also offers an opportunity for an interactive activity: I ask students to match the styles of language with the styles of clothing in the pictures. It helps engage them, explains the new terminology, and teaches a few things about French culture, because the activity inevitably leads to a short discussion about French fashion and European dress habits.

Once the comparison between language and fashion has been established, the metaphorical associations can be continued in a kind of semiotic game: each group of students is given the task of finding a correlation in style-literary, formal, regular, informal, low-key, and vulgarin all language and fashion components: pronunciation and the choice of fabrics; the choice of words and the selection of clothing items; the careful or careless matching of words and garments. The game provides a lot of fun and creates vivid memories about the correspondences. Students later even reported that-well beyond giving them a better understanding of levels of language - the comparison made them more aware of their habits of both language and dress.

\section{Fashion metaphors in the presentation of word structure}

In morphology, it is usually trickier to explain the linguistic terminology used to discern the structure of complex words than to teach the analysis of the structure itself. The distinction between the root (racine) and the stem (radical) somehow does not embed itself in students' minds easily. In my experience, they kept confusing the terms until I came up with a seemingly natural way to represent them through images of actual vegetable roots and stems, as in Figure 3.

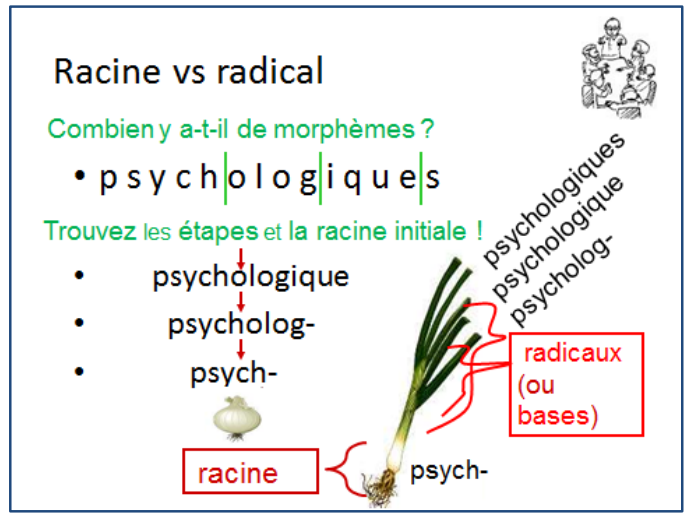

Figure 3. Root (racine) and stem (radical)

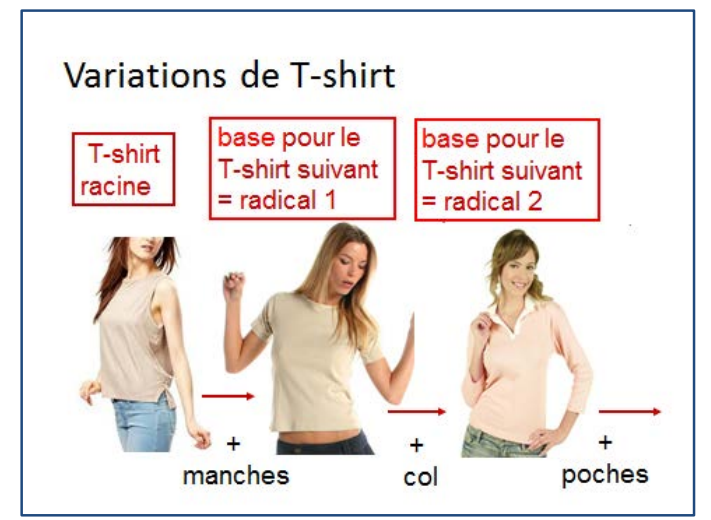

Figure 4. Root (racine) and stem (radical) in fashion 
However, some students particularly interested in fashion asked for a clothing analogy, and for the review, I had to come up with a new image (Figure 4), which helped to explain the concept further.

The root would be an item's initial, basic structure: on the one hand, it cannot be simplified without being destroyed; on the other, many further elements can be added to it-which transforms the original item, though it recognizably remains the main element in all garments of the same type. In the same way, the root of a word is the initial part that cannot be divvied up further and that can be recognized in all words built on it.

On the test I gave on the topic, students made no mistakes in the use of the terms, displayed a good understanding of the matter in most term definitions, and generally succeeded in identifying the root of complex words correctly.

\section{Fashion metaphors in the presentation of phrase structure}

The study of syntax provides even more opportunities to create metaphors and activities that use images of fashion. It is usually considered sufficient to simply provide examples (Figure 5) to illustrate the notion of verbal valence-a verb's capacity to take arguments (subject and complements), called thematic roles or $\theta$-roles in linguistics.

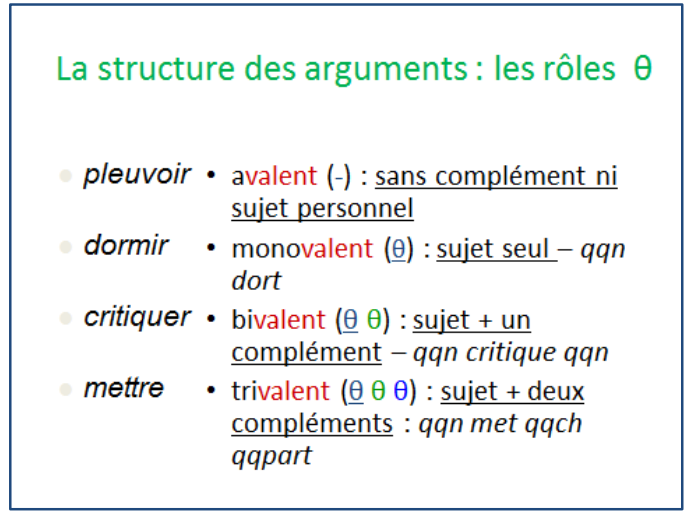

Figure 5. French examples for verbal valence

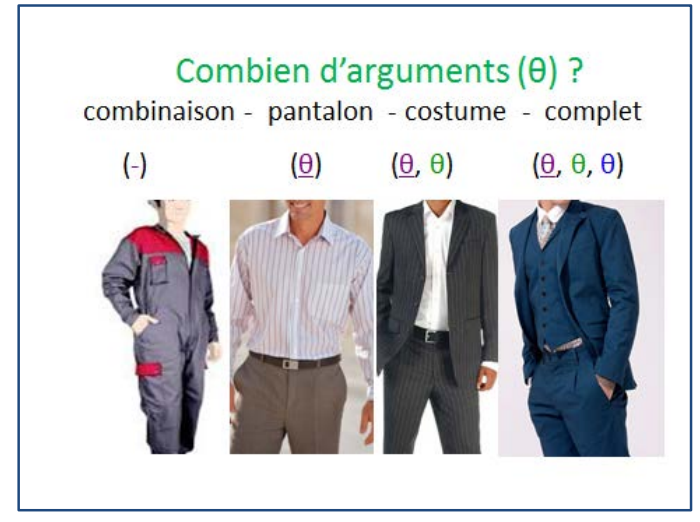

Figure 6. Fashion examples illustrating verbal valence

Yet students tend just to learn the examples without realising the conceptual importance of valence-it forms part of verbal meaning, of its nature, and verbs can be divided into classes according to this important characteristic. In the past, I used the chemical concept of valence as an explanation, but my efforts helped only those who had studied chemistry before, while tending to complicate things even more for those who had not.

Fashion metaphors (Figure 6) work for everyone and provide the groundwork for an interactive task: match a verb to a garment according to the number of $\theta$-roles it can accommodate. Verbs may require complementary items to fulfil their function in a phrase, just like articles of clothing may require other garments to constitute an outfit: a verb with a zero valence can be used by itself or with a purely grammatical subject (it rains), just like an overall is sufficient by itself; most verbs need a proper subject (somebody sleeps) to constitute the basis of a phrase, just like a pair of pants is usually complemented by at least a shirt. Many verbs take two arguments - a subject and a complement (somebody criticises something), just like suit pants demand both a shirt and a jacket. Quite a few verbs need to fill at least three $\theta$-roles to have a proper meaning (somebody puts something somewhere), just like a suit called complet in French always includes a vest besides the typical shirt and jacket. 
The interactive activity in class consists of assigning one of the pictures from the slide to each group of students, giving them a list of French verbs and asking them to identify all the verbs on the list that have the same number of $\theta$-roles as the clothing item on their picture. It makes the activity more fun than just choosing the verbs from the list, and, most important, it makes students understand that the verbs would not work without their arguments, just like some clothing items do not work without additional garments.

The same analogy helps explain that not all arguments of a verb (called "complementizers" in generative grammar) have an equal value: some of them are absolutely necessary, while others are optional, just like a T-shirt (Figure 8) seems like an absolutely necessary addition to the skirt, whereas a vest might complement these two garments or not. The slide in Figure 7 provides illustrations for a playful group activity to help distinguish compulsory and optional garments, after which students tend to follow the syntactic representation of compulsory and optional complementizers (Figure 8) with greater attention and interest.

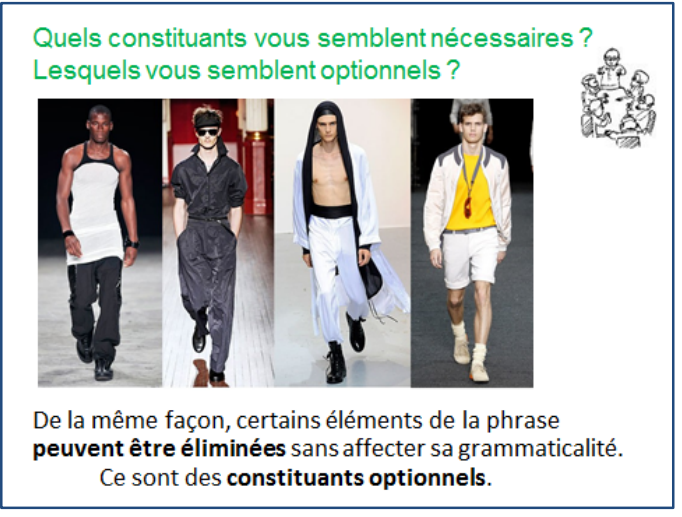

Figure 7. Optional and compulsory complementizers

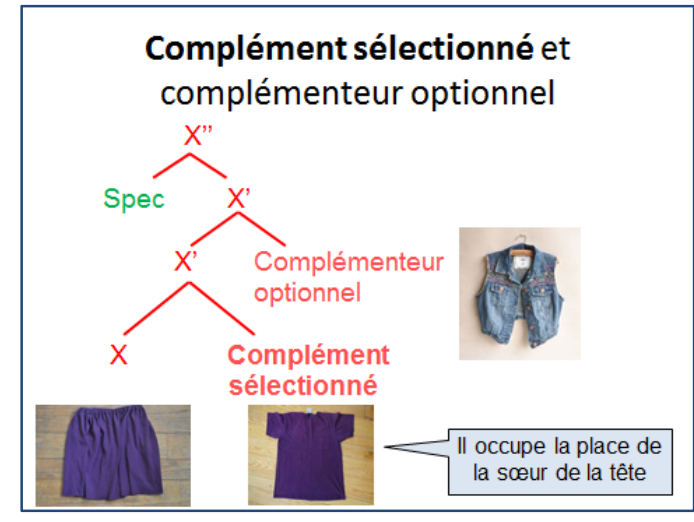

Figure 8. Complementizers in syntax and fashion

Fashion analogies provide a familiar element when we venture into representations of syntactic structures using syntactic trees and X-bar theory. We must convey to students that-despite their more complicated appearance with numerous symbols like $X^{\prime}$ and $X^{\prime \prime}-X$-bar representations actually simplify syntactic trees because they repeat the same structure over and over. In figure $9, \mathrm{X}$ is a variable replaced by $\mathrm{N}$ that stands for 'noun' to represent the structure of the noun phrase une jupe plissée (a pleated skirt) that includes one specifier and one complementizer - an article and an adjective/participle.

The picture of the same skirt in the middle of Figure 10 is associated with average length, and a description of this skirt provides an example of the most typical nominal phrase "a pleated skirt," where the noun "skirt" is used with a specifier, the article "a", and a complement, the adjective "pleated." Now this basic structure can be amplified with many complements of different natures, both in reality and in description- "a bicoloured, ankle-long pleated skirt," so that the corresponding syntactic tree gets longer, like the skirt on the picture. Yet the same basic structure $X$ ”- $X$ ' - X, in which the element " $X$ ' + Complement” is repeated several times, remains. In the same way, a skirt can be stripped of all its details, and the word "skirt" can be used without any specifiers or complements, as in a catalogue heading, for example. In its syntactic representation, however, we should still keep all three basic elements X”- X' - X, even if only to maintain the consistency of the representation. 


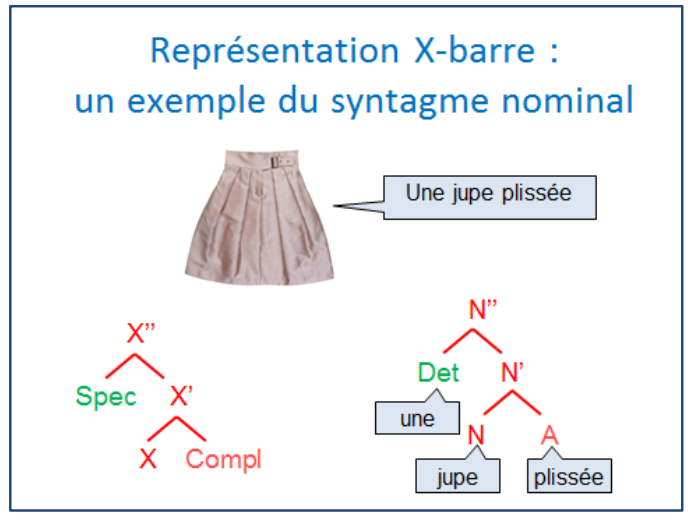

Figure 9. X-bar representation of a noun phrase trees

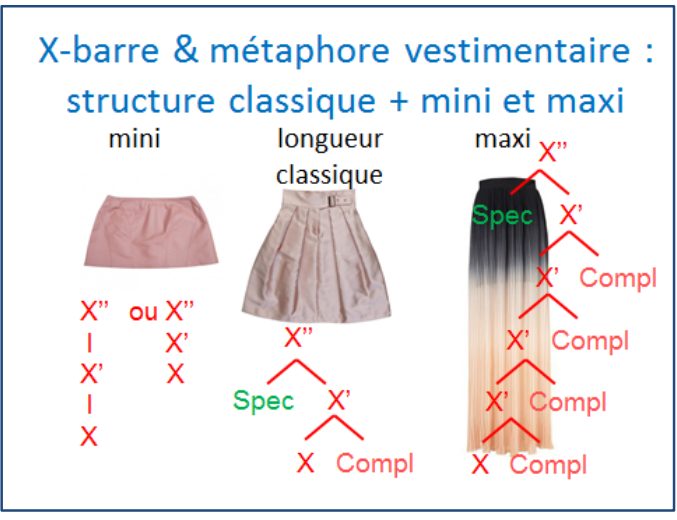

Figure 10. Fashion examples to explain syntactic

Many students reported that this analogy helped them remember to stick to the basic structure and to repeat it over and over when they switched from analysing to drawing syntactic trees. Once students manage to discern this basic structure in all trees, they experience a real breakthrough in their understanding of syntax.

\section{Conclusions}

Students greatly appreciate the comparisons described above. They become more attentive and participate more enthusiastically in class activities when fashion pictures are involved-this becomes obvious in class, and it is also reflected in their comments about fashion analogies in course evaluations. In 2014, out of 33 comments on course instruction, 16 mentioned the visual metaphors: 12 students found them helpful in understanding the concepts, 2 had mixed sentiments, and 2 more did not find them useful but fun nonetheless. In 2015, out of 19 comments, 12 were positive, 2 mixed, and none negative. Those who found the fashion metaphors helpful often mentioned their usefulness both in grasping the concept and in remembering it on a test.

The main significance of teaching through visual metaphors therefore lies in students understanding and remembering the material better. This improved comprehension clearly manifests in their tests and exams: the definitions of complex concepts explained with metaphors always exhibit a better understanding than even the ones that seemed simple enough to not require any illustration with pictures. Quizzes based on the activities comparing language and fashion practically display a 100 percent success rate, and students always remember the picture slides whenever I return to them during our review sessions.

In the ancient world, as Aristotle explains in Rhetoric, metaphor was praised as the greatest tool for the transmission of knowledge and thought. In modern times, the linguists George Lakoff and Mark Johnson have demonstrated the fundamental role of metaphor in language and mind (1975) as a mechanism allowing us to use what we already know from experience to understand numerous other subjects. The Internet provides almost limitless possibilities for finding images to illustrate any metaphorical analogy. Yet very little is written and done to promote this great teaching tool in higher education: for instance, in a recent volume on teaching linguistics, only 1 out of 18 chapters (Burridge, 2011) is dedicated to metaphors, and its excellent comparison of a language to a garden, penned by Kate Burridge, remains purely verbal. 
From my teaching experiments with fashion metaphors in linguistics, I have mainly derived encouragement to produce more visual analogies and to refine and develop the ones that have already proved useful. The project's implication for higher education in general is that instructors should use more visual representations and analogies in their classrooms and textbooks. In my own experience, I have found comparisons between fashion and language as two similar sign systems particularly useful. Fashion and clothing analogies appear appealing and understandable to all, and thus they might work just as well in other disciplines, much as the example in Figure 6 might be employed to explain the concept of valence in both linguistics and chemistry.

\section{References}

Aristotle. (1909). The Rhetoric (a translation by Sir Rchard Claverhouse Jebb; edited with an introduction and supplementary notes by John Edwin Sandys). Cambridge: Cambridge University Press.

Burridge, K. (2011). 'Two loaves where there seems to be one': metaphors we teach by. Teaching Linguistics: Reflections on Practice, K. Kuiper, ed. London: Equinox, 222-233.

Lakoff, G., \& M. Johnson. (1981). Metaphors We Live By. Chicago: University of Chicago Press.

Mollica. A, D. (2010). Ludolinguistica e glottodidattica. Toronto: Guerra-Soleil.

Ozick, C. (1989). Metaphor and Memory. New York: Knopf.

Tapscott, D. (1998). Growing Up Digital: The Rise of the Net Generation. New York: McGraw-Hill. 


\title{
Motivation: A key to success in the foreign language classroom? A case study on vocational training and higher education English courses
}

\author{
Begoña Bellés-Fortuño*, Noemi Ollero Ramírez* \\ * Universitat Jaume I
}

\begin{abstract}
Motivation in the EFL classroom has aroused the interest of researchers in the last 20 years or so with the solely purpose of fostering students' interest and eagerness to learn a foreign a language (Gardner 2001; 2007, Dörnyei 2001, Dörnyei \& Schmidt 2001, Carrió-Pastor \& Mestre 2014 among others). This study analyses two groups of students. On the one hand, an intermediate language level Trade Course with ages ranging from 18-23 years old in a vocational training high school and a first year university degree classroom (18-21 years old), both groups in an ESP setting. We tried to observe and analyse the degree of motivation in the English as a Foreign Language classroom in a vocational training high school setting and a university class. A couple of questionnaires have been developed in order to survey these two groups of students in different educational institutions. The results show that university students learning EFL feel more motivated towards language learning than vocational training students due to several reasons that are not exclusively related to the language teacher. Relevant methodologies in which students feel they have an active role in the learning process should be considered.
\end{abstract}

Keywords: EFL, motivation, vocational training courses, higher education classroom

\section{Introduction}

Factors affecting foreign language learning are many, namely, age, sex, culture, identity, learners' variables, students' interests, etc. However, according to Dörnyei and Schmidt (2001) learner's enthusiasm, commitment and persistence are key determinants of success or failure in the process of mastering a foreign language. If this is so, how can we motivate our students to improve their English language learning? If motivation provides learners with the primary stimuli for initiating foreign language learning (Dörnyei 2001), lecturers/teachers have to consider aspects such as the structure of the course to be taught, their interactions with the students, the nature of the assignments or even classroom environment, factors which may also have a large effect on students' motivation towards the learning of a foreign/second language.

Spanish students learning English as a Foreign Language (EFL) find themselves involved in classrooms where the level of English is by no means homogeneous. Sometimes, they find themselves helpless against the English language level certification requirements and bound to the European commission language policies (European Commission 2014) and the Common European Framework of Reference for Languages (CEFR), since language certification has become a compulsory requirement for most academic applications. These factors increase the level of stress to which students are subjected to when learning a foreign language. The most recent strategic framework, Education and Training 2020 (ET2020), for European cooperation on education and training displays some common strategic objectives that the Member States have to achieve by 2020. This framework sets some priority areas such as foreign language competences. One of the objectives set for 2020 related to foreign language competence establishes that at least $50 \%$ of the Spanish students should reach an independent user language level B1 or higher (according to de CEFR) in a foreign language. Statistics in 2011 revealed that in Spain only a $26.7 \%$ of the students at the end of Secondary Education reached a B1 level or higher (Objetivos 
educativos y españoles. Informe 2013), this percentage is far from the objective of $50 \%$ set out by the European Commission for the Member States.

This situation invites reflection regarding foreign language learning issues in Spanish institutions, there is a need to analyse the scare success in foreign language teaching and find new methodologies and language teaching theories where students be the central part of the learning process. Many language teachers assume that their students a highly motivated towards the language and its culture, and therefore they come to class in a very positive attitude, but this is a wrong believe, learning a foreign language can produce a negative attitude on certain occasions (Nocon 1991, Robinson-Stuart \& Nocon 1996)

Without motivation, as Gardner (1968) points out, "even the brightest learners are unlikely to persist long enough to attain any really useful language proficiency". This motivating psychological factor might not be the panacea, but it can definitely help and enhance a successful foreign language process. Having a positive attitude towards learning a foreign language can minimise negative attitudes towards the language and lessen the number of dropouts. Within motivation our study centres on intrinsic motivation, understood as somebody's internal desire to perform a particular task itself or the sense of satisfaction in completing or even working on a task (Venkatesh 1999).

The objectives of this research are twofold. On the one hand to check the degree of intrinsic motivation in Spanish students learning EFL in two different educational settings within the same age range, that is, vocational training courses and first year university students. On the other hand, to get valuable and qualitative information about how effective and motivating the language methodologies used are for students.

\section{Method}

Thirty-eight students learning English as a foreign language were surveyed. Twenty students (18-23 years old) enrolled in an English Trade course within a vocational training module in a high school. Eighteen first year university students enrolled in the English for Health sciences subject were also asked. In both cases English is taught in a specific context (ESP), the former Trade and Commerce, the latter Health Sciences (see Table 1).

Table 1. Educational centres and number of students surveyed.

\begin{tabular}{|c|c|c|c|c|}
\hline Group & \# students & Age & Course & Level \\
\hline A & 20 & $18-23$ & $\begin{array}{c}\text { English Trade } \\
\text { Course }\end{array}$ & $\begin{array}{c}\text { Secondary } \\
\text { education }\end{array}$ \\
\hline B & 18 & $18-21$ & $\begin{array}{c}\text { English for } \\
\text { Health Sciences }\end{array}$ & Higher education \\
\hline
\end{tabular}

Two questionnaires have been developed in order to survey these two groups of students in different educational institutions following Dörnyei’s (2010) argumentation in favour of questionnaires as research instruments. Students were asked to answer a first survey (S1) including 17 items or questions in a ranging scale from I totally agree to I totally disagree, the survey includes questions such as: Q6. El libro me aburre, quiero hacer actividades más dinámicas con mis compañeros/The 
book is boring, I would prefer to do more dynamic activities with my classmates , Q13. No creo que sea necesario aprender lenguas extranjeras. Debería ser optativo/Learning a foreign language should be elective not compulsory, or Q16. Participaría más si los ejercicios fueran en grupo y de "speaking", me canso de tanto escribir/ I would participate more if activities were in group and spoken, I get tired of writing (see Appendix). The second survey (S2) included 10 questions, wh-questions and yes-no questions, where students had to answer more subjectively facilitating us qualitative results. The S2 questions are:

1. How do you prefer to work in the language classroom, individually or in groups?

2. Do you think you learn more working mainly in groups? Why?

3. What do you think about the combination of the course book with other teaching materials?

4. Do you think that your lack of motivation regarding the Foreign Language is maybe due to the teacher's attitude?

5. Does the teacher present the activities in an attractive way making use of the new technologies (ICTs)?

6. Is working in groups and doing speaking activities with your classmates important to you to improve you language learning?

7. Do you consider relevant the use of the new technologies (videos, on-line activities) or other resources as useful learning tools in the classroom? Why?

8. Do you feel more comfortable and confident working with the course book in class? Yes? No? Which other materials would you suggest?

9. Do you like working with everyday life situations? Would your learning process be more successful if working with the spoken language and real life situations?

10. Do you feel motivated to continue your Foreign Language learning process or, on the contrary, you feel you are not going to improve anymore?

Both groups answered the surveys (S1, S2). They were given the option to answer the S2 questions in Spanish as to feel more comfortable and confident explaining their feelings and attitudes towards the language learning environment; we did not want students to feel unease or transmit the idea that their English level was going to be assessed or analysed from the surveys, it could interfere their answers.

\section{Results and Discussion}

An overview of the results obtained show remarkable similarities between the groups in both surveys. However, a closer look to questions revealed certain teaching aspects that deserve special attention. Regarding S1, Figure 1 below illustrates the most relevant answers in questions $6,7,13$ and 17. 


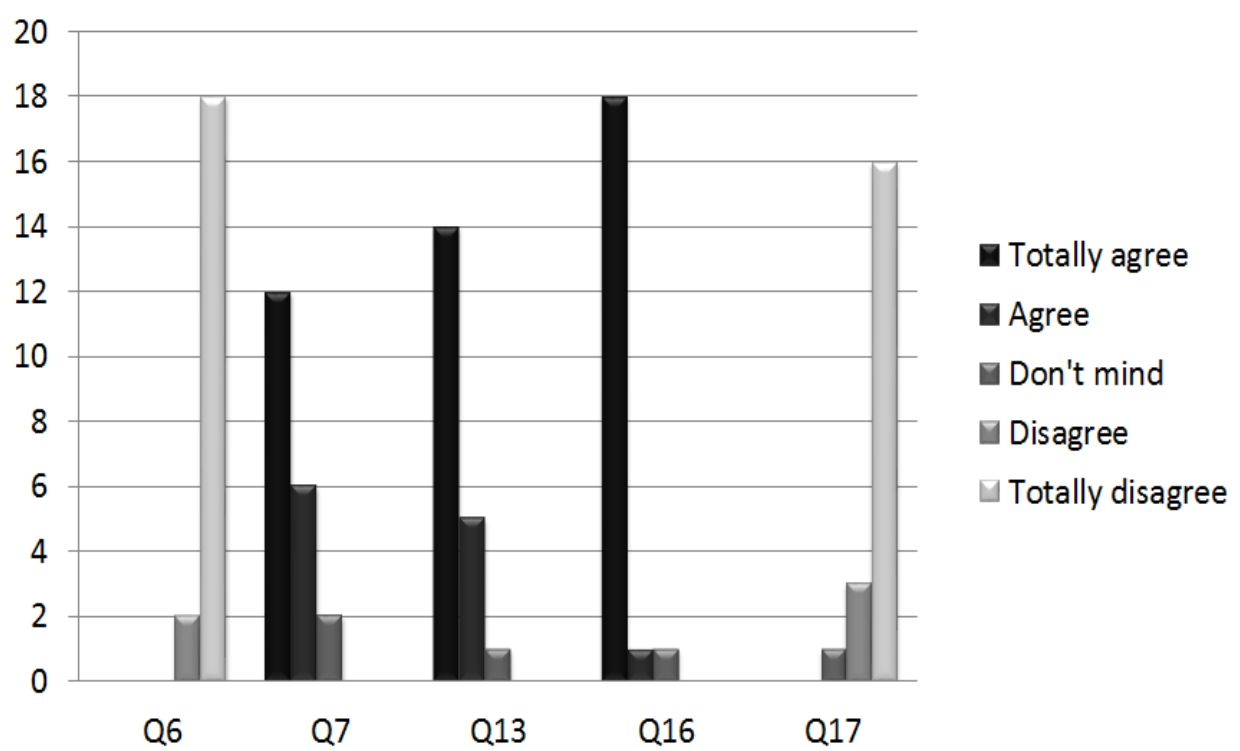

Figure 1. Group A most relevant results from S1.

As to question 6 (Q6): The teacher is not creative and he/she does not present the activities in an attractive way making use of new technologies; the students in Group A answered overwhelmingly, 18 out of 20 strongly believe that the activities are not presented in an attractive or motivating way. In Q7 they mostly answered positively to the statement: I prefer working in groups and using spoken language because that would be better for my learning process. In Q13 the student was asked: I consider really important the use of new technologies as well as the use of other relevant materials as useful learning tools in the classroom; most of them strongly or simply agree with the importance of using ICTs in the language classroom. Regarding Q16, that is, I would find English lessons more useful if we practiced the spoken language and with real life materials, the vast majority totally agreed to this idea, which makes us believe that spoken language activities are rarely presented in the English classroom. Q17 results are also relevant since nearly all the students totally disagree (16 out of 20) or disagree with the statement: I feel that in every English class I learn more and that makes me continue learning. This last item underlines the low level of motivation among the students in the Foreign Language learning process in Group A.

The results obtained in the second group (Group B) are quite similar to those obtained from the vocational training group (see Figure 2 below). However, there are some differences worth to mention. For example, the answers for Q6 are mostly opposed to Group A. In this case, 15 of 18 students totally or simply agree with the teacher being creative and using dynamic materials. Another outstanding difference with Group A occurs in Q17 where the majority of the students fully or simply agree to the statement I feel that in every English class I learn more and that makes me continue learning, and no one feels giving up learning English. This shows a high degree of motivation among group $\mathrm{B}$, first year degree students. There might be a close relation between this question and Q6 regarding the use of motivating activities in the language classroom by the lecturer. 


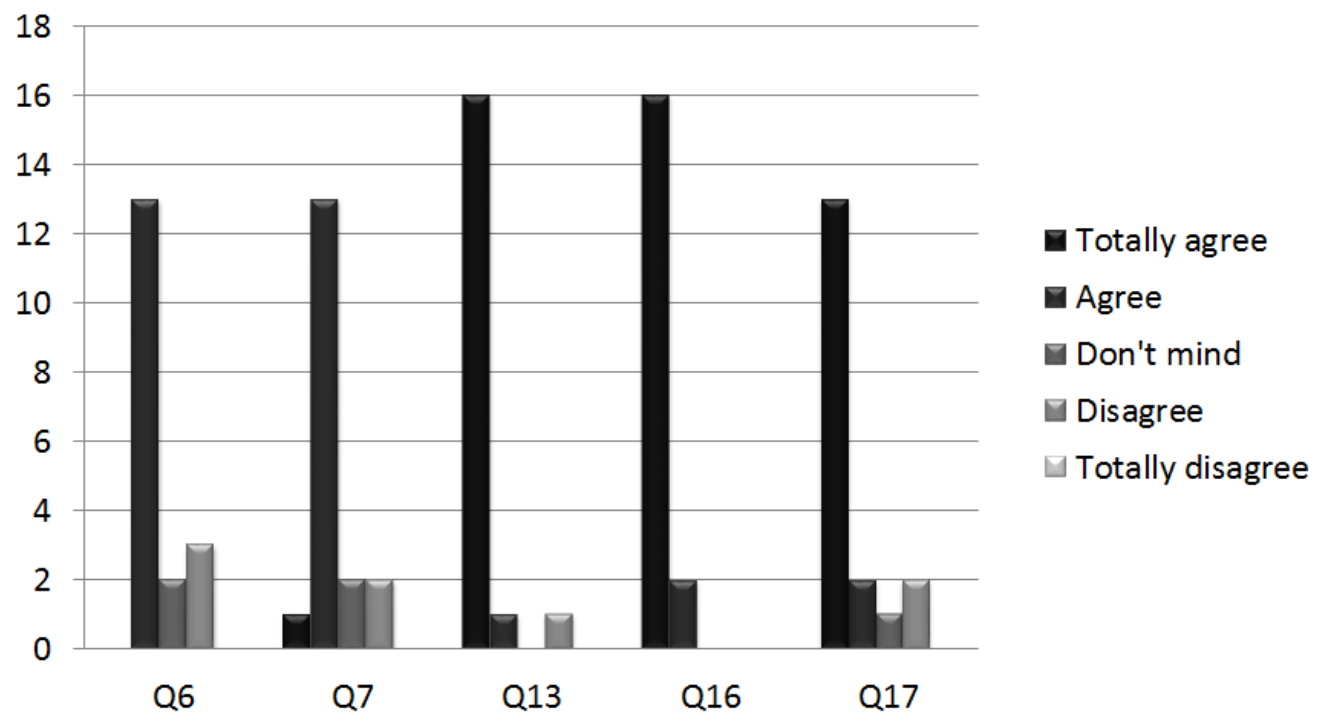

Figure 2. Group B most relevant results from $\mathrm{S} 1$.

As to S2, the majority of the students in Group A wrote comments highlighting their likeness towards group work and cooperative activities, they consider the textbook should be a help but not the only material used in the classroom. For example, one student wrote: "I prefer to work cooperatively rather than individually, I can learn from my classmates". Another student said: "The textbook should be a kind of help in class but not the only material used. There're many other resources that we could use.” When they were asked Q10, Do you feel motivated to continue your Foreign Language learning process or, on the contrary, you feel you are not going to improve anymore?, they wrote comments such as: 'I feel completely stuck', 'I can't learn anymore English', 'I need a change, something that could motivate me, I don't feel like improving."

Group B feels highly motivated and eager to learn as the answers from S2 show. When answering to Q10 they wrote comments such as: "I'd like to improve my English level in the following years", "I'd like to have a native-like level of English". This group seems also to be satisfied with the different materials used in the classroom.

\section{Conclusions}

Based on the results obtained from the surveys and the students' comments, one may conclude that foreign language learning success is not only a matter of how much students are motivated rather of how rejection towards the learning of a foreign language can be avoided. Relevant methodologies in which students feel they have an active role in the learning process should be considered. The development of lesson plans, innovative and attractive activities according to students' interests and topics which are close to their social environment, adaptation of course books and the upgrading of materials are some of the actions that should be carried out if we are to change the EFL landscape in Spanish educational institutions.

We aimed at showing the need to enthuse and motivate our students for a successful and fruitful learning process and to find the tools that can arouse students' motivation in the process of learning a foreign language for a specific purpose and try to overcome students' difficulties and rejection towards the English language learning. 
Motivation seems to be more visible among higher education students, maybe due to better and more effective methodologies and use of materials by the university lecturer or maybe due to higher future expectations among university students that see, in mastering a foreign language, a more prosperous future employment in Spain or abroad. Already in 2010, Oxbrow and Rodríguez carried out some research about motivation with Spanish tertiary level learners to see how motivation could be influenced by strategy training. They concluded that intrinsic motivation is crucial for the development of leaner's autonomy.

Regardless the profile of a student, the truth is that lack of motivation in the foreign language classroom leads to lack of effort and ultimately lack of learning success. Therefore, motivating EFL students should be paramount to teachers/lecturers.

\section{References}

Carrió-Pastor, M. L. \& Mestre, E. (2014). Motivation in Second Language Acquisition. Procedia-Social and Behavioural Sciences, 116, 240-244.

Dörnyei, Z. \& Taguchi, T. (2010). Questionnaires in second language research. Construction, administration and processing. New York, UK: Routledge.

Dörnyei, Z. (2001). Motivational strategies in the language classroom. Cambridge: CUP.

Dörnyei, Z., \& Schmidt, R. (Eds.). (2001). Motivation and second language acquisition. Honolulu, HI: University of Hawai'i, Second Language Teaching and Curriculum Center.

European Commission 2014. Erasmus + Programme 2014-2020. Retrieved from http://ec.europa.eu/dgs/education_culture/index_en.htm

Gardner, R. C. (1968). Aptitude and motivation: Their role in second-language acquisition. TESOL Quarterly, 2, 141-150.

Gardner, R. C. (2001). Integrative motivation and second language learning: practical issues. Journal of Foreign Language Education and Research, 9, 71-91.

Gardner, R.C. (2007). Motivation and second language acquisition. Porta Linguarum. 8, 9-20.

Ministerio de Educación, Cultura y Deporte. Objetivos educativos europeos y españoles. Estrategia educación formación 2020. Informe 2013. Retrieved from http://www.mecd.gob.es/dctm/inee/indicadoreseducativos/informeet20202013.pdf?documentId=0901e72b81732dc8

Nocon, H. (1991). Attitude and motivation of beginning students of Spanish at a border university. Unpublished Master Thesis. San Diego State University, CA.

Oxbrow, G. \& Rodríguez, C. J. (2010). Language learning motivation and leaner autonomy: Bridging the gap. Revista Canaria de Estudios Ingleses, 61, 57-72.

Robinson-Stuart, G. \& Nocon, H. (1996). Second culture acquisition: Ethnography in the Foreign Language classroom. The Modern Language Journal, 80, 431-449. doi: 10.1111/j.1540-4781.1996.tb05463.x

Summaries of European Legislation. EUR-Lex. Access to EU law. Education and Training 2020 (ET 2020). Retrieved from

Venkatesh, V. (1999). Creation of favourable user perceptions: Exploring the role of intrinsic motivation. MIS Quarterly, 23 (2), 239-260. 


\section{Appendix: Survey 1, Students' Motivation Questionnaire}

\begin{tabular}{|c|c|c|c|c|c|}
\hline & 1 & 2 & 3 & 4 & 5 \\
\hline $\begin{array}{l}\text { 1. I consider a waste of time having to learn a Foreign Language. It should be } \\
\text { optional. }\end{array}$ & & & & & \\
\hline $\begin{array}{l}\text { 2. If something does not appear in the exam I do not make an effort to } \\
\text { understand it. }\end{array}$ & & & & & \\
\hline 3. I would participate more in class if we worked with dynamic activities. & & & & & \\
\hline 4. I only want to pass the exam. Why do I need getting better marks? & & & & & \\
\hline $\begin{array}{l}\text { 5. When the English teacher explains something in class that I do not } \\
\text { understand, I almost always ask her/him. }\end{array}$ & & & & & \\
\hline $\begin{array}{l}\text { 6. The teacher is not creative and he/she does not present the activities in an } \\
\text { attractive way making use of new technologies. }\end{array}$ & & & & & \\
\hline $\begin{array}{l}\text { 7. I prefer working in groups and using spoken language because that would } \\
\text { be better for my learning process. }\end{array}$ & & & & & \\
\hline 8. I like that everybody knows I'm good at English. & & & & & \\
\hline $\begin{array}{l}\text { 9. I like Foreign Languages. I know they are important and I would like to be } \\
\text { able to speak English perfectly. }\end{array}$ & & & & & \\
\hline 10. I already know what my professional specialisation will be in the future. & & & & & \\
\hline $\begin{array}{l}\text { 11. When I get lost in the teacher's explanations I do not try to understand } \\
\text { him/her again. I simply 'disconnect'. }\end{array}$ & & & & & \\
\hline 12. P I always participate in the activities that the teacher suggests in class. & & & & & \\
\hline $\begin{array}{l}\text { 13. I consider really important the use of new technologies as well as the use } \\
\text { of other relevant materials as useful learning tools in the classroom. }\end{array}$ & & & & & \\
\hline $\begin{array}{l}\text { 14. I get bored when using the textbook in the classroom. I want to work with } \\
\text { more dynamic activities with my classmates. }\end{array}$ & & & & & \\
\hline $\begin{array}{l}\text { 15. I would participate more in the English classroom if the activities were } \\
\text { more dynamic. }\end{array}$ & & & & & \\
\hline $\begin{array}{l}\text { 16. I would find English lessons more useful if we practiced the spoken } \\
\text { language and with real life materials. }\end{array}$ & & & & & \\
\hline $\begin{array}{l}\text { 17. I feel that in every English class I learn more and that makes me continue } \\
\text { learning. }\end{array}$ & & & & & \\
\hline
\end{tabular}


HEAd'15

SESSION 2C

MEDIA 


\title{
Convergence in Media Education Curricula
}

\author{
M Karmasin*, S Diehl**, I Koinig** \\ * Austrian Academy of Science, Austria \\ ** Alpen-Adria-Universität Klagenfurt, Austria
}

\begin{abstract}
The paper intends to investigate current university degree programs in numerous European countries and compare them with offerings in the United States with regard to their suitability to contemporary workplace requirements in the age of convergence. Recent trends in convergence, defined as the merging and growing together of previously distinct industrial branches, professions, devices and skills (Jenkins, 2008) have changed and dramatically transformed the ways people communicate as well as interact with each another. As a consequence, academic and professional representatives are asked to respond to these far-reaching alterations in varying ways.

By use of an extensive content analysis, our study intends to analyze to which degree universities in Europe and the United States have started to already offer adequate programs on different educational levels (Bachelor, Master and $\mathrm{PhD}$ ) in an attempt to provide the kind of media education needed today and in the future. The paper takes a closer look at educational trainings and degree programs offered by post-secondary institutions throughout the world, scrutinizing whether convergence and related terms such as multimedia and cross-media have already managed to gain an (academic) foothold yet.
\end{abstract}

Keywords: convergence, education, cross-media, multimedia, university curricula, international comparison

\section{Introduction}

Media occupy a powerful role in present-day society. Besides transporting messages, they shape current opinions and allow for user participation, empowering numerous parties, such as producers, consumers etc. Empowerment is especially brought about on grounds of the increasing number of vehicles - digital and traditional, which is conditioned by trends of convergence (Perez Tornero et al., 2008). Hence, over the past years, convergence has risen and continued to affect the domains of both people's personal and professional lives. In a narrow sense, convergence refers to "complex, multi-layered interactions between 'traditional' (or 'old') communication cultures and emerging ('new') online, mobile media” (Allan, 2010, p.: xiivf.). In a broader sense, blurring boundaries are characteristic of present-day interactions and environments, thus, changing technological devices, workplace settings, industrial co-operations as well as communicative encounters and exchanges. Convergence, therefore, needs to be perceived as "a phenomenon resulting from the overlapping and merging of different media forms and functions that once operated separately” (Diehl et al., 2013, p. 354). The elimination of formerly distinct industrial sectors, job profiles and competencies, as well as the merging of private and occupational matters pose new challenges to educational institutions that need to be tackled in time to ensure companies' survival and lasting success in a globalized and connected world. Following recent claims, new media competencies and forms of literacy need to be addressed and emphasized in media education programs order to provide future staff with appropriate competencies to manage present and future challenges, familiarizing them with the tools and skills that might become of uttermost importance to corporate success (Arnolds-Granlund \& Kotilainen, 2010). 


\section{Convergence}

In general, convergence is perceived as a phenomenon resulting from the merging and overlapping of different media functions and forms which once operated separately and independently (Diehl et al., 2013). It can take numerous forms and primarily concerns media, businesses/industries, technologies and content. (1) Convergence of media recognizes the merging of previously independent devices and technologies, leading to the emergence of new services such as mobile TV, mobile Internet, Internet TV, Internet radio or "connected TV". (2) Convergence of businesses suggests that firms and industries formerly operating in different economic areas choose to cooperate and collaborate by (partially) leaving their original fields of expertise. Thereby, cross-functional operations are characterized by varying degrees of duration, intensity, and objectives. (3) Convergence of technologies, with its prime examples being Unified Messaging (UM) as well as Unified Communications (UC), collects and incorporates different communication forms (e.g., e-mails, text or fax messages) into one common ("unified") form that can be accessed as well as processed by a variety of devices (e.g. smartphones or e-mail clients) independent of their actual location. (4) Convergence of content postulates media content being not only used in different media channels and at multiple times, but also its adaptation to different media environments and their requirements respectively (Diehl et al., 2013); this is the case with news is being published on different platforms, such as the Internet or on TV and the radio (Karmasin \& Winter, 2000). Thereby, convergence is conditioned by the "three C's of convergent media, [namely] computing and information technology (IT), communications networks and digitized content” (Flew, 2008, p. 2). Yet, limiting convergence to the media realm is by far too simplistic since it has implications for other (related) domains as well and as such, convergence "is a word that manages to describe technological, industrial, cultural, and social changes depending on who [is] speaking and what they think they are talking about” (Jenkins, 2008, p. 3).

\section{Convergence’s Increasing Relevance}

For Dennis (2003), convergence does not cover changes in technical/technological services and platforms, business models and/or legal regulations alone; he claims that it is, first and foremost, a process „blurring the lines between media“ (Pool, 1983, p.: 24). However, it is not only limited to the media realm but recent trends of convergence (e.g., market deregulation tendencies, globalization, technical as well as technological innovation and altered customer expectations; Rhodes et al., 2006) exercise an impact on other disciplines as well.

Convergence and the Media: Convergence has had a drastic impact on the media and communication landscape, where it is perceived as an ongoing process in the course of which new technologies are integrated into existing ones. The media industry has been hit by convergence to the largest extent and in a two-fold manner: on the one hand, the sector has experienced an over-expositional increase in communication channels, conditioned by the rapid rise of the Internet and Internet-related technologies; on the other hand, convergence has managed to gain ground by eliminating previously established sectorial boundaries (Tambini, 2001). As a result, the media sector has to face new challenges quite similar to those of the IT industry (Noam, 2009). Thereby, changes predominantly concern the sector's major agents 
(McPhillips and \& Merlo, 2008), namely media owners as well as consumers, who are given the chance to use multiple services without changing platforms or devices respectively, and can use the same service on a variety of devices (Ofcom, 2008).

Convergence and the Business Environment: Technical innovations and technological advancements lead to new working environments, specifically in the areas of production and distribution, also affecting consumption. At the same time, sectorial convergence is taking place, which is to be understood as "a 'blurring' of boundaries between industries, induced by converging value propositions, technologies and markets that lead to the emergence of inter-industry segments" (Bröring et al., 2006, p.: 487). Through the convergence of industries new (convergent) products and services emerge; they do, however, not present novel inventions per se but instead presuppose the creation of innovative business models and more flexible organizational structures (Schwarz and \& Gustafsson, 2013). Convergence devices, such as smartphones or tablets are responsible for newly emerging competencies repeatedly uttered by enterprises, who expect their (prospective) job candidates not only to multi-task, but also to possess knowledge in different areas (Zorn, 2011). Predominantly, these skills concern dealing with more flexible working environments, technological knowledge, short-term team structures as well as intercultural competencies (Diehl et al., 2013). Business owners and managers alike are asked to ensure that work is done properly and in time, albeit staff is dividing their work between their home and their actual office workplace. The divided notion of the workplace has also been fostered through technological advancements (such as Cloud Services and Unified Communication Systems) which do not only support but also facilitate the exchange of data independent of people's locations. The use of these services also requires both new skills and a new form of media literacy to be successfully managed, and must be addressed in education.

Convergence and the Customer: In addition, media consumption has been drastically changed. For reasons of content convergence, media offerings are used multiple times, courting consumers along a variety of platforms. Technological infrastructures, especially communication technologies, experience a rapid growth which is mirrored by rising broad band Internet usage rates and an increasing dissemination in mobile communication devices (International Delphi Study, 2009). As a result, technical background knowledge becomes inevitable for users and (digital) consumers in order to ease their navigation (Zorn, 2011; Roth-Ebner, 2012). On grounds of this characteristic, users are enabled and encouraged to contribute online, transform and edit (digital) media content (Zorn, 2011), whereby the Internet - characterized by a high degree of participation - is the source driving change to unknown dimensions (Roth-Ebner, 2012). New age-media consumers are migratory and socially active, and publically connected (Jenkins, 2008) - all because of trends of convergence.

Convergent Journalism: Technical and technological convergence have changed the journalistic profession as its core, with news consumption having not remained the same either, for present-day consumers receive and respond (share and contribute) to news differently than only a few years ago (Erdal, 2007). In the professional domain, convergence journalism describes "some combination of technologies, products, staffs and geography amongst the previously distinct provinces of print, television and online media” (Singer, 2004, p.: 3). As a precondition for cross-media work, these trends foster dramatic changes across newsrooms, with agencies following multichannel strategies, multiplatform publishing and cross-media reporting 
(Kaltenbrunner and \& Meier, 2013). Today, news coverage has to happen quicker, at a more regular pace and simultaneously across platforms; therefore, management practices in content providing agencies have to be rethought and innovative news formats (e.g. cross-media storytelling, convergent platforms etc.) have originated in response to public pressure for exiting and unique content preparation.

All these trends discussed before lead to fractured notions of work and, as such, make the work process less predictable and controllable. As a result, it can be said that competencies do not exist by themselves but also converge, possibly bringing to mind the term "convergence of competencies". And since convergence is a trend playing into a variety of disciplines with diverse effects, these need to be (at least, partially) borne in mind by media education, which is called upon to provide suitable and tailored degree programs in order to educate the workforce of the future.

\section{Methods}

By the use of an extensive content analysis, our study sets out to analyze whether universities in selected European countries (Germany, Austria, Switzerland, Slovenia, Ireland, Great Britain, Scotland and Wales) and the United States are already responding to the new requirements of convergence by offering degree programs which provide the kind of media education needed today and in the future. Countries were selected if they offered a study portal which aided (prospective) candidates in their search for suitable educational programs. The present paper takes a closer look at educational offerings (Bachelor, Master, Diploma and $\mathrm{PhD}$ degree programs) provided by post-secondary educational institutions, scrutinizing whether convergence has already been able to gain an (academic) foothold yet. As convergence concerns numerous areas, such as media communications, journalism as

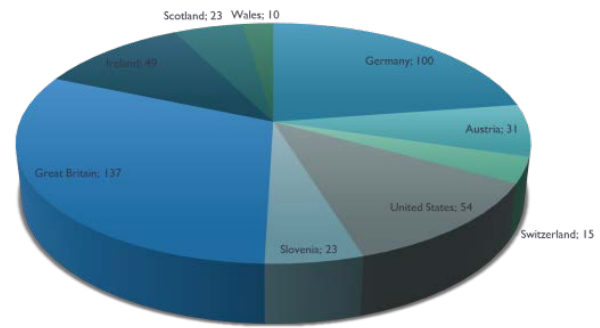

Figure 1: Number of Programs by Country $(n=443)$ well as economics, management and technical sciences, programs from these diverse backgrounds will be consulted.

For the present study, 443 different degree programs from six counties (for scores, see Figure 1) were analyzed in detail over a period of two months (July and August 2013: Germany, Austria, Switzerland, and the U.S. and/or February and March 2014: Slovenia, Ireland, Great Britain, Scotland, and Wales) for the purpose of revealing their focus on convergence and related fields. Hence, a detailed Internet analysis was conducted, whereby programs offered at the time of survey (2013/14) were investigated. In order to get a good overview about the programs offered, well-renowned study portals ${ }^{1}$ were consulted when available, with the exception of the U.S., where a plain Google search was conducted.

1 Austria: www.studieren.at; Germany: www.studieren.de; Switzerland: www.studium-schweiz.ch; Slovenia: http://www.studij.si/; Ireland: http://www.educationinireland.com/en/What-can-I-study-/; Scotland: Www.scottland.org/study-in-scottland; Wales: http://www.wales.com/en/content/cms/english/study/wales_universities/wales_universities.aspx; Great Britain: www.educationuk.org and www.studybritain.com. 


\section{Results}

Most degree programs are offered by universities (both private and public; $67.3 \%$ ) followed by universities of applied sciences (15.8\%) as well as colleges and/or academies (16.9\%). In terms of program type, Bachelor (54.6 \%) and Master (38.8 $\%)$ degrees clearly outnumber other educational trainings (like preparation classes or colleges), which constitute the smallest proportion (6.6 \%). In countries where English does not present an official language, a clear trend towards bilingual programs can be noted; in total, English is featured in 297 (67\%) of all cases, alluding to how globalization and convergent markets have altered present-day workplace settings by attributing a higher degree of importance to (foreign) language proficiency and raising English to the world's common language. Programs currently offered only in the country's national language take a backseat (with the exception of Slovenia, where programs are exclusively taught in Slovenian); they might be even doomed unsuitable in the long run and, if demand increases, it would be wise to adapt them accordingly. Yet, even though convergence is said to dismantle fixed working structures and makes them more flexible, this trend is not mirrored in the programs' design, for most programs are still full-time. By contrast, part-time degrees would enable students to get more used to current workplace settings and conditions, further enabling them to pursue a part time job in form of an internship, which would then allow them to put the knowledge acquired into practice.

Counting occurrences of the word convergence alone would proof to be insufficient; hence, two related concepts - namely cross media and multimedia - will be additionally used in this paper to achieve meaningful results. While convergence has already been defined extensively, cross media and multimedia still need to be conceptualized briefly in order to justify their selection for analysis. While cross media means all communicative efforts involving more than one media channel (Cambridge Dictionary, 2013a), multimedia refers to "communicating or sharing information in the form of sound, pictures, and video as well as text" (Cambridge Dictionary, 2013b). Since some overlapping between the definitions of convergence (especially between the definitions of convergence of media and content) can be found, the terms were regarded suitable for inclusion in the present study.

Table 1: Example of Term Occurrence ('Convergence') by Place of Listing

\begin{tabular}{|l|l|l|}
\hline \multicolumn{1}{|c|}{ Use of 'Convergence' Category } & \multicolumn{1}{c|}{ University } \\
\hline Media and Convergence Management & Study Title & $\begin{array}{l}\text { Alpen-Adria-University Klagenfurt, } \\
\text { Austria }\end{array}$ \\
\hline $\begin{array}{l}\text { Convergence Journalism } \\
\begin{array}{l}\text { Integrating Media: Convergence in } \\
\text { Practice (4) }\end{array}\end{array}$ & Study Title & $\begin{array}{l}\text { University of Missouri, United } \\
\text { States }\end{array}$ \\
\hline $\begin{array}{l}\text { Cross-media journalism and journalism in Content } \\
\text { convergent media }\end{array}$ & Module & $\begin{array}{l}\text { Penn State University, United States } \\
\text { Kommunikation und Wirtschaft, } \\
\text { Berlin, Germany }\end{array}$ \\
\hline $\begin{array}{l}\text { Media Literacy/Education - audiovisual } \\
\text { culture and communication }\end{array}$ & Module & $\begin{array}{l}\text { Otto von Guericke - University of } \\
\text { Magdeburg }\end{array}$ \\
\hline $\begin{array}{l}\text { Culture and Media Education } \\
\text { University of } \\
\text { Ludwigshafen }\end{array}$ \\
\hline
\end{tabular}

Out of 443 degree program offerings, 215 (38\%) mention the term convergence (C) in one way or another; cross-media (CM) is included in relatively few instances (53/9 
\%), while multimedia (MM) is most frequently included (301/53 \%). Rare occurrences of all terms are found for the usage in the actual program title (C: $7 \%$ /CM: $6 \%$ /MM: $12 \%$ ), while it is slightly more commonly utilized as a module title (C: $20 \%$ /CM: $20 \%$ /MM: $35 \%$ ); most occurrences can be noted as module content (C: $73 \%$ /CM: $74 \%$ /MM: $53 \%$ ). For example occurrences, see Table 1. In the modules containing the key terms as module content, the terms' mention predominantly concerns course content (261/58.9\%) and in fewer cases an actual course title (156/35.2\%). As to place of mention, multiple occurrences can be noted (in order of cases): in the program description (C: 57 \% /CM: $41 \%$ /MM: $69 \%$ ), in the course of study (C: $25 \%$ /CM: $39 \%$ /MM: $19 \%$ ), in the course offerings (C: 13 \% /CM: 11 \% /MM: $11 \%$ ) and in the degree program's curriculum (C: 5 \% /CM: $9 \%$ /MM: $1 \%)$.

In general, definitions of the term convergence are missing and are given in less than $1 \%$ of all results; hence, determining the degree program's focus is a rather complicated matter. Therefore, content was scrutinized in more detail, especially with regard to its relation to different fields of study, which are said to converge in presentday (workplace) environments. While a clear focus on media and communication sciences was immanent to all programs, only $27 \%$ of all programs solely put their focus on communication theories. Rather, they have started to broaden their horizon to other disciplines for input by taking up theories from other scientific backgrounds to varying degrees: journalism (29\%), economics and management (4\%) and technical sciences (15\%) respectively. Programs with interdisciplinary focus are, thus, starting to gain ground, accounting for already $20 \%$.

Additionally, education seems not to be solely theoretical anymore, for already $44 \%$ of the programs scrutinized offer practical courses paired with theoretical input. Yet, purely practical classes alone hardly exist (1\%). This indicates that applied classes, in which knowledge is utilized in a practical setting, are becoming increasingly relevant. They are usually to be found in the area of journalism (in form of cross-media and multimedia classes), where a balance between theoretical and practical teaching formats is achieved. As far as these new trends are integrated into the complete program, most degree offerings either assign a single class (63\%) or a module (two or more classes; $29 \%$ ) to this particular topic, while others (very few, though) even dedicate the complete degree program (8\%) towards this newly emerging area.

\section{Discussion of Results, Recommendations and Future Outlook}

Present study results clearly indicate that convergence and related concepts have started to increase in relevance in the media education realm throughout Europe and in the United States. Of all the terms scrutinized, multimedia is most commonly used ( $\sim 53 \%$ ), followed by convergence $(\sim 38 \%$ ) and crossmedia $(\sim 9 \%)$. Within those programs, all terms are used to almost equal parts as module content ( $65 \%$ ), module titles ( $\sim 20 \%)$, with study titles ranking last $(\sim 7 \%)$. Yet, some countryspecific differences are noteworthy: while in all countries the terms are mostly applied as module content, they are more often used as study titles in the U.S. (24 \%), which could indicate the increased importance attributed to this specialization overseas. In terms of the degree programs' foci, a clear tendency towards the area of communication surfaces as all programs can be clearly traced back to their media studies' origins. While some programs still focus on media and communication topics alone (27\%), they are almost equal up with programs stressing journalistic topics (29 
$\%)$. The second place, however, is already assigned to programs with interdisciplinary focus (20\%), combining media elements with concepts taken from economic and management as well as technical sciences. These disciplines are practiced to a smaller degree in their pure forms but are of benefit to the area of research as convergence is based on technical developments and changing numerous professions at their core: 15 $\%$ technical sciences, as well as $4 \%$ economics and management. The extent to which convergence is taught at universities, seems to be indicative of these results as well. Predominantly (in $63 \%$ of all cases), single classes are dedicated towards this subject area, whereas one module (defined as consisting of two or more classes) can be found in second place (29\%). Full degree programs account for $8 \%$.

Amongst practitioners and academics, the term convergence has become used "as a rhetorical toll in order to facilitate reform, [with the] media landscape undergoing significant change" (Fagerjord and Storsul, 2007: 28). As a consequence, the academic landscape has to change as well to allow for integrated program solutions: it is universities' educational duty to provide appropriate means in form of tailored educational trainings that take present-day and future challenges into account. This means that they must not only (exclusively) center on media convergence but should also pay tribute to other trends and social developments (e.g., the transformation from an information society to a knowledge society), globalization as well as altered political and legal regulations. The present study has demonstrated quite plainly that missing definitions of the core terms impede determining the subject area's exact focus. Yet, these should be included for definitions are meant to provide some guidance and/or orientation on what to expect of the actual program. Additionally, the extent and amount of information available on each program differs considerably; therefore, information should be presented in a unified way and cohesive structure.

Trends of convergence are meant to change the educational landscape forever. Yet, the above elaboration is far from being complete as technologies and competencies pointed out in this text solely fit current requirements, but since changes are often unpredicted, surprising and faster than ever imagined this paper does neither present permanent solutions nor fixed answers. Rather, it tried to draw attention to already identified trends, which indicate that convergence increasingly dissolves academic boundaries. And as such, it also needs to be mirrored in future media education programs.

\section{References}

Allan, S. (2010). Series Editor's Foreword. In T. Dwyer (ed.). Media Convergence. Maidenhead: Open University Press. xiii-xiv.

Arnolds-Granlund, S.B.; \& Kotilainen, S. (2010). Media Literacy Education: Nordic Perspectives. Gothenborg: Nordicom.

Bröring, S.; Coultier, L.M.; \& Leker, J. (2006). The front end of innovation in an era of industry convergence. $R \& D$ Management. 36(5). 487-498.

Cambridge Dictionary. (2013a). Cross-media. Retrieved 25 September 2013 from http://dictionary.cambridge.org/dictionary/british/multimedia

Cambridge Dictionary. (2013b). Multimedia. Retrieved 25 September 2013 from http://dictionary.cambridge.org/dictionary/business-english/cross-media

Dennis, E.E. (2003). Prospects for a big idea - Is there a future for convergence? The International Journal on Media Management. 5. 7-11. 
Diehl, S.; Karmasin, M.; Leopold, A.; Koinig, I. (2013). New Competencies for the Future. In S. Diehl \& M. Karmasin (eds.). Media and Convergence Management. (pp. 355-378). Berlin, Heidelberg: Springer.

Erdal, I.J. (2007). Researching Media Convergence and Crossmedia News Production: Mapping the field. Nordicom Review. 28(2). 51-61.

Fagerjord, A. \& Storsul, T. (2007). Questioning convergence. In T. Storsul \& D. Suedahl (eds.). Ambivalence towards convergence: digitalization and media change. Göteborg University: Nordicom.

Flew, T. (2008). New Media: An Introduction. $3^{\text {rd }}$ edition. Oxford: Oxford University Press.

International Delphi Study. (2009). Zukunft und Zukunftsfähigkeit der Informationsund Kommunikationstechnologien und Medien. Retrieved 2 May 2013 from http://www.tnsinfratest.com/presse/pdf/Zukunft_IKT/Zukunft_und_Zukunftsfaeh igkeit_der_IKT 2009.pdf

Jenkins, H. (2008). Convergence Culture: Where Old and New Media Collide. $2^{\text {nd }}$ ed. New York, London: New York University Press.

Kaltenbrunner, A. \& Meier, K. (2013). Convergent Journalism - Newsroom, Routines, Job Profiles and Training. In S. Diehl and M. Karmasin (eds.). Media and Convergence Management. (pp. 285-298). Berlin, Heidelberg: Springer.

Karmasin, M. \& Winter, C. (eds.) (2000). Grundlagen des Medienmanagements. Munich: UTB.

McPhillips, S. \& Merlo, O. (2008). Media convergence and the evolving media business model. The Marketing Review. 8(3). 3. 237-253.

Noam, E.M. (2009). Media ownership and concentration in America. Oxford: Oxford University Press.

Ofcom, (2008). The International Communications Market 2008. Convergence. December. London: Ofcom.

Perez Tornero, J.M.; Jacquinot-Delaunay, G.; Tayie, S.; \& Carlsson, U. (2008). Empowerment Through Media Education. Gothenborg: Nordicom.

Pool, I.d.S. (1983). Technologies of Freedom. Cambridge, MA: Harvard University Press

Rhodes, J., Walsh, P. \& Lok, P. (2006). Convergence and Divergence Issues in Strategic Management. Retrieved 26 August 2013 from http://w3.unisa.edu.au/igsb/docs/wp-lok1.pdf

Roth-Ebner, C. (2012). Medienkompetenz und Genderkompetenz. Retrieved 17 July 2013 from http://www.medienimpulse.at/articles/view/352

Schwarz, E. \& Gustafsson, V. (2013). Business Modelling and Convergence. In S. Diehl and M. Karmasin (eds.). Media and Convergence Management. (pp. 9-24). Berlin, Heidelberg: Springer.

Singer, J. (2004). Strange Bedfellows? The Diffusion of Convergence in Four News Organizations. Journalism Studies. 5(1). 3-18.

Tambini, D. (2001). Revolution, Communication and Reform. London: Institute for Public Policy Research.

Zorn, I. (2011). Medienkompetenz und Medienbildung mit Fokus auf Digitale Medien. In H. Moser; P. Grell \& H. Niesyto (eds.). Medienbildung und Medienkompetenz. (pp. 175-209). Munich: Kopaed. 


\title{
The use of horizontal social networks to promote and publicize university teaching
}

\author{
E. Lahuerta-Otero*, R. Cordero-Gutiérrez* \\ * University of Salamanca, Department of Business Administration. Campus Miguel de Unamuno, \\ 37007, Salamanca, Spain.
}

\begin{abstract}
The purpose of this paper is to examine the effectiveness of the online advertising techniques through the social network Facebook, as a broadcasting and promotion tool to disseminate information of universities. By means of a case study, we present the findings on a research center belonging to the public sector. Results show that these techniques are able to get a large number of impressions and clicks, which impacts (in terms of awareness and recognition) go beyond the initial targeted group. Although the results are based on a single public teaching center and therefore they cannot be used to make generalizations, the conclusions of the study show the cost-effective effect relationship of these innovative techniques when promoting universities among the online community. Consequently, these methods represent and important supporting point on the universities' marketing strategies when addressing the challenges of this new, digital society.
\end{abstract}

Keywords: Social networks, universities, promotion, advertising, case study, Facebook.

\section{Introduction}

Our society is experiencing an unstoppable development of the information and communication technologies (ICTs). With the rapid digitalization of media, advertising landscape has changed dramatically. Spain accounted for 28.9 million Internet users in 2013 (ONTSI, 2013), 84\% of which consulted the social media very often (ONTSI, 2011). Furthermore, almost 56\% of the Spanish internet users buy on the Internet, which means 15.2 million shoppers spending €816 on average per year (ONTSI, 2013). Consequently, companies invested 874.4 million Euros in digital advertising in Spain in 2013 (IAB Spain, 2014). Online and social advertising accounted for the $21 \%$ of the total share, consolidated its second position only behind a traditional media such as television.

Even if online advertising is becoming more important day by day, it has not replaced the traditional advertising yet, as both techniques are conceived as complementary to each other (Barreto, 2012). This is the reason why several authors point out the need to study the use of the Internet as an advertising tool more in deep (Ailawadi et.al, 2009). The Web 2.0 is understood as a new generation of internet services based on the creation of communities, the network concept and the use of the new ICTs for information dissemination (Musser and O'Reilly, 2006). It includes a set of social media so that users can co-create, organize, edit, share, comment and evaluate content by forming social networks that interact with each other.

This research will focus on horizontal social networks, which are those formed by users with no particular interest or objective on a particular topic (ONTSI, 2011). Individuals participating in these types of networks are looking for entertainment and communication, so they become a powerful tool to gain and build customer loyalty from a business perspective (Cordero-Gutiérrez and Santos-Requejo, 2014).

Businesses can no longer afford to ignore the benefits of using social media. In the past, customers consulted with a limited number of family members of friends before making a purchase. The frequent use of social media increases that number to thou- sands of opinions from all over the world on a single click. This means that 2.0 services rely on 
a disintermediation process (Criado-Grande, 2012) that makes customers and businesses engage in a closer relationship. When customers are involved in the purchasing process, they feel valued and they generate a positive feedback that spreads instantly at no cost. Cost reduction and greater participation and customer involvement makes from online advertising no longer a luxury; but an affordable necessity. Recent studies found that social media marketing techniques can generate more business exposure, increased traffic and improved search engine rankings (Stelzner, 2011). Even if the media landscape has dramatically changed, and investments in digital advertising increase every year, is not yet well understood how firms can use this forms of publicity and their impacts on organizational goals (Stephen and Galak, 2010). Today's consumers expect companies to have an online presence in social media and it is not just another channel for disseminating corporate information. It represents a tremendous opportunity to engage and create social bonds with customers and followers, with helps to improve corporate reputation (Nair, 2011).

To help filling this literature gap, this study presents an empirical case study to test the effectiveness of the online advertising techniques in horizontal social networks.

\section{Theoretical framework}

According to Barreto (2012), social network sites have three main functions: personal, social and infomercial. First, social network are build based on public profiles build by users that enter the network to express themselves, make comments, and share contents that become public. Secondly, social networks have an undeniable social aspect as they act as spaces where users can find other people with similar interests and share opinions, and all kinds of content (text, images, audio, and video). This imply that shared content has a wider diffusion thanks to the social network sites. Finally, social network sites are an excellent platform to broadcast information in which companies interact as the Internet allows for a direct and dynamic contact between firms and users or customers. Firms use social networks in order to promote their services, increase brand awareness, and understand shoppers better or get them involved in the co-creation of content. This implies a double informational and commercial interest (infomercial) by companies when using social networks.

Regarding the use of social networks in teaching environments, it is clear that universities need a consolidated social presence as their "customers": students, teachers, researchers, administrative staff... are in direct and daily contact with these platforms. By creating these profiles in horizontal social networks like Facebook, teaching centers can integrate the diverse community members together in an informal and participative environment that favors a better service quality. Besides detecting and solving problems, this channel acts as an excellent promotion means for prospective students, as $97.7 \%$ of the young Spaniards who are about to start university studies are present at one or more social networks (eTítulo, 2013). Accordingly, Facebook it the horizontal social network present at most Spanish universities with 8,413 followers on average (eTítulo, 2013) of which 58\% are students. The University of Salamanca is situated in the sixth place of the national ranking (Avanzaentucarrera.com, 2013) with 45,482 followers on their official Facebook profile. Most of these social pages interact with users by answering questions and comments from students, which favors interaction and increases the diffusion of contents. Most universities post several times a day, so their profiles are also up to date (eTítulo, 2013). 
Companies and organizations are aware of the power of advertising in the online world, as it is capable of adapt the content according to the rapid technological changes and, besides it implies a direct contact with the prospective customers. Companies have now a unique opportunity to connect with their customers by offering unique, adapted and personalized promotions using the social network sites (Ailawadi et al., 2009). This also means that online advertising has suffered from severe criticisms, as some users consider it to be deceitful, mean, abusive and annoying (Forrester Research, 2006). Bearing in mind the fact that these social networks may not be the ideal place to show annoying and intrusive advertisements, the platforms have redesigned their strategies so they can generate customer trust by using the power of social networks and the effects they have in the contact list of the users. If publicists progressively incorporate social elements to advertisement, it is easier for users to accept, cooperate and transmit the message. Moreover, peer and social pressure can turn users' attitudes, values or behaviors in regard of a company, brand or service so they conform to the group norms. This will ultimately increase potential customers (Barreto, 2012).

Following this theory, users become fans of a Facebook page, so they get the latest updates of the organization on their walls, and they can keep up with the latest promotions, latest arrivals, contests or relevant information. When users see this type of content they can indicate they like it using the "like button" and they can also share it. This makes information spread so it can reach other users that belonging to the fans' network. In this manner, a single user transmits broadcasts and expands the information generated in origin by a company. This is one of the reason several authors describe the remarkable characteristics (in terms of efficiency with a relative low cost) of the social networks as a way to distribute online advertising (Neff, 2009).

Authors such Harris and Rae (2009), point out that this social benefits can also extend to SMEs as brand awareness increases exponentially at a minimum cost. Furthermore, as Facebook allows for a complete personalization and segmentation of the targeted population in the campaign, unnecessary costs can be avoided (Anon, 2011). The positive impacts of an advertising campaign are also capable of improving the natural positioning (SEO) of a webpage (Lahuerta-Otero, Muñoz-Gallego and Pratt, 2014). Therefore, when businesses create public social profiles and interact successfully with their fans, the search engines improve the position of those websites the publications are mentioning. In this way, when a user is looking on the Internet for information related with these companies, their results will rank organically (without conducting a SEM paid advertising campaign) on the first positions of the search engine.

Companies using social media proclaim they are receiving measurable business benefits including increased sales and market size, improved customer satisfaction and relationships, improved employee relationships, better and faster technical support, reduced marketing expenses and improved search engine rankings (e.g., Angel and Sexsmith 2011; Askook and Nakata, 2011; Stelzner 2011).

\section{Methods}

This research will use the case study method to analyze the results obtained by a research group of the University of Salamanca (Spain) using Facebook ads campaigns. We will focus on the teaching part, as the case study method has been used before in similar environments (Roa, 2013; Chan 2011 and 2012). This group is dedicated to teaching in the new technologies area. They regularly conduct online and offline 
courses, seminars and conferences and they also have official masters and degrees. Their presence on social networks started back in 2012 when they created public profiles in horizontal social networks such as Twitter, Facebook, LinkedIn and Google + .

We chose to conduct an advertising campaign through Facebook as it is a simple, effective and economic way to promote teaching with a potential reach of 1.35 billion users worldwide. Facebook is the main global social network accounting for the 23.39\% of the worldwide traffic, and it is the main social network in Spain (Shareaholic, 2014). With 13.5 billion users and 864 million daily active users, this networks gets 1.8 million likes per minute and shares 41,000 publications every second (Qmee, 2013). Users mainly join this social network to look for friends, to get social support, to entertain themselves, to look for information and also due to its convenience. Consequently, we may say that users spend time on Facebook in search for social capital (Pikas and Sorrentino, 2014).

\section{Results and Discussion}

As observed in table 2, the case study presents extremely positive results. This center increases their fans number and publication's reach significantly. The description of the most important metrics and KPIs (key performance indicators) of the campaigns are described below:

- Reach: The number of people the ad was served to. The number of people reached is really high as with only 670 fans we got 417,000 people reached This means there is a chance to increase the contacts with other Facebook members in 4 persons for every fan in case 1, and of 662 persons for each fan.

- Impressions. The number of times the ad was served. We need to bear in mind that a high impression rate is necessary, as firms are never alone when advertising at a users' wall. This is the reason why in order to get a higher reach levels we see a 3-5 times frequency (on average) per every individual that sees the ad.

- Cost per 1,000 impressions (CMP). The average cost the firm pays to have 1,000 impressions on its ad. This cost will depend on the number of ads with similar segmentation criteria competing to appear on a users' wall. In this case, we can see that when competing with similar ads, the cost of publication (although economic) is bigger than in other similar Facebook campaigns. This may be because these ads have more general content and also stronger competence in this social network. The degree of engagement of the fans with the firm is also an important factor.

- Clicks. The number of total clicks the ad gets. We can observe that in both cases the number of clicks is remarkable, reaching 8,376 clicks. These results can be obtained thanks to a good strategic planning and content of the ad, as well as its attractiveness for the targeted users.

- Unique total clicks. The total number of unique people who have clicked on the ad. This is a very important metric as it allows us to know if our advertisements get several clicks from the same user. This means our ad is catching users' attention so they repeat the action to get informed on the proposed offer (26.83\%). This fact increases the chances that an individual will enroll on some of the teaching courses or seminars advertised. We can also observed that there is a significant different between clicks and unique clicks in both case studies, but the results are consistent as the landing website 
contains all information related to masters, $\mathrm{PhD}$ or courses offered by this research center.

- Click-Through Rate (CTR). The number of clicks the ad gets, divided by the number of impressions. This metric indicates the effectiveness of the publicity. In this case we can see that ads get an important number of clicks related with impressions (CTR = 0.47). This means that the ads on this case study is related with high-demand teaching areas, so the potential students are willing to show an interest on the ads.

- Cost per click (CPC). The average cost per click for these ads, calculated as the amount spent divided by the number of clicks received. As shown in table 1, the cost for clicks when the objective is to get website clicks is lower (3 times less on average). This result is logical as when users click on the like button, they show a big commitment with the page. They will get the latest news and updates about the research centers and some individuals do not want this kind of information to appear on their Facebook wall. Nevertheless, the relative cost of Facebook ads campaigns is lower compared to other type of similar platforms where the CPC can be 15 or more times higher (e.g. Google Adwords).

- Actions: the number of actions taken on the page, page app or event after the ad was served to someone, even if they did not click on it. Actions include page likes, comments, shares, app installs, conversions, event responses and more. Results show that the center got the most actions when getting website clicks. Raisons may be the won content of the ad, and also the great amount of information an individual gets by visiting the landing page. However, the ads created to increase the number of "likes" got worse results, as explained above.

- Money spent: total money spent on a particular campaign. The cost of the different ad sets was below the established budget for both case studies, as campaigns were redefined to adjust budget depending on the ads' needs (more money was spend on the website clicks campaign than on the "likes" one).

Table 1. KPI of the different Facebook campaigns on the case study.

\begin{tabular}{|c|c|c|}
\hline & \multicolumn{2}{|c|}{ Results } \\
\hline Initial campaign date & $08 / 09 / 2014$ & $31 / 07 / 2014$ \\
\hline End campaign date & $01 / 11 / 2014$ & $30 / 10 / 2014$ \\
\hline Objective & Website clicks & Page likes \\
\hline Reach & 416.979 & 8.429 \\
\hline Frequency & 4,263423 & 3,210108 \\
\hline Impressions & 1.777 .758 & 27.058 \\
\hline CPM (Euros) & 0,30224 & 0,845591 \\
\hline Clicks & 8.376 & 126 \\
\hline Total unique clicks & 6.604 & 122 \\
\hline Click-through rate (CTR) & 0,471155 & 0,465666 \\
\hline CPC (Euros) & 0,064149 & 0,181587 \\
\hline Actions & 6.789 & 52 \\
\hline Total spent (Euros) & 537,31 & 22,88 \\
\hline
\end{tabular}




\section{Conclusions}

In the light of the results obtained by the two case studies, this research shows the efficacy of advertising in horizontal social networks to promote teaching-related content. The success of both campaigns was bigger than expected, thanks to the improvement of the attention and awareness from Facebook users to the organizations. However, we need to point out that impressions or clicks do not necessary mean attitudes or future students' behaviors, as we did not measure conversions in this research.

As our results show, a well-structured and oriented campaign may have a significant reach. This makes these social platforms a valuable tool to sell and promote universities. However, we need to highlight that in order to reach its potential, advertising campaigns need to act on Facebook pages with a sufficient number of users. This also means that Facebook pages content must be updated, relevant and carefully designed so universities and faculties can create an own social brand among users (Chan, 2011).

It should be noted that faculties or research centers dependent on public universities do not have a large advertising budget. Our study reveals that the use of paid advertising in horizontal social networks can become an effective communication solution without wasting resources away. The effort in terms of time, resources and money is relatively small compared to the good results obtained. This is the reason why we can affirm that horizontal social networks are a good communication platform for organizations involved in teaching, which can increase the ratio of enrolled students in the different activities promoted such as courses, research seminars, degrees or conferences.

Thanks to the big development of the advertising tools in the social networks (especially in Facebook and Twitter), there is greater flexibility to launch diverse campaigns adapted to a segmented targeted population. These characteristics allow for further promotion and diffusion possibilities among potential users, which would be difficult to reach using traditional media.

In this line, the new 2.0 advertising techniques, more precisely the use of the Facebook Ads tool, allows for the creation of fully personalized and segmented publications, adapted to the target university's need in every one of the ad sets. Accordingly, social network sites become a powerful and original information and promotion tool that channels and understands the needs of their users' community (which differ depending on the role of the user: follower, student, teacher, prospective student, administrative staff...) and meets them in a personalized and specific manner.

These advertising techniques are cost-efficient and innovative, and so they become an excellent attraction tool for prospective students. Consequently, we strongly recommend that both public and private universities, aware of this new technological change, adapt their communication strategies so they include active social profiles in the most relevant horizontal social network sites: Facebook, Twitter, LinkedIn, Google + or even Instagram.

\section{Limitations and further research lines}

The present research suffers from several limitations that we intend to improve with future studies. First, even if the quantitative results seem to indicate the campaign's success, we cannot prove the real impact of the advertising on users. Future research 
should collect the opinion of the recipients of advertising in order to prove their real effectiveness. Moreover, we cannot deny that many social network users are reluctant to advertising, so the ignore the ads they are exposed to. Consequently, this variable should be taken into account in future studies to measure the advertising effectiveness more precisely. Furthermore, this case study belongs to a teaching center with already consolidated social profiles located in the same city of a single country, so future studies should enlarge the sample to study the effects of these campaigns in different contexts. It would also be relevant to collect data on other, alternative campaigns available on Facebook, as well as the effect that, within the same campaign, different ads have on the targeted public in order to determine the most effective attraction factors (content, image, design, ad placement...). Due to the fact that the number of social network users grows every day, it is logical to think that future research will aim to determine the most effective variables to include in this new, innovative online advertising techniques.

\section{References}

Ailawadi, K.L.; Beauchamp, J.P.; Donthu, N.; Gauri, D.K. \& Shankar, V. (2009). Communication and promotion decisions in retailing: A review and directions for future research, Journal of Retailing, 85(1), 42-55.

Angel, R., \& Sexsmith, J. (2011). Social Networking: The Corporate Value Proposition. Available at: http://iveybusinessjournal.com/topics/leadership/social-networkingthe-corporate-value-proposition\#.VL90JUeG840

Anon. (2011). Friends in online places, Strategic Direction, 27(10), 19-22.

Askool, S., \& Nakata, K. (2011). A conceptual model for acceptance of social CRM systems based on a scoping study. AI and Society, 26(3): 205-220.

Avanzaentucarrera.com. (2013). Las universidades en las redes sociales, available at: http://www.avanzaentucarrera.com/llegaraser/especiales/especial-carreras/lasuniversidades-en-las-redes-sociales/

Barreto, A.M. (2012). Do users look at banner ads on Facebook?, Journal of Research in Interactive Marketing, 7(2), 119-139.

Chan, C. (2011). Using online advertising to increase the impact of a library Facebook page, Library Management, 32(4/5), 351-370.

Chan, C. (2012). Marketing the academic library with online social network advertising, Library Management, 22(8/9), 479-489.

Cordero-Gutiérrez, R. \& Santos-Requejo, L. (2014). La confianza y la actitud hacia la red social como determinantes de aceptar herramientas de marketing. Diferencias según intensidad de uso de la red, DOCFRADIS, Colección de documentos de trabajo Cátedra Fundación Ramón Areces de Distribución Comercial, DOC 03/2014

Criado-Grande, I. (2012). Redes sociales y open government. Hacia unas administraciones locales en red y abiertas, Revista Democracia y Gobierno Local, 18/19, 5-12.

eTítulo. (2013). Informe eTítulo 2013, desarrollo e influencia de las TICs en la universidad española, available at: https://www.signe.es/sites/www.signe.es/files/eTitulo\%20informe\%20TIC2013.p df 
Forrester Research (2006). Consumers love to hate advertising”, Forrester Research, Cambridge, MA.

Harris, L. \& Rae, A. (2009). Social networks: the future of marketing for small business, The Journal of Business Strategy, 30(5), 24-31.

IAB Spain (2014). La publicidad digital aumenta su peso en el reparto de la inversión publicitaria, available at: http://www.iabspain.net/noticias/la-publicidad-digitalaumenta-su-peso-en-el-reparto-de-la-inversion-publicitaria/.

Lahuerta-Otero, E., Muñoz-Gallego, P.A \& Pratt, R. (2014). Click-and-mortar SMEs: Attracting customers to your website?, Business Horizons, 57(6), 729-736.

Musser, J \& O’Reilly T. (2006). Web 2.0 principles and best practices, O’Reilly Radar, ISBN-0-596-52769-1.

Nair, M. (2011). Understanding and measuring the value of social media. The Journal of Corporate accounting \& Finance, 22(3) 45-51.

Neff, J. (2009). Study: ROI may be measurable in Facebook, MySpace after all, Advertising Age, 80(12), 1.

ONTSI. (2011). Las Redes Sociales en Internet, available at: http://www.ontsi.red.es/ontsi/es/estudios-informes/estudio-sobre-elconocimiento-y-uso-de-las-redes-sociales-en-espa\%C3\%B1

ONTSI. (2013). Perfil sociodemográfico del internauta, análisis de datos INE 2013, available http://www.ontsi.red.es/ontsi/sites/default/files/perfil_sociodemografico_de_los_i nternautas_2013_0.pdf

Pikas, B. \& Sorrentino, G. (2014). The effectiveness of online advertising: consumer's perception of ads on Facebook, Twitter and YouTube, Journal of Applied Business and Economics, 16(4), 70-81.

Qmee (2013). What happens online in 60 seconds, available at http://blog.qmee.com/qmee-online-in-60- seconds/

Roa, J.M (2013). Las redes sociales, una potente herramienta al servicio del Open Government, Las redes sociales digitales en la gestión y las políticas públicas. Barcelona: Escola d’Administració Pública de Catalunya.

Shareaholic. (2014). Facebook and Pinterest are the King and Queen of Social Referralls, available at: https://blog.shareaholic.com/social-media-traffic-trends04-2014/

Stelzner, M. A. (2011). 2011 Social Media Marketing Industry Report: How Marketers Are Using Social Media to Grow Their Businesses. Available at: http://www.socialmediaexaminer.com/social-.

Stephen, A. T \& Galak, J. (2010). The complementary roles of traditional and social media publicity in driving marketing performance, Faculty and Research working paper, INSEAD, 2-40. 


\title{
Observatorio de la Calidad de la Información en Televisión. A Research and Teaching Project: 'Cloud' Analysis of Contents. Collaborative and Interactive Learning
}

\author{
R. Díaz Arias, J. Sotelo González \\ Universidad Complutense de Madrid
}

\begin{abstract}
The Observatorio de la Calidad de la Información en Televisión (Observatory for the Quality of Information on Television) of the School of Media \& Communications Science of the Complutense University of Madrid is a project for the innovation and enhancement of teaching quality. The project seeks to use the course titled Information on Television to forge links between research and training, between theory and practice. Using a special-purpose online platform for collaborative and interactive work, students engage in the analysis of the contents of news programs in the five nationwide TV networks active in Spain. Throughout the project, students acquire, in addition to other skills and further knowledge, academic and professional competencies around the topic of television information. Participants recognize this teaching and learning initiative as highly satisfactory and beneficial.
\end{abstract}

Keywords: Observatorio; Observatory; news programs; television; content analysis; teaching innovation project; journalism.

\section{Introduction}

It is well known that University professors devote their time to both teaching and research activities. While both compete for the professors' dedication, they also interact in positive ways. Spanish universities often suffer from a lack of integration between research projects and teaching activities, the latter favoring theory at the expense of practice. The project that we are introducing in this paper aims precisely at establishing links between research and teaching, and between theory and practice. The project stakeholders are, furthermore, convinced that there is a need for platforms for the collaboration and interaction between teachers and students. To this end, a group of professors from the Journalism II Department of the School of Media \& Communications Science of the Complutense University of Madrid (UCM) has launched the Observatorio de la Calidad de la Información en Televisión during the 2014-2015 academic year with a twofold purpose: 1) to devise a permanent tool for the analysis of the contents of TV news programs, and 2) to develop practical training mechanisms for the Journalism Degree students taking the Information on Television course during their fourth year. The project is, therefore, both a research project and an educational one.

The inception of the project goes back to the second term of the 2013-2014 academic year, when initial tests were carried out with just one group of students. In view of the positive results of the pilot, the project was extended to seven groups of students (seven classes). Nine professors are involved in the Observatorio de la Calidad de la Información en Televisión, four of which teach the Information on Television course. The project was submitted to the 2014 Call for the Recognition and Funding of Projects for the Innovation and Enhancement of Teaching Quality organized by the UCM, and was rated very positively. We are currently waiting for the relevant call to establish a UCM Emerging Research Group.

Throughout the next pages we offer our educational experience with the Observatorio. In order to that first it all we review briefly the theoretical framework to stop right after in 
methodological questions to develop the project. Finally we analyze the project results and from them we close our statement with conclusions.

\section{Theoretical framework}

As pointed out by M. I. Molina, “teaching and research have coexisted in education as two separate activities due to, among other reasons, the different concepts used by teachers and researchers" (2010, p. 1). As for the theory-practice dichotomy, theory and practice seem at times to shape two independent realities that manage knowledge with various degrees of significance, and seem to breed constant tension between them: they need each other, and one explains the other, but oftentimes they engage in mutual disregard, and this rupture has become one of the major sources of issues in teachinglearning processes (Álvarez, 2012).

Teaching is an interactive, reflective activity (Rajadell, 1993). It is interactive in that it guides learning, which is an educational transformation involving the three dimensions of individuals: the cognitive one (knowing), the effective one (doing) and the affective one (being). And it is reflective because teaching also implies training critical minds, in other words, 'making others think.' Departing from these premises, we decided to develop an educational project related to the teaching of televisual journalism and targeting the development of the aforementioned personal dimensions of our students: the cognitive dimension — through the acquisition of theoretical knowledge-; the effective dimension - by putting theory into practice-, and the affective dimension - by stimulating students in various ways.

Any course that sets out to provide students the required professional skills and competences (González and Wagenaar, 2003) to use the television for informative purposes needs to combine theoretical and practical approaches. Theory: the role of television as an information media in democratic societies; languages; genres and formats; and production practices, including the generation of information and the editing of programs. Practice must deal with analytical and synthetic exercises. The former, to dissect discourses and to reflect on their contents and structure. The latter, to generate information that is suitable for TV. Normally, in this project, these synthetic exercises basically materialize in the creation of a news program by groups of students, including the generation of each piece of news, and the edition and production of a complete news program. Until now, analytical exercises had been developed at the classroom level, following the different guidelines defined by each professor. The Observatorio de la Calidad de la Información en Televisión has provided a shared analysis model for all groups, professors and students, and a platform for collaborative and interactive work, which contribute an environment that nurtures student autonomy and accountability with regard to the learning process itself (Marín et al., 2011; Torrelles et al., 2012).

\section{Methods}

The project proposes the continual monitoring of the quality of information on television in Spain. To that end, a number of quality parameters were defined that, for simplification purposes, can be summarized as two: pluralism and professional treatment. Pluralism: diversity of locations, informative agents, and topics. Professional treatment: sources, balance, genres and formats, 'soft' and 'hard' information. 
The driving force behind the project is a permanent technology platform for the analysis of the contents of news programs in the five nationwide TV networks active in Spain. The unit of analysis is the piece of news (format-defined information). Analysis variables are organized around the scope of information, who speaks and about whom, what is being discussed, and how (type of sources, images, rethorical treatment, balance, contextualization, fit with the TV network). The analysis was completed in two waves during fall and spring. 43 news programs were analyzed during the 2014 fall term, or 1.753 pieces of news. Results were basically quantitative. It is well known that Social Sciences quantitative research has limitations and shortcomings that need to be addressed by combining it with qualitative research. Notwithstanding this, quantitative results provide insight for the subsequent development of more specific qualitative studies based on the information collected.

We decided to allocate two students to the analysis of each news program. One of them records or downloads the appropriate program and uploads it to a video repository so that the other member of the team and the supervising professor can watch it. The two students take on the roles of analyst and supervisor in turns. One student completes the analysis of the first half of the news program and the other reviews the analysis, and vice versa for the second half of the news program. Corrections made by each reviewer are inputted in the database, so that a Coding Reliability Index can be derived in the end. A professor verifies the analysis and its compliance with the applicable protocols. The students need to complete and review their analyses within one month from the date of broadcasting of the news program.

This project is voluntary, because it calls for a level of commitment that would not be found in certain students if the project were mandatory. The students who decide not to participate in the project are assigned alternative work involving the overall analysis of news programs. This would be an individual piece of work with little interaction with their professor, apart from the usual problem-solving. On the other hand, the students who participate in the project get to experience an environment in which they collaborate and interact with students and professors from different class groups, thus nurturing cooperation strategies and skills (García et al., 2001). All project participants, both students and professors, interact mostly through a specific forum that has been set up in the Virtual Campus. Students can make questions that professors resolve while they reinforce analysis criteria. In addition, as new hot topics appear, professors provide guidelines for their analysis: general categories to be used, tags and keywords. Lastly, upon conclusion of their work, students put together a report including lessons learned about the course as well as their overall project experience. Those students who sign up for the Observatorio de la Calidad de la Información en Televisión and successfully complete all the assignments are awarded two free elective credits.

Participants attend an initial two-hour lesson on the nature of the project, its operation, the fields of analysis, and the values of each specific variable. It must be noted that some significant components of this analysis (sources, formats, genres, treatment) relate directly to the theory that students are exposed to in the course. Coding protocols are previously defined, as in any other content analysis project. In this regard, students have access to all the necessary documents through the Virtual Campus: operations manual, analysis and review protocol, and variable categories charts. This information is also included in the database application associated to each data field that students need to fill out.

The analysis database is powered by Xolomon, a data management and analysis application available to UCM faculty and staff. Some research (Gil et al., 2011) suggests 
that the use of this type of resources in work groups can further collaborative learning. Following a preliminary pilot completed using Google Forms, the project team developed a more powerful, Xolomon-powered database. This database contributes the ability to assign tasks to each team, and to limit group access rights to their own tasks, thus preventing interference between difference groups. The design of the Xolomon-powered database was supported by Xolomon professionals. A special acknowledgement should be made of the support provided by Carmen Bravo, of the UCM Research Support Unit, to make sure that the data structure was suitable for subsequent statistical analysis. The database is hosted in the UCM servers and can be accessed by students and professors from any Internet connection. This allows professors to monitor student work, make individual or collective remarks or suggestions, and issue new guidelines as the analysis progresses.

The UCM Virtual Campus (Moodle 2.6) acts as a meeting point for all project participants. It is used to assign news programs, upload work documents, share preliminary data reporting and, most importantly, to channel interaction through its forum (or, at an individual level, through the Virtual Campus email or instant messenger application). The Virtual Campus is also used by students to upload their project summary report, and by professors to post the lists of students who have successfully completed each assignment and who have been granted the appropriate credits.

The Observatorio de la Calidad de la Información en Televisión has its own NAS (Network Attached Storage) drive, which was acquired with the funds awarded following the aforementioned Call for Recognition and Funding of Projects for the Innovation and Enhancement of Teaching Quality organized by the UCM. Following analysis, videos are stored in the NAS drive for verification and use in subsequent qualitative research projects. Lastly, data are subject to statistical analysis using IBM SPSS Statistics version 19 and SAS 9.4 software, although students are not involved in this final analysis.

\section{Results and Discussion}

By participating in the Observatorio de la Calidad de la Información en Televisión, students:

- dissect news programs to study their contents, observe their degree of pluralism, and understand the processes used to edit pieces of news in different formats and genres. These are fundamental competencies for their training as future television information professionals;

- input information in a database, which allows them to learn the use of these information sorting and classification tools. In addition to this, while performing these tasks, students categorize information events according to general labels. These skills are useful for information management purposes;

- get exposed for the first time to one of the most widely used research techniques in the communication field, content analysis, which they can later on harness to complete their Graduation Dissertations and during a subsequent academic career.

In their project summary reports, students rate this teaching-learning experience as being positive or very positive. Virtually all of them stress the fact that, although they are close to graduation, they had never approached TV news programs from such professional and academic perspectives. They admit to being, until now, passive spectators uneducated to appreciate content diversity, sequencing and editorial treatment. Several students are 
surprised that they have not been exposed to similar exercises until now, and they acknowledge that this project has helped them to find a purpose for previously acquired knowledge. The following three quotes taken from project summaries reports are testament to these views:

"I have learned, first of all, how to put four years of theory on journalism genres into practice. This has allowed me to see what goes into creating a headline, to look for the use of the 5 W's, to tell a piece of news apart from a feature story, and to analyze what information should news anchors provide not to overlap the information provided by reporters, and vice versa. I have also learned how to structure a news program, the types of pieces of news included in them, and how they work."

"The Observatorio has allowed be to build a mental picture of the running order of a news program, of the production process behind the program, and of the elements that shape up the program.”

"We get to practice everything that we have learned, thus helping us to single out our weaknesses and areas for improvement, while allowing us to see the reality behind news programs and appreciate the amount of work that goes into them. I feel it would be beneficial to develop similar projects for other course dealing with other media such as the radio or written press."

Only 3 of the project's 86 participants (from a potential participant base of 240) failed to complete their assignments, while two others left the project after the first week and were replaced.

A number of students confess their initial reservations towards group work. While some studies analyze student profiles in order to build ideal groups and improve group performance (Durán, 2006), and others issue recommendations based on different variables (Haller et al., 2000), our project decided to charge professors with assembling work pairs rather randomly, instead of having students deciding who they would like to work with. In general, participants report good group coordination and a good experience in this regard too.

Based on project results, it can be said that the predefined analysis rules are clear, and that the category definitions included in the database facilitate work. The students appreciate the guidance received through the (Virtual Campus) forum, despite some complaints about people disrupting the forum operation by making personal queries (e.g., questions about lost access credentials). For some students, the project was 'enjoyable', while for others it was overly thorough.

Most complaints are related to the use of the Xolomon platform. Although users find it to be intuitive, they (rightfully) complain about the platform freezing every time there was a mistake while inputting dates or durations, which made it impossible to continue working on the affected record. In addition, they find it inconvenient to have to save their work before the application automatically logs them off after twenty minutes.

\section{Conclusions}

The project proves that a direct link can be successfully established between teaching and research, also along the lines of using "research as a form of teaching", to trigger students research appetite. The provision of a scenario for collaboration and interaction beyond the classroom makes practical training and skills acquisition more homogeneous and coherent (Fleury \& Fleury, 2001). The students experience an instance of team work using 
various technology platforms; they rate the activity very positively, and regret not having been exposed to similar opportunities earlier during their degree.

\section{References}

Álvarez, C. (2012). La relación teoría-práctica en los procesos de enseñanza-aprendizaje. Educatio Siglo XXI, 2 (30), 383-402.

Duran, E. B. (2006). Modelo del alumno para sistemas de aprendizaje colaborativo. Actas del Workshop de Inteligencia Artificial en Educación, Mendoza (Argentina), 11-15. From:

http://www.researchgate.net/publication/228733123_Modelo_del_alumno_en_siste mas_de_aprendizaje_colaborativo

Fleury, M. T., Fleury, A. (2001). Construindo o conceito de competência. Revista de Administração Contemporânea (RAC), special number, 183-196. From http://www.scielo.br/pdf/rac/v5nspe/v5nspea10.pdf

García, R., Traver, J. A., Candela, I. (2001). Aprendizaje cooperativo: fundamentos, características y técnicas. Madrid: CCS.

Gil, C., Montoya, M. G., Herrada, R. I., Baños, R., Montoya, F. G., Manzano-Agugliaro, F. (2011). Cooperative learning and electronic group portfolio: tutoring tools, development of competences and assessment. International Journal of Learning Technology, 6 (1), 46-61.

González, J., \& Wagenaar, R. (Eds.) (2003). Tuning Educational Structures in Europe. Informe Final, Fase 1. Bilbao: Universidad de Deusto. Web site:

http://www.unideusto.org/tuning/tuningal/index.php?option=com_docman\&task=down \&bid=3

Haller, C. R., Gallagher, V. J., Weldon, T. L., Felder, R. M. (2000). Dynamics of peer education in cooperative learning workgroups. Journal of Engineering Education, 89 (3), 285-293.

Marín, V., Ramírez, A. \& Sampedro, B. (2011). Moodle y estudiantes universitarios: dos nuevas realidades del EEES. Profesorado, Revista de Currículum y Formación del Profesorado, 15 (1), 109-120. From http://www.ugr.es/ recfpro/rev151ART7.pdf

Molina, M. I. (2010). El vínculo docencia-investigación: una respuesta a la necesidad de pensamiento crítico. Razón y Palabra, 73. From http://www.razonypalabra.org.mx/N/N73/Varia73/24Molina-V73.pdf

Rajadell, N. (1993). Estrategias de intervención educativa: estrategias de enseñanza y estrategias de aprendizaje. Barcelona: PPU.

Shön, D. A. (2000). Educando o Profissional Reflexivo: um novo design para o ensino e a aprendizagem. Porto Alegre: Artes Médicas Sul.

Torrelles, C., Coiduras, J., Isus, S., Carrera, F. X., París, G. \& Cela, J. M. (2012). Competencia de trabajo en equipo: definición y categorización. Profesorado, Revista de Currículum y Formación del Profesorado, 15 (3), 329-344. From http://www.ugr.es/ recfpro/rev153COL8.pdf 
HEAd'15

SESSION 3A

ECONOMICS 


\title{
Does family background affect job allocation for college graduates in China?
}

\author{
Changjun YUE \\ Peking University, China
}

\begin{abstract}
Based on large-scale national survey data on college graduates employment in China, this paper explores the impact of family background on job allocation, through both descriptive and regression analyses. The result shows as follows. Firstly, family occupational, educational and regional status are significant influential factors. College graduates with better family occupational and educational background, living in big/medium cities have more chances to enter Emerging Industry, Monopoly Industry, Government Industry and SECH Industry. Secondly, College graduates with better family occupational and educational background, living in big/medium cities have more chances to enter Governments Sector and State-Owned Enterprise. Better family educational background may help college graduates enter Foreign-Invested Enterprise. Since the difference between the primary and secondary labor market is very large, the finding that college graduates with better family socio-economic background have more chances to enter primary labor market reveals an unfair competition in China.
\end{abstract}

Key words: higher education; employment allocation; labor market

\section{Introduction}

Since the implementation of the reform and opening door policy in 1978, China has enjoyed a long-term and fast-growing economic boom. China's GDP reached to about 10.4 trillion US dollars in 2014 (National Bureau of Statistics, 2015). Meanwhile, the income gap is so large that the Gini coefficient in 2014 exceeded 0.469. Income gap in China reveals among industries, sectors, cities, regions and so on.

Since 1999, the scale of higher education in China began to expand quickly and the entrance rate of higher education has greatly improved. In 2002, the gross entrance rate of higher education reached $15 \%$, indicating that China entered the era of mass higher education. By 2013, the rate rose to 34.5\% and the gross scale of higher education reached 34.6 million (Ministry of Education, 2014). Meanwhile, the number of college graduates increased gradually, which rises to 7.49 million in 2015. The employment of college graduates has become a key problem faced by Chinese government. College graduate not only feel difficulty to find a job but also feel hard to get a good job which can reach their expectation. Because China's job market is still in transition, the wages in different industries/sectors vary a lot. The theory of labor market segmentation can explain the huge gap between the primary sector and the secondary sector in China. Usually, people working in emerging industry and monopoly industry or in Foreign-invested enterprises and State-owned enterprises can obtain higher wages.

Parents' education, income, or occupations affect children's education and their earnings, and the wage premium of having a cadre parent is $15 \%$ (Li, 2012). Father's education had positive impacts on a Chinese college graduate's educational and employment outcomes (Li, 2010). Wang (2012) found the college premium is larger for people in state-owned enterprise in China. Is job allocation determined by merit? Does family background play an important role? May college graduates from families of higher socioeconomic status have higher earnings than those of lower socioeconomic status? This paper will focus on the job distribution of Chinese college graduates from different family backgrounds. 


\section{Sample description}

\section{Data}

The data set is from National College Graduates Employment (NCGE) survey conducted by Peking University in June, 2013. This survey includes 30 universities/colleges in 21 provinces. There are nine "211-Project" universities which means elite universities in China, nine ordinary universities, seven two-year colleges or vocational colleges, three independent college, and two private universities. The survey records students' demographic characteristics (including family background), scholarly performance, perception and activities with regard to job search, and final outlets including job location and starting salaries. There are 15060 valid sheets turned in. This paper selects a subsample which only includes students with a bachelor degree. After excluding the observations with missing or invalid values of the key variables, our final sample contains 10206 individuals.

\section{Variable description}

Industry: There are 19 kinds of industries in China, this paper merged them into 6 groups. The first group is Emerging Industry including "Information Transmission, Software and Information Technology", "Financial Intermediation" and "Real Estate". The second group is Government Industry including "Public Management, Social Security and Social Organization". The third group is SECH Industry including "Scientific Research and Technical Services", "Education", "Culture, Sports and Entertainment" and "Health and Social Service". The fourth group is Monopoly Industry including "Production and Supply of Electricity, Heat, Gas and Water", which is related to natural resource and owned mainly by state. The fifth group is Manufacturing Industry which belongs to a relative competitive market. The sixth group is Other Industry including 9 remaining industries, namely: "Agriculture, Forestry, Animal, Husbandry and Fishery" ,"Mining”, "Construction”, "Wholesale and Retail Trades", "Transport, Storage and Post”, "Hotels and Catering Services", "Leasing and Business Services", "Management of Water Conservancy, Environment and Public Facilities”, “Services to Households, Repair and Other Services”.

Sector: There are 12 kinds of sectors in the survey. This paper merged them into six groups as follows: Governments, State-Owned Enterprise, SECH Sector (Science, Education, Culture, Health and so on), Foreign-Invested Enterprise, Domestic Private Enterprise, and Other Sector.

Family occupational status: This paper deals family occupational status with parents' occupation as a proxy variable and analyzes its influence on student's employment opportunity. 9 major types of occupations are involved in the survey. According to specific national conditions, this paper defines levels of occupations as follows: (1) government official, organizational staff, manager and specialist, all of which enjoy higher social prestige, as "Upper occupation". (2) Individual businessman, sales, private entrepreneur, laborer, rural migrant worker and farmer, which enjoy lower social prestige, as “Lower occupation”.

Family educational status: This paper deals family educational status with parents' academic qualification as a proxy variable. The types of parents' academic qualifications in the survey are classified into seven groups. This paper defines the former 3 groups (graduate school, 4-year university and 2-year college) as "College 
degree and above", and the latter 4 groups (high-school \& equivalence, junior middle school, primary school, and illiterate or semiliterate) as "High school and below".

Family economic status: Family income per capita is a key variable of the economic family background. It is a categorical variable with seven intervals in the survey. This paper defines family with income per capita less than 10,000 Yuan as "Low income", family with income per capita between 10,001 Yuan and 20,000 Yuan as "Middle income", family with income per capita greater than 20,001 Yuan as "High income".

Family regional status: In the survey home area is classified into five groups. This paper defines metropolis and medium city as "Big/middle city", and county/town, small town and countryside as "County and below".

\section{Statistical description}

Table 1 shows the comparison on monthly starting salary. It shows that college graduates from families of higher socioeconomic status have higher earnings than those of lower socioeconomic status. (1) The monthly starting salary of college graduates from families of upper occupation is $12.0 \%$ higher than that of other college graduates. (2) The monthly starting salary of college graduates from families of college education and above is $13.4 \%$ higher than that of other college graduates. (3) The monthly starting salary of college graduates from families of middle income and high income are $8.8 \%$ and $18.4 \%$ higher than that of college graduates from families of low income, respectively. (4) The monthly starting salary of college graduates from families of big/middle city is $6.2 \%$ higher than that of other college graduates.

Table 1. Statistical description of monthly starting salary

\begin{tabular}{|c|c|c|c|}
\hline Variable & Mean(Yuan) & Std. Dev.(Yuan) & $\mathrm{N}$ \\
\hline \multicolumn{4}{|l|}{ By parents' occupation: } \\
\hline Lower occupation & 3155 & 1281 & 2356 \\
\hline Upper occupation & 3533 & 1655 & 919 \\
\hline \multicolumn{4}{|l|}{ By parents' education level: } \\
\hline High School and below & 3156 & 1279 & 2375 \\
\hline College degree and above & 3578 & 1676 & 849 \\
\hline \multicolumn{4}{|c|}{ By annul family income per capita: } \\
\hline Low income family & 3006 & 1238 & 1129 \\
\hline Middle income family & 3272 & 1294 & 1196 \\
\hline High income family & 3558 & 1667 & 922 \\
\hline \multicolumn{4}{|l|}{ By Home location: } \\
\hline County and below & 3172 & 1283 & 1794 \\
\hline Big/middle city & 3370 & 1530 & 1419 \\
\hline
\end{tabular}


Table 2 shows the comparison on monthly starting salary by employment industry. It shows that there are significant gaps among the incomes of 6 kinds of industries. Emerging Industry enjoys the highest monthly starting salary averaging 3660 Yuan. Monopoly Industry ranks the second highest monthly starting salary averaging 3317 Yuan. Thus, most college graduates regard these two industries as ideal employment goal. Although the monthly starting salaries of both Government Industry and SECH Industry are not high, these two industries in China have more invisible welfare and benefited from stable jobs and better working environment. Therefore, these two industries also receive welcome from college graduates.

Table 2. Monthly starting salary comparison by industry (Yuan)

\begin{tabular}{lcccccc}
\hline \hline Industry & $\begin{array}{c}\text { Emerging } \\
\text { Industry }\end{array}$ & $\begin{array}{c}\text { Government } \\
\text { Industry }\end{array}$ & $\begin{array}{c}\text { SECH } \\
\text { Industry }\end{array}$ & $\begin{array}{c}\text { Monopoly } \\
\text { Industry }\end{array}$ & $\begin{array}{c}\text { Manufacturing } \\
\text { Industry }\end{array}$ & $\begin{array}{c}\text { Other } \\
\text { Industry }\end{array}$ \\
\hline Salary & 3660 & 3132 & 3043 & 3317 & 3129 & 3114 \\
\hline \hline
\end{tabular}

Table 3 shows the comparison on monthly starting salary by employment sector. It shows that there are significant gaps among the incomes of 6 kinds of sectors. Foreign-invested enterprise enjoys the highest monthly starting salary. State-owned enterprise ranks the second place. These two sectors are college graduates' ideal job units. Although the monthly starting salaries of both Government sector and SECH sector are not high, these two sectors can provide more invisible welfare, job stabilization and better environment. Thus, these two sectors are also college graduates' choice.

Table 3. Monthly starting salary comparison by sector (Yuan)

\begin{tabular}{lcccccc}
\hline \hline Sector & Governments & $\begin{array}{c}\text { State-owned } \\
\text { enterprise }\end{array}$ & SECH & $\begin{array}{c}\text { Foreign- } \\
\text { invested } \\
\text { enterprise }\end{array}$ & $\begin{array}{c}\text { Domestic } \\
\text { private } \\
\text { enterprise }\end{array}$ & Sector \\
\hline Salary & 3251 & 3387 & 2909 & 3625 & 3133 & 3207 \\
\hline \hline
\end{tabular}

\section{Regression analysis}

\section{Regression model}

This section analyses the influential factors on college graduates' job allocation using regression model. The dependent variable represents different types of industries/ sectors, so it is a categorical dependent variable, with the value equals to $1,2,3,4,5$ and 6, respectively. Therefore, Multinomial Logit model will be used, with one type as the base category. This paper sets the group of Manufacture Industry / Domestic private enterprise as base category. The regression model of is as follows:

$$
\operatorname{Logit}\left(P_{i / 5}\right)=\ln \left(\frac{P(Y=i \mid X)}{P(Y=5 \mid X)}\right)=\beta_{i 1}+\beta_{i 2} X_{2}+\cdots \beta_{i K} X_{K} \quad(i=1,2,3,4,6)
$$

The independent variables can be divided into three groups. The first group is graduates' family background variables including: (1) Parents' occupation. (2) Parents' schooling year on average. (3) Family economic status, classified into Low income family (accounting for 37.5\%), Middle income family (accounting for 35.4\%), 
and High income family (accounting for 27.1\%), using Low income family as the base category. (4) Home location. The second group is individual personal characteristics, including: (1) Gender. (2) Minority or not. (3) Only one child or not in family. The third group is graduates' human capital variables, including: (1) College's prestige, classified into "211-project" elite university, ordinary four-year university, other university (two-year college or vocational college, independent college and private university), with the last one as the base category. (2) Academic grades, classified into top 25\% group and last $75 \%$ group. (3) English certificate. (4) Communist Party of China (CPC) member.

\section{Regression results}

Table 4 shows the regression results examining the effect of family background on the job opportunity of college graduates to enter each industry. In general, family occupational, educational and regional status are all significant influential factors on chances to enter Emerging Industry, Monopoly Industry, Government Industry and SECH Industry compared to Manufacturing Industry. Graduates with better family occupational and educational background, living in big/medium cities have more chances to enter Emerging Industry, Monopoly Industry, Government Industry and SECH Industry.

(1) Parents' occupation is a significant explanatory variable, as three out of four coefficients of it are positive significantly, indicating that students with superior occupational background have better chance to enter Emerging Industry, Government Industry and SECH Industry. (2) Parents' average schooling year is also a significant explanatory variable, as two out of four coefficients are positive significantly, indicating that students with high academic qualification family have better chance to enter Emerging Industry and Monopoly Industry. (3) Home location a significant explanatory variable as well, since three out of four coefficients are positive and statistically significant, indicating that students living in big/medium cities have better chance to enter Emerging Industry, Monopoly Industry and SECH Industry. (4) Family economic status seems not to be an important variable since most of coefficients are insignificant. The reason may be that the family income per capita is not an ideal variable in that most students don't know the exact number of family income. Besides, human capital and personal characteristics also play important roles on job allocation. Graduates with good academic grades from elite university and from one-child family have better chance to enter Emerging Industry, Monopoly Industry, Government Industry and SECH Industry compared to Manufacturing Industry. 
Table 4. Probability of entering each industry

\begin{tabular}{|c|c|c|c|c|}
\hline Dependent variables & $\begin{array}{c}\text { Emerging } \\
\text { Industry } \\
\text { (1) }\end{array}$ & $\begin{array}{l}\text { Government } \\
\text { Industry } \\
\text { (2) }\end{array}$ & $\begin{array}{c}\text { SECH } \\
\text { Industry } \\
\text { (3) }\end{array}$ & $\begin{array}{c}\text { Monopoly } \\
\text { Industry } \\
\text { (4) }\end{array}$ \\
\hline $\begin{array}{l}\text { Parents’ occupation } \\
\text { (Upper occupation=1) }\end{array}$ & $\begin{array}{l}0.3202^{*} \\
(0.1843)\end{array}$ & $\begin{array}{l}0.6215^{* *} \\
(0.3058)\end{array}$ & $\begin{array}{l}0.5351^{* * *} \\
(0.2066)\end{array}$ & $\begin{array}{c}0.3550 \\
(0.2567)\end{array}$ \\
\hline Parents' schooling year & $\begin{array}{l}0.0590^{* * *} \\
(0.0221)\end{array}$ & $\begin{array}{c}0.0539 \\
(0.0426)\end{array}$ & $\begin{array}{c}0.0220 \\
(0.0252)\end{array}$ & $\begin{array}{l}0.1071^{* * *} \\
(0.0322)\end{array}$ \\
\hline Middle income family & $\begin{array}{c}0.0242 \\
(0.1439)\end{array}$ & $\begin{array}{l}-0.1431 \\
(0.2966)\end{array}$ & $\begin{array}{l}-0.0576 \\
(0.1634)\end{array}$ & $\begin{array}{l}-0.3511^{*} \\
(0.2070)\end{array}$ \\
\hline High income family & $\begin{array}{c}0.2391 \\
(0.1684)\end{array}$ & $\begin{array}{c}0.0724 \\
(0.3113)\end{array}$ & $\begin{array}{l}-0.2205 \\
(0.1957)\end{array}$ & $\begin{array}{l}-0.4766^{*} \\
(0.2545)\end{array}$ \\
\hline $\begin{array}{l}\text { Home location } \\
\text { (Big/middle city=1) }\end{array}$ & $\begin{array}{l}0.3975^{* * *} \\
(0.1337)\end{array}$ & $\begin{array}{c}0.1648 \\
(0.2505)\end{array}$ & $\begin{array}{l}0.3276^{* *} \\
(0.1538)\end{array}$ & $\begin{array}{l}0.4531^{* *} \\
(0.1948)\end{array}$ \\
\hline $\begin{array}{l}\text { Gender } \\
(\text { Male=1) }\end{array}$ & $\begin{array}{l}-0.7084^{* * *} \\
(0.1377)\end{array}$ & $\begin{array}{c}-1.0291^{* * *} \\
(0.2441)\end{array}$ & $\begin{array}{c}-0.9887^{* * *} \\
(0.1553)\end{array}$ & $\begin{array}{l}0.4365^{*} \\
(0.2369)\end{array}$ \\
\hline $\begin{array}{l}\text { Minority } \\
(\text { Han=1) }\end{array}$ & $\begin{array}{l}-0.4749^{*} \\
(0.2524)\end{array}$ & $\begin{array}{l}-0.4769 \\
(0.4394)\end{array}$ & $\begin{array}{l}-0.0296 \\
(0.3015)\end{array}$ & $\begin{array}{l}-0.5144 \\
(0.3346)\end{array}$ \\
\hline $\begin{array}{l}\text { One child } \\
\text { (One child=1) }\end{array}$ & $\begin{array}{l}0.4955^{* * *} \\
(0.1463)\end{array}$ & $\begin{array}{l}1.1473^{* * *} \\
(0.2781)\end{array}$ & $\begin{array}{l}0.5591^{* * *} \\
(0.1671)\end{array}$ & $\begin{array}{l}0.6636^{* * *} \\
(0.2121)\end{array}$ \\
\hline “211-project” elite university & $\begin{array}{l}0.8489^{* * *} \\
(0.1748)\end{array}$ & $\begin{array}{l}1.1064^{* * *} \\
(0.2735)\end{array}$ & $\begin{array}{l}0.8342^{* * *} \\
(0.1934)\end{array}$ & $\begin{array}{l}-0.0179 \\
(0.3029)\end{array}$ \\
\hline Ordinary four-year university & $\begin{array}{c}-0.4487^{* * *} \\
(0.1432)\end{array}$ & $\begin{array}{l}-0.7976^{* *} \\
(0.3516)\end{array}$ & $\begin{array}{l}-0.3926^{* *} \\
(0.1696)\end{array}$ & $\begin{array}{l}0.4647^{* *} \\
(0.1987)\end{array}$ \\
\hline $\begin{array}{l}\text { Academic grades in top 25\% } \\
\text { group (Yes }=1 \text { ) }\end{array}$ & $\begin{array}{l}0.5083^{* * *} \\
(0.1456)\end{array}$ & $\begin{array}{c}0.2418 \\
(0.2672)\end{array}$ & $\begin{array}{l}0.6686^{* * *} \\
(0.1625)\end{array}$ & $\begin{array}{l}0.8928^{* * *} \\
(0.2010)\end{array}$ \\
\hline $\begin{array}{l}\text { English certificate } \\
(\text { Yes }=1)\end{array}$ & $\begin{array}{l}-0.2926^{*} \\
(0.1633)\end{array}$ & $\begin{array}{l}-0.0396 \\
(0.3350)\end{array}$ & $\begin{array}{l}-0.7100^{* * *} \\
(0.1788)\end{array}$ & $\begin{array}{l}-0.6259^{* * *} \\
(0.2170)\end{array}$ \\
\hline $\begin{array}{l}\text { CPC member } \\
(\text { Yes }=1)\end{array}$ & $\begin{array}{c}0.0777 \\
(0.1282)\end{array}$ & $\begin{array}{l}0.8339^{* * *} \\
(0.2417)\end{array}$ & $\begin{array}{c}0.1607 \\
(0.1468)\end{array}$ & $\begin{array}{c}0.0066 \\
(0.1898)\end{array}$ \\
\hline Intercept & $\begin{array}{c}0.4517 \\
(0.3644)\end{array}$ & $\begin{array}{l}-2.3175^{* * *} \\
(0.7037)\end{array}$ & $\begin{array}{c}0.2343 \\
(0.4199)\end{array}$ & $\begin{array}{l}-2.1499^{* * *} \\
(0.5248)\end{array}$ \\
\hline Observations & 3370 & 3370 & 3370 & 3370 \\
\hline Pseudo R-Square & 0.154 & 0.154 & 0.154 & 0.154 \\
\hline
\end{tabular}

Notes: The reference category is Manufacturing Industry. Standard errors in parentheses. ***, ** and * indicate statistical significant levels of $1 \%, 5 \%$ and $10 \%$, respectively.

Table 5 shows the results of logistic regression examining the effect of family background on college graduates' job opportunity enter each sector. In general, family occupational, educational and regional status are all significant influential factors on chances to enter Governments, State-Owned Enterprise and Foreign-Invested 
Enterprise compared to Domestic Private Enterprise. Graduates with better family occupational and educational background, living in big/medium cities have more chances to enter Governments Sector and State-Owned Enterprise. Graduates with better family educational background have more chances to enter Foreign-Invested Enterprise.

Table 5. Probability of entering each sector

\begin{tabular}{|c|c|c|c|c|}
\hline Dependent variables & (1) & $\begin{array}{l}\text { State-owned } \\
\text { enterprises } \\
\text { (2) }\end{array}$ & $\begin{array}{l}\text { SECH } \\
\text { sector } \\
(3)\end{array}$ & $\begin{array}{c}\text { Foreign- } \\
\text { invested } \\
\text { enterprises } \\
\text { (4) }\end{array}$ \\
\hline $\begin{array}{l}\text { Parents' occupation } \\
\text { (Upper occupation=1) }\end{array}$ & $\begin{array}{l}0.3668^{*} \\
(0.2046)\end{array}$ & $\begin{array}{l}0.3166^{* * *} \\
(0.1250)\end{array}$ & $\begin{array}{c}0.2992 \\
(0.1931)\end{array}$ & $\begin{array}{c}0.1318 \\
(0.1903)\end{array}$ \\
\hline Parents' schooling year & $\begin{array}{l}0.1909^{* * *} \\
(0.0303)\end{array}$ & $\begin{array}{l}0.0446^{* * *} \\
(0.0159)\end{array}$ & $\begin{array}{c}0.0310 \\
(0.0252)\end{array}$ & $\begin{array}{l}0.0589^{* *} \\
(0.0254)\end{array}$ \\
\hline Middle income family & $\begin{array}{l}-0.6911^{* * *} \\
(0.2026)\end{array}$ & $\begin{array}{l}-0.2576^{* * *} \\
(0.1056)\end{array}$ & $\begin{array}{l}-0.0978 \\
(0.1667)\end{array}$ & $\begin{array}{l}-0.2017 \\
(0.1707)\end{array}$ \\
\hline High income family & $\begin{array}{l}-0.4247^{* *} \\
(0.2076)\end{array}$ & $\begin{array}{l}-0.1784 \\
(0.1217)\end{array}$ & $\begin{array}{l}-0.3695^{*} \\
(0.1977)\end{array}$ & $\begin{array}{c}0.1342 \\
(0.1833)\end{array}$ \\
\hline $\begin{array}{l}\text { Home location } \\
(\text { Big/middle city=1) }\end{array}$ & $\begin{array}{l}-0.1173 \\
(0.1751)\end{array}$ & $\begin{array}{l}0.2096^{* *} \\
(0.0960)\end{array}$ & $\begin{array}{c}0.1983 \\
(0.1532)\end{array}$ & $\begin{array}{c}0.0481 \\
(0.1492)\end{array}$ \\
\hline $\begin{array}{l}\text { Gender } \\
(\text { Male=1) }\end{array}$ & $\begin{array}{c}0.1553 \\
(0.1687)\end{array}$ & $\begin{array}{l}0.7080^{* * *} \\
(0.0981)\end{array}$ & $\begin{array}{l}-0.1176 \\
(0.1491)\end{array}$ & $\begin{array}{c}0.0021 \\
(0.1445)\end{array}$ \\
\hline $\begin{array}{l}\text { Minority } \\
(\text { Han=1) }\end{array}$ & $\begin{array}{l}-0.4060 \\
(0.3007)\end{array}$ & $\begin{array}{l}-0.3142^{*} \\
(0.1840)\end{array}$ & $\begin{array}{l}-0.3694 \\
(0.2753)\end{array}$ & $\begin{array}{l}-0.0725 \\
(0.3032)\end{array}$ \\
\hline $\begin{array}{l}\text { One child } \\
\text { (One child=1) }\end{array}$ & $\begin{array}{l}0.6844^{* * *} \\
(0.1918)\end{array}$ & $\begin{array}{l}0.4028^{* * *} \\
(0.1038)\end{array}$ & $\begin{array}{c}0.2199 \\
(0.1648)\end{array}$ & $\begin{array}{c}0.0843 \\
(0.1618)\end{array}$ \\
\hline “211-project” elite university & $\begin{array}{c}0.1828 \\
(0.1908)\end{array}$ & $\begin{array}{l}-0.5397^{* * *} \\
(0.1154)\end{array}$ & $\begin{array}{l}-0.2042 \\
(0.1683)\end{array}$ & $\begin{array}{l}-0.0506 \\
(0.1683)\end{array}$ \\
\hline Ordinary four-year university & $\begin{array}{c}0.1270 \\
(0.2050)\end{array}$ & $\begin{array}{c}0.1024 \\
(0.1061)\end{array}$ & $\begin{array}{l}-0.4987^{* * *} \\
(0.1859)\end{array}$ & $\begin{array}{c}0.0897 \\
(0.1707)\end{array}$ \\
\hline $\begin{array}{l}\text { Academic grades in top } 25 \% \text { group } \\
(\text { Yes }=1)\end{array}$ & $\begin{array}{l}-0.0754 \\
(0.1815)\end{array}$ & $\begin{array}{c}0.0954 \\
(0.0995)\end{array}$ & $\begin{array}{c}0.1232 \\
(0.1575)\end{array}$ & $\begin{array}{c}0.0946 \\
(0.1527)\end{array}$ \\
\hline $\begin{array}{l}\text { English certificate } \\
(\text { Yes }=1)\end{array}$ & $\begin{array}{c}0.1163 \\
(0.1953)\end{array}$ & $\begin{array}{l}0.3181^{* * *} \\
(0.1089)\end{array}$ & $\begin{array}{l}-0.2915^{*} \\
(0.1624)\end{array}$ & $\begin{array}{l}0.8308^{* * *} \\
(0.2030)\end{array}$ \\
\hline $\begin{array}{l}\text { CPC member } \\
(\text { Yes }=1)\end{array}$ & $\begin{array}{l}0.5023^{* * *} \\
(0.1643)\end{array}$ & $\begin{array}{l}0.2289^{* * *} \\
(0.0927)\end{array}$ & $\begin{array}{l}-0.0175 \\
(0.1480)\end{array}$ & $\begin{array}{l}-0.0206 \\
(0.1440)\end{array}$ \\
\hline Intercept & $\begin{array}{c}-3.8960^{* * *} \\
(0.4891)\end{array}$ & $\begin{array}{c}-0.9660^{* * *} \\
(0.2625)\end{array}$ & $\begin{array}{c}-1.0270^{* * *} \\
(0.3962)\end{array}$ & $\begin{array}{c}-2.6055^{* * *} \\
(0.4384)\end{array}$ \\
\hline Observations & 3674 & 3674 & 3674 & 3674 \\
\hline Pseudo R-Square & 0.124 & 0.124 & 0.124 & 0.124 \\
\hline
\end{tabular}

Notes: The reference category is Domestic Private Enterprises. Standard errors in parentheses. ***, ** and * indicate statistical significant levels of $1 \%, 5 \%$ and $10 \%$, respectively. 


\section{Conclusions}

Based on national college graduates employment survey data of China, this paper explores the impact of family background on job allocation, through both descriptive and regression analyses. The empirical result shows that the income gap among industries/sectors is significantly large which is in accord with the severe market segmentation (Knight and $\mathrm{Li}, 2005$ ). Emerging Industry, Monopoly Industry, Government Industry and SECH Industry belong to primary labor market in China. Governments Sector, State-Owned Enterprise and Foreign-Invested Enterprise are ideal job sectors for most Chinese college graduates. The empirical result also shows college graduates with better family socio-economic background have more chances to enter primary labor market.

College graduates from elite university are easy to enter the advantage industries/sectors. However, Yue (2015) found that students with better family occupational, educational, regional, and economic status have more chances to enter elite universities. Therefore, employment opportunity inequality in college graduates market has enhanced after China's college expansion. Chinese economy is undergoing middle income trap and job chances become scarce especially for college graduates. How to reduce job inequality in college graduates market is a serious challenge for the effective allocation and use of senior human resources.

\section{References}

Knight, J. and S. Li (2005).Wages, firm profitability and labor market segmentation in urban China. China Economic Review 16, 205-228.

Li, H., L. Meng, X. Shi and B. Wu (2012). Does having a cadre parent pay? Evidence from the first job offers of Chinese college graduates. Journal of Development Economics 99, 513-520.

Li, T. and J. Zhang (2010). What determines employment opportunity for college graduates in China after higher education reform? China Economic Review 21, 38-50.

Wang, L. (2012). Economic transition and college premium in urban China. China Economic Review 23, 238-252.

Yue, C. (2015). Expansion and Equality in Chinese Higher Education. International Journal of Educational Development 40(1), 50-58. 


\title{
How Financial Education affects Mathematics performance? Evidence from Spain in the context of the Program School 2.0
}

\author{
C. Vilaplana-Prieto* \\ * University of Murcia (Spain)
}

\begin{abstract}
In this paper we evaluate the effect of participation in the Program School 2.0 on both Financial Education and Mathematics performance using data from PISA 2012. The School 2.0 Program was implemented in 2009 in some Spanish Autonomous Communities. This program promoted the use of computers, both in school and at home, among elementary and high school students. We detect that a greater benefit is obtained when the contents of Financial Education are taught in conjunction with the contents of the subject of Mathematics, although the mean effect of Financial Education over Mathematics is more intense in Communities that have not participated in the Program School 2.0. This result may be related to the fact that only a moderate use of computer for personal use increases Mathematics and Financial Education performance. Nevertheless, given the recent implementation of the Program School 2.0, we should expect some "learning effects" that should be confirmed with future data.
\end{abstract}

Keywords: Program evaluation; PISA; Financial Education; Mathematics

\section{Introduction}

The recent economic and financial crisis has demonstrated that economic recovery requires the participation of all economic stakeholders (Lester and Williams, 2010). Financial Education enables the individual to acquire a series of very useful skills for adulthood and this should be a component of student learning. Studies have indicated that people who have received Financial Education show a greater tendency to manage their savings before retirement (Cole et al., 2010), participate more in the stock markets (Van Rooij et al., 2011), and take greater care when choosing mortgages or loans with lower interests and fees (Lusardi and Tufano, 2009).

As indicated by Lusardi and Mitchell (2009), the incorporation of Financial Education into the academic curriculum has a positive impact on young people and facilitates the development of skills in the areas of savings, loans, investments, critical thinking and problem solving.

This article analyses the relationship between performances in Mathematics and Financial Education, subject to their participation in School Program 2.0. First, some studies (Suiter and McCorkle, 2008) have found that the melding of Mathematics and Financial Education favours the development of responsible financial behaviours. Second, the majority of problems that students need to resolve on the PISA-Financial questionnaire require the completion of numerical calculations. In addition to linking Mathematics and Financial Education skills, this paper aims at introducing a third analytical element: the influence of ICT (Information and Communication Technologies) in schools in regards to School Program 2.0.

\section{Material and Methods}

\section{Program School 2.0}

In July 2009, the Spanish Education Sector Conference adopted an investment of $€ 98,182,419$ for the implementation of the Program School 2.0 (Resolution of 3 August, 
2009, of the Technical Secretariat General, for which it published the Agreement of the Council of Ministers of 31 July, 2009)

The allocation of these funds was to co-finance $50 \%$ of the following activities, within the Autonomous Communities: (1) The transformation of all 5th and 6th Primary Education and all 1st and 2nd Compulsory Secondary Education classrooms into digital classrooms at public schools; (2) The provision of computers for the personal use, (3) The development of digital content that may be used by teachers. However, the Autonomous Communities' participation in School Program 2.0 was not homogeneous and three levels of participation were discernible:

(i) Total Participant Communities (TP): Andalusia, Aragon, Cantabria, CastileLeon, Castilla-La Mancha, Catalonia, Extremadura, Galicia, Navarra, Basque Country, La Rioja, Ceuta and Melilla

(ii) Partial Participant Communities (PP): Asturias, Balearic and Canary Islands. These one will not be considered in the following analysis.

(iii) Non-participat Communities (NP): Madrid, Murcia and the Valencian Community.

\section{Econometric model}

We consider two latent variables $\mathrm{FE}_{\mathrm{i}}^{*}$ and $\mathrm{MAT}_{\mathrm{i}}^{*}$ that denote "knowledge in Financial Education" and "knowledge in Mathematics", respectively. Both variables are influenced by observable characteristics (family group, resources available at home and at the school) and unobservable characteristics (innate aptitudes of students, their level of motivation). Additionally, the relationship between them can flow in both directions. On the one hand, Financial Education can provide a more applied perspective for certain mathematical concepts, so it can be useful to reduce the degree of abstraction that is so often argued as a difficulty by students when dealing with exact sciences. Moreover, students with a greater ability for numerical reasoning may find it easy and attractive to choose the field of Financial Education. In general, the score obtained in both areas may be expressed using the following system:

$$
\begin{aligned}
& F E_{i}^{*}=X_{1 i}^{\prime} \beta_{1}+\varepsilon_{1 i} \\
& M A T_{i}^{*}=\alpha E F_{i}^{*}+X_{2 i}^{\prime} \beta_{2}+\varepsilon_{2 i}
\end{aligned}
$$

where $X_{1 \mathrm{i}}^{\prime}$ and $X_{2 \mathrm{i}}^{\prime}$ are vectors of observable characteristics, $\beta_{1}$ and $\beta_{2}$ are vectors of parameters, $\varepsilon_{1 \mathrm{i}}$ and $\varepsilon_{2 \mathrm{i}}$ are both error terms, which we assumed follow a bivariate normal distribution with zero mean, unit variance and correlation coefficient: $\rho$ :

$$
\left(\begin{array}{l}
\varepsilon_{1 i} \\
\varepsilon_{2 i}
\end{array}\right) \sim N\left(\left(\begin{array}{l}
0 \\
0
\end{array}\right),\left(\begin{array}{ll}
1 & \rho \\
\rho & 1
\end{array}\right)\right)
$$

and such that $\mathrm{E}\left[\mathrm{X}_{1 \mathrm{i}}^{\prime}, \varepsilon_{1 \mathrm{i}}\right]=0$ and $\mathrm{E}\left[\mathrm{X}_{2 \mathrm{i}}^{\prime}, \varepsilon_{2 \mathrm{i}}\right]=0$. Thus, if $\rho$ is equal to zero, $\mathrm{FE}_{\mathrm{i}}^{*}$ it is not endogenously determined and both equations may be solved separately.

The following explanatory variables were introduced in both equations: characteristics of students and family (gender, nationality, repetition of grade level, availability of a computer at home, educational level of parents), and characteristics of the school (average size of class, ratio of schoolgirls at the school, size of residing municipality). In the equation for MAT, we considered the following explanatory variables: if there is a school-policy on the use of computers in the classroom and on the quality assessment of Mathematics, the percentage of teachers with ISCED5A qualifications, if the student has a computer in the classroom and the frequency of ICT use to do homework. 
In the equation for FE, explanatory variables introduced were the following: if the contents of Financial Education are compulsory, if it is delivered within a specific subject (Mathematics, Economics, Social Sciences and Humanities), the length of time Finance Education has been delivered, if teaching staff of Financial Education belong to the school's faculty and if the teachers have received specific training.

Regarding student environment, two instrumental variables were introduced taking as a reference evidence from the literature on Financial Education (Pinto et al., 2005; Williams, 2010): (i) a binary variable that takes value 1 if the student indicates talking to his/her parents almost every day or 1-2 times a week about financial issues (savings, household spending, banks, etc.) and (ii) a binary variable that takes value 1 if the student indicates earning money from working (tutoring, babysitting) or helping out in a family business.

However, we did not observe the level of knowledge in Mathematics and in Financial Education $\left(\mathrm{FE}_{\mathrm{i}}^{*}\right.$ or $\mathrm{MAT}_{\mathrm{i}}^{*}$ ), rather the results of PISA (FE $\mathrm{F}_{\mathrm{i}}$ and $\mathrm{MAT}_{\mathrm{i}}$ ). PISA (2012) scores are based on calculations on a metric scale, with a 500 point average for all OECD countries and a standard deviation of 100 points. For a better understanding, they are usually divided into proficiency levels. This classification, recommended by PISA Technical Report is useful because it allow us to communicate about the proficiency of students in terms other than numbers.

The variable $\mathrm{FE}_{\mathrm{i}}$ is an ordered variable that classifies the PISA-Financial results into 5 levels: (1) "lowest performers": less than 400.33 points, (2) "low performers": between 400.33 and 475.10 points, (3) "moderate performers": between 475.10 and 549.86 point, (4) "strong performers": between 549.86 and 624.63 points and (5) "top performers": over 624.63 points.

The variable $\mathrm{MAT}_{\mathrm{i}}$ is another ordered variable that classifies the PISA-Mathematics results into 6 Levels: (1) "lowest performers": less than 357.7 points, (2) "low performers": between 357.5 and 420.1 points, (3) "low moderate performers": between 420.1 and 482.4 points, (4) "high moderate performers": between 482.4 and 544.7 points, (5) "strong performers" between 544.7 and 607 points and (6) "top performers": over 607 points. Observed variables are linked to the latent variables according to the following expressions:

$$
\begin{gathered}
F E_{i}=\left\{\begin{array}{l}
1 \text { if } F E_{i}^{*}<\omega_{1} \\
2 \text { if } \omega_{1}<F E_{i}^{*}<\omega_{2} \\
3 \text { if } \omega_{2}<F E_{i}^{*}<\omega_{3} \\
4 \text { if } \omega_{3}<F E_{i}^{*}<\omega_{4} \\
5 \text { if } \omega_{4}<F E_{i}^{*}
\end{array}\right. \\
M A T_{i}=\left\{\begin{array}{l}
1 \text { if } M A T_{i}^{*}<\tau_{1} \\
2 \text { if } \tau_{1}<M A T_{i}^{*}<\tau_{2} \\
3 \text { if } \tau_{2}<M A T_{i}^{*}<\tau_{3} \\
4 \text { if } \tau_{3}<M A T_{i}^{*}<\tau_{4} \\
5 \text { if } \tau_{4}<M A T_{i}^{*}<\tau_{5} \\
6 \text { if } \tau_{5}<M A T_{i}^{*}
\end{array}\right.
\end{gathered}
$$

where $\omega_{1}<\omega_{2}<\omega_{3}<\omega_{4}$ and $\tau_{1}<\tau_{2}<\tau_{3}<\tau_{4}<\tau_{5}$ are the cut-off points.

We proceeded to calculate two bivariate probit models. In the first one, the effect of EF on MAT is considered as a constant, and therefore, a standard ordered bivariate probit model was calculated. The second alternative is a bivariate probit with mixed effects assuming that the parameter $\alpha$ follows a normal distribution with mean $\mu_{\alpha}$ and standard deviation $\sigma_{\alpha}$. The denomination "mixed effects" makes reference to the existence of 
heterogeneity regarding the impact of FE over MAT across students. Using a statistical distribution allow us to distinguish between those who are able to transform the skills gained in FE into better results in MAT, and also, those students with higher difficulty in cross-curriculum learning in MAT from skills learned in FE. With regard to computational aspects, the calculation for the standard model was done using the command proposed by Sajaia (2008), while for the model with mixed effects we have adapted the routine proposed by Buscha and Conte (2010).

\section{Data}

PISA is a cross-sectional study, conducted every three years that commenced in 2000 for 15 year old students, with the purpose of evaluating their performance in the areas of mathematics, reading and science, as well as cross-curriculum problem solving skills. In addition to the general module and the CBA module (computer based assessment), a third type of test was conducted to measure financial literacy.

Regarding the specific module concerning Financial Education, the sample for Spain contains 1,108 observations, even if we restrict the sample to public schools this is reduced to 765 observations. Regarding participation in School Program 2.0, there are 167 observations for non-participating communities (NP), 532 for totally participating Communities (TP) and 66 for partially participating Communities (PP). In this paper we will only focus on TP and NP Communities.

\section{Results and Discussion}

Table 1 shows the results for the models of TP Communities with and without mixed effects, and Table 2 offers the same results for NP Communities. This existence of substantial heterogeneity in the effect of Financial Education on the results in Mathematics among the students is confirmed by the significance of the parameters $(\mu$ and $\sigma$ ) for TP and NP Communities.

In both types of Communities, a moderate use of computer/tablet, whether for homework or for class lessons, is associated with a better performance in Mathematics and Financial Education. Nevertheless, this positive effect is not observe for the case of almost daily or everyday use. This result could be indicative that the adaptation process to new methodologies may require a revision. For the model with mixed effects for TP Communities, schools that have a policy on the use of computers in the classroom and for quality assessment in Mathematics tend to score higher for this subject.

Regarding to the placement of Financial Education in the teaching project, a positive effect is observed when there is an obligation to teach this subject and it has been delivered for more than two years at the school. The latter result may be related to the existence of learning outcomes within the teaching plans, since with an increased number of years of "running", teachers know better how to reach students.

Talking with parents about issues related to Financial Education or having work are significant positive variables, with the first variable having great influence on the score for Financial Education.

The fact that teaching faculty corresponds to the school teachers instead of professionals from public, private or NGOs is not significant for TP Communities, but it is (positively) for NP Communities. The percentage of teachers who have received 
specific training in Financial Education during the past year is not significant for TP Communities, however, it is for NP Communities.

Table 1. Estimation of Bivariate Ordered Probit Model for Mathematics and Financial Education Scores. Communities with Total Participation

\begin{tabular}{|c|c|c|c|c|c|c|}
\hline \multirow[b]{2}{*}{ Mathematics } & \multicolumn{3}{|c|}{ Without Mixed Effects } & \multicolumn{3}{|c|}{ With Mixed Effects } \\
\hline & Coef & Std.D & & Coef & Std.D & \\
\hline Financial Education Score & 1.215 & 0.069 & $* * *$ & & & \\
\hline Student (boy) & 0.457 & 0.103 & $* * *$ & 0.433 & 0.193 & $* * *$ \\
\hline Immigrant & -0.149 & 0.077 & $* *$ & -0.339 & 0.090 & $* * *$ \\
\hline Non-repeating & 0.175 & 0.041 & $* *$ & 0.334 & 0.045 & $* * *$ \\
\hline Use of Computers Policy & 0.224 & 0.100 & $* *$ & 0.180 & 0.032 & $* * *$ \\
\hline Mathematics Quality Policy & 0.011 & 0.163 & & 0.050 & 0.028 & * \\
\hline Average Class Size & 0.005 & 0.007 & & -0.006 & 0.008 & \\
\hline Ratio of Schoolgirls & -0.928 & 0.360 & $* *$ & -0.599 & 0.413 & \\
\hline Ratio of ISCED5A Teachers & 0.142 & 0.110 & & 0.181 & 0.143 & $* *$ \\
\hline Computer/tablet at home & 0.349 & 0.117 & $* * *$ & 0.431 & 0.218 & ** \\
\hline Computer/tablet at school & -0.136 & 0.010 & $* * *$ & -0.146 & 0.035 & $* * *$ \\
\hline ICT for homework & & & & & & $* * *$ \\
\hline 1-2 times/week & 0.230 & 0.113 & $* *$ & 0.141 & 0.148 & \\
\hline Almost every day & -0.068 & 0.011 & $* * *$ & -0.245 & 0.105 & $* *$ \\
\hline Everyday & -0.440 & 0.241 & $* *$ & -0.695 & 0.288 & $* * *$ \\
\hline \multicolumn{7}{|l|}{ Financial Education } \\
\hline Non-repeating & 1.198 & 0.121 & $* * *$ & 1.250 & 0.236 & $* * *$ \\
\hline Student (boy) & 0.363 & 0.091 & $* * *$ & 0.315 & 0.102 & $* * *$ \\
\hline Immigrant & -0.305 & 0.162 & $*$ & -0.238 & 0.108 & * \\
\hline Student talks to parents & 0.092 & 0.011 & $* * *$ & 0.172 & 0.011 & $* * *$ \\
\hline Student works & 0.041 & 0.071 & $* *$ & 0.102 & 0.026 & $* * *$ \\
\hline Computer/tablet at home & 0.454 & 0.205 & $* * *$ & 0.239 & 0.146 & $* * *$ \\
\hline Subject, less than 2 years ago & 0.304 & 0.154 & $* *$ & 0.572 & 0.192 & $* *$ \\
\hline Subject, more that 2 years ago & 0.407 & 0.202 & ** & 0.635 & 0.188 & $* *$ \\
\hline Compulsory subject & 0.276 & 0.155 & $*$ & 0.664 & 0.207 & $*$ \\
\hline \multicolumn{7}{|l|}{ Explanation } \\
\hline Cross-curricular subject & -0.342 & 0.126 & $* * *$ & -0.403 & 0.177 & $* * *$ \\
\hline Within Economics Subject & -0.331 & 0.013 & $* *$ & -0.420 & 0.137 & $* *$ \\
\hline Within Mathematics Subject & 0.270 & 0.065 & $* * *$ & 0.221 & 0.103 & $* * *$ \\
\hline Within Science or Humanities Subjects & -0.128 & 0.050 & $* *$ & -0.093 & 0.177 & $* *$ \\
\hline Teacher Training Courses & 0.042 & 0.139 & & 0.086 & 0.135 & \\
\hline Teacher: Teacher from School & 0.175 & 0.147 & & 0.260 & 0.156 & \\
\hline Average Class Size & -0.016 & 0.006 & $* *$ & -0.023 & 0.175 & $* *$ \\
\hline Ratio of Schoolgirls & -0.066 & 0.281 & & -0.017 & 0.007 & \\
\hline \multicolumn{7}{|l|}{ Interaction: Computer/tablet at school and } \\
\hline Financial Education within Mathematics & -0.485 & 0.056 & $* * *$ & -0.602 & 0.289 & $* * *$ \\
\hline \multicolumn{7}{|l|}{ Interaction: ICT for homework and in Financial } \\
\hline $1-2$ times/week & 0.207 & 0.062 & ** & 0.326 & 0.173 & ** \\
\hline Almost every day & -0.192 & 0.082 & $* *$ & -0.047 & 0.200 & ** \\
\hline Everyday & -0.804 & 0.323 & $* *$ & -0.147 & 0.278 & $* *$ \\
\hline Constant & -0.736 & 0.245 & $* * *$ & -0.935 & 0.445 & $* * *$ \\
\hline$\mu($ mixed effect $)$ & & & & 1.222 & 0.254 & $* * *$ \\
\hline$\sigma($ mixed effect) & & & & 0.653 & 0.287 & $* * *$ \\
\hline$\rho$ & 0.627 & 0.149 & $* * *$ & 0.351 & 0.178 & $* * *$ \\
\hline Log likelihood & & $-1,174.959$ & & & $-1,147.912$ & \\
\hline $\mathrm{N}$ & & 532 & & & 532 & \\
\hline
\end{tabular}

All cut-off points are significant at 5\%. In both equations, the size of the residing municipality and the highest educational level of the father/mother have been included as an explanatory variable. Omitted variables: schoolgirls, repeating students, national, use computer for homework 1-2 times/month or less frequently, non-compulsory Financial Education, Financial Education subject not available. (***: Significant at $1 \% ; * *$ : significant at $5 \%$; : significant at $10 \%$ ).

Table 2. Estimation of Bivariate Ordered Probit Model for Mathematics and Financial Education Scores. Nonparticipating Communities

\begin{tabular}{lccccc}
\hline & \multicolumn{2}{c}{ Without Mixed Effects } & \multicolumn{2}{c}{ With Mixed Effects } \\
Mathematics & Coef & Std.D & & Coef & Std.D \\
\hline Financial Education Score & 1.291 & 0.142 & $* * *$ & & \\
Student (boy) & 0.688 & 0.199 & $* * *$ & 0.624 & 0.201 \\
Immigrant & -0.616 & 0.278 & $* *$ & -1.844 & 0.419 \\
Non-repeating & 0.826 & 0.338 & $* *$ & 2.051 & 0.548 \\
Use of Computers Policy & 0.332 & 0.203 & & 0.490 & 0.858 \\
Mathematics Quality Policy & 0.547 & 0.371 & & 1.670 & 2.336 \\
Average Class Size & -0.040 & 0.025 & & -0.142 & 0.199 \\
Ratio of Schoolgirls at class & -1.257 & 0.568 & & 1.060 & 2.313
\end{tabular}




\begin{tabular}{|c|c|c|c|c|c|c|}
\hline Computer/tablet at home & 0.592 & 0.256 & $* *$ & 0.845 & 0.316 & $* *$ \\
\hline Computer/tablet at school & -0.064 & 0.021 & $* * *$ & -0.226 & 0.112 & $* *$ \\
\hline \multicolumn{7}{|l|}{ ICT for homework } \\
\hline 1-2 times/week & 0.029 & 0.009 & $* * *$ & 0.021 & 0.006 & $* * *$ \\
\hline Almost every day & -0.049 & 0.024 & $* *$ & -0.216 & 1.482 & $* *$ \\
\hline Everyday & -0.102 & 0.050 & $* *$ & -0.614 & 0.201 & $* * *$ \\
\hline \multicolumn{7}{|l|}{ Financial Education } \\
\hline Non-repeating & 1.180 & 0.210 & $* * *$ & 1.240 & 0.189 & $* * *$ \\
\hline Student (boy) & 0.350 & 0.128 & $* *$ & 0.310 & 0.098 & $* * *$ \\
\hline Immigrant & -0.503 & 0.272 & $*$ & -0.391 & 0.115 & $*$ \\
\hline Student talks to parents & 0.228 & 0.100 & $* *$ & 0.344 & 0.165 & $* *$ \\
\hline Student works & 0.257 & 0.130 & $* *$ & 0.195 & 0.068 & $* * *$ \\
\hline Computer/tablet at home & 0.631 & 0.349 & $* *$ & 0.241 & 0.108 & $* *$ \\
\hline Subject, less than 2 years ago & 0.121 & 0.016 & $* * *$ & 0.798 & 0.378 & $* *$ \\
\hline Subject, more than 2 years ago & 0.728 & 0.321 & $* *$ & 0.941 & 0.450 & $* *$ \\
\hline Compulsory subject & - & - & & - & - & \\
\hline \multicolumn{7}{|l|}{ Explanation } \\
\hline Cross-curricular subject & -0.607 & 0.134 & $* * *$ & -0.214 & 0.064 & $* * *$ \\
\hline Within Economics Subject & -0.670 & 0.216 & $* * *$ & -0.771 & 0.349 & $* * *$ \\
\hline Within Mathematics Subject & 0.105 & 0.038 & $* * *$ & 0.297 & 0.084 & $* * *$ \\
\hline Within Science or Humanities Subjects & -0.249 & 0.036 & $* * *$ & -0.242 & 0.015 & $* * *$ \\
\hline Teacher Training Courses & 0.786 & 0.279 & $* * *$ & 0.952 & 0.445 & $* * *$ \\
\hline Teacher: Teacher from School & 0.789 & 0.382 & $* *$ & 0.808 & 0.323 & $* *$ \\
\hline Average Class Size & 0.038 & 0.026 & & 0.863 & 0.515 & \\
\hline Ratio of Schoolgirls at class & 0.573 & 0.874 & & 0.039 & 0.030 & \\
\hline \multicolumn{7}{|l|}{ Interaction: Computer/tablet at school and } \\
\hline Financial Education within Mathematics & -0.434 & 0.132 & $* * *$ & -0.830 & 0.211 & $* * *$ \\
\hline \multicolumn{7}{|l|}{ Interaction: ICT for homework and in Financial } \\
\hline \multicolumn{7}{|l|}{ Education within Mathematics } \\
\hline $1-2$ times/week & 0.184 & 0.067 & $* * *$ & 0.180 & 0.063 & $* * *$ \\
\hline Almost every day & -0.263 & 0.025 & $* * *$ & -0.350 & 0.075 & $* * *$ \\
\hline Everyday & -0.337 & 0.067 & $* *$ & -0.413 & 0.065 & $* *$ \\
\hline Constant & 0.468 & 0.421 & & -0.998 & 0.572 & $* *$ \\
\hline$\mu($ mixed effect $)$ & & & & 1.410 & 0.308 & $* * *$ \\
\hline$\sigma($ mixed effect $)$ & & & & 0.257 & 0.081 & $* * *$ \\
\hline$\rho$ & 0.751 & 0.178 & $* * *$ & 0.271 & 0.101 & $* * *$ \\
\hline Log likelihood & & -360.159 & & & -347.454 & \\
\hline $\mathrm{N}$ & & 166 & & & 166 & \\
\hline
\end{tabular}

Same footnote than previous table.

Figure 1 shows the density functions corresponding to the effect of Financial Education on Mathematics in TP and NP Communities. The mean effect of the Financial Education variable on Mathematics is more intense in NP Communities than for TP Communities (1.410 compared to 1.222) and it is also more concentrated. This implies that in TP Communities there are students who receive great benefit from learning Financial Education in regards to Mathematics scores (30\% of the distribution is above $2)$, but there are also students who are found in the opposite situation $(10.62 \%$ are below zero), i.e., that obtain good results in Financial Education, but poor results in Mathematics.

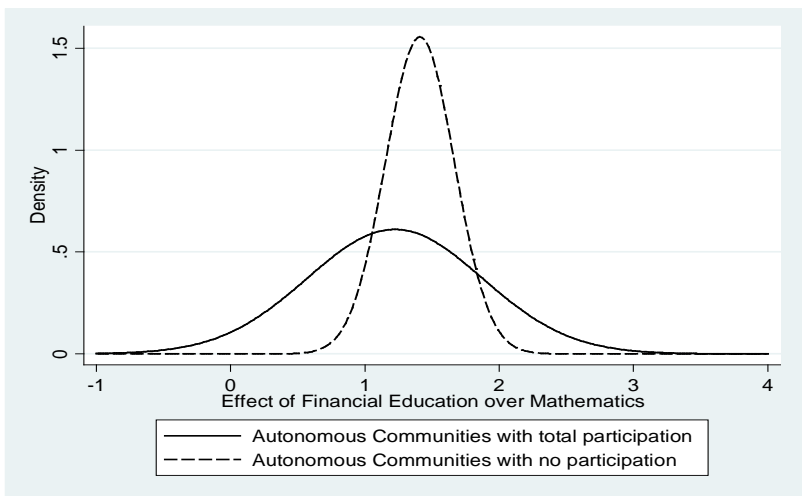

Figure 1. Density Functions of the Effect of Financial Education on Mathematics Scores According to Participation in School Program 2.0 (repeating and non-repeating students are included) 
The sample size of the TP Communities allows calculation of the bivariate probit model with mixed effects distinguishing between repeating and non-repeating students $\mathrm{We}$ consider that this analysis is interesting given the relevant proportion of repeating students (for TP Communities, $25 \%$ of students had repeated one year and nearly $10 \%$ had repeated two years). The results of the estimation are not shown due to their size, but are available on request from the authors. Figure 2 shows the density functions for repeating and non-repeating students in TP Communities.

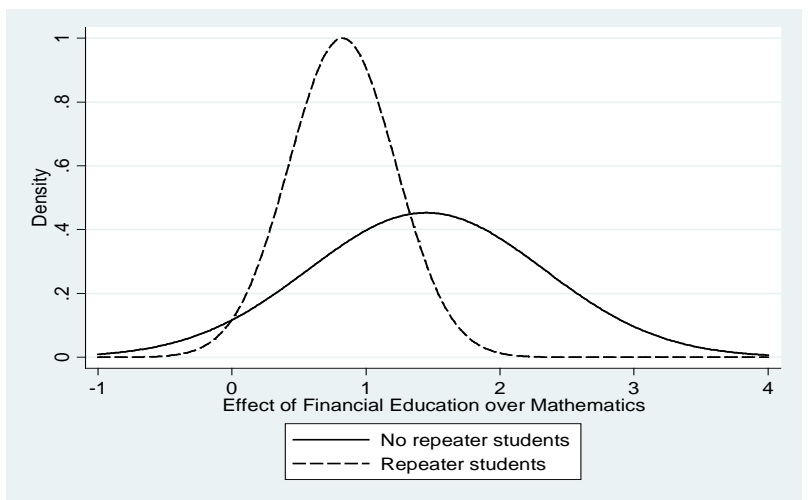

Figure 2. Density Functions of the Effect of Financial Education on Mathematics Scores According to Repeating a School Year. Only Communities with Total Participation in School Program 2.0

The effect of Financial Education on Mathematics is, on average, 1.4491 for nonrepeating students compared to 0.8234 repeating students. Consequently, in TP Communities, there is a multiplicative effect (which also might be described as a positive externality) of Financial Education on Mathematics for non-repeating students. However, for students who have repeated a school year, the transmission of knowledge or skills from Financial Education to Mathematics occurs at a lower rate (the sample size does not allow us to differentiate between students who have repeated on one or two school years).

These results appear to suggest that for some students learning operates like an osmosis system, in a manner that knowledge/skills from Financial Education are transferred to the field of Mathematics with a clearly positive effect. However, there are other students that seem to operate within a separate system, whereby they "do" well in Financial Education but have less satisfactory results in Mathematics.

\section{Conclusions}

This work has confirmed the importance of young people to understand Financial Education concepts, not only because it involves a significant improvement for scores in this area, but also because it holds, to a great extent, a beneficial effect on the skills acquired within the subject of Mathematics. It has shown that a greater benefit is obtained when the contents of Financial Education are taught in conjunction with the contents of the subject of Mathematics. From the point of view of Higher Education, the main recommendation of this paper is that faculties preparing teachers for primary and secondary schools should include the standards of financial literacy and the relationship with mathematical concepts in their academic programmes. 
Regarding the influence of ICT on the skills for both subjects, the benefit of having a computer for personal use by students is observed, both for school and home use. This positive effect is associated with a moderate use of computers (1-2 times/week), but is not observed for the case of daily use. However, we must interpret the results with certain caution, as not much time has passed since the implementation of these new teaching methodologies, so we should expect to see a "learning effect" over time. In this case, future waves of PISA should be should be used to test this hypothesis.

It has been verified that $100 \%$ of students in Communities that have not participated in School Program 2.0 have experienced a positive effect of Financial Education on Mathematics, meanwhile Communities with total participation had approximately $10 \%$ of students with mixed results in both areas. Given that the analysis included variables related to the student, his/her family, the use of ICT as a teaching methodology, and the means of explaining how Financial Education in relation to other subjects, we must consider which other variables (motivational, linguistic, procedural) are hindering student learning, since these deficiencies in their education could imply a major detriment to his/her subsequent development as an adult.

\section{References}

Buscha, F., Conte, A. (2010). The impact of truancy on educational attainment: a bivariate ordered probit estimator with mixed effects. JENA Economic Research Papers N0. 062. Volpe

Cole, S., Sampson, T., Zia, B. (2011). Prices or knowledge? What drives demand for financial services in emerging markets? The Journal of Finance, 66, 1933-1967.

Lester, W.F., Williams, V.J. (2010). Interactive investor education: an exploratory impact study in non-traditional learning environments. Business Education Innovation Journal, 2, 44-52.

Lusardi, A., Mitchell, O.S. (2009). How ordinary consumers make complex economic decisions: financial literacy and retirement readiness. Working Paper 15350. National Bureau of Economic Research.

Lusardi, A., Tuffano, P. (2009). Debt literacy, financial experiences and overindebtedness. NBER Working Paper No. 14808.

OECD, (2014). PISA 2012. Technical Report. Available at: http://www.oecd.org/pisa/pisaproducts/PISA-2012-technical-report-final.pdf

Pinto, M.B, Mansfield, P.M., Parente, D.H. (2005). Information learned from socialization agents: its relationship to credit card use. Family and Consumer Sciences Research Journal, 33, 357-367.

Sajaia, X. (2008). Maximum likelihood estimation of a bivariate ordered probit model: implementation and Monte Carlo simulations. The Stata Journal 3(2), 311-328.

Van Rooij, M.A., Lusardi, A., Alessie, R. (2011). Financial literacy and stock market participation. Journal of Financial Economics, 110, 449-472.

Williams, S. (2010). Parental influence on the financial literacy of their school-aged children: an exploratory study. Exceptional Children, Journal of Special Education, I, 23-33. 


\title{
The Winding Path Back to School: Hidden Obstacles to Higher Education for Low-Income Single Mothers
}

\author{
Amanda Freeman
}

Boston College

\begin{abstract}
This paper explores obstacles to the pursuit of higher education for low-income single mothers in the United States. Findings are based on a three-year qualitative study, including 66 in-depth interviews with 37 low-income single parents who were pursuing educational goals through an anti-poverty program in Boston, Massachusetts. Respondents were questioned about their past and current experiences, goals, motivation, and fears related to post-secondary education. All mothers interviewed believed that getting a college degree would help them to secure employment and move their families out of poverty. Findings revealed institutional and practical obstacles to their pursuit of higher education, including conflicting advice from "experts" and difficulty retaining public benefits while attending school. The primary obstacles that emerged were categorized as follows: (a) winding paths and dead ends, (b) difficult transitions, (c) short-sighted decisions, and (d) inflexible institutions. Also evident among interviewees were misconceptions about the policies and practices of institutions of higher education, such as not predicting the difficulty of transferring credits between schools and lack of understanding about differences between degree programs. These obstacles have yet to be explored in literature about higher education for low-income parents. Policy and practical implications for higher education as a route out of poverty are discussed.
\end{abstract}

Keywords: Higher education, poverty, low-income families, qualitative research

\section{Introduction}

Education is one of the most effective ways for low-income single mothers to increase their earning capacity and gain access to highly skilled, quality, sustainable employment (Adair and Dahlberg 2002; Institute for Women's Policy Research (IWPR) 2008; Strawn and Martinson 2000). Single mothers with dependent children are the most likely of any demographic group in the United States to be poor (Olson and Banyard 1993; Seecombe and Walters 1998). Attaining high school, college and other forms of education allows access to higher lifelong earnings and employment benefits. Education also makes low-income women less likely to rely on public benefits for their economic wellbeing (Adair 2001). Pursuing educational opportunities has been shown to improve the self-esteem and job prospects of low-income single mothers (IWPR, 2008) and to positively impact the educational attainment of their children (Jimerson, Egeland and Two 1999). Still, very few low-income single mothers actually earn college degrees in the United States. As such, it is of paramount importance to add to the dearth of research about lesser known obstacles to the educational achievement of low-income single mothers.

\section{Recognized Obstacles to Higher Education for Low-Income Single Mothers}

Perhaps the most obvious and well-documented obstacle to the educational achievement of low-income single mothers is financial stress. College tuition is expensive even for middle class and wealthy Americans, and low-income single mother-headed families are already under tremendous financial strain. Add to this strain, the reality that welfare benefits could be to be taken away if a recipient is attending school or attending school for too long. Furthermore, financial aid and scholarship applications, which have the potential to alleviate some financial stress, create their own maze of deadlines and forms for overwhelmed single parents. 
The prospect of going back to school also raises the issue of finding convenient, affordable, quality childcare. Classes are often offered at different times during the day or evening on alternating days of the week, and they change every semester, making it difficult to negotiate a set schedule with a sitter or daycare center. Many struggle fulfill work and family responsibilities while patching together childcare arrangements to cover classroom and working hours. (Mason 2002; Bullock and Limbert 2003; Deprez, Butler and Smith 2004; Christopher 2005). Even those students who qualify for subsidized childcare often have difficulty retaining childcare vouchers when they return to school. At the same time, "non-traditional" student mothers require longer periods of time to complete degree programs, which come into conflict with the time limits imposed by many public assistance programs. Pearson (2007) found that because of Georgia's 20-hour work requirement to receive welfare benefits, many students eventually dropped out.

The Personal Work Opportunity Reconciliation Act (PRWORA) passed by Congress in 1996 as part of "welfare reform" severely limited the ability of low-income women to pursue educational opportunities. Temporary Assistance for Needy Families (TANF), implemented requirements that capped lifetime benefits, required recipients return to work, and restricted the classification of education as work. Since PRWORA was passed in 1996, drastically fewer welfare recipients have pursued higher education. Researchers tracking the college enrollment of welfare recipients since 1996 have reported decreases between 29 and 82 percent (Polakow 2004, 8; IWPR 1998). In 1995, more than 27,000 welfare recipients were enrolled in classes at the City University of New York (CUNY). By 2000, that number had decreased to 5,000 (Pearson 2007, 725; Cox and Spriggs 2002) where it remains.

\section{Methods}

This research took place over a three-year period, as part of a larger study on lowincome single parents who were participants in a community based antipoverty program in Boston. The program targeted single parents living in public housing who were attempting to go back to school and move "up and out." The qualitative portion of the research, upon which this paper is based, included annual interviews with participants and ethnographic field notes. Interviewees were asked about their educational plans for themselves and their children, as well as their day-to-day experience pursuing work and school.

In all, 66 interviews were conducted with 37 unique participants, and seven interviews were conducted with the four primary staff members of the antipoverty program. The participants were all mothers (with one single father participating for one year) who ranged in age from 26 to 55 and were raising between one and four children. Their children ranged in age from newborn to adult (with an average of 1.7 children per family). Data about the participants' racial/ethnic background was recorded as follows: 13 were White, 15 were Black or African-American, eight were Hispanic/Latino, and one was Asian. The majority of participants lived in public housing developments in South Boston, though this was not a formal requirement. All participants were interviewed annually after they had taken part in the program for a minimum of six months. Each year, researchers applied for and received IRB approval to conduct the interviews with participants. 
The research and analytical approach were guided by principles of feminist inquiry, specifically, placing the lived experiences of the low-income single mothers at the center of the analysis. Researchers here were guided by empathy for the women, taking into account conditions of inequality and oppression while recording and analyzing their stories Dorothy Smith (1997) points to the importance of learning about society from this type of standpoint on the sidelines.

\title{
Results and Discussion
}

In all, we identified four major obstacles to the women's pursuit of higher education: 1). Winding paths and dead ends, 2). Difficult transitions, 3). Short-sighted decisions, and 4). Inflexible institutions. While these obstacles included some elements typically explicated in literature about higher education for low-income women, few have been explored through in-depth, qualitative study.

\section{Winding Paths and Dead Ends}

Collectively, the women interviewed here logged hundreds of post-secondary classroom hours, but many of those hours were never counted towards degrees. Instead of cumulating in a degree or professional skill set, hours were often logged in vocational programs that did not lead to jobs. Credit hours were lost when they changed degree programs, in effect stretching out the length of time needed to complete a given degree. The "career" track taken by most of the interviewees was fluid and, at times, dictated by paperwork, deadlines, logistics, and advice from friends. Kim, a mother of two, was told by a friend there were lots of high paying jobs available in the medical field, although she worried she was not "a blood and guts type person." This is how she described her plans,

\begin{abstract}
“I'm starting next Friday for a certified nurse assistant, and in January I'll start the medical assistant program. The CNA is just something to fill in right now until I actually go to school for the medical assistant. I'd definitely rather do that than the certified nurse assistant, but you know, this way I'll have two different certificates... Nothing else really interested me that much. I just don't even know if this is something I really want to do, but I don't think I will really know until I start the classes. I'll just have to wait and see.”
\end{abstract}

Once she started classes, Kim realized a career in the medical field would not work for her and said she was looking for another trade. In many cases, taking a job they believed would provide the fastest route to a sustainable wage led the women to pursue fields for which they were ill-equipped in terms of their personal interests and experience. In turn, this led to changes in their course of study.

\section{Difficult Transitions}

Another interviewee, Sheila, encountered a setback when she first returned to school and realized that none of the credits from a two-year Associates degree in legal administration, which she'd earned years ago, were transferrable. 
"You'd think I'd be further along, because I have an Associates degree already...but actually my degree doesn't help at all. I have to start over as a freshman everywhere, because the school where I got my degree was not accredited. Nobody takes their credits, and I didn’t know that.”

This situation was common among the women interviewed. Of those who reported transferring colleges or switching programs, all reported losing some credits in the transition. One mother said, "When I first got to the new school, I was upset because I already took some classes and I was going to have to take them over again."

In addition, all students who earned degrees or certificates from non-accredited schools reported a lack of understanding that losing credits was a possibility. One mother of a young son said,

"I have a certificate in Marketing, but they (her new school) wouldn't take that...because it’s like a degree in itself I guess. I didn't know. I don't really understand that, because I got a certificate. So anyway, I am pretty much starting from scratch.”

Interviewees said they did not understand they were earning non-transferrable, standalone degrees. Most did not understand the model of college as a business or the ways in which their winding paths would impact their ability to get a degree.

\section{Short-term Degree Decisions}

As poor mothers, all interviewees expressed the primacy of providing for their children. In order to provide and care for their children, they wanted to pursue whatever educational program would lead them into a sustainable job in the least amount of time. Laura, a mother of two living in public housing, learned about a local for-profit, preprofessional school online. The ads she saw promised graduates would "land you a job within six months of graduation," so she had taken out loans to pay for the classes. When I spoke with her, she had completed the program more than a year before and was still waiting for the school's career services center to return her calls and help her find the promised job.

Even when interviewees did manage to complete Certificate or specialized Associate degree programs, many reported the degree had not impacted their job prospects. One mother with a six-year-old son, who had recently moved out of public housing, said, "I went to a two-year college for my associates in medical assistant, which was really kind of useless...I wound up going back into medical billing, because medical assisting didn't pay as much as medical billing once you had experience... "With several years experience, she did not earn enough to pay rent.

Many interviewees expressed the fear that "time is running out," so they chose programs that were currently available to them. However, several of the respondents eventually circled back to their original program choice or career choice after spending time and money pursuing other opportunities. The first year I spoke with Emma she was working at a local hospital, working to gain acceptance into a nursing program. The next year she said, "I am still trying for the nursing program, but it was closed. Now I have been going to school for my Associates in surgical tech. I applied for RN, 
radiology and ultrasound to give me a better chance, but I am still waiting for them to call me.” By the third year, Emma was closer to completing her Associates in surgical tech, but was still trying to get into nursing, what she "really wanted to do."

\section{Inflexible Institutions}

Many of the degree programs described by interviewees did not allow part-time status, and non-profit and community often required adherence to strict time limits for completion, despite the fact that single mother students often take longer to complete degree programs. One of the mothers interviewed, Lilah, who struggled with depression, was dropped from a scholarship program designed for low-income single mothers because she was taking too long to complete her degree, despite receiving high grades in her classes. Studies show unmarried mothers are prone to mental illness including anxiety and depression (McGrath, Keita, Strickland and Russo 1990; Quinn and Allen 1989). In order to finish on time, Lilah would have had to take five classes during one semester while taking care of her son.

Overall, interviewees reported that their schools were not equipped to help them arrange class schedules around parenting and work obligations or to assist with childcare, which all of the interviewees with young children mentioned as an obstacle to their education. Roughly half of interviewees reported some family support available to help with childcare while they went to school. One interviewee said, "Well this program is at night...so I'd go to the school at night. It (childcare) is not a problem because I had my family, which is huge, to watch him." Women who were without support from family members reported difficulty in securing childcare. Five of the women said they took classes online so they would not have to hire childcare help, but all of those who took online classes said it was very difficult to do schoolwork and listen to lectures while their children were at home.

Even those with childcare vouchers had difficulty retaining consistent care when they went back to school. One mother said, "My time is up. I can't get no more childcare vouchers while being in school. They want me to go to work or nothing at all." According to another interviewee, "I finally got the voucher after waiting many years. But I have to work for thirty hours or be in school full-time to keep the voucher. But I was working twenty and going to school, so it won't work." Many of the women expressed confusion about the way in which school hours "counted" towards retaining a childcare voucher. According to Mia,

\footnotetext{
"They just sent me a notice for childcare termination because they said some of my classes aren't like classes where you go and you sit with the teacher for two hours. They were trying to give me trouble but there is just a lot of confusion because like I don't know. I am in school full-time, but what they don't get is that like for college like, the class will be 3 hours long, but the teacher will tell you, you need to do 6 hours at the school altogether, like literally they want you to sign in and be studying for 3 hours during week but it's not like with the teacher. So there is like no way for them to say yeah, you were sitting in front of me for all this time."
}

Three interviewees sought legal assistance to retain childcare benefits while attending school. Samantha was told by a caseworker that she could keep her benefits if she added 
two classes per semester to become a full-time student, but she said, "I just cannot do that. I can't handle two classes with my kids and everything else, that's it, you know? I tried to do before, and it was just too much." Many expressed frustration at the lack of support for their pursuit of education from benefit programs.

When low-income single mothers attain college degrees, they are less likely to rely on public benefits (IWPR 2008). However, public benefit programs often make it difficult for low-income women to attend school while continuing to receive childcare vouchers and cash assistance, which allows their families to subsist. Welfare reform was considered, by many, to be a success simply because the number of people receiving benefits at any given time was cut by half. In reality though, "welfare reform” severely limited the pursuit of educational opportunities.

\section{Conclusion}

This paper provides insight into undocumented, practical difficulties encountered by motivated low-income single mothers attempting to go back to school to complete postsecondary educational programs. Although the findings here shed light on the difficult educational paths tread by poor mothers, further research is needed to understand the applicability of these findings for other low-income single mothers. Qualitative, as well as quantitative research, is called for to further investigate obstacles to the educational pursuits of low-income single mother students.

What might be done to make education a more viable pathway out of poverty for poor mothers is an even more difficult question. In some ways, the obstacles outlined in this paper have their roots in early educational and career counseling experiences (or the lack thereof) in the schools attended by these low-income single mothers. Without advice from friends and family members who have attended college, for instance, institutional support becomes even more important. From a young age, many of these women did not understand college to be a viable option for them. The majority of interviewees had no close peers or family members who had attended four-year colleges. In fact, studies suggest that many low-income mothers would like to pursue a college degree but most doubt their ability to attain one (Bullock and Limbert 2003).

Further, all of our interviewees reported being advised against pursuing a college degree in a liberal arts field, because of the pressing need to make money. However, college is one of the key opportunities for the transmission of cultural capital the building of which could impact career and class status (Bourdieu 1964). Also, it is difficult to gauge problems associated with pursuing jobs and careers that do not align with personal interest. In fact, this may lead to further changes in direction that low-income single women can ill afford.

Presumably a centralized system of career counseling even after high school graduation would have benefited the low-income single mothers interviewed here. Often nontraditional, single mother students require individualized attention to remedy gaps in their education and help them to navigate the maze of educational options. Instead, we observed a conflicting array of information gleaned from caseworkers, counselors, friends, teachers, and the internet, which led to frequent changes of plans.

At some point, the majority of interviewees had pursued some type of short-term, vocational training program. While there is no question that a four-year degree offers the most significant benefit to a person's lifetime wages and employability (IWPR 
2008), research is also needed to determine what kinds of basic education, technical skills and job training courses are the most effective in helping low-income single mothers move forward. An evaluation of welfare-to-work policies found that in a sample of people who had not graduated from high school, those who participated in basic education combined with post-secondary education earned $47 \%$ more than those who received only basic education (Workforce Alliance 2002; Bok 2004, 47). For women who want to move past basic remediation, but for whom a college degree is not a viable option, it is important to choose the best vocational training available.

Perhaps what the data here suggest as the most vitally important to the success of lowincome single mothers in their pursuit of higher education is increased flexibility of educational institutions to meet the needs of single mother students. One of the mothers said of her experience attending a new college, “I don't feel real supported. I mean I'm coming in as a non-traditional student and I just realized how much you have to just do on your own, like there's no one to help." Single mother students have different needs, like arranging class schedules around childcare, which are not shared by traditional college students. Colleges often do not offer specific remediation programs to help students to catch up or fill the gaps created by stretches of time away from school. Counseling and community-building opportunities might also help to prevent feelings of isolation among low-income single mother students (Adair 2001). Educational institutions must be made aware of the experiences and specific educational needs of low-income single mother students, and the research here is a part of the effort to fill this gap in understanding.

\section{References}

Adair, V.C. (2001). Poverty and the (broken) promise of higher education. Harvard Educational Review, 71 (2), 217-239.

Adair, V. C., and Dahlberg, S. L. (2003). Reclaiming class: Women, poverty, and the promise of higher education in America. Philadelphia, PA: Temple University Press.

Blank, R.M. (2009). Economic change and the structure of opportunity for less skilled workers. In M. Cancin and S. Danziger (Eds.), Changing Poverty, Changing Policies. New York: Russell Sage Foundation.

Bullock, H. E., and Limbert, W. M. (2003). Scaling the socioeconomic ladder: Lowincome women's perceptions of class status and opportunity. Journal of Social Issues, 59(4), 693.

Christopher, K. (2005). A 'pauperization of motherhood'? single motherhood and women's poverty over time. Journal of Poverty, 9(3), 1-23.

Cox, K. L., and Spriggs, W. E. (2002). Negative effects of TANF on college

enrollment. Washington, DC: National Urban League Institute for Opportunity and Equality.

Deprez, L.S., Butler, S. S., and Smith, R. J. (2004). Securing higher education for women on welfare in Maine. In V. Polakow, S. S. Butler, L.S. Deprez and P. Kahn (Eds.), Shut-Out: Low-Income mothers and higher education in post welfare reform America. New York: SUNY Press. 
Institute for Women's Policy Research. (Feb 2008). Resilient and Reaching for More: Challenges and Benefits of Higher Education for Welfare Participants and Their Children. Washington, DC: Avis Jones-DeWeever \&Barbara Gault.

Institute for Women's Policy Research. (1998). Education and job training under welfare reform. IWPR Welfare Reform Network News, 9/10, 1-15.

Jimerson, S., Egeland, B., and Teo, A. (1999). A longitudinal study of achievement trajectories: Factors associated with change. Journal of Educational Psychology, 91(1), 116.

Mortenson, T. G. (2000). Poverty, race, and the failure of public policy: The crisis ofaccess in higher education. Academe, 86(6), 38-43.

Olson, S.L., and Banyard, V. (1993). "Stop the world so I can get off for a while": Sources of daily stress in the lives of low-income single mothers of young children. Family Relations, 42(1), 50-56.

Pearson, A. F. (2007). The new welfare trap: Case managers, college education, and TANF policy. Gender and Society, 21(5), 723-748.

Polakow, V. (2004). Shut out : Low income mothers and higher education in postwelfare America. Albany, NY: State University of New York Press.

Sands, R. G., and Nuccio, K. E. (1989). Mother-headed single-parent families: A feminist perspective. Affilia, 4(3), 25-41.

Seccombe, K., James, D., and Walters, K. B. (1998). "They think you ain't much of nothing": The social construction of the welfare mother. Journal of Marriage and Family, 60(4), 849-865.

Smith, D. E. (1997). From the margins: Women's standpoint as a method of inquiry in the social sciences. Gender, Technology and Development, 1(1), 113-135.

Strawn, J., and Martinson, K. (2000). Steady work and better jobs: How to help lowincome parents sustain employment and advance in the work force. Washington, DC: Manpower Demonstration Research Corporation. 


\section{HEAd'15}

\section{SESSION 3B}

\section{ENGINEERING}




\title{
Analysis of Students’ Out-of-Class Work in Current University Studies
}

\author{
E. Antonino Daviu, D. de Andrés Martínez, A. Palomares Chust, J. C. Ruiz García, \\ C. Gisbert Doménech, A. Peña Cerdán, J. V. Ballester Server, C. Villavieja Llorente
}

Universitat Politècnica de València, Camino de Vera s/n, 46022 Valencia (Spain)

\begin{abstract}
This paper analyses to what extent, and how, student's work can be used to improve students' on-site learning experience and enrich the course evaluation process. The work presented focuses on gathering and analysing different information related to the out-of-class work carried out by students in various Bachelor and Master courses taught at the Universitat Politècnica de València. Results show that there is not a clear relationship between the time devoted to a given task and the attained results, but they highlight especial cases to be considered, like a number of students that devote excessive time to the task but get poor marks. Moreover, the lack of adequate supervision of outof-class work leads to situations where teachers underestimate or overestimate this time. Supervision of student's outof-class work is thus an essential asset for adequately tuning and improving courses content and scheduling, providing meaningful feedback to students, and rewarding the personal work they invest on tasks, something of major importance for keeping students' motivation in continuous learning and evaluation processes.
\end{abstract}

Keywords: Out-of-class work, feedback, analysis, time demands

\section{Introduction}

Within the context of the Bologna Process as director plan for university studies, outof-class work is acquiring a greater relevance in the teaching-learning process. Outof-class work constitutes a fundamental strategy to train and develop students' specific competencies, being also a very useful tool to carry out formative and continuous evaluations (Mohanan, 2005).

Nowadays, the teaching-learning process is not so much oriented to know what and how much the students know, but rather to assess how are they able to use the acquired knowledge in order to interpret and solve realistic problems. This new way of understanding the students' learning process is settled in the theoretical framework known as SAL (Students Approaches to Learning) (Houghton, 2004). The idea is to provide university students with the necessary strategic tools to address the learning process from a more competent perspective, through a metacognitive reflection of learning and study competences (Fry, Ketteridge, \& Marshall, 2014).

Out-of-class work is usually limited to deliver some reports for their subsequent evaluation, but there exist some parameters that cannot be controlled or evaluated with a simple deliverable. For example, the evaluation process could be enriched by knowing how students organize and coordinate their work, which strategies they deploy to reach a solution, how long they need for achieving their objectives, what their opinion about the completed work is, and how they are motivated by the out-ofclass work done. Furthermore, this information would also improve the feedback finally provided to students (Bain, 2004).

The "Tools and Strategies for Competences Assessment" (TASCA) "Innovation and Quality Education Team” (EICE) from the Universitat Politècnica de València (UPV) aims at analysing, applying, and assessing formative and continuous methodologies and strategies to evaluate, in all its dimensions, students' out-of-class work (de Andrés, et al., 2014). The goal is to process all the gathered information to improve and adapt the content of in-class course materials, and increase students' motivation 
and participation in lectures, while providing a more specific and adapted feedback to each student. This will increase the degree of freedom of students over their learning process by allowing them to address their particular weaknesses and reinforce their strengths (Barr \& Tagg, 1995). Figure 1 summarizes the objectives pursued with the analysis of out-of-class work (de Andrés, et al., 2014).

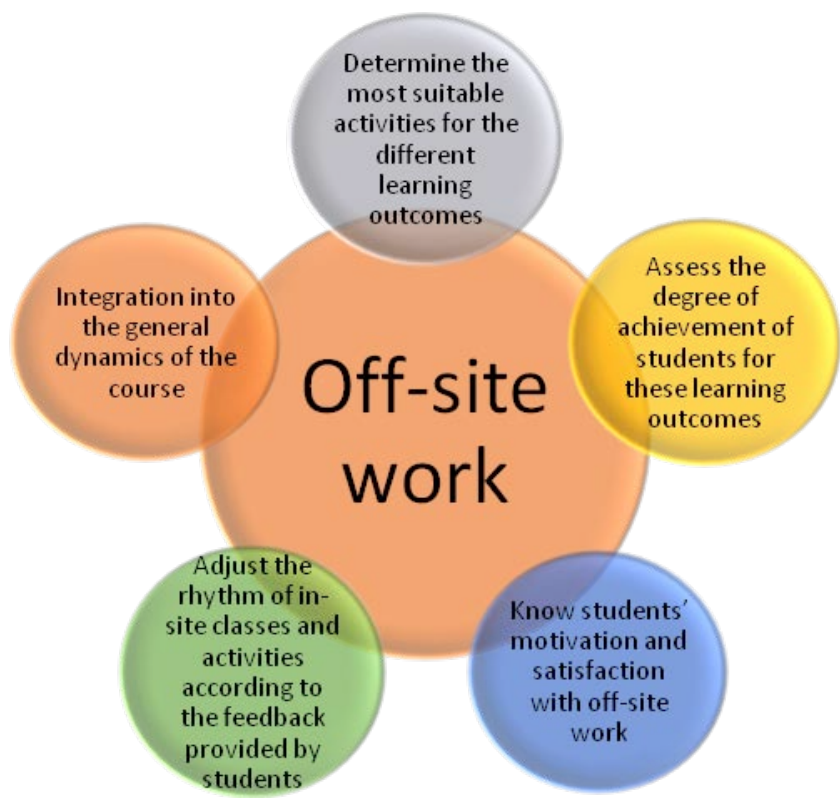

Figure 1. Objectives of out-of-class work analysis.

This paper presents the methodology followed by the TASCA team to obtain and analyse results of out-of-class work activities carried out in different courses, as well as different outcomes resulting from the analysis of questionnaires aimed at collecting students' opinions about out-of-class work. Discussion of the results and conclusions will be presented at the end of the paper.

\section{Method}

The first step consisted in the definition of those questionnaires used to collect and analyse information about out-of-class work. These questionnaires, listed in Table 1, include questions, opinions, and comments about the activity performed and also about the time and effort devoted to such activity, its suitability and usefulness.

They were handed are part of the deliverable of the proposed activities, so information could be quickly gathered in a fluid manner. Students' answers are more reliable when they fill out each questionnaire just after finishing each activity, as their work is recent and they have a clear idea of the whole process that has been followed to address such activity. So these data are very useful to get an immediate and meaningful feedback about out-of-class work.

The second step consisted in the use of these questionnaires after the completion of the out-of-class work. The defined mechanisms for collecting information about students' out-of-class activity have been applied in two semesters. Due to the multidisciplinary nature of the team of teachers conforming TASCA, questionnaires have been adapted according to teachers' criteria, degree, course, kind and duration of the activity. For this study, and as listed in Table 2, courses from different Bachelor and Master's Degrees were considered. Courses have a semester or annual duration 
and in the particular case of the Projects course from the Bachelor's Degree in Architecture, it has students from three different years.

Finally, information collected has been analysed during the third step, taking into account the different kind of proposed activities. Results and discussion are shown in the following section.

Table 1. Analysed out-of-class activities through the associated questionnaires.

\begin{tabular}{|c|c|}
\hline Out-of-class activity & Questionnaire \\
\hline \multirow{4}{*}{$\begin{array}{l}\text { A. Reading a scientific } \\
\text { paper before the } \\
\text { lecture, and answering } \\
\text { a number of relevant } \\
\text { questions. }\end{array}$} & What is the most interesting idea you have learned? Why? \\
\hline & Which question would you like to get answered in the next lecture? Why? \\
\hline & What aspects do not require further explanation after reading the paper? \\
\hline & How long did it take you to read the paper and answer these questions? \\
\hline \multirow{5}{*}{$\begin{array}{l}\text { B. Applying the } \\
\text { contents of a lecture to } \\
\text { students' projects. }\end{array}$} & Is the main concept of the lecture clear? Do you have any doubts? \\
\hline & Have you found it difficult to apply it to your project? Why? \\
\hline & Has this exercise helped you in clarifying the main lecture's concepts? \\
\hline & Which new questions or doubts do you have after making this exercise? \\
\hline & How long did it take you to review the lecture and make the exercise? \\
\hline \multirow{5}{*}{$\begin{array}{l}\text { C. Searching a paper, } \\
\text { extracting information } \\
\text { as shown in lectures, } \\
\text { and preparing a } \\
\text { presentation about the } \\
\text { paper's contents. }\end{array}$} & How long did it take you to select the paper? \\
\hline & Was it difficult to comprehend and extract the information? Why? \\
\hline & What is the conclusion of the paper? \\
\hline & Have you acquired new competencies and/or knowledge? \\
\hline & How long did it take you to work on the paper and presentation? \\
\hline \multirow{3}{*}{$\begin{array}{l}\text { D. Solving long } \\
\text { problems about the } \\
\text { content of some } \\
\text { lectures. }\end{array}$} & How long did it take you to solve the problem? \\
\hline & Did it allow you to review and better understand the lectures’ contents? \\
\hline & Do you have questions or doubts about the content of the exercise? \\
\hline
\end{tabular}

\section{Results and Discussion}

The first problem faced during this work was the difficulty in making all students to answer the questionnaire. Even although it was handed as part of the deliverable, as commented before, some students refused to answer it. Moreover, in courses were out-of-class work was optional, some students even declined to present the work.

Figure 3 shows an example of two courses taught in our Bachelor of Telecommunications, the "Telecommunications Networks and Systems II" course (TNS2) with two proposed exercises (Figure 3a and Figure 3b) and the "Propagation" course (Figure 3c). As observed, optional out-of-class work was only performed by around $80 \%$ of the students. From these students, a $73 \%$ completed the questionnaire about exercise I of TNS2, 88\% about exercise II of TNS2 and 91\% answered the questionnaire about the problem in "Propagation" course. In this last case, participation in the questionnaire was rewarded with some extra points ( 0.25 points over 10) in the mark, which may justify the observed higher participation. 
Table 2. List of target courses.

\begin{tabular}{|c|c|c|}
\hline $\begin{array}{l}\text { Out-of-class } \\
\text { activity }\end{array}$ & Degree & Course \\
\hline \multirow{2}{*}{ A } & $\begin{array}{l}\text { Bachelor's Degree in } \\
\text { Informatics Engineering }\end{array}$ & Design of digital systems \\
\hline & $\begin{array}{l}\text { Master's Degree in Computer } \\
\text { and Network Engineering }\end{array}$ & Design of architectures in VLSI \\
\hline B & $\begin{array}{l}\text { Bachelor's Degree in } \\
\text { Architecture }\end{array}$ & Projects \\
\hline \multirow{2}{*}{$\mathrm{C}$} & $\begin{array}{l}\text { Bachelor's Degree in } \\
\text { Biotechnology }\end{array}$ & $\begin{array}{l}\text { In vitro culture and genetic transformation of } \\
\text { plants }\end{array}$ \\
\hline & $\begin{array}{l}\text { Master's Degree in Plant } \\
\text { Genetics and Breeding }\end{array}$ & $\begin{array}{l}\text { Application of in vitro culture to plant } \\
\text { improvement }\end{array}$ \\
\hline \multirow{2}{*}{$\mathrm{D}$} & \multirow{2}{*}{$\begin{array}{l}\text { Bachelor's Degree in } \\
\text { Telecommunications } \\
\text { Systems, Sound and Image } \\
\text { Engineering }\end{array}$} & Propagation \\
\hline & & Telecommunication Networks and Systems II \\
\hline
\end{tabular}

Telecommunications Networks and Systems II: Exercise 1

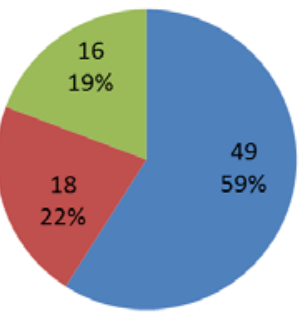

- Problem done and participate

- Problem done but don't participate

Problem not done

(a)

Telecommunications Networks and Systems II: Exercise 2

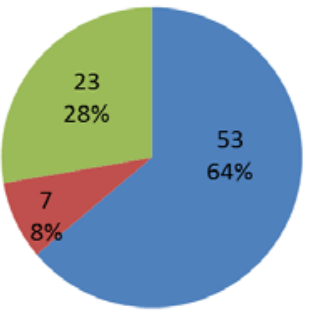

Problem done and participate

- Problem done but don't participate

- Problem not done

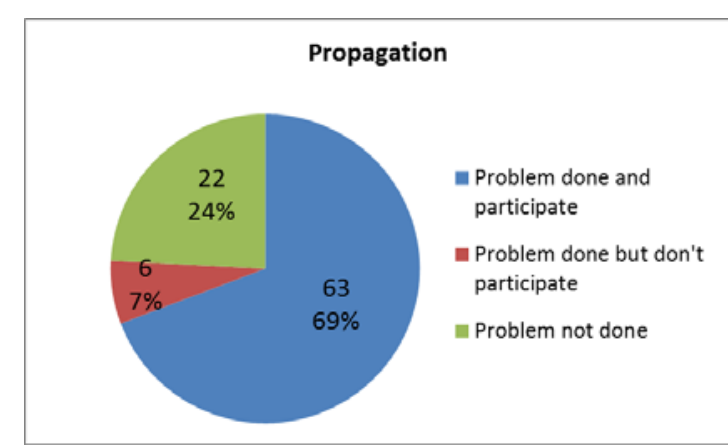

(c)

Figure 3.Participation in out-of-class work and questionnaires.

One of the questions formulated in all questionnaires was about the time students' devoted to out-of-class work. In Figure 4 the cumulative distributed function (CDF) of students having finished the activity in a given time is presented for different target 
courses. The red line in the graphs represents the time expected by the teacher to complete the out-of-class activity.

Through this type of graph it is possible to estimate whether the teacher has underestimated the time required to finish the out-of-class activity or, on the contrary, students' needed less time that expected to finish the task. As observed, in Figure 4a less than $75 \%$ of students finished in the expected time, less than $50 \%$ in Figure $4 \mathrm{~b}$, and less than $30 \%$ in Figure 4c. This shows that, mostly at the third case, time estimated by the teacher was too short, which has helped to re-adjust the duration of the exercise and workload for successive proposals of this activity.

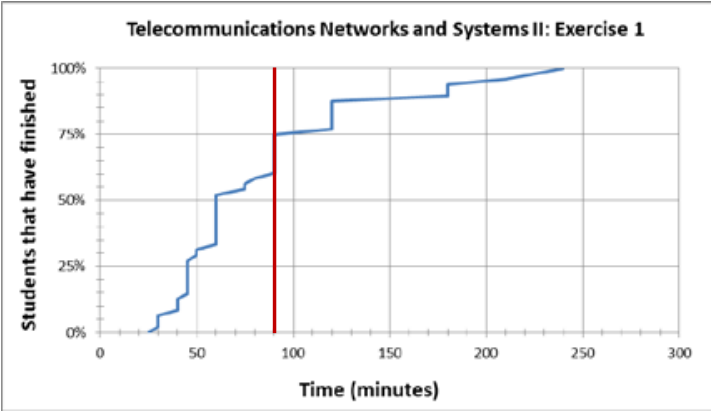

(a)

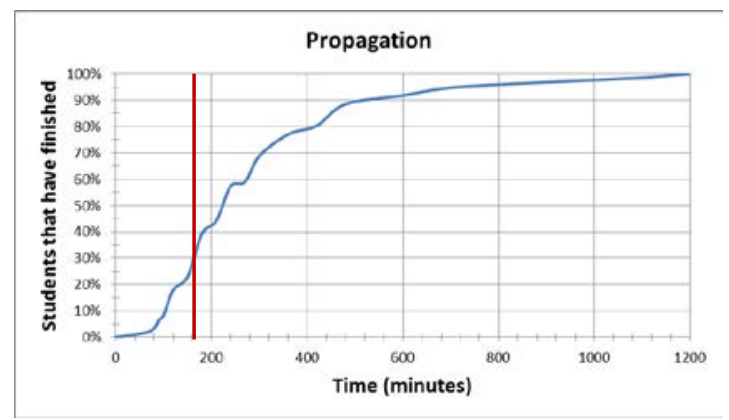

(c)

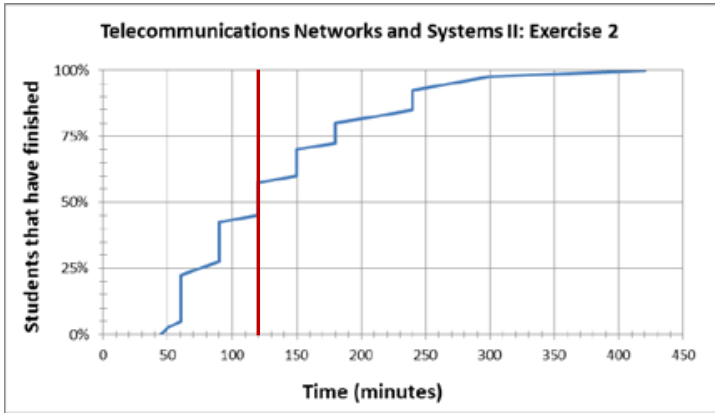

(b)

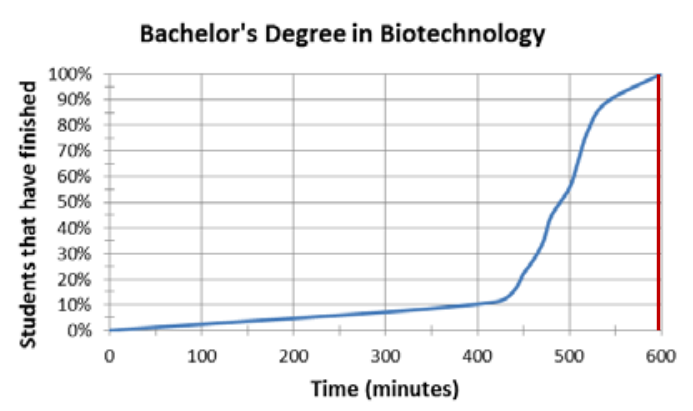

(d)

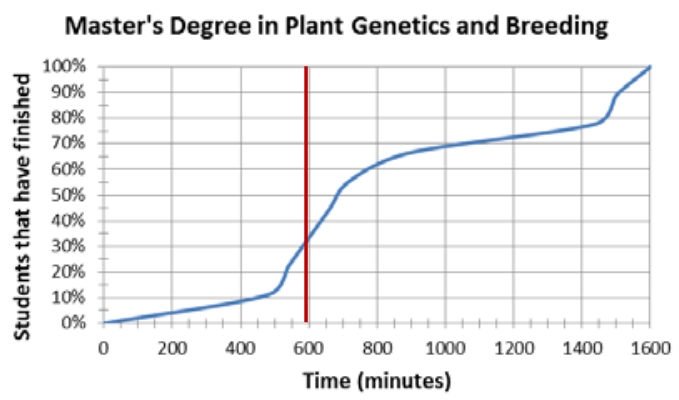

(e)

Figure 4.Cumulative distributed function of students having finished the activity in a given time, for different courses.

The same activity was proposed in the "Bachelor's Degree in Biotechnology" (Figure 4d) and the "Master's Degree in Plant Genetics and Breeding" (Figure 4e). As can be seen, all students from the "Bachelor's Degree in Biotechnology" finished the activity before the estimated time. Nevertheless, it seems that the task is not too easy either, as barely any student completed the deliverable in less than 450 minutes. In the case of master students just about $30 \%$ of them finished the task in that time. In fact, twice 
that time was required for $75 \%$ of students to finish the activity. This clearly points out a problem that could be related to the heterogeneity of students enrolled in the master course, whereas degree students have a more homogenous profile that better fits the task at hand. Probably, it could be a good idea to complement the task for master students with a previous lecture or activity for them to acquire a homogeneous knowledge.

By progressively repeating this kind of approach in successive years we expect to properly adjust the workload and duration of each considered activity, and probably introduce new activities or remove some of them, according to ECTS-based requirements and observed students’ performance.

Figure 5 shows the grades obtained by students in the out-of-class activities previously explained. Grades are represented with respect to the time required by the student to complete the task. This will help us to determine whether there is any relationship between the time devoted to the task and the marks finally obtained. It is worth mentioning that the Spanish grading system uses a 10-based scale, where 10 is the maximum grade and the student fails if his/her grade is lower than 5 .

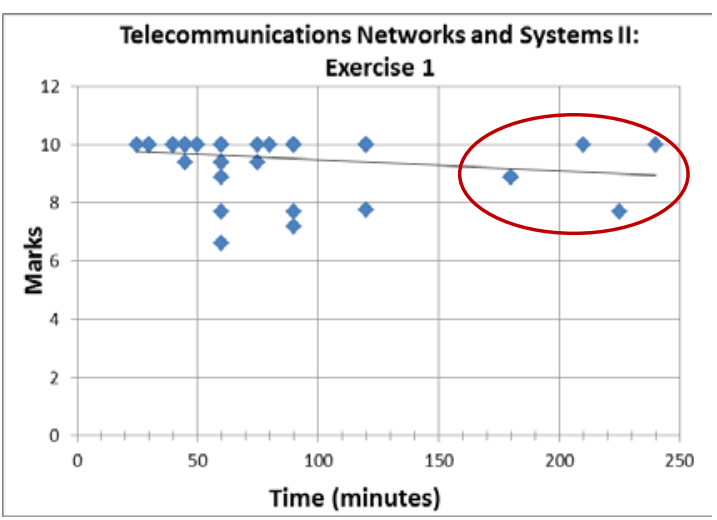

(a)

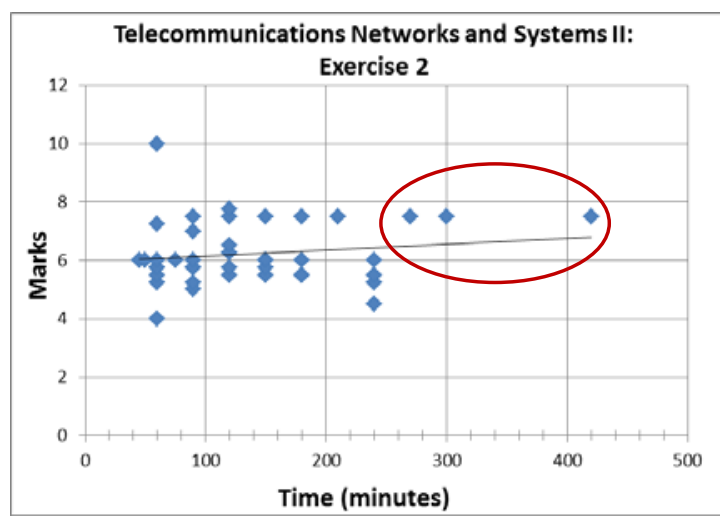

(b)

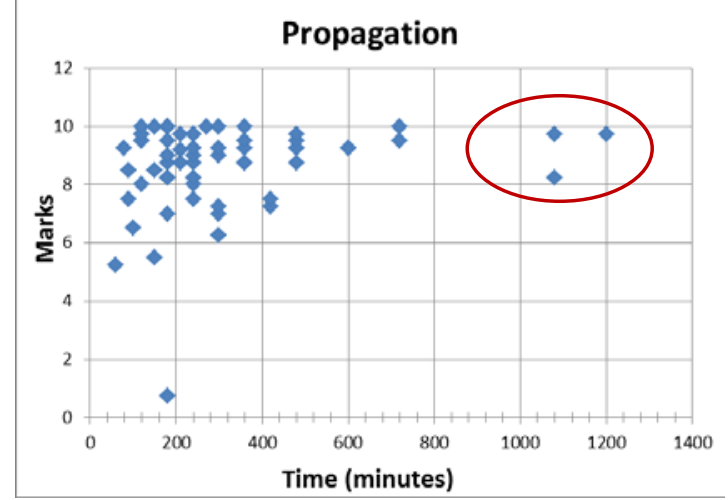

(c) 


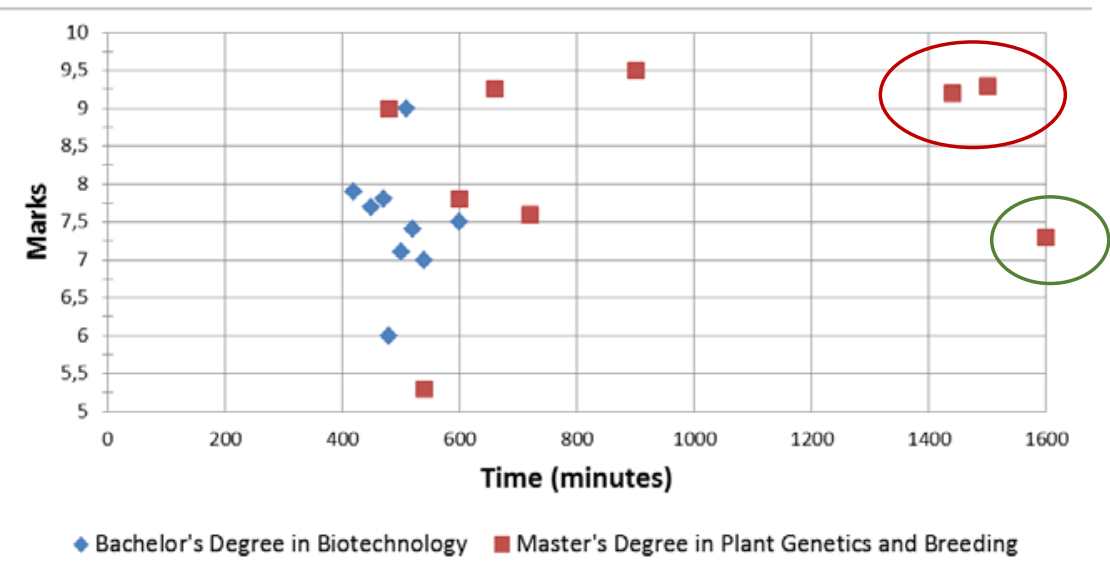

(d)

Figure 5.Relationship between marks assigned and time devoted to the task.

The first thing to be noted is that it does not seem to be any clear relationship between the assigned marks and the time devoted to the task. There exist, in all courses, high grades for deliverables declaring relatively low dedication, and low grades for deliverables that reported a long time to complete.

However, with this kind of graph it is easier to detect possible problems. For instance, the case of students employing much more time than the rest to finish the task (highlighted with a red circle in Figure 5) and students reporting the longest time devoted to the task and achieving low mark (highlighted with a green circle in Figure 5). These cases could probably point out some difficulties with the content of related lectures, for instance, and a meeting with these students for clarification and guidance may be necessary. The early detection of recurring cases is of prime importance to be able to help students with learning or organisational problems, possibly redirecting them to the UPV's Institute of Education Sciences (ICE) where specially trained staff may attend their necessities.

\section{Conclusions}

The progressive integration of out-of-class work assessment in the courses' dynamics could become a basic tool in the teaching-learning process. On the one hand, the assessment of out-of-class work does not limit its scope to the delivered final result, but also to its development process and the student progress, leading to fairer and more objective evaluation. On the other hand, feedback of prime importance is obtained regarding students' satisfaction with activities and courses, their strengths and weaknesses, which can be used to improve the scheduling, scope, and structure of out-of-class activities and the organisation of the course in general.

In spite of the heterogeneity of degrees, courses, and activities considered by TASCA team members, obtained data have constituted a key tool to detect opportunities and menaces in the deployed teaching-learning process. Reliable information about the ongoing progression of students, both individually and as a group, enables the early detection of learning problems that teachers may tackled by deploying appropriated countermeasures.

The steady use of these kinds of questionnaires also enables students themselves to reflect about their own learning process, so they have the possibility of changing their work and study methods to improve their performance and efficiency. 
The future work of the TASCA team aims at deploying that kind of approach on a large scale in all out-of-class activities defined for the considered courses, fine tuning the proposed questionnaires to find a single pattern that could match all kind of activities, and verifying that the potential benefits of this approach by direct observation and comparison with previous years results.

\section{Acknowledgement}

This work has been sponsored by Universitat Politècnica de Valencia's projects PIME 008-A-2013 and PIME/2014/A/022/A.

\section{References}

Bain, K. (2004). What the Best College Teachers Do. Harvard University Press.

Barr, R., \& Tagg, G. J. (1995). From teaching to learning - A new paradigm in undergraduate education. Change, 27(6), 13-15.

de Andrés, D., Ruiz, J., Antonino, E., Palomares, A., Gisbert, C., Peña, A., Villavieja, C. (2014). Towards integrating mechanisms to assess students' off-site work within the regular teaching-learning process. International Conference of Education Research and Innovation, (pp. 3025-3034). Seville, Spain.

Fry, H., Ketteridge, S., \& Marshall, S. (2014). A Handbook for Teaching and Learning in Higher Education: Enhancing academic practice (4th ed.). Routledge.

Houghton, W. (2004). Engineering Subject Centre Guide: learning and teaching theory for engineering academics. (L. Willis, Ed.) Higher Education Academy Engineering Subject Centre, Loughborough University.

Mohanan, K. P. (2005). Assessing Quality of Teaching in Higher Education. Retrieved from Centre for Development of Teaching and Learning: http://www.cdtl.nus.edu.sg/publications/assess/default.htm 


\title{
The Contextual Learning Approach in Engineering Education
}

\author{
Ida Kukliansky*, Shai Rozenes ** \\ * Department of Industrial Engineering and Management, School of Engineering, Ruppin Academic \\ Center, Emek-Hefer, Israel \\ ** Department of Industrial Engineering and Management, Afeka Tel Aviv Academic College of \\ Engineering, Israel
}

\begin{abstract}
This study presents a learning approach that educates Industrial Engineering and Management students to perform their future job more successful. This approach embeds a practical project within the learning program. The theoretical framework of our learning process is contextual learning, which claims that a learning process occurs when students link new formal knowledge with real-life experience. The project stimulates the student to implement the theoretical knowledge in a practical environment. This approach was applied in two important academic courses: project management and new service development. 129 engineering students, participants of this study, had to implement the academic know-how into the embedded project. The study utilizes a quantitative tool to measure the students' response to the approach. This evaluation tool included 'preferred' and 'actual' questionnaire forms. The results indicate that the majority of the students were satisfied with their learning environment; their actual form rank was at least like the preferred form rank.
\end{abstract}

Keywords: Engineering education; hands-on-experience; contextual learning; active learning

\section{Introduction}

The aim of this paper is to present a methodological academic training framework for the students studying Industrial Engineering and Management (IEM) during undergraduate studies. The study reveals an embedded real-life project that enables the students to gain both profound know-how and experience during their studies. This approach was applied in two academic courses: project management and new service development. These disciplines are expanding within many engineering and business activities and can facilitate strivings toward successful accomplishment of engineering projects and sustainable entrepreneurships. Therefore, many academic institutes teach these programs. In order to manage projects processes successfully, a training process is needed (Rozenes \& Vitner, 2009).

The theoretical anchor of the teaching process presented in this paper is contextual learning, which claims that a learning process occurs when students link new formal knowledge with real-life experience. This approach, developed at the beginning of the 20th century by John Dewey (Dewey, 1916), adapts the learning process to the experiences and interests of the learner. Learning is understood to be more effective when new material is tied to previous knowledge, and involves the learner in the learning process. The key to successful learning lies in the connectedness of the learned knowledge to what seems meaningful to the learner (Caine \& Caine, 1991). Much research supports this type of learning and argues that it is significant for the learners (Klassen, 2006). Roth \& Roychoudhury (1993) found a link between contextual learning and learner's motivation. According to Binnie (2004) contextual learning is very efficient, especially for raising learners' interest and increasing students' participation in the learning process. In addition, contextual learning elements not only increase the learner's motivation for the study task, but also provide cognitive support to see the similarities and differences and to organize ideas (Rivet \& Krajcik, 2008). Contextual learning emphasizes higher-level thinking, knowledge transfer across 
academic disciplines, and collecting, analyzing and synthesizing information and data from multiple sources and viewpoints (Smith, 2000). Contextual learning facilitates learning in which students employ their academic understanding and abilities in a variety of out-of-school contexts to solve complex, real-world problems, both alone and in various groups (Shelley-Tolbert et al., 2000). Applying the context-based approach to learning was also found to be effective for engineering students who learn how to analyse experimental data, in the context of the laboratory, rather than learning data analysis skills in a non-contextual form such as in a mathematic-based course (Kukliansky \& Eshach, 2014).

\section{Methods}

\section{The education methodology}

The common teaching practice is the combination of lectures with tutorials. The education methodology combines lectures with life experience that facilitate the learning process. The education process combines academic theory and practice. The program is conducted as a workshop, in which all the participants take part in discussions, while performing genuine assignments. Contextual learning is applied, while each participant is required to choose a real-life project to facilitate the learning process. Creativity and innovation are important during the entire process. The project is presented during the workshop, to illustrate the implementation of tools and techniques within their organizational environment.

The program consisted of fourteen weekly four-hour sessions. The teams of the participants were required to implement each program subject into their suggested project. The projects were executed in different knowledge areas such as education, healthcare, hospitality, entertainment, wholesale/retail and food. Based on contextual learning, these projects were performed as real-life projects. For example, a project in the food sector was to construct a new pub for elderly people, whereas a project in the hospitality sector was to build a special motel catering to honeymooners. The same lecturer has taught both of the courses performing the monitoring processes according to the following guidelines:

- Supervisory meetings were scheduled for every alternate week.

- Progress reports were prepared by the student team for each meeting.

- Discussions with the students about the scheduled work.

The project supervisors performed the assessment process according to the following:

- $\quad$ Progress reports assessment: The supervisor received a progress report at each meeting. These reports were assessed during the entire semester.

- Final reports: The project team wrought an engineering report that describes the entire process with a scientific approach.

- Viva: The IEM staff examined each project team member to ascertain his or her knowledge. 


\section{Participants}

The participants were 129 students (82 males and 47 females) in the Industrial Engineering and Management (IEM) department at a school of engineering.

\section{Questionnaire structure}

The evaluation tool included 'preferred' and 'actual' questionnaire forms. The 'preferred' form, reflecting the students' personal perceptions of their preferred learning environment was filled out by the students at the beginning of the course (pretest), while the 'actual' form, showing the students' personal perceptions of their actual learning environment, was filled out at the end of the course (post-test). Our instrument was based on the Science Laboratory Environment Inventory (SLEI) questionnaire (Fraser et al., 1995). The SLEI was validated among 7000 students in university classes in several countries. Fraser et al. suggest that this tool can be used to monitor students' views and to investigate the impact of different environments on student outcomes. Furthermore, it can facilitate the improvement of learning environments

The questionnaire includes 28 questions divided into four categories (subscales). Each category contains seven items. The items are arranged in cyclic order in seven blocks of four questions each. All of the questions have five response alternatives on a Likert scale from 1 to 5 ( 1 - strongly disagree to 5 - strongly agree.). To increase the questionnaire's reliability, some of the questions were worded and scored in the regular manner $(+)$, and some of the questions were worded and scored in the reverse manner $(-)$. The categories were defined as follows:

(a) Student supportiveness - The extent to which students know, help, and are supportive toward each other; for example: Members of my group help me $\left({ }^{+}\right)$.

(b) Independent learning - The extent to which students learn by themselves, including acquaintance with designated software; for example: I don't use special software to work on the project (-).

(c) Integration - The extent to which practical activities are integrated with theory classes; for example: Performing the project helps me to understand the topics that I learned $(+)$.

(d) Guidance - The extent to which guidance contributed to the students; for example: My advisor supports me in performing the project (+).

The Cronbach's Alpha coefficient showing the internal consistency reliability of the questionnaire was 0.815 for the 'preferred' form and 0.855 for the 'actual' form.

\section{Results and Discussion}

Each category included 7 questions, so the number of responses of the 129 students in each category was $129 \times 7=903$. Almost all of the responses in both forms of the questionnaire were at least 3 , whereas responses of 1 and 2 were rare. Table 1 presents the mean, median and the standard deviations (SD) of the 129 participants computed for each category of the preferred and actual form of the questionnaires. 
Table 1. Questionnaires Summary

\begin{tabular}{|c|c|c|c|c|c|c|}
\hline \multirow[t]{3}{*}{ Category } & \multicolumn{2}{|c|}{$\begin{array}{c}\text { Actual form } \\
\text { (Post-test) }\end{array}$} & \multicolumn{4}{|c|}{$\begin{array}{c}\text { Preferred } \\
\text { form(Pre- } \\
\text { test) }\end{array}$} \\
\hline & \multicolumn{2}{|c|}{ Mean } & SD & \multicolumn{2}{|c|}{ Mean } & SD \\
\hline & \multicolumn{2}{|c|}{ Median } & \multicolumn{4}{|c|}{ Median } \\
\hline (a) & 4.10 & 4 & 0.87 & 4.39 & 5 & 0.68 \\
\hline (b) & 3.32 & 4 & 0.82 & 3.61 & 4 & 0.77 \\
\hline (c) & 3.84 & 4 & 0.89 & 4.06 & 4 & 0.75 \\
\hline (d) & 3.57 & 4 & 0.79 & 3.92 & 4 & 0.77 \\
\hline
\end{tabular}

The median response in both forms of the questionnaire was 4 in almost all of the categories. The normal distribution assumption was rejected using the KolmogorovSmirnov test; therefore, we could not apply the parametric methods and used the nonparametric Wilcoxon signed ranks test. Significant difference between the preferred and actual responses were found in all of the categories $(\mathrm{p}<0.01)$.

Table 2 compares the preferred and actual ranks, presenting the percentage of responses in each category and in the entire questionnaire, where the preferred rank is equal, less or more than the actual rank. For example: in $45.08 \%$ of all the questions in category (a) the students ranked the parallel questions in the 'preferred' and 'actual' forms identically; the percentage in brackets (24.69\%) shows the percentage of responses in which the preferred rank was higher than the actual rank by 1 unit.

Table 2. Students' responses percentage to the preferred form (X) and actual form (Y)

\begin{tabular}{cccccc}
\hline Category & (a) & (b) & (c) & (d) & $\begin{array}{c}\text { Entire } \\
\text { questionnaire }\end{array}$ \\
\hline $\mathrm{X}=\mathrm{Y}$ & 45.08 & 36.33 & 31.40 & 38.76 & 40.12 \\
\hline $\mathrm{X}<\mathrm{Y}$ & 17.72 & 25.13 & 23.14 & 20.15 & 21.53 \\
\hline $\mathrm{X}>\mathrm{Y}$ & 37.20 & 38.53 & 36.54 & 41.09 & 38.34 \\
$(\mathrm{X}-\mathrm{Y}=1)$ & $(24.69)$ & $(24.03)$ & $(25.58)$ & $(26.80)$ & $(25.27)$ \\
\hline
\end{tabular}

The actual rank was at least as the preferred one in most (61.65\%) of all of the responses. In $25.27 \%$ of all of the responses the actual rank was higher than the preferred one by one unit only.

Defining students giving a rank of 4 or 5 as satisfied, the hypothesis that the median rank in the actual form of the questionnaire is at least 4 was tested using Binomial test. The results enable us to confirm the hypothesis $(\mathrm{p}<0.0001)$. 
We present an approach where the practical aspects are implemented by using a real life project within the organizational framework. According to the Anderson and Krathwohl (2001) adaptation of the well-known Bloom Taxonomy of Educational Objectives (Cognitive Domain), the six levels of cognition required in learning are a) to remember b) to understand c) to apply d) to analyse e) to evaluate and f) to create. Students had to exercise all these levels during their project development. For example, one of the projects was to establish a new bus line that would connect the college to the nearest city. The students had to make a feasibility study by surveying the college students and teachers; then they had to plan and design all the logistic aspects related to the new bus line. The final step was to establish a business plan to justify their project.

Moving to the learning environment (that consisted of student supportiveness, independent learning, integration between the practical activities and theory classes, and guidance contribution) positive students' attitudes are important in evaluating a course. Students' positive attitudes strengthen their motivation and interest, and thus promote meaningful learning. The results show that the majority of the students were satisfied with their learning environment; their actual form rank was at least like the preferred form rank. It can be seen that the preferred rank in all the categories is significantly higher than the actual rank. These results are consistent with other studies showing attitudes to actual and preferred learning environments, which revealed that students rank their attitudes to the preferred learning environment higher than the existing one (e.g. Dorman, 2008). The average difference between actual and preferred ranks in the entire questionnaire was 0.3 unit only. According to Fraser (1998) the greater this difference is the more dissatisfied students are with their learning environment. The relatively small gap between actual and preferred learning environments indicates that the students were satisfied with the educational process.

Like the ancient Chinese proverb "Tell me and I will forget. Show me and I may remember. Involve me and I will understand” (Confucius, 450 B.C.), active learning is considered to be an effective learning strategy (Smith et al., 2005).

\section{Conclusions}

We present a training process, based on contextual learning, that ensures the student's updated knowledge and enhance creativity and innovation. The novelty of the presented approach is the use of an embedded project within the program learning process. This project stimulates the student to implement the theoretical knowledge in a practical environment. The combination of academic knowledge with practical know-how can facilitate the engineering student's integration in their future job.

\section{References}

Anderson, L.W. (Ed.), Krathwohl, D.R. (Ed.), Airasian, P.W., Cruikshank, K.A., Mayer, R.E., Pintrich, P.R., Raths, J., \& Wittrock, M.C. (2001). A Taxonomy for Learning, Teaching, and Assessing: A Revision of Bloom's Taxonomy of Educational Objectives, Complete edition, New York: Longman.

Binnie, A. (2004). Development of a senior physics syllabus in New South Wales. Physics Education, 39(6), 490-495.

Caine, R.N. and Caine, G. (1991). Making connections: Teaching and the human brain. Alexandria, VA: Association for Supervision and Curriculum Development. 
Dewey, J. (1916). Democracy and education: an introduction to the philosophy of education. New York: Macmillan.

Dorman, J. P. (2008). Using student perceptions to compare actual and preferred classroom environment in Queensland schools. Educational Studies, 34, 299-308.

Fraser, B.J., Giddings, G.J., and McRobbie, C.J. (1995). Evolution and validation of a personal form of an instrument for assessing science laboratory classroom environments. Journal of Research in Science Teaching, 32, 399-422.

Fraser B. J. (1998). Science learning environments: Assessment, effects and determinants. In B.J. Fraser and K.G. Tobin (Eds.), International handbook of science education (pp. 527-564). Dordrecht, The Netherlands: Kluwer.

Klassen, S. (2006). A theoretical framework for contextual science teaching. Interchange, 37(1-2), 31-62.

Kukliansky, I. \& Eshach, H. (2014). Evaluating a Contextual-Based Course on Data Analysis for the Physics Laboratory. Journal of Science Education and Technology, 23(1), 108-115.

Rivet, A.E., and Krajcik, J.S. (2008). Contextualizing instruction: Leveraging students' prior knowledge and experiences to foster understanding of middle school science. Journal of Research in Science Teaching, 45(1), 79 -100.

Roth, W.M., and Roychoudhury, A. (1993). The development of science process skills in authentic contexts. Journal of Research in Science Teaching, 30(2), 127-152.

Rozenes, S., \& Vitner, G. (2009). The training methodology of project management office (PMO) personnel. Industrial and Commercial Training, 41(1), 36-42.

Shelley-Tolbert, C.A., Conroy, C.A., and Dailey, A. L. (2000). The move to agriscience and its impact on teacher education in agriculture. Journal of Agricultural Education, 41(4), 51-61.

Smith, A.J. (2000). The Washington state consortium for contextual teaching and learning .Center for the Study and Teaching of At-Risk Students, Seattle.

Smith, K.A., Sheppard, S.D., Johnson, D.W., and Johnson, R.T. (2005). Pedagogies of Engagement: Classroom-Based Practices, Journal of Engineering Education, 94(1), $87-101$. 


\title{
Choosing degree among engineering students; Influence on the success
}

\author{
M. Preciado*, M. Rojo*, I. Moreno**, M. Solaguren-Beascoa*, H. Gonzalo* \\ *Departamento de Ingeniería Civil, Universidad de Burgos. Escuela Politécnica Superior, Calle \\ Villadiego, s/n. 09001 Burgos \\ ** Departamento de Ingeniería Electromecánica. Universidad de Burgos. EscuelaPolitécnica Superior, \\ Avda. Cantabria, s/n, 09006 Burgos
}

\begin{abstract}
The success rate of a university should be calculated taking into account, in addition to students who complete their studies, if they do it with the feeling that the choice of the grade has not been wrong. In this paper, the factors that can influence the feelings error / success of students have been investigated. Three groups were surveyed: high school, first year and final year. It is shown how their expectations and perceptions evolve. Good information appears as an important factor, not only in terms of the studies themselves but it has appeared the need for this information to provide a realistic idea of future employment. The vocation that has been called secondary corresponds to the predilection for a particular branch of engineering and, as expected, also plays a very important role. All students surveyed were engineers, but they pointed, as a reason for feeling wrong, not being in the branch that they liked. The motivational aspects of everyday life in college influence the commitment and performance of students, so they must be analyzed and action should be undertaken to improve the deficiencies identified.
\end{abstract}

Keywords: Vocation; Engineering; Information

\section{Introduction}

The assumption that the vast majority of pupils in the Polythecnic have a vocation which we call primary vocation and this is to be engineers is not enough. The question is whether, what could be called secondary vocation, which is a clear preference for one of the branches of engineering, plays a fundamental role or not in the future success and how students are able to identify the secondary vocation. In fact, in this study, all of the students had choices in the engineering field but what they called their "first choice” (specific branch in engineering) was their supposed real vocation.

The student perceptions change and the study of these changes over the years during which they are studying is fundamental. Develop an identity as an engineer along their studies serves, as Dick and Duffy (2009) stated, as stabilizers in turbulent and dynamic instructional and professional environments. There are two types of changes: professionals (how they analyze their professional future as this is approaching) and social (how they perceive the university and its integration within it). The latter has been proved to be vital as Chen et al. (2008) and Lee et al. (2006) studied, in the sense that it allows us to empower and strengthen aspiring and future engineering professionals to pursue, succeed and find fulfillment in engineering.

Decrease abandonment would be a key objective, but when a student does not leave and finish the degree convinced that he/she was wrong, the university should not be counted it as achievement. The choice of grade will be made when the student has little or no contact with the University. If people is involved in one or another way to the decision it would be important to know if any of those people is an engineer and if somehow represented the model of engineer that these students wanted to be, as it was pointed out by Adams et al. (2011). Also Lichtenstein et al. (2009) studies were made during four years on the changes in students, and they found the strong influence of isolated experiences and contacts with someone who advised them. Jofre and Joanfra 
(2010) also point out that in developed countries, the number of students-minded engineer has a downward trend. Governments are promoting plans to increase it because it is expected to increase labor market for them. The key is to create a clear, positive and realistic view of the role of engineering in society. The good news, according Tansley et al. (2007) are that decisions of students are malleable and engineering can be marketed to engineering students.

Dropouts are more common in the first year and it is necessary to look after this point. Contrary to intuition and according Besterfield-Sacre et al. (1997), many students leave college normally have a good academic performance. In this regard there have been important implantations like the tutorial or mentoring program at which Meyers et al. (2012) referred to, but it would be also necessary to know if these students were wrong in their choice or they simply lost their motivation due to other factors.

After the first year it should be analyzed what we have defined as success through three key points: vocation, commitment and motivation. These last two have been widely developed in the literature by authors like Ohland et al (2008) and Brown et al (2014) respectively. The first reason, ie change in secondary vocation, that a student can suffer because "this is not what he/she expected" has not been treated in the literature too deeply and it is delved in this work. If part of the lack of motivation and commitment is due to the "wrong" choice of the engineering branch (lack of information, misguided advice, changing the social landscape ...), and according to Walden and Foor (2008), it would be essential an easy bureaucracy to encourage students to redirect their academic life.

The goal of this study is to research the influence of the chosen branch on the success feeling of the students. The paper is organized in a first part that explains the questionnaire, a second part with the results and finally the analysis and conclusions based on the results.

\section{Methods}

Some drafts were submitted for the evaluation of the students. The questionnaire was complete though short (one sheet), answers were rated from 1 to 5 and some spaces were available for open answers. Three types of polls were elaborated: $2^{\circ}$ Bachiller (last year before University), $1^{\circ}$ Year and Last years.

Table 1. Blocks of the questionnaires for the students

\begin{tabular}{|c|c|c|}
\hline & Future engineers & Actual students \\
\hline \multirow[t]{2}{*}{ Block 1} & \multicolumn{2}{|c|}{ Sex, age, provenance } \\
\hline & \multicolumn{2}{|c|}{ Actual grade and options in order of preference } \\
\hline Block 2 & \multicolumn{2}{|c|}{ Reasons, influences and difficulties in the choice } \\
\hline \multirow[t]{2}{*}{ Block 3} & What do you expect to find? & What have you found? \\
\hline & \multicolumn{2}{|c|}{ Expectations about professional future } \\
\hline Block 4 & & Feeling success/error \\
\hline
\end{tabular}

\section{Results and Discussion}

While the role of friends and/or acquaintances is the most important, there are more students who believe they were misinformed that well informed. Apparently the two sources of information that report better than the others are press/TV and visit to the University (Figure 1a). 


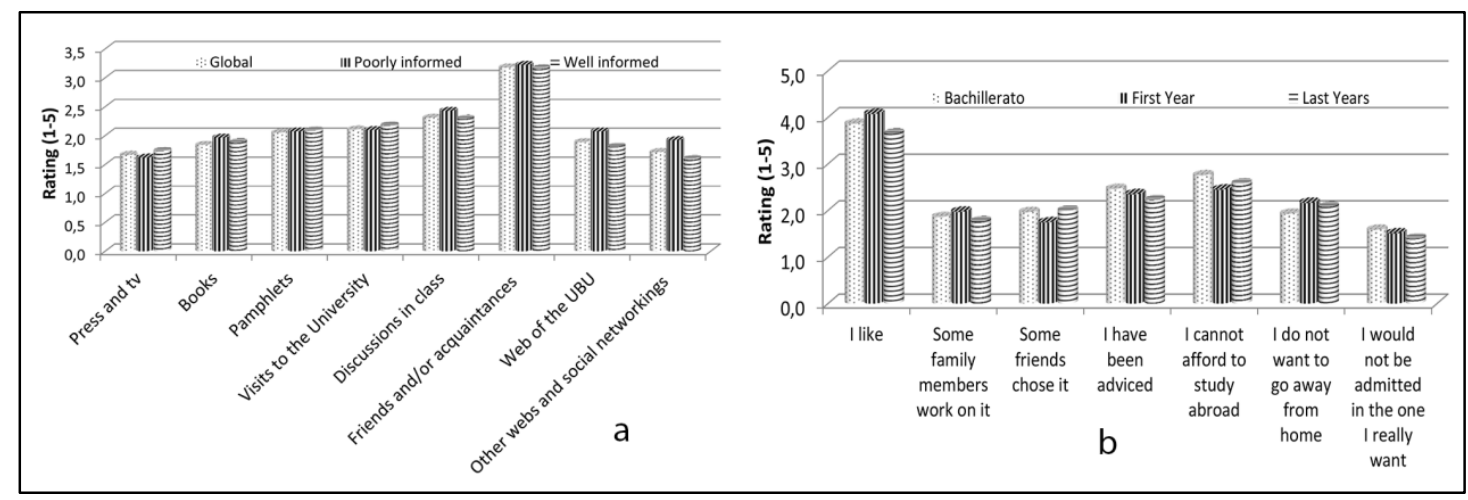

Figure 1. a) Information received by students. b) Relevant reason in the choice of the Grade.

About the reasons that direct the students towards one grade or another (Figure 1b), most students choose to go into engineering because they like (51\%), a factor that we link closely with the vocation.

There is approximately a $65 \%$ of students in the first courses and only $50 \%$ in the last courses that believe that they are not mistaken. This last $50 \%$ is what really should be considered a success rate at universities. In the last years, a $20 \%$ of the students openly believed to have been wrong.

There has been variability in expectations about the everyday life (Figure 2a), which mostly have to do with motivation, it is remarkable the difference that is pointed out by the last years students about questions like: "Much theory and little practical", "New technologies applied to learning" "Teachers explain clearly", "Teachers who encourage," "approve easily." In all of them University come out the loser, so it should be worth analyzing these factors internally. In a book on how to create a good engineer, Goldberg \& Somerville (2015) analyze the great importance of the emotional variables. However, the question "I enjoyed while learning" hasn't fared too badly with a 3.

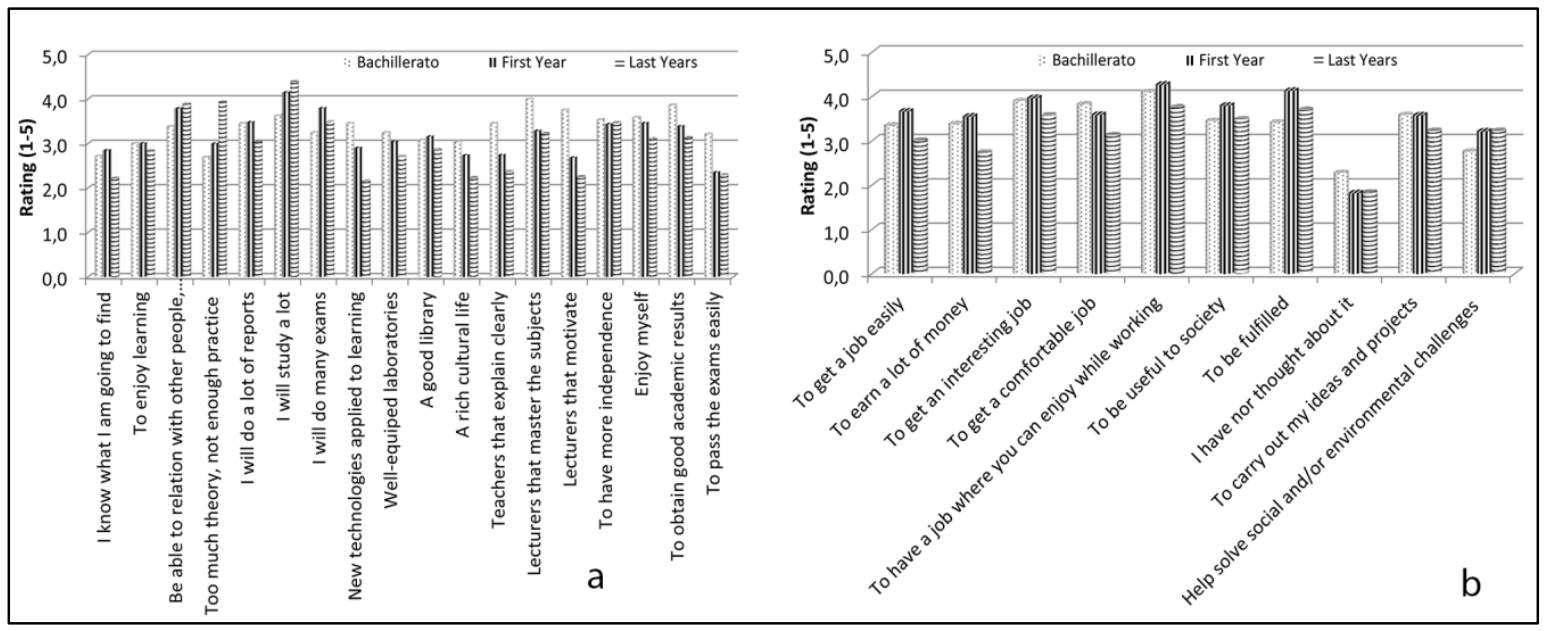

Figure 2. Expectations about a) the everyday life of the university, b) professional future

Regarding their professional future (Figure 2b), there are no questions with large variations, but high values on all major issues (above 3) transmit the "good intentions" of our students and some optimism about their expectations, which is truly commendable in an economic-financial environment such as the one that we have gone through.

Among the analyzed models, it was studied first the influence of the various sources of information used by students to determine whether they have really helped in their 
choice of degree or not. Thus, in the first model, the dependent variable is the feeling of misinformation and the independent variables the sources of information rated from 1 to 5 .

According to this model, the most reliable sources of information, from the viewpoint of, are the press releases and TV and visits to the University. This does not mean they are the best from an objective point of view, but those who feel well informed designated them as accurate. By contrast, the consultation of books, pamphlets, web pages and talks in schools does not appear to have a significant effect on decisionmaking capabilities of students.

Furthermore, the influence of various parameters on the overall sense of success or failure in the choice of degree has been also modeled. In this sense, global models, valid for the average student have been calibrated and specific models with systematic variations that can have students. The variables considered in this stratification are introduced as dummy variables, and were: gender ( 0 male and 1 female) and the year of the student ( 0 in the first year and 1 in final year). In both cases, the dependent variable is the feeling of a wrong choice, all the variables varying from 1 to 5 .

Table 2. Models of failure in the choice.

\begin{tabular}{|c|c|c|c|c|}
\hline & \multicolumn{2}{|l|}{ Global } & \multicolumn{2}{|c|}{$\begin{array}{l}\text { Variations depending } \\
\text { on the type of student }\end{array}$} \\
\hline Variable & Coefficient & Test-t & Coefficient & Test-t \\
\hline Misinformation & 0.7396 & 3.409 & 0.8365 & 3.946 \\
\hline Choice "I like" & 0.2072 & 4.868 & & \\
\hline Choice “I like” (Last years) & & & 0.3634 & 3.764 \\
\hline Choice "I was nort admitted in the one I liked" & 0.6072 & 6.526 & 0.6365 & 6.719 \\
\hline $\begin{array}{l}\text { Choice "I was nort admitted in the one I liked" } \\
\text { (women) }\end{array}$ & & & -0.4389 & -2.006 \\
\hline Choice” I was adviced" & & & 0.2357 & 3.289 \\
\hline Choice "I was adviced” (Las years) & & & -0.3985 & -2.679 \\
\hline Choice "Some Friends chose it" (women) & & & 0.4538 & 2.318 \\
\hline
\end{tabular}

Also, seeing the variables that influence their success or mistake, we can draw interesting conclusions. From the general model it can be stated that success is clearly influenced by the good information and the secondary vocation (since the fact of not being admitted where it is desired is the 2nd cause of failure, and all of them studied engineering). The choice of the degree only because they initially liked (or believing they would like) can also lead to an error. Social-economic reasons are behind this statement.

Analyzing the model with variations depending on the type of respondent, it can be seen that the main reason for failure is still a lack of information. Not to be admitted in the desired grade is again the second cause but this time only for men; women do not consider that serious. However, the choice of the degree just because they liked (before attend it), is considered a wrong way only by final year students, while first year students, perhaps more unconscious, do not perceived it as a bad motive. Relying on the advice of others is regarded negatively by the first year students, but not by the final years, and finally, choosing a degree because the friends enroll is only seen as a bad reason by women while men do not find it a bad reason.

Along with quantitative analysis previously discussed, it is interesting to analyze the responses in the form of opinion or reflection the students surveyed provided. Indeed, certain aspects are difficult to quantify, especially when asked about personal choices, expectations or feelings. 
On the sources of information, the most important point is the lack of knowledge about the actual content of the degree. It is common for high school students to watch a video, receive a brochure or a talk; however, these sources used to be advertised in the same university. This information is often biased, focusing solely on the positive aspects of university life or a brilliant professional future. These perceptions match well with the results of the regression analysis that established as the most influential sources of information press and television (where they can have a more realistic view of careers and the job market for graduates) and visits to the university (where they can hear from those who are studying or at least, watching facilities on site).

Closely related to the information that the students receive when choosing the degree are the high expectations of the new students about what they will encounter at the University. The responses offered when explaining why compliance or not, comments on unmet expectations predominate. The correspondence is almost directly with the data obtained from the evolution of the specific expectations, which highlighted as items that suffered more variation between first and last years: lecturers who can motivate $(-1.5)$, too much theory and not enough practice $(-1,2)$ new technologies for learning (-1.2), teachers who explain clearly (-1.0). It is clear that students who enter to the University has a different vision that the students that are in the last year. The illusion of starting a new project generates expectations that in many cases are cut short by the reality which, in the light of comments, would greatly improve if the inertia of the university system is overcome.

As for the feeling of being wrong, answers are mainly about the relationship between choice and vocation. Most of the comments are from students who believe they have made an excellent choice because "it was what I liked", which agrees with the data of the relatively low sense of being wrong (2.1). Negative responses are performed on all senior students and are related to the wrong choice with the current economic crisis and difficulty observed in finding a job in your field. These statements explain the increased feeling of being wrong from a low value in the first year (1.94) and a higher value the last year (2.45), when thoughts about their professional future become more important as the end of their academic studies is closer.

\section{Conclusions}

The expectations with which a student enters college are relatively high. They expect mostly quality teaching and practice, to enable them to perform a work in the future. Often these expectations are generated by the university system itself. The competition between universities to attract students, makes that the information is too idealized: more than inform, advertise. This is an important factor in the wrong choices of students.

However, even though many of the expectations of high school students do not match the reality, the feeling of being wrong is relatively low. The error in the choice was mainly fixed in the first courses with abandonment or migration to other degrees, driven almost equally by three causes: the failure to meet expectations, the difficulty in passing and lack of vocation. Despite this correction, the feeling of being wrong picks up again closer to the start of working life. This is probably caused by the uncertainty to find work in their field exacerbated by the current economic crisis.

It should be improved the information regarding the characteristics and possibilities for future work that, along with his secondary vocation, are the factors that most influence 
the feeling of success: if the students are well informed, like what the study and know what to expect in their future working life, the success rate will increase.

\section{References}

Adams, R., Evangelou, D., English, L., Dias de Figueiredo, A., Mousoulides, N., Pawley, A. L., Schifellite, C., Stevens, R., Svinicki, M., Martin-Trenor, J., Wilson, D. M. (2011).Multiple perspectives on engaging future engineers, J. of Engineering Education, 100, (1), 48-88.

Besterfield-Sacre, M., Atman C., Shuman L. (1997). Characteristics of freshman engineering students: models for determining student attrition in engineering. Journal of Engineering Education 86(2), 139-50.

Brown, P. R., Rachel, E., McCord, E., Matusovich, H. M., Kajfez, L. (2014). The use of motivation theory in engineering education research: a systematic review of literature, European J. of Engineering Education, DOI: 10.1080/03043797.2014.941339.

Chen, H. L., Lattuca, L. R., Hamilton, E. R. (2008).Conceptualizing engagement: Contribution of faculty to student engagement in engineering. J. of Engineering Education, 97(3), 339-353.

Dick, B. J., \& Duffy, R.D. (2009). Calling and vocacion at work: Definitions and prospects for research and practice. The Counseling Psychologist, 37 (3), 424-450.

Goldberg, D., Somerville, M. (2015). The making of a whole new engineer: four unexpected lessons for engineering educators and education researchers. J. of Engineering Education, 104, (1), 2-6.

Jofré, L., Joanfra Córdoba, L. R. (2010). Attacting student vocations into engineering careers. IEEE EDUCON Education Engineering - The future of global learning engineering education, April 14-16, Madrid, Spain.

Lee, L., Hansen, L. E., Wilson, D. (2006). The impact of affective and relational factors on classroom experience and career outlook among first-year engineering undergraduates, Proceedings of the frontiers in education annual conference, San Diego, CA.

Lichtenstein, G., Loshbaugh H. G., Claar B., Chen, H. L., Jackson, K. Sheppard, S. D. (2009). An engineering major does not an engineer make. J. of engineering education, 227-234.

Meyers, K. L., Silliman, S. E., Gedde N. L., Ohland M. W. (2012).A comparison of engineering students'reflections on their first-year experiences, J. Engineering Education, 169-178.

Ohland M. W., Sheppard S. D., Lichtensteis G., Eris O., Chachra D., Layton R. A. (2008).Persistence, Engagement, and Migration in Engineering Programs. J of Engineering Education, 259-278.

Walden, S. E., Foor, C, (2008). “What's to keep you from dropping out?” student inmigration into and within engineering,J. of engineering education, 191-204. 


\title{
Face-based constructive approach in 3D environment to facilitate the interpretation of multiview orthographic projection to future engineers
}

\author{
V. Pérez-Belis, V. Gracia- Ibáñez, R. Plumed, M. Gómez-Fabra, M.J. Agost, A. Piquer, \\ C. González-Lluch, M. Núñez-García
}

* Universitat Jaume I, Castellón de la Plana, España

Departamento de Ingeniería Mecánica y Construcción

\begin{abstract}
One of the main objectives of Engineering Graphics' syllabus is to improve the capacity of spatial vision of students, as well as providing essential teaching of graphic representation techniques. In this course, students should create and interpret engineering drawings. However, a significant number of them have problems interpreting and understanding multiview orthographic projections. The course is commonly studied at first year of several engineering Bachelor's Degrees. In this course, the capacity of spatial vision is critical, as students have to interpret a real object from different projection methods. Nevertheless, this is not an obvious task for most students, since either they have no prior training or traditionally this training has no effect on student's capability of reflexion and interpretation. We consider that facilitating the object interpretation may involve a significant educational improvement. For this reason, in this work we present the approach and development of a specific method to interpret an object. It is focused on harnessing the three dimensional (3D) environment of AutoCAD ${ }^{\circledR}$ software which is used in the course, for the face-based construction of objects.
\end{abstract}

Keywords: multiview visualization; teaching strategy; face-based constructive approach.

\section{Introduction}

As McGrath \& Brown outlined in their White Paper (McGrath \& Brown, 2005), to develop appropriate skills in the fields of science and engineering visual learning is necessary. These skills, facilitate the collaborative learning and develop the students' creativity. We consider that the inclusion of the visual thinking in the curriculum of engineering education is needed.

At first sight, it was easy to think that the advent of available 3D methods would imply the annihilation of the previous two-dimensional methods-well established throughout the twentieth century as 'Projection Methods'. In recent years, 3D was incorporated in academic environments generally in Bachelor's Degrees. This approach has coexisted, in many engineering areas, with the traditional approach (pencil and paper) being complemented with digital work in $2 \mathrm{D}$ previous to incorporate the $3 \mathrm{D}$, by means of orthographic and axonometric projections.

Obtaining the orthographic views from the axonometric projection of an object and vice versa were, and still are, core activities in any basic course of Engineering Graphics. 3D commercial software could easily obtain 2D main projections from a 3D model, but it is unable to interpret an engineering object from its orthographic projection views where the highest difficulty lies.

'The ability to visualize objects in three dimensions is a key skill for engineering design. Physical models for proposed designs often do not exist, and an engineer must be able to envision, manipulate, and modify designs when they are presented in the form of 2-D drawings', this is a transcript from Chapter 11 'Advanced Visualization Techniques', of 'Visualization, modeling and graphics for Engineering Design' (Lieu \& Sorby, 2008), which is characterized by assuming the need to updating the graphic fundamentals for engineering. The authors show different methods to obtain the 
axonometric two-dimensional projections from the orthographic projection with high level of detail.

The aim of this work is focused on how students can reach the comprehension of the orthographic views represented. This is made by means of providing a new method that organizes systematically, step by step, under certain conditions, the construction of a 3D model of an object starting from the orthographic views. This method partially agrees with the section "Strategy for Constructing Pictorials by Inverse Tracking of Surfaces" described in the previously cited work. This is not the only influence in this work. In addition to our daily academic life in contact with engineering students, we would like to point out contributions to this work from nearby universities to the city where the Congress is performed (Melgosa Pedrosa, 2012; Mugika, 2010), as well as more distant sources (Suh \& McCasland, 2009). In all of them, as in many other proposals, it can be found common aspects to our approach. At minimum all agree in the desire to improve the learning experience in the field of Engineering Graphics.

The most common 3D construction system used is the Constructive Solid Geometry (CSG), which is not the one used in this work. Instead, the method uses a construction system by faces, consisting in sealing all the external surfaces of the 3D object, like a B-Rep. The comprehension of the object is by adding material (in an affirmative way). Unlike the negative way (Gómez-Fabra, 2007) which has the purpose of identify the geometry by looking for volumes without material and removing them.

After the appearance of 3D technology, several research groups arose using artificial intelligence resources to face this problem. In case of success, this would imply a necessary reorientation of graphical fundamentals. Although our approach does not correspond with that ambitious line of work (Company, Piquer, Contero, \& Naya, 2005; Dori \& Tombre, 1995), it highlights the intrinsic difficulty of the merits of the problem referred in this communication.

\section{Method}

The method consists on the construction of the object through 3D tools, by going step by step from their orthographic views. It provides the students a global understanding through the concordance of these orthographic views resulting in the final construction of the 3D object. It is considered that this method can be a key factor for students who do not have the innate ability of spatial vision, as shown in Figure 1.
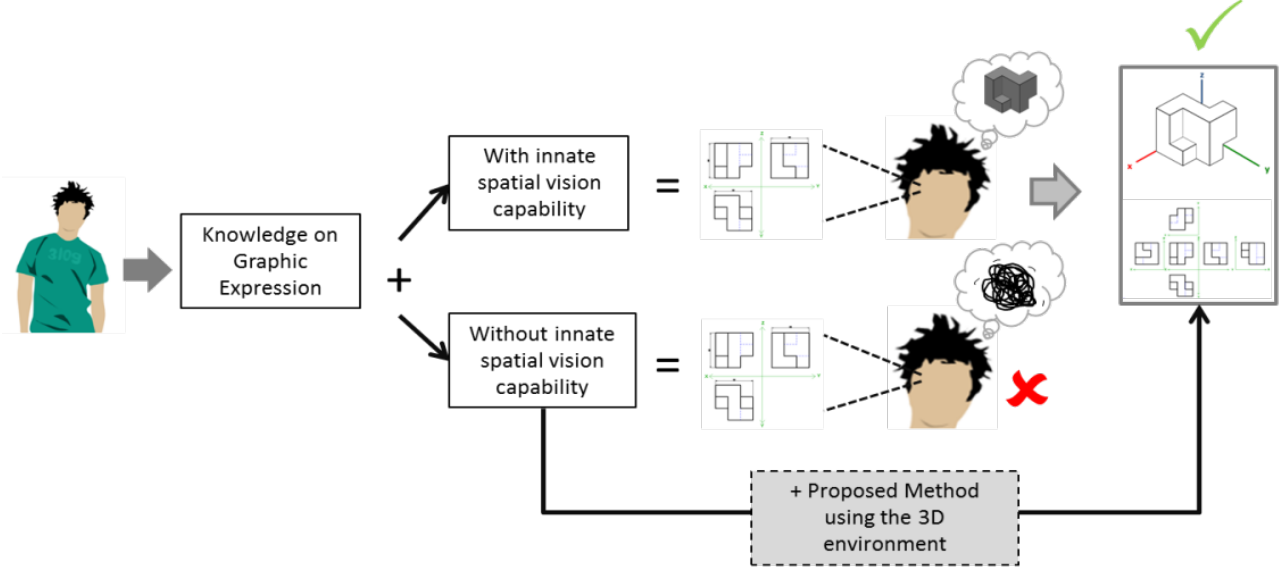

Figure 1. Context of the method implementation. 
The method is implemented with the software AutoCAD® 2015, which is used in teaching Engineering Graphics. It consists on the steps listed below in Table 1.

Table 1. Detailed description of the method.

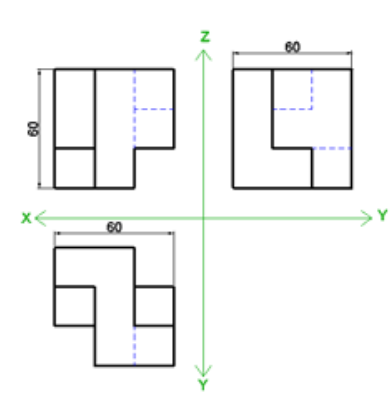

1. The starting point corresponds to the orthographic views in European system, drawn in a $2 \mathrm{D}$ environment. It is essential to cut the drawing lines into segments whenever there is an intersection, in order to be able to select any closed circuit as a face.

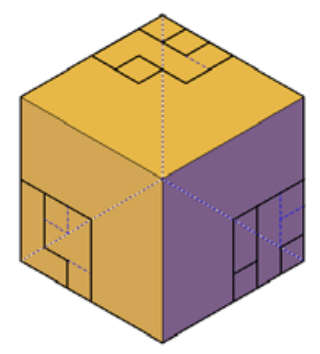

3. Next, the views are copied on the corresponding faces of the prism (in their accurate 3D position). ${ }^{3}$

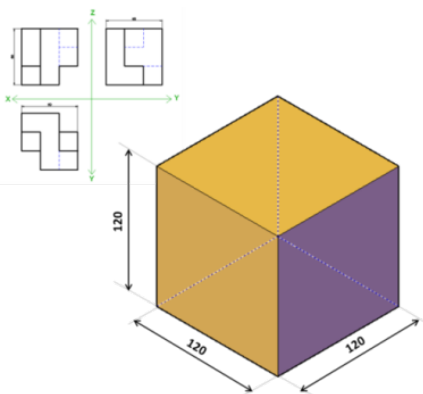

2. In the workspace "3D Modeling”, a prism is created. Its maximum dimensions are twice of the maximum dimensions of the orthographic views according to the three axes. ${ }^{1}$ This allows the students to work in a more comfortable way. ${ }^{2}$

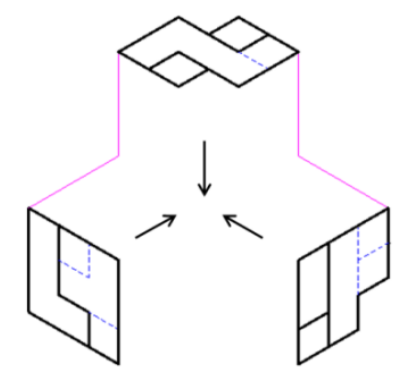

4. Once each face is located, the prism is hidden and the views are analyzed with the objective of creating the object step by step, according to the concordance of the views.

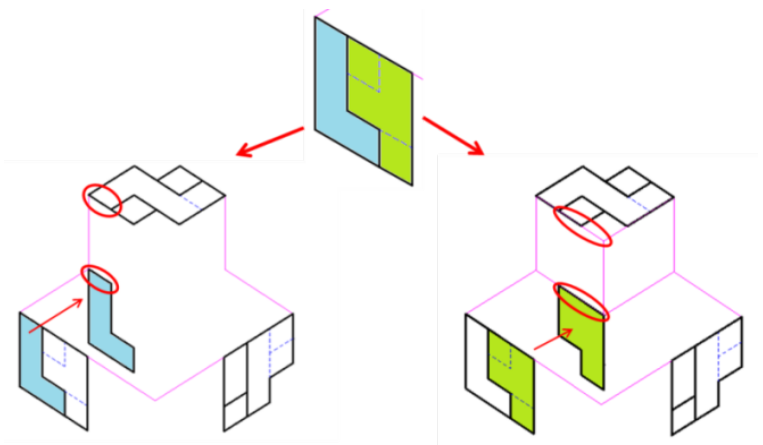

5. First, external faces should be created on the object from the initial orientation. To do this, from each external face, closed circuits without continuous interior lines should be identified. After that, these circuits should be copied and converted into regions. These regions will shape the solid faces of the object to work with. ${ }^{4}$

6. In this case, we start by analyzing the side view. It is shown that there are two circuits without continuous interior lines, so there are two possibilities to place the faces in the first position. However, if the top view it is observed, no concordance between the side and the top view is presented, therefore, this face should not be in the first position.

\footnotetext{
${ }^{1}$ AutoCAD provides the workspace "3D Modeling" where it is possible to define the box. This could be created through the "box" command or with the multiple tools that AutoCAD offers.

${ }^{2}$ In order to visualize the faces of the object, "Conceptual Visual Style" should be activated.

${ }^{3}$ In order to place each view on each face, it is necessary to copy and paste them directly $(\mathrm{Ctrl}+\mathrm{shift}+\mathrm{c} / \mathrm{ctrl}+\mathrm{v})$ without forgetting to maintain activated dynamic UCS.

${ }^{4}$ The regions are created using the "region” command from the group “drawing”. These entities are key in the process.
} 


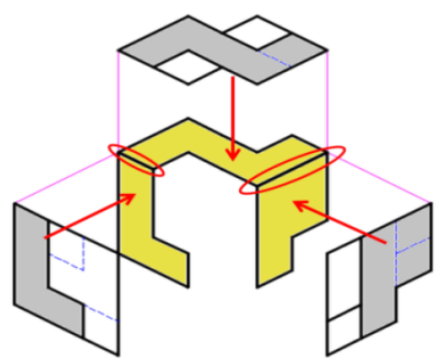

7. Following systematically this process, external faces are created.

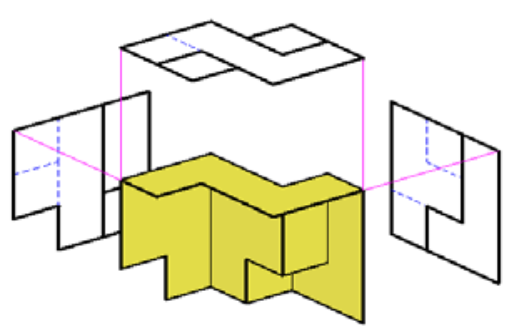

9. Once each side is finished, the object orientation is changed until the remaining sides are created.

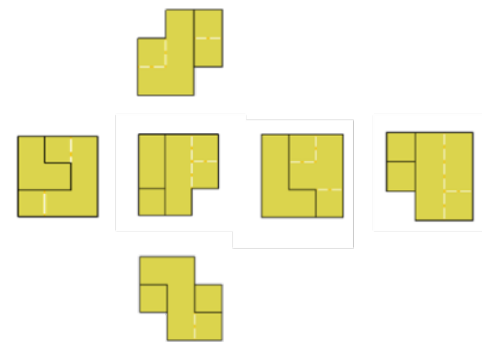

11. After finishing the object we obtain a full 3D model of the original object created face by face. Orientation can be changed to see the different orthographic views which could be drawn and checked with the original ones provided on this problem. $^{5}$

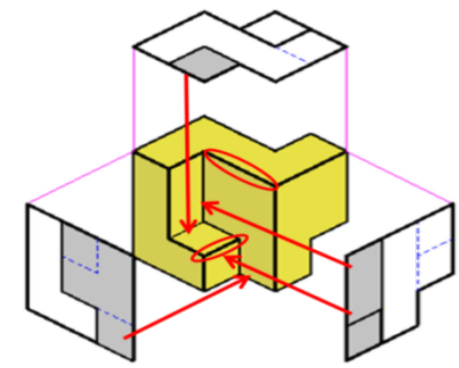

8. Next, the object is finished using a coherence pattern on the views, starting from external faces edges.
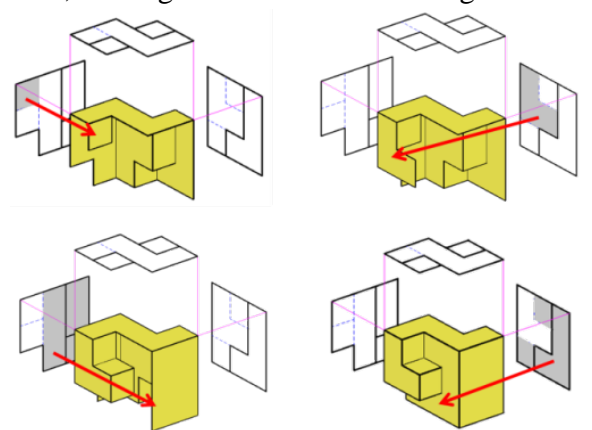

10. In this particular case, it is essential to analyze all hidden edges as they provide valuable information about the object, including hidden faces so it will be necessary to analyze its concordance.

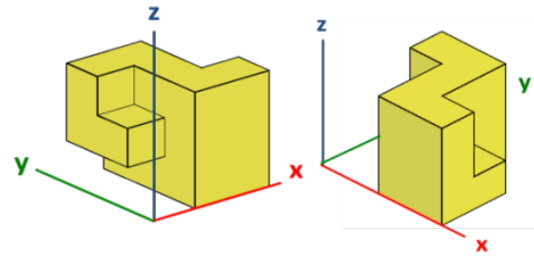

12. In addition, the intended axonometric projection can be obtained using 3D modeling tools and changing its orientation. Taking those views as an starting point any axonometric projection needed could be drawn. ${ }^{5}$

The purpose of this method is to provide a tool to interpret objects through the construction of 3D model, without losing perception details by the student when he is creating the object from the given views. This is why the objects are created side by side instead of the traditional solid pattern CSG.

This method is primarily conceived to construct polyhedral objects since the guidelines of the course are focused on planar surfaces before introducing curves. It could also be used to construct any polyhedral object whose faces are parallels to the projection plane. If those faces are not parallel to the projection planes, the steps to follow are shown in Table 2.

\footnotetext{
${ }^{5}$ From object's interpretation, any orthographic view and axonometric projections can be drawn. Also they can be extracted as a 2D representation in a block by using "Flatshot" located in the group "Section". AutoCAD does not allow too much flexibility in the "Layout" workspace, so obtaining those representations are not immediate.
} 
Table 2. Example of polyhedral object whose faces are not parallel to the projection planes.

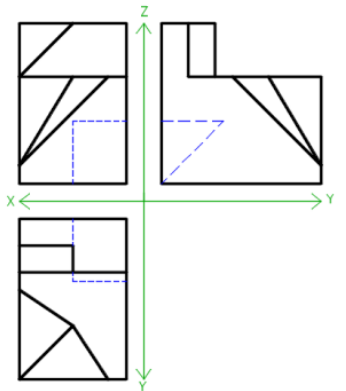

1. The method starts from the orthographic views of the object.

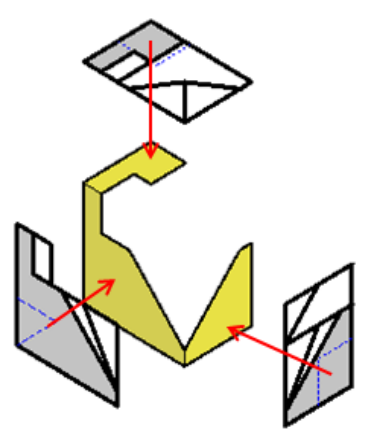

3. The process starts with the external faces.

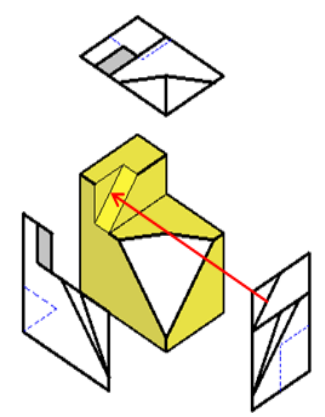

5. If faces are not parallel to coordinate planes but they are included in a projection plane on any of them, parallel edges have to be copied. ${ }^{6}$

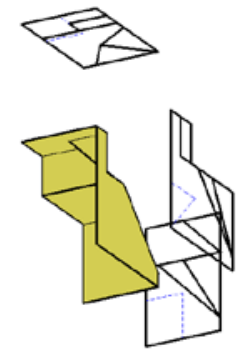

7. In order to visualize the backside of the object, orientation system should be changed.

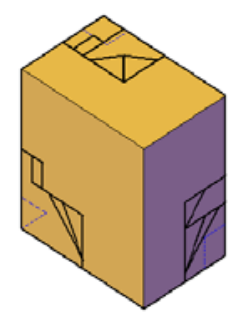

2. According to the previous explanation, the orthographic views have to be located on the corresponding faces of the box.

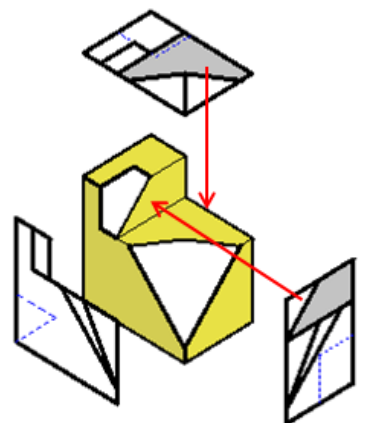

4. Successively, it has to be applied to secondary faces

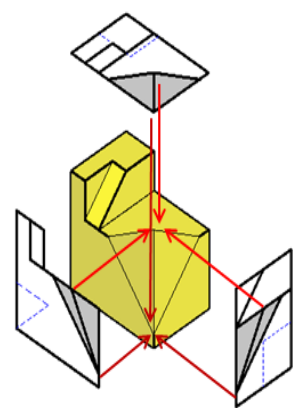

6. If faces are not parallel to any coordinate plane, edges should be outlined from their starting and ending point. ${ }^{6}$

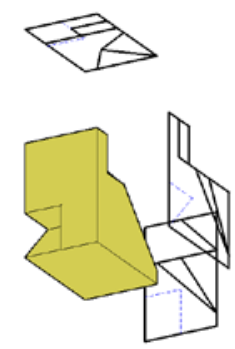

8. The process continues until the object is completely closed.

\footnotetext{
6 To construct the object "face-by-face", the current user coordinate system (UCS) should be the same as the orientation of the face, in order to create the region. This region is the result of a polyline which has been converted into a region.
} 


\section{Results and Discussion}

A method to facilitate the interpretation of multiview through the construction of the object "face by face" is proposed since a lack in methods to help students without inborn visualization skills it is aimed to be covered. AutoCAD ${ }^{\circledR}$ is the software used because it is the one available for students to be checked. Currently, this method it is being put to the test. Unfortunately, thus far quantitative data about its effectiveness are not available, however, some results from a simple tests show a quite good acceptance among students.

\section{Conclusions}

Spatial vision capability is one of the skills needed in subjects related to Engineering Graphics, but if students do not have this ability within their innate capacities, it would be desirable to be developed or improved through different methods and tools. Since the main problem of students seems to be the orthographic views interpretation, this paper presents a method to scaffold them to understand different objects from their orthographic multiviews through some 3D tools.

The method, helps the students to understand, step by step, the different stages of the process improving the comprehension of the object, since they are continuously linking the two dimensional projections with the three dimensional representation. This process results especially interesting in this subject since the objects of the problems tend to be irregular and far from the reality even helping in that case those students with visualization abilities.

Future lines of research could include the consideration of the construction of objects with curved surfaces.

\section{References}

Company, P., Piquer, A., Contero, M., \& Naya, F. (2005). A survey on geometrical reconstruction as a core technology to sketch-based modeling. In Computers and Graphics (Pergamon) (Vol. 29, pp. 892-904). doi:10.1016/j.cag.2005.09.007

Dori, D., \& Tombre, K. (1995). From engineering drawings to 3D CAD models: are we ready now?

Gómez-Fabra, M. (2007). Colaboración de un programa 3D en la lectura diédrica y obtención del modelo. In Congresso Internazionale Congiunto XVI ADM - XIX INGEGRAF Congreso Internacional Conjunto XVI ADM - XIX INGEGRAF Perugia, 6 - 8 Giugno 2007 (pp. 6-8).

Lieu, D., \& Sorby, S. (2008). Visualization, Modeling, and Graphics for Engineering Design (p. 1088). Delmar Celgage Learning. Retrieved from http://books.google.com/books?hl=ca\&lr=\&id=lHO79rg6VT8C\&pgis=1

McGrath, M.B., \& Brown J.R. (2005). Visual learning for science and engineering. Computer Graphics and Applications IEEE.vol. 25(5), pp. 56-63.

Melgosa Pedrosa, C. (2012). Diseño y eficacia de un gestor web interactivo de aprendizaje en ingeniería gráfica para el desarrollo de la capacidad de visión espacial. Retrieved from http://riubu.ubu.es//handle/10259/178

Mugika, E. S. U. and M. G. (2010). New Achievements in Technology Education and Development. Chapter 8. Methodology for Part Visualization Problem Solving - the Importance of the Process. In S. Soomro (Ed.), . InTech. doi:10.5772/219

Suh, Y. S., \& McCasland, J. (2009). Interactive construction of solids from orthographic multiviews for an educational software tool. Computer-Aided Design and Applications, 6, 219-229. doi:10.3722/cadaps.2009.219-229 
HEAd'15

SESSION 3C

\section{ETHICS AND CULTURE}




\title{
Fostering a Technologically Innovative Teaching Culture
}

\author{
J. Banks, J. Cheng, S. Payne
}

UTS:Insearch

\begin{abstract}
UTS:Insearch is a pathways provider preparing students from diverse language and learning backgrounds for study in Australia, particularly at UTS. With education increasingly moving towards technology enhanced delivery we identified the need to use these approaches with our students, however as a starting point realised that for this to be successfully embedded into our subjects we would have to create a technologically innovative teaching culture amongst our teaching staff. In fostering this culture the organisation needed to clearly articulate the concept of 'blended learning' to our teaching staff. Following this a suite of strategies to engage teaching staff with diverse understandings of technology enhanced teaching and the opportunities it offers for improving students' learning experiences and understanding were implemented. The strategies that were most successful were those that were 'hands on' and employed blended learning approaches where teaching staff could experience first-hand how students could be engaged with content through the appropriate and meaningful use of technologies. While the project is on-going, the approach has led to $76 \%$ of the learning strategies in our subjects either well progressed or fully compliant with a blended learning approach within a year.
\end{abstract}

Keywords: innovation; teaching culture; blended learning

\section{Introduction}

UTS:Insearch is the premium pathways provider to the University of Technology, Sydney (UTS), one of Australia's leading universities. At UTS:Insearch students are prepared for Undergraduate study at UTS through provision of leading academic English programs, UTS Foundation Studies (on behalf of UTS) and a broad choice of higher education diplomas including Business, Design, Science, Engineering, Information Technology and Communication. Our students are primarily international from a variety of Asian, sub-continent and Middle Eastern learning and language backgrounds. In 2014 in response to the diverse learning and language backgrounds of our students and in recognition that for all students in the 21st century learning is situational, complex, diverse and rapidly changing, and where students need to be able to connect understanding across disciplines, UTS:Insearch began to introduce blended learning approaches into the learning and teaching activities of its academic programs with the intention of having a significant proportion of subjects employing elements of blended learning from Semester 1, 2015. The aim was to create a curriculum that provides students with an environment where learning occurs through seamless integration of technology-enhanced strategies and face-to-face activities, characterised by the best features of interaction within a subject that will promote academic enhancement and innovation in learning and teaching.

Underpinning this, we recognised the need to create a teaching culture in which innovation and embracing of change is the norm, and where the learner and the quality of their learning experience is central to our practice. To foster this culture we introduced initiatives that provided our teaching staff with supportive professional development opportunities that help them feel comfortable and safe in using a range of technologies in relation to their own and students' learning experiences. We contend that by encouraging this technologically innovative teaching culture among our staff blended learning can be embedded in our practice as a 'natural component'. 


\section{Methods}

Our starting point was the development of a clear understanding of what a 'blended learning approach' meant in our context. As outlined in Table 1 below, a wide variety of definitions exist that attempt to delineate what 'blended learning' actually comprises, although some argue "that the phrase 'blended learning' is meaningless, and that it has gained considerable currency in both commercial and educational contexts because of its ambiguity" (Oliver and Trigwell, cited in Chew et al 2010). It was also noted by Partridge et al (2011) that a key challenge in developing a blended learning project is the "lack of a universally accepted definition".

Table 1. Definition of blended learning by various researchers

\begin{tabular}{|c|c|}
\hline Researchers & Definitions of Blended Learning \\
\hline Thorne (2003) & $\begin{array}{l}\text { Represents an opportunity to integrate the innovative and technological advances offered } \\
\text { by online learning with the interaction and participation offered in the best of traditional } \\
\text { learning. }\end{array}$ \\
\hline $\begin{array}{l}\text { Graham, Allen and } \\
\text { Ure (2003); } \\
\text { Graham (2006) }\end{array}$ & $\begin{array}{l}\text { (1) combination of delivery media and tools employed (Singh and Reed, 2001; Orey, } \\
\text { 2002; } \\
\text { (2) combination of a number of pedagogical approaches or instructional methods } \\
\text { (Driscoll, 2002; Rossett, 2002); and } \\
\text { (3) Combination of face-to-face traditional learning with online instruction (Reay, } \\
\text { 2001; Rooney, 2003; Ward and La Branche, 2003). } \\
\text { The first two positions above dilute the definition of blended learning and do not clearly } \\
\text { define what blended learning is. The first two definitions provide an amorphous idea that } \\
\text { almost anything can be defined as blended learning. It would be difficult to find any } \\
\text { learning system that did not involve more than one media and tools; similarly, it would } \\
\text { be difficult to find any teaching and learning scenarios that did not embrace multiple } \\
\text { pedagogies or multiple instructional approaches. Graham (2006) argues that the third } \\
\text { stance specifies more precisely the meaning of blended learning. }\end{array}$ \\
\hline $\begin{array}{l}\text { Vaughan and } \\
\text { Garrison (2005) }\end{array}$ & $\begin{array}{l}\text { The thoughtful integration of face-to-face classrooms (spontaneous verbal discourse) and } \\
\text { Internet based (reflective text-based discourse) learning opportunities is neither an add- } \\
\text { on to a classroom lecture nor an online course. It is the fundamental redesign and an } \\
\text { optimal (re)design approach to enhance and extend learning by rethinking and } \\
\text { restructuring learning and teaching to create blended learning. }\end{array}$ \\
\hline $\begin{array}{l}\text { Littlejohn and } \\
\text { Pegler (2007) }\end{array}$ & $\begin{array}{l}\text { The "blend" which may refer either to the combination of e-learning with other } \\
\text { approaches such as face-to-face instruction, or the mixture within the e-learning mix of } \\
\text { media. }\end{array}$ \\
\hline $\begin{array}{l}\text { Sloan-Consortium } \\
\text { (Vignare, 2007, } \\
\text { pp.38) }\end{array}$ & $\begin{array}{l}\text { (1) the integration of online with face-to-face instruction in a planned, pedagogically } \\
\text { valuable manner and } \\
\text { (2) do not just combine but trade off face-to-face time with online activity (or vice } \\
\text { versa). }\end{array}$ \\
\hline Allan (2007. pp.4) & $\begin{array}{l}\text { (1) The use of different internet-based tools including chat rooms, discussion groups, } \\
\text { Podcasts and self-assessment tools to support a traditional course and } \\
\text { (2) A mixture of face-to-face and e-learning. }\end{array}$ \\
\hline $\begin{array}{l}\text { Garrison and } \\
\text { Vaughan (2008) }\end{array}$ & $\begin{array}{l}\text { No more about reshaping and enhancing the traditional classroom than it is about } \\
\text { making e-learning more acceptable. It necessitates that educators question what is } \\
\text { important and consider how much time should be spent in the classroom. }\end{array}$ \\
\hline
\end{tabular}

Taken from Chew et al 2010, page 3.

To ensure a clearly articulated starting point to our project that could later serve as a reference point for teaching staff, a Blended Learning Working Group was established in August 2013 to research and discuss how this concept was being understood and implemented in other education organisations, and how these experiences might inform our project. Given the plethora of definitions that emerge from technological, instrumental, pedagogic and educational theoretical perspectives we considered the best 'advice' was that our blended learning approach needed to respond to research, the needs of the organisation and our learners (Allan, cited in Chew et al 2010) and keep in 
mind that our 'blend' was one that could be dynamic, transforming over time as research, needs and technologies change. The Working Group ultimately developed a definition of how blended learning sat within an UTS:Insearch context: "A learning environment where students learn through seamless integration of technologyenhanced strategies and face-to-face activities, characterised by the best features of interaction within a subject."

The Blended Learning Working Group also evaluated the level of understanding teaching staff had of blended learning. This qualitative evaluation was conducted by surveying curriculum materials, teacher discussions and classroom observations. We found that the concept of a 'blended learning approach' was new to many of our teaching staff, and was met with a degree of scepticism by some. Certain teachers were of the opinion that the notion was 'just another education fad' and we would be 'back to chalk and talk in five years', while others had concerns about the amount of time it would take to 'blend' their subjects, and some were concerned about having to use technology within their subjects because they were less competent in their use. At the other end of the continuum, we also had a number of early adopters who had already begun using some aspects of blended learning in their classes. These early adopters were an important resource in promoting the use of blended learning approaches in our subjects because, as peers, they were able to demonstrate on a practical level how different technologies could be used to enhance delivery and student experience and achievement. For those teachers who felt less confident in their use of technology and those who had become somewhat ossified in their current practice we also needed to promote a growth mind set (Dwerk 2006) that would encourage teachers to try new approaches and technologies and see themselves as learners who have the capacity to learn and improve their skillset (Gerstein 2014).

To encourage acceptance of the concept, and in addition to encouraging our early adopters to share their experiences, we chose a 'softly, softly' approach to allow sceptical and ambivalent teachers to become accustomed, and less resistant, to the idea and to start exploring ways that would work for them in their classes and with their teaching style and subject matter. Our overriding message to all teaching staff was that blended learning approaches in their subjects must be led by their interpretation of the subject matter to find the best approach to make it accessible to the students (Mishra and Koehler 2006). We stressed that the enhancement of delivery and student experience and achievement was at the core of the approach, not simply the use of one or more technologies, and we actively discouraged the perception that simply 'tacking on' a technology would be acceptable. This multimodal conceptual model seeks to meet the needs of our diverse student population and largely reflects the six basic pedagogical objectives and activities outlined by Picciano (2009). With these considerations as a starting point we undertook a number of initiatives to begin enculturating teaching staff to blended learning that demonstrated our definition of "technology-enhanced strategies and face-to-face activities" both from a theoretical standpoint, by providing scholarly articles that discussed the efficacy, challenges and possibilities of blended learning approaches, and a practical standpoint by modelling practices, applications and software that could be used by teachers in the delivery of their subjects. These initiatives were:

- Establishing various online UTS:Insearch sites, such as:

o 'yammer' to encourage online collaboration and discussion; 
o 'Pinterest', allowing staff to view articles discussing case studies, collaborative technologies, use of social media in education, teaching with technology, and general information on the research underpinning the approach;

o 'symbaloo' with links to various online resources and apps that teaching staff could use as a 'tool box';

- Emailing weekly 'discussion articles' to all teaching staff, giving teaching staff the opportunity to make comments via yammer;

- Providing professional development days to showcase different technologies and give teaching staff opportunities to interact with them and allow early adopters to present on their experiences;

- Providing workshops on the use of blended learning in other areas of the wider UTS institution;

- Appointment of a Learning Technology Coordinator who was also a teacher within one of the UTS:Insearch programs to act as a mentor to assist teachers in incorporating various technologies into the delivery of their classes;

- Establishing a work pod in the teaching staff work area for teachers to investigate and familiarise themselves with appropriate technologies at their own pace.

An action research approach was taken to examine the success of UTS:Insearch's approach. Action research was deemed the best approach because the primary reason for using this research method is to assist the improvement and refining of actions and, in relation to education, gauging the effectiveness of teaching and development of students (Sagor, 2000). An additional consideration was that new programs were being introduced at UTS:Insearch in both Foundation and Diploma areas where blended learning approaches were integral and this method would allow us to both identify successes and areas for improvement, and then refine our approaches, use of technology and content to better meet the needs of our diverse student population.

\section{Results and Discussion}

While the Blended Learning Working Group began working with teaching staff from 2013, the blended learning strategy was not rolled out within subjects until 2014. This lead time allowed the Working Group to consistently articulate its aim of creating enhanced opportunities for teacher-student interaction, increased student engagement, added flexibility to the learning and teaching environment, and to provide opportunities for continuous improvement within subjects through a blended learning approach. We had the opportunity to discuss with teaching staff how blended learning approaches increased interaction between teachers and students, and students and students and have been demonstrated as promoting richer in-class interactions via increased class discussions and higher level exploration of concepts (Association for the Advancement of Computing in Education, 2007). We reiterated that this approach had the potential to not only improve student experience and achievement, but more authentically prepare them for future study and professional lives, and were able to demonstrate to our staff that they were a pivotal and valued component of the success of the project.

UTS:Insearch's academic teaching staff is comprised of around 130 teaching staff, all employed on a sessional basis, working across Foundation and Diploma levels. They 
teach International students with a minimum of IELTS 5.5 for Foundation and IELTS 6 for Diploma, and Domestic students. The Foundation program is a generalist pathways program, while the Diplomas teach first year Undergraduate programs in the areas of Business, Engineering, Science, Communication, Information Technology and Design. Teaching staff have various combinations of a degree in their subject area and/or a teaching degree and/or professional experience. The average age of teaching staff is 47 years, and the average length of time teachers have worked at UTS:Insearch is eight years. This particular teacher demographic in itself presented the Blended Learning Working Group with some challenges:

- The teachers were not 'digital natives' and had widely varying experience and/or confidence in the use of technologies;

- There was varying acceptance/interest in the idea of changing teaching practices which they felt were 'tried and true' - an 'if it ain't broke don't fix it' attitude;

- Due to the unpredictable nature of sessional employment there can be a tendency for some teachers to feel there is little personal gain in modifying habitual practices resulting in less acceptance of change.

UTS:Insearch values its teaching staff and their contribution to the organisation and student achievement, so a conscious decision was made to try to bring existing staff, who have a very comprehensive knowledge of content, on a learning journey rather than recruit new teaching staff. As the organisation is a small one, support for the teachers and the process was drawn from the active leadership of the Blended Learning Working Group and early adopters within the current staff. As previously discussed, our approach to blended learning is understood as the use of technology to support and enhance students' interaction with teachers, each other and content. It also recognises the centrality of the role of the teacher in creating more interactive approaches which potentially create classroom cultures that are co-constructed, redefined and modified as the students move through online and face-to-face activities and teaches students to mediate their own, and other students', learning (Takahashi, Austin \& Morimoto, 2000). Additionally, this conceptualisation which asks teachers to draw upon their "pedagogical content knowledge" to best select the technologies and approaches “...most germane to its teachability” (Shulman, 1986) invites them to examine their subject content to identify how to enhance their teaching practice and their students' learning and understanding.

By having over a year's 'lead in' time before the strategy was rolled out the Working Group was able to incrementally break down many of the barriers teachers initially had about the concept of blended learning, of the difficulties they may have with the technology, and create an acceptance that this approach was to be 'standard practice' within UTS:Insearch. In addition to being supportive of the teachers' central role in moving to blended learning approaches and practices, initiatives were undertaken to enculturate the teaching staff to the concepts. These initiatives, outlined previously, met with various levels of success:

- The take-up of online resources was, and continues to be, low with teachers feeling that having to log on to another site to comment or read articles was an impost on their time. While some teachers continue to use yammer, Pinterest 
and Symbaloo have had little patronage and their impact on enculturating staff has been minimal.

- Directly emailing staff with discussion articles initially appeared to have little impact as teaching staff were not commenting on the articles nor did they appear to be involved in any easily discernible discussion about them. However as professional development days progressed there appeared to be more interest, with teaching staff replying to the emails with their opinions and observations, rather than using yammer, and teachers commenting in person that the emails gave them new ideas and more information about the concept, how they might approach it, and how this would benefit their students.

- Initial professional development days were cautiously greeted by teachers both in terms of content and format. We departed from the 'usual chalk and talk' format to a more interactive workshop style demonstrating the principles on which our approach was based. This proved popular with teachers and attendance at professional development days has increased from an average of $10 \%$ of staff to an average of $40 \%$. Teachers also report a preference for this format, finding professional development days more enjoyable and relevant to their practice, allowing them to directly experience how a blended learning approach can improve learning experiences.

- The appointment of a Learning Technology Coordinator (LTC) was an important step forward in the enculturation process. As a peer, the LTC was able to demonstrate within our context how the principles and practices could be implemented and provide support and suggestions to fellow teachers in a very accessible way. The LTC also identified a number of key applications for teachers to be able to use easily, and which students enthusiastically engaged with in class. In this on-going role, the LTC works individually with teachers assisting them with support and selecting applications that best enhance the content and meet the teachers' needs.

- The provision of iPads and various Android devices has been moderately successful, with time constraints on teaching staff being the largest issue affecting their use.

The varying success of the approaches served as an important learning exercise for both the Blended Learning Working Group and for teaching staff. The differing levels of uptake demonstrated what types of technologies and applications people are willing to engage with, allowing individual teachers to reflect on what they might choose to implement as part of blended learning in their subjects.

While the introduction of blended learning approaches as part of the teaching culture at UTS:Insearch is still in its infancy, we feel the approach the Blended Learning Working Group took in slowly enculturating teaching staff to the concept while clearly valuing their roles has been successful. At the conclusion of Semester 3 2014, Subject Coordinators completed a survey to indicate the level at which blended learning was embedded in their subjects. The survey indicated that in regards to embedding blended learning approaches to learning strategies, on average, $38.39 \%$ of subjects were fully compliant; $37.5 \%$ well in progress; $17.86 \%$ in progress; $1.78 \%$ unclear on how to go about this; and $4.46 \%$ not commenced. 


\section{Conclusions}

Our project identified that the successful implementation of a blended learning approach to learning and teaching required UTS:Insearch to develop a technologically innovative teaching culture that was based on a very clear understanding of what this was in our context. To foster this culture we slowly introduced the concept to teaching staff, while encouraging them adopt a growth mind set by learning more about the approach and clearly articulating their importance in the project. We also adopted a number of initiatives, but found those that were more 'hands on' were more successful in communicating the approach to teaching staff. Having the teaching staff engaged and supportive of a blended learning approach allows us to better and more 'naturally' embed learning strategies that engage students, and teachers, enhance our students' learning experience and more authentically prepare them for future study and work. By approaching the introduction of the concept in a gradual, supportive manner where we continuously stressed that pedagogy leads technology we were able to encourage our teaching staff to adopt a non-traditional approach to their practice and to begin building a dynamic and innovative teaching culture within our organisation.

\section{References}

Association for the Advancement of Computing in Education (2007), Perspectives on blended learning in higher education. http://ablendedmaricopa.pbworks.com, accessed 30/12/2014.

Chew, E., Turner, D. A., \& Jones, N. (2010). In Love and War: Blended Learning Theories for Computer Scientists and Educationists. In F. L. Wang, J. Fong,

\& R. C. Kwan (Eds.), Handbook of Research on Hybrid Learning Models: Advanced Tools, Technologies, and Applications (pp. 1-23). Hershey, PA:

Information Science Reference. Retrieved from http://www.igiglobal.com.ezproxy.lib.uts.edu.au/gateway/chapter/full-text-pdf/40366

Dweck, Carol S. (2006) Mindset: The New Psychology of Success. New York: Random House.

Gerstein, Jackie. "The Educator with a Growth Mindset: A Staff Workshop." User Generated Education. August 28, 2014.

https://usergeneratededucation.wordpress.com/2014/08/29/the-educator-with-agrowth-mindset-a-staff-workshop/ accessed 26/11/2014.

Mishra, P., \& Koehler, M.J. (2006) Technological Pedagogical Content Knowledge: A framework for teacher knowledge. Teachers College Record, 108 (6), 1017-1054.

Partridge, H., Ponting, D., \& McCay, M. (2011) Good Practice Report: Blended Learning. Australian Learning and Teaching Council Ltd, an initiative of the Australian Government Department of Education, Employment and Workplace Relations.

Picciano, A.G. (2009). Blending with a Purpose: The Multimodal Model. Journal of Asynchronous Learning Networks, 13(1), pp. 7-18.

Sagor, R. (2000). Guiding School Improvement with Action Research. Alexandria: Association for Supervision \& Curriculum Development (ASCD). 
Shulman, L.S. (1986). Those who understand: Knowledge growth in teaching. Educational Researcher, 15(2), pp. 4-14.

Takahashi, E., Austin, T. and Morimoto, Y. (2000). 'Social Interaction and Language Development in a FLES Classroom'. Second and foreign language learning through classroom interaction. Hall, J. C. and Verplaetse, L. S. (eds), New Jersey: Lawrence Erlbaum Associates, pp.139- 157. 


\title{
Spiralling up Professionalism - An integrated model for Higher Education
}

\author{
A. Davies* ${ }^{*}$ H. Lynch ${ }^{*}$ \\ *School of Policing, Charles Sturt University
}

\begin{abstract}
Globally the higher education community continues to explore curriculum delivery models which connect theory to practice to support the transfer of learning from the classroom to operational practice. Police recruit education is no exception and utilises a myriad of curriculum design and delivery models. Since 1998 the New South Wales Police Force in Australia has worked in partnership with Charles Sturt University on a degree based recruit education program. Continuous improvement and evaluation of the program has resulted in the implementation of an innovative curriculum design and delivery approach which challenges the traditional university subject learning process. This paper discusses the innovative model which is built on (1) the concept of situated learning and (2) the constructive alignment approach to teaching and learning. The learning delivery design is supported by a unique distributed content technology environment. The model and the initial results of its evaluation are presented. The initial findings suggest an increase in the level of preparedness of the student recruit for operational practice. The approach offers a contribution to higher education course development in which a central tenant is establishing a seamless segue from student to professional.
\end{abstract}

Keywords: policing; integrated curriculum; integrated assessment; distributed environment

\section{Introduction}

Whilst there is a sustained debate surrounding situating police recruit education in the higher education paradigm (see Lee \& Punch, 2004; Cox,2001; Rydberg \& Terrill, 2010) the NSW Wood Royal Commission (1997) recommended the NSW Police Force (NSWPF) partner with a university to promote academic rigor and professionalism in police recruit education. Charles Sturt University has partnered with the NSWPF since 1998 in delivering the NSWPF recruit education program through the study of initially, a Diploma in Policing Practice and since 2003 the Associate Degree in Policing Practice (ADPP). In the traditional curriculum design of university studies, the learning in these two study programs was centred on the study of individual subjects which collectively contributed to the awarding of the Diploma/Associate Degree. In parallel, students completed physical skill training relevant to operational policing e.g. officer safety skills, pursuit driving skills and personal physical fitness skills. The learning objectives of the curriculum are to prepare the policing student for their operational duties. Further the studies are designed to provide academic rigor to the student learning through underpinning the curriculum content with study of the theories which provide the guiding principles for policing in a western democratic society. In practical terms the study of policing practice through an academically founded program provides insight and knowledge as to 'why police do what they do'. A catalyst for rethinking the design and delivery of the ADPP centred on the analysis of field based evaluations conducted on a four yearly basis. The analyses consistently identified the curriculum developed the students' knowledge of theory however there remained opportunity to more adequately connect theory to practice for the policing students to support the quantum shift from student to operational police officer.

\section{Historical model of learning delivery}

Prior to January 2014 students studying the ADPP were enrolled, studied and assessed in individual subjects e.g. Communications in Policing, Police Crime and Society, Policing and Road Safety. The enrolment and progression pattern for the ADPP pre and post 2014 is similar in design to align with university enrolment policies and the NSWPF optional study pathways 
requirements. Students are enrolled in individual subjects which collectively comprise a degree program. The post January 2014 ADPP course as depicted in Figure 1 indicates the flexible nature of the program enabling full-time on campus or distance education study pathways for the commencing session of the program. The study program presented in Table 1 portrays on the surface, the hallmarks of traditional university study programs: retention of a collective of subjects comprising a course of study. Rethinking the delivery design of the program to enhance student learning defaulted therefore to below the subject and course surface.

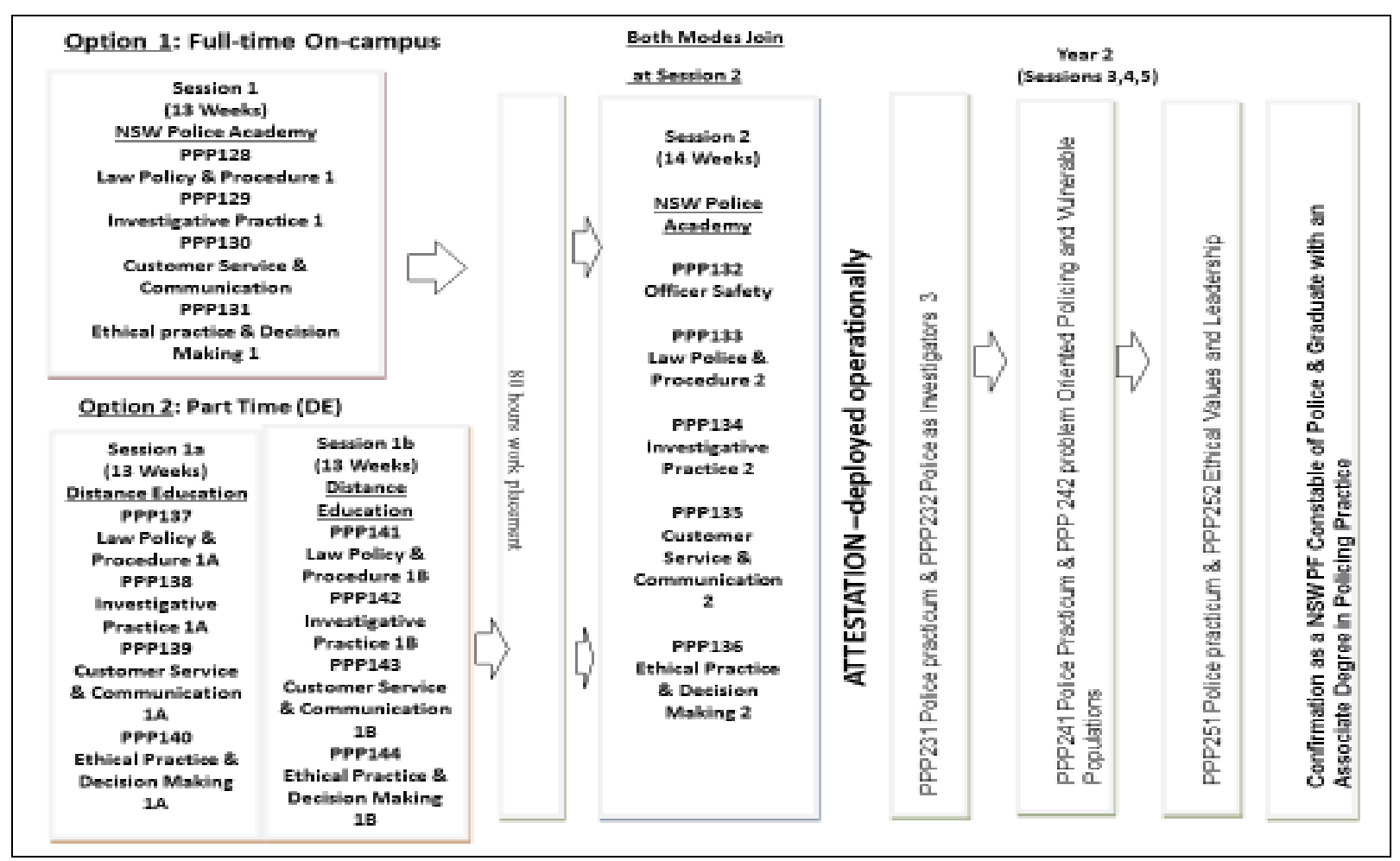

Figure 1 Associate Degree in Policing integrated curriculum study program

The key objective in the redesign of the ADPP curriculum and assessment was to draw the operational field into the classroom offering increased contextualisation of curriculum content.

\section{Integrated curriculum content and assessment}

Integrated curriculum as a design concept for learning has produced a myriad of literature which examines the advantages and disadvantages from multiple perspectives. It is not a new concept, however, as suggested by Zhou and Kim (2010, p. 123) a consistent universally accepted definition remains unresolved:

...debate has not yet resulted in an agreement over the meaning and the appropriate practice of curriculum integration”

Gresnight et.al. (2014) provided a comprehensive insight into the historical debate in referring to the work of Beane (1997), Drake $(2000,2007)$ and Fogarty (2009). The implication of the continued debate suggests the concept of an integrated curriculum therefore has no singular stand-alone role model, rather it is adapted and moulded by educators to meet specific overarching parameters (social, political, environmental, economic and legal) relevant to the education institution. The development of an integrated curriculum and assessment model for the ADPP is an example of such flexible adaptation of the concept of integration. The ADPP model reflects a combination of the three categories of integration as proffered by the early 
work of Drake (2000) in this field and includes: content focus, skill focus and the combination of life-context focus.

The revised ADPP curriculum is premised on mirroring the field based duties of police officers, scaffolding the learning on core operational tasks. Modules of delivery have been designed which draw learning content from each of the individual subjects to address the policing responsibilities and skills attached to the focus of the module. Figure 2 offers graphic representation of the relationship between course, subject, module and learning environment for the commencing Session One of the program. A similar design principle underpins Session Two of the program. Session Two has no distance education study option, all students are full time on campus. Sessions Three, Four and Five are studied during the first 12 months of a probationary constable's (PC) operational deployment. Each field based session comprises study of one academic subject via distance education and one practicum subject related to field based activities.

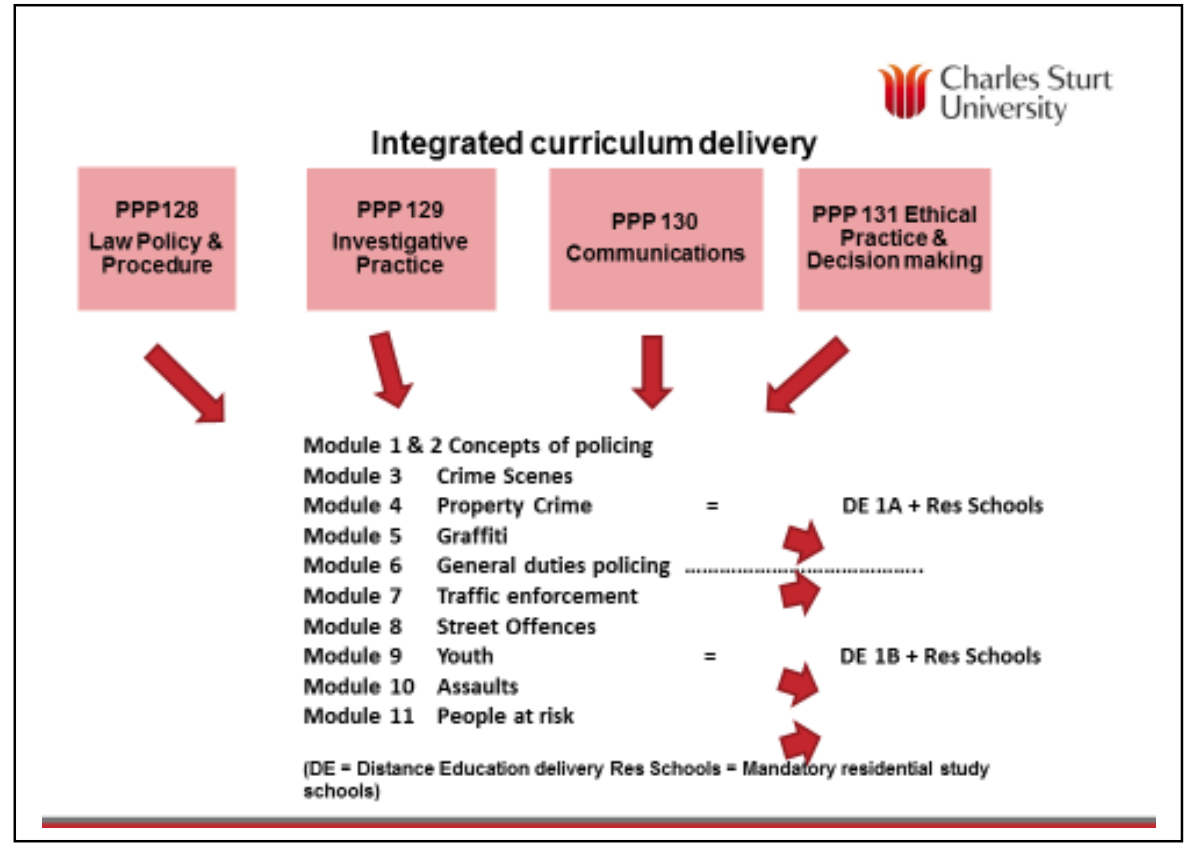

Figure 2 ADPP integrated curriculum delivery model Session 1

An important consideration underpinning this integrated learning design is the inclusion of learning experiences which afford the student opportunity to apply the knowledge and skills they acquire on a continual basis throughout the sessions of study. Contextualising the learning content and experience is a pivotal design characteristic which aids students' recognition and acknowledgement of the relevance of acquiring the knowledge and skills presented within the ADPP curriculum. Not only is contextualised practical application built into the module lessons in the classroom, this learning approach is extended through student participation in weekly simulated policing exercises within a purpose built scenario village at the Academy. Guiding principles which have contributed to the design of module lessons have been drawn from the concepts of situated learning (Collins, 1999) and the work of Herrington, Herrington, Oliver and Reeves in design constructs for authentic learning and assessment (see Herrington \& Herrington, 1998, 2006; Herrington \& Oliver, 1995, Herrington, Reeves \& Oliver, 2007; Herrington, Oliver \& Reeves, 2003). Herrington heralded the complexities faced by educators in seeking to align university teaching with contextualisation of learning in commenting:

...The challenge they have faced is to align university teaching and learning more substantially with the way learning is achieved in real-life settings, and base instructional methods on more authentic approaches such as situated learning (2006, p. 3). 
In parallel with embedding the principles of authentic and situated learning, the integrated curriculum has followed a constructive alignment approach. The seminal work of Biggs in the field of constructive alignment principles - where the learners' activities are pivotal in creating meaning (Biggs, 1996, p.347) has underpinned the design framework for the integrated curriculum. The alignment of learning objectives for the whole of course with learning objectives for individual lessons and assessment followed by scaffolding these to learning exercises and content within individual lessons enables the continual and transparent monitoring of adherence to the underpinning course design principles.

The integrated ADPP curriculum accommodates the traditional university method of awarding subject credits whilst maintaining an integrated assessment process. Figure 3 presents an example of the integrated assessment design.

\begin{tabular}{|c|c|c|c|c|}
\hline Subject & $\begin{array}{l}\text { Credit } \\
\text { Points }\end{array}$ & $\begin{array}{l}\text { Assessment Item } 2 \\
\text { Theory Exam Part a, b, c, d }\end{array}$ & Assessment Item & $\begin{array}{l}\text { Assessment } \\
\text { Item }\end{array}$ \\
\hline \multirow[t]{2}{*}{$\begin{array}{l}\text { PPP128 } \\
\text { Law Policy and } \\
\text { Procedure } \\
\end{array}$} & 16 & $\begin{array}{l}\text { 2A \& } 2 \text { B Exam m/c questions } \\
\text { 2C \& 2D Exam m/c questions } \\
\text { Combined Pass mark 70\% }\end{array}$ & $\begin{array}{l}\text { Item } 6 \text { Law Exam } \\
\text { Pass mark 50\% }\end{array}$ & $\begin{array}{l}\text { Item } 3 \\
\text { Police Practical } \\
\text { Graded SY/US }\end{array}$ \\
\hline & & Combined weighting of $50 \%$ & $50 \%$ & SY/US \\
\hline \multirow[t]{2}{*}{$\begin{array}{l}\text { PPP129 } \\
\text { Investigative } \\
\text { Practice } 1\end{array}$} & 8 & $\begin{array}{l}\text { 2A \& } 2 \text { B Exam m/c questions } \\
\text { 2C \& 2D Exam m/c questions } \\
\text { Combined Pass mark 70\% }\end{array}$ & $\begin{array}{l}\text { Item } 5 \\
\text { Investigations } \\
\text { Assign/Exam } \\
\text { Pass mark 50\% }\end{array}$ & $\begin{array}{l}\text { Item } 3 \\
\text { Police Practical }\end{array}$ \\
\hline & & Combined weighting of $50 \%$ & $50 \%$ & SY/US \\
\hline \multirow[t]{2}{*}{$\begin{array}{l}\text { PPP130 } \\
\text { Customer Service } \\
\text { Communication } \\
1 \\
\end{array}$} & 8 & $\begin{array}{l}\text { 2A \& } 2 \text { B Exam m/c questions } \\
\text { 2C \& 2D Exam m/c questions } \\
\text { Combined mark } 70 \%\end{array}$ & $\begin{array}{l}\text { Item } 1 \\
\text { Communications } \\
\text { Exam ( CAPS) } \\
\text { Pass mark 50\% } \\
\end{array}$ & $\begin{array}{l}\text { Item } 3 \\
\text { Police Practical }\end{array}$ \\
\hline & & Combined weighting of $50 \%$ & $50 \%$ & SY/US \\
\hline \multirow[t]{2}{*}{$\begin{array}{l}\text { PPP131 } \\
\text { Ethical Practice } \\
\text { Decision Making } \\
1\end{array}$} & 8 & $\begin{array}{l}\text { 2A \& } 2 \text { B Exam m/c questions } \\
\text { 2C \& 2D Exam m/c questions } \\
\text { Combined Pass mark 70\% }\end{array}$ & $\begin{array}{l}\text { Item } 4 \\
\text { Ethics (Essay) } \\
\text { Assignment } \\
\text { Pass mark 50\% }\end{array}$ & $\begin{array}{l}\text { Item } 3 \\
\text { Police Practical }\end{array}$ \\
\hline & & Combined weighting of $50 \%$ & $50 \%$ & SY/US \\
\hline
\end{tabular}

Figure 3 ADPP Session 1 Integrated Assessment model

The pivotal assessment item which provides for an integrated approach to assessing student learning is a theory exam consisting of multiple choice questions and short/extended answer responses. The theory exam is based on one or several scenarios to which blocks of questions from each individual subject area are applied. The performance in each subject block contributes to the overall student mark for the subject. Additional assessment items for each individual subject are included allowing for assessment of student knowledge and skills from multiple perspectives. The assessment process requires students to undertake a simulated policing response exercise, their performance is marked against learning objectives for each individual subject category e.g. demonstration of communication skills is awarded a satisfactory or unsatisfactory mark and attributed to the overall Communications in Policing subject mark awarded. The integrated assessment design is cognisant of the necessity in terms of student progression and transcript of studies to identify in each subject area where a student passes or fails. One of the products and processes which has (1) supported the integrated approach for the full time and distanced education learning and (2) allowed for monitoring of the contextualisation of learning content and creation of authentic contextualised learning experiences is the introduction of a distributed content environment (DCE). 


\section{Learning materials and a distributed content and environment (DCE)}

The Distributed Content Environment (DCE) was specifically designed to facilitate the development, reuse, management and distribution of curriculum and learning resources. The DCE makes learning materials available to F2F students, teaching staff, the classroom and distance learners online in a range of highly accessible digital content formats (Lynch, 2015). In a learning environment driven by authentic and situated learning principles real-time, any place access to resources that support contextualised learning is pivotal. With a DCE students have instant access to their audio-visual and textual resources inside and outside of the classroom for lesson preparation, in class activities, field activities, and lesson and learning review. For ADPP students the DCE provides a Study Guide in .epub and markable .pdf format for mobile devices or laptops (which draws resources via weblink from websites or digital object repository sites wrapping them in relevant instructional text). The DCE becomes a conduit through which student resources can be presented, watched, heard or enacted at any time.

In parallel, teaching staff are provided identical flexibility of access to teaching resources, which are a repackaged version of the student accessible content, with additional instructional guidance. The facilitator package allows for the presentation of selected digital resources via the university's online learning environment and classroom display technologies. A major benefit realised is the facilitation of the continuous improvement of the curriculum by providing an environment in which content is readily and seamlessly updated and distributed. This is an important consideration in policing studies which requires accommodation of continuous changes to legislation, police policies and practices. As this innovative approach to the development and distribution of learning materials and a holistic learning environment is a 'new system' the full potential of the DCE has yet to be explored. However, in the evaluation project undertaken in March 2015, students provided feedback as to their experience with the online environment and its relationship to supporting their field based activities.

\section{Evaluation}

It was to be expected as with new courses, there would need to be revision and amendment, the reality being a lesson written on paper can 'look' quite different when experienced in the classroom. A formal evaluation study was conducted in March 2015. The timing of the evaluation was premised on allowing a 'settling in' of the learning delivery design for students and teachers. Importantly, this time frame offered opportunity for the PCs to respond from a position of 6-8 weeks operational experience.

\section{Method}

A case study approach was undertaken in the preliminary formal evaluation research project. The project objectives aligned with the case study characteristics advocated by Stake (2005) of issue choice; triangulation; experiential knowledge; contexts and activities. There is a sound body of literature devoted to reasoning for situating evaluation of education initiatives within a case study frame work (see: Simons 2009, Merriam 2009; Burns, 2000.) A qualitative data collection approach was employed aligning with the rationale proffered by the seminal work in this field of Bryman (1988); Miles and Huberman (1994) and Patton (2002). Allowing the PCs and their field based trainers and supervisors to give voice to their observations had the potential to offer rich insight into the relationship between the curriculum and the field of operational practice. Worthy of note is the preliminary nature of this evaluation project as the first phase of future broader evaluative studies of the ADPP program. 
The complete cohort of 300 PCs who commenced operationally in January 2015 (2 ${ }^{\text {nd }}$ cohort to graduate through the integrated curriculum) were invited to complete an on-line survey comprised of short answer questions. A total of 153 participants completed the survey. In addition total of 15 participants were invited to participate in a short telephone interview. The selection of interviewees was based on capturing a range representative of the cohort by age, gender, and location of the NSW Police Station to which they were deployed (country, metropolitan and coastal). The survey and semi-structured interview questions focused on: (1) level of preparedness for operational policing; (2) content/experiences within the Academy based studies which they consider of most valuable for their operational practice; (3) areas of learning they consider would be helpful if studied prior to deployment; and (4) the value of the technology employed in the delivery of the curriculum as it relates to their operational practice. The PCs are supervised in the first 6 weeks of their field based operation by Field Training Officers (FTO) and Educational Development Officers (EDO). These officers have experience with training and supervising PCs who have studied under the previous non-integrated curriculum and the current integrated curriculum. This experience situates them appropriately to offer insight into variances they have observed with graduates of the two programs. A total of 15 EDO/FTOs were interviewed, their selection premised on gender and NSW Police Station location (country, metropolitan and coastal). The evaluation study embraced wide ranging issues, however for this paper it is the data which informs on the relationship between the integrated curriculum and its influence on the field based preparedness of the recruit officers which is included in the following section.

\section{Results and Discussion}

A note of caution is offered in relation to the following data it is preliminary in nature and does not at this stage explore potential influences other than the curriculum on the level of preparedness of the PCs. As presented in Table 1, the data reported $93.62 \%$ of the PCs feeling confident in their level of preparedness for operational practice. Whilst not detracting from the encouraging positive response and reflection on the curriculum, the PCs also offered suggestions for curriculum inclusions which may further build their level of preparedness. The level of confidence indicated in Table 1 is supported by the observations from the EDO/FTO interviews.

Table 1 Confidence in level of preparedness reported by PCs

\begin{tabular}{|c|c|c|c|c|}
\hline \multicolumn{4}{|l|}{$\begin{array}{l}\text { Question 4: How confident did you feel in your level of preparedness for operational duty when you attested } \\
\text { from the Academy? Responses=153 (\% calculated on response identifying level } n=141 \text { ) }\end{array}$} \\
\hline $\begin{array}{l}\text { Not very; less } \\
\text { than confident }\end{array}$ & $\begin{array}{l}\text { Somewhat; } \\
\text { slightly }\end{array}$ & $\begin{array}{l}\text { Confident; fairly; 50\% } \\
\text { moderate; good }\end{array}$ & $\begin{array}{l}\text { Solid; very } \\
\text { confident; 7/10 }\end{array}$ & $\begin{array}{l}\text { Confidence level not } \\
\text { indicated }\end{array}$ \\
\hline 9 & 18 & 96 & 18 & 12 \\
\hline $6.38 \%$ & $12.765 \%$ & $68.08 \%$ & $12.765 \%$ & \\
\hline
\end{tabular}

The general response from the EDO/FTOs was that the PCs displayed a broader confidence and awareness of their role and the job and more faith in their abilities. Table 2 presents examples of the EDO/FTO responses to interview Question 3. 
Table 2 EDO/FTO Observations of Level of Preparedness of PCs

\begin{tabular}{|c|c|}
\hline $\begin{array}{l}\text { EDO (Coastal Local } \\
\text { Area Command) }\end{array}$ & $\begin{array}{l}\text { The PCs we have at the moment are on the ball, in relation to level of preparedness } \\
\text { it is like they have been here before and doing it the } 2^{\text {nd }} \text { day on the job }\end{array}$ \\
\hline $\begin{array}{l}\text { EDO (Metropolitan } \\
\text { Local Area } \\
\text { Command) }\end{array}$ & $\begin{array}{l}\text { I think particularly this group, they seem to be more switched on in so far as a } \\
\text { holistic approach. They seem to have a broader confidence about them and } \\
\text { awareness, more faith in their abilities. }\end{array}$ \\
\hline $\begin{array}{l}\text { EDO ( Country Local } \\
\text { Area Command) }\end{array}$ & $\begin{array}{l}\text { I have been an EDO for } 8 \text { years... the quality of work seems a lot more switched } \\
\text { on...they seem like they have been in the job before. I used to get 100's of } \\
\text { questions, but it all just seems to happen naturally with this group. }\end{array}$ \\
\hline
\end{tabular}

An interesting trend emerged from the data collected which focussed on the relationship between embedding a distributed content environment with all learning materials in a digital format and the useability and connection for the PCs. The 15 PCs interviewed agreed that having to work with digital resources in the Academy studies developed their confidence and capability with technology for policing. The interesting trend which emerged during interview was that the PCs indicated they are returning to their digital resources utilised during studies at the Academy to now use as reference sources in their field based operations. This trend was universal across the 15 PCs interviewed. The following comment from Participant 12 is indicative of this trend:

...they are really valuable, I find if I have a bit of time at work I jump on line and recap

some of the information. Having it available 24/7 is really helpful;

and Participant 10:

...The materials are always there for you, sometimes I look at the Session One and Two material, I attend a lot of traffic issues so I went back to look at the traffic material on line. I also look up everyday things like move along directions.

The data offered here is a snapshot of the overall data collected for the project, this data is that which is specifically relevant to providing initial understanding if the curriculum design approach is heading in the right direction.

\section{Conclusion}

The innovative design approach for the ADPP has not been without challenges in preparation of the course material and transitioning both teaching staff and students to a 'new way of thinking' about learning. Whilst the early indicators offer evidenced based validation and support for this innovative approach to higher education for police recruits, it offers also a model for consideration by educators in pursuit of the nexus which connects theory with practice in a wide range of professions.

\section{References}

Beane, J.A. (1997). Curriculum integration: designing the core of democratic education. New York, NY: Teachers College Press.

Biggs, J. (1996). Enhancing teaching through constructive alignment. Higher Education, 32, 347-364.

Biggs, J. (1999). Teaching for Quality Learning at University, Buckingham, UK: SRHE and Open University Press.

Bryman, A. (1988). Quantity and quality in social research. London, England: Unwin Hyman.

Burns, R. B. (2000). Introduction to research methods (4th ed.). Sydney, Australia: Pearson Education Australia. 
Collins, A. (1988). Cognitive apprenticeship and instructional technology (Technical Report 6899). Cambridge, MA: BBN Labs Inc.

Cox, D. (2001). Educating police for uncertain times: The Australian experience and the case for a 'normative' approach. Journal of Policing, Intelligence and Counter Terrorism. 6(1), 3-22.

Drake, S. (2000) .Integrated curriculum: A chapter of the curriculum handbook. Alexandria, VA: Association of Supervision and Curriculum Development.

Drake, S. (2007). Creating standards-based integrated curriculum: aligning curriculum, content, assessment and instruction. ( $2^{\text {nd }}$ ed.). Thousand Oaks, CA: Corwin Press.

Fogarty, R. (2009). How to integrate the curricula. ( $3^{\text {rd }}$ ed.). Thousand Oaks, CA: Corwin Press.

Gresnight, R., Taconis, R., van keulen, H., Gravemeijer, K. \& Baartman, L. (2014). Promoting science and technology in primary education: a review of integrated curricula. Studies in Science Education. 50(1), 47-84. DOI: 101080/3057267.2013.877694

Herrington, J., \& Herrington, A. (1998). Authentic assessment and multimedia: How university students respond to a model of authentic assessment. Higher Education Research \& Development, 17(3), 305-322.

Herrington, J., \& Herrington, A.(2006). Authentic learning environments in Higher Education. Hershey, PA: Idea Group, Inc.

Herrington, J., Oliver, R., \& Reeves, T. C. (2003). Patterns of engagement in authentic online learning environments. Australian Journal of Technology, 19(1), 59-71.

Herrington, J., Reeves, T. C., \& Oliver, R. (2007). Immersive learning technologies: Realism and online authentic learning. Computing in Higher Education, 19(1), 80-99.

Lynch, H. (2015). The Distributed Content Environment. Retrieved from https://slidebean.com/p/TSo6f9t16V/The-Distributed-Content-Environment

Lee, M. \& Punch, M. (2004) Policing by degrees: Police officers' experience of university education. Policing and Society: An International Journal of Research and Policy, 14(3), 233-249.

Merriam, S. B. (2009). Qualitative research: A guide to design and implementation. San Francisco, CA: Jossey-Bass.

Miles, M. B., \& Huberman, M. A. (1994). Qualitative data analysis:An expanded sourcebook (2nd ed.). Thousand Oaks, CA: Sage.

New South Wales. Royal Commission into the New South Wales Police Service \& Wood, J. R. T. (James Roland T.) (1997). Final report. Royal Commission into the New South Wales Police Service, Sydney, N.S.W.

Patton, M. J. (2002). Qualitative research and evaluation methods (3rd ed.). Thousand Oaks, CA: Sage.

Reeves, T.C., Herrington, J., \& Oliver, R. (2002). Authentic activities and online learning. In A. Goody, J. Herrington \& M. Northcote (Eds), Quality conversations: Research and Development in Higher Education, Volume 25, (pp. 562-567). Jamison, ACT: HERDSA. http://www.ecu.edu.au/conferences/herdsa/papers/ref/pdf/Reeves.pdf

Rydber, J. \& Terrill, W. (2010). The effect of higher education on police behaviour. Police Quarterly, 13, 92-120.

Simons, H. (2009). Case study research in practice. London, England: Sage.

Zhou, G. \& Kim, J. (2010). Impact of an integrated methods course on pre-service teachers' perspectives of curriculum integration and faculty instructors' professional growth. Canadian Journal of Science, Mathematics and technology Education. 10(2), 123-138. 


\title{
Teaching Professional Ethics in Mexican and Spanish Universities
}

\author{
A. Hirsch, C. Navia** \\ * National Autonomous University of Mexico \\ ** National Pedagogical University, Ajusco Campus - Mexico
}

\begin{abstract}
The main purpose of this presentation is to explore the proposals to teach professional ethics to university students, which were expressed by scholars from institutions in Mexico and Spain. The ideas and results we present, derive from current formative proposals and from the application of surveys and a scale questionnaire to professors from the National Autonomous University of Mexico and some Spanish universities, within different phases and times. Coincidences have been encountered towards the central idea that the scientific and technical contents should be addressed in a conjoint manner with those about professional ethics. We found consensus in certain contents, for instance, the principles of professional ethics and participative formative strategies that should be employed, taking into account the work context and real situations. Among the conclusions, it can be highlighted that in general the majority of the professors interviewed have considered the necessity to include a preparation in this domain, in an explicit, systematic and articulated way with the research processes for university students.
\end{abstract}

Keywords: Teaching Professional Ethics; Professors; Universities; Mexico; Spain

\section{Introduction}

This paper is part of the Research Project about Professional Ethics at the National Autonomous University of Mexico (UNAM). The main objectives are: to contribute in the enrichment of knowledge about professional ethics at the university, and ultimately, to propose a series of guidelines for their teaching.

The previous papers, articles and book chapters we published articulated theoretical issues with empirical data. They focused in gathering and generating knowledge about professional ethics, with the idea to fulfil the first objective of the research project. Unlike the previous effort, in this work, we are committed to answer the second porpoise, which is the definition of guidelines for teaching professional ethics for university students.

The research has been developed through many years, in two different countries: Mexico and Spain. We believe that one of the achievements of this paper is the comparative analysis from the results in the research in both countries.

We present the research that was undertaken with Mexican and Spanish professors about the contents and methodologies to promote the teaching of professional ethics for university students. At the beginning of the research project, we search for implemented proposals in some universities, especially in Spain, about this theme. The topic was later investigated at the graduate level, among different stages, with professors from UNAM and various Spanish universities.

We will present the following aspects: the background of the research project; the process for gathering information through three strategies: documental analysis, interviews and a questionnaire; the central elements of the theoretical framework; the methodological section that refers to the application of the two empirical instruments; the discussion of the principal comparative findings; conclusions and the bibliographical references. 


\section{The research project background}

At the beginning of the research project (2002) we constructed the first State of the Art about professional ethics, recuperating empirical studies that were made in Mexico (Hirsch, "et al.", 2003). Ten years later, we participated in the second State of the Art (Hirsch, 2013).

Simultaneously we searched for bibliographical and periodical materials with the finality to construct the theoretical framework and to be able to define their principal elements. Even thought we have more or less completed this construction, we have and open mind about it, because we found new materials and open new topics that were not previously considered.

The third activity refers to the empirical phase, with the construction of a questionnaire (with an open question about the principal features of "being a good professional" and an attitude scale with 55 items). This instrument was developed between UNAM and the University of Valencia, in 2003, for the graduate level. We first applied the questionnaire to a sample of students in Valencia and Murcia in Spain, in 2003 - 2004 and later on in Mexico, in UNAM, to a sample of students in $2004-2005$ and a sample of professors and researchers in 2006 - 2007.

We also developed an interview guide that was used with professors from some Spanish universities in 2004 and 2011 and in UNAM with the forty graduate program coordinators in 2009. All of this allowed us to achieve the first objective of the research that is the enrichment of knowledge in this specific applied ethic.

At the same time, we searched for proposals to teach professional ethics to university students. This paper emphasizes the second porpoise which is the definition of guidelines about teaching professional ethics. We recover some of the proposals we found and also the answers given by the research subjects to direct questions about this theme.

\section{Methods}

In this paper, the acknowledgement of the retrieved information is given through three data collection strategies: documental analysis, interviews and a questionnaire. The instruments were structured, taking into consideration the theoretical framework specifically built for the research project. We analyzed the work of many authors from several countries, and chose as fundamental: Tom Beauchamp and James Childress (2012) from the United States of America; Augusto Hortal (2002) from Spain and Martin Aluja and Andrea Birke (2004) from Mexico.

The theoretical framework is composed by the following elements: professional ethics principles and rules, professional characterization in general and professional ethics in particular, professional ethics as part of the applied ethics; differences between professional ethics and professional deontology; economic, technical and organizational influences in professional practice; fundamental values, especially responsibility, dilemmas and ethical conflicts, non-ethic behaviour, professional identity, science ethics and research ethics, professional ethics of professors and proposals for teaching ethics in the university. 


\section{Professional ethics principles}

During the long process of constructing the theoretical framework we realised that the central theme was about the principles of professional ethics. Even though mostly all the literature we consulted referred to that topic, we decided to focus in a very important book from Tom Beauchamp and James Childress (2012): Principles of Biomedical Ethics.

The four moral principles presented by them are: Respect for Autonomy, Nonmaleficence, Beneficence and Justice. In the preface of the seventh edition, they clearly expressed "that it is a mistake to assign priority to any basic principle over other basic principles" and that "the better strategy is to appreciate the contributions and the limits of various principles, virtues, and rights”.

These four principles are fundamental to biomedical ethics, but because they have proved to be significant as a reflection framework to take ethical decisions in the conflicts and dilemmas that professional encounter in their daily work, they have been recovered and interpreted by the other areas of knowledge.

Respect for autonomy means "self - rule that is free from both controlling interference by others and limitations that prevent meaningful choice, such as inadequate understanding. The autonomous individual acts freely in accordance with a self-chosen plan... In contrast, a person of diminished autonomy is in some material respect controlled by others or incapable of delivering or acting on the basis of his or her desires and plans... (p. 101-102).

"The principle of Nonmaleficence obligates us to abstain from causing harm to others"(p. 150). This principle supports several specific rules. Beauchamp and Childress (2012:154) prioritized: do no kill, do not cause pain or suffering, do no incapacitate, do not cause offense and do not deprive others the goods of life”.

The risk of harm in the biological and health sciences and in the scientific research in all areas of knowledge has been enormous in relation to the vulnerable people and communities: "the unjustified overutilization of members of these populations has long been a matter of deep moral concern” (p. 156).

In reference to the principle of Beneficence, the authors distinguish two related concepts: positive beneficence and utility. The first one "requires agents to provide benefits to others" and the second "requires that agents balance benefits, risks and costs to produce the best overall results” (p. 202).

The principle of Justice search to "determine how social burdens, benefits, opportunities, and positions ought to be distributed". They consider that our obligations are limited to fundamental needs for essential resources (p. 252).

The empiric work was performed in four phases within Mexican and Spanish universities. The documental strategy allowed us to obtain concrete proposals on how teaching professional ethics is performed among educational institutions.

\section{Interview program}

The interview strategy was used on two occasions in Spain. The first one, in 2003 2004 (Hirsch, 2004), comprised eleven professors: Pedro Ortega from Murcia University; Bernardo Martínez-Mut and José Felix Lozano from the Polytechnic University of Valencia; Gonzalo Jover from the Complutence University of Madrid; Juan Manuel Cobo, Augusto Hortal and Julio Martínez-Martínez from the Pontifical 
University of Comillas in Madrid; Miguel Angel Santos and María del Mar Lorenzo from the Santiago of Compostela University and Juan Escámez and Rafaela GarcíaLópez from the University of Valencia.

From the eleven academics that were interviewed, several criteria were prioritized, knowledge, experience and concrete formative proposals from three experts on the thematic field. These professors are Augusto Hortal (1995 and 2002) and Juan Manuel Cobo (2003 and 2004) from the Pontifical of Comillas University in Madrid and José Félix Lozano (2000 and 2003) from the Polytechnic University of Valencia. The principal questions that were sought to be answered were: Why it is important to teach professional ethics? How this formative need can be solved? What to teach on professional ethics?

The second interview was performed in 2011. The principal feature of the Spanish respondents in 2003 -2004 was that they all were active in philosophy and educational sciences. Those performed in 2011 included professors from other disciplines. Eleven of the fourteen interviews were made in the University of Valencia, with the following academics: Juan Escámez, Cruz Pérez, Bernardo Gargallo, Rafaela García-López, Victoria Vázquez, Inmaculada López, Manuel Dolz, Pilar Martínez-Arocas, Vicente Barberá, Rafael Pla and María Carmen Antolín. The other three were: José Felix Lozano from the Polytechnic University of Valencia and Roberto Sanz and Lucía Ballester from the Catholic University of Valencia San Vincent Martyr.

The interview guide was applied in 2009, to the forty coordinators of all the graduate programmes at UNAM. This university classifies its forty graduate programmes in four distinct areas of knowledge: Physics - Mathematical and Engineering Sciences (with seven graduate programmes: Mathematical Sciences and the Specialization of Applied Statistics, Engineering, Astrophysics, Computational Science and Engineering, Science and Engineering of Materials, Earth Sciences and Physical Sciences); Biological, Chemical and Health Sciences (with ten graduate programmes: Biomedical Sciences, Neurobiology, Nursery, Biochemical Sciences, Production and Animal Health, Medical - Dentistry and Health Sciences, Chemical Sciences, Psychology, Biological Sciences and Sea and Limnology Sciences); Social Sciences (with eight programmes: Social Work, Anthropology, Administration Sciences, Political and Social Sciences, Law, Economy, Latin-American Studies and Geography) and Humanity and Arts (with fifteen programmes: Industrial Design, Master in Teaching for the College Level, Architecture, Library Sciences and Informational Studies, Mesoamerican Studies, Philosophy, Philosophy of Science, History, Literature, Linguistics, Music, Pedagogy, Urbanity, Art History and Arts and Design).

Considering that the interview guide was applied in different moments and countries, the questions were adapted as the research was advancing in its course.

\section{A scale questionnaire about professional ethics}

A scale questionnaire was designed and applied to a sample consisting in 719 professors from UNAM in 2009. The questionnaire was structured as follows: four major open questions and an attitude scale about professional ethics integrated with 55 items (Hirsch, 2010). From this instrument we only included in this paper the open question: Do you consider that professional ethics should be taught to all university students? If your answer is affirmative: Which are the main contents and strategies to be implemented? 
The sample was of 384 men (53.40\%) and 335 women (46.59\%). The highest percentage was from professors in the age range of 46 to 50 years $(21.97 \%)$ and in the wider one from 46 to more than 60 years $(70.38 \%)$. The data about the age is coincident with the academic antiquity, because the highest percentage is the group of teachers and researchers with 30 years of service $(20.59 \%)$. The two following places in a descendant order are 21 to 25 years and 26 to 30 years working in UNAM. In these three we found more than half of the sample (50.91\%).

$70.51 \%$ had a PHD and $24.34 \%$ a Master. In the sample, we located $13.35 \%$ of subjects' teachers, $13.07 \%$ researchers and $11.40 \%$ professors with the highest category and level. The instrument was also answered by seven emeritus professors $(0.98 \%)$. The rest was situated in a dispersed manner in the other academic categories and levels of UNAM.

For the analysis of the information gathered, categories and subcategories were constructed in order to cluster the responses from the informants. These categories allowed us to establish comparisons.

\section{Results and Discussion}

\section{First moment: experts from Spanish universities}

In a first encounter, in 2004, experts from Spanish universities were interviewed about teaching professional ethics. One trend we found is that the professors considered that even though scientific-technical knowledge is central, ethical considerations are also important. This affirmation is relevant, since a predominant cognitive and ethical content was found on the professional formation of university students.

The experts (mainly philosophers and educational science professors) also considered that the systematic reflection on basic principles should be fostered among students, such as Beneficence, Non-Maleficence, Autonomy and Justice (Beauchamp \& Childress, 2012). They expressed the necessity to teach essential ethic values, mainly responsibility; the goods and services that each profession provides to society, the direct and indirect people benefited; their rights and obligations and the dilemmas and ethical conflicts that they could face in their professional practice.

A fact is highlighted, which consists in the consideration that the methodology employed at universities about professional ethics should be practical, participative, and group-oriented. Conversely, the experts thought on the possibility to include additional professional ethics-related subjects, as part of the curriculum in all university programmes. This consideration encompassed the support of the presentation of all topics with examples, to utilize problem-solving methods and professional case study techniques involving ethical dilemmas and analyzing the ethical codes of each profession or of each knowledge area, considering the interdisciplinary actual practice.

Second moment: graduate professors from the National Autonomous University of Mexico (UNAM)

A questionnaire which included an attitude scale about professional ethics was applied at UNAM between 2006 and 2007 to a sample of 719 professors representing the forty graduate programs. As we indicated before, one of the open questions asked was if they considered the need (or not) of a compulsory subject about professional ethics for all students, its contents and strategies. The majority of professors agreed on the necessity to implement that type of subjects. 
Even though it was clearly presented that the survey instrument was about professional ethics, some interviewed professors responded on aspects that were directly linked to general or civic ethics. It was surprising to find the fact, that professors had difficulties to differentiate these three theoretical ambits. From one side, general ethics has a considerable abstraction level and the civic ethics on the other hand, - which is an application field - refers fundamentally to the citizen's sphere. The professional domain is distinct from the other ethics, because it comprises its own theoretical framework, specific values and particular experiences that are associated on a high degree to the work space. This difficulty could be related to the fact that some values are common between professional and civic ethics (both ethics are applied), such as responsibility, honesty and respect. In this research these values were classified as binding values.

The matters that are directly linked to professional ethics that were highlighted by the respondents were: social competencies, legality, norms and principles; non-ethical behaviour and their consequences; identity; cognitive competencies; professional values; the orientation that professional ethics has to be able to take adequate decisions; ethics in the scientific and technological research and teacher's professional ethics.

In order to teach this thematic, some of the ideas are: it is important to generate transversal contents; "to teach with the example" and to recognize the contribution of a good professional practice in relation to society. It is significant that, as for the phase previously described, many of the responses emphasized the use of participatory methodologies, such as case study workshops, critical analysis of the professional practice, a good preparation for professors in this field of knowledge, and ultimately, to create communitarian participation activities.

\section{Third moment: coordinators of graduate programmes at UNAM}

In 2009, coordinators of the forty graduate programmes from UNAM were interviewed about the encouragement of professional ethics on students. The most quoted response was that this encouragement was mainly performed through professors and mentors. We believe that this fact is relevant, because it emphasizes the formative contribution of interaction among professors and students.

It was mentioned as well, that it is associated to the research processes and to the search of higher levels of intellectual capacity. Another area of responses dealed with guidelines, reflection about behaviour and ethical dilemmas, values such as responsibility in general, social responsibility and honesty, trans-disciplinary strategies, collaborative work, integral education and the acknowledgement of effort and hard work.

\section{Fourth moment: professors from universities in Valencia}

Fourteen professors from three universities in Valencia - Spain were interviewed in 2011 on how to teach students the importance and principal contents about professional ethics. Responses pointed to two main postures. One of these established the possibility to implement professional ethics-related subjects on the programme curriculum, with the idea that this determination contributes to the reflection of this knowledge field. Other professors expressed, that this problematic should be addressed in a transversal manner, given the fact that some study plans are over-charged, and that these types of subjects are regarded as "soft skills" or subjects that do not need formal examination processes.

In general, a combination of several strategies was proposed, such as the practical study cases, to work situations that contain ethical dilemmas and conflicts, re-take 
experiences, to invite professionals to explain the ethical problems that they have encountered, and finally, to foster student's awareness. We found certain coincidences among the professors on the strategies and on setting the students in a context in which they will be prepared to take ethical decisions.

\section{Conclusions}

Professional ethics is a relevant current matter. Within the diverse stages and countries (Mexico and Spain), where this research was performed, a great coincidence on the identification of severe problems in the domain of work were encountered. Such issues were linked to conflicts, ethical dilemmas and non-ethical behaviour.

From the phases that were described, it can be highlighted that in the view of the majority of the interviewed professors, professional ethics is a significant and necessary matter for the integral education of students, and that it can be taught through explicit and systematic strategies.

There was an agreement on the strategies that were applied by the university professors, such as study cases, approach of dilemmas and ethical conflicts. It was emphasized the need to count with exemplary situations based on real events, and the collaboration from active professionals that share their experiences with the students. Additionally, they expressed the need to generate problem solving methods; analysis of professional codes and service programmes.

It was stated - more associated to the scientific research processes - the relevance to generate ideas with respect to trans-disciplinarily and group-oriented work, the relationship within the production of knowledge and its possible application, the search of high levels of excellence and autonomy: both of students and professors and the development of skills associated to innovation. The professional identity was linked with the individual identity, considering the development along their personal life.

Also, certain relevance is highlighted about the professor - student link, and the participation of students on research processes. The idea related to the phrase "to teach with the example" was repeatedly expressed among the interviewed.

As it has been stated on the introduction, one of the main objectives related to the professional ethics research project in UNAM is to foster guidelines for teaching students this thematic field. What has been encountered - from the theoretical side and taking as a reference the empirical work that was conducted with professors from both Mexican and Spanish universities - was useful to outline such guidelines and formative strategies, in order to put them into practice.

\section{References}

Aluja, M. \& Birke, A. (2004). General panoramic about the ethical principles in scientific research and higher education. In M. Aluja and A. Birke (Eds.), The role of scientific ethical research and higher education, (pp. 87-143). Mexico, Economical Culture Publisher and Mexican Academy of Science.

Beauchamp, T. \& Childress, J. (2012). Principles of Biomedical Ethics. $7^{\circ}$ edition, New York, Oxford University Press. 
Cobo, J.M. (2003). Pedagogy Curriculum: Fourth Subject (2003-2004). Madrid, Spain, Pontifical University of Comillas in Madrid.

Cobo, J.M. (2004). University and Professional Ethics. Educational Theory Interuniversity Journal, 15, 258-276.

Hirsch, A., "et al." (2003). University and Professional Values Researches. In M. Bertely, (ed.), Education, Social Rights and Equity. Educational Research in México 1992-2002 (pp. 1007-1032). Mexico, Mexican Council of Educational Research, Ministry of Public Education and UNAM.

Hirsch, A. (2004). Utopia and University: Teaching Professional Ethics. Reencounter: Analysis of University Problems, 41, 32-37.

Hirsch, A. (2010). Considerations of the Graduate Professors of UNAM about the Necessity to Offer a Professional Ethics Subject for all the Alumni. In A. Hirsch (Ed.), Ethics, Values and Socio-Cultural Diversity (pp. 5-28). Mexico, National Council of Science and Technology, National Autonomous University of Mexico and Díaz de Santos Editions.

Hirsch, A. \& Pérez-Castro, J. (2013). State of the Art about Professional Values and Professional Ethics. In A. Hirsch \& T. Yurén. (Eds.), The Research in Mexico in the Field of Education and Values 2002 - 2011 (pp. 79-149). Mexico, National Association of Universities and Institutions of Higher Education and Mexican Council of Educational Research.

Hortal, A. (1995). Professional Ethics in the University Context. In Deusto University (Ed.), Ethics Classroom. Ethics in the University. Basic Orientations (pp. 57-71). Spain, Deusto University.

Hortal, A. (2002). General Ethics of Professions. Spain, Desclée de Brouwer.

Lozano, J.F. (2000). Engineering Ethics Pedagogy. Education and Pedagogy Journal, 28, 59-67.

Lozano, J.F. (2003). Ethical Responsibility in Engineering: A Foundation and Proposition of a Pedagogic Methodology. Proceedings of the International Conference on Engineering Education, Valencia, Spain, 21-25. 
HEAd'15

\section{SESSION 4A}

\section{HeALTH}




\title{
The contributions of social interdisciplinary practices in problem-based learning medicine course.
}

\author{
MF da Silva, PAD Costa, MCS Fernandes, ACALL Tavares, MN Santana, MAS \\ Margotto \\ College of Medicine, State University of Santa Cruz, Bahia, Brazil
}

\begin{abstract}
Traditional and basic disciplines of medicine schools are rarely invited to participate of interdisciplinary experiences outside the classroom. Although exists vast literature on problem-based learning medicine courses, there are few studies focusing the socialization of students to learn more complex topics. In this paper, the authors revisited the diagnostic of local health based on Charles Maguerez's arch method that enables the collective construction of knowledge, starting with the observation of family health center attributions. Students were encouraged to collaborate with health agents to investigate the causes of illness in the community. Dengue emerged as a main health problem and it was used as central theme. After the students had theorized about main problems, they developed a strategy in order to propose alternatives for a communitarian intervention plan. Then, day-care and healthcare centers, schools, health agents and students of medicine were involved in a multiple educational approach to increase the awareness of community on dengue prevention. The analysis of data reveals that problem-based learning with social insertion helped the students to develop skills and core competences to a more realistic practice of socialized medicine integrated with health service.
\end{abstract}

Keywords: Medicine, problem based learning, health promotion

\section{Introduction}

The Brazil's Unified Health System (SUS) was developed over the last 25 years, shaped by the history and democracy consolidation based on politics, economics, social and cultural transformations. As a cornerstone, the 1988 Constitution was based on the principles of universality, integrality, equity, community participation, political and administrative decentralization of health services (Paim et al. 2011). Health care services are used to be divided into primary, secondary and tertiary levels which organize health demands according to the level of its complexity. More advanced comprehension on health management was achieved by the notion of primary care offered by local arrangements of different health services (Silva, 2011). Then, medicine schools had to face the demands of medical resources according to the reality of a new and up challenging health care system. Although the bases of the SUS encompass the problem-based learning (PBL) and the case studies, medicine schools have chosen different strategies to attend government policies on education and the reality of health services.

The medicine course in State University of Santa Cruz (UESC) offers a regular module as Interdisciplinary Practices of Education, Health Service and Community (IPEHSC). This module was designed up to enable a first approximation and precocious contact of medicine students with community and current health practices on the basis of SUS. Thus IPEHSC has as main objective to provide an innovation in the learning in multi professional health and interdisciplinary teamwork environment, seeking a new health professional to contribute in the construction of the model of health based in primary care.

The model of PBL perfectly meets National Curriculum Guidelines for Undergraduate Medicine (National Council of Education, 2001) which pointed out the demands of egress/medical professional as a generalist, humanist, critical and thinking, based on 
ethical principles, able to work the process of health and disease at different levels of care. It is expected that the students learn promotion, prevention, recovery and rehabilitation of health from the perspective of more comprehensive care, with a subtle sense of social responsibility and committed to citizenship, as promoter of the human wellness.

\section{A case study: Teotônio Vilela village and dengue fever}

The UESC promotes the education on the basis of social requirements at south Bahia, Brazil, where it has social and political range including Ilhéus surroundings (Midlej, 2007). The city of Ilhéus has 184,236 inhabitants, distributed in 1,760,111 km concentrating $84 \%$ of its population in urban areas, whose average income per capita is US\$ 506,00 monthly. Of the total population, 15,685 individuals live in households with inadequate sanitation (Brazilian Institute of Geography and Statistics, 2013). Earlier known in the 1980's as “Gomeira” (because the first residents were known to sell gums in downtown) the Teotônio Vilela village was mainly occupied by rural housing to many workers who had lost their belongings with the collapse of cocoa monoculture in 80's and 90's (Alger \& Caldas, 1994). The territory has physically borders as the Cachoeira river, which establishes a mangrove region, and by a forest preservation area. Despite the attempts of environmental preservation made by public agents, the process of occupation in these areas was not restrained in decades and still persists. Typical geographic and demographic phenomena occur discretely within this periphery as the overvaluation of land and homes and verticalisation of the buildings creating peripherals (Lonardoni, 2014). After 30 years, there is a severe lack of sanitation, crescent violence indexes, insufficient pavements and garbage. The health system is sustained at local level by four Family Health Centers (FHC), emerged in 2006, with the aim of facilitating the population's access to health services. The objective of this paper is present the contribution of extramural social interdisciplinary practices in PBL medicine course focusing the social demands of health care service dealing with inequity and different causes of illness.

\section{Material and Methods}

Subjects and ethic implications: The present paper is based on the public databases analysis and IPEHSC on professor's observations of the joint work of medicine students enrolled in and the CHA during one regular academic year. It has no ethical implications, but complies with the Helsinki Declaration on ethical issues (World Medical Association, 2014).

Observing, understanding and collection of data from reality: The first step of the Maguerez's arch method (Prado et al. 2012) is the viewing of a given situation from many angles, which allows the student to extract and identify the problems that exist in the community. It presupposes a conception of cumulative knowledge from the reality in an effort to build an effective understanding, seeking, intervening and modification; students should observe the territory regarding environmental, housing, sanitation, health assistance and other aspects of local reality, such as schools, day-care and social centers, churches, party offices and others social equipments. The health and social National Databases were consulted in this respect aimed to build a local health diagnosis. 
Problems raised and their explanations: The second stage of the method refers to prioritizing the problems encountered, along with the CHA and inhabitants in collective workshop. At that time students should be applied to the Planning and Programming on Local Health - PPLH. By monitoring the work of CHA and contact with the population, national databases on dengue helped to identify as major health problem recurring in the community and also a feasible theme for an intervention plan. Therefore, taking advantage of the imminence of Children's Day Celebration, the medicine students developed recreational and educational project having dengue themed involving the child, parents, and teachers' audience.

Theorizing to solution, intervention planning and monitoring: The third step involves theorizing of the topics. The group was responsible for the literature review and autonomy of study and the development of educational resources. The participation of the CHA and the inhabitants was considered critical and must be performed, also based on the PPLH. In Noah's Ark school, it was showed a video about the life cycle of the Aedes aegypti mosquito that transmits dengue and the game "Right or Wrong on the Prevention of the Dengue Fever" was performed. In addition, sketches were designed to measure, before and after the activity, in order to analyze the level of previous knowledge of children, as well as the learning results of the proposed action. Finally, children were invited to participate in the contest "CHA junior" which task was to eliminate reservoirs of mosquitoes from their homes and more than two neighbors, under supervision of parents and at least one member of Center of Endemic Control. Two weeks later, aided by Endemics Coordinator of the Department of Health Education of City of Ilhéus, the medicine students visited 30 homes of CHA junior contender - to ensure the fulfillment of objectives proposed. To the completion of the project, the community was invited to hold a march against dengue fever involving students of Noah's Ark as well as their parents and community's representatives. Awards to CHA junior were given to participants who had known how to eliminate reservoirs of the mosquitoes.

Statistical analysis: The data analysis was based on a qualitative study consisting of interpretation of 88 reports and 10 individual interviews. It was applied Chi-square test considering as the expected responses the equitable apportionment among all the alternatives compared to the amount of answers observed in reports. Student's t test was applied to compare mean and standard deviation between two groups. The significant level was $5 \%$. Linear correlations among quantitative data were performed observing the goodness of fit $\left(\mathrm{r}^{2}\right)$ and a confidential interval of $95 \%$ and its significance. Data were analyzed by using GraphPad Prism 4.

\section{Results and Discussion}

\section{Diagnostic of local health:}

The first information on 2012 demographic and health indicators were obtained from public databases (Ministry of Health, 2014). The Figure 1a reveals that the city of Ilhéus had worse health indicators when compared to cities of similar size in other Brazilian regions (Nossa Ilhéus Institute Report, 2013). Most bad indicators refer to circulatory and respiratory diseases and also maternal, neonatal and child morbidity and mortality. Certain infectious and parasitic diseases (not shown) are among the major causes of mortality whereas neglected diseases were seen to be very prevalent among children when compared to other similar surveys (Barreto et al. 2007). In addition, by observing 
the CHA surveying the population, students could include other complaints $(n=88)$ regarding diseases among inhabitants of Teotonio Vilela village. Hypertension has been identified as a major problem (27\%), followed by dengue (15\%) diabetes (8\%) and diarrhea (6\%). The rest of inhabitants referred multiple other causes of diseases (14\%) and healthcare services inaccessibility (30\%). Dengue cases were measured by accessing public databases (Ministry of Health, 2014) and it was possible to confirm the high incidence of disease when compared to other cities with similar territory, demography and urban characteristics of Ilhéus (Figure 1b). As it can been seen, the other cities could have adopted successful strategies to prevent dengue spread and better management of the epidemic when compared to Ilhéus.

\section{Dengue prevention: From biology to action:}

The PBL reached the objective to pose medicine students to develop active strategies of learning such as systematic studies, organization, collaboration in workgroup, guidance and leadership, discussion and decisions having dengue as proposed theme. Hence, it was possible to note the development of skills and core competencies to communicate better with child, parents, teachers and community's representatives regarding the strategies to combat mosquitoes, early recognition of symptoms, diagnosis, care and guidance to seek for medical assistance in neighborhood. Through various delivery modes (Figure 2) medicine students were able to elaborate adequate lectures to child less than 7 years old (Figure 2a); also mobilize community to hold a thematic march (Figure 2b) and to create a successful intervention plan to reduce Aedes aegypti reservoirs in the houses. Children having the greatest performance in this goal were awarded with a medal and a certificate of CHA jr (Figure 2c and 2d). The effort of medicine students to achieve the objective of the intervention plan was partially successful, since the number of houses visited by CHA jr were below $(n=30)$ of the minimal estimated (IC 95\%: 63 - 117). It was possible to verify that the CHA jr initiatives were frustrated mostly by security risks involved or neighbour's disapproval. Nevertheless, there was a positive increment in the number of houses without Aedes aegypti reservoirs (Figure 2e). The experience of socialized PBL on health promotion yielded better evaluation of the medicine students, since their grades were significant higher during the social experience of PBL (Figure 2f).

\section{Contribution of social interdisciplinary practices in $P B L$}

It was possible to note an achievement in the PBL used in a medicine course to study social determination of health and disease in a community living in inequity. The results presented herein showed that the immersion of the students in this context during PBL caused a subtle questioning and a significant learning experience. Students learn beyond the health services and their interrelationships within community, since they learned more about people and the multiple aspects involved with their health, disease and care.

Traditionally, medicine courses have been providing new professionals by subsequently progress of the novices along the curriculum, giving the concepts and knowledge needed to emerge as graduates (Madsen \& Bell, 2012). However, for complex fields of study such as health promotion, there is more theoretical development rather than one that is strictly based on the social praxis (Brosnan, 2013). This raises questions for those teaching such subjects regarding how to connect learning with the social demands on health promotion. 
In Brazil, the teaching of medicine further includes a challenging and contradictory debate since the ideal health workforce - should be composed of professionals skilled, evidence-oriented and well trained and committed to SUS principles - not corresponds to the profile of the professionals who operate the system; this disparity is partly due to general influence of private medical corporations' ideology that public service is considered as just a stable poorly paid job rather than more profitable jobs in private sector or in healthcare companies, consistently more rewarding and strivingly (Almeida-Filho, 2011). Also, the infrastructure, resources and supplies of SUS is widely noted deficient (Siqueira, 2013) historically in northeast of Brazil (Vitoria et al. 2011; Leite, 2011) what contributes to inequity in the access to the services.

In 2006, a university reform took place to reorient the curriculum of medicine and other professions (Ministry of Health, 2013). Further, a plan of massive federal investment intended to double the size of the federation universities (Ministry of Education, 2013) allowing the implementation of undergraduate courses in an interdisciplinary system (Santos \& Almeida-Filho, 2013). As a result, tensions have arisen among Brazilian universities, since there was resistance led by conservatism against the rearrangement of the new ideological basis of teaching. However, the SUS has provoked a replacement of the standard reductionist, disease-oriented, focused on hospital-oriented specialization current vocational education, by another model that is more humanistic, health-oriented, with focus on primary health care and social compromised (AlmeidaFilho, 2011).

The academic education for SUS is causing profound changes in the training for health teamwork; new pedagogical tendencies indicate the need for educational of a critical reflective professional, able to transform their social reality (Madsen \& Bell, 2012). If medical education takes up the challenge of engaging more fully with social science theory, the question of how medicine students will learn about it must be resolved. Although some medical teachers have social science backgrounds, the most come from basic science or clinical disciplines. This fact poses a challenge to fulfill the requirements of a more socialized medicine practice. The incorporation of social learning opportunities, mainly in community, on theoretical perspectives at PBL, is also a positive development for both students and teachers (Bronsnan, 2013). 
Figures

a)

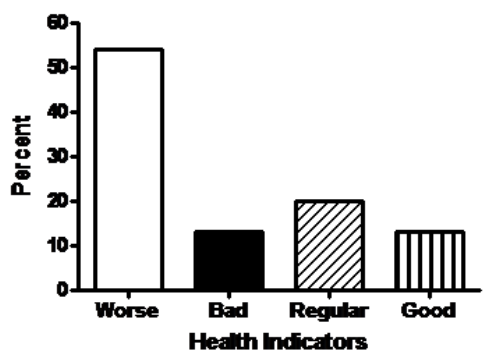

b)

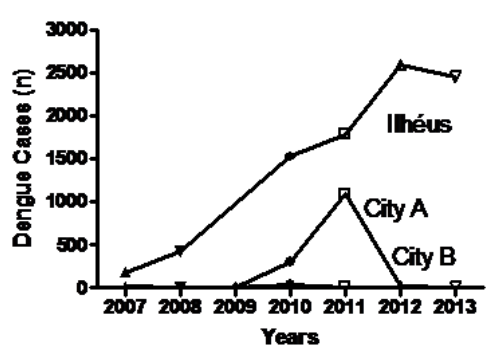

Figure 1. a) Classification of health indicators of Ilhéus, Bahia, Brazil when compared to similar cities. b) Dengue emerged as main disease when compared to other cities with similar demography and territory.

a)

b)

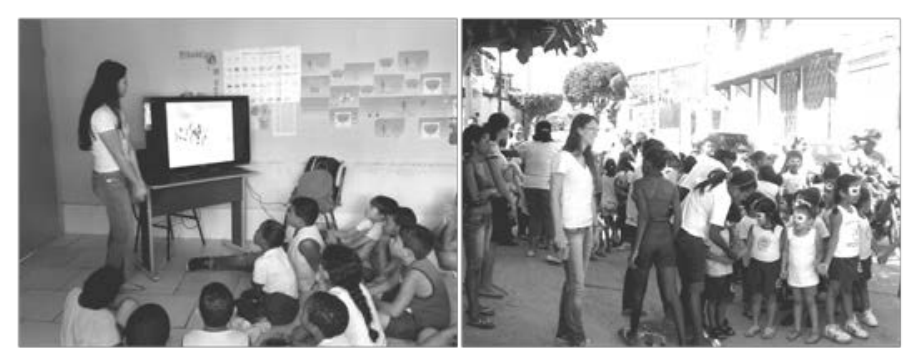

c)

d)

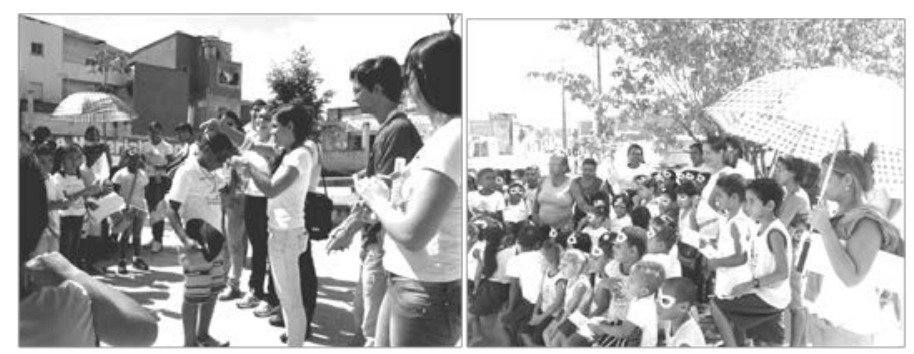

e)

f)

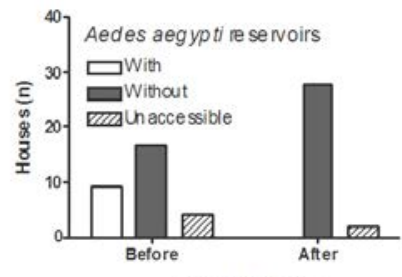

CHA jr visitation

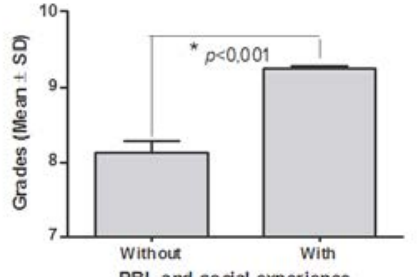

PBL and social experience

Figure 2: Intervention planning developed by medicine student after PBL theme on dengue prevention.

a) Lecture and video on Aedes aegypti cycle and prevention of dengue to Noah's Arch school. b)

Dengue Prevention thematic parade. c) Awards of CHA jr contest. d) Social mobilization of students, parents and community's representatives. e) Results of CHA jr contest in the increase of houses without domestic Aedes aegypti's reservoirs. f) Increase in students' grades was related to PBL with social experience. * $\mathrm{p}<0,001$ Student's t test. 


\section{Conclusions}

Hence, UESC gives an important contribution by adding the social experience to PBL for first-year medicine students. IPEHSC turns to stimulate the dialog between university and healthcare service in order to understand better the demands of public health in south Bahia, Brazil. Thus, through Charles Maguerez Arch method contributed on social interdisciplinary practices in PBL medicine course by following the steps of observing the reality, key-points, theorizing, hypothesis construction and application. The mobility to extramural environment helped the medicine student to develop skills and core competences linked to a more realistic practice of socialized medicine.

\section{References}

Alger K. \& Caldas M. (1994). The declining cocoa economy and the Atlantic forest of southern Bahia, Brazil: conservation attitudes of cocoa planters. Environmentalist, 14, 107-119.

Almeida Filho, N. (2011). Higher education and health care in Brazil. The Lancet, 377(9781),1898- 1900.

Barreto L.M., Genser B., Strina A., Assis A.M.O., Rego R.F., Teles C.A., Prado M.S., Matos S.M.A., Santos D.N., Santos L.A., Cairncross S., Teixeira M.G. (2007). Effect of city-wide sanitation programme on reduction in rate of childhood diarrhoea in northeast Brazil: assessment by two cohort studies. The Lancet, 370 (9599), 1622-1628.

Brazilian Institute of Geography and Statistics (2013). Brasilia, FD: Brazilian Government. Retrieved from: http://www.ibge.gov.br/cidadesat/topwindow.htm1

Brosnan C. (2013). How and why social science theory can contribute to medical education research. Medical Education, 47, 3-17.

Leite, R.M.B. (2011). Fatores de risco para mortalidade materna em área urbana do Nordeste do Brasil. Cad. Saúde Pública, 27(10), 1977-1985.

Lonardoni, F.M. (2012). Informality of house production: rental markets in favelas and challenges for land regularization in Brazil. In: Technologies and innovations for development. J.C. Bolay et al (eds). Springer-Verlag Paris. France 55p.

Madsen W., \& Bell T. (2012). Using health promotion competencies for curriculum development in higher education. Global Health Promotion, 19, 43-49.

Midlej M.M.B.C. (2007). Universidade e região: territorialidade da Universidade Estadual de Santa Cruz - UESC. Rev HISTEDBR On-line, 28, 323 -324.

Ministry of Education. (2013) Brasilia, FD: Brazilian Government. Retrieved from http://portal.mec.gov.br/sesu/arquivos/pdf/diretrizesreuni.pdf

Ministry of Health. (2013). Brasilia, FD: Brazilian Government. Retrieved from: http://dtr2001.saude.gov.br/sas/PORTARIAS/Port2006/GM/GM-648.html

Ministry of Health. (2014). Department of Informatics. Brasilia, FD: Brazilian Government. Retrieved from:

http://tabnet.datasus.gov.br/cgi/deftohtm.exe?sih/cnv/nrba.def

National Council of Education (2001). Resolution 4. Diretrizes Curriculares Nacionais do Curso de Graduação em Medicina. Diário Oficial da União, 11 (1), 38-43. 
Nossa Ilhéus Institute Report. (2013). Indicators for local actions on health. Kairós social development 2012. From:

http://nossailheus.org.br/Fotos/18_ini_indicadores_saude.pdf

Paim J., Travassos C., Almeida C., Bahia L., Macinko J. (2011). The Brazilian health system: history, advances, and challenges. The Lancet, 377(9799), 1778-179.

Prado M.L., Velho M.B., Espíndola D.S., Sobrinho S.H., Backes V.M.S. (2012). Charles Maguerez arch: reflecting methodology strategies on active training for health professionals. Escola Anna Nery, 16(1), 172-177.

Santos B.S., \& Almeida-Filho N (2008). The university of the 21st century: towards a new university. Coimbra: Almedina Press. Retrieve from:

http://www.boaventuradesousasantos.pt/media/A\%20Universidade\%20no\%20Se culo\%20XXI.pdf

Silva S.F. (2011). The organization of regional and integrated healthcare delivery systems: challenges facing Brazil's Unified Health System. Ciência \& Saúde Coletiva, 16(6), 2753-2762.

Siqueira J.E. (2013). SUS (Unified Health System) after 25 years: is there anything to celebrate? O Mundo da Saúde São Paulo, 37(1),56-6.

Victora C.G., Vaughan J.P., Barros F.C., Silva A.C., Elaine T. (2011). Explaining trends in inequities: evidence from Brazilian child health studies. The Lancet, 2000 (356),1093-1098.

World Medical Association. (2014). Declaration of Helsinki - Ethical Principles for Medical Research Involving Human Subjects From:

http://www.wma.net/en/30publications/10policies/b3/ 


\title{
The preparedness of medical students from the Middle East for the modern curriculum: a cross-sectional study
}

\author{
F Rashid-Doubell, TP Doubell, R O’Sullivan, K Elmusharaf
}

RCSI-Bahrain, PO Box 15503, Adliya, Bahrain

\begin{abstract}
:
Aim

This study aims to examine whether there were any differences in self-directed learning readiness (SDLR) between students who entered medicine with a local Bahraini schools certificate and those students who entered with an international schools certificate.

Results

We analysed how self-management, desire for learning, self-control and total SDLR scores varied in relation to the student's previous exit award: 'A' levels (or equivalent) or Bahrain Secondary School (BSS) certificate. BSS certificate students had a significantly lower mean standardised desire for learning score (63.5) compared to those 'A' levels or equivalent (73.6; $\mathrm{p}=0.003$ ). BSS certificate students also had a significantly lower mean total self-directed learning readiness score (192.3) compared to those with the ' $\mathrm{A}$ ' levels and equivalent (214.5; $\mathrm{p}=0.015)$. When we controlled for all the other factors, secondary school award certificate was the only independent predictor of self-control (standardised beta $0.4 ; \mathrm{p}=0.02$ ) and SDLR (standardised beta 0.36; $\mathrm{p}=0.043$ ).

Conclusion

Self-directed learning is a key skill in the modern curriculum. Students who exit with a local Middle Eastern secondary school certificate are finding it difficult to prepare themselves for independent learning in medical school. This poses a challenge for institutions bringing a more active-learning type of curriculum to the Middle East.
\end{abstract}

Keywords: Self-directed learning; self-control; desire for learning; self-management; individualism; collectivism

\section{Introduction}

Promoting life-long learning amongst health professionals has been the main aim of a radical shake-up of medical education (Jackson \& Calman, 2006). Students have moved from the memorisation of facts to problem-solving and self-directed study, two skills found to be necessary for the practice of medicine (Barrows, 1983). Modern medical curricula have transformed from being delivered using a passive, didactic teaching approach to a more student-centred, active, self-directed learning one (Shin, Haynes et al., 1993). The importance of self-directed learning cannot be overstated; some authors have gone so far as suggesting that neglecting the development of a selfdirected learning is considered a serious disadvantage for the student learner (Kek \& Huijser, 2009). Part of this life-long learning process involves the need for students to adopt self-directed learning readiness often described as the process of deciding what to learn, and to what depth and breadth (Candy, 1991). Others have defined the concept of learning readiness as the degree to which the individual possesses the attitudes, abilities and traits necessary for self-directed learning (Wiley, 1983). When it comes to self-directed learning readiness, one thing that is widely agreed upon is the need for more research to explore how culture impacts on self-directed learning readiness in students outside of North America and Europe in this world of globalised medical education (Gukas, 2007). 
The globalisation of medical education has been rapid and intensive with very few medical schools escaping the effect (Jippes \& Majoor, 2011). But only a handful of studies have gone on to explore the cultural impact on the preparedness of students for self-directed learning from a cross-cultural perspective, Ahmad and Majid's appraisal was one such study, which showed that culture can strongly influence the development of self-directed learning readiness (Ahmad \& Majid, 2010). A second study reporting how culture challenges self-directed learning concluded that uncertainty, tradition and hierarchy impacted on self-directed learning, thus impeding the uptake of the new learning approach (Frambach, Driessen, et al., 2012).

Cultural identity can be broadly categorised as either collectivist or individualist. The main difference between collectivist and individualist cultures is the relative importance each places on the goals of the individual compared to the goals of the group (Braman, 1998). Children from collectivist cultures such as those living in the Middle East are situated in an environment which resolves around obedience, reliability, duty, cleanliness and order (Triandis, 2004). Taking charge of their own learning poses a major challenge to the majority of students entering tertiary education in the Arabian Gulf region (Al-Saadi, 2011a). Grow, 1991 observes that educational practices in public school and universities, does more to perpetuate dependency than to create self-direction (Grow, 1991). This practice is further emphasised by a recent report describing the "spoon-feeding learning model" practiced by students and teachers in Oman (Al-Saadi, 2011b). Al-Saadi argues that learning becomes more effective when learners are in control of their learning and aware of the learning process and of themselves as learners.

The objective of the study was to examine whether there were any differences in selfdirected readiness amongst students who entered medicine with a local Bahraini schools certificate and those students who entered with an international schools certificate. This study forms part of a larger ongoing study which introduced an intervention to enhance self-directed learning readiness (SDLR) in students regardless of their educational backgrounds.

\section{Methods}

\section{Setting}

Our study was conducted on the Bahrain campus of the Royal College of Surgeons in Ireland (RCSI-Bahrain) in Bahrain; an international university which delivers an Irish five-year undergraduate medical curriculum to students from all over the world with local Bahraini students making $40 \%$ of the overall cohort. The students varied in their ethnic background and their approaches to learning, amongst other things.

In the first year the cohort was composed of three distinct groups of students. The first group consisted of those who have directly entered the programme by either having appropriate 'A' level qualifications or equivalent (International Baccalaureate or High School Diploma). The second group was composed of students entering through a Foundation Year with a Bahrain Secondary School (BSS) certificate. The third group consisted of those students who already had a university degree.

\section{Study design}

In a cross-sectional study, we explored self-directed readiness amongst our first year medical students before they had undertaken any proper classes at the institution. Ethical permission was sought and obtained from the RCSI-Bahrain Research Ethics 
Committee. In the first week, of the first semester, students were given a brief overview of the study and invited to participate and if they agreed, written consent was obtained. Paper copies of the self-evaluation tool were then distributed to student who had consented, and they were asked to complete the questionnaire.

\section{Participants}

All 150 students' first year medical students in semester one were invited to participate in the study. From the first year cohort 65 students responded and completed the questionnaire (response rate 43\%). The inclusion criterion was set to include those students with a BSSC or 'A' levels or equivalent who directly entered the programme or who came through the Foundation Year (50 students were included). Students who were excluded from the study were those entering the programme that possessed a Higher Education exit award or repeating students (15 students were excluded).

\section{Tool}

The learning readiness of undergraduate medical students was determined using a scale originally devised by Fisher and his colleagues (Fisher, King, \& Tague, 2001) and later used to assess learning readiness amongst physiology students (Abraham et al., 2011). The SDLR questionnaire is a self-evaluation tool determining the SDLR of an individual student. Our questionnaire was a modification of one previously used by Fisher with nursing students (Fisher et al., 2001). The questionnaire was divided into three subcategories namely: self-management (9 items); desire for learning (13 items); self-control (11 items), giving a total of 33 items. Students were requested to respond to each item on a Likert scale (where 5=always, 4=often, 3=sometimes, 2=seldom, $1=$ never). The scale gave us the opportunity to calculate their subcategory scores as well as their total self-directed learning readiness. All items were scored in a forward manner and no reverse manner questions were posed.

The validity of the modified questionnaire was determined by content validity (exploring pertinent literature) and face validity (experts' opinion on the modified questionnaire). The reliability of the internal consistency was determined by calculating Cronbach's alpha for self-management (0.7), desire for learning (0.8) and self-control (0.76) as well as the overall value for self-directed learning readiness (0.9).

\section{Data management}

We calculated the total for each subcategory (self-management, desire for learning and self-control) by adding the scores of each item in that subcategory. The total scores were then standardized out of 100 by dividing the total score by the maximum score possible in that subcategory and multiplying by one hundred. For example, in the self-management scale there are 9 items with each item having a maximum score of 5 and so the student score was divided by 45 and multiplied by one 100 to provide a standardized subcategory score out of a 100 . The three subcategory scores were then added together to produce the standardized self-directed learning readiness total out of three hundred.

\section{Statistical analysis}

The data obtained from the questionnaire were entered, cleaned and prepared for analysis using IBM SPSS Statistics for Windows (IBM Corp., Armonk, NY, USA); 
data were summarised and presented using appropriate statistics: mean (standard deviation) and frequency (percentage) for normal-like and categorical variables respectively. Differences of SDLR and its three subcategories (self-management, desire for learning and self-control) in relation to students' characteristics were compared using independent student's t-test and 95\% confidence intervals (95\% CI) for the means. All statistical tests were two-sided. A Type I error rate of $p \leq 0.05$ was used for statistical significance. Furthermore, to address our primary research question, a multivariate regression analysis was performed to see the net effects of each of the students' characteristics (independent variables) in explaining variation in SDLR and its three subcategories.

\section{Results and Discussion}

\section{Participants' characteristics}

The majority of the participants were female (66\%). The predominant age group of students was less than 20 years (56\%). The students that left school with a Bahrain Secondary School Certificate comprised $28 \%$ of the respondents. Those entering from the RCSI-Bahrain Foundation Year course made up the largest proportion of students entering the Junior Cycle (58\%). The majority of the students were residents of the Middle East (86\%) and the remainders were residents in Asia. Table 1 summarises the general characteristics of the participants.

\section{Descriptive statistics}

Analysis of data revealed larger differences between the maximum and minimum values for each subcategory, self-management (35.5, 88.9), desire for learning (40, 90.77), self-control $(43.6,90.9)$ and the overall SDLR $(126.9,260.8)$. However, the mean scores (SD) for self-management was 68.6 (11.4), for desire for learning was 70.8 (11.2), for self-control was 68.9 (10.7), and for self-directed learning readiness was 208.3 (29.4). The descriptive statistics of the subcategories and the total SDLR are shown in Table 2.

\section{Determinants of SDLR}

The univariate results are shown in Table 3, indicating the mean difference between the two groups with $95 \%$ confidence interval as well as the p value.

When the total SDLR scores and its three subcategories were compared among different age groups there was little difference between those students who were less than 20-years-old and those who were older. Country of residence also had no impact on any of the three subcategories and neither did type of entry into the Junior Cycle.

Where there was a statistically significant difference it was between male and females students desire for learning, with male students having a higher desire for learning score (75.6) than females (68.3) (95\% CI of the Difference: 0.8 to 13.7, p value: 0.029).

The largest difference was found between students who had entered with a local Bahrain Secondary School Certificate and those students who were admitted with 'A' levels or an equivalent such as an IB or High School Diploma.

Students with IB and 'A' levels tend to have more desire for learning (73.6) compare to students with BSSC (63.5) (95\% CI of the Difference -16.6 to -3.6, P value 0.003). 
They also tend to have more self-control (71.2) compare to students with BSSC (63.1) (95\% CI of the Difference -15.8 to -0.4 , p value 0.04 )

The differences between the total SDLR scores amongst these two groups were also significantly higher among Students with IB and 'A' levels (214.5) than students with BSSC (192.3) (95\% CI of the Difference -39.8 to -4.5 , p value $=0.015)$

\section{Predicting factors which affect SDLR}

Table 4 shows the multivariate regression analysis which allowed us to see the net effects of each of the students' characteristics (independent variables) in explaining variation in SDLR and its three subcategories. When we controlled for all other factors, secondary school award certificate was the only independent predictor of the self-control (Standardized beta 0.4, $\mathrm{p}=0.02$ ) and SDLR (Standardized beta 0.36, $\mathrm{p}$ value $=0.043)$.

This study set out to examine whether there were any differences in SDLR amongst students who entered medicine from the local Bahraini schools and those students who exited schools with ' $A$ ' levels or equivalent awards. We found that there were indeed statistically significant differences between these students especially in the desire for learning and self-control categories. Our results plainly indicate that students who have exited from a local school with a secondary school certificate are not prepared in any of the any subdomains of self-learning readiness, selfmanagement; desire for learning; self-control, with the last two being statistically significant.

When exploring the literature for reasons to explain this difference between the two groups, one obvious factor jumps out, culture. Culture has been shown to play an important role in adult learning (Brookfield, 1980). Our local students are nurtured in a collectivist culture where the emphasis is on social harmony. This cultural influence does not encourage the development of traits such as motivation and readiness to accept responsibility essential for the successful self-directed learner (Garrison, 1992). A study done on Malaysian students, another good example of a collectivist culture, identified that Malaysian students struggle with the development of SDLR (Ahmad \& Majid, 2010). A conflict often arises in the minds of such students in adhering to their cultural values while attempting to promote their learning by developing their individualism, which is described much more explicitly by Knowles as 'a process in which the individual takes the initiative, with or without the help of others' (Knowles, 1975).

A possible second explanation why students from the local schools are struggling with SDLR could be the passive learning process adopted in most regional secondary schools. This type of passive learning was described in a study conducted at a Nepalese medical school where rote learning and reproduction of factual information predominated in their local schools (Shankar et al., 2011). In the Middle East, it was reported that spoon-feeding was prevalent in local schools in Oman, with pupils having no say on what to study and how to study it, and skills such as metacognition and reflection being largely excluded from the curriculum (Al-Saadi, 2011a). In an unpublished article Al-Saadi also concluded that taking charge of their own learning posed a major challenge for the majority of students entering tertiary education in the Arabian Gulf region [15]. This is reflected in our own findings where we show a statistically significant difference between the SDLR subgroup self-control local 
school students scoring who scored 63.1 out 100 and those taught using the British school system with the 'A' levels who scored 71.2 out of 100 , p value 0.04 .

The limitations of the study were that the data were collected on a self-reporting basis which could be subject to recall bias. Additionally, the small unequal sample size among the two groups could have contributed to some of the observed differences.

Integrating unprepared students into modern Western medical curricula remains an interesting challenge for those of us engaged in teaching. Whilst students struggle to adopt individualistic traits in order cope with modern learning, teachers working in international medical schools have to devise strategies to expedite the transition of local students into their Western curricula, with the emphasis squarely placed on SDLR as a learning strategy for formal undergraduate studies and beyond into for life-long learning.

\section{Figures and Tables}

Table 1: General characteristics of the participants

\begin{tabular}{|c|c|c|c|}
\hline Main group & Sub-group & Frequency & Percent \\
\hline \multirow[t]{2}{*}{ Age groups } & $<20$ years & 28 & 56 \\
\hline & 20 years or more & 22 & 44 \\
\hline \multirow[t]{2}{*}{ Gender } & Male & 17 & 34 \\
\hline & Female & 33 & 66 \\
\hline \multirow[t]{2}{*}{ Secondary school award } & Bahrain Secondary School Certificate & 14 & 28 \\
\hline & IB and A levels & 36 & 72 \\
\hline \multirow[t]{2}{*}{ Country of residence of student } & Middle Eastern & 43 & 86 \\
\hline & Asian & 7 & 14 \\
\hline \multirow[t]{2}{*}{ Type of entry in to Junior Cycle } & Foundation Year & 29 & 58 \\
\hline & Direct Entry & 21 & 42 \\
\hline
\end{tabular}

Table 2: Descriptive statistics of the three subcategories and combined SDLR score of the participants

\begin{tabular}{|l|l|l|l|l|}
\hline Statistics & Self-management & Desire for learning & Self-control & SDLR \\
\hline Mean & 68.6 & 70.8 & 68.9 & 208.3 \\
\hline Std. Error of Mean & 1.6 & 1.6 & 1.5 & 4.2 \\
\hline Median & 71.1 & 72.3 & 70 & 207.7 \\
\hline Std. Deviation & 11.4 & 11.2 & 10.7 & 29.4 \\
\hline Minimum & 35.6 & 40 & 43.6 & 126.9 \\
\hline Maximum & 88.9 & 90.77 & 90.9 & 260.8 \\
\hline
\end{tabular}


Table 3: Mean differences between the two groups of participants

\begin{tabular}{|c|c|c|c|c|c|}
\hline & & $\mathrm{SM}$ & DFL & SC & SDL \\
\hline \multirow[t]{5}{*}{ Age groups } & $<20$ years & 68.4 & 73.1 & 68.3 & 209.8 \\
\hline & 20 years or more & 68.8 & 67.9 & 69.8 & 206.4 \\
\hline & Mean Difference & -0.4 & 5.2 & -1.4 & 3.4 \\
\hline & $\begin{array}{l}95 \% \text { CI of the } \\
\text { Difference }\end{array}$ & -7 to 6.2 & $\begin{aligned} &-1.1 \text { to } \\
& 11.5 \\
&\end{aligned}$ & $\begin{array}{ll}-7.6 \quad \text { to } \\
4.8 & \\
\end{array}$ & $\begin{array}{ll}-13.6 & \text { to } \\
20.3 & \\
\end{array}$ \\
\hline & $\mathrm{P}$ value & 0.91 & 0.1 & 0.64 & 0.69 \\
\hline
\end{tabular}

\begin{tabular}{|l|l|l|l|l|l|}
\hline \multirow{5}{*}{ Gender } & Male & 69.5 & 75.6 & 70.5 & 215.6 \\
\cline { 2 - 7 } & Female & 68.1 & 68.3 & 68.2 & 204.6 \\
\hline & Mean Difference & 1.5 & 7.2 & 2.3 & 11.0 \\
\hline & $\begin{array}{l}95 \% \text { CI of the } \\
\text { Difference }\end{array}$ & $\begin{array}{l}-5.5 \\
8.4\end{array}$ & 0.8 to 13.7 & $\begin{array}{l}-4.2 \\
8.8\end{array}$ & $\begin{array}{c}-6.5 \\
28.5\end{array}$ \\
\hline & P value & 0.673 & 0.029 & 0.474 & 0.213 \\
\hline
\end{tabular}

\begin{tabular}{|l|l|l|l|l|l|}
\hline \multirow{5}{*}{ Secondary school award } & BSSC & 65.7 & 63.5 & 63.1 & 192.3 \\
\cline { 2 - 6 } & IB and A levels & 69.7 & 73.6 & 71.2 & 214.5 \\
\hline & Mean Difference & -4.0 & -10.1 & -8.1 & -22.2 \\
\hline & $\begin{array}{l}95 \% \text { CI of the } \\
\text { Difference }\end{array}$ & $\begin{array}{l}3.2 \\
\text { If to }\end{array}$ & $\begin{array}{l}-16.6 \text { to }- \\
3.6\end{array}$ & $\begin{array}{l}-15.8 \text { to }- \\
0.4\end{array}$ & $\begin{array}{l}-39.8 \\
4.5\end{array}$ \\
\hline & P value & 0.27 & 0.003 & 0.04 & 0.015 \\
\hline
\end{tabular}

\begin{tabular}{|c|c|c|c|c|c|}
\hline \multirow{5}{*}{$\begin{array}{l}\text { Country of residence of } \\
\text { student }\end{array}$} & Middle Eastern & 68.6 & 71.0 & 69.0 & 208.7 \\
\hline & Asian & 68.3 & 69.5 & 68.6 & 206.3 \\
\hline & Mean Difference & 0.4 & 1.6 & 0.4 & 2.4 \\
\hline & $\begin{array}{l}95 \% \text { CI of the } \\
\text { Difference }\end{array}$ & $\begin{array}{ll}-9.1 & \text { to } \\
9.8 & \end{array}$ & $\begin{array}{ll}-7.7 & \text { to } \\
10.8 & \\
\end{array}$ & $\begin{array}{ll}-8.5 & \text { to } \\
9.3 & \\
\end{array}$ & $\begin{array}{cc}-22 & \text { to } \\
26.7 & \\
\end{array}$ \\
\hline & $\mathrm{P}$ value & 0.94 & 0.73 & 0.92 & 0.85 \\
\hline
\end{tabular}

\begin{tabular}{|l|l|l|l|l|l|}
\hline \multirow{3}{*}{$\begin{array}{l}\text { Type of entry in to Junior } \\
\text { Cycle }\end{array}$} & Foundation Year & 69.5 & 68.4 & 67.8 & 205.7 \\
\cline { 2 - 6 } & Direct Entry & 67.3 & 74.1 & 70.6 & 212.0 \\
\cline { 2 - 6 } & $\begin{array}{l}\text { Mean Difference } \\
\text { M CI of the }\end{array}$ & $\begin{array}{l}-4.4 \text { to } \\
8.8\end{array}$ & -12 to 0.5 & -9 to 3.4 & -23.3 \\
\cline { 2 - 6 } & $\begin{array}{l}\text { 95\% to } \\
\text { Difference }\end{array}$ & 0.51 & 0.071 & 0.37 & 0.46 \\
\cline { 2 - 6 } & P value & & -2.8 & -6.3 \\
\hline
\end{tabular}


Table 4: Results of Multivariate Regression Analysis

\begin{tabular}{|c|c|c|c|c|c|c|c|c|}
\hline & \multicolumn{2}{|l|}{ SM } & \multicolumn{2}{|l|}{ DFL } & \multicolumn{2}{|l|}{$\mathrm{SC}$} & \multicolumn{2}{|l|}{ SDL } \\
\hline & Beta & $\begin{array}{l}\mathrm{P} \\
\text { value }\end{array}$ & Beta & $\begin{array}{l}\mathrm{P} \\
\text { value }\end{array}$ & Beta & $\begin{array}{l}\mathrm{P} \\
\text { value }\end{array}$ & Beta & $\begin{array}{l}\mathrm{P} \\
\text { value }\end{array}$ \\
\hline Age groups & -0.06 & 0.77 & -0.06 & 0.737 & 0.33 & 0.087 & 0.07 & 0.707 \\
\hline Gender & 0.00 & 0.987 & -0.15 & 0.331 & 0.05 & 0.732 & -0.04 & 0.820 \\
\hline Secondary school award & 0.25 & 0.171 & 0.30 & 0.07 & 0.40 & 0.02 & 0.36 & 0.043 \\
\hline Country of residence & -0.02 & 0.873 & -0.02 & 0.874 & -0.07 & 0.629 & -0.04 & 0.769 \\
\hline $\begin{array}{l}\text { Type of entry in to Junior } \\
\text { Cycle }\end{array}$ & -0.25 & 0.24 & 0.04 & 0.828 & 0.18 & 0.353 & -0.01 & 0.946 \\
\hline Constant & $\begin{array}{l}69.4 \\
5\end{array}$ & 0 & 65.89 & 0.000 & 39.43 & 0.017 & 174.77 & 0.000 \\
\hline R Square & $\begin{array}{l}0.06 \\
2\end{array}$ & & 0.198 & & 0.178 & & 0.125 & \\
\hline
\end{tabular}

\section{Conclusions}

Self-directed learning is a key skill in the modern medical curriculum. Students who exit with a local secondary school certificate seem unprepared for this type of new learning strategy. This creates an educational challenge for institutions bringing a more active-learning modern curriculum to the Middle East. Consideration must therefore be given to the development of appropriate mechanisms to assist such students in adopting this style of learning.

Some recommendations include:

1. To realign the secondary school curriculum in order to adjust for the mismatch between secondary and tertiary education

2. Make an adaptation to introduce skills in the preparatory year at the tertiary degree level to enhance the transition

3. An opportunity is created for private sector to produce short courses to help bridge the gap for autonomous students

Any future research should focus on the two key areas to enhance the transition for students from secondary to tertiary education.

1. Identify implementation challenges

2. Design innovative approaches

\section{References}

Abraham, R. R., Fisher, M., Kamath, A., Izzati, T. A., Nabila, S., \& Atikah, N. N. (2011). Exploring first-year undergraduate medical students' self-directed learning readiness to physiology. Advances in Physiology Education, 35(4), 393-395.

Ahmad, B. E., \& Majid, F. A. (2010). Self-directed Learning and Culture: A Study on Malay Adult Learners. Procedia-Social and Behavioral Sciences, 7, 254-263.

Al-Saadi, H. M. (2011a). From spoon-feeding to self feeding: helping learners take control of their own learning. Arab World English Journal, 2 (3), 95-114. 
Al-Saadi, H. M. (2011b). Towards a pedagogy for autonomy in language education in Oman. Retrieved from http://www.researchgate.net/profile/Hashil_Al-Saadi/publications

Barrows, H. S. (1983). Problem-based, self-directed learning. JAMA, 250(22), 3077-3080.

Braman, O. R. (1998). The cultural dimension of individualism and collectivism as a factor in adult self-directed learning readiness. (1998 Dissertation). Retrieved from http://aquila.usm.edu/theses_dissertations/1806

Brookfield, S. D. (1980). Independent adult learning. [electronic resource]: University of Leicester.

Candy, P. C. (1991). Self-direction for lifelong learning: a comprehensive guide to theory and practice. San Francisco: Jossey-Bass.

Fisher, M., King, J., \& Tague, G. (2001). Development of a self-directed learning readiness scale for nursing education. Nurse Education Today, 21(7), 516-525.

Frambach, J. M., Driessen, E. W., Chan, L.-C., \& van der Vleuten, C. P. M. (2012). Rethinking the globalisation of problem-based learning: how culture challenges selfdirected learning. Medical Education, 46(8), 738-747.

Garrison, D. R. (1992). Critical Thinking and Self-Directed Learning in Adult Education: An Analysis of Responsibility and Control Issues. Adult Education Quarterly, 42(3), 136148.

Grow, G. O. (1991). Teaching Learners To Be Self-Directed. Adult Education Quarterly, 41(3), 125-149.

Gukas, I. D. (2007). Global paradigm shift in medical education: issues of concern for Africa. Med Teach, 29(9), 887-892.

Jackson, M., \& Calman, K. (2006). Medical Education past, present and future. Medical Education, 40(3), 190-192.

Jippes, M., \& Majoor, G. D. (2011). Influence of national culture on the adoption of integrated medical curricula. Adv Health Sci Educ Theory Pract, 16(1), 5-16.

Kek, M. Y. C. A., \& Huijser, H. (2009). What makes a deep and self-directed learner: exploring factors that influence learning approaches and self-directed learning in a PBL context at a Malaysian private university. Proceedings of the 2nd International Problembased Learning Symposium (PBL 2009), 708-718.

Knowles, M. S. (1975). Self-directed Learning: A Guide for Learners and Teachers: Association Press.

Shankar, R., Bajracharya, O., Jha, N., Gurung, S. B., Ansari, S. R., \& Thapa, H. S. (2011). Change in medical students' readiness for self-directed learning after a partially problembased learning first year curriculum at the KIST medical college in Lalitpur, Nepal. Educ Health (Abingdon), 24(2), 552.

Shin, J. H., Haynes, R. B., \& Johnston, M. E. (1993). Effect of problem-based, self-directed undergraduate education on life-long learning. CMAJ, 148(6), 969-976.

Triandis, H. C. (2004). Culture and Social Behavior: McGraw Hill Custom Publishing.

Wiley, K. (1983). Effects of a self-directed learning project and preference for structure on self-directed learning readiness. Nurs Res, 32(3), 181-185. 


\title{
Flipped classroom as a methodology to acquire knowledge and skills in an integrated manner in basic subjects in Medicine.
}

\author{
C. Azpeleta*, B. Gal", F. Suárez*, C. Sánchez-Camacho*\# \\ Dpto. Ciencias Biomédicas Básicas, Facultad de Ciencias Biomédicas y de la Salud \\ Universidad Europea de Madrid \\ C/ Tajo s/n, Villaviciosa de Odón, 28670 Madrid \\ \#e-mail: cristina.sanchez-camacho@uem.es
}

\begin{abstract}
The present study analyses the inclusion of the flipped classroom methodology in the Physiology I (Cellular Physiology) course of the Degree in Medicine. This methodology was carried out as an integrated activity including the concepts acquired in some lessons of the course, all of them related to the different types of muscle: skeletal, cardiac and smooth. With this aim, after two months explaining the theoretical concepts about this topic, the Professors laid out an activity focused on the review of these concepts by searching the common and differential characteristics of each type of muscle. A survey designed by teachers was used to analyze the assessment of the activity by the students and the suggestion of possible improvements. The results obtained show a very positive global evaluation (87\% of the students), with $98-99 \%$ satisfied or highly satisfied with the objectives of the activity, and $89-98 \%$ who assessed positively this methodology. Thus, our results support the use of the flipped classroom methodology in the teaching process, as a useful tool for the improvement of students' learning, and encourage us to include more activities following this methodology in academic years to come.
\end{abstract}

Keywords: Flipped classroom; integration; physiology; satisfaction.

\section{Introduction}

In recent years, Spanish Universities have been working to implement new teaching methodologies in the context of the European Higher Education Area (http://www.magna-charta.org/resources/files/BOLOGNA_DECLARATION.pdf).

New technological advances are now being applied to improve teaching and learning. However, an appropriate balance between the acquisition of knowledge and the acquisition of skills and abilities is a major issue. On the one hand, it has been shown that traditional lectures are effective in transmitting information and guiding student's learning (Gage and Berliner, 1998; Hudson and Buckley, 2004). On the other hand, numerous studies have reported that the use of different methodologies such as problem-based learning, internships, and other participatory approaches enhance the integration of knowledge acquired during lectures (Hudson and Buckley, 2004; Walters, 1999; Waters et al., 2005). However, developing teaching methodologies aimed at maximizing acquisition of knowledge and skills still remains a real challenge.

One of the most powerful techniques in higher education is the flipped classroom (http://flippedclassroom3.weebly.com/iquestqueacute-es-flipped-classroom.html).

This learning methodology implies "doing the class in reverse order". Traditionally, students learn from lectures first to then deepen their understanding or apply concepts through independent work. Applying the flipped classroom method is "reversing the learning process". By using different technological and communication tools, students have access to content, prior to and away from the classroom. These resources enable students to establish a first contact with the contents to learn. Back in the classroom, students have to use the acquired knowledge by doing different tasks (asking 
questions, discussing, developing resources, practical work, etc.) under the facilitation of the Professor.

Physiology I (Cellular Physiology for the remainder) is taught in the first year of the Degree in Medicine. It has a basic and transversal character, and its content is essential for learning through later stages. A team of Professors on Physiology of the Universidad Europea de Madrid (UEM) have recently worked to integrate concepts explained in different physiology contents, with a dual purpose: first, that the students do not consider each system isolated, but the organism as a whole, and second, to understand that the specific characteristics of every cell, tissue and organ is what determines its function. This integrated approach provides a deeper understanding and a more holistic view of human physiology when compared with classical lecturebased teaching (Bain, 2007; Gal et al., 2013). This approach is especially suitable for promoting important skills such as autonomous learning or critical thinking. The flipped classroom represents an example of a possible methodology to acquire knowledge and skills in an integrated manner.

Consequently, the major goals of this work are:

- To increase the proportion of advanced learning methodologies versus traditional lecture-based teaching in the syllabus of Cellular Physiology for the first year of the Degree in Medicine. In particular, we will focus on using the flipped classroom as an alternative methodology.

- To encourage integrated learning.

- To promote the following skills: autonomous learning and critical thinking.

- To improve and quantify our own perception of student's learning through this activity.

\section{Methods}

As Professors in Physiology of the first year in Medicine, we planned an activity for our students to integrate distinct concepts related to muscle tissue. This activity was developed during the 2013-2014 academic year, by introducing a new methodology of teaching and learning known as flipped classroom, as described below.

\section{Activity plan}

For two months, the Professor taught the content of the activity in the classroom by using lectures, which included five units in the syllabus of Cellular Physiology. These lessons comprise the study of the three types of the muscle tissue: skeletal, cardiac and smooth. During this period, we went into detail about distinct aspects of muscle physiology. After finishing this part of the subject, we proposed to our students that they reviewed these contents looking for shared and particular characteristics of each type of muscle, including biochemical, histological or physiological features. These characteristics should be presented in a table undertaken as homework. After doing this activity, the students valued different aspects of it by means of a survey designed by the Professors of Physiology.

The activity, initially planned as non-graded, was undertaken in a total number of 9 distinct groups of the first year in Medicine and the survey was valued for a total number of 130 students. We would like to note that apart from using this new methodology, the flipped classroom, we also integrated the contents of distinct lessons in the activity, so that the students could compare the characteristics of the three types 
of muscles. We dedicated 60 to 90 minutes on average for doing this activity in the classroom.

\section{Survey}

We created a satisfaction survey for the students in which we included items to evaluate the objectives of the practice session (level of satisfaction and level of learning) and the methodology used (structure, organization and length of the activity), as well as a question to assess the global valuation of the activity. Also, we added a section in the survey for the students to include their comments and suggestions on the activity (Fig. 1).

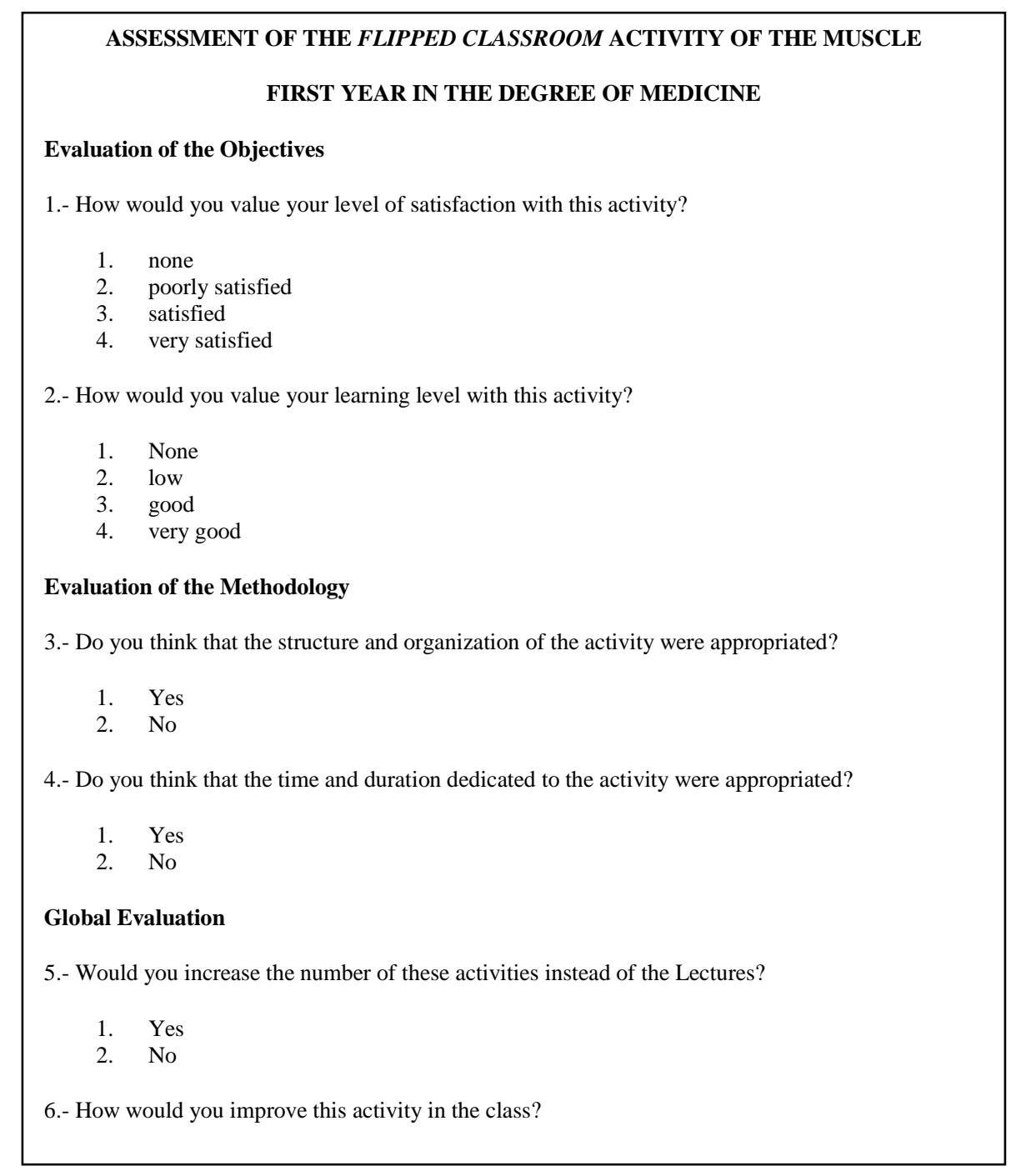

Figure 1. Survey taken by the students to value the activity. 


\section{Results and Discussion}

In this work we implemented a flipped classroom methodology on Cellular Physiology for medical students. As a result, we empowered the students to be part of the class, collaborating with others (peer instruction; Lasry et al., 2008; Manzur, 2009). To achieve this purpose we chose the muscle physiology because this physiological system is very suitable to establish similarities and differences amongst muscle types. Nevertheless, there are several other areas of our subject where this methodology could, potentially, be employed as well: transport across cell membranes, neurochemistry and immunology, to name just a few of them.

The authors of this article evaluated this methodology in a very positive way. In addition, students' perception was in the same direction as ours. In general, our results demonstrated a very positive assessment of the activity by most of the students in all the sampled groups. Students evaluated positively all the items included in this survey: satisfaction, learning, structure and organization, duration and global outcome.

For the evaluation of the objectives, two items were analyzed: level of satisfaction and level of learning. Regarding to the first, most of the students (54\% satisfied; $45 \%$ very satisfied) were quite satisfied with the activity and the outlined objectives (Fig. 2). This evaluation was correlated with the level of learning, in which $98 \%$ of the students considered it good (58\%) or very good (40\%) (Fig. 3).

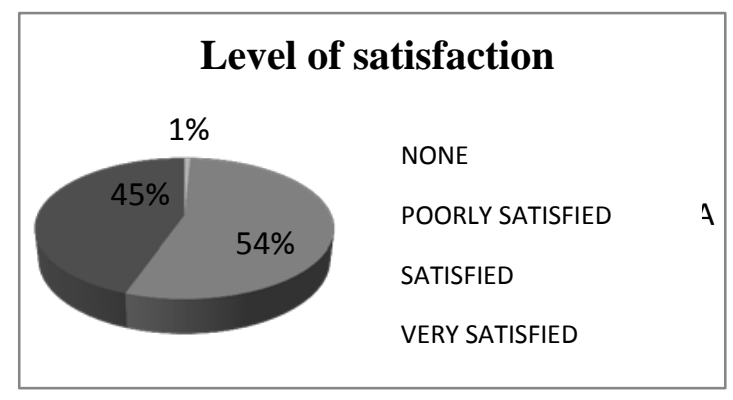

Figure 2. Assessment of the level of satisfaction with the activity.

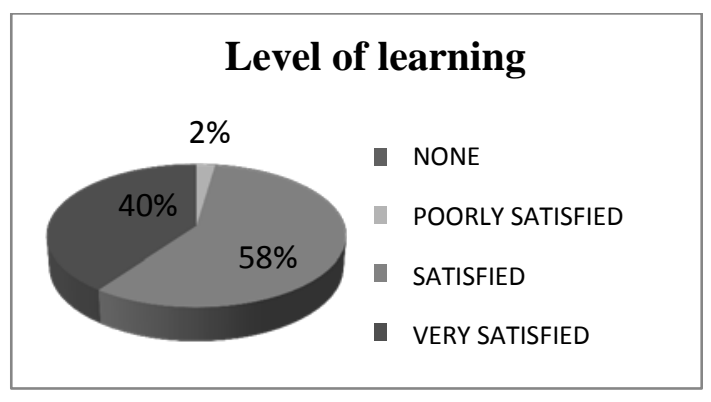

Figure 3. Assessment of the level of learning with the activity.

Another parameter analyzed was the methodology, including the evaluation of structure, organization and duration of the activity. Almost all the students (98\%) considered that the structure and organization were appropriate (Fig. 4), whereas the remaining $2 \%$ stated that the time allotted to accomplish the activity was insufficient, probably due to the lack of time in previous classes for explaining the theoretical concepts of the lesson. Regarding the duration of the activity, $89 \%$ of the students considered it adequate, while the remaining $11 \%$ considered that more time should be allotted (Fig. 5). This latter case includes the mentioned group in which the duration of the activity was shorter. 


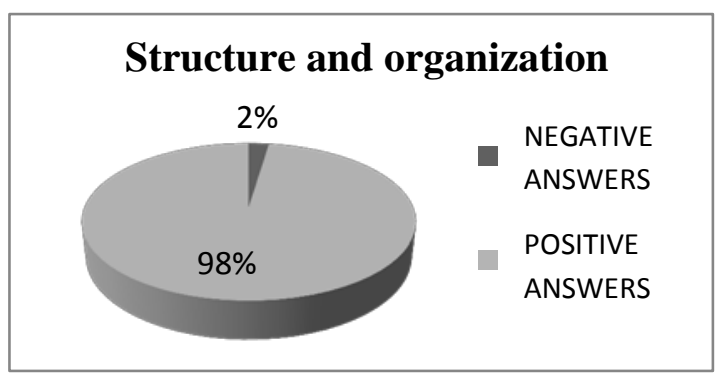

Figure 4. Assessment of the structure and organization of the activity.

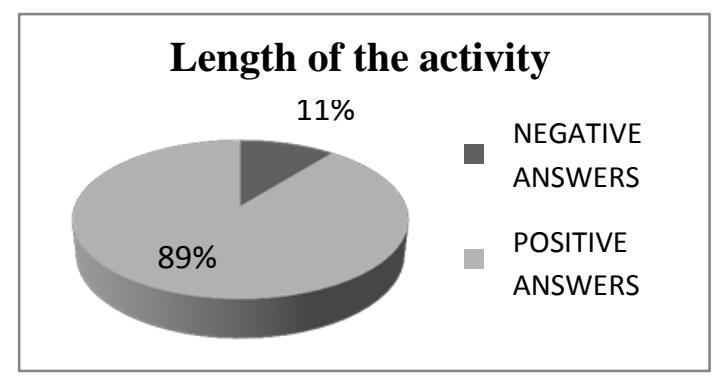

Figura 5. Assessment of the duration and time allotted for the activity.

With respect to the global evaluation, $87 \%$ of the students would increase the frequency of this kind of activities instead of master classes, while the remaining $13 \%$ would not (Fig. 6).

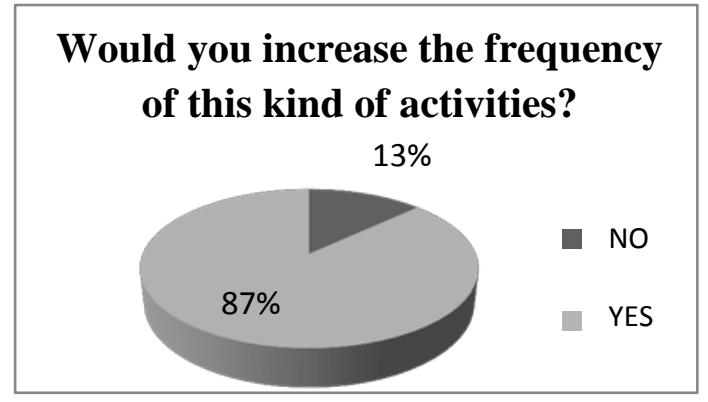

Figure 6. Global evaluation of the activity.
Finally, although the response was very positive, $60 \%$ of the surveyed students had some comments regarding the improvement of this activity. These suggestions were grouped in four categories:

- Encouraging student participation.

- Increase in the frequency of this type of activities in the course.

- Increase in the time allotted for the activity.

- Other: grading the activity, the use of other methodologies such as clinical cases, etc.

In general, comments about the activity were quite good and only $7.7 \%$ of the students considered that the activity could not be improved. It was a surprise the fact that $14 \%$ of the students would like their peers to be more proactive. This is something we had already observed in previous classes. As a way to improve proactivity, we are determined to increase the weight given to this activity on the final mark, as well as to include peer-review evaluation.

As cited by Manzur (http://harvardmagazine.com/2012/03/twilight-of-the-lecture) many students pay a huge amount of money not to work in class but for someone (the Professor) to work for them: in the master class. In our experience, we have seen that our students enjoyed these activities regardless of this. Moreover only $14 \%$ of the students pointed out improvements of the activity, suggesting repeating this activity in the future, but closer to exam preparation. For all the above mentioned, we consider that the flipped classroom is a very useful methodology to improve the learning and some skills of our students, such as autonomous learning and critical thinking, that can be used as a complement within the master classes and other activities in the classroom. Moreover, the use of this methodology could be transferred to basic subjects in Medicine as Biochemisty, Cell Biology, Genetics or Anatomy. 


\section{Conclusions}

- The flipped classroom methodology is a very useful tool for teaching Cellular Physiology in the first year of the Degree in Medicine, as it encourages integrated learning and promotes autonomous learning and critical reasoning in students.

- Students state to be highly satisfied with the inclusion of this activity as a complement to master classes and they demand of doing even more similar activities to encourage their learning.

- The Professors of Physiology are considering increasing the frequency of this type of activities in the syllabus of the course in the future, including improvements based on the suggestions of the students.

- The Professors of Physiology consider that this activity should be evaluated so that the students could receive feed-back of their knowledge.

\section{References}

Bain, K. (2007). Lo que hacen los mejores profesores universitarios. Valencia: Editorial Universidad de Valencia.

Gage, N., Berliner, D. (1998). Educational Psychology. Boston, MA: Hoghton Mifflin.

Gal, B., Fernández-Santander, A., Palau, L., Sánchez, A. (2013). Integrar asignaturas básicas en primero de Medicina: análisis cuantitativo y cualitativo de una experiencia piloto. Educación Médica, 16(4), 225-231.

Hudson, J.N., Buckley, P. (2004). An evaluation of case-based teaching: evidence for continuing benefit anda ralization of aims. Advances in Physiology Education, 28, $15-22$.

Lasry, N., Manzur, E., Watkins, J. (2008). Peer Instruction: From Harvard to Community Colleges. American Journal of Physics, 76, 1066-1069.

Manzur, E. (2009). Farewell, Lecture? Science, 323, 50-51.

Walters, M.R. (1999). Case-stimulated learning within endocrine physiology lectures: an approach applicable to other disciplines. Advances in Physiology Education, 276, 74-78.

Waters, J.R., Van Meter, P., Perrotti, W., Drogo, S., Cyr, R.J. (2005). Cat dissection vs. sculpting human structures in clay: an analysis of two approaches to undergraduate human anatomy laboratory education. Advances in Physiology Education, 29, 27-34. 


\title{
Outside the classroom: Community health education to prevent diseases in South Bahia, Brazil.
}

\author{
V N C Leal*, N P Santos*, M L Santos*; P S Mendes*, T A G Pellizzoni*, M F Silva**. \\ * Biomedical Sciences, State University of Santa Cruz, Ilhéus, Bahia, Brazil; * * Department of \\ Biological Sciences, State University of Santa Cruz, Ilhéus, Bahia, Brazil
}

\begin{abstract}
The objective of this paper was to report the achievements of a workgroup which was focused on outside of classroom activities linked to the social demands of primary health care to improve the learning of diseases among health students in South Bahia, Brazil. The methodology encompassed a pedagogical approach including local diagnostic of health and development of strategy actions of continuing education on health promotion. This has strengthened the development of new teaching resources that favored the learning of the biology of diseases frequently found in these communities. While on the one hand it has improved the quality of information on health in self-care and sexually transmitted diseases, on the other hand it has helped health students develop skills and acquire competencies aligned to the principles of health promotion. The authors suggest that continuing education activities are the best strategies underlying the mechanisms of collective knowledge and the relations between learning and practical action. New approaches on health education span the notions of individual and family hygiene and practices in health, with emphasis on prevention and prophylaxis, which are the objectives of programs health promotion and disease prevention.
\end{abstract}

Keywords: Health; Education; Meaningful learning; Brazil

\section{Introduction}

Experiences outside the classroom can be defined as any learning experience with benefits for both students and community. The range of the benefits to higher education students depends on their ability to comprehend the reality and their interest for meaningful learning; in the dimension of social benefits, they allow the exchange of knowledge between community and University and stimulate healthier habits (Falcão Júnior et al., 2007). A community health profile consists of indicators of sociodemographic characteristics, health status and quality of life, health risk factors, and the health human resources that are relevant for most communities (Durch et al., 1997). Interdisciplinary outside of classroom programs are thought to be the strategies that better emphasize improvement of life quality for individuals and families lacking financial resources and living in inequity (Whitehead et al. 2001). In the case of this paper, examples of health risks of great social importance stand out as sexually transmitted diseases (STDs). This can be explained by the high incidence of STDs worldwide, especially among the least developed countries (Bhutta et al., 2014).

In the late twentieth century, one of the Brazilian Sanitary Reform movement's claims was to improve the training of health students from the perspective of linking the social needs to the formation of a better health professional, which would act as a generalist and critic, obedient to the principles of the Brazil's Unified System of Health - SUS (National Council of Education, 2001).

The State University of Santa Cruz (UESC) promotes continuing education activities on the basis of the social demands of South Bahia, Brazil. The city of Ilhéus has 184,236 inhabitants distributed in $1,760,111 \mathrm{~km}^{2}$. The population chiefly concentrates in urban areas (84\%), and the average income per capita is US\$ 506.00 monthly. Of the total population, 15,685 individuals are subjected to inadequate sanitation conditions. Itabuna has 204,667 inhabitants distributed in $432,244 \mathrm{~km}^{2}$ and $97 \%$ of the total 
population lives in urban areas. The average income per capita is US\$ 554.00 monthly. The number of residents in private households with inadequate sanitary conditions is 4,790 people. (Brazilian Institute of Geography and Statistics, 2014).

Thus, increasing urbanization associated with the growth of population, especially in Ilhéus, favors the emergence of unplanned communities and the consequent lack of access to basic services, inadequate housing conditions and exposure to various environmental contaminants. (Fontes et al., 2010). This contributes to the low quality of life and health, as observed in other cities and regions. (Graham et al., 2004; Shobha et al., 2013). Infectious diseases are closely enmeshed to sanitary conditions and public health, with higher prevalence among individuals of low socioeconomic status, which contributes to increased rates of morbidity and mortality especially in infants and children. (Korkes et al., 2009; UNAIDS, 2013).

Thus, beyond the best infrastructure and sanitation, the improvement of life quality greatly depends upon the performance of professionals committed to health education, under the aegis of the SUS, in encouraging self-care and promoting comprehensive health care. (Flavigna et al, 2013). The objective of this study was to report the experience of the continuing education program in the development of skills and competencies of forthcoming health professionals while addressing the strategies on biological and health education linked to social demands of South Bahia, Brazil.

\section{Material and Methods}

\section{Subjects and ethical implications}

The study was conducted from January 2011 to November 2013, and started by accessing public databases to select indicators of social, demographic and health conditions of the communities in the vicinity of UESC. The city of Ilhéus, more specifically, the villages of Juerana, Sambaituba, Urucutuca, and Teotônio Vilela were chosen. Initially, a meeting was scheduled for discussing the importance, ethical implications, and the acceptance of the study by all community leaders, children, parents, health professionals or directors of schools. Only fully informed volunteers participated in the study, in line with the Brazilian regulatory act on ethics and research with human volunteers. (National Council of Health, 2012). The study was approved by the ethics committee of the State University of Santa Cruz and all subjects, or its legal representatives, gave written informed consent. The sample size was calculated at a confidence level of $95 \%$. Then calculated study population size was 280 .

\section{Continuing education activities}

Secondary meetings were again scheduled to deliver results and discuss the scenario of contamination with parents, community leaders, health professionals or responsible for the schools. At that time, there were lectures, workshops, music and sketches for children and adults regarding most prevalent diseases and STD. In the same way, there have been orientations on the importance of preventing individuals and families, as well as medical care, in order to have efficient treatment.

\section{Assessment of health education}

After the survey on health conditions, children and adults were evaluated for previous information by applying an appropriated questionnaire that evaluated the level of knowledge on the prevention of STD. Briefly, volunteers respond to questions by raising a card with the answer they considered correct, according to their previous 
knowledge. After that, each STD was presented in the form of interactive lecture, in which participants had the opportunity to watch content on the etiology, transmission, symptoms and prevention of the most prevalent STD. After the lecture and the presentation of songs and plays, the same questions were reapplied and the overall hit rate was calculated. Health students were also evaluated on the impact on learning and acquiring of competences and skills along the experience in the communities.

\section{Statistical analysis}

Chi-square test $\left(\mathrm{X}^{2}\right)$ was used to evaluate the significance of the results in the application of questionnaires to assess health education. It was considered as the expected responses the equitable apportionment among all the alternatives compared to the amount of correct answers observed before and after the continuing education activities. The significant level was 5\%. Data were analyzed by using GraphPad Prism 4.

\section{Results and Discussion}

The continuing education experiences included multiple approaches: community visits, completion of questionnaires and the production of resources for recreational and educational activities in the communities. Despite there were differences between the epidemiological surveys conducted at each of the four selected communities, the most significant results were observed in Teotonio Vilela. This result allowed for developing instructional resources for educational purposes, with a focus on the most frequent diseases, mainly STD.

In order to increase the bond of students with the community during activities and enable the development of humanistic actions, recreational and educational alternatives were important so as to better understand the health-disease process and self-care, both from the individual and the community. In effect, this is essential to promote a more comprehensive health care. This fact entails the community experience, as it allows the interaction between theory and practice and awakening of vocation for public health and humanitarian care. Accordingly, the authors highlight the contribution of health promotion, which is linked to community action in the training of students, in line with the new curriculum guidelines for healthcare careers in Brazil (Lopes Neto, 2007).

In the Table I it is depicted the socioeconomic profile of Teotonio Vilela; one can easily note the prevalence of low family income and educational levels among inhabitants. In this scenario, under a broader conception of health education, it is considered that, in order to educate an adult to self-care, one must do more than expose health as advertising or give loose information. We have evaluated the accuracy of prior information provided by adults on the prevention of STDs before and after recreational and educational activities. The overall results depicted in Figure 1 pointed out that the ludic and pedagogical approaches of adults were significant $(p<0.05)$ in the acquisition of new knowledge about prevention of STDs since the correct rate of individual and general issues were higher after educational actions were presented. It can be noticed that, in such case, adult education is a voluntary process which provides resources that spark the interest of the individual health.

The experience on health education contributes to improve the learning of parasitc diseases and STDs among biology and health students. It was possible to calculate the positive self-assessment of health students (100/82) on dedication to the activities 
(acting, planning and collaborating; $\mathrm{X}^{2}=16.97$ and $p<0.001$ ) also on the reaction of the audience (participatory, curiosity and sympathy; $X^{2}=9.97$ and $p<0.01$ ) to the educational resources available.

One limitation of the study was the sample size not very representative of the population due to the lacking of fully validated questionnaires, which caused a higher exclusion index. Despite these facts, this study has revealed that health education should be incorporated on everyday basis in the classroom and, for this purpose the activities must be replaced from conventional classes to extramural experience. We assume that universities are built from their subjects, teachers or students so as to improve their practices and educational projects. UESC makes a significant and original contribution in the training of human resources for public health aligned to SUS (Paim et al., 2011). It appears that the formal education on health lacks more comprehensive approaches that combine the essential characteristics of diseases under different learning perspectives. Changing the meaning perspectives or health habits serve as perceptual and cognitive codes to structure the way one perceives, thinks, feels, and acts on one's health care.

Table 1. Socio-demographic characterization of Teotonio Vilela. Ilhéus. Bahia, Brazil

\begin{tabular}{lcc} 
Table 1. Socio-demographic characterization of Teotonio Vilela. Ilhéus. Bahia, Brazil \\
\hline & $\mathbf{n}(\%)$ & $\mathbf{p}$ \\
Education & & 0,001 \\
Illiterate & $2(1,7)$ & \\
Primary & $34(29,05)$ & \\
Secondary & $79(67,52)$ & \\
Higher & $1(0,85)$ & 0,001 \\
Undeclared & $1(0,85)$ & \\
& & \\
Family income (MW) & & \\
Up to 1 MW & $93(79,48)$ & \\
Between 2 and 3 MW & $22(18,80)$ & \\
Above 4 MW & $1(0,85)$ & \\
Undeclared & $1(0,85)$ & \\
& & \\
Gender & & \\
Female & $69(58,97)$ & \\
Male & $48(41,02)$ &
\end{tabular}

MW: Minimum Wage 


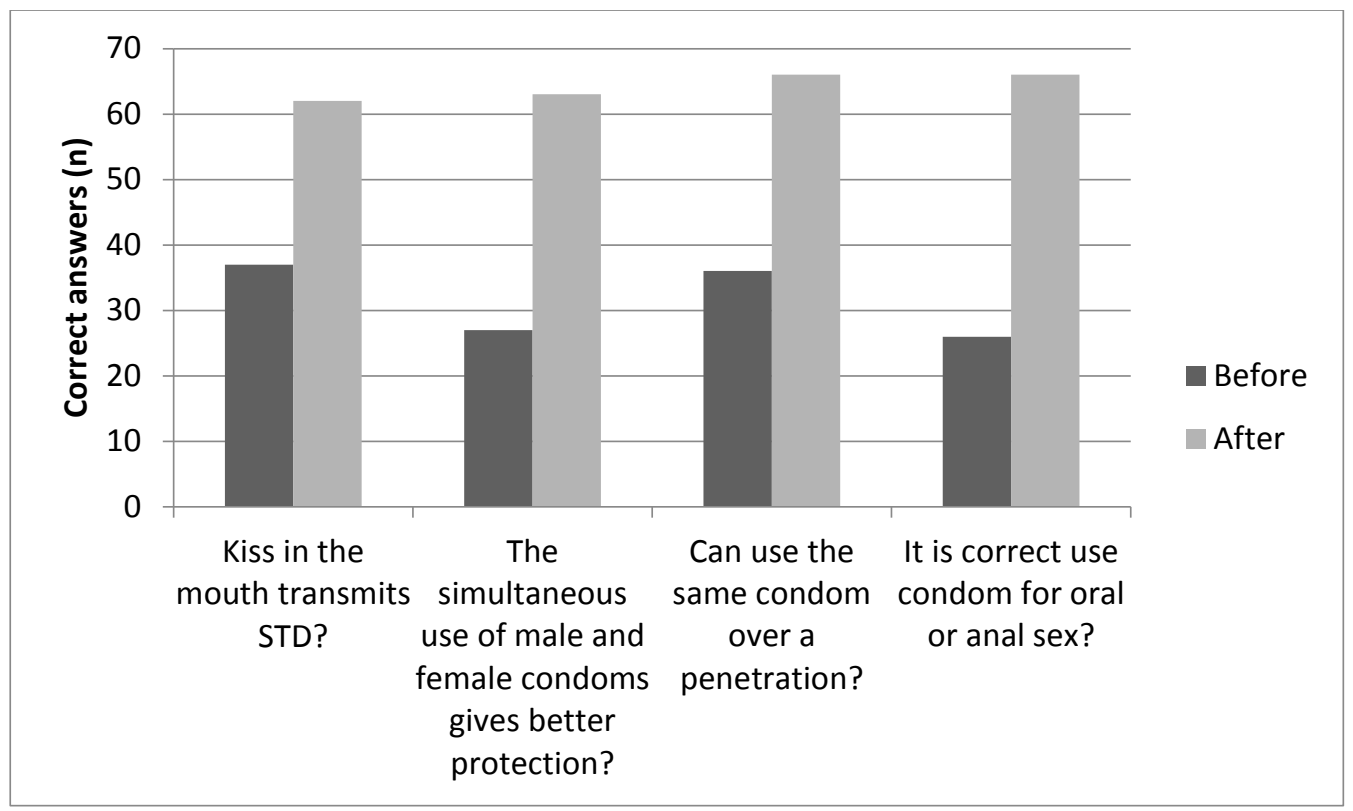

Figure 1. Examples of the STD prevention before and after ludic and pedagogical approaches. All differences were considered significant (Chi-square test $p<0,05$ ).

\section{Conclusions}

The authors conclude that the outside of the classroom experiences contributed to better understand of STD in the community. The continuing health education activities helped the students to develop fundamental skills for health promotion, awake collective and social transformation through education in order to reduce the incidence STDs in South Bahia, Brazil.

\section{References}

Barreto, M. L., Genser B., Strina A., Teixeira G., Assis A. M., Rego R. F., Teles C. A., Prado M. S., Matos S., Santos D. N., Santos L. D., Cairncross, S. (2007). Effect of city-wide sanitation programme on reduction in rate of childhood diarrhoea in northeast Brazil: assessment by two cohort studies. The Lancet. 9599:1622-1628.

Brazil. (2012). Resolution 466/2012 from National Council of Health. Diário Oficial da União. 12:59-62.

Brazil. National Council of Education. Resolution cne/ces $n^{\circ} 4$, of 7 november 2001: Retrieved April 2014 ,

from: (http://portal.mec.gov.br/cne/arquivos/pdf/CES04.pdf)

Bhutta, Z. A., Sommerfeld, J., Lassi, Z.S., Salam, R. A., Das, J.K. (2014). Global burden, distribution, and interventions for infectious diseases of poverty. Infectious Diseases of Poverty. 3:21-28.

Durch J. S., Bailey L. A., Stoto M. A. (1997).Committee on using performance monitoring to improve community health. In: Improving Health in the Community: A Role for Performance Monitoring. Washington, DC: National Academy Press. 496.

Falcão Júnior, J.S.P. et al. (2007). Perfil e práticas sexuais de universitários da área de saúde. Esc Anna Nery R Enferm. 11 (1): 58 - 65 
Flavigna A., Canabarro C. T., Medeiros G. S. l. (2013). Health system and medical education in Brasil: history, principles and organization. World Neurosurgery. 80:723-727.

Fontes E.O., Souza T.P. (2010). Transformações ambientais no município de Ilhéus: uma análise da vulnerabilidade social. VI Seminário latino-americano de geografia física II Seminário ibero-americano de geografia física Universidade de Coimbra. Retrieved August 2014, from:

(http://www.uc.pt/fluc/cegot/VISLAGF/actas/tema3/ednice)

Graham J., Gurian P., Corella-Barud V., Avitia-Diaz, R. (2004). Periurbanization and in-home environmental health risks: the side effects of planned and unplanned growth. Int J Hyg Environ Health. 207:447-454.

Brazilian Institute of Geography and Statistics. Retrieved August 2014, from: (http://cidades.ibge.gov.br/painel/painel.php?codmun=291360).

Korkes F., Kumagai F. U., Belfort R. N., Szejnfeld D., Abud T. G., Klienman A., Florez G. M., Szejnfeld T., Chieffi P. P. (2009). Relationship between intestinal parasitic infection in children and soil contamination in an urban slum. $J$ Trop Pediatr. 55:42-45.

Lopes Neto D., Teixeira E., Vale E. G., Cunha F. S., Xavier I. M., Fernandes J. D., Shiratori K., Reinbnitz K. S., Sordi M. R. L., Barbieri M., Boccardi M. I. B. (2007). Adherece of nursing graduation courses to the national curricular guidelines. Rev Bras Enferm;60:627-34.

Nossa Ilhéus Institute Report (2012). Indicators for local actions on health. Kairós social development 2012. Retrieved August 2014, from: (http://nossailheus.org.br/indicadores/compara.html).

Paim J., Travassos C., Almeida C., Bahia L., .Macinko J. (2011).The Brazilian health system: history, advances, and challenges. The Lancet. 377:1778-179

Shobha M, Bithika D, Bhavesh S.The prevalence of intestinal parasitic infections in the urban slums of a city in Western India. J Infect Public Health 2013;6:142-9.

Toledo M. J. O., Paludetto A. W., Moura F. T., Nascimento E. S., Chaves M., Araújo S. M., Mota L. T. (2009). Evaluation of enteroparasite control activities in a kaingáng community of southern Brazil. Rev Saúde Pública. 43:1-10

Whitehead M, Dahlgren G, Gilson L. Developing the policy response to inequities in health: a global perspective. In: Challenging inequities in health care: from ethics to action. New York: Oxford University Press. 200, 309, 2001. 
HEAd'15

\section{SESSION $4 B$}

Problem-BASEd LEARNING 


\title{
A Project Based Learning interuniversity experience in materials science
}

\author{
L. Cabedo*, T. Guraya**, P. Lopez-Crespo***, M. Royo****, J. Gamez-Perez*, M.

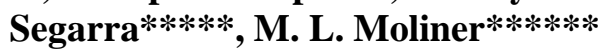

* Departamento de Ingeniería de Sistemas Industriales y Diseño (ESID), Universitat Jaume I, Av. Vicent Sos Baynat, s/n, 12071 Castellón, Spain.

** EUITI, University of the Basque Country, Rafael Moreno Pitxitxi 3, 48013 Bilbao, Spain.

*** Departamento de Ingeniería Civil, de Materiales y Fabricación, University of Málaga,

C/ Dr. Ortiz Ramos, s/n. 29071 Málaga, Spain.

**** Departamento de Ingeniería Mecánica y Construcción, Universitat Jaume I, Av. Vicent Sos Baynat, s/n, 12071 Castellón, Spain.

*****Departamento de Ciencia de los Materiales e Ingeniería Metalúrgica. Facultad de Química. Universitat de Barcelona. C/Martí i Franqués 1, 08028 - Barcelona, España.

****** Departamento de Educación, Av. Vicent Sos Baynat, s/n, 12071 Castellón, Spain.

\begin{abstract}
One of the peculiarities of the present Information and Communication Society is its complexity and changing character. Our education systems, within this new model of society, require a substantial change in their goals and practices. Thus, it is necessary for teachers to adapt to this reality and propose changes on one of the key elements of the curriculum: a methodology in which the student must be the real axis of university education and the teacher a mediator or guide the process. Among the methods that facilitate this transition, the Project Based Learning (PBL) allows learning different basic and/or specific skills, such as interdisciplinary teamwork, personal relationships, ethical commitment or critical thinking. In this paper, we present a proposal for educational innovation based on PBL methodology, conducted with the aim of analyzing its viability in core subjects of materials science engineering in different degrees in Spain. Specifically, it presents a PBL experiment carried out simultaneously by professors of materials science in four Spanish public universities, where the project has been tailored for each curriculum. The results show that this methodology arouses more interest in students than the traditional methodology , while allowing work transversal competences as well as providing a way to evaluate them.
\end{abstract}

Keywords: Project Based Learning (PBL); Interuniversity; Materials Science;

\section{Introduction}

\section{A new educational paradigm}

The information and knowledge society entails a culture sustained by globalization processes involving, among others, the acquisition and assimilation of new knowledge, new ways of seeing the world, the use of new tools and languages, etc., requiring therefore great efforts and skills that facilitate adaptation to this complex and changing scenery (Castells, 1996). The educational systems within the European Higher Education Area require models of teaching and learning to meet the demands of this new paradigm. In this sense, educational institutions must consider three fundamental aspects that facilitate the transition to these social and educational models (Pozo, 2006). First, be aware that the formal environments are no longer the primary, and sometimes not even the main, source of knowledge. Teachers must attend and recognize learning from non-formal and casual spaces. Second, understand that knowledge is multiple and uncertain. The large amount of information that we be accessed raises new skills such as search, evaluate, organize, select and use all this information to be really valid, useful and productive. Finally, it must be considered that learning is a continuous process and extended along life. The world of work demands new requirements; the efficient performance of a profession requires solving tasks in an increasingly higher level and the link between education and job career every day becomes more urgent. 
In addition to these considerations, we must follow the assumptions made by Delors in his report, not just about learning to learn, but learning to do, learning to be and learning to live together (Delors, 1996). This holistic and integrated view of education intends to train citizens that are competent and able to adapt to the social context of change, complexity and uncertainty.

All these ingredients, cooperation, peer learning and skills such as learning to learn or selection and analysis of information, can only be achieved by democratizing the teaching - learning and applying methods of learning that increase activity and participation of the students, who are the real protagonists.

\section{Project Based Learning: basics}

Once described the current educational context we believe that a good tool to address this issue is the Project Based Learning (PBL).

The PBL is a model of learning in which students raise, implement and evaluate projects that have an application in the real world. This method uses problems as a starting point for the acquisition and integration of new knowledge (Barrows, 1986). As other methodologies, it requires a series of well-structured and planned steps set by the teacher.

Moust, Bouhuijs and Schmidt (2007) and Schmidt (1983) proposed seven steps to implement the resolution of the project:

1. Clarification of concepts and terms that appear in the proposal project from the dialogue between group members.

2. First tentative definition of the problem. After steps 3 and 4 this step can be repeated if considered necessary.

3. Analysis of the problem from the contributions of all group members through brainstorming.

4. Development of a systematic summary with several explanations to the analysis of the previous step. Once generated the greatest number of ideas about the problem, the group tries to systematize and organize them, highlighting the possible associations among them.

5. Set up of learning objectives and common decision on aspects of the problem, which are to be investigated and understood.

6. Search for more information, individually.

7. Synthesis of collected information and writing a report on the acquired knowledge.

These phases point the many cognitive processes and competencies required to the students. As already mentioned above, from the organization of work the student develops skills such as problem solving, decision making, teamwork and communication (Michael, 2005). Thus, knowledge is gained while they learn to learn in a progressively independent way as well as they learn to apply that knowledge in solving various problems similar to those they face in the performance of different facets of this work: working in teams under supervision, being progressively autonomous, identifying learning goals, managing time effectively, identifying which aspects of the problem can be ignored or need to explore more deeply and investigating 
on their own, thus directing their own learning. Through this process, they benefit from the participating peers, which provide the necessary contrast to their inquiries and ways of understanding what they are studying (Vizcarro and Juárez, 2009).

One of the strengths that characterize the PBL is its application to different educational levels as well as its versatility to be able to deal with various areas of knowledge. The literature review offers examples of these benefits. Reeves and Laffey (1999) used PBL in an Introduction to Engineering lecture and found an increase in the students' problemsolving skills. However, its implementation in the materials science knowledge area is not very common, being that one of the most traditional engineering subjects and where the introduction of non-traditional teaching methods such as PBL seems to be more difficult. In this sense, Jonassen and Kanna (Jonassen and Khanna, 2011) have analyzed the feasibility of introducing a similar methodology (PBL) in a subject in the field of materials science for mechanical engineers at the University of Missouri and have found that this methodology is very difficult to implement unless this introduction is carried out in curricular way. Thus, their findings show that the introduction of this methodology in only one subject (for this type of degrees) requires great effort from both parties involved: teachers and students, whereas if the methodology is implemented at the level of curriculum for the whole degree, it is much more effective than the traditional learning methodologies.

Despite the predictable difficulty that would involve the implementation of this methodology in material science subjects in engineering degrees, the potential benefits for the students motivated us to start this educational experience, addressed to study the feasibility of using PBL methodology in those subjects in different degrees of Spanish public universities.

The experience is part of a network of educational innovation in materials science formed by teachers from seven Spanish public universities (IdM@ti). Within this network, it was decided to implement the PBL simultaneously on their respective courses, with the aim of analyzing if it was possible to apply it in subjects in this field, regardless the specific degree in which the course is given or any other particular situation of the university. The participating universities were University of the Basque Country-Euskal Herriko Unibertsitatea (hereinafter UPV/EHU), Universitat Jaume I (hereinafter UJI), the University of Barcelona (hereinafter UB) and the University of Málaga (hereinafter UMA).

To the best of our knowledge, this experience is pioneer in Spain, both in the field of knowledge to which it applies, as for its interuniversity character. So in this article we describe the essential elements of our proposal and bring some of the most interesting perceptions of the agents involved, faculty and students.

\section{Methods}

The activity was developed with students from four universities enrolled in different degrees studying subjects related to materials science, all in the field of engineering. This fact brings some aspects worth noting:

- Each engineering degree has a different curriculum and consequently the level of the students' prior knowledge of the subjects is different.

- Objectives and skills to develop in each subject are different. 
- The students are from different school years and this implies different groups regarding the maturity of the students and miscellaneous group circumstances.

- The weight of the ABP activity in the evaluation of the subject is different in each university.

Table 1 summarizes the casuistry.

Table 1. Curriculum of the students and group characteristics.

\begin{tabular}{|c|c|c|c|c|c|}
\hline $\begin{array}{c}\text { University and } \\
\text { degree }\end{array}$ & $\begin{array}{l}\text { Subject } \\
\text { (course) }\end{array}$ & $\begin{array}{l}\text { Size of the } \\
\text { main group }\end{array}$ & $\begin{array}{l}\text { Number of } \\
\text { students in } \\
\text { PBL group. }\end{array}$ & $\begin{array}{c}\text { Number of } \\
\text { PBL } \\
\text { groups. }\end{array}$ & $\begin{array}{c}\text { Weight of } \\
\text { PBL activity } \\
\text { on final grade. }\end{array}$ \\
\hline $\begin{array}{l}\text { UPV-EHU } \\
\text { Industrial } \\
\text { Engineerings } \\
\text { (Ingenierías } \\
\text { Industriales) }\end{array}$ & $\begin{array}{l}\text { Materials } \\
\text { Science } \\
\text { (Ciencia de } \\
\text { materiales) } \\
\left(2^{\circ}\right)\end{array}$ & 60 & 5 & 12 & 30 \\
\hline $\begin{array}{c}\text { UJI } \\
\text { Industrial Design } \\
\text { and Product } \\
\text { Development } \\
\text { (Diseño Industrial } \\
\text { y Desarrollo de } \\
\text { Producto) }\end{array}$ & $\begin{array}{c}\text { Materials II } \\
\text { (Materiales II) } \\
\left(2^{\circ}\right)\end{array}$ & 126 & 5 & 3 & 100 \\
\hline $\begin{array}{c}\text { UB } \\
\text { Materials } \\
\text { Engineerings } \\
\text { (Ingeniería de } \\
\text { Materiales) }\end{array}$ & $\begin{array}{c}\text { Materials } \\
\text { Laboratory } \\
\text { (Laboratorio de } \\
\text { materiales) } \\
\left(3^{\circ}\right)\end{array}$ & 16 & 4 & 4 & 50 \\
\hline $\begin{array}{c}\text { UMA } \\
\text { Industrial Design } \\
\text { and Product } \\
\text { Development } \\
\text { (Diseño Industrial } \\
\text { y Desarrollo de } \\
\text { Producto) }\end{array}$ & $\begin{array}{l}\text { Materials } \\
\text { Science } \\
\text { (Ciencia de } \\
\text { materiales) } \\
\left(2^{\circ}\right)\end{array}$ & 119 & 5 & 11 & 20 \\
\hline
\end{tabular}

As a common element to all projects, the methodology is structured in three sections defined in the documentation provided to the students:

-The project and its objectives are described.

-A closed proposal with minimal requirements within and outside the classroom

-The exact details of the evaluation methodology.

With such common minima each participating university adapted the methodology to their needs and abilities. 
The main focus of the project is to study the design and the redesign of a commercial product, a razor blade. The choice of such a product was based on the following criteria: be affordable for the development of the activity, involving a set of teaching materials of interest and ease to be disassembled and studied. Indeed, it was considered that this product was familiar to the students and easy to access technical and commercial information over the Internet.

While in the UPV/EHU and UB, the whole group of the subject has performed the activity, in the UJI only 15 volunteer students have participated in it. The project was proposed only to a subgroup of high performance students because of the high volume of students enrolled in this course. The selection of them was based on a mixed approach between their average grades in all classes and a motivation letter that was asked to provide to those interested in participating. In the case of UMA, they also decided to implement the PBL activity in a fraction of the total students, as in the UJI, given that there were too many enrolled students. However, it was extended to a larger percentage of students (around 50\% of total enrollment).

The different ways of selection of students to develop the PBL activity show advantages and disadvantages. On the one hand, a selected group does not allow a direct comparison of all results with the whole class, because of the differences in the student's motivation. On the other hand, this method can explore the behavior and performance of students in slightly different contexts. This will allow drawing conclusions such as the suitability of the different ways of selecting students for participating in the PBL activity.

The project proposal varied slightly for each of the four centers in order to adapt it to the different student profiles. Thus, in the case of the UPV / EHU and UMA the statement was that the participants assumed the role of a group of students willing to take part in a contest organized by a major razor blades brand. The purpose was to look for a new design oriented to new market niches, either by consideration of groups of people, environmental considerations, innovative designs, innovative design etc. Once formed the working groups, every member of each group would assume specific tasks, adopting: i) the role of industrial design engineer or ii) role of materials and process engineer. The UMA activity was conducted in coordination with another subject, Industrial Processing. Therefore, special attention to the manufacturing processes used for each component of the blade was given. They also studied in detail the properties of all the materials used.

At the UJI this activity was carried out in coordination with the subject of Conceptual Design, which goes by simultaneously for the first half of the second year. The onset of the activity was proposed as a role playing game (RPG) in which each group was constituted as a design studio, while the teacher was the intermediary between them and the promoter. In this case, the promoter was a foreign razor company that aims to open markets in Spain. Each of the three groups was proposed a project that was slightly different from each other, looking for manufacturing blades intended for a very specific niche market. Thus, one group was asked to design a product for young women, other for sport/leisure which in turn should be fully biodegradable and the third group had to seek maximum profit making a generic product.

In the course of Materials Laboratory at UB, the stated objective was that the students were able to justify the choice of materials in three different commercial blades. As a selection criterion it was used the price-performance ratio evaluated using different experimental tests performed by students. The project was conducted in blended 
learning, combining laboratory sessions and study time of each student. Monitoring the work was carried out by conducting regular control meetings over the duration of the activity, as well as with the presentation of three "deliverables" throughout the activity.

The evaluation methodology was extensively detailed in the documentation provided for the project. A set of criteria to be evaluated in one or more of the activities, such as minutes of meetings, participation in wikis, ICT use, content and presentation videos, reports, etc. were defined In this way it was possible to conduct a competency assessment in agreement with the Bologna process (specific knowledge and transversal skills). However, each teacher had to adapt it to their university systems. With the evaluation of various activities it was possible to draw a note, which had the weight in the final grade indicated in table 1. This percentage is key to the development of the activity, since it has been shown that when the activity has no weight in the final grade the motivation of a large majority of students decreases dramatically (Antepohl, Herzig, 1997).

\section{Results and Discussion}

Acceptance of the project and the involvement of students had different nuances in each university. In the UPV/EHU and in the UMA it has been good; students generally have welcomed with interest the project although the degree of involvement has been uneven. At the UB it has been noticed that as they were senior students and small groups, their involvement was very high and so was the quality of their work. At the UJI, as it was a volunteer project with the most motivated students, their reception was excellent and the students were involved very much. Nevertheless, the average number of hours dedicated to the project exceeded $15 \%$ the plan. It was also noticed a certain degree of competitiveness that we believe may be beneficial since it reflects a personal involvement with the project and desire to excel. A direct correlation between the number of students involved in the PBL activity and the level of involvement and student motivation is observed then. We observed how a great number of students who developed PBL activity increased their interest in the subject. Possibly this behavior comes motivated by greater attention to the student by the teacher. A similar trend between the percentage of PBL activity on the final grade for the course and the level of involvement and student motivation is observed.

The project has eased to find objective ways to evaluate transversal competences as well as its evolution over the semester in the four universities. This process involves a change in evaluation methodology, hard to implement in the field of engineering.

It has been observed that the level reached in the competences of specific knowledge of the subject during the PBL activity had direct positive relationship in the outcome of the evaluation of the same competences by traditional methods (development of a written answer to a question). Therefore it is found that the specific knowledge gained through independent learning is solid and remains after the activity is finished.

In the discussion meetings that were held with students after the experience, the following perceptions were recorded: the students were very receptive and said it was an experience that allowed them to find their way. They noted that, initially, the transfer of responsibilities from the teacher to the students disturbed them, but as they proceeded with the project they developed more autonomous and more independent learning strategies. They agreed that, through the PBL, learning stayed longer. Unlike rote learning, this system provided them with greater retention over time. Despite the 
difficulties encountered with some members of their group, all participants recommend this method of learning to the rest of his classmates. The teachers, on their side, were satisfied with the experience, given the good results obtained; however, the project required an immense amount of work from the teachers and it was concluded that its organization should optimize instrument/evaluation criteria to make the evaluation more objective and less time consuming.

\section{Conclusions}

As a conclusion obtained from this work, the project-based learning arouses interest in the students and helps them to understand their own knowledge of the subject and therefore more successful working with specific skills. Also, this type of approach facilitates working transversal skills and creating and implementing activities and evaluation criteria for these competencies. Specifically, the PBL activity has improved skills in the students such as writing technical documents, search for information, teamwork and presentation of results. As the assessment was continuous, we observed great progresses in the different tests. For example, the quality of their exposition increased during the process. Therefore, this experience has been very positive for teachers but also for students. Some proposals for the future that we think that must be considered are:

- Involve the students in evaluating their peers

- Develop tools to carry out team work effectively and thus reduce the workload of students and teachers

- Improve the efficiency of the evaluation instruments

- Use evidence assessment activity (surveys) for internal use by teachers

Finally, we have demonstrated the feasibility of implementing the methodology of project-based learning with a similar project for different degrees and curricula, which opens prospects for their collaboration. This is the line of work that is intended to continue within the network of educational innovation IdM@ti.

\section{Acknowledgements}

Authors wish to thank the Vicerrectorado de Estudiantes, Ocupación e Innovación Educativa from Universitat Jaume I de Castellón for the financial support throught the Project (PIE 2907/14). Additionally the authors thank the Vicerrectorado de Innovación Docente from Universidad del País Vasco the financial support.

\section{References}

Antepohl, W., Herzig, S. (1997) Problem-based learning supplementing the course of basic phamacology - results and perspectives from two medical schools. NaunynSchmiedeberg's Archives of Pharmacology, 355, R18.

Barrows, H.S. (1986). A Taxonomy of problem-based learning methods. Medical Education, 20(6), 481-486.

Castells, M. (1996). La era de la información. Economía, sociedad y cultura. Vol. 1 México: Siglo XXI. 
Delors, J. (Coord) (1996): La educación encierra un tesoro. Informe a la UNESCO de la Comisión Internacional sobre la educación para el siglo XXI. Madrid, Santillana.

De Miguel, M. (coord.). (2005). Metodologías de enseñanza para el desarrollo de competencias. Orientaciones para el profesorado universitario ante el Espacio Europeo de Educación Superior. Madrid: Alianza.

Jonassen, D. H., S.,Khanna K., Implementing problem based learning in materials science, Proceedings of the 2011 ASEE Annual Conference and Exposition, Vancouver, 2011.

Moust, J.H.C., Bouhuijs, P.A.J., Schmidt, H.G. (2007). El aprendizaje basado en proyectos: Guía del estudiante. Cuenca: Ediciones de la UCLM.

Orozco, J., Guraya, T., Ibarretxe, J., Cabedo, L., Gómez, J., Izquierdo, R., Sales, D., González, D., Lopez-Crespo, P., Segarra, M., Salan, N., Olivella, G., (2012) Interuniversity network for Innovation in Materials Science Teaching, Proceedings of 4th International Materials Education Symposium.

Pawson, E., Fournier, E., Haight, M., Muniz, O., Trafford, J., And Vajoczki, S. 2006. Problem-based learning in geography: Towards a critical assessment of its purposes, benefits and risks. Journal of Geography in Higher Education 30 (1), 103-116.

Pozo, J.I. (2006). La nueva cultura del aprendizaje en la sociedad del conocimiento. In J.I Pozo; N. Scheuer; M. del P. Pérez; M. Mateos; E. Martín y M. de la Cruz. Nuevas formas de pensar la enseñanza y el aprendizaje. Barcelona: Graó.

Reeves, T Y Laffey, J. (1999). Design, assessment, and evaluation of a problem-based learning environment in undergraduate engineering.Higher Education Research and Development, 18(2), 219-232.

Schmidt, H.G. (1983). Problem-based learning: rationale and description. Medical Education, 17, 11-16

Vizcarro, C. Y Juárez, E. (2009) ¿Qué es y cómo funciona el aprendizaje basado en proyectos? La metodología del Aprendizaje Basado en proyectos. Consultado en fecha 20/01/2015. http://www.ub.edu/dikasteia/LIBRO_MURCIA.pdf 


\title{
Assessment of problem-solving skills in subjects related to mechanical and materials engineering
}

\author{
J. Martínez-Casas, O. Sahuquillo, A. Sonseca, J. Carballeira, F. D. Denia, O. Marco \\ Departamento de Ingeniería Mecánica y de Materiales, Universitat Politècnica de València (UPV), \\ Camino de Vera s/n, 46022 Valencia (Spain)
}

\begin{abstract}
The international accreditation for the Master and Bachelor degrees offered at our university, together with the demands of the employers, have made it clear that students' curricula should specify not only what they have studied, but also what they are actually able to do. Although the competence based curricula approach has been used in the development of the new programmes for Master and Bachelor degrees within the European Higher Education Area in recent years, the assessment of generic competences is still a pending task. This work presents an 'outcomes' approach for the assessment of the problem-solving capacity in subjects related to mechanical and materials engineering. In particular, this paper proposes a scale in order to quantify the level of achievement and shows some tools developed for this purpose. These tools are based on the evaluation of some learning outcomes that can be observed by using different strategies during the course. Conclusions about preliminary results and the difficulties found in order to create these tools and the scale are also described here.
\end{abstract}

Keywords: competence assessment; learning outcomes; capacity for problem analysis

\section{Introduction}

Bachelor and Master degree programmes developed at our university within the frame of the European Higher Education Area follow a competence based approach (A. Sursock, 2010; Murias, de Miguel, \& Rodríguez, 2007; Rieckmann, 2012). These programmes clearly define the specific and generic competences to be worked in each degree, and also, the particular subjects along the degree. The assessment of the specific competences continues to be reflected on the students' curricula by using numerical qualifications, but the assessment of the generic competences has been passed over somehow, and it is understood that the students would have acquired these capacities and skills at the end of the studies. The international accreditation of these programmes, together with the requirements of the employers to have better information on the students' competences, have put the university to work on this issue (Andrews \& Higson, 2008; Entwistle \& Peterson, 2004).

This paper presents some results obtained in the frame of an innovative project (PIME program) on the evaluation of three generic competences that have been traditionally worked in subjects of mechanical and materials engineering: capacity for problem solving; capacity for applying knowledge in practice; and communication skills, using name convention from Tuning (2014). In particular, in this work a methodology for the assessment of the competence on problem solving has been developed.

The definition used in this work for the competence on problem solving refers to the capacity to analyse and solve a problem in an effective way, identifying and determining the most relevant parts of it. The main aim in developing this competence is that the students increase their self-confidence and promote their own capabilities and skills to learn, understand and apply their knowledge. It is an important competence that contributes to the lifelong self-learning of the student, and helps in the developing of some other competences as team working, creativity, critical analysis and leadership.

It should be also noticed that problems are not exercises, i.e., problems refer to new open situations that encourage individuals to use new approaches (Pozo Municio, J.I., 
\& Pérez Echevarría, M.P 2009). These situations can be solved by using different strategies, and they do not usually have only one solution. Solving a problem implies using thinking skills, and not only repeating a known procedure to obtain the solution.

This competence can be decomposed in different learning outcomes that can be summarised as follows (see also Table $\mathbf{1}$ ):

- To identify a real problem and define precisely the most relevant facts.

- To apply the methods learned to analyze a problem, gather relevant information and propose different alternative solutions.

- Using the experience and judgment to generate an efficient and effective solution.

First in this paper, the methodology proposed for the assessment of the competence on problem solving is presented. This methodology is based on the use of real complex problems that force the students to put the aforementioned skills into practice. The solution process is then evaluated by using a checklist that has been developed from the learning outcomes. This checklist allows the authors to quantify the level of achievement of the students in order to give a numerical evaluation.

Some preliminary results regarding a first attempt to use this checklist in two subjects of Bachelor and Master degrees are also described here. Finally, some conclusions are derived from this experience in order to improve the methodology in the future.

\section{Methods}

To carry out the evaluation of the competence on problem solving in Bachelor and Master degree students, they are asked to solve an individual problem. This problem and its evaluation are designed to make clear if the learning outcomes have been achieved: from problem identification to critical analysis of solution, together with the information gathering, the proposed methodology as well as the reasoning to choose it. Proceeding in this way, the student is not only encourage to problem solving, but also self-learning, based problems learning, critical thinking and written communication competence are promoted in an indirect manner.

In Table 1, the learning outcomes are developed into increasing levels of achievement: "low", "low-medium", "medium”, "medium-high", "high" and "master", and some evidences regarding these outcomes are proposed. From these evidences, the checklist detailed in Table 2 has been considered as the evaluation tool. It is structured in nine items in order to evaluate the different key aspects of problem solving. Items 1 and 2 refer to the first learning outcome; items 3-6 to the second one; and items 7 to 9 to the last one. 
Table 1. Learning outcomes and achievement levels for the competence on problem solving

\begin{tabular}{|c|c|c|c|c|c|c|c|}
\hline $\begin{array}{l}\text { LEARNING } \\
\text { OUTCOMES }\end{array}$ & Low & Low-Medium & Medium & $\begin{array}{l}\text { Medium-High } \\
\text { undergraduate }\end{array}$ & High & Master & EVIDENCES \\
\hline $\begin{array}{l}\text { To identify a real } \\
\text { problem and define } \\
\text { precisely its most } \\
\text { important facts }\end{array}$ & $\begin{array}{l}\text { The student is able to } \\
\text { identify with difficulty a } \\
\text { real problem and } \\
\text { define the most } \\
\text { important facts }\end{array}$ & $\begin{array}{l}\text { The student is able to } \\
\text { identify a real problem, but } \\
\text { discriminating with } \\
\text { difficulties proven facts } \\
\text { from speculations }\end{array}$ & $\begin{array}{l}\text { The student is able to } \\
\text { identify a real problem } \\
\text { and its causes, but } \\
\text { provides very limited } \\
\text { assumptions about its } \\
\text { origin }\end{array}$ & $\begin{array}{l}\text { The student is able to } \\
\text { identify a real problem } \\
\text { and evaluate the origin } \\
\text { and impact of the } \\
\text { different causes }\end{array}$ & $\begin{array}{l}\text { The student is able to } \\
\text { identify complicated } \\
\text { problems, to evaluate } \\
\text { its causes and split } \\
\text { them into manageable } \\
\text { parts }\end{array}$ & $\begin{array}{l}\text { The student is able to } \\
\text { identify complicated } \\
\text { problems in diverse } \\
\text { areas with global point } \\
\text { of view }\end{array}$ & $\begin{array}{l}\text { To stablish } \\
\text { parallelisms; to find } \\
\text { real examples; to } \\
\text { formulate a } \\
\text { theoretical problem } \\
\text { from real situations }\end{array}$ \\
\hline $\begin{array}{l}\text { To apply the methods } \\
\text { learned to analyze a } \\
\text { problem, gather } \\
\text { relevant information } \\
\text { and propose different } \\
\text { alternative solutions }\end{array}$ & $\begin{array}{l}\text { The student is able to } \\
\text { analyze a problem in } \\
\text { a limited way by the } \\
\text { methods learned and } \\
\text { shows difficulty to } \\
\text { distinguish different } \\
\text { alternative solutions }\end{array}$ & $\begin{array}{l}\text { The student is able to } \\
\text { analyze a problem using } \\
\text { learned methods, but } \\
\text { reproduces them in an } \\
\text { associative and } \\
\text { monotonous way, } \\
\text { distinguishing relevant } \\
\text { information and proposing } \\
\text { alternatives with difficulties }\end{array}$ & $\begin{array}{l}\text { The student is able to } \\
\text { analyze a problem } \\
\text { using learned } \\
\text { methods, collecting } \\
\text { relevant information, } \\
\text { but proposing few } \\
\text { alternatives }\end{array}$ & $\begin{array}{l}\text { The student is able to } \\
\text { analyze an original } \\
\text { problem using learned } \\
\text { methods, collecting } \\
\text { relevant information and } \\
\text { proposing alternatives }\end{array}$ & $\begin{array}{l}\text { The student is able to } \\
\text { analyze a complicated } \\
\text { problem arguing, } \\
\text { approximately, the } \\
\text { risks and benefits of } \\
\text { several possible } \\
\text { solutions }\end{array}$ & $\begin{array}{l}\text { The student is able to } \\
\text { analyze a complicated } \\
\text { problem evaluating } \\
\text { possible solutions } \\
\text { based on scientific } \\
\text { and technical } \\
\text { feasibility }\end{array}$ & $\begin{array}{l}\text { To evaluate solving } \\
\text { problem process; to } \\
\text { suggest problems } \\
\text { with multiple } \\
\text { solutions; to justify } \\
\text { the methodology } \\
\text { and data used }\end{array}$ \\
\hline $\begin{array}{l}\text { Using the experience } \\
\text { and judgment to } \\
\text { generate an efficient } \\
\text { and effective solution }\end{array}$ & $\begin{array}{l}\text { The student is } \\
\text { capable of solving, } \\
\text { with difficulties, known } \\
\text { problems by means of } \\
\text { a learning method }\end{array}$ & $\begin{array}{l}\text { The student is able to } \\
\text { efficiently solve known } \\
\text { problems using learned } \\
\text { methods }\end{array}$ & $\begin{array}{l}\text { The student is able to } \\
\text { solve an original } \\
\text { problem using known } \\
\text { methodology and } \\
\text { validating the solution } \\
\text { according to its order } \\
\text { of magnitude }\end{array}$ & $\begin{array}{l}\text { The student is able to } \\
\text { solve original problems } \\
\text { discussing the chosen } \\
\text { solution }\end{array}$ & $\begin{array}{l}\text { The student is } \\
\text { capable of solving } \\
\text { complicated problems } \\
\text { anticipating the } \\
\text { solution intuitively }\end{array}$ & $\begin{array}{l}\text { The student is able to } \\
\text { solve a complicated } \\
\text { problem with a global } \\
\text { point of view, from the } \\
\text { analysis of its causes } \\
\text { to monitoring the } \\
\text { chosen solution }\end{array}$ & $\begin{array}{l}\text { Spent time; order of } \\
\text { magnitude; to justify } \\
\text { implications } \\
\text { (causes, alternative } \\
\text { solutions) }\end{array}$ \\
\hline
\end{tabular}


Table 2. Checklist as assessment strategy to evaluate the competence

\begin{tabular}{|c|c|c|c|}
\hline & Checkpoint & Yes or no? & To what extent? \\
\hline 1 & The student clearly identifies the object of the problem & $\begin{array}{l}\text { Yes } \square \\
\text { No } \square\end{array}$ & $\begin{array}{ll}\text { 1. } & \text { Inappropiate } \\
\text { 2. } & \text { Sufficient } \\
\text { 3. } & \text { Appropiate }\end{array}$ \\
\hline 2 & $\begin{array}{l}\text { The student splits the problem into simpler, more } \\
\text { manageable parts }\end{array}$ & $\begin{array}{l}\text { Yes } \square \\
\text { No } \square\end{array}$ & $\begin{array}{ll}\text { 1. } & \text { Inappropiate } \\
\text { 2. } & \text { Sufficient } \\
\text { 3. } & \text { Appropiate }\end{array}$ \\
\hline 3 & $\begin{array}{l}\text { The student collects relevant information for the } \\
\text { resolution of the problem }\end{array}$ & $\begin{array}{l}\text { Yes } \square \\
\text { No } \square\end{array}$ & $\begin{array}{ll}\text { 1. Inappropiate } \\
\text { 2. Sufficient } \\
\text { 3. Appropiate }\end{array}$ \\
\hline 4 & $\begin{array}{l}\text { The student describes schematically the resolution } \\
\text { procedure followed to obtain the solution }\end{array}$ & $\begin{array}{l}\text { Yes } \square \\
\text { No } \square\end{array}$ & $\begin{array}{ll}\text { 1. } & \text { Inappropiate } \\
\text { 2. } & \text { Sufficient } \\
\text { 3. } & \text { Appropiate }\end{array}$ \\
\hline 5 & The student proposes several methods of resolution & $\begin{array}{l}\text { Yes } \square \\
\text { No } \square\end{array}$ & $\begin{array}{ll}\text { 1. } & \text { Inappropiate } \\
\text { 2. } & \text { Sufficient } \\
\text { 3. } & \text { Appropiate }\end{array}$ \\
\hline 6 & $\begin{array}{l}\text { The student states the methods used and justifies their } \\
\text { utilization }\end{array}$ & $\begin{array}{l}\text { Yes } \square \\
\text { No } \square\end{array}$ & $\begin{array}{ll}\text { 1. } & \text { Inappropiate } \\
\text { 2. } & \text { Sufficient } \\
\text { 3. } & \text { Appropiate }\end{array}$ \\
\hline 7 & $\begin{array}{l}\text { The student justifies, if necessary, estimated values using } \\
\text { its own knowledge and background }\end{array}$ & 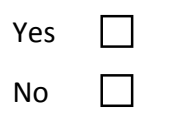 & $\begin{array}{ll}\text { 1. } & \text { Inappropiate } \\
\text { 2. } & \text { Sufficient } \\
\text { 3. } & \text { Appropiate }\end{array}$ \\
\hline 8 & $\begin{array}{l}\text { The student discusses or criticizes the solution obtained } \\
\text { and compares it with the expected order of magnitude }\end{array}$ & $\begin{array}{l}\text { Yes } \square \\
\text { No } \square\end{array}$ & $\begin{array}{ll}\text { 1. } & \text { Inappropiate } \\
\text { 2. } & \text { Sufficient } \\
\text { 3. } & \text { Appropiate }\end{array}$ \\
\hline 9 & $\begin{array}{l}\text { The student is efficient to achieve the solution and does } \\
\text { not need many detours }\end{array}$ & $\begin{array}{l}\text { Yes } \square \\
\text { No } \square\end{array}$ & $\begin{array}{ll}\text { 1. } & \text { Inappropiate } \\
\text { 2. } & \text { Sufficient } \\
\text { 3. } & \text { Appropiate }\end{array}$ \\
\hline
\end{tabular}

** The answer “No" gives a score of 0 points. It is not necessary to complete the field “To what extent?”

\begin{tabular}{|c|c|c|c|c|c|c|c|c|c|c|}
\cline { 2 - 7 } & $\begin{array}{c}\text { Item } \\
1\end{array}$ & $\begin{array}{c}\text { Item } \\
2\end{array}$ & $\begin{array}{c}\text { Item } \\
\mathbf{3}\end{array}$ & $\begin{array}{c}\text { Item } \\
\mathbf{4}\end{array}$ & $\begin{array}{c}\text { Item } \\
\mathbf{5}\end{array}$ & $\begin{array}{c}\text { Item } \\
\mathbf{6}\end{array}$ & $\begin{array}{c}\text { Item } \\
7\end{array}$ & $\begin{array}{c}\text { Item } \\
8\end{array}$ & $\begin{array}{c}\text { Item } \\
\mathbf{9}\end{array}$ & TOTAL \\
\hline Score & & & & & & & & & & \\
\hline
\end{tabular}

Table 3. Range values to obtain the achievement level of the competence

\begin{tabular}{cccccc}
\hline \multicolumn{5}{c}{ PROBLEM SOLVING SCALE } \\
\hline LOW & $\begin{array}{c}\text { LOW- } \\
\text { MEDIUM }\end{array}$ & MEDIUM & MEDIUM-HIGH & HIGH & MASTER \\
From 0 to $<5$ & From 5 to $<10$ & From 10 to $<14$ & From 14 to $<18$ & From 18 to $<23$ & From 23 to $<27$ \\
\hline
\end{tabular}


The problem identification, and whether it is split up into smaller and easier units to solve, respectively, are considered in the first two items. The information gathering is reflected in item 3. Regarding the proposed methodology, items 4-6 involve its description taking into account if several proposals are used to validate the resolution and if the choice of the followed method is justified, respectively. Item 7 refers to the estimation of the data for problem resolution and its justification, while item 8 comprises the analysis done of the problem solution guarantying the expected order of magnitude. Finally, the efficacy in problem resolution is captured in item 9.

According to Table 2, each of these checkpoints is assigned with a score from 0 to 3 when the level of achievement is "inappropriate", "sufficient" and "appropriate", respectively. A value range is ascribed to each level, detailed in Table 3. Consequently, depending on skills reflected in the total mark obtained from the checklist, the student will achieve one competence level or another. These competence levels have been defined so that all the Bachelor degree students can be included in the first four levels, while Master students should be in the two latter.

\section{Results and Discussion}

The methodology described above and used to evaluate the competence of problem solving, consists of the activity and assessment tool and the decomposition of the competence in learning outcomes and achievement levels. This methodology has been implemented in both Bachelor degree and Master subjects. The results obtained are analyzed and discussed below.

Figure 1 shows the score of the activity assessment, which has consisted of solving problems independently and individually. This evaluation has been carried out by the Checklist, where each item is scored on a $0-3$ range, and the maximum score for activity is 27 points. In Figure 1a) the final score for each evaluated evidence is detailed, for Bachelor degree and Master students. In all evidence collected during the course, a higher final score is observed for Master students compared to Bachelor degree students. If the analysis is performed for each item defined in the Checklist (except item 5 that has been discarded because it could not be assessed in the Bachelor degree problems), as shown in Figure 1b), the average score on each checkpoint for Master students is again higher than the one corresponding to Bachelor degree students. It is important to note that the evaluations of items 7 and 8 show the lowest scores, associated with a poor justification of the used data and insufficient analysis of results, respectively.

Figure 2 is obtained if the items are grouped into learning outcomes, as discussed in the previous section. The score is reflected in terms of percentage of the total score. It should be noted that in the first learning outcome there is little discrepancy (3.5\%) between Bachelor degree and Master students, that is, both are able to identify the objective of the problem and split into simpler parts. Regarding the second learning outcome, which is based on the collection of information, description and justification of the methodology followed to solve the problem, a notable discrepancy (19\%) is observed, the Master students showing higher skills. Finally, in the third learning outcome, there is a large discrepancy between Master and Bachelor degree students, 52\% approximately. Therefore, Master students have greater skills to estimate and justify problem data, critically analyse the solution and do it effectively and efficiently. 


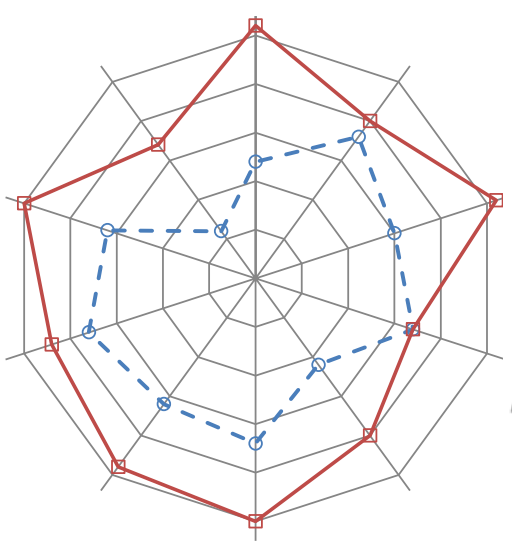

a)

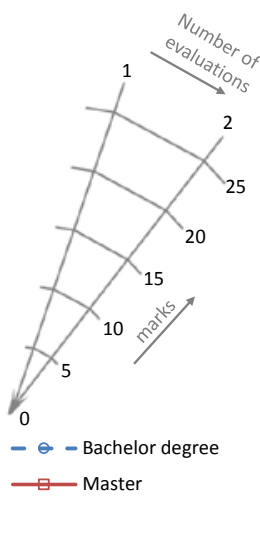

)

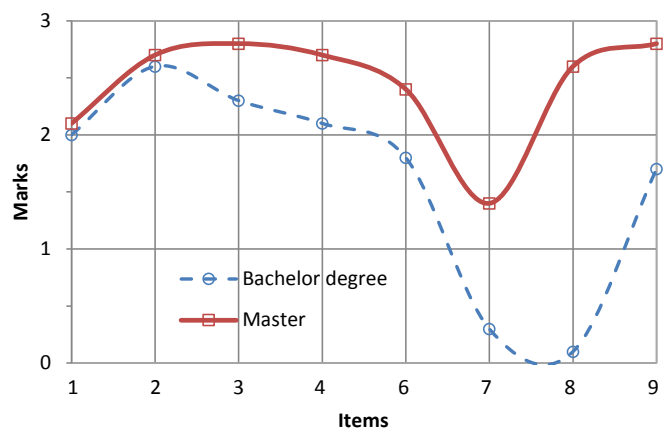

b)

Figure 1. Marks obtained on the different evidences collected during the course for Bachelor degree and Master students. a) Total marks from Checklist. b) Average marks for each item of Checklist

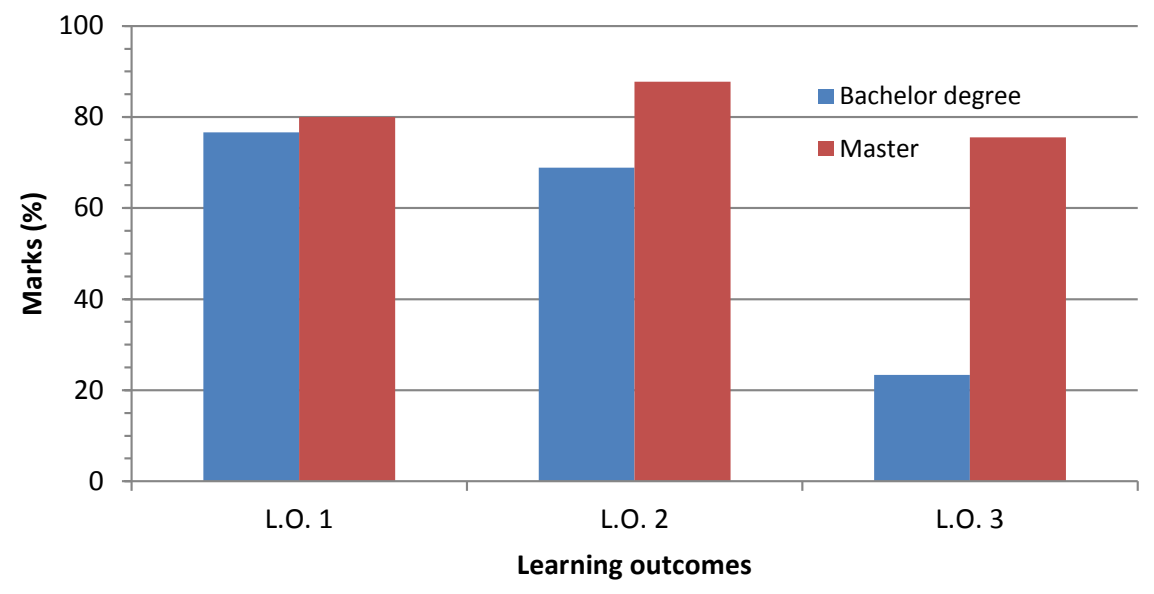

Figure 2. Percentage marks obtained on three learning outcomes for Bachelor degree and Master students

Taking into account that the aim of the work is to develop a methodology able to evaluate the competence on problem solving, Figure 3 details the assessment of such competence for Bachelor degree and Master students by applying the methodology described before. Regarding Bachelor degree students, it is observed that $80 \%$ of them reach levels of competence framed in the first 4 levels associated with Bachelor degree courses. As it can be seen, the approximate distribution yields $10 \%$ "low-medium" level, 20\% "medium" level and 50\% "medium-high" level, the remaining being $10 \%$ "high" level, reserved for Master skills. On the other hand, it is observed that the level achieved by Master students is higher than that for Bachelor degree students, as expected. In this case, $80 \%$ of Master students are in areas associated with Master courses (last two levels), 30\% being "high" level and 50\% reaching "master" level. The remaining $20 \%$ has a "medium-high" level associated with the last course of Bachelor degree. 


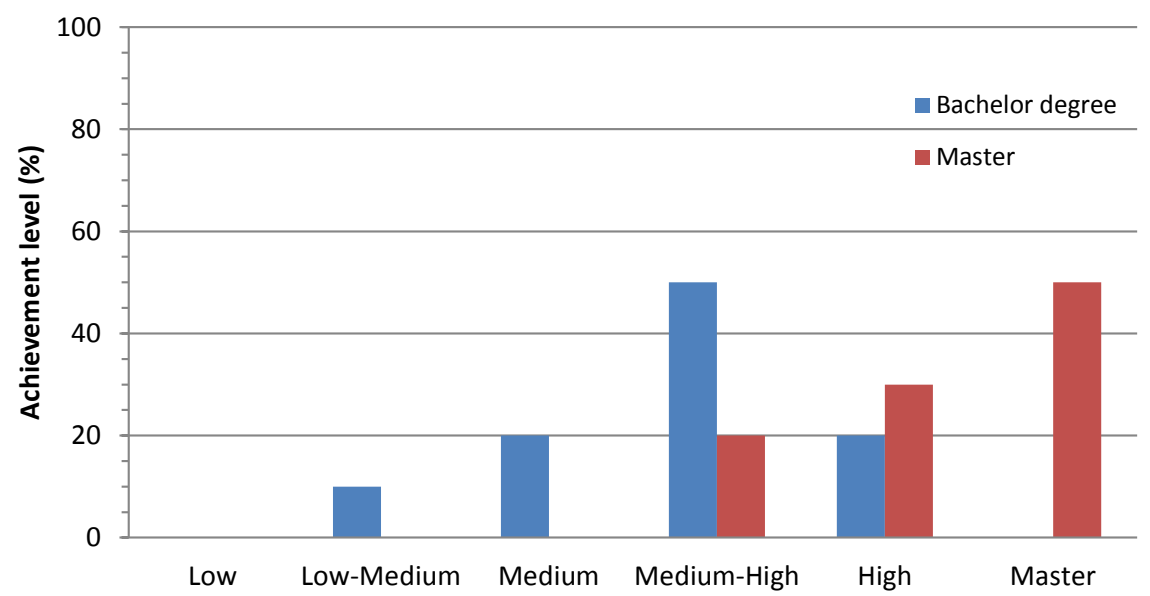

Figure 3. Comparison of competence achievement levels for Bachelor degree and Master students

After analysing the different results, that is, the individual items' assessment, the total scores of evidences and the achievement levels, it is observed in all of them that Master students have more skills to solve problems, as expected. Therefore it can be stated that the methodology described for carrying out the assessment of the problem solving competence is effective and reliable, from activity and assessment tool to the definition of its learning outcomes and achievement levels.

\section{Conclusions}

A methodology has been defined to carry out the assessment of the problem solving competence achieved by Bachelor degree and Master students. For this purpose, an individual and complex real problem has been adopted as the evaluation activity. The student must identify the problem and gather the necessary information, propose and justify solving methodologies in order to obtain an efficient and effective solution and critically analyze it.

To evaluate such activity, a Checklist has been defined as an evaluation tool. It is split into 9 items that collect the most relevant aspects of problem solving and are scored at a range of $0-3$ points, the maximum score for evidences being 27 points. In order to identify the achievement level, once the evidence is evaluated, the competence is decomposed in three learning outcomes, each one structured into six achievement levels, with a score range assigned. Consequently, the methodology allows to identify the problem solving skills of the students and to assign them an achievement level.

The proposed methodology has been proved in Bachelor degree and Master courses, and the results have been analysed. It is concluded from the analysis that Master students have higher skills than Bachelor degree students in all checkpoints assessed for problem solving. However, it is important to note that the lowest score is found in items 7 and 8 for Bachelor degree and item 7 for Master students. That is, the students show deficiencies when justifying the estimates data for problem solving and perform a very limited review of the solution obtained. On the other hand, the students show a good ability to split the problem into simpler parts, to collect relevant information and 
to describe schematically the resolution procedure followed to obtain the solution, items 2-4 respectively.

In general terms, after comparing the achievement levels, the Master students show competence levels mostly "high" and "master", while Bachelor degree students are located on "medium" and "medium-high" levels. As expected, Master students have more skills than Bachelor degree students, so it can be concluded that the proposed methodology is valid and reliable to perform the assessment of the competence on problem solving.

\section{Acknowledgements}

The authors acknowledge the financial contribution of Universitat Politècnica de València through the project PIME/2014/A/012/B.

\section{References}

A. Sursock, H. S. (2010). Trends 2010: A decade of change in european higher education. Brussels: European University Association.

Andrews, J., \& Higson, H. (2008). Graduate employability, 'Soft skills' versus 'Hard' business knowledge: A european study. Higher Education in Europe, 33, 411-422.

Entwistle, N. J., \& Peterson, E. R. (2004). Conceptions of learning and knowledge in higher education: Relationships with study behaviour and influences of learning environments. International Journal of Educational Research, 41, 407-428.

Murias, P., de Miguel, J. C., \& Rodríguez, D. (2007). A composite indicator for university quality assesment: The case of Spanish higher education system. Social Indicators research, 89, 129-146.

Pozo Municio, J.I., \& Pérez Echevarría, M.P (2009). Psicología del aprendizaje universitario. Madrid: Morata.

Rieckmann, M. (2012). Future-oriented higher education: Which key competencies should be fostered through university teaching and learning?. Futures, 44, 127-135.

Tuning project. (2014). Approaches to teaching, learning and assessment in competences based degree programmes. Retrieved July 22, 2014, from http://www.unideusto.org/tuningeu/teaching-learning-a-assessment.html 


\title{
Interdisciplinary and integrative learning of neuroscience in first-year Psychology students
}

\author{
M.J. Álvarez Comino*, G. González Cuevas*, B. Navarro-Galve**, E. Velarde \\ Fernández** \\ * Department of Psychology, School of Biomedical Sciences and Health, European University of \\ Madrid \\ ** Department of Biomedical Basic Sciences, School Of Biomedical Sciences and Health, European \\ University of Madrid
}

\begin{abstract}
This work describes a novel learning experience designed by professors from four distinct first-year Psychology courses at the European University of Madrid. In general, first-year Psychology students are lacking a sense of interfield integration and unity of neuroscience. Therefore, our ultimate goal was to help students perceive continuity between neuroscience-related courses, promote interprofessionalism, and avoid compartmentalization. The specific aims were to generate transversal knowledge and integrate contents by coordinating and developing interdisciplinary learning activities. These courses share the common thread of teaching the psychological processes: sensation, perception, attention, learning and memory, as well as their biological and neurophysiological bases. This practice was designed to utilize high-impact educational methodologies based on meaningful and experiential learning approaches, in addition to active learning methods such as problem-based learning (PBL). All in all, students improved their knowledge of transversality and interprofessionalism required in learning neuroscience. Introducing these concepts in the training of first-year Psychology students may help in fostering effective strategies in the teaching of psychology.
\end{abstract}

Keywords: interdisciplanarity, neuroscience, experiential learning, transversality, interprofessionalism, psychology

\section{Introduction}

During the academic year of 2013-2014 the undergraduate degree in Psychology (BSc) was inaugurated at the European University of Madrid (EUM). In the beginning weeks we noticed that students showed difficulties in integrating the contents of their interdisciplinary courses, especially in appreciating the complementary value of courses such as Sensation, Perception and Attention, and Learning and Memory (basic psychological processes) and Biology and Physiology (their underlying biological and physiological substrates). For this reason, we set out to create an innovative experience for first-year Psychology students.

Undoubtedly, the field of neuroscience is partly comprised of the above subjects. Therefore, it is important for our students to consider them as forming a cohesive block. The interdisciplinary nature of neuroscience in the context of Health Sciences is a topic that has been introduced into the classroom since the last decade. Indeed, it is of special importance nowadays in Psychology when referring to concentrations, interprofessionalism, and future professional work (Bombín y Caracuel, 2008).

These courses provide knowledge at the forefront of interdisciplinary research, as well as training in skills related to the collection and interpretation of relevant data. In addition, they are also in agreement with the MECES competences (for a review, see Pereira \& Molina, 2012), which include the demonstration of knowledge regarding: (a) the basic laws ruling the various psychological processes; (b) the abnormal and normal processes as well as main stages of psychological development, and (c) the biological underpinnings of human behavior and psychological functions. 
Furthermore, a series of transversal competences are in line with these subjects, such as autonomous learning, information management, capacity to apply practical knowledge, communication and information technology skills, and capacity of analysis and synthesis. The specific competence found in all of the courses is the capacity to describe and measure variables (personality, intelligence and other aptitudes, attitudes, and so on) and cognitive, emotional, psychobiological and behavioral processes.

A common denominator shared by these courses is the inclusion of the psychological processes: sensation, perception, attention, memory, and learning, as well as their underlying biological and neurophysiological substrates. Our priority was to increase the sense of unity of these various subjects by the integration of scientific research methodologies, the application of practical cases through problem-based learning, and basic research knowledge. For this reason, we designed a set of activities meant to contribute to the development of meaningful learning and the above competencies. These activities consisted of visiting the Cerebral Cartography Center and completing an assignment by using material by various courses (a problem-based learning activity with similar structure and orientation) and other specific tasks.

Meaningful learning refers to a way of learning where the new knowledge acquired is related to previous knowledge (Ausubel, 2002; Palmero, 2004). In accordance with this method of learning, this project helped learners connect contents from diverse courses, previous knowledge, and personal experiences. Given that personal experiences played an important role in the learning process, this project also promoted experiential learning (Kolb, 1984).

The main objective was to cover the topics of multidisciplinarity and interprofessionalism in the field of neuroscience. Professors from four different courses taught over three trimesters in the first year of the Psychology degree set out the challenge of generating transversal knowledge and integrating of contents by coordinating and designing of interdisciplinary activities. The specific aims were: (1) to encourage interprofessionalism by sharing a common core that gave students a sense of content continuity; by eliminating content overlapped and compartmentalization; and (2) to create experiencies coordinated by professors belonging to distinct departments and faculties with the ultimate goal of developing projects focused on multidisciplinarity learning.

The concrete actions we implemented to reach the objectives in this project were (a) the design of curricular activities (not only specific for each course but also integrative); (b) the evaluation of such activities; as well as (c) the assessment of the degree of interest and motivation students show.

\section{Methods}

Two groups of students participated in the practice: 19 students from the Psychology degree (all of them taking the four subjects in a transversal manner) and 17 students from the Psychology-Criminology double degree (only taking one of the subjects, Physiology). This second group served as a control to evaluate global results and perception differences among students. 
The subjects that got involved in the experience were: Behavioral biology and Sensation, Perception and Attention (both from the first trimester); Physiology (from the second trimester and the common link between both groups of students); and Learning and Memory processes (from the third trimester).

A variety of formative activities were designed and developed as part of the evaluation system of each subject, including individual tasks, oral presentations, analysis of scientific texts, and tests regarding the contents prepared by the different methodologies (problem-based learning, visit to a Cerebral Cartography Center). The methodologies regarding the present work are summarized below:

Problem Based Learning (PBL) was applied in the four subjects according to a common perspective: introducing the students to the scientific method and neuroscience research, as well as its potential role in diagnosis and clinic application in Psychology (Wood F., 2003). Professionals in neuroscience research from other institutions also participated in specific sessions with the students, in order to tell their experiences and provide information of current neuroscience research. Grades obtained in these PBL assignments were part of the global evaluation plan of the four subjects.

There was an organized visit to the Cerebral Cartography Center, which is dedicated to the study of cerebral function from different experimental approaches including neurophysiology, behavioral tests and microPET neuroimaging (positron emission tomography). This institution is part of the Centers for Research Support coordinated by the Research School of the Complutense University of Madrid, but it is also a Research Entity from the Pluridisciplinar Institute.

All the students were asked to make a reflection prior to the visit to focus their attention on three key points: types of experimental techniques, research projects and their application in Psychology. All answers were divided into two options: yes or no. Sixteen reflections were handed in and their results were analyzed by means of descriptive statistics. After the visit, the students were given an assignment regarding neuroimaging techniques and their role on mental diseases diagnosis. The grade obtained in this task was part of the Physiology evaluation.

Finally, both groups of students filled out a survey requesting their opinion about the transversal activity and the other formative assignments, as well as their perception on connection among subjects. Comparison between both groups of students was used to evaluate the impact of the transversal development of contents. The students from the double degree were used as a control as they only took one of the subjects. Results were organized by means of Likert-type ordinal scales, and data were analyzed by descriptive statistics methods. Mean comparison between groups was estimated by ttest (for independent groups).

\section{Results and Discussion}

Each subject included the grades for the formative activities described above as part of their evaluation plan. 
From the data obtained in the reflection prior to the visit to the Cerebral Cartography Center, it can be inferred that whereas a high percentage of psychology students is aware of the role played by neuroimaging techniques in the study of mental processes such as thinking and emotion (81.3\%), or in lying detection (68.8\%), most of them (93.8 \%) consider that the psychologist's work cannot be replaced by new technologies (Fig 1).

\section{QUESTION 1}

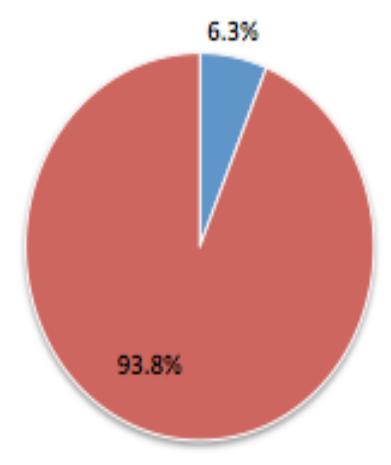

QUESTION 2

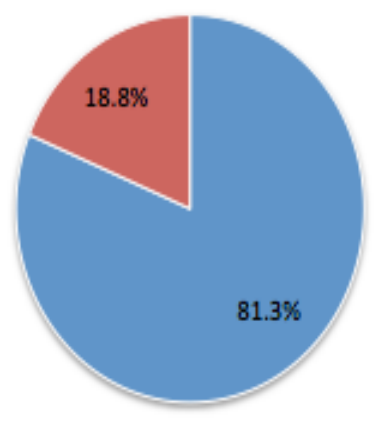

QUESTION 3

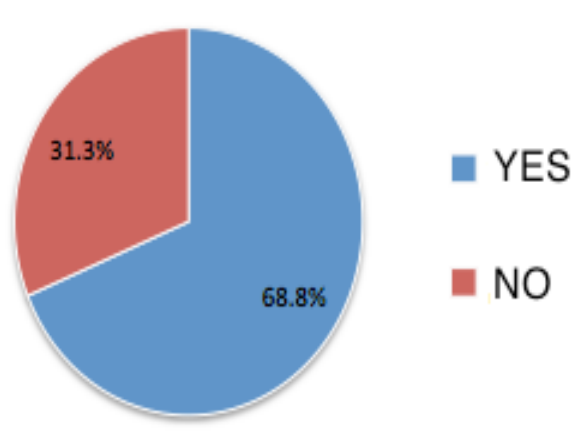

Figure 1. Data obtained from the reflection prior to the visit expressed as percentages to QUESTION 1) Can technological development replace a psychologist work?, QUESTION 2) Can neuroimaging techniques be considered as a way to access thoughts and emotions?, and QUESTION 3) Is it possible to spot a liar?

The results gathered after the visit to the Cerebral Cartography Center show that students from the Psychology group rated it as "quite interesting" (47.1\%) or "very interesting" (52.9\%), meanwhile the double degree students considered it "fairly interesting" (63.6\%) or "quite interesting" (36.4\%) (Fig 2a, Annex). There is a statistically significant difference between each group means: Psychology (4.53 \pm 0.13$)$ vs. Psychology-Criminology (3.36 \pm 0.15$) ; \mathrm{p}<0.001$.

Most of the students from both groups rated the visit at least as "fairly related" to each subject contents. However, the percentage of students that evaluate it as "quite related" or "very related" was higher within the Psychology degree students (100\% in the Psychology group compared with 36,4\% in the Psychology-Criminology group). Among the students of the double degree group, 27.3\% estimated the visit was "slightly related" to class contents. (Fig. 2b, Annex). No statistically significant differences could be found between means of each group: Psychology $(4.00 \pm 0.15)$ vs. Psychology-Criminology (3.55 \pm 0.34$)$; NS.

Regarding a possible collaboration in research projects at the encephalography (EEG) laboratory, $94.1 \%$ of the Psychology group students and $81.8 \%$ of the double degree group showed their interest in taking part (Figure 2c, Annex). We found a statistically significant difference between each group means: Psychology $(3.47 \pm 0.12)$ vs. Psychology-Criminology (2.73 \pm 0.30$) ; \mathrm{p}<0.05$.

Different factors modulated the motivation to participate in a research project in the EEG laboratory, as it can be seen in figure 2d. In the majority of cases (59\% and $62.5 \%$ respectively for each group) the schedule was the main restraint. It is noteworthy that $6.3 \%$ of the Psychology students were willing to participate either way. 
QUESTION 1

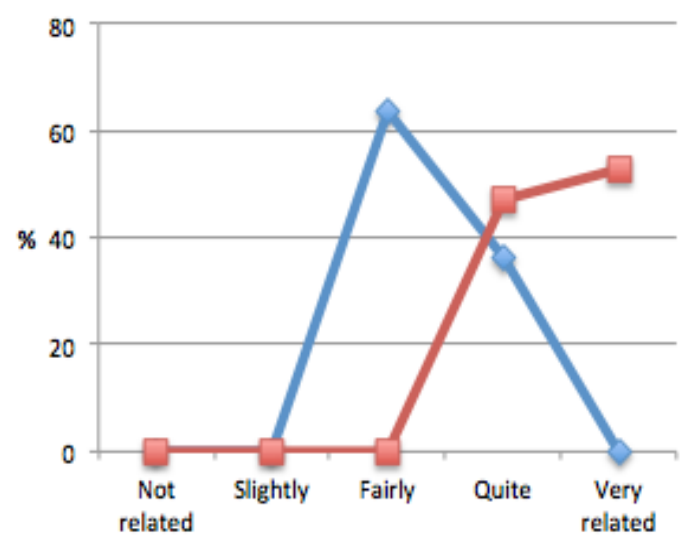

QUESTION 2

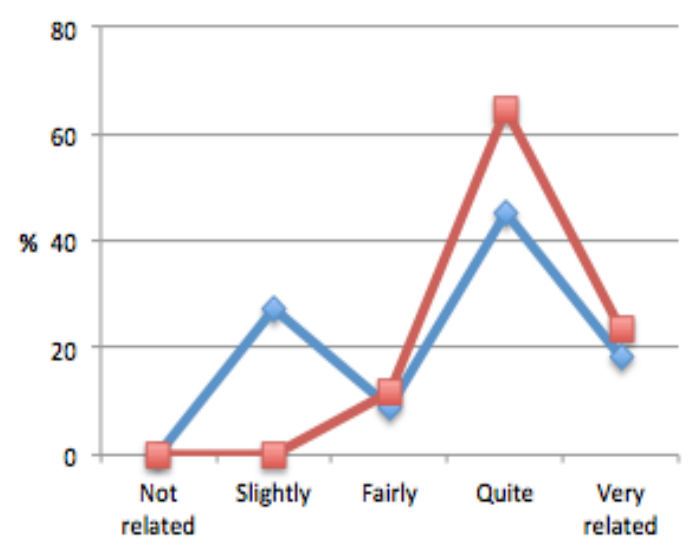

QUESTION 3

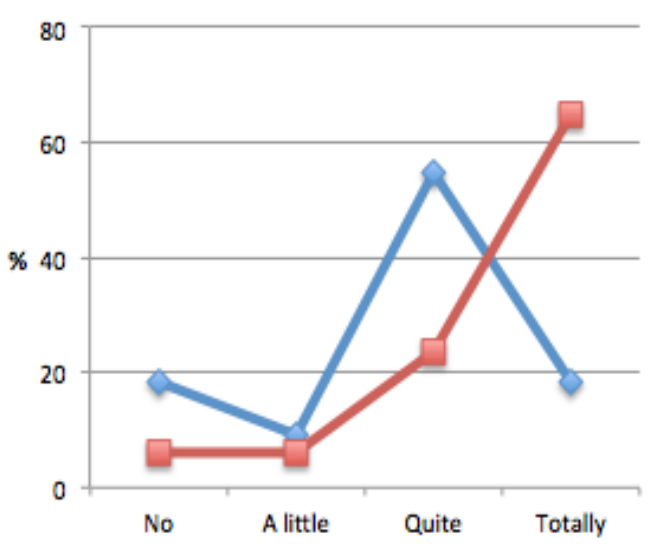

\section{QUESTION 4}

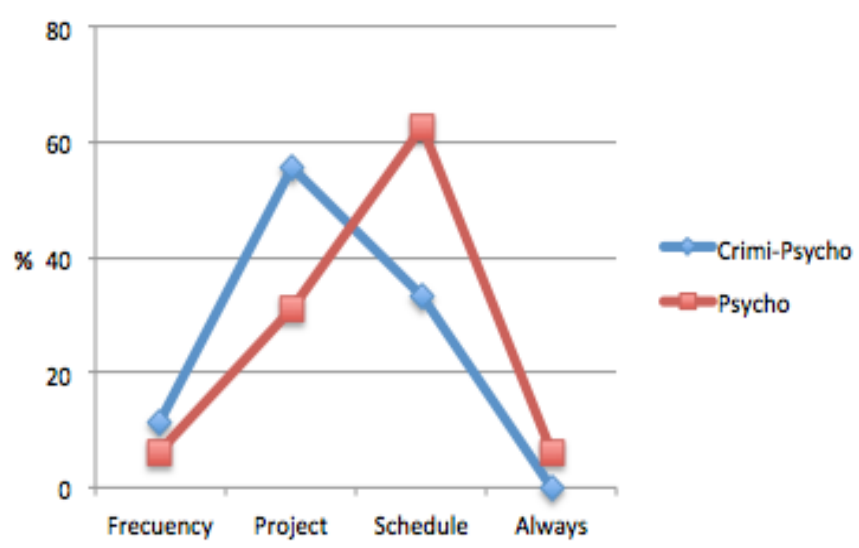

Figure 2. Data obtained from the survey after the visit to the Cerebral Cartography center. a) Evaluate in general terms the visit. b) To what extent do you consider this visit is related to the contents previously seen in class? c) Would you be interested in taking part in some of the research projects developing at the EEG laboratory? d) If so, what would your participation depend on?

These preliminary results suggest that the Psychology group perceived the activity as more interesting, more related to the contents previously studied in class and showed more motivation for taking part in future research programs developed in the center. The reasons for these divergences can be due, in part, to the different subject programming of both groups, as the Psychology-Criminology group did not have some key subjects in the same course as the Psychology group ("Behavioral biology", "Sensation, perception and attention" and "Learning and memory"). Those subjects are fundamental to the correct integration of transversal contents, as well as to the practical application of theoretical knowledge.

In conclusion, coordinated efforts in promoting interdisciplinary and integrative learning of neuroscience in transversal courses increase the satisfaction of students about their learning process, as well as improves the practical implementation of active learning methods. 


\section{Conclusions}

Some of the conclusions that can be inferred from this experience are:

The methodology described in the present work helps to reach an interdisciplinary and transversal teaching approach, which sustains on the fact that most Psychology students found a direct relationship between the proposed transversal activity and the contents explained within each subject. The developed activities allowed the students to be closer to a real research environment, both from a basic and applied perspective, since the very beginning of their higher education, and contributed to spread this kind of learning to other subjects. Moreover, subjects that are normally independently taught were designed in a correlated manner, so that the student can self-integrate the contents. In addition, students were given the valuable opportunity to know the insides of a center for basic and applied research, the Cerebral Cartography Center at the Complutense University of Madrid, which is well-known in the field of neuroimaging. Furthermore, some students were recruited as experimental subjects in research studies of the EEG laboratory at the center, which provided them with firsthand experience in research projects. Last but not least, this practice contributed to improve coordination, not only among departments and schools, but also among professionals, enriching both students and teachers. Professors from two different but complementary neuroscience disciplines (clinical psychologist and neurobiologist) have participated in the present practice coordinating work not only among departments but also schools. Furthermore, professionals from other research institutions and universities have also been involved in the development of the problem-based learning methodology, improving the perceived importance of basic subjects for the student professional future.

The coordination process among teachers of different subjects has contributed to enhance and complement the contents of each subject, to favor the learning process of the students in all subjects as a whole, and to improve student interest and motivation. One of the transversal competences registered in the White Book of the Psychology degree (ANECA, 2005) is "the ability to work in interdisciplinary teams", which is considered by Psychology professionals as one of the most important for future psychologists. Previously described interdisciplinary learning experiences for the Psychology degree reveal some of the benefits of this perspective, such as a more coordinated effort among teachers, better student perception of unity of contents, and a more integrated and less isolated development of subjects.

This novel learning experience can be considered an example of an interdisciplinary and transversal approach on courses for the same degree and academic year.

\section{References}

ANECA (Agencia Nacional de Evaluación de la Calidad y Acreditación). (2005). Libro blanco del título de Grado en Psicología.

http://www.aneca.es/publicaciones/librosblancos.aspxhttp://www.aneca.es/publicaciones/libros-blancos.aspx

Ausubel, D. P. (2002). Adquisición y retención del conocimiento. Una perspectiva cognitiva. Ed. Paidós. Barcelona. 
Bombín, I., \& Caracuel, A. (2008). La especialización en Neuropsicología: desde la necesidad clínica hasta la conveniencia estratégica. Papeles del psicólogo, 29, 291-300.

Gracia, E., García, F., \& Lila, M. (2007). Socialización familiar y ajuste psicosocial: un análisis transversal desde tres disciplinas de la psicología. Valencia: Universitat de València.

Kolb, D. A. (1984): Experiential Learning. Experience as the source of learning and development. Englewood Cliffs, N.J.: Prentice-Hall, Inc.

Insel, T.R. (2010). Circuitos defectuosos. Investigación y Ciencia. 24-31

Ministerio de Educación y Ciencia (2006). Propuesta de directrices para la elaboración de títulos universitarios de Grado y Máster. Secretaría de Estado de Universidades e Investigación: Ministerio de Educación y Ciencia.

Molina, J. G., Rodrigo, M. F., \& Bonavia, T. (2011). La docencia de Estadística en el grado de Psicología: una experiencia de colaboración interdisciplinar con la asignatura de Psicología Social del Trabajo. @tic. revista d'innovació educativa. 6, 21-29.

Moreira, M. A. (2000). Aprendizaje Significativo: teoría y práctica. Ed. Visor. Madrid.

Palmero, M. L. R. (2004). La teoría del aprendizaje significativo. Proceedings of the First International Conference on Concept Mapping, 1, 535-544.

Pereira, C. C., \& Molina, C. M. (2012). La aprobación del marco español de cualificaciones para la educación superior y la empleabilidad del alumnado universitario. REJIE: Revista Jurídica de Investigación e innovación Educativa, (5), 67-86.

Velarde, E., \& Marco, E. M. (2014). Participación interuniversitaria para el diseño y el desarrollo de un ABP. XI Jornadas Internacionales de Innovación Universitaria.

Disponible en:

http://universidadeuropea.es/myfiles/pageposts/jiu/jiiu2014/index.html?_ga=1.26 3099468.1178424653.1382621289

Wood, F. (2003) Problem based learning. Brit Med J. 326:328-330. 
HEAd'15

\section{SESSION 4C}

\section{INNOVATIVE TEACHING \\ METHODS (II)}




\title{
Elective Interdisciplinary Project Laboratories combined with Lectures on Demand as an innovative Teaching Method for Highly motivated Students
}

\author{
A. Bailleu, S. Kröger, M. Menge, A. Münchow-Carus \\ Hochschule für Technik und Wirtschaft Berlin - University of Applied Sciences \\ Department 1 - Energy and Information, \\ Wilhelminenhofstraße 75A, 12459 Berlin / Germany
}

\begin{abstract}
To join learning in interdisciplinary project teams and special lectures only offered on demand is a very effective and also an innovative teaching method for highly motivated students. This kind of teaching is characterized by very active participation by the students in the teaching process. Students exert influence on the contents in the projects and lectures during the course, professors exert influence of the scientific methods. The teaching process is consequently based on partnership of the students and the teaching staff.
\end{abstract}

Keywords: Interdisciplinary Project Laboratory; Soft skill exercising; Lectures on Demand

\section{Introduction}

At the Hochschule für Technik und Wirtschaft Berlin (University of Applied Sciences, HTW) we offer our students a new kind of elective courses for some semesters. In particular two consecutive courses are offered. Every course runs one semester. The first one is called Project Laboratory course, the second one is called Research and Development Laboratory course. Both courses arose within the context of natural science and of technology problems.

However, the subject matter of these courses isn't an expert knowledge of a special scientific discipline. Course participants should practice important soft skills instead. They get a methodological background and learn general fundamental methods to solve a problem.

Interdisciplinary team work and cross-cultural competences are the goal.

That's why these courses are open to all students (all terms and Bachelor's and Master's degree programs). That means students with different specialities (Engineering, Information Technology, Economics, Culture and Design) come to work and learn together in interdisciplinary and term-overlapping structures.

\section{Teaching Method}

\section{General description of the teaching method}

The teaching method is practice-orientated project work instead of lectures or classical tutorials. Classical lectures and tutorials are offered in these courses only as an additional support on demand. The teaching and administration staff consists of three full professors, one laboratory engineer and one student assistant. This team is supported by several other laboratory engineers and/or professors according to the relevant expertise which is needed. 
Normally an individual introduction for every participant and project proposal are given by the students and by the teachers during a first unit. This unit is one of only three units with compulsory attendance for all participants of the courses. So a lot of very different and interesting ideas for realizable projects are listed at the beginning of a course (Zahn, M., et al). A course runs only one semester.

Furthermore students get during this first unit a short lecture to basics of project management, team work, efficient communication structures, and presentation skills. Additionally the formalities concerning the conditions of examination and grading are clarified.

Then the students have to build small teams. A project team consists of two to six participants. Every project team has to choose a concrete project now. Often the teams realize a project idea of their own. That's why the students are highly motivated during the whole courses.

In each case one of the teaching staff is allocated as direct contact person for the project teams. Otherwise the teams work on their own without compulsory attendance in principle. The students are invited to use synergy effects of the other project teams.

Supervision and monitoring are organized in kind of intermediate colloquium for all participants of both courses after half-way through the semester. This and the examination unit at the end of the semester are those with compulsory attendance. Every participant has to present a part of the project team work there.

\section{Tasks of the teaching staff}

In addition to the monitoring of the projects, the teaching and administration staff ensures the smooth running of the courses: room and laboratory management combine with other tasks to ensure excellence are provided. The professors and laboratory engineers work as senior consultants for all projects in the both consecutive courses "Project Laboratory" and "Research and Development Laboratory".

As accompanying support the professors and laboratory engineers offer elective units on demand, for instance:

- Brainstorming sessions

- CAD-tools and CAD-systems (CAD: computer-aided design)

- EDA-tools (EDA: electronic design automation)

- Programming (LabVIEW)

- Data analysis

- Project planning and controlling (MS Project).

\section{Examinations}

Examinations of students consist of the individual oral presentations and discussions. In addition, there is a practical presentation of the project results by the project team. Furthermore the project teams have to deliver written project documentation, consisting of

- Description of the aims of the project

- Project plan (schedule, cost planning, role allocation in the project)

- Project results (experimental setups and measurement reports, mechanical drawings, wiring diagrams, layouts, printed circuit designs, source codes, etc.). 


\section{Results and Discussion}

\section{Special Facts and Project Results}

136 students took part in the course "Project Laboratory" so far. About 4\% of participants of this course drop out within four weeks for reasons of work overload, disinterest or difficulties with team building and integration. The other $96 \%$ have finished the course, most of them with very good results. About $60 \%$ of the projects were realized by interdisciplinary teams. $25 \%$ of the participants of the "Project Laboratory" course also attend the consecutive course "Research and Development Laboratory". This course was only offered in two semesters as yet.

Figures 1-9 show selected results realized by the students in the courses. Often the students look enthusiastically for solutions in context of biomedical applications or in context of energy generation during the project laboratories.

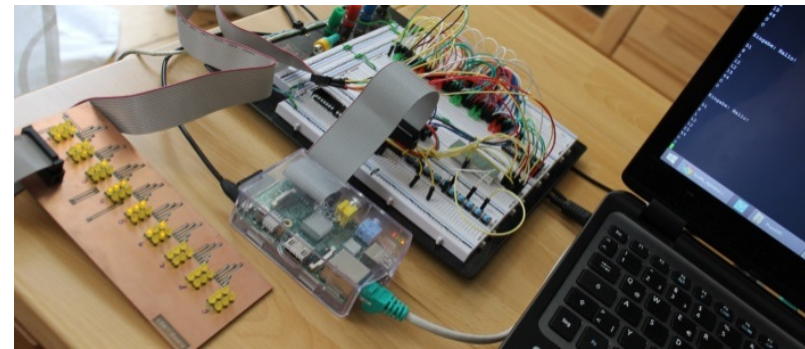

Figure 1. E-book-reader with Braille lettering output

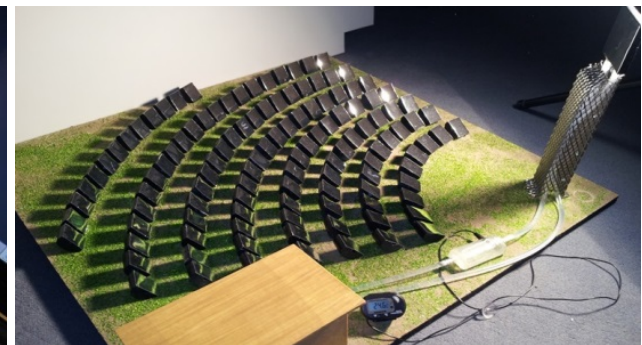

Figure 2. Model of a concentrated solar power plant (CSP)

As first example a part of the realisation of an e-book-reader with Braille lettering output is shown. It is possible to translate any text into Braille with this setup. You can see 9 segments, written is "hallo" (Figure 1). The Braille display is symbolized by LED cells. It provides 6 dots per cell. Every dot of the 9 cells is individually controlled by a microcontroller.

Another example shows a concentrated solar power model with a field of mirrors (Figure 2). The mirrors concentrate sunlight onto a central solar power tower. This model produces energy to warm up water.

Figure 3 shows an experimental setup of an apparatus uses falling water to generate voltage differences by electrostatic induction occurring between interconnected, oppositely charged systems. William Thomson (Lord Kelvin) invented this idea in 1867. The principle is described in (Zaiei-Moayyed M. et al). It becomes an interesting object to demonstrate the principles of electrostatics in physics and chemical education (Zaiei-Moayyed M. et al). The device resulting from this project was subsequent to the course used for teaching purposes in regular courses. This is one of the projects, which are continued in the second semester. In the "Research and Development Laboratory" course, the project team systematically investigated the influence of different parameters (as for example diameter of the vessels and concentration of salty solution) on the behaviour (e.g. the loading speed of the high voltage). 


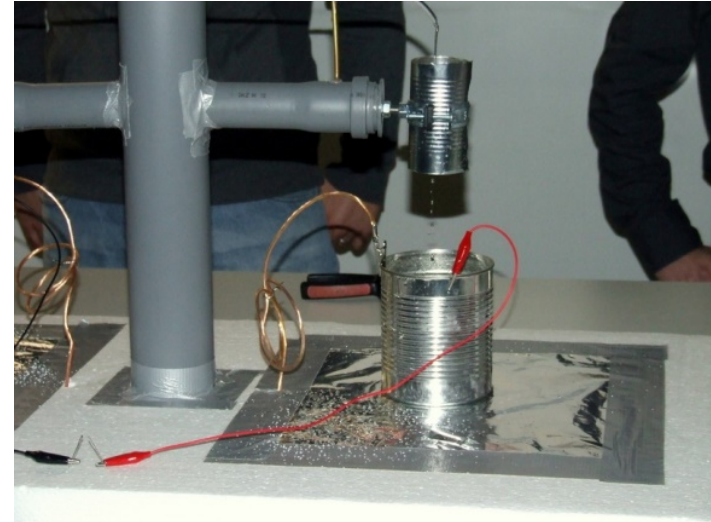

Figure 3. Kelvin water dropper as a kind of an electrostatic generator

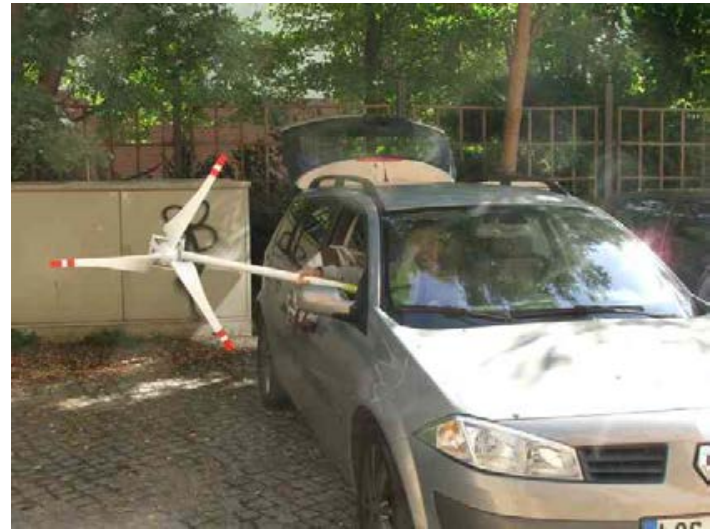

Figure 4. Self-made wind generator

The last but not least example of this group of projects is the self-made wind generator (Figure 4).

Such practical results (e.g. Figures 1-4) are impressive considering to the scheduled workload for the course (100 hours) and the very small budget (50 €) for the students. After finishing the projects the realized models are also sometimes used as demonstrators in regular lessons of other courses. Then it derives an additional benefit from the project laboratories.

Another idea of the Project Laboratory course was that the students should present their projects to the public, for example during an 'open day' at our university or on events in school. Besides the presentation exercises for the students, this is a good possibility to increase attractiveness and visibility of scientific and technical studies. Examples for projects, which have been presented to the public, are the investigation of the flow behaviour of non-Newtonian fluids (Figure 5) and the Theremin, an electronic musical instrument controlled by changes of electric capacity caused be the relative position of the hands (Figure 6).

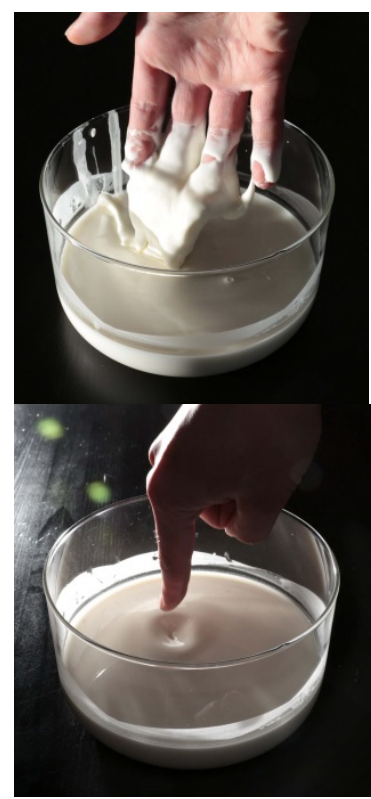

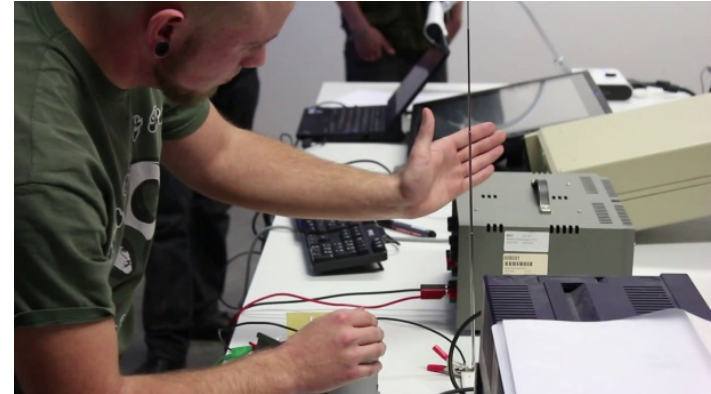

Figure 6. Theremin

Figure 5. Investigation of the flow behaviour of non-Newtonian fluids 
Other project results, e.g. the gimbals (Figure 7-9), appear almost like professional developments. These gimbals are the practical results of a project team of 2 highly motivated students. High-end materials and technologies to realize their ideas are used in these projects. Sponsoring is essential in such cases.

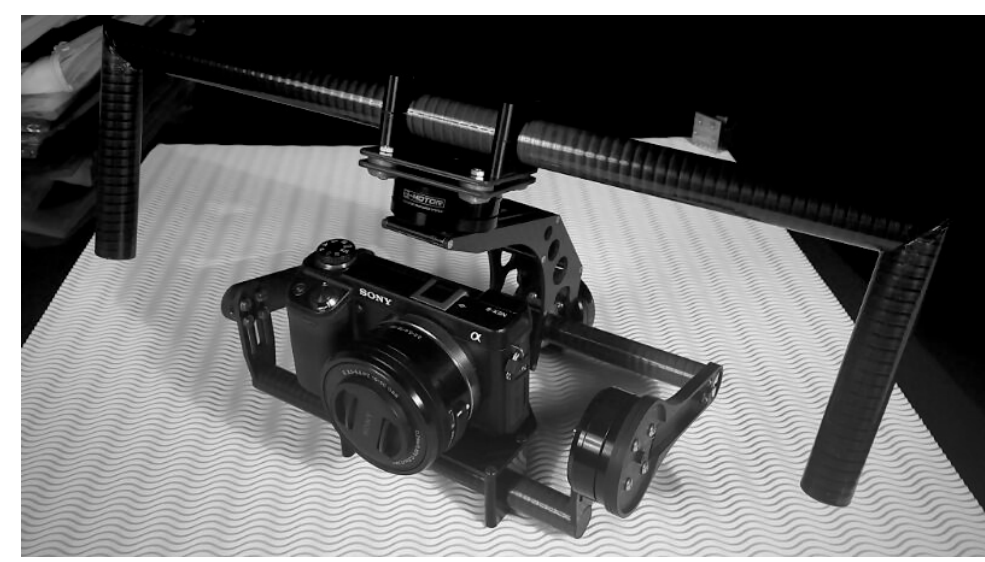

Figure 7. Gimbal 1for bigger cameras in helicopters

In Gimbal 1, developed and prototyped in the last semester for use in a helicopter (Figure 7), an industrial sponsor has been found. Gimbal 1 became an industrial duplicate part by now.

The Gimbal-project 2 (Figure 8, Figure 9) for GoPro-action-cameras and for industrial CMOS-cameras is a successor of the first Gimbal-project, because new applications were found in two current research projects of HTW Berlin.

Also in this case it derives a multiple benefit from the presented teaching method.

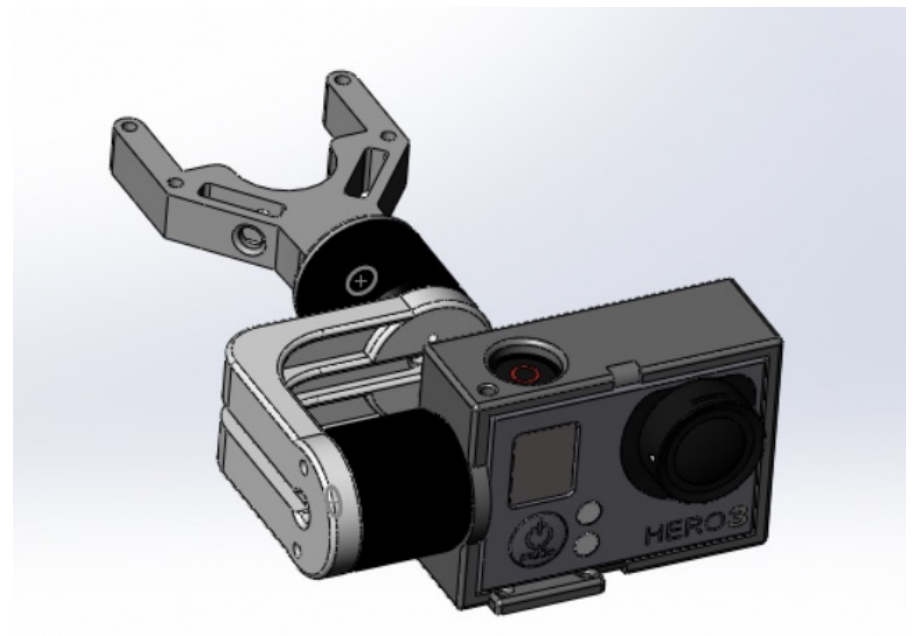

Figure 8. Construction of Gimbal 2 for use small cameras like GoPro-action- or industrial cameras

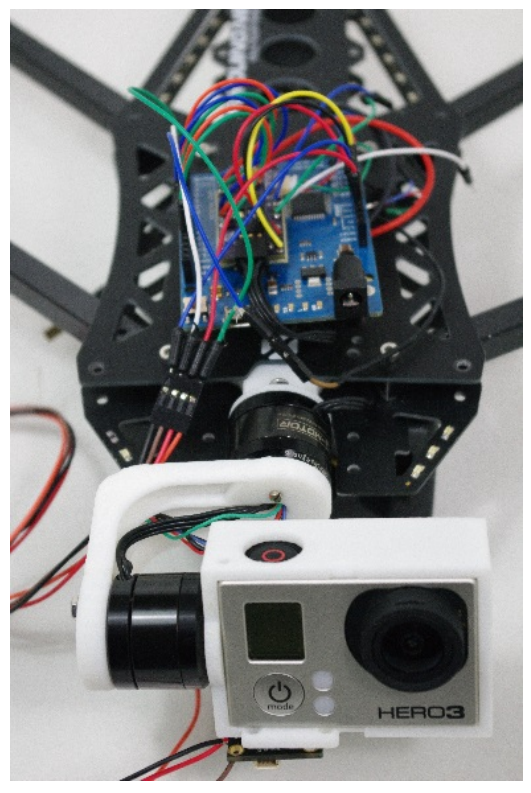

Figure 9. Realization of Gimbal 2 with GoPro-action-camera

The housing of the Gimbal 2 was produced with a 3D-printer. 


\section{Teaching field report}

Here are briefly illustrated the experiences of 5 semesters. 136 participants took part there.

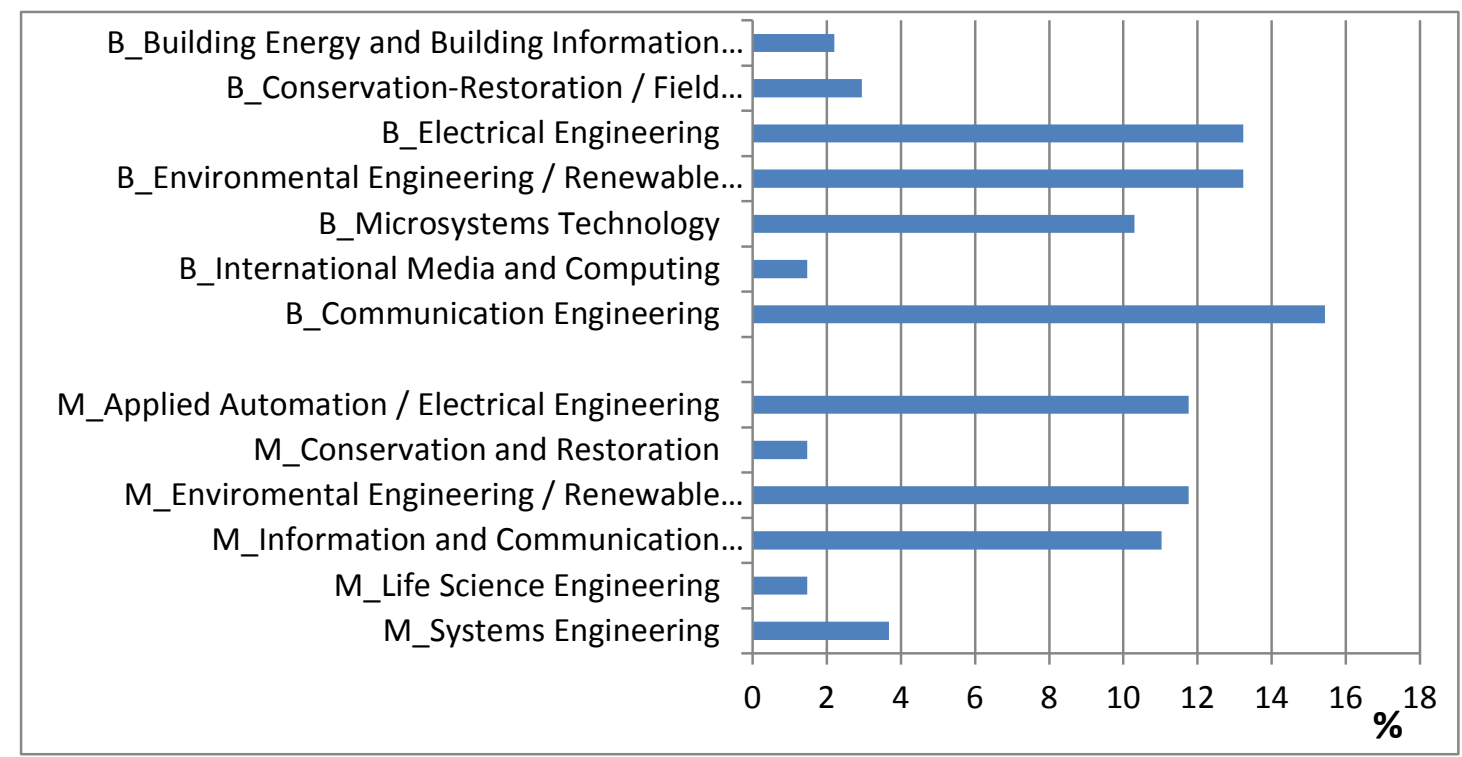

Figure 10. Bachelor’s (B_) and Master’s (M_) programs where the participants came from

$59 \%$ of all students came from the Bachelor's programs, $41 \%$ came from the Master's programs (Figure 10). Most of project teams consist of 4 members. Two member teams are often to find as well (Figure 11). 58\% of the project team were constituted interdisciplinary (Figure 12).

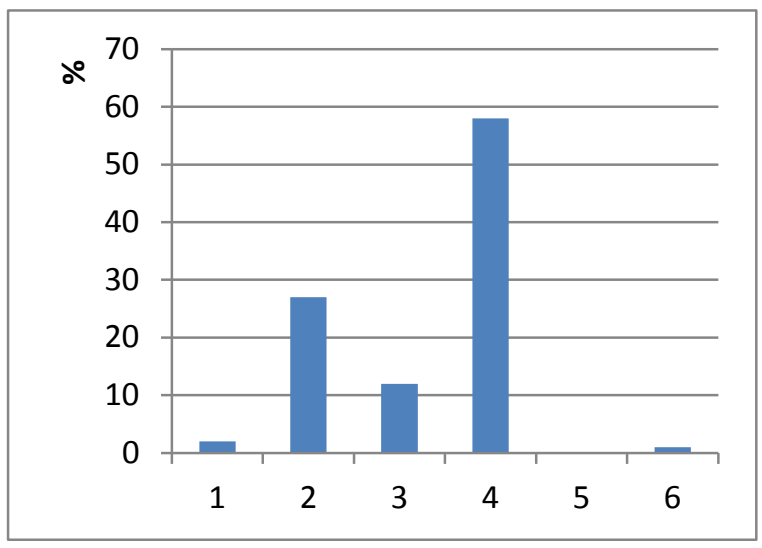

Figure 11. Number of team members

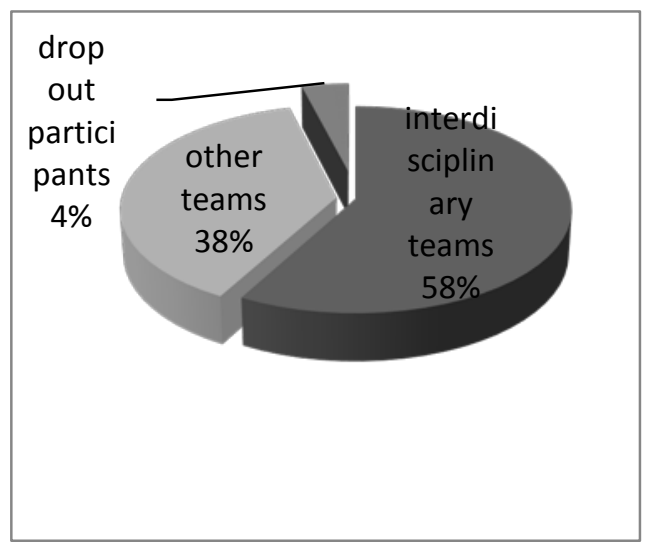

Figure 12. Constitution of the project teams

Although the consecutive course "Research and Development Laboratory" was only offered in two semesters, $25 \%$ of the participants of the first course also attend the consecutive second course. Success makes addicted!

To awareness that project laboratories joined with lectures on demand are a very successful teaching method for students and for the teaching staff, the number of participants of these elective courses is continuously high.

The most restricting fact to such kind of teaching is the financial basis. 


\section{Conclusions}

All in all, the presented teaching method has more advantages than disadvantages. A lot of students prefer to do some practical work during their studies. In the most cases they are very involved in their own projects. The learning process takes place nearly by the way because it is a kind of learning by doing. The students exert influence on the contents in the projects and lectures during the course, professors exert influence on the scientific methods. Point by point the students reach an advanced knowledge in a special scientific field but also in general fundamental approaches to solving a problem. The students acquire many important soft skills during working in an interdisciplinary project team. This is the most important significance of this teaching method.

Often especially such students which haven't the best success in normal, classical university courses excel by trying to get optimal project results. They are highly motivated from the beginning to the end of the project laboratories or they become highly motivated during the courses because of the direct feedback, the practical success, the appreciation of the team and of the teaching staff.

About $40 \%$ of the project results provide multiple benefits. Results can be taken as demonstrators in other courses. This means students learn by themselves and produce learning tools for other students in the same process. Sometimes the results can be used for a research project. Industrial products are developed in exceptional cases, too.

Our conclusion is: We recommend this teaching method. It is an interesting and a demanding kind of education, for the students and also for the teachers.

\section{Acknowledgements}

We gratefully acknowledge the head of university for benevolent support and the involved colleagues for active assistance.

The courses have been supported in the years 2012-2014 by the "Berliner Qualitätsoffensive für die Lehre" (BQOL)

Gimba1 1-project has been sponsored by Ingo Raeke.

\section{References}

http://home.htw-berlin.de/ kroeger/PL-Themenvorschlaege.html

Zahn, M. (1973), Self-excited a.c. high voltage generation using water droplets, American Journal of Physics, 41, 196-202.

Zaiei-Moayyed M., Goodman E., \& Williams P. (2000). Electrical deflection of polar liquid streams: A misunderstood demonstration, Journal of Chemical Education, 77(11), 1520-1524. 


\title{
Microproject-based teaching/learning methodology focused on emerging technologies and international entities cooperation.
}

\author{
J. Fernández-Ceniceros*, A. Sanz-García**, F. Antoñanzas-Torres*, \\ M. Alía-Martínez*, A. Pernía-Espinoza* \\ * EDMANS Research Group, Department of Mechanical Engineering, University of La Rioja, C/ San \\ Jose de Calasanz 31, Logroño 26004, Spain. \\ ** Faculty of Pharmacy, Centre of Drug Research (CDR), University of Helsinki, Viikinkaari 5 E (P.O. \\ Box 56), 00014, Helsinki, Finland.
}

\begin{abstract}
This paper deals with the implementation of an educational methodology based on microprojects into the subject 'Manufacturing Technology' of the EHEA (European Space of Higher Education) engineering degrees. The main idea is to consolidate the theoretical background by working on microprojects ordered by foreign entities. Under this approach students implement the theoretical knowledge acquired in the classroom facing real world problems, such as scope definition, planning and team work, while promoting the use of English and information and communication technologies (ICTs). Results show higher motivation and level of interest among students as well as an improvement on their scores when compared with traditional teaching/learning methods.
\end{abstract}

Keywords: Microproject; PBL; English; Engineering; Manufacturing Technology.

\section{Introduction}

The European Space of Higher Education or EHEA (EEES in Spanish) (http://www.eees.es/) promotes educational models that focus on student's autonomous workload and learning activities based on projects (Project Based Learning, PBL) (Buck Institute for Education, 2002). Besides this, a growing demand for professionals with greater leadership skills, international experience and adaptation capabilities for changing environments boosts the updating of traditional teaching methods to meet the needs of companies.

Traditional teaching methods have shown the lack of promoting interactions among students and between teachers and students. Student become passive characters who in some cases are overwhelmed by the theoretical contents and consequently, they, find serious difficulties to apply these concepts in real world problems. Moreover, the jump onto working life makes a huge change on the student's life, whose role must turn to an active attitude. The student has to show personal skills, such as leadership, communication capacity, integration in multidisciplinary groups, problem solving capacity and, the last but not the least, mastering English as a universal language within the engineering circle. For these reasons, it is necessary to introduce some changes in the traditional teaching methods enhancing the student's personal work, the interpersonal relationships, the use of a second language and the use of Information and Communication Technologies (ICTs).

The PBL model includes some of these points, and its use is widely spread in technical studies. Particularly, PBL promotes student's active work throughout the planning, development and evaluation of different projects with a real application beyond educational purposes (Marti et al., 2010). Several experiences have been reported up to date in this field (Garcia-Almiñana \& Amante, 2006; Labra et al., 2006; Aliane \& Bemposta, 2008; Villalba et al., 2009) and all of them reveal multiple advantages: it fosters cooperation and creativity, stimulates autonomous learning and provides learnings on a higher cognitive level. 
The methodology herein presented has been implemented through a Teaching Innovative Project during two consecutive academic years: 2013/2014 (FernandezCeniceros et al., 2014) and 2014/2015, adding some upgrades in the last year. Along these two courses the methodology has shown to lead to substantial improvements in the teaching methods. It is clear that student's motivation for the subject increased and also average scores and success rates raised when comparing to the traditional teaching used during previous years (years 2007-2008 and 2009-2010).

\section{Objectives}

The general objective of the methodology proposed herein is to foster the students' motivation when learning a specific applied subject such as 'Manufacturing Technology'. It is crucial for their academic training to acquire information about industry through the contact with several companies, research centres and other universities. In this sense, the student can assimilate better the theoretical concepts presented in the classroom. Moreover, in a globalized world, it is very motivating to collaborate with international entities/companies, promoting the use of the English as a second language and pointing out the barriers and difficulties a different culture and working habits, at the same time that fosters the use of ICTs as an interchange platform among the agents.

The specific objectives are the following:

- Establish communication networks between University of La Rioja and other international entities from both the teaching and the industrial world, with the aim of bringing the professional environment closer to the student. Specifically, 'microprojects' are presented, where foreign institutions act as petitioners.

- Promote the use of a second language. This is addressed through the use of English in scientific articles and multimedia content to develop issues related to the manufacturing processes that lie under the microprojects, and as the interchange language between the foreign collaborators and the students. The petitioner establishes the tasks to be developed also in English. Previously, the student is provided with all the information translated to its mother language and a glossary with the most important terms. It must be highlighted that our aim is not to implement English as the main language in this subject, but to familiarise the student with the key concepts presented in English due to its great importance for his future working life.

- Boost the use of ICTs through the use of new communication and teleworking environments. Relating microprojects to foreign entities represents a great opportunity to make use of different ICTs resources such as: a web environment to exchange information between petitioners/professors and students, videoconference and digital blackboard to state projects scope and objectives between the involved parts.

- Provide the student a state of the art about the current manufacturing technologies. The collaboration with technologically advanced institutions brings novel manufacturing techniques closer to students. One of these new techniques is the additive manufacturing, implemented in 3D printers. Along one of the microprojects, students have to learn how to use these printers to make 3D prototypes and elaborate tangible pieces. Besides, following the opensource-RepRap-philosophy (http://reprap.org), the student can contribute with ideas that improve designs, materials and software, putting into practice the 
contents learnt in the subject. The most innovative designs can be manufactured in the $3 \mathrm{D}$ printer available.

- Improve educational techniques by including seminars given by experts from the industry or institutional world to provide another professional point of view of the concepts applied in the microprojects. Also, improve educational assessment by providing the student with an evaluation sheet for each microproject. In this way, the student can objectively know what and how is going to be evaluated. In addition to these, in order to improve continuous evaluation, guided discussions and small tests are driven after the seminars, promoting the student participation.

- Track the experience and evaluate how students' motivation evolves along the course and how the execution of the microprojects influences on that. To this end, several anonymous questionnaires are addressed. In addition, different written tests after ending the microprojects are carried out to evaluate how these practical experiences help to acquire theoretical knowledge.

\section{Material and Methods}

\section{Methodology}

The methodology is based on the PBL model and problem solving of study cases from the real world. It is all complemented with seminars given by experts in the three areas selected for the microprojects. The methodology is as follows:

- Theoretical classes to address basic knowledge along with resolution of real cases related to the topic of the particular microproject.

- Microproject presentations.

- Seminars given by an expert on the topic related to the same topic.

- Short tests about basic concepts that will be developed further.

- A platform to integrate everyone involved in the microproject, also useful to exchange information (text, glossaries, videos, etc.). This platform will be based on Moodle (http://moodle.org/, Rivas, 2006), an educational resource management platform, which also allows groups to have a forum to discuss about different topics and questions.

- Generate and show the students the evaluation record that will be use to assess the microprojects. Not only the knowledge applied in solving technical issues will be evaluated but also the quality and clarity in the reports as well as the degree of cooperation of each member in the groups (by a survey to the other group members).

- Work groups are created, which will involve 4 people per group (this number is related to the total of student in the classroom, normally is around 60). The 'Group Constitution' is signed, which compromise the student to do the assigned tasks on time. It also incorporates the concept of 'expulsion rules'. Since three degrees (Electrical, Electronic and Mechanical Engineering) are involved, the groups will be created as much multidisciplinary as possible.

- The international entity (along with the Innovation Group) defines the objectives, tasks, time and costs. This is done through a video and documents in English, which are found in Moodle. Reports can be written in Spanish or in English, as students prefer. 
- Each group distribute their tasks to each group member, with the deadlines. The Innovation Group coach this assignment. Besides, each group will name a coordinator which will be in charge of supervising the activities and organising meetings to put in common the works and solve doubts. The coordinator will be the link between the group and the members of the innovation group.

- Problems stated in microprojects are solved according to the distribution of abovementioned tasks. Therefore, everyone should understand the particular problem studied, search for useful information and make hypotheses in order to solve the problems.

- Clarify doubts through forums or tutoring with the members of the Innovation Group. Professors have to supervise work on a systematic and periodic basis.

- Each group reports the solutions for the problems outlined in the microproject through a report, paying attention to the evaluation sheet previously presented.

- The members of the Innovation Group proceed to the final evaluation of the microproject by using the same evaluation sheet abovementioned.

- Surveys will be carried out along the whole course to track students' evolution and then elaborate statistics. Partial results will be taken into account for the approach of the next microproject. At the end of the experience, a final report will be performed with the complete statistical analyses.

\section{Implementation into the subject 'Manufacturing Technology'}

The methodology explained above was implemented in the subject 'Manufacturing Technology', which is studied in the second year. It is offered in three engineering degrees at the University of La Rioja: Mechanical Engineering, Electrical Engineering and Industrial Electronic and Automation Engineering. The professors of the Innovation Group involved in this project belong to the Department of Mechanical Engineering and, more precisely, to the areas of Manufacturing Processes and Engineering Projects. Moreover, taking advantage of the post-doctoral period of one of the member of the Innovation Group, who is in the Division of Biopharmaceutics of the University of Helsinki and currently researching at the Tokyo Women's Medical University, that institution (University of Helsinki) acted as the petitioner for the microprojects.

Currently, the subject 'Manufacturing Technology' combines a variety of teaching/learning methods along with the learning through microprojects. Three of the seven topics are under the microproject modality. The remaining four topics use several teaching/learning techniques like real case solving problems, forum discussions, oral presentations, workshop practices and quizzes. The three microprojects are described as follows:

- Microproject 1: Filling process analysis of the plastic injection of a piece. The objective of the project is to analyse the plastic injection of a part under different process conditions, using the specific software Simulation Moldflow Adviser Ultimate $2014 \AA$, which is available for free downloading for students. Students have to learn about plastic injection molding and simulate the process, using one or two gates for injection. They are asked to report about some issues, such as the filling time, injection pressure, surface orientation of molecules, weld lines, possible defects, etc. This microproject is linked to the seminar 'CAE (CAD) tools for modelling polymers in the automotive industry' given by an expert from the automotive industry. 
- Microproject 2: Metal forming processes. Forging, cold rolling, blanking and deep-drawing are presented as sequential processes involved in the manufacturing of a cylindrical cup. Students are asked to analyse each process and define their main parameters, such as the press power, rolling force, appropriate punch and die diameters or the holding force. This microproject is linked to the seminar 'Mould and die design for sheet metal plastic forming' given by a mould-maker expert.

- Microproject 3: 3D Printer. This project introduces additive manufacturing in the shape of 3D printing to students, from CAD modelling to G-code generation and the communication with the 3D printer. The project makes extensive use of University of Helsinki expertise in this manufacturing technique, which is used for cell bioprinting in tissue regeneration. The software used was Repetier-host (http://www.repetier.com), which allows to complete all the steps necessary for $3 \mathrm{D}$ printing and is available for free download. In this project, students were asked to import the CAD model from the piece to be printed to the software Repetier, varying the parameters in the Repetier to meet requirements, print the piece and report about the process, time and cost required for printing. This microproject is linked to the seminar 'The future of 3D printing in regenerative medicine and tissue engineering' given by two experts on additive manufacturing applied to regenerative medicine.

\section{Results and Discussion}

After conducting this teaching/learning experience several observations might be extracted:

- Students complement the theoretic and practical knowledge acquired during the lessons and the practical classes with a realistic vision of working by projects. Working by projects involves many tasks, such as information research, selflearning and self-management, along with team working competences. Moreover, students must confront situations where the definition of the scope, the correct understanding of the proposed requirements or the deadlines must match with the correct resolution of the proposed project.

- Collaboration with international organizations, in this case, with the Division of Biopharmaceutics of the University of Helsinki, provides an open vision that enriches the student learning through different technics such as the use of ICTs as communication and contact methods. The student must overcome the language barrier and use English as an international and scientific language. Moreover, the student must confront the cultural differences and problems due to different working hours.

- The collaboration with the University of Helsinki provides students the possibility to access to modern fabrication methods such as additive manufacturing or more particularly 3D bioprinting. The possibility of using these innovative methods is a great motivating experience for students.

- The interrelation between the fabrication methods, traditionally linked to the industry, and a specific area of knowledge drastically different such as biomedicine, can give the student an innovative vision of the wide spectrum of applications in which fabrication methods can be involved. Additionally, students have to cope with an unknown discipline. 
- Seminars provided an interaction tool for students with expert from the industry and institutions that also motivates the knowledge acquisition.

Once the semester has already finished, students filled a survey to canvass the interest in the teaching/learning methodology based in microprojects, compared to the traditional method. Figure 1 depicts the results from the survey. It shows that the use of English does not suppose an important barrier to properly develop the objectives stated. Besides, the percentage of students that consider of high or very high interest learning through microprojects raised from 82 to $93 \%$ with respect to last year. This can be explained by the improvements introduced, such as glossaries, evaluation sheet, the 3D printing of the pieces and seminars given by experts (86\% of the students considered them of high or very high interest), which make the subject more complete. It is also derived from Figure 1 the importance of 3D printing the piece designed to motivate the students along the process.

1. Do you consider the use of English a great language barrier to develop the tasks along the microprojects?

2. From 1 to 4 (where 1 represents 'low' and 4 'very high'), how interesting did you find the microprojects based teaching/learning methodology compared to traditional teaching model?

3. From 1 to 4 (where 1 represents 'low' and 4 'very high'), how important was the possibility of printing the piece in a 3D printer?

4. From 1 to 4 (where 1 represents 'low' and 4 'very high'), How interesting were the seminars given by experts during the course?
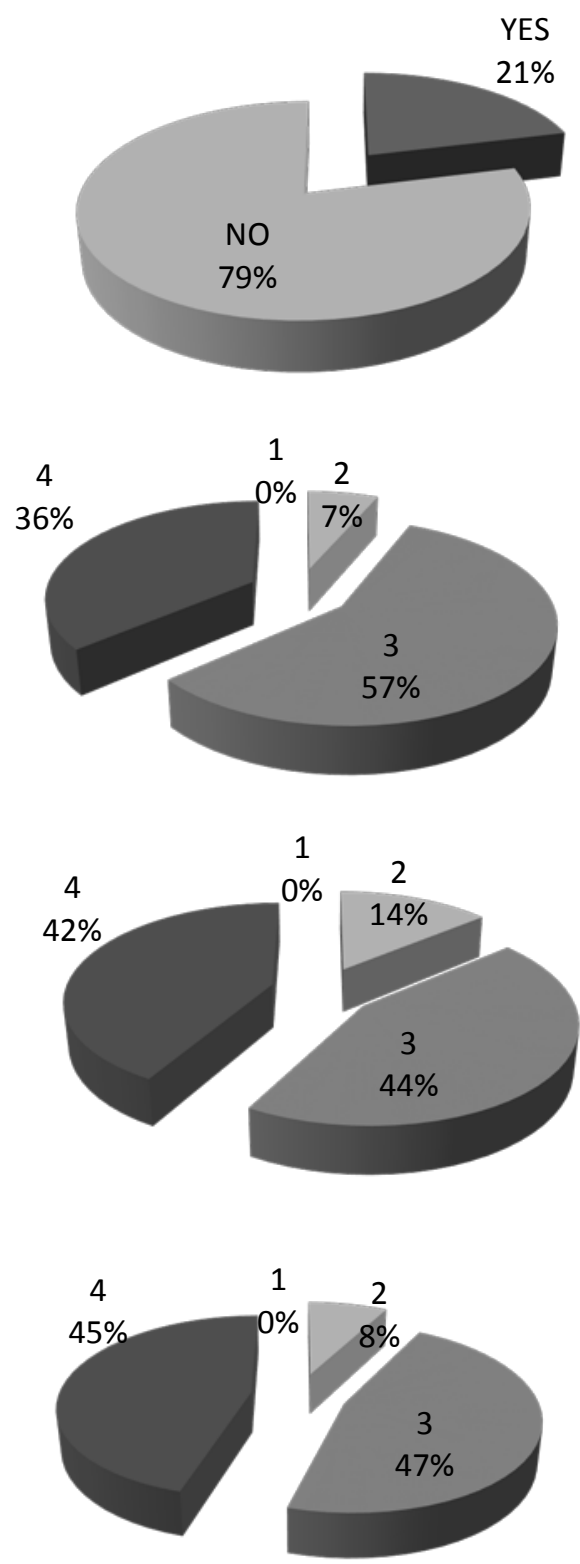

Figure 1. Results obtained from survey at the end of the semester, year 2014/2015. 
Finally, Figure 2 shows average score and success rates of the subject studied during previous semesters (from year 2007 to year 2014), i.e. before and after implementing microproject teaching/learning methodology: during years 2007-208 and 2009-2010 traditional teaching model was used, and in years 2013-2014 and 2014-2015, microproject methodology was adopted.

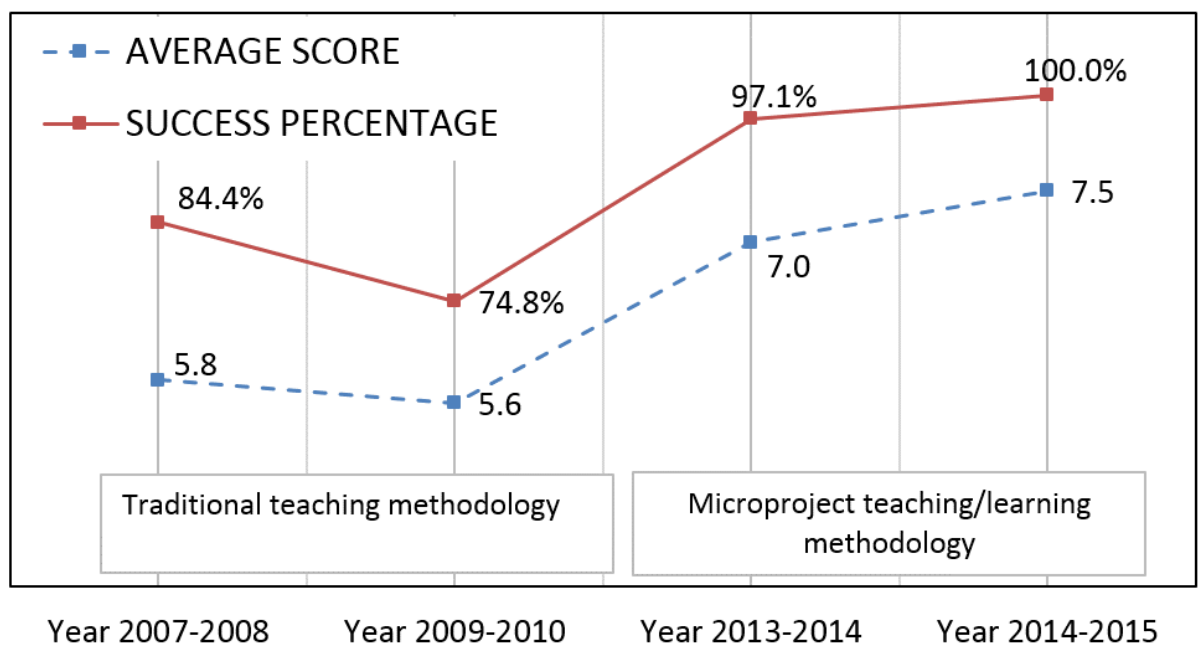

Figure 2. "Manufacturing Technology” subject average score and success rate for years from 2007 to 2014.

The results obtained, both this course (2014-2015) and the previous one (2013-2014), sustain the convenience of the microproject teaching/learning model herein proposed for technical subject.

\section{Conclusions}

This paper deals with the application of small projects or microprojects requested by foreign institutions, with the goal of bringing the working life close to undergraduate students. They must deliver reports in which they combine the appropriate technical solution of a problem under a strict deadline, following specific scopes and using teamwork. One of the main characteristic of the proposed project is the use of English as a means of communication as well as the use of ICTs as a working tool. All of this was additionally complemented by seminars with experts and assessment tool provided to the students.

The methodology explained herein was applied to the subject 'Manufacturing Technology', in cooperation with the Division of Biopharmaceutics of the University of Helsinki. Students showed a higher level of satisfaction with this educational method in comparison to the traditional one. Collaborating with real petitioners gave students an extra motivation as they could make use of their gained knowledge in real applications.

Finally, although the methodology was just applied to the subject 'Manufacturing Technology', it might be extendable to other subjects in technical careers. International mobility of researchers can play an important role to connect universities, companies and research centres and act as foreign petitioners in this kind of experiences. 


\section{Acknowledgements}

The authors would like to acknowledge University of La Rioja for the financial support received through the program 'Proyectos de Innovación Docente 2014/2015', as well as for the fellowships FPI-UR to train researchers (J. Fernandez-Ceniceros and F. Antoñanzas-Torres). The authors also want to express their gratitude to the Instituto de Estudios Riojanos (IER), to the Banco Santander for the project PROFAI 13/06 and to the Agencia de Desarrollo Económico de La Rioja for the project ADER-2012-I-IDD00126 (CONOBUILD). One of the authors, A.S.G., would also like to acknowledge the financial support with the grant No. 273689 (FINSKIN) and the mobility grant No. 276371 (VATURP) by the Academy of Finland.

Finally we would like to thank to the special collaboration of all student involved in this experience. Their comments and suggestions enriched the methodology proposed in this communication.

\section{References}

Aliane, N. \& Bemposta, S. (2008). A learning experience based on projects for Robotics. Ibero-American Magazine of Learning Technologies, 3(2), 71.

Buck Institute for Education, An overview of Project Based Learning (2002). http://www.bie.org/pbl

European Space of Higher Education. http://www.eees.es/

Fernandez-Ceniceros, J., Sanz-Garcia, A., Urraca-Valle, R., Martinez-de-PisonAscacibar, F. J. \& Pernia-Espinoza, A. V. (2014). Teaching-learning model based on micro-projects for the subject 'Manufacturing Technology'. XXII University Congress on Educational Innovation on Technical Studies, Almaden (Spain).

Garcia-Almiñana, D. \& Amante, B. (2006). Experiences of implementation of cooperative learning and learning based of projects. I Seminar on Educational Innovation, Zamora (Spain).

Labra, J. E., Fernandez, D., Clavo, J. \& Cernuda, A. (2006). A learning experience based on projects using open-source software development collaborative tools. XII Seminar on University Education of Informatics, Bilbao (Spain).

Marti, J. A., Heydrich, M., Rojas, M. \& Hernandez, A. (2010). Learning based on projects: an educational innovation experience. University EAFIT Magazine, 46(158), 11.

Moodle: Open-source Learning Platform. http://moodle.org/

Repetier: the software driving your 3D printer. http://www.repetier.com

Rivas, F.C. (2006). Learning platform Moodle as a tool for social work in the European Space of Higher Education context. Social Actions and Research, 1, 367.

Villalba, G., Zamora, M. A., Santa, J. \& Herrero, D. (2009). Experiences on learning implementation based on projects to develop creativity in domotics subjects. $I X$ Seminar on Cooperative Learning and II Seminar on Educational Innovation, Almeria (Spain). 


\title{
Pedagogical Tools for Teaching Exploration
}

\author{
Terence Reilly \\ Babson College
}

\begin{abstract}
A common problem faced in post-secondary education is how do we move our students past being satisfied with the first answer they find and to a more thoughtful, more complete, and more nuanced solution? Once our students have 'solved' a case problem, they believe there is nothing more to do. Students, especially freshmen and sophomores, are not accustomed to exploring the case situation for additional insights beyond the first solution. This paper presents two pedagogical tools that have dramatically improved my students' performance in using the methods presented in the classroom. These tools have helped my students understand how to go beyond the first solution and explore the situation from more than their own perspective and thereby gain valuable insights into the situation. The first tool is a two-step grading procedure, in which I grade both a rough draft and a final draft. Instead of the grading being a punitive exercise, it has become a way to guide and further educate my students. The second tool is specifically designed inclass demonstrations that highlight the improvements that result when exploring beyond the first solution.
\end{abstract}

Keywords: Cooperative Learning; Grading Case Reports; Mathematical Models

\section{Introduction}

One of the main differences between secondary and post-secondary education is that college and graduate students are expected to go beyond simply applying the concept to becoming proficient with them. In my mathematical modelling classes, I expect my students to not be satisfied with their first model and solution; rather, I want them to treat it as a first approximation that can be improved. I spent many frustrating years pushing and prodding my students, especially freshman and sophomores, to dig deeper into the analysis, to explore the situation from more than their own perspective, and to use the model to explore for improved solutions. I present here two pedagogical tools that have (based on anecdotal evidence) dramatically improved my students' performance. These tools have helped the students understand that by exploring, they can find more nuanced solutions and gain valuable insights into the situation.

\section{Pedagogical Tools}

These tools came about after I took some responsibility for the students' failures and assessed why it was they were satisfied with their first solution. Finding the answer, then moving on to the next problem was certainly learned behaviour on their part, which I tried (unsuccessively) to counter. I started using the case teaching methodology (Christensen, 1981) and replaced my exams with case reports (Dehler, 1996; Emig, 1977). Although the case reports were helpful, students were still struggling with how to explore the situation for additional insights.

I provided extensive feedback on their case reports, that is, their deliverables. I was spending from 30 - 40 minutes grading each student's deliverable carefully pointing out various ways they could have improved their model and solution. All this time and effort spent pointing out their mistakes only made them feel they had no mastery of the subject and frustrated me as they would make the same type of mistakes on the next deliverable. True, by the end of the semester, they were performing better, but it was a frustrating path for both parties. 
Using Value-Focused Thinking (Keeney, 1992), I asked what was it I wanted to obtain and what were my means? This lead me to the realization that, in a perfect world, I wanted to be pre-emptive and advise students on ways to improve their model before they handed it in for grading. Somehow, I wanted to help, but without doing their work for them. I wanted a way to advise them on improvements, on ways they could further explore case, but only after they put a substantial amount of work into the deliverable. I discovered two ways to be preemptive: in-class demonstrations focused on exploration and a two-step grading procedure. First, I discuss the two-step grading procedure and then provide two examples of actual in-class demonstrations.

\section{Two-Step Grading Procedure}

Students often only do the minimum analysis in their deliverable and do not explore the data or model for additional insights. Students will often ask: "Do we need to report on the sensitivity analysis?" "How many hypotheses tests do we need to do?" or "Which regression is the right one?" These questions are as frustrating as the proverbial "Will this be on the test?” One solution is to use a two-step grading procedure, where I grade both a rough draft and a final paper. This allows me to provide feedback via the rough draft directing the students toward further explorations of the material.

I use cooperative-learning techniques by assigning each member of a four-person group a specific role. For each case report, I assign two roles and have two deliverables. After the group, as a whole, builds the model and does the analysis for a specific case, I assign, a subgroup of two to write a rough draft of the paper and the other two members are responsible for the final draft.

Key to the procedure is that I grade the rough draft. Knowing that it will be graded, the students work surprisingly hard on their rough draft. I typically, assign a weight of $50 \%$ of the deliverable's weight to the rough draft. This high weight has led to rough drafts comparable to the final drafts of students in a typical course. The two students responsible for writing the rough draft have peer pressure to do well and, as these papers are between 20 and 35 pages in length, a rough draft is a substantial amount of work. As the group of four receive only one score, there is often editing and collaboration from the other two members.

Another advantage of grading the rough draft is that it allows me to furnish copious comments on improvements to both the writing and the mathematical analysis. Whereas before I was never sure my comments were being read, the comments in the rough draft are not only being read, but also acted on. I now feel that the 20 minutes required to grade each rough draft is time well spent. Instead of these comments being taken as punitive by the students, the students actually see additional ways to explore the situation. For those students who missed the point of the case, I can nudge them back to the correct analysis. For all the students, I suggest possibilities and scenarios they can investigate. With these improvements in hand, the whole group meets a second time to carry out the suggested analysis (and hopefully go beyond). Then, the two remaining group members are assigned to write the final draft. I typically have three to four deliverables per semester and rotate the group roles for each one.

Instead of following a one-step grading procedure (grade deliverable, providing feedback and hoping the next one will be better), I use a two-step procedure (grade rough draft, grade final draft). Students work hard on the analysis and the paper knowing that it will be graded. Being able to provide suggestions, hints, comments, etc. on the rough draft is an excellent way for students to learn how to master a subject. 
They see what they did, what could be done, and they have the opportunity to carry out the additional modeling and analysis. Instead of being penalized, they can proudly show they do understand the material and enjoy the class more.

Grading each paper twice certainly increases my workload, but not by $200 \%$. I read the rough drafts closely and spend most of my grading time on them as I know they will be scrutinized and acted on. The final draft is read and graded relatively quickly. I make only minimal comments on the final draft, greatly speeding up the process. Thus, for me, the two-step procedure takes about $25 \%$ longer than the traditional method.

I conclude by noting that when the whole group gets together to build and analyse the model, I assign cooperative learning roles (Barkley, Cross, \& Major, 2005) to each group member. Typically, I assign one student to be the Reporter, who writes down all the questions, all the insights, and anything else the group wants recorded. I assign one student to be the Questioner, who asks questions about the model, the analysis, the interpretations of the results, and ways to improve the analysis. Finally, the other two group members are Analysts and carry out the model building and analysis with input and suggestions from all group members.

Over the years, the feedback from these projects has been phenomenal and many students have discussed these papers in their job interviews. The students are proud of their work, and recruiters have been impressed with our student's ability to communicate to a lay audience.

\section{In-Class Demonstrations}

In addition to a two-step grading procedure, I use in-class demonstrations and breakout sessions focused on showing students how to go beyond the first solution and find improved and more nuanced solutions. I now present two of these demonstrations, one in optimization and one in simulation. With the optimization example, I discuss exactly how to go beyond the first answer and with the simulation example, I only point out model extensions that are possible and straightforward.

\section{Optimization Demonstration}

Len owns Back Bay Sports, a sports store that stocks 3 types of bicycles - road racing, touring bikes, and mountain bikes. The cost per bike, the sales price, and the time it takes to assemble and sell a bike are given in Table 1 broken down by type. Len has space for 35 bikes in his store and has allocated a budget of $\$ 72,000 /$ month for purchasing bikes. He has staff that assembles and sells the bikes and has allocated 200 hours/month for assembly and sales. Len also sells at least twice as many mountain bikes as the other two combined. Assuming Len sells every bike he orders, how many bikes by type should he order each month?

Table 1. Break down of costs, revenue, and staff hours for Back Bay Sports

$\begin{array}{lcll} & \text { Road Racing } & \text { Touring Bikes } & \text { Mountain Bikes } \\ \text { Cost/bike } & \$ 3,200 & \$ 2,100 & \$ 2,800 \\ \text { Sales Price } & \$ 4,500 & \$ 3,000 & \$ 4,000 \\ \text { Assembly \& Sales } & 8 \mathrm{hrs} / \mathrm{bike} & 6 \mathrm{hrs} / \mathrm{bike} & 10 \mathrm{hrs} / \mathrm{bike}\end{array}$


The above problem (modified from Taylor, 2013) is one of the first models students work on when we are building optimization models. The students and I build it together, me at the podium and them following on their laptops. After a discussion on Len's objectives, deciding to maximizing profit, we derive the mathematical equations describing the model, then insert these into Excel. The first solution shows that Len maximizes his marginal profit by ordering 7.14 road bikes, 0 touring bikes, and 14.28 mountain bikes resulting in a marginal profit of \$26,429/month.

The first discussion point of the results is the non-integer solution values; how can Len order 7.14 bikes? I mention that next week we cover an advanced solution method, called integer programming that is designed to only give integer solutions. As we have yet to learn this, we must work with this solution. As a class, we decide if we should round up our solution or truncate the order quantities to integers. One of the hardest lessons for students to learn in mathematical modelling classes is that their model is only an approximation. Students want to incorporate each and every aspect of the problem or situation into the model. Thus, I point out that this is a situation in which we forego one aspect of the problem (integer solutions) so that we can build and solve the model.

The next set of discussion points focuses on Excel's Answer Report, which shows that the budget of \$72,000 and the space to hold 35 bikes are non-binding constraints while the mountain bike ratio and staff hours are binding. Here the students learn that the only way to increase Len's monthly profit is to relax a binding constraint. For example, Len is only using $\$ 62,857$ of the allotted $\$ 72,000$. Thus, relaxing this constraint does not help Len at all. However, what happens if we relax either the mountain bike ratio or the staff hours? By exploring this idea, we can (perhaps) find a better solution for Len.

To explore relaxing these constraints, we turn to Excel's Sensitivity Analysis Report, particularly, the shadow price for staff hours. The shadow price is $\$ 132$, meaning that each additional staff hour increases Len's profit by $\$ 132$. As Len is not paying his staff $\$ 132 / \mathrm{hr}$, it is cost effective for Len to increase staff hours. How many additional hours should Len add? Again, the Sensitivity Analysis report tells us: add at least 29.09 hours. Note that the students are learning how to interpret the model's reports not in the abstract, but towards a specific goal, viz., increasing maximum profit.

As a class, we add 30 hours to the monthly staff hours, upping the bound from 200 to 230 hours, and rerun the optimization model. We are now on our second solution, which reports that Len maximizes profit by ordering 7.7 road bikes, 0.60 touring bikes, and 16.5 mountain bikes resulting in a marginal profit of $\$ 30,311 /$ month. Therefore, we increased monthly profit by $\$ 3,882$ by adding 30 staff hours. I make sure to point out that we have increased Len's marginal profit by more than $\$ 45,000$ annually simply by exploring the model and solution for improvements.

We see Len now needs all $\$ 72,000$ of his budget and he has three binding constraints: the budget, the mountain bike ratio, and assembly \& sales hours. I tell the class that we ignore the MTB Ratio constraint until next class and, turning to the new Sensitivity Analysis report, the shadow price for the budget constraint is $\$ 0.29$ and is $\$ 41.67$ for the assembly \& sales constraint. Again, focusing on assembly \& sales, we can add up to 13.1 hours and the marginal profit will increase by $\$ 41.67$ per added hour. Adding 14 hours to the monthly staff hours for a new upper bound of 244 hours, we have our third solution, which reports that Len maximizes profit by ordering 0 road bikes, 9.4 touring bikes, and 18.7 mountain bikes resulting in a marginal profit of $\$ 30,857 /$ month. This is a \$547 increase from solution two and a \$4429 increase over the first solution. 
At this point, the students break into groups to explore relaxing the budget constraint as an in-class exercise. After successive explorations, the budget should be raised to $\$ 76,686$ with a monthly profit of $\$ 32,243$-an increase of $\$ 1,386$.

Not only has exploring the situation improved Len's profitability, but we have also discovered a number of insights into the optimal bike order. We found that restricted staff hours was not saving Len money, but costing him $\$ 132 / \mathrm{hr}$. We also see that optimal order quantity for the bikes is quite sensitive to the bounds. For example, when staff hours had a 200 hour bound, then Len should order 7 road racing bikes, but when the bound is 244 hours, then he should order 0 road bikes. Moreover, when the budget bound increases to $\$ 76,686$ and the staff bound stays at 244 hours, then he should order 8 or 9 road bikes. All these insights help Len make his order decision and came about from exploring the model and solution.

From, this point, there are many different directions this problem can be taken. For example, we could add hourly rate for staff, such as \$25/hour. This will allow us to subtract the staff costs from the marginal profit thereby improving the model. We could also explore adding integer constraints, so that there are no factional bicycles being bought and sold.

\section{Simulation Demonstration}

As the manager of a local college bookstore, every September, we must decide how many calendars to order. The calendars arrive October 1st and are displayed until January 31st, after which all unsold calendars are returned to the publisher for a small refund. Specifically, each calendar costs $\$ 4.25$, which we retail for $\$ 11.95$, and unsold calendars are refunded at $\$ 1.45$ each. Using past sales data combined with current estimates of market conditions, our best guess of the distribution of the number of calendars demanded is given in Table 2.

How many calendars should we order? What are the associated risks?

Table 2. Distribution of Demand

\begin{tabular}{|c|c|}
\hline Demand & Probability \\
\hline 500 & .10 \\
\hline 550 & .25 \\
\hline 600 & .35 \\
\hline 650 & .20 \\
\hline 700 & .10 \\
\hline
\end{tabular}

The above problem is adapted from Winston (2004). Instead of walking though the exploration of the solution, I discuss natural ways to extend the base model.

After solving the model together, I ask the students how to extend the model - In what ways can we modify the model to make it better? Students struggle at first, but after some help, they start to offer suggestions. First, we replace the discrete distribution given in Table 2 with a continuous distribution. This allows us to discuss types of distributions, such as normal or triangular. We can model multiple products instead of just selling calendars. We then discuss ways to incorporate the relationship between two products. Are the products substitutes for one another or are the complementary or 
are they not related at all? This allows us to discuss how to use correlations or regression equations to model dependency.

\section{Conclusions}

The results in this paper are all anecdotal, based on my classroom experiences, and I have found these two pedagogical tools to be quite helpful. Students are not accustomed to thinking critically of their solution, but they need this ability (Bobrowski \& Cox, 2003). Case reports are an excellent vehicle as the students must write and think about what the analysis means to them and the decision maker. To further help my students explore the situation, I grade both a rough draft paper and their final. I spend considerable time providing feedback on the rough draft, thereby providing individual guidance to each report. I also use in-class demonstrations coupled with breakout sessions that are focused on methods to explore the situation.

\section{References}

Barkley, E. F, Cross, K. P. \& Major, C. H. (2005). Collaborative Learning Techniques: A Handbook for College Faculty. San-Francisco: Jossey-Bass.

Bobrowski, P. E. and Cox, P. L. (2003). Critical Thinking Exercise: Causes of Premature Death in America. Decision Sciences Journal of Innovative Education, 1: 145-149.

Christensen, C. R. (1981). Teaching By the Case Method. Boston: Harvard Business School.

Dehler, G. E. (1996). Management education as intentional learning: A knowledgetransforming approach to written composition. Journal of Management Education, 20(2), 221-235.

Emig, J. (1977). Writing as a model of learning. College Composition and Communication, 28, 122-128.

Keeney, R. (1992). Value-focused thinking: A path to creative decisionmaking. Cambridge, Mass.: Harvard University Press.

Taylor, B.W. (2013). Introduction to Management Science, Eleventh Edition. Custom Edition for Babson College, Boston: Pearson Custom Publishing.

Winston, W. (2004). Financial models using simulation and optimization (3rd ed.). Newfield, NY: Palisade. 
HEAd'15

SESSION 5A

\section{ENTREPRENEURSHIP}




\title{
The model of cooperation with employers as the support measure for the development of entrepreneurial university potential
}

\author{
Aleksandra Kulpa-Puczyńska \\ Cardinal Stefan Wyszyński University in Warsaw
}

\begin{abstract}
Engaging the scientific sector into the development of economy, especially the regional one, influences the image of a modern higher education facility (creative and open towards the surrounding environment), whose traditional functions have been expanded by striving towards innovativeness and entrepreneurship. This paper attempts to contribute to the discussion of practitioners (which is held also in Poland) about the current condition and perspectives for the evolution of entrepreneurship at higher education facilities. The purpose of this elaboration is to present a particular model of cooperation with employers - a solution that has been introduced and is continuously being developed (assessed, analyzed) by the Cardinal Stefan Wyszyński University (UKSW) in Warsaw - and calling attention to additional opportunities for the development of entrepreneurial potential on the example of one of its faculties. The analysis of the given problem leads, among others, to the following conclusions: in order to achieve effective functioning of the described model it is necessary that the project is coordinated internally (at the level of a given department), it is also important to act systematically (and to initiate new actions determined by current needs of the labour market) and according to the academic policy of entrepreneurship and innovativeness.
\end{abstract}

Keywords: higher education facility; employers; model of cooperation; academic entrepreneurship

\section{Introduction - entrepreneurial nature of a modern higher education facility}

Higher education facilities have recently devoted much attention to spreading information about their scientific achievements and conducting an academic policy of commercialization. The "new" role of this education sector is accompanied by the Triple Helix model, which sets out the dynamics of university-industry-government relations. The model is based on the premise that the above-mentioned areas overlap and are increasingly dependent on one another. Moreover, each area plays roles that had earlier been assigned to another sector, reflecting a new emphasis on their relationships (Leydesdorff \& Etzkowitz, 1998). Thus, universities have begun to display a more entrepreneurial mindset (they are a place where new businesses start and local communities are mobilized to become active), companies participate in academic projects and local governments set up business incubators. Furthermore, the mutual overlapping of roles leads to the emergence of bridge institutions that operate within these three areas (Gunasekara, 2006).

The influence of higher education on economic growth is also a subject of the engaged university concept, which focuses on the development of education facilities and their potential of adapting to regional needs (Goldstein, 2010). By undertaking a variety of actions, a university does not strive towards replacing companies or governmental institutions but constitutes an important initiator of cooperation between local institutions (OECD, 2012; Olechnicka, 2012). Taking into account the current situation, where larger engagement of the academic sector in economical development (in Poland, among others) gives rise to concern, the above-mentioned model seems a more suitable solution. This is because it does not assume excessive focusing on 
economic outcomes and generating labour market needs. Moreover, it does not exclude open, pro-innovative and entrepreneurial nature of a higher education facility.

An entrepreneurial university - considered an important component of a local innovative environment - is characterized by modern management, economic-friendly structure, pro-innovative initiatives and enthusiasm towards finding new sources of financing its activity. This entrepreneurship refers also to university communities (academic personnel and students) that should be open to collaborate with local businesses and seek to apply and commercialize their knowledge and skills (Matusiak, 2006; Matusiak 2010). An entrepreneurial university builds and develops its relations with external environments - and this area of its activity is being referred to in this paper. This elaboration also attempts to (1) characterize examples of activities that strengthen university-employer relations and (2) outline the opportunities for the development of entrepreneurial university potential on the example of one of its faculties, taking into account the importance of non-material innovations - an area of pedagogues' interest.

A tendency of looking for values outside the consumption area emphasizes the meaning of innovations concerning the social area - innovations that change the way of thinking, the view of the world and interpersonal relations (Duraj \& PapiernikWojdera, 2010). A definition that encompasses the wide scope of innovations has been introduced in Oslo Manual. Here, innovation is considered in terms of implementing a new or enhanced product, service, process, marketing or organization method, workplace organization or relations with the surroundings (OECD \& EC, 2005). This knowledge is relevant, as we usually associate innovations with the implementation of new products or production methods, often forgetting about organizational innovations that may be of humanists' interest (Kulpa-Puczyńska, 2013). There are still many scientists, including those that have just started their careers, who are not sufficiently familiar with commercialization principles and possibilities of obtaining (not only financial) support to realize their projects.

The Polish Law on Higher Education, Article 4, Section 4 (2005) states that: "higher education institutions shall co-operate with the socio-economic environment, in particular by conducting research and development for business entities, [...] as well as through the involvement of employers' representatives in the development of study programmes and teaching processes" (p. 7). According to the act, the senates of higher education institutions are obliged to prepare and adopt statutes of intellectual property protection and rules for commercialization of scientific research results. The last amendment to the act allows for studying in the dual system - supported by employers who will be able offer apprenticeships and internships more easily - and people with practical experience will be able to conduct classes at higher education facilities. The above-mentioned changes in the law are intended to reinforce the cooperation of universities with labour market environment (MNiSW, 2014).

\section{Material and Methods}

A starting point for the analyses described in the next chapter is the claim that we today we are facing an expanded scope of traditional functions that have been assigned to a higher education institutions. Thus, one of the attributes of a modern university is the diversification of its goals (Drucker \& Goldstein, 2007). In Misja $i$ Strategia Uniwersytetu Kardynała Stefana Wyszyńskiego (UKSW) w Warszawie na 
lata 2014-2020, in the chapter titled "Współpraca z biznesem, otoczeniem społecznym i instytucjonalnym" (Cooperation with business, social and institutional environment) we read, among others, that: "the development of relations with the economic environment aims to create and commercialize innovations, shape education programmes with regard to employers' needs and promote creativity and entrepreneurship among students” (p. 34). When attempting to analyse selected aspects of the problem of academic entrepreneurship, including the the aspect of cooperation with employers, the author has based the provided content on the experience of the above-mentioned Institution.

References to subject literature have been made, using, among others, reports from the research on education-business relations and documents referring to tasks of a higher education institution in terms of its cooperation with the external environment. The author has also reviewed the recommendations contained in Raport $\mathrm{z}$ samooceny wydziatów UKSW and other elaborations associated with the realization of the project titled "Kwalifikacja jakości w Uniwersytecie", including the material prepared by one of the coordinators. The content of this elaboration is based on author's experience in knowledge commercialization, who has also been working as an Employer Relations Department Coordinator and who in her work follows the view of F. Trias de Bes and P. Kotler (2013) that only in organizations of creative culture "[...] ideas are born everywhere, in every department and at all levels of responsibility”(p. 252).

\section{Model of Cooperation with Employers - Results and Discussion}

The activity of the selected Institution matches the presumption that good infrastructure - i.e. libraries, laboratories, workrooms - translates into an atmosphere that favours creativity, sharing various ideas and setting up new ways of conduct (Drozdowski \& Zakrzewska et al., 2010). In case of the Cardinal Stefan Wyszyński University in Warsaw we speak about the following facilities: The Center for Training and Vocational Guidance, the state-of-the-art Center for Interdisciplinary Research and Education and the Open University (including the Academy of Entrepreneurship and the Academy of Career and Development), which helps gain and deepen the knowledge in many various scientific fields. Moreover, the university makes efforts to improve the information flow between the academic community and the external environment. One example is the Model of Cooperation with Employers, introduced on 31 October 2014 as part of the project titled "Kwalifikacja jakości w Uniwersytecie", co-financed by the European Social Fund of the European Union.

The described model is intended to serve as an element of the internal system of quality assurance in education and the contained therein procedures are expected to improve the coordination between Department Committees and other University units that are involved in building relations with the social and economic environment. The tool's priority goal is to facilitate the cooperation between the Institution and employers in terms of: development of education results' projects and projects of educational programmes; specification of a graduate's profile and education paths; conducting scientific research and organization of professional trainings and apprenticeships. The model covers procedures associated with ordering specific postgraduate studies, seminaries, expertises by external stakeholders, as well as procedures concerning the cooperation with employers in the field of publishing scientific elaborations or organization of conferences. 
The implementation of this model entails the need of appointing Department Business Councils and incorporating them into the structure of employers' delegates representing a department-specific business sector, as well as Employer Relations Department Coordinators, whose competencies include:

- coordinating actions related to the analysed area - by making use of, among others, a virtual platform for cooperation with employers;

- updating the faculty business offer, together with the Departmental Didactics Committee and the Dean's Representative for promoting the faculty business offer;

- creating databases of employers who offer apprenticeships and databases of academic teachers with practical experience;

- preparing a tool for educational results' draft evaluation or a form for educational programme draft evaluation.

It is noteworthy that in the framework of the foregoing cooperation (up to November 2014) with the previous department coordinators the following projects were realized: departmental databases of employers, leaflets addressed to employers that included profiles of graduates of all study courses, study visits at employers' facilities for all study courses aimed at consulting education programmes. Departmental Business Councils can make proposals for adapting educational offer to current needs of the labour market, indicate educational areas that should make use of practical training and recommend solutions aimed at commercialization of scientific research results. The rules regarding the appointment and specific tasks of Departmental Business Councils and coordinators are contained in the Disposition of the Rector of the UKSW, which has introduced the discussed model (No. 68/2014).

In conjunction with the presented Model of Cooperation with Employers and relevant objectives set out in Misja $i$ Strategia Wydziatu Nauk Pedagogicznych (WNP) there are additional actions held regarding the development of departmental entrepreneurship, including the enhancement of cooperation with external stakeholders. The initiatives, presented in Chart 1 , have been scheduled for realization within the period of the forthcoming two years and include, among others, the results of survey research contained in the report titled Studenci o funkcjonowaniu swojej uczelni, elaborated by the Center for Research and Evaluation of Education Quality at UKSW. They also refer to the need of students being submitted during didactic classes (e.g. at the request of organizing additional meetings with labour market experts) and to the information available in SWOT Analysis of Faculty of Pedagogical Sciences where the need of broadening the cooperation by local associations and employer groups has been underscored. The actions listed in the chart do not constitute a closed list of planned forms of activity.

Chart 1. Faculty Initiatives that support academic entrepreneurship, including the cooperation with external stakeholders

\begin{tabular}{|l|l|}
\hline \multicolumn{1}{|c|}{$\begin{array}{c}\text { Selected operational objectives resulting } \\
\text { from Misja i Strategia WNP UKSW } \\
\text { (2014-2020) }\end{array}$} & $\begin{array}{c}\text { Activities that reinforce the cooperation with } \\
\text { external stakeholders - examples }\end{array}$ \\
\hline $\begin{array}{l}\text { IN TERMS OF THE QUALITY OF } \\
\text { EDUCATION AND THE DEVELOPMENT }\end{array}$ & $\begin{array}{l}\text { The work on enriching the didactic offer with } \\
\text { entrepreneurship workshops that shall prepare } \\
\text { students to effective functioning on the labour } \\
\text { market, including self-employment; recruiting } \\
\text { (aside from the WNP workers with practical }\end{array}$ \\
\hline - Adjusting the didactic offer to current
\end{tabular}




\begin{tabular}{|l|l|}
\hline labour market requirements & $\begin{array}{l}\text { experience) external experts specializing in the } \\
\text { above-mentioned field (including self-employed } \\
\text { graduates); } \\
\text { Organization of a methodical seminary, } \\
\text { focusing on the practical experience among the } \\
\text { WNP students (with the participation of } \\
\text { students, Deanery Authorities, apprenticeship } \\
\text { coordinators, Career Offices and local } \\
\text { employers); taking care of the cyclical and } \\
\text { pragmatic nature of the above-mentioned } \\
\text { project. }\end{array}$ \\
\hline $\begin{array}{l}\text { IN TERMS OF THE COOPERATION } \\
\text { INSTITUTIONAL ENVIRONMENTS }\end{array}$ & $\begin{array}{l}\text { Inviting practical specialists within the } \\
\text { framework of regular open lectures (combined } \\
\text { with a discussion) in order to improve the match } \\
\text { of the WNP students' competencies to social and } \\
\text { economic needs; the lectures are also intended to } \\
\text { support cooperation with graduates who are } \\
\text { environment, particularly including employer } \\
\text { associations, in order to determine the } \\
\text { demand for specific skills and competencies } \\
\text { and/or speakers. } \\
\text { The work on creating the Departmental Center } \\
\text { of Educational Initiatives, intended for } \\
\text { becoming a cooperation platform between the } \\
\text { university and social-life institutions - a } \\
\text { platform constituting a tool for encouraging the } \\
\text { WNP students and graduates to be active, a } \\
\text { place for gaining their first professional } \\
\text { experience and realizing their own projects. }\end{array}$ \\
\hline
\end{tabular}

*WNP - Faculty of Pedagogical Sciences

(Source: own elaboration)

The scope of activities that facilitate the development of academic entrepreneurship includes students' involvement in the realization of departmental projects, which can help them develop skills valued today (organization of work, effective communication skills). This sort of initiatives gives access to wide research material and unexplored practical solutions. Another important things is the support that is being offered to students in terms of their integration to the labour market, through e.g. sharing information about recruitment opportunities at institutions and companies cooperating with the WNP. Here, it is noteworthy that the department relies, first of all, on the cooperation with employers who can offer workplaces for graduates and who have been using modern methods and technologies in relation to didactic processes. On the other hand, the general activities undertaken by universities, relevant for the content of this elaboration, include encouraging the UKSW students and graduates to establish their own businesses and supporting their activity, as well as providing academic teachers with suitable skills and competencies concerning the process of commercialization of scientific research results. More information on this matter can be found, among others, in Misja $i$ Strategia Uniwersytetu Kardynata Stefana Wyszyńskiego w Warszawie na lata 2014-2020.

The knowledge, relevant in terms of the developed activities, comes from internal academic sources and is rooted in the concluded and planned contracts with: companies, employer associations, business-related institutions, training companies, labour market institutions, local governments, non-profit organizations, schools and $\mathrm{R} \& \mathrm{D}$ centers. It should be noted that the Polish system of business-related institutions 
includes: entrepreneurship centers, e.g. business incubators, business centers; innovation centers, including science parks, knowledge and technology transfer centers and financial institutions as e.g. local loan funds, business angel networks. The above-mentioned institutions constitute a diversified group of non-commercial establishments. When writing about the cooperation with employers it is worth mentioning - referring to the results of the study titled Universum Student Survey 2012. University Report - Polish Edition - Cardinal Stefan Wyszyński University in Warsaw (Humanities/Liberal Arts/Education) - that students are interested in being employed particularly in the following branches: Media and Advertisement, Educational and Research Institutions, Public Sector and Governmental Agencies. This, however, leads to raising the following questions: Should higher education institutions fulfil students' expectations and cooperate mainly with employers representing the above-mentioned branches? Will this sort of professional preparation be effective? Students also prefer to work in small and medium-size companies and their career objective is to achieve safe and stable employment.

\section{Conclusions}

The presented herein Model of Cooperation with Employers is intended to make it easier for the representatives of the business world to access academic databases and results of the research conducted by universities. It consists in preparing a comprehensive offer of cooperation with employers and cooperation of all UKSW departments in this field. It is necessary to point out that the sustainability of advantages associated with implementing this model will in the longer term depend on University's interest in following the path of entrepreneurship and innovativeness and offering appropriate support. It seems certain - especially in the context of a developing economy based on knowledge and challenges of a flexible labour market. However, it is necessary to secure internal coordination of the project and initiate further activities, as described in, among others, Misja i Strategia UKSW and strategies of its departments.

According to also the author, the development of the entrepreneurial potential of higher education facilities (the humanistic ones too) can include also other initiatives than the previously mentioned ones, i.e.: reinforcing the activity of academic interdisciplinary research teams which include students; organizing apprenticeships in innovative companies; employers' initiatives concerning the organization of additional professional trainings and consultations; establishing partnerships between employers and particular departments (e.g. WNP) - as an important intermediary in the process of transferring knowledge to economy and as a source of ideas; cooperation between particular departments in favour of academic entrepreneurship; promoting cooperative activities (good practices) through, among others, conferences and publications.

There are also several challenges associated with the above-mentioned activities, which include: reluctance of a part of the academic community to the process of commercialization and striving towards cooperation with business entities, which can result from the need of focusing on other activities, as scientific development or publishing; insufficient competencies of research and didactic personnel for developing and offer of cooperation with external establishments; limited capabilities of many higher education institutions regarding their financial contribution to the realization of projects; limited scope of international cooperation regarding conducting research, which is indispensable in the context of global competitiveness. 
Barriers can also be found on the companies' side or result from external factors. This topic, however, due to its complexity, constitutes material for a separate elaboration.

More information about the condition and capabilities of cooperation between Polish higher education institutions and local environments can be found, among others, in the following publications: Polskie szkolnictwo wyższe - stan, uwarunkowania i perspektywy, a report compiled as a part of an environmental project titled "Strategia rozwoju szkolnictwa wyższego 2010-2020", conducted by, among others, the Polish Rectors Foundation; Diagnoza stanu szkolnictwa wyższego w Polsce by Ernst\&Young and the Institute for Market Economics as a part of the preparation of "Strategia rozwoju szkolnictwa wyższego w Polsce do 2020 roku" and Biznes dla edukacji. Raport specjalny dotyczacy wspólpracy biznesu i edukacji $w$ Polsce, developed as a part of a project realized by the Polish Agency for Enterprise Development in cooperation with the Polish Human Resources Management Association.

\section{References}

Act of 27 July 2005 Law on Higher Education (Official Journal of Laws of 2005, No. 164, item 1365, as amended). Retrieved January 15, 2015, from http://www.nauka.gov.pl/g2/oryginal/2013_12/d687905792f5ff6a3ecf84d7df4f8e 57.pdf

Cardinal Stefan Wyszyński University (UKSW) in Warsaw. (2014). Misja i Strategia Uniwersytetu Kardynała Stefana Wyszyńskiego w Warszawie na lata 2014 2020. Retrieved January 15, 2015, from http://ksztalcenie.uksw.edu.pl/content/misja-i-strategia-uksw

Drozdowski R., Zakrzewska A., Puchalska K., Morchat M., \& Mroczkowska D. (2010). Wspieranie postaw proinnowacyjnych przez wzmacnianie kreatywności jednostki. Warszawa: Polish Agency for Enterprise Development. Retrieved January 15, 2015, from http://www.e-msp.pl/files/74/81/380/9721.pdf

Drucker J. \& Goldstein H. (2007). Assessing the regional economic development impacts of universities: a review of current approaches. International Regional Science Review, 30 (1), 20-46.

Duraj J., \& Papiernik - Wojdera M. (2010). Przedsiębiorczość i innowacyjność. Warszawa: Wydawnictwo Difin.

Goldstein H. A. (2010). The'entrepreneurial turn' and regional economic development mission of universities. Annals of Regional Science, 44 (1), 83-109.

Gunasekara, C. (2006). The generative and developmental roles of universities in regional innovation systems. Science and Public Policy, 33 (2), 137-150.

Kulpa-Puczyńska A. (2013). Szkoła wyższa jako instytucja wspierająca działalność innowacyjną przedsiębiorstw. Wybrane problemy. Problemy Profesjologii, 1, 89100.

Leydesdorff L. \& Etzkowitz H. (1998). The Triple Helix as a model for innovation studies. Science and Public Policy 25 (3), 195-203.

Matusiak K. B. (2006). Rozwój systemów wsparcia przedsiębiorczości. Radom Łódź: ITE-PIB The Institute for Sustainable Technologies - National Research Institute. 
Matusiak K. B. (2010). Budowa powiązań nauki z biznesem w gospodarce opartej na wiedzy. Rola i miejsce uniwersytetu w procesach innowacyjnych. Warszawa: SGH Warsaw School of Economics.

Ministry of Science and Higher Education (MNiSW). (2014). Nowelizacja ustawy o szkolnictwie wyższym opublikowana w Dzienniku Ustaw. Retrieved January 15, 2015, from http://www.nauka.gov.pl/aktualnosci-ministerstwo/nowelizacjaustawy-o-szkolnictwie-wyzszym-opublikowana-w-dzienniku-ustaw.html

OECD \& European Commission (2012). A Guiding Framework for Entrepreneurial Universities, Final version 18th. Retrieved April 15, 2015, from http://www.oecd.org/site/cfecpr/EC-

OECDEntrepreneurialUniversitiesFramework.pdf

OECD \& European Commission (2005). Oslo Manual. Guidelines for Collecting and Interpreting Innovation Data (3rd ed.). Paris.

Olechnicka A. (2012). Potencjał nauki a innowacyjność regionów. Warszawa: Wydawnictwo Naukowe Scholar.

Trías de Bes F., \& Kotler P. (2013) Innowacyjność. Przepis na sukces. Model „od A do F” (M. Zawiślak \& J. Środa, Trans.). Poznań: REBIS Publishing Hause Ltd. (Original work published 2011). 


\title{
Analyzing double degrees in Spain: A proposal
}

\author{
Norat Roig-Tierno*, Alicia Mas-Tur**, Belén Ribeiro-Navarrete** \\ *Universitat Politècnica de València \\ **Universitat de València
}

\begin{abstract}
This article reviews the situation of single and double degrees in both public and private Spanish universities. To do so, this study analyzes information from the Registry of Universities, Centers, and Qualifications (RUCT) and Universia Spain. After analyzing the programs currently available to students, we present a proposal to establish a double degree in Administration and Business Management/Industrial Management Engineering. The proposal specifies the degree's main objectives, specific nature, and fundamental aims and benefits in terms of technical, corporate, innovative, and entrepreneurial competencies.
\end{abstract}

Keywords: Double degree, Administration and Business Management, Industrial Management Engineering

\section{Introduction}

This study presents a proposal to create a double degree in Administration and Business Management/Industrial Management Engineering. This degree would cover the full range of industry needs in the following knowledge areas: production process management, resource management, quality management, innovation management, internationalization strategies, and other aspects including accounting, marketing, and entrepreneurship.

To support the proposal, this study analyzes existing double degrees in Spain. According to Universia Spain, two types of university qualifications exist in Spain: official university qualifications and qualifications granted by specific universities. This study focuses only on official university titles. Spanish universities offer 3,160 undergraduate degrees, 8,235 postgraduate degrees, and 1,574 $\mathrm{PhD}$ programs. Of these 3,160 undergraduate degrees, 441 are double degrees. This study analyzes these 441 double degrees to discover whether a double degree in Administration and Business Management/Industrial Management Engineering is viable.

Section 2 outlines the university degrees currently available in Spain. Section 3 describes the double degree proposal. Finally, section 4 presents conclusions and future research opportunities.

\section{University degrees}

The Registry of Universities, Centers, and Qualifications (RUCT) provides relevant information about universities, centers, and qualifications in the Spanish university system, including the new official degrees (grados in Spanish), master's degrees, and PhD programs. The RUCT institution is a public and administrative tool that is constantly updating the information it offers.

According to Universia Spain, there are currently 50 public universities and 32 private universities in Spain. Furthermore, Spanish degrees may be official national degrees (títulos oficiales) or degrees granted only by a particular university (títulos propios). All universities, regardless of whether they are public or private, can issue both qualifications. 
Official degrees (grados, master's degrees, and PhDs), which are valid throughout Spain, appear in the RUCT and meet the requirements established by the European Higher Education Area (EHEA). Therefore, these degrees are valid in all countries within the EHEA. These degrees are also equivalent to degrees granted in other countries outside the EHEA.

An individual university's degrees have several labels: non-official degree, non-official master's degree, Master's for Specialists, or Master's for Experts, among others. Unofficial qualifications are created by universities and are not valid within the EHEA. Generally, unofficial qualifications are not equivalent to degrees in other countries and are recognized only by the university that offers them.

This study focuses on official degrees. In Spain, there are currently 3,160 undergraduate degrees (441 of which are double degrees), 8,235 postgraduate degrees, and 1,574 $\mathrm{PhD}$ programs. General degrees consist of 240 European Credit Transfer and Accumulation System (ECTS) credits (including a final degree dissertation), whereas double degrees consist of 360 ECTS credits. The Spanish provinces with the highest numbers of double degrees are Madrid (211), Valencia (45), Barcelona (40), and Seville (27). All other provinces offer fewer than 15 double degrees each. Table 1 lists Spanish universities and the single degrees and double degrees on offer.

Table 1. BA degrees and double degrees at Spanish universities (Source: RUCT and Universia)

\begin{tabular}{|c|c|c|c|}
\hline University & $\begin{array}{c}\text { All degrees } \\
\text { (RUCT) }\end{array}$ & $\begin{array}{l}\text { All degrees } \\
\text { (Universia) }\end{array}$ & $\begin{array}{c}\text { Double } \\
\text { degrees }\end{array}$ \\
\hline Universidad Europea de Madrid & 46 & 53 & 49 \\
\hline Universidad Rey Juan Carlos & 55 & 55 & 42 \\
\hline Universidad San Pablo-CEU & 32 & 35 & 28 \\
\hline Universidad Cardenal Herrera-CEU & 20 & 21 & 26 \\
\hline Universidad Antonio de Nebrija & 30 & 26 & 23 \\
\hline Universidad Camilo José Cela & 33 & 38 & 19 \\
\hline Universidad de Sevilla & 62 & 67 & 18 \\
\hline Universidad Alfonso X El Sabio & 42 & 33 & 16 \\
\hline Universidad Autónoma de Barcelona & 79 & 87 & 12 \\
\hline Universidad Católica de Valencia San Vicente Mártir & 24 & 25 & 12 \\
\hline Universidad de Cádiz & 42 & 49 & 12 \\
\hline Universidad de Navarra & 34 & 43 & 12 \\
\hline Universidad Europea Miguel de Cervantes & 12 & 12 & 10 \\
\hline Universidad Católica San Antonio de Murcia & 29 & 30 & 9 \\
\hline Universidad Francisco de Vitoria & 21 & 18 & 9 \\
\hline Universidad Pablo de Olavide & 20 & 19 & 9 \\
\hline Universidad Pontificia Comillas & 18 & 15 & 8 \\
\hline Universitat de València (Estudi General) & 53 & 57 & 8 \\
\hline Universidad Carlos III de Madrid & 27 & 28 & 7 \\
\hline Universidad Católica Santa Teresa de Jesús de Ávila & 10 & 11 & 7 \\
\hline Universidad de Deusto & 21 & 27 & 7 \\
\hline Universidad Complutense de Madrid & 69 & 85 & 6 \\
\hline Universidad de Barcelona & 63 & 67 & 6 \\
\hline Universidad de Girona & 41 & 46 & 6 \\
\hline Universidad de Huelva & 29 & 28 & 6 \\
\hline Universidad Ramón Llull & 34 & 34 & 6 \\
\hline UniversitatAbatOliba CEU & 11 & 12 & 6 \\
\hline Universitat Internacional de Catalunya & 14 & 14 & 6 \\
\hline Universidad de Extremadura & 59 & 64 & 5 \\
\hline Universidad de Málaga & 52 & 58 & 5 \\
\hline Universidad de Granada & 62 & 78 & 4 \\
\hline Universidad de Lleida & 31 & 31 & 4 \\
\hline Universidad Autónoma de Madrid & 40 & 41 & 3 \\
\hline
\end{tabular}




\begin{tabular}{|l|c|c|c|}
\hline Universidad de Burgos & 27 & 27 & 3 \\
\hline Universidad de Las Palmas de Gran Canaria & 36 & 32 & 3 \\
\hline Universidad Pompeu Fabra & 29 & 34 & 3 \\
\hline Universidad de Alcalá & 36 & 34 & 2 \\
\hline Universidad de Alicante & 37 & 37 & 2 \\
\hline Universidad de Córdoba & 32 & 29 & 2 \\
\hline Universidad de Oviedo & 49 & 55 & 2 \\
\hline Universidad de Valladolid & 56 & 71 & 2 \\
\hline Universidad del País Vasco/EuskalHerrikoUnibertsitatea & 69 & 73 & 2 \\
\hline Universidad Pública de Navarra & 19 & 21 & 2 \\
\hline Universidad San Jorge & 14 & 13 & 2 \\
\hline Universitat de les Illes Balears & 32 & 30 & 2 \\
\hline Universitat Politècnica de València & 30 & 30 & 2 \\
\hline IE Universidad & 10 & 7 & 1 \\
\hline Universidad de A Coruña & 37 & 40 & 1 \\
\hline Universidad de Jaén & 33 & 38 & 1 \\
\hline Universidad de Zaragoza & 54 & 55 & 1 \\
\hline Universidad Politécnica de Catalunya & 43 & 44 & 1 \\
\hline Universidad Rovira i Virgili & 39 & 39 & 1 \\
\hline Mondragón Unibertsitatea & 15 & 15 & 0 \\
\hline Universidad a Distancia de Madrid & 23 & 15 & 0 \\
\hline Universidad de Almería & 29 & 27 & 0 \\
\hline Universidad de Cantabria & 29 & 27 & 0 \\
\hline Universidad de Castilla-La Mancha & 46 & 64 & 0 \\
\hline Universidad de La Laguna & 45 & 50 & 0 \\
\hline Universidad de La Rioja & 19 & 19 & 0 \\
\hline Universidad de León & 37 & 37 & 0 \\
\hline Universidad de Murcia & 48 & 50 & 0 \\
\hline Universidad de Salamanca & 64 & 74 & 0 \\
\hline Universidad de Santiago de Compostela & 44 & 48 & 0 \\
\hline Universidad de Vic-Universidad Central de Catalunya & 26 & 29 & 0 \\
\hline Universidad de Vigo & 40 & 41 & 0 \\
\hline Universidad Internacional de La Rioja & 17 & 14 & 0 \\
\hline Universidad Politécnica de Madrid & 40 & 42 & 0 \\
\hline Universidad Pontificia de Salamanca & 22 & 22 & 0 \\
\hline UniversitatOberta de Catalunya & 15 & 17 & 0 \\
\hline Universidad Jaume I de Castellón & 31 & 32 & 0 \\
\hline Universidad Miguel Hernández de Elche & 27 & 25 & 0 \\
\hline Universidad Nacional de Educación a Distancia & 27 & 27 & 0 \\
\hline Universidad Politécnica de Cartagena & 18 & 20 & 0 \\
\hline Universidad Europea de Canarias & 5 & -- & -- \\
\hline Universidad Europea de Valencia & 10 & -- & -- \\
\hline Universidad Internacional Isabel I de Castilla & 10 & -- & -- \\
\hline Universidad Loyola Andalucía & 11 & -- & -- \\
\hline Universitat Internacional Valenciana & 5 & -- & -- \\
\hline Total & & & $\mathbf{4 4 1 8}$ \\
\hline
\end{tabular}

Of the 441 double degrees, 108 are in Administration and Business Management, 88 are in Law, 69 are in Communication Sciences, and 49 are in Technology and Engineering. Spanish universities also offer double degrees in other subjects like Teaching, Political Sciences, Marketing and Advertising, and Computing.

Nevertheless, only 53 double degrees are registered in the RUCT. This number is low because double degrees are actually two complete degrees and therefore ultimately provide the student with two different qualifications rather than one (double) degree. This is the case for most double degrees. For example, a student taking the double degree in Administration and Business Management/Law at the University of Valencia would obtain two qualifications upon completing the degree: one qualification as a graduate in Administration and Business Management and another as a graduate in Law. The 
University of Valencia's webpage describes this particular degree's structure as follows: 'These studies are planned so that the student may obtain a degree in Administration and Business Management ( $A D E$ in Spanish) and a degree in Law after studying for a period of five academic years'.

In this study, we make no distinction whatsoever because we understand that the two ways of obtaining the double degree are equally valid and provide students with the necessary knowledge in both fields.

\section{New double degree proposal}

After performing the above analysis, we propose the creation of a double degree in Administration and Business Management/Industrial Management Engineering.

The double degree Administration and Business Management/Industrial Management Engineering would cover industrial environment's needs through the following knowledge fields: production process management, resource management, quality management, innovation management, internationalization strategies, and other aspects that include accounting, marketing, and entrepreneurship. This approach means this degree would provide students with the knowledge and tools required to adapt to the changing industrial environment, while adding value by combining competencies from different technical, business, and international fields.

The education/training of students enrolled in this double degree responds to the increasing demand for versatile professionals in small and medium enterprises (SME), large enterprises, and enterprises with a technological basis because of the double degree's technical, managerial, and international components (Asgary \& Robbert, 2010). Hence, students of the double degree in Administration and Business Management/Industrial Management Engineering would be trained to perform a range of tasks such as strategic decision-making, innovation management for competitive advantage, optimization and management of limited resources, and planning, development, and implementation of expansion and internationalization strategies.

Thus, the double degree proposed in this study has two objectives: (1) to train versatile professionals with strong scientific and technical skills together with a solid theoretical grounding in industrial management engineering; and (2) to train professional graduates in business management using a practical approach based on models, case studies, and experiences.

The main objectives and benefits of this double degree are technical, business, and innovative and entrepreneurial competencies. Technical competencies are attained by (1) acquiring knowledge related to industrial management based not only on advanced textbooks but also on avant-garde business; and (2) understanding and mastering the basic concepts and techniques of different scientific and technological fields such as thermodynamics, electricity, design, materials, electromagnetism, chemistry, acoustics, environment, and quality.

Business-related competencies refer to the following areas. (1) Building knowledge of existing business structures and their evolution and developing capabilities in business management for decision-making. (2) Compiling, selecting, and interpreting relevant information to analyze and judge relevant social, scientific, and ethical topics. Students would also learn to communicate and transmit information and ideas, solve problems, analyze data, and find solutions. (3) Acquiring resources and abilities to provide 
enterprises with differentiating characteristics (e.g., developing databases to manage and use ICTs, developing tools to manage resources related to the control, implementation, and design of processes, developing the ability to implement management and quality control systems, and defining follow-up and monitoring mechanisms through evaluation processes.

Innovation and entrepreneurial competencies refer to students' training with an international, entrepreneurial, and innovative orientation to generate sustainable competitive advantage.

The double degree in Administration and Business Management/Industrial Management Engineering is aimed at all kinds of students who want to build a career working in organizations and enterprises by combining strong technical competencies with an innovative and international approach. This degree is also aimed at managers and professionals keen to reinforce their knowledge and skills in managing available resources to obtain competitive advantage, while deepening their knowledge of industrial management.

\section{Conclusions and future research}

This study proposes the creation of a new qualification: a double degree in Administration and Business Management/Industrial Management Engineering. Similar double degrees are Electrical Engineering/Establishment and Operation of Companies at the Universidad Europea de Madrid; Industrial Technology Engineering/Administration and Business Management at the Universitat de Girona and the Universidad de Deusto; Computer Engineering/Administration and Business Management at the Universidad Rey Juan Carlos and the Universidad de Las Palmas de Gran Canaria; and Industrial Electronics Engineering and Automation/Establishment and Operation of Companies at the Universidad Europea de Madrid.

These double degrees include modules related to Administration and Business Management. However, they do not allow students to combine Administration and Business Management with Industrial Management Engineering, which is a key degree to link technological knowledge, society's needs, and business management. So far, no university offers the double degree this study proposes. Nonetheless, industry and the economy have two main features that call for such a degree: the need to optimize companies' resources management; and the increasing competition and complexity of national markets, which forces firms to internationalize. Thus, this study proposes the creation of a double degree that will educate and train versatile professionals with strong scientific and technical skills together with a solid theoretical grounding in industrial management engineering. Graduates will gain insight and competencies in administration and business management through a practical approach based on models, case studies, and experience. Furthermore, the degree can offer an international approach that will allow graduates to develop their abilities in a globalized context (Culver, Puri, Spinelli, DePauw \& Dooley, 2011).

Future research could design a triple degree in Administration and Business Management and Industrial Management Engineering. According to Universia, only two triple degrees exist in Spain: the triple degree in Journalism/Audiovisual Communication and Multimedia/Advertising and the triple degree in Media and Performing Arts/Musical Creation/Dance Sciences, both at the Universidad Europea de Madrid. 


\section{References}

Asgary, N., \& Robbert, M. A. (2010). A cost-benefit analysis of an international dual degree programme. Journal of Higher Education Policy and Management, 32(3), 317-325.

Datos Básicos del Sistema Universitario Español (2014). Ministerio de Educación Cultura y deporte.

Farrior, S., \& Davis, L. (2012). Eligibility and Academic Requirements for Participation in International Dual Degree Programs.

Culver, S. M., Puri, I. K., Spinelli, G., DePauw, K. P., \& Dooley, J. E. (2011). Collaborative dual-degree programs and value added for students: Lessons learned through the EVALUATE-E project. Journal of Studies in International Education, 1028315311403934.

RUCT - Registro de Universidades, Centros y Títulos. Recuperado el 28 de enero de 2015, de https://www.educacion.gob.es/ruct/home

UNIVERSIA. Last consulted 25/01/2015 de http://www.universia.es/ 


\title{
Higher Education in El Salvador: Pertinence and Education for Entrepreneurship
}

\author{
P. Pinazo-Dallenbach*, D.X. Tutistar-Rosero** \\ *ESIC Business and Marketing School \\ ** Universitat de Valencia
}

\begin{abstract}
The training of human resources is crucial for the economic and social development of territories that are striving to become knowledge-based economies. Although the number of student enrolments in El Salvador has increased in recent years, some elements of the higher education system have hindered the country's development from this approach. El Salvador's population is generally poorly qualified and particularly poorly specialized. In addition, El Salvador has a low-quality higher education system, which employs poorly qualified teaching staff with outdated methods and syllabuses. The lack of pertinence of the higher education system in El Salvador is reflected in the conflict between the country's education and labour systems. This conflict has especially negative effects on younger generations' social mobility. To remedy this situation, this research presents proposals to improve the higher education system's pertinence and to implement a compulsory entrepreneurship education module across all areas of higher education.
\end{abstract}

Keywords: Higher education; El Salvador; Pertinence; Entrepreneurship; Qualifications

\section{Introduction}

Numerous studies have highlighted the benefits of knowledge-based economies in terms of the economic and social development of territories (Schramm, 2006; Audretsch, 2007; Levie \& Autio 2008). Nevertheless, most Latin American economies are in the efficiency-driven stage (López-Claros et al., 2006). These countries should therefore encourage innovation to reach the technological frontier and become knowledge-based economies - a characteristic of the innovation-driven stage (Porter et al., 2002). Wennekers et al. (2005) report that if policymakers in Latin America resign themselves to following natural tendencies without prioritizing entrepreneurship, they will merely reduce the rates of necessity-driven entrepreneurship without achieving higher growth in opportunity-driven entrepreneurship, which is based on innovation and value creation. Thus, policymakers should implement policies that foster innovative entrepreneurship to create new and improved firms with novel business models (Miles et al., 2005).

El Salvador falls into the aforementioned group of countries. As illustrated in the 2012 GEM Report (Sanchez-Masferrer, 2013), the quality of entrepreneurship in El Salvador fails to meet that of a knowledge-based economy. The rate of necessity-driven entrepreneurship is 35\%, far higher than the regional average, whereas opportunitydriven entrepreneurship - the driver of the creation and application of innovation - has a rate of just 39\%, which is lower than the regional average. These data imply that the entrepreneurial orientation in El Salvador is not conducive to innovation and projects offering high value added. The high abandonment rate among businesses $(7.9 \%$ - the highest in the region) compounds the weakness of El Salvador's entrepreneurial profile. 
Table 1. Entrepreneurship in El Salvador and the region (Latin America and the Caribbean)

\begin{tabular}{|l|c|c|c|}
\hline & $\begin{array}{c}\text { Necessity-driven } \\
\text { entrepreneurship }\end{array}$ & $\begin{array}{c}\text { Opportunity- } \\
\text { driven } \\
\text { entrepreneurship }\end{array}$ & $\begin{array}{c}\text { 12-month } \\
\text { abandon rate }\end{array}$ \\
\hline El Salvador & $35 \%$ & $39 \%$ & $7.9 \%$ \\
\hline Regional average & $22 \%$ & $51 \%$ & $5 \%$ \\
\hline
\end{tabular}

Source: Authors’ own work based on Sánchez-Masferrer (2013)

The large number of barriers to creating knowledge-based economies in Latin America hinders the creation of firms that fit the mould of the "entrepreneurial economy" (Amorós \& Cristi, 2008; Terjesen \& Amorós, 2010). The training of human resources, especially in the higher education system (Clark, 2004), is a pillar of this kind of economy. Nevertheless, despite massive efforts over the last 20 years in terms of democracy, property rights, and macroeconomic stability in the region, areas such as education and knowledge creation remain weak (Acs \& Amorós, 2008). An abundance of highly qualified workers would foster innovation-based entrepreneurship with high value added, which in the medium and long term would lead to the creation of new jobs for qualified candidates and would hence improve the sustainable human development of the territory. As reported by Alburquerque (2004), a country's education and training should meet the specific innovation needs of the local production systems. Offering a basic generalist education is not enough. Instead, the education system must meet the specific needs of the local production system (i.e., the available education must be relevant), and it must encourage creativity and new technology adoption.

The Ministry of Education (MINED) is the governing body of El Salvador's education system. Technical education and university education make up the higher education system, understood as systematic efforts in education and training after secondary education (Ley de Educación Superior de El Salvador. Cap. I, Art. 4). El Salvador has 7 technical institutes, 9 specialist higher education institutes, and 24 universities. The aim of these institutes is threefold: teaching, scientific research, and social outreach.

The limited resources assigned to education explain, in part, the education system's weak performance, particularly in terms of quality and pertinence. Despite advances in the last decade, public spending on education in relation to El Salvador's GDP is still low. According to the MINED's annual accounts, public spending on education rose from $3.44 \%$ of GDP (588.7 million USD) in 2005 to $3.93 \%$ of GDP (834.3 million USD) in 2010. According to country profiles published by the Information System on Educational Trends in Latin America (SITEAL, 2013), however, El Salvador performs poorly in comparison with other countries in the region. El Salvador's investment in percentage terms is lower than that of all neighbouring countries, except that of Guatemala, which invests $2.9 \%$ of its GDP. Excluding Panama, the country with the highest percentage spend is Honduras (7.6\%), followed by Costa Rica (5.9\%), both of which spend considerably more than El Salvador does.

By presenting a bibliographical analysis of public and private reports, this article characterizes El Salvador's higher education system. Analysis focuses on data relating to admissions, pertinence, and quality to identify major weaknesses that affect entrepreneurship and labour market integration by university graduates. This article proposes two actions to mitigate these weaknesses. The first proposal relates to improving the education system's pertinence. The second proposal, in contrast, relates to developing entrepreneurial aptitudes and attitudes of young university students in El 
Salvador. To do so, the proposal advocates the introduction of a compulsory module on education for entrepreneurship. Finally, conclusions and future research opportunities are presented.

\section{Data on admissions to higher education in El Salvador}

Crucially, El Salvador's labour force is generally poorly qualified. As shown by the Information System on Educational Trends in Latin America (SITEAL, 2013), just 18\% of El Salvador's population aged between 20 and 21 years enter higher education, of which only 53\% complete their studies. The following paragraphs summarize the main features of admissions to higher education in El Salvador.

In recent years, the number of higher education students in El Salvador has grown. According to the National Committee for Higher Education (Dirección Nacional de Educación Superior, 2014), in 2013 the number of students increased by 3.65\% with respect to 2012 levels. The same year, 176,063 students were enrolled in higher education. Of these students, 77,022 were men (46.5\%) and 88.597 were women (53.5\%). The enrolment rate was distributed across institutes as follows: 162,578 students (92.34\%) were enrolled in universities; 8,680 (4.93\%) were enrolled in specialist institutes; and 4,805 (2.73\%) were enrolled in technical institutes.

Around $86 \%$ of the higher education students were aged between 16 and 29 years. The most common age range was 19 to 23 years old. The population according to the Directorate-General of Statistics and Censuses (DIGESTYC) was 666,702 inhabitants, yielding a gross higher education admissions rate of $26.41 \%$. According to higher education institutions' records, for the same year, 86,934 students aged between 19 and 23 years enrolled in higher education, yielding a net higher education admissions rate of $13.04 \%$.

Despite improvements in recent years, however, general figures are too low, particularly those referring to postgraduates in specialist studies leading to $R \& D$, a pillar of knowledge-based economies. Only $3 \%$ of students enrolled in higher education were studying master's or PhD courses.

Table 2. Students enrolled in higher education in El Salvador by academic level and sex

\begin{tabular}{|l|c|c|c|}
\hline \multirow{2}{*}{ Academic level } & \multirow{2}{*}{ Total } & \multicolumn{2}{c|}{ By sex } \\
\cline { 3 - 4 } & & Male & Female \\
\hline Postgraduate (master's and PhD) & $3 \%$ & $48 \%$ & $52 \%$ \\
\hline Undergraduate (bachelor's) & $84 \%$ & $46 \%$ & $54 \%$ \\
\hline Technical student & $14 \%$ & $48 \%$ & $52 \%$ \\
\hline & $100 \%$ & $47 \%$ & $53 \%$ \\
\hline
\end{tabular}

Source: Authors’ own data using data from the National Committee for Higher Education (Dirección Nacional de Educación Superior, 2014)

\section{Pertinence and quality of higher education in El Salvador}

El Salvador's Ministry of Education defines 10 subject areas within professional training, each comprising degrees with similar characteristics: I) Art and Architecture; II) Economics, Management, and Business; III) Health; IV) Science; V) Agriculture and Environment; VI) Law; VII) Humanities; VIII) Technology; IX) Education; and $\mathrm{X})$ Social Sciences. The most popular subject area among El Salvador's students is Economics, Management, and Business (25.18\% of the student population). The second 
most popular area is Technology (19.79\%), and the third most popular area is Health (18.78\%).

Table 3. Percentage of enrolment by subject area and sex in El Salvador

\begin{tabular}{|c|c|c|c|}
\hline Subject area & Male & Female & $\begin{array}{c}\text { \% of students } \\
\text { enrolled }\end{array}$ \\
\hline $\begin{array}{c}\text { Economics, Management, and } \\
\text { Business }\end{array}$ & $42 \%$ & $58 \%$ & 25.18 \\
\hline Technology & $78 \%$ & $22 \%$ & 19.79 \\
\hline Health & $28 \%$ & $72 \%$ & 18.78 \\
\hline Law & $44 \%$ & $56 \%$ & 9.10 \\
\hline Education & $32 \%$ & $68 \%$ & 8.92 \\
\hline Humanities & $42 \%$ & $58 \%$ & 5.67 \\
\hline Social Sciences & $38 \%$ & $62 \%$ & 4.80 \\
\hline Art and Architecture & $53 \%$ & $47 \%$ & 4.17 \\
\hline Science & $45 \%$ & $55 \%$ & 1.82 \\
\hline Agriculture and Environment & $68 \%$ & $32 \%$ & 1.76 \\
\hline Total & $\mathbf{4 7 \%}$ & $\mathbf{5 3 \%}$ & $\mathbf{1 0 0}$ \\
\hline
\end{tabular}

Source: Authors' own data using data from the National Committee for Higher Education (Dirección Nacional de Educación Superior, 2014)

At the university level, the most popular degrees are the bachelor's degree in Business Management (8.58\% of the enrolled student population in 2013), the bachelor's degree in Law (7.50\%), and the bachelor's degree in marketing (5.44\%) (Dirección Nacional de Educación Superior, 2014). These three degrees cover more than $20 \%$ of total demand.

The excess of demand for these degrees shows that academic courses available in El Salvador's higher education system (UNDP, 2013) are of little pertinence. The regional needs of the labour market and of the country in general were not analysed before considering which academic courses to offer. Failure to consider these issues hinders the absorption of new graduates in the labour market and contributes to the devaluation of degree qualifications. These effects are consequences of the surplus of graduates enrolled in certain degrees, which depresses nominal wages. In addition, human resources are underused, and graduates from these degrees end up working in jobs where they are overqualified.

Another challenge facing El Salvador is the low quality of its education system in general, but in particular its higher education system. As reported by USAID (Sanders et al., 2012) in El Salvador: Higher education assessment and recommendations, a large number of the programmes use outdated syllabuses and fail to teach the right competencies to respond to market needs. Likewise, teachers lack qualifications - only 29.38\% have postgraduate studies and less than 2\% have PhDs (Dirección Nacional de Educación Superior, 2014). Furthermore, in many cases, teachers lack motivation and apply outdated pedagogical methods.

The poor quality of El Salvador's education system also devaluates national higher education qualifications. This devaluation triggers a cascade effect whereby firms hire university graduates when they need people with vocational training, people with vocational training when they need people with secondary school studies, and so forth. This cascade effect has arisen because the education system does not allow students to 
develop competencies in accordance with their level of education. Hence, firms hire overqualified candidates. Likewise, firms offer salaries in keeping with the qualification required of the position, which leads to a general reduction in graduates' nominal wages (UNDP, 2013).

In addition to the devaluation of degree qualifications and the reduction in nominal wages, unemployment is a major issue affecting higher education graduates. As highlighted by the UNDP (2013), people in unemployment in El Salvador have been in education on average one year longer than people in work have. This difference is greater among the younger population, which is better trained. Unemployed people aged between 16 and 25 years have been in education for 10 years on average, whereas employed people in this age range have been in education for just 8.8 years on average. This difference is even greater among unemployed and employed women in this age group (10.8 years and 9.5 years, respectively). In the 26-35 age group, differences between the unemployed and employed groups are similar to differences in the younger age group. Likewise, women are also more affected. Unemployed women aged 26 to 35 years have been in education for 11.7 years on average, whereas those in employment have been in education for just 9 years on average.

Table 4. Educational level of people in employment and unemployment in El Salvador in terms of average years in education

\begin{tabular}{|l|c|c|c|c|c|c|}
\hline & \multicolumn{3}{|c|}{ Employed } & \multicolumn{3}{c|}{ Unemployed } \\
\hline Age group & Men & Women & Total & Men & Women & Total \\
\hline $\mathbf{1 6 - 2 5}$ & 8.4 & 9.5 & 8.8 & 9.6 & 10.8 & 10.0 \\
\hline $\mathbf{2 6}-\mathbf{3 5}$ & 8.8 & 9.3 & 9.0 & 9.8 & 11.7 & 10.5 \\
\hline $\mathbf{3 6 - 4 5}$ & 7.9 & 8.0 & 8.0 & 6.8 & 11.1 & 8.1 \\
\hline $\mathbf{4 6 - 5 5}$ & 7.0 & 7.0 & 7.0 & 5.7 & 4.3 & 5.5 \\
\hline $\mathbf{5 6}$ or older & 4.7 & 4.0 & 4.4 & 3.4 & 1.0 & 3.3 \\
\hline Total & $\mathbf{7 . 6}$ & $\mathbf{7 . 9}$ & $\mathbf{7 . 8}$ & $\mathbf{8 . 0}$ & $\mathbf{1 0 . 7}$ & $\mathbf{8 . 8}$ \\
\hline
\end{tabular}

Source: Authors’ own data using data from the UNDP (2013)

The pattern described contradicts the assumption that better education and training lead to better work opportunities. Thus, not only are young people the worst affected, but also El Salvador's society as a whole views its opportunities for development as limited. This view demonstrates how El Salvador's human resources are being wasted in the quest for economic and social development.

\section{Conclusions and proposals}

As already described, the features of higher education in El Salvador represent a barrier to the development of a knowledge-based economy and therefore to reaching satisfactory levels of sustainable human development. In general, El Salvador has a poorly qualified population, which, in particular, is poorly specialized. Furthermore, higher education is characterized by its low quality - outdated methods and syllabuses and poorly qualified and poorly motivated teachers - and its lack of pertinence, reflected in conflicts between education and labour systems with serious consequences for social mobility among young people. In light of this situation, the following 
proposals are aimed at improving university graduates' chances of entering the labour market.

The first proposal concerns improving the education system's pertinence by seeking a balance between the realities of the labour market and the needs of the territory. Better interministerial collaboration within El Salvador's government could help to achieve this goal. Such collaboration would allow the Ministry of Education to adjust the academic courses available to students by using data from the Ministry of Economy and the Ministry of Work and Social Support. The Ministry of Education could thus limit the number of places available for oversubscribed degrees. Participatory Territorial Diagnosis can contribute to meeting this goal. Likewise, fostering publicprivate partnerships can help new graduates to enter the labour market. Internship programmes could and should help this process.

The second proposal consists of introducing a module on education for entrepreneurship, which would be compulsory for all higher education programmes in El Salvador. Such a module could help graduates to enter the labour market, encouraging high-quality and sustainable self-employment, completely consistent with the previous approach, thus stimulating opportunity-driven entrepreneurship and reducing the high level of graduate unemployment. Thus, this module's teaching objectives would be to develop entrepreneurial aptitudes and attitudes, thereby counteracting the current lack of emphasis on fostering entrepreneurial spirit, creativity, and reflection (Sanders et al., 2012). Implementing models based on the development of general and specific characteristics is important to train and educate well-rounded human beings.

This proposal nonetheless has some limitations. Despite the pertinence of the aforementioned proposals, alone they are inadequate to ensure that education trains and educates well-round human beings. The design of an educational system along these lines should cover all stages of education from primary education onwards. These goals cannot be attained by changing higher education only. In addition, as per the McKinsey report entitled How the world's best performing school systems come out on top (Barber \& Mourshed, 2007), the teaching faculty must be capable of achieving these goals. Hence, there must be an emphasis on the selection of teachers with suitable attitudes and aptitudes and on their ongoing training so that they may offer the best education to each student.

Future studies should focus on the issue of training and educating El Salvador's young people as well-rounded human beings and key contributors to El Salvador's development. Likewise, it is important to design new indicators to measure quality, pertinence, and internal institutional processes, particularly regarding how to foster entrepreneurship in El Salvador's higher education system.

\section{References}

Acs, Z. J., \& Amorós, J. E. (2008). Entrepreneurship and competitiveness dynamics in Latin America. Small Business Economics, 31(3), 305-322.

Amorós, J. E., \& Cristi, O. (2008). Longitudinal analysis of entrepreneurship and competitiveness dynamics in Latin America. International Entrepreneurship and Management Journal, 4(4), 381-399. 
Audretsch, D. B. (2007). The Entrepreneurial Society. Oxford, UK: Oxford University Press.

Barber, M., \& Mourshed, M. (2007). How the world's best-performing schools systems come out on top. McKinsey \& Company. Retrieved January 15, 2015, from http://mckinseyonsociety.com/downloads/reports/Education/Worlds_School_Syst ems_Final.pdf

Clark, B. R. (2004). Delineating the character of the entrepreneurial university. Higher Education Policy, 17(4), 355-370.

Dirección Nacional de Educación Superior (2014). Resultados de la información estadística de instituciones de educación superior 2013. San Salvador: Ministerio de Educación de El Salvador.

Levie, J., \& Autio, E. (2008). A theoretical grounding and test of the GEM model. Small business economics, 31(3), 235-263.

Ley de Educación Superior, Decreto 468, Diario Oficial n ${ }^{\circ} 216$ Tomo $^{\circ} 365$. Asamblea Legislativa República de El Salvador, San Salvador, El Salvador, 14 de octubre de 2004.

López-Claros, A., Blanke, J., Drzeniek, M., M1'a, I., \& Zahidi, S. (2005). Underpinning economic growth: Results from the competitiveness indexes. In A. Lopez-Claros, M. Porter \& K. Schwab (Eds.), Global competitiveness report 2005-2006: Policies underpinning rising prosperity (pp. 3-42). New Hampshire: Palgrave Macmillan.

Miles, R., Miles, G., and Snow, C. (2005). Collaborative entrepreneurship. Stanford, CA: Stanford University Press.

Ministerio de Educación (2014). La Educación de El Salvador en cifras 2009-2013. San Salvador: Ministerio de Educación de El Salvador. Gerencia del Sistema de Estadísticas Educativas. Retrieved January 15, 2015, from https://www.mined.gob.sv/estadisticas/Publicacion_Eduacacion_2009-2013.pdf

Ministerio de Educación (2010). Cuentas Nacionales de Inversión en Educación. Indicadores de inversión en el sistema educativo de El Salvador. San Salvador: Ministerio de Educación de El Salvador.

Ministerio de Educación (2009a). Cuentas Nacionales de Educación Versión General. San Salvador: Ministerio de Educación de El Salvador.

Ministerio de Educación (2009b). Cuentas Nacionales de Inversión en Educación (CNIE). Actualización de estimaciones de inversión en el sistema educativo de El Salvador 2008-2009. San Salvador: Ministerio de Educación de El Salvador.

Porter, M., Sachs, J., \& McArthur, J. (2002). Executive summary: Competitiveness and stages of economic development. In M. Porter, J. Sachs, P. K. Cornelius, J. W. McArthur \& K. Schwab (Eds.), The global competitiveness report 2001-2002 (pp. 16-25). New York: Oxford University Press.

Sánchez-Masferrer, M. (2013). Global entrepreneurship monitor: informe nacional El Salvador 2012. GEM Consortium. Retrieved January 15, 2015, from http://www.gemconsortium.org/docs/3121/gem-el-salvador-2012-report

Saunders, R., Rivas, F., Rabossi, M., Ruiz, A. M., Avanzini, D., \& Helwig, J. (2012). El Salvador: Evaluación de la Educación Superior y recomendaciones. USAID. Retrieved January 15, 2015, from http://pdf.usaid.gov/pdf_docs/pa00hx9k.pdf

Schramm, C. J. (2006). The entrepreneurial imperative. New York: Collins. 
SITEAL (2013). Perfil de El Salvador. IIPE UNESCO y OEI. Retrieved January 05, 2015 , from http://www.siteal.iipeoei.org/sites/default/files/perfil_el_salvador_2013_06.pdf

Terjesen, S., \& Amorós, J. E. (2010). Female entrepreneurship in Latin America and the Caribbean: Characteristics, drivers and relationship to economic development. European Journal of Development Research, 22(3), 313-330.

UNDP (2013). Informe sobre Desarrollo Humano El Salvador 2013: Imaginar un nuevo país. Hacerlo posible. San Salvador: United Nations Development Program.

Wennekers, S., Van Wennekers, A., Thurik, R., \& Reynolds, P. (2005). Nascent entrepreneurship and the level of economic development. Small business economics, 24(3), 293-309. 
HEAd'15

SESSION 5B

TEACHER EDUCATION 


\title{
Training kindergarten and primary education student teachers to plan learning units combining TPACK, LAT and multimodality
}

\author{
L. Messina*, S. Tabone** \\ * University of Padova, Italy \\ ** PhD, University of Padova, Italy
}

\begin{abstract}
This contribution presents an educational proposal, which will be the prelude to an action research project aimed at the operative integration of technologies in the education and training of future kindergarten and primary school teachers. The contribution proposes, in particular, an instrument for planning learning units that has been developed according to specific theoretical models - TPACKTechnological Pedagogical And Content Knowledge (Mishra \& Koehler, 2006), LAT-Learning Activity Types (Harris \& Hofer, 2009), multimodality (Cope \& Kalantzis, 2000) - and can be used in a learning path for the above-mentioned future teachers both as part of courses on educational technology as well as those for specific disciplines. This contribution illustrates and justifies the structure of such an instrument, the use of which could help enable future teachers to develop an integrated planning procedure that should be dynamic and open to refinements and improvements as they meet with different knowledge domains during their training.
\end{abstract}

Keywords: Student teachers' training, TPACK, learning activities types, multimodality, instructional planning

\section{On TPACK and its operationalization}

Research into the integration of technology in education, from kindergarten to higher education, has reached quite notable dimensions, suggesting various study approaches - e.g. case studies, teacher self-reports, descriptions of good practices or experimentations of specific technologies (Lawless \& Pellegrino, 2007) - and developing different models and strategies aimed at integrating technology into teachers' training (Kay, 2006; Tondeur et al., 2012).

However, surveys and research continue to point out that teachers, in general, do not have adequate preparation to profitably integrate technology in educational practices, emphasizing the importance of initial training (Enochson \& Rizza, 2009; Eurydice, 2011).

Among the theoretical models that can guide teachers' training, those that focus on teacher knowledge, developing the PCK-Pedagogical Content Knowledge (Shulman, 1986, 1987), and that are synthesized in TPCK or TPACK acronyms (Angeli \& Valanides, 2005; Mishra \& Koehler 2006; Niess, 2005; Pierson, 2001), seem to be particularly interesting and appropriate for teachers' training and are achieving increasing success (Voogt et al., 2013).

The TPACK proposed by Mishra and Koehler (2006; Koehler \& Mishra, 2008), in particular, is today one of the most popular models (Finger et al., 2013) and has also been adopted by us in some research with in-service teachers, student teachers and Education faculty (Messina \& Tabone, 2011, 2012, 2013, 2014).

The model of Mishra and Koehler contemplates:

- three basic forms of knowledge: Content (CK), Pedagogy (PC), Technology (TK);

- their intersections: Pedagogical Content Knowledge (PCK) - how to teach specific content; Technological Content Knowledge (TCK) - dealing with the best 
technologies to represent particular content; Technological Pedagogical Knowledge (TPK) - how to use specific technologies in teaching;

- their integration in another form of knowledge: Technological Pedagogical And Content Knowledge (TPACK) - how to teach content, using technologies that best represent it in ways that are appropriate to students' characteristics (Koehler \& Mishra, 2008, pp. 17-18).

The TPACK represents the "dynamic and transactional relationship between content, pedagogy and technology" (Koehler et al., 2007, p. 741) and it is a conceptual framework that teachers should master to effectively integrate technology in their present or future classrooms.

Despite the success of TPACK, some limitations have been attributed to it, including the unclear boundaries between the components of the model (Cox \& Graham, 2009; Archambault \& Barnet, 2010), the lack of precise and shared definitions for "new technology" (Grahm, 2011), the "parsimony" of the model, which excludes important personal features, such as teachers' values and beliefs regarding teaching and learning (Angeli \& Valanides, 2009, p. 157), to which we can also add the relevant dimensions of motivation (Cullen \& Greene, 2011) and emotion (Kay, 2008).

What in general emerges from the research is that TPACK is an extremely useful theoretical model to help teachers and student teachers to reflect on possible intersections of content, pedagogy and technology, but one of the problems that it presents lies in how it can be translated by teachers into operative instructional planning and classroom practices.

Several scholars have dealt with how to operationalize the TPACK or TPCK, providing guidance for teachers' training. For example, Koehler and Mishra (2005) propose a training approach, learning by design, that "allows teachers to explore the ill-structured domain of educational technology and develop flexible ways of thinking about technology, design and learning, and thus develop Technological Pedagogical Content Knowledge” (Koehler \& Mishra, 2005, p. 99); Angeli and Valanides suggest a "situative methodology", technology mapping, that enables "teachers to develop complex and interrelated ideas between the affordances of technology and their pedagogical content knowledge" (Angeli \& Valanides, 2013, p. 204); Niess and colleagues, observing mathematics teachers, have developed a model that represents "teacher levels as their thinking and understanding merge toward the interconnected and integrated manner identified by TPACK" (Niess et al., 2009, p. 10); Harris and Hofer (2009) propose an operationalization of TPACK based on activity types, considered as "the building blocks for instructional planning", since "each activity type captures what is most essential about the structure of a particular kind of learning action as it relates to what students do when engaged in that particular learningrelated activity (e.g., 'group discussion'; 'role play'; ‘field-trip')” (Harris \& Hofer, 2009, pp. 100-101).

Harris and Hofer (http://activitytypes.wmwikis.net) have elaborated taxonomies of activity types for different subjects, from literacy to mathematics, physical education, visual arts and so on, and they encourage teachers to plan a lesson or teaching units or a project by: "choosing learning goals; making practical pedagogical decisions about the nature of the learning experience; selecting and sequencing appropriate activity types to combine to form the learning experience; selecting formative and summative assessment strategies that will reveal what and how well students are learning; 
selecting tools and resources that will best help students to benefit from the learning experience being planned” (Harris \& Hofer, 2009, p. 100).

The operationalization proposal of Harris and Hofer (see also Harris et al., 2009), in addition to introducing an extremely relevant element that is often neglected in instructional planning, i.e. specific activities in which teachers intend to engage students, considers another element omitted perhaps more often during planning and equally, if not more, important: the knowledge forms involved in the different activity types, which range from knowledge building to expression of knowledge, being the knowledge convergent or divergent, product- or process-oriented and related both to verbal language as well as to other meaning representation modalities.

Regarding this final aspect, in our opinion the proposal made by Harris and Hofer (2009; Hofer \& Harris, 2010) can be effectively integrated with the theories of Cope and Kalantzis (2000), especially with respect to the multimodal representation of meaning making, which is made possible through various forms of language divided by them into the following categories: written language, oral language, visual representation, audio representation, tactile representation, gestural representation, spatial representation.

In a certain sense, this is also the direction followed by Angeli and Valanides (2009), who consider also the representation modalities that tool affordances make possible, but see them as means to transform a content into representations that can actually foster or augment students' conceptual understanding.

From the point of view of Cope and Kalantzis, multimodal representation, which is at the core of their "pedagogy of multiliteracies" - or simply "literacies" (Kalantzis \& Cope, 2012), brings to mind those particularities that the process of symbolization can assume, given the multimodal environments in which children live. In relation to this process, the different forms of language, together with the respective ways of meaning making, can act as “a kind of cognitive keyboard” (Rivoltella, 2012, p. 139).

This is why we believe that, together with knowledge forms (Harris \& Hofer, 2009), also modalities of knowledge representation have to be contemplated (Cope \& Kalantzis, 2009). Consequently, during their training path and their activities of instructional planning, teachers also need to be trained to consider students' "mental activities", which nowadays are heavily influenced by the multimodal languages of the new technologies in which they are immersed.

\section{An instrument for integrated instructional planning}

Starting from the theoretical assumptions that have just been briefly summarised, and in light of the research we had already carried out (especially Messina \& Tabone, 2013), we have outlined an instrument of training - a grid for instructional planning that is intended to help develop an integrated procedure for the planning of learning units.

This instrument is one of the resources used in an integrated teaching course that consists of two modules - each covering 30 hours of lessons - namely Teaching Methodology and Educational Technology, held by two different professors. Each module is completed by workshop activities of 16 hours, and the Educational Technology module is held by L. Messina, one of the authors of this article, who also supervises the related workshop. 
The teaching course is part of the second year of the single-cycle degree in Primary Education at our university and it is attended by 200 students each year. The Educational Technology module comes immediately after that of Teaching Methodologies and its workshop activities.

The Educational Technology module begins with a presentation of national and international educational policies, together with an introduction to the role of technology as well as to youth culture. After this, a substantial number of lessons are given over to the theoretical approaches that have been mentioned above, in particular PCK (Shulman, 1986, 1987) TPACK (Mishra \& Koehler, 2006), LAT (Harris \& Hofer, 2009), and multimodality (Cope \& Kalantzis, 2000, 2009). Parallel to these lessons, students study the theories concerned and, dividing themselves into groups of 25 to 30 according to the field of experience (in the case of kindergarten) or to the discipline (primary school) they are interested in, they are free to explore the technologies and educational resources fitting their chosen area. They then share the results of their individual explorations in discussion forums on the university's Moodle platform, where the module has a dedicated page. Upon conclusion of the lessons of the module and before the beginning of the related Educational Technology workshop, each group of students uploads onto the platform a list of all the resources they have found, singling out 6 to 8 of these, each of which is evaluated using a series of criteria indicated by us.

In the Educational Technology workshop the groups of students, further subdivided into smaller groups of 5 or 6 students and under the guidance of specially-trained tutors, have to plan a learning unit for one of the two levels of school in question (kindergarten or primary), transforming the theories they have studied into action plans.

For the present academic year, we have given the students an instrument outlined by us for planning a learning unit, i.e. a grid to refer to for the purposes of their planning. This grid is shown below in two separate tables to help visualize the innovations we are proposing. We have left in the Tables 1 and 2 the same numeration as is found in the overall grid used by the students. The grid is also accompanied by a brief legend to remind students of the agreed meaning of the individual elements and, in some cases, the theoretical references that they refer back to.

Table 1. Elements usually considered in instructional planning.

\begin{tabular}{|l|l|l|l|l|l|l|}
\hline 1.Context & $\begin{array}{l}\text { 2.Goals/ } \\
\text { Objectives }\end{array}$ & $\begin{array}{l}\text { 3.Time } \\
\text { schedule }\end{array}$ & $\begin{array}{l}\text { 4.Content/ } \\
\text { Topic }\end{array}$ & $\begin{array}{l}\text { 5.Knowledge/ } \\
\text { Skills }\end{array}$ & $\begin{array}{l}\text { 6.Teaching } \\
\text { approach }\end{array}$ & $\begin{array}{l}\text { 11.Assessment/ } \\
\text { Evaluation }\end{array}$ \\
\hline & & & & & & \\
\hline & & & & & & $\ldots$ \\
\hline
\end{tabular}

Table 1 shows the elements that are normally used by teachers for instructional planning, in accordance with the national curriculum indications in force in Italy (MIUR, 2012), and namely: 1. context, considered in the broad sense and with reference also to pupils' characteristics; 2. goals for competence development and learning objectives; 3 . time that should be dedicated to the planned unit; 4 . disciplinary content or topic of the unit; 5. knowledge and skills that pupils should acquire or develop during the learning unit; 6. teaching approach or approaches that 
one intends to use, considering models, methods, formats, strategies and techniques; 11. tools for assessment and evaluation.

Table 2. New element for planning with integration of technology.

\begin{tabular}{|l|l|l|l|}
\hline 7.Technology & 8.Activity types & 9.Knowledge forms & $\begin{array}{l}\text { 10.Representation } \\
\text { modalities }\end{array}$ \\
\hline & & & \\
\hline & & & $\ldots$ \\
\hline
\end{tabular}

Table 2 contains the new elements that the students have studied from a theoretical point of view in the Educational Technology module. These elements have to be taken into consideration together with those in Table 1 . For point 7 , the students have to indicate in detail which technologies, both digital and nondigital, can be used. They are required to relate this point to points 4 and 6 in Table 1, bearing in mind the connections with content/topic and teaching approach, and consequently the constructs of PCK and TPACK. For point 8, activity types, they should specify each of the activities that pupils will carry out, in line with the theories of Harris and Hofer. The same theoretical reference is necessary also for point 9, knowledge forms, which should make it clear whether these activities are for knowledge building or knowledge expression, and, in the latter case, specifying of what kind. Finally, point 10 refers back to the theories of Cope and Kalantzis, and should include detailed explanations of the representation modalities that are implied.

To sum up, by using the combination of elements in Tables 1 and 2, the student teachers should develop an integrated planning procedure, structured on the following premises and questions:

- in a well-defined learning context with specific students;

- with well-defined goals for competence development and learning objectives;

- with a clearly-planned time schedule for the achievement of such objectives;

- within a field of experience or discipline area and a well-established content or topic, which it is believed can foster the acquisition and development of specific knowledge and skills;

a) which are the most suitable teaching approaches, technologies and activity types for dealing with such content and for developing such knowledge and skills, assuring that the learning experience be productive for the pupils?

b) which knowledge forms and representation modalities can be activated through the use of such approaches, technologies and activities?

c) which aspects of the learning experience is it useful or necessary to assess?

\section{Future developments}

At the moment this is a rather theoretical planning procedure which we started to use during the present academic year. We presented this planning instrument to the student teachers during the Educational Technology workshop which is due to be concluded at the end of January 2015. 
At the end of the workshop, the authors of this article intend to work closely with workshop tutors to examine the units planned by the student teachers and uploaded to the dedicated platform, gather their reflections on the planning and, presumably, carry out in-depth interviews with small groups of students (see Harris \& Hofer, 2011), in order to look more deeply into how they conceived the relationships between the various elements, how they passed from one to another and what were the difficulties they came across.

The ultimate aim is to develop an action research project that involves students and Primary Education Faculty to verify empirically the instrument we have outlined, about which some doubts still remain, among which whether we should consider the affordance of technologies as a further and entirely separate element (Angeli \& Valanides, 2013; Wang, 2008).

Our interest in defining a planning instrument that comprises the elements useful for an effective integration of technologies in teacher training, and in developing around it a suitable research project, goes well beyond any preoccupation about the organization of the Educational Technology workshop in itself and the general preparation of students in this field. Our ambition is wider and contemplates two separate aims: on the one hand to put students in a position to develop a framework in some way in line with the one suggested by Mishra and Koehler (2006) - which is at the same time procedural and dynamic, in such a way that it can be progressively refined and improved according to the knowledge domains that students will come into contact with during their training; on the other, to offer to university faculty of those disciplines to be nurtured in kindergarten and taught in primary schools a tool that could help them to provide more effective training in the integration of technologies in their specific disciplinary areas.

\section{References}

Angeli, C., \& Valanides, N. (2005). Preservice elementary teachers as information and communication technology designers: An instructional systems design model based on an expanded view of pedagogical content knowledge. Journal of Computer Assisted Learning, 21(4), 292-302.

Angeli, C., \& Valanides, N. (2009). Epistemological and methodological issues for the conceptualization, development, and assessment of ICT-TPCK: Advances in technological pedagogical content knowledge (TPCK). Computers and Education, 52(1), 154-168.

Angeli, C., \& Valanides, N. (2013). Technology mapping: An approach for developing technological pedagogical content knowledge. Journal of Educational Computing Research, 48(2), 199-221.

Archambault, L.M., \& Barnett, J.H. (2010). Revisiting Technological Pedagogical Content Knowledge: Exploring the TPACK framework. Computers \& Education, 55(4), 1656-1662.

Cope, B., \& Kalantzis, M. (Eds.) (2000). Multiliteracies: Literacy learning and the design of social futures. London: Routledge.

Cope, B., \& Kalantzis, M. (2009). "Multiliteracies”: New literacies, new learning. Pedagogies: An International Journal, 4(3), 164-195.

Cox, S., \& Grahm, C.R. (2009). Diagramming TPACK in practice: Using an elaborated model of the TPACK framework to analyze and depict teacher knowledge. TechTrends, 53(5), 60-69. 
Cullen, T. A., \& Greene, B. A. (2011). Preservice teachers' beliefs, attitudes, and motivation about technology integration. Journal of Educational Computing Research, 45(1), 29-47.

Enochson, A., \& Rizza, A. (2009). ICT in initial teacher education: Research review. OECD. Working paper n. 38.). Retrieved January 5, 2015, from http://www.oecd-ilibrary.org/education/ict-in-initial-teacher-training-researchreview_220502872611

Eurydice (2011). Cifre chiave sull'utilizzo delle TIC per l'apprendimento e l'innovazione nelle scuole in Europa. Retrieved January 5, 2015, from http://eacea.ec.europa.eu/education/eurydice/documents/key_data_series/129IT.p $\mathrm{df}$

Finger, G., Jamieson-Proctor, R., Cavanagh, R., Albion, P., Grimbeek, P., Bond, T., Fitzgerald, R., Romeo, G., \& Lloyd, M., (2013). Teaching teachers for the future (TTF) project TPACK survey: Summary of the key findings. Australian Educational Computing, 27(3), 13-25.

Grahm, C.R. (2011). Theoretical considerations for understanding technological pedagogical content knowledge (TPACK). Computers \& Education, 57(3), 19531960.

Harris, J., \& Hofer, M. (2009). Instructional planning activity types as vehicles for curriculum-based TPACK development. In C. D. Maddux (Ed.), Research highlights in technology and teacher education 2009 (pp. 99-108). Chesapeake, VA: Society for Information Technology in Teacher Education (SITE).

Harris, J. B., \& Hofer, M. J. (2011). Technological pedagogical content knowledge (TPACK) in action: A descriptive study of secondary teachers' curriculum-based, technology-related instructional planning. Journal of Research on Technology in Education, 43(3), 211-229.

Harris, J., Mishra, P., \& Koehler, M. (2009). Teachers’ technological pedagogical content knowledge and learning activity types: Curriculum-based technology integration reframed. Journal of Research on Technology in Education, 41(4), 393-416.

Hofer, M., \& Harris, J. (2010). Differentiating TPACK development: Using learning activity types with inservice and preservice teachers. In D. Gibson \& B. Dodge (Eds.), Proceedings of Society for Information Technology \& Teacher Education International Conference 2010 (pp. 3857-3864). Chesapeake, VA: AACE.

Kay, R. H. (2006). Evaluating strategies used to incorporate technology into preservice education: A Review of the literature. Journal of Research on Technology and Education, 38(4), 383-408.

Kay, R. H. (2008). Exploring the relationship between emotions and the acquisition of computer knowledge. Computers \& Education, 50(4), 1269-1283.

Kalantzis, M., \& Cope, B. (2012). Literacies. Cambridge: Cambridge University Press.

Koehler, M. J., \& Mishra, P. (2005). Teachers learning technology by design. Journal of Computing in Teacher Education, 21(3), 94-102.

Koehler, M. J., \& Mishra, P. (2008). Introducing TPCK. In AACTE Committee on Innovation and Technology (Ed.), The handbook of Technological Pedagogical Content Knowledge (TPCK) for Educators (pp. 3-29). Mahwah, NJ: Lawrence Erlbaum Associates.

Koehler, M.J, Mishra, P., \& Yahya, K. (2007). Tracing the development of teacher knowledge in a design seminar: Integrating content, pedagogy and technology. Computers \& Education, 49(3), 740-762. 
Lawless, K. A., \& Pellegrino, J. W. (2007). Professional development in integrating technology into teaching and learning: Knowns, unknowns, and ways to pursue better questions and answers. Review of Educational Research, 77(4), 575-614.

Messina, L., \& Tabone, S. (2011). Integrating technology into instructional practices: A training research-intervention with in-service teachers. REM-Research on Education and Media, 3(1), 142-163.

Messina, L., \& Tabone, S. (2012). Integrating technology into instructional practices focusing on teacher knowledge. Procedia: Social \& Behavioral Sciences, 46, 1015-1027.

Messina, L., \& Tabone, S. (2013). Technology proficiency, TPACK and beliefs about technology: A survey with primary school student teachers. REM-Research on Education and Media, 5(1),11-29.

Messina, L. \& Tabone, S. (2014). Technology in university teaching: An exploratory research into TPACK, proficiency, and beliefs of Education faculty. Cadmo, XXII(1), 89-110.

Mishra, P., \& Koehler, M. J. (2006). Technological pedagogical content knowledge: A framework for integrating technology in teacher knowledge. Teachers College Record, 108(6), 1017-1054.

MIUR-Ministero Istruzione, Università, Ricerca (2012). Indicazioni nazionali per il curricolo della scuola dell'infanzia e del primo ciclo di istruzione. Annali della Pubblica Istruzione, LXXXVIII. Special Issue.

Niess, M. L. (2005). Preparing teachers to teach science and mathematics with technology: Developing a Technology Pedagogical Content Knowledge. Teaching and Teacher Education, 21(5), 509-523.

Niess, M. L., Ronau, R. N., Shafer, K. G., Driskell, S. O., Harper S. R., Johnston, C., Browning, C., Özgün-Koca, S. A., \& Kersaint, G. (2009). Mathematics teacher TPACK standards and development model. Contemporary Issues in Technology and Teacher Education, 9(1), 4-24.

Pierson, M. E. (2001). Technology integration practices as a function of pedagogical expertise. Journal of Research on Computing in Education, 33(4), 413-429.

Rivoltella, P. C. (2012). Neurodidattica. Insegnare al cervello che apprende. Milano. Raffaello Cortina.

Shulman, L. S. (1986). Those who understand: Knowledge growth in teaching. Educational Researcher, 15(2), 4-14.

Shulman, L. S. (1987). Knowledge and teaching: Foundations of the new reform. Harvard Educational Review, 57(1), 1-22.

Tondeur, J., van Braak, J., Sang, G., Voogt, J., Fisser, P., \& Ottenbreit-Leftwich, A. (2012). Preparing pre-service teachers to integrate technology in education: A synthesis of qualitative evidence. Computers \& Education, 59(1), 134-144.

Voogt, J., Fisser, P., Pareja Roblin, N., Tondeur, J., \& van Braak, J. (2013). Technological pedagogical content knowledge - a review of the literature. Journal of Computer Assisted Learning, 29(2),109-121.

Wang, Q.Y. (2008). A generic model for guiding the integration of ICT into teaching and learning. Innovations in Education and Teaching International, 45(3), 411419. 


\title{
Interdisciplinary learning and use of tics, a way of innovating in education
}

\author{
Pilar, R., Marcos, P., Arana, A., Barroso, A., Larretxi, N. \\ Begoñako Andra Mari. Escuela Universitaria de Magisterio \\ Begoñako Andra Mari.Teacher Training University College
}

\begin{abstract}
The ability to find information and how to process it is one of the main challenges of education in the information society where vast amounts of information are easily available. Process information implies testing its reliability, reaching a diagnosis about its accuracy and/or combining information if it comes from different sources or has peculiarities that require verification. Collaboration between diverse cultural institutions such as archives, museums and libraries is substantially important and future teachers of primary and secondary schools should teach how to acquire these skills. In the Teacher Training College BAM (Bilbao) it is offered a subject shared by the BAM, the Archive and the Museum named "Laboratory of active methods for interdisciplinary learning sciences" which is included in the Curriculum of Primary Education pathway in curricular deepening (6ECTS). During the course of this subject, students take part in various workshops where they create scientific-didactic materials for social and natural sciences where the use of ICT's is fundamental. Students work in projects and use ICT-s with the aim of making real the comprehensive rethinking of teaching and learning that is needed which highlights innovation and multidisciplinary.
\end{abstract}

Keywords: multidisciplinary, use of tics, information management, innovation

\section{Introduction and Theoretical Framework}

Our aim in this paper is to present this college subject as a commitment to interdisciplinary collaboration between the Archive, the Museum and the University. The projects seeks to generate knowledge networks and break with the isolated strategies and dynamics that institutions sometimes tend to deploy. Not only three institutions are taking part in this project but also five professionals of different disciplines. Both the planning and the implementation, are clear and innovative commitments to the interdisciplinarity. Owe to this, materials and projects are developed from different points of view and diverse professional perspectives (arts, psychology, didactics, philosophy, history, files, the use of tics and so on).

The educational project that takes shape in the course "Laboratory of active methods for interdisciplinary learning science" emerges in the context of creating the European Higher Education Area, more popularly known as "Bologna Process ". In Spain, the implementation of Bachelor's degrees has been a substantial part of this process. Bachelor degrees have replaced traditional degrees and diplomas, based on ECTS (European Credit Transfer System) credits. This situation involved a redesign of the curriculum in different majors, which allowed the introduction of new subjects such as the present one. This laboratory is part of the Bachelor of Primary Education pathway in Curricular deepening. The course is taught in Begoñako Andra Mari Teacher Training University College, attached to the University of Deusto (Bilbao) since the course year 2011-2012.

The main competences of this subject are the use of ICTs and the level 2 of written communication (fluent writing skills, good content structure and the use of graphics to facilitate the understanding of the information and increase the interest of the reader in medium length writings) 
The specific skills are:

- promote learning that emphasizes the comprehension of the reality and the problemsolving skills from a transdisciplinary perspective which is appropriate to their developmental stage;

- enter the socio-cultural and natural reality in the curriculum for analysis, intervene on it and see the possibilities of its transformation, generating civic learning communication; and

- applying information technologies and communication with an educational focus, leveraging its potential to contribute to learning and the acquisition of the intended skills.

The title of the course "Laboratory of active methods for interdisciplinary learning sciences" shows the three theoretical pillars on which our project is based. The core of this proposal relays on combining active methods of learning to learn, an interdisciplinary perspective and a project methodology, all seasoned with the use of ICTs. The preparation and development of the subject has been a laboratory both for teachers and students.

\section{Methods}

The following projects are the product of the joint thinking of a team formed by five professionals that come from different areas and that have their own. We believe that future generations of teaching professionals need to be equipped with the largest possible amount of resources to carry out its work because of this we have joint together with the aim of contributing to such training. Additionally, we want to provide a different viewpoint of archives and museums, breaking some stereotypes and preconceived images that keep them away from being conceived as potential educational resources.

We believe in the complexity of the reality and the need for future teachers to reflect on the necessity of approaching it from different perspectives that complement and enrich the information we have. Therefore, we have developed projects of interdisciplinary work that provide different views of the same reality and provide our students with the specific tools that we think they will need in the future for doing the same in the performance of their work.

In the preparation of this subject, we have gone through several stages. In the first course we taught, each of us gave his/her own vision and the educational possibilities of her/his resources and institutions. From that experience, we understood the need of deepening and improving our skills to conduct a real interdisciplinarity. After common self-assessment and taking into account the views of our students through a survey, we decided to launch, as we have noted, the work by projects.

During the second year, we changed the methodology. In the first session we present the subject and teaching and educational possibilities offered by the Museum and Archive. We highlighted that the students had to use different educational resources, manage various types of information and generate projects with a guiding theme, without forgetting the use of ICTs. In the current year 2014-2015, we have decided to go a step further. We want to use the Tics as a cross-cutting element and also develop integrated projects without presenting our activities as watertight projects, but as integrated projects to develop the assessments. 
After the presentation of the subject, methodology and evaluation criteria, we proceed to the formation of groups formed by 3-4 students (first year teams were formed by 67 students and last year by 3-4 students). Preparing the subject first we chose the possible topics within the primary curriculum. We valued what each institution could provide and looked for the guiding theme. Our students will develop two tutored projects. For management reasons, projects will be developed in four-hour sessions per workweek.

Each of this two projects includes a part of work tutored by the professors and another part of work (the adequacy of these proposals to the stage of Primary) that will be submitted by the students before the deadlines. After the completion of the two tutored projects, we request the preparation of a final project for each group where students should show their mastery on the previously trained and developed skills and the use of ICTs (WEBQUEST, Googlesite, WIKI, Blog...).

On the final project, students must define the guiding theme that will integrate all the perspectives and propose a number of activities related to each of the sources and institutions. In addition, they will have to prepare an oral proposal of their project and defend it in front of the rest of teams. We will guide the process and suggest them activities in order to enrich their projects.

So far we have developed the following projects topics: Mediums for communication, Ecosystems, Light and color, Social and family structures, Metallurgy, Values and the Human Being. The results over the years have been satisfactory. We need to take one step towards testing them straightly in elementary classrooms, which would be the result of that we develop this course.

An important aspect was to develop criteria for evaluating the different projects that have been done by our students. We must bear in mind that this subject is part of a process referred to a university course and therefore the listed skills of our program must be respected.

The first thing we want to emphasize is the complexity of working together several professors and three institutions with different origins and purposes. We cannot underestimate the different professional paths and demands that arise from them, which could be translated into a different way of implicating common criteria. We have tried to circumvent this difficulty by developing a tool that allows us to make the most objective assessment. After a process of reflection and taking into account both the skills to be developed by our students and the guidelines given for each project, we have agreed in a table of assessment rubrics for the written projects and the oral defense of their final project. We have also decided to use a virtual classroom for sharing different contributions and comments that each professor wants to make.

Another issue we had to solve was related to the different route our students had to make related to their development. On the first two proposals (especially on the first one), they provided with bigger guidance and we have tutored them in their process. In contrast, as we believe that on the last project they will be able to show what they have internalized during the first two projects they will be asked for more autonomy. Hence, we propose that the first two proposals worth together a $30 \%$ of the final mark and the latter one will be the $60 \%$ of the total mark. From our experience in previous years, we have introduced a small "correction factor", a $10 \%$, that is related to oral expression and participation on the areas designated for that purpose. It is mandatory to pass both sections separately to apply these percentages. 
As the first two proposals are only assessed on their written part and to enhance the part of the oral presentation, at the last project $(60 \%$ of the final mark) the oral presentation will worth a $60 \%$ and the written part a $40 \%$. We apply here the same exception as in the previous case, only two passing both parts these percentages will be applied.

The results of this project can be consulted at:

https://sites.google.com/site/aprendizajeinterdisciplinar/home/

https://www.youtube.com/watch?v=mAYLU-RxYU4 [comunicación presentada al Congreso Educación y Aprendizaje, Nueva York, 15-17 julio de 2014

https://www.youtube.com/watch?v=mlnaaBePcEU [comunicación presentada en el Moodlemoot Euskadi 2014, Bilbao, 13 de junio de 2014 http://mooteu14.moodlemoot.net/.

\section{Conclusions}

The subject "Laboratory of active methods for interdisciplinary learning sciences", has, so far, a short but exciting journey. We have had four years of students from the 2011-2012 academic year to the present, 2014-2015, ranging between 39 and 32 students per year and including three students undertaking an Erasmus program (European Community Action Scheme for the Mobility of University students): two from the Czech Republic and one from Austria. It goes without saying that during these years numerous changes have been done around the same original idea and, in some cases, significant changes have been done result of particular experiences. Furthermore, as teachers we have learned a lot during this educational process.

The development of the subject has been a laboratory, coordinating five teachers and three institutions (including geographical movement of students between three different spaces and two cities), maintaining the unity and coherence of the different projects.

We should train that unity of viewpoint, which we will ask for to our students, to avoid one of the most common dangers that many interdisciplinary projects suffer. With other words, it may happen that even having very good principles and magnificent wills it end up becoming a disiecta membra amalgam. Our previous experiences have made us better understand potential problems and difficulties that our students could find. We have had to unlearn previous and traditional educational models to find out new paradigms that were in line with our project. Of course this is a work under progress that could be refined by many ways and where the work of our students is key.

We believe we have achieved, to the extent of our ability, the old concept of meaningful learning (Ausubel 1976), supplemented by classic studies such as those of Novak and Gowin (Novak 1998 Gowin, 1981. Novak and Gowin 1988). Starting from the level of development of the students and the cognitive and ecological-contextual paradigms. This is, students should learn by themselves, with other words, learning to learn (Caballero 2009). We also share the concept of critical meaningful learning developed by Professor Moreira (Moreira 2005). 
"A través del aprendizaje significativo crítico es como el alumno podrá formar parte de su cultura y, al mismo tiempo, no ser subyugado por ella, por sus ritos, sus mitos y sus ideologías. Es a través de ese aprendizaje como el estudiante podrá lidiar, de forma constructiva, con el cambio, sin dejarse dominar, manejar la información sin sentirse impotente frente a su gran disponibilidad y velocidad de flujo, beneficiarse y desarrollar la tecnología, sin convertirse en tecnófilo. Por medio de este aprendizaje, podrá trabajar con la incertidumbre, la relatividad, la no causalidad, la probabilidad, la no dicotomización de las diferencias, con la idea de que el conocimiento es construcción (o invención) nuestra, que apenas representamos el mundo y nunca lo captamos directamente".

We believe from these paradigms that, in large part, thanks to this subject, we have achieve to develop in our students a certain epistemological curiosity through a interdisciplinary perspective. In addition, we believe that they will be able to create learning strategies, placed on their different contexts (the archives and libraries, museums, social and natural sciences), without losing the overview and planning processes being aware on the same time of their own learning processes.

We firmly believe that the teacher's role is mainly a mediator one (Vergnaud 1998), and that although meaningful learning is not a discovery learning, it is also true that discovery learning can be, in case it is well done, a meaningful learning. If we have achieved that during these years, our students can manage among the vastness of sources and information that surrounds us with critical awareness, skills and strategies to detect false "truths" or conceptual distortions, and they can transfer these knowledge to the field of primary education, we think that our objectives, in some way, have been achieved.

\section{References}

Ausubel, D.P. (1976). Psicología educativa. Un punto de vista cognitivo. México: Trillas.

Caballero, C. (2009). "¿Qué aprendizaje promueve el desarrollo de competencias? Una mirada desde el aprendizaje significativo".Qurriculum, 22 octubre.

Gowin, D.B. (1981). Educathing. Ithaca, N.Y.: Cornell U.P.

Moreira, M.A. (2005). "Aprendizaje significativo crítico (Critical meaningful learning)". Indivisa, Bol. Estud. Invest., $\mathrm{n}^{\circ} 6$.

Novak, J.D. (1998). Conocimiento y aprendizaje. Los mapas conceptuales como herramientas facilitadoras para escuelas y empresas. Madrid: Alianza Editorial.

Novak, J.D. y Gowin, D.B. (1988). Aprendiendo a aprender. Barcelona, Martínez Roca.

Vergnaud, G. (1998). "A comprehensive theory of representation for mathematics education". Journal of Mathematical Behavior, 17 (2). 


\title{
Teachers Education: a Project for Evaluation/Self Assessment in Educational and Lifelong Learning Way. A first Report of Research Experience
}

\author{
Gabriella Aleandri*, Luca Girotti** \\ * Associate Professor of General and Social Pedagogy at Dept. of Education, Cultural Heritage and \\ Tourism, \\ University of Macerata, Italy \\ ** Assistant Professor of Experimental Pedagogy at Dept. of Education, Cultural Heritage and \\ Tourism, \\ University of Macerata, Italy
}

\begin{abstract}
The paper aims at stressing the discussion about the significant and topical issues that are evaluation and self-assessment in educational contexts, from teachers' initial tertiary education and training to in-service and lifelong one. Finally, we will point out the strategic functions derived from building an organic evaluation system, which may allow a systemic and overall look about the whole scope of evaluation, as well as promote and improve a monitoring network. It will be useful primarily for teachers to know about their professional activities and have thus the opportunity to improve. Moreover, we will illustrate some results of a first experience on the investigation into the knowledge and ideas of the students attending the Primary Education degree course at the University of Macerata (Italy). Such survey is included within a broader research project about outcomes of future teachers. The methodologies used are both quantitative (most used statistical methods) and qualitative (a method autonomously adapted from Grounded Theory by Glaser and Strauss). A first data analysis shows that, as written by the students of the pilot sample, the characteristic that must not fail the teacher to be a good evaluator is objectivity, an aspect also much discussed within the scientific community.
\end{abstract}

Keywords: Teacher Education, Pedagogical research, Evaluation and Assessment, Lifelong Education.

\section{Introduction}

Nowadays, the pedagogical issue about evaluation matter has become a priority both in everyday school and university life and as discussing among scholars and in the most recent educational policies. That topic became ever more significant both at international and national level.

Therefore, in Italy, a series of legislative measures have been taken, that have resulted, among other things, in establishment of INVALSI institution (which replaced the past CEDE assessment institution) as well as the "younger" ANVUR and AVA. All those allow us to highlight the growing awareness at all levels that the evaluation is a strategic lever to revive and upgrade the education and training system, both within university degree programs and in in-service and lifelong learning way. In fact, it has come to have, on the one hand, a considerable literature - pedagogical one too - on the subject and, on the other hand, a significant wealth of experience in/of schools.

However, in this debate the risk both of the absence of an adequate systemic overall design and of the "actual" marginality of the teachers' professional, with the deempowerment of those involved, is still actual.

The plurality of times and school assessment tools are likely to be devoid of meaning and direction, without a vision system and a non-adequate initial nor in-service teachers education and training (in a perspective of lifelong learning and education). 
Instead, although that difficult context, the years of teachers university education and training can be an important resource in theoretical (docimological education) and practice (internship experience) terms, especially in a strategic pedagogical perspective to promote a culture of evaluation and self-assessment.

It is therefore relevant and meaningful, within pedagogical reflection and educational research, reflecting about the idea that the future teachers have about the aims of school evaluation and about the characteristics that the teacher must have to be a good evaluator. Furthermore, we will propose evaluation tests and self-assessment about their curricular knowledge to such students, in view of the Dublin descriptors too that make up the references in preparing the educational objectives of university courses, as well as bearing in mind the subject areas of the curriculum of school cycles at which they will teach.

\section{Methods and results}

The research project consists in several steps in which they were used, and will be used, both quantitative methodology choosing the most common statistical methods in education and social sciences and qualitative methodology, by autonomously planning and modifying in a more flexible and adaptable way the Grounded Theory primarily conceived by Glaser and Strauss.

In this report about initial phase, we highlighted positive aspects, deficient or to be implemented or improved through a careful pedagogical reflection that will result in proposals for revision/integration of both the initial university curriculum and in the perspective of lifelong education.

The several moments and school assessment tools are likely to be devoid of meaning and direction, with no:

- An overview of the system and

- An inadequate initial and in-service (in a perspective of lifelong learning and education) of teachers.

The idea underlying the research project lies in the reflection that comes from what argued above, that the years spent in teachers university education and training can be an important resource both in theoretical terms (docimological training) and practical (internship experience), especially in a strategic pedagogical perspective that aims to promote a culture of evaluation and self-assessment.

It is therefore relevant and significant, in terms of pedagogical reflection and educational research, making the object of reflection:

- The idea that future teachers have of the school evaluation and the characteristics that must have the teacher to be a good evaluator;

- The data obtained from tests of self-assessment and evaluation of the course curriculum by future teachers. That is strategic also in view of the Dublin descriptors that constitute the references in preparing the educational objectives of the university courses, as well as keeping in mind the subject areas of the curricula of school cycles in which they will teach.

In this paper we will present some data related to a research phase that is part of a broader research project concerning the education and training of future kindergarten 
or primary teachers, both as regards the initial university education and as regards the more complex and still "nebulous" education and training in the perspective of lifelong and life-wide learning. They will be investigated and analyzed according to a framework as possible systemic and global.

The pilot-sample is made up by enrolled students attending third year of Primary Education Course degree at University of Macerata. It is a first pilot sample to test the instruments used for surveys.

Subsequently we will analyze all the results of those initial findings, we will do any changes of the tools used, and progressively enlarged the sample: first of all, to each Primary Education Course students enrolled at the University of Macerata, and then, further, to Primary Education Course students attending in many Italian universities.

That phase of the research is based on the use of a test made up of several areas for evaluation/self-assessment of knowledge and competences of the students, as we have already said, of Primary Education Sciences Courses at the University of Macerata, Italy.

The objectives of this first phase concerning the self-assessment / evaluation of the knowledge and skills of students in the following areas:

1) assessment: by identification of essential features in the opinion of the students (pre-survey phase)

2) general and transversal skills (in the same perspective with the project TECO and with the objectives set by the Dublin descriptors)

3) knowledge and skills in main basic contents, analytical reasoning, problem solving and written communication, as well as critical analysis, relating to the curricular competences taken from the pedagogical disciplines and the other planned for the first year of studies in Primary Education Course

4) knowledge and skills extrapolated from the National Guidelines for Curriculum of Primary School in 2012, prepared by the Italian Ministry of Education, University and Research.

About instruments and procedures, the first stage they consists in freely writing and then discussing in the classroom; the second stage in administration of three composites test (understanding and critical analysis, writing, multiple choice answers); third stage in self-assessment by the students themselves according to the criteria given in rehearsal; and last fourth stage in evaluation by the research team.

The main purposes of such four stage are to:

- Measure the ability of self-assessment,

- Detect the level of skills,

- Identify matching curriculum offer of the Primary Education Course or a shortcoming compared to the required skills and outcomes.

Thereafter, taking into account the data obtained we will perform and share careful pedagogical reflections that will result in proposals for revision / integration / improvement of both the initial university curriculum and in-service and lifelong education and training.

About the first report of survey on the identification of the characteristics of the evaluation, in particular regarding the conduct of the test, we specify that during 
exercise in the classroom there were 31 students, including 1 Spanish (Erasmus), who was not taken into account in this survey.

So thirty were the tests were considered valid.

The gender composition of the class is a clear predominance of women, as shown in the pie chart below (Chart 1 ).

\section{Chart 1.}

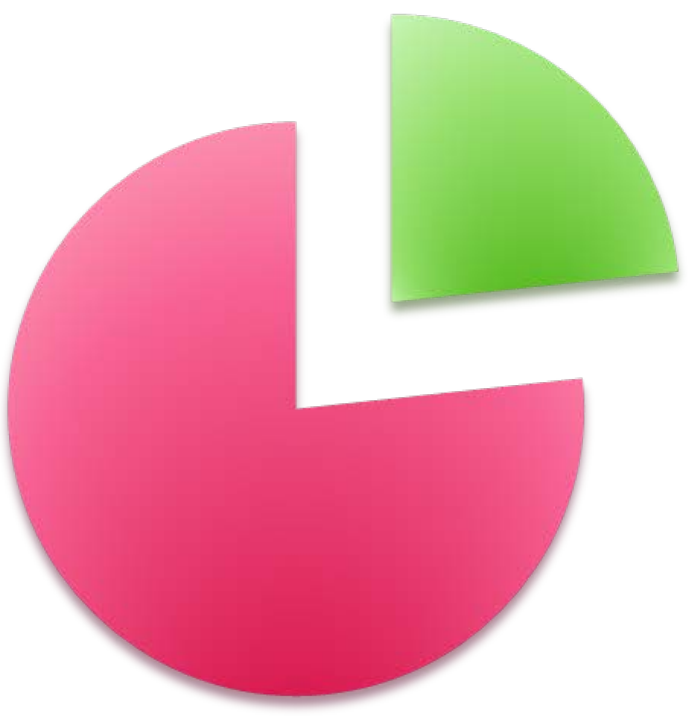

MASCHI

- FEMMINE

The age of participants was rather uniform: about $2 / 3$ of the students is 20 years old, and just under one third is 21 years old, and only three have different ages (Chart 2).

\section{Chart 2.}

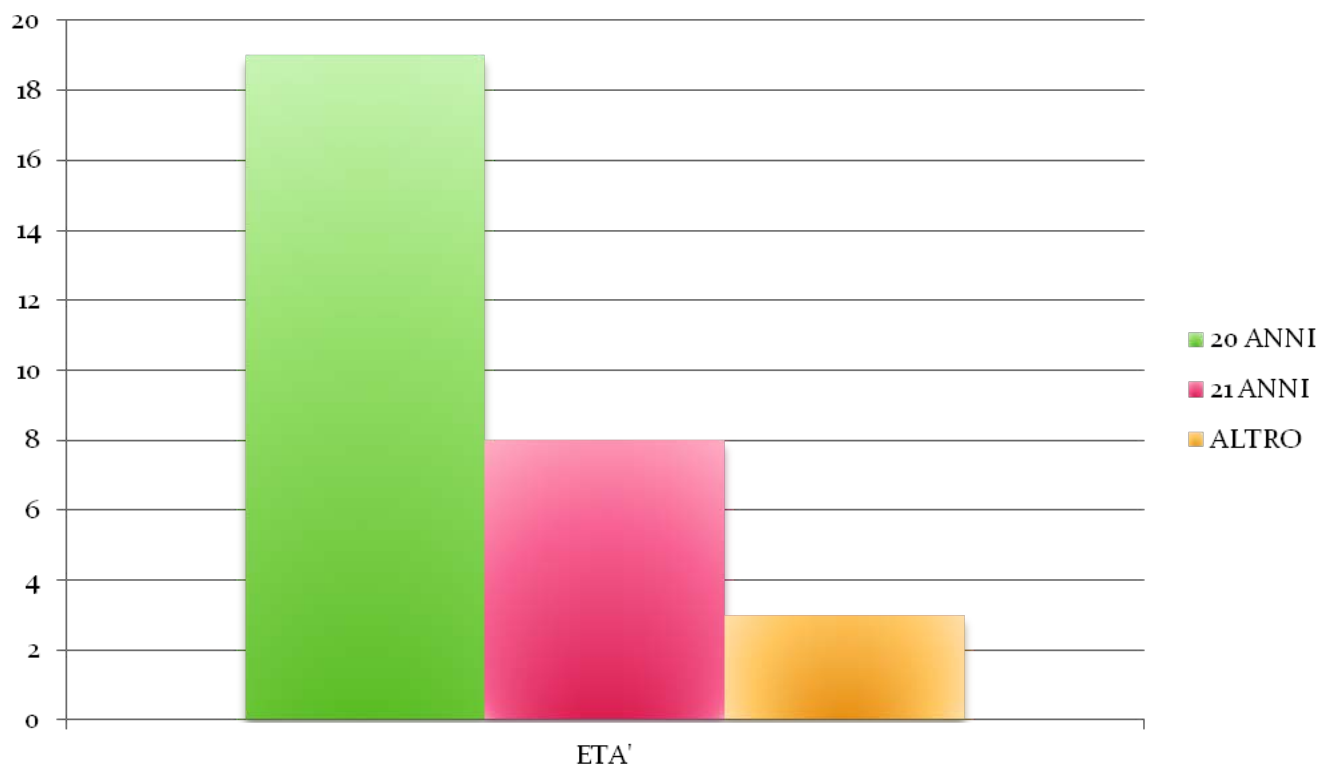

Regarding the year of course it is been also highlighted the correlation between years of student enrolment and years of placement of the course in the curriculum and age of students placed between 20 and 21 years (Chart 3). 


\section{Chart 3.}

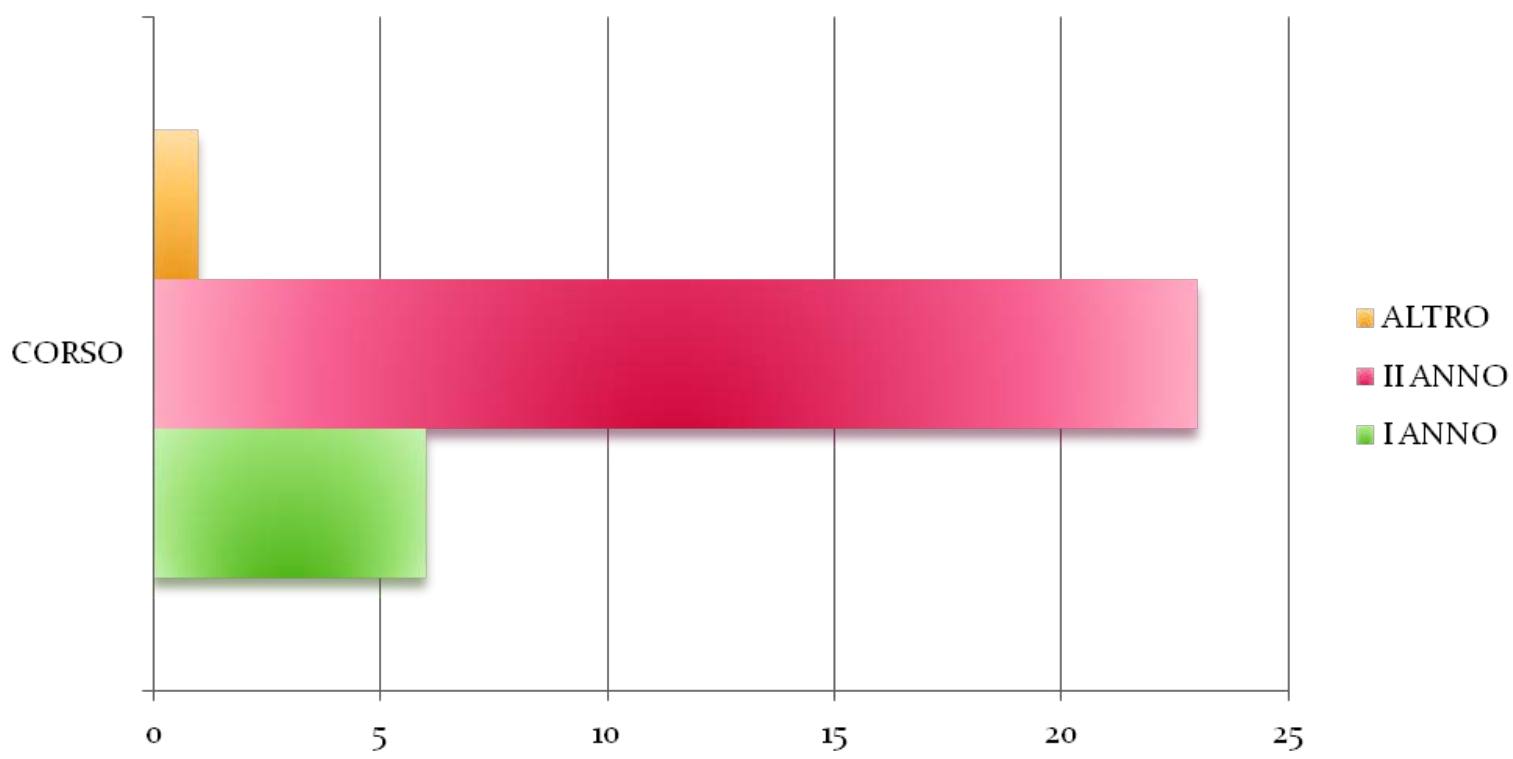

The main question / stimulus was: "What feature should not be lacking to the teacher to be a good evaluator?” Students answered as following shown in Chart 4.

Chart 4.

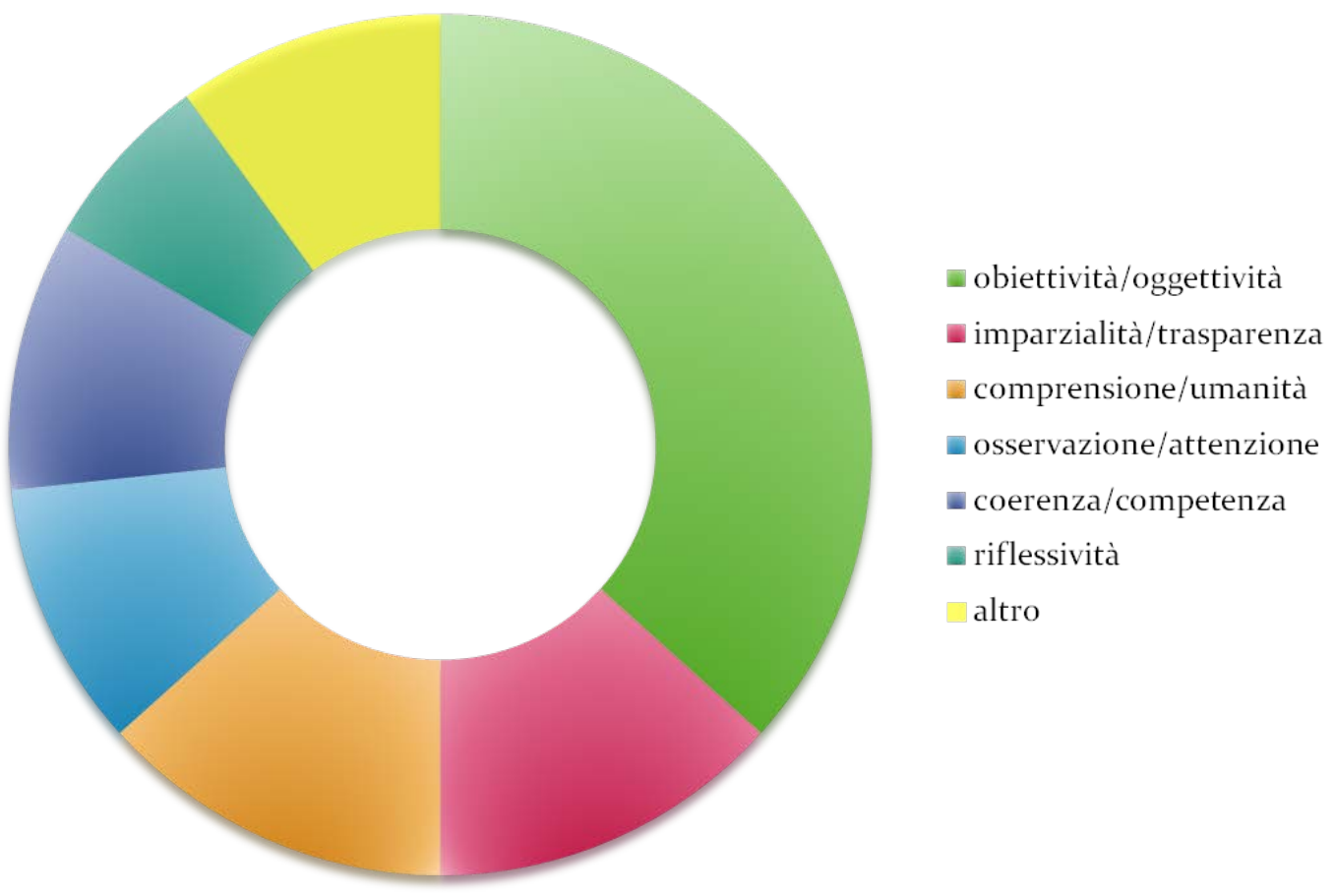


According as written by the students from the pilot sample, the characteristic that must not fail the teacher to be a good evaluator, which is clear, is that objectivity to confirm that, even in the perception of future teachers, this appears the primary need.

To this are added other features in the same perspective, such as transparency and impartiality.

\section{Discussion and Conclusions}

This paper discusses the results of a first experience of survey in the initial stages of a research and evaluation project in order to university education and training (in this step we refer to the initial one) of teachers of kindergarten and primary school, at the University of Macerata. Italy, which is part of a larger research project.

The above shown data are early, initial, and not representative, results. Nevertheless, they are still very interesting, as it seem they are going towards the opposite direction to what, however, has been clearly emphasized in the literature. We refer for example to the contributions by G. Domenici (2010) and M. Castoldi (1995), that is the critical approaches to this issue, in which it is highlighted that the objectivity on the one hand lies in the test, on the other hand that this is a "myth" of the traditional theories and point of view on evaluation.

Initial prospects of reflection: of course, we point out again this is only a first, episodic, survey that needs further study before we can proceed by offering significant reflections, but probably it is not entirely misplaced to hypothesize that the proximity to their experience as students at higher secondary schools - in which the perception is not the objectivity of the evaluation suffered - can constitute an experiential reference which may have weighed in answering to the question.

Note, finally, the appearance (albeit reduced), in the opinion of the students, of all those features that recall the idea of a caring teacher of the student, able "to read" the situation and be able to refer to evaluation also his evaluating. We think that it is important reflecting starting from these initial findings about evaluation towards meanings near to "take care, analyse in depth", to be aware and responsible, in teaching professions, and, on the opposite site, far from evaluation resulting in punishment or ranking.

After the above presented first phase, subsequent assessment tests / self-evaluation are currently carrying out. We're going to test general and transversal knowledge and skills related to: a) TECO test by Italian Conference of Rectors, b) progress test and c) knowledge and skills extrapolated from the National Guidelines for Curriculum of Primary School in 2012, prepared by the Italian Ministry of Education, University and Research (see above), of which we will be able to report the results in further research papers.

\section{References}

Aleandri, G. (2003). I sistemi formativi nella prospettiva dell'economia globale. Per una pedagogia del lifelong learning. Roma: Armando.

Aleandri, G. (2011). L'educazione permanente nella prospettiva del lifelong e lifewide learning. Roma: Armando. 
Aleandri, G., \& Girotti, L. (2010). Educational research and Policy-making. Questions, Challenges and Perspectives for a pedagogical debate. Education Sciences \& Society, (2), 64-117.

Aleandri G., \& Girott,i L. (2011). Admission test to Primary Teacher Education: some empirical evidences and reflections from UNIMC experience. Education Sciences \& Society, (2),162-175.

Aleandri, G., \& Girotti, L. (2013), Lifelong learning and training: a never ending challenge and choice for educational system. Procedia - Social and Behavioral Science.

ANVUR (2014), Assessing the generic competences acquiring by students graduating form Italian universities. Rome: Anvur.

Castoldi, M. (1995). Verso una scuola che apprende. Strategie di autoanalisi d'istituto. Roma: SEAM.

Cavalli, A., \& Argentin, G. (a cura di), (2010). Gli insegnanti italiani: come cambia il modo di fare scuola. Terza indagine IARD sulle condizioni di vita e di lavoro nella scuola italiana. Bologna: Il Mulino.

CERI-OECD (2007). Evidence in Education. Linking research and policy. Paris: OECD.

CERI-OECD (2008). Innovating to learn, Learning to Innovate.Paris: OECD.

Cochran-Smith, M. [et al.] (eds.), (2008) Handbook of research on teacher education: enduring questions in changing contexts.New York: Routledge.

Day, C. (ed.) (2012). International handbook of theacher and school development. London: Routledge.

Delors, J. (1996), Learning: the Treasure within. Paris: UNESCO. Tr. It. Nell'educazione un tesoro. 2nd ed. Roma: Armando, 2000.

Domenici, G. (a cura di), (2010). La valutazione come risorsa. Napoli: Tecnodid.

EUROPEAN COMMISSION (1996). Teaching and Learning: towards the learning society (White Paper on Education and Training). Brussels: European Commission.

Furlong, J. [et al.] (eds.), (2009). Policy and politics in teacher education: international perspectives. New York: Routledge.

Girotti, L. (2009). La ricerca educativa per l'orientamento. Macerata: EUM.

OECD, (2007). Education at a Glance: OECD Indicators - 2007 Edition. Paris: OECD (EAG 2007), tr. it. Uno sguardo sull'educazione. Gli indicatori dell'OCSE 2007. Roma: Armando.

OECD, (2008). Education at a Glance: OECD Indicators - 2008 Edition. Paris: OECD (EAG 2008), tr. it. Uno sguardo sull'educazione. Gli indicatori dell'OCSE 2008. Roma: Armando, 2009.

OECD, (2009). Education at a Glance: OECD Indicators - 2009 Edition. Paris: OECD (EAG 2009), tr. it. Uno sguardo sull'educazione. Gli indicatori dell'OCSE 2009. Roma: Armando, 2010. 
HEAd'15

SESSION 5C

MISC 


\title{
Out-of-classroom experiences: a survey of students’ perceptions of the learning process during internships
}

\author{
J. Alemany-Costa*, X. Perramon-Tornil** \\ * Pompeu Fabra University, Spain \\ ** Independent Consultant
}

\begin{abstract}
A survey has been conducted during the 2013-2014 academic year among the first graduating class after the EHEA in the Faculty of Economics and Business Sciences at Universitat Pompeu Fabra (UPF), with the aim of comprehending the students' perception of the learning process developed through the out-of-classroom activities of professional internships. In this work such activities are considered an integral part of the knowledge acquisition process, on the basis of the constructivism paradigm of learning-by-doing. The results of the survey show that, in general, student's perceptions are positive about the overall process, although the weakest point is in the perceived connexion between the theory explained in the classroom and its practical application in the workplace. The conclusion is that from the students' point of view the introduction of the new post-EHEA internship courses at UPF has been successful in many aspects, while in some other aspects, particularly in the relationship between theory and practice, some further analysis is recommended.
\end{abstract}

Keywords: Internship, out-of-classroom, EHEA, workplace learning, e-survey, constructivism.

\section{Introduction}

The convergence process to the European Higher Education Area (EHEA) has implied a redesign of curricula, degree structures and teaching methods in European universities. At Universitat Pompeu Fabra (UPF) of Barcelona this process started with a pilot in 2008 and was extended to all degrees in 2009. One of the effects of establishing the EHEA has been a change in out-of-classroom activities, and in particular the professional internships, which used to be an option in some of the curricula, and now, are an intrinsic part of most degrees.

The interest of the study presented in this paper focuses on the internship students' perception on their own integral learning process. From this perspective the basic model that describes how practical activities, including the internships, contribute to the student's learning is provided by the constructivist theory.

\section{Theoretical approach}

Constructivism from the viewpoint of the experiential learning model (Kolb, 1984) can be understood as the continuous process of knowledge and learning based on individual experiences and interactions with the environment, taking into account that the sociocultural aspects also have to be considered (Billet, 1996). In this model, active experimentation is complemented in a balanced way with the reflexive observation of the acquired experience. Many authors have addressed the constructivism theory from different perspectives (see the compilation by Tynjälä, 1999) but of all of them have in common that the knowledge acquisition is metaphorically described as a construction process where knowledge is actively built by individuals or social communities. Therefore constructivism refuses the idea that knowledge is received in a passive manner.

The student interprets the newly received information on the basis of their own previous knowledge. Thus, the constructivism theory describes learning as a process of 
reelaboration of knowledge according to previous conceptions and reflection on acquired experience.

The concept of experiential learning is present in many works which have studied how students apply concepts learned in classroom to real life situations and how they reflect on this. The majority of works (e.g. Kosnik et al. 2013, Nesbit 2014) define the essence of the internship based on the theory of constructivism, in which the learning process is building in a continuous process. Tynjälä (1999) compares the constructivism and the traditional learning in the university. According to Tynjälä, learning is not passive reception of information but a learner's active continuous process of constructing and reconstructing his or her conceptions of phenomena, and that is the constructivism.

Experiential learning emerges in much of the literature in that students get to apply concepts learned in class to real life situations and then have the opportunity to reflect on this. In a study by Kosnik, Tingle \& Blanton (2013) the benefits of using experiential learning projects from a pedagogical viewpoint were analysed using Kolb's Experiential Learning Cycle (Fig. 1). This study concludes that "learning by doing and applying previously acquired knowledge through experiential learning projects provide students with outstanding opportunities to hone their professional skills, apply and expand their academic knowledge, and develop moral character” (Kosnik et al. 2013).

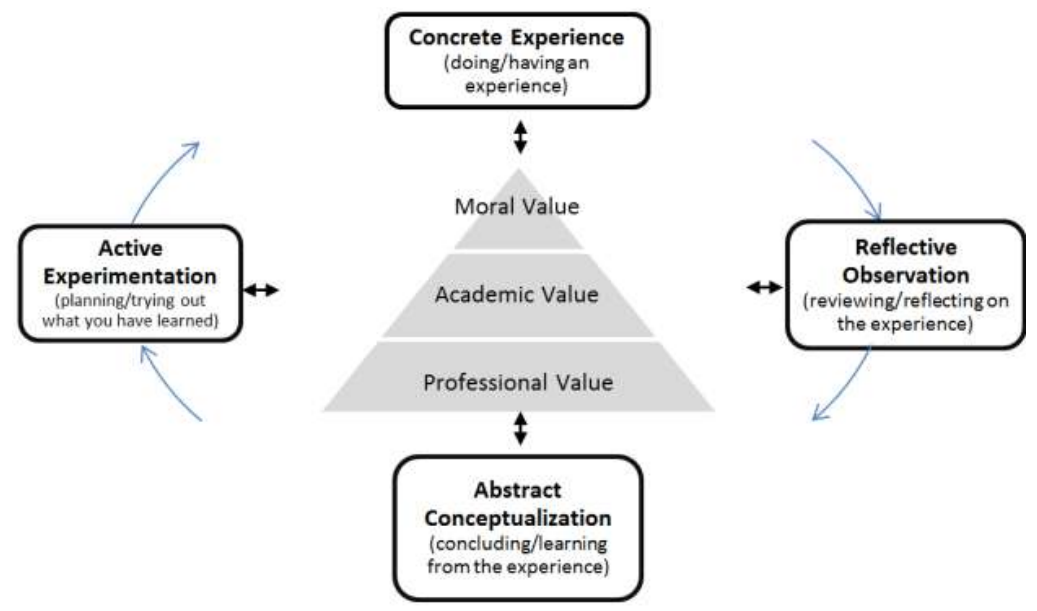

Figure 1 - Kolb’s Experiential Learning Cycle. Reproduced from Kosnik, Tingle \& Blanton (2013)

\section{Brief summary of the literature about internship and Business studies curricula}

The fundamentals of constructivism are established in Kolb's (1984) work on experiential learning. Further models that describe the benefits of experiential learning are described by Jaques, Gibbs and Rust (1993). Fenwick (2008) elaborates a deep review of the research done from 1999 to 2004 concerning the relationship between individual and collective learning in the workplace. Regarding internships, their theoretical framework has been analysed by many authors; for a comprehensive list of works we refer the reader to the compilation articles by Zabalza (2011) and Cid et al. (2011).

Hergert (2009) concluded that internships have an important role in the business curriculum in that they help students to make connection between course work and the workplace. In his study, more value was placed on internships particularly when there was a connection between the internships and the students' career goals. In describing transformations taking place in higher education in the early $21^{\text {st }}$ century Grubb \& Lazerson (2005) identified the increased importance of higher order skills including 
communication skills, problem solving and reasoning. The development of these skills was possible through the use of internships. The value in experiential education that integrates students' academic learning with the opportunity for direct learning was one of the drivers behind the case for requiring experiential learning to become part of the business curriculum that was made by McCarthy \& McCarthy (2006).

The value of business students completing internships was the focus of the study by Lang \& McNaught (2013). In this study the students indicated that their internship was the most useful part of their studies with many feeling that they had developed professionally and had increased their preparation for entering the graduate employment market. Other highlights of this study included a number of students gaining employment as a direct result of their internships.

Nesbit (2014) focused on the internships in business specific courses, also providing a summary of the relevant literature, and used a model for capstone projects developed by McNamara, Kift, Butler, Field, Brown and Gamble (2012) based on six principles (transition, closure, diversity, engagement, assessment and evaluation) that can be used for the evaluation of internship courses across a range of disciplines.

Besides the six principles proposed by McNamara et al. (2012), Nesbit (2014) identifies three threads emerging from the state-of-the-art research on internships:

- The opportunities for soft skill development (Andrews \& Higson, 2008; Grubb \& Lazerson, 2005; Lang \& McNaught, 2013; Kosnik et al 2013).

- Integrating theory or course work with practice (Hergert, 2009; McCarthy \& McCarthy, 2006; Kosnik et al 2013).

- Preparation for employment or career aspirations (Hergert, 2009, Lang \& McNaught, 2013; Kosnik et al 2013).

\section{Methods}

In order to achieve the main goal of this study, i.e. knowing the students' perspective on the effects of internships in their wholistic learning process, the methodology used is based on the administration of anonymous e-surveys.

As part of a wider project aiming at analysing multiple aspects of the post-EHEA internships at UPF, an online survey was sent in September 2014 to the whole population of students of the Faculty of Economic and Business Sciences who took an internship during the 2013/14 year ( $N=657), 293$ of which responded the questionnaire. The survey included questions related to the three research topics identified by Nesbit (2014): development of soft skills (e.g. competences) in internships, integration of theory with practice, and preparation for employment. These research subjects correspond to items 1 to 3 in the topics list below. A fourth item is added in this study to compare the results of items 1 to 3 with the global students' assessment of the internships. A final question in the survey, described in item 5 below, was open for students to express their observations, comments or suggestions if they wished to do so.

In summary, the following topics were addressed in the questionnaire:

1. The survey included an item querying about soft skills development: 
- $\quad$ To what extent have you developed the following competences during the internship: (a) group work, (b) give presentations in public, (c) speak, write or prepare reports in foreign languages, (d) group leadership, (e) defend opinions or ideas in public, and (f) group coordination.

2. Students' perception on the integration of theory and practice was inquired in the following questions:

- To what extent do you agree with the following statements: (a) during the internship I found situations that had been explained in class, (b) I have applied in the internship the theoretical knowledge learnt in class, (c) the classes discussed topics that have been useful for the internship, (d) the internship is well related to the acquired knowledge, and (e) there is little relationship between classes and the activity performed at the internship.

3. Regarding the role of internships as a preparation for a future job placement, the survey contained the following questions:

- After the internship, you have been offered (a) a labour contract, (b) an internship extension, or (c) you have received no offer.

- $\quad$ If you have received a job offer, how related are your studies to the offered job.

- Do you think the internship you have developed will be useful for your professional future.

- What is your satisfaction level with the labour experience you have acquired.

4. The following questions summarized the students overall perceptions of the internships:

- What is your satisfaction level with your learning during the internship.

- $\quad$ Auto-assessment of your own work during the internship.

- $\quad$ Global grade of the internship.

5. Open question: comments and suggestions.

\section{Results and Discussion}

The results of the survey according to the previous topics are the following:

1. The e-survey answers related to soft skills showed the results presented in Table 1.

Teamwork and the use of foreign languages are the most developed competences, while group leadership is the least developed one. These results match with what is expected of a student at the internship level. Surprisingly, three out of four interns did not develop presentations in public.

Table 1. Students perceptions on soft skills development: 1= very low, 4= very high

\begin{tabular}{|l|c|}
\hline \multicolumn{1}{|c|}{ Soft skills developed during the internships } & Average \\
\hline Group work & $\mathbf{3 . 1}$ \\
\hline Give presentations in public & 1,92 \\
\hline Speak, write or prepare reports in foreign languages & $\mathbf{2 , 5 8}$ \\
\hline Group leadership & 1,73 \\
\hline Defend opinions or ideas in public & 2,31 \\
\hline Group coordination & 2,29 \\
\hline
\end{tabular}

2. Concerning the students perceptions of the integration of theory and practice, the results are shown in Table 2. 
All of the average results are very close to 2,50 that is the mean between 1 and 4 . Only the statement that the internship is well related to the acquired knowledge is slightly above the mean. This implies that students do not perceive the theory-practice integration as especially negative nor positive.

Table 2. Students' perception on the integration of theory and practice: 1= very low, 4= very high

\begin{tabular}{|l|c|}
\hline Students' perception on the integration of theory and practice & Average \\
\hline During the internship I found situations that had been explained in class & 2,22 \\
\hline I have applied in the internship the theoretical knowledge learnt in class & 2,35 \\
\hline The classes discussed topics that have been useful for the internship & 2,34 \\
\hline The internship is well related to the acquired knowledge & $\mathbf{2 , 5 2}$ \\
\hline There is little relationship between classes and the activity performed at the internship & $\mathbf{2 , 4 7}$ \\
\hline
\end{tabular}

3. Internships as a preparation for a future job placement.

The students' opinion about the internships and employment are in general very positive, especially in the satisfaction level of the labour experience acquired in the internship: two out of three students are very satisfied with this. 57\% of the students believe that the internships will be very useful for their professional career. The results can be seen in Table 3 .

Table 3. Students' perception of the relationship between internship and employment: 1=very low, 4= very high

\begin{tabular}{|l|c|}
\hline Employment related questions & Average \\
\hline If you have received a job offer, how related are your studies to the offered job & 2,85 \\
\hline Do you think the internship you have developed will be useful for your professional future & 3,40 \\
\hline What is your satisfaction level with the labour experience you have acquired & $\mathbf{3 , 5 5}$ \\
\hline
\end{tabular}

According to the results, half of the interns have received an extension offer, which represents a very high proportion. The motivation explaining why companies offered these extensions has been discussed in Alemany et al. (2014). Furthermore, 17\% of students have received a labour contract offer, which implies that, together with the internship extension offers, around $70 \%$ of the students have been proposed a continuation of the internship in the same company. These results are shown in Figure 2.

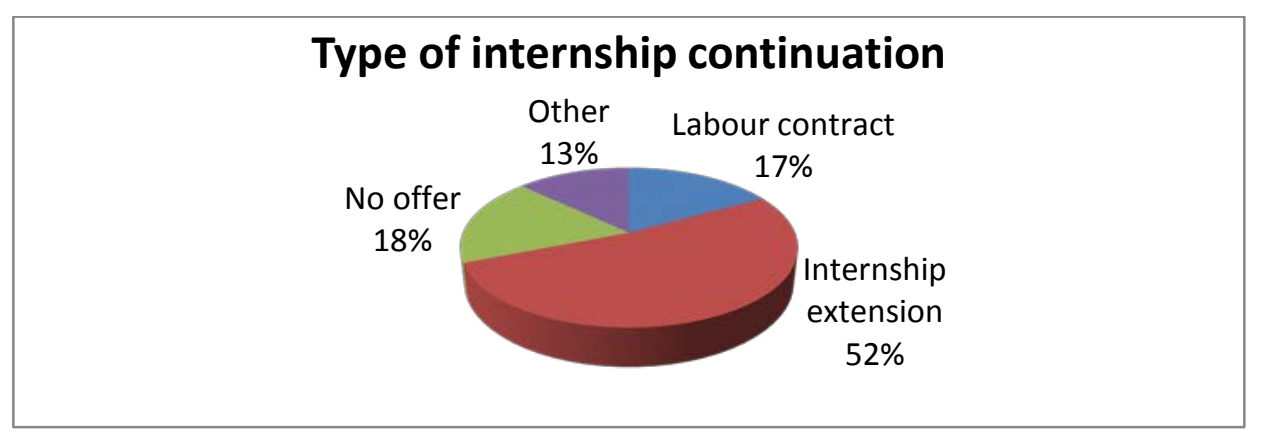

Figure 2. Internship continuations offers

4. Questions that summarized the students overall perceptions of the internships 
The students' global valuation of the internships is high or very high, and especially in the auto-assessment of their own work, as can be seen in Table 4. However, their satisfaction with the learning acquired during the internship, while positive, is not as high.

Table 4. Students' global assessment of the internships: 0 to 10 scale

\begin{tabular}{|l|c|}
\hline Global Assessment questions & Average \\
\hline What is your satisfaction level with your learning during the internship & 7,87 \\
\hline Auto-assessment of your own work during the internship & $\mathbf{8 , 4 4}$ \\
\hline Global grade of the internship & $\mathbf{8 , 3 9}$ \\
\hline
\end{tabular}

These results are consistent with those of a prior survey conducted in May 2013 for the 2012-2013 academic year.

\section{Open question to express observations, comments or suggestions}

A total of 33 students answered the free open question at the end of the survey, and 6 of them made comments related to their learning experience, summarised in Table 5.

Table 5. Students' comments on their learning during the internships.

\begin{tabular}{|c|l|}
\hline Student & Comment \\
\hline 18 & $\begin{array}{l}\text { Internships are a perfect opportunity to enter the labour world and start developing the } \\
\text { professional competences needed to complement the technical knowledge acquired at college. }\end{array}$ \\
\hline 44 & $\begin{array}{l}\text { The knowledge I have acquired at the faculty has been of little use in my internship, since in } \\
\text { the } 4 \text { years of my degree I have not taken any course on equity investments (stock market). } \\
\text { The concepts of company assessment through balances were of great help, but regarding the } \\
\text { technical analysis that these circles require, the university does not offer any training on this } \\
\text { subject. }\end{array}$ \\
\hline 67 & $\begin{array}{l}\text { I would suggest that the internships could also be curricular for second year students, since } \\
\text { the effort and the acquired experience and knowledge are the same as can be achieved in the } \\
\text { third and fourth years. }\end{array}$ \\
\hline 202 & $\begin{array}{l}\text { The work I did at XXX company was very mechanical. I did not use any knowledge acquired } \\
\text { at college. }\end{array}$ \\
\hline 209 & $\begin{array}{l}\text { To a certain extent I find it OK that there is not so much relationship between classes and } \\
\text { practices, as I understand that the academic and labour worlds are not the same. I mean that } \\
\text { the internship has been a good complement to my studies, as it provided a different viewpoint } \\
\text { from what I have studied, and a way of learning without the need to study. }\end{array}$ \\
\hline $\begin{array}{l}\text { At YYY company you learn a lot, and if you do your job well and make an effort, you feel } \\
\text { rewarded with a contract upgrade. }\end{array}$ \\
\hline
\end{tabular}

Four of the six students commented about the relationship between theory and practice, another two commented on the relationship to the employment process, and another one on the knowledge acquisition process during the studies.

In general, students' opinions reflect that what they learn at college is not fully connected with their learning at the workplace, an impression that is not necessarily negative if both learning environments are not regarded as disconnected but complementary. Indirectly related to this perception is also the opinion of a student who remarked that, while most internships are completed during the third or the fourth 
and final year of the degree, they could be perfectly completed during the second year as well. This contrasts with Nesbit's (2014) study, which found differences between students completing the internship before or after certain theory courses were taken. In the first case, students started the learning cycle (Fig. 1) at the concrete experience phase, whereas in the latter case the starting point was the abstract conceptualisation phase.

Furthermore, Nesbit (2014) found that when students reflected on their learning at the internship many of them valued the development of skills like teamwork and enhanced communication. In the survey presented here students also valued these types of skills, although they were not explicitly mentioned in the free comments, as the opinions collected were more directly focused on employment opportunities.

The results of the survey also show how the internships adhere to the six principle model proposed by McNamara et al. (2012). The transition principle is evident in the job orientation of the internships and, looking at the survey results, in the students' interests. The closure principle is present in the recapitulation character of the internship when concepts from different subjects throughout the degree are applied. The diversity principle is present when students have to work in a variety of professional contexts and interact with a variety of other people. The engagement principle applies when students assume active roles in a real work environment. The assessment principle is present when students reflect on their own performance in the internship. The results in this respect are very positive as shown earlier in Table 4. And the evaluation principle is evident when the students' activities are periodically monitored and finally graded at the end of the internship.

\section{Conclusions}

The reformulation of the internship courses at UPF after the EHEA has been successful on a number of aspects, including the students' perception on the development of soft skills, the transition to the labour market, and the overall evaluation of the experience, as can be observed from the survey presented in this study.

But the survey also identifies an issue where further consideration is required, which is the relationship between theoretical knowledge acquired in the classroom and practical experience gained in the internship. While some students' responses showed certain dissatisfaction with this subject, the perceived unrelatedness of theory and practice does not necessarily contradict Kolb's (1984) experiential learning paradigm, as it is modelled as a cycle that can start at the theoretical conceptualisation phase or at the experiential phase.

\section{References}

Alemany-Costa, J., Perramon-Tornil, X. \& Panadés-Estruch, L. (2014). “The internship in the EHEA adaptation process. The UPF first year of graduates' opinion”. REDU Revista de Docencia Universitaria, 12(4).

Andrews, J. and Higson, H. (2008). Graduate employability, 'Soft Skills' versus 'Hard' business knowledge: A European study. Higher Education in Europe, 33(4). 
Billet, S. (1996). Situated learning: Bridging sociocultural and cognitive theorising. Learning and Instruction, 6 (3), 263-280.

Cid, A., Pérez, A. \& Sarmiento, J. A. (2011). La tutoría en el Practicum. Revisión de la literatura. Revista de Educación, 354, 127-154.

Fenwick, T. (2008). "Workplace learning: Emerging trends and new perspectives". New Directions for Adult and Continuing Education, 119(3). DOI: 10.1002/ace.302

Grubb, W. N., \& Lazerson, M. (2005). Vocationalism in higher education: The triumph of the education gospel. The Journal of Higher Education, 76(1).

Hergert, M. (2009). Student perceptions of the value of internships in business education. American Journal of Business Education, 2(8).

Jaques, D., Gibbs, G., Rust, C. (1993). Designing and Evaluating Courses. New South Wales: Educational Methods Unit, Oxford Brooke University.

Kolb, D. (1984). Experiential Learning. New Jersey: Prentice Hall Inc.

Kosnik, R.D., Tingle, J.K. and Blanton, E.L. (2013). Transformational learning in business education: the pivotal role of experiential learning projects. American Journal of Business Education, 6(6).

Lang, R. \& McNaught, K. (2013). Reflective practice in a capstone business internship subject. Journal of International Education in Business, 6(1).

McCarthy, P.R. and McCarthy, H.M. (2006). When case studies are not enough: integrating experiential learning into business curricula. Journal of Education for Business, 81(4)

McNamara, J., Kift, S. M., Butler, D., Field, R. M., Brown, C., \& Gamble, N. (2012). Work-integrated learning as a component of the capstone experience in undergraduate law. Asia-Pacific Journal of Cooperative Education, 13(1), 1-12.

Nesbit, T. (2014) Final year accounting internship courses: Initial Experiences. Presented at Society for Research into Higher Education (SRHE) Annual Research Conference. Newport (U.K.).

Tynjälä, P. (1999). Towards expert knowledge? A comparison between a constructivist and a traditional learning environment in the university. International Journal of Educational Research, 31, 357-442.

Zabalza, M. A. (2011). El Practicum en la formación universitaria: estado de la cuestión. Revista de Educación, 354, 21-43. 


\title{
Talk That Counts: Participation in Practicums and Student Success in Civil Engineering
}

\author{
Z. Simpson*, J. Bester** \\ * Faculty of Engineering and the Built Environment, University of Johannesburg, South Africa \\ ** Department of Civil Engineering Science, University of Johannesburg, South Africa
}

\begin{abstract}
Engineering courses across the globe include practical components generally undertaken in small groups. This study aims to determine whether the quantity and quality of students' participation in these group-based practicums could be correlated with their academic performance. A first year course in Concrete Technology was selected, and groups of students were filmed as they undertook a practicum that required them to mix, test, cast and crush concrete cubes as per the guidelines of two established procedures. Approximately four hours of film was then time-coded according to student activity. The resulting transcripts were analysed quantitatively in terms of total time spent on specific activities, and qualitatively in terms of the nature of student engagement with those activities. The results show that group discussion may have a greater impact on student learning than time spent on the task itself. However, this depends on the specific nature of this talk. Implications of the study include the fact that attention needs to be given to designing group tasks in such a way that they facilitate group interaction, and the fact that tutors and lecturers should promote group discussion and be aware of interactional dynamics that act to the detriment of student learning.
\end{abstract}

Keywords: Practicums; student success; engineering education

\section{Introduction}

"Science educators readily agree that laboratory learning should include hands-on activities, student-centered learning, problem identification and solving, and collaboration" (Lerner, 2007, p. 192). However, the learning achieved through such measures often fails to meet educators' expectations. It is by no means a given that students will be able to apply what they have learnt in practicums: in fact, groups are often dysfunctional in their collaboration with each other. The civil engineering curriculum at the research site studied herein includes a number of courses that include laboratory, or practical, components. In these practicums, students are required to perform, in groups, experimental laboratory work before writing about their activities in the form of a laboratory report. The purpose of this is to replicate, in as authentic a manner as possible, the practices of professionals in industry (Lerner, 2007). This study aims to determine whether relationships can be drawn between students' participation in these practicums and their performance, both in subsequent laboratory reports (that should reflect their mastery of underlying theory) and in the course as a whole.

The course chosen was called Concrete Technology, which aims to equip students with knowledge and skills relevant to successful casting, testing and maintenance of structural concrete. This course forms part of the first year of a four-year degree in civil engineering, and included a strong practical component. During the semesterlong course, the main practicum required students to cast concrete cubes as per the guidelines of two established procedures for doing so. The one procedure, the eyeball method, requires the concrete technologist or engineer to use a high degree of judgement in attaining the desired concrete mix. Such judgement requires experience, and experienced concrete technologists are able to make sophisticated judgements about the nature of concrete through mere visual inspection. The second method, the Cement and Concrete Institute method, is far more rigid in its delineation of exact 
quantities of cement, stone, sand and additives. In the practicum under study herein, students were required to mix sufficient concrete to cast three cubes of each mix. Once cast, the cubes were placed in a curing bath for seven days, after which the cubes were crushed so as to determine their compressive strength.

The remainder of this paper begins with a more detailed description of the methods deployed in the study. Thereafter, the results are presented and discussed before final conclusions and recommendations are drawn.

\section{Methods}

The concrete mix design practicum was undertaken over a series of Friday afternoons. Each week, groups were asked to volunteer to participate in this study and the first group to agree was given further information about the project and asked to give informed consent to be filmed; included herein was a guarantee of the anonymity of the research participants (Cohen et al., 2007 provides a useful overview of research methods in educational settings). Filming was selected as it facilitated more reliable observation (Swann, 1994), as it would have been difficult to generate useful field notes given the pace of activity of the students. In total, two groups of students were filmed as they mixed, tested and cast their two batches of concrete. Each group consisted of four members. The groups broadly reflected the demographics of the classroom and the overall student body. A sample of 8 students is relatively small, but this was done intentionally as the subsequent analytical approach was highly detailed, in that both the quantity and quality of students' engagement in the practicum was examined.

The casting practicum took between one and two hours per group. A week later, the same group was filmed as they crushed the cubes, using a crushing machine, and obtained the seven-day compressive strength of the cubes. This process took approximately 30 minutes per group. In total, around four hours of footage was obtained. All footage was time-coded, a process which was aggregated per individual group member. That is to say, the activities of each group member were separately time-coded. This allowed for analysis of individuals' time spent on various activities. Activities were grouped into four categories: physical engagement with the concrete, discussion with colleagues, doing nothing, and a generalised other category. The other category included items such as asking the lecturer questions, collecting tools and equipment and so on. Time spent on each category of activity was summed for correlation with the students' academic performance, measured by way of their results achieved in the subsequent practical report, and in their overall performance in the course. This constituted the quantitative component of the analysis.

The selected students also gave permission for copies of their practical reports to be made available to the researchers. Within each broad category used for the quantitative analysis, fine-grained qualitative analysis was undertaken of the nature of the students' engagement in the practicum. This engagement was correlated with their actual reports. That is to say, at the point at which specific calculations were undertaken, for example, analysis of the nature of the engagement, as seen in the film data, and the product of that engagement, as seen in the practical report produced, was performed. 


\section{Results and Discussion}

\section{Physical Engagement with Concrete Casting Process}

As part of the practicum, participants were required to measure out quantities of sand, cement, stone, water and additives, mix these together, perform a slump test (which measures the consistency of the concrete), and pour the concrete into cubes. The amount of time each student spent engaging physically with the process of casting concrete was tracked quantitatively, and correlated with the students' performance in the lab report and in the course as a whole. The results of the study indicate that there was no correlation evident between the amount of time individual students spent directly working with the concrete, and their performance (see Figure 1).

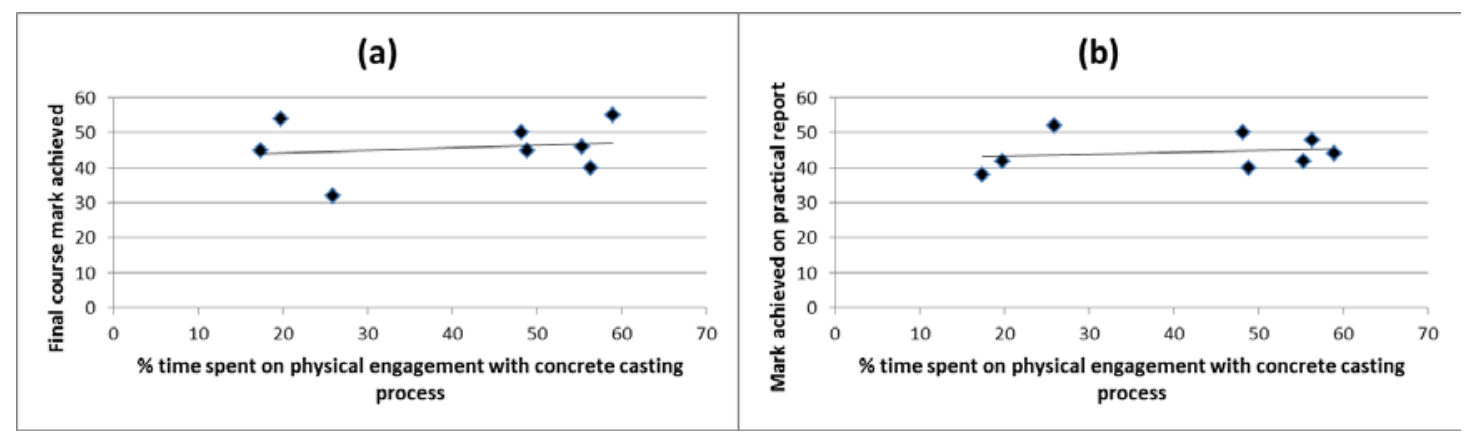

Figure 1. Correlation of percentage time spent on physical engagement with the concrete casting process with (a) performance in the course as a whole, and (b) performance in report submission.

Although no correlation in this regard was evident, it is worth noting that there is a divide between the (largely) theoretical impetus of tests and exams in higher education, and the more practical basis for practitioner knowledge. As such, although direct physical engagement with the concrete did not benefit students in subsequent report writing, tests and exams, the experience of doing so may well benefit them as potential future concrete technologists. This is because expertise as a concrete technologist resides in practitioners' ability to read concrete: that is, to make deductions about its properties and visually inspect it to determine its suitability for use in construction. This notion of reading concrete is taken from Wang and Heath (2011 - see also Scollon and Scollon, 2009), who argue that aspects of the built environment carry complex and diverse signs that are meaningful to the expert viewer. Such expertise requires extensive experience and direct physical engagement in the concrete casting process.

\section{Talk that Counts}

The quantitative analysis revealed that there was some degree of correlation between the amount of time participants spent in discussion with one another and their academic performance (see Figure 2). This correlation was weak at best, and did not apply to their performance in the report. This may be because the written report introduced issue around report writing ability, which influenced their overall performance. However, in both groups, it was evident that the students that spent the most time engaging their fellow group members in discussion, performed better in the course (though not in the practical report submitted after the practical). In one of the groups, the correlation was direct in that the member who performed best in the 
course, spent the most time in discussion with his peers (and, interestingly, the least time physically engaged with the concrete casting process), the second-best performer spent the second most time in discussion with peers, and so on. In the other group, the correlation was evident, but not as direct (a point returned to in the following section). Nonetheless, in the second group, the member who spent the least time engaging with his peers, performed the worst amongst his group members, ultimately achieving a failing grade.

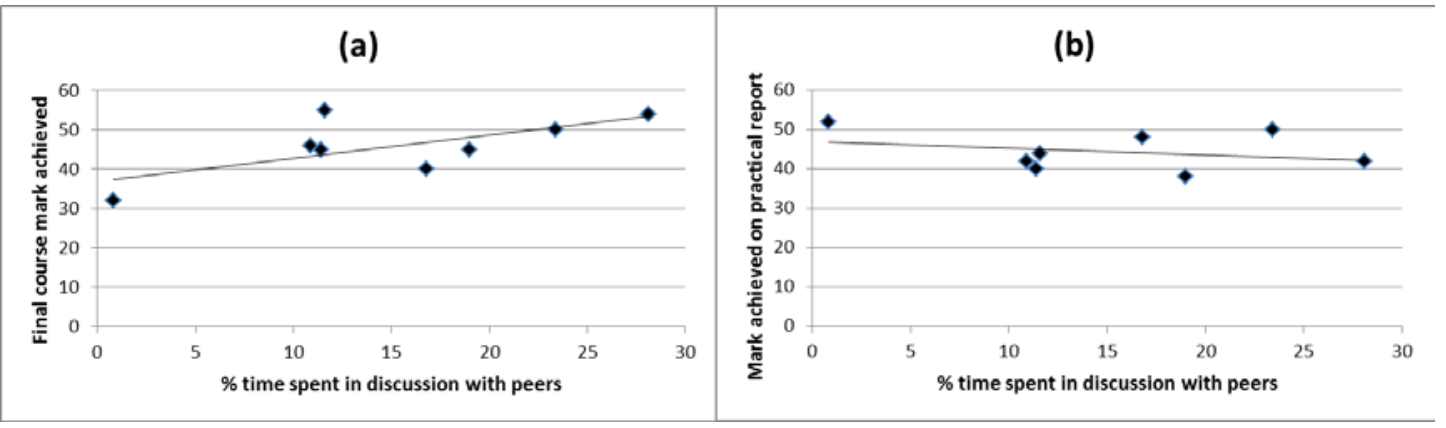

Figure 2. Correlation of percentage time spent on discussion with group peers with (a) performance in the course as a whole, and (b) performance in report submission.

These results suggest that group discussion is an integral learning component within group-based practicums, and may be of greater pedagogic value than direct physical engagement with the object of focus of the practicum. Such discussion with peers appears to foster connections between theory and practice that assist student learning in the mid- to long-term. However, the qualitative analysis revealed that not only is it the case that talk counts more than physical engagement, but that specific kinds of talk count more than others.

\section{The Talk that Counts}

It is unsurprising that a correlation exists between group interaction and academic performance. As Luff et al. (2009) demonstrate, ideas emerge from and are articulated through interaction. However, the correlation between academic performance and discussion with peers was not without anomalies. The focus of subsequent qualitative analysis was on these anomalies. In the discussion that follows, two individual student participants are discussed: they have been given the pseudonyms Thabo and Miriam.

Thabo spent more time than anyone else in his group directly and physically engaged in the concrete casting process. Regarding time spent in discussion with peers, the two top performers in his group spent $28 \%$ and $23 \%$ of their time in discussion respectively. Thabo spent the third most time in discussion with peers: $17 \%$. What was noticeable in this group was the qualitative difference in the type of talk that Thabo had with his peers, and the type of talk that the two top performers had with each other.

Thabo primarily engaged with his peers on matters regarding logistics and practicalities. He would debate with his colleagues as to which equipment to use, how best to achieve certain logistics, and so on. His input in this regard was valued by his fellow group members, who regularly agreed with his suggestions and praised his ideas as good. However, any and all discussion within the group that involved referring back to the course textbook, and to underlying principles, as well as to the calculation tasks required as part of the practicum, was held between the two top 
performers. Thabo never participated in such discussions, and nor did the fourth member of the group. Whereas the top two performers' discussion with each other centred around the use of documents (the textbook and the information sheet provided), Thabo's engagement with his peers primarily centred around equipment and materials. In such contexts, documents such as the textbook and information sheet serve to shape practices as meaningful (Street et al., 2009) and access thereto can thus act as a proxy for access to learning.

It was evident within this group, therefore, that there was a division of labour between the group: where the top performing students were responsible for the intellectual aspects of the practical task, and where Thabo (and, to a lesser extent, the fourth member of the group) was responsible for the practical components. As previously mentioned, in the world of the professional concrete technology practitioner, these practical tasks may be highly valued, but in the academic environment, it is the focus on underlying principle, and on achieving the set academic requirements, for which students are given credit. Assuring good knowledge-sharing routines between students is vital to the success of engineering education (Juhl and Lindegaard, 2013). Furthermore, the ability to find and use knowledge are important for future employability and lifelong learning (Evers et al., 1998), and all students should thus be included in such activities.

In the other group, Miriam spent more time than any of her peers in discussion with group members (19\% of her time was spent on this). However, two of her peers ultimately performed better, despite the fact that they spent only $12 \%$ and $11 \%$ of their time in discussion with group members respectively. The participant who spent $12 \%$ of his time in discussion with peers was the best performing student in the group, by some margin. Again, it was evident that this student was primarily involved in discussion about the task and the underlying expectations and principles. This discussion was largely held with Miriam, and not with the other two members of the group (the one, like Thabo, was consulted largely only on practical matters, and the other generally avoided all discussion and simply did what he was told to do by other group members).

Despite the fact that Miriam was a core participant in the decision-making within the group, she still performed relatively poorly in the module. Upon closer inspection of the data, it became evident that the explanation for this may reside in the nature of her activity when she was neither working directly with the concrete or engaged in discussion with her peers, which accounted for more than $60 \%$ of her time. Whereas other student participants (in both groups) spent this time standing watching their group members, or discussing matters with tutors and lecturers, or fetching, cleaning and returning equipment, Miriam spent this time in discussion with her friends who were in another group nearby. Her involvement in her own group was, therefore, fleeting and characterised by bursts of involvement. She would return to the group, catch up on what had been done, give input into what needed to be done next, and then leave the group to return to her friends. Her attention was thus scattered and, despite the fact that she was relatively strong academically, it could be argued that her lack of focus and continuous engagement, may have been to the detriment of her academic performance.

The benefits of group work, and co-operative learning, include the fact that weaker students can benefit from one-to-one tutoring from stronger team mates and stronger team mates gain a greater depth of understanding that comes from teaching others 
(Bullard and Felder, 2007). However, as Bullard and Felder (2007) further argue, these benefits can only be realised if positive interdependence can be fostered within the group. As such, tutors and lecturers should be cognisant of potential behaviours that work against group interdependence. This may include strategies that reward group collaboration and positive group behaviours, rather than just examining the final product.

\section{Conclusions}

The important of team work and effective communication in engineering education has been well documented (see Sulcas and English, 2010, for an example from the South African literature). This study has presented a small-scale but fine-grained investigation of two groups of first year civil engineering students, as they cast, tested and crushed concrete cubes as part of a concrete technology practicum. It was found that, in this context, the discussion that group members have with their peers may have greater impact on their understanding of principles and practices underpinning their chosen field of study, than their direct physical engagement with the object of focus of the practicum. More importantly, it has demonstrated that the nature of this discussion is of importance: those group members who discussed issues on the basis of the academic requirements and the principles underpinning them fared better than those who focused on the practical issues involved in completion of the task. Indeed, as Evers et al. (1998) argue, the ability to gain knowledge from everyday experiences is an integral component of learning.

The implications of these findings are three-fold. Firstly, it implies that group-based practicums should be designed in such a way that group discussion is a crucial component of the practicum, and the focus should not be placed solely on the completion of the actual experimental work. That is to say, students should be given opportunities to discuss and interrogate what they are doing, as such discussion is integral to the meaningful completion of the task.

Secondly, tutors and lecturers should receive training as to the dynamics of group activity, so that they can become attuned to the nuances of group dynamics and intervene where learning alliances are formed that exclude other group members from the intellectual and decision-making life of the group. Linked to the first point, these tutors and lecturers should be less focused on the completion of the task per se, but on the group interactions and dynamics, which may play a greater role in fostering or hindering learning.

Finally, from a methodological perspective, this paper demonstrates how the combined quantitative and qualitative analysis of film data can be used productively to understand the learning activity of group members, and identify behaviours that may be detrimental to student learning. Such understanding arises from the methodological process of grouping student activities, identifying anomalies and probing these anomalies through in-depth investigation and analysis. 


\section{References}

Bullard, L.G. \& Felder, R.M. (2007). A student-centered approach to teaching material and energy balances: 2. Course delivery and assessment. Chemical Engineering Education, 41(3), 167-176.

Cohen, L., Manion, L. \& Morrison, K. (2007). Research Methods in Education. London: Routledge.

Evers, F. T., Rush, J. C. \& Berdrow, I. (1998). The Bases of Competence: Skills for Lifelong Learning and Employability. San Francisco: Jossey-Bass.

Juhl, J. \& Lindegaard, H. (2013). Representations and visual synthesis in engineering design. Journal of Engineering Education, 102(1), 20-50.

Lerner, N. (2007). Laboratory lessons for writing and science. Written Communication, 24, 191-222.

Luff, P., Heath, C. \& Pitsch, K. (2009). Indefinite precision: Artefacts and interaction in design. In: Jewitt, C. (ed). The Routledge Handbook of Multimodal Analysis. London: Routledge.

Scollon, R. \& Scollon, S. W. (2009). Multimodality and language: A retrospective and prospective view. In: Jewitt, C. (ed). The Routledge Handbook of Multimodal Analysis. London: Routledge.

Street, B., Pahl, K. \& Rowsell, J. (2009). Multimodality and New Literacy Studies. In: Jewitt, C. (ed). The Routledge Handbook of Multimodal Analysis. London: Routledge.

Sulcas, G. \& English, J. (2010). A case for focus on professional communication skills at senior undergraduate level in Engineering and the Built Environment. Southern African Linguistics and Applied Language Studies, 28(3), 219-226.

Swann, J. (1994). Observing and recording talk in educational settings. In: Graddol, D., Maybin, J. \& Stierer, B. (eds). Researching Language and Literacy in Social Context. Clevedon: Multilingual Matters/Open University.

Wang, Q. \& Heath, T. (2011). Towards a universal language of the built environment. Social Semiotics, 21(3), 399-416. 


\title{
The role of self-concept and expectations in academic achievement: a preliminary study
}

\author{
L.E. Pettersson, R. Muñoz-Luna \\ University of Málaga, Spain
}

\begin{abstract}
As early career students face new challenges at university, the relationship between second language skills and academic success depends upon self-perception to a greater extent than previously assumed. Up to the moment, most levelling courses have focused on developing students' skills in specific subjects in order to bridge the gap between the knowledge that the high school alumni have and university teachers expect them to possess. Yet, early academic failure remains elevated. For this reason, we have decided to focus our English Degree levelling course on academic strategies, expectations and procedures with the aim to disclose the role of students' self-perception on second language performance in an academic context. We have designed a two-staged method consisting of a survey and a standardized placement test to measure learners' self-perception. The results of both stages are measured by following a mixed method procedure, combining quantitative and qualitative analyses. Results show that there is a close relationship between students' self-concepts, academic expectations, and final outcomes. When the learning of new contents occurs by means of a foreign language, the implications of learners' confidence and their academic awareness are even clearer. Therefore, we conclude that learners' self-concepts, and awareness of their academic expectations should play a key role in initial undergraduate training.
\end{abstract}

Keywords: self-concept; expectation; second language performance; levelling course; higher education; learning experience.

\section{Introduction and context}

First year in Higher Education is always demanding for new students who have to face new challenges regarding schedules, contents, levels, and teachers. In a matter of months, a higher level of maturity and autonomy is required from them as part of their academic success. In many universities, first-year undergraduates are offered an introductory levelling course with the aim of providing an overview of contents and expected learning outcomes. In this regard, we aim to focus on a group of English Studies undergraduates, and to examine the role of academic self-perceptions in learners' second language performance. The notions of self-perception and selfconcept are used interchangeably in this paper and refer to the mental image that study subjects possess of themselves as students (Jurkovic, 2013).

Teachers at the University of Malaga have noted a significant gap between the level of knowledge high school alumni are expected to have and actually possess when commencing their university careers. In addition, the teacher-learner dynamics at university places greater emphasis on students as active learners than earlier whereas teachers assume a moderating role. Consequently, first-year students face unexpected difficulties, which in some cases entails early academic failure. In order to decrease the number of first-year dropouts and enhance learning consistency, different degrees have implanted introductory levelling courses to bridge the gap between high-school and university studies. 


\section{State of the art}

In the present paper, we investigate the relationship between students' previous knowledge, academic self-concepts and expected outcomes. Previous research on student achievement tests and learning strategies indicates that mixed-ability groups present too varied score ranges; therefore, strategy-based teaching is not effective in these cases. On the contrary, focusing on self-perceptions and academic awareness contributes to more efficient learning of a foreign language (Jurkovic, 2013, 210). Other studies in the field have addressed motivational aspects across disciplines (Bong, 2004), as well as language awareness in second language academic achievement (Bolitho, et al., 2003). Peacock (2001), Johns (2008), Nacera (2010) and Yasuda (2011), among others, have traditionally analysed the role of language awareness and academic strategies in the process of foreign language learning. However, they did not trace the intersection among students' self-perceptions, academic expectations and motivations, and final academic results.

Several scholars have demonstrated concern for students' awareness of their learning and consequences on academic success. Madsen, García-Jiménez, Páez-Moguer, Jiménez-Cebrián and Pettersson have proposed self-monitoring tasks that enhance learners' performance efficiently. Although these scholars do not address selfperception, they claim that self-reflective activities foment autonomous learning and stimulate critical thinking (2014, 10-11). Similarly, Smith and Kling highlight that the risk of failure is anchored in low self-esteem: "while self-reflection is an extremely powerful process that can significantly improve self-perception, the low perception of self initially held by many individuals will act to prevent them from engaging in any meaningful way in an exploration and evaluation of their existing knowledge and skills acquired through experience” (Smith and Kling, 2011, 16). In these lines, we find that self-assessment makes learners aware of their learning processes, and subsequently, students' achieve better results. We argue that self-reflective learning testifies to the relevance of self-perception to effective learning.

Whereas previous studies have focused on learners' insight into linguistic skills when learning a foreign language, we have opted for a case study of first-year students starting the degree of English Studies. Our aim is to explore the level of selfperception when entering into university, and the extent to which this perception affects their academic expectations and second language performance. In the present preliminary study, the previous variables are considered since we compare and contrast students' self-perception survey results with their second language results in a standardised language placement test.

\section{Defining theoretical constructs}

\section{Self-perception and academic success}

Self-regulating processes seem to play an important role in obtaining high academic marks. Those regulation procedures shape academic self-concepts which are projected onto academic results. The interrelation between students' perception of themselves as capable learners and their confidence in achieving results denotes "[a] relationship [that] is mutually reinforcing: as our self-perception increases, our willingness to engage in learning increases and as a consequence our level of learning achievement 
increases, which in turn improves our self-perception as a learner, and so the cycle continues” (Smith and Kling, 2011, 256).

Self-concepts are more than objective perceptions of ourselves. They are emotions and reactions towards our own attributes (Bong, et al., 2012, 337). Positive results revert to higher self-perceptions, which at the same time produce better academic results. Such virtuous circle leads us to formulate the following research question: what impact does academic self-perception have on actual English performance in academic contexts? Self-efficacy, or the perception on our cognitive capabilities to do an academic task, shapes our own beliefs in our possibilities to do something. Task value will evidently affect our own perception to do it, becoming a good indicator of academic success. Creativity and analytical skills correspond to formal and logical thinking, what has been recently related to academic success as well (González, et al., 2012). Taking into consideration the importance placed on self-perceptions and beliefs in academic success, we claim that subjectivity and emotions play a key role in achieving study objectives. In fact, according to our preliminary results discussed later in this paper, subjective perceptions of the academic reality will lead towards success or failure in empirical academic tests.

\section{Students' academic expectations and academic success}

Students' academic expectations can be understood as knowledge, motivation and affect regarding an academic challenge (Benevides, et al., 2014, 50). These expectations derive from both academic institutions and the individuals who participate in them (e.g. teachers, students, colleagues). In this regard, self-perception encompasses our individual subjective responses to learning as well as the view we think others have of us. According to recent studies in the field, those students having higher expectations from institutions and institutional resources perform poorer academically. On the contrary, those learners expecting higher from their own academic performance and relying on their personal academic skills achieve better results (Benevides, et al., 2014; Muñoz-Luna, 2013). Hence, students' perception of themselves as learners is a major determinant in academic success.

\section{Methods}

Academic failure in the degree of English Studies is often caused by either students having an insufficient level of English from high school, or learners not having the appropriate development of English language skills during the initial years of their studies. While other levelling courses focus on specific subjects that are central to the degree in question, we have opted for a more global approach. Given the importance of self-perception for academic success, the present research is developed during a levelling course which focuses on academic strategies, expectations and procedures.

Students' awareness of their learning processes enhances their performances as active learners. Yet, to measure self-perception is complicated as this cognition self-image is embedded in individual beliefs and emotions. In order to evaluate the scope of selfperception, we have designed a two-staged method consisting of a placement test and a survey (see Appendix). The questions in the survey were elaborated to disclose students' expectations, motivation, awareness of learning process (survey questions based on González, et al., 2012; Jurkovic, 2013), while the placement test was aimed 
at revealing students' actual English level according to the Common European Framework of References for Languages (hereinafter, CEFR). One important issue to clarify is the variables under analysis in this study. The analysis of these variables will provide insight into undergraduates' self-perception and academic expectations. Our research variables are two, and they aim to respond to the general research question: "what impact does academic self-perception have on actual English performance in academic contexts?”:

- Students' academic expectations. What are the academic expectations of a group of first-year undergraduates in the degree of English studies?

- Students' academic self-perceptions. How do undergraduates perceive themselves regarding their own academic performance?

The participants in the study were a group of fourteen first-year undergraduates who were starting their degree in English Studies. These students enrolled in this levelling course in which two of their future teachers explained academic competences and contents they would be learning during the following four years. During the first day of the course, learners participated in both the survey and the placement test described above; they answered the survey firstly, and then the test. In this manner, their answers were not influenced by what they learned in the course, by new information, group pressure or by their own test performance.

\section{Preliminary results and discussion}

The different questions in the self-perception survey provide data corresponding to the following areas, all of them related to our research variables: personal data, participants' background, course expectations, self-evaluation, degree level expectations, perceptions on Inglés Instrumental/Instrumental English. In order to preserve students' identity, subjects were numbered (001M, 002F..., the letter being the indicator of gender). Regarding participants' gender, there were 5 males and 9 females. They were all aged between 18-20 years with the exception of one student over 25.

As an example of high-scoring participant, we have the case of $007 \mathrm{M}$, who obtained the highest mark in the placement test. In this case, a deeper analysis of the research variables in this student's survey shows that both his academic expectations and his self-concept are very high and positive ("I have always been one of the best students in my class”, 007M). On the contrary, 001F shows a significantly lower level at the language placement test, and her self-concept is remarkably different ("I consider myself inefficient when communicating in English”, 001F); moreover, her academic expectations on the degree in English Studies are poorer ("English Studies was not my first degree option", 001F). At this stage, the results shown in this section are partial and tentative as the study sample is small; further implementations of this study are programmed for the next months.

Some language learning factors are inevitably uncontrollable by students. Although they are imperceptible variables, they influence both speed and quality during the learning process. Group make-up, teaching styles and policies, and teacher-student relationships are all actions occurring in the class but they are not always predictable or manageable by students. Nevertheless, there is something they can change, though 
not effortlessly, which is internal to them, and which directly influences their second language performance: their learning self-concept and their academic expectations. In this regard, we agree with Pajares and Schunk who hold that "students' self-concept and self-efficacy beliefs are each related to and help mediate the impact of other motivation constructs on academic achievement” (2001, 254).

It is widely agreed that academic success in a second language is determined by language features of the activity, by the student's knowledge of the topic, and by a number of skills in the students. Within the last group, learners' self-beliefs and concepts of their second language performance result to be crucial in their actual success. Self-beliefs and self-reliance are as important as social perceptions of others, as it is shown by Gomes and Soares (2013, 782); these authors claim that students with lower academic results pay more attention to social relations and extra-curricular activities.

Awareness of the academic self is related to students' metacognitive knowledge, that is, higher-order cognitive processes and strategies which are transferable from L1 to second language. High-scoring students are more confident and, therefore, they expect more from their academic career. On the contrary, the students who present non-realistic and lower perspectives about their academic phase at university have higher probabilities of failure than those learners who visualise their academic tasks clearer (Gomes and Soares, 2013, 787).

\section{Conclusions}

Students' beginnings in Higher Education bring new academic and professional expectations which are more challenging than the ones they used to have in High School (Gomes \& Soares, 2013, 781). Some new undergraduates feel the pressure of challenge and go through their academic times with more anxiety than relief. Families, academic institutions and governments must work cooperatively in order to provide a more comprehensive educational context for students. Closer attention to internal beliefs, concepts and expectations may redound in favour of academic results and learning. Academic success seems to be related to the ability to conceive more ambitious projects and to design alternative routes to achieve scholarly goals. This is the reason why we advocate for more comprehensive levelling courses in higher education as a way to demonstrate the importance of self-concept and academic awareness in obtaining satisfactory results.

\section{Appendix}

\section{Question 1. Indicate your English level according to the European Framework of Reference for Languages.}

$-\mathrm{A} 1$

$-\mathrm{A} 2$

$-\mathrm{B} 1$

$-\mathrm{B} 2$

$-\mathrm{C} 1$

$-\mathrm{C} 2$

- I'm not familiar with the levels of the European Framework of Reference for Languages. 
Question 2. Regarding your academic language skills level:

-1: I cannot use English effectively in any academic context.

-3: I can use English effectively in a few contexts.

-5: I can use English effectively in some academic contexts.

-7:I can use English effectively in many academic contexts.

-10: I use English correctly and effectively in all academic situations.

Question 3. What expectations do you think your English teachers have from you?

- Teachers expect me to have an A2 level of English

- Teachers expect me to have a B1 level of English

- Teachers expect me to have a C1 level of English

- Teachers expect me to be an autonomous and efficient student, apart from having good language skills

Question 4. What is your level of English in use?

- I consider myself efficient when communicating in English (both writing and speaking)

- I consider myself inefficient when communicating in English

- I am more efficient in English when I try to communicate by writing

-I am more efficient in English when I try to communicate by speaking

Question 5. What expectations do you have for your degree?

- I expect to improve my English level (both written and oral skills)

- I expect to learn about England and English-speaking countries

- I expect to learn how to become a good English teacher

- I expect to learn about English literature and culture

- Others: please, specify

Question 6. Was English Studies your first degree option?

-Yes

-No

-If not: My first option was

$$
\text { English Studies was my__ option }
$$

Question 7. Are you aware of the English language difficulties you experience while studying English?

-Yes

-No

Question 8. What difficulties do you normally experience while studying English?

- Pronunciation difficulties

- Lack of vocabulary

- Comprehension difficulties (Difficulties in understanding sentences)

- Production difficulties (speaking and/or writing)

- I cannot identify my language difficulties

- None of the above. Please, indicate:

Question 9. What are your strengths in English language? (You can choose more than one option)

- I am good at speaking in English

- I am good at writing in English

- I am good at reading in English

- I am good at listening in English 
Question 10. Are you aware of your own learning process?

- I know how much I have learned/studied, and I am aware of what I do not know yet

- My studying is well organised and carefully planned

- I schedule my study time as I go

- I do not know about my study progress

Question 11. While studying, when does your concentration start to fail?

- After less than 30 minutes

- After 30-45 minutes

- After 45-60 minutes

- After 60-90 minutes

- I find it hard to concentrate at all

Question 12. While studying... (You can choose more than one option)

- I am connected to the Internet

- I am connected to social networks

- I set my mobile to silence

- I have the tv on

- I need to be undisturbed

Question 13. How do you see yourself as a student of English?

- I have always been one of the best students in my class

- I have been an average student in my class

- English has always been a difficult subject for me, but I always managed to pass

- I have always had very low marks in English

Question 14: My marks in English were usually

- lower than expected

- as expected

- higher than expected

Question 15: Where did you study English?

- at school only

- I have been tutored or taken extra classes outside school

- I have studied abroad

- I am bilingual

- I have tutored other students / children

Question 16: What was your qualification at the University entry exam?

Global mark:

English:

\section{References}

Benevides, A., et al. (2014). O impacto das expectativas na adaptaçâo acadêmica dos estudantes no Ensino Superior. Psico-USF, Bragança Paulista 19(1), 49-60.

Bolitho, R., Carter, R., Hughes, R., Ivanic, R., Masuhara, H. \& Tomlinson, B. (2003). Ten Questions about Language Awareness. ELT Journal, 57(3), 251-259.

Bong, Mimi. (2004). Academic Motivation in Self-Efficacy, Task Value, Achievement Goal Orientations, and Attributional Beliefs. The Journal of Educational Research, 97(6), 287-98.

Bong, Mimi, Catherine Cho, Hyun Seon Ahn and Hye Jin Kim. (2012). Comparison of Self-Beliefs for Predicting Student Motivation and Achievement. The Journal of Educational Research 105(5), 336-52. 
Gomes, Gil and Adriana Benevides Soares. (2013). Inteligência, habilidades sociais e expectativas acadêmicas no desempenho de estudantes universitários. Psicologia: Reflexao e Crítica 26(4), 780-789.

González, M.L., et al. (2012). Autoconcepto y talento: una relación que favorece el logro académico. Psykhe 21(1), 37-53.

Heiberg-Madsen, Lea and Rocio García-Jiménez, Joaguín Páez-Moguer, Ana Jiménez-Cebrián and Lin Elinor Pettersson (2014). Estrategias docentes para la internacionalización del alumnado universitario. SEECI: Prospectiva en innovación y docencia universitaria Madrid: Universidad Complutense de Madrid, 1-15.

Johns, A. (2008). Genre Awareness for the Novice Academic Student: An Ongoing Quest. Language Teaching, 41(2), 237-252.

Jurkovic, V. (2013). Effect of strategy based instruction on achievement test scores in a mixed language ability group of ESP learners. Ibérica, 25, 195-214.

Muñoz Luna, Rosa. (2013). ¿Cómo escriben los universitarios en inglés? Claves lingüísticas y de pensamiento. Sevilla: Thémata.

Nacera, A. (2010). Languages Learning Strategies and the Vocabulary Size. Procedia Social and Behavioural Sciences, 2(2), 4021-4025.

Pajares, Frank and Dale H Schink. (2001). Self-Beliefs and School Success: SelfEfficacy, Self-Concept, and School Achievement. Self-Perception, 239-265.

Peacock, M. (2001). Language Learning Strategies and EAP Proficiency: Teacher Views, Student Views, and Test Results. In J. Flowerdew \& M. Peacock (Eds.), Research Perspectives on English for Academic Purposes (pp. 268-285). Cambridge: Cambridge University Press.

Smith, Larry and Margaret Kling. (2011). The Impact of Self-Perception on Vocational Learning. Vocational Learning, 14, 243-257.

Yasuda, S. (2011). Genre-Based Tasks in Foreign Language Writing: Developing Writers' Genre-Awareness, Linguistic Knowledge, and Writing Competence. Journal of Second Language Writing, 20(2), 111-133. 


\section{HEAd'15}

\section{SESSION 6A}

\section{SCIENTIFIC AND \\ RESEARCH EDUCATION}




\title{
A Happy Marriage: Academia, Professional and Scientific Associations
}

\author{
Alfonso Díez Minguela* and $M^{\mathrm{a}}$ Ángeles Pons Brias*
}

* Universitat de València

\begin{abstract}
This paper advocates for a greater integration between Higher Education and Professional and Scientific Associations (PSAs). With the development and adoption of Information and Communication Technologies (ICTs), the costs associated with the collection, storage, processing and transmission of information have been reduced. Eventually, the supply of information has boomed. However, more does not necessarily imply better. Free online resources can enhance the learning process, but the lack of quality controls is still a major concern. Additionally, learning demands some degree of organisation and structure. We argue that Higher Education can potentially benefit from a closer relationship with PSAs. In doing so, we introduce the Spanish Economic History Association efforts to organise and prepare high-quality teaching resources. Our brief discussion could provide a route-map for other PSAs.
\end{abstract}

Keywords: Online resources; Professional associations; Higher Education

\section{Introduction}

On September 15, 2008, a well-established investment bank, Lehman Brothers, filed for bankruptcy. Although the financial crisis had already begun, the sudden collapse of the fifth largest investment bank in the world was an eye-opener to many people. The unexpected was occurring, and few had foreseen it. However, the 2008 financial crisis opened up further opportunities for some. As Barry Eichengreen put it in the 2011 Presidential address to the Annual Meeting of the Economic History Association: "This has been a good crisis for economic history.... Journalists, market participants, and policy makers all turned to history for guidance on how to react to this skein of otherwise unfathomable events" (Eichengreen, 2011). A year earlier, Vicky Price, then Joint Head of the Government Economic Service (GES), had argued that, "for the economist, history remains the laboratory through which we are best able to seek to understand how different policies might impact on economic performance. The recent global financial crisis in particular has reminded us how analysis of past periods of economic history can be invaluable in informing contemporary policy questions" (in Crafts et al., 2010).

Although economics had "missed the boat in 2008”, as Carlin (2013) said, the general public demanded an explanation, and a subsequent plan of action. What caused the 2008 financial crisis? What could be done to prevent it? What was to be done? More notably, the study of economic history gained momentum or simply, the demand for economic history increased. For example, a group of economists launched the CORE project (URL: http://core-econ.org/) to promote a new curriculum in economics where economic history plays a central role. Barry Eichengreen, a distinguished economic historian, became a media mogul in the United States. More than a few journalists, policy-makers, professional and academic economists, students and enthusiasts, are looking at the past to better understand the present. Moreover, with the Twenty-First century came the rapid development and diffusion of Information and Communication Technologies (ICTs). By ICTs, we simply refer to Internet, PCs and laptops, mobile 
phones and tablets, and software packages capable of collecting, storing, processing, transmitting and presenting information. Clearly, ICTs have greatly reduced the costs associated with accessing information, which eventually opened up new opportunities in education.

a) Before ICTs

RESTRICIED ACCESS

University degree

- Short courses

b) After ICIs

RESTRICTED ACCESS

University degree

Short course

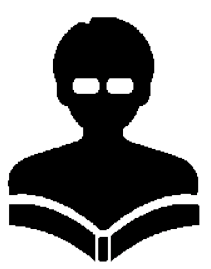

FREE ACCESS

- Public library

FREE ACCESS

Online courses

Online resources (i.e. blogs, webs)

Public library

Figure 1. ICTs and the supply of knowledge

Figure 1 illustrates the opportunities that an individual enjoys in a context before/after ICTs. Before ICTs, knowledge was mainly transmitted via university degrees and/or short courses organised by either academics or professionals. Additionally, books and academic journals were the main sources. ICTs have thus facilitated a greater supply of information. Online resources (academic and non-academic articles; blogs, courses, websites) provide a wider range of tools in the learning process, and in most cases are free. But, how reliable are these? More quantity does not necessarily imply high quality. In fact, the lack of quality controls appears to be a major concern. Moreover, the learning process requires structure and organisation. For this, several institutions have launched Massive Open Online Courses (MOOCs). MOOCs are usually openaccess courses with a proper structure, and materials such as lecture notes, reading lists, and problem sets. Additionally, MOOCs provide students with the opportunity to regularly interact with lecturers or teaching assistants. Therefore, online courses have quality control mechanisms and a basic structure. However, the completion rates hardly reach $20 \%$ (Jordan, 2013). In this brief paper, we propose an approach to balance demand and supply within the traditional context of university degrees: Professional and Scientific Associations (PSAs).

University degrees and short courses provide quality controls and structure, but what if the expertise does not entirely match with the demand for knowledge? For example, suppose there is no faculty expert on the history of financial crises. Under these conditions, there are numerous alternatives. First, doing nothing, hence the demand remains unmatched. Second, there could be faculty openings. Third, if hiring is not viable, those faculty members responsible for organising the course will incur into an extra cost, unless guidance and reliable materials are available. In this paper, we argue that Professional and Scientific Associations (PSAs) could and should play a greater role in Higher Education. 
Traditionally, PSAs were created to promote and support excellence in a particular discipline. The Royal Society, founded during the second half of the 1600s, was aimed at encouraging "the development and use of science for the benefit of humanity". Since then, the number of Professional and Scientific Associations (PSAs) has boomed. Notwithstanding the crucial role played by these associations or clubs in the dissemination of frontier knowledge and values, modern times call for further action. In the United States, the American Economic Association (AEA) offers online resources, while the Economic History Association (EHA) has a website with articles and other materials prepared by broad bunch of experts. In some cases, these articles have been peer-reviewed. In the United Kingdom, the Economic History Society (EHS) also provides online resources, e.g. podcasts. Interestingly, the Bank of England and the Federal Reserve Bank of St. Louis offer a great amount of educational resources too. Then, what role should PSAs play in Higher Education? Should PSAs be responsible for quality control?

In this brief paper we advocate for a greater integration between Higher Education and PSAs. We firmly believe that PSAs could coordinate efforts across researchers. In fact, PSAs could bridge the gap between frontier research and Higher Education. High quality teaching materials can be produced and disseminated. Recent developments can be easily incorporated, thereby linking frontier research and teaching. To motivate our claim, we first introduce our own personal experience at the Universitat de València. Then, we present the Spanish Economic History Association case.

\section{Economic History at the Universitat de València}

The Área de Historia e Instituciones Económicas at the Universitat de València has always made a great effort to promote the study of economic history. In 2010-11, the Facultad de Economía established several new degrees: Business Administration (GADE); Economics (GECO); Finance and Accounting (GFYC) and International Business (GIB). The Área de Historia e Instituciones Económicas or the Economic History Group (EH-Valencia) is in charge first-year courses such as World Economic History and Spanish Economic History (GECO), World Economic and Business History in (GADE; GFYC), and Geopolitics and Globalisation (GIB). Moreover, EHValencia also runs optional four-year courses.

Last summer, EH-Valencia published an up-to-dated world economic history book, which was accompanied by online teaching materials (Palafox, 2014). Our initial aim was to supply students with a well-structured, easy-to-read textbook. Moreover, our economic history courses show students how economic analysis allows us to better understand the past. Furthermore, EH-Valencia has launched an online platform (website; blog; facebook; twitter) too. Our objectives were threefold: (i) To encourage the study of economic history; (ii) To introduce students into major topics and debates; (iii) To promote students' abilities in terms of analysis and discussion. For example, within the EH-Valencia facebook and twitter accounts, students can easily find online resources (web links) related to the main topics explained in the lectures. This has encouraged the interaction between students and lecturers in the classroom. 
There are other platforms within economic history in Spain. Our colleague at the Universidad Pablo de Olavide (UPO), Fernando Ramos Palencia, launched a Blog on Historia Económica, Globalización y Desarrollo/Economic History, Globalisation and development, with numerous entries and a great bunch of teaching resources. There are other blogs, but mostly research-oriented, e.g. Juan Flores (University of Geneve) with other colleagues launched a blog on Past and Present of the World economy. Personal web pages are also another source of knowledge. In these, authors provide their personal opinions and materials, which are selected according to the courses taught or their research expertise. Table 1 summarises the online opportunities available. All in all, the supply of information exceeds the capacity that an individual or a group of teachers have to evaluate and organise.

Table 1. Online resources by type, purpose and main client

\begin{tabular}{|l|cc|}
\hline & \multicolumn{1}{c}{$\begin{array}{c}\text { Personal and } \\
\text { Departmental websites }\end{array}$} & PSAs websites \\
\hline Main purpose & Research \&Teaching & Research \&Teaching \\
\cline { 1 - 3 } & & \\
Main client & Academics Students & Academics
\end{tabular}

Therefore, PSAs could provide greater uniformity and homogeneity. Moreover, by selecting and classifying educational online resources, PSAs could guarantee a highquality standard. Even more, PSAs could create a discussion forum for teaching and educational purposes. In this line of thinking, we would like to present and discuss the active role played by the Asociación Española de Historia Económica (AEHE) in the development of online teaching materials. Although this is a just a simple case, it can easily illustrate how PSAs could participate more actively in Higher Education.

\section{The Spanish Association of Economic History}

The Spanish Association of Economic History or Asociación Española de Historia Económica (AEHE) was founded in 1972. Since then, it has promoted research and teaching related to economic history. The AEHE organises a national congress every three-four years to encourage the exchange of frontier research in economic history. The last one was held in Madrid on September 4-5, 2014. In 2005, the academic journal Investigaciones de Historia Económica was launched too. In addition, several initiatives have recently been introduced to promote excellence in teaching and research. One of these was the Sección de Docencia or Teaching Section (URL: http://www.aehe.net/docencia.html). This portal is free, and is currently organised by Elena Catalán Martínez (Universidad del País Vasco) and Miguel Ángel Bringas (Universidad de Cantabria). Pablo Gutiérrez González (Universidad de Sevilla) and Alfonso Díez Minguela (Universitat de València) have also collaborated.

The Teaching Section has four main goals: (a) To provide further information about the discipline of economic history across Spanish universities (i.e. syllabus); (b) To supply educational and teaching resources related to the discipline; (c) To encourage the use of novel teaching methodologies; (d) To encourage discussion forums among 
lecturers. Figure 2 shows the main organisation of the Teaching Section. First, GUÍAS DOCENTES include the available course syllabus across Spanish universities by region, whereas MANUALES provides information on the main textbooks by subject. The front cover and index of these textbooks have been scanned and uploaded as guidance for prospective teachers. CURSOS EN ABIERTO and MATERIAL AUDIOVISUAL is a collection of online courses, videos, films, and pictures related to economic history. MOOCs have also been included in the former one.

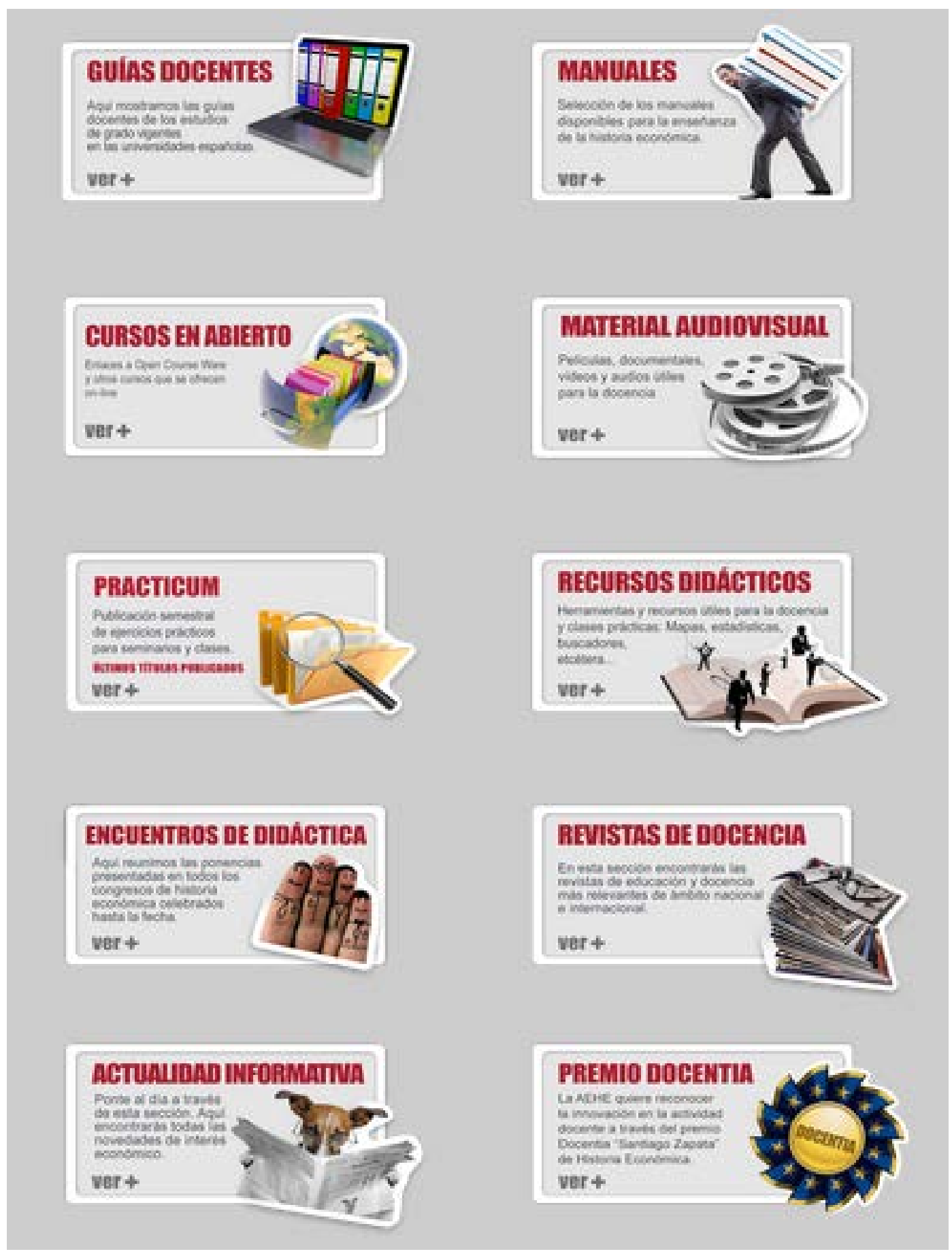

Figure 2. The Teaching Section, Spanish Economic History Association 
One of the most interesting is PRACTICUM, where several teachers have prepared online materials for a specific topic. All these have been properly peer-reviewed by an Advisory Board, which acts as a quality control mechanism. Furthermore, teachers are also researchers, and these materials are closely related to their interests. This is an example of how a greater integration between Higher Education and PSAs could potentially benefit Higher Education. Moreover, biographies, databases, maps and list of teaching tools can be found in RECURSOS DIDACTICOS. ENCUENTROS DE DOCENCIA and REVISTAS DE DOCENCIA mainly refer to the series of events organised by the Spanish Economic History Association to promote the teaching of economic history, and a list of journal on Higher Education in social science. Press articles, special issues, blogs and websites of interest are organised in ACTUALIDAD INFORMATIVA. Finally, the Spanish Economic History Association also awards a prize, the Docentia Prize, to individuals or groups for their outstanding contribution to the teaching in economic history.

There is little doubt that this Teaching Section has had a tremendous impact within the discipline. But, amassing and organising all these resources is costly. Each voluntary contribution needs to be reviewed, thus a committee has been created. Free riding is another major limitation. Although the Spanish Economic History Association has achieved a good deal of participation, coordinating reviewers and encouraging new entries has required a great commitment by the organisers. Finally, to maintain and update online resources is costly too. This, in turn, is one of the main problems of the Teaching Section. Whether or not funds will be available to carry on will depend upon its financial capacity.

Despite of the limitations, we believe that the Spanish Economic History Association provides evidence that PSAs could be the way forward. Since PSAs have as ultimate goal to promote and support excellence in a given discipline, and the vast amount of available information exceeds the capacity of an individual or small group, PSAs could play a role of intermediation and bring up-to-date frontier research to the class.

\section{Conclusions}

With the development and adoption of Information and Communication Technologies (ICTs), the costs associated with the collection, storage, processing and transmission of information have been reduced. Eventually, the supply of information has boomed. These online resources provide a wider range of tools in the learning process, but more does not imply better. For this reason, we advocate for a greater integration of Higher Education and Professional and Scientific Associations (PSAs). With ICTs, several PSAs have greatly increased curriculum-linked online materials, but mostly for primary and secondary education. For example, the Royal Society in the United Kingdom organizes Summer Science Exhibitions and provides teaching resources in its recently developed website: Invigorate. Why not marrying Academia with PSAs to enhance teaching in Higher Education? Teaching materials could be reviewed, organised and structured. To further support our claim, we introduce the Spanish Economic History Association effort to promote the teaching of economic history. Although the Teaching Section can be greatly improved, we regard it as first step in the right direction. ICTs can greatly enhance the learning process, but teachers alone cannot cope with the vast amount of available information. The greater degree of 
specialisation could potentially increase the gap between frontier research and the classroom. PSAs are a potential solution, as we have discussed above.

\section{References}

Carlin, W. (2013), Economics explains our world -but economics degrees don't, The Financial Times, November 17, 2013.

URL: http://core-econ.org/wendy-carlin-in-the-ft-teaching-what-matters-in-economics/

Crafts, N.G, Bakker G., Michie R, Leuning T, Tennet N, Owen N and K. Hartley (2010). Learning from some Britain's successful sector: a historical analysis of the role of government. BIS Economic Papers 6.

Eichengreen, B. (2011), Economic History and Economic Policy, Presidential address to the Annual Meeting of the Economic History Association, Boston, MA, September 2011.

URL: http://eml.berkeley.edu/ eichengr/EHA Pres Add 9-9-11.pdf

Jordan, K. (2013). MOOC Completion Rates: The Data.

URL: http://www.katyjordan.com/MOOCproject.html

Palafox, J. (ed.) (2014). Los Tiempos Cambian: Historia de la Economía, Valencia: Tirant Humanidades. 


\title{
Innovating approaches for scientific education and research in environmental and marine sciences
}

\author{
Erika Mioni*, Silvia Merlino** \\ * Istituto Comprensivo Statale n²- Complesso “2 Giugno”, Viale A. Ferrari, 19121 La Spezi, Italy \\ ** Istituto di Scienze Marine del CNR, Forte Santa Teresa, 19032 Pozzuolo di Lerici, La Spezia, Italy
}

\begin{abstract}
Citizen-science can give a valid help to scientific investigation, and this is especially true for environment monitoring programs. However, motivate and enable volunteers in a long-term commitment to a scientific problem represents an essential problem. The presented project is an example on how this long-term commitment can be guaranteed trough an educational path that involves students, not only in data collection but also in problem definition and data analysis. We tried to identify and harmonizing the existing educational plans for improving STEM teaching and learning (STEM is a curriculum for educate students in Science, Technology, Engineering and Mathematics in an interdisciplinary and applied approach, integrating the four disciplines into a cohesive learning path based on real-world applications), prioritizing hands-on learning to increase student interest and engagement. In particular, we describe an example of how two different approaches for educate students on marine sciences can interact in the context of environmental monitoring, applied to problems such as biodiversity, pollution from marine litters, and the the impact of this problem on the marine environment.
\end{abstract}

Keywords: Environment; marin-litter; citizenscience; peer-education; non-formal-education; biocenosis, inter-generational education.

\section{Introduction}

Now day, more and more often students already possess cultural heritage in many discipline, thanks to the easy access to information (internet, media, television, etc.). Nevertheless (or perhaps precisely because of this!) a key role is played by education, to avoid a mere accumulation of information not controlled and even referenced, and of short-living concepts, but, instead, identify and develop, in students, the necessary skills and competences that will help them to "participate in an effective and constructive way in social and working life in an increasingly diverse society"1. Especially for scientific discipline, an innovative pedagogical approach is necessary, to overcome traditional science teaching made of huge amount of concepts, often not related with the real world, and to build a critical but conscious attitude towards technological innovation, scientific research and environmental issues, that will encourage the development of free and motivated personalities able to make personal choices. It is only through a constant exercise on situations drawn from reality, that we can build an appropriate scientific attitude. Moved by such considerations, teachers of Istituto Comprensivo ISA 2 of La Spezia, in collaboration with researcher of ISMAR-CNR Institute, decided to involve students of secondary school in projects concerning monitoring programs in marine field, sharing methodologies and practices developed in two different contexts, i.e. BluePaths project and Seacleaner project, in conveying non-formal education, research and environmental awareness. Both are projects born, independently, with the intention to take into account both science education and scientific investigation. The former monitor biocenosis of beaches and sublittoral zone, analysing littoral flora and fauna from upper and middle shore, using

\footnotetext{
${ }^{1}$ Recommendation of the European Parliament and of the Council (2006/0962/EC) on Key Competences for Lifelong Learning ,
} published in the Official Journal of the European Union on 30 December 2006/L394. 
and integrating the Reef-Check Protocol ${ }^{2}$ to the Ligurian and North Thyrrenian sea, since these areas are subject to intensive boat traffic, and biological invasions of new species, a daily and common treat for coastal communities that is often underestimated; the latter is devoted to estimate the quantity, typology, accumulation rates of marine litter, i.e. "number of items (or weight or volume) per unit surface of beach per unit of time" of beached trash, for the most part deposited ashore from the sea. This is one of the negative consequence of our "plastic age", and the survey is performed following and adapting the UNEP/IOC (Cheshire 2009) protocol for marine litter and the $\mathrm{MSFD}^{3}$, as described in next sections.

Both projects provide data collected during repeated monitoring campaigns in the same place and at a distance of months, to allow to deduce information on the type and rate of accumulation of materials (the biological one and the anthropogenic one), estimate the possible origin and even make assumptions about the prevalence of marine currents and wave motion in the area under study. It result clear that a problem for visual survey of the littoral is that data collection of marine litter requires long time and the work of a lot of people. The need of long-term data series, to increase collected information, can be satisfied by the citizen-science, i.e. the active participation of volunteers in both kind of scientific projects (Cerrano et al. 2013, Newman et al., 2012). On the other hand, motivating and enabling all these volunteers in a long-term commitment to a scientific problem can represent a problem. For this reason, in 2013 BluePaths and SeaCleaner decided to collaborate in an unique project, sharing resources, methods, means and objectives, with the idea that the requested long-term commitment can be ensured trough a comprehensive educational path that involves students, not only in data collection but also in problem definition and data analysis. This has been possible, specially for high school students, thank to an innovative tool in higher education and vocational training: the "work-related learning”4, with the Italian Legislative Decree n. 77 of April 15, 2005 (Article 4). In our particular case, we used this tool to design an experience that is, in our opinion, particularly profitable as it presents vantages in the education of the students, as well as in research; the final product is also twofold: an educational experience which is highly motivating for students, and a scientific and technological "output" with a sound scientific and also social value.

BluePaths and SeaCleaner are actually still cooperating and operating in sampling sites of the coastal Tuscan and Ligurian $\mathrm{MPA}^{5}$. The selected areal is of great importance because it surrounds the Pelagos Santuary of marine mammals, animals at particular risk for micro-plastic pollution. From the scientific point of view, so, merging data of the two projects will represent the starting point necessary to proceed in trying to evaluate the effect that fragmentation of marine litter can have on coastal ecosystem (filter feeders such as bryozoans and other benthonic indicators) and evaluate the impact on the food chain.

\footnotetext{
2 Protocols for the Coastal Environmental Monitoring (CEM) along Italian coasts ( www.reefcheckitalia.it) partner of the world wide Reef Check Foundation (www.reefcheck.org))

3 MSFD-Marine Strategy Framework Directive: Guidance on Monitoring of Marine Litter in European Seas, Reference Report by the Joint Research Centre of the European Commission., 2013.

4 The work-related learning is a different way of connecting the school with work, through courses designed, implemented and evaluated under the responsibility of schools and on the basis of appropriate agreements with public and private companies, chambers of commerce, etc., available to accommodate students for periods of learning in the work situation.

5 Marine Protected Areas of 5 parks: National Park of the Tuscan Archipelago and of Cinque Terre, Regional Natural Park of Migliarino-San Rossore-Massaciuccoli, of Montemarcello-Magra and of Portovenere.
} 
Characteristic of both projects is to have an educative moment that extends outside the school and becomes an opportunity for students to practice theoretical skills acquired at school in their family environment. Moreover, both projects are harmonizing the existing educational plan, by adding hands-on learning activities to increase student interest and engagement in the STEM fields.

\section{Marine litter problem and biodiversity loss: two starting point for motivate students.}

The Anthropogenic Marine Debris (AMD), or marine litter problem, is a current global problem: it damages fisheries, environment, tourism, and can represent a threat to human health. AMD includes any processed solid material discarded or abandoned that ends up in the marine environment, for the most part of plastic material that, upon fragmentation, is transformed into particles easily assimilated in the food chain. Waste' introduction progressively increases with the gradual urbanization of the coasts, and the effect is even more enhanced for 'closed' basins such as the Mediterranean. Studies show the establishment of zones of accumulation also in the Mediterranean Sea (Suaria and Aliani, 2014), even if in the central and western part of this sea the rate of accumulation of floating AMD up now is not so well known. Thus, we are not able to evaluate the severe consequences that macro and micro litter could have on marine and coastal communities (Fossi et al., 2014), especially those belonging to the valuable biological areas such as the "Pelagos Sanctuary" (shelter of marine mammals in the Nord part of Mediterranean) and MPA. Recently, the European Community has been included marine litter amongst the 11 descriptors of MSFD, incorporating 56 indicators of Good Environmental Status (Galgani et al., 2013), soliciting researchers to fill the gap existing in the presently available data: especially for the coasts surrounding the Pelagos Sanctuary in Mediterranean Sea, information are still very scarce (http://www.strategiamarina.isprambiente.it/sintesirisultati-consultazione-2014). Moreover no study has been carried on to establish clear relationships between litter density and possible effects on benthic communities, and studies are lacking which provide extensive beach survey data in Mediterranean area and a clear picture of the trends in the medium/long-term, with possible biodiversity loss consequences. These environment problems are often unknown by students, and not treated in standard scholastic programs. For better motivate pupils we decided, so, to involve a group of high schools students not only in the monitoring actions, but also in the phase of "problem solving": for marine litter surveys, their task was create a protocol useful and friendly, able to be applied by a large range of people, and design the informatics architecture of an application for Android device, easy-to-use but methodologically correct (the app SeaCleaner). We tried to lead students to broaden their perception of the problem quantifying it, observing with their eyes, counting and classifying the enormous amount of anthropogenic waste that is dumped into the sea every day, analyzing the possible main sources of waste drained into the sea and how it interacts with the biosphere. Strictly linked to this topic, in fact, the one of the loss of biodiversity is a problem that involves more and more natural environments, and it is interesting to study the possible correlation with the crescent pollution from non-biodegradable waste of our coasts. For this reason, through the BluePath project a group of secondary school students have been trained on marine biology and monitoring techniques, with scholastic and extra scholastic paths, in order to be able to realize, under supervision of teachers and experts, visual census of beached and underwater bio-indicators belonging to benthonic communities. Biological monitoring activities has started in 2014 and are continuing 
until today, focusing on two areas in particular: the reserve of San Rossore and the island of Pianosa, in the park of the Tuscan Archipelago (Fig.2).

\section{Methods}

\section{Participation in science activities: a teaching strategy for the consolidation of skills.}

SeaCleaner design: during firsts step of the project (2013), students involved in the ideation and construction of the app SeaCleaner collected information about the marine litter problem and about existing standard protocols for monitoring it. After that, they have been divided into two groups, depending on their scholastic training. Task of first group was to adapt existing material to our specific purposes, i.e. to design a table of data collection for macro-litter [longer $>2,5 \mathrm{~cm}$ ] that could be used also by volunteers but it was at the same time exhaustive and rigorous, and it was adapted to be inserted in an informatics device. The second group' task was to transfer this table in an electronic format, and develop the utilities necessary for the acquisition and recording of data in the device, implementing the application for the Android operating system. Both groups were involved in the final phase: to test the effectiveness of the app and any shortcomings of structural design. The use of a similar device in data acquisition campaign is very fruitful, as very important is the standardization of the acquired data in order to allow the comparison of different campaigns of study, performed in different places and times. Without a common standard, data are not consistent, especially for the purpose of environmental planning, that need careful information about the amount of macro-waste streams beached or floating (UNEP 2012). For this reason, students involved in the protocol design have payed attention to use protocol available in literature, and to adapt it to their purposes analyzing the situation of the places where they live. The app still have different aspects to be completed, as the graphical interface: this affects its use and public spread, and for this reason it is still under test. Nevertheless, the protocol SeaCleaner it is available; it has been used by students during the second part of the project, in 2014, to acquire information on the distribution and fragmentation of marine-litter in different areas of the monitored areas, in parallel to the acquisition of information on biological communities (biocenosis) of different marine organism (benthos) in the same distribution areas, essential in order to investigate possible correlations between the state of health of ecosystems studied and the abundance of litter found (Project BluePaths).
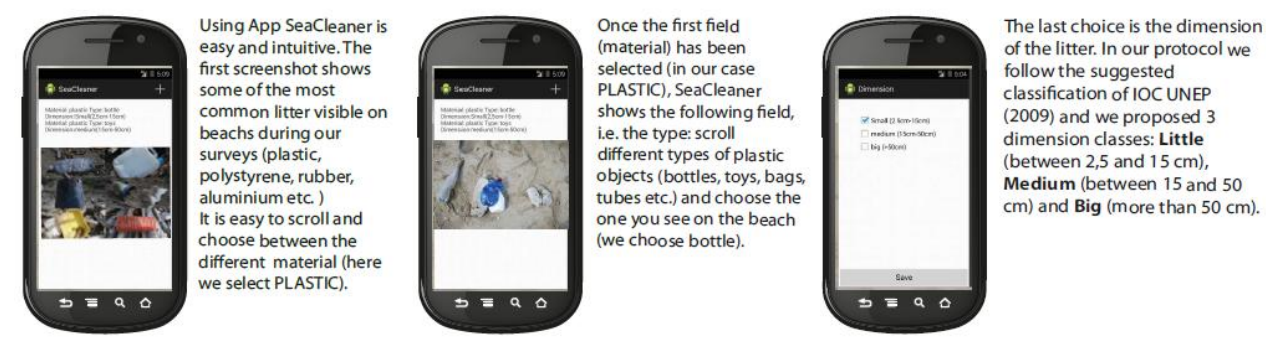

Figure 1. Application SeaCleaner, developed with the aim to be extremely "user-friendly following Guidelines of UNEP/IOC-“Quick poll” case (Cheshire et al. 2009). Added value is identified in the ease of acquisition, management and storage of data directly into electronic format and stored on Remote Server. The final layout is not yet ready, but here we can show how it would appear once completed in all the graphical part. 
BluePaths, i.e. education and training in marine monitoring activities: starting from the environmental potential that the natural area surrounding La Spezia itself offers, the project tries to stimulate the observation skills and intellectual curiosity, encouraging the development of rational assumptions and disseminating the basic principles of experimental scientific method. We are aware that, in the age of secondary school, the possibility to acquire skills in marine biology allow students to apply them directly in surveys of benthic species, in the supralittoral, interditial, upper infralittoral coastal areas. Students are involved in the study of biodiversity, and a technical language is used but, above all, our hope is to trigger a conscious learning of the experimental scientific method and its application to the monitoring techniques for coastal emerged and submerged zones. Principal arguments of the training phase are awareness of marine ecological interactions, classification of marine living or beached/dead organisms and classification of beached, floating marine natural and anthropogenic litter, techniques of coastal monitoring. Students are pushed to build their own sampling instruments (quadrats of $50 \mathrm{~cm} \mathrm{x} 50 \mathrm{~cm}$ ), and tools (manual, checklists etc.); as they become experts during this training period, they have to perform tasks of tutoring towards smaller students, peers or adults (volunteers or students' families) that get trained and are and involved in activities of Citizen Science in the framework of the project. This phase of peer-education and inter-generational education is very important, especially for students of the age between 11-14 years. This approach has proved very useful to increase the self-esteem and sense of responsibility of students, and greatly improve their academic performance as well as social behaviour. After data collection, students learn basic techniques of statistical data processing and produce their own table and graphs. This scientific training is also an occasion for orientating students towards Upper Secondary Schools. The threeyear training educational path can be so summarized:

- 1st year: basic training in marine biology, acquisition techniques for autonomy in monitoring emerged coast; acquisition of operating methods for visual census in submerged coast, peer learning: "how to be part of a Research Team”; Tutoring role with families; active participation in Citizen Science.

- 2nd year: knowledge' enhancement in marine biology, start autonomous monitoring; active participation of Citizen Science; "how to remain in a Research Team”.

- 3rd year: upgrading of skills, selection of Peer educators, assigning tutoring roles in Research campaigns, participation in research campaigns; active participation of Citizen Science; permanence in the research team; active engagement in dissemination activities, peer education and Citizen Science.

\section{Results and Discussion}

SeaCleaner involves 7 students of high school in 2013, and 17 students of high school and 20 of middle school in 2014. In 2015 is active with 40 students coming from different high schools of Liguria, Tuscany and Emilia Romagna regions, and 40 students of middle school of La Spezia province. Participation of students from different schools and degrees resulted in highly motivating experiences especially for the younger people, and may be effective in contrasting the school dropout, mainly perceived in the range of age between 14 and 17 years. Moreover, students were involved in real research operation, working with scientists, educators and environment operators: from the set up of the SeaCleaner App, to the beach 
monitoring and the following classification and analysis of collected items and preparation of tables and graphic; These approach have proven their value in order to stimulate the students and pupils to the topics covered and the methods used (Locritani et al., 2013, Merlino et al., 2014).

In the same way, Blue Paths have involved, in scholastic period 2013-2014, 34 classes of secondary school students, networking 3 Scholastic institutes (one high school and two middle school) and, moreover, 100 family (parents of the students) in citizen-science activities. In the same period (May 2014), 6 students were engaged in scientific activities of visual survey (up and under-water) in the Pianosa Island, working with researcher of ISMAR Institute. During scholastic year 2014/2015 the number of networking Institute has grown (with the adhesion of another high school of La Spezia and one of the town of Ancona, on Adriatic Sea). In addition to the involvement of students (35 classes) and families (100) in the monitoring activities conducted mainly in the San Rossore Park, a research internship was carried out in the Island of Pianosa (September 2014, participants 11 students of secondary schools, two teachers and two researchers) and a third internship is foreseen for May 2015, with the participation of 13 secondary school students, one university students and four researchers/teachers).

For both projects, participation and co-working of students coming from different institutes/regions, has been essential for fostering social skills and intra-and intergenerational communication (peer education), a result that is giving essential clues to researchers and teachers - for improving and evaluating, in the future, this kind of informal teaching methods.
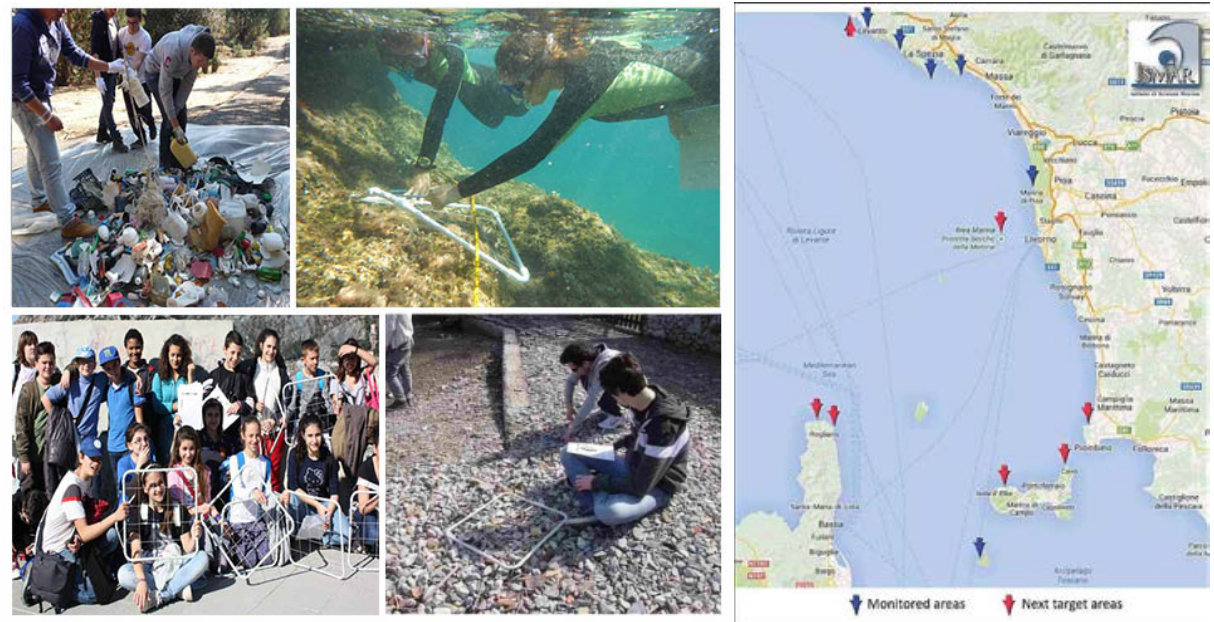

Figure 2a. Monitoring the beaches where marine litter is deposited by currents get feedback on the quantities and types of waste in our sea. Collected data will be compared with biological information investigated, in the same areas, with PVC quadrates on beach and underwater, by high and middle school students. 2b. BluePath/SeaCleaner are monitoring 6 coastal protected areas (blue arrows), surrounding a part of Mediterraneo included in the Pelagos Santuary, thanks to a network of research organizations and university, schools, marine parks and volunteers. Red arrows are next target areas.

Scientific results of this cooperation are indeed interesting, as presentation of preliminary results during European and International Conferences ${ }^{6}$; collection of

\footnotetext{
${ }^{6}$ EGU, European Geological Union, Wien, 17-21 April 2013; Congress "Ecology for a sustainable blue and green growth, Ancona, 16-18 Settembre 2013; IORC International Conference, Barcelona, 17-21 november 2014
} 
important awards and grants $^{7}$; preliminary indication about litter distribution and check list of benthic fauna and flora of studied areas (Merlino et al. 2014); but other outcomes, social and educational, shared by both projects, should be pointed out:

- hands-on experiences are successful in influencing individual behaviour for preventing and reducing, as possible, marine pollution and for perceiving the importance of environment conservation.

- synergy among very different partners (parks, researchers, local authorities, citizens, environmental centres, teachers and students) represent an effective pushpull impulse for maintaining a long lasting engagement in scientific research.

- activities carried out in parks are effective for increasing the interest and importance of these areas and to consider tangible actions aimed at preserving the environment.

- the involvement of many students and families in survey/educational/awareness activities is one of the most important output of the project, raising to spontaneous "peer education" and “inter-generational education”.

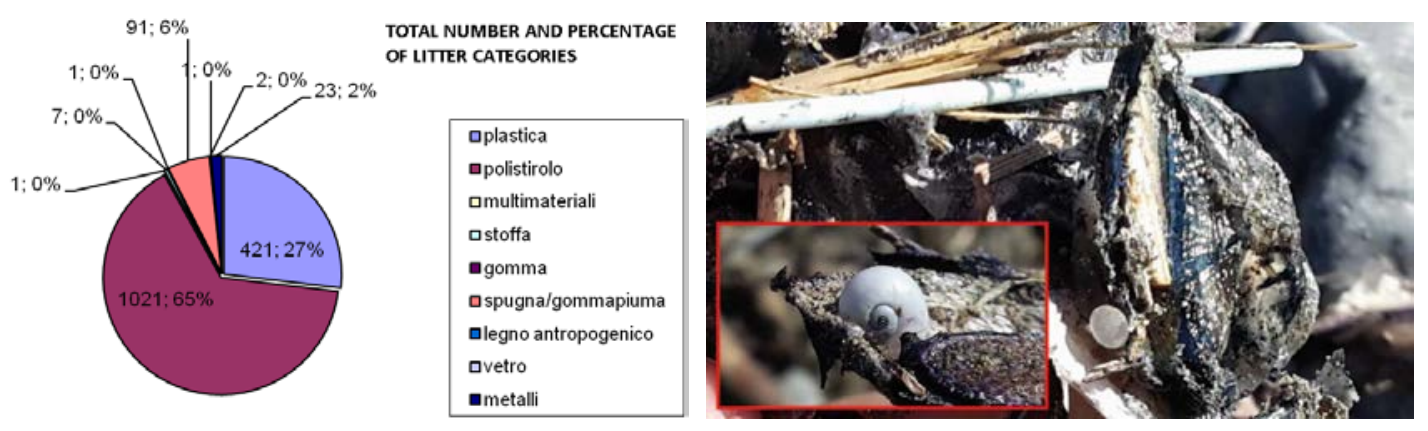

Figure 3. Examples of project's output realized by students: in the photo the bio-indicator "Janthina Palida”, frequent in Pianosa island and, in March 2015, found in Palmaria island; it is often associated with "floating rafts" formed by "Velella Velella” and polystyrene fragment/plastic pellet. The graphic shows the abundance of litter in Palmaria in the same period (March 2015): polystyrene and plastic prevail.

\section{Conclusions and further improvements}

Cooperation between the projects BluePaths and SeaCleaner show a clear example of interdisciplinary methodology in both didactic approach and scientific research; it has led students to discover little-known aspects of matters just mentioned in class, to deepen their knowledge of some aspects of the world of environmental research and computer science. The shared project not only has grown for number of students and schools, but also, now, include the membership of the Liguria District of Marine Technology, the Department of Biology of the University of Pisa, the National Institute of Geophysics and Volcanology, and MPA in Liguria and Tuscany, in order to continue in next years, with the enlargement of the network of involved organizations and schools, as well as of the areal under study. Different acquisition and analysis methods will be used (high definition photography, microscope observation) and a GIS system for data storage, maps and information will be implemented. The increasing number of adhesion of students and Parks implies a grown, day after day, of collected data: our next scientific goal would be the statistical analysis of correlations between parameters emerged from SeaCleaner survey

\footnotetext{
${ }^{7}$ Special International Award Ramoge “Alain Vatricain” 2012, EU Days for Scientific dissemination and Best-practice of workrelated learning in 1st National Convention on work-related learning, ‘Salone dell’Orientamento’ of Genoa, November 2013.
} 
(accumulation rates, fragmentation index, distributions of materials' type in different beaches etc.) and biological data on biocenosis and benthic communities provided by BluePaths survey.

As concern the educational/social goals, we are satisfied by the growing interest of the scholastic institutions towards our project. Our first goal it is not to form good scientists, but to form good citizens, and we think we are doing everything that we can to pursue it

\section{References}

UNEP, United Nations Program for Environment (2012). State of the Mediterranean Marine and Coastal Environment 2012. Highlights for Policy Makers UNEP Mediterranean Action Plan (MAP). Barcelona Convention, Athens, 2012.

Suaria G. \& Aliani S. (2014). Floating debris in the Mediterranean Sea. Marine Pollution Bulletin. 86(1-2): 494-504.

Locritani M., Furia S., Giacomazzi F., Merlino S., Mori A., Nacini F., Nardi E., Stroobant M., Talamoni R., and Zocco O. (2013). La Spezia and the research network for outreach and education in marine sciences. In: Proceedings of European Geosciences Union General Assembly. Wien: EGU 2013, April 7-12.

Fossi M.C., Coppola D., Baini M., Giannetti M., Guerranti C., Marsili L., Panti C., de Sabata E., Clò S. (2014). Large filter feeding marine organisms as indicators of microplastic in the pelagic environment: The case studies of the Mediterranean basking shark (Cetorhinus maximus) and fin whale (Balaenoptera physalus). Marine environmental research. 100: 17-24

Galgani F., Hanke G., Werner S., Oosterbaan L., Nilsson P., Fleet D., Kinsey S., Thompson R.C., van Franeker J., Vlachogianni T., Scoullos M., Mira Veiga J., Palatinus A., MatiddiM., Maes T., Korpiunen S., Budziak A. Leslie H., Gago J and Liebezeir G. (2013). Guidance on Monitoring of Marine Litter in European Seas 2013. JRC Scientific and Policy reports, European Commission.

Cheshire A.C., Adler E., Barbière J., Cohen Y., Evans S., Jarayabhand, S., Jeftic L., Jung R.T., Kinsey S., Kusui E.T., Lavine I., Manyara P., Oosterbaan L., Pereira M.A., Sheavly S., Tkalin, A., Varadarajan S., Wenneker B., Westphalen G. (2009). UNEP/IOC Guidelines on Survey and Monitoring of Marine Litter. UNEP Regional Seas Reports and Studies, No. 186; IOC Technical Series.

Cerrano C, Milanese M, Mioni E, Palma M, Pantaleo U, Previati M, Rossi G, Scinto A, Turicchia E, Ponti M. (2013). Reef Check Italia onlus: a network to improve civil participation in marine environment assessment. In: Riassunti del XXIII Congresso della Società Italiana di Ecologia (S.It.E). pp 16-18. Ancona, 16-18 September.

Merlino S., Stroobant M., Locritani M., Talamoni R., Furia S., Muccini F., Abbate M., Nacini F., Mori A. e C. Carmisciano. (2014). ALLA SCOPERTA dei TESORI del MARE: Scienza e Tecnologia, Memoria Popolare e Identità Culturale di una città della costa ligure. Miscellanea INGV. (22): 21 pp.

Newman, G., Wiggins, A., Crall, A., Graham, E., Newman, S., Crowston, K. (2012). The future of citizen science: emerging technologies and shifting paradigms. Frontiers in Ecology and Environment. 10(6): 298-304. 


\title{
Assessing the Teaching and Achieving of Research Skills
}

\author{
Henk von Eije* and Tanja Jaklofsky* \\ *Faculty of Economics and Business, University of Groningen
}

\begin{abstract}
We present a method to empirically analyse the relation between faculty wide intended learning and concomitant achieved learning outcomes. The method is applied to the Master of Science in Business Administration (MSc BA) program of the Faculty of Economics and Business (FEB) of the University of Groningen. Intended learning is measured from the students' exposure to seven research aspects taught according to course specific learning goals. The achieved learning outcomes are derived from the grades that the FEB professors gave on these research aspects when grading the students' final Master theses. We find that the intended learning of the research aspects in the MSc BA program does not benefit the students with a previous Bachelor of Science background at the FEB. However, external students with no previous FEB background do benefit from such teaching. Because of these plausible results we expect that our method may also be relevant for accreditation committees/managers of other Business Schools. Moreover, the application results may also be interesting for professors who (intend to) teach research skills.
\end{abstract}

Keywords: analysing teaching outcomes, intended learning, AACSB, research skills

\section{Introduction}

To be eligible for accreditation of the Association to Advance Collegiate Schools of Business (AACSB), a business school has to prove that it is able to achieve its targets $^{1}$. In this context we focus on the program of Master of Science in Business Administration of the Faculty of Economics and Business (FEB) of the University of Groningen. This program aims at teaching content as well as research skills. We focus here on the intended teaching of the research skills and the concomitant learning outcomes.

At the FEB the basic research skills are taught in the Bachelor of Science program, while more content specific research skills are acquired by students in the Master program. In their final thesis the students have to show that they master the research skills. These research skills are measured at the end of the Master program by grades given on seven aspects of the Master thesis. These seven aspects are also explicit in several courses that precede the Master thesis. By studying whether the exposure to the courses in the program do indeed relate to the grades that students receive on their final Master thesis, we relate intended learning to the achieved learning outcomes at the curriculum level. ${ }^{2}$

This paper contributes to the knowledge of teaching and learning in at least three ways. First, the AACSB accreditation assumes that a positive relation should exist between the intended learning outcomes and the achieved learning outcomes. Our method $^{3}$ may assist in giving evidence of such a relationship. Second, our results may be interesting for professors who teach -or intend to start to teach- research skills.

\footnotetext{
${ }^{1}$ AACSB accreditation procedures are available at the AACSB-website (AACSB International, 2013).

${ }^{2}$ Intended learning outcomes shift "the emphasis from input and process to the celebration of student learning” (Allan, 1996, p. 93). It is therefore not only important to know whether the intentions are realized per course, but also at the curriculum level (Harden, 2002).

${ }^{3}$ In contradiction to research summarized by Belland et al. (2009), we assess ultimate faculty wide targets that are incorporated within a multitude of courses. In line with some of the summarized researchers we use student grades by which to assess the curriculum.
} 
Third, we show what student groups (male/female, good or not, internal/external) benefit most of the teaching of the seven research skills.

\section{Background, data and method}

The dataset consists of students who finalized their Master program in the period 2008-2011. Students had to be exposed to courses with at least one research aspect before finalising their Master thesis and there should be an assessment form available with scores on all seven Master thesis aspects. 4 The passing grade for the thesis is a 6 and the maximum grade is a 10 (excellent), though the grade 9 (very good) is already rare. The frequency of the grades in our sample of 692 students is: 6 (sufficient, 18\%), 7 (satisfactory, 49\%), 8 (good, 28\%) and 9 (very good, 5\%). 5 The FEB target is that at least $80 \%$ of the students score standard (grade 7 ) or higher.

We measure the exposure of students to research skills teaching by analysing the actual courses that the student passed successfully. For each course with an intended teaching of research skills we know what research aspect(s) the course covers. Each of the covered aspects is then multiplied by the number of ECTS (European Credit Transfer and Accumulation System) multiplied by 28 hours for the specific course. Then all the hours for each aspect are summed over the courses that the student followed before finalising his or her Master thesis and that sum is divided by the total number of hours in the official program, namely 1680 . This means that if a research aspect is taught in a 5 ECTS course, that this aspect gets a weight of $(5 * 28) / 1680=0.0833$. A student who follows four 5 ECTS courses with this aspect, gets a weight on the relevant research aspect of $4 * 0.0833=0.333$. The average on all seven research aspects for each student is dubbed "Overall Research Skills Exposure", or ORSE. The ORSE averaged over all students is 0.322.6 The variety of the exposure to research skills teaching proves to be relatively large at the FEB. One reason for this is that the students could choose between nine programs within the MSc BA. Another reason is that quite some students started their Master program before the intended learning outcomes were instituted. A third reason is that many students followed more courses than the minimum number required.

We also know the gender of the student and whether the student was an external student, or had a Bachelor degree from the FEB. $66.8 \%$ of the student population is male and $42.3 \%$ has an external background. Students are also dichotomized in the

\footnotetext{
${ }^{4}$ The seven aspects that are used to evaluate the Master thesis are: 1) Introduction. This requires from the professor i.a. an evaluation of the initial motive and an assessment of the relevance of the problem from academic and professional perspectives. 2) Research framework. This assesses whether the problem is adequately grounded in the literature, and whether the research objective, and research questions and/or hypotheses are clearly formulated. 3) Research design. This aspect requires an evaluation of the research method and the data. 4) Analysis, discussion and/or design. This evaluates whether the research data are adequately presented, analysed, interpreted and discussed. 5) Conclusions and recommendations. This evaluates the relevance of the conclusions and whether the thesis conclusions are related to the thesis objective, and questions. 6) Report. This aspect requires that the professor evaluates whether the report is well structured and that the references are complete, consistent and that the argumentation is clear and convincing. 7) Process. Finally the professor assesses whether the student worked independently and made effective use of feedback.

${ }^{5}$ Detailed descriptive statistics of the data and additional information are available in a paper upon request.

${ }^{6}$ It is tempting to conclude that therefore on average $32.2 \%$ of the official Master time is research related. That is, however, not necessarily the case, because the relative time weights of the research aspects within a course are unknown.
} 
group of students with an average grade per previous attempt (AGPA) below the median (Low AGPA) and students with an average grade above the median (High AGPA).

\section{Analysis}

Ordered probit analysis (not reported) showed that the grades for all research aspects were significantly and positively related to the final grade on the Master thesis. Factor analysis (not reported) also showed that all seven research aspects scored high on the major factor. Therefore we measured whether the average exposure of the teaching of research skills aspects (ORSE) influenced the grades of the several student groups (not reported). This proved to be significant for the external students only. So the research skills teaching in the Master year had relevance for the students which did not get the previous FEB Bachelor's research skills training. Then we checked whether the grades given with the Master thesis on each of the seven research aspects depended on the exposure of the teaching of these aspects, on the interaction of the aspects' exposure and being an external student, and on the other two student characteristics (male/female) and (good previous performance or not). Because the grades on the research skills aspects follow an ordering from low (6) to high (9), we apply ordered probit analysis.

Table 1 shows that the exposure of internal students to teaching individual aspects is only significant for aspect 5 (conclusions and recommendations), but negatively so. External students, however, do benefit significantly from the teaching on several aspects as can be seen from the interaction of each aspect's teaching and the external students' dummy. The teaching improved external students' performance on aspect 1 (introduction), aspect 4 (analysis and discussion), aspect 5 (conclusion), aspect 7 (process) and (marginally significantly) on aspect 6 (reporting). Students with higher quality as indicated by higher average grades on previous attempts (AGPA) do perform significantly better on all aspects, while male students underperform significantly on aspects $1,2,3$ and 6. 
Table 1. The impact of aspects teaching and the grades received on the seven aspects (Asp.) with a distinction between teaching internal and external students, MSc BA cohorts 2008-2010 (p-values between parentheses)

\begin{tabular}{lrrrrrrr}
\hline & Asp. 1 & Asp. 2 & Asp. 3 & Asp. 4 & Asp. 5 & Asp. 6 & Asp. 7 \\
\hline Aspect teaching & -0.450 & 0.445 & -0.177 & 0.069 & -0.706 & -0.336 & -0.391 \\
& $(0.227)$ & $(0.212)$ & $(0.675)$ & $(0.831)$ & $(0.045)$ & $(0.348)$ & $(0.205)$ \\
& & & & & & & \\
Aspect teaching * & 1.051 & 0.236 & -0.150 & 1.262 & 1.401 & 0.876 & 1.172 \\
External student & $(0.044)$ & $(0.656)$ & $(0.788)$ & $(0.009)$ & $(0.009)$ & $(0.087)$ & $(0.012)$ \\
& & & & & & & \\
AGPA & 0.510 & 0.421 & 0.477 & 0.593 & 0.594 & 0.539 & 0.580 \\
& $(0.000)$ & $(0.000)$ & $(0.000)$ & $(0.000)$ & $(0.000)$ & $(0.000)$ & $(0.000)$ \\
& & & & & & & \\
Male & -0.189 & -0.272 & -0.222 & -0.122 & -0.140 & -0.208 & -0.074 \\
& $(0.049)$ & $(0.004)$ & $(0.019)$ & $(0.201)$ & $(0.149)$ & $(0.024)$ & $(0.433)$ \\
& & & & & & & \\
External student & -0.539 & -0.104 & -0.017 & -0.554 & -0.398 & -0.468 & -0.489 \\
& $(0.028)$ & $(0.628)$ & $(0.917)$ & $(0.005)$ & $(0.017)$ & $(0.020)$ & $(0.018)$ \\
& & & & & & & \\
\hline Observations & 645 & 645 & 645 & 645 & 645 & 645 & 645 \\
Wald Chi2 & 64.62 & 63.10 & 63.82 & 104.46 & 94.06 & 88.74 & 98.37 \\
P (Wald Chi2) & $(0.000)$ & $(0.000)$ & $(0.000)$ & $(0.000)$ & $(0.000)$ & $(0.000)$ & $(0.000)$ \\
Pseudo R2 & 0.057 & 0.040 & 0.044 & 0.064 & 0.067 & 0.059 & 0.059 \\
\hline
\end{tabular}

\section{Conclusions}

We analyse the relation between intended learning outcomes and achieved learning outcomes of the MSc BA program of the Faculty of Economics and Business (FEB) of the University of Groningen. We focus on the intended teaching exposure that students received on seven research skills. We relate the teaching exposures to research skills received by individual students to the concomitant grades that they received on their final Master thesis. All research skills aspects are important in generating the grade for the final thesis. However the teaching of research skills does not influence the grade on the Master thesis positively, except for the students with no Bachelor background at the FEB.

These results would make it important for the FEB management to consider if the teaching of research skills should be improved for internal students, or whether it is satisfied with the low research skills benefits for internal students (who still have learned specialization specific content) and the positive benefits of teaching research skills for the external students. This choice was however not explicitly made, as there has been an overhaul of the program that focused even more explicitly on research driven education. We therefore suggest that the current research is repeated for the FEB in the future and at a less ad-hoc basis (Moskal, 2008). Such a research would, moreover, become more precise if explicit knowledge were available on the amount of time spend on teaching the several aspects in each course.

Also other Business Schools might benefit from our research, if they want to analyse the results of their teaching on a curriculum level, by applying a similar method. We 
show that this can be done without having recourse to assessments made by students on how much they learned from these aspects in separate courses. If there is a relatively large variety of courses available from which students can choose, our method gives quantitative results which may help the boards of directors to pinpoint teaching weaknesses and to improve teaching quality. Finally, we also think that professors who (intend to) teach research can benefit from this research.

\section{References}

AACSB International (2013), AACSB Assurance of Learning Standards: An Interpretation, AACSB International, Tampa.

Allan, J (1996), Learning Outcomes in Higher Education, Studies in Higher Education, 21 (1), 93-108.

Belland, B.R, et al (2009), Validity and Problem-Based Learning Research: A Review of Instruments Used to Assess Intended Learning Outcomes, Interdisciplinary Journal of Problem-Based Learning, 3 (1), 59-89.

R.M. Harden (2002), Learning outcomes and instructional objectives: is there a difference? Medical Teacher, 24 (2), 151-155.

Moskal, P., et al. (2008), Summary of Assessment in Higher Education and the Management of Student-Learning Data, Academy of Management Learning and Education, 7 (2), 269-278. 
HEAd'15

SESSION 6B

MOBILE LEARNING 


\title{
Smartphone: a new device for teaching Physics
}

\section{J. A. Sans, F. J. Manjón, V. Cuenca-Gotor, M. H. Giménez-Valentín, I. Salinas, J. J. Barreiro, J. A. Monsoriu, and J. A. Gomez-Tejedor*}

\author{
Departamento de Física Aplicada, Escuela Técnica Superior de Ingeniería del Diseño, \\ Universitat Politècnica de València, Camí de Vera s/n, 46022 València (Spain), ${ }^{*}$ jogomez@fis.upv.es
}

\begin{abstract}
This paper reports on the use of smartphone's sensors to perform several experiments designed to teach fundamentals of Physics. We have adapted traditional physics laboratory sessions to the use of the different sensors that can be found in a typical smartphone, such as an accelerometer, and light and magnetic field sensors. The existence of a large repository of free AndroidTM and AppleTM applications which exploit the characteristics of these sensors facilitates the design of new experiments. A survey was done to the students in order to obtain feedback and to evaluate the success of the experience. The results of the survey showed a good acceptance of this method triggering their curiosity, with an average mark of 9 over 10. This project offers to the student a new way to think on smartphones as an attractive tool for possible application in experimental measurements and scientific demonstrations and not only as a socializing tool.
\end{abstract}

Keywords: Smartphone, Physics, Lab practice

\section{Introduction}

The use of portable devices in all teaching levels of Physics has increased significantly in the past decade. Sensors found in these new electronic devices can be used as new instruments and detectors in experimental measurements in the Physics laboratory. For instance, digital cameras, ${ }^{1}$ webcams, ${ }^{2}$ optical computer mice, ${ }^{3,4}$ Wii classic controller, ${ }^{5}$ Xbox Kinect sensor ${ }^{6}$ and other video game console controllers ${ }^{7}$ have been already exploited. In this respect, Wiimote and Xbox Kinetic sensor are the most outstanding controllers to be considered since they can be applied to several Physics experiments. ${ }^{8}$ The use of the Wiimote allows tracking several objects simultaneously by Bluetooth connection thanks to the use of three axis accelerometers which describe the trajectory of the objects in 3D. Additionally, the Xbox Kinect sensor includes the timeline parameter to 3D positioning. The main drawback of these devices is that they require specific software and are not widely available in the Physics laboratory. On the contrary, the use of mobile phones among young people is widely spread and the constant evolution of their technology, as well as the availability of free applications, makes them an attractive tool to perform experimental measurements and scientific demonstrations.

Recently, our group has worked in the use of the different smartphone's sensors on Physics experiments. For instance, we exploited the use of the smartphone's digital gyroscope to study a system of coupled oscillators ${ }^{9,10}$ and presented a similar study using the smartphone's ambient light sensor. ${ }^{11}$ Additionally, we used the smartphone's microphone to measure Doppler effect in sound waves. ${ }^{12,13}$ This background has allowed us to design and perform new experiments based on the smartphone's sensors previously described and even propose new experiments using the magnetic field sensor in order to explore the Physics of Electromagnetism. 


\section{Methods}

We have designed three different experiments in order to exploit the characteristics of the accelerometer, ambient light and magnetic field smartphone's sensors. The experiments are designed to cover different Physics fields leading from oscillatory movement, optics, and electromagnetics. All these experiments are based on classical lab practices, whose functioning have been tested along several years. The experiments proposed are:

\section{Experimental setup to characterize spring properties with the accelerometer sensor}

The use of the accelerometer sensor is suitable for experiments when the variation of the speed is decisive to characterize a certain physical magnitude. In this case, we propose the description of the oscillatory movement produced by a weight attached to a spring.

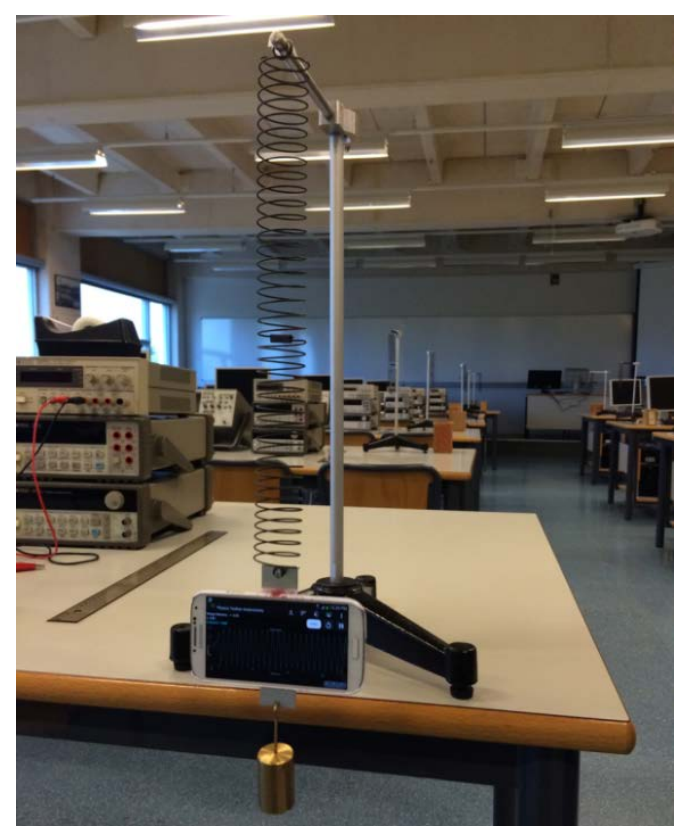

Figure 1. Picture of the experimental setup designed to measure the properties of the spring using the accelerometer sensor of the smartphone

The modification of the classical experimental setup consists in the introduction of a smartphone between the spring and the calibrated weight. The smartphone is glued with double-sided pressure-sensitive tape (or Scotch tape) to a thin aluminium sheet. The top extreme of the sheet is attached to the spring while on the bottom extreme of the sheet there is a hole for hanging the weights (see Fig. 1).

The oscillatory movement along the vertical axis $(z)$ of an object with mass $m$ hanged up to a spring with stiffness $k$ and shifted with respect to the equilibrium position is described by the simple harmonic movement equations:

$$
z(t)=A \sin \left(\omega_{0} t+\varphi\right)
$$




$$
T=\frac{2 \pi}{\omega_{0}}
$$

where $A$ is the shift amplitude, $\varphi$ is the initial phase and $\omega_{0}$ is the angular frequency, which is related to the oscillation period $T$ by Eq. (2). Once the frequency of the simple harmonic movement is known, the spring constant $k$ can be calculated using the following expression:

$$
k=m \omega_{0}^{2}
$$

The use of different calibrated weights allows obtaining an accurate value of the spring constant by a linear least-square fit of the square of the period of the oscillatory movement as a function of the corresponding weight of the system.

$$
T^{2}=\frac{4 \pi^{2}}{k} m
$$

\section{Experimental setup to measure the variation of the light intensity as a function of the distance to a light source using the ambient light sensor}

The smartphone's ambient light sensor allows adjusting the brightness of the screen to the environmental light in order to save battery and adequate the maximum visibility to the existent conditions. This ambient light sensor acts as a luxometer and there are several applications which allow determining in a quantitative way the light power measured by this sensor.

The experimental setup we propose for measuring the variation of the light intensity as a function of the distance to a light source is composed by a light source (dichroic halogen lamp without focusing optics) and a rule to measure the distance from the light source to the smartphone's ambient light sensor (see Fig. 2). With this simple setup it is possible to evidence the inverse proportionality between the light intensity and the square of the distance between the light source and the sensor. Care must be taken when using dichroic halogen bulbs since they cannot be touched with bare hands (neither before nor after its use). Note that, on one hand, bulbs can be poisoned when handled inappropriately, and, on the other hand, one can be burned if lamp is touched after its use because of the very high temperatures reached by the lamp filament. In this respect, we consider much better the use of high intensity light emitting diodes (LEDs) for the present experiment.

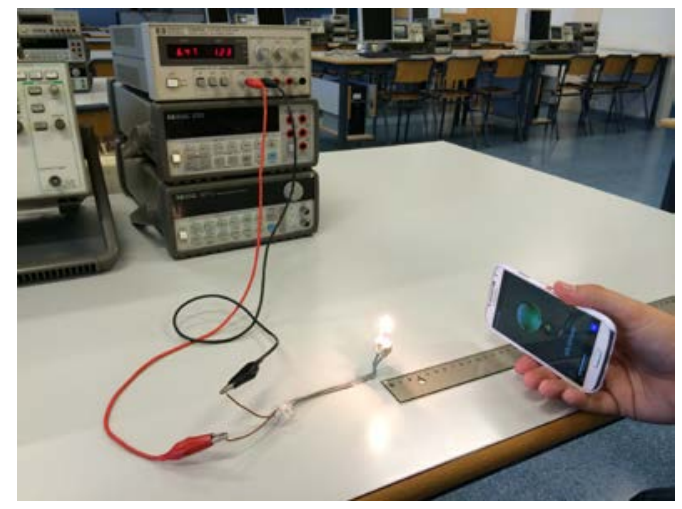

Figure 2. Picture of the experimental setup designed to measure the variation of the light intensity with the distance using the ambient light sensor of the smartphone. 
If we consider our lamp as a point light source, the radiation emitted by this one is spread by means of a spherical wave front. The ambient light sensor is considered as well as a point detector, due to their small area compared with the total spherical wave front. In this way, the intensity detected by the sensor is the light power of the lamp divided by the sphere area corresponding to the distance at which the sensor is placed. The light intensity measured by the smartphone at each distance will follow the inverse square law with the distance as follows:

$$
I(d) \propto I_{0} \frac{1}{d^{2}}
$$

\section{Experimental setup to measure the direction of the magnetic field induced by a DC electrical current in a linear wire}

Typically, smartphones contain three magnetic sensors perpendicular to each other. These sensors allow orienting the screen with respect to the Earth's magnetic field, which is very useful in navigation applications. We have used these sensors to describe the Oersted's experiment; i.e., to show how the direction of the magnetic field at the smartphone's location can change when the magnetic field induced by a continuous electrical current is added to the Earth's magnetic field. This experiment shows the relationship between electric and magnetic fields and was the origin of Electromagnetism.

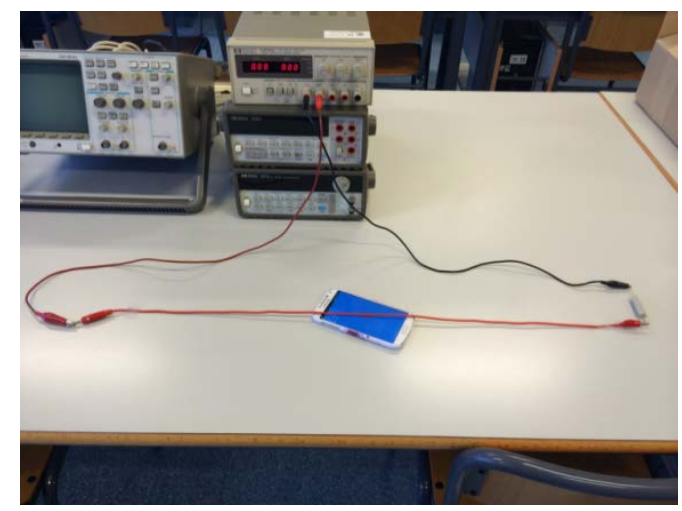

Figure 3. Picture of the experimental setup designed to measure the variation of the light intensity with the distance using the ambient light sensor of the smartphone.

In our setup, we plug a long linear wire and a serial resistance to a DC power supply. Then, we place the wire crossing over the smartphone's magnetic sensor in such a way that the wire is parallel to the direction of the Earth's magnetic field, as it is shown in Fig. 3. In this way, the direction of the magnetic field induced by the DC electrical current (obtained following the well-known right-hand rule) is perpendicular to the Earth's magnetic field and the deviation of the needle of the digital compass in the app (once the DC current is set on) is maximally visualized. 


\section{Results and Discussion}

\section{Periodic oscillatory movement}

We have used the free "Physics Toolbox Accelerometer" application to record the oscillatory movement exhibited by the system (smartphone + weights) as can be observed in Fig. 4(a). The curves plotted in the application allow determining the period (and frequency) of the system for different weights. Experimental data visualized in Fig. 4(a) show a weak damping that can be neglected as a first approximation. The period of the oscillation and the mass of the system are the parameters used to fit to Eq. (4), where a regression coefficient $\mathrm{R}^{2}$ higher that 0.995 was obtained in all cases, thus indicating the good quality of the data (see Fig. 4(b)).
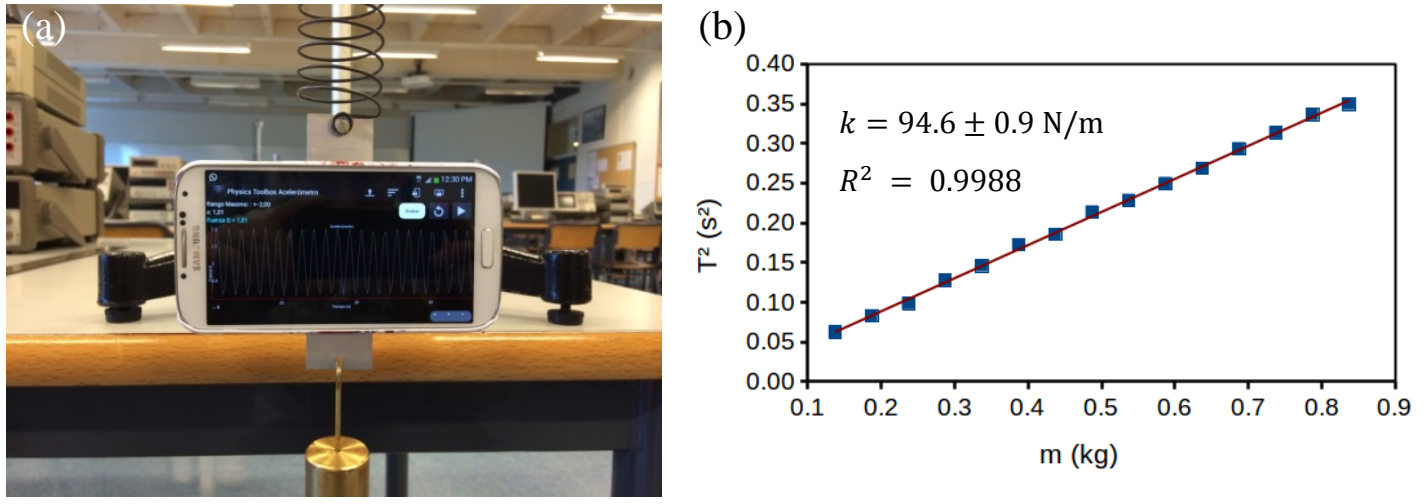

Figure 4. (a) Picture of the experimental curve obtained in the smartphone. (b) Fit of the experimental data to equation 4 to obtain a realistic value of the stiffness of the spring

\section{Inverse square law of light intensity vs distance}

We have used the "light sensor" section of the free application "Android sensor box". This application does not allow recording the intensity for each distance but we propose the students to plot the intensity value obtained as a function of the detector-source distance. The experimental intensity as a function of the inverse of the square of the detector-source distance will follow a linear trend line, as shown in Fig. 5(b).

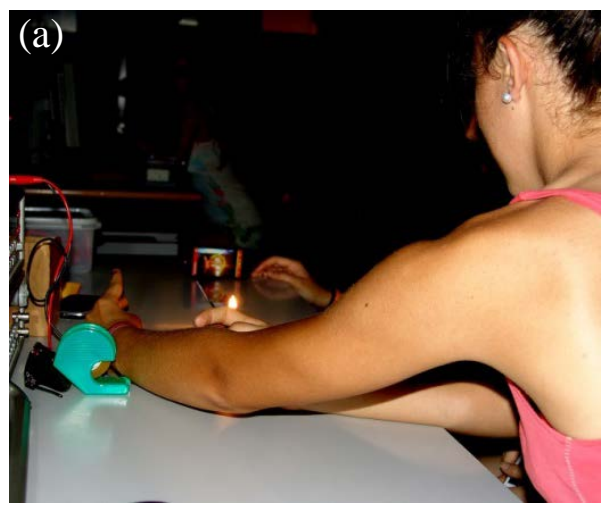

(b)

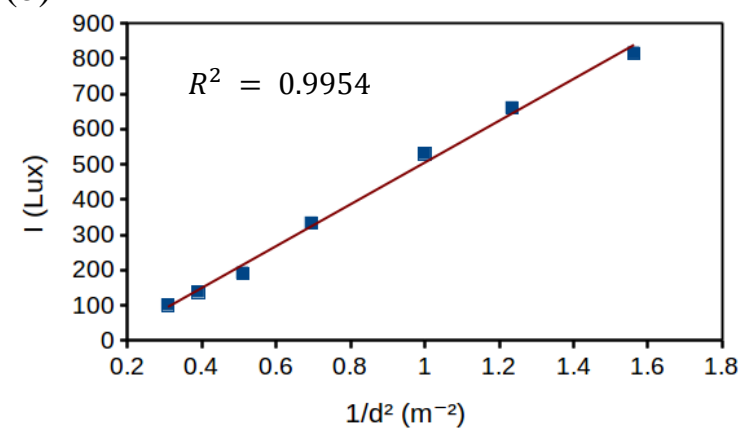

Figure 5. (a) Picture of the practice performed by students. (b) Experimental evolution of the intensity with inverse of the square of the detector-source distance. 


\section{Oersted's law experiment}

Unlike the previous two experiments proposed, the Oersted's law practice is only qualitative. Here, students are guided to identify the close relationship between electric and magnetic fields. The free application used to perform this experiment is "Magnetic Field Sensor". The introductory part of the practice serves to explain to the students how the magnetic field's lines turn around a linear wire.

First of all, students are told to find the position of the magnetic sensors in their smartphones. This could be done by rotating the speaker of a smartphone around another smartphone fixed with the application running or with the help of a small neodymium magnet. The position at which the magnetic flux is maximum determines the location of the sensor. Note that in case of using the neodymium magnet, magnet should not be placed too close to the smartphone in order to avoid interference of the strong magnetic field of the magnet with the inner processes of the own smartphone.

After knowing the position of the magnetic field sensor in each smartphone, students are triggered to place the linear wire crossing it, as shown in Fig. 3. At that moment, we encourage students to change the intensity and direction of the electrical current and study the variation in the orientation of the needle of the digital compass shown by the application.

\section{Report of the survey}

In order to obtain feedback from the students for improvement of the proposed lab experiences using smartphones, we designed a survey to elucidate the impact of these lab sessions on students. In general, we can appreciate a very good acceptance of the lab sessions by students with an average assessment of the sessions of 9 points over 10 (see Table 1). This result corresponds to the survey done to 30 students.

Table 1. Survey results obtained from students

\begin{tabular}{|l|c|}
\hline Application field of the question & $\begin{array}{c}\text { Average } \\
\text { (Mark over 10) }\end{array}$ \\
\hline 1: Teachers seemed to dominate the session's subject. & $\mathbf{9 . 7 5}$ \\
\hline 2: Teachers have solved every question with accuracy and clarity. & $\mathbf{8 . 2 1}$ \\
\hline 3: Teachers encouraged me to participate in the session. & $\mathbf{8 . 2 9}$ \\
\hline 4: Teachers achieved to stir my interest for the session's subject. & $\mathbf{7 . 3 8}$ \\
\hline 5: Session's objectives have been clearly exposed at the beginning. & $\mathbf{8 . 7 4}$ \\
\hline 6: Session's contents fit the general subject of the global project. & $\mathbf{6 . 7 5}$ \\
\hline 7: Duration of the session was suitable to the experiments proposed. & $\mathbf{8 . 3 8}$ \\
\hline 8: Methodology employed and activities were adequate. & $\mathbf{9 . 1 7}$ \\
\hline 9: Material used was adequate. & $\mathbf{9 . 4 6}$ \\
\hline 10: My average evaluation of the session is good. & $\mathbf{9 . 0 0}$ \\
\hline
\end{tabular}




\section{Conclusions}

The different sensors available in smartphones are useful tools for possible applications in experimental measurements and scientific demonstrations as we have proved along this article. The lab practices here designed cover different Physics areas and open the door to students to carry out their own experiments at home by exploiting the technology implemented in their smartphones. Here, we have presented the development of classical Fundamental Physics Lab practices using three different sensors of the smartphone. These practices were tested by students who passed a survey in order to check the validity of the experiences. The results of the survey show the success in the objectives proposed and the warm welcome of the experiments designed.

\section{Acknowledgements}

Authors would like to thank the Institute of Education Sciences of the Universitat Politècnica de València (Spain) for support of the Teaching Innovation Groups MoMa and e-MACAFI and for the financial support through PIME Project PIME/2014/A/031/B. J.A. Sans thanks “Juan de la Cierva” fellowship program for financial support and Instituto de Diseño para la Fabricación y Producción Automatizada de la Universitat Politècnica de València (Spain) for let him to get a venia docendi at the Departamento de Física de la Universitat Politècnica de València (Spain).

\section{References}

Monsoriu, J. A., Giménez, M. H., Riera, J., \& Vidaurre, A. (2005). Measuring coupled oscillations using an automated video analysis technique based on image recognition. European Journal of Physics, 26, 1149-1155.

Shamim, S., Zia, W., \& Anwar, M. S. (2010). Investigating viscous damping using a webcam. American Journal of Physics 78, 433-436.

Romulo, O. O. \& Franklin, K. N. (1997). The computer mouse as a data acquisition interface: Application to harmonic oscillators. American Journal of Physics 65, 1115-1118.

Ng, T. W. \& Ang, K. T. (2005). The optical mouse for harmonic oscillator experimentation. American Journal of Physics 73, 793-795.

Tomarken, S. L., Simons, D. R., Helms, R. W., Johns, W. E., Schriver, K. E. \& Webster, M. S. (2012). Motion tracking in undergraduate physics laboratories with the Wii remote. American Journal of Physics 80, 351-354.

Ballester, J. \& Pheatt, Ch. (2013). Using the Xbox Kinect sensor for positional data acquisition. American Journal of Physics 81, 71-77.

Vannoni, M. \& Straulino, S. (2007). Low-cost accelerometers for physics experiments. European Journal of Physics 28, 781-787.

Skeffington, A. \& Scully, K. (2012). Simultaneous Tracking of Multiple Points Using a Wiimote. The Physics Teacher 50, 482-484.

Castro-Palacio, J. C., Velázquez-Abad, L., Giménez, F. \& Monsoriu, J. A. (2013). A quantitative analysis of coupled oscillations using mobile accelerometer sensors. European Journal of Physics 34, 737-744. 
Castro-Palacio, J. C., Velázquez-Abad, L., Serrano, M. H., \& Monsoriu, J. A. (2013). Using a mobile phone acceleration sensor in physics experiments on free and damped harmonic oscillations. American Journal of Physics 81, 472-475.

Sans, J. A., Manjón, F. J., Pereira, A. L. J., Gómez-Tejedor, J. A., \& Monsoriu, J. A. (2013). Oscillations studied with the smartphone ambient light sensor. European Journal of Physics 34, 1349-1354.

Gómez-Tejedor, J.A., Castro-Palacio, J.C., \& Monsoriu J.A. (2014). The acoustic Doppler effect applied to the study of linear motions. European Journal of Physics 35 (2), 25006-25015.

Gómez-Tejedor, J.A., Castro-Palacio, J.C., \& Monsoriu J.A. (2015). Frequency Analyser: A New Android Application for High Precision Frequency Measurement. Computer Applications in Engineering Education. DOI 10.1002/cae.21618 


\title{
The Use of Mobility and Social Media to Improve Student Involvement
}

\author{
S. N. Baldridge, A. W. Roberts, A. J. Reed, A. C. Ellard \\ Abilene Christian University
}

\begin{abstract}
The present study examined the effects of integration of mobile technologies and social media through the lens of remote teaching on quality and quantity of student interactions. Classroom interactions were observed over two academic semesters with a separate group of students each semester. The sampling frame included college students enrolled in a social sciences introductory course. Students comprised two separate groups, based on the course they attended. Group 1 included the students in the fall semester of the course. Group 2 included the students in the spring semester of the course.
\end{abstract}

A paired samples $t$ test was completed for the total sample (Groups 1 and 2) frequency of comments. This showed no significant difference between the frequency of in class $(M=3.71, S D=4.418)$ and online $(M=5.31, S D=2.309)$ student comments $(p=.055)$. A paired samples $t$ test was also completed for the total sample (Groups 1 and 2) quality of comments. This showed a statistically significant difference between the quality of in class $(\mathrm{M}=1.78, \mathrm{SD}=1.037)$ and online $(\mathrm{M}=2.36, \mathrm{SD}=0.519)$ student comments $(\mathrm{p}<.05)$.

Keywords: Social Media, mobile learning, interaction

\section{Introduction}

Mobility and means of communication are increasing as an array of devices and media outlets expand the interconnectedness of individuals. Incorporation of familiar mobile technologies instantly expands the classroom beyond the geographical location of the learner to include the diverse expanse of expertise available through mobile devices. This is especially true when compared with traditional lecture-based teaching models.

Beyond inclusion of mobile devices in the educational setting, social media provides a forum for dissemination of information. Students are able to utilize the ubiquitous technology to access networking sites that are increasingly becoming a component of daily interactions. Integration of social media through mobile devices into the educational setting allows for increased instantaneous communication, feedback and information dissemination for the educator and learner alike.

The present study examined the effects of integration of mobile technologies and social media through the lens of remote teaching on quality and quantity of student interactions. The researchers observed student interactions on social media facilitated by educator and interactions within the traditional classroom structure.

\section{Mobile learning}

As technology is constantly evolving and the breadth of mobile technology is vast, it is difficult to form a distinct, all-encompassing definition of mobile learning. However, a working definition of mobile learning utilized for this study will be, “...learning by means of wireless technological devices that can be pocketed and utilized wherever the learner's device is able to receive unbroken transmission signals" (El-Hussein, Osman, \& Cronje, 2010, p. 12). The devices utilized in mobile learning encompass personal electronic devices such as laptops, tablets, smart phones, and compatible media players (Baldridge, Reed, \& Knettle, 2013). In order for mobile learning to be constructive for 
students, the student must actively participate, utilizing a mobile device. El-Hussein, Osman, and Cronje (2010) identify the "mobility of technology, mobility of learner, and mobility of learning (p. 17)" as key components of mobility in the educational setting. However, other sources include that mobile learning may be conducted within the confines of the classroom, merely using mobile devices for information dissemination and student participation (Baldridge et al, 2013). With the increasing rate of mobile device ownership, with $98 \%$ of students owning at least one mobile device dating back to a 2007 study (Diamanduros, Jenkins, \& Downs), it is important to assess the utility of mobile technology in higher education. The incorporation of this seemingly ubiquitous technology into educational settings appears to hold great promise for the advancement of the traditional classroom, incorporating mobility and learner-centered instruction.

\section{Remote teaching}

An extension of mobile learning that has been relatively uncharted is the concept of remote teaching. This study will utilize an adapted definition of remote teaching from Baldridge, Reed, and Knettle. (2013) being: The use of mobile devices to deliver course content remotely, without the necessity of face-to-face interaction. Remote teaching employs many of the same characteristics as distance education in that remote teaching is mediated, collaborative learning between the professor and students separated from one another by location (Moore, Dickson-Deane, \& Galyen, 2011). Remote teaching offers a unique educational experience as mobile devices are utilized to relay information, mediate discussion, and facilitate active learning. Remote teaching could take place in both face-to-face teaching models as well as integrated into online courses.

Utilization of current mobile learning techniques in combination with distance learning principles can form a basis for foreseeable benefits of remote teaching in educational settings. Interactive capabilities of social networking sites can be employed to encourage an open learner-centered environment merely facilitated by the distant educator. For example, the use of Twitter through mobile technology is beginning to be explored to facilitate discussion and interaction outside of the traditional classroom (Dunlap \& Lowenthal, 2009; Rinaldo, Tapp, \& Laverie, 2011). A student utilizing Twitter for course interaction tweeted a question pertaining to course material, to which she received responses from professionals within the field of question who were thoroughly educated on the distinct topic at hand (Dunlap \& Lowenthal, 2009). Incorporating the use of such media and social networking capabilities allows students to actively participate in seeking information from a source outside of the classroom, making the professor the facilitator of education, but not the primary source of all information (Baldridge et al, 2013). Students are able to access primary source information that otherwise may not have been available in the traditional lecture method.

\section{Social media}

With the evolution and expansion of social media, the growing number of social media outlets makes the term difficult to inclusively define. For the purpose of this study, a definition by Junco, Heiberger, and Loken (2011) will be used: "Social media are a collection of Internet websites, services, and practices that support collaboration, community building, participation, and sharing” (as cited in Joosten, 2012, p.9). 


\section{Methods}

The present study was an exploratory study to compare the frequency and quality of student comments for both in-classroom discussions and remote teaching through social media. For the in-classroom discussions, the professor utilized traditional pedagogy through both the lecture and active models of classroom learning. Lessons typically consisted of traditional lecture, small group interaction/discussion, and project-based learning.

For the remote teaching, the professor utilized the social media site Facebook, and allowed students to determine whether to interact on mobile phones, tablets, or in rare instances, on laptop computers. The remote teaching lessons typically consisted of facilitating both synchronous and asynchronous discussions via Facebook. Discussions took place both in class (i.e. during a film, while students were completing community based projects) or outside of class based on course content. Additional lessons included mobilizing the students to locations outside of class and pushing/receiving content with the class on the course Facebook page. Lessons were based on current best remote teaching pedagogy as defined in the literature (Baldridge et al, 2013).

The Facebook remote teaching was facilitated through a class group page, and students joined the page prior to the remote class meetings. A researcher other than the course professor conducted observations of the student interactions. Frequency of student comments was calculated manually. Quality of student interactions was based on a rubric adapted from John Immerwahr (2008) resulting in a rating of one to three. Scores of one indicated lower levels of quality while scores of three indicated high levels of quality in student discussion/interaction.

\section{Sample}

The population for this study included students attending a mostly traditional, residential, faith-based liberal arts university in Texas. The sampling frame included college students enrolled in a social sciences introductory course during the 2013 academic year. This sampling frame yielded 41 (\# of students enrolled in the course). Students that did not complete the course or did not want to participate in the study were not included in the sample.

Students comprised two separate groups, based on the course they attended. Group 1 included the students in the fall semester of the course. Group 2 included the students in the spring semester of the course.

\section{Human subjects protection}

Students were given the option to participate in the study, and participation was not required for course completion. All students who chose to participate in the study signed a participation and confidentiality agreement before participating therein. Students were provided both written and verbal confirmation that participation in the study would not have an effect on the individual's grade. No incentives were given to students that chose to participate in the study.

\section{Instrumentation and procedures}

Data were gathered into Google documents and exported to Excel. Data were analysed through the Statistical Package for the Social Sciences (SPSS). In SPSS, frequency and $t$ test analyses were completed. Data was analyzed at the .05 level of significance. 


\section{Data collection}

Classroom interactions were observed over two academic semesters with a separate group of students each semester. Students from both semesters were enrolled in the same course. The content in both semesters of the course was identical. In addition, the same professor and research observer were used for both semesters to ensure consistency in the course content and comment evaluation. The research observer attended every class meeting in order to prohibit students from knowing which class discussions were and were not being rated.

\section{Classroom observation}

Student comment frequency and quality were rated during the classroom discussions.

\section{Online observation}

Online discussions were rated for student comment frequency and quality after interactions were complete.

\section{Results}

\section{Frequency of student comments}

Frequencies were calculated for the number of student interactions both in the classroom and remotely online. As Table 1 indicates, the average number of interactions for both Group 1 and Group 2 were higher for the online discussions as compared to the in class discussions.

Table 1. Frequencies of the Number of Student Comments

\begin{tabular}{|r|l|l|l|l|l|}
\hline & $\mathrm{N}$ & Mean & Median & Mode & SD \\
\hline Classroom & & & & & \\
\hline Group 1 & 22 & 3.46 & 1.37 & $.00 *$ & 4.658 \\
\hline Group 2 & 18 & 2.91 & 1.00 & .00 & 3.573 \\
\hline Online & & & & & \\
\hline Group 1 & 22 & 5.53 & 4.33 & 4.33 & 2.607 \\
\hline Group 2 & 19 & 5.78 & 4.66 & 4.00 & 3.370 \\
\hline
\end{tabular}

*More than one mode was found, and the lowest mode was reported.

A paired samples $t$ test for Group 1 revealed no statistically reliable difference exists between the average frequency of comments between in class $(\mathrm{M}=4.53, \mathrm{SD}=5.066)$ and online $(\mathrm{M}=5.33, \mathrm{SD}=2.011)$ comments $(\mathrm{p}=.499)$. However, for Group 2 a paired samples $t$ test revealed a statistically significant difference between the frequency of in class $(M=2.90, S D=3.643)$ and online $(M=5.29, S D=2.641)$ comments $(\mathrm{p}<.05)$.

A paired samples $t$ test was completed for the total sample (Groups 1 and 2) frequency of comments. This showed no significant difference between the frequency of in class $(\mathrm{M}=3.71, \mathrm{SD}=4.418)$ and online $(\mathrm{M}=5.31, \mathrm{SD}=2.309)$ student comments $(\mathrm{p}=.055)$. 


\section{Quality of student comments}

Frequencies were calculated for the quality of student interactions both in the classroom and remotely online. As Table 2 shows, the average student comment quality for both Group 1 and Group 2 was higher for the online discussions as compared to the in class discussions.

Table 2. Frequencies of the Quality of Student Comments

\begin{tabular}{|c|l|l|l|l|l|}
\hline & $\mathrm{N}$ & Mean & Median & Mode & SD \\
\hline Classroom & & & & & \\
\hline Group 1 & 22 & 1.69 & 1.71 & .00 & 1.266 \\
\hline Group 2 & 18 & 1.61 & 1.75 & .00 & 1.038 \\
\hline Online & & & & & \\
\hline Group 1 & 22 & 2.19 & 2.12 & $1.44^{*}$ & .450 \\
\hline Group 2 & 19 & 2.49 & 2.65 & $1.81^{*}$ & .529 \\
\hline
\end{tabular}

*More than one mode was found, and the lowest mode was reported.

A paired samples $t$ test for Group 1 revealed no statistically reliable difference exists between the mean average quality of comments between in class $(\mathrm{M}=1.87, \mathrm{SD}=1.085)$ and online $(\mathrm{M}=2.24, \mathrm{SD}=.449)$ comments $(\mathrm{p}=.187)$. However, for Group 2 a paired samples $t$ test revealed a statistically significant difference between the quality of in class $(\mathrm{M}=1.68, \mathrm{SD}=1.012)$ and online $(\mathrm{M}=2.48, \mathrm{SD}=.569)(\mathrm{p}<.05)$.

A paired samples $t$ test was completed for the total sample (Groups 1 and 2) quality of comments. This showed a statistically significant difference between the quality of in class $(\mathrm{M}=1.78, \mathrm{SD}=1.037)$ and online $(\mathrm{M}=2.36, \mathrm{SD}=0.519)$ student comments $(\mathrm{p}<.05)$.

\section{Discussion}

While the current study was relatively small and isolated, the implications it presents to teaching pedagogy (both face-to-face as well as teaching incorporating the utilization of many types of media and technology) are noteworthy.

\section{Frequency of student interactions}

As detailed previously, the cumulative number of interactions between online discussion and face-to-face discussion with students was not significant. This, however, should not be interpreted as an indictment on using social media to facilitate learning. It should be considered that using social media paired with mobility actually increases the opportunity for instructors to conduct class outside of the traditional four walls of the classroom. While tradition (even active learning tradition) may dictate class only takes place between certain hours each week in a physical location, the initial findings of studies such as this indicate that learning can take place without students being in the physical classroom (referring to face-to-face classroom models). Utilizing social media to facilitate synchronous communication between instructor and students actually provides a more direct and effective way to engage in active learning as defined 
in the review of literature by Malik \& Janjua, (2011). By enabling discussion to take place wherever students are, this study suggests that there is no differentiation between being face-to-face with a professor and being engaged in social media discussion regarding the frequency of in-class interactions. Instructors can expect a similar amount of discussion to take place whether students are in class or anywhere else physically (even around the world). This opens the door for many possibilities of active learning, including, but not limited to instructors teaching students engaged in community based learning projects, students located at internships away from campus, teaching while instructors are traveling, or engaging students in lessons that require them to be in different locations. By allowing the instructor to give and receive information from students regardless of location, possibilities are great in the amount and quality of active learning that can take place.

Another implication of these results pertains to the use of asynchronous learning. While these results were largely collected during class hours, the use of most online platforms (including Facebook or other social media outlets) can remove the requirement for synchronous learning. Face-to-face classes rely exclusively on immediate discussion and feedback. Based on the lack of difference between the number of interactions during class both on social media and in a physical classroom discussion as measured by this study, it is possible to expect that the number of interactions would possibly increase throughout the time students are outside of class. An example of this may be a student who thinks of a comment after class is over. In an exclusive face-to-face environment, they would not be able to make this comment to the group. By using online platforms as described in this study, however, students can literally comment on class content 24 hours a day, 7 days a week. This is even possible after the semester is over.

\section{Quality of interaction}

Possibly some of the most important implications from this study are suggested by the significant difference in the quality of interactions between the face-to-face discussions and the discussions facilitated via social media. As discussed in the review of the literature, active learning is the active synthesis and evaluation of information (Malik \& Janjua, 2011), within the context of a classroom or group environment. Active learning as a group or a class is contingent upon discussion and quality synthesis of information as a collective. This simply cannot take place without students being willing to speak (quantity of comments). In addition to this, it could be argued that an even more important aspect of the active model is that it cannot happen without a certain depth and quality of conversation. If the active model is truly seeking to help learners construct their own knowledge (as opposed to accepting that of the instructor), quality of integration is essential (Cojocariu, 2010). While it may not be responsible or accurate to state definitively that moving class discussion to social media would accomplish higher levels of active learning, the results of this study suggest that moving aspects of class discussion and activity to these platforms could greatly enhance students' abilities to be involved in deep, meaningful conversations with one another, as well as the instructor, about class content. By limiting class conversations to face-to-face alone, instructors may be missing out on a vital aspect of communication that is prevalent today and could be used to bring about a greater level of learning and synthesis than traditional pedagogy would dictate. 


\section{Conclusions}

The results of this study extend beyond those discussed above. Based on the initial findings, there are important implications to consider in the area of teaching, research, and policy.

\section{Teaching}

Learning has traditionally been contingent upon the instructor's own knowledge or experience; students could only learn what the instructor already knew. By incorporating different learning methodologies as described in this study, however, learning can be shaped and influenced not only by the instructor, but by the other students as well. Instead of simply lecturing about class content, the instructor now has the option of sending the class out of the classroom to experience the content first hand, all while staying in synchronous contact with one another and the instructor. In the hard sciences this could be realized by having students go observe a natural phenomenon in person, and communicate with one another about the experience. In the social sciences this could take the shape of students going and working directly with a population instead of simply learning how to work with said group. With the ability to push and gather information to and from students, the possibilities for learning are greatly expanded. The results of this study suggest that quality and quantity of interactions may not be decreased (or may actually be increased in some circumstances) and allow for instructors to take a much more passive role in relaying information to their students, along with enabling them to have students discuss and interact with course content on several different levels (without a loss of quality). This could be attributed to students feeling a part of a community with fellow learners due to being involved in both a faceto-face setting (class) as well as an online setting (social media). These results are consistent with the literature suggesting that students, when involved in community based learning, could be more encouraged to be actively engaged in their own learning (Joosten, 2012).

\section{Online education}

While this study pertained solely to face-to-face instruction, the implications of the results span to online education as well. By integrating learning as described in this study, community based learning and class participation can mimic that of a face-toface class, even if learners are spread throughout the world. By having the ability to push information directly and instantly to mobile devices, online education no longer has to be limited to the traditional model. This is true for both synchronous as well as asynchronous teaching models. Using remote teaching methods enables courses to contain rigorous, engaging classes both "live" as well as at the pace of the learner.

\section{Limitations}

The limitations presented by this study are both substantial and recognized. One of the largest limitations of this study is an extremely small sample size $(\mathrm{N}=41)$. Inferences made about results with a sample size this small should be taken with extreme caution. While further research should be done that incorporates larger numbers of participants, the availability of students and professors willing to use this pedagogy is still very small.

Another limitation that should be noted is the use of only one rater when examining student interactions. While the use of the same rater may have ensured some level of 
continuity, multiple raters would have allowed for establishment of inner-rater reliability and would have greatly strengthened the results of the data.

Finally, this study only looked at a small amount of content from a specific course. Overall course learning throughout a semester was not examined. This study did not account for different disciplines or differing ages of students. All of these factors certainly have the potential to significantly alter results.

\section{References}

Baldridge, S.N., McAdams, A., Reed, A., \& Knettle, A. (2013). Mobile classrooms: Using mobile devices to enhance BSW education. Journal of Baccalaureate Social Work. 18, 17-32.

Cojocariu, V. (2010). (Inter)active learning - Value and applicability. Petroleum - Gas University of Ploiesti Bulletin, Educational Sciences Series, 62(1B), 154-161.

Diamanduros, T., Jenkins, S., \& Downs, E. (2007). Analysis of technology ownership and selective use among undergraduates. College Student Journal, 41(4), 970-976.

Dunlap, J.C., \& Lowenthal, P.R. (2009). Tweeting the night away: Using twitter to enhance social presence. Journal of Information Systems Education, 20(2), 129135.

El-Hussein, M., Osman, M., \& Cronje, J.C. (2010). Defining mobile learning in the higher education landscape. Journal of Educational Technology \& Society, 13(3), 12-21.

Immerwahr, J. (2008). Participation rubric from Traditions in Conversation. Retrieved from https://www.temple.edu/tlc/resources/handouts/grading/ParticipationRubric.pdf.

Joosten, T. (2012). Social media for educators: Strategies and best practices. San Francisco, CA: Jossey-Bass.

Junco, R., Heiberger, G., \& Loken, E. (2011). The effect of twitter on college student engagement and grades. Journal of Computer Assisted Learning, 27(2), 119-132.

Malik, S. \& Janjua, F. (2011). Active lecturing: An effective pedagogic approach. International Journal of Academic Research, 3(2), 963-967.

Moore, J., Dickson-Deane, C., \& Galyen, K. (2011). E-learning, online learning, and distance learning environments: Are they the same? The Internet and Higher Education, 14(2), 129-135.

Rinaldo, S.B., Tapp, S., \& Laverie, D.A. (2011). Learning by tweeting: Using twitter as a pedagogical tool. Journal of Marketing Education, 33(2), 193-203. 


\title{
Towards a mobile flipped classroom: Using mobile instant messaging to enhance distributed learning of academically challenged students
}

\author{
Patient Rambe \\ Central University of Technology, South Africa
}

\begin{abstract}
While mobile devices have been touted by technology optimists as silver bullets for tackling the challenges of asymmetrical access to learning resources and 'fixing' inflexible traditional educator-dominated pedagogies, the irony is that educators' expectations for emerging technologies to mediate untransformed pedagogical practices have impeded the optimal utilisation of mobile applications like mobile instant messaging. Since profound shifts in pedagogical designs are necessary for the adoption of mobile instant messaging to ensure distributed collaborative learning by students, this study adopted a mobile flipped classroom to re-engineer pedagogical delivery. The mobile flipped classroom comprised the use of a mobile application (i.e. WhatsApp) by geographically dispersed students to collaboratively engage with content after demonstration of IT concepts and processes by the educator. Evidence from WhatsApp-enabled collaborative engagements (i.e. lecturer-student, student-peer) and in-depth interviews with students suggest that mobile flipped classrooms enabled student self-paced learning, heightened their access to distributed learning, enhanced their cogitative processes, promoted on-task activities and informal playback of academic videos watched by students. The study recommended that successful adoption of emerging technologies necessitates a consideration of student grasp of disciplinary knowledge, ability to work collaboratively and sustained willingness to engage on academically purposeful activities.
\end{abstract}

Keywords: Distributed collaborative learning; mobile instant messaging, WhatsApp, flexible learning

\section{Introduction}

Although the academic potential of mobile devices has been discussed over the past one and half decades, the capacity of mobile phones to enhance distributed mobile learning is a relatively new discourse in contemporary academic literature (Pocatilu et al., 2010; Winters, 2006). Distributed mobile learning describes the collaborative learning among geographically dispersed learning communities that is mediated by portable computing devices like mobile phones, smart phones and laptop computers.

While mobile applications are hailed for the opportunities they provide for students to work collaboratively in different environments (Uden, 2007), access shared resources simultaneously (i.e. concurrency) (Pocatilu et al., 2010) and accentuate learning flexibility by fitting learning into student work processes (Uden, 2007), these affordances cannot be assumed to guarantee distributed collaborative learning. This is because the realisation of distributed collaborative learning necessitates appropriate pedagogical strategies that draw on these mobile phone capabilities to enhance student learning seamlessly across temporal, spatial and time zones. Hamdan et al. (2013) warns that although educators are using emerging technologies (e.g. video, digital simulations and mobile instant messaging) to personalise learning for students, these technologies will have limited effects unless there are profound alterations to the traditional teaching model. Consistent with the need for transformed pedagogies, this study adopted a mobile flipped classroom to support the distributed collaborative learning of previously disadvantaged IT students at a South African university. Previously disadvantaged students (PDSs) are those that enter South African universities underprepared (academically, socially and even linguistically) to deal with academic complexities of tertiary education. 
In view of the foregoing discussion, the following research questions were posed: 1 . How can a mobile flipped classroom be designed to enhance the distributed collaborative learning of historically disadvantaged IT students? 2. What educational benefits did students accrue from using mobile flipped classroom?

\section{Literature review}

In a flipped model, lessons are delivered outside the class using available technologies and class time is harnessed for hands-on learning of students, collaboration with peers, evaluation of their progress and for provision of one-on-one assistance, guidance and inspiration by the educator (Hamdan et al., 2013). There are multiple educational benefits of flipped classrooms. For Caperton (2012), flipped learning can have a significant and scalable impact on students if technology is used to promote constructionist learning spaces and make students designers and owners of their learning. This makes mobile flipped classrooms ideal candidates for distributed collaborative learning as they combine student generation of content with individual and collaborative engagement with educational resources in distributed locations. For Horn (2013) this online instruction gives students ownership of learning by rewinding and re-viewing sections [of videos] they do not understand or fast-forwarding through material they have already mastered while in-class contact supports interactive engagement through practical problem solving, discussion and executing specific projects.

The flipped model, however, is not without its critics. It is often criticised for recycling traditional instruction through the back door under the guise of motivating students to learn and increasing contact time for engagement (group work, individual study, assessments etc.). For instance, Caperton (2012) critiques the flipped classroom for being indifferent to/ignoring the fundamentals of cognitive and social constructivism (which emphasise cognition and learning by doing) by emphasising speaker-centred instructional video tutorials, streaming of impersonal, frontal teaching or filmed lectures aimed at mass audiences. Nielsen (2011) warns educators to exercise caution when adopting flipped classrooms for several reasons: lack of home access to technologies by students, it does not compensate for poor pedagogical delivery, and the need for a careful redesign of the learning environment to meet learning needs of heterogeneous students.

\section{Theoretical Framework}

The theory of distributed learning provides human centric perspective on learning, which emphasises activity and usage of technology rather than technologies per se (Fischer \& Konomi, 2007). Fischer and Konomi's (2007) framework for the interpretation of distributed intelligence in mobile technologies stresses: Who is using device/application? What are they doing? Where are they doing it? 4 When are they able to do it? 5 Why are they doing it? 6 How do they do it? As such distributed learning mediated by mobile applications necessitates a rigorous analysis of human actors, their motivations, learning strategies and activities, embedded social and cultural practices, and their situated contexts of interaction.

For Winters (2006), a distributed learning perspective necessitates that the technology assumes a secondary role while the situated context, social considerations (such as communication and appropriation) and learning activities are given more 
preponderance. Emphasis is placed on: learning activities, access to information and people, communication, community building and appropriation. Oblinger and Maruyama (1996) argue that effective learning environments should advance knowledge about the ways students learn and the obstacles they face (cognition), student meaningful interactions with information, peers and educators (collaboration), access to powerful communication to reach colleagues, experts and diverse information (communication) and student familiarity with technology uses to transform student learning experiences (computing). The table below summarises the interpretive and analytical framework adopted in this work.

Table 1: Analysis of distributed learning through networked mobile devices

\begin{tabular}{|c|c|c|c|}
\hline Category & $\begin{array}{l}\text { Fischer and Konomi } \\
(2007)\end{array}$ & Winters (2006) & $\begin{array}{l}\text { Oblinger and Maruyama } \\
\text { (1996) }\end{array}$ \\
\hline Human actors & $\begin{array}{l}\text { Who is using the mobile } \\
\text { application? }\end{array}$ & People (learners, peers, teachers) & $\begin{array}{l}\text { Student, peers and } \\
\text { educators }\end{array}$ \\
\hline $\begin{array}{l}\text { Human } \\
\text { motivations }\end{array}$ & Why are they doing it? & & Cognition \\
\hline $\begin{array}{l}\text { Teaching/ learning } \\
\text { designs and } \\
\text { activities }\end{array}$ & What are they doing? & $\begin{array}{l}\text { Learning activities (motives, creativity, } \\
\text { knowledge building, co-construction), }\end{array}$ & $\begin{array}{l}\text { Collaboration } \\
\text { Content creation }\end{array}$ \\
\hline $\begin{array}{l}\text { Socio-cultural } \\
\text { practices }\end{array}$ & How do they do it? & $\begin{array}{l}\text { Communicating (conversations and } \\
\text { discourse); } \\
\text { Appropriating (interaction and levels of } \\
\text { engagement); } \\
\text { Learning informally (prior experiential } \\
\text { learning, socialisation, distributed learning } \\
\text { networks) } \\
\text { accessing information (sharing, moving) }\end{array}$ & $\begin{array}{l}\text { Appropriation (interaction } \\
\text { and levels of engagement) } \\
\text { Access to communication } \\
\text { On demand access to } \\
\text { networks and educational } \\
\text { resources from distributed } \\
\text { locations }\end{array}$ \\
\hline $\begin{array}{l}\text { Technological } \\
\text { affordances }\end{array}$ & $\begin{array}{l}\text { When are they able to do } \\
\text { it? }\end{array}$ & & $\begin{array}{l}\text { Computing, storage and } \\
\text { management of } \\
\text { information }\end{array}$ \\
\hline Situated contexts & Where are they doing it? & Community & \\
\hline
\end{tabular}

\section{Methodology}

A virtual ethnographic approach was adopted to unravel the pedagogical design of a mobile flipped classroom, students' experiences of its educational benefits they accrued from its use. Virtual ethnography involves the adoption of interpretive methodologies by a researcher participating in the field to capture and document the lived experiences of participants (Fouchè \& Schurink, 2011). The researcher was a participant observer in a second year IT course at South African university in which geographically distributed PDSs used a mobile instant messaging application (i.e. WhatsApp) to voluntarily consult with their educator afterhours (6-8pm) in preparation for the following lectures. The student-peer and educator student interactions on WhatsApp, which lasted 6 months, involved clarifications and discussions of complex IT concepts, which were given as an assignments on a weekly basis. While web metrics were not conducted to evaluate the rate of participation, the postings per group demonstrated sub-optimal participation in many groups. However, conversations were well structured around questions peers posed to their groups and those posed by the educator to all groups. Few cases of student discussion of extracurricular interests and sharing humour stories were evident because the educator stipulated that WhatsApp was to be used for academic discussion exclusively.

Adopting virtual ethnography, the ethnographer often captures the perspectives of the informants where the interaction happens with the intention of studying the cultural 
concepts and generating a cultural portrait (Fouchè \& Schurink, 2011, p. 315). Mindful of researcher's experience in IT related issues, the IT educator whose class the researcher studied first solicited the researcher's social presence on WhatsAppmediated student clusters for a duration of a semester and a half (approximately 6 months). The researcher' role was: 1 . To informally track discursive trajectory of the lecturer-student and student-peer conversations on WhatsApp. 2. To provide on demand IT support and guidance to student queries only in situations where the educator was unavailable. 3. To make meaning from the data (queries, questions and answers) that student generated through their consultations with peers and their educator. 4. Make suggestions to the IT lecturer about improving pedagogical design of the WhatsApp consultative environment.

\section{Design of the flipped classroom}

Most PDSs complained to educator about limited contact time and their difficulties in understanding complex IT concepts in lectures. The educators then considered WhatsApp as a "trendy" communication tool among students that could support distributed collaborative learning. Subsequently, he encouraged students to download WhatsApp mobile service onto their mobile phones. He then split the class of 93 students into 14 clusters, assigned all students to clusters comprising between 8-12 students in addition to the lecturer. To ensure the "anonymity" of interactants and to foreground academic interactions and consultations, students were expected to save their cluster members' mobile numbers on WhatsApp as their IDs. While it was possible for a member to know other members if s/he saved their numbers, the size of the class and/ groups meant that it was not automatically guaranteed to know everyone in the group. The lecturer, however, saved both the cluster members' names and mobile numbers so that he could authenticate the participants' identities as well as trace the trajectory of distributed collaborative learning.

The educator normally gave short 10 minutes lectures on a concept via screen cast followed by two IT questions to all clusters so that they could consult with peers via WhatsApp. As a guest participant, the researcher maintained social presence in all clusters to track student conversations while the educator scaffolded students in problem solving when they were stranded. Materials availed on WhatsApp (the screen casts of educator's lecture, additional resources, peers and the guest) served as educational resources for student preparation for classroom sessions the following day. The sessions focused more on clarification of concepts discussed in screen casts, critical questioning by students and group discussions of answers the peers and educators provided on WhatsApp. In class, students were tasked to form small groups (4-7 members) and to discuss their interpretations of the online discussions and write their reflections down. They would then exchange their reflections with other groups and critique other groups' reflections. Thereafter, a representative from each group would be tasked to summarise their critique on peer groups' reflections. This hands-on approach allowed all group members to participate as well as train students to improve their intra and inter-communication skills.

\section{Data Analysis}

The educator authorised the researcher to download all postings on his interactants with students on WhatsApp (data mining), printed and analysed them thematically to develop themes and categories as shown in Table 2 below. In thematic content analysis, researchers identify topics or themes by means of line-by-line analysis, continually 
name categories by comparing new data incidents with categories already identified (Schurink et al., 2011). Themes were drawn from the topics discussed and messages embodied in the postings to develop a nuanced analysis of the postings. The themes were then compared with the theoretical framework (Fischer \& Konomi, 2007; Oblinger \& Maruyama, 1996; Winters, 2006) to provide a unified analytical framework as shown in the Table 2. Categories that emerged related to human actors, pedagogical motivations, pedagogical activities, learning designs and social and cultural practices.

Table 2: Analysis of distributed learning through WhatsApp-enhanced flipped classrooms

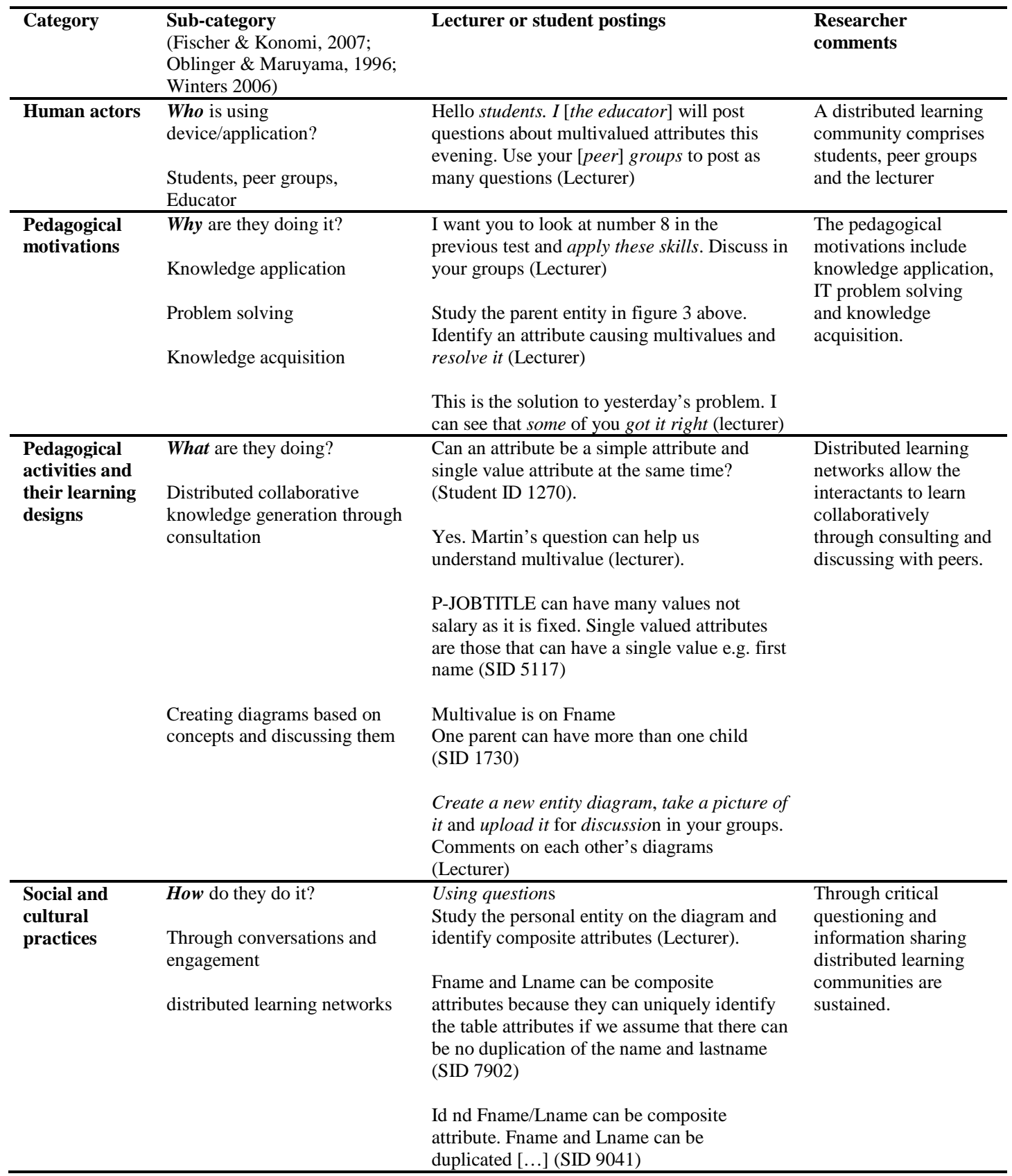

\section{Interviews}

The interviews were conducted in the second semester with 43 students to establish the appropriate pedagogical design that could support distributed learning of historically disadvantaged IT students and the educational benefits of a WhatsApp-mediated flipped classroom. A focus on historically disadvantaged students was to ensure their 
academic inclusion as they felt alienated by self-regulated learning normally expected of them at university. The interviews lasted about 40 minutes and were conducted in lab foyers where students often "hanged out". The transcripts were audio-recorded transcribed verbatim and analysed thematically

\section{Findings}

The research questions and the analytical framework guided the reporting results.

\section{Pedagogical design of mobile flipped classrooms}

The pedagogical design of mobile flipped classrooms necessitated the involvement of human actors (i.e. educator, students and peer groups) who collaboratively worked on learning tasks and activities through questions, contributions and meaningful engagement with learning resources. Under the human actors category the following distinct issues emerged: meaningful academic activities (focusing on cogitative processes), persistent social presence and anonymous interaction. These are discussed in detail is the following sections.

\section{Meaningful cogitation}

Human actors mediated the pedagogical design and effective application of mobile flipped classrooms, which comprised short recorded video lectures which students watched via screen cast followed by educator-student and student-peer engagements on WhatsApp. A learning strategy that necessitated their participation in authentic academic task activities (such as watching short video lectures, critical questioning and peer group discussions) was pivotal in sustaining meaningful cogitation and collaborative engagement among these geographically-remote online communities (see educator and student postings under human actors in Table 2 and Table 3 respectively). Yet effective student cogitation required activities that combined collaborative studentpeer interaction, authentic construction of knowledge and complex problem solving to increase student mastery of IT concepts. These complementary issues are addressed in subsequent sections.

\section{Persistent social presence}

Besides the foregrounding of academic tasks and group learning activities by human actors, the design of mobile flipped classrooms necessitated the continued social presence and strategic positioning of the educator as a "guide on the side", mentor and resource consultant. A scaffolding strategy involving intensified guidance to students during the inceptive phases of collaborative interaction followed by "fading" (i.e. gradually reducing the level of support with increased student mastery of concepts) was only feasible when students demonstrated progressive mastery of complex concepts and problem solving. As such, the complaints about educators' delayed responses that contributed to student anxiety and frustration can be interpreted as student misconceptions about scaffolding by the educator. The following student complaints about delayed responses and the educator's response are symptomatic of academically challenged students' expectations for educators to be "on their backs":

I said da same thng so many times bt u didn't say anything (Student post).

I saw that your answer was correct but I wanted to give other a chance to respond but thanks for picking discrepancy (Educator post).

Lol, I think we shd then wait for sir to set us straight (Peer's post). 
Although WhatsApp-mediated flipped classrooms were designed to provide an ambient environment for optimising academic engagement through anonymous consultations, the pressure to participate often exposed academically-challenged students' lack of understanding of IT problems. Some learning contradictions manifested in student comfort in fictitious participation on the one hand and their feeling of impotence when they sensed that their postings were bordered on ignorance on the other (see the posting below).

We are all going to get lost without some direction. Hehehe, I might just convince myself that all I say is correct and we all know that I know ZERO (Student post)

\section{Anonymous interactions}

The pedagogical design of mobile flipped classrooms necessitated anonymous interactions to foreground impersonal and authentic academic interactions as well as guard against asymmetrical academic engagement caused by differential student learning capabilities and digital literacies. The educators designed WhatsApp-based clusters to support anonymous interactions by requiring students to use their phone numbers as personal IDs. Anonymous interactions protected the identity of shy, less confident, and academically challenged students who struggled to express their views publicly online. One low self-esteem student explained in an interview: "I like WhatsApp [anonymous] interactions because I can pose questions without feeling inferior to my peers. This is unlike face-to-face contact session where I feel exposed if I pose a question or make a statement publicly (STD 14). Another previously disadvantaged student concurred: "I am shy to ask questions face-to-face so I prefer to ask on WhatsApp, and if I missed class I can always access things done in class.”

\section{The educational benefits of WhatsApp-based flipped classrooms}

\section{Pedagogical motivations and activities}

Pedagogical motivations and activities of WhatsApp flipped classrooms shaped and influenced educational outcomes of these classrooms. The design's motivations included increasing student reflection, promoting practical application of knowledge, enhancing problem solving, supporting on-demand learning by students and private study. The pedagogical activities included drawing IT diagrams, capturing them using mobile phone camera and posting them online, understanding and identifying the different concepts the diagrams illustrated, critical questioning and complex problem solving, group contributions and explaining complex concepts.

Given the fragmentation of student-led discussions and the educator's scaffolding strategy that involved non-interference in student discussions to allow them to explore and generate solutions, the aforementioned educational benefits were not always realised consistently. The following section discusses the major educational benefits of the WhatsApp-based flipped classroom identified in the study.

\section{Student reflection}

WhatsApp flipped classrooms promoted critical reflection through asynchronous discussions that enabled student cogitation before formulating questions, answers and critique. Asynchronous conversations shielded students from the urgency of immediate responses normally characteristic of traditional classrooms: 
Flipped classes (using WhatsApp) are self-empowering because they allow me to think critically before answering questions (STD 43). (WhatsApp) gives me more time to think about the videos I watch, formulate and change my answers (STD 09)

Replaying videos provided opportunities "to repeat sections / points I did not understand unlike in class where I am scared to ask or interrupt" (STD 28) suggest the ambience of WhatsApp flipped classrooms for academically struggling students.

\section{Self-paced learning}

Short video lectures and WhatsApp discussions allowed academically at-risk students who normally struggled with the swift pace of lectures to self-pace their learning without the additional pressure of having to capture everything the lecturer taught:

With flipped classrooms I get watch videos and do my work at my own time, therefore it is relatively easier to handle the pressure (STD 30)

It requirements for individual effort and interaction allow me to do tasks at an easier pace with more information at hand (STD 16)

All these views point to the flexible and self-management opportunities embedded in productive use of flipped classrooms.

Problem solving

Since IT is a significantly problem-based discipline, the use of WhatsApp allowed students to propose solutions to social technical and human related problems. Both the lecturer and students drew on paper some technical IT diagrams, which represented problems relating to various concepts (e.g. simple attributes, single valued attributes and multivalued attributes), photographed them using their mobile devices and uploaded them on WhatsApp for discussion. The affordances for uploading images of diagrams, open dialogue and collaborative knowledge constructions were the distinct educational benefits of lecturer-student and student-peer discussions via WhatsAppenhanced flipped classroms.

\section{Discussion}

\section{Student-centred and context-aware designs}

A realistic pedagogical design of a mobile flipped classroom, which enhanced the distributed learning of academically challenged IT students necessitated a broader understanding and incorporation of student needs, authentic learning activities and socio-cultural context into the design of this learning environment. Practically, the design involved making appropriate choices about the lecture content to be delivered and the available video technologies that would support the delivery of this content. In this study, students watched the video lectures mainly using WhatsApp in addition to YouTube or Vimeo, depending on their availability. More so, a developmentally appropriate flipped design necessitates recognition of the fact that no student in a particular cohort is at the same level of psychological development at any given time (Nielsen, 2011). Findings revealed that some PDSs lacked confidence and self-esteem in WhatsApp group collaboration due to communication difficulties and fear of public expression of their views. Notwithstanding the lurking of some students, anonymous 
communication overall, served to equalise participation among these academically challenged students.

Hamdan et al. (2013) highlight that the design of the flipped learning model necessitates a deliberate shift from a teacher-centred classroom to a student-centred approach that allows students to choose when and where they learn. In these flexible learning environments, in-class time is meant for exploring topics in greater depth and creating richer learning opportunities (Ibid). While bridging student learning context and learning needs is an inexorably complex matter, our finding suggests that studentcenteredness and context-sensitive designs are achievable through de-emphasising the technology and foregrounding human actors, pedagogical motivations and pedagogical activities in context. Emphasising the interface between human actors (educator, students and peer groups), their pedagogical tasks and activities in context (cogitative processes, anonymous collaborative interactions, sustained educator-directed support systems) advanced the learning trajectory of students through: increased focus on authentic learning tasks, enhanced student psychological development and empowerment of subdued voices to contribute publicly to discussions. From a distributed learning perspective, designing a student-centred learning context necessitates an adaptation of individual students' social and physical environment to suit their information needs, enabling new forms of learning support through ubiquitous multimodal notifications, ubiquitous multimodal messaging and ubiquitous content exchange and sharing (de Jong et al., 2008, p. 120).

\section{Persistent social presence}

To promote meaningful interactions and balanced participation from all group clusters, the design of the mobile flipped classrooms required the continued social presence of the educator. Social presence ensured persistent provisioning of support from educators, tracking effective utilisation of education materials by students, reducing parasitic behaviour engrained in lurking, and guarding against discussions of little substance and the "tyranny of participation". As such, for mobile flipped classrooms to support distributed learning, they need to: provide tools for learning grounded in a 'scaffolding with fading' perspective and autonomous performance by students (Fischer \& Konomi, 2007) to enhance the participation of academically challenged students. Such design should also provide support not only to individuals but to groups and communities, exploit the power of social creativity based on informed participation (Fischer et al., 2005) and contextualize generic systems to person and task-specific environments (Fischer, 2001). In our study this necessitated understanding of students' psychology (confidence in public online participation, internet access, and selfregulation behaviour) to ensure meaningful, balanced participation.

\section{Social-constructivist learning}

The educational benefits of mobile flipped classrooms laid in their potential to support knowledge-centred learning, engender social constructivist learning and authentic interactional environments. Students reported that the adoption of the mobile flipped classrooms to support educator-student and student-peer engagements allowed them to reflect on content and foreground more critical questioning. This finding buttresses Marlowe's (2012) findings that flipped classrooms improved student desire to explore concepts they found interesting in greater depth as well as their semester grades. Although the current study identified no marked improvement in the student grades, evidence of lurking by some students on WhatsApp co-existed with manifestations of increased participation in academic tasks and activities on WhatsApp compared to face- 
to-face lectures. This buttresses claims that the learning gains from flipped classroom remain unsubstantiated: as there is lack of evidence on measurement of the practice or assessment of its impact on student learning (Horn, 2013).

\section{Conclusion}

The study investigated how the mobile flipped classroom could be designed to support distributed collaborative learning of academically challenged students, explored the educational benefits that could be derived and learning barriers to be overcome by this intervention. Evidence suggests that human actions (i.e. anonymous interactions, meaningful cogitation and persistent social presence of educators), meaningful pedagogical motivations and activities (reflection, self-paced learning, problem solving) were critical to the design of mobile flipped classrooms. The latter also constituted educational benefits of using flipped classrooms while erratic connectivity, communication delays and limited self-discipline impeded coherent distributed collaborative learning.

\section{References}

Caperton, I.H. (2012). Education trends: Before we flip classrooms, let's rethink what we're flipping to. Edutopia blog (Posted October 17, 2012)

http://www.edutopia.org/blog/rethinking-the-flipped-classroom-idit-harel-caperton

de Jong, T., Specht, M., \& Koper, R. (2008). A reference model for mobile social software for learning. International Journal of Continuing Engineering Education and Lifelong Learning, 18(1), 118-138.

Fischer, G. \& Konomi, S. (2007). Innovative socio-technical environments in support of distributed intelligence and lifelong learning. Journal of Computer Assisted Learning, 23, 338-350.

Fischer G., Giaccardi E., Eden H., Sugimoto M. \& Ye, Y. (2005). Beyond binary choices: integrating individual social creativity. International Journal of Human-Computer Studies, 63, 482-512.

Fischer G. (2001). User modeling in human-computer interaction. User Modeling and User-Adapted Interaction (UMUAI), 11, 65-86.

Fouchè, C. \& Schurink, W. (2011). Qualitative research designs. In A. De Vos, H. Strydom, C. Fouche, \& C. Delport (Eds), Research at grassroots: For the social sciences and human service professions (pp. 307-327), Pretoria: Van Schaik Publishers.

Hamdan, N., McKnight, P., McKnight, K. \& Arfstrom, K. (2013). The flipped learning model: A White Paper based on the Literature review titled a review of flipped learning. The flipped learning Network.

Horn, M. (2013). The transformational potential of flipped classrooms: Different strokes for different folks. Education next, 13(3), Accessed online

http://educationnext.org/the-transformational-potential-of-flipped-classrooms/

Marlowe, C. (2012). The effect of the flipped classroom on student achievement and stress Masters Thesis, Montana State University, Bozeman, Montana.

Nielsen, L. (2011). Five reasons i'm not flipping over the flipped classroom. Teaching and Learning Advisor Blog (Posted Nov 8, 2011)

http://www.techlearning.com/Default.aspx?tabid=67\&EntryId=3379

Oblinger, D. \& Maruyama, M. (1996). Distributed Learning. CAUSE Professional Paper Series, Boulder, Colorado.

Pocatilu, P., Doinea, M., \& Ciurea, C. (2010). Development of distributed mobile learning systems. CSECS '10 Proceedings of the 9th WSEAS international conference on Circuits, systems, electronics, control \& signal processing (pp. 196-201), Wisconsin, USA.

Schurink, W., Fouchè, C. \& De Vos, A. (2011). Qualitative data analysis and interpretation. In A. De Vos, H. Styrdom, C. Fouchè \& C. Delport (Eds), Research at grassroots: For the social sciences and human service professions (pp. 397-423). Pretoria: Van Schaik.

Uden, L. (2007). Activity theory for designing mobile learning. International Journal of Mobile Learning and Organisation, 1(1), 81-102.

Winters, N (2006). What is mobile learning? In M. Sharples, (Ed). Big issues in mobile learning. Report of a workshop by the Kaleidoscope Network of Excellence Mobile Learning Initiative, University of Nottingham. 
HEAd'15

\section{SESSION 6C}

\section{PlanNing AND \\ ORGANIZATION}




\title{
An Assessment of an Adult Learning Model: Implications for Replication
}

\author{
J.A. Serowick*, A.J.F. Cardelle** \\ * East Stroudsburg University, Director of Extended Learning \\ ** East Stroudsburg University, Dean, College of Health Sciences
}

\begin{abstract}
In response to the national agenda to increase the number of adults with bachelor's degrees, East Stroudsburg University (ESU), a regional master-degree granting university, has implemented several degree completion programs geared towards non-traditional students. Using the Council for Adult and Experiential Learning (CAEL) "Eight Principles of Effectiveness for Serving Adult Learners,” this study assessed the first three years of the program's implementation. This assessment used primary data collection, including a student and faculty survey. The study found that the program is replicating its teaching processes, use of technology for teaching, and advising and mentoring well. However, the assessment revealed that the program was weaker on three primary items more unique to adult learners: 1) Flexible financing options; 2) Awarding credit for prior learning; and 3) Enhancing strategic community partnerships. Parallels are drawn to similar challenges Europe faces in meeting the social dimension of the Bologna Process. The paper concludes that in order to implement successful degree completion programs, key in advancing completion goals and equity demands in both the U.S. and Europe, institutions need to commit themselves to going beyond the replication of traditional undergraduate programs, and plan for the long-term transformation of current models of education.
\end{abstract}

Keywords: Degree Completion; Models of Teaching; Adult Learners; Assessment; Bologna Process, Innovation in Higher Education.

\section{Introduction}

Adults are increasing in numbers in American higher education. By 2016, adults, defined as age 25 and older, will represent $42 \%$ of students in post-secondary education (Aud, 2013). This growing population, combined with a shrinking high school population in some parts of the country, has led to competition for adult enrollment. Add to that the fact the United States is now $14^{\text {th }}$ in the number of college degree holders, and increasing federal policy pressure to be first by 2020 (Advisory Committee on Student Financial Assistance, 2012). Colleges have responded by creating programs in accelerated formats, granting credits for competencies, establishing services specifically geared towards adults, and dedicating admission staff specifically to recruit adult students. However, graduation rates for adult students remain notoriously low, in part due to an increasing trend in student movement across institutions. In other words, students "swirl" in and out of two- or four- year institutions transferring multiple times ( $\mathrm{Li}, 2010)$ and losing credits along the way because of rigid transfer policies. Students are no longer staying at the colleges where they started. The result is a nation of students who are starting college and not finishing, or taking upwards of eight years to finish.

This problem is not unique to the United States. As evidence by the goals of the Bologna process, European higher education institutions also struggle with student mobility between institutions, transferability of credits, completion rates, and educational access for underserved student populations (Clark, 2014). While both American and international institutions have, and continue to respond to meet these goals, the efficiency and success of programs designed to meet the needs of new student markets demand continued research in best practices. Ultimately, the success of 
emerging student populations such as the adult student market, will assist institutions to progress national and international degree completion goals.

\section{Purpose and Significance}

In response to the national agenda and student demographic trends, East Stroudsburg University (ESU), a regional master-degree granting university, has implemented several degree completion programs geared toward adult students. This paper is an assessment of this pilot program's success at meeting degree completion goals for adult students including adult learning best-practice models, and the social goals of degree completion. The assessment was a key component of the institution's future planning to grow the programs from pilot status to institutionalized supported strategic initiatives. The lessons learned from the study may inform other American and European institutions in building new programs to meet the completion goals set by recent US educational initiatives and the Bologna process.

\section{Adult Education Strategies}

The commonalities of adult oriented programs surround the necessity for institutions to remove the barriers that adults typically face. Savvy consumer oriented adult students are shopping the market for programs providing them the right fit for their individual needs. To that end, institutions must market themselves as "adult friendly." The recent focus on outcomes in higher education also necessitates the need for institutions to demonstrate not only an adult oriented approach to education, but an approach that works. As a basis for instituting effective degree completion models, institutions can be guided by existing theories that contribute to the enrollment and retention of adult students.

Adult learning theory is founded on the need for an approach to teaching based on the way adults learn. Coined "andragogy" by Malcolm Knowles, the basic tenants are that adults are self-directed; actively involved in their learning; maximize prior experiences to absorb new knowledge; learn best in experiential environments; and are heavily influenced by their life factors while in school (Dunlap, Dudak, \& Konty, 2012). Learning environments, therefore, should be relevant, respectful, and supportive to best accommodate adult learning.

Reflecting the principles of adult learning theory, and therefore serving as the framework for this study, the Council for Adult Experiential Learning (CAEL) developed "Eight Principles of Effectiveness for Serving Adult Learners” (2005). The principles are listed in Table 1 below and serve as a baseline of services that institutions need in order to be effective with adult students. 
Table 1. Eight principles for serving adult learners.

\begin{tabular}{|c|c|}
\hline Outreach & $\begin{array}{l}\text { The institution conducts outreach to adult learners by } \\
\text { overcoming barriers of time, place, and tradition in order to } \\
\text { create lifelong access to educational opportunities. }\end{array}$ \\
\hline $\begin{array}{l}\text { Life \& } \\
\text { Planning }\end{array}$ & $\begin{array}{l}\text { The institution addresses adult learners' life and career } \\
\text { goals before or at the onset of enrolment in order to assess } \\
\text { and align its capacities to help learners reach their goals. }\end{array}$ \\
\hline Financing & $\begin{array}{l}\text { The institution promotes choice using an array of payment } \\
\text { options for adult learners in order to expand equity and } \\
\text { financial flexibility. }\end{array}$ \\
\hline $\begin{array}{l}\text { Assessment of } \\
\text { Learning Outcomes }\end{array}$ & $\begin{array}{l}\text { The institution defines and assesses the knowledge, skills, } \\
\text { and competencies acquired by adult learners both from the } \\
\text { curriculum and from life/work experience in order to assign } \\
\text { credit and confer degrees with rigor. }\end{array}$ \\
\hline $\begin{array}{l}\text { Teaching-Learning } \\
\text { Process }\end{array}$ & $\begin{array}{l}\text { The institution's faculty uses multiple methods of } \\
\text { instruction (including experiential- and problem- based } \\
\text { methods for adults to connect curricular concepts to useful } \\
\text { knowledge and skills. }\end{array}$ \\
\hline $\begin{array}{l}\text { Student } \\
\text { Systems }\end{array}$ & $\begin{array}{l}\text { The institution assists adult learners using comprehensive } \\
\text { academic and student support systems in order to enhance } \\
\text { students' capacities to become self-directed, lifelong } \\
\text { learners. }\end{array}$ \\
\hline Technology & $\begin{array}{l}\text { The institution uses information technology to provide } \\
\text { relevant and timely information and to enhance the learning } \\
\text { experience. }\end{array}$ \\
\hline Strategic Partnerships & $\begin{array}{l}\text { The institution engages in strategic relationships, } \\
\text { partnerships, and collaborations with employers and other } \\
\text { organizations in order to develop and improve educational } \\
\text { opportunities for adult learners. }\end{array}$ \\
\hline
\end{tabular}

\section{Benefits of a Degree}

The need for policies and programs that facilitate degree completion would not be vital if there would be no benefits to degree completion. These benefits are rooted both at the individual and societal level. These are also specifically spelled out in the European Bologna Process.

\section{Individual benefits}

It has been widely documented that the benefits of a college degree are numerous. The financial benefits tend to be a primary driver of bachelor degree completion in the United States. Workers with a bachelor's degree earn about $\$ 20,000$ more per year than workers with a high school diploma or a General Educational Development (GED) certificate (Ryan \& Siebens, 2012). Over a lifetime, this could mean a college graduate could earn approximately a half million more than a high school graduate (Schneider \& Lin, 2011). Because of the financial benefits which include higher income and access to health insurance, college graduates live longer, are healthier, and have 
healthier children (from infancy to adulthood) than high school graduates or even adults with some college but no degree (Robert Wood Johnson Foundation, 2009). College graduates also see personal benefits including a greater sense of control over their lives, better social standing and higher levels of emotional and social support from friends and peers, social mobility, and an overall better quality of life (Robert Wood Johnson Foundation, 2009).

These themes are echoed in the social dimensions component of the Bologna process. The primary tenants include lifelong learning, increased access to higher education, and cultural competence on the part of individuals (Clark, 2014). While the concept of lifelong learning varies across institution and needs further defining, the benefits of broadened access to the individual include increased mobility because of the ability to complete academic credentials without barriers related to social or economic standing (Clark, 2014). Additionally, as is true in the United States, the educational attainment of parents in Europe is positively correlated with that of their children (Clark, 2014). Finally, the mobility afforded via advanced degrees ensures an individual's competiveness and preparation for the international job market.

\section{Societal benefits}

College graduates also positively impact the financial health of states and nations by creating a competitive and healthy workforce. Because of their increased income, college graduates pay higher income tax which contributes to increased state budgets (Schneider \& Lin, 2011). Low levels of college graduation have high direct costs, adversely affect the U.S. economy and contributing to socioeconomic inequity (Paulson, 2012). Additionally, the job market is changing such that employers who used to demand technical expertise are now demanding employees who have wellrounded skills including communication skills, problem solving and critical thinking. By 2020, approximately 15 million jobs will require a baccalaureate degree but only about 3 million Americans will have a degree (Angel \& Connelly, 2011).

Again, the foundation of the Bologna process reinforces the societal benefits reaped from citizens with advanced degrees. The 2007 action line of the Bologna process sets the background for those benefits by calling for a student body as diverse as the European population in order that leaders and scholars have cross-cultural representation (Clark, 2014). Tracing back to the Lisbon Agenda, a major goal of the Bologna process is also to meet regional economic objectives "which seek to boost the competitiveness, dynamism and knowledge base of the European economy" (Clark, 2014). Increasing the numbers of college graduates will benefit employers, the workforce, and nations.

\section{Results and Discussion}

The assessment was designed using CAEL's “Eight Principles of Effectiveness for Serving Adult Learners" as the theoretical framework, and the assessment benchmarks for this study. The results were organized and analyzed using the eight principles. In addition, the assessment was guided by the following two primary research questions:

1) Does the program accurately reflect adult learning theories?

2) What components of the programs input and process need to change to improve the product? 
This assessment used primary data collection, which included a student and faculty survey. The student survey, a gap analysis, was given to 44 students at one of the extended learning locations. Faculty surveys were administered to 26 faculty who had taught in the programs. The survey employed similar language to the eight practices and included 20 questions. A total of 14 faculty responded. All responses were anonymous. Data from the two surveys were analyzed using descriptive statistics and some of the qualitative data was reviewed and coded into the eight best practices for institutions serving adult learners.

\section{Results}

The student survey gap analysis data presented in table 2 shows student mean scores on the CAEL principles. Students were asked to measure existing programs and services against the standards: (1) Agree; (2) Agree Somewhat; (3) Disagree Somewhat; (4) Disagree. According to the student survey data, students agreed that ESU was achieving the standards relating to the more traditional pedagogical process. In other words it seems as if students feel the program is replicating its teaching processes and its use of technology for teaching and even its advising and mentoring well. However on three primary items: 1) Flexible financing options; 2) Awarding credit for prior learning; and 3) Enhancing strategic community partnerships, that are more unique to adult learners, the students rate the program much lower.

Table 2. Student mean scores compared to CAEL's principles of effectiveness.

\begin{tabular}{|l|l|}
\hline CAEL Principle & Mean student score \\
\hline Outreach & 1.7 \\
\hline Life \& Career Planning & 1.52 \\
\hline Financing & 2.09 \\
\hline Assessment of Learning Outcomes & 2.02 \\
\hline Teaching-Learning Process & 1.8 \\
\hline Student Support Systems & 1.9 \\
\hline Technology & 1.3 \\
\hline Strategic Partnerships & 2.1 \\
\hline
\end{tabular}

The faculty survey data, summarized in table 3 below, reflects faculty members' level of agreement that ESU's degree completion program achieved CAEL's standards. According to these results (grouped by CAEL's standards), faculty reported that the program needs to focus on the following principles: 1) Student support systems; and 2) Strategic partnerships. However the relatively high frequency of "Do not Know" responses, may indicate that the faculty lack the information of the available resources available to meet the specific needs of adult learners. Specifically, faculty seem not to be aware of services with regard to, life and career planning, financing and assessment of prior learning outcomes. 
Table 3. Faculty rankings of ESU in comparison to CAEL's principles of effectiveness.

\begin{tabular}{|l|l|l|l|}
\hline CAEL Principle & $\begin{array}{l}\text { Strongly } \\
\text { Agree and } \\
\text { Agree }\end{array}$ & $\begin{array}{l}\text { Strongly } \\
\text { Disagree and } \\
\text { Disagree }\end{array}$ & $\begin{array}{l}\text { Do not } \\
\text { Know }\end{array}$ \\
\hline Outreach--times of courses & $83 \%$ & $8 \%$ & $0 \%$ \\
\hline Outreach--location & $83 \%$ & $8 \%$ & $0 \%$ \\
\hline Outreach--format & $67 \%$ & $20 \%$ & $0 \%$ \\
\hline Life \& Career Planning & $17 \%$ & $16 \%$ & $58 \%$ \\
\hline Financing & $8 \%$ & $0 \%$ & $83 \%$ \\
\hline Assessment of Prior Learning Outcomes & $42 \%$ & $0 \%$ & $58 \%$ \\
\hline Teaching-Learning Process & $83 \%$ & $8 \%$ & $25 \%$ \\
\hline Student Support Systems & $42 \%$ & $25 \%$ & \\
\hline Technology & $66 \%$ & $16 \%$ & $42 \%$ \\
\hline Strategic Partnerships & $8 \%$ & $41 \%$ & \\
\hline
\end{tabular}

\section{Discussion}

The two primary research questions set out by the assessment are used to report the assessment's conclusions.

Does the program accurately reflect adult learning theories?

ESU's extended learning programs compare well to some of the benchmarks set by CAEL for institutions that effectively serve adult learners. The ESU degree completion model in its first phase of implementation focused on providing access to higher education programs through location, format, and flexible times. Hence the program was rated well by students and faculty on: times of courses; location; format and the learning process.

The areas that are in need of improvement include 1) Providing flexible financing options; 2) Awarding credit for prior learning; 3) Enhancing strategic community partnerships; and 4) Increasing student support systems primarily in advising and academic support. This assessment highlights that for degree completion programs to be fully implemented they require attention to ancillary support services that are also the more specialized services for degree completers and may be part of a second phase of implementation.

What components of the programs input and process need to change to improve the product?

While one of the weaknesses of the evaluation is that it does not suggest causal relationships, the assumption is that if students feel more satisfied, and have the services they need, graduating student numbers may increase. To improve the program inputs 
and processes, in addition to the recommendations made in the answers to the question above, ESU may want to consider the following list of improvements:

- Increased availability to academic advising and support (faculty and peer)

- Analyze need for additional course schedules, programs, and relevant services

- Increase life and career planning (both prior to enrollment and during)

- Assist faculty to develop alternate methods of instruction to appeal to adult learners

- Investigate and standardize quality of courses offered in extended learning programs

- Conduct faculty orientation to ensure they are aware of services available to students

- Improve new student orientations to be inclusive of ancillary services

- Increase technology support and training for faculty at off campus locations

- Increase campus initiatives in developing strategic partnerships to adult learners

The findings from the assessment reveal the underlying factors long suspected to be affecting the slow development of degree completion programs - a poor institutional fit, and increasing human capital needs. This assessment has shown that despite ESU's institutional commitment to these programs, its significant investment in infrastructure (a new teaching site), in faculty time and its moderate investment in human capital for program administration, the program has struggled to address the distinctive requirements for degree completers within its institutional culture. The resources invested have allowed for the degree completion programs to replicate the institution's good undergraduate teaching and advising tradition to the new sites and the new populations, however the mere replication of these processes to the new venues and new populations does not mean that they are the right fit for adult learners.

\section{Conclusions}

Clark (2014), in a review of the past 15 years of Bologna, cites factors necessary for Bologna to meet its goals of expanding access to traditionally underserved populations. These include transferability; minimizing barriers for diverse students; employability; completion; and mobility.

This assessment found that the needs of adult learners surround: 1) Providing flexible financing options; 2) Awarding credit for prior learning; 3) Enhancing strategic community partnerships; and 4) Increasing student support systems primarily in advising and academic support.

The factors identified in this assessment that support adult degree completion--financial support, dedicated admission representatives, outreach recruitment programs, career counseling services, flexible learning pathways, previous learning assessments, and external strategic partnerships--are similar to those needed for a successful implementation of the Bologna process.

According to Clarke (2014), the eventual measure of the efficacy of the Bologna process will be in the implementation details--details that rely on buy-in from institutions and faculty in a bottom-up process, a similar experience to that found in this 
assessment. These needs are not addressed by the simple replication of traditional undergraduate student models. Rather, a systems change that encompasses the best components of andragogy in- and outside- of the classroom is required.

This transformation, because of the scarcity of resources at many higher education intuitions, will at the very least require a refocusing of existing human capital. This assessment suggests that institutions new to degree completion, like ESU, may not be able to start with all of best practices, but still need to plan for a phased-in implementation of programs and ancillary services unique to the needs of vulnerable populations. As is true with most pilot programs, the first phase includes the build-up and adaptation of existing areas of expertise to increase access to populations who would not otherwise have it.

Full implementation, however, requires a potential second and even third phase where the specialized degree completion services follow after a period of refocusing limited resources. The lessons from this assessment should contribute to the growing evidence of best practices and potentially serve as a model for baseline needs of new programs. If new programs can replicate this idea of a phased-in implementation from the start, it may limit the learning curve to improve student retention and completion, thereby increasing efficacy and efficiency.

The process of expanding higher education access to under-served, new student markets requires a dual and somewhat contradictory process - universalization of institutional commitment but at the same time the development of a niche expertise and human capital that can respond to the needs of the population. In the long term, higher education may discover that the models that work for degree completers are worth universalizing to all student populations to meet national and international completion goals. However, in the short-term, to advance completion goals for the fastest growing student population in US, and to meet the demands of equity in Europe, institutions need to commit not to replicating, but transforming current models of education.

\section{References}

Advisory committee on student financial assistance. (2012). Pathways to success: Integrating learning with life and work to increase national college completion. Washington DC.

Angel D., \& Connelly, T. (2011). Riptide: The new normal for higher education. Lexington, KY: The Publishing Place.

Aud, S., Wilkinson-Flicer, S., Kristapovich, P., Rathbun, A., Wang, X, \& Zhang, J. (2013). The condition of education 2013 (NCS 2013-037). U.S. Department of Education, National

Center for Education Statistics. Washington, DC. Retrieved from http://nces.edu.gov/pubsearch

Clark, N. (2014, June). Towards a European higher education area: 15 year of Bologna. Retrieved from http://wenr.wes.org/2014/06/towards-a-european-highereducation-area-15-years-of-bologna/

Dunlap, E., Dudak, B., \& Konty, M. (2012). A synthesized model for integrating principles of adult learning in the higher education classroom. Kentucky Journal of Excellence in College Teaching and Learning 10, 19-35. 
Council for Adult and Experiential Learning (CAEL). (2005). Principles in practice: Assessing adult learning focused institutions. Retrieved from http://www.cael.org/pdfs/22_alfi_case_study

Li, D. (2010) They need help: Transfer students from four-year to four-year institutions. The Review of Higher Education 33(2), 207-238.

Paulson, A. (2012) Transition to college: Nonacademic factors that influence persistence for underprepared community college students. (Doctoral Dissertation). Available from ProQuest Dissertations and Theses database. (UMI No.3546033)

Robert Wood Johnson Foundation, Commission to Build a Healthier America. (2009). Education and health [Issue Brief 6]. Retrieved from http://www.commissiononhealth.org/ PDF/c270deb3-ba42-4fbd-baeb2cd65956f00e/ Issue\%20Brief\%206\%20Sept\%2009\%20\%20Education\%20and\%20Health.pdf

Ryan, C. L., Siebens, J., \& US Census, B. (2012). Educational Attainment in the United States: 2009. Population Characteristics. Current Population Reports. P20-566. Retrieved from http://www.pathwaylibrary.org/ViewBiblio.aspx?aid=20616

Schneider, M., Yin, L., \& American Institutes for Research (2011). The high cost of low graduation rates: How much does dropping out of college really cost? Retrieved from http://www.air.org/resource/high-cost-low-graduation-rates 


\title{
Information technology students’ beliefs on industry certifications
}

\author{
M. Koivisto* \\ * Mikkeli Universtity of Applied Sciences
}

\begin{abstract}
The common challenge of Information Technology (IT) educators all over the world is to design a curriculum that is relevant to the evolving needs of the industry and society in general. One method many universities have started to use is to embed industry certifications to their curriculums. In this paper IT students' beliefs on these certifications are analysed. The aim of the study is based on the following research question: How taking part on the certification training and exams changes students' beliefs on industry certificates, do students value the industry certification similarly today than earlier and do students see that the industry certificates are more important in some job roles than in others. The results of the study suggest that students have realistic idea what industry certificates are and where they are needed. Although the ever-increasing popularity of industry certificates have maybe somewhat decreased their value, students still believe that they are valuable especially when entering the labour markets. Therefore, the results of the study suggest that industry certifications should have a role in higher education curriculums also in the future.
\end{abstract}

Keywords: Industry certification; higher education; student beliefs

\section{Introduction}

The role and importance of Information Technology (IT) industry certification has been a topic amongst higher education institutions like colleges and universities for more than twenty years. Multiple stakeholders like certification providers, employers as well as some scholars have claimed that professional certifications are vital indicators of professionalism (Teske \& Philips, 2010; Chilton et al., 2010) and majority of hiring managers use professional credentials, such as industry certification, to identify properly skilled IT candidates (Microsoft, 2012). Although a formal degree and earlier work experience are essential for job applicants, industry certifications can give them a competitive advantage and set them above the competition.

The focus of the paper is on IT students' attitudes towards industry certifications and it is analysed from three different perspectives. First, possible changes in students' beliefs on industry certification is analysed by comparing opinions of students in different grades toward industry certificates. Because the first year students have not yet done any certification exams unlike the older students, the first research question of the paper is: Does participation on the certification training and exams change students' beliefs on industry certificates?

Second, the effect of time on certification beliefs is analysed also by comparing the current results against a study conducted in 2008. This lead us to the second research question of the study: Do students value the industry certification similarly today than earlier? The motivation of this question is that some critics (e.g. Snyder, 2012; Cinalli, 2015) have suggested that the increased popularity of IT certification programs has decreased the value of the certificates.

Third, IT students entering a labour market can select different careers and job roles (including e.g. a network or security professional, project manager, software developer, and database administrator). These tasks have different kinds of 
requirements and skills. Thus the third research question of the paper is: Do students see that the industry certificates are more important in some job roles than in others?

The structure of the paper is as follows. The next chapter of the paper is a short literature review on industry certificates and their believed benefits. After that research method and data collection process of the reported study are described. The results of the study are then presented and discussed and the paper ends with a conclusions section.

\section{Literature review}

Industry certification programs organized by vendors or professional societies focus on developing the skills and knowledge of a person to perform a job or task. The first corporate vendor certification (Certified Novel Engineer, or CNE) was issued already in 1989 (Adelman, 2000) and after that the number of companies and industry or professional associations offering them has increased dramatically. Lloret et al. (2013) distinguished three main types of certifications:

- Profession-wide certifications which do not depend on the company's definition of a certain job and they provide a professional knowledge and experience to the persons.

- Internal certifications, which are internal of a corporation, and can only be achieved by their personnel.

- Product or technology certifications. This kind of certificates have been very common in IT industry where personnel should be certified on a specific version of software or hardware.

Today certification is a big industry in which the leading companies deliver more than a ten million tests each year (PearsonVUE, 2015; Prometric, 2015). However, the benefits of certifications goes far beyond the testing centres. According to Randall \& Zirkle (2005) embedded certification programs offer benefits to multiple stakeholders including students, employers, vendors and educational institutions. Students can use the certificates and related skills to get employment. Employers can use certifications as a way to differentiate qualified candidates in a sea of resumes. Educational institutions gain access to ready-made, industry-sponsored IT curriculums that are responsive to workforce needs. A vendor benefits by gaining trained workers to support their product, service, or technology.

Although certifications benefit vendors and employers, the largest benefactors of IT certifications are the IT professionals. Some scholars suggest that certification particularly benefits inexperienced employees, who can market themselves using IT certification as a substitute for job experience. (Hitchcock, 2006). Kabia et al. (2013) however pointed out that this assumption is erroneous. They emphasized that experience does not necessarily imply skill or knowledge but the value of the certifications is in a person's ability to apply the gained knowledge and competency.

Multiple studies suggest that certifications do not only increase the chances of job acquisition, but it also, increases pay. For example, a survey conducted amongst 700 networking professionals concluded that after certification acquisition, 40 percent earned more pay and increased an average of ten percent (Bort, 2011).

Reinicke \& Janicki (2013) analysed the importance of certifications across areas of Information Systems. They found out that certification were far more popular in some 
jobs than in others. For example, 69 per cent of professionals working in networking or security have a certification. Similar high percentage was measured among IT project managers (63\%). On the other hand, in software development and database administration the percentage were remarkably lower (14\% and $20 \%$ respectively).

\section{Methods}

In this study IT students' beliefs on industry certifications was collected with a simple questionnaire. The questionnaire was distributed to IT students of a small Finnish university. The university has embedded two Cisco professional training courses (CCNA and CCNA Security) and three Microsoft MTA certifications (Networking fundamental, Security fundamentals and HTML5 to its curriculum). Because the CCNA course is divided to four parts the total number of compulsory certification tests in the curriculum is eight.

The target group of the survey was students in different grades and phases of their studies. This selection gave a possibility to analyse how student attitudes change over time. The first year students had not done any certification tests unlike the students on higher grades. The second year students had already done three or four tests and they had certification training during the data collection time. The third and the fourth year students had done all or almost all compulsory certification exams already (5 - 8 tests).

The total number of students was 49 (36 male and 13 female) and the distribution of the students for the classes is shown in Table 1 below. The third and fourth year students were combined into a single group because there are no compulsory certification exams during the fourth year.

Table 1. Number of students.

\begin{tabular}{|c|c|c|c|}
\hline & Male & Female & Total \\
\hline First year students & 15 & 3 & 18 \\
\hline Second year students & 10 & 5 & 15 \\
\hline Third and fourth year students & 11 & 5 & 16 \\
\hline
\end{tabular}

The data was collected with a paper questionnaire during the normal lecture times. The questionnaire contained the following sections: Background information, completed industry certifications or trainings, and students' general and sector specific beliefs on certifications. The general belief questions used in the survey were identical to questions used by Hunsinger \& Smith (2008) in their study on factors that influenced information system undergraduates to pursue IT certifications. The use of same questions gave a good possibility to compare our results against earlier findings.

\section{Results}

The students'general perceptions of outcomes of IT certification was captured through nine positive statements. These statements as well as results for different student groups are shown in Table 2 . The result are surprisingly similar for all grades. There is no statistical difference (p. <05) in any dimension between freshmen and older student groups. 
Table 2. Averages and standard deviations of students' general beliefs. (Likert scale: $7=$ strongly agree, $1=$ strongly disagree).

\begin{tabular}{|l|c|c|c|}
\hline I believe that certifications & $1^{\text {st }}$ year & $2^{\text {nd }}$ year & $\begin{array}{c}3^{\text {rd }} \text { and } \\
4^{\text {th }} \text { year }\end{array}$ \\
\hline Would increase my likelihood of getting hired by an employer. & $\begin{array}{c}6.07 \\
(0.64)\end{array}$ & $\begin{array}{c}6.30 \\
(0.62)\end{array}$ & $\begin{array}{c}5.64 \\
(0.94)\end{array}$ \\
\hline Would differentiate me from other job candidates applying for a & $\begin{array}{c}5.60 \\
(0.96)\end{array}$ & $\begin{array}{c}5.80 \\
(1.12)\end{array}$ & $\begin{array}{c}5.64 \\
(0.84)\end{array}$ \\
position. & 5.67 & 5.70 & 5.64 \\
& $(0.82)$ & $(1.06)$ & $(0.62)$ \\
\hline Would increase my marketability to potential employers. & 5.67 & 5.90 & 5.91 \\
& $(1.23)$ & $(1.39)$ & $(0.76)$ \\
\hline Would increase my qualifications for a job. & 5.93 & 6.20 & 6.27 \\
& $(1.17)$ & $(0.58)$ & $(0.83)$ \\
\hline Would give me an advantage over other job candidates who do & 4.93 & 5.40 & 5.00 \\
not hold an IT certification. & $(1.44)$ & $(1.31)$ & $(1.29)$ \\
\hline Would increase my helpfulness to a company. & 4.87 & 5.60 & 5.18 \\
& $(1.24)$ & $(1.07)$ & $(0.90)$ \\
\hline Would make me more valuable to a company. & 4.93 & 4.80 & 4.55 \\
& $(1.31)$ & $(0.94)$ & $(0.95)$ \\
\hline Would help me to make more money than a similar job candidate & 4.93 & 5.20 & 4.82 \\
who does not hold an IT certification. & $(1.12)$ & $(0.94)$ & $(1.28)$ \\
\hline Would help me to earn more respect. & &
\end{tabular}

In an earlier study over $90 \%$ of respondents replied with some measure of agreement (somewhat agree, agree, or strongly agree) to all nine statements used also in our study (Hunsinger \& Smith, 2008). Our results are compared against these earlier findings in Table 3.

Table 3. Summaries of the results in two studies.

\begin{tabular}{|l|c|c|c|c|c|c|}
\hline \multirow{2}{*}{ I believe that certifications } & \multicolumn{3}{|c|}{ Our results (N=49) } & \multicolumn{3}{c|}{ Hunsinger\&Smith (N=120) } \\
\cline { 2 - 7 } & $\begin{array}{l}\text { Percent } \\
\text { agree }\end{array}$ & $\begin{array}{l}\text { Percent } \\
\text { neutral }\end{array}$ & $\begin{array}{l}\text { Percent } \\
\text { disagree }\end{array}$ & $\begin{array}{l}\text { Percent } \\
\text { agree }\end{array}$ & $\begin{array}{l}\text { Percent } \\
\text { neutral }\end{array}$ & $\begin{array}{c}\text { Percent } \\
\text { disagree }\end{array}$ \\
\hline $\begin{array}{l}\text { Would increase my likelihood of } \\
\text { getting hired by an employer. }\end{array}$ & 93.9 & 6.1 & 0.0 & 97.5 & 2.5 & 0.0 \\
\hline $\begin{array}{l}\text { Would differentiate me from other job } \\
\text { candidates applying for a position. }\end{array}$ & 87.8 & 6.1 & 6.1 & 95.9 & 1.1 & 0.0 \\
\hline $\begin{array}{l}\text { Would increase my marketability to } \\
\text { potential employers. }\end{array}$ & 89.8 & 10.2 & 0.0 & 95.8 & 4.2 & 0.0 \\
\hline $\begin{array}{l}\text { Would increase my qualifications for a } \\
\text { job. }\end{array}$ & 91.8 & 2.0 & 6.1 & 95.8 & 2.5 & 1.7 \\
\hline $\begin{array}{l}\text { Would give me an advantage over other } \\
\text { job candidates who do not hold an IT } \\
\text { certification. }\end{array}$ & 93.9 & 4.1 & 2.0 & 95.0 & 5.0 & 0.0 \\
\hline $\begin{array}{l}\text { Would increase my helpfulness to a } \\
\text { company. }\end{array}$ & 71.4 & 12.2 & 16.3 & 92.6 & 5.0 & 2.4 \\
\hline $\begin{array}{l}\text { Would make me more valuable to a } \\
\text { company. }\end{array}$ & 77.6 & 14.3 & 8.2 & 92.6 & 5.8 & 1.6 \\
\hline $\begin{array}{l}\text { Would help me to make more money } \\
\text { than a similar job candidate who does } \\
\text { not hold an IT certification. }\end{array}$ & 59.2 & 32.7 & 8.2 & 90.0 & 7.4 & 1.6 \\
\hline Would help me to earn more respect. & 59.2 & 32.7 & 8.2 & 81.0 & 16.5 & 2.5 \\
\hline
\end{tabular}

Our results suggest that students still believe in positive outcomes of the certificates but our results are lower in all cases. The noticeable difference can be found in four last statements related to personal helpfulness, value to a company, higher earnings and respect. 
According to our survey students believed that certifications are not equally important in all sectors of information technology. They found certificates most valuable in network and security related jobs. For software developers certifications were considered to be less important. Descriptive statistics are shown in Table 4.

Table 4. Believed value of certification in different job roles.

(Likert scale: $7=$ strongly agree, $1=$ strongly disagree).

\begin{tabular}{|l|c|c|c|c|}
\hline Job type & Mean & SD & $\begin{array}{c}95 \% \text { CI } \\
\text { lower bound }\end{array}$ & $\begin{array}{c}95 \% \text { CI } \\
\text { upper bound }\end{array}$ \\
\hline Networking professional & 6.42 & 0.52 & 6.28 & 6.55 \\
\hline Security professional & 6.22 & 0.68 & 6.04 & 6.40 \\
\hline Project manager & 5.17 & 0.95 & 4.91 & 5.42 \\
\hline Software developers & 4.94 & 1.16 & 4.64 & 5.25 \\
\hline Database administrators & 5.58 & 1.01 & 5.31 & 5.85 \\
\hline
\end{tabular}

\section{Discussion}

This discussion section is organized according to the three research questions stated in the introduction.

\section{Research question 1: Does participation on the certification training and exams change students' beliefs on industry certificates?}

Our results are clearly suggesting that students' beliefs remain very stable before, during and after participating industry certification training and exams. We believe that this indicates that students have a good understanding of certification and therefore they do provide neither positive nor negative surprises to them. The certifications are essential part of current IT environment and according to our study students are aware of this.

\section{Research question 2: Do students value the industry certification similarly today than earlier?}

The finding of the study indicated that students still believed that certificates can help them to get a job and differentiate them from other applicants. When asked about various positive outcomes that could await them as a result of holding an IT certification, the average score was 5.47 (in Likert scale: $7=$ strongly agree, $1=$ strongly disagree).

When comparing our results against an earlier study we found out that in our study the number of students with some measure of agreement (somewhat agree, agree, or strongly agree) was lower in all nine statements and the average difference was 12.4 per cent. In some areas (like helpfulness to the company, higher earnings and respect) our results were remarkably lower (21.2, 30.8 and 21.8 respectively) than what was reported in 2008.

What could be the reasons for this development? It is too early to state some final conclusions but the popularity of industry certifications and increased number of institutions using them might have somewhat decreased the perceived value of industry certificates among students. 


\section{Research question 3: Do students see that the industry certificates are more important in some job roles than in others?}

Our results are indicating statistically significant differences between students' beliefs on importance of certifications in different jobs. They believed that certificates are most valuable for network and security specialist but less important for project managers, database administrators and especially for software developers. These results supports the findings of Reinicke \& Janicki (2013) although they pointed out even bigger differences between career paths.

\section{Conclusions}

This paper focused on IT students' attitudes towards industry certifications. The results of the study are suggesting that IT students' beliefs on professional certifications are realistic and therefore there is no statistically significant change during their study time. The increased number of different kinds of certificates and wide adaptation of certifications to university curriculums may have decreased the value of certifications but students still see them especially important when applying for a new job. Students seem to have also a quite clear idea in which jobs the certificates are almost a requirement and where they are currently so strongly required. This information is a vital when students are personalising their study plans according to their future career paths.

Our study has its limitations. First of all the study was conducted only in one university and the results cannot be generalized to all countries and cultures. Second, the sample size was quite small and discussion was limited only to the students' beliefs. Therefore, more studies are still needed to analyse the role of industrial certificates in academic education. For example, the employers' opinion about advantage of certifications in recruitment processes as well as professors' and teachers' views and best practices on embedding industry certifications to academic studies should be analysed.

Even with its limitations, the findings of the study clearly pointed out that students have positive attitude towards industry certifications and therefore industry certifications should have a role in higher education curriculums also in the future.

\section{References}

Adelman, C. (2000). A parallel universe, expanded: Certification in the information technology guild. Retrieved January 5, 2015, from Internet: http://www.aahe.org/change/paralleluniverse.htm

Bort, J. (2011). Will IT certs get you jobs and raises? Survey says yes. Network world, Nov 14.

Chilton, M. A., Hardgrave, B. C., \& Armstrong, D. J. (2010). Performance and strains levels of IT workers engaged in rapidly changing environments: A person-job fit perspective. ACM SIGMIS Database archive. 41 (1), 8-35

Cinalli, F. (2015). Are IT Certifications losing their value? Retrieved April 16, 2015 from Internet: http://federicocinalli.com/ 
Hitchcock, L. (2006). Methodology in computing education: a focus on experience, Proceedings of the 19th Annual Conference of the National Advisory Committee on Computing Qualifications. Wellington, New Zealand

Hunsinger, D. S., \& Smith, M. A. (2008). Factors that Influence Information Systems Undergraduates to Pursue IT Certification. Journal of Information Technology Education, 7, 247-265.

Kabia, M., Oni, O., \& Booher, L. (2013). Information Technology Certification as a Predictor of Job Performance. Journal of Leadership and Organizational Effectiveness, 1, (1), 15 - 32.

Lloret, J., Vela. M., Plaza E., de Soria, J., \& Pena-Ortiz, R. (2013). Industry Certificate Courses Enhance University Experts and Masters. Proc. of $4^{\text {th }}$ UNIVEST Conference, Girona.

Microsoft. (2012). Microsoft Certification Program Satisfaction Study.

PearsonVUE. (2015) Discover Pearson VUE. Retrieved January 20, 2015 from http://home.pearsonvue.com/About-Pearson-VUE/Discover-Pearson-VUE.aspx.

Prometric. (2015) About Prometric. Retrieved January 20, 2015 from https://www.prometric.com/en-us/about-prometric/pages/prometric-advantageoverview.aspx.

Reinicke, B. A. \& Janicki, T. (2013). Who Needs Certifications? A Survey of Certifications in the IT Industry. Proc. of the Information Systems Educators Conference, San Antonio, Texas, USA

Randall, M. H., \& Zirkle, C. J. (2005). Information Technology Student-Based Certification in Formal Education Settings: Who Benefits and What is Needed. Journal of Information Technology Education, Vol. 4.

Shaeiwitz, J.A., \& Turton, R. (2003). Educating chemical engineers in product design. International Journal of Engineering Education, 19, 153-157.

Snyder, B. (2012). The IT certs that no longer pay extra -- and the new skills that do. InfoWorld.

Teske, M. \& Philips P. (2010). Microsoft Technology Associate Student study guide 98-367.

Van Vugt, M., Hogan, R., \& Kaiser, R. B. (2008). Leadership, followership, and evolution: Some lessons from the past. American Psychologist, 63(3), 182-196. 


\title{
Teaching Histories Critically: Developing Pedagogies for Historical Literacy Across the Disciplines
}

\author{
N. R. November \\ The University of Auckland
}

\begin{abstract}
How can we leverage students' historical curiosity in order to develop deeper and more analytical engagement with the past? This essay identifies a problem in history education, a gap in our knowledge of history pedagogy. It then proposes a solution by showing why and how history educators can pursue a cross-disciplinary critique of their own pedagogies, with a view to transforming history education and expanding historical literacy. Where previous writers have focused on practices, and pre-tertiary history education, the present essay is centred on developing a methodology that will go deeper, enabling history educators to examine the pedagogical principles that underpin what happens in the tertiary-level classroom. In the research paradigm proposed here, knowledge and perceptions from teachers and students across historical disciplines are synthesised. This gives the pedagogical designs that result from engaging in collaborative 'crossover teaching' an unusually broad inter-disciplinary reach and utility. The innovative teaching designs that educators create when following this research paradigm incorporate best practices in teaching histories, and promote a newly revised 'index of historical literacy'.
\end{abstract}

Keywords: crossover pedagogies; history; historical literacy; inter-disciplinary research; pedagogy

\section{Introduction: a call for research into history pedagogies}

History is everywhere in our modern lives: on television, at the movies, on the bestseller lists. There is a thirst for knowledge of the past and a desire to use the past to situate ourselves in the present. New research into tertiary-level pedagogies of history is timely, also essential. This essay is a call to historians across the tertiary disciplines to leverage students' historical curiosity - and their responses to tertiary level learning experiences - in order to develop deeper and more analytical engagement with the past. I first identify problems and perspectives in teaching the past, then outline a five-step research process that seeks to expand the historical-critical horizons and skills of students and scholars alike.

\section{Historical literacy: problems and perspectives}

Many tertiary-level disciplines engage with historical subject matter. The ability to ask pertinent and probing questions about the past underpins many attributes of graduate study attributes in the humanities, arts, commerce, law and sciences. Asking such questions leads not only to new insights about the past and present, but also helps students to acquire transferable skills such as critical thinking, the use of evidence to support arguments, the interpretation of textual and visual sources, reflective practice and empathy. As Nokes (2011) observes, the objective of developing this kind of 'historical literacy' is to produce students 'who are able to negotiate and create the complex texts of the Information Age'.

But what exactly is 'historical literacy', and how can we best teach it? Responses to these questions are, to date, unclear. Indeed, the teaching of history has become the site for a central debate in both public and professional circles (Roberts, 2011). Several studies, including recent research, suggest that educators are not fully mining the potential of historical enquiry for developing students as 'critical beings' - individuals who, in Barnett's words, 'exert some unity of critical power over their experiences in relation to knowledge, themselves and the world' (2011, p. 109). For instance, 200- 
level Music students surveyed at the University of Auckland in 2012 tended to view music history as established fact and to have great difficulty formulating and answering complex, critically-oriented questions, as well as constructing critical, evidence-based arguments. These students' lack of skills highlights a gap in pedagogic understanding. Which other factors contribute to, or inhibit, their learning of historical literacies? What specific problems do students with various backgrounds and learning styles encounter in other historical disciplines? Which teaching strategies have tertiary educators employed to solve these problems and to what effect? These questions demand the attention of tertiary-level history teachers across the disciplines.

Historical literacy is already of critical interest in history studies (Duvenage, 1993; Monte-Sano, 2001; Nokes, 2013; Nokes, 2010; Reddy \& Van Sledright, 2010; Wineberg, 2001). Historians and history educators have given much attention to historical literacy, and how best to promote it in teaching and research. There has also been some research into developing historical literacy within various disciplines (Shanahan \& Shanahan, 2008; Damico and M. Baildon, 2011; Broomhead, 2005). A large body of literature is devoted to 'content area literacy', that is, the effective teaching of literacy skills, broadly conceived, within various subject areas. For instance, a recent New Zealand research project explores the role of the National Certificate of Education Achievement in motivating students to develop disciplinary expertise (M. Sheehan, K. Hunter, \& J. Howson, 2013). This study, and much of the related literature, deals with pre-university education, although it is at the tertiary level that learners usually first encounter sharply divided 'communities of practice' in the various academic disciplines (Shanahan \& Shanahan, 2008). A new standard of literacy is demanded at university, and students struggle with the tasks of asking and interpreting questions posed —and historical questions are often by nature complex.

To date there is no consensus on the definition of historical literacy. In a stock-take of teaching historical literacy, Taylor and Young (2003) define the term as 'a systematic process with particular sets of skills, attitudes and conceptual understandings that mediate and develop historical consciousness'. They develop an index of historical literacy comprising thirteen categories, which are a mixture of 'skills, attitudes and conceptual understandings'. These categories include, for example, 'narratives of the past', 'representational expression', and 'ICT [Information and Communication Technology] understandings'. This index is a start towards a definition of historical literacy, but it is also loose and mixed in terms of its categories. In 2009, Lee signalled the need for further work in this area: 'we need a workable notion of historical literacy'. Such a notion is, however, still not available.

\section{The fundamental question: how are we teaching history?}

There is a need for a definition of historical literacy that is both comprehensive and coherent. |One can start with the usefully broad and yet practical and cohesive idea of historical literacy as a set of practices that can be brought into classroom teaching and learning practice. New practice-centred teaching models in history have already been developed, which one can critique and adapt. For example, Indiana University’s History Learning Project identifies the six 'operations' involved in what they term 'historical thinking' (http://www.iub.edu/ hlp/beta/hlp.html). These operations are broader, more inclusive, and at the same time more unified than those offered by Taylor and Young. They are 'understanding the nature of the historical discipline and analysis', dealing with primary and secondary sources, 'constructing and evaluating arguments', and historical research and writing. These operations can help in compiling the components 
of the practice of historical literacy; however, they do not recognise the diversity of approaches of teachers in historical disciplines other than history itself. More research is needed into how historical literacy can best be promoted across the historical disciplines. Which concepts of historical literacy can be effectively shared and transferred within the disciplines, and why?

Ways of obtaining answers to these questions are outlined below. More fundamentally, though, we need explore not just what we are teaching when we teach historical literacy or historical thinking, but also how. History pedagogy is woefully under-researched. In an important investigation into teaching history, for example, Lévesque (2008) explores interdisciplinary approaches to history, but remains moored to 'historical thinking' (considering what we are teaching), rather than investigating the range of relevant pedagogies that would be appropriate to those disciplines (considering how we might best teach). Roberts (2011) recognises this gap and calls for a 'pedagogy of historical literacy and thinking'. His call has yet to be fully heeded: new research still tends to focus on the 'what' of historical studies teaching; hence the generation of lists or indexes of 'historical literacy' and 'historical understanding'. As Roberts notes, each list or index assumes or implies a particular pedagogy, but the question of why certain skills, concepts or attitudes germane to the historian are taught in that way, in comparison to other ways, remains largely unexamined. This is the case, for example, in Shep's (2014) project 'Moving beyond the Threshold: Investigating Digital Literacies and Historical Thinking in New Zealand Universities'. Shep's research team explored the extent to which 'digital media and methodologies' (related to Taylor and Young's 'ICT understandings') play a role in learning that involves the acquisition and retention of disciplinary 'threshold concepts' (core concepts that transform one's perception of a given subject, once understood). Which other concept types do educators and students consider useful in learning history, and (equally importantly) which are the most effective ways of teaching those concepts?

\section{Methods: 'Crossover Pedagogies'}

We need to first capture how historical literacy is taught across disciplines and then use that to establish a dialogue between history educators about the most useful and transferable pedagogies across the historical disciplines. Roberts' first step in building a pedagogy of history is to collaborate with museum educators in order to develop a more encompassing definition of historical literacy. This is a helpful start, but museum studies is just one of several historical disciplines that can inform the pedagogies that develop historical literacy. Research is needed into how historical literacy can best be promoted in diverse learners studying diverse histories.

To move forward with this research, and specifically to enable pedagogical exchange between history educators across disciplines, one can utilise Nash's (2009) concept of a 'crossover pedagogy'. Nash brings a co-teacher from another area of the university (student affairs) into his philosophy classroom to help open up dialogues with his students on moral and philosophical questions. His approach allows for multiple viewpoints, and a broad, critical understanding of meaning and knowledge; but he provides no theory as to what a 'crossover pedagogy entails', nor how one might assess and promote the most useful pedagogies across the disciplines.

One can both clarify and broaden Nash's work with a new concept of 'crossover pedagogies'; that is, approaches to teaching that are drawn from, or applied in, 
disciplines other than one's own. An ideal methodology for exploring 'crossover pedagogies' is one that is broadly based on action research and informed by educational design research (also termed 'design-based research') with two (or more) cycles of action and reflection (described in Phases 3 and 4, below; see especially Reeves, Herrington, \& Oliver, 2005; and Reeves, McKenney, \& Oliver, 2010). Educational design research typically proceeds from a complex, general question to specific course designs that are to be implemented in cycles. In educational design research, investigators seek out and apply guidelines or 'design principles' developed by other educators working in similar contexts. They then refine these educational designs iteratively, based on feedback from students and peers. These cycles can be carried out by what I will term 'crossover teaching partnerships', where each member of the partnership is from a different historical discipline.

One can usefully focus attention on upper-level (primarily 200-level) students because tertiary students are to some extent socialised within their chosen discipline by their second year. They are starting to understand what it means to study that discipline and to have a sense of their own approaches to and preferences for learning in the discipline. One can then draw on these students' discipline-based understandings and learning preferences as part of the research.

Five phases for the research are outlined below, with aims and methodological suggestions for each step. Phase 1 entails data gathering. Phase 2 then involves analysis and theorising about best practices in the teaching of historical literacy. Phases 3 and 4 comprise cycles of action and reflection: implementation of crossover teaching interventions, and analysis of feedback on these, respectively. Procedures for obtaining further feedback on the entire process are then detailed in Phase 5.

\section{Phase 1: exploring history pedagogies}

Aim The primary aim of Phase 1 is to gather data on history pedagogies that are applied across the historical disciplines, together with understandings of historical literacy. This will enable a broadening and re-formulation of previous scholars' indexes and categories of 'historical literacy' and 'historical understanding' in Phase 2. Researchers will then be in a position to examine their teaching, describing and evaluating the various pedagogies that they implicitly or explicitly deploy.

Methods In this phase, teachers from different historical disciplines pair up and have an initial discussion about their understandings of historical literacy and their approaches to teaching it. Discussion questions should be designed to encourage the sharing of information about pedagogical approaches, and their efficacy in the selected disciplines. One can be guided in here by the HEART strategy (HEaring And Realising Teaching-voice) developed by Blake and Donald (2009). This strategy uses visualisation techniques and concept mapping in order to build up a picture of the pedagogical beliefs that underpin a given teacher's practices. Concept mapping will also help the crossover teaching partners to establish a working list of the practices that they consider central to teaching historical literacy.

\section{Phase 2: reformulating the index of historical literacy}

Aims To analyse and reflect on the pedagogical approaches and definitions that one uncovers in Phase 1, then use the knowledge gained in reformulating the 'index of historical literacy', drawing on best practices from across the historical disciplines.

Methods Ultimately, the HEART strategy is designed to assist with the sharing of teaching designs and resources, but Blake and Donald (2009) recognise the need to first 
make explicit underlying teaching beliefs of the participants. In analysing results, one can to try to understand why a given history teacher, working within a given discipline, chooses certain content and 'delivers' that content in certain ways. The visual output of the HEART strategy facilitates comparisons of teachers' approaches from across the disciplines.

Shulman (2005) develops a typology of 'signature pedagogies in the professions', types of teaching that organise the fundamental ways in which future practitioners are educated for their new professions. As well as using the visual output of the HEART strategy, one can compare the data gathered in Phase 1 to the 'signature pedagogies' outlined by Shulman, to see if the typologies that he outlines are present and whether they are helpful for categorising the new data. Here, 'future practitioners' are 200-level university students, and the 'professions' are the historical disciplines.

Researchers can also compare the concept maps produced by staff participants to the published lists of 'historical literacy' and 'historical understanding' by key spokespeople and institutions, such as Taylor and Young, and Indiana University History Department. Questions to ask include: to what extent are their models duplicated here? Are there new categories? Crucially: how do teachers' practices vary across the disciplines?

Regarding instructors' evaluative comments on their teaching, the well-established Learning Paradigm developed by Barr and Tagg (1995) can provide guidance as to what constitutes 'best practice'. Under this paradigm, knowledge is understood as shaped by individual experience; learning is considered as student centred; and ideal learning environments are considered to be those that are cooperative, collaborative, and supportive. This model of learning as it fits in with social constructivists' views of fostering 'communities of practice' and 'student-centred learning' (Wenger, 1998; Wenger, McDermott, and Snyder, 2002).

\section{Phase 3: Crossover Teaching Part I}

Aim The overall aim of this phase is to implement and then evaluate new teaching interventions, based on the critical evaluation of the history pedagogies that one has surveyed and reflected on in Phases 1 and 2.

Method Using the pairs of teachers from Phase 1, a pedagogical strategy for teaching history that has proven useful (to teachers and students alike) in one's own discipline can be applied in that of one's partner. For example, a teacher in History might deploy an effective teaching practice from History Studies in a Music History course, and vice versa. One can exchange not only 'signature pedagogies' but also the respective subjects' key historical practices. Thus, for example, music students might consider how an 'event'- or conflict-centred view of history (rather than a composeror musical score-centred view) helps them to think about the concept of periodization.

In Phases 3 and 4, the teaching partners should meet as soon as possible after each teaching intervention, to reflect on what worked and what did not in the respective classes, and why. Critical Incident Questionnaires (CIQs), as developed by Brookfield (2006), can form a key source of information on student perceptions following from each of the teaching interventions. These questionnaires provide 'awareness of how students are experiencing their learning and perceiving [the teacher's] actions' (p. 27).

\section{Phase 4: Crossover Teaching Part II}


Aim The overall aim of this phase is to further develop the Crossover Teaching begun in Phase 2. Here one can move from the teaching of a known concept with a known pedagogical style in another discipline, to the application of a new pedagogy from another discipline in one's own course.

Methods A pedagogical strategy for teaching history that has proven useful by one's crossover teaching partner can now be tried out in one's own class. For example, a teacher in English Literature might deploy a new teaching strategy, adapted from that of a colleague in Art History, to illustrate a key concept within his/her own course, and vice versa.

\section{Phase 5: obtaining and analysing feedback on the interventions}

Aim Ultimately, one needs to discover the extent to which the various history pedagogies are transferable and useful in new disciplinary contexts, from both the staff and student perspective, and to assess the degree to which student learning of key practices, operations and understandings in historical studies were improved.

Methods After Phase 4, surveys of those history educators who have carried out interventions can be carried out, with questions targeted to the crossover teaching partners' assessment of both the 'what' (content) and the 'how' (pedagogical basis) of the interventions deployed. One can then compare the results of these surveys to the data obtained from pair discussions carried our in Phase 1, mapping and documenting any shifts in understanding that might relate to a given educator's discipline.

A further evaluation tool that is useful in this context is 'ipsative' assessment. As discussed by Hughes (2009), this tool is ideal for the 'before and after' study of student outcomes that is deployed in this research. Here, the 'ipsative' assessment could, for example, be a form of formative student self-assessment, entailing two linked assignments, one at the beginning of the course and one at the end. The first assignment can provide a picture, albeit a partial one, of what students know about history in relation to the given discipline at the start of the course, allowing the instructor to identify and use this prior state of understanding as the basis for development. The second assignment can be designed to provide information about what knowledge students gain from the 'cross taught' units and new pedagogies.

\section{Conclusion: potentials of the process}

The research outlined here is firmly focused on enhancing learner outcomes: it aims to lead to significant improvements in terms of historical skills and understandings across various disciplines for diverse learners, including men and women, mature students, and international students from various cultures. These learner outcomes are expected to include new insights about the past and present, and also the acquisition of transferable skills such as critical thinking, use of evidence to support arguments, selfreflection, empathy and interpretative facility with many textual and visual sources.

In carrying out 'crossover pedagogies', teachers are simultaneously cast as educational researchers, and their perceptions and actions inform all stages of the research process, as do those of their students. Thus the investigators stand to gain many insights from each other, and from their students. The interventions that the teaching partners develop and implement can be expected to significantly strengthen their abilities to teach historical literacies, and to broaden pedagogical practices so as to engage a wider variety of learners more deeply in history studies than previously. Further, insofar as 
researchers seek through this process to encompass 'other histories' and other ways of studying/narrating history than the mainstream ones, it will help to promote equity in tertiary education.

The project's research processes are designed to enable educators' active learning from one another in two cycles, which proceed from 'known' pedagogies (one's own), to relatively unknown ones (those of one's partner). Of course, these cycles of planning, action, and reflection can be extended, so that educators involved in the project can be engaged in reflective and developmental teaching activities with other partners, and pedagogical practices drawn from other disciplines, or those that are based on other practices in the revised Index of Historical Literacy.

While this project focuses on tertiary-level education, researchers can also aim to engage the attention and feedback of secondary-level teachers. This can be carried out with a view to improving the logic and scaffolding of history teaching across educational sectors. This broader purview is important: tertiary-level history study demands new levels of literacy, creating significant new demands on learners; but these learners come to tertiary study with views of history and approaches to learning that have already been decisively shaped through their secondary-level studies.

\section{References}

Barnett, R. (1997). Higher Education: A Critical Business. Buckingham, UK: SRHE and Open University Press.

Barr, R. \& Tagg, J. (1995). From Teaching to Learning: A New Paradigm for Undergraduate Education, Change, 27(6), 12-25.

Blake, A. \& C. Donald, C. (2009). Reviewing Learning Designs with HEART: A Learning Design Support Strategy. Paper presented at ASCILITE 2009, Auckland:

http://www.academia.edu/5632327/Reviewing_learning_designs_with_HEAR T_A_learning_design_support_strategy.

Broomhead, P. (2005). (Re)Imagining Literacies for the Music Classroom. In R. J. Draper (Ed.), (Re)Imagining Content-Area Literacy Instruction (pp. 69-81). New York: Teacher's College Press.

Brookfield, S. (2006). The Skillful Teacher: On Technique, Trust, and Responsiveness in the Classroom, 2ed. San Francisco: Jossey Bass.

Damico, J. S. \& Baildon, M. (2011). Content Literacy for the $21^{\text {st }}$ Century:

Excavation, Elevation and Relational Cosmopolitanism in the Classroom, Journal of Adolescent \& Adult Literacy, 55(3), 232-43.

Duvenage P. (ed.). (1993). Studies in Metahistory. Pretoria: Human Sciences

Research Council.

Hughes, G. (2011). Towards a Personal Best: A Case for Introducing Ipsative

Assessment in Higher Education, Studies in Higher Education, 36(3), 353-367.

Lee, P. (2009). Historical Literacy: Theory and Research, International Journal of Historical Learning, Teaching and Research, 9: http://www.heirnet.org/IJHLTR/journalstart.htm.

Lévesque, S. (2008). Thinking Historically. Toronto: University of Toronto Press. Nash, R. J. (2008). Crossover Pedagogy: The Collaborative Search for Meaning, About Campus, 14, 2-9.

Nokes, J. (2013). Building Students' Historical Literacies: Learning to Read and Reason with Historical Texts and Evidence. New York: Routledge. 
Nokes, J. (2011). Historical Literacy, Social Studies: Newsletter of the Utah State Office of Education, 6-9.

Nokes, J. (2010). Reimagining Literacy for History Classrooms. In A. P. Jensen, J. D., Nokes, \& D. Siebert (Eds.), (Re)imagining Literacies for Content-Area Classrooms (pp. 159-171). New York: Teachers College Press.

Reddy K., \& Van Sledright, B. (2010). 'Epistemic Change in History Education' Paper presented at the annual conference of the College and University

Faculty Assembly, Denver Colorado.

Reeves, T., Herrington, J. \& Oliver, R. (2005). 'Design Research: A Socially Responsible Approach to Instructional Technology in Higher Education', Journal of Computing in Higher Education, 16(2), 97-119.

Reeves, T., McKenney, S. \& Oliver, R. (2010). 'Publishing and Perishing: The Critical Importance of Educational Design Research’. Paper presented at ASCILITE 2010, Sydney.

Roberts, P. (2011). 'From Historical Literacy to a Pedagogy of History'. Paper presented at Building Bridges for Historical Learning: Connecting Teacher Education and Museum Education, Canberra:

http://learnonline.canberra.edu.au/file.php/5882/Discussion_Paper_From_hist orical_iteracy_to_a_pedagogy_of_history.pdf.

Shulman, S. (2005). 'Signature Pedagogies in the Professions’, Daedalus, 134(3),

59.

Shanahan, T. \& Shanahan, C. (2008). 'Teaching Disciplinary Literacy to Adolescents: Rethinking Content-Area Literacy', Harvard Educational Review, 78(1), 40-59.

Sheehan, M., K. Hunter, \& Howson, J. (2013). “"Thinking Historically”: The Role of

NCEA Research Projects in Motivating History Students to Develop Disciplinary Expertise'. Website: http://www.tlri.org.nz/tlri-research/researchcompleted/school-sector/\%E2\%80\%98thinking-historically\%E2\%80\%99-rolencea-research-projects.

Shep, S. (2014). 'Moving Beyond the Threshold: Digital literacies and historical thinking in New Zealand Universities'. Website: http://www.ee.ucl.ac.uk/ mflanaga/abstracts/TC14Abstract30.pdf.

Taylor T. \& Young, C. (2003). Making History: A Guide for the Teaching and Learning of History in Australian Schools. Website: http://www.hyperhistory.org/index.php?option=displaypage\&Itemid=220\&op $=$ page.

Wenger, E. (1998). Communities of Practice: Learning, Meaning, and Identity. Cambridge, UK: Cambridge University Press.

Wenger, E., McDermott, R., and W. C. Snyder, W. (2002). Cultivating Communities of Practice: A Guide to Managing Knowledge. Boston: Harvard Business School Press.

Wineberg, S. (2001). Historical Thinking and Other Unnatural Acts. Philadelphia: Temple University Press. 
HEAd'15

SESSION 7A COMPUTER-BASED
LEARNING 


\title{
Computer based learning and comprehension of power generation cycles using a model programmed in Engineering Equation Solver (EES): Analysis of a Gas- Turbine Brayton cycle
}

\author{
C. Montagud*, J. Pons-Llinares*, M.C. Rodríguez-Monzonís** \\ * Instituto de Ingeniería Energética \\ Universitat Politècnica de València \\ València, Spain \\ ** Instituto de Ciencias de la Educación \\ Universitat Politècnica de València \\ València, Spain
}

\begin{abstract}
The comprehension of the influence of each design and operation parameter in a power generation cycle requires a complex analysis mainly due to coupled effects existing in these cycles and which is too hard to be assessed manually by the students during a practical session. Therefore, the use of a software tool specially developed for this purpose becomes essential. The present work presents a model of a Gas-Turbine Brayton cycle developed in EES (Engineering Equation Solver), which enables the student to make simulations in the software and easily determine the optimal design parameters that would maximize the electric energy production in this kind of cycle. In order to evaluate the usefulness of this tool, two questionnaires with the same questions were prepared and were provided to the students before and after the practical session. After analyzing the results of the questionnaires, and taking into account the comments provided by the students, it was concluded that using this methodology helps to stimulate the student's understanding during the session, and enables to verify that students put into practice their theoretical knowledge, being able to make a better transfer to more complicated and real applications in the future.
\end{abstract}

Keywords: Computer-aid learning and comprehension, engineering application, analysis and optimization of complex processes.

\section{Introduction}

\section{Context of the analyzed subject}

This paper presents a practical methodology to help the learning and comprehension of the students enrolled in a subject of the official master degree in "Energy Technology for a Sustainable Development" at the Universitat Politècnica de València (UPV) in Valencia, Spain. The master is divided in two main parts as shown in Figure 1: the first one comprises 4 compulsory fundamental subjects which cover 15 credits ECTS and the second, consists of 3 different specializations which cover the next 27 credits ECTS each. The subject that will be analyzed in this paper is called 'Introduction to Energy Technology', and it is one of the fundamental subjects taught during the first semester of the master.

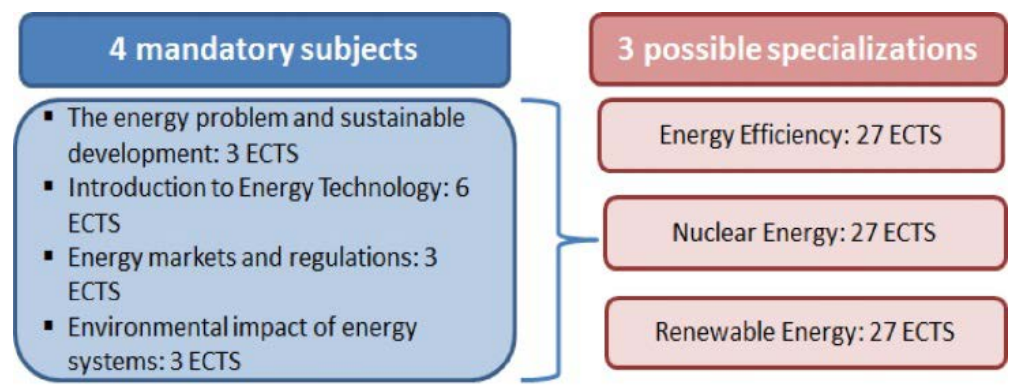

Figure 1. Structure of the "Master in Energy Technology for a Sustainable Development". 
"Introduction to Energy Technology" is divided into two main parts: the first one covers an overview of the different energy sources, where their main technological aspects are studied; and the second one, covers the study of power generation cycles where not only the components are analyzed but also the optimal design and operation parameters. Among the different practical lessons proposed, the one that is trying to be improved with the descriptive work here presented is dedicated to analyze the Gas- Turbine Brayton cycle for power generation.

The subject has been taught by the authors for four years now, i.e, since the 2009-2010 academic year. Since then, a systematic observation was carried out and the feedback information collected by the students was reflected on a diary according to Zabalza (2004). Further analysis of this information allowed to have evidence of the students' opinion and thus enabled the authors to improve in their teaching-learning process, especially during the practical lessons of the subject. It was observed that, it was too hard and time consuming to students to manually analyze the influence of each of the design and performance parameters in a power generation cycle in a single practical lesson which turned out to be very time consuming and unfeasible in the duration of the subject. Therefore, it was considered the need of providing students with a software tool able to easily identify the main performance and design parameters of this kind of cycles, study its influence in the cycle efficiency and learn to find their optimal values. This way, students could put into practice their theoretical knowledge by means of a software tool during the practical sessions of the subject.

This paper will present the results obtained for this teaching technique of the GasTurbine Brayton cycle which was recently carried out during the academic year 20132014. This same technique could be also applied to any other type of power generation cycle. The equations that describe the performance of the Gas- Turbine Brayton cycle were programmed in a software tool that was described and provided to the students who learned how to use it. The model developed is very friendly to use, and it helps students to develop some other similar models in their future work. Therefore, it also contributes to the development of some of the competences related to the master: decision making, system design, research skills, applying knowledge to the industrial practice, or performing energy audit.

The usefulness of this tool is assessed by means of a descriptive study on teaching strategy developed in class. To this end, two questionnaires with the same questions are provided to the students: one before and another one after the practical session. Then, the student can compare the answers provided before and after the practical session and determine whether it has been useful to improve their understanding during the practical session and to a latter extent in their learning process. Nevertheless, as there are many other factors that could influence the student's performance, the authors are aware that, through the strategy employed, it cannot be ensured that this is the only factor affecting the achieved progress in the student's learning and comprehension.

No empirical data are presented by the authors in this work for two main reasons: first of all, the process will be repeated during the next academic courses in order to improve the software itself; and second, more information will be compiled by the authors over the next several years of teaching in order to have a greater amount of data and be able to make a more complete diagnosis. 


\section{Gas- Turbine Brayton Cycle Model Developed}

Description of an ideal Gas- Turbine Brayton cycle

The Gas- Turbine Brayton cycle is a thermodynamic cycle that describes the operation of a constant pressure heat engine. Gas turbine engines use the Brayton Cycle. Although the Brayton cycle is usually run as an open system (and indeed must be run as such if internal combustion is used), it is conventionally assumed for the purposes of thermodynamic analysis that the exhaust gases are reused in the intake, enabling analysis as a closed system (Closed Brayton cycle). Figure 2 shows the components of a basic Gas- Turbine Brayton cycle: a gas compressor, a burner (or combustion chamber) and a gas turbine.
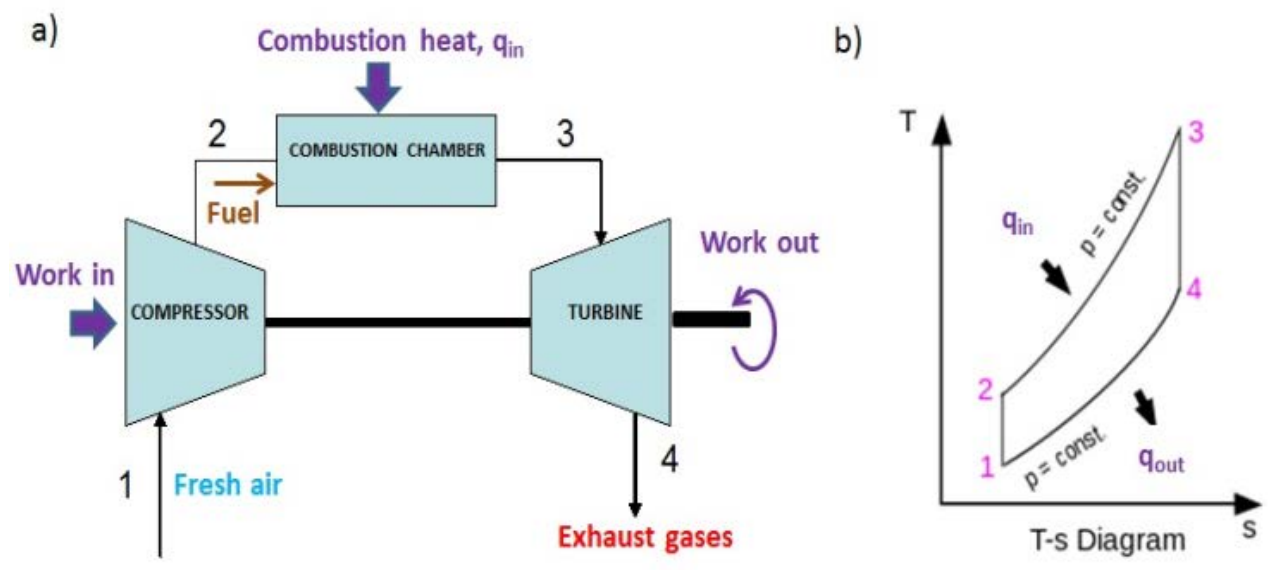

Figure 2. a) Gas- Turbine Brayton cycle: main components; b) T-s diagram of an ideal Gas- Turbine Brayton cycle.

There are four main processes that take place in a Gas- Turbine Brayton cycle:

1-2: Isentropic Compression. Ambient air is drawn into the compressor, where it is pressurized.

2-3: Isobaric Heat Transfer. The compressed air then is introduced in a combustion chamber, where fuel is burned, heating the compressed air at constant-pressure.

3-4: Isentropic Expansion. The heated and pressurized air enters the gas turbine (or series of turbines), and it expands obtaining useful energy. It should be stressed that some of the work extracted by the turbine is used to drive the compressor.

4-1: Isobaric Heat Rejection in the atmosphere. The exhaust gases in the gas turbine cool down at constant ambient pressure in contact with the atmosphere.

The efficiency of the power generation Gas- Turbine Brayton cycle is defined by equation (1):

$$
\eta_{\text {cycle }}=\frac{W_{\text {net, cycle }}}{W_{c}}
$$


Where $\mathrm{W}_{\text {net,cycle }}=\mathrm{W}_{t}-\mathrm{W}_{c}$, is the difference between the useful energy obtained in the turbine $\mathrm{W}_{t}$, and the consumed energy needed in the compressor, $\mathrm{W}_{c}$.

The calculation of heat and work per unit of mass of operating fluid can be expressed as the difference between the inlet and outlet enthalpy of the operating fluid at each component of the cycle.

\section{Inefficiencies of Real Gas- Turbine Brayton Cycles}

In real plants, each stage of the Gas- Turbine Brayton cycle is associated with irreversible processes, which reduce the overall efficiency. On one hand, turbine and compressor present irreversibilities that reduce the overall efficiency of the cycle. The isentropic efficiency of the turbine and the compressor is defined by equations (2) and (3) respectively, where subscript 'is' indicates isentropic values.

$$
\begin{aligned}
& \eta_{t}=\frac{W_{t}}{W_{t, i s}} \\
& \eta_{c}=\frac{W_{c, i s}}{W_{c}}
\end{aligned}
$$

Looking at the formulas (2) and (3), and taking into consideration that the efficiency takes values lower than $100 \%$, it can be concluded that the irreversibilities make the real work obtained in the turbine decrease, and the real compression work needed increase. The turbine efficiency directly reduces the work produced in the turbine and, therefore, the overall efficiency. The same thing happens with the compressor efficiency: the work needed in the compressor increases and reduces the overall efficiency. On the other hand, the heat transfer processes at the combustion chamber are not ideal and there exist associated irreversibilities. The heat combustion process will not be considered in the equations and the combustion chamber will be considered as a heat exchanger where the combustion heat is added to the compressed air at constant pressure.

\section{Increasing the Efficiency of Gas- Turbine Brayton Cycles: parameters of influence}

The optimization of the cycles for power generation highly depends on the right choice of the design parameters. There are four main design and/or operation parameters that have an influence in the overall cycle efficiency:

- $\quad$ Temperature of the air entering the turbine: the higher the inlet temperature at the turbine, the higher will be the expansion work obtained.

- Pressure ratio: relation between the inlet pressure at the turbine and the inlet pressure at the compressor (ambient pressure in open cycles). In principle, the greater the pressure ratio (greater inlet pressure at the turbine), the greater will be the efficiency of the cycle, but there is an optimum that will be analyzed by the students in the practical session.

- Isentropic efficiency of the turbine: the higher the isentropic efficiency, the higher the efficiency of the cycle.

- Isentropic efficiency of the compressor: the higher it is, the greater is the cycle efficiency. 


\section{Methods}

This section describes the steps and methodology that were followed during the teaching strategy followed in class.

The practical session took place in a computer lab where 22 students were grouped in pairs, carrying out a cooperative work as proposed by Slavin (1990), and Reynolds et al. (2013).

First, a brief review of the theoretical knowledge needed to develop the tasks corresponding to the practical session was carried out. The equations needed to characterize the Gas- Turbine Brayton cycle which had already been presented during previous theoretical lessons, were reminded to students in order to make sure that they had the background needed to follow the practical session. After this short review, the software tool was presented to the students, explaining them its main features and tools, and they were given some free time to get used to it.

Finally, a descriptive evaluation of the learning and comprehension of the students was carried out as presented in the following subsections.

\section{Software tool developed in the Engineering Equation solver}

In the Gas- Turbine Brayton cycle presented in this paper, there is a strong interdependency between the different design and operation parameters. Some of the states (2, 3, and 4), presented in Figure 2a, are interdependent. For each state, the thermodynamic properties need to be determined, and therefore, changing one design parameter implies that the student would need to redo all the calculations, which normally takes the student thirty minutes. As the duration of the practical session is two hours, it is unfeasible to make many parametric studies in order to find the optimal design and operation parameters for such a cycle. Therefore, there is a need to use a software tool in which the necessary equations to calculate each state are already programmed, so that the student can check the effect of each parameter in the cycle performance in a very fast and easy way. This kind of software tools become especially important when analyzing a real power generation plant, in which the thermodynamic cycle gets more complex as it includes several expansion and regeneration processes. With the aid of such software tools, it is possible to carry out several parametric studies and easily determine the optimal design parameters at any cycle independently of its complexity.

Engineering Equation Solver (EES: Engineering Equation Solver, 2015) was the software chosen to program the equations of the Gas- Turbine Brayton cycle. The EES is a general equation-solving program able to numerically solve a great number of coupled non-linear algebraic and differential equations. The main reason why it was chosen is the high accuracy of its thermodynamic and transport property database, available for hundreds of substances, which can be used with the equation solving capability. Among other features, the software allows carrying out parametric studies which are useful for optimization purposes.

Figure 3 presents the interface that was developed in EES and provided to the student in order to analyze the influence of each design parameter on the cycle performance.

Using this tool, the student can analyze the influence of each design parameter (which appear framed in Figure 3 on the cycle efficiency, just by changing its value and clicking on the 'Calculate' button For instance, they could determine the optimal 
pressure ratio by making a parametric study, as shown in Figure 4a. Figure 4b shows another parametric study carried out by the students where they could analyze the influence of the temperature inlet of the air in the turbine (T3 in Figure 3) in the efficiency of the cycle.
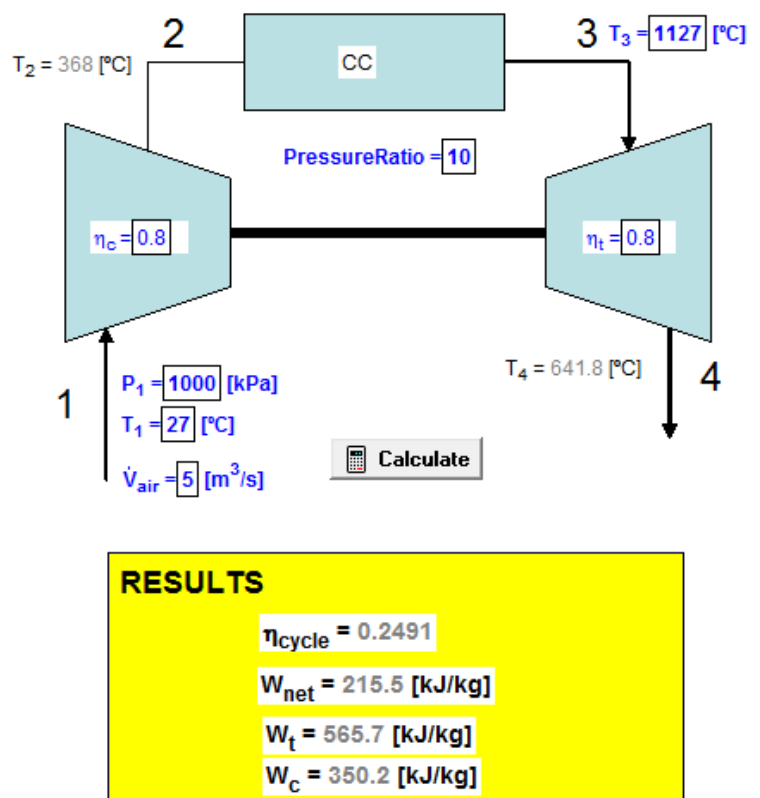

Figure 3. Basic Gas- Turbine Brayton cycle: diagram window programmed in EES.
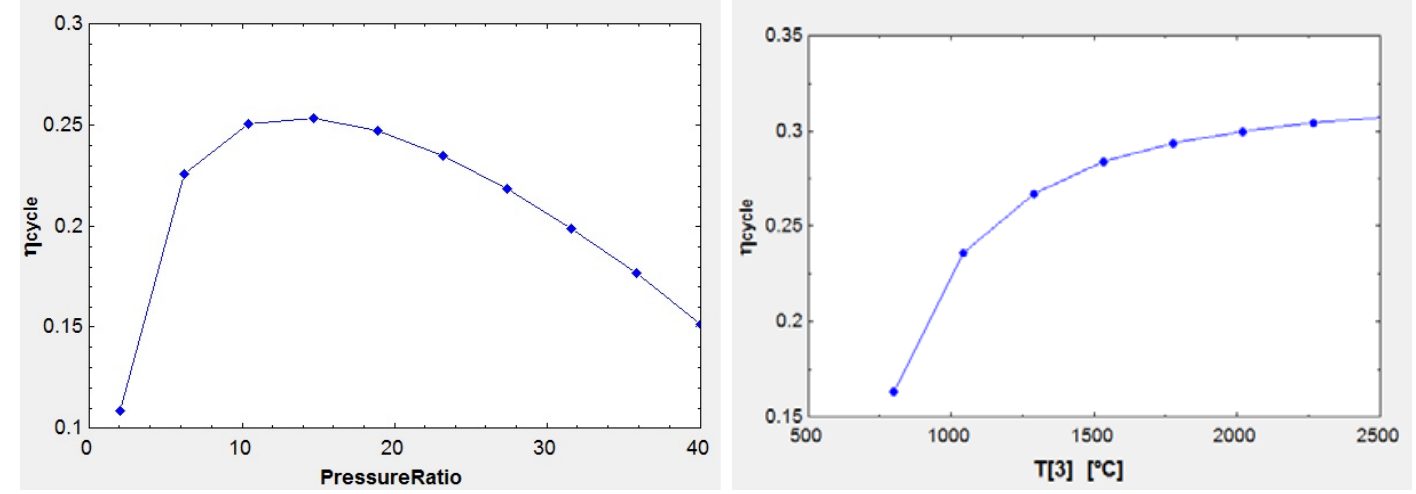

Figure 4. a) Influence of the pressure ratio in the cycle efficiency. b) Influence of the temperature of the air entering the turbine, T3, in the cycle efficiency.

\section{Evaluation of the learning and comprehension}

In order to carry out a diagnostic evaluation of prior knowledge as explained in Gibbs (2003), a simple questionnaire was provided to each group (2 students) before starting the practical session. The following questions were raised:

- Which are the three main components of a basic Gas- Turbine Brayton cycle and which process does it take place in each of them?

- Which are the four main design parameters that have an influence on the efficiency of the cycle? 
- How does the efficiency of the cycle vary when diminishing the value of each of the design parameters?

- Which is the main parameter that has a greater influence on the efficiency of the cycle?

Once the students had filled in the questionnaires, a brief theoretical review was carried out and the software tool was presented to the students so that they could program the equations of the cycle. Among the main features of the EES software, extra time was dedicated to the use of the parametric studies tool and the diagram window previously presented in Figure 3. After introducing the equations of the cycle in the EES software, students were asked to carry out several parametric studies (like the ones previously presented in Figure 4a and Figure $4 \mathrm{~b}$ in order to analyze the influence in the cycle efficiency of the following parameters: inlet pressure of the air at the turbine (P3), which varies modifying the value of the pressure ratio; inlet temperature of the air at the turbine, (T3); isentropic efficiency of the turbine, $\eta_{t}$, and isentropic efficiency of the compressor, $\eta_{c}$. Finally, the same questionnaire was provided to the students who were asked to answer exactly the same questions that were raised at the beginning of the practical session.

\section{Results and Discussion}

The results of the pre-test and post-test are presented in Figure 5a and Figure 5b respectively.
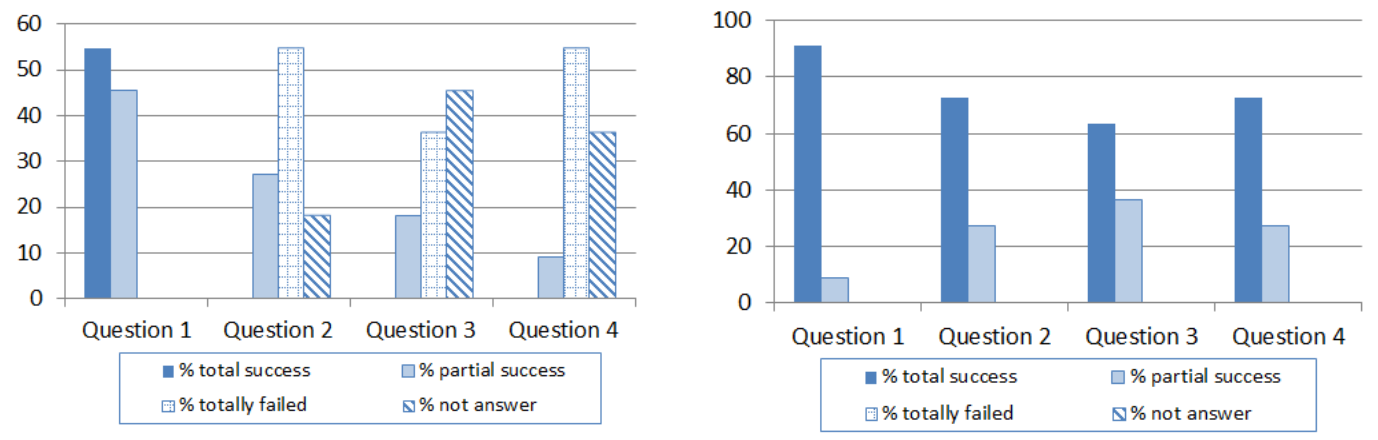

Figure 5. a) Results obtained in the pre-test. b) Results obtained in the post-test.

Results are expressed as the percentage of students that successfully answered to each question, those that partially succeeded in their answer, those that totally failed, and finally, those that left it blank notes. As shown in Figure 5a, most students knew the correct answer to the first question, since it was the most basic one, and they could easily answer it from the theoretical knowledge taught in other lessons which took place before the practical session. On the other hand, it can also be observed that, as the difficulty of the questions increased (question 2, 3 and 4), the percentage of students who totally succeeded dramatically decreased until values of $0 \%$ in all the questions, with a small percentage of $15 \%$ to $20 \%$ of students that partially answered correctly to questions from 2 to 4 . On the other hand, it can also be observed that approximately a fairly high percentage of students (in some cases higher than the 50\%) just left it blank notes, probably for fear of being judged by providing a wrong answer.

Figure 5b shows the results obtained after the practical session. As it can be observed, almost $100 \%$ of students correctly answered the first question. With respect to the second question, the percentage of students who answered correctly highly increased 
in comparison with the pre-test results, being the percentage of students that totally succeeded around $70 \%$. The same happened in questions 3 and 4 , in which the success rates clearly increased from $0 \%$ in the pre-test to $53 \%$ and $45 \%$ in the post -test respectively. It is observed that the percentage of students that totally failed the questions or those who leave it blank has become $0 \%$ in the pre -test up to values greater than $60 \%$ in the post-test, with maximum values of up to $70 \%$ on question 4 . Finally, taking a look at the results, it can be concluded that the practical session was useful for students who, after the practical session, had acquired a better comprehension of how the Gas- Turbine Brayton cycle performs as well as the influence of each of the design parameters on the efficiency of the cycle.

\section{Conclusions}

Based on the results observed in this descriptive study and considering the feedback provided by the students after the practical session, it was concluded that the developed tool and methodology followed helped to ease the student's comprehension during the session, making it possible to verify that it may have contributed to an improvement and stimulation in their personal learning process. Early feedback from students was very positive, as some of them informed the authors that they used it to prepare the exam, and confirmed their willing to use it in future works.

In order to allow a more complete analysis, the following future actions are proposed:

- Perform a qualitative analysis of the data through the development of surveys in which the students express their opinion on the usefulness of the methodology presented.

- Repeat the process along different academic courses, and take into account the feedback from students to improve both the software and the teaching strategy followed.

- $\quad$ Analyze if the software could be used in other subjects of the same master and get coordinated with the corresponding teachers in order to help them develop similar teaching strategies.

- Follow up with some students during their early working life and check whether they use it or they would find it useful at their work.

\section{References}

EES: Engineering Equation Solver. Retrieved January 21, 2015, from www.fchart.com/ees/

Gibbs, G. (2003) Uso estratégico de la evaluación en el aprendizaje. In Brown \& Glasner (Ed.). Evaluar en la universidad. Problemas y nuevos enfoques (pp. 6170). Madrid: Narcea.

Reynolds, W., Miller, G., \& Weiner, I. (Eds.) (2013). Cooperative Learning and Achievement: Theory and Research. Handbook of Psychology (2nd ed., Vol.7, pp. 199-212). Hoboken, NJ: Wiley.

Slavin, R.E. (1990). Cooperative learning. New Jersey: Prentice-Hall.

Zabalza, M. Á. (2004). Diarios de clase: un instrumento de investigación y desarrollo profesional, Madrid: Narcea. 


\title{
Development of a Classification Scheme for Errors Observed in the Process of Computer Programming Education
}

\author{
D. Zehetmeier* **, A. Böttcher**, A. Brüggemann-Klein*, V. Thurner** \\ * Technische Universität München, Faculty of Informatics \\ Boltzmannstraße 3, D-85748 Garching \\ ** Munich University of Applied Sciences, Faculty of Computer Science and Mathematics \\ Lothstr. 64, D-80335 München
}

\begin{abstract}
Every semester, we observe more or less the same principal difficulties among our students who are striving to learn the intricacies of software development. Basically, they run into the same kind of errors throughout their learning process as previous student generations. Based on this fact, we suspect that there is a set of underlying problems which are causing these errors. Our goal is to identify and tackle these basic problems, in order to deal with errors effectively in our teaching and coaching activities, rather than merely treating observable symptoms. To achieve this, we develop a comprehensive and topic-independent error classification scheme and employ this to classify errors found in literature and in our own courses. This classification scheme is mainly based on the cognitive dimensions of the revised Bloom's taxonomy for educational objectives. Each error is based on a deficiency in certain competencies. Therefore, it is possible to develop a set of interventions for each error class, which focuses on the specific deficits that are the main cause for all the errors of this class.
\end{abstract}

Keywords: Computer Science Education; Student assessment

\section{Introduction}

Many years of experience in teaching software development and software engineering in higher education have shown that over and over again, a significant part of each new generation of students runs into more or less the same principal difficulties and produces the same kind of errors throughout their learning process. Informal discussions with colleagues (both national and international), as well as literature research, implies that many of these difficulties and errors occur universally and thus seem to be of a more general nature, rather than being caused by our own individual teaching styles.

For example, the notion of 'if-loop' (rather than if-then-else being a 'choice') is still widely spread, although all the lecturers whom we have personally asked so far swear that they have never ever said 'if-loop' when students were present.

As the work of a significant number of students shows the same errors, we suspect that there is some set of underlying problems that is responsible for causing these errors. To deal with these errors in an effective way, we therefore have to identify these basic problems, rather than merely curing the symptoms that have been observed in individual cases.

\section{Goals}

Students' difficulties and errors observed in the process of computer science education and, more specifically, software development education, are manifold. In fact, there are so many of them that it is almost impossible to deal with each error individually.

Instead, we attempt to categorise the observed difficulties and errors and cluster them into classes. As key criterion for this classification, we use the underlying problem that causes the observed difficulties and errors. More precisely, we focus on which basic 
competency is insufficient or lacking completely, but would avoid the problem if it were sufficiently developed.

To validate our classification scheme, we categorise a number of typical errors, both from literature and those identified in class work of our own students.

Thus, firstly we aim to understand the underlying causes of the observed errors. Secondly, we boil them down to a manageable set of crucial competencies that must be sufficiently developed in our students, so that they are able to effectively acquire the computer science related expertise required for the academic degree they aspire to. On this basis, we plan to develop a set of interventions which systematically address those base competencies that are identified as being crucial, but missing in our students.

\section{State of the Art}

Error classification schemes have already been investigated to a certain extent. To gain a comprehensive overview of typical faults and 'things that are done wrong', we extended our literature review on errors to the general area of STEM (science, technology, engineering, and mathematics). However, as classification schemes tend to be more domain-specific, we focused our review of existing classifications on the domain of computer science.

\section{Errors and Misconceptions}

The most comprehensive term for 'things that are done wrong' is the concept of error. An error is "the state or condition of being wrong in conduct or judgment" (Dictionary). For example, an error in an exam is everything that is incorrect, or a missing answer where an answer would be required. A study that extensively uses this term is published by Hristova et al. (Hristova, Misra, Rutter, \& Mercuri, 2003).

Another common term is misconception. It is often used in scientific papers, but usually not defined explicitly. Misconceptions and their influence on teaching are discussed in many disciplines, like physics, chemistry (Barke, 2006), biology (Dreesmann, Graf, \& Witte, 2012) or computer science (Pea, 1986).

For the notion of misconception, many synonymous terms are used in literature, such as alternative conceptions (Barke, 2006), preconceptions (Barke, 2006), naive beliefs or bugs (Pea, 1986). Bahar (Bahar, 2003) states that the term misconception is widely used in research, is well-known to the public, and indicates that the concept in a student's mind differs from the scientific concepts. Therefore, we adopt this expression throughout this work.

If the students' existing ideas are a misconception rather than correct knowledge, problems will occur when new content in this area is provided, e.g. when the misconception runs contrary to the true scientific concept. As a consequence, as all new information is interpreted based on existing knowledge, undetected misconceptions will seriously inhibit the learning process.

In our opinion, Dreesmann (Dreesmann, Graf, \& Witte, 2012) uses the most complete definition, naming all relevant characteristics of a misconception. Accordingly, in this paper we use the following definition translated from (Dreesmann, Graf, \& Witte, 2012): 
Misconception is a logical and coherent concept. Thus, it fits into personal experience and knowledge. Nevertheless, it is wrong or contrary to scientific concepts.

\section{Known Error Classifications}

Most of the errors described in literature are either not classified at all (such as Humbert (Humbert, 2006) and Rabel (Rabel, 2011)), or classified by a schema based on the content domain, in whose teaching the error occurred.

For example, Sorva (Sorva, 2008) uses three classes of errors: understanding of variables, understanding of object variables, and understanding of the relationship between primitive and object variables. These error classes are specific for the understanding of data storage topics, but would not work with algorithms, for example.

The paper "Exploring Programming Misconceptions" (Sirkiä \& Sorva, 2012) investigates different types of errors, classified as: miscellaneous basic concepts, functions, or object-oriented programming. Thus, they are following the topics of introductory courses on software development.

As a consequence, errors in more advanced topics, like threading or generics, are difficult to classify, as they usually involve a variety of problems from different fundamental topics.

In contrast, Hristova (Hristova, Misra, Rutter, \& Mercuri, 2003) and Pea (Pea, 1986) introduce more general classifications. Pea (Pea, 1986) derives three classes of errors from one "superbug". The superbug describes that many students implicitly assume that a computer can think, or interpret, or has a mind. From this initial superbug, students derive a variety of erroneous notions; for example, that different lines of code can be active at the same time; or that a program can act in foresight; or that computers can do something that has not been specified in the program.

In addition, Hristova et al. (Hristova, Misra, Rutter, \& Mercuri, 2003) classify errors according to a schema which is well-established in computer science, i.e. into syntactic, semantic and logic errors.

Syntax errors are the ones based on misspelling, punctuation and word order in a program.

Semantic errors occur on a higher intellectual level. They deal with the meaning of the code and arise from mistaken ideas of how a programming language interprets certain instructions.

Finally, logic errors are the most general type of error, as they result from the programmer's misguided thinking, rather than from language characteristics.

\section{Detection and Clustering of Errors}

In order to use any classification scheme, it is necessary to be aware of the errors that have to be classified. Several methods to identify errors are known from literature:

Sirkiä (Sirkiä \& Sorva, 2012) analyses solutions that students submitted to a system for Visual Program Simulation (VPS). In contrast to this, in the study of Sorva (Sorva, 2008), students are interviewed. 
To identify and cluster errors, we use the following techniques:

- Similar to (Sirkiä \& Sorva, 2012), we analyse solutions that students turned in as assignments or in exams. To this end, we go through the pile of solutions twice. In the first iteration, we scan through all the solutions, to identify and take notes on the observed errors. Then, we organise the observed errors into clusters, leading to a collection of some three to eight main clusters. In the second iteration, we resurvey all the solutions and assign each erroneous solution to an error cluster. Having accomplished this, we are able to count the number of hits for each cluster. The higher the number of solutions in a cluster, the more important it is to identify the cause of the error and to find an adequate remedy. This process is depicted in Figure 1.

- We observe our students through lab sessions and try to analyse and categorise their errors on the fly. In this setting, we are able to immediately ask them questions regarding their solutions. Thus, we can retrieve valuable information on underlying problems that led to their errors.

- In our previous teaching experience, we have collected errors that are made by a significant number of programming novices. If we are aware of an error that frequently occurs in a specific context, we ask questions or design assignments in a way that is likely to provoke this error, thereby making the underlying problems visible. Thus, we help students to become aware of their error, to reflect on their own thinking and, finally, to reach a correct solution on their own.

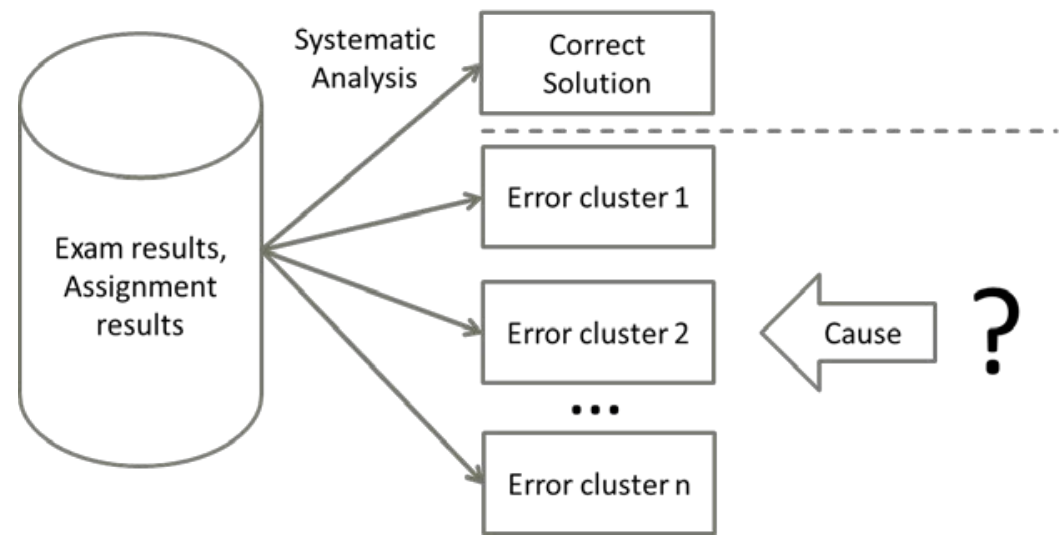

Figure 1. Error identification process

As an example, we look into one of the initial exercises that our first year students have to solve in their introductory course on software development. Here, students are required to implement a Java class Sheep, to represent and draw a sheep composed from several ellipses, which are used as basic shapes. We provide a class for drawing ellipses, hints on coordinates of the sheep's parts, as well as a screenshot showing a prototype of our sheep. In the exercise, the sheep is required to change its colour and its position.

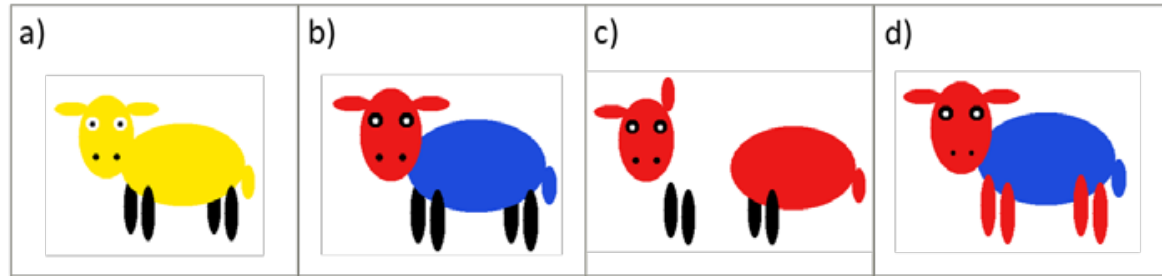

Figure 2. Different examples of sheep programmed and turned in by our students. We see one correct variant (a) and three kinds of errors: Colour hard-coded (b), insufficient passing of parameters for coordinates (c), and wrong drawing order (d). 
Figure 2. (a) depicts a correct solution, where all the woolly parts of the sheep are of the same colour and the sheep is topologically correct. Sheep (b) is multi-coloured. When the sheep is moved, sheep (c) has its torso severed from the rest of its body parts. Sheep (d) is multi-coloured like sheep (b), and has all of its four legs in front of its body, rather than two legs on the off-side and two on the side facing the front. In addition, several students did not have any clue what to do, and were unable to create anything at all. Each of these errors represents one error cluster.

For all the identified and clustered errors, in a next step we try to conjecture the reason why students solved the problem exactly in the way they did. This is crucial for finding the cause of this kind of error, which, in turn, is a prerequisite for successfully dealing with the principal error, rather than just correcting mere symptoms.

To achieve this, we look into the technical realisation of the different sheep error classes. Here, we discover that the error in sheep (b) is caused by hard-coding colour values by copy-and-paste, rather than parameterising the colour information. Sheep (c) was butchered by not passing parameters for coordinates from the body to the parts, whereas the creators of sheep (d) first drew the sheep's body and all the sheep's legs afterwards, being unaware that the sequential processing order of the different statements influences the final result.

Obviously, the visible error symptoms are highly specific to the exercise in question. However, the underlying problems as well as their causes are of a more general nature. Therefore, as a next step we develop a scheme to classify errors according to their causes.

\section{Classification Scheme}

We deem the error classifications described in literature so far to be insufficient, as they are highly specialised and thus do not provide a single general classification approach that is suitable for a large variety of errors.

When searching for a more comprehensive and topic-independent classification scheme, our central idea is to relate error causes to the competency levels and categories of cognitive processes that were defined by the revised Bloom's taxonomy (Anderson, et al., 2001). In our teaching experience, this taxonomy has proven to be a suitable basis for describing teaching goals. Usually, the revised Bloom's taxonomy is used to describe competencies on different skill levels. Analogously, it is possible to categorise the identified deficiencies according to the corresponding Bloom levels.

More precisely, the revised Bloom's taxonomy focuses on the cognitive domain. It is structured into six increasingly complex levels called cognitive process dimensions (see Table 1.), which classify the learners' thinking behaviour. Each of these dimensions has several sub-dimensions, to allow for a more detailed clarification of the levels (Anderson, et al., 2001). Furthermore, Anderson et al. distinguish four general types of knowledge, i.e. factual, conceptual, procedural and metacognitive knowledge. 
Table 1. Cognitive process dimensions according to (Anderson, et al., 2001), and their definitions.

\begin{tabular}{|l|l|l|}
\hline Level & $\begin{array}{l}\text { Categories and } \\
\text { cognitive processes }\end{array}$ & Definition \\
\hline 1 & REMEMBER & $\begin{array}{l}\text { Retrieve relevant information from long-term } \\
\text { memory. }\end{array}$ \\
\hline 2 & UNDERSTAND & $\begin{array}{l}\text { Construct meaning from instructional messages. Build } \\
\text { connections between new information and prior } \\
\text { knowledge. }\end{array}$ \\
\hline 3 & APPLY & $\begin{array}{l}\text { Locate and use procedures to perform exercises } \\
\text { (familiar and routine approaches) and solve problems } \\
\text { (procedure initially not known). }\end{array}$ \\
\hline 4 & ANALYSE & $\begin{array}{l}\text { Break material down to its components and identify } \\
\text { how the parts are related and what is the overall } \\
\text { structure. }\end{array}$ \\
\hline 5 & EVALUATE & $\begin{array}{l}\text { Make judgments based on criteria (e.g. quality, } \\
\text { effectiveness, efficiency and consistency) and } \\
\text { standards. }\end{array}$ \\
\hline 6 & CREATE & $\begin{array}{l}\text { Put elements together to form a new product. Mentally } \\
\text { reorganise parts into a pattern not clearly presented } \\
\text { before. }\end{array}$ \\
\hline
\end{tabular}

In our error classification scheme, we organise errors in a way that is similar to Bloom's taxonomy, in that it specifies what kind of competency is lacking, thus causing the observed error (see Table 2.). In addition, we name and characterise each error class and relate it to its corresponding Bloom level, i.e. the competence level that is deficient if this error occurs.

Lack of accuracy (sloppiness) is independent of all the cognitive processes described in the revised Bloom's taxonomy. Therefore, we introduce another category that is below all of those categories defined by (Anderson, et al., 2001). Inspired by Donald E. Knuth (Knuth, 1989), we name it MENTAL TYPO, indicating a lack of concentration, accuracy or, as Knuth says, 'less brainpower left for small details'. An example would be to leave out the brackets after a method call or to forget a semicolon.

KNOWLEDGE GAP is the second class of error. It correlates to Bloom's REMEMBER level. Typical deficits would be not knowing one's type of learner, too little diligence or not learning definitions by heart. In a context of informatics education, this could occur if students do not know the definition of the terms class and object. Furthermore, it could be that students think Java String is a primitive data type, as they REMEMBER a misconstrued and thus incorrect definition.

The third class is called MISCONCEPTION, which is partly what has been defined in section 'State of the Art'. The new definition includes wrong and missing connections. 
Table 2. Classification scheme for errors, including a description of the error, the underlying deficits as well as the competencies that are lacking in each case.

\begin{tabular}{|c|c|c|c|}
\hline \multicolumn{2}{|c|}{ Error Class } & \multirow{2}{*}{$\begin{array}{l}\text { Description } \\
\text { Inability to imagine a new } \\
\text { product or synthesise a new } \\
\text { solution from known } \\
\text { information and methods. }\end{array}$} & \multirow{2}{*}{$\begin{array}{l}\begin{array}{l}\text { Deficits in Base Competencies } \\
\text { (Lack of) }\end{array} \\
\text { Ability to synthesise a lot of } \\
\text { information (being creative, being } \\
\text { innovative) }\end{array}$} \\
\hline 6 & $\begin{array}{l}\text { LACK OF } \\
\text { INNOVATION }\end{array}$ & & \\
\hline 5 & $\begin{array}{l}\text { QUALITY } \\
\text { GAP }\end{array}$ & $\begin{array}{l}\text { Inability to evaluate software } \\
\text { (either self-created or ready- } \\
\text { made) against general quality } \\
\text { standards. }\end{array}$ & \begin{tabular}{lrr}
\multicolumn{2}{l}{ Pragmatism, transfer } & general \\
criteria to specific & $\begin{array}{r}\text { example } \\
\text { (thinking concretely, } \\
\text { thinking } \\
\text { critically) }\end{array}$
\end{tabular} \\
\hline 4 & $\begin{array}{l}\text { STRUCTURAL } \\
\text { BLINDNESS }\end{array}$ & $\begin{array}{l}\text { Inability to distinguish } \\
\text { components and their internal } \\
\text { interaction, in a given setting. }\end{array}$ & $\begin{array}{l}\text { Structuring unknown/external data } \\
\text { according to a systematic and } \\
\text { methodical approach (being able to } \\
\text { structure) }\end{array}$ \\
\hline 3 & $\begin{array}{l}\text { WRONG } \\
\text { CHOICE }\end{array}$ & $\begin{array}{l}\text { Wrong problem classification } \\
\text { and selection of solution } \\
\text { process. }\end{array}$ & $\begin{array}{l}\text { Assignment of a problem to a } \\
\text { solution process (decision-making, } \\
\text { evaluating), context-sensitivity } \\
\text { (thinking holistically, analytically) }\end{array}$ \\
\hline 2 & $\begin{array}{l}\text { MIS- } \\
\text { CONCEPTION }\end{array}$ & $\begin{array}{l}\text { Faulty concept in mind that } \\
\text { fits into previous personal } \\
\text { experiences, or not } \\
\text { understanding a concept at all. }\end{array}$ & $\begin{array}{l}\text { Correct connection between new } \\
\text { information and previous } \\
\text { knowledge (thinking holistically) }\end{array}$ \\
\hline 1 & $\begin{array}{l}\text { KNOWLEDGE } \\
\text { GAP }\end{array}$ & $\begin{array}{l}\text { Not knowing definitions or } \\
\text { terms. }\end{array}$ & $\begin{array}{l}\text { Diligence, knowledge about } \\
\text { oneself (e.g. type of learner) (being } \\
\text { able to reflect) }\end{array}$ \\
\hline 0 & $\begin{array}{l}\text { MENTAL } \\
\text { TYPO }\end{array}$ & Sloppy work & $\begin{array}{l}\text { Concentration, brainpower to get } \\
\text { the small details right, nervousness } \\
\text { (being accurate, being focused, } \\
\text { being efficient) }\end{array}$ \\
\hline
\end{tabular}

Thus, if students interpret new information in a wrong way, and form their understanding on this basis, this results in a misconception. Furthermore, not understanding an issue or a topic is also a misconception in this schema. Hence, students with an error in this class were not able to connect new information correctly with previous knowledge, or they built wrong connections. One common example is that students are often unable to distinguish between identity and equality, which is an important concept in many programming languages.

WRONG CHOICE is the term selected for the fourth class. It indicates as a deficit a faulty mapping of a problem to the solution process, and vice versa. This error can have two reasons: a wrong problem classification or the selection of an inappropriate solution mechanism. Using an enum instead of inheritance is an example of this error class.

Error class five describes the inability to identify and to distinguish components and their internal interaction, in a given setting. Thus, we call this error class STRUCTURAL BLINDNESS. An instance of this error class is that students are unable to understand or debug external code. Another example is that students have difficulties in analysing a task description. The underlying deficit is the inability to structure unknown content, a lack of identifying structure and the inability to work systematically and methodically. 
A QUALITY GAP occurs if a deficit in pragmatism exists. Another error that is rather specific for the area of computer science is a transfer problem. Students are not able to transfer quality standards concerning software to their personal or unknown code. This could appear in code snippets like FIVE $=\mathbf{5}$; for a definition of a constant value. More generally, any student who writes code that is logically correct, but does not meet the quality standards, has a quality gap - provided we are sure that they had already been taught about quality standards (otherwise this could also very well be a knowledge gap).

The final error class is LACK OF INNOVATION, corresponding with Bloom's level CREATE. For example, students are unable to create an appropriate algorithm to solve a specific task. Furthermore, if a student copies another student's solution or does not hand in anything at all, this is included in this error class as well. Deficits behind this error might be insufficient creativity or the inability to synthesise individual pieces of information.

\section{Examples for the Assignment of Errors in the Scheme}

To demonstrate the classification process as well as the universality of the scheme, we classify errors both from literature and from our own courses. As an example, we refer to the papers of Hristova et al. (Hristova, Misra, Rutter, \& Mercuri, 2003), Sorva (Sorva, 2008) and Pea (Pea, 1986).

- Unbalanced brackets (Hristova, Misra, Rutter, \& Mercuri, 2003): This error is caused by sloppiness. Thus, it is a MENTAL TYPO.

- Java String is a primitive data type (Sorva, 2008): This is a KNOWLEDGE GAP. Students learned a faulty definition, or did not learn the definition at all, even though they had been provided with the correct definition.

- $\quad$ Not knowing the meaning of an object declaration (Sorva, 2008): This is also a KNOWLEDGE GAP. Students are not able to remember the definition of a declaration.

- Computer knows different lines at the same time (Pea, 1986): This is a MISCONCEPTION as students have a faulty understanding of how a computer really works.

- Code has more meaning than it actually has (Pea, 1986): This is also a MISCONCEPTION, as students have a faulty understanding, which might originate from their human interaction experiences. The communication partner interprets much more than just the spoken words, such as facial expression, gesture and the context of the conversation. Thus, statements within a conversation are interpreted. If students transfer this understanding to a computer, they are not grasping the fact that a computer needs precise and self-contained instructions.

- Only move the Sheep's body [course]: This is a MISCONCEPTION, too. Here, students are actually transferring their knowledge from everyday experience: If they move their body, the head and everything else follows automatically. In programming, this has to be explicitly expressed in the code.

- While-loop instead of if-statement [course]: In our courses, it sometimes happens that students use a while-loop instead of an if-statement. They evaluate the condition and do something once. In order to achieve this, they change the condition variable within the loop, so that the loop's body is executed only once. This is an error which belongs in the WRONG CHOICE category, as students decided to use an inappropriate construct, although he or she had already learned the appropriate one.

- Not revealing the object structure [course]: In the assignment 'Sheep', many students just used the basic parts of the sheep and put them together in the main method, rather than hierarchically structuring them into more complex objects such 
as eyes or head. For example, eyes have an iris and a pupil. Correspondingly, a head includes nostrils, eyes and ears. Note that the required parts and their relationships were depicted in a UML-diagram. Nevertheless, students simply ignored these relationships. Therefore, this error is of type STRUCTURAL BLINDNESS.

- 20 conditions in if-statement instead of loop [course]: In our practical course, students used 20 conditions in an if-statement to check whether a word (with a maximum length of 40 characters) is a palindrome or not. Although the code worked fine, this is a bad programming style. Hence, students have a QUALITY GAP.

- Duplicate code [course]: We mentioned above that students often have duplicate code in their programs. Classification schemes from literature do not cover this type of error. Within our schema, it is a QUALITY GAP. Although the produced code works correctly, it neither meets known quality standards, nor conforms with proven practice. As students already had lecture units on good programming style, they should have known better.

- $\quad$ Not solving a problem [course]: One of our assignments had two parts, which were only slightly different. All the students solved the first part. Although the second part did not require any additional expert knowledge, only half of the students managed to solve the second task. The difficulty was that they had never had a similar task before. Hence, they were unable to develop a new solution. This indicates that students have a LACK OF INNOVATION.

\section{Conclusion}

Summing up, we first described an approach to find error clusters based on students' exam or assignment results. As a next step, we introduced our error classification scheme and applied this to classify these errors. Finally, we sketched the underlying causes of the observed error clusters.

The developed classification scheme is based on the well-known revised Bloom's taxonomy (Anderson, et al., 2001). We applied it for classifying errors that we observed in the process of computer science education. In addition, we mapped deficits to our teaching goals, as both are based on the same taxonomy. The resulting classification scheme is comprehensive and topic-independent. It is possible to classify all the errors found in literature and throughout our courses. As a set of examples, we classified around further 30 errors during our research.

A benefit of this scheme is that new errors can be classified by various people. Thus, it is not necessary to present a complete list of all possible errors. Rather, any person able to follow our classification process can classify errors. To verify whether our classification scheme is applicable in a more general way, in future work we will attempt to classify errors from other disciplines.

On the basis of our error classification scheme we can now explicitly create teaching goals that specifically address common errors. Currently, we are looking for existing interventions, as well as developing new ones, for each error class of the scheme. These interventions should focus on typical underlying deficits for each error class. Furthermore, interventions must be general enough to be appropriate for every error correctly classified in the corresponding class. 


\section{References}

Anderson, L. W., Krathwohl, D. R., Airasian, P. W., Cruikshank, K. A., Mayer, R. E., Pintrich, P. R., . . . Wittrock, M. C. (Eds.). (2001). A Taxonomy for Learning, Teaching, and Assessing. A Revision of Bloom's Taxonomy of Educational Objectives (1 ed.). New York: Longman.

Bahar, M. (2003). Misconceptions in Biology Education and Coneptual Change Strategies. Educational Sciences: Theory \& Practice, 3, 55-64.

Barke, H.-D. (2006). Chemiedidaktik - Diagnose und Korrektur von Schülervorstellungen. Springer.

Dictionary, O. E. (n.d.). Misconception. Misconception. Retrieved from http://www.oed.com/

Dreesmann, D. C., Graf, D., \& Witte, K. (2012). Evolutionsbiologie - Moderne Themen für den Unterricht. (S. B. Heidelberg, Ed.) Spektrum Akademischer Verlag. Retrieved from http://link.springer.com/book/10.1007/978-3-8274-2786-1

Hristova, M., Misra, A., Rutter, M., \& Mercuri, R. (2003). Identifying and Correcting Java Programming Errors for Introductory Computer Science Students. Proceedings of the 34th SIGCSE Technical Symposium on Computer Science Education (pp. 153-156). New York, NY, USA: ACM. Retrieved from http://doi.acm.org/10.1145/611892.611956

Humbert, L. (2006). Didaktik der Informatik - mit praxiserprobtem Unterrichtsmaterial. Teubner. Retrieved from http://link.springer.com/book/10.1007/978-3-8351-9046-7

Knuth, D. E. (1989). The errors of TEX. Software: Practice and Experience, 19(7), 607-685.

Pea, R. D. (1986). Language-independent conceptual "bugs" in novice programming. Journal of Educational Computing Research, 2, 25-36.

Rabel, M. (2011). Grundvorstellungen in der Informatik. Informatik mit Kopf, Herz und Hand - Praxisbeiträge zur 14. GI-Fachtagung "Informatik und Schule" (INFOS2011), (pp. 61-70).

Sirkiä, T., \& Sorva, J. (2012). Exploring Programming Misconceptions: An Analysis of Student Mistakes in Visual Program Simulation Exercises. Proceedings of the 12th Koli Calling International Conference on Computing Education Research (pp. 19-28). New York, NY, USA: ACM. Retrieved from http://doi.acm.org/10.1145/2401796.2401799

Sorva, J. (2008). The Same but Different - Students' Understandings of Primitive and Object Variables. Proceedings of the 8th International Conference on Computing Education Research (pp. 5-15). New York, NY, USA: ACM. Retrieved from http://doi.acm.org/10.1145/1595356.1595360 


\title{
Learning from Feedback on Work-Related Learning: Skills Acquisition and Reality Check
}

\author{
D Palmer-Brown*, FF Cai* ${ }^{* *}$ P Patel ${ }^{* * *}$ \\ ${ }^{*}$ London Metropolitan University, ${ }^{* *}$ Anglia Ruskin University, ${ }^{* * *}$ London Metropolitan University
}

\begin{abstract}
An increasingly strong focus of higher education is now placed on the acquisition of skills that will strengthen the employability prospects of learners. This has led to, among other provisions, the embedding of work-related, workbased and project-based components into the academic curriculum for which newer forms of assessment and assessment feedback are necessary.

This paper reports on a pilot study which aims to understand the relationship between learning development in the last stages of an undergraduate's journey and their first experiences of employment. The study was conducted with a small cohort of computing graduates whose degree includes an embedded final year work-related learning module. The outcome of this study shows that whilst employability skills were reported to have indeed improved through this module, the graduates felt ill-prepared for the productivity demands of the workplace. There was also a strong reflection among them now in employment that an additional exposure, as part of the module, to formal appraisal techniques and competency terminology utilised throughout industry sectors would have had an added benefit.
\end{abstract}

Keywords: feedback, work-related learning, employability, graduate skills, learning agreements

\section{Introduction}

The past decade has seen the fortifying of employability skills acquisition into Higher Education (HE) programmes in all subject disciplines. On the one hand, the priority placed by students on developing generic, transferable and work-related skills as an integral part of their academic study in order to enhance their employment prospects has never been higher. On the other hand, employers continue voicing their strong concerns over graduates who are lacking necessary problem-solving, business communication and team-working skills required in the workplace. These dual demands have been responded to by the HE sector with the introduction and embedding of several work-related learning initiatives into the academic curriculum.

Venables \& Tan (2009) describe work-related learning as a form of experiential learning where students learn through their experiences rather than from direct transmission of material. The term work-related learning is sometimes used to mean that learning which is developed and experienced in the workplace, Simons \& Ruijters (2008); possibly outside an academic programme. This is seen to be a form of training and is perhaps better termed work-based learning, where the learning experiences arise directly from the work tasks to hand.

Work-related learning initiatives are particularly predominant in the computing, science and business disciplines where most take the form of a module with a work placement opportunity and a series of assessments, for example Clements \& Cord (2013). Many programmes include such a module in the final year of study, whereas McKinnon \& McCrae (2012) believe that work-related activities should be embedded into the first year curriculum in order to allow for early exposure to the benefits of enhancing employment skills. The work of Jollands et al. (2012) on project-based learning for engineers gives an insight into how 'aspects of undergraduate experiences assisted with their transition into the workplace'. Graduates (and their managers) were interviewed to ascertain their work-readiness in a number of skills including project management, problem solving and communication. The study explores the degree of work-readiness 
but does not examine the use of assessment feedback and how that was understood and deciphered by the recipient and which elements have direct applicability and effectiveness to workplace tasks. Hopkins (2008) places emphasis on engaging with college leavers in order to learn how they experience the benefits of work-related learning.

Learning has many facets: theory, experience, reflection, practice and social interaction. Lappia (2011) acknowledges that all these elements should ideally come into play during a work-related learning arrangement. Additionally, learners also learn effectively by the type of feedback they receive, including explicit improvement indicators. Although Clements \& Cord (2013) highlight the importance of choosing assessment methods with care, there is little evidence as to the type of feedback, and the effectiveness of it in the preparation of new graduates, which has been provided on their 'experiential learning programme'. Initiatives such as CDIO (Conceive-DesignImplement-Operate) for engineers and PBL (Problem-Based Learning) for medical scientists have forged the path to actively instilling experiences of workplace requirements into the academic syllabus.

Given that there is currently a profusion of research activity and ever-increasing output of publications describing and evaluating assessment feedback types, a recent substantial work from Evans (2013) represents a monumental attempt at a systematic review of the literature where initial searches found 1,131 possible articles. Rowe \& Wood (2008) conclude that assessment feedback as a motivator is particularly well received by students. Jessop et al. (2013) report that students on a programme with a work placement receive significantly more oral feedback. One useful method of feedback provision involves self-assessment and reflection, but Jackson (2014) finds that when it comes to undergraduates assessing their own capability of employment skills there can be varying degrees of over and under rating.

Given the prominent emphasis on work-related learning within the HE curriculum, there appears to be insufficient coverage of feedback mechanisms which are directly relevant to assessment and practice in the work-related learning context. The exploratory hypothesis is that current feedback practices in this area lack rigour and precision and should ideally reflect those used in mainstream commercial and public industry sectors.

\section{Methodology}

In this pilot study an online survey questionnaire and qualitative interview methodology have been employed to elicit opinion and commentary on the extent to which assessment criteria and the feedback received map onto the participant's ability to perform work tasks. The online survey is designed to re-engage the new graduates and remind them of their experiences on completing assessment on a work-related learning module. A follow-up interview was based on a semi-structured question framework with opportunity for open-ended discussion. Interview participants were encouraged to describe workplace practices with examples where possible and also to make comparisons between their work-related learning experiences and their current work experiences.

Graduates from the 2014 cohort of three computing degree programmes who had completed a work-related learning module were included for participation. The online 
survey was kept brief (10 questions) to generate as much interest as possible, and 41 leavers out of 84 actually took the survey.

\section{The work-related learning module}

Students on a Computing related set of undergraduate programmes undertake a 6 month work-related learning module whose main aim is to enhance and extend their learning experience by applying academic skills to tackling real life problems in the workplace. At the start of the module, all students develop a learning agreement in conjunction with stakeholders. The learning agreement specifies the way in which learning outcomes will be developed and how they will be evidenced. The assessment tool is a learning portfolio which comprises of a weekly learning log, employer evaluation, a business report with supporting evidence/artefacts and a final presentation/demonstration. Feedback mechanisms used include criteria-based written comments from the employer and also annotations on the portfolio report by the tutor. Verbal feedback is given during the final presentation, which also includes an element of peer feedback.

\section{Results and Discussion}

The responses to the online survey and subsequent interviews give an indication of the benefits and the potential gaps in the work-related learning experience. Survey questions based on the improvement of skills as a direct result of the work-related learning module were posed. The results give some insight into the perception of graduates at that important transitional period of leaving the university educational environment and spending 6+ months in the workplace. However it is the individual interviews that have shed more light on other aspects of the perceptions of graduates in the workplace.

The results of responses to questions are discussed below which asked participants to rate their effectiveness at six core skills: before taking the work-related module, after taking it and at their current workplace. In general there is a marked improvement in skills acquisition and enhancement during the work-related learning module, with the most significant improvement being in teamwork skills. This is reassuring as that is one of the main learning outcomes of the module. More interestingly though is the perceived improvement of several other skills at the workplace, in particular organisation and time management. Professional conduct appears to be an area needing more focus within the module, as it is only in the workplace that respondents relate an improvement in this aspect.

\section{Communication and Interpersonal skills}

These skills would have been practiced repeatedly during the module, with verbal and written communications with clients, employers, tutors and peers; and culminating in a formal presentation.

Therefore an improvement during the module is to be expected, but in this case there is a further and extremely significant improvement beyond the module $-73 \%$ responded in the 'good' and 'very good' categories after the module, which rose to $93 \%$ in the workplace. Graduates relate that the positive feedback they received during the module resulted in them becoming more confident and competent in this skill in the workplace. 


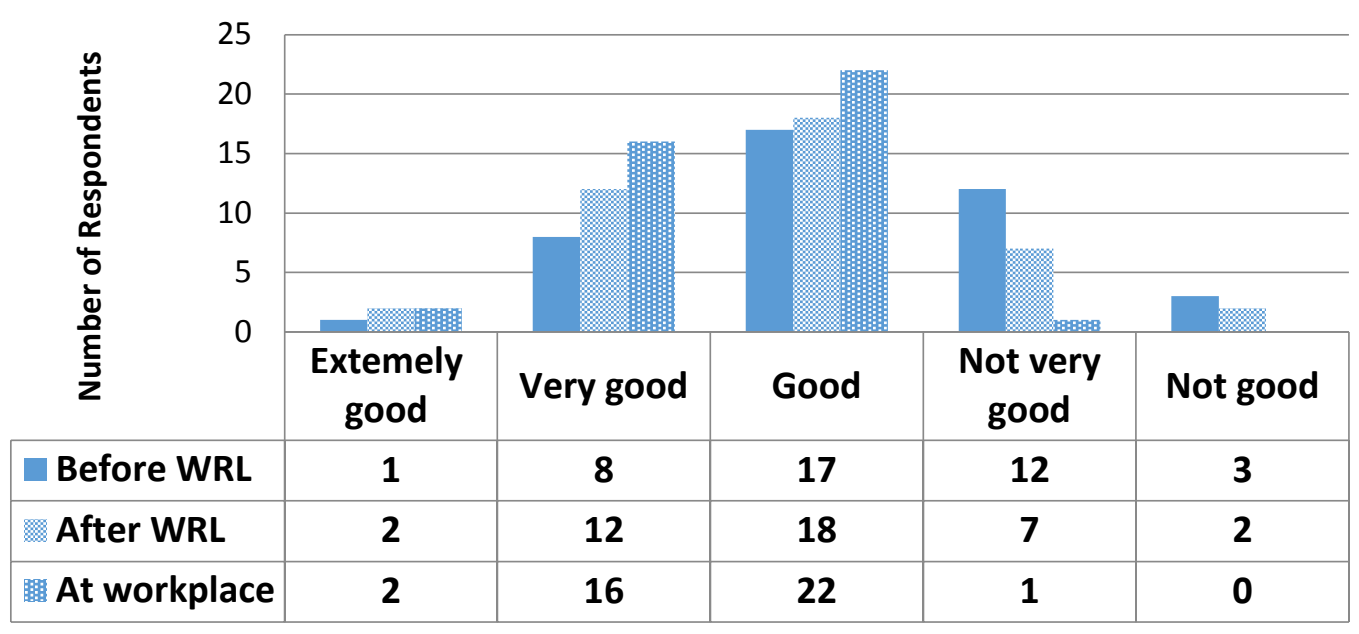

Figure 1. Effectiveness at Communication and Interpersonal skills

\section{Teamwork skills}

These skills appear to have improved dramatically during the module but showed barely any change thereafter. Many participants comment that although they are part of a team (varying from 2-8) in the workplace they have not yet had an opportunity to contribute fully and have instead being allocated manageable tasks to be completed under supervision. This suggests an underdeveloped knowledge and experience of what it means to be a member of a team, making a contribution to its overall achievement by completing designated tasks to a high standard and in a timely manner.

\section{Initiative and Problem-solving skills}

These skills showed the most movement in ratings with half of all respondents moving from the 'not very good' category at the end of the module to the 'good' category at the workplace. This result may be attributed to the prominence given during the undergraduate programme to mastery of these skills as being extremely desirable to potential employers. Some participants comment that they were formally tested on these skills during the job selection process; others relate their experiences of having to answer questions in this area during a job interview. These skills have a heightened interest for computing graduates as their perception is that is what employers are particularly interested in.

\section{Organisation and Time Management skills}

These skills have the most significant movement in terms of respondents' perception of how effective they have become at them in the workplace. In part this may be explained by the fact that several graduates were either on temporary contracts or paid hourly which may have enabled them to structure their time more effectively in order to meet deadlines. During the interviewing several participants related that they surprised themselves at how they had made these skills a priority when commencing employment, whereas they had given them very little thought during University life.

\section{Professional Conduct skills}

During the module, respondents were not very good (80\%) at these skills and there was very little improvement during the module. However, in the workplace that belief had been minimised to just $17 \%$. Workplace induction and initial training may have 
attributed to this improvement. During the module skills in this area related to student awareness of codes of dress, behaviour expectations, confidentiality and diversity.

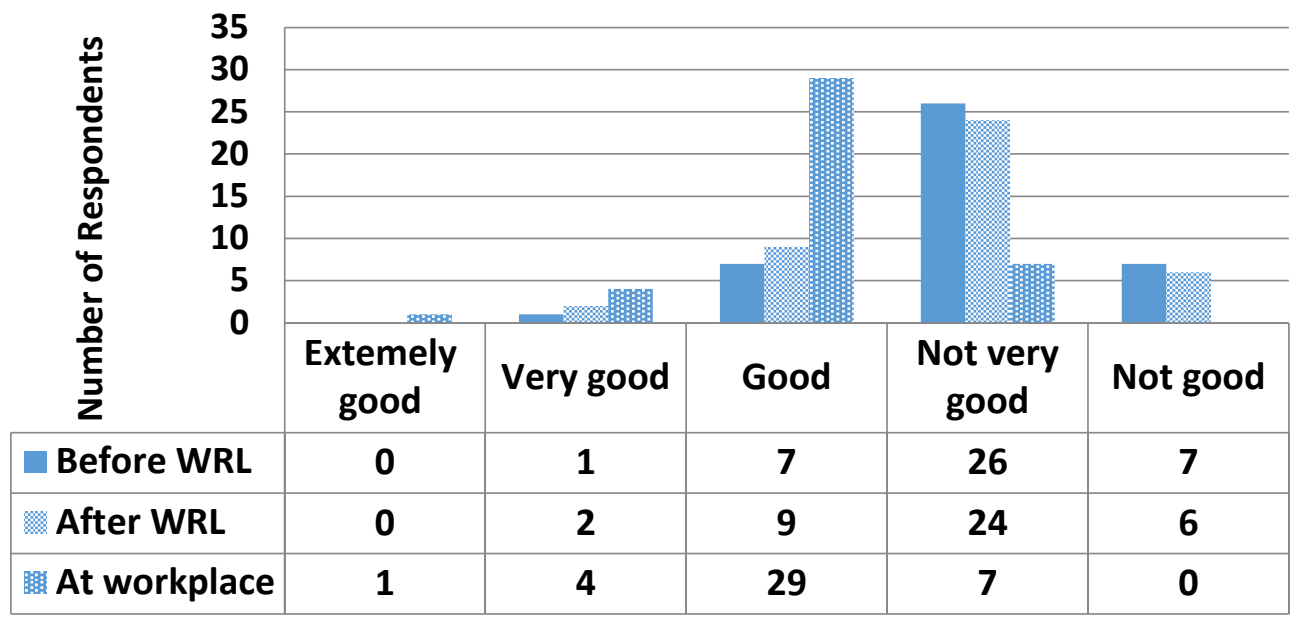

Figure 2. Effectiveness at Professional Conduct skills

Jollands et al. (2012) pinpoint a work-readiness skill termed ethical considerations which in their study was found to be sometimes misunderstood by both graduates and their managers. Understanding professional and ethical implications and how to apply them appears to be an area that requires more attention - something which professional bodies can help with. Trustworthiness is not only difficult to measure but is also challenging to teach, learn and feedback on - yet it is a competency that many employers require.

\section{Information Technology skills}

A significant improvement is shown in all categories here, particularly in the response that indicates that participants felt they are 'extremely good' at this skill in the workplace. This could be the result of training provided by the employers or sustained practice within the organisation's IT environment.

\section{Skills ranking}

The survey also asked participants to rank each of these six skills in the order of which feedback during the module has helped most in the workplace tasks. Feedback provided on communication and interpersonal skills was regarded as being the most useful, whilst the feedback related to professional conduct was found be the least useful. Professional conduct, it seems is best learnt within the workplace.

In the context of the work-related module, respondents preferred feedback to be either verbally provided or as short comments on their work. They preferred not be given feedback as a group or even a small team and less than half the respondents placed value on the final grade as a means of valuable feedback.

\section{Discussion arising from interviews}

The interviewing process was based on a series of semi-structured questions to cover those aspects in the workplace that were challenging and to gauge the extent to which 
the feedback given during the work-related learning module helped or is helping. The most overwhelming aspect to arise from these discussions was the stark difference in feedback given to assessment and the feedback given in terms of performance and capability at work. All participants, even those that were employed on a temporary or voluntary capacity, felt strongly that they had not been prepared for receiving what was sometimes felt to be quite harsh and very direct feedback on their performance at work. A number of respondents had undergone a formal appraisal process and perceived that nothing at university had prepared them for it. Examples of aspects of appraisal processes which graduates would not have come across typically include objectivesetting with targets and stretch targets, financial as well as non-financial objectives, accountabilities and goals, key indicators, self-assessment and forward-looking development plans.

Another area that caused some concern is around the terminology for competencies used widely in industry. Participants believed that they did not have a clear understanding of how to evidence competency and therefore were unable to adequately relate their abilities to employers. Examples of desirable competencies used by many organisations including a prominent magic circle employer, include 'cultural awareness and sensitivity', 'resilience', 'following through', 'business alignment', 'judgement' and 'influence'. Participants felt that some awareness of the language of competency as utilised in industry could have been usefully included in the work-related learning module.

All participants related a considerable difference in their experience of the work undertaken for the work-related learning module itself (even where it was for an industry-based client) and the work they were now doing at the workplace; with many citing the 'pressure to produce' as being infinitely more challenging in the workplace.

\section{Conclusions}

The concept of work-readiness has come to mean framing the academic curriculum with sufficient opportunities for gaining the experience of work as possible and thereby developing those employability skills that industry demands of new graduates. However, what of the graduates themselves? They also need to be prepared for the manner in which employers will measure and reward their performance. This study has revealed that work-related learning does play an important role in allowing students to acquire and/or improve employability skills but that more can be done during this experience, for example, to expose them to the formal appraisal schemes utilised in the workplace. Also it can be argued that HE fails to cultivate within the classroom the ability of new graduates to respond to the 'pressure to produce' which they will face in the workplace.

As a result of these findings, the learning agreement used in the work-related learning module requires enhancement to reflect industry-style appraisal formats using competency terminology commonly used for that process. Students should ideally be exposed to setting their own targets and stretch targets within a more direct and formalised feedback environment; thereby developing a degree of maturity in students. It is evident that negotiated learning agreements as used in work-related learning initiatives need further enhancements to align them better to the performance measuring tools used in industry. Also evident is that students need to be better equipped to learn 
how to negotiate and reflect on their professional practice and thereby avoid the reality check.

Acknowledgement: Thanks to ALDinHE (The Association for Learning Development in Higher Education) for financial support of this project.

\section{References}

Clements, M. D., \& Cord, B. A. (2013). Assessment Guiding Learning: Developing Graduate Qualities in an Experiential Learning Programme. Assessment \& Evaluation in Higher Education, 38(1), 114-124.

Evans, C. (2013). Making Sense of Assessment Feedback in Higher Education. Review of Educational Research, 83(1), 70-120.

Hopkins, E. A. (2008). Work-related learning: hearing students' voices. Educational Action Research, 16(2), 209-219.

Jackson, D. (2014). Self-assessment of employability skill outcomes among undergraduates and alignment with academic ratings. Assessment \& Evaluation in Higher Education, 39(1), 53-72. doi: 10.1080/02602938.2013.792107

Jessop, T., El Hakim, Y., \& Gibbs, G. (2014). The whole is greater than the sum of its parts: a large-scale study of students' learning in response to different programme assessment patterns. Assessment \& Evaluation in Higher Education, 39(1), 73-88. doi: 10.1080/02602938.2013.792108

Jollands, M., Jolly, L., \& Molyneaux, T. (2012). Project-based learning as a contributing factor to graduates' work readiness. European Journal of Engineering Education, 37(3), 143-154.

Josephine H. Lappia. (2011). Towards design guidelines for work related learning arrangements. Journal of European Industrial Training, 35(6), 573-588. doi:10.1108/03090591111150103

McKinnon, S., \& McCrae, J. (2012). Closing the Gap: Preparing Computing Students for Employment through Embedding Work-Related Learning in the Taught Curriculum. Industry and Higher Education, 26(4), 315-320.

Rowe, A. D., \& Wood, L. N. (2008). Student Perceptions and Preferences for Feedback. Asian Social Science, 4(3), 78-88.

Simons, P. R.-J., \& Ruijters, M. C. P. (2008). Varieties of work related learning. Organisational and Personal Contributions to Workplace Learning Environments, 47(4), 241-251. doi:10.1016/j.ijer.2008.07.001

Venables, A., \& Tan, G. (2009). Realizing Learning in the Workplace in an Undergraduate IT Program. Journal of Information Technology Education, 8, IIP-17. 
HEAd'15

SESSION 7B INTERNSHIPS 


\title{
A formative approach to the relation of the university to companies: Beyond obtaining resources
}

\section{N. T. Álvarez Aguilar, J. A. Castillo Elizondo, A. Torres Bugdud, J. A. Cupich Guerrero}

Universidad Autónoma de Nuevo León, México

\begin{abstract}
In Mexico the linking of universities to companies has traditionally being intended to obtain resources and little attention has been given to its formative dimension. The relation university- companies has been renewed at the Faculty of Mechanics and Electric Engineering to foster the formative contribution of professional practice. Nevertheless, as a dynamic and multifactorial process, it requires permanent monitoring and improvement of students' training. This paper is aimed at analyzing the effect of linking university faculties to companies on the education of would-be engineers. The findings include the foundations and assessment of the formative approach resulting from a theoretical inquire and gathering opinions of professors, students and managers by means of interviews and other techniques. The study proved that a comprehensive strategy oriented to the students' education is needed to influence upon social development.
\end{abstract}

Keywords: formative approach, linking process; education of engineers

\section{Introduction}

The main social responsibility of the university is the training of the students with human high values and a comprehensive education that allows them to be agents of changes and development once graduated.

Mexican universities, and in particular the "Universidad Autónoma de Nuevo León” has kept a permanent contact with companies to join efforts in attaining the fulfillment of their main functions. Nevertheless, a lack of clarity and general consensus in relation to the links between universities and companies is still present. The need to face such problem demands going beyond obtaining profits and resources by giving priority to the formative dimension.

Castillo and Cols (2013) consider that the resources generated by the diverse models or linking means should be used in the universities to assist the necessities that contribute to their mission. However, the general practice indicates that the economic criterion prevails and the formative potentials of students' involvement in production is currently underestimated.

Consequently the strengthening of formative actions in the linking process is needed. The solution might be to introduce a formative approach that develops the orientation of the linking process toward student's education both as citizen and professionals. Following these ideas, this paper is aimed at analyzing the potentials of the linking process for the training of students, aside from the economic resources it eventually produces. The findings, resulting from a research project of the Faculty of Mechanics and Electric engineering, include the foundations of the formative approach to the university and the companies linking process.

\section{Methods}

The population under study was made up company professionals, and university professors and students belonging to the Faculty of Mechanics and Electric Engineering 
of the "Universidad Autónoma de Nuevo León". The sample includes only agents involved in the linking process, organized in representative and proportional strata, on intentional bases corresponding to the regional context and the relations set among the different agents. In selecting the size of the sample (" $n$ ") the following equation was used.

$$
n=\frac{N Z_{\alpha}{ }^{2} p q}{d^{2}(N-1)+Z_{\alpha}{ }^{2} p q}
$$

Where

$\mathrm{N}=$ Size of the sample.

$\mathrm{Z}=$ Trust level.

$\mathrm{P}=$ Success probability, or expected proportion.

$\mathrm{Q}=$ Failure probability.

$\mathrm{D}=$ Precision, (margin of proportional error) .

The population comprises 689 students, 518 university professors, 64 university directives and 120 company directives, making a total of 1389 . The sample includes a total of 123 subjects corresponding to the same categories (62 students, 26 professors, 10 university directives and 25 company personnel.

Quantitative and qualitative methodologies were combined in doing the research, in a range going from statistical procedures to essay writing technique. Data arrangement was facilitated by setting four categories related to the linking process that influence the formative dimension in one way or another. These categories are the following;

Category 1: Interrelation level of the agents in the linking process.

Category 2: Level of recognition of the linking process significance in students' education.

Category 3: Level of satisfaction of different agents.

Category 4: Level of contribution of different agents to the linking process.

\section{Results and Discussion}

\section{Framework}

During the first decade of the XXI century the topic of the linking of the university to the company has been the object of discussion in forums with increasingly frequency, the topic has become an important aspect of the higher education calendar. However, Martínez describes a tendency to reduce the linking process to the relation of the university with the productive sector of society, without taking into account how it impacts in a precise way in the education of the would-be engineers (2000).

The conception of the National Association of Institutions of Higher Education (ANUIES) shows a transcendent appreciation of the linking process by understanding such relations of university institutions with the productive sectors as a mechanism to positively contribute to education and upgrading students and scholars in facing local, regional and national problems. This conception favors the pedagogic training of the university staff, the innovation and improvement of the processes that take place in both 
places, as well as the effective insertion of students in the cultural community life (ANUIES, 2000).

There are evidences of implementations of several linking models with the productive sectors in Mexico. Nevertheless, these models are usually copycats of those devise for the North American context, in such a way that the obtained results are far from the level of success achieved in North American universities, operating high budgets derived from the linking to companies or foundations (Arocena and Sutz, 2001). This reality indicates the necessity to outline alternatives suited to the national context which will naturally allow giving an answer to social requirements in each moment.

The modern social and professionals demands are challenging the design of the curriculum of universities studies in all branches of sciences, namely in engineering and technology. Hence, the authors agree with the idea of (Shigwara,) that raising the university education demands an integrate system and interactive with the transformational governorship and leadership (2014).

The linking process is frequently conceived as a way for getting mutual benefits for the company and the university, as a way for finding financial support to university process leading to subordinate projects to company interests and distracting the attention from the formative process.

To go step further the linking process conception has to be renewed. Consequently, the authors has defined it as a net of relationships between the university, the government, the company and the society to coordinate efforts for common benefits allowing to favor the formative process of the students, as well as obtaining resources through different coordinated projects under the leadership of the university. This definition subsumes former models of the linking process but at the same time excel them for its students-centered-approach, the priority given to the formative process and the leading role of the university in society. The proposed model correspond to the already mentioned formative approach.

\section{The state of art of the linking process at the Faculty of Mechanics and Electric Engineering}

Category 1: Interrelation level of the agent in the linking process.

The following is a description of the information gather by means of the interviews given to each group of subjects.

The level of interrelation between the Faculty of Mechanics and Electric Engineering and companies (Table 1) was regarded as "high" by the majority of the subjects, 88,9\% of professors graded it as high, $62,9 \%$ of students give the same answer, but $50 \%$ of companies personnel valued it only as average. Apparently, these findings are satisfactory and suppose there is an area of opportunities for the interrelation of agents. However, it seems recommendable to monitor the criteria of companies permanently. 
Table 1. Valuation of interrelation level between agents of the linking process

\begin{tabular}{|l|l|l|l|}
\hline Agents & High & Average & Low \\
\hline Professors & $88,9 \%$ & - & - \\
\hline Students & $62,9 \%$ & - & - \\
\hline Managers & - & $50,0 \%$ & - \\
\hline
\end{tabular}

Category 2: Interrelation level of recognition of the linking process significance in students' education

To go deeper into the evaluation of the level of recognition of the linking process significance, managers and professors were asked to write an essay under the title "Present and future of the linking of the university to the companies". Most of those implied in the technique carried out a favorable valuation about the importance of the linking, they also manifested critical judgment on what the linking process should be.

The most representative expressions of managers are the following:

1) "The linking process is very important for all and we should promote a higher level of participation."

2) "Society will be more capable of facing its problems if the interrelation between university and companies were perfected."

3) "The linking process might be a source of social and economic initiative to increase the quality of life."

4) "The linking process should be more clear, tenacious and effective to achieve better results".

5) "To fulfill the objectives innovative technology should be introduced in the linking process”.

6) "The lack of systematic arrangement should be avoided in the linking process.

On the part of professors the most interesting opinions were the following:

1) "Innovation in any service should surpass the triple propeller model".

2) "The linking process should be regarded as an important function to be developed at the university".

3) "A definition of joint working criteria should lead to the synergy of different levels".

\section{Category 3: Level of satisfaction of different agents}

An important aspect to value the current state of this category is knowing the degree of students' satisfaction in relation to the linking process. The findings are shown in table 2. Professors, and students are included at the average level of satisfaction (55.6\% and $53.2 \%$ respectively), whereas $65 \%$ of managers presents a low level of satisfaction. 
Table 2. Agents satisfaction in relation to the linking process.

\begin{tabular}{|l|l|l|l|}
\hline Agents & Satisfy & Half-satisfy & Low-satisfaction \\
\hline Professors & $55,6 \%$, & $87,9 \%$ & $12,1 \%$ \\
\hline Students & $53,2 \%$ & - & - \\
\hline Managers & $25 \%$ & $10 \%$ & $65 \%$ \\
\hline
\end{tabular}

Category 4: Level of contribution of different agents to the linking process

The finding shows there are difficulties in the enrolment of different actors in the linking process. Almost a half (48.4\%) of the students consider their participation is low. On the contrary, approximately the same proportion (45\%) of managers qualify it as average; whereas a large part of the professors (66.7\%) consider their participation is high. Nevertheless, this result should rather be interpreted as an aspiration; in practice professors show little interest for the linking process.

\section{A formative approach to the linking process}

The analysis of the antecedents and the gathering of data just discussed contributed to the construction of a framework and a new model of the linking process for the Faculty of Mechanics and Electric Engineering. The management of the linking process should be aimed at the education of engineer students, without disregarding other objectives and functions. As it is described in figure 1, the linking process has two fundamental focuses that are guided to the improvement of the student's professional and social training. The dynamic of the relationship between them depends on the potentials and necessities of each of the agents involved in the process of linking. The proposed model takes the formative function as the central focus or main function, and considers the rest as subsidiary functions.

Figure 1 contributes to a general vision of the linking process. The formative process makes emphasis on the participation in the social development, the development of personal and professional competencies and the preparation for the future labor context, taking into account several objectives shown in the figure.

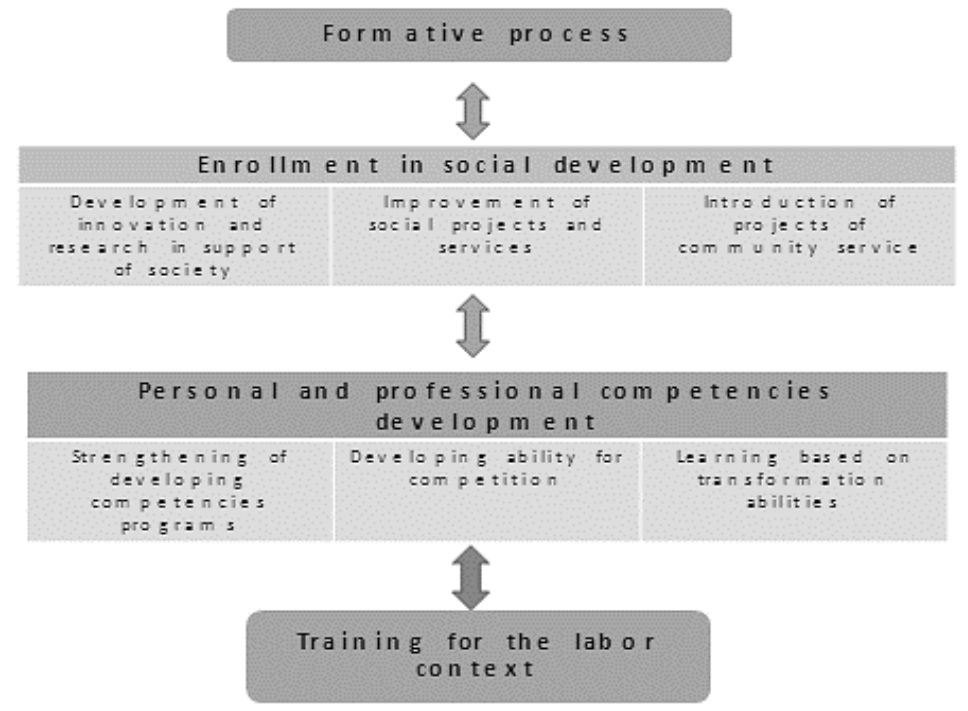

Figure 1. The formative approach of the linking process (Castillo, Álvarez, Cupich, 2014.) 
Those approaches related to obtaining results, or traditional models of linking, include a number of objectives that contribute to students' education in one form or another, as well as to other processes that are related with it. However, as it has been previously explained that little attention is given to its educative potentials.

\section{The linking process as way of obtaining resources}

The foundations of the formative approach constitute a theoretical platform for designing strategies to carry out the linking process and pursuing definite objectives. The general practice proved that the process is usually performed following certain routinized actions and patterns. Additionally the agents tend to be only partially involved. This is clearly expressed when surveyed agents declared that their enrollment is insufficient.

It is widely known that the linking process is a way of obtaining resources for the development of the university. These resources are beneficial to the infrastructure, the professors' staff and the students. These resources are usually invested in the creation or improvement of facilities, in updating technology, creating new academic areas, carrying out new research projects, developing programs for professors' development, offering scholarships, creating social services for the students and other incentives programs for the staff.

\section{Conclusions}

The data gathered in this study show areas of opportunities and potentials for the satisfaction of the different agents taking part in the linking process. For these reason the authors reach at the conclusion that the interrelation among these agents needs to be perfected. One solution might be a comprehensive strategy allowing the increase of the efficiency of the linking patterns oriented towards the training of students, this focus on students' education produces not only the traditional source of resources but the development of professional competencies, creating conditions for successful performance in the future labor context and its corresponding favorable impact on social development.

Similarly, the authors observed the necessity of strengthening the process of the student's education and in writing this paper has coined it as the formative approach to the linking process. In a general sense, the following strengths and weaknesses are highlighted.

Strengths: There are favorable conditions for the interrelation of all the agents of the linking process and a positive valuation of the potential of the linking process for the student's formative process.

Weaknesses: The professor's insufficient participation in the linking process and the agents' poverty of arguments on the importance of the linking process for the engineering student's integral education.

Opportunities: The possibility of increasing the interrelation between the agents of the linking process, together with the capacity of the university to design the necessary strategies and to exert a leadership in the relations with companies and society in general.

Two different approaches to the linking process are clearly identified in this paper. The possibility of following a formative approach contributing to would-be engineers' 
education, without disregarding the university need to obtain resources proved that the design of a comprehensive strategy is viable. The linking process may and should go beyond obtaining resources.

\section{References}

ANUIES. (2000). La Educación Superior en el siglo XXI. Líneas estratégicas de desarrollo. Una propuesta de la ANUIES. Ciudad México: Asociación Nacional de Instituciones de Educación Superior .

Arocena, R., \& Sutz, J. (2005). Latin American Universities: From an original revolution to an uncertain transition. Higher education, 5(1), 573-592.

Castillo, J., \& Cols. (2013). La vinculación y formación integral del estudiante de ingeniería. Ciudad México: Pearson.

Castillo, J., Álvarez, N., \& Cupich, J. (2014, June). Linking as a Potentiality for the Students Training at the Mexican University. International Journal of Humanities and Social Science, 4(8), 188-192.

Martínez, F. (2000). Nueve retos para la educación superior. Funciones, actores y estructuras. Retrieved diciembre 16, 2013, from Asociación Nacional de Universidades e Instituciones de Educación Superior: DOI: www.worldcat.org/.../nueve-retos-para-laeducacion-superior-funciones-

Shigwara, S. (2014, February). Effect of Implementing Transformational Leadership and Gobernorship in Assuming Societal Responsability by the Universities "The Middles East Univerty ( MEU) is a Model. International journal of Humanities y Social Sience, Vol.4, No., 4(3), 127-150. 


\title{
Evaluation competency-based in Internship: especial reference to evaluation rubric and final reports
}

\author{
M. Moltó-Aribau*, A. Tena-Torruella* and A. Vendrell* \\ * Departament of Bussines Administration. University of Lleida
}

\begin{abstract}
A working group of lecturers of University of Lleida (UdL), involved as academic tutors in Internship, propose to adapt the traditional model of evaluation of Internship to a new competencybased model as proposes The European Higher Education Space (EEES, its acronym in Spanish). This implies to redefine the evaluation process, introducing objective elements and guaranteeing the integral performance assessment of the students, according both academic and professional profile. The proposal includes the definition of: evaluation process, evaluator agents, competences to evaluate, indicators/evidence of every competency and finally scales and levels of achievements. As a result, we built a rubric of evaluation which includes: competences, indicators, scales, agents and moments of evaluation that can be applied in different degrees of UdL. Moreover we define a final evaluation report which contains learning outcomes and shows findings, conclusions, and recommendations that can be used to guide student's improvement and decision making about them. This proposal was partially implemented in the degrees of Industrial Engineering, Computer Engineering and Business Administration with very positive students' acceptation but we need more experience and to refine our model, making it simpler and more usable if we want to generalize it to other higher education institution.
\end{abstract}

Keywords: competence-based evaluation; rubric; final evaluation report; learning outcomes

\section{Introduction}

Our team is formed by lecturers and part time professors from two centres of UdL and has being working as academic tutors o coordinators in Internship at UdL for a very long time. Internship are supervised practice in companies and offers students a period of practical experience in the industry relating to their field of study. Students spent in the companies four months part-time or two months full-time. This experience is valuable to students as a means of allowing them to experience how their studies are applied in the "real world". Internship courses are compulsory in all UdL's degrees.

Most of the members of the group are lecturers of UdL da and all of us were involved in Internship as academic tutors or members of the staff of our faculties: Polytechnic School and Faculty of Economy and Law of University of Lleida. Our team is interdisciplinary and our proposal tries to be general and applicable to several UdL's degrees and also to other higher education institutions.

In concordance with the necessary review promoted by European Higher Education Space (EEES, its acronym in Spanish) we start working on the incorporation of the competency-based evaluation in Internship as a way to verify the assessment of our students. As a result we defined an integral competency-based evaluation process for Internship, applicable in the same field in other higher education institutions, with few adaptations.

We also define a final evaluation report that shows learnings outcomes of every student. This is the innovative contribution of our work because the use of rubrics is generalized in a huge range of higher educational institutions but not the elaboration 
of a personalized report where students can have detailed the qualification of every competency evaluated.

\section{Methodology}

The methodology used to build the integral competency-based evaluation of the Internship has being developed following the next process. First of all we design the rubric, detailing the definition of competences and determining evidences of every competency (phase 1). A rubric is an evaluation tool or set of guidelines used to promote the consistent application of learning expectations, learning objectives or learning standards. In instructional settings, rubrics clearly define academic expectations for students and help to ensure consistency in the evaluation of academic work from student to student, assignment to assignment, or course to course. Rubrics are also used as scoring instruments to determine grades or the degree to which learning standards have been demonstrated or attained by students.

After this we define and determine the evaluator agents, their role and which competences should be evaluated by everyone (phase 2). Evaluator agents are the responsible of following the students learning process. We have to determine the evaluation times along Internship course (phase 3) and built and design the partial evaluation reports (phase 4). With all information we can conclude the final mark of the student, joining the partial evaluation of the agents (phase 5). That mark will be the final qualification of the student but we add to it a final evaluation report detailed and personalized for every student which will contain every student' learning outcomes. This final report is unusual in public universities and we think could be a differentiation element from other institutions.

Future work will consist in testing this proposal in two groups of students of the degrees of Computer Engineering and Business Administration to evaluate and improve the model. Knowing it has to manage a lot of information it is need some computer support why otherwise the agents can be reticent to adopt and check the model.

\section{Results and Discussion}

First step, we split of the design of our rubric of evaluation (phase 1), which contains each all the competences fixed in the plan of studies of the corresponding degree. This rubric contents (see a summary of the rubric in table 1):

1. The definition of every competency

2. Its evidences

3. The moments of evaluation time

4. The agents who have to evaluate it.

This was the first step of the design of the integral process evaluation of Internship.

In this rubric is basic to have the description and clear detail of what understands /comprises in each one of the competency considered, because this will determine the different indicators/evidence of evaluation. To make this exercise is important to review studies like the Tejada (2005) and the one of De la Mano and Moro (2009), which help us to know the keys or fundamental contents that has to have a competency. As example, in the table 1 we show an item of the evaluation rubric of 
the Degree of Computer Science, where details the competency "Oral and written correction”, competency defined by the university of Lleida for all its degrees.

Table 1. Description and evidence of the competency: "Correction in the oral and written expression"

Competency UDL1: Correction in the oral and written expression

\section{Description}

Capacity to express with clarity and opportunity the ideas, knowledge and own feelings through the word, the writing and the graphic support, adapting to the characteristics of the situation and the audience.

Evidences of the competency (indicators that shows that the student has acquired the competency)

The student has to be able to answer to the following items:

a) Explains ideas and concepts of a comprehensible form.

b) Uses with precision form the technical vocabulary.

c) Uses the suitable vocabulary in each circumstance.

d) Uses of suitable form, the no verbal communication in the oral exhibition.

e) Relates properly the concepts along the speech.

f) Writes with linguistic correction.

g) Structures of coherent form the different sections of the documentation.

When we have defined every competency and the evidences linked to it we had to translate the theoretical model (rubric) to the reality of the classrooms and the companies (phase 2). In this point, is relevant to develop a new work with the main agents involved in the evaluation process, to identify and contrast what considers each one that has to or can be evaluate with the different competences. First of all we have to define the agents involved in the evaluation:

- Academic tutor: Person responsible in the School of Internship.

- Tutor of the company: Person responsible in the company of Internship.

- Tribunal of Internship: A tribunal formed by three academic tutors.

- Student: Responsible of his/herself process of assessment.

A same competency should be evaluated by different agents in different moments, and it is necessary to adapt the evidences under distinct criteria, as a way to collect the different perspectives or surroundings of evaluation. From the initial rubric we initiated a process of discussion and collected of suggestions of the different evaluator agents, with the object to obtain a realistic form and to contrast the indicators/moments of evaluation by competences of the Internship (phase 3). This point of previous discussion was basic and tried to take advantage of previous experiences/capabilities that several agents had, because all of them have participated in Internship as evaluators.

As a result of phases 2 and 3, we determine which competences will be evaluated for every agent and in which moment. (See table 2) 
Table 2. Assessment Matrix (without evidences), Evaluator agents and Evaluation moments for each competency.

\begin{tabular}{|c|c|c|c|c|c|c|}
\hline \multirow{3}{*}{ COMPETENCES/SKILLS } & \multicolumn{6}{|c|}{$\begin{array}{l}\text { MOMENTS/EVALUATOR } \\
\text { AGENTS }\end{array}$} \\
\hline & \multicolumn{2}{|c|}{ M I } & \multicolumn{2}{|c|}{ M II } & \multicolumn{2}{|c|}{ M III } \\
\hline & $\mathrm{S}$ & AT & $\mathrm{S}$ & AT & $\mathrm{TC}$ & $\mathrm{T}$ \\
\hline SOCIAL SKILLS AT WORK & $\mathbf{X}$ & $\mathbf{X}$ & & $\mathbf{X}$ & & \\
\hline COMP UDL1: Correction in written and oral expression & & & & $\mathbf{X}$ & & $\mathbf{X}$ \\
\hline $\begin{array}{l}\text { COMP EPS3: Capacity to gather and interpret data, in the context } \\
\text { of an area of study, with the aim to made value judgments on } \\
\text { subjects related to social, scientist and ethical topics }\end{array}$ & & & & $\mathbf{X}$ & $\mathbf{X}$ & $\mathbf{X}$ \\
\hline $\begin{array}{l}\text { COMP EPS7: Capacity to work in situations of fault of } \\
\text { information and/or under pressing. }\end{array}$ & $\mathbf{X}$ & $\mathbf{X}$ & & & & \\
\hline $\begin{array}{l}\text { COMP EPS9: Capacity of work in team, unidisciplinar and } \\
\text { multidisciplinary. }\end{array}$ & & & & & $\mathbf{X}$ & $\mathbf{X}$ \\
\hline \multirow[t]{2}{*}{$\begin{array}{l}\text { COMP EPS10: Capacity to integrate inside the structure of the } \\
\text { company. }\end{array}$} & & & $\mathbf{X}$ & & $\mathbf{X}$ & \\
\hline & & $\mathbf{X}$ & $\mathbf{X}$ & & $\mathbf{X}$ & \\
\hline
\end{tabular}

It is important to emphasize that one competency can be evaluated by two or more different agents. For example EPS12 is evaluated by the academic tutor and the tutor of the company (see table 3). Therefore, we have adapted the checklist of evidence to each agent and we have designed a different report for each evaluator agent (Phase 4).

Table 3. Item EPS12 of evaluation report of academic tutor and tutor of the company

EPS12: Motivation for quality and continuous improvement

\begin{tabular}{|l|l|}
\hline Evaluation report of academic tutor & $\begin{array}{l}\text { Evaluation report of tutor of the } \\
\text { company }\end{array}$ \\
\hline $\begin{array}{l}\text { Evidences: } \\
\text { - He/She is methodical and } \\
\text { systematic with the work and } \\
\text { deadlines }\end{array}$ & $\begin{array}{r}\text { Evidences: } \\
\text { - He/She is methodical and } \\
\text { systematic with the work and pays } \\
\text { He/She complies with the formal } \\
\text { requirements }\end{array}$ \\
$\begin{array}{l}\text { He/She is capable of applying } \\
\text { the technical knowledge he/she } \\
\text { has acquired }\end{array}$ & $\begin{array}{l}\text { He/She get involved to the work } \\
\text { and shows concern about the work }\end{array}$ \\
& $\begin{array}{l}\text { He/She acts with motivation for } \\
\text { quality and even proposes } \\
\text { improvements. }\end{array}$ \\
\hline
\end{tabular}

The following step in this phase is to propose transparent and comparable evaluation descriptors suitable to the indicators of evaluation. We want to put the student in the varying degrees of command of each competency and also facilitate his qualification.

We define four levels of command of the competency and, at the same time, link these with numerical marks (from 0 to 10 ) 
1. Very high: It would correspond with a numerical qualification between 9 and 10

2. High: It would correspond with a numerical qualification between 7 and 8

3. Basic: It would correspond with a numerical qualification between 5 and 6

4. No surpassed: It would correspond with an equal numerical qualification or under to 4.

Finally, we describe the meaning of the level of command for every evidence of every competency/agent/moment of evaluation.

See in the table 4 the different levels of command proposed for the evaluation of the competency EPS12: Motivation for quality and continuous improvement, evaluated by de Academic tutor.

Table 4. Example of indicators and levels of command for EPS12: Motivation for quality and continuous improvement. Report of academic tutor

\begin{tabular}{|c|c|c|c|c|}
\hline \multirow[b]{2}{*}{ Evidence } & \multicolumn{4}{|c|}{ Levels of command } \\
\hline & $\begin{array}{l}\text { Very High } \\
\text { (Mark: Between } \\
9 \text { to 10) } \\
\end{array}$ & $\begin{array}{c}\text { High } \\
\text { (Mark: Between } 7 \text { to } \\
\text { 8) }\end{array}$ & $\begin{array}{c}\text { Basic } \\
\text { (Mark: Between } 5 \text { to } \\
\text { 6) }\end{array}$ & $\begin{array}{l}\text { No surpassed } \\
\text { (Mark: Between } 9 \text { to } \\
\text { 10) }\end{array}$ \\
\hline $\begin{array}{l}\text { He/She is methodical and } \\
\text { systematic with the work and } \\
\text { deadlines } \\
\text { Mark: }\end{array}$ & $\begin{array}{l}\text { He/She does the } \\
\text { tasks with method, } \\
\text { tenacity and on } \\
\text { time. Usually is } \\
\text { organized and } \\
\text { takes care about } \\
\text { the presentation }\end{array}$ & $\begin{array}{l}\text { He/She does the tasks } \\
\text { with method, tenacity } \\
\text { and on time. Usually is } \\
\text { organized and takes } \\
\text { care about the } \\
\text { presentation with any } \\
\text { exception }\end{array}$ & $\begin{array}{l}\text { He/She does the tasks } \\
\text { with method, tenacity } \\
\text { but not on time. } \\
\text { Sometimes is } \\
\text { organized and takes } \\
\text { care about the } \\
\text { presentation } \\
\end{array}$ & $\begin{array}{l}\text { He/She has trouble } \\
\text { doing the tasks with } \\
\text { method, tenacity and } \\
\text { on time. Usually is not } \\
\text { organized and doesn't } \\
\text { take care about the } \\
\text { presentation }\end{array}$ \\
\hline $\begin{array}{l}\text { He/She complies with the } \\
\text { formal requirements } \\
\text { Mark: }\end{array}$ & $\begin{array}{c}\text { He/she shows will } \\
\text { to do the assigned } \\
\text { tasks and makes } \\
\text { them with win }\end{array}$ & $\begin{array}{l}\text { He/she shows will to } \\
\text { do the assigned tasks } \\
\text { and makes them with } \\
\text { win but with some } \\
\text { exception }\end{array}$ & $\begin{array}{l}\text { He/she shows will to } \\
\text { do the assigned tasks } \\
\text { and makes them with } \\
\text { win but with a few } \\
\text { exceptions }\end{array}$ & $\begin{array}{c}\text { Only on rare occasions } \\
\text { He/she shows will to } \\
\text { do the assigned tasks } \\
\text { and makes them with } \\
\text { win }\end{array}$ \\
\hline $\begin{array}{l}\text { He/She is capable of applying } \\
\text { the technical knowledge that } \\
\text { he/she has acquired } \\
\text { Mark: }\end{array}$ & $\begin{array}{l}\text { He/she tries to do } \\
\text { the tasks applying } \\
\text { the technicians } \\
\text { learnt and even } \\
\text { proposes } \\
\text { alternative } \\
\text { solutions }\end{array}$ & $\begin{array}{l}\text { Often he/she tries to do } \\
\text { the tasks applying the } \\
\text { technicians learnt and } \\
\text { few times proposes } \\
\text { alternative solutions }\end{array}$ & $\begin{array}{c}\text { Often he/she tries to do } \\
\text { the tasks applying the } \\
\text { technicians learnt but } \\
\text { not proposes } \\
\text { alternative solutions }\end{array}$ & $\begin{array}{l}\text { Only few times he/she } \\
\text { does the tasks applying } \\
\text { the technicians learnt } \\
\text { and never proposes } \\
\text { alternative solutions }\end{array}$ \\
\hline
\end{tabular}

In this point, once defined each level of command for each evidence, adapted to every evaluator agent, we can elaborate all the reports (phase 4).

We have to say that reports have a standard format of rubric but really are subrubrics from the global rubric. In the evaluation process we define two types of reports: weekly Reports of Follow-up and Evaluation Reports. The Follow-up Reports are completed by the student, under the review of the tutor of the company, during the stay in the company. Instead, the five Evaluation Reports are made by the different agents at the end of the stay in the company of practices and when the period of Internship is finish (semester or quarter). In figure 1 we summarize the reports management. 


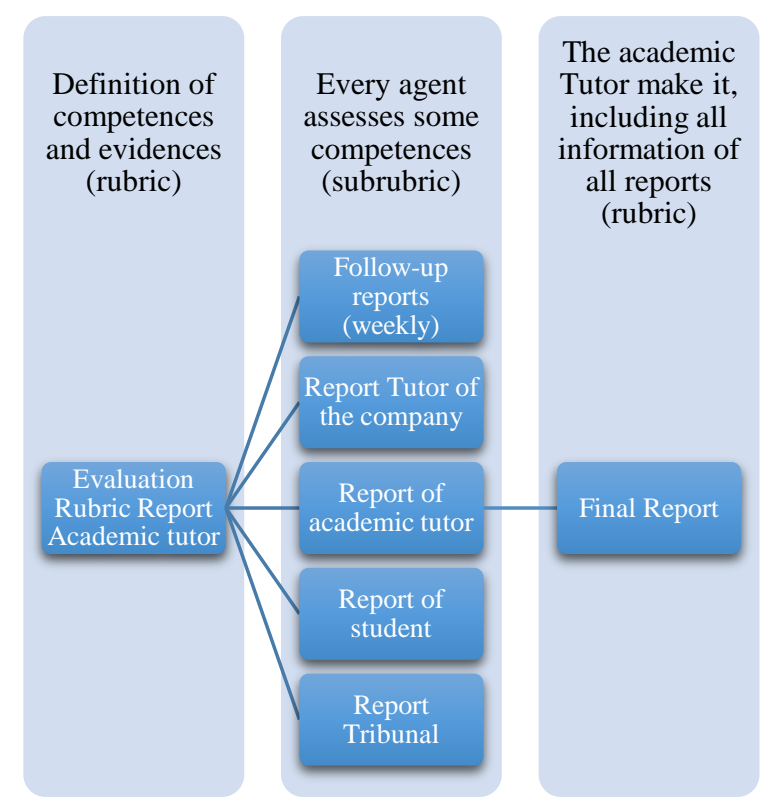

Figure 1. Summarize of reports management

Besides, each report of evaluation will have a specific weighting on the final qualification and the academic tutor has to join all information from all evaluation reports (Phase 5) and to calculate the final mark of student. The weight of the evaluation of every agent is:

- Evaluation report of the student: $10 \%$ of final mark

- Evaluation report of the tutor of the company: $30 \%$

- Evaluation report of the academic tutor: $40 \%$

- Evaluation report of the tribunal: $20 \%$

This model was tested by two groups of students of Internship along academic years 2012-2013 and 2013-2014 and our team had refined its design and ads, delete or redefine evidence. Different evaluator agents, students and companies have contributed to this process with suggestions that we incorporated in the rubric initially proposed.

Now, we are giving to the student a final qualification but without any detailed information about the level of acquirement of every competency, despite we have this information completed and structured. We thought that this information could be very significant because the competences of Internship are very useful to integrating students into the labour market. Therefore, we started to work in phase 5 of this project that consist in the design and definition of a final evaluation report, which include the final evaluation of every competency, of every agent, and final recommendations of the academic tutor.

This final report has to include:

1. GENERAL INFORMATION:

- The name of the student

- The name of the course

- The name of the Degree

- The name of School and University

- The year of the course 
- The name of the company where student did the internship

- The name of all evaluator agents

2. SPECIFIC INFORMATION:

- Every competency with every qualification of every agent (the whole rubric)

- The final qualification of every competency

- The final qualification of Internship

- Personalized recommendations of the academic tutor, who has being supervising the whole process of assessment.

However, given the high number of competences, evaluator agents, as well as, the students, it is crucial to have some software to automatize almost one part of this final report. This software should be integrated in our campus virtual based in Sakai and compatible with UdL information systems.

\section{Conclusions}

The redesign of the rubric of evaluation is the first result obtained from the implementation of our work during the 2 academic years 2012-13 and 2013-14. We have modified definitions and added some evidences with the aim to adapt the rubric to students and companies' needs and real situation in general.

Our proposal is able to have a final mark, combining complex information from all the evaluator agents in different time moments. As well as it guarantees that all the competences are evaluated at least by two agents. Our competency-based model shows learning outcomes and provide a clear set of expectations to students and companies. More over our proposal of final report allows students clearly to know about their level reached for every competency and some advice or comments from de academic tutor in order to improve their learning process.

This experience encourages our group to continue working in the Internship evaluation model with the final report.

\section{References}

Conde, A. \& Pozuelo, F.(2007). Las plantillas de evaluación (rúbrica) como instrumento para la evaluación. Un estudio de caso en el marco de la reforma de la enseñanza universitaria en el EEES. Investigación en la Escuela,63,77-90.

De La Mano González, M. \& Moro Cabero, M. (2009). La evaluación per competències: proposta d'un sistema de mesura per al grua d'Informació i Documentació. BiD. Textos universitaris de biblioteonomia i documentació, $n^{o}$ 23, desembre. Facultat de Biblioteconomia i Documentació Universitat de Barcelona.

Gallizo, J.L.; Badia, F.; Balcells, M.; Moltó, M.; Monyarc, J.; Motilva, MJ.; Ramos, A.; Tena, A. \& VendrelL, A. (2010). Adaptació específica del prácticum de la UdL en les noves titulacions de grau. VII Convocatòria d'ajuts per a Projectes d’Innovació Docent de la UdL.

Garcia, R. \& Puig, J (2011). A model for Improving the Quality of Student Internship Placements in Engineering Degrees. International Journal of Advanced Corporate Learning (iJAC), 2011, Vol.4(1), p4. 
KAN, A.(2007). An alternative method in the new educational program from the point of performance-based assessment. Rubric scoring scales, Educational Sciences: Theory \& Practice: 7 (1), 144152 (2007).

Moskal, B. M. \& Leydens, J. A. (2000): Scoring rubric development: validity and reliability. Practical Assessment, Research \& Evaluation, 7(10). Recuperado de http://pareonline.net/getvn.asp? $v=7 \& n=10$, Consultado el 12 de marzo de 2014

Tejada Fernández, J. (2005): El trabajo por competencias en el prácticum: cómo organizarlo y cómo evaluarlo. VIII Symposium Internacional sobre Prácticum y Prácticas en empresas en la formación universitaria, Poio, 30 junio-2 julio 2005.

Torres, J. J. \& Perera, V. H. (2010): La rúbrica como instrumento pedagógico para la tutorización y evaluación de los aprendizajes en el foro online en educación superior. Píxel-Bit. Revista de Medios y Educación, 36, 141-149 (2010) 


\title{
Linking projects with value in credits to validate realisation of professional internship, the protocol in the FIAD - UABC.
}

\author{
J. L. J. Sánchez González*, J. I. Aguilar Duque**, J. Salinas Coronado**, G. Amaya \\ Parra**, V. M. Juárez Luna**, J. A. Michel Macarty**，J. I. Nieto Hipólito** \\ Universidad Autónoma de Baja California, Mexico \\ Facultad de Ingeniería, Arquitectura y Diseño
}

\begin{abstract}
This work presents the curricular professional internship Protocol, within the framework of linking projects with value in credits (PVVC), in the Faculty of Engineering, Architecture and Design (FIAD) of the Autonomous University of Baja California (UABC). (Initials come from the names in Spanish). This Protocol defines the mechanism to start, to register and to follow-up to fruition the curricular professional internship (PP's). The benefits of this Protocol include but are not limited to standardization of documents and deadlines of the procedures. It regulates the actions of supervision of the activities of the students at the receivers' premises. It is obligatory to write a report of activities in a format of publication. It involves academics in a way that promotes interaction with the productive sector for a possibility of linking academic at the same time or after the realization of this student bonding. In addition to that we have implemented a tool that facilitates the available formats, control, monitoring, broadcasting and Bank of storage of the generated PVVC's and their reporting.
\end{abstract}

Keywords: Internship; linking; projects; protocol; FIAD-UABC; PVVC.

\section{Introduction}

In the FIAD, all educational programs require the realisation of a professional internship (PP's) as a mandatory curricular element; a number of credits are assigned to it, and therefore is a degree requirement. On the other hand, linking projects with value in credits are defined in the plans of study, as a container for a number of actions, forms of teaching - learning and accreditation, resulting in the operation of an educational scheme within the social or productive sector. In this way students can obtain credits with the activities carried out in the companies (public or private), as well as social service or professional internship.

Particularly in the Industrial Engineering education program (PE), was defined that mandatorily students carried out stays in business, and to frame these activities in the PVVC's would be very convenient for companies, students and teachers. As a professor is responsible for defining, monitoring and evaluating this mode of teaching-learning, the need to organize and store the substantiating documents for an appraisal, certification and/or PE monitor, was addressed in different ways. The experience gained during several semesters, has matured into the Protocol which is presented below, and has already spread to the other PE's of the FIAD.

\section{Methods}

The educational model of the UABC, contemplates the choice of modes of learning, as an alternative to traditional teaching, so that the student develops their intellectual potential and abilities, through learning experiences that are creative and innovative; at the same time obtaining credit as part of their graduation requirement. The curriculum is structured by stages, these being: basic stage (knowledge inter or multidisciplinary), disciplinary stage (or knowledge) and terminal stage (applications knowledge). It is in this last stage where the student is focused on increasing practical 
work and their participation in the occupational field. All University programs have the requirement of 300 credits (cr) minimum and 350 credits maximum, there bare compulsory subjects around $70 \%$, optional subjects and professional internships.

In the Educational Status of the UABC, chapter ninth of patterns of learning and earning credits, mark in its article 155 subsection IX brand linkage projects with value in credits as one of these modalities, where each respective curriculum establishes the characteristics and scope of them.

Table 1. Modalities obtain credit for the UABC, Educational Status UABC

I. Mandatory learning units,

II. Learning units optional ,

III. Other elective courses ,

IV. Independent study,

V. Teaching assistantships,

VI. Research assistantships

VII. Investigative exercise,

VIII. Support outreach and liaison,

IX. Linkage project value credits (PVVC),

X. Projects by degree,

XI. Artistic and cultural activities,

XII. Sport activities,

XIII. Social community service associate to the curriculum

XIV. Professional social service, associated with the curriculum

XV. Professional practices associated with the curriculum

XVI. University entrepreneurs program

IVII. Activities for training in securities

VIII. Intersemestrales school courses or other periods

XIX. Student exchange

$\mathrm{XX}$. Foreign language, and

XXI. The cases of the University established

UABC has recently developed guidelines and tools of control, within these new guidelines, flexibility for implementation at any time of the year, and a variability of stay length are allowed. Linkage projects (PVVC) are defined as follows:

PVVCs are optional projects (not compulsory to get a title), they are developed in coordination between the University and social or industrial sectors in the community. They are a learning experiences supervised by university faculty and external professionals and the linkage council of every school. This projects have the purpose of application and generation of knowledge, and problems solutions, either through research activities or professional services, in order to enhance educational outcomes and learning goals. (Title V, chapter 9, article 158, Educational Status, UABC).

This PVVCs are containers, that can encapsulate, compulsory subjects, optional subjects, modalities of learning (research or teaching internships, 
independent studies, social service, etc), taking in consideration regulation of each program.

Table 2. PVVCs Level.

\section{LEVEL 1}

$\checkmark$ Two months and 160 hours

$\checkmark$ Two learning units (maximum up to 6 credits each) and PVVC (2 credits) itself.

$\checkmark$ Being up to 14 credits in total to assign.

\section{LEVEL 2}

$\checkmark$ Three months and 240 hours.

$\checkmark$ Two learning units (up to 6 maximum credits each) and a mode of learning (professional practice, 15 credits or other form, 6 credits) and PVVC (2 credits).

$\checkmark \quad$ Being up to 29 credits in total to assign.

\section{LEVEL 3}

$\checkmark$ Four months and 360 hours

$\checkmark$ To most three learning units (up to 6 credits maximum each) and maximum three modes of learning (eg: professional practice, 15 credits and investigative exercise, 6 credits) and PVVC (2 credits).

\section{$\checkmark$ Being up to 41 credits total for assigning and do not exceed five shares in total.}

The Protocol FIAD - UABC of linking projects with value in credits (PVVC) is a guideline recommended to students for registration, execution, control, protection, evaluation and request for validation of the associated PP's.

\section{Protocol FIAD - UABC}

Below the objective, the procedure of execution of the PVVC's and the application of validation for the PP's, are defined.

\section{Objective}

The student in conjunction with FIAD-UABC and a company define a technical project that reinforces the theoretical knowledge - acquired during their academic preparation. The company can be public, private or agency. The PVVC scheme helps us to validate the request for release of the internship.

\section{Procedure}

\section{II.a Begining:}

- Find a company in which the linking project (PVVC) could be carried out.

- Request presentation letter to the Coordinator of linking FIAD sending by email the following information: 
- Student data: a) full name, b) registration number and c) career.

- Company data: d) full name of the contact, e) his profession title (Eng., Lic., etc.), f) position d) full name of the company

\section{II.b Registration:}

- The technical project is described in a document named Colaboration Agreement (Convenio de Colaboración in Spanish) signed by all parts involved. This document must be delivered before a deadline, defined every semester by the FIAD administration. There is a format that must be followed.

\section{II.c Follow up:}

- Request permission to the company to make a supervision visit. The Tutor responsible must make this visit within the 1st month of the PVVC period.

- Weekly attendance (face-to-face or virtual) with its tutor responsible at UABC is compulsory.

- Delivery of partial reports to the Tutor responsible UABC, with the time frame agreed.

- Register attendance, on the sheet control of PVVC's on the hosted site. (Access from your mail account in UABC).

- Submit partial reports to the hosted site.

\section{II.d Validation:}

- A final report must be delivered for review the responsible tutor UABC (1 week before the end of the PVVC period). The Tutor responsible for UABC supports the presentation of the PVVC final version either in the ordinary or extraordinary Colloquium pf PVVC.

- One week before the Colloquium, the student must deliver, in paper and electronic, the following six documents (pdf):

1. Final project report

2. Responsible tutor participation letter ( emitted by company)

3. Collaboration Agreement

4. Grade letter emitted by company

5. Evidence of surveys (employers and students).

\section{II.e Evaluation:}

- The project must be presented in person before a group of evaluators from the corresponding Academy, during the Colloquium of PVVC. This committee assigns a grade according with results presented. Final grade will be the average of this mark and the one from Company.

\section{Validation of professional internship:}

- The grade obtained by the student by a PVVC is enough to request for release of the professional internship. 


\section{Results and Discussion}

In the period from 2011 to 2014, the Faculty of Engineering, Architecture and Design (FIAD-UABC) registered and evaluated 346 PVVC, being: 40 made with Public Sector, 19 made with the Social Sector and 287 made with the private Sector (mainly in the city of Ensenada, Baja California, Mexico). Whereas the results by PE of the faculty, are: 282 from Industrial Engineering, 17 of Electronic Eng., 17 Civil Eng., 22 from Computer Eng., 4 of Bioengineering, and 4 from Architecture.

Table 3. 2011 to 2014 FIAD's PVVC Resum, by period and PE of the FIAD.

\begin{tabular}{|cc}
\hline Sector's Impact & \\
Public & 40 \\
Social & 19 \\
Private & 287 \\
\hline FIAD's PVVC & \\
(2011 to 2014) & 346
\end{tabular}

Figure 1. Results of PVVC for the period from 2011 to 2014 by Sector's impact on the city of Ensenada, Baja California, Mexico.

\section{FIAD’s PVVC (2011 to 2014) by Sectors Impact}

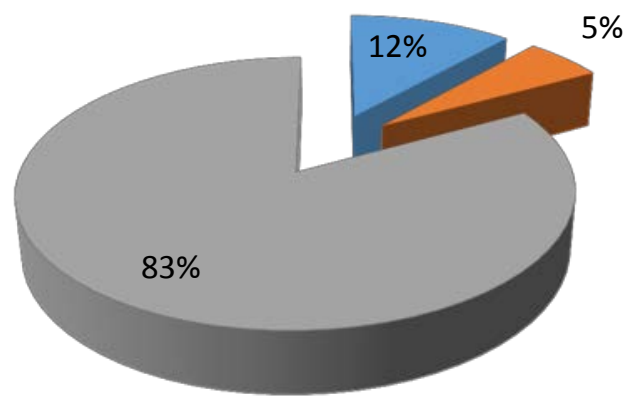

$\square$ Public 40

$\square$ Social 19

$\square$ Private 287

Table 4. 2011 to 2014 FIAD’s PVVC Resum, by period and Sector's impact.

$\begin{array}{cc}\text { Educational Program (PE) } \\ \text { Industrial } & 282 \\ \text { Electronic } & 17 \\ \text { Civil } & 17 \\ \text { Computer } & 22 \\ \text { Bioengineering } & 4 \\ \text { Architecture } & 4 \\ \text { FIAD's PVVC } & \\ \text { (2011 to 2014) } & 346\end{array}$


Figure 2. Results of PVVC for the period from 2011 to 2014 a by PE of the FIAD.

\section{FIAD’s PVVC (2011 to 2014) by Educational Program}

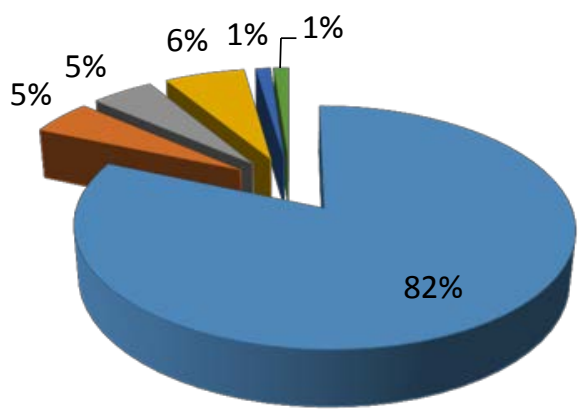

$\square$ Industrial 282

$\square$ Electronic 17

$\square$ Civil 17

$\square$ Computer 22

• Bioengineering 4

$\square$ Architecture 4

\section{Conclusions}

The implementation of this Protocol FIAD - UABC has been very effective to improve the transit of the students at the Terminal stage, to provide clear mechanisms for mapping, monitoring, evaluation and validation of professional internships, within the framework of the PVVC's. 2012 and 2013 cycles, other PE's of the FIAD, in addition to the Industrial engineering students have been incorporated and he is expected for 2015, increase the number of students who register a PVVC, so that standardize this Protocol.

The evaluation of the results of these PVVC's, is carried out within the framework of a colloquium FIAD - UABC's PVVC, that in addition to the virtual library provides a valuable opportunity for the dissemination of the interaction of the FIAD with the productive sector of the city. Also it has a memory that feeds and guides future actions of bonding, so that professional practices, are more profitable, the productive sector, for both students, teachers, the Faculty and University.

It should be mentioned that it is important to consider activities that help a recognition of national and international competition and a validation of their expertis in graduates, which is why we have made efforts by our government with the governments of Canada and the United States, professional practices and the application model of PVVC's could help in this regard. It is noteworthy that Mexico and the United States signed, on March 16, 2015, the Memorandum of Understanding for the Creation of Professional Practice. A memorandum of understanding for the creation of the Internship Program that seeks to expand academic exchanges and opportunities for professional practices for Mexican and American students, college students and recent graduates. This will increase opportunities for educational exchange with the aim of developing the regional workforce to position North America as a more competitive and dynamic region in the world. 


\section{References}

Universidad Autónoma de Baja California (2006). Estatuto Escolar de la Universidad Autónoma de Baja California, Ed. Gaceta Universitaria, 170, 38-39.

http://sriagral.uabc.mx/Externos/AbogadoGeneral/index_htm_files/ESTATUTOESC OLARUABC(REFORMASDEOCTUBRE2014).pdf

Universidad Autónoma de Baja California (2013). Modelo Educativo de la UABC, Cuamea Velázquez, F.

Facultad de Ingeniería, Arquitectura y Diseño - Universidad Autónoma de Baja California (2015). 3er Informe de Actividades 2014-1 y 2014-2, Nieto Hipólito, J. I.

http://fiad.ens.uabc.mx/index.php/formacionprofesional/vinculacionextencion

Facultad de Ingeniería, Arquitectura y Diseño - Universidad Autónoma de Baja California (2012). Los proyectos de vinculación con valor con crédito validan la realización de la prácticas profesionales, el protocolo en la FIAD - UABC, Ed. ANUIES - UABC, Sánchez González, J. L. J., Nieto Hipólito, J. I.

http://saladeprensa.sre.gob.mx/index.php/es/comunicados/5771-141

Secretaria de Relaciones Exteriores (2015). Comunicado firma de memorándum de entendimiento para la creación de prácticas profesionales México - Estados Unidos, Gobierno de México. 


\section{HEAd'15}

\section{SESSION 7C}

\section{TEACHING AND LEARNING EXPERIENCES}




\title{
Blended Learning in a Postgraduate ICT course
}

\author{
Sandra Sendra, Jose M. Jiménez, Lorena Parra, Jaime Lloret \\ Universitat Politècnica de València. C/ Camino de Vera s/n. 46022. Valencia (Spain) \\ sansenco@posgrado.upv.es, jojiher@dcom.upv, loparbo@dcom.upv.es, jlloret@dcom.upv.es
}

\begin{abstract}
University subjects trend to be very theoretical, while enterprise generally demands graduate students with high practical skills. The major concern in remote teaching and online learning is the high trend to create a theoretical course. This is usually solved adding remote practices and hands on practices in a real laboratory. In this paper, we present a blended learning training plan carried out during three years with graduate students. First, we will present the course content and the pursued objectives. Then, we will show the learning methods performed to achieve our goals. This paper also analyses the profile of the students included in this course and reviews, in terms of age and gender, how they impact to the class results. The most part of course is conducted through an online learning platform where all students are supervised through tutorials. During the attendance days, students perform collaborative practices with real devices. Finally, we will analyze the student's opinions and their qualifications during the three years. As results show, the level of acceptance of this kind of teaching innovations depends on the age of the participants and their previous knowledge of these new technologies.
\end{abstract}

Keywords: Cisco Networking Academy, practical skills, online platform, postgraduate courses, new methodologies.

\section{Introduction}

In the last years, the way of teaching in university classes are changing from traditional methods, based on magisterial classes, to a new way of teaching based on new technologies (Lloret, 2009). This change is possible thanks to the integration of new technologies in universities and daily routine of professors and students. The use of Information and Communication Technologies (ICT) in the classrooms and outside the classrooms allows students preparing their lessons more easily than using classical methods. The knowledge acquisition is also benefited by the introduction of new didactic methodologies. The ICTs can be a good way to motivate the students and offer them a desirable autonomy for their future working life. Finally, the ICTs can bring to the students the opportunity of performing more complex practices in real environments that are difficult to recreate in master class lessons.

Postgraduate students, who decide performing masters and postgraduate courses, want to acquire those practical skills and specific knowledge not obtained during the university courses. Students should be able to work individually but also as a part of a team work. The practices that students can develop in the classroom with the limited time cannot be enough in some cases. For engineering students, the capacity of solving real problems is required in their immediate future, but those real problems are quite difficult and complex to recreate in classroom. So the possibility of performing these practices, under a remote supervision or specific software at home can be a good option to solve it (Garcia, 2008), (Coll, 2008) (Lloret, 2008).

In this paper, we show our experience teaching a course for postgraduate students. It is a blended learning course, which uses online learning platforms (Bri, 2009). We will present the content, tools used and the evaluation method. Finally, the students' ratings and their overall opinions are analyzed. The results are very satisfactory because they are improving over the years. Most part of the course is practical, which allows the students to acquire many hands-on skills to solve real problems, more autonomy to work individually and good capacity to work in teams or collaborative 
groups. All of these facts offer to graduate students the possibility of obtaining better jobs. This course includes a certification given by Cisco Networking Academy. In our previous works (Lloret, 2013a), we observed along the years that the fact of including industry certifications in the university curricula (especially in the university experts and masters) generate bigger confidence to the students with their professional skills, while they are able to acquire more practical knowledge on real cases.

The rest of the paper is structured as follows. Section 2 shows some proposals of learning innovation applied to different fields. Section 3 explains the content of our course and the students' profile. Section 4 shows the tools and techniques used to form our postgraduate students. The students' results and their opinions about the course are explained in Section 5. Finally, conclusion and future work are presented in Section 6.

\section{Related Work}

In last 10 years, our society has suffered significant changes. The way we relate, communicate, work, buy, and even how we learn, are changing. These changes are generated by the improvements and appearance of new technologies, new systems and smart systems such as telephones and tablets (Marcelo, 2013) (Lloret, 2013b). Currently, we are using these technologies to improve our daily routines. Considering these aspects, we need to change how to transmit the knowledge to our students making use of these new resources. In this section, we will show some previous works where authors use ICT tools in higher education for different purposes.

C. C. Chen et al. presented in (Chen, 2007) a comparison of their experience teaching a blended learning course vs. teaching a traditional class in higher education with the same evaluation process. The students were divided into two groups, i.e., 38 students followed the course using the traditional class and 58 students followed the course with blended learning methodology. In the traditional classroom the professor teaches 75 minutes lessons twice a week. In blended lessons, the professor meets the students using two hours online meetings every week and one face to face meeting at the beginning of the course. A questionnaire passed at the end of courses showed that students in traditional classroom were happier with the clarity of instruction. On the other side, the students of blended learning indicated that their analytical skills were increased with the course and they were interested on realizing more courses with that methodology. Results suggested that both methodologies offer the same final results and indicated the possibility of improving them through the combination of both.

M. Paechter et al. in (Paechter, 2010) showed which aspects were more important in e-learning according to the students' opinion. To have enough information, the authors sent questionnaires to 2196 students from 29 different universities of Austria. 1361 of them were females (62\%) and 928 were males (37.4\%) and only, the $7.88 \%$ were 31 year old or older. 12\% of students were attending to pure e-learning courses, while the rest were attending to blended learning course. According to results, there are two main aspects that contribute to course satisfaction and learning achievements. On the one hand, students consider especially important the learning of competences and skills, which made them to experience higher satisfaction. On the other hand, the instructors with highest experience had students with highest satisfaction. An important revelation was that in blended learning the role of the teacher does not become less important. 
F. Alonso et al. (Alonso, 2011) analyzed the impact of using blended learning by the academic achievement and the dropout rate. They compared the results of computer science subject between the years 2006 to 2008 with face-to-face classroom and the results of the course in 2009 when distance learning and blended learning were offered. The total number of students surveyed was 693 where, the 107 of them received the course during the last year ( 55 students chose blended learning while 52 followed the distance learning). The teachers of the subjects were the same in all cases. Results showed that students that followed the e-learning course reached higher scores, due to the flexibility of the course. There were more students passing the course in 2009 than in the previous years and students obtained higher marks in 2009.

A. Lopez (López-Martínez, 2014) studies the incorporation of ICT tools in formative activities in classrooms. The author shows different tools that have been proposed in different teaching innovation projects for the elaboration of teaching material. The material was by tested 508 students distributed on the first course of pedagogy and third course of teaching in primary and infant education. Students had to learn how to manage the learning platforms and they participated in the creation of learning networks. The results show that students who have used these tools have notably improved their theoretical and practical knowledge.

S. Sendra et al. (Sendra, 2014) proposed a blended training plan based on the use of two online learning platforms. In this case, the course was given to employees of a national enterprise. Authors presented the content of the course and the online learning platforms used during the course. The experience was performed during 3 years and the results of polls allowed extracting several conclusions. The most important issue was the satisfaction of the students, which was much related to their ages. Nonetheless, all of them obtained very good marks.

D. Healy et al. (Healy, 2005) presented the experience of using a virtual platform for the students with the aim of complement their experience during the practices. The virtual platform was used with 148 medical undergraduate students at the University College Dublin. The students had 42 weeks of practices in the surgical area of hospitals. During 14 weeks, students used the platform to complement their real experience with different study cases. The results show that students who used the platform on weekdays and in day-time hours were positively associated with improvement in class rank. While the usage of virtual platform in weekends and out of day-time hours do not have this positive relation. Authors conclude that the use of e-learning and ICT offers the possibility to the students to keep learning outside of classroom and this learning is reflected in their academic marks.

As we have seen, the use of ICT technologies in different areas such as social, engineering (Medrano, 2012) or medical (Healy, 2005), among others, is becoming a widespread practice because of their several benefits. Most of these works were focused on undergraduate students in higher education. For this reason, in this paper, we have focused our efforts on postgraduate courses in order to improve the students' acquirement of knowledge and their hands on skills in order to form better professionals.

\section{Content and Course Goals}

The course "Computers, network operating systems and computer security" (its original name in Spanish is "Ordenadores, sistemas operativos de red y seguridad 
informática”) is aimed at training professionals to repair and maintain computers and on the design, installation and maintenance of computer networks. This course allows students to detect and correct typical failures in computers. Students also acquire the necessary knowledge for the configuration of local computer networks, in terms of hardware and operating systems. Finally, students acquire advanced skills on security in operating systems. This course is included in the University Expert called "University Expert on networks and computer communications" (its original name in Spanish is "Especialista universitario en redes y comunicaciones de ordenadores"). The content of this course is shown in Table 1.

Table 1. Course content divided by chapters

\begin{tabular}{|c|c|}
\hline Chapter and Title & Description \\
\hline $\begin{array}{l}\text { Chapter } 1 \text {. Introduction to the Personal } \\
\text { Computer }\end{array}$ & Describe a personal computer system \\
\hline Chapter 2. Lab Procedures and Tool Use & Describe the safe lab procedures and proper tool use \\
\hline Chapter 3. Computer Assembly & $\begin{array}{l}\text { Describe the procedure to assemble a computer from } \\
\text { compatible components and update a computer system. }\end{array}$ \\
\hline $\begin{array}{l}\text { Chapter 4. Overview of Preventive } \\
\text { Maintenance and Troubleshooting }\end{array}$ & $\begin{array}{l}\text { Explain the purpose of and basic rules of preventive } \\
\text { maintenance and the troubleshooting process }\end{array}$ \\
\hline Chapter 5. Operating Systems & $\begin{array}{l}\text { Install, upgrade, navigate and troubleshoot various } \\
\text { operating systems }\end{array}$ \\
\hline Chapter 6. Networks & Describe, create and maintain a network \\
\hline Chapter 7. Laptops & $\begin{array}{l}\text { Describe how laptops are constructed, their basic } \\
\text { configuration, maintenance, and troubleshooting }\end{array}$ \\
\hline Chapter 8. Mobile Devices & $\begin{array}{l}\text { Describe operating systems, basic configuration, } \\
\text { maintenance, security and repair for mobile devices }\end{array}$ \\
\hline Chapter 9. Printers & Demonstrate all procedures required for printers \\
\hline Chapter 10. Security & $\begin{array}{l}\text { Explain importance of security, describe procedures, } \\
\text { and perform security measures }\end{array}$ \\
\hline Chapter 11 . The IT Professional & $\begin{array}{l}\text { Describe the communication and related skills needed } \\
\text { by an IT professional }\end{array}$ \\
\hline Chapter 12. Advanced Troubleshooting & $\begin{array}{l}\text { Advanced troubleshooting procedures on computers, } \\
\text { operating systems, laptops, printers and network } \\
\text { security }\end{array}$ \\
\hline
\end{tabular}

\section{Course Goals}

The specific objectives pursued in this course are:

- Provide to the student the adequate technical training on professionals for computers repair and the maintenance of computers networks installations, enabling them to detect and correct typical failures in computers, at hardware and operating system levels.

- Discuss computer security topics in operating systems.

- Design, install, configure and manage computer networks for small and medium enterprises.

- Know the Ethernet technologies in order to find failures in computer networks.

\section{Students Profile}

Students attending this course are graduate students in engineering related to telecommunications. There are some other students from companies who work in the ICT sector. We usually have both men and women in the courses, but the number of 
women is quite small. We also observed large differences in the ages of the students. In fact, groups are quite distinct. On the one hand, we receive young people with extensive knowledge of new technologies and computer skills. The second group is formed by people over 50 years old who did not have great fluidity handling computers. These differences do not happen in other similar courses taught in the first degree (Jimenez, 2014). Figure 1 shows a summary of the student profiles who have attended our course in the last three years. We can see that most of people are men older than 40, but there was no women older than 40 .

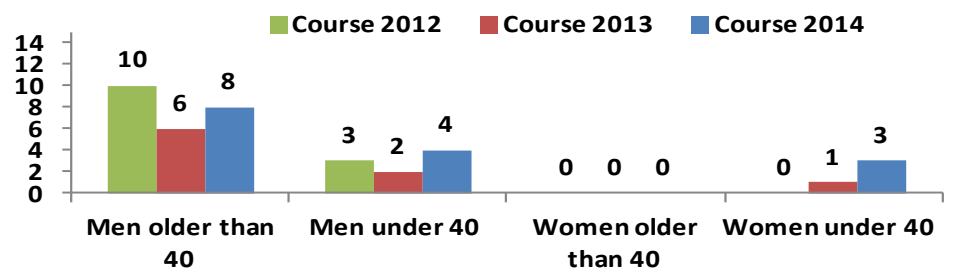

Figure 1. Students profile in the last three years

\section{Development of innovation}

In this section, we present the methodology carried out within this course and the learning platforms used to provide the students the course content and the online tutorials.

The course duration is five weeks, in which students must study and prepare the issues addressed in the curricula. Each topic has associated several practices that should be regularly delivered, according to pre-established dates. Finally, the content is evaluated by remotely controlled exams. This methodology includes personalized monitoring through online tutorials.

\section{Course Activities}

The course "Computers, network operating systems and computer security" follows a blended learning scheme which was initiated in 2012. The online platform makes possible the improvement of the dynamics of the course and its progress but also requires the development of specific training materials specially designed for this new learning environment. The use of Internet and computer networks allowed us to develop a more flexible teaching model where the activity, students participation and acquisition of knowledge prevails to the evaluation itself and its numerical assessment of the acquired knowledge.

However, due to the characteristics and profile of our students, we can find the disadvantage of having to encourage the habit of continuous study and increase the students' effort. Therefore, this course requires that professors make an almost personalized supervision through online tutorials and email. The methodology of this course is mainly focused on the students' participation in their own learning process, so that students are not only recipients of knowledge. This course aims to give and show the students the necessary tools, so they can build their expertise in cooperation with the professor and the rest of their classmates. This strategy is known as Model of Educational Reconstruction (MER) (Duit, 2012) and it is intended to generate strategic learners. 
To this end, it is important to specify a set of specific tasks and objectives to promote the cognitive strategies of exploration and discovery. With this, we help students to learn to plan their activities. Organizing and preparing the course information contribute to a better understanding of the contents. With this goal, we proposed a set of activities that involve a continuous effort of the students. It allowed the professors to know the students' progresses. The educational activities are structured on both autonomous and collaborative work of the students.

\section{Non-Classroom activities: Autonomous Work of the Students}

The self-study is a methodological strategy based on self-education and the ability of students to learn at their own initiative and motivation. Students perform some individual activities. Additionally, we include a set of 5 or 6 practices per module that students should perform to be sent to the tutors. There is another remote practice where students should perform several activities on a remote server. These practices are oriented to install and configure different operating systems which can be installed on virtual machines or natively. Finally, outside the Non-Classroom activities, partial exams are included. They should be done through the Cisco learning platform.

\section{Classroom activities: Collaborative work of the Students}

In order to promote the collaborative work, we use a forum, where students and professors can share comments and questions, which can be answered by any member of the forum. In addition, there are 3 face sessions where students perform several practical activities on real equipment and the final exams. These practices are totally collaborative. In fact, if the team is not able to work together, the implementation of these practices can be very long. With these, it is encouraged the participation of all members. We can also demonstrate the leadership skills of some members.

\section{Online learning platform: NetSpace Cisco Networking Academy.}

The process of this course is done with the help of an online learning platform. This platform is used by students and tutors to exchange all kinds of information, doubts and questions, tutorials, teaching material, software for making practices, etc. As important and distinct parts, this platform includes (See Figure 2):

- Course content allows students to access to the course content. They can also see a calendar with the most important dates.

- Qualifications section where students can see their ratings.

- Course forum where students and professors can send message to all group members. The forum is used to raise widespread doubts that will be answered by the tutors. Students often make contributions on the issues raised.

- Tasks section, where students can find the exams and other activities created by the professors.

The theoretical course content is provided through the online learning platform NetSpace by Cisco Networking Academy. At the beginning of the course, each student is registered as a member of the local academy which manages the course. Each student has a username and password to access to the course content as well as other resources offered by Cisco. Figure 2 shows the main window of Cisco NetSpace platform. This web page contains direct links to the different course modules as well as the qualifying examinations of the chapter and the questionnaire prepared for each chapter. By clicking the "Start Course", we access to the content window (see Figure 
3). In this window, students can read and study the chapters' contents. In addition, all text is accompanied by illustrations and demonstrative videos that help the understanding of theoretical content. At the end of each chapter, students have available non-evaluable questionnaires that help them to check their knowledge of this chapter and deepen in those aspects they have failed. In addition, we have developed an online platform through which students can download the practice statement and answer sheets. The tutorials are also used for the delivery of practices.

\section{Evaluation of activities}

Within the classroom activities, the final evaluation of the course is included. On the one hand, individual exams evaluate the theoretical and practical knowledge acquired during the course. Practical skills exam is performed in groups following a similar methodology to the face sessions. The rating of the practical exam consists of two parts, i.e., the tasks performed individually by each student and the group mark where it is evaluated whether they have met the overall objectives of the exam. These objectives are related to the correct interconnection of all devices, their settings and clients' authentication over a server. The theoretical exams are conducted through Cisco NetSpace platform that specifies that the minimum grade to pass their exams is $70 \%$ (equivalent to 6 out of 10). This rule is set by Cisco in order to ensure that all students meet the requirements and objectives of the course, before receiving their certification. The evaluation of this course takes into account all tasks performed by students, both online part and final exams following the next distribution:

- Review Skills Exam (10\%): Individual exam performer at the beginning of course through the NetSpace platform.

- Practice skills tests (20\%): Performed in groups in the laboratory and encompasses all the acquired knowledge during the delivered practices and the practices in classroom sessions.

- 12 partial exams and Checkpoint Exam (40\%): Partial exams conducted over the course. The checkpoint exam covers theoretical contents of chapters 1 to 6 . All of them are individually performed through the NetSpace platform.

- Final theoretical exam (30\%): This exam includes the theoretical contents of all chapters and it is individually performed through the NetSpace platform.

\section{Students Results and Course Statistics}

At the end of the course, students perform a poll where they can express their opinions on different aspects such as the content of the course, resources, teaching methods, professors, methodology and organization of the course, among others. In this section, we present the results of the courses carried out in 2012, 2013 and 2014.

\section{Students results}

This section shows the results of our students during the years where this methodology has been applied. Figure 4 shows the students results for 2012. During that year, we had 13 students but two of them left the course (red circle). The rest of the students had qualifications above 8 out of 10. Figure 5 shows the students results for 2013. During that year, we had 9 students and only one of them left the course (red circle). Most of the remaining students had final qualifications above 9 out of 10 . 


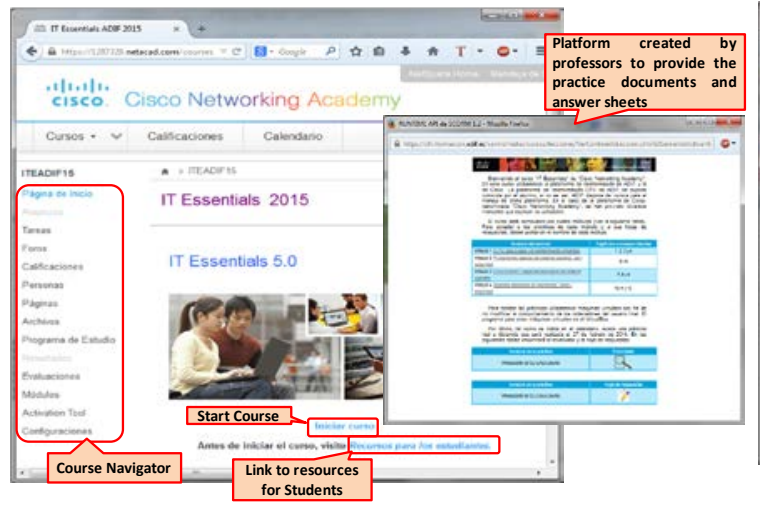

Figure 2. Main window of NetSpace platform and platform created by professors

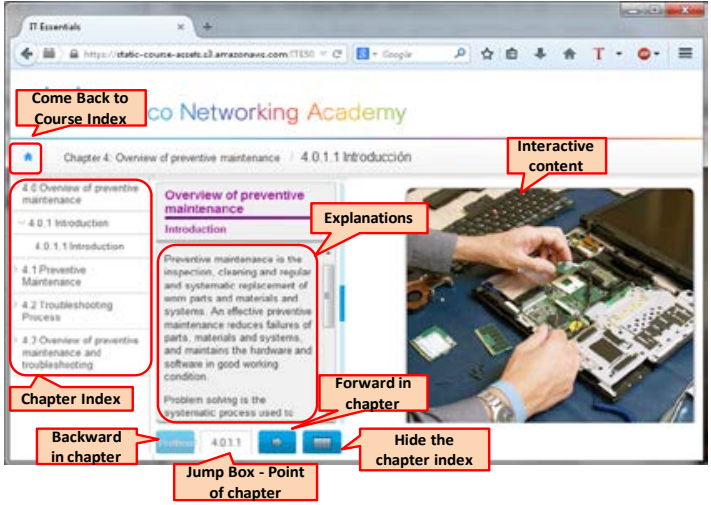

Figure 3. Course curricula with the contents of each chapter

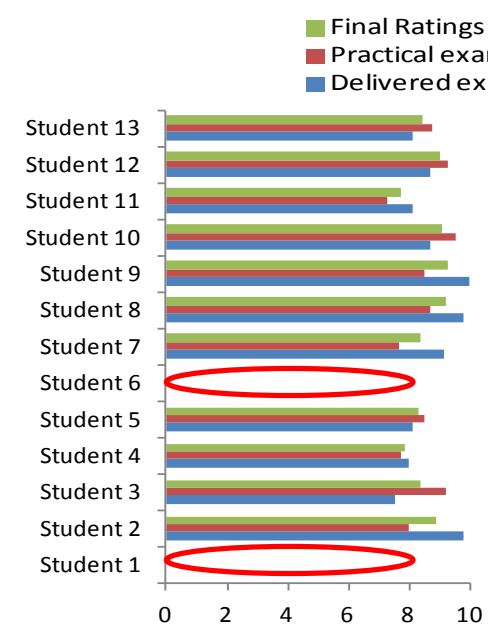

Figure 4. Students marks for 2012.

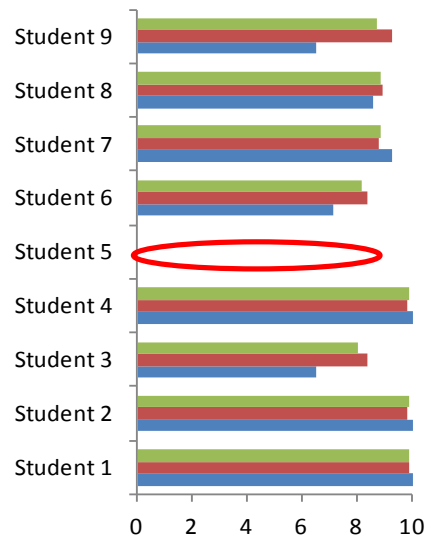

Figure 5. Students marks for 2013.

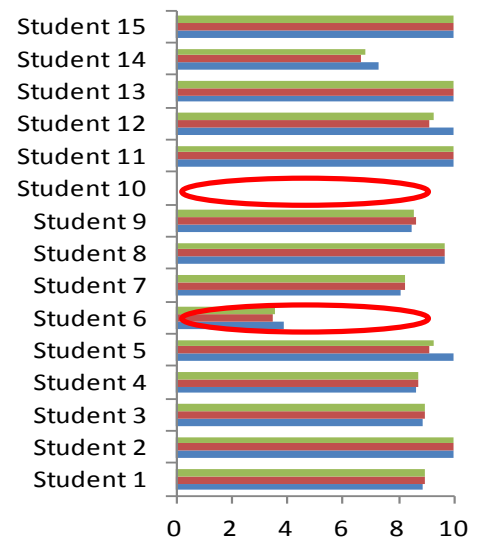

Figure 6. Students marks for 2014.

Finally, Figure 6 shows the students results for 2014. In that year, we had 15 students and two of them left the course (red circle). Most of the remaining students had final qualifications above 9 out of 10, and 4 of them achieve the maximum ratings.

From these results, we can deduce several conclusions. The number of students older than 40 years was higher in the first year. In most cases, this implies that students need more efforts to become familiar with the learning tools. These persons generally attend the course to learn some concepts and the skills they need for their works.

\section{Students opinion and course statistics}

The poll results are pretty good and there was a positive evolution over the years. Figure 7 shows the results of the surveys for three courses. As we can observe, the results were quite satisfactory. During the 2012 course, the results are placed above 5 (being 5 the mark that lets the students pass the exam). We highlight the aspects related to the contents, methodology and distance learning resources. All of them have a rate of 7 out of 10. In 2013, the results are better than the results obtained in the previous year, as they have increased the ratings in all aspects. Comparing both results, we highlight that the rating for the professors and technical media has increased. Finally, we can see that the opinion of the students for 2014 has also been improved in comparison to previous courses. Most cases present a qualification above 7 out of 10. Figure 8 shows a summary of the students' opinion in regard to the overall opinion about the course, general satisfaction and the overall opinion of course 
assessments for 2012, 2013 and 2014. As we can see, over the years, the general opinion has been improved. In 2012, the course was valued with 6 out of 10, in 2013 the valuation was 6 out of 10 and finally, in 2014, students evaluated the course with a rate higher than 7 out of 10 .

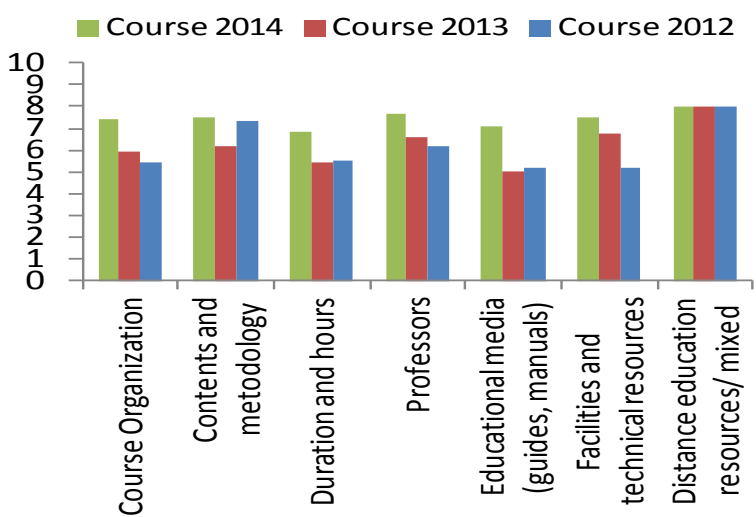

Figure 7. Results of the surveys for course of the 2012 year.

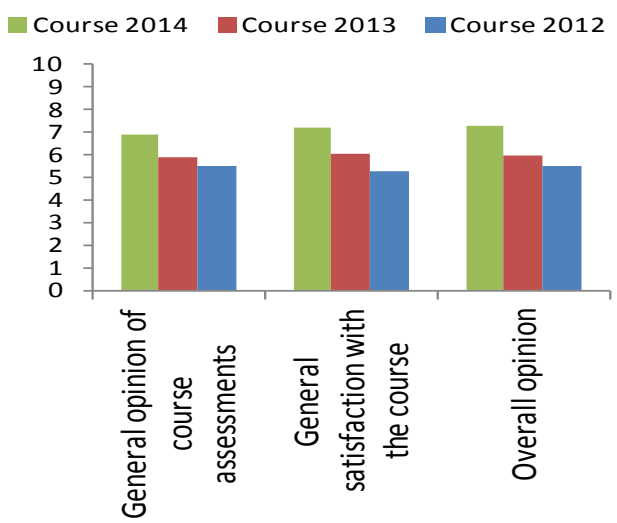

Figure 8. Summary of global opinion for 2012, 2013 and 2014.

\section{Conclusion}

In this paper, we have presented a training plan of a blended learning course for graduate students that were taught at the Universitat Politècnica de Valencia during the years 2012, 2013 and 2014. From the analyzed results, and taking into account the profile of students we had, we draw several conclusions. The first is that taking into account the average marks obtained by the students, this methodology is very effective, as it makes students learn the skills defined by the course. Students also meet the requirements demanded by Cisco Systems Inc. for their courses. Moreover, the results of the surveys and students' ratings have been improved year by year, which indicates that the teaching methodologies based on ICT are well accepted by the students. As future work, we would like to extend this methodology to some subjects of university degrees where students are younger and therefore their knowledge about new technologies is higher. We are confident that this training plan will give good results, both in terms of grades and student's satisfaction.

\section{References}

Alonso, F., Manrique, D., Martínez, L., \& Viñes, J. M. (2011). How blended learning reduces underachievement in higher education: An experience in teaching computer sciences. IEEE Transactions on Education, 54(3), 471-478.

Bri, D., Garcia, M., Coll, H., \& Lloret, J., (2009). A study of virtual learning environments. WSEAS Transactions on Advances in Engineering Education 6 (1), 33-43

Chen, C. C., \& Jones, K. T. (2007). Blended Learning vs. Traditional Classroom Settings: Assessing Effectiveness and Student Perceptions in an MBA Accounting Course. Journal of Educators Online, 4(1).

Duit, R., Gropengießer, H., Kattmann, U., Komorek, M., \& Parchmann, I. (2012). The Model of Educational Reconstruction-a Framework for Improving Teaching and 
Learning Science. In Science education research and practice in Europe (pp. 1337). SensePublishers.

H Coll, H., Bri, D., Garcia, M., Lloret, J., (2008). Free software and open source applications in higher education. The 5th WSEAS / IASME International Conference on Engineering Education (EE'08). Heraklion, Creta (Grecia). July 22-24, 2008.

Garcia, M., Coll, H., Bri, D., \& Lloret, J. (2008). Software Tools and Simulators in the Education of Engineering of Telecommunications. The 5th WSEAS / IASME International Conference on engineering education (EE'08), Heraklion, Creta (Grecia), 22 - 24 July, 2008

Healy, D. G., Fleming, F. J., Gilhooley, D., Felle, P., Wood, A. E., Gorey, T., McDermott, E. W., Fitzpatrick, J. M., O'Higgins, N. J., \& Hill, A. D. (2005). Electronic learning can facilitate student performance in undergraduate surgical education: a prospective observational study. BMC medical education, 5(1), 23.

Jiménez, J. M., Lloret, J., Sendra, S., Parra, L., (2014). Implementation and Evolution of a Cisco Networking Academy Course into the First Year Degree. 13th International Conference on EDUCATION and EDUCATIONAL TECHNOLOGY (EDU’14), Lisboa (Portugal). October 30 - November 1, 2014

Lloret, J., Jimenez, J. M., Diaz, J. R., \& Lloret, G. (2008). A Remote Network Laboratory to Improve University Classes. The 5th WSEAS / IASME International Conference on engineering education (EE'08), Heraklion, Creta (Grecia), 22 - 24 July, 2008.

Lloret, J., Garcia, M., Bri, D., Coll, H., (2009) Using Multimedia Activities for Homework and in-Class Exercises to improve the results of university students. WSEAS Transactions on Advances in Engineering Education 6, 22-32

Lloret, J., Vincent Vela, M. C., Poza Plaza, E. D. L., Domènech de Soria, J., \& PeñaOrtiz, R, Industry Certificate Courses Enhance University Experts and Masters, In IV Congreso Internacional - Estrategias hacia el aprendizaje colaborativo,(UNIVEST2013), Girona (Spain), July 4-5, 2013.

Lloret, J., Vincent-Vela, M. C., Peña-Ortiz, R., Domènech, J., de la Poza, E., Utilización de Dispositivos de Computación en las Clases Teóricas de Primero de Grado, IV Jornada nacional sobre estudios universitarios (IV JNEU), Castellón (España), 8-9 de Julio 2013

López-Martínez, A. (2014). Proyectos de innovación para integrar las TIC en la formación inicial docente. Pixel-Bit: Revista de medios y educación, (44), 157168.

Marcelo, C. (2013). Las tecnologías para la innovación y la práctica docente. Revista Brasileira de Educação, 18(52), 25-47.

Medrano, M., Basora, E., Martorell, I., Hernández, M., Traveria, M., Bret, D., \& Gavaldà, J. (2012). Mejora del proceso de enseñanza-aprendizaje en entornos tecnológicos extremadamente cambiantes mediante la implantación de tic. El caso cesda. CIDUI-Llibre d'actes, 1(1).

Paechter, M., Maier, B., \& Macher, D. (2010). Students' expectations of, and experiences in e-learning: Their relation to learning achievements and course satisfaction. Computers \& Education, 54(1), 222-229.

Sendra, S., Jiménez, J.M., Lloret, J., \& Vincent-Vela, M-C, (2014), Evolución de una Experiencia de Formación Semipresencial para una Empresa Nacional, Jornadas de Innovación Educativa y Docencia en Red (IN-RED 2014), Valencia (Spain), July 15-16, 2014 


\title{
Collaborative web-based learning spaces: Introduction to Housing
}

\author{
N. Charalambous*, C. Sentieri** \\ * Department of Architecture, University of Cyprus \\ ** School of Architecture, University of Valencia, Spain
}

\begin{abstract}
This paper explores a collaborative web-based learning space named "Introduction to Housing" created in the context of the Erasmus Lifelong Learning Project OIKONET. The learning space mainly draws on the curriculum of the design studios in the Polytechnic University of Valencia and the University of Cyprus and includes work from a 3D Visual Communication course at the University of Belgrade. All learning activities developed in this learning space aim at the introduction of students to housing studies through a collaborative learning environment that cuts across traditional and institutional boundaries. The paper starts with a brief discussion on design studio teaching, its importance in architectural education and recent impacts of emerging information technologies on traditional teaching methods. The transformation of the traditional design studio learning into a "blended" learning environment is then discussed through the presentation of the web-based learning space. The paper concludes with a discussion of the participants' experience which renders the proposed learning space as a fruitful and potentially innovative learning environment. Tutors had the opportunity to incorporate blended learning in their teaching and get familiar with different and diverse teaching methods and learning resources in different academic environments. Participating students on the other hand, were exposed to different cultural and academic contexts and were able to experience different methods of learning through the virtual campus.
\end{abstract}

Keywords: Web based learning; blended learning; design studio; collaborative learning space

\section{Introduction}

The collaborative teaching activity described in this paper was initiated during the spring semester 2013-14, as part of the European research project OIKONET. The creation of a collaborative web-based learning space was proposed aiming at the introduction of first year students to architectural principles with a focus on housing studies. The new learning space builds on a pedagogic model developed and implemented in the OIKODOMOS virtual campus developed in previous projects (www.oikodomos.org) and is based on the collaborative design and implementation of sequences of learning activities. These activities are carried out in digital learning environments specifically developed for the project, as well as in seminars and design studios taking place at the participating universities.

The paper is mainly based on a reflection on the collaborative teaching process developed through the learning space "Introduction to housing" (available online at: http://www.oikodomos.org/workspaces/). Through the analysis of the collaborative process and the content of the learning space, the discussion is directed towards examining potentials and limitations of web-based collaborative learning activities in introducing housing issues to architecture students. It highlights the challenges for both teachers and students collaborating through a common pedagogic structure while exposed to a wider international academic audience within the OIKONET project (www.oikonet.org). Furthermore, the paper attempts to identify the benefits of exposing early year architecture students to an international learning community, gaining knowledge and skills related to a general yet context-specific topic such as housing in a design studio environment, the backbone of architectural education (Charalambous et al 2007, 2012). 


\section{DESIGN STUDIO TEACHING}

The design studio has undoubtedly been at the core of architectural design education since its inception in the 19th century. The traditional studio-based pedagogy has remained fairly stable and unchanged, based on the historical models of the Beaux-Arts and the Bauhaus. The "design project", as the vehicle for project-based learning was adopted on the assumption that the expertise needed by architects could only partially be learned through the traditional methods of knowledge and experience transmission. The perceived benefits of the design project was that it simulated, albeit in a simplified and directed way, the actual processes of professional activity by requiring students to apply their accumulated knowledge and skills in an integrated way to a design problem. The model of "practice informs teaching" in an integrated environment of theoretical and practice related artistic creativity and research can trace its origin back to the Bauhaus workshop at the beginning of the 20th century. Architecture students became familiar with the materials and the profession, while possessing at the same time theoretical knowledge and experience that enabled a comprehensive project development. The integration of different types of knowledge in architectural education through a collaborative environment has been a perennial concern since then (Cunningham 2005).

The overriding primacy given to the studio as the main forum for creative exploration, interaction and assimilation remains a common characteristic in architectural education (Charalambous et al 2007). Students encounter fundamental principles and skills in design, supported by analytical and abstract thinking, integration of design aims in visual environments, as well as cultural, technological and other parameters. However, research related to contemporary pedagogical approaches to the studio reveals considerable differences in the process of education of future architects around the world; schools of architecture adopt different models of how learning within a design studio may occur. In some situations (the year system), students will all work on the same project, within a shared studio environment for a whole semester or year. In other situations (the unit system), students from various backgrounds may work together in a similar way to the Fine Arts ateliers.

Although studio teaching is still based on the traditional models of design process new forms of research have been developed aiming at a redefinition of the landscape of architectural education and practice within the design studio. Advances of disciplines, specialization, material- and systems-science and digital technology have brought a radical change in the contextual frameworks in which architectural design and production are normally placed. A major concern has been the relationship between the digital and the analogue worlds which forms a central issue for architectural design, research and production. Advances in digital technologies are paving the way to achieve "integrated inter-, multi- or even trans-disciplinary design" - in all cases a type of practice that covers a mind-set of collaboration and cross-disciplinary communication and experimentation, visualization and research at all or possibly at different stages of the design process (Charalambous et al 2012, Nicolescu 1997). This approach requires designers to rethink alternative strategies in order to establish sound links between disciplines and specializations. An aptitude for exploration is needed for the entire design process, from the early conceptual stage until the production phase.

This observation implies rethinking buildings as integral systems rather than the juxtaposition of optimized and mono functional layers but also rethinking design pedagogy which needs to address the challenge of both virtual and analogue modes of 
design and collaboration. The web-based collaborative learning environment "Introduction to Housing" has been developed with the aim to address such concerns and to promote pedagogic innovation in the field of introductory housing studies.

\section{Methods}

\section{CREATING A COLLABORATIVE LEARNING SPACE}

The house is undoubtedly one of the most important vehicles of exploring the social and experiential dimensions of architecture. An understanding of the ways in which the house as a spatial form, relates to the social, the cultural, the individual in the context of the increasingly divided, complex and differentiated experiences of contemporary life, is an important concern for architecture educators across the globe. The pedagogic purpose of the web based learning space "Introduction to Housing" is to address such concerns through the collaborative design and implementation of sequences of learning activities that introduce students to the basic principles of the design of a house. These learning activities attempt to overcome boundaries between physical and digital learning spaces by promoting a blended learning approach across institutions.

As already mentioned contemporary pedagogical approaches to the studio reveal considerable differences in the process of education of architecture students; schools of architecture adopt different models of how learning within a design studio in general or a housing design studio in particular may occur. Each school has its own particular curriculum, timetable and educational culture. So, the first challenge faced in the design of this learning space was to agree on a common plan of collaborative teaching on this specific topic which reflects the pedagogic objectives of the participating institutions.

An important first step was to establish a common understanding of the educational processes and the language used to describe them; this was based on the pedagogic methodology developed in the OIKODOMOS virtual campus. The definition of goals and learning outcomes in conjunction with the method of aligned learning and teaching to describe the process by which learning would take place is therefore used

The web-based learning environment OIKODOMOS Workspaces (www.oikodomos.org/workspaces), developed in the previous OIKODOMOS projects with the support of the Life Long Learning Programme2007-2011, formed the pedagogic structure of the new learning space. The structure of the Workspace enabled architecture educators from the three participating institutions to design a joint learning structure made up of collaborative Learning Activities and Learning Tasks. The pedagogic model underlying the learning environment is based on the structure presented in Figure 1: 


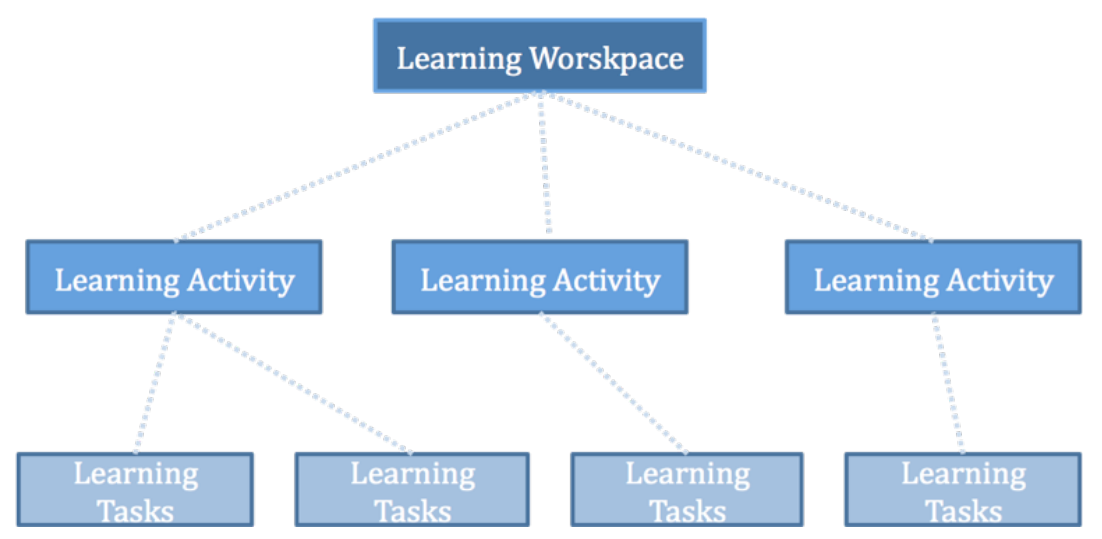

Figure 1. The pedagogic model of the collaborative learning environment "Introduction to Housing"

Learning Activities ${ }^{1}$ and Learning Tasks ${ }^{2}$ were collaboratively designed in alignment with the common pedagogic goals which are reflected in the learning outcomes set by the participating institutions. The underlying consideration is that everything to be assessed is supported by a learning process (http://www.oikodomos.org/resources/compendium.pdf). Teachers from the participating institutions aimed at collaboratively designed learning activities and tasks, describing at the same time the learning outcomes to be used to jointly assess students' work.

Learning Activities included precedents analysis, understanding of the concepts of home and house, context analysis and analysis of users' profiles. Learning Tasks included demonstration of knowledge of the relevant theoretical background, demonstration of coherence and continuity in the development of the design process, appropriate use of different representation techniques (verbally, textual and graphicdigital and analogue) in order to communicate the ideas (concepts and design proposals) in an effective manner, ability to demonstrate team working skills through their contribution to each project and ability to critique their own work and that of others by reference to established models of good practice and the appropriate standards. The Learning Activities and Learning tasks of the Workspace "Introduction to Housing" can be seen at www.oikodomos.org/workspaces, Figure 2.

\footnotetext{
${ }^{1}$ A Learning Activity is a well-defined stage in the process of learning, for instance, "Site analysis", "Analysis of precedents".

${ }^{2}$ A Learning Task is an assignment given to students within the context of a Learning Activity, for example,"Visual analysis of the site", "Studying a set of concepts".
} 


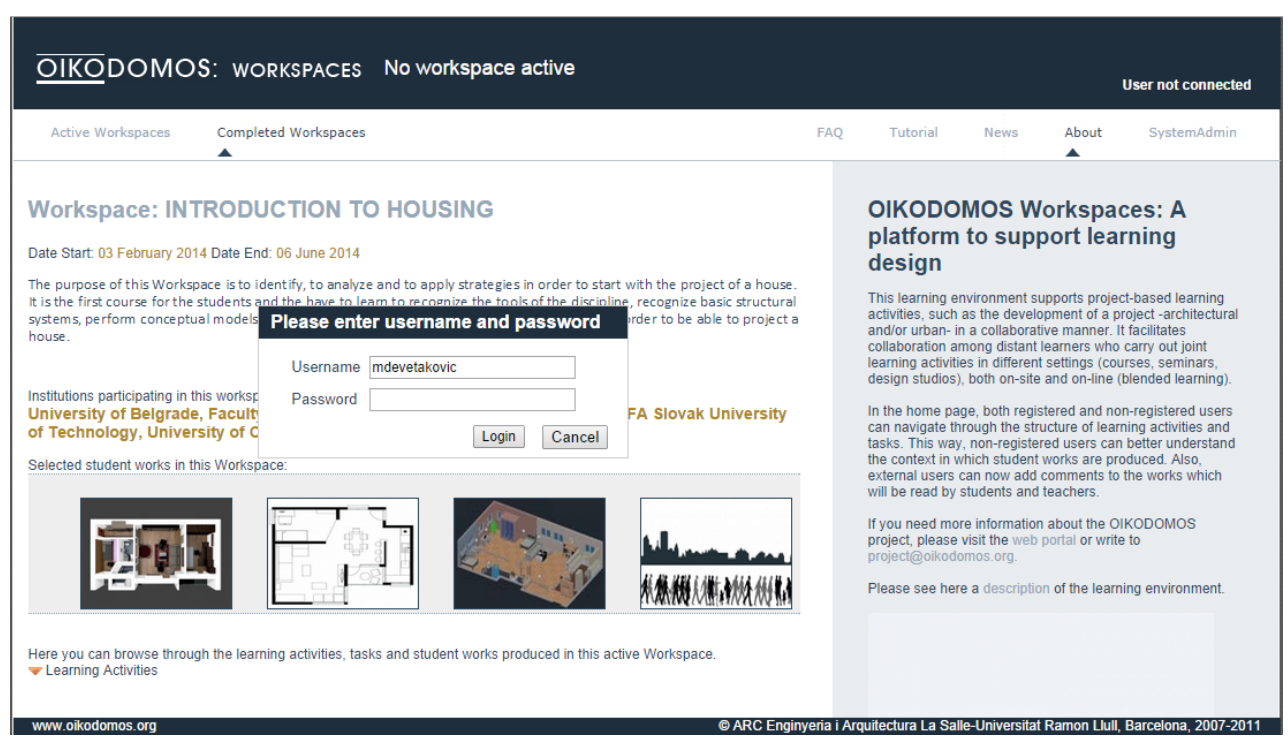

Figure 2. Home page of OIKODOMOS Workspaces

\section{Results and Discussion}

Each participating school implemented learning activities and tasks through the pedagogic structure of their curriculum. Overall, there were four groups of students enrolled with a total of 120 participants in the collaborative teaching and learning process. Final students' work was uploaded in the Workspace as deliverables, at the completion of each task. Students and tutors from all participating institutions were then invited to comment and give feedback to the submitted work, Figures 3 and 4.

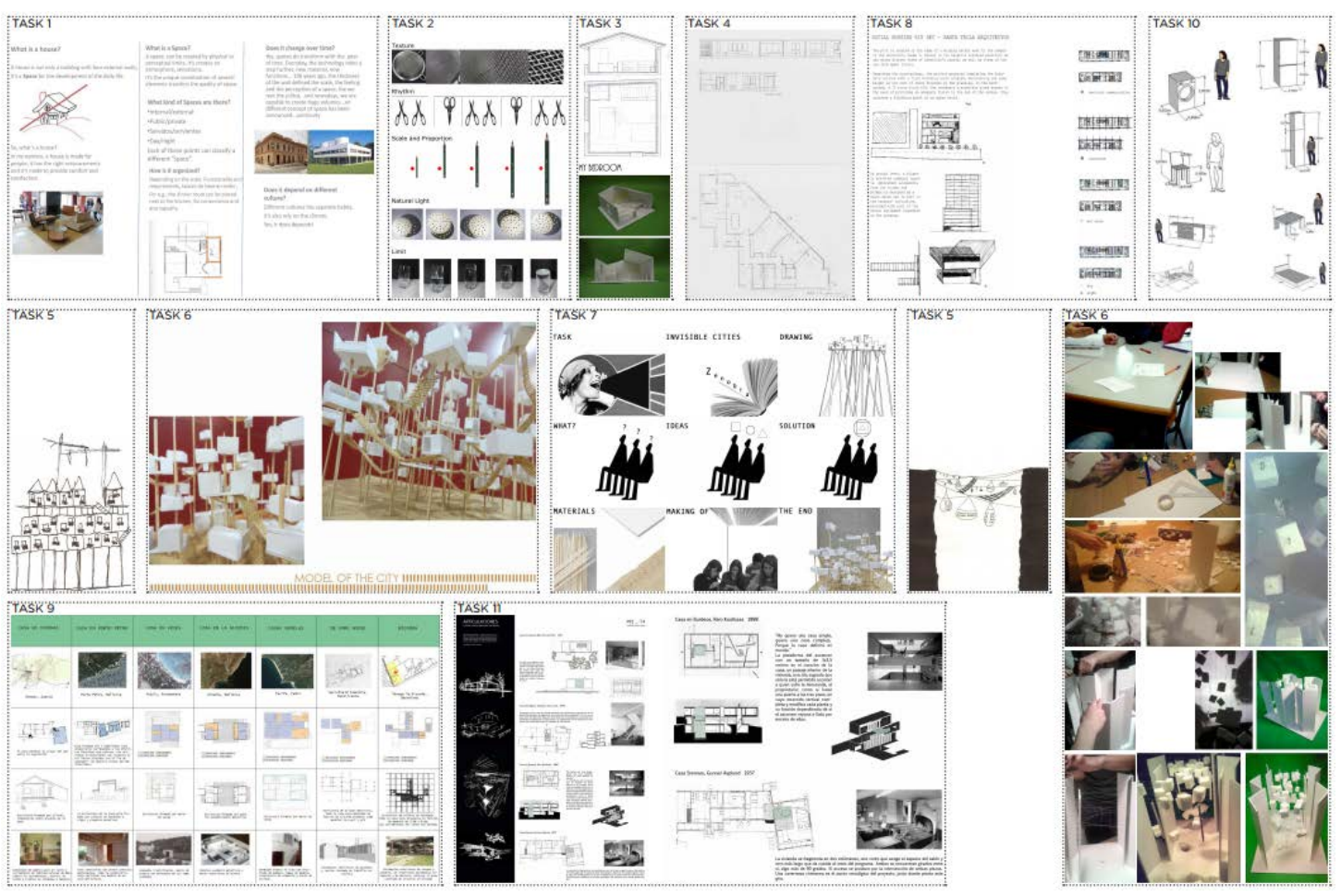

Figure 3. ETSAV students' deliverables 
The Workspace gave students the opportunity to be exposed to the work of fellow students but also to present their work to both students and colleagues from the participating schools. It also gave tutors the opportunity both to work in collaboration but also to come across diverse teaching methods as well as students work from other schools.

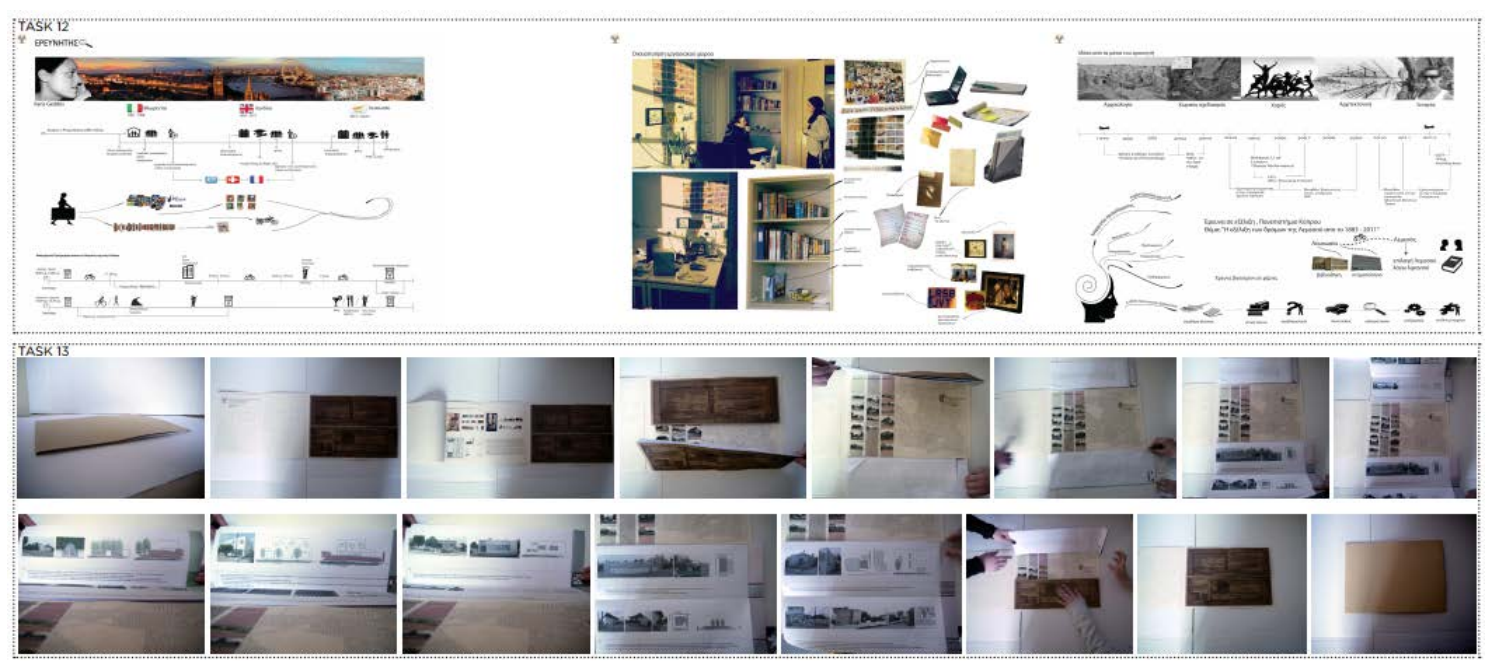

Figure 4. UCY students' deliverables

However, it proved that more time and better planning was required in order to make full use of the potentials of the Workspace. The learning environment has not been used to its full potential due to different deadlines set by the partner universities involved due to different starting and ending dates of the semesters; this did not facilitate a smooth collaborative building up of tasks (preceding and succeeding tasks). Work uploaded from partner universities was presented by the tutors and was discussed in class but students did not engage as actively as expected by themselves through the Workspace.

\section{Conclusions}

The teaching activity analyzed in this paper is regarded as the first in a series of similar activities that is going to be realized using the presented collaborative learning space "Introduction to Housing". The pedagogic structure created within this learning space is a base for future modifications and developments.

Both students and tutors found OIKODOMOS Workspaces a fruitful and potentially innovative learning environment. The tutors involved had the opportunity to incorporate blended learning in their teaching, get feedback from colleagues in different academic environments and get familiar with different and diverse teaching methods and learning resources. Participating students on the other hand, were exposed to different cultural and academic contexts, were able to experience different methods of learning through the virtual campus and had the opportunity to comment on other students' work but also receive feedback from both peers and tutors.

Participating teachers noted the potential of blended learning environments and OIKODOMOS Workspace technology to be used in an even more effective way, facilitating a more intensive interaction between students from various institutions and 
thus contributing to a better understanding of the multiplicity and complexity of housing issues.

\section{Acknowledgements}

OIKONET is an Erasmus Networks project co-financed by the Executive Agency Education, Audiovisual and Culture Executive of the European Union with the project number 539369-LLP-1-2013-ES-ERASMUS-ENW. We would like to thank our project partners who have contributed to the work reported in this paper.

\section{References}

Charalambous, N. and Phocas, M. (2012) "Research in the Studio: Integrated, Research Based Design Process", proceedings of the International conference Theory by Design: Architectural Research Made Explicit in the Design Teaching Studio, Antwerp, Belgium.

Charalambous, N. and Hadjisoteriou, M (2007) "Introductory Architectural Design Studio: (Re)Searching for a New Approach”, EAAE Transactions on Architectural Education: Teaching and Experimenting with Architectural Design: Advances in Technology and Changes in Pedagogy, No.35, pp. 285-293, Lisbon, Portugal.

Cunningham, A. (2005): Notes on education and research around architecture, The Journal of Architecture, 10:4, 415-441.

Devetakovic, M.; Arsic, P.; Nikolic, I. (2011). INTEGRATION OF E-LEARNING CONCEPTS IN URBAN DESIGN STUDIO, The case of a virtual learning environment supporting a specific educational mode , YU Info 2011, Kopaonik, March 2011, http://www.e-drustvo.org/proceedings/YuInfo2011/html/pdf/190.pdf (accessed September 2014)

Calvino, I. (1978) Invisible Cities, Harcourt Brace Jovanovich.

Madrazo, L. (2012): OIKODOMOS Technological Platform, in OIKODOMOS Innovating Housing Learning (ed. Madrazo, L.; Verbeke, J.; Ooms, T.; Riddy, P), pp. 48-61

Madrazo, L. (2011): OIKODOMOS Compendium, EU Lifelong Learning Programme retrieved from http://www.oikodomos.org/private/downloads/conferences/edulearn_oikodomos. pdf

Nicolescu, B. (1997). The transdisciplinary evolution of the university condition for sustainable development.

URL: http://www.perso.clubinternet.fr/nicol/ciret/bulletin/b12/b12c8.htm

Rasmussen S.E. (1964) Experiencing Architecture, Architecture (M.I.T Press)

Websites:

OIKODOMOS Project Website, Erasmus Lifelong Program 2009-2011. Available at http://www.oikodomos.org/.

OIKONET Project Website, 2014, Available at http://www.oikonet.org/ 


\title{
Correlation of figurative insight indicators in the experience of future art pedagogues
}

\author{
B. Reinberga*, B. Garjāne** \\ * Daugavpils University \\ ** Riga Teacher Training and Educational Management Academy
}

\begin{abstract}
:
Aim - to reveal the correlations among the indicators of figurative insight for its development. The self-development and self-actualization in the study process that include also the development of figurative insight of future art pedagogues are stressed in this paper.
\end{abstract}

Methods - research on the correlations among the figurative insight using Factor Analysis. The development opportunity is determined by the concepts of personality traits: creativity, self-expression, personal attitude, emotional and intellectual experience. The paper is based on a quasi-experimental research - the communication by future art pedagogues using visual and verbal dominant images in three kinds of exercises.

Results - the indicators determining the figurative insight which correlations encourage the development of figurative insight. Results allow setting a goal to reveal the correlations of figurative insight indicators for its development. According to the aim for the research of the indicators the factor analysis method was chosen. Finally, to determinate validity of the results four criteria were set: openness, flexibility, plasticity and creativity.

Conclusions - in the process of art subject teaching if purposefully working on separate indicators of figurative insight, the overall figurative insight of future art pedagogues can be further developed.

Keywords: figurative insight phenomenon, figurative insight criteria (openness, flexibility) and indicators, figurative insight development

\section{Introduction}

In the aspect of figurative insight the development of creative self-experience rarely conforms to the theoretical knowledge and usage skills. The human comprehension of issues is mainly determined by competition and patterns that in turn endangers one's creative personality and being. Bernard Sordet recognises "The time has come when Le tutorat method regains the importance in education and research. This method states that teacher is a guide in life, spiritual and intellectual support, an adviser and promoter and passes the knowledge through the generations“ (Sordet, 2013). This humanitarian paradigm allows new opportunities to connect the education with spirituality (transcendent) dimensions as well as one's self-development and selfactualization opportunity through the creative processes that include also figurative insight. The personality of a creative pedagogue as well as pedagogical approaches promote self-development, while "in the educational practice figurativeness familiarisation always is more connected to the perception of the art and the analyses of an art work - crafts and handicrafts” (Brikša, 2011, 114-115). In order to advocate the inclusion of the development of figurative insight as a necessity in the study process for future art pedagogues the model of figurative insight (MFI) was created (Reinberga, Garjāne, 2013). The components of the model determine the factors for figurative insight's development. MFI methodological trait is developed according to the iconic principle, when the theory of metaphor is reduced to the linguistic nature of the image. In the metaphor the image is not connected to the sensual images, but depicted in the form of language focused towards the potential experiences of future art pedagogues that can develop their own and student's figurative insight. 


\section{Methods}

Creativity can be further developed throughout the life as the process of spiritual selfexpression and as self-realisation opportunity - "for the person to self-realise and selfexplore in new kinds of artistic acts, opportunity to unleash the individual's creative potential and promote its development" (Grīcs, 1998). It is common when art pedagogues do not connect the knowledge about figurativeness with creative action practice because they believe that figurative insight includes the knowledge that can be defined as "information that is relevant and useful in action, based in experience" (Leonard, 2005). That is the knowledge about figurativeness that has an intangible dimension - the aspects of knowledge that are not articulate, thus the representation of knowledge becomes more and more abstract and the intangible has an opportunity to become more dominant connecting with the sixth sense - intuition. Self-expression shows the direction for thinking and comprehension while searching approaches that helps to centre one's view on self-expression in the language. The holistic content of MFI is targeted towards learning (as individual sphere) correlation with art (as context, subtext sphere) and reveals the opportunity that helps to further develop figurative insight using the images of two arts - literature and visual art. The expression in the self-expression helps the individual to gain new experience in connection with new creative acts.

The linguistic conciseness and inclusive cognitive conciseness are united in significant expression - communication with images in any kind of art, thus when acting on it the figurative insight of respondents can be developed when more attention is paid not on the theory of the art, but on the multidimensionality of the vertical levels of the plural language, (See Figure 1), that determines the insight of figurativeness and indirect meaning, the associative network and fields.

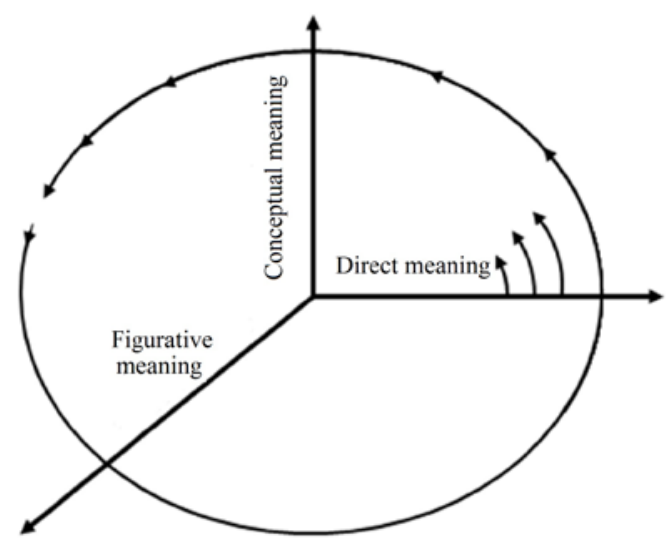

Figure 1. Multidimensionality of word's meaning in regard to criteria (Reinberga, 2009)

The figurative insight that is based in the language and its development is the task of study process (to show that figurative insight can be changed) and the result of study process (recognising certain level of figurative insight). The meaning of the word is a universal medium between the human thinking and notion of the world (Reinberga, 2009). Using the uniqueness of individual's personal figurative insight, with the help of meanings the language can be attributed to all non-linguistic (including figurative insight) phenomenon, this applies also semiotic not only to reality but also to irreality (that metaphorically exists in the images of literature and art), that way becoming universal self-expression in the cognition of the figurativeness, thus semiotic approach can be implemented in the literature and other art sciences. As a result of figurative 
insight the concepts of the creative personality trait in the creative process are determined - creativity, self-expression, personal attitude, emotional and intellectual experience. "These are accepted in order to describe the presence and to gain the understanding” (Gadamer, Ricoeur, 1982). Latvian philosopher M. Kūle, when characterising this process on a deeper level, recognises "the boundaries of thoughts do not come from the outside - from the richness or poorness of the experience that is met by one's mind, but from the inside - from the conceptual force, from the truthfulness of formulated notion that helps the mind to meet the experience." (Kūle, 1989, 110).

Wolfgang Welsch stresses the connection between hermeneutics of art and philosophy - "the art and philosophy must be fundamentally comparable, otherwise there would be a lack of interpretation options that has the compatibility not incompatibility foreseen" (Velšs, 2005, 186-190). "Thanks to the interpretation and its correlate - the understanding, it is possible to move from the material sphere of world's reflection to the subjective sphere of reflection - the perception experience and the insight sphere" (Grīcs, 1998).

Based on the described framework the approach for the interpretation of dominant image approbated in the quasi-experimental research (the communication by future art pedagogues using visual and verbal dominant images in three kinds of exercises) determines the creative environment for the development of figurative insight when the use of a verbal tittle changes the aspect of the repeated dominant image in various exercises, that way the figurative perception and insight are trained in the form of creative multiple variations. The strategy of quasi-experimental research is formed with a goal to compare the results (creative result constructed by subjective imagination and fantasy) of the figurative insight in exercises about two dominant (verbal/visual image) integrative insight using statistically validated six test results. The level of result was categorized according to the levels of MFI (the task of the research is not to unfold the construction process of figurative meanings). Numerical data and the statistical testing of the result using four criteria and their indicators (4 criteria/24 indicators) ensure the validity of the research. MFI and its determined levels of figurative meaning: three didactically various sets of dominant exercises based on the holistic content of an integrated creative action of two subjects. In order to test the validity of the result of dominant exercises four criteria were chosen openness, flexibility, plasticity, creativity (See Figure 2). Openness is an ability to recognise dominant image perceiving the situation offered by the dominant as replicable and as further developable associative content. Flexibility is an ability to move from the given image to another using aspect as a tool of imagination.

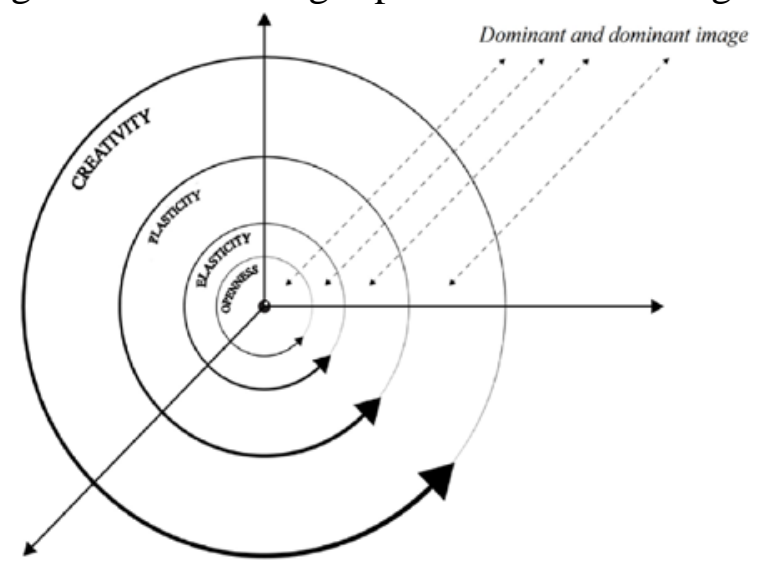

Figure 2. Criteria of figurative insight determined by the dominant (from Brikša, 2011) 
By offering creative process of cognition to the students using the mediation of the dominant, it is tried to determine the opportunity to further develop figurative insight through the previous mentioned factors as purposefully inserted, cognisable, solvable, always potentially further developable. Subjective artistic communication ability is objectively relevant to the existing dominant image; for the visual dominant it is "cognition that is sensitive to visual form elements" (Brikša, 2011, 108), for the verbal dominant, it is the insight of notional and figurative meanings of figurative expression. The interaction of the components forming the interpretation of dominant helps:

- To comprehend complicated relations and attitudes of visual and verbal images,

- To percept and comprehend the figurative meanings offered by dominant,

- To make creative decisions in the level of fantasy in order to form other figurativeness,

- To form other figurativeness text by reforming the former experience of insight to higher level of figurative meaning (Reinberga, Garjāne, 2012).

The future Art, Literature and primary school pedagogues from various universities in Latvia - University of Latvia, Liepaja University, Daugavpils University, Riga Teacher Training and Educational Management Academy - took part in the quasiexperimental research. The main criteria for respondent selection were their affiliation to various higher education institutions, their study programme connection with teaching of art subjects in the future. It was tried to determine if the figurative insight as a part of creative self-expression characterises future art pedagogues (significantly assessing their creativity in the pedagogical practice in the future). The quasiexperimental research allows to:

1) Separate the figurative insight in literature from metaphorisation (figurative expressions of the art science in general);

2) Replicate it in various auditoriums changing the pedagogical means.

The collected data was processed applying statistical methods - according to Cronbach's Alpha test reliability is met only for openness and flexibility because it is impossible to statistically measure creativity, but plasticity is too uncertain category for statistical data inclusion. This paper describes only three significant correlations among the figurative insight indicators. These correlations were determined using Factor Analysis.

\section{Results}

The factor analysis classifying the indicators of figurative insight in levels shows correlation among variables. The correlations explored in the Factor Analysis have pedagogical value that can be implemented in practice in the form of the didactical methods. That way, it puts forefront the opportunities of figurative insight development where interaction between pedagogue and respondent is manifested as a stimulus on one hand and as a certain reaction on the other hand. Matrixes of factor analysis reveal: 1) if students can use figurativeness and its means of expression according to the multidimensional offer of the dominant (7) then it is possible to promote their skill in the creative action to form the images in the figurative meaning (4) and ability to percept the offer of the personal creative action as replicable 
situation (2) as well as ability to recognize the figurative meaning incorporated in a visual image (5) (See Figure 3).

\begin{tabular}{|l|r|}
\hline & Component \\
\cline { 2 - 2 } & 1 \\
\hline 7: Uses figurativeness according to the multidimensional offer of the dominant &, 891 \\
1: Knows figurative means of expression according to the literature theory &, 772 \\
2: Perceives the situation as replicable &, 825 \\
3: Recognises the figurative meaning incorporated in the title &, 740 \\
4: Forms the images in the figurative meaning & \\
5: Recognises the figurative meaning incorporated in a visual image & 6: Chooses the useful for the fantasy \\
8: Perceives figurative contrasts & \\
9: Perceives the dimensionality of images & \\
\hline
\end{tabular}

Extraction Method: Principal Component Analysis.

Rotation Method: Varimax with Kaiser Normalization.

Figure 3. Rotated Component Matrix 1

2) If students know how to use aspect as a method for the imagination (17) then they can verbalise the image of visual dominant in the level of fantasy at a greater capacity (13) and comprehend the symbolic (16) (See Figure 4).

\begin{tabular}{|l|r|}
\hline & Component \\
\cline { 2 - 2 } 17: Uses aspect as a method for imagination &, 909 \\
10: Can unite different phenomenon in the level of fantasy & \\
11: Can interpret the common meaning of 2 visual images & \\
12: Can unite the common meaning of 2 phenomenon &, 858 \\
13: Can verbalise the image of visual dominant in the level of fantasy & \\
14: Senses the subtext &, 889 \\
15: Comprehends the paradox & \\
16: Comprehends the symbolic & \\
\hline
\end{tabular}

Extraction Method: Principal Component Analysis.

Rotation Method: Varimax with Kaiser Normalization.

Figure 4. Rotated Component Matrix 2

3) If students can interpret the common meaning of two visual images (11) then they can also unite the common meaning of two phenomenon (12) and vice versa (See Figure 5).

\begin{tabular}{|l|r|}
\hline & Component \\
\cline { 2 - 2 } 17: Uses aspect as a method for imagination & \\
10: Can unite different phenomenon in the level of fantasy & \\
11: Can interpret the common meaning of 2 visual images &, 980 \\
12: Can unite the common meaning of 2 phenomenon &, 980 \\
13: Can verbalise the image of visual dominant in the level of fantasy & \\
14: Senses the subtext & \\
15: Comprehends the paradox & \\
16: Comprehends the symbolic & \\
\hline
\end{tabular}

Extraction Method: Principal Component Analysis.

Rotation Method: Varimax with Kaiser Normalization.

Figure 5. Rotated Component Matrix 3 


\section{Conclusions}

According to the results of the quasi-experiment the correlations among the separate indicators of figurative insight reveal the receiver's communicative culture with the image of an artwork, one's ability to see the subjective (non-standard) content of dominant, to overcome the habitual, to be ready to synthase the knowledge in creative action. While realizing the emotional comfort through the revelation of new images, students can form their own text based on the perception and insight correlations. In the process of creative self-expression the figurative insight can be further developed pedagogically organising individual's creative self-expression in the direction of the dominant idea, thus forming a dominant images in the level of fantasy.

\section{References}

Briška I, (2011). Topošo skolotāju profesionālo vērtību veidošanās mākslinieciski radošā darbībā. [Development of student teachers professional values in artistic creativity] Rīga, LU, 210 lpp. (in Latvian)

Gīrcs V. (1998). Kultūru interpretācija [Interpretation of Cultures] Rīga; AGB, 11-12. lpp (in Latvian)

Kūle M. (1989). Ceľ̦̌ saprašanas labirintos. [Itinerary in the Labyrinth of Understanding] Rīga. Zinātne, 111 lpp. (in Latvian)

Leonard, D., Swap, W. (2005). Deep Smarts. How to cultivate and transfer enduring business wisdom.Boston, Harvard Business School Press.

Reinberga B.(2009). Verbālā un vizuālā tēla integrācija tēlainās izpratnes pilnveidei pedagogiskajā procesā /DU 51. starptautiskās zinātniskās konferences materiāli. DUAA Saule/ (In Latvian)

Reinberga B., Garjāne B., Reinberga M. (2012). Plenary Lecture Code ID 0132012The philosophy of language in the context of writing - the opportunity to further develop the figurative insight, Creativity in school's curricula with the form of project based learning, Portorož, 18. - 20. April 2012, Slovenia

Reinberga B, Garjāne B. (2013). Integration of the figurative insight with the ecology of personality, Rural Environment. Education. Personality (reep), Jelgava, Latvia

Ricoeur G., Gadamer H. (1982). The conflict of interpretations

Sordē B. (2013). Pārskatīt izglìtību un pētniecību http://www.lsm.lv/lv/raksts/esejas/arpus-etera/bernars-sorde-parskatiit-izgliitiibuun-petnieciibu.a64106/ (In Latvian)

Velšs V. (2005). Estētikas robežcel̦i [Borderline of the Esthetics]. Rīga: Laikmetīgās mākslas centrs. 


\title{
Introducing emotions in the architectural design process
}

\author{
F. Juan-Vidal*, S. Iñarra-Abad* \\ * Departamento de Expresión Gráfica Arquitectónica. Universidad Politécnica de Valencia (UPV)
}

\begin{abstract}
D images or architectural renders are expressive tools widely used by architectural students to communicate their projects. Not only do these images have the task of transmitting the formal and functional characteristics of the project, but also need to evoke in users the sort of feelings and emotions which can only be aroused by experiencing the architecture. An experiment we undertook enabled us to find that these emotions can be quantified and may relate to the design parameters of the image, moreover there are also substantial differences in the valuation between architects and non-architects. Thus, the aim of this paper is to incorporate the results of our research on the learning of this graphical tool into the learning of architecture. Therefore we have established a teaching methodology in which the images are not only employed to show the final result of design, but are also incorporated into the creative process to investigate emotional and aesthetic responses of the user of the designed space..
\end{abstract}

Keywords: architectural design process, architectural rendering, emotions, subjective evaluation

\section{Introduction}

Learning the process of architectural conception has always been a complex task. Nowadays, its intrinsic difficulty is added to by an epistemological slippage of the concept of "architectural space" as well as by the impact of new computer-based tools in the virtual representation of architecture.

\section{The process of designing}

It is said that drawing "represents" architecture in the sense that it specifies its anticipation, its imitation, or even, in some senses, its substitution. Authors such as E. H. Gombrich ('Art and Illusion', 1959) show that the level of representation of a drawing depends less on the degree of imagination or imitation, rather the use made of it as a "substitution" of the physical reality. Whereas the graphical object it evokes is made possible by its 'illusion'.

Once the idea of the project has been reached, the architect needs to involve others in it. The architect is usually required to communicate their project to two different parties; on the one hand to the developer or the party which requires the project and on the other to the builder or agent who will construct it.

The promoter is the driver and initiator of the project. For them, the intention will be of an illustrative nature, with the purpose of "presenting" the project, expressing it so it quickly communicates the idea. It generally consists of pure anticipatory and figurative representation of the architectural object. Following the tradition that began in the Italian Renaissance, for this purpose the architect resorts to the use of realistic visions based on perspective and in more or less gimmicky graphical techniques (textures, lighting and shadows) or mock-ups or three-dimensional scale models. Nowadays, architectural render is used for this function.

In each case, the concept of these presentations depends not so much on the choice of tool, rather on the success in transmitting the 'essence' of the architecture. Perhaps it is less about showing the form rather it is about being able to express everything else through it. 


\section{The 'essence' of architecture}

During the latter third of the 20th Century the Modern theories of supremacy of physical space at the core of architecture started to be challenged, above all as a reflection of new waves of thought beginning a conceptual change in the understanding of art. With the existentialism of Heidegger's (1889 - 1976) 'Being-inthe-world', the world is no longer a collection of objects in which the individual finds himself subject, rather as the fundamental characteristic of human existence. In first place will be 'my world' rather than the presumed objective world as proposed by science.

Authors such as C. Norebrg-Schulz ('Intentions in Architecture', 1963) in keeping with these lines of thought propose the substitution of the idea of 'interior space' with the concept of 'existential space'. Space is defined as an existential dimension of an individual whose essence is given from 'place' and not from the physical dimensions

Architecture accommodates human activities. It encompasses their home life, work, study, worship, recreation... Not only this, but it also provides order and comfort. However when architecture, as well as satisfying these specific human specifications, responds to the existential experience of 'dwelling', it creates 'places' and is also a source of well-being.

Now, spaces are not the most important things; rather the environments. Small details perceived by the senses become worthy (the early morning light through a Mallorcan shutter, the rustling of a poplar grove, the smell of dew on a lawn, the creaking of footsteps on antique oak-wood floorboards). Emotions now come into play. The differences between doing architecture and the form of living it become blurred. Design now is not only the search of a particular aesthetic but the provision of places and environments which accommodate the emotions of others.

\section{Expressing and conceiving places}

However, if limitations are found in Modern theories of representing the spatial essence of architecture: What problems do today's architects face in representing environments, fantastic places or habitats in their projects? How to represent these feelings and emotions? In what way can the existential component of the architecture be expressed and presented? Without doubt, there is no possibility of drawing 'wellbeing'.

Of course, if we pay attention to those who hold that the architectural element, with all its material complexity, conventional, spatial and existentialistic, can only be represented by itself. To try substitution (representation) would be little more than a pipe-dream and we would have to conclude that it is not possible to represent the existential component of architecture. However, in contrary to this, if we accept the structuralist's view that it is possible to get close to a comprehension of an architectural element through its components or parts; If give up in our attempt to take in the whole complexity in one go and we apply the method of breaking up; If we accept the whole and admit that a representation can only try to create a substitute capable of a specific, partial result, then we have to admit that it is possible to provoke in the imagination the illusion of a material, form, space and even attain similar sensations to those which are felt in a place or during an experience, even though it is in a limited and fragmented form. 
In this way the illustration may function as a substitute of the existential space that contributes to architectural projects and evoke some of the emotions which arise from occupying them. For this motive, besides being a medium for the illustrative presentation of the final result of the project it may also be an active and effective means, in the initial phases, of orientating the process of conception of spaces which favour certain emotions.

\section{Material and Methods}

Nowadays the architectural render is an indispensable medium of expression for the communication of an architectural project. The rapid advance of computer programs for digital modelling has allowed architects to produce sophisticated images as a valuable tool to entice viewers. The emotional impressions evoked in the viewer by these images produce a more or less favourable opinion about the space that the image represents.

The emotional process by which we analyse our environment is a complex one, in which our perception and cognition take part. The personality and psychological state of the observer, their reactions to their circumstances, previous experiences of spaces, etc. also have a role in the process. Given the complexity of the whole process, Nasar (1994) proposed a probabilistic model of the aesthetic response which is summarised in figure 1.

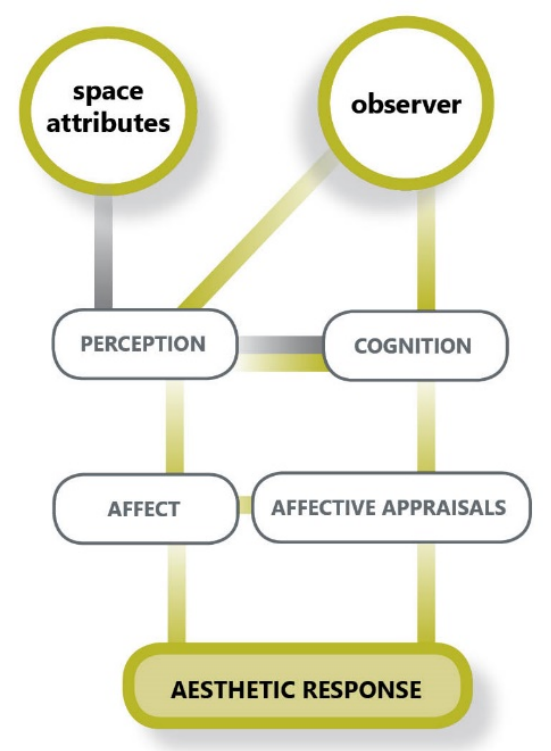

Figure 1. Probabilistic model of aesthetic response to the built environment.

According to the scheme, when we try to improve the value that observers will put on a space represented by a digital image, or try to obtain a better aesthetic response from an image, it is important to recognise and identify which emotions the observer felt before that particular observation.

In the Departamento de Expresión Gráfica de la Escuela de Arquitectura de Valencia, we have conducted an experiment to determine the emotional state of an observer evoked by an image during the process of assessment of an architectural project and, in turn, how this emotional state relates to the overall appraisal of the project. 
The method was based on Osgood's semantic differential (Osgood et al, 1957). A field study was carried out on a sample of 217 subjects (104 architects and 113 nonarchitects) who were asked to express their opinions on 48 renders of architectural spaces.

The results show that the perception of the architectural render can be expressed through 6 independent concepts or semantic axes, which explains 55\% of the variance in the sampled perception. These axes or factors are, by order of explained variance: tranquillity - well-being; innovation - futuristic; happiness - warmth; nostalgia romanticism; functionality and monumentality - luxury.

The results also show that, for both groups, the success of a render is associated with the emotions of innovation - futuristic and tranquillity - well-being.

Figure 2 shows the relationship between these semantic axes with global assessment. Also the results show that there are significant differences between the architects and non-architects. Thus what is innovative or evokes well-being in one group is not so in the other group. In general, architects are more critical in their assessments (Llinares and Iñarra, 2014).
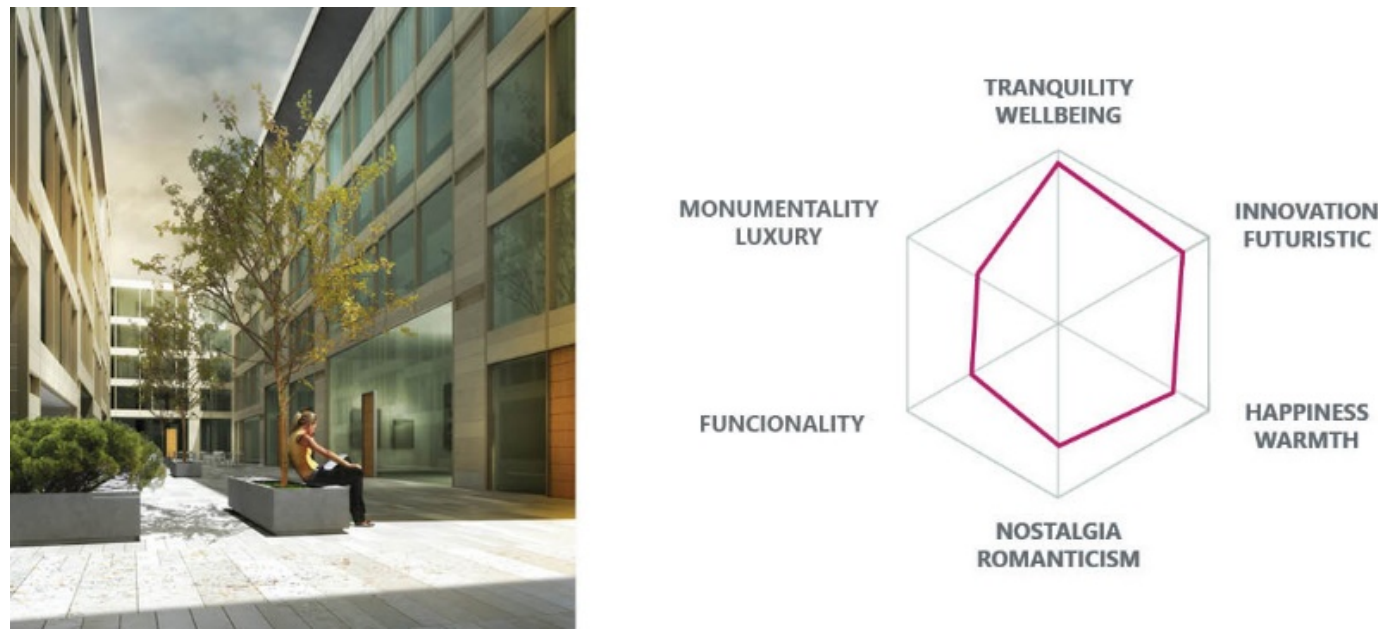

Figure 2. Relation of semantic axes with global assessment

These results provide evidence that it is necessary for the student of architecture, in the process of the conception of the project besides the formal conditions and aesthetics, to also take into account the emotions that their project will promote in the future user of the space. In order to incorporate this new determinant in the design process, besides the architect's own intuition and feelings, there are methods which have been developed in the field of product design which can quantify the emotions experienced by the user and translate them into particular criteria of a space.

We have designed a working method with the objective of using the results of this educational study in the field of architectural graphic expression to apply them to different subjects of architectural study.

\section{Materials}

In order that the architectural student can investigate the emotions that the representations of their projects will awaken in the observer, questionnaires developed from the results of our experimental work will be employed. In this way, we consider that the six semantic concepts obtained (tranquillity - wellbeing; innovation futuristic; happiness - warmth; nostalgia - romanticism, functionality and 
monumentality - luxury) will serve as a basis for the development of the questionnaires.

The student will prepare 3 render images (or virtual perspectives) of the architectural project for each of the distinct phases of the process: 1 . of conception; 2 . of reflection; and 3. of presentation (a total of 9 rendered images per student). These images will be subject to observation by a sample of subjects, ensuring an acceptable level of statistical power and statistical significance for this type of comparison. The criteria will involve obtaining at least 6 records for each variable and project.

In the fieldwork, subjective information for each image will be collected as a function of the semantic axes evaluated on a Likert scale of 5 levels (totally agree, partially agree, indifferent, partially disagree and totally disagree). Also the participant will be asked to express their global assessment.

Given the difference in the answers between the architects and non-architects, it is suggested that the questionnaire be conducted with two different groups of participants: on one hand architecture students and on the other a determined number of external individuals from various backgrounds outside the field of architecture.

\section{Methods}

The study will be divided into three parts corresponding with the three phases in the process of the project (conception, reflection and presentation). A specific questionnaire will be carried out at the end of each phase.

In the first phase the students will be organised in sub-groups of 4 , in the second phase in sub-groups of 2 and in the third they will work individually. Each sub-group will work on a project with the same given theme. Supposing there are a group of 20 students, there will be 5 projects in the first phase, 10 in the second phase and 20 in the third.

At the end of the first phase we will have 5 questionnaires (one for each project), each one comprising of 3 render images. In the same way, by the end of the second phase, there will be 10 questionnaires. Finally, at the end of the study, there will be 20 questionnaires.

With this method it is hoped to generate a feedback process using the results of the questionnaires in two directions: one horizontal, in each phase where conclusions will be drawn for compassion between projects; and the other vertical, in each project, allowing the reshaping the results and increasing as much the level of development as the degree of personalisation of each project.

\section{Results and Discussion}

In order to extract and analyse the data obtained from the questionnaires, the students will be given a basic knowledge of statistics.

The results obtained in each phase of the creation of the project will allow a classification of the images into two levels: on one hand based on the emotions evoked in the observer and on the other hand, based on the assessment of the project that the image represent.

The comparison between the different modes of three dimensional representation for the same project will allow the students to establish conclusions as to how the design 
parameters evoke different emotions. For example, the absence of people increases the sensation of nostalgia, the presence of nature evokes greater tranquillity, blue sky awakens happiness...

Knowing at the same time which emotions are related to a better valuation of the project, the student will be able to work this into the project to give rise to better success in the later phases of the project.

Analysis of the differences in opinion between the students and people outside of the architecture field will allow the student to understand the semantic distance which exists between the two groups, which has previously been tested in different experimental works (Devlin and Nasar, 1989; Gifford, 2002).

\section{Conclusions}

The architect creates living spaces and these must awake in the user favourable emotions that promote the activity for which the space has been created: well-being in the home; security in urban spaces; sobriety in work places; monumentalism in the symbols of the city, etc.

Until now, the capacity of the architect to delve into these aspects has been developed through their own experience. Our proposal is an attempt to equip future architects with experimentally validated tools to investigate the emotional response of the user and to incorporate this response into the design of the architectural space.

This contribution to the education of future architects will allow the definition of new design criteria for spaces oriented around the user at the emotional level, achieving a more human and efficient architecture, resulting in a better quality of life for the inhabitants.

\section{References}

Devlin, K. \& Nasar, J. (1989) The beauty and the beast: some preliminary comparisons of "high" versus "popular" residential architecture and public versus architect judgments of same. Journal of Environment Psychology, 9, 333-344.

Gifford, R. (2002) Why architects and laypersons judge buildings differently: cognitive properties and physical bases. Journal Architecture Planning Research, 19 (2), 131-148.

Gombrich, E. (1959). Art and ilusion. Consulted the Spanish edition of Gustavo Gili, Barcelona, 1979.

Juan-Vidal F. (2006). Figurando Lugares. Funciones del dibujo en la producción actual de Arquitectura. Universidad de Sevilla.

Llinares, C., \& Iñarra, S. (2014). Human factors in computer simulations of urban environment. Differences between architects and non-architects' assessments. Displays, 35(3), 126-140.

Nasar, J. (1994) Urban design aesthetics: The evaluative qualities of building exteriors. Environment \& Behaviour, 26 (3), 377-401.

Norberg-Schulz, C. (1963). Intentions in architecture. Consulted the Spanish version by J. Sainz y F. González Fernández. Ed. Gustavo Gili. Barcelona, 1979.

Osgood C.E., Suci G.J. \& Tannenbaum P.H. (1957) The Measurement of Meaning. Illinois: University of Illinois Press. USA. 


\title{
Teaching Musical Expression through Visualization of Musical Cues
}

\author{
P.J. Peiris-Perera* \\ *Dept. of Western Music, University of Visual and Performing Arts, Colombo, Sri Lanka.
}

\begin{abstract}
Many musicians agree that some music recital performances seem more academic than artistic. These performances fail to convey the character of the music. An important aspect of teaching music is to develop abilities of students in musical expression. Performance studies have shown that music teachers and students are often unaware of tools they could utilize to develop musical expression. In order to find a solution to this problem, this paper based its groundwork on Patrick Juslin's GERMS model. The GERMS model provides a mechanism to conceptualize musical expressions as a multi-dimensional phenomenon. In this work we introduce an innovative visualization model named EmoGraph that can be used to visualize the emotional expression aspects of music scores using the GERMS model in order to help the students grasp the cues of musical expressions. This visualization tool helps to capture the cues for emotional expressions in a musical score for the purpose of using it as a teaching tool to teach musical expressions. This work also introduces an experimental setup that can be used to evaluate the effectiveness of the proposed teaching tool at an undergraduate academic environment.
\end{abstract}

Keywords: Musical-Expressions; Emotions; GERMS; Pianists; Musical-Performance

\section{Introduction}

How often have we heard performances that were played with absolute faithfulness to the score but which failed to convey the character of the music? A study conducted by Karlssohn and Juslin on teachers' opinions about musical expression showed that teachers thought that musical expression was one of the most important elements in music making and teaching (Karlsson \& Juslin, 2008). However, many teachers do not know about the tools that could aid in the development of musical expression. This work explores and examines recent studies in music and emotion in order to develop successful strategies that can be used to teach musical expression. This work focuses on just one aspect of musical expression; that is emotional expression. This aspect has been noted as the least explored in terms of research and also one of the hardest elements to teach.

The term "musical expression" encompasses many different facets, meanings, and definitions. In his study, the "Five Facets of Musical Expression: A Psychologist's Perspective on Music Performance,” Patrick Juslin constructed the "GERMS” model, which is based on a wide array of previous research from multiple sources on this subject (Juslin, 2003). This model can be used as a tool to analyse musical expression in performances as well as a teaching model. He proposed five facets for this model, which he believes to be a multi-dimensional approach to enhancing musical expression. The five facets of this GERMS model are: Generative rules (G), Emotional expression (E), Rhythmic properties (R), Motion principles (M), and Stylistic unexpectedness (S). For the purpose of this paper, This work examines only the application of the "Ecomponent" of the GERMS model, which is "Emotional Expression."

The "Emotional Expression" component has been noted as the most challenging and complicated aspect to establish data (Meyer, 1957). In addition, there are different uses of the word expression in the literature, and sometimes it has been used to refer to the emotional qualities of music by listeners (Davies, 1994). Nonetheless it is accepted that these two senses of the word are related (Davies, 1994). Thus Juslin and Persson 
defines "Emotional Expression” as the “...use of systematic variations in performance parameters (such as timing, dynamics, timbre) to convey emotions to listeners (Juslin \& Persson, 2002).”

Sometimes things that are most important to learn are the most difficult to teach(Karlssohn \& Juslin, 2008). Musical expression should be taught from the beginning, but emotional expression can be hard to teach. This does not mean that the teacher should completely overlook the possibilities of encouraging emotional expression; rather, the teacher will need to incorporate it whenever possible. Elementary-level repertoire often lacks the properties which contribute to emotional expression due to limitations in scope (for example, pieces which are extremely short). On the other hand, intermediate literature can provide a good foundation for developing the emotional expression component, because the pieces become much more elaborate in terms of their content, harmonic language, and dynamic range, where opportunities to express one's self abound. In this work we recommend and use intermediate repertoire for teaching emotional expression to students.

Emotional response and musical expectation are closely linked (Meyer, 1957). The theory here is that emotion is experienced when a musical outcome is different from that expected by the listener. For example, when the expectation is a perfect cadence but the actual outcome is an interrupted cadence, this evokes an emotional response in the listener and it has been found that listeners' familiarity with pieces of music does not affect this emotional response. Emotional expression involves the use of cues which are interpreted by both the performer and the listener. These cues might be tempo, loudness, timing, timbre, etc., and they are used by the performer to express emotions such as anger, sadness, and love/tenderness (Juslin, 2003). There is evidence to suggest that happiness is expressed through "fast tempo, high sound level, staccato articulation, large articulation variability, fast tone attacks, and bright timbre" (Juslin, 2003) whilst sadness is expressed through "slow tempo, low sound level, legato articulation, small articulation variability, slow tone attacks, and dull timbre” (Gabrielsson \& Juslin, 1996).

Using the Emotional expression (E) component of the GERMS model it is possible to quantify the level of emotional expression of a musical score. Multi-dimensional nature of the quantification of the musical scores requires a visualisation that can display multivariate data. In this work we suggest the use of a standard radar-chart to visualise the musical expression as a teaching aid named EmoGraph, which is a six dimensional graph that combines the tempo, temp-variability, sound sound-variability, articulation and articulation-variability. Figure 1 shows the basic visualisation template suggested in this paper. Basic colours Red, Green and Blue are used to separate the tempo, sound and the articulation as the background. The colour of the resultant EmoGraph will combine the Red, Green and Blue intensity based on the values required to represent the respective musical score similar to what is normally done on a standard heat map visualization. Table 1 shows the suggested mapping for the visualization and Figure 2 show samples of visualizations for the basic emotional expressions for Happy, Sad, Tender, and Anger based on the suggested visualization scheme in this paper. 


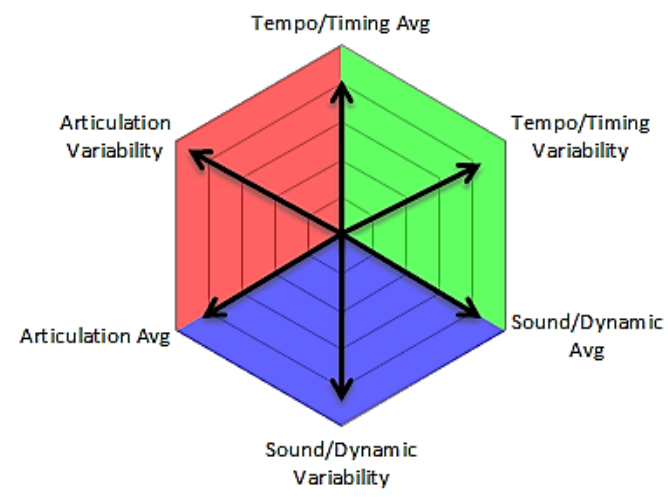

Figure 1 Basic Musical Score Visualization (EmoGraph) Template

Table 1 Mapping of Musical Cues for Visualization

\begin{tabular}{|c|c|c|c|c|c|}
\hline \multirow[b]{2}{*}{ Musical Cue } & \multirow{2}{*}{$\begin{array}{l}\text { Nominal Scale Categories for Musical } \\
\text { Cues }\end{array}$} & \multirow{2}{*}{$\begin{array}{l}\text { Value } \\
\text { Range }\end{array}$} & \multirow{2}{*}{$\begin{array}{l}\text { Vis. } \\
\text { Step } \\
\text { Wt. }\end{array}$} & \multicolumn{2}{|c|}{ Example Computation For “Happy" } \\
\hline & & & & $\begin{array}{l}\text { Musical Cue } \\
\text { Value }\end{array}$ & $\begin{array}{c}\text { Visualization } \\
\text { Weight }\end{array}$ \\
\hline Tempo-Average & $\begin{array}{l}\text { V.slow / slow / med.slow/ med.fast / fast / } \\
\text { V.fast }\end{array}$ & $1-6$ & 0.167 & (Fast) & 0.83 \\
\hline Tempo-Variability & Low / medium / high & $1-3$ & 0.333 & (low) & 0.33 \\
\hline Sound-Average & $\mathrm{ppp} / \mathrm{pp} / \mathrm{p} / \mathrm{mp} / \mathrm{mf} / \mathrm{f} / \mathrm{ff} / \mathrm{fff}$ & $1-8$ & 0.125 & (ff) & 0.88 \\
\hline Sound- Variability & Low/ medium / high & $1-3$ & 0.333 & (low) & 0.33 \\
\hline $\begin{array}{l}\text { Articulation- } \\
\text { Average }\end{array}$ & Legato / strong / accents / portato / staccato & $1-5$ & 0.200 & (staccato) & 1.00 \\
\hline $\begin{array}{l}\text { Articulation- } \\
\text { Variability }\end{array}$ & Low / medium / high & $1-3$ & 0.333 & (high) & 1.00 \\
\hline & \multicolumn{5}{|c|}{ Visualization Weight $=$ Musical Cue Value $\times \frac{1}{\text { Max Musical Cue Value }}$} \\
\hline
\end{tabular}
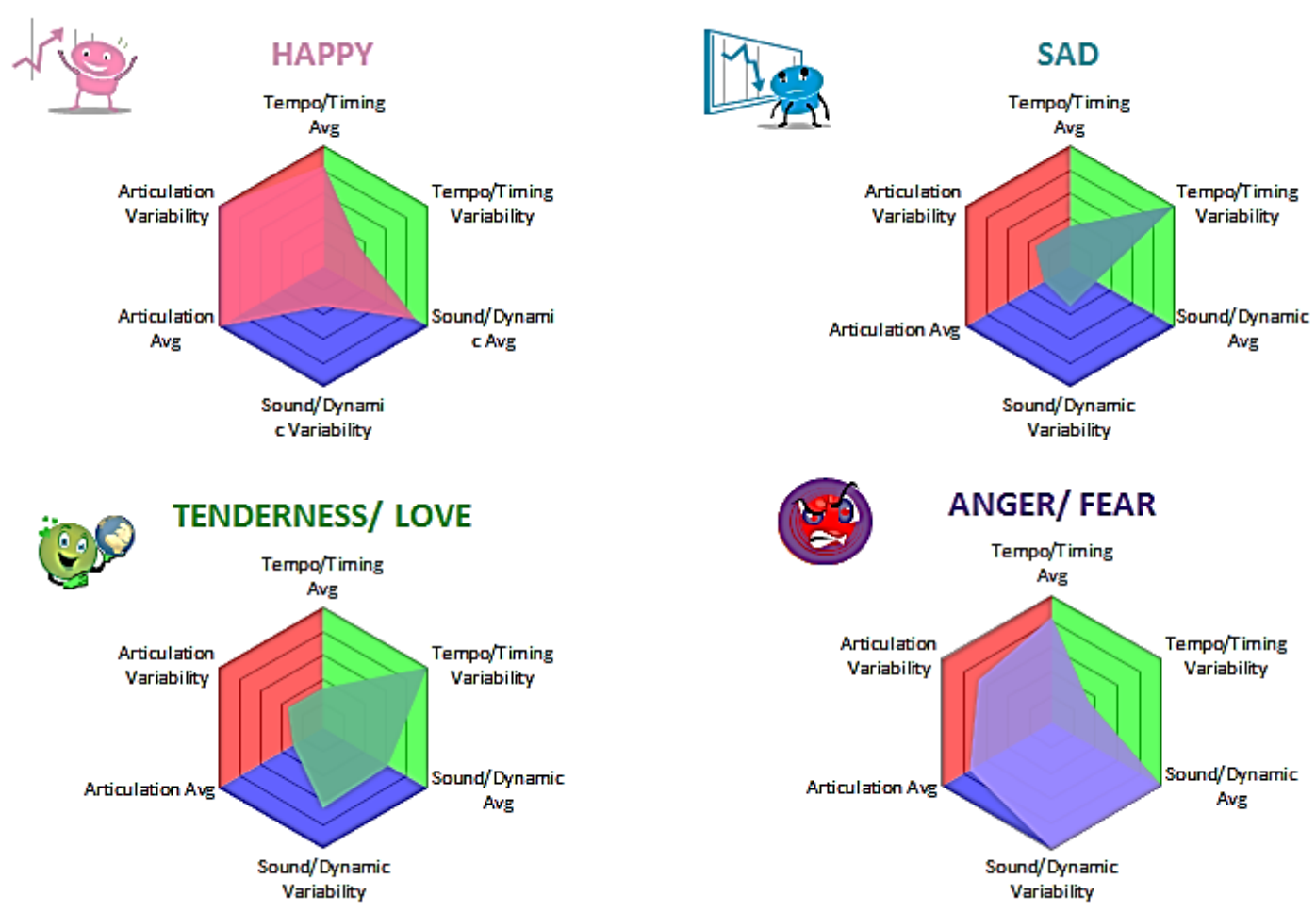

Figure 2 EmoGraph Visualization of Expressive Cues 
In Table 1, the range of values for each attribute and the value selections for each emotion is based on the suggestions in the GERMS model (Juslin, 2003). Last two columns of Table 1 includes the computation of the visualisation mapping for the emotion "Happy" as an example. Note that the clipart images used in conjunction with the corresponding visualization is intended only for the purpose of enhancing the emotional expression and can be replaced with any other appropriate artwork.

\section{Methodology}

The purpose of this study is to introduce and examine the effects of utilizing the computer-based visual model as a teaching aid to increase musical expression in piano performances. Subjects are undergraduate piano majors and minors at the Department of Western Music of the University of Visual and Performing Arts, Colombo, Sri Lanka, enrolled for class piano study. Subjects were asked to briefly review a piece that has been previously studied. We identified two sections that were musically challenging in the piece where students were more likely to play without much musical expression. After recording a play-through of the piece they rated the level of musical expression on a scale of 1 to 5 (with 1 indicative of "no expression" and 5 representative of "Highest level of expression") when performing each of the passages. Approximately one week following, one group received instructions on the "visualization" to develop musical expression to the piece while the control group did not, instead they practiced and recorded the piece. The group with EmoGraph "visualization" were allowed to practice for several minutes. Following this session they recorded a play-through of the piece. Figure 3 shows a sample visualization for one musical score used in the study by modern composer Emma Lou Diemer called "Anger". The colour of the graph indicates more Red and Blue and also the values indicate more sound and articulation in parts of the score that were selected for emotional expressions.

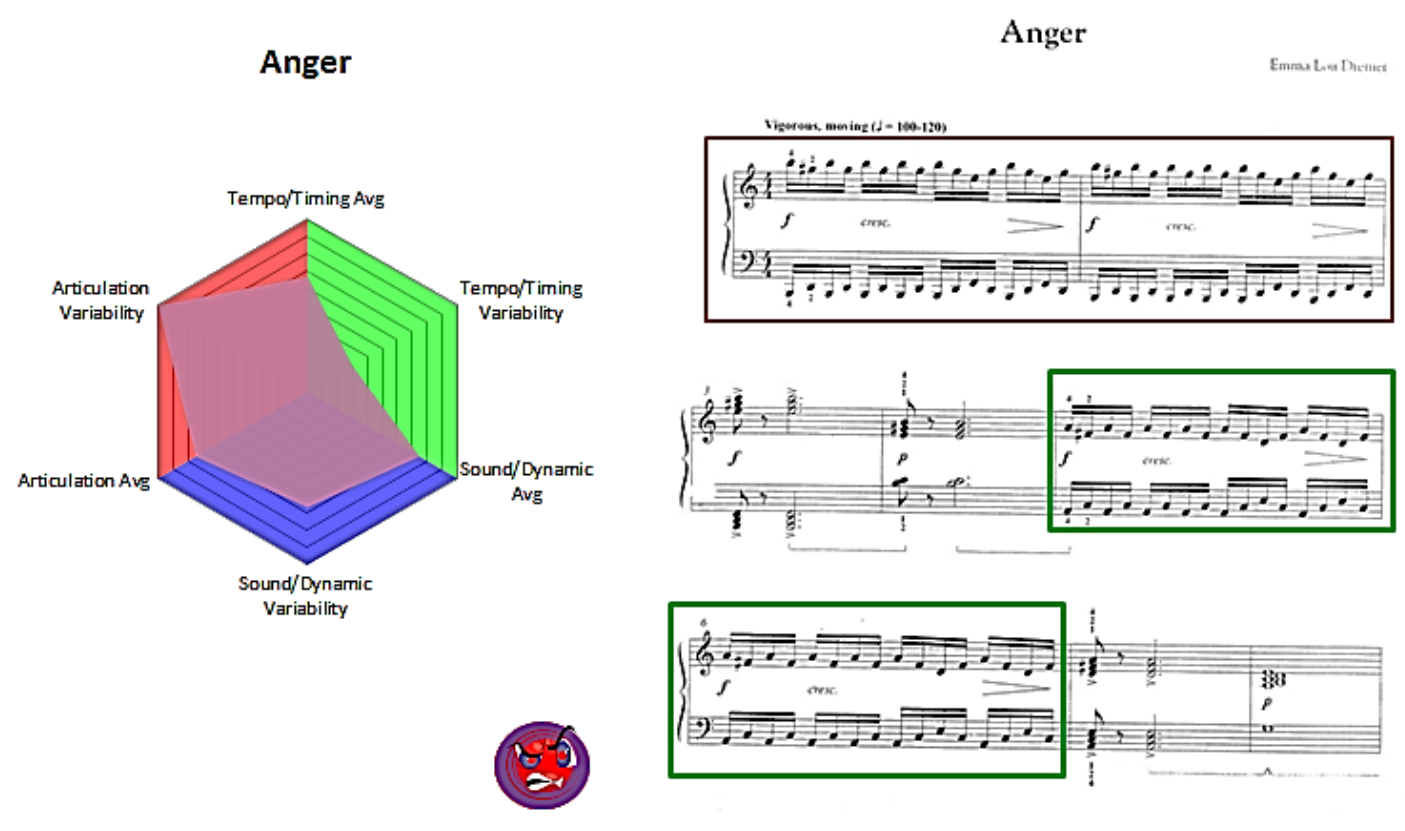

Figure 3 Example Visualization for “Anger” by Emma Lou Diemer 
The selected parts are highlighted in the score. Note the difference between this visualization and the visualization for the emotion anger given in Figure 2. Figure 2 shows the visualization for the particular emotion anger and Figure 3 shows the visualization for the musical score "Anger."

Following the process of performing in the class room for the study, audio recordings were extracted, compiled, and randomly ordered on a CD. Five independent adequately qualified judges were requested to listen to the recordings of the pieces and rate each performance, based on an evaluation rubric taking into account performers' note, rhythm accuracy, and musicality. A basic statistical comparison with the control group is sufficient to show the effectiveness of the EmoGraphs as a teaching aid to teach musical expression.

\section{Results and Discussion}

Musical expression is a very important aspect in music. Teaching musical expression is a challenge to most teachers based on available studies and is also evident when witnessing most university music student performances. Most university music majors also choose teaching music as their future careers. It is vital that teachers, engaged in teaching university students utilize all available tools to teach musical expression so that the future generation of music teachers are exposed to these techniques. Emotional expression is a major component in musical expression. This work introduces a novel visualization technique called EmoGraph based on the GERMS model to extract the emotional cues in a musical score to enable a student to easily identify and relate to the expected emotional expressions in a repertoire. The teaching tool will prompt, guide and help the student to identify the cues but still allow the freedom to express emotions based on their own interpretation of the score.

A basic experimental study is also outlined to test the validity of the proposed tool. Subjects' performance evaluation for musical expression is based on human judgements. In practice it is very hard to collect evaluations from experts in the field of musical judgement on a voluntary basis, thus the data collection for the study is still continuing with most of the data collected. Preliminary results indicate a positive impact to the use of the EmoGraphs. To make a scientifically conclusive judgment all results should be compiled and statistically analysed.

As a future study it is suggested to do the subject performance evaluation for musical expression based on software analysis and visualization of subjects' performances, on musical tracks using a software such as "Reason" (Propellerhead, 2015). Most of the modern piano keyboards used for teaching university class piano courses allow the recording of performances as MIDI tracks and currently, the available audio recording and editing software such as "Reason," allows the automated capture and visualization of emotional cues such as sound, tempo and articulation. This cannot completely eliminate the human judges but can reduce the involvement. The use of computer tools in conjunction with the voluntary human judges could address the issue of data collection faced by the current work.

The framework introduced in this study can also be used appropriately for the other aspects of the GERMS model. This could lead to the introduction of other visualizations similar to the EmoGraph that can aid in teaching other aspects of musical expressions that are vital to produce a properly interpreted, outstanding musical performance that is not a mere academic mechanical reproduction of the musical score. 


\section{Conclusion}

An important aspect of teaching music is to develop musical expression though it is considered hard in many studies. This work attempts to address the difficulty of teaching musical expression to students using a visualization based on the GERMS model. This visualization captures the musical cues in a musical score for emotional expression as an EmoGraph that can be used as a teaching aid. A six dimensional radarchart combined with a heat map is used as the basis for the EmoGraph visualization. An experimental framework that can be used to evaluate the proposed EmoGraph based teaching of musical expression is also suggested in this work.

\section{References}

Davies, S. (1994). Musical Meaning and Expression. CA, USA.: Cornell University Press.

Gabrielsson, A., \& Juslin, P. N. (1996). Emotional Expression in Music. Handbook of Affective Sciences 503-534. New York, NY, USA: Oxford University Press.

Juslin, P. N. (2003). Five Facets of Musical Expression: A Psychologist's Perspective on Music Performance. Psychology of Music, 31, 273-302.

Juslin, P. N., \& Persson, R. (2002). Emotional Communication. In Science \& Psychology of Music Performance: Creative Strategies for Teaching and Learning. New York, NY, USA: Oxford University Press.

Karlssohn, J., \& Juslin, P. N. (2008). Musical Expression: An Observational Study in Instrumental Teaching. Psychology of Music, (36), 309-337.

Karlsson, J., \& Juslin, P. N. (2008). Musical Expression: An Observational Study of Instrumental Teaching. Psychology of Music, 36: 3, 309-337.

Laukka, L. (2004). A Report From Music Conservatoires. Music Education Research, 6, 45-56.

Marcel, T. (1999). Pedagogical Concepts and Practices for Teaching Musical Expressiveness (D.M.A.). Ohio State University, Ohio.

Meyer, L. (1957). Emotion and Meaning in Music. Chicago, IL, USA.: University of Chicago Press.

Parmer, C. (1996). Anatomy of a performance: Sources of musical expression. Music Perception (Vol. 13, pp. 433-454).

Parncutt, R., \& McPherson, G. (2002). The Science \& Psychology of Music Performance: Creative Strategies for Teaching and Learning. New York, NY, USA: Oxford University Press.

Propellerhead. (2015). Reason. Retrieved from https://www.propellerheads.se/reason

Radocy, R., \& Boyle, D. (2003). Psychological Foundations of Musical Behaviour. Chicago, IL, USA.: Charles Thomas Pub. 
HEAd'15

Posters 


\title{
Academic Freedom as a Fundamental Right
}

\author{
R. Cippitani* \\ *Università degli Studi di Perugia
}

\begin{abstract}
The paper aims at defining in particular the concept of academic freedom within the context of the European legal sources.

Even though the idea of a special corporative status for professors was born during the Middle Ages, it was only during the second half of the twentieth century that the Constitutions recognised academic freedom as an individual's legal right. Such an individual right is regulated within the category of the freedom of expression, even if it is characterised by particular aspects.

Like any individual right that is recognised at the constitutional level, the freedoms of teaching and research are subject to limitations that protect other fundamental rights.

Furthermore, today the academic freedom has lost its traditional sense as a defence against public powers and is now granted to play a social function, protecting not only the corporative interests of teachers.

It can then be concluded that only through the developing of the social role of education and research, by the principles of quality, transparency and accountability, ensures the individual and institutional rights of the teachers and researchers, strengthening and upgrading the role that universities are playing in the last 900 years.
\end{abstract}

Keywords: Academic Freedom, Fundamental Rights, Accountability, Ethics rules, European Union, Bologna Process

\section{Introduction}

Despite a long history, the interest of the law in the organization of teaching and research activities has only been during the last two centuries.

More recent is the legal discipline of the role of Universities and the people involved in research and educational activities. Such a role received recognition in particular by the Constitutions and international legal sources of the second part of the twentieth century.

Furthermore, during the last three decades research and education have been included in the European integration process (especially with the Maastricht Treaty) and only in the last years have they been put in the edge of the EU policies concerning development and growth (see the «Lisbon Strategy» of 2000 and Europe 2020 of 2010), which, aim at solving the problems of the European economy, argued that the Union had to become a « knowledge-based »society (see Cippitani, 2012).

The position of the teachers and researchers in the legal framework may be described in early stages as the transit from the phases of the "privileged", the "public functions", the "constitutional right", and the "accountability".

\section{Teaching as Privilege}

Traditionally, the occupation of teacher has been conceived as a privileged position, such as it occurred in the Middle Ages.

During that period, a new social group was formed, the «intellectuals» (Le Goff, 1957), who in spite of practical difficulties, were lecturing throughout Europe, constituting a «transEuropean wave» which built the continental culture (Morin, 1987).

At that time teachers and students were grouped within associations, on the base of the scheme of the professional corporations, which deeply changed the traditional social structure which was composed of nobles, religious leaders and peasants.

From such associations born the Studii or Universitates (Borio, 2007).

The Universitates became an important social (and economic) phenomenon. Thus, the ecclesiastical and civil authorities recognised several important privileges to students 
and professors, who enjoyed a special status in matters such as jurisdiction, military service, and even tax exemptions (FerradaBórquez, 2001, 65).

However, the recognition of some kind of autonomy and privileges did not mean ideological multiculturalism or tolerance.

Initially the teaching of the classic works, like those of Aristotle were prohibited, and scholars who did not follow the official orthodoxy, such as William Occam, Giordano Bruno and, later, Galileo Galilei were pursued by the authorities.

Therefore, within the history of teaching in Europe, there also exists the tragic history of repression (Schoijet, 2009).

\section{The Professor as a Public Officer}

Another aspect regarding teaching positions is their relationship with the public powers. During the fifteenth century significant economic, social and cultural transformations were put in place, which were based on the philosophy of the Enlightenment and the affirmation of the scientific method as the dominant form of knowledge (AguilóBonet, 2009).

As Voltaire argued in his Le Siècle de Louis XIV, men of culture had to be considered as members of a unique independent Républiquelitteraire (see also Chabod, 2001, 45). However, in the following centuries a new and powerful phenomenon impacted the culture which was the birth of the national States.

During the XIX century, science and teaching became powerful tools to build on the idea of a nation and nationality (about the «method» on the construction of the «national identity», see Thiesse, 2001; Id. 1999).Science and education were no longer the product of an open and continental community of scholars, but they were nationalised. Wilhelm Von Humboldt in his «Über die innere und äußereOrganisation der höherenwissenschaftlichenAnstalten in Berlin» («On the internal and external organization of the high scientific institutions in Berlin») of 1810 underlined the role of the universities and other scientific institutions to shape the spiritual and moral culture of a Nation.

Therefore, in the nineteenth century the university model was elaborated on, and Immanuel Wallerstein defines the «modern university system» (Wallerstein, 2007, 77), as a system in which the university acts as a bureaucratic institution with full-time employed professors, characterised by reduced autonomy, being subject to the centralised decisions on educational matters by the State.

During the European totalitarianisms, especially in Italy and Germany, State control was extremely severe and the organs of the universities were appointed by the central government. The university professors were considered public officials with the duty to swear loyalty to the regime (in Italy, during Fascism, among the 1,200 university professors, only 12 refused the oath and in consequence were expelled).

\section{Academic Freedom as an Individual Right}

The Enlightenment begun to identify the freedom of teaching among the natural rights of men (Schoijet, 2009; see also Jolibert, 1993).

However, the freedom of teaching and research became rights in the technical legal sense, only by virtue of the Constitutions of the second half of the twentieth century, 
which were anticipated by the Weimar Constitution of $1919^{1}$ and the Spanish Constitution of 1931 (Article 48.3) ${ }^{2}$.

At that time, after the physical and moral destruction of the European continent, individual rights were asserted against the excessive power of the States (Álvarez Ledesma, 1998; Id., 2013a).

Today, the freedom of teaching and research are recognised by all European Constitutions, such as the paragraph 5 of the German Grundgesetz of 1949; the first paragraph of Article 33 of the Constitution of the Italian Republic of 1948; the Article 20 of the Spanish Constitution (1978); etc.

Academic freedom was also recognised and protected at the supranational and international levels, as it has happened with other individual rights in the previous century.

The international organisations have adopted several legal instruments concerning the matter. It is the case of the «World Declaration on Higher Education in the TwentyFirst Century: Vision and Action» issued by UNESCO on October 9, 1998. Similarly, the Universal Declaration of Human Rights of UN 1948, were it recognises the freedom of expression and opinion, which includes the right " to hold opinions without interference and to seek, receive and impart information and ideas through any media and regardless of frontiers. » (Article 19).

In the European law, the Charter of Fundamental Rights of the European Union recognises as a right the freedom of education and the Article 13 states that: «The arts and scientific research shall be free. Academic freedom is respected. " (For a commentary of this disposition, see Molina del Pozo\&Archontaki, 2013)

According those legal sources, the freedom of teaching and research could be considered a derivation of the freedom of expression (see Spanish Constitutional Court, herein after referred as "SCC", in the leading case of 13 February 1981, n. 5; Rodriguez De Santiago, 2012, 228) ${ }^{3}$.

However, while the freedom of expression must be accorded to every citizen without any limitation relating to the personal conditions or age (see Articles $24 \mathrm{ff}$. Charter of Fundamental Rights of the European Union), the academic freedom (including the freedom of teaching and of research) depends on professional qualities.

As matter of fact, the academic freedom is applicable only in relation to citizens professionally involved in the academic activities (Lorenzo Vázquez, 1994, 259). Not all persons enjoy of that freedom but only the «citizens teachers» (or researchers) (Pototschnig, 1971).

As a freedom that is recognised only to particular professionals, the academic freedom does not include the right to indoctrinate or distort the truth or scientific or historical truths (CámaraVillar, 1988, 2189), nor the right to propaganda (Crisafulli, 1956, 71$72)^{4}$.

With this respect, Norberto Bobbio, in the beginning of his work «The future of democracy», remembers that Max Weber, in a lecture at the University of Munich, said: «The university chairs are neither for demagogues nor for prophets».

\footnotetext{
${ }^{1}$ According to the Article 142 « Die Kunst, die Wissenschaft und ihreLehresindfrei. Der StaatgewährtihnenSchutz und nimmt an ihrerPflegeteil ».

${ }^{2}$ See the Article 48.3, which after affirming that the public professors were «official», established that «La libertad de cátedraquedareconocida y garantizada».

${ }^{3}$ See Italian Corte Costituzionale, judg. 8 July 2004, no. 256; see alsoSCC n. 5/1981, para. 7 and ECHR, judg. Campbell and Cosans v. United Kingdom, 25 February 1982, § 33, series A no. 48.

${ }^{4}$ See in Italy the judgment of the Consiglio di Stato, 21 March 1963, n. 725, in Rivistagiuridicadellascuola, 1964, 439.
} 


\section{Positive and negative contents of the Academic Freedom}

Freedom of the teachers/researchers education has both positive and negative content. The positive content involves «freedom of program », that is to say that the teacher has to determine his/her own program of studies, defining the content and system of teaching the subject, freely orienting their explanations and choosing the texts that he/she will use.

For UNESCO Recommendation above mentioned, the teachers « (...) should play a significant role in determining the curriculum » (para 28; cfr. also paragraphs 61 and 62 of joint ILO Recommendation and the UNESCO Recommendation concerning the Status of Teachers, 1966).

The freedom of program includes the choice of evaluation method. This freedom also considers the option of choosing the tools necessary to carry out the activities of teaching, particularly the respective method and teaching materials of the case (Expósito, 2012).

Nevertheless, the rights of the teachers and researchers, being related to a «freedom», have in particular a negative content, in the meaning of the prohibition of the invasion by others, especially by the public authorities (SCC n. 5/1981, para. 9; see para. 27 and 28 of the UNESCO Recommendation 1997).

This duty of abstention is applicable also to private schools and universities.

In some constitutions, such as Italy (see Article 33 of Constitution) the freedom of individuals to establish private schools is respected. This freedom potentially may conflict with the freedom of education, as rightly argued by Crisafulli $(1956,74)$.

But while the Italian Constitutional Court affirmed in the case Cordero, that the freedom of the professor would consist in joining or not joining the university, the European Court of Human Rights in the analogous case Vallauri (ECHR, judg. 20 October 2009, Vallauri v. Italy, n. 39128/05), stated that restrictions on freedom of teachers cannot go beyond the unavoidable need to protect the freedom of conscience and expression of each teacher (Mattioni, 1993, 433).

The same approach is adopted in the jurisprudence of the Spanish Constitutional Court, which affirms «Academic freedom of the teachers of these [private] schools is as full as that of teachers in public schools» that no provision establish the limitation of the freedom of the professors in order to respect the ideology of the University (TC 5/1981, para. 10).

\section{Limitations of academic freedom and research}

As an individual right, academic freedom cannot be considered as absolute and therefore it is subject to the legislative limitations (see the Italian Corte costituzionale, judg. 4 June 1958, n. 36), taking into account all the precautions needed in the case of the fundamental rights (Álvarez Ledesma, 2013b)

Thus, the academic freedom must be coordinated with other constitutional interests of equal rank, such as honour, public image, privacy, etc. (See in Italy, Cassazionepenale, judg. 7 May 2008, n. 37581)

With respect to other interests, considered as superior, such as health, the limitations of the right to teach or research are stronger.

Therefore is considered as legitimate for the State to verify the existence of cultural preparation, scientific and technical skills necessary for the exercise of professions which can affect the health of the persons (see for example the Italian Corte Costituzionalejudg. n. 36/1958 ref.).

Furthermore, the Constitutions provide that the right to education is the origin as well 
as the limit of academic freedom.

Education and «vocational and continuing training» (Article 14, para. 1 Charter of Fundamental Rights of the European Union) are considered fundamental rights of all human beings (CarmonaTinoco, 2013). Therefore, the academic freedom is instrumental to the enjoyment and realisation of the right to education; teachers must exercise their rights consistent with that purpose (see paragraph 34 of the UNESCO Recommendation 1997).

The exercise of academic freedom should take into account the age, maturity and education level of the students, in particular promoting their participation in the process of their own formation and guarantying his/her intellectual autonomy (Lozano Cutanda, 1997).

Other limits to the individual academic right and research arise from the institutional dimension in which these freedoms are developed.

In general, the teacher and the researcher must respect the organisation responsible for the educational and scientific activity and the rules governing the use of infrastructure (rooms, laboratories), and schedules of classes and exams.

A fortiori, they do not constitute, from the general point of view, illegitimate restrictions on freedom of professors and researchers, the obligation to comply with norms such as the regulation of public procurement and the rules set by the funding bodies like as the European Union (see the European Charter for Researchers) ${ }^{5}$.

\section{The Age of Accountability}

In order to grant its social function, the modern legal sources recommend the compliance of the academic freedom with principles such as transparency and accountability.

The already mentioned UNESCO Recommendation 1997 states that education should be considered a «public service» that "requires (...) a sense of personal and institutional responsibility for the education and welfare of students and of the community at large and for a commitment to high professional standards in scholarship and research. » (para. 6).

Academic research and teaching responsibilities involve a set of obligations included in the concept of «accountability» (see paragraph 22 of the UNESCO Recommendation).

Schools and universities should ensure transparency of management, including applying principles such as «honesty and transparency of accounting» like «the efficient use of resources».

To implement these principles, is essential to proceed with the evaluation of the quality of teachers and universities as established at the international level (see in particular paragraph 47 of Recommendation 1997), by European regional legal sources, by the Bologna process (Cippitani \&Gatt, 2010) and by several national regulations(Tavenas, 2004).

\section{Conclusions}

According to the previous paragraphs, the freedom of teaching and research derived from the corporatist privileges of the class of intellectuals in the Middle Ages.

As all privileges, the legal position of teacher did not have the status of right but of a

${ }^{5}$ Commission Recommendation of 11 March 2005 on the European Charter for Researchers and on a Code of Conduct for the Recruitment of Researchers. 
concession unilaterally attributed by the civil or religious power, until the power wanted. This did not prevent the repression of the teachers and the non orthodox ideas. Academic freedom became a legal right by the Constitutions of the second half of the twentieth century.

However it can be avoided the interpretation of such a right as an ancient privilege.

As matter of fact, there is a negative consequence of academic freedom today, which is the lack of transparency..

This is an old problem. Adam Smith (in his work «The Wealth of Nations» of 1776), thought that universities were the «sanctuaries» of the protection of obsolete prejudices. Today, within the pluralist and democratic State, academic freedom, although as a fundamental right must be «taken seriously » (Dworkin, 1978), however the academic freedom has lost its traditional function as a defence against the public powers (Vinokur, 2008).

This freedom, more than other rights arising from modern Constitutions, is attributed in order to play a social function (Pototschnig, 1971; Crisafulli, 1956,p. 70)

The academic freedom does not only satisfy the interests of teachers, but also those of the students and of others persons (such as parents), as well as other subjects involved in the educational process and, finally, of society as a whole (Mura, 1976, 235).

Indeed, the social relevance of modern education leads to reconsider the idea of the academic freedom as an exclusive privilege of an isolated, closed and privileged corporation.

Therefore, it can be concluded that only by the full achievement of the social function of academic activities, and through the application of principles of quality, transparency and accountability, can we ensure the rights of the teachers and allow the strengthening and upgrading of the role that universities are playing in the last 900 years.

\section{References}

Aguiló Bonet, A. J. (2009). La universidad y la globalización alternativa: justicia cognitiva, diversidad epistémica y democracia de saberes. In Nómadas. Revista Crítica de Ciencias Sociales y Jurídicas. 22, 2, Publicación Electrónica de la Universidad Complutense.

Álvarez Ledesma, M. (2013a) Derechos Humanos (Teoria General). InÁlvarez Ledesma, M. I., Cippitani R. (coord.), Diccionario analítico de Derechos humanos e integración jurídica, Roma-Perugia-México: ISEG

- (2013b) La libertad de expresión en el sistema electoral mexicano desde una perspectiva juridical. In López Montiel, G. Tamés Muñoz,E. (coord.) Libertad de expresión en el proceso electoral 2012 , Tecnológico de Monterrey-Coparmex, PNDU/ONU. México: Porrúa.

- (1998) Acerca del concepto «derechos humanos», México: McGraw Hill

Borio, C. (2007). Storiadell’Università (dalle originiaglianniottanta del XX secolo). In Sediari, T. (coord.), Cultura dell'integrazione europea. Torino: Giappichelli, pp. 47-80

Cámara Villar, G. (1988). Sobre el concepto y los fines de la educación en la constitución española. In X Jornadas de Estudio. Introducción a los Derechos Fundamentales, Ministerio de Justicia, Madrid, Vol. III, pp. 2159-2191

Chabod, F. (2001) Storiadell'idea di Europa. Bari: Laterza

Cippitani, R. (2012) El Derecho en la Sociedad del Conocimiento. Roma-Perugia: ISEG 
Cippitani, R. Gatt, S. (2009). Legal Developments and Problems of the Bologna Process within the European Higher Education Area and European Integration. In Higher Education in Europe, Vol. 34, Issue 3-4, 2009, pp. 385-397.

Crisafulli, V. (1956). La scuolanellaCostituzione. In Rivistatrimestraledirittopubblico. p. $54 \mathrm{ff}$.

Dworkin, R. (1978). Taking Rights Seriously. Harvard: Harvard University Press

Expósito, E.(2012-2013) Libertad de cátedra del profesor universitario. In Revista de Educación y Derecho/ Education and LawReview. n. 7, October 2012 - March 2013

Ferrada Bórquez, J.C. (2001) La autonomía universitaria: algunas reflexiones generales acerca de su contenido jurídico. In Estudios Sociales / Corporación de Promoción Universitaria, Santiago del Chile, no. 108 (semestre 2), p. 59-89

Fernández-Miranda Campoamor, A. (1988) De la libertad de enseñanza al Derecho a la educación. Madrid: CEURA, pp. 137-138.

Le Goff, J. (1957).Les intellectuellesauMoyenÂge. Paris:Seuil

LozanoCutanda, B. (1997) La libertad de cátedra y sus límites. In El País.monday 13 January

Lorenzo Vázquez, P. (1994) Acerca de la libertad de cátedra. In Derecho y opinión, n. 2, 1994, pp. 255-266

Molina del Pozo, C.F., Archontaki, C. Libertad de artes y de Investigación Científica, Libertad de Cátedra. InÁlvarez Ledesma, M. I., Cippitani R. (coord.), Diccionario analítico de Derechos humanos e integración jurídica, Roma-Perugia-México: ISEG

Morin, E. (1987).Penserl'Europe.Paris: Folio

Mattioni, A. (1993) Insegnamento (libertà di), en Digesto Pubblico, VIII, Torino, p. 433

Mura, A. (1976) ComentaryArticles 33-34 ItalianConstitution. In Branca, G., CommentarioallaCostituzione. Rapportietico-sociali. Bologna-Roma: Zanichelli.

Pototschnig, U. (1971) Insegnamento (libertà di). In Enciclopedia del diritto. Milano: Giuffrè, vol. XXI.

Schoijet, $M$. (2009)Libertad académica y represión: algunos antecedentes históricos. In Desacatos, n. 31, September-December. pp. 137-144

Tavenas, F. (2004) A Reference System for Indicators and Evaluation Procedures. Brussels: EUA

Thiesse, A.M. (2001). La creazionedelleidentitànazionali in Europa, trad.ital. de La Création des identitésnationales. Europe XVIII-XX siècle. Bologna: IlMulino

Wallerstein, I (2007)El universalismo europeo. El discurso del poder. Siglo XXI. Madrid 


\title{
Assessment feedback in higher education: preliminary results in a course of strategic management
}

\author{
Montserrat Boronat-Navarro*, Beatriz Forés*, Alba Puig-Denia*
}

Universitat Jaume I

\begin{abstract}
Assessment feedback improves the process of learning by giving students the possibility to analyze their own learning process and the points in which they fail in the activities. Nevertheless, their application in the higher educational environment could have some difficulties due to the number of students in each group. The aim of this project is to analyze the assessment feedback concept and its importance in teaching strategic management subjects. The study presents descriptive results of the perceptions of the students in a group in which feedback is included as a usual activity in the development of the subject. Students positively evaluate the feedback provided by the teacher, and also their academic marks are positive.
\end{abstract}

Keywords: assessment feedback; higher education; strategic management

\section{Introduction and background}

Assessment feedback in higher education has been theoretically and empirically studied due to its potential to enhance the student's learnig process. As Evans (2013: 71) pointed, the concept of assessment feedback "includes all feedback exchanges generated within assessment design [...] in the learning context". Feedback aims to improve the level of performance in learning by reducing the gap between the actual level of performance and the learning goal (Draper, 2009; Lizzio and Wilson, 2008; Wiliam, 2011).

Although its potential benefits seem to be clear, its application in the higher educational environment could have some difficulties due to the number of students in each group. It could be a reason for the lack of studies that empirically analyze feedback strategies in the Spanish higher education environment, and specifically, in management subjects in which this project focuses on. Therefore, there is a challenge the application of feedback assessment and the improvement of the feedback quality in this context.

Therefore, as teachers in strategic management subjects, we included assessment feedback in one group of students in the third year of the Degree in Business Administration, in the first semester of this academic course. We present in this study preliminary descriptive results from a survey that analyzes students' perception of the feedback activities introduced in the classroom. The objective of the paper is to analyze the assessment feedback concept and their importance in teaching strategic management subjects.

The next section defines the concept and types of assessment feedback and explains the importance of this activity in subjects related with strategic management in higher education. In the methods section, the main characteristics of the educational project are described. Then, we present some descriptive results of the survey completed by the students related to their satisfaction with the activities that include feedback from the teacher and comment briefly academic marks of the group. Finally, we analyze the main conclusions. 


\section{Background}

\section{Assessment feedback}

There are different types of feedback depending on their purpose (Hattie and Timperley, 2007). The first one, task feedback, clarifies aspects of the task carried out to reinforce the learning. Process feedback, as a second type, is centred on how the student addresses a specific task. The third one, self-regulation feedback evaluates the strategies the student uses. Finally, self-feedback analyzes personal attributes of the student in the process. In this study, we focus on the first one, task feedback, although the feedback process in a learning environment could be difficult to differentiate because this process includes also some aspects of the other types pointed out. Furthermore, the different objectives of feedback must be considerate as integrated dimensions of feedback (Evans, 2013). It includes motivational, reinforcement and informational aspects (Nelson and Schunn, 2009).

Distinction between the cognitivist and socio-constructivist perspectives of feedback is also highlighted in the literature. Whereas the first one emphasizes feedback as corrective information provided by an expert, in the last one feedback is a facilitative process to help students. Nevertheless, both perspectives are reinforcing each other rather than being exclusive points of view (Evans, 2013). By using feedback as a corrective tool we should also provide students a better understanding on how the task must be carried out.

\section{Management studies}

Strategic management subjects have some characteristics that make more complex the process of teaching and learning. As a social science, it analyzes unstructured and complex problems, the high diversity of the object under study and the influence of the environment (markets, competitors, economy, laws, technology, etc.). The importance of social factors and the ambiguous relationships among variables, together with the difficulty in measuring the variables involved, and the multiple approaches and paradigms, gives more complexity to the subjects related to strategic management.

Due to this ambiguity in the aspects analysed by strategic management subjects, students must be involved in continuously searching and analysing qualitative and quantitative information to solve practical cases related to real problems. The different variables involved in determining the success or failure of organisations together with the importance of social and behavioural factors, make more difficult the learningteaching process.

Strategic management subjects require that teachers are able to provide the students a wide range of capabilities that allow them to perform their future job. Learning based on a constructivist view puts its strength on the knowledge building in an autonomous way by the students who adopts an active role in the process. Teacher acts a mediator agent between the learning and the student. The methodology in this kind of learning includes different strategies such as classroom debate, group debates, working in teams, tutorials, etc., which stimulate the participation of the students (Slavin, 1990). Where the number of students is high, to take benefit of the advantages that these methodologies offer it is possible to combine them in different moments of the learning process development. 
In this context, the importance of assessment feedback is clear. In this type of subject, the process of analyzing a specific problem, case or activity, is even more important than the solution achieved. Therefore, feedback should provide benefits to the process of learning in the management area.

\section{Methods}

In this section we explain the project carried out in the third course of a Degree in Business Administration in Jaume I University (Castellón, Spain) in a subject related to strategic management. In this subject, the syllabus includes all the aspects of the process of analyzing and formulating business strategies.

In the theoretical sessions of the subject, individual or group activities are proposed to students to learn and to analyze in depth some aspects of the syllabus that are also explained by the teacher. Students write a brief report of the activity (one page) and the teacher helps to solve doubts, to focus the question and the answer, etc. This fact also constitutes an activity of feedback, in the sense that the teacher guides students in how they must approach to the activity and in the comprehension of doubts or problems they find to answer the question. In following sessions, the teacher also explains the main problems observed in the activity and returns the correction of the activity.

The methodology in the practical part of the subject is based on teamwork in tutorial sessions. Considering the objective of bringing reality to students, the sessions are designed to analyse the process of strategic management in a real firm they select. Students must prepare a final project based on the firm and the teacher should guide the development of this project in tutorial sessions. The assessment feedback is also carried out in these sessions, because all of them are focused on guiding the project, solving doubts, etc.

Furthermore, the second part of the syllabus includes typologies of strategies, their application, advantages and disadvantages. Teams in tutorial sessions must also analyze strategies and their applicability to their firm. Then, they must explain and defend in theoretical sessions one strategy to the other teams. The teacher selects the appropriate strategy to analyze in each firm and each group must expose it in front of the other students, evaluating the applicability of different strategies to each of the firms. Therefore, the feedback to each group in relation to the strategy they must present to the other students in the classroom is given before the date of the presentation. Feedback is therefore included as a key element throughout the development of the subject.

After the end of the semester (December 2014), an anonymous online survey was completed by the students to have also feedback of the satisfaction with the methodology and the process of learning. A total of 82 students were registered in this group, and 52 students filled in the questionnaire (63.41\% answer the questionnaire). Four of the questions were related with the feedback provided by the teacher, and we present results of these questions in next section. 


\section{Results and Discussion}

In this section, descriptive results of the questionnaire are presented graphically. The four questions related to feedback the survey includes are the following:

1. Please, indicate your degree of satisfaction with the feed-back that the teacher gives you in the theoretical sessions (1 very low, 5 very high).

2. Please, indicate your degree of satisfaction with the feed-back that the teacher gives you in the practical (tutorial) sessions (1 very low, 5 very high).

3. Please indicate in which degree the feed-back that the teacher gives you in the theoretical sessions improves your motivation for the subject ( 1 a negative influence, 4 a very positive influence).

4. Please indicate in which degree the feed-back that the teacher gives you in the practical (tutorial) sessions improves your motivation for the subject ( $1 \mathrm{a}$ negative influence, 4 a very positive influence).

Descriptive results of the first and second questions are showed in graphs 1 and 2 .

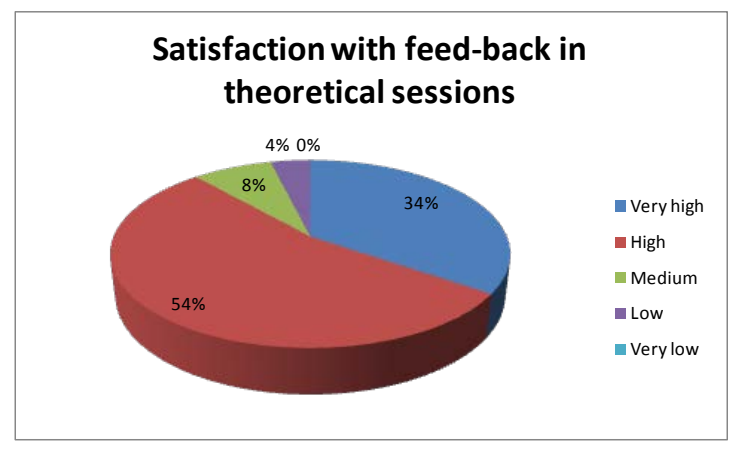

Graph 1. Degree of satisfaction with feed-back in theoretical sessions

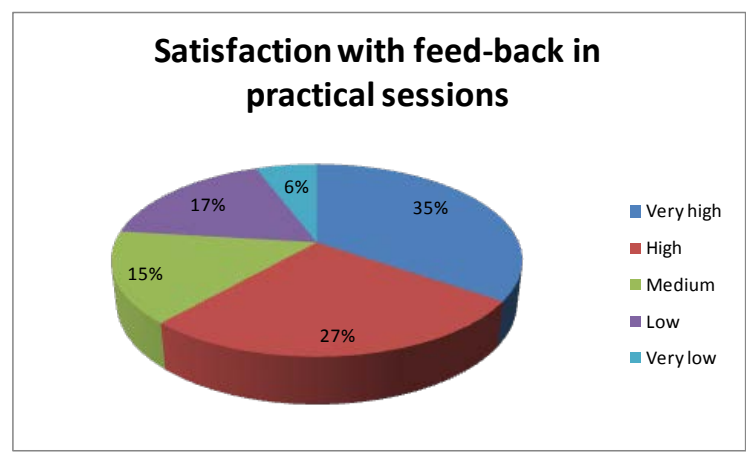

Graph 2. Degree of satisfaction with feed-back in practical sessions

The degree of satisfaction in theoretical sessions is very high or high to the $88 \%$ of the students (Graph 1), which is an important percentage. In the case of the practical sessions, the percentage of students with a high or very high satisfaction is $62 \%$ (Graph 2), which represents also a significant percentage of students that positive evaluate this feed-back.

Descriptive results of the third and fourth question are presented in the two following graphs. 


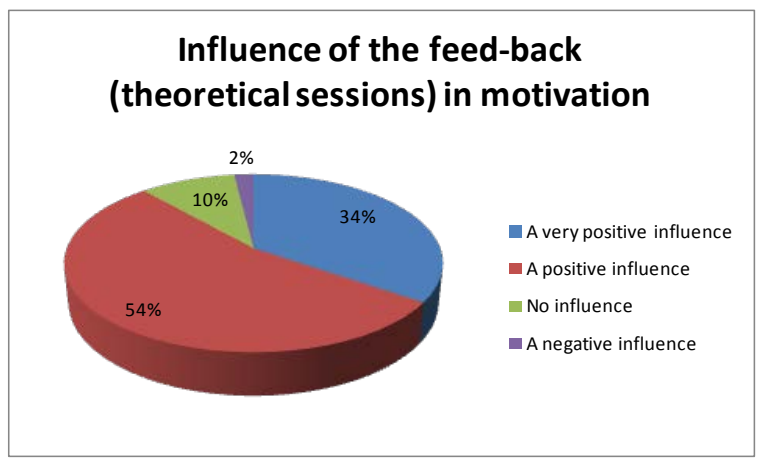

Graph 3. Influence of the feed-back of the theoretical sessions in the motivation for the subject

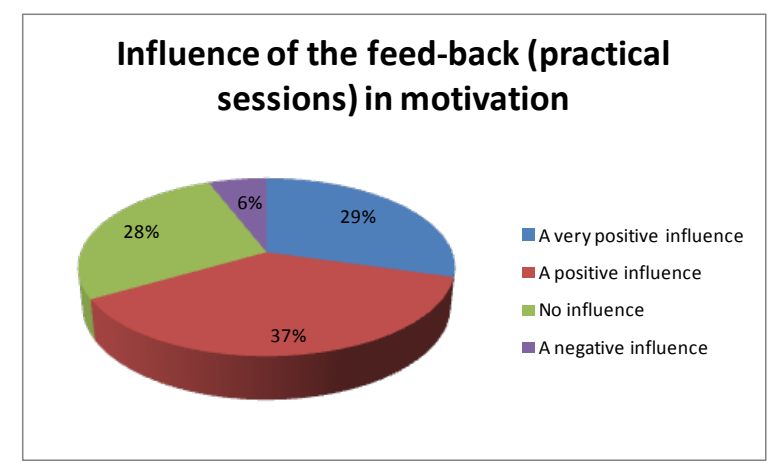

Graph 4. Influence of the feed-back of the practical sessions in the motivation for the subject

Results of the perception of the influence of the feedback on the motivation for the subject are similar as the degree of satisfaction, with an 88\% (Graph 3) of students with a positive evaluation in the case of theoretical sessions, and a percentage of $66 \%$ (Graph 2) in practical sessions. Therefore, the results are positive.

Finally, we also report academic results of the subject. Only 10 students of a total of 82 do not pass the subject and 6 have not been presented to the exam. Therefore, a percentage of $80.49 \%$ of the students passed the subject, which is a high percentage.

Although we cannot extract conclusions and causality from this descriptive data, the development of the learning process has been very satisfactory from the point of view of the teacher, and the inclusion of the feedback is one of the activities that improve the learning process.

\section{Conclusions}

Assessment feedback is an important tool to improve the learning process in high education. The role of teacher in guiding this process is stressed with this type of initiatives. In many subjects related with social sciences, as in the case of strategic management subject, there are not deterministic solutions to problems. Management in organizations requires different skills, knowledge and capabilities to deal with different complex situations. In the course, the importance of social factors, the high diversity of the firms, the influence of different variables, should be highlighted. In this learning context, the process of achieving a solution is more relevant the than the final result. Assessment feedback is necessary in the learning process in the management area. 
Preliminary results of this project, carried out in a subject of strategic management in the degree of Business Administration, show how the learning process is improved from the students' point of view. Also, this perception is confirmed by the good marks that the students achieved in the subject.

Limitations of the study are related to the descriptive nature of the data presented. Results could only be explained from a qualitative point of view and causality could not be tested. Future studies should also control from other variables that may have an influence in the results, by comparing, for example, with other groups of students.

\section{References}

Draper, S.W. (2009). What are learners actually regulating when given feedback? British Journal of Educational Technology, 40, 306-315.

Evans, C. (2013). Making sense of assessment feedback in Higher Education. Review of Educational Research, 83(1), 70-120.

Hattie, J., \& Timperley, H. (2007). The power of feedback. Review of Educational Research, 77, 81-112.

Lizzio, A., \& Wilson, K. (2008). Feedback on assessment: students' perceptions of quality and effectiveness. Assessment and Evaluation in Higher Education, 33, 263-275.

Nelson, M. M., \& Schunn, C. D. (2009). The nature of feedback: How different types of peer feedback affect writing performance. Instructional Science, 37, 375-401.

Slavin, R. E. (1990). Cooperative learning. Theory, research and practice. Needham Heights, MA: Allyn and Bacon.

Wiliam, D. (2011). What is assessment for learning? Studies in Educational Evaluation, 37, 3-14. 


\title{
Bridging Classroom to Experiential Learning: A Review of Signature Pedagogies in Two Disciplines
}

\author{
Beck, V.* and King, K.** \\ *Department of Criminal Justice.University of Wisconsin Oshkosh \\ 316 Halsey South.Oshkosh, WI 54901-865 (United States) \\ beckv@uwosh.edu \\ **Public Administration Program.University of Wisconsin Oshkosh \\ 320 Halsey South. Oshkosh, WI 54901 (United States) \\ kingk@uwosh.edu
}

\begin{abstract}
The focus of this review is to promote and advance discussions on the importance of applied learning techniques in bridging the gap between the classroom and the real world experiences, by reviewing the empirically identified benefits and limitations of two signature pedagogies. The authors conclude that it may be advantageous to develop a set of shared standards flowing from lessons learned in the application of applied learning approaches across the curriculum. The authors also suggest students should be encouraged to participate in experiential education to liberate their thinking and gain practical work experience.
\end{abstract}

Keywords: Applied learning; experiential learning; case studies; internships; public administration; criminal justice.

\section{Introduction}

To become competent public servants, students must understand the theories and best practices in their discipline, as well as how to apply that information. To help students make connections between the classroom and real world experiences, some disciplines have adopted specific teaching pedagogies to organize "the fundamental ways in which future practitioners are educated for their chosen professions" (Shulman, 2005, p. 52). While these "signature" pedagogies have proven to be valuable resources, they are not necessarily the exclusive domain nor used solely by a particular discipline. In this paper, scholars from public administration and criminal justice share signature pedagogies used to provide a bridge between classroom learning and the real world of public service.

\section{Case Studies in Public Administration}

Educators in the discipline of public administration use a wide variety of instructional techniques to help students take what they have learned in class and apply it to the world of public service and one such technique is the case study. While the move toward using the case study approach for training pre-professional students in public administration classes emerged in the mid-1930s, it originated with the Harvard Law School around 1870 (Lynn, 1999). Viewing the approach in an abstract sense, Stein (1952) defined a case study as an "examination of the particulars prior to or as part of a generalization” (pp. xx-xxi). More specifically, however, Lynn (1999) describes a teaching case as "a story, describing or based on actual events and circumstances, that is told with a definite teaching purpose in mind and that rewards careful study and analysis” (p.124). Lynn (1999) identifies three characteristics of a case study: it furthers the development of professional intellectual and behavioral skills; it is issueor problem-oriented; and it is essentially concerned with interpreting real-world experience (p. 3). Brooks, Harris and Clayton (2010), referencing Desanto-Madeya, conclude that "case-based pedagogy is a creative learning strategy that not only 
enhances critical thinking and problem-solving but also decision-making skills” (p. 55).

Public administration policy case studies come in all sizes and are used to accomplish a variety of pedagogical purposes. Cases, sometimes as short as one page and dealing with a very specific set of circumstances, can be used to stimulate class or small group discussions that are related to a specific unit within a larger subject for examination. For example, PA TIMES, the newsletter of the American Society for Public Administration (ASPA), regularly prints a column titled “An Ethics Moment” which incorporates brief case studies on ethics in a public service setting for classroom use. Case studies that focus on more complex political or economic questions can be studied over the course of a semester and, if appropriate, presented as a group project at the end. For example, a discussion of the concept of "Budgeting as a Political Choice" can be linked with a state's budget deficit.

\section{The benefits of the case study method}

Public administration instructors use the case study method extensively because it has the ability to prepare "learners for a world that demands critical thinking skill and the ability to create convincing arguments, often with little time and incomplete information" (Lynn, 1999, p. 2). While managerial situations are often unique, certain types (i.e., disciplining employees) tend to appear on such a regular basis that studying cases about them in class does present an approximation of the world of public service that is not possible from reading a textbook account (Golembiewski \& Stevenson, 1998). Further, some case studies, especially the longer more complicated ones, can be written in such a way as to challenge readers to delve further into the subject

The most common use of case studies in a classroom setting is for students to react to prepared cases in public policy and administration supplied by their instructor. However, writing assignments can require students to discuss their actual experiences in an organizational setting, which helps students to analyze a workplace problem by organizing issues in a logical manner, presenting interesting narrative, and developing compelling questions that expanded the participants' understanding of the case.

The limitations of the case study method

While the case study method is a versatile teaching strategy, challenges have been noted. For example, not all case studies are well-written or easily implemented, even when written by experts and/or appearing in textbooks. Also, case studies can sometimes appear overly theoretical or unrealistic. Further, the questions that are supposed to help students connect the circumstances of the case study to broader issues and practices in public administration may fail to do so.

Students sometimes express frustration with case studies. The fact that the ultimate outcome of a case might not be known perturbs some. Students also complain that there is not enough information for them to undertake a comprehensive analysis of the case, or make a logical recommendation for action. Of course, it is appropriate at this point to remind students that the kinds of situations they will encounter as government workers are typically characterized by insufficient information, inadequate time, and lack of follow-up, which is why it is important to practice critical thinking skills in class by engaging with real cases. 
Despite the above noted limitations, case studies provide a focus on the application of classroom activities to situations that public administrators might encounter in the field. Consequently, the case study teaching method is an excellent resource for instructors whose students are the government workers of the future.

\section{Internships in Criminal Justice}

In many disciplines, the integration of theory into experiential learning is an essential part of education (Ciofalo, 1992; Parilla \& Smith-Cunnien, 1997; Reed \& Carawan, 1999), and one way to achieve such integration is through the use of internships. The variety of internship opportunities in criminal justice is almost boundless and perhaps limited only by a student's ability to: find time to participate; grade point average, since some programs require a specific GPA for interns; and prior criminal record, as most social agencies run a criminal background check on interns.

Although the use of internships dates back to medieval times (Ross \& Elechi, 2002), it is a controversial pedagogy (Stone \&McLaren, 1999). The core of the debate surrounding the use of internships focuses on the purpose of a university education. "Academic purists view the university as a place where people are taught to think" (Stone \& McLaren, 1999, p. 171) and are concerned that internships will not contain sufficient academic content (Sgroi \& Ryniker, 2002), while professionally oriented academic programs endorse internships and potential employers believe universities should help prepare young people for employment (Stone \& McLaren, 1999). Historically, the debate on the use of internships in academics has, perhaps, been more common in criminal justice, as a discipline struggling to attain legitimacy as a social science rather than as a "cop shop" (Durham, 1992). Consequently, not all criminal justice programs include internships.

\section{The benefits of internships in criminal justice}

Despite the debates surrounding the pedagogical use of internships, research on criminal justice internships have noted a variety of pedagogical and social benefits. In addition to having the opportunity to apply classroom learning to real world experiences, internships assist students in: building social relationships and interacting with diverse populations; determining how to respond to challenging situations; improving problem solving and communication skills; improving the ability to make appropriate career decisions and transitioning from school to work (Stichman and Farkas, 2005).

Community agencies also benefit from the use of internships in academic programs. In the discipline of criminal justice, specifically, community agencies benefit when: interns provide current skills and knowledge that may encourage updates to agency practices; interns energize agency staff and help promote agency image; and interns provide temporary qualified workers at little to no cost (Stichman and Farkas, 2005). The benefits for academic programs include: enhanced knowledge of agency needs and issues in the field, which can inform teaching; and improved student retention (Stichman and Farkas, 2005).

\section{The limitations of internships in criminal justice}

While it is clear that criminal justice internships provide reciprocally beneficial relationships between student, community and the academic program, there are noted limitations. According to Stichman and Farkas (2005) internships: may not always 
promote integration of theory with practice; may be viewed as an easy way to improve GPA; may result in anecdotal application of information; may create legal liability; may result in students being assigned to menial tasks unrelated to learning. Other limitations may include lack of a faculty or student handbook delineating clear guidelines and policies for the internship; lack of time and resources for faculty supervisors to review and assess agencies and students; and lack of compensation, which may prevent working students from participating (Stichman and Farkas, 2005).

Internships have been and continue to be a prominent pedagogy in criminal justice programs (Reed \& Carawan, 1999), as well as other programs such as psychology and sociology. Indeed, based on data from National Survey of Student Engagement, Kuh (2008) found internships to be one of the "high impact" educational experiences that increase rates of student retention and engagement. The results in Kuh (2008) have led to a set of suggested standards to improve the quality of the internship experience, across disciplines: internships should be effortful (commitment to task); help students build substantive relationships with faculty, staff and/or co-workers; help students experience diversity and new ways of thinking; provide rich feedback; promote integration and application of knowledge; and provide opportunities for students to reflect on the person they are becoming (see also discussion of Kuh, 2008 in O'Neil, 2010). Unfortunately, it is not known to what extent these suggested standards have been widely adopted, nor does there appear to be research on the effectiveness of these suggested standards. Nonetheless, the Council for Advancement of Standards in Higher Education and Kuh (2008) do provide a framework to begin the discussion on standardizing definitions of and practices in internships to ensure a consistent and quality experience for students, across disciplines.

\section{Conclusions}

Applied learning courses vary widely and continue to proliferate in universities across the U.S. Nonetheless, curricular standards associated with experiential learning techniques have developed independently and with little interaction among advocates (Freeland, 2009 p. 9). This lack of interaction, even among those who believe in their value, leaves applied learning techniques open to criticism that such approaches can be merely career oriented, which does not fit within the tenets of a liberal arts degree. Perhaps one of the ways to curtail criticism of applied learning as being simply "career oriented" is to develop a set of shared standards, which flow from lessons learned in the application of applied learning approaches across the curriculum.

The preceding sections provide practical guidelines for exploring pedagogies bridging classroom learning to real world experiences. While each discipline may have a signature pedagogy to building a bridge, all can benefit from observing the best practices of their colleagues in other fields of study. The information discussed herein also suggests that students should be encouraged to participate in experiential education to liberate their thinking and gain practical work experience, which may result in graduating students who reflect the importance of a well-rounded education and who are well prepared to succeed in their careers and lives. 


\section{References}

Brooks, E., Harris, C.R. and Clayton, P. H. (2010). Deepening applied learning: An enhanced case study approach using critical reflection. Journal of Applied Learning in Higher Education, 2, 55-76.

Ciofalo, A. (1992). What every professor and work-site supervisor should know about internships. In A. Ciofalo (ed.), Internships: Perspectives on experiential learning (pp. 3-7). Malabar, FL: Krieger.

Freeland, R. M. (2009). Liberal education and effective practice: The necessary revolution in undergraduate education. Liberal Education, 95(1), 6-13.

Golembiewski, R. T. \& Stevenson, J. G. (1998). Cases and applications in nonprofit management. Itasca, IL: F.E. Peacock Publishers, Inc.

Kuh, G.D. (2008). High-impact educational practices: What they are, who has access to them, and why they matter. Washington, DC: Association of American Colleges and Universities. www.neasc.org/downloads/aacu_high_impact_2008_final.pdf

Lynn, Jr. L. E. (1999). Teaching and learning with cases: A guidebook. New York, NY: Chatham House Publishers.

O’Neill, N. (2010). Internships as a high-impact practice: Some reflections on quality. Peer Review 12(4), 4-8.

Parilla, P.F. \& Smith-Cunien, S.L. (1997). Criminal justice internships: Integrating the academic with the experiential. Journal of Criminal Justice Education 8(2), 225-242.

Reed, J.G. \& Carawan, .W. (1999). Beyond sibling rivalry: Criminal justice internship on a social work model. Journal of Criminal Justice Education 10(1), 153-170.

Ross, L.E. \& Elechhi, O.O. (2002). Student attitudes towards internship experiences: From theory to practice. Journal of Criminal Justice Education 13(2), 297-312.

Sgroi, C.A. \& Ryniker, M. (2002). Preparing for the real world: A prelude to a fieldwork experience. Journal of Criminal Justice Education 13(1), 187-200.

Shulman, L. (2004). Teaching as a community property: Essays on higher education (JB-Carnegie Foundation for the Advancement of Teaching). San Francisco, CA: Jossey-Bass Publishers.

Stein, H. (1952). Case method and the analysis of public administration. In Public administration and policy development: A case book. New York: Harcourt, Brace and Co.

Stone, W.E. \& McLaren, J. (1999). Assessing the undergraduate intern experience. Journal of Criminal Justice Education 10(1), 171-183. 


\title{
Data mining teaching throughout cards game competition
}

\author{
J. Antonanzas-Torres*, R. Urraca*, E. Sodupe-Ortega*, F.J. Martinez-de-Pison*, \\ A. Pernía-Espinoza* \\ * EDMANS Research Group, Department of Mechanical Engineering, University of La Rioja, C/ San \\ Jose de Calasanz 33, Logroño 26004, Spain.
}

\begin{abstract}
Data-mining techniques and statistical metrics learning can be complicated because of the complexity and overwhelming nature of this field. In this paper a class competition to improve learning of designing Decision Support Systems (DSS) by playing a classic cards game named "Copo" is proposed. The fact that this game is based on a probabilistic problem and that different solutions can be obtained represents a very typical kind of problem in the field of engineering and computer science. During the last four years in which this methodology has been applied to students of Computer Engineering Grade at University of La Rioja, both professors and students h satisfied with the results achieved. The programing of this project was performed in WEKA free software, a data mining suite widely spread in universities and companies. Therefore, not only students learn how to solve stochastic and probabilistic problems, but also the software tools and functions to develop DSS solutions.
\end{abstract}

Keywords: data mining; learning by playing; decision support systems; WEKA, soft-computing.

\section{Introduction}

Educational models that focus on student's autonomous workload and Project-based learning (PBL) (Buck Institute for Education, 2002; Boss \& Krauss, 2007) are promoted by the European Space of Higher Education or EHEA (EEES in Spanish, 2015). These methods allow students to better internalise concepts and learn how to apply them to specific situations. Traditional teaching methods have shown the lack of promoting interactions among students, who in some cases becomes a passive character that has difficulties in assimilating the theoretical content of the subject and in thinking of possible real applications of what he is studying. For these reasons, it is necessary to introduce some changes in the traditional teaching methods, enhancing the student's personal work, their interpersonal relationships and communication skills (Reynolds \& Miller, 2013). Some alternatives to traditional teaching have risen, such as PBL, Problem-based Learning (Merril, 2007) or Collaborative-based Learning (Slavin, 1980).

In this paper, a Competition-based Learning (CnBL) (Gredler, 2004; Burguillo, 2010; Andreu-Andrés \& García-Casas, 2011) scheme was used to enhance student's motivation, which normally leads to a better understanding of the subject (Bergin \& Reilly, 2005). CnBL promotes learning through a class competition, but without the scores affecting the student's learning results. It can be combined with other teaching techniques, listed above.

In this experience, a class competition, with students divided in teams, have to work and collaborate to win the quiz. Thus, students take active part in the course and get enthused to be in the top of the classification.

The methodology herein presented has been implemented during the last four academic courses in the subject 'Knowledge Engineering' of Computer Engineering Grade at University of La Rioja. Along the course, the methodology has lead substantial improvements in the teaching methods, as motivation for the subject among the students has increased.

The main objective of the methodology proposed is to make the students assimilate the concepts shown during the course and to boost their motivation in the learning of the 
subject in which the methodology is applied. This is driven through putting student's acquired theoretical knowledge into practice by designing Decision Support Systems (DSS) for supporting decisions in real problems. Students, organized in groups, have to construct a useful DSS for a card game, developing a model as precise as possible based on a database of historical results of a game of cards and deciding how to use it to maximize the benefit. In addition to applying the knowledge to a real case and interpreting the results obtained, students also interact and discuss with each other to put ideas in common and reach the solution, which enables to develop communication skills.

\section{Methodology}

The methodology is based on the competition between groups of students, who must develop an expert system to play a Spanish cards game known as 'copo'. Students have to apply the knowledge discovery databases (KDD) process in order to make explicit the knowledge on a large database of different “соро” plays. In general, a KDD process consists on extracting 'hidden' knowledge from large datasets, which is obtained after processing the data, applying data mining techniques and interpreting the results. Therefore, in this experience, after analysing the different plays (dataset), an expert system composed by a classifier with some additional rules was obtained.

The game is played with the Spanish pack of cards, which is comprised by 4 different suits (coins, cups, clubs and swords) and 10 cards per suit (Figure 1). For this game, the cards from the same suit are sorted as follows: 2, 4, 5, 6, 7, 10 (jack), 11 (knight), 12 (king), 3, 1 (ace); according to the traditional numbering of the Spanish deck. However, to keep it simple, hereafter, cards will be referred from 1 to 10 based on the previously described sorting position.
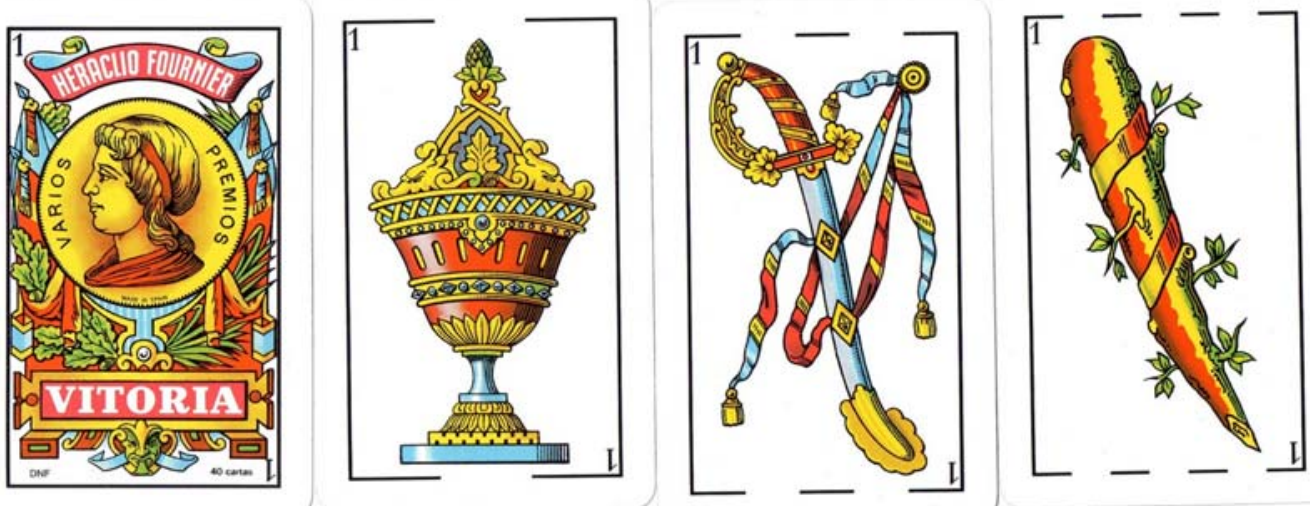

Figure 1 Suits of the Spanish deck: coins, cups, swords and cubs from left to right.

The game can be played by a variable number of players and it is comprised by the following stages.

1. Initially, each player puts an initial amount of money in the centre of the table in order to comprise the pot.

2. Four cards are dealt to each player.

3. Each player chooses whether he wants to bet or not and the amount of money bet. The bet cannot be superior to the pot. The player will have to pay or receive from the pot the amount of money bet depending on if he wins or loses.

4. Once each player has made his bet, the top card from the deck is turned over.

5. The player wins if he owns a higher card of the same suit of the uncovered card. 
In brief, the logic behind the game is quite simple as the probability of winning or losing can be straightforwardly obtained by dividing the number of cards which defeat the 4 cards owned by the player by the total amount of cards in the deck. Nevertheless, a KDD methodology was proposed in order to teach students a more general procedure that could be extended to model more complex situations.

In order to ease the work, it was considered that only one player was playing at each time. The development of the expert system was divided into the following steps:

1. The students received a training set composed by 1000 plays, with the cards owned by the player and the uncovered card.

2. Based on the training set, each group of students had to select the best classification technique. They could choose between: decision trees, decision rules, Bayes-based methods, logistic regression, neural networks, support vector machines or instance-based learners, and besides, they had to select the proper metric to evaluate each classifier: Kappa statistic, Precision, TP-Rate, Recall or F-Measure among others (Witten \& Frank, 2005). This process was carried out in the WEKA suite (Hall et al., 2009).

3. Once each group had selected the best classifier, students received a testing set composed by 500 additional plays, where they had to decide how to use the model to support the decision to bet or not. Then, for each play, the classifier predicted if the student was going to lose or win and its probability. Afterwards, for the wining plays, each group had to set a threshold to decide if the probability of wining was high enough to bet. Finally, if the decision of betting was taken, the system had to decide the amount of money to bet. Students fine-tuned this expert system based on a trial-and-error procedure until they maximized their gains.

4. Once every group had completed the training stage, each group uploaded a .doc file with all results and steps followed in the process, the selected model, and the threshold and formula which defined the DSS.

5. Lastly, the professor organized a competition in class with a new testing set composed by other 500 additional plays unseen by the expert systems of each group. The grade obtained by each group was related to the amount of money gained in this competition. The group with more gains was graded with a 10/10, while the remaining groups were graded proportionally.

The experience was carried out along two session, of 2 hours each, within practical classes of the subject. During the first session steps 1 and 2 were accomplished. Steps 3, 4 and 5 (final class competition) were developed during second session.

\section{Results and Discussion}

The afore-mentioned methodology was applied during four different courses of "Knowledge Engineering" subject in the Computer Engineering Grade at University of La Rioja, from academic years 2010/2011 to 2014/2015. Results presented herein describe results obtained from academic year 2013/2014, with 25 students.

This cards game is a stochastic and probabilistic problem based on determining the probability of finding a win-case (hereinafter referred to as WIN). The database was not balanced in order to keep probabilities of appearance as they were. If balanced, the model could derived a wrong probability distribution and therefore, provide good results in cross-validation but then fail when testing with new data. 
Students had to deal with statistical metrics such as TP-Rate or Sensitivity, which indicates the percentage of winning cases the model detects from all WIN's in the database; Precision, which shows the percentage of cases guessed rightly from all WIN's predicted by the model; F-Measure which is the harmonic average of previous TP-Rate and Precision; and others. As a result, different strategies came up, such as very conservator models with very high Precision and low TP-Rate, or models with higher risk with higher TP-Rate and lower Precision.

At the end of the course, a survey was conducted to quantify the level of satisfaction of the students with the methodology proposed, whose results are shown below.

1. From 1 to 5 (where 1 represents 'very low' and 5 'very high'), how interesting did you find the card game competition based-learning compared to traditional teaching model?

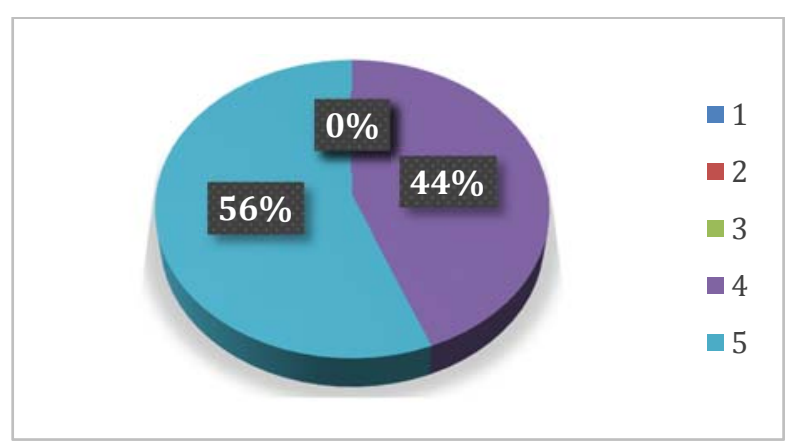

2. From 1 to 5 (where 1 represents 'very low' and 5 'very high'), how do you grade the students' involvement in the card game competition based-learning?

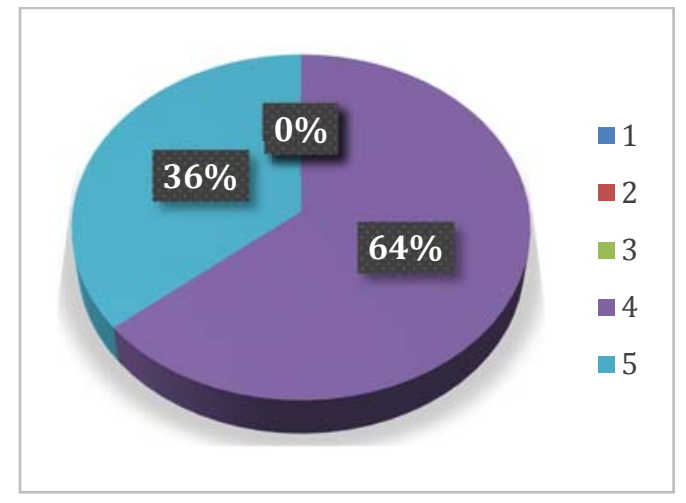

3. From 1 to 5 (where 1 represents ‘very low' and 5 'very high'), do you think the number of practical cases is enough for a correct understanding of the subject?

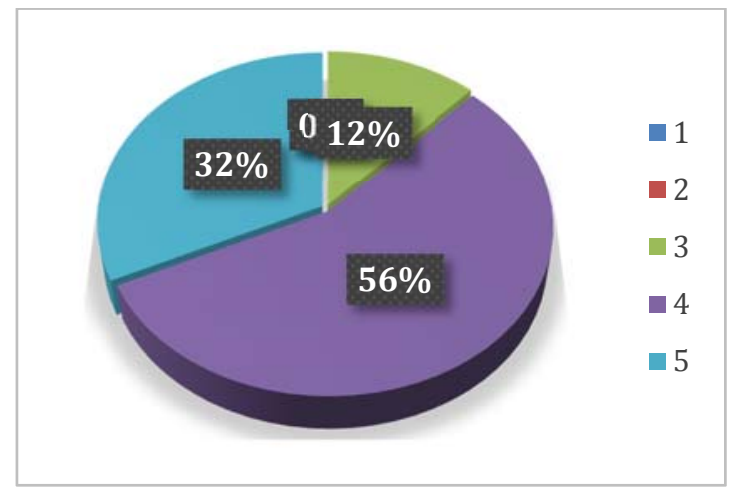


The following positive experiences were obtained:

- High level of attention and participation of students during the lessons corresponding to soft-computing and DSS. All students considered involvement to be "high" or "very high" in class, as well as the degree of interest, which resulted to be very high. This is very important for students as previously to this methodology they were over-whelmed by the great number of techniques taught in a relatively short period of time.

- Class competition to optimize results can be considered a success, since students are motivated because they consider learning as a game indeed.

Students combine theoretic and practical knowledge in soft-computing and DSS during the course to solve other real life projects, which can be approached in a similar way. $32 \%$ of students found that this experience was complete enough so as to proportionate a good understanding of the subject (while other 56\% considered the experience almost complete enough).

\section{Conclusions}

This innovative teaching-learning project deals with the teaching of data mining and decision support systems in "Knowledge Engineering" course for students of Computer Engineering Grade at University of La Rioja, throughout the application of softcomputing techniques to conventional problems. A typical-within students' cards game ("copo") was chosen. Students had to learn and apply different soft-computing techniques and statistical metrics, and also understand possible strategies (conservator or higher risk player) to achieve best results. By making this task a class competition, students kept a high level of attention during the whole class and a high level of satisfaction in comparison to traditional teaching-learning method.

To conclude with, not only this methodology can be applied to 'Knowledge Engineering', but it could be also applied to other technical courses, where a great number of techniques and metrics are taught in a reduced period of time.

\section{Acknowledgements}

The authors would like to acknowledge the University of La Rioja for the financial support received through the call of proposals 'Proyectos de Innovación Docente 2014/2015', as well as for the fellowships FPI-UR to train researchers (J. Antonanzas and R. Urraca). The authors also want to express their gratitude to the Instituto de Estudios Riojanos (IER), to the Banco Santander for the project PROFAI 13/06 and to the Agencia de Desarrollo Económico de La Rioja for the project ADER-2012-I-IDD-00126 (CONOBUILD). Finally we would like to thank to the special collaboration of all student involved in this experience.

\section{References}

Andreu-Andrés, M. A. \& García-Casas, M. (2011). Perceptions of Gaming as Experiential Learning by Engineering Students. International Journal of Engineering Education Vol. 27(4), 795-804.

Bergin, S., \& Reilly, R. (2005). The influence of motivation and comfort-level on learning to program. Proceedings of the 17th workshop on psychology of programming- 
PPIG'05, 293-304.

Boss, S., \& Krauss, J. (2007). Reinventing project-based learning: your field guide to real-world projects in the digital age. Eugene, OR: International Society for Technology in Education.

Buck Institute for Education, An overview of Project Based Learning (2002). http://www.bie.org/pbl

Burguillo, J. C. (2010). Using game theory and Competition-based Learning to stimulate student motivation and performance. Computers \& Education 55, 566-575.

European Space of Higher Education. http://www.eees.es/

Gredler, M. E. (2004). Games and Simulations and their Relationships to Learning. Handbook of Research on Educational Communications and Technology, 2nd ed., Lawerence Erlbaum Associates, Mahwah, NJ, 571-582.

Hall, M., Frank, E., Holmes, G., Pfahringer, B., Reutemann, P., \& Witten, I.H. (2009). The WEKA data mining software: an update. SIGKK Explorations, 11(1).

Merrill, M. D. (2007). A task-centered instructional strategy. Journal of Research on Technology in Education, 40(1), 33-50.

Reynolds, W.M. \& Miller, G.E. (2013). Educational psychology: Contemporary perspectives. Handbook of Psychology, Educational Psychology, 7 Wiley, Hoboken, NJ, $1-22$.

Slavin, R. E. (1980). Cooperative learning. Review of Educational Research, 50(2), 315-342.

Witten, I.H. \& Frank, E. (2005). Data mining: practical machine learning tools and techniques. San Francisco, CA. Morgan Kaufmann Publishers Inc. 


\title{
Diagnostic and assessment of specific and transversal competences in Chemistry studies in a distance education
}

\author{
program
}

\section{González-Gómez*, A. Gallego-Picó**, R.M. Garcinuño**, M.J. Morcillo**, J.S. Durand $^{* *}$, P. Fernández**}

* Department of Didactics of Experimental Sciences, Faculty of Education, University of Extremadura (UNEX), Cáceres (Spain)

** Department of Analytical Sciences, Faculty of Sciences, National University of Distance Education (UNED), Madrid (Spain)

\begin{abstract}
The current socioeconomic conditions require highly educated professional with new curricula requirements and new skills, professionals with initiative and abilities able to be adapted to different situations and contexts. Consequently, the university education system must ensure that students achieve competences that involve the combination of knowledge, attitudes and values that enable a qualified person to undertake the resolution of problems or able to evolve in a new professional or social context. To achieve this goal, universities must find and use the most suitable tools to adapt and create higher education programs to respond to the needs of today's society, tuning academic and professional profiles. On the other hand, there is a significant growth of enrolling students in distance education universities and several distance education programs are available in most universities. Thus, the aim of this communication is to share the results obtained during the development of a teaching innovation project, which assessed interdisciplinary, specific and transversal competences, by means of a post-task objective test, in the Chemistry undergraduate studies at the National University of Distance Education, (UNED) of Spain. The results of this study have allowed to the professors board to analyse and assess the competences acquired by the students, pointing out the main deficiencies to be solved by re-designing the teaching activities and methodologies to ensure a complete success.
\end{abstract}

Keywords: Blended learning; High Education; Formative assessment; Innovative pedagogical strategy

\section{Introduction}

In Europe, as a result of the Bologna Process the educational systems in all European countries have made a significant process of change. Society demands from the academia the production of a more knowledgeable workforce, improving employee onthe-job performance and solving organizational problems (Richey et al., 2001). In this context, some professional organizations have already addressed this challenge and define these professional competencies as required learning outcomes. In order to provide these requirements, universities have re-designed the curricula keeping the coherence between objective, competences and contents, teaching methodology, learning activities and assessment system. On the other hand, the European Higher Education System has being overhauled to guarantee more comparable, compatible, and coherent systems in European countries according to the directives established in the Bologna Process (van der Wende, 2000). This new education system prioritizes the learning of generic competencies that will allow the acquisition of more specific knowledge and skills needed in a specific field. And therefore, teaching material and methodologies need to be updated to ensure the development of interdisciplinary specific and transversal skills, and way to assess them. In online and blended learning, teachers also need to reconceptualise fundamental issues of teaching, learning and assessment in non-traditional spaces (Gikandi et al., 2011).

This communication is focused on online formative assessment in order to create learner and assessment learning environments (Pachler et al., 2010; Wang et al., 2008). 
The objective of this research is to assess the learning results of students of Chemistry Undergraduate Program at National University of Distance Education in terms on specific and transversal competencies, as well as to evaluate the learning achievements from students of two different subjects (Basic Chemistry and Advanced Analytical Chemistry). The student's feedbacks about the instructional methodology, teaching material and resources have been also evaluated. Data were collected during four year comparing different methodologies.

\section{Methods}

The study was carried out with students of the subject Advance Analytical Chemistry taught in the last year of the Chemistry Degree Program and students of the subject Basic Chemistry (pre-university students), both on the bases of distance education system. The student's participation in this study was not compulsory. Data were collected from 2006 to 2010 to Advance Analytical Chemistry students, and during three years (2007-2010) to Basic Chemistry.

For this project, a Study Guide was designed with the aim of providing the student with a global overview of the subject contents, the knowledge to be learnt and more important highlighting the competencies (generic, specific and transversals) that students must develop within the subject. The Study Guide also includes basic instruction to guide the students in the learning process, content schedule and assessment calendar. In addition, the students are provided with interactive instructional material through the virtual campus, such as podcast, hot potatoes exercises, lectures presentation, conceptual maps and summaries of theoretical contents. Some of these activities were applied as a source of on-going feedback with the aim to improve teaching and learning and consequently as a tool of formative assessment. Formative assessment has been defined as a iterative processes of establishing what, how much and how well students are learning in relation to the learning goals and expected outcomes in order to inform tailored formative feedback and support further learning, a pedagogical strategy that is more productive when role is shared among the teacher, peers and the individual learner (Gikandi et al., 2011). In addition, e-learning environments including the complementary role of ICT in these activities (Pachler et al. 2010). Thus, the virtual classroom constitutes the main interaction scenario between professors and students and the collaborative work between students. On the other hand, asynchronous interaction allowed students to rethink and assess their own understanding of content before they posted their responses that facilitated reflective and self-assessment processes. Traditional exams also were present to evaluate specific skills.

Portfolio was other assessment tool employed to analyse the student's evolution in terms of learning contents and competences. Each student's portfolio includes selfassessment results, on-line and in-person test evaluations and students' opinion surveys. Portfolio was a multimodal tool in the learning processes (Dysthe et al., 2007).

The assessment indicators, used to evaluate the results were:

- Usability perception of the provided teaching resources and instructional methodology 
- Learning achievements

- Students satisfaction

- Professor perception and satisfaction

The transversal competencies were assessed by means of an objective on-line diagnostic test developed by the Institute of Knowledge Engineering (Instituto de Ingeniería del Conocimiento, ICC, Spain). More precisely, tools eValue and eCat were used (http://www.iic.uam.es/). These tests were only made with the Advance Analytical Chemistry students in the course 2008-2009.

\section{Results and Discussion}

During project achievement, a total of 60 students from a total of 183 enrolled in Advance Analytical Chemistry participated in this study. Only 63 students from a total of 1898 enrolled in Basic Chemistry participated in the project.

The age of the majority of students was over 30 years old (80\%) and female sex predominated, around $60 \%$. However, there is great variability in data for the different years.

Regarding the educational background, most of Advance Analytical Chemistry students already had another university degree and the participants were already workers of chemistry field companies. In last year of project, $54 \%$ of student already had another university degree and $46 \%$ were worked in chemistry companies. In the other subject, similar percentage of student was worked in chemistry field companies.

Finally, the vast majority reported to have medium or strong knowledge of how to use computer technologies.

\section{Assessment of specific competencies and learning achievements}

The results of the student's perception to the different assessment indicators are summarized in Table 1. In general terms, students have found useful or very useful all the teaching resources provided, and were specially useful to understand, analyse and study the subject contents. Conceptual Map tool only was implemented in Advances Chemistry subject.

Table 1. Student's perception of the different assessment indicators used in this study

\begin{tabular}{|c|c|c|c|c|c|}
\hline Assessment indicator & Parameter & $\begin{array}{c}\text { Little } \\
\text { useful }\end{array}$ & $\begin{array}{c}\text { Mild } \\
\text { Useful }\end{array}$ & Useful & $\begin{array}{c}\text { Very } \\
\text { useful }\end{array}$ \\
\hline \multirow{4}{*}{$\begin{array}{c}\text { Usability perception of the } \\
\text { provided teaching resources }\end{array}$} & Study Guide & $0 \%$ & $6 \%$ & $59 \%$ & $35 \%$ \\
\cline { 2 - 5 } & Lecture presentation & $0 \%$ & $0 \%$ & $75 \%$ & $25 \%$ \\
\cline { 2 - 5 } & Self-evaluation & $0 \%$ & $0 \%$ & $35 \%$ & $75 \%$ \\
\cline { 2 - 6 } & Conceptual Map & $6 \%$ & $0 \%$ & $88 \%$ & $6 \%$ \\
\cline { 2 - 6 } & $\begin{array}{c}\text { Debate virtual forums and } \\
\text { virtual classroom }\end{array}$ & $0 \%$ & $6 \%$ & $77 \%$ & $17 \%$ \\
\hline \multirow{3}{*}{$\begin{array}{c}\text { Usability perception of the new } \\
\text { instructional methodology }\end{array}$} & To plan the course & $0 \%$ & $40 \%$ & $60 \%$ & $0 \%$ \\
\cline { 2 - 6 } & To understand the contents & $0 \%$ & $10 \%$ & $80 \%$ & $10 \%$ \\
\cline { 2 - 6 } & To analyse the contents & $0 \%$ & $10 \%$ & $90 \%$ & $0 \%$ \\
\cline { 2 - 6 } & To study & $0 \%$ & $10 \%$ & $90 \%$ & $0 \%$ \\
\hline
\end{tabular}

In comparison, basic level subject had valued more positively the resources.

In Advanced Chemistry subject, regarding to the learning achievements, $63 \%$ of the students participating in this study passed the final exam. Considering the total number 
of students enrolled in the subject, 35\% passed the final exam, $18 \%$ did not reach the minimum score and $47 \%$ did not attend to the final exam. According to the survey results, students have found very positive the learning achievements and were very satisfied with the implemented instruction methodology.

\section{Assessment of transversal competencies}

Transversal competencies such as customer focus, leadership, flexibility to change, self-control, initiative, confidence, negotiation, communication and teamwork, were assessed. Results are summarized in Figure 1.

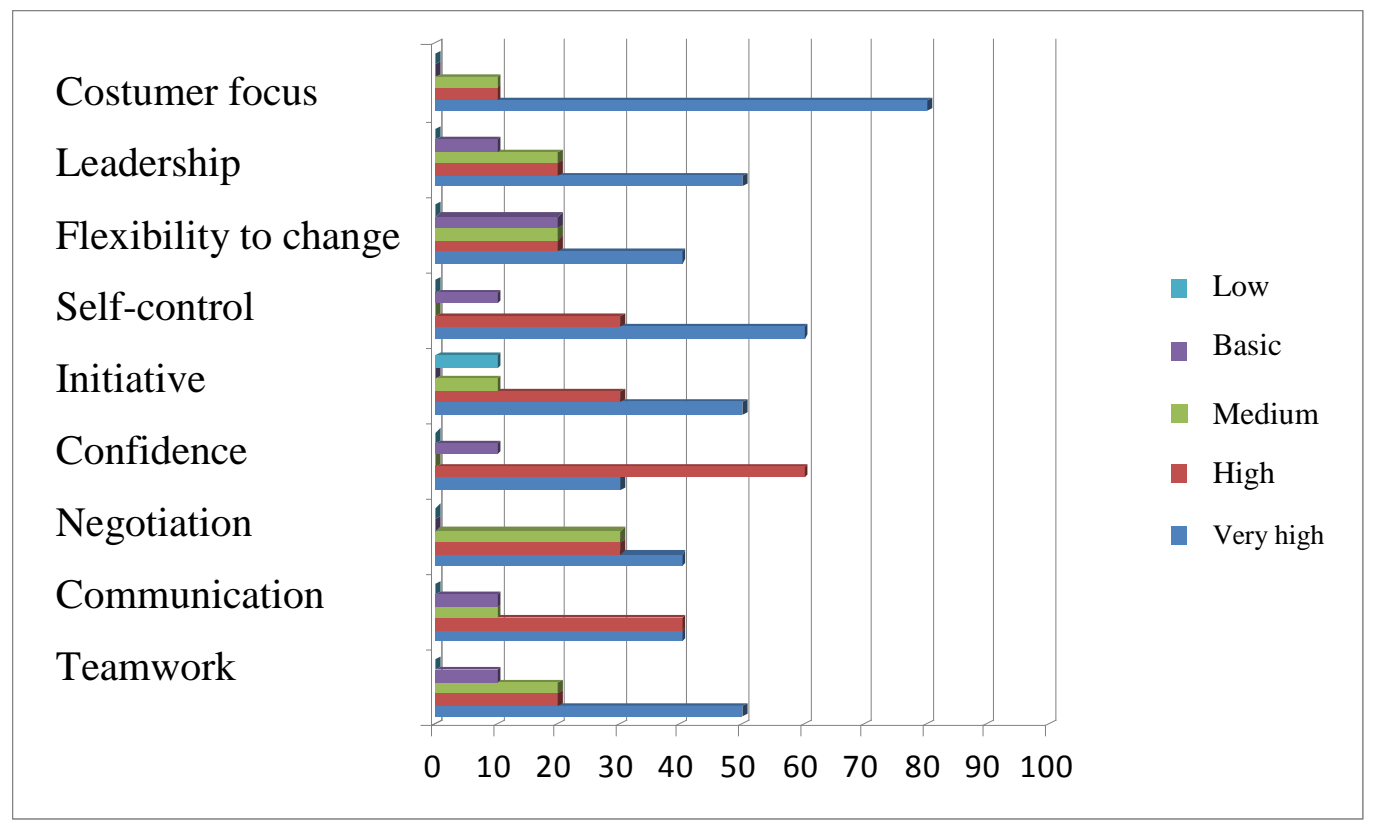

Figure 1. Transversal competencies assessment results

English skills (oral and written) were also evaluated, and over $60 \%$ of the students had a low or very low level of these skills.

\section{Conclusions}

Among the main achievements of this innovative project was the high students participation in the teaching activities and their high motivation towards the learning process. Student learning was more efficient because they have more resources to plan their activities, resulting in continuous dedication to the subject study. The high level of acceptance of the methodological resources by the students, and their acknowledge that it has served to improve not only their academic results but also the perceived learning level, lead to the conclusion that the experience can be considered as highly successful. This is supported as well by the fact that the level of involvement in virtual learning environments has clearly improved, both for new students in distance education and for students in the final year of the degree.

Regarding the transversal competencies, the results revealed that students have to improve their self-control, initiative and confidence skills. It is also important to highlight, that English communication skills, both oral and written, were also not satisfactory. 
All activities and recourses were applied as a source of on-going feedback with the aim to improve teaching and learning and consequently as a tool of formative assessment.

\section{References}

Dysthe, O., Engelsen, K.S. \& Lima, I. (2007). Variations in portfolio assessment in higher education: Discussion of quality issues based on a Norwegian survey across institutions and disciplines. Assessing Writing, 12, 129-148.

Gikandi, J.W., Morrow, D., \& Davis, N.E. (2011). Online formative assessment in higher education: A review of the literature. Computers \& Education, 57, 23332351.

Instituto de Ingeniería del Conocimiento. eValue. [http://www.iic.uam.es/pdf/eV.pdf]. Last access January 2015.

Instituto de Ingeniería del Conocimiento. eCat. http://www.iic.uam.es/pdf/eC.pdf. Last access January 2015.

Pachler, N., Daly, C., Mor, Y., \& Mellar, H. (2010). Formative e-assessment: Practitioner cases. Computers \& Education, 54, 715-721

Richey, R.C., Fields, D.C. \& Foxon, M. (2001). Instructional design competencies: the standards. Third edition. New York: Eric publication.

van der Wende, M.C. (2000). The Bologna Declaration: Enhancing the transparency and competitiveness of European Higher Education. Higher Education in Europe, 25, 305-310.

Wang, T.H., Wang, K.H., \& Huang, S.C. (2008). Designing a web-based assessment environment for improving pre-service teacher assessment literacy. Computers \& Education, 51, 448-462. 


\title{
Enhancing the formative value of self- and peer-marking through 'Test Workshops'
}

\author{
L C Woollacott \\ University of the Witwatersrand, South Africa
}

\begin{abstract}
This paper reports on the development of 'Test Workshops' in a first year chemical and metallurgical engineering course in a South African university. The workshops were designed to enhance student learning through a combination of selfassessment, reflection and group interaction. The development began with an investigation into the summative and formative value of self- and peer-assessment in the context of the course and how the students responded to these unfamiliar forms of assessment. While the accuracy of both self- and peer-marking was found to be inadequate for summative purposes, their formative value was found to be considerable. Based on these findings, the Test Workshop format was designed as a sequence of activities that consisted of writing a short problem-based test under summative test conditions, followed immediately by a group discussion of the solution to the problem, followed by self-marking of the individual solutions against a model answer and marking rubric, followed by a written reflection. Analysis of the students' experiences found that the effectiveness of this format as a learning methodology was very encouraging and that it had applicability in a wide range of contexts.
\end{abstract}

Keywords: peer assessment; self-assessment; formative assessment; reflection

\section{Introduction}

The formative value of self/peer-assessment and its potential to enhance student learning in a course is widely recognized (Dochy et al., 1999; Race, 2001; van Zundert et al., 2010). Many benefits for student learning have been reported, such as developing reflective skills and a greater sense of a student's responsibilities (Dochy et al., 1999); becoming better informed about the nature of the assessment systems being used (Bloxham \& West, 2004); and the development of critical thinking and higher-order cognitive skills (Snowball \& Mostert, 2013).

This paper describes the development of a formative assessment methodology - 'Test Workshops' - that is based on self- and peer-marking. It was developed in the context of a first year process engineering course in a South African university. The course was an introduction to process engineering but had as one of its objectives the development and reinforcement of skills needed for academic success at university.

The methodology developed through two phases over the period 2007 to 2013. The first investigated the efficacy of self/peer-marking in the context of the process engineering course. This is described in Part 1 of the paper. The second was the design and evolution of the 'Test Workshop' format and a study of its efficacy. This is described in Part 2 of the paper.

\section{Part 1: Self- and peer-marking in the context of the engineering course}

The introduction of a self/peer assessment component into the course was motivated by four objectives: to enhance student learning; to familiarize students with how their work was marked; to improve the students' skill and self-awareness with regard to engineering problem-solving and test-taking practice; and to reduce the marking load. In order to establish the extent to which such a component was likely to achieve these objectives in the context of the course, a pilot exercise was conducted in 2007 over a six week period. The exercise involved a series of three short class tests that were both peer- and self-marked followed by a class survey to solicit student reaction to the assessment process. The first two tests were treated as training exercises to familiarize the students with the system because it 
was clear from the literature cited earlier that such training was essential for the success of any self/peer assessment strategy. Prior to the first test, the self/peer marking exercise and the rationale behind it was explained and students were made aware that the third test would contribute to their final mark.

The tests were written bi-weekly and copies of the scripts were self/peer marked by the students the day after a test. To make the peer marking blind, students were allocated predefined script numbers and wrote these and not their names or student numbers on their answer scripts.

Each test involved a single question and consisted of a numerically based engineering problem that was typical of questions students would encounter. To guide their marking, students were given marking instructions, an example of a marked script, and the marking memo. The memo had two sections: a 'technical section' that was essentially the marking rubric a course coordinator would use when grading; and a 'quality of practice' section intended to focus the students' attention on issues of good practice with respect to categories labelled 'perception', 'thinking', and 'communication'. Each of these issues were assessed according to the sub-categories listed in Table 1 and required the students to make a judgement about each sub-category on a seven point scale: i.e. perfect, excellent, good, OK, needs work, poor, hopeless.

Table 1: Sub-categories of 'Quality of Practice' used in the marking rubric

\begin{tabular}{|c|c|c|}
\hline Perception & Thinking & Communication \\
\hline $\begin{array}{l}\text { Distinguishing relevant from } \\
\text { irrelevant information } \\
\text { Translating information into } \\
\text { appropriate technical terms, concepts, } \\
\text { notation } \\
\text { Making relevant connections between } \\
\text { different items of information } \\
\text { Interpreting text accurately } \\
\text { Visualizing the situation } \\
\text { appropriately }\end{array}$ & 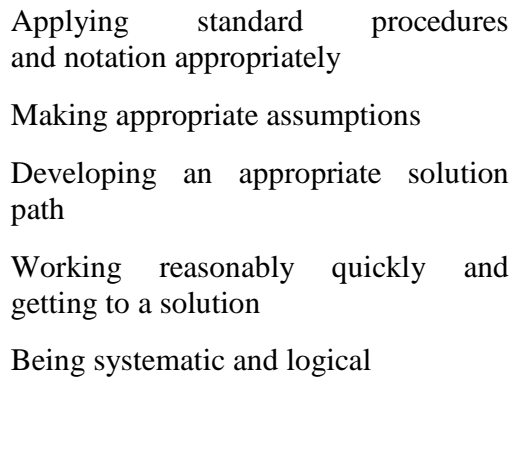 & $\begin{array}{l}\text { Fluency and clarity of written English } \\
\text { Clear, logical explanations that are } \\
\text { comprehensible to the reader } \\
\text { Absence of errors in spelling, grammar } \\
\text { and vocabulary }\end{array}$ \\
\hline
\end{tabular}

The scripts from the third test were marked by the course coordinator for summative purposes and as a basis for evaluating the accuracy of the students' marking. In both cases, attention was given only to the 'technical' marks. The results are summarized in Figure 1 and show that neither self-marking nor peer-marking were sufficiently reliable to be used for summative purposes. Figure 1A shows the extent to which self-marking diverged from marks given by the coordinator. In some cases, the divergence was as high as $50 \%$ in absolute terms with weaker-performing students deviating more than the stronger.

With regard to peer-marking, Figure $1 \mathrm{~B}$ shows that the accuracy of peer-marking was not much better than that of self-marking. It was less biased but significant deviations were still evident. No correlation was evident between the extent of deviation and the apparent academic strength of the students. It was however apparent that although students' tended to over-mark their own work (by about $6.4 \%$ on average) this tendency fell away when marking the work of peers. 

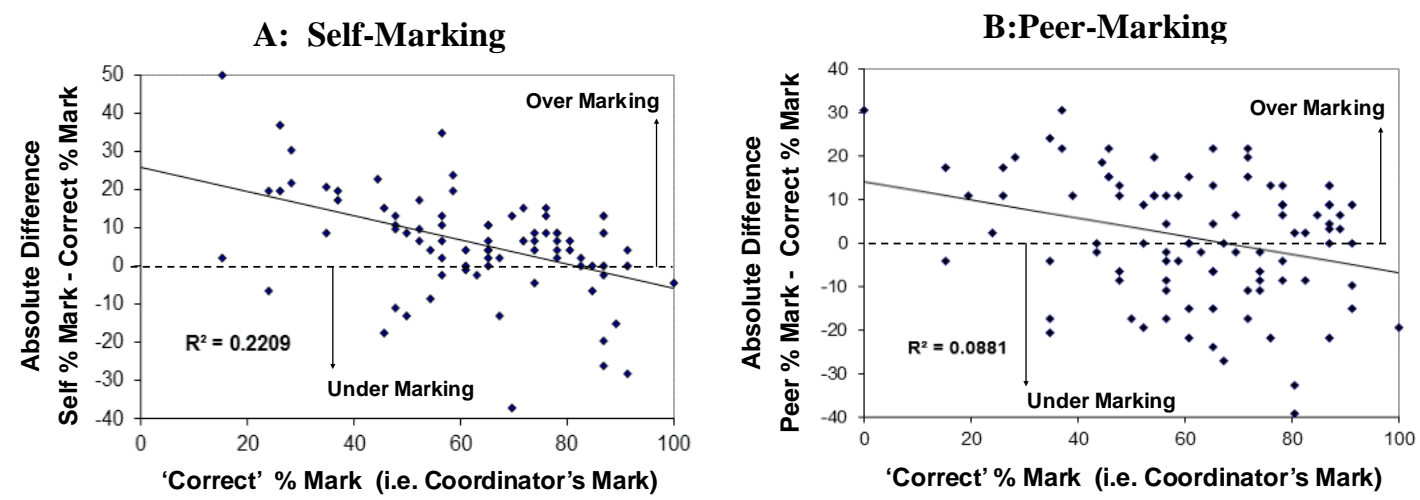

Figure 1: Relative Accuracy of Self and Peer Marking

\section{Students Reactions to the self / peer-marking exercise}

The class survey conducted a week after the last test consisted of six fixed-response questions using a five point Lichert scale. It also solicited open comments. With regard to the students' reactions to the self/peer-marking exercises as a whole, the survey found that the majority of students responded positively to the self/peer marking exercise. The responses indicated that $22 \%$ regarded the exercise very favourably and $69 \%$ reasonably to very favourably while $20 \%$ of students were unsure. However, $12 \%$ were negative towards it but no students were very negative. More significantly, an overwhelming majority (95\% of the students) saw benefits in the system: $41 \%$ saw major benefits while $5 \%$ saw no benefits. The open ended comments in the survey returns indicated the following general reasons why students endorsed the system.

- Seeing a variety of ways of solving the problem improved their problem solving skills and understanding of the associated concepts.

- Becoming more accurately aware of their own mistakes had a similar effect.

- Acquiring a better understanding of the workings of the assessment process itself helped students to know what to expect and how to answer questions more effectively.

The negative comments made by the students focused almost exclusively on the issue of the marking standard of peers. In addition, a number of concerns were expressed about details of the marking process (such as how to award part-marks) and a small number of students indicated that they found the process to have little value and to be tedious and time consuming.

With regard to the students' perspectives on the educational value of the self/peer-marking exercises the survey indicated the following. Fully $67 \%$ of the students believed their understanding of the course material improved reasonably or substantially, while 8\% believed it was not helpful in this regard. When asked a more general question ("To what extent has your learning improved as a result of the self/peer marking system?”), 88\% of the students indicated some, good or very good improvement while $46 \%$ indicated a good improvement, and $8 \%$ no improvement. With regard to the extent to which the self/peer marking exercises were seen to be helpful for understanding the marking process and, consequently, for improving their understanding of what was required of them in tests and exams, the indications from the survey were again positive: $71 \%$ indicated it had been reasonably to very helpful; $37 \%$ indicated it had been very helpful; while only $2 \%$ indicated it had not been helpful at all. With regard to gaining a better understanding of what was expected of them in tests and exams, $99 \%$ of the students indicated that it had been helpful to some degree: $27 \%$ 
indicated that it had been very helpful; 57\% that it had been quite helpful and 15\% that it had helped a little.

\section{Summary of findings}

The survey suggested that many of the intended outcomes of the self/peer-marking process had been achieved. A majority of students reported gaining greater familiarity with the assessment processes and greater clarity about what examiners expected and so benefited accordingly in the tests. Many reported improved learning at a number of levels as was expected from the literature (Falchikov \& Boud, 1989; Falchikov \& Goldfinch, 2000). In general, the students responded positively to the system and its formative value seemed to be considerable.

More negatively, it was apparent that student marking was not reliable enough for summative purposes. Also, the complexities associated with making peer-marking blind in order to promote marking accuracy were somewhat detrimental to the formative value of the assessment system; for some students the complexity created confusion and for others tedium. While there were many positive aspects of the self/peer marking that was piloted, it was clear that its format needed to be modified if it was to be implemented on a more ongoing basis.

\section{Part 2: Test Workshops}

Based on the encouraging findings just described, a different kind of formative assessment system was developed over several years and evolved into what became known as 'Test Workshops'. The format that emerged was based on self-marking but also included guided reflection and group interaction that were intended to enhance the formative impact of selfassessment. It was designed to be conducted during the three hour period allocated for an afternoon tutorial and consisted of a series of linked activities as follows.

1) Test: Under summative test conditions students write a short test (20 to 40 minutes) that consists of a single problem requiring the calculation of one or more numerical answers.

2) Transfer: Students copy their answers onto an answer sheet that is handed in for grading. The scripts themselves are kept by the students for the subsequent activities.

3) Group interaction: Students form groups of three or four to discuss their solutions, to compare solution methods, and to reflect on their performance.

4) Self-marking: A model solution and a marking rubric similar to the one described in the previous section are handed out and students mark their own work.

5) Reflective assignment: Students reflect on various aspects of their performance and write individual reflections which they hand in for grading along with their self-marked scripts.

6) Portfolio and review assignment: Within a week of a Test Workshop, the scripts and reflective assignments are returned to the students. Students are required to build a portfolio of these along with other work from the course. The portfolio constitutes the data for a review assignment which the students are required to hand in (with their portfolios) at the end of the semester for grading. In this assignment the students are required to reflect on their learning experience in the course and the combined impact of its various components on their learning and development, including the impact of the test workshops.

The rationale behind some of the features of the Test Workshop format requires explanation. The first to consider is that a summative test environment is retained even though the primary focus of the workshops is formative. The rationale here is to exploit the intensity with which 
students engage with set problems and tasks in a summative environment - in the students words, the work is 'for marks'. The result of this intense engagement is a degree of familiarity with the particularities of the task or problem that is deeper than is likely to be achieved by a student under any other circumstances given the same amount of time commitment. This means that all the subsequent activities in the workshop are conducted from the perspective of that depth of awareness and engagement thus enhancing their formative value. Because all but one of these activities follow immediately after the test, the formative impact is maximized.

A second feature of the Test Workshop to consider is the inclusion of group interaction. In effect, group interactions, together with the self-marking activity, replace the peer-marking aspect of the original format described in Part 1 and provide a broader range of formative benefits than is normally associated with peer-marking. For example, in the group interaction phase of a test workshop, each student is able to view scripts from two or three peers and is also able to engage with those peers on any issues that might arise.

A third feature to discuss is the inclusion of reflective exercises in the Test Workshop format. The rationale here derives from the broad consensus that good reflective skills are important for quality learning and student development. In the same way as the prompts in Table 1 in the original format were designed to help students to make judgements about aspects of the 'quality of performance' evident in a script, so a list of reflective prompts are provided in a Test Workshop to guide students in their reflections and, in this way, to help foster the further development of this important graduate attribute.

\section{The impact of the Test Workshops}

The work which the students collected in their portfolios and their review assignments provided the most meaningful data available for an evaluation of the impact of the workshops on the students' learning and development. Ten submissions from the 2012 cohort (319 students) were selected for the evaluation. (More are currently being analysed to increase the representivity of the sample.) However, what is currently indicated by an analysis of the sample of student work is the following.

The detail given by the students in the post-test reflections and in their portfolio assignments indicated that the test workshop had been successful in fostering a high level of student engagement with the problems set in the tests and in the reflective and group interactions associated with it. With regard to the latter, several students commented on insights they had gained from their peers in the group interactions. One of them commented as follows.

My second problem during this test was pointed out to me by my partner when comparing answers. He highlighted the fact that although I am strict with how I answer the question, I forgot to include a key, nomenclature, units in calculations and consistency with significant figures. I will endeavour to remedy these problems from now on.

It was also clear that the test workshops had achieved the objective of familiarising students with the assessment systems used in the course. One student wrote ...

There was definitely an improvement in (my) marks as I ... gained a better understanding of how to study and tackle (process engineering) problems. This can be seen in the general improvement in marks from ... test to ... test as I got more familiar with how the questions were asked and what information to look for.

What was particularly evident was growth in the students' understanding, application and appreciation of reflective practices. All students in the sample reported this. In summary, they explained that the reflective activities in the test workshop had lead them to recognize shortcomings in their conceptual grasp, in problem solving and test-taking skills, and/or in 
the quality of their performance in the tests. Further, the format had enabled them to make appropriate and timely adjustments in order to overcome these shortcomings. Four examples from the student portfolios illustrate this.

I (became) much better at critically assessing myself and communicating my point of view. I think this was because I had had more practice in writing those necessary (reflective) reports. I also noticed this improvement when reading through the reflections we did after every test.

From my reflection I realized that the inability to understand the question had pulled me down. In the following week when we wrote the (test) I managed to get the solution presented in a manner that was more like that of the model solution. ... I had managed to work on my previous week's weakness through reflection. Reflection is a learning practice that has helped me to understand this course better and other courses as well.

From last week I learned that writing (out the) given information helps me solve the problem so that this week I did exactly that. ... By doing this I could see where I could find my required calculation from. This was the first tut test (i.e. test workshop) in which I panicked but instead of concentrating on the panic, I focused on what I was given and verified everything I did. In so doing I made sure that my panic wasn't making (me) short-sighted (sic).

I found the ... reflective exercises after each tut test (i.e. test workshop) were of particular importance to me. Not only did they assist me in identifying where my shortcomings were, but they also helped me discover new learning guidelines that were especially beneficial for me.

A further point that is illustrated by these examples is the personal growth that had occurred in the students apparently as a result of their experiences in the test workshops and the associated reflective activities. Some students reported understanding concepts better, gaining new insights, developing new problem solving techniques or "new learning guidelines" or an enhanced ability to "critically assess" oneself. Others mentioned a greater ability to overcome the effects of panic in tests; a greater awareness of their "strengths and weaknesses" and of the link between doing well in tests and concentrating in lectures, and completing as many tutorial problems as possible. A student who described himself as a "rather private person” predisposed 'to shyly working on his own' (his words) reported gaining confidence to engage with class mates in the group discussions and also more generally. One student remarked that their improved reflective skill was transferring to their work in other courses.

The overall conclusion from analysing the work of the 2012 cohort was that all the features built into the test workshop format to enhance its formative value had been sufficiently efficacious to justify a continuation of the implementation of the format on an ongoing basis.

\section{Summary and Conclusion}

The significance of the work reported in this paper is that an innovative combination of pedagogies has been developed as a methodology for enhancing the formative potential of self-assessment. In addition, it has provided some evidence of the efficacy of that methodology in the context of an engineering course. The methodology consists of a combination of self-marking, group interaction and guided reflection activities that are carried out immediately after a short summative test. It appears that the learning benefits which students derive from this arrangement are maximized because the environment of a summative test prompts deep student engagement with the questions posed in the test and consequently results in as deep a familiarity with the particularities of the question or issue that the student can develop in a short period of time. It appears that this not only enhances the expected learning effectiveness associated with each of the pedagogies individually but also enhances the synergetic benefits that derive from them in combination. 
Two additional features of the Test Workshop format are considered to be important. These are the reflective environment created in a Test Workshop and the use of an expanded rubric in the self-marking activities so that the attention of the students is drawn not only to the disciplinary concepts and issues raised by the test but also to more generic issues of skill, individual performance and 'quality of practice'. As such the methodology is considered to have relevance and applicability for a wide range of learning contexts.

\section{References}

Bloxham, S., \& West, A. (2004). Understanding the rules of the game: marking peer assessment as a medium for developing students' conceptions of assessment. Assessment \& Evaluation in Higher Education, 29(6), 721-733.

Dochy, F., Segers, M., \& Sluijsmans, D. (1999). The use of self-, peer and co-assessment in higher education: a review. Studies in Higher Education, 24(331-350).

Falchikov, N., \& Boud, D. (1989). Student self-assessment in higher education: A metaanalysis. Review of Educational Research, 59(4), 395-430.

Falchikov, N., \& Goldfinch, J. (2000). Student peer assessment in higher education: A metaanalysis comparing peer and teacher marks. Review of Educational Research, 70, 287322.

Race, P. (2001). Assessment: A briefing on self, peer and group assessment. LTSN Generic Centre Assessment Series Number 9 (pp. 29). York: LTSN Generic Centre

Snowball, J. D., \& Mostert, M. (2013). Dancing with the devil: formative peer assessment and academic performance. Higher Education Research \& Development, 32(4), 646-659.

van Zundert, M., Sluijsmans, D., \& van Merrienboer, J. (2010). Effective peer assessment processes: Research findings and future directions. Learning and instruction, 20, 270279. 


\title{
Experimental characterisation of the motion of an inverted pendulum
}

\author{
J.A. Gómez-Tejedor*, M. Mollar**, and J.A. Monsoriu*** \\ *Centre for Biomaterials and Tissue Engineering, CBIT, Universitat Politècnica de València, Camí de \\ Vera s/n, 46022, València, Spain.jogomez@fis.upv.es \\ **Institute for Research in Design and Manufacturing, IDF, Universitat Politècnica de València, Camí \\ de Vera s/n, 46022, València, Spain. \\ ***Centro de Tecnologías Físicas, Universitat Politècnica de València, Camí de Vera s/n, 46022, \\ València, Spain.
}

\begin{abstract}
In this paper, we present a home-made experimental set-up to study the falling movement of an inverted pendulum. The experimental set-up allows preparing a laboratory session for first year Physics or Engineering students. This set-up has been used in the Bachelor's Degree in Mechanical Engineering at the School of Design Engineering of the Universitat Politècnica de València. The experimental data are fitted to the theoretical equation of motion, obtaining a very good agreement between experiment and theory. In addition, direct measurement of the parameters involved in the equations was carried out, showing a very good agreement with the calculated parameters.
\end{abstract}

Keywords: Inverted pendulum; electro-optical sensor; Physics; Energy conservation

\section{Introduction}

An inverted pendulum is a pendulum that has the centre of mass above its pivot point. It can be make with a rigid rod which rotates in a vertical plane: Stephenson (1908), Phelps \& Hunter (1965), Blitzer (1965), Friedman (1982) and Douvropoulos (2012). The inverted pendulum has the remarkable property to be stable in a vertical position when the supporting point oscillates vertically above a certain frequency: Corben \& Stehle (1994) and Semenov el al. (2013). This system has been used for teaching purpose in nonlinear dynamics and control theory engineering: see for instance Hovland (2008), Magana \& Holzapfel (1998), Zhao \& Spong (2001), among many other references that can be found in the literature.

Analytical and approximate solutions for the differential equation of the non-linear pendulum can be found in the literature (see for instance Matthews el al. (2005) and references therein).

In this paper, we present a home-made experimental set-up to study the falling movement of an inverted pendulum. The theoretical analysis of the system is based in the law of conservation of mechanical energy, that is an important topic of physics in the first year of many Engineering Bachelor's Degrees. In particular, this set-up has been used in a laboratory session in the subject of physics in the Bachelor's Degree in Mechanical Engineering at the School of Design Engineering of the Universitat Politècnica de València.

\section{Material and Methods}

The experimental set up is shown in Figure 1a. It consists of two rigid rods (1) than can rotate around an articulated joint (2). Between the two rods, there is a half circle protractor (3) marked in degrees, with 7 holes, and the set-up also has an electro-optical sensor (4) for detecting the pass through the holes. The holes have an angular size of 2 
degrees, and the distance between holes is gradually increased. The first hole is placed at 7 degrees due to the size of the detection system.

The electro-optical sensor is composed of a light-emitting diode (led) and a receiver phototransistor, placed one in front of the other. When the system is passing in front of the holes, the light radiation from the led is received by the phototransistor producing a current which is measured in an oscilloscope connected to the system.
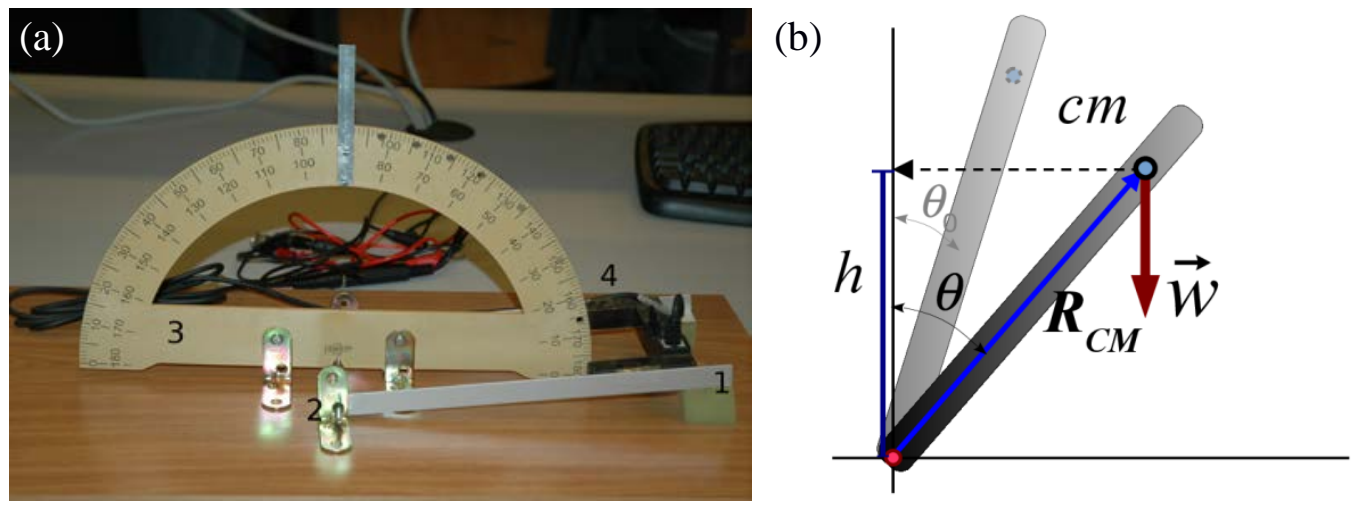

Figure 1. (a) Experimental set-up for measuring the free fall of an inverted pendulum. (b) Schematic representation of the set-up for measuring the free fall of an inverted pendulum.

It should be important to note that the cost of the proposed system is very cheap, except for the oscilloscope, which is used for data measuring, although this should not be an implementation difficulty as this is very common general equipment in Physics and Electricity laboratories.

The system is schematically represented in Figure $1 b$, where $\theta$ is the angle between the vertical line and the rod. The represented point $\mathrm{cm}$ is the position of the Centre of Mass of the system, and $\vec{w}$ is the weight of the rod.

The potential energy of the system when the rod makes an angle $\theta$ with the vertical line is given by:

$$
U=m g h=m g R_{C M} \cos \theta
$$

where $m$ is the total mass of the system, $g$ is the gravitational acceleration, $h$ is the height of the centre of mass and $R_{C M}$ is the distance from the rotation point to the system centre of mass.

The kinetic energy is given by,

$$
K=\frac{1}{2} I \omega^{2}=\frac{1}{2} m R_{g}^{2} \omega^{2}
$$

where in this last expression $\omega$ is the angular velocity, $I$ is the moment of inertia, and the radius of gyration, $R_{g}$, has been introduced:

$$
R_{g}=\sqrt{\frac{I}{m}}
$$

The system is dropped from an initial angle $\theta_{0}$, without initial velocity. From the energy conservation of mechanical energy, neglecting the loss of energy due to frictional forces, the kinetical initial energy at the initial point has to be equal to the total energy when the rod makes an angle $\theta$ with the vertical line:

$$
m g R_{C M} \cos \theta_{0}=m g R_{C M} \cos \theta+\frac{1}{2} m R_{g}^{2} \omega^{2}
$$


Then, we can obtain the square of the angular velocity:

$$
\omega^{2}=2 K^{2}\left(\cos \theta_{0}-\cos \theta\right)
$$

where, for simplicity in the expression, we have introduce the constant $K$ :

$$
K^{2}=\frac{g R_{C M}}{R_{g}^{2}}
$$

Then, the students should measure the angular velocity as a function of the angular position. The angular velocity can be approximately calculated as the size of the hole ( 2 degrees $=0.0349$ rad in the proposed set-up) divided by the time it takes to pass over the hole, that it is measured with the oscilloscope:

$$
\omega \simeq \frac{\Delta \theta}{\Delta t}
$$

Within this approximation, the students should graphically represented the square of the angular velocity $v$ s the cosine of the angle position, and a straight line should be obtained. From this data, performing a linear fit, the slope of the straight line is equal to $2 K^{2}$. From the y-intercept of the line, the value of the initial angle can be calculated.

\section{Results and Discussion}
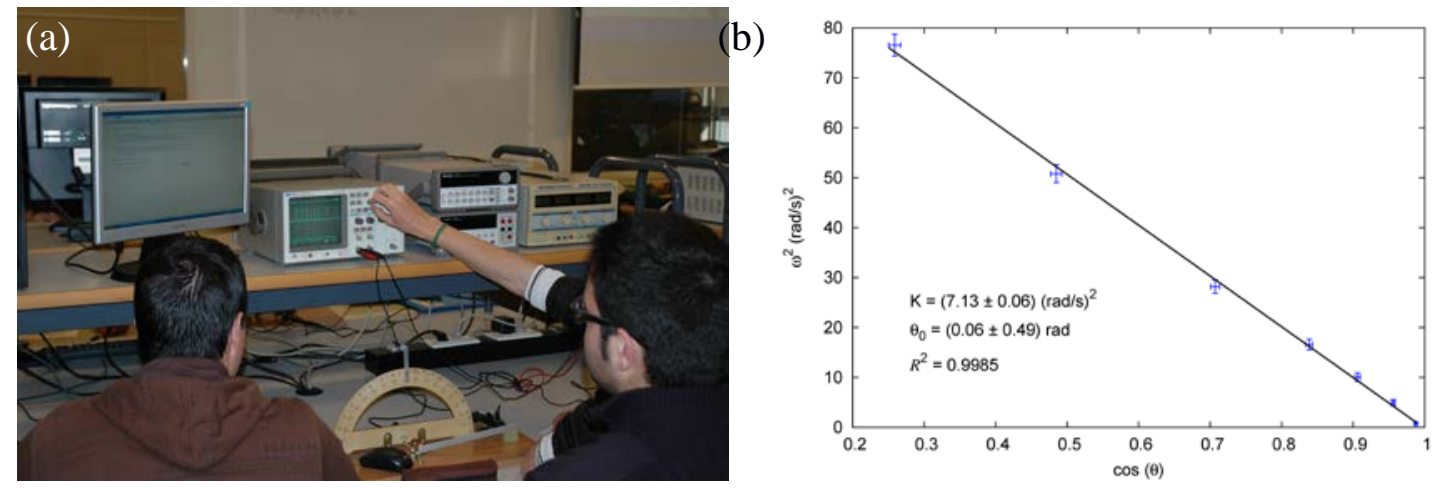

Figure 2. (a) A group of students performing the measurement. (b) Angular velocity squared vs $\cos \theta$; crosses represent data points with error bars, and solid line the linear fit.

In the picture of Figure 2a, it can be seen a group of students performing the measurement in the oscilloscope with the proposed set-up. In Figure 2b, the square of the angular velocity as a function of angular position is represented. A linear fit has also been carried out in order to obtain the slope $=-(101.7 \pm 1.8)(\mathrm{rad} / \mathrm{s})^{2}$ and the $\mathrm{y}$-intercept point $=(101.5 \pm 1.4)(\mathrm{rad} / \mathrm{s})^{2}$. From these results, the value of $K$ and $\theta_{0}$ shown in Figure 2 are obtained.

The results obtained for the value for the fit parameters are very good, with relative errors smaller than $2 \%$, calculated as the ration between the absolute error and the result of measurement. This result is quite remarkable, because of the simplicity of the experimental set-up together with the approximations done in calculations. Some points in the graph of Figure $2 b$ vary slightly from the trend line, which can be attributed to the approximation for the value of the angular velocity.

In order to compare the results obtained, direct measurement of the parameters can be performed by the students. For the angle $\theta_{0}$, the initial position of the rod can be directly measured with the half circle protractor, obtaining the value $\theta_{0}=(0.096 \pm 0.009) \mathrm{rad}$. The agreement is not very good. The reason of this discrepancy for the angle $\theta_{0}$ is due 
to the fact that we have represented the value of $\cos \theta$, that for the case of $\theta_{0}$ is very close to 1 . Then, when the arccos of this number is calculated and the propagation of error is performed, a large value of the error is obtained.

On the other hand, the fundamental equation is the same for the pendulum in inverse position as for the normal position (Matthews et al., 2005). Therefore, students can place the moving part in the normal pendulum position, and make it oscillate over its equilibrium position. The angular frequency of the oscillation is equal to the $K$ constant. From the oscillation period for small oscillations, they can find the value of the $K$ constant $(7.09 \pm 0.06) \mathrm{rad} / \mathrm{s}$. In this case, we have a very good agreement between the obtained value and the direct measurement of the $K$ constant, with a discrepancy smaller than $1 \%$.

\section{Conclusions}

In this paper we have presented a home-made experimental set-up to measure the motion of an inverted pendulum fall. This experimental set-up has been implemented as a laboratory session in the subject of physics in the first year of the Bachelor's Degree in Mechanical Engineering at the School of Design Engineering of the Universitat Politècnica de València.

In spite of the approximation done to calculate the angular velocity, a very good agreement between the fitted parameters and direct measurement of these parameters has been found.

After the lab session, the students have to present a laboratory report. From the results of this laboratory report, we have checked that most of the students reach the planned learning objectives. During the lab session, we have checked that the students are motivated by this experiment. In particular, the students are surprised about the good results in spite of the simplicity of the experiment. In any case, to complete this study, we are planning to take a survey to the students, in order to have feedback, and to check their motivation.

\section{Acknowledgments}

The authors would like to thank the Institute of Education Sciences, Universitat Politècnica de València (Spain), for the support of the Teaching Innovation Groups, MoMa and e-MACAFI, and for the financial support through the PIME project "Experimenta la Física con tu Smartphone: una experiencia multidisciplinar para el desarrollo de competencias transversales”. 


\section{References}

Blitzer, L. (1965). Inverted Pendulum. American Journal of Physics, 33(12), 10761077. doi:10.1119/1.1971158

Corben, H. C., \& Stehle, P. (1994). Classical Mechanics. New York: Yohn Wiley \& Sons.

Douvropoulos, T. G. (2012). Simple analytic formula for the period of the nonlinear pendulum via the Struve function: connection to acoustical impedance matching. European Journal of Physics, 33(1), 207-217. doi:10.1088/0143-0807/33/1/018

Friedman, M. H. (1982). The inverted pendulum: A mechanical analog of the quadrupole mass filter. American Journal of Physics, 50(10), 924-930. doi:10.1119/1.13015

Hovland, G. (2008). Evaluation of an Online Inverted Pendulum Control Experiment. IEEE Transactions on Education, 51(1), 114-122. doi: 10.1109/TE.2007.906612

Magana, M.E., \& Holzapfel, F. (1998). Fuzzy-logic control of an inverted pendulum with vision feedback. IEEE Transactions on Education, 41(2), 165-170. doi: 10.1109/13.669727

Matthews, M. R., Gauld, C. F., \& Stinner, A. (2005). The Pendulum: Scientific, Historical, Philosophical and Educational Perspectives. The Netherlands: Springer Science \& Business Media.

Phelps, F. M., \& Hunter, J. H. (1965). An Analytical Solution of the Inverted Pendulum. American Journal of Physics, 33(4), 285-295. doi:10.1119/1.1971474

Semenov, M. E., Shevlyakova, D. V., \& Meleshenko, P. A. (2013). Inverted pendulum under hysteretic control: stability zones and periodic solutions. Nonlinear Dynamics, 75(1-2), 247-256. doi:10.1007/s11071-013-1062-x

Stephenson, A. (1908). On induced stability. Philosophical Magazine Series 6, 15(86), 233-236. doi:10.1080/14786440809463763

Zhao, J. \& Spong, M.W. (2001). Hybrid control for global stabilization of the cartpendulum system, Automatica, 37(12), 1941-1951. doi:10.1016/S00051098(01)00164-9. 


\title{
Facebook usage by students in higher education
}

\author{
N.F. Wesseling* \\ * Amsterdam University of Applied Sciences (the Netherlands) \\ n.f.wesseling-weijers@hva.nl
}

\begin{abstract}
In this paper I measure first year student Facebook usage as part of a broader $\mathrm{PhD}$ study into the influence of social media usage on the success of students in higher education. A total of 906 students were asked to complete 3 surveys on Facebook usage with their peers, for two consecutive years (2011-2012 and 2012-2013). The different purposes for Facebook usage, in addition to whether or not students used (self-created) Facebook-groups, were measured and the relationship between the use of pages compared to the purpose of Facebook usage. This resulted in significant correlations between the purpose of Facebook usage and the use of different pages, as well as correlations between the purpose and use of different pages. This study hereby explores the variation in student Facebook usage and provides valuable insight into the potential value of Facebook for students in an educational setting, without the interference of teachers. It is also the next logical step in revising existing integration and engagement theories that predict student success in higher education in contemporary society.
\end{abstract}

Keywords: Facebook, student success, higher education, social network site, integration theory, engagement.

\section{Introduction}

This study measures Facebook usage between first year students in the Department of Media, Communication and Information, at the Amsterdam University of Applied Sciences for two consecutive years (2011-2012 and 2012-2013 later referred to as 2011 and 2012), and forms part of my $\mathrm{PhD}$ research into the potential correlation between social media usage and the success of first year students in higher education.

Research into student success in the Netherlands is greatly influenced by Tinto's integration theory $(1975,1993)$, in which he states that the more a student is integrated, the less chance there is of attrition. However, this integration theory dates back to the late 1970's and is based on the American situation, and thus requires adjusting to reflect the contemporary Dutch situation. Whilst Tinto ascribes a positive influence to campuses in comparison to commuting colleges for example, such residential institutions rarely exist in the Netherlands. He states that commuting colleges don't benefit from a significant on-campus community and argues that these students are likely to spend less time interacting with fellow students (Tinto, 1993), compared to residential students.

However, in contrast to the American '80/'90's situation, modern Dutch students enjoy new ways of interacting with their peers, without necessarily being physically present at the institute. Indeed, the way in which most of us interact has changed significantly in the last 7 years, with Ping, WhatsApp and social media platforms, such as Facebook (FB) and Twitter, all emerging. And, although FB isn't the only social network site (SNS); it's by far the most popular amongst students (Hargittai, 2008; Junco, 2012c; Special \& Li-Barber, 2012; Wesseling, 2012a).

\section{Facebook and Education}

Research into the influence of FB on education has increased in line with its growth. Some studies into FB usage focused on the potential difference in students' average grade point (GPA) between FB users and non-users (Kirschner \& Karpinski, 2010; 
Kolek \& Saunders, 2008). Others centred on the difference between time spent on FB per day or week, and/or the number of applications and groups used (H.E.R.I., 2007; Heiberger, 2008; Junco, 2012d; Kirschner \& Karpinski, 2010; Wohn \& LaRose, 2014), or frequency of use of different activities (Junco, 2012c, 2012d). A few studies also measured the influence of FB usage in class or during study (multitasking) (Junco, 2012a, 2012b; Rosen, Carrier \& Cheever, 2013). And almost every study compared FB usage with the amount of time and effort a student spent in educational activities (H.E.R.I., 2007; Heiberger, 2008; Junco, 2012c, 2012d; Kirschner \& Karpinski, 2010). However, these studies were inconsistent in their findings. 'The Higher Education Research Institute (2007) and Heiberger's (2008) study both found a positive correlation between time spent on FB and student engagement. Kirschner (2010), Junco (Junco, 2012c, 2012d) and Wohn \& LaRose (2014) on the other hand, found a negative correlation to the hours spent on FB when compared to overall GPA. In the latter this relationship was negligible. Junco also found, a) a negative correlation between the frequency of posting updates on FB and GPA and, b) the higher the frequency of chat function usage, the less time a student spent studying. However, he found a positive correlation between checking friends on FB and GPA. In two additional studies, Junco (2012a, 2012b) found that, when used as a multitasking tool, FB had a negative influence on GPA' (Wesseling, in review).

A potential explanation for the contradictory results in the above-mentioned studies, is that they each measured FB usage in their own individual way. They did, however, all focus on the quantitative aspects of FB usage. As proposed in a previous paper (Wesseling, 2012b), I on the other hand measure FB usage not by quantity or amount of time spent, but rather by quality of usage (determined via the categorisation of the purpose of FB usage). Furthermore, this study focuses exclusively on contact between students, without teacher contact, initiation, coordination or participation, even as a silent member of a FB group or community. This is in direct contrast to other studies on FB usage and its engaging factor, where teachers and students do have FB contact in one form or another (Bosch, 2009; Çoklar, 2013; De Villiers, 2013; Ivala, 2012; Rambe, 2011, 2014) - studies that do reveal an engaging factor of FB within education.

\section{Methods}

Although I focus on the quality of FB usage, this doesn't imply that my study employs a qualitative method. On the contrary, the data is gathered from selfreported FB usage by students. All first-year students in the Department of Media, Communication and Information at Amsterdam University of Applied Science were sent digital surveys with fixed answer categories for two consecutive years (2011 and 2012). In both years 904 students were enlisted at the beginning of the year. Each student was supplied with three Google doc surveys throughout the college year (from September to July). The data from these surveys was subsequently downloaded into an SPSS file using Microsoft Excel. After screening for anomalies ${ }^{1}$, it was then analysed using PASW (formally SPSS) Statistics 22.0. Although the surveys were part of a career-counselling program, not all students participated.

\footnotetext{
1 Some students filled out the survey more than once. In those cases the last entry was used independent of the answers given.
} 
This led to a diminished participation during the course of the year ${ }^{2}$. All three surveys remained unchanged in the second year, except for the distribution timing of the third survey. They were sent via email to student addresses provided by the Institution.

The first survey (conducted in January 2012 and 2013) measured general student FB usage. The second survey investigated the way in which students communicate with each other and whether or not they use FB for communication with other students and if so, whether they use individual pages: 1) project group (6-9 students per group), 2) class page (+/- 30 students per class) and 3 ) year page (all first year students, max. 904). The purpose of FB usage was measured using four different categories: 1) information sharing (receiving/providing information and generating ideas), 2) sharing for educational purposes (for learning, problem solving and sharing of work), 3) social purposes (retrieving personal information about others or themselves, to chat, make appointments and generally keep in touch), 4) leisure (gaming and relaxation). The third survey, conducted in May/June (2011 cohort) and in April/May (2012 cohort), additionally measured the use of different FB pages.

\section{Results and Discussion}

The students identified Ping and WhatsApp as the most popular services. Indeed, in 2011 and 2012, some $51.9 \%$ and $88.4 \%$ of respondents respectively specified these as their preferred method for contacting other students. However, the surveys also revealed that students use FB for such contact. For the 2011 cohort, some 95.3\% of respondents had contact with other students via FB, whilst in 2012 the percentage increased still further to $98.5 \%$. As the year progressed the percentages of various FB pages used by students also increased. Over the two consecutive years, project page use increased from $37.2 \%$ to $89 \%$ (2011), and $58.1 \%$ to $88.4 \%$ (2012). The class page appeared somewhat less popular in 2011; increasing from $24.5 \%$ to $57.2 \%$. However, as it was mandatory to join the class page in the 2012 career-counselling module, the two years were not compared. Finally, the first year page witnessed the largest rise in 2011; from $8.3 \%$ to $71.0 \%$, and in 2012 ; from $16.8 \%$ to $74.6 \%$. Clearly, students use FB for contact with each other, without either encouragement from, or request to do so by teachers.

In 2011, some $76.9 \%$ of students used SNS for social purposes, and in 2012, some $68 \%$. FB usage for the purpose of exchanging information was $72.6 \%$ and $91.7 \%$ for both years respectively. In 2011, some $57.6 \%$ of students used FB for educational purposes, whilst in 2012 this grew to $66.6 \%$. Leisure recorded the lowest score: just $24.8 \%$ and $8.5 \%$ respectively.

The purpose of FB usage was tested for any correlation to the use of different FB pages, using Spearman's rho (one-tailed), displayed in table $1^{3}$. As shown in the third

\footnotetext{
${ }^{2}$ When taking into account the number of dropouts (voluntarily or mandatory due to insufficient study results) the percentages of participants in 2011 were: 88.94\% in September 2011 (804 out of 904 students), 76.50\% in January 2012 (599 out of 783 students) and 55.11\% in June 2012 (415 out of 744 students). In 2012 the percentages were: 85.73\% in September 2012 (775 out of 904 students), 59.34\% in January (432 out of 728 students) and 39.88\% in April (276 out of the 692 students).

${ }^{3}$ Due to the limited number of pages available, all output related to this correlation has been compiled in one table.
} 
column of table 1, there's both a demonstrable positive and negative correlation between the purpose of FB usage and the use of different FB pages. With a correlation coefficient of 0.300 , the most significant $(\alpha=0.01$ ) positive relationship in 2011was found between FB usage for educational purposes and the membership of a FB project group page.

Table 1. Correlation purpose of Facebook usage and contact by Facebook and the use of pages survey 2 in (January), 2011 and 2012.

\begin{tabular}{|c|c|c|c|c|c|c|}
\hline $\begin{array}{l}\text { Purpose of } \\
\text { Facebook } \\
\text { usage }\end{array}$ & $\begin{array}{l}\text { Facebook } \\
\text { contact and } \\
\text { pages }\end{array}$ & $\begin{array}{l}2011 \\
\text { Spearman's } \\
\text { rho }\end{array}$ & $\begin{array}{l}2012 \\
\text { Spearman's } \\
\text { rho }\end{array}$ & $\begin{array}{l}\text { Correlation within purpose, } \\
\text { between contact \& page use \& } \\
\text { within page use }\end{array}$ & $\begin{array}{l}2011 \\
\text { Spearman's } \\
\text { rho }\end{array}$ & $\begin{array}{l}2012 \\
\text { Spearman's } \\
\text { rho }\end{array}$ \\
\hline Information & Contact & $0.179 * *$ & 0.009 & Information /Education & $0.501^{* *}$ & $0.150 * *$ \\
\hline Information & Project page & $0.227 * *$ & -0.010 & Information/Social & -0.024 & $0.280 * *$ \\
\hline Information & Class page & $0.250 * *$ & $0.144 !^{* *}$ & Information/Leisure & $-0.126 * *$ & 0.000 \\
\hline Information & Year page & $0.106 * *$ & 0.068 & Education/Social & 0.030 & $0.177 * *$ \\
\hline Education & Contact & $0.181^{* *}$ & 0.030 & Education/Leisure & -0.027 & 0.072 \\
\hline Education & Project page & $0.300 * *$ & $0.146 * *$ & Social/Leisure & $0.316^{* *}$ & $0.151^{* *}$ \\
\hline Education & Class page & $0.225^{* *}$ & $-0.015 !$ & Contact/Project & $0.192 * *$ & $0.081^{*}$ \\
\hline Education & Year page & $0.077 *$ & 0.051 & Contact/Class & $0.114 *$ & $0.200 ! * *$ \\
\hline Social & Contact & $0.177^{* *}$ & -0.017 & Contact/Year & $0.159 * *$ & 0.032 \\
\hline Social & Project page & 0.045 & $0.115^{* *}$ & Project/Class & 0.051 & $-0.182 !^{* *}$ \\
\hline Social & Class page & -0.040 & $0.137 ! * *$ & Project/Year & -0.013 & $-0.370 * *$ \\
\hline Social & Year page & $-0.090 * *$ & $0.079 *$ & Class/Year & 0.048 & -0.026 \\
\hline Leisure & Contact & 0.046 & $-0.106 *$ & & & \\
\hline Leisure & Project page & $-0.199 * *$ & 0.009 & & & \\
\hline Leisure & Class page & $-0.098 *$ & $0.077 !$ & & & \\
\hline Leisure & Year page & 0.013 & 0.037 & & & \\
\hline
\end{tabular}

Other correlations greater than $0.199(\alpha=0.01)$ in 2011 were found between: FB usage for information sharing and a) membership of a class page $(0.250, \alpha=0.01)$ and b) membership of a project page $(0.227, \alpha=0.01)$, FB for educational purposes and membership of a class page $(0.225, \alpha=0.01)$. The most negative correlation coefficient $(-0.199, \alpha=0.01)$ in 2011 was found between FB usage for leisure purposes and contact via a project page. There are also correlations between the various categories of FB usage. The most powerful correlation of all, however, was not between the purpose of FB usage and the use of a particular page, but rather between $\mathrm{FB}$ usage for education and information (0.501, $\alpha=0.01)$. Another demonstrable correlation exists between $\mathrm{FB}$ usage for leisure and social $(0.316, \alpha$ $=0.01$ ). These figures are even more compelling when taking into account the negative correlation between FB usage for leisure and FB usage for information ($0.126, \alpha=0.01)$.

Table 2 (column three) displays correlations between the purpose of FB usage, measured in the second survey (January 2012), and contact via FB and the use of pages in the third survey (June 2012). None of the correlations are greater than 0.199. The strongest of these weaker correlations exists between the use of a FB project page and information sharing $(0.172, \alpha=0.01)$. Other weak correlations exist between: project page and education- $(0.124, \alpha=0.05)$ and social use $(0.130, \alpha=0.01)$; the use of a class page and information $(0.112, \alpha=0.05)$ and education $(0.115, \alpha=0.05)$ and social 
$(0.116, \alpha=0.05)$; contact via FB and the use of a project page $(0.192, \alpha=0.01)$, class page $(0.114, \alpha=0.05)$ and year page $(0.159, \alpha=0.01)$.

Table 2. Correlation between purpose of Facebook usage and contact by Facebook and the use of pages. Purpose of Facebook usage taken from survey 2 in 2011 and 2012, contact and page use taken from survey 3 in 2011 and 2012.

\begin{tabular}{|c|c|c|c|c|c|c|}
\hline $\begin{array}{l}\text { Purpose of } \\
\text { Facebook } \\
\text { usage (survey } \\
\text { 2) }\end{array}$ & $\begin{array}{l}\text { Facebook contact } \\
\text { and pages (survey } \\
\text { 3) }\end{array}$ & $\begin{array}{c}2011 \\
\text { Spearman's rho }\end{array}$ & $\begin{array}{c}2012 \\
\text { Spearman's rho }\end{array}$ & $\begin{array}{l}\text { Correlation within } \\
\text { contact and page } \\
\text { use survey } 3\end{array}$ & $\begin{array}{c}2011 \\
\text { Spearman's rho }\end{array}$ & $\begin{array}{c}2012 \\
\text { Spearman's rho }\end{array}$ \\
\hline Information & Contact & 0.061 & 0.032 & Contact/Project & $0.192 * *$ & 0.071 \\
\hline Information & Project page & $0.172 * *$ & -0.006 & Contact/Class & $0.114 *$ & 0.142 !** \\
\hline Information & Class page & $0.112 *$ & $-0.022 !$ & Contact/Year & $0.159 * *$ & $0.100 *$ \\
\hline Information & Year page & 0.039 & $0.141^{*}$ & Project/Class & 0.051 & -0.027 \\
\hline Education & Contact & 0.037 & 0.038 & Project/Year & -0.013 & 0.049 \\
\hline Education & Project page & $0.124 *$ & -0.002 & Class/Year & 0.048 & $0.145^{* *}$ \\
\hline Education & Class page & $0.115^{*}$ & $-0.114 !$ & & & \\
\hline Education & Year page & -0.011 & 0.032 & & & \\
\hline Social & Contact & $0.125^{*}$ & 0.102 & & & \\
\hline Social & Project page & $0.130 * *$ & 0.108 & & & \\
\hline Social & Class page & $0.116^{*}$ & $-0.028 !$ & & & \\
\hline Social & Year page & $0.109 *$ & 0.090 & & & \\
\hline Leisure & Contact & 0.068 & 0.037 & & & \\
\hline Leisure & Project page & -0.077 & $0.120^{*}$ & & & \\
\hline Leisure & Class page & -0.045 & $0.070 !$ & & & \\
\hline Leisure & Year page & 0.082 & 0.057 & & & \\
\hline
\end{tabular}

Although the correlation between FB usage for educational purposes and the membership of a Facebook project group page is weaker in 2012 (see table 1), it's also the strongest correlation found that year; $0.146(\alpha=0.01)$. Unlike 2011, the strength of this and all other significant correlations is less than 0.199. However, this is not the case for the correlation between the use of different pages and purposes. The greatest correlation for the use of different pages is found between social and information $(0.280, \alpha=0.01)$. Remaining correlations of note are less than 0.199 (social/education; 0.177, $\alpha=0.01, \quad$ social purposes/leisure; $0.151, \quad \alpha=0.01$, education/information; 0.150, $\alpha=0.01$ ). Although negative, the second strongest correlation thus far, is between the use of a project- and a year page $(-0.370, \alpha=0.01)$. The use of FB for contact has a positive correlation with the class page $(0.200$, $\alpha=0.01$ ). The weak, yet negative correlation between the use of a project- and class page $(-0.182, \alpha=0.01)$ in 2012 is unexpected, especially bearing in mind the mandatory membership of a class page as part of the career-counselling program that year. The correlations between purpose of FB usage (measured in the second survey) and contact via FB and the use of pages (in the third survey) are also displayed in table 2 (column seven). Again, in 2012, none of these correlations are greater than 0.199 . 


\section{Conclusions}

Certain correlations were expected, such as FB usage for educational purposes and the use of a project page; the positive correlation between education and information and the use of a class and a year page; contact via FB and its use for education and information; the use of a project and a class page with education and information. It's also not surprising that social purposes positively correlate with contact and use of different pages. When accompanied by the negative correlation between, 1) leisure and a), the use of a project and, b) of a class page in 2011 and, 2) between leisure and FB contact in 2012, it appears that those using FB for educational purposes, do so via their FB page and project page; those using FB for leisure purposes on the other hand, make less use of a project or class page. The negative correlation in the second survey of 2012, between the use of a project page and a year page, and the slightly negative correlation with class page, supports the notion that those using FB in small groups (project) don't use year or class pages. These correlations do, however, provide an even greater incentive for measuring SNS activities, particularly if one wishes to accurately predict student success using (elements of) the integration and engagement theory. Furthermore, those less positive correlations found in 2012, when membership of a class page was mandatory, and the negative correlations between the use of a class page and contact between students, membership of a project page and FB usage for social purposes, demonstrate that Facebook isn't necessarily a positive influence on education. One might even go as far as to suggest that teachers shouldn't interfere, by keeping 'their' tools separate, or by using another platform with the same capabilities, which is more informal and less distracting.

\section{References}

Bosch, T. E. (2009). Using online social networking for teaching and learning: Facebook use at the University of Cape Town. Communicatio: South African Journal for Communication Theory and Research, 35(2), 185-200.

Çoklar, A., N. (2013). Evaluations of students in Facebook as an educational environment. Turkish Online Journal of Qualitative Inquiry, 3(2), 42-53.

De Villiers, M. R., Pretorius, M.C., Nagle, T., Sammon, D. (2013). Evaluation of a Collaborative Learning Environment on a Facebook Forum. The Electroninc Journal Information Systems evaluation, 16(1), 56-70.

H.E.R.I. (2007). College freshman and online social networking sites: Higher Education Research Institute.

Hargittai, E. (2008). Whose Space? Differences Among Users and Non-Users of Social Network Sites. Journal of Computer-Mediated Communication, 13(1), 276-297. doi: 10.1111/j.1083-6101.2007.00396.x

Heiberger, G. H., R. (2008). Have you Facebooked Astin lately? Using technology to increase student involvement. In R. T. Junco, D.M. (Ed.), Using emerging technologies to enhance student engagement. New Directions for Student Services (Vol. 124, pp. 19-35). San Francisco, CA: Jossey-Bass.

Ivala, E., Gachago, D. (2012). Social media for enhancing student engagement: the use of Facebook and blogs at the University of Technolojgy South African Journal of Higher education, 26(1), 152-167. 
Junco, R. (2012a). In-class multitasking and academoc performance. Computers in Human Behavior, 28, 2236-2243. doi: 10.1016/j.chb.2012.06.031

Junco, R. (2012b). No A 4 U: The relationship between multitasking and academic performance. Computers \& Education, 59, 505-514. doi: 10.1016/j.compedu.2011.12.023

Junco, R. (2012c). The relationship between frequency of Facebook use, participation activities, and student engagement. Computers \& Education, 25, 162-171. doi: 10.1016/j.compedu.2011.08.004

Junco, R. (2012d). Too much face and not enough books: The relationship between multiple indices of Facebook use and academic performance. Computers in Human Behavior(28), 187-198. doi: 10.1016/j.chb.2011.08.026

Kirschner, P. A., Karpinski, A.C. (2010). Facebook and academic performance. Computers in Human Behavior, 26(1237-1245).

Kolek, E. A., Saunders, D. (2008). Online disclosure: An empirical examination of undergraduate Facebook profiles. NASPA Journal, 45(1), 1-25.

Rambe, P., Ng'ambi, D. (2011). Towards an information sharing pedagogy: A case of using Facebook in a large first class. Informing Science: the International Journal of an Emerging Transdiscipline, 14, 61-89.

Rambe, P., Ng'ambi, D. (2014). Learning with and from Facebook: Uncovering power asymmetries in educational interactions. Australian Journal of Education Technology, 30(3), 312-325.

Rosen, L. D., Carrier, L.M., Cheever, N.A. (2013). Facebook and texting made me do it: Media-induced task-switching while studying. Computers in Human Behavior, 29, 948-958. doi: 10.1016./j.chb2012.12.001

Special, W. P., Li-Barber, T.K. (2012). Self-disclosure and student satisfaction with Facebook. Computers in Human Behavior(28), 624-630. doi: 10.1016/j.chb.2011.11.008

Tinto, V. (1975). Dropout from higher education. Review of Educational Research, 45(1), 89-125.

Tinto, V. (1993). Leaving College: Rethinking the Causes and Cures of Student Attrition (Rev.ed) (2 ed.). Chicago: University of Chicago Press.

Wesseling, N. F. (2012a). Differences in computer usage and background variables of first year students in higher education. Paper presented at the 6th annual International Technology, Education and Development Conference, Valencia, 5-7 March, Spain.

Wesseling, N. F. (2012b). How students use Facebook. Paper presented at the WEI International European Academic Conferennce Proceedings, Zagreb 14-17 September, Croatia.

Wesseling, N. F. (in review). New ways of engagement in higher education. The International Journal of Technology, Knowledge and Society.

Wohn, D. Y., LaRose, R. (2014). Effects of loneliness and differantial usage of Facebook on college adjustment of first-year students. Computers \& Education, 76, 158-167. doi: 10.1016/j.compedu.2014.03.018 


\title{
Formative Learning Evaluation of university students as success factor
}

\author{
Olga Bombardelli \\ University of Trento (Italy)
}

\begin{abstract}
This paper deals with the impact of formative evaluation on the learning success of the university students. A lot of young people interrupt their academic career before the end of it or meet big delays and demotivation. That is due to many reasons; one of them is the lack of clear understanding of the expected outcomes. The aim of this paper is considering how a formative evaluation process with clear indicators for transversal skills together with consistent teaching forms may help students to reach the main aims of university studies. I'll focus on competences as learning to learn, scientific and critical thinking, initiative and entrepreneurship, active citizenship, communication and social skills. Different ways of assessing lead to reach different aims. This contribution includes an ongoing study, describes data drawn from the use of a portfolio and from a qualitative questionnaire with closed and open questions for self assessment filled-in by the students of the subject area group "Citizenship Learning" at the University of Trento. Intermediate results highlight the importance of articulating learning goals explicitely for improvement of the students outcomes.
\end{abstract}

Keywords: University teaching and learning; formative assessment; transversal competences; empowerment

\section{Introduction}

The present paper is motivated by the belief that all students should be equipped with the knowledge, skills, work habits, and character traits they will need to pursue good results in their studies and challenging careers after graduation, and that a failure to adequately prepare students effectively denies them opportunities, with potentially significant consequences for them and for our economy, democracy, and society. A complex mix of factors act upon, and are embedded in empowerment of students boths through teaching/ evaluation strategies and student-faculty interactions. The aims of university learning included in the Dublin Descriptors (2004) remind the need of a balanced development of learning.

Assessment is a crucial part in the acquisition of key competences but most current assessment methods have a strong emphasis on knowledge and do not sufficiently capture transversal skills and the attitudes of key competences, while these are regarded as increasingly important for 21st century learning. In this paper I discuss the importance of formative evaluation for sussessful learning and present a good practice in the use of a portfolio by students.

Methods of this paper are partly recognition of the most relevant studies on the topic choosing them according to the practicability and the efficacy of the proposals in the daily teaching experience, referring to international official documentation as well, and partly are linked to use of formative evaluation at the University of Trento based on the outcomes of an European Comenius project: ECLIPSE (European Citizenship Learning in a Programme for Secondary Education), conducted in the years 2011-2014 by six European partners (Germany, Italy, Portugal, Romania, Spain, UK). The methodology includes the use of qualitative formative assessment tools like portfolio and self evaluation questionnaire, keeping in mind that different ways of assessing lead to reach different aims in the enacted curriculum, and that evaluation forms are in interaction with teaching methods and with the curricula development. 
Assessment is the process instructors gather data about their teaching and their students' learning (Hanna \& Dettmer, 2004). There are formative, and summative assessment procedures. The goal of formative assessment is to monitor student learning to provide ongoing feedback by instructors, helping students to identify their strengths and weaknesses.

Summative Assessments has the goal to evaluate student learning by comparing it against some standards at the end of an instructional unit whereas no further revisions can be made. Types of Summative Assessment are mid-term exams, final examination (in oral or written form), tests at the end of course units, term papers, final projects, and presentations. Grades are usually an outcome of summative assessment: they indicate whether the student has an acceptable level of knowledge-gain.

Formative evaluations differ from summative exams which provide a static picture of students' learning and do afford students opportunities to adjust their study habits; it is confidential, ungraded and informal, and not used for purposes of tenure or promotion decisions. Such evaluation is typically conducted during the development or improvement of a program or course; it is accompanied by instructional feedback that enables students to make learning adjustments and improve future work.

\section{Aims and Educational strategies}

The assessment of transversal skills is mostly done in implicit form. Teachers ask for transversal skills, anyway most of them pay insufficient attention to clarify what they appreciate and neglect developing them esplicitely. Althoughs several main skills are not easy to define teachers should be able to articulate learning goals more intentional, especially about teaching cross-disciplinary skills. For example, in a science course students might be required to learn research methods that can also be applied in other disciplines.

Discussion and exchange among teaching persons help agreement, while the specific skills may be defined, categorized, and determined differently from person to person, and that is confusing for learners. In turn, students can benefit from frequent and thoughtful feedback that promotes their own self-awareness and self-regulation of their learning process. Formative evaluations encourage an ongoing, reciprocal exchange between faculty and student(s) that can move students toward self-monitoring of their work and intellectual persistence; it encourages students to learn from mistakes and empower them for self-efficacy.

Learning success requires the acquisition of the fundamental basic skills such as literacy, numeracy skills, the analysis and summary abilities, the written and oral communication or the ability to organize and plan the work. Articulating general, technical, and scientific concepts in verbal, written, and graphic forms, or using sophisticated technologies, software programs, and multimedia applications are an extension of the expected outcomes.

Skills refer to a broad set of knowledge, work habits, and character traits that are believed by educators, parents, employers, and others to be critically important in today's world. Transversal skills like (A) learning to learn, included scientific culture, and (B) entrepreneurship are now increasingly needed. Very important is the development of attitudes and dispositions like (C) active citizenship, (D ) social, and intercultural competence (respect for diversity: gender, cultures, religion, age, learning styles etc.), cross-national perspektives replacing stereotypes, developing a sense of belonging to one's own community, and to the world.

(A) Learning to learn is the ability to organise one's own learning, effective 
management of time and information. This competence includes awareness of one's learning process and needs, identifying available opportunities, and the ability to overcome obstacles in order to learn successfully. It means gaining, processing and assimilating new knowledge and skills as well as seeking and making use of guidance. It requires an individual to know and understand his/her preferred learning strategies, the strengths and weaknesses of his/ her skills and qualifications, and to be able to search for the education and training opportunities and guidance (Recommendation 2006/962/EC).

This requires effective management of one's learning, career and work patterns, and, in particular, the ability to persevere with learning, to concentrate for extended periods and to reflect critically on the purposes and aims of learning. Individuals should be able to dedicating time to learning autonomously and with self-discipline, but also to work collaboratively as part of the learning process, draw the benefits from a heterogeneous group, and to share what they have learnt. A positive attitude includes the motivation and confidence to pursue and succeed at learning throughout one's life, the desire to apply prior learning and life experiences and the curiosity to look for opportunities to learn.

(B ) Initiative and entrepreneurship include self knowledge, and self-planning, problem solving, coping with ambiguity, assessing risks, informed decision-making;

(C ) Education for active Citizenship includes knowledge of contemporary events, as well as the main events and trends in national, European and world history. In addition, an awareness of the aims, values and policies of social and political movements should be developed.

Responsible citizenship means participation, information, for the personal life, and for democracy. It implies supporting pupils to develop the competences of acquiring information, using appropriate data from a range of sources, selecting, interpreting, and evaluating them (autonomy in looking for information, choosing sources, awareness of different points of views, precision, etc.).

(D) Social competentce requires skills for working with others, conflict prevention and solution, participating in the social life with a supportive attitude, showing personal and group involvement Propose solutions that require their involvement as individuals and as a group, caring for community assets.

There is a need to a profound and lasting change in teaching methodologies. Competence-based teaching/ learning goes hand in hand with developing transversal competences as well, besides providing information. Educational strategies such project-based learning tend to be cross-disciplinary in nature, and students may have to use a variety of applied skills, and new ways of analyzing and processing information, while also taking initiative, thinking creatively, planning out the process, and working collaboratively in teams with other students.

Educational processes, curriculum content are thaught successfully with innovative teaching /learning methods, adopting strategies like interactive, experiential and reflexive learning, using a multi-perspective approach, to support students both to acquiring information, and to work with documented and coherent argumentation, linking formal and non formal learning. Useful are strategies like lecturing, interactive lectures, seminars, student-led seminars, group work, case studies, small group exercises, blended learning (MOOC ecc.), tutoring and peer tutoring, project work, caring for classroom discussions and open debates, giving reasoned arguments and motivation for the own opinions. Cooperative learning and jigsaw technique allow the students to assume some responsibilities as a member of a group; enquiry tasks for 
students, interviews, school journals on line, work experiences are very helpful for the development of competences.

Curriculum materials and resources, media inputs (films, TV, videos, radio, Internet, newspaper, books, games), teaching tools like maps, schoolbooks, fotocamera, etc. are useful to support teaching. Essential is media literacy (search and selection of information on the topics, interpreting the media messages, use of the media in an active way as a producer of media content).

The working climate, the daily practices refer mainly to a system of attitudes, values, norms, beliefs, principles, rules, teaching methods and organizational arrangements which have to be consistent with the desired aims.

Exchange of good practices among professors in the different countries improves evaluation practices as well, analysing testing materials, and developing new ones. Students in different places can perfom bilateral work including discussions and production of common results. Cooperation among the schools can take place face to face, with meetings and visits, and on line in videoconference and webinars, pen/ mail friendships etc.; of course ICT teaching is not expected to substitute face to face teaching.

\section{Formative Assessment}

The old maxim “if it isn't tested it isn't taught” is quite true. For the learners, assessment shows what is valued as a learning outcome. The assessment methods have a major influence on how the key competences are taught, and therefore, on what learners learn (Looney, 2009).

The way in which the outcomes have been agreed upon, described and assessed, may influence what the learners are motivated to achieve. However, some assessment practices may damage motivation and self-esteem, especially for 'low-achievers'.

Some strategies of assessment stress passive repetition, on the contrary independent learning implies a real understanding of the learning process by the students (metacognition). Self knowledge, and self-planning include awareness of their own skills by the learners, improving their self confidence, fostering the interest and the energies in a gradually self-regulating plan (ex. the student portfolio). The teacher will report back to the students about the results of the evaluation, providing feedback during the instructional process, while learning is taking place. Formative assessment also helps to identify the intended outcomes as well as any unintended outcomes of instruction, and are basis to ensure that students have sufficient opportunities to achieve them.

Assessment involves a variety of methods and techniques. Formative Evaluation of Student Learning includes any form of classroom interaction that generates information on student learning, which is then used by faculty and students to fine-tune their teaching and learning strategies.

Types of Formative Assessment are formal and informal, especially: (a) observation, (b) interaction, (c) production of midterm outcomes, (d) selfevaluation forms:

(a) Teachers practice direct observation of in-class activities (teamwork, the way pupils organize work), of students' skills and attitudes, and the product, with the aid of records and rating scales of observation, check lists, assessment scales.

(b) Informal and structured mid-term feedbacks ensure students thet they are on track. It can be formative oral interviews, 'question and answer sessions', both formal, planned and spontaneous, discussion board responses (on content-specific prompts), directed paraphras after working through a topic, asking students to explain the content to a lay audience in their own words. An instructor can do his/her own formative 
assessment by having students respond to a mid-term questionnaire. Pre-tests on content and abilities (including several types of questions: multiple-choice, true-false etc.), clickers may be used as well.

As the time is very short in the University modules, lecurers may use 'one-minute papers', checking student understanding in a lesson by asking them to take out a sheet of paper and take one minute to, for example, write down an explanation of a concept, or submit one sentence identifying the main point of a lecture.

Techniques like polls/surveys gathering of data on student opinions, attitudes, or confidence in understanding, even online, can help students develop skills to monitor their own learning; lecture wrappers are questions at the beginning of class about what students anticipate getting out of a lesson and/or questions at the end of class about the key points of the lesson.

(c) In-class activities, class deliverables are opportunities where students informally present their results. Open book questions give the chance to assess not only what students remember and allow to check how they are able to use information and to perform organized and systematic reasoning. Homework exercises and homework wrappers include questions about students' confidence in applying their knowledge and skills both before and after completing an assignment. Having students work in pairs or small groups to solve problems creates space for powerful peer-to-peer learning. Alternative forms of work and formative assessment are preparing an exhibition, a poster, reflections journals; filming and exchanging DVD, Podcasts, etc.

(d ) Self-assessments forms, identifying skills and competencies, can be face to face or developing a portfolio as a way for students to see their progress. Instructors can roam the classroom as students work, helping those who get stuck and guiding those who are headed in the wrong direction.

Diagnostic strategies can help teachers to identify students' current knowledge of a subject, their skill sets and capabilities, and to clarify misconceptions; they facilitate the evaluation of competences for the student, as they clearly perceive the different dimensions that are being evaluated in each activity, increasing, with that, their academic performance.

\section{An example of formative assessment in education for citizenship: a portfolio}

Citizenship Education aims to the development of the students tranversal competences, gives information, encourages kritical knowledge, in order to avoid acritical adherence to a specific model. It is never indoctrination, instead it is an effort for reflexion and documented coherent decision making.

An European Comenius project ECLIPSE (European Citizenship Learning in a Programme for Secondary Education) (Bombardelli, Santana, 2014), which I coordinated, developed a Portfolio for the pupils as a monitoring tool, used in the six partner countries at least in three schools each. It helps pupils to think about their own development focussing on (1) Political Culture (I know my rights and responsibilities, I am aware of social and cultural diversity, I actively participate in democratic life), (2) European Citizenship (I know about the European Union, I understand the rights and duties of citizens); (3) Skills needed to co-exist (I can prevent conflicts and solve them non-violently, I can give opinions, discuss and debate, I can understand others and communicate well), Values needed to co-exist (I understand the importance of selfesteem, autonomy and responsibility, I have respect for others and reject discrimination), (4) Participation in local environment, I get involved in school and 
local community groups, I participate in sports teams, citizenship and solidarity associations), (5) Entrepreneurship (I show initiative and autonomy, I can communicate and co-operate in a team, (6) Active learning and self-planning (I can plan, manage and organise my time, I can take constructive criticism).

The ECLIPSE portfolio has been revised for the level of University students, and has been used at the University of Trento; about the effectiveness of this work students answered a questionnaire/ selfevaluation sheet, focussing mainly on learning processes; the major outcomes are measured through group discussion as well, integrated by individual dialogue when it has been asked for by the students. Respondents are twenty students from different geographic areas; as result about $90 \%$ declared the high impact of the portfolio on their learning, while $10 \%$ of them required extra help to understand what they were expected to perform.

The outcomes of education for citizenship are difficult to be assessed; I provide here general tabular results (Table 1).

Table 1. Level of learning confidence by the students in the 6 sections of the portfolio

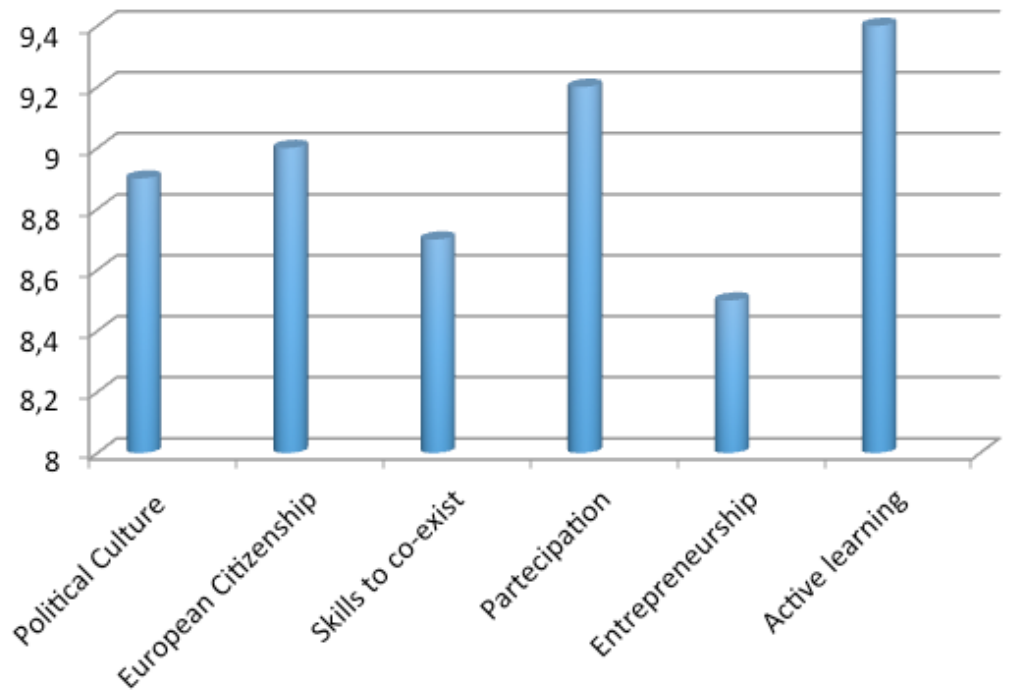

Monitoring transversal skills (e.g. learning processes: memorising, selecting information, etc. s. http://events.unitn.it/ecein) and values developes the ability to identify one's strengths and weaknesses. The obtained results look promising, anyway the work of the performed study has been done with a small group; during the next years bigger groups of students will cooperate in this project. Until now we can say that this approach has given better results in term of grading at the end of the module, which can be explained both by more interest by the involved students and by more detailed clarification of the transversal skills through formative evaluation.

\section{Conclusions}

While there is broad agreement that today's students need high skills, and that crossdisciplinary competences such as writing, critical thinking, self-initiative, active citizenship, and social skills are essential to success in higher education, in modern workplaces, and adult life, there is still a compliance gap among needs and results in tertiary education. Clear explanation of indicators to reach the main aims and formative evaluation help students to understand clearly what they are ecpected to learn; benefits 
are more likely when evaluation techniques are accompanied by providing feedbacks and instruction.

The present study highlights that learning results at the University are higher when there is a clear conceptual framework of expected learning outcomes; it implies the need to develop further work concerning formative evaluation in relation to competence-based curricula. Teaching persons need to be convinced of the importance of this task, to know how to manage this new approach to learning, to master effective formative assessment approaches, and to be aware of the opportunity of explaining explicitely transversal skills and the ways of assessing them.

\section{References}

Anderman, E.M., Austin, C.C., and Johnson, D.M. (2002). The development of goal orientation. In: The Development of Achievement Motivation, ed. A. Wigfield and J.S. Eccles, 197-220. New York Academy Press.

Bombardelli, O. (2010). Education for responsible citizenship and sustainable development in Lifelong Learning and Active Citizenship, London: CiCe, 364-371.

Bombardelli, O. (2014). Learning citizenship competences: the project eclipse.

Bombardelli, O., Santana, L. (2014). European citizens are growing up. Madrid: EOS.

Dublin Descriptors (2004) http://www.tcd.ie/teaching-learning/academicdevelopment/assets/pdf/dublin_descriptors.pdf (last access January 2015).

ECLIPSE (European Citizenship Learning in a Programme for Secondary Education), eclipse.lett.unit.it

Hanna, G. S., Dettmer, P. A. (2004). Assessment for effective teaching: Using contextadaptive planning. Boston, MA: Pearson A\&B.

Recommendation of the European Parliament and of the Council of 18 December 2006 on key competences for lifelong learning (2006/962/EC).

Kerr, D., Sturman, L., Schulz, W., Burge, B. (2010). ICCS 2009 European report: Civic knowledge, attitudes, and engagement among lower-secondary students in 24 European countries. Amsterdam: IEA (International Association for the Evaluation of Educational Achievement).

Kingston, N., Nash, B. (2011). Formative Assessment: A meta-analysis and call for research. Educational Measurement: Issues and Practice, 30(4). 28-37.

Looney, J. (2009). Assessment and Innovation in Education: OECD Working Paper No. 24, Paris; OECD/CERI, 11-16. 


\title{
Game boards as a review tool: an experience with undergraduate engineering students
}

\author{
C. Ibáñez, R. Palma, D. Hernández-Figueirido \\ Department of Mechanical Engineering and Construction \\ Universitat Jaume I, Castelló de la Plana (Spain)
}

\begin{abstract}
The use of games with educational purposes has a lot of benefits since it creates attractive scenarios for learning combining different techniques like rewards, competitions or challenges. Computer games as a teaching instrument have been very popular among educators in the last years. However, some difficulties may arise to find the appropriate game given the specific aims of each subject which is more remarkable in higher education. Besides, the current reduced education budgets have led lecturers to search for alternatives. Game boards can be a good option since they have a low cost and can be easily customized. In the present work, an experiment carried out with undergraduate students of mechanical engineering at the Universitat Jaume I (Castelló de la Plana, Spain) is described. A questions game board created by the students was used as a review tool. During the course, the students proposed questions to be incorporated to the game working in groups. In the last session it was used in an organized competition among the students. Working in groups enhances communication and collaboration whereas using the elaborated game as a review tool help to summarize and reinforce essential concepts. In general, students were very interested and motivated to acquire new knowledge.
\end{abstract}

Keywords: board games; questions games; traditional games; engineering students; creating games

\section{Introduction}

The use of games with educational purposes has several advantages. Including games as a method for teaching encourage simultaneously collaboration and discussion and sharpen up students thinking. Besides, games can be used as review tools to summarize and reinforce essential concepts and information since they offer an attractive environment for information assimilation. According to Salies (2002) the interactive structure generated during a game improves the transfer of learning and presents social benefits for the student.

Traditionally the use of games has been more present in primary and high school classes maybe due to the ratio of students per class, but in the last years their use has been extended to the university frame. Games are very versatile and, as Sharp (2012) pointed out, they can fit in almost every subject creating original learning opportunities which accommodate the different learning styles of the students

Several authors, such as Hays (2005), Fisch (2005) and Katmada (2014), who carried out game-based experiences obtained encouraging findings: the students had very good disposition to realize the activity and appreciate learning activities based in games.

In addition, as Carlson remarked (2005), the new generation of undergraduate students is specially focused on new technologies. They get distracted easily, are impatient and exceptionally capable of multitasking. Therefore, keeping their attention and motivation during a whole class is a hard task which leaves educators in the position of looking for new learning techniques and innovative activities to encourage learning among their students as Sharp (2012) noted. Marzano (2007) identified this situation as an appropriate opportunity for educators to take advantage to generate enthusiasm, encourage competition and increase student engagement by 
means of the development of game-based activities which, at the same time, refocus their attention on the curriculum.

With regard to computer games and accordingly to Whitton (2012), there is no discussion about their benefits as a tool for teaching but it can be an expensive option when new software needs to be purchased or when it is necessary to develop new interfaces or graphics.

Due to the global financial crisis, education budgets are readjusted every academic year and educators suffer the pressure of reducing costs from their daily teaching practice. Besides the economic issue, another inconvenient that may arise during the election of a commercial game is finding the one which fits the specific content to be covered. Commercial games are in general designed with the aim of entertaining and rarely they match the educators expectations. In those cases, a good option for educators can be designing and developing their own games but, sometimes, the lack of programming skills and the development time required make it not possible to create computer games of an acceptable quality as explained Whitton (2012).

However, some authors like Baker et al. (2003) and Moseley (2011) suggested that, for those lecturers eager to implement their innovative ideas, a great alternative could be going back to traditional games. Board games is an excellent option since it only involves the ability of producing the components related to the game being developed but technical skills are not needed.

In particular, board games are suitable for multitude of different situations and allow students to recover the proximity and the face-to-face component of traditional games which provide so many benefits in terms of cooperative development and social skills.

This paper describes the experience of developing a questions game board and using it as a review tool. The game was developed by third grade undergraduate students along the duration of the course. The experiment was carried out in the subject of Industrial Constructions and Structures within the frame of the Mechanical Engineering degree at the Universitat Jaume I (Castelló de la Plana, Spain).

The aim of the activity was to create a game-based learning situation where the students were engaged in a project and were motivated to study. Besides, this project was also developed with the objectives of reinforcing the retention of concepts, developing skills to work in groups and also promoting healthy competition among the students as part of their preparation for their future career.

\section{Method}

The project planned is based on the principle of learning through questions game boards. However, in this case, there is a peculiarity since the students not only are going to reinforce their knowledge when playing the game; they are also the producers of the whole game and therefore they are going to study and practice while the game board is being elaborated.

The activity is developed during the semester when the course takes place and it finishes at the last session. Periodically, at the end of some of the lectures of the course, the students, working in groups, are asked to propose several questions related to the content of the course explained until that moment. 
At this point, the labour of the lecturer is checking the quality of the composition and assuring that the questions proposed and their corresponding answers are correct, giving to the students the proper feedback and indications if part of the elaborated material needs to be modified. Each group only knows its own questions. The remaining work deals with the elaboration of the board.

The agreement on the game rules is a very important part to avoid problems and conflicts in the future. If the game rules are agreed for all the students of the course, then all of them will be obliged to obey such rules.

Finally, to complete the experience, the last session of the course is dedicated to play the developed game. Once the game is over, the students are asked to give their opinions and suggestions about the experience to have the proper feedback. This will help the lecturers to focus their future efforts in the right direction.

\section{Results and Discussion}

The game board elaborated by the students as the final product of the activity is shown in Figure 1. As observed, it is a game board based on the Game of the Goose (a very popular game in Spain) but customized to integrate the game into the context of the subject. Thus, the game consists of 63 numbered spaces arranged in a spiral. The game is played by several teams formed by heterogeneous groups of students. Each team is represented in the board by a piece which is moved by throwing one dice.

Contrary to the traditional game, there are no spaces with gooses or other shortcuts to allow the players to move again. In this case, it is the students' level of knowledge what allow them to continue playing. If a team answers correctly the formulated question, it can move again and try to answer a new question. If the answer given to a question is not correct, the team loses its turn.

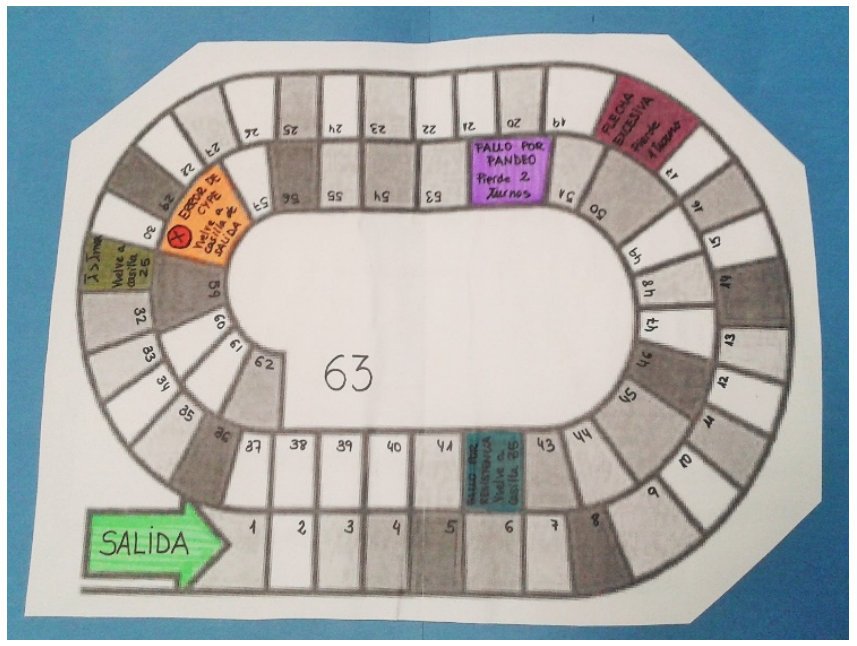

Figure 1. The game board elaborated.

There are some penalty spaces which make the players lose one or more turns if they land on them. Another type of penalty spaces are the ones that oblige the players to move back to a specified space or, in the case of landing in the most harmful, to move back to start.

The penalty spaces are represented by the typical types of failure that can occur in metallic structures. For instance, the space number 52 corresponds to "Buckling 
failure" and landing in it makes the players lose two turns; or the space number 42 is represented by "Cross-sectional resistance failure" and forces the players to move back to the space number 35 .

With regard to the number of students participating in the project, it is necessary to point out the next. The project was carried out during the spring semester of the academic year 2013-2014 and, at the beginning, the percentage of students attending the course was $85 \%$ (30 of the 36 enrolled students attended, in average). It was a really high percentage compared to the number of students attending the last sessions of the course, which was about $48 \%$ (the average number of attendees was 17).

The diminution on the number of students was due to the increase of the work density during the last weeks of the semester jointly with the proximity of the final exams. As a result, the final part of the activity, which dealt with the preparation of the board and the participation in the final competition, was followed by 17 students.

However, there was an increment in the percentage of students who attended the last sessions of the course with respect to the one registered in the academic year 20122013 when the activity was not performed. The percentage of students increased from $30 \%$ to $48 \%$. This shows the commitment of an important part of the students with the activity developed and the fact that it made them maintain their interest in the subject during the whole semester.

Regarding to the groups created during the course to elaborate the questions, they were composed in an informal way and were different each time with no fixed roles established. For the final competition, students formed heterogeneous teams by themselves, without any kind of restriction but the number of components.

In the present work, no quantifiable results about the student satisfaction with the experience were obtained since the activity was not evaluated but, on the contrary, feedback from the students in form of personal opinion and recommendations was collected.

In general, their opinions expressed that they were satisfied with the development of the activity. With regard to working in groups, some of them indicated that although it was an idea that did not motivate them at the beginning, finally they were comfortable with it since the task had been carried out in a relaxed environment. As usual in heterogeneous teams, some of the students were more passive than others but, in general, all of them were participating in the game.

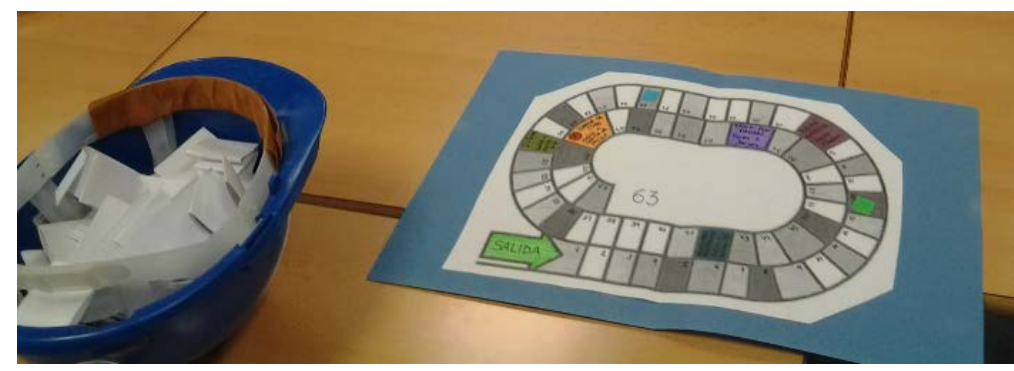

Figure 2. Left, redacted questions in a helmet as a wink to the main topic of the course; right, the game board elaborated. 
Also there were opinions referring to the competition factor. Since the questions they proposed would be included in the game, they were very focused on its elaboration in order to not to facilitate the other groups to win the competition.

Slightly different opinions came from those adult students, generally people with an active professional life, who at the beginning of the project were a little sceptic and did not trust in the effectiveness of the game-based learning. However, these people recognized the novelty of the activity and the effort of the lecturers and students to carry out such task.

With respect to the final stage of the activity, most of them pointed out the importance of seeing that their efforts were worthy because they had built a tool useful to study and review the concepts of the course. Most of the students agreed in being satisfied knowing that they had created something that not only benefited them but also their colleagues.

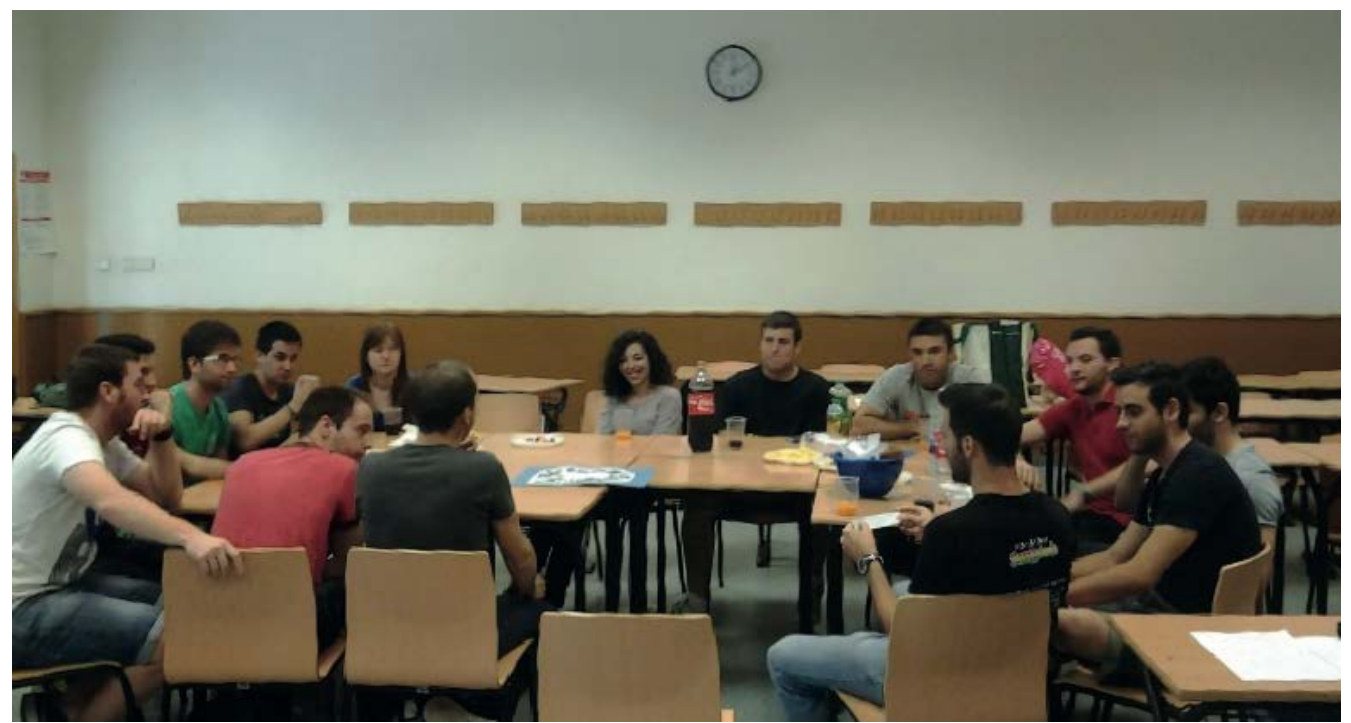

Figure 3. Students during the competition with the questions game board, June 2014.

The authors believe that the familiar atmosphere created helped the students to really enjoy the activity and take profit of it. This enhances the importance of the ludic nature of the activity, which allows the students to not be stressed while they are studying and reinforcing their knowledge.

For future editions of this project, the authors are working in proper questionnaires to accurately capture the satisfaction and opinion of the students about the activity. By means of this, it would be possible to quantify the results. It will allow the lecturers to compare results from different academic years and extract well-founded conclusions.

\section{Conclusions}

After carrying out the presented activity with undergraduate students, the authors of this work have detected that the development of a questions board game can result in a challenging and engaging activity. According to the collected opinions, it was also highly satisfactory since they see their efforts reflected in a very useful tool to review the concepts of the subject. 
Besides, communication and collaboration are enhanced by means of working in groups whereas using the elaborated game as a review tool help to summarize and reinforce essential concepts. In general, students are very interested and motivated to acquire new knowledge during the execution of this project.

Due to the positive results, the authors are determined to repeat this project and apply the gained experience as a starting point for a better structured experiment. Controls in form of pre and post questionnaires could be used as a better manner to collect the opinions and satisfaction level of the students and to detect changes in their motivation and knowledge as a result of participating in the activity.

\section{References}

Baker, A., Navarro, E. O., and van der Hoek, A. (2003). Problems and programmers: an educational software engineering card game. Proceedings of the 25th International Conference on Software Engineering, 614-619. Hilton, Portland.

Carlson, S. (2005). The Net Generation goes to college. The Chronicle of Higher Education, 52(7), A34.

Fisch, M.S. (2005). Making Educational Computer Games 'Educational'. Proceedings of the 2005 conference on Interaction design and children, Boulder, Colorado, ACM Press, New York, NY, 55-61.

Hays, R.T. (2005). The effectiveness of instructional games: A literature review and discussion. Technical Report No. NAWCTSD-TR-2005-004, Naval Air Warfare Center Training Systems Division, Orlando, FL, 2005.

Katmada, A., Mavridis, A., and Tsiatsos, T. (2014). Implementing a Game for Supporting Learning in Mathematics. The Electronic Journal of e-Learning, 12(3), 230-242.

Marzano, R. J. (2007). The art and science of teaching: A comprehensive framework for effective instruction. Alexandria, VA: Association for Supervision and Curriculum Development.

Moseley, A. (2011). Pass go Quickly: Use of a Board Game to Provide Efficient and Effective Training in Course Design Concepts. Proceedings of the 5th European Conference on Game-Based Learning. Athens: University of Athens.

Salies, T. G. (2002). Simulations/gaming in the EAP writing class: Benefits and drawbacks. Simulation \& Gaming, 33(3), 316-329.

Sharp, L. A. (2012). Stealth learning: Unexpected Learning Opportunities Through Games. Journal of Instructional Research, 1, 42-48.

Whitton, N., (2012). The place of game-based learning in an age of austerity. Electronic Journal of e-Learning, 10(2), 249-256. 


\title{
Implementing Formative Assessment at the Workplace: A Contribution to the Students’ Achievement
}

\author{
Mohd Nasri Awang Besar*, Saharudin Ahmad*, Mohamad Nurman Yaman*, \\ Muhammad Arif Kamarudin*, Siti Mariam Bujang
}

* National University of Malaysia

\begin{abstract}
Nurturing formative assessment at the workplace is worthwhile to enhance students' learning in real performance. Mini Clinical Evaluation Exercise (mini-CEX) is a work based assessment conducted at the community clinic during Family Medicine posting at the Faculty of Medicine of The National University of Malaysia. As part of formative assessment, students would be given immediate feedback after performing the first mini-CEX to improve their performance in the following mini-CEXs examination.

This study was designed to evaluate the final year medical students' achievement in formative assessment at the workplace.

A quasi-experimental with repeated intervention methodological design by analysing a the scores of a group of 232 final year medical students who performed in mini-CEX 1 without receiving a feedback (intervention), and the scores after receiving a feedback in mini-CEX 2 and mini-CEX 3. This study was conducted at the Family Medicine Department in Faculty of Medicine, The National University of Malaysia. The data were analysed using the Statistical Package for the Social Sciences (SPSS) Version 19.0. A One-Way Repeated Measures ANOVA was conducted to compare mean scores in three mini CEXs (mini-CEX 1 and mini-CEX 2 and mini-CEX 3).

The mean score of the students' achievement was $5.35 \pm 0.84$ on the mini-CEX $1 ; 5.8 \pm 0.82$ on the miniCEX 2; and 5.79 \pm 0.78 on the mini-CEX 3. The ANOVA showed that the mean scores were significantly different, $F(2,462)=34.36$, $p<0.0005)$. Further analyses showed that there were significant improvement of the students' achievement in mini-CEX 2 or mini-CEX 3 compare to mini-CEX $1(\mathrm{p}<0.0005)$. However, result showed a non-significant improvement between mini-CEX 2 and mini-CEX 3.

We concluded the element of feedback at the end of mini-CEX's in the formative assessment may contribute to the improvement of the students' achievement. The authenticity of the mini-CEX assessment and the reliability of the mini-CEX scores might explained to the poor students' achievement. Further analyses are critical to explore the content of the feedback and its relation to the students' achievement.
\end{abstract}

Keywords: Formative assessment; Work-based assessment; Mini-Clinical Evaluation Exercise; Feedback

\section{Introduction}

\section{Formative assessment}

Formative assessment is an important component in the medical curriculum to measure clinical competencies among undergraduate medical student. Formative assessment is defined as utilizing the judgement on student performance during assessment to improve student competency (Sadler 1989). Student learning may be assisted, perhaps through feedback. Information generated through feedback may enhance learning to both the lecturers and the students.Ilgen and Davis (2000) and Kluger and DeNisi (1996) proposed the combination of formative assessment and feedback should be merge for better effect. 


\section{Mini-Clinical Evaluation Exercise (mini-CEX)}

Medical competencies can be achieved by testing the ability of medical student in integrating knowledge, skills and attitude (Daelmans et al. 2004). The mini-CEX assessment entailed direct observation by an examiner of a student's performance in real clinical setting such as clinics and wards. The element of feedback is a crucial part at the end of mini-CEX to augment the educational impact to the students. Providing feedback is deemed valuable to improve trainee's performance (Norcini and Burch 2007). Both lecturer and student would identify strengths, areas for development and suggest an action plan.

\section{Mini-CEX assessment process during Family Medicine Posting}

Mini-CEX is a work-based assessment and a part of formative assessment to promote students learning in their clinical performance. Students are required to demonstrate their cognitive skills, patients' examination skills or communication skills related to the task. Students' knowledge and skills in term of diagnostic or therapeutic decisions would be assessed by family physicians as examiners. Each student will be given different case or task and assessed by different examiners. The score will be given based on the standardised mini-CEX form. Students will be given a feedback as part of formative assessment after performing the first mini-CEX to improve their performance in the following mini-CEXs examinations.

\section{Objectives}

The objective of this study was to evaluate the final year medical students' achievement in formative assessment at the workplace.

\section{Material and Methods}

A quasi-experimental with repeated intervention methodological design by analysing a the scores of a group of 232 final year medical students who performed in mini-CEX 1 without receiving a feedback (intervention), and the scores after receiving a feedback in mini-CEX 2 and mini-CEX 3. This study was conducted at the Family Medicine Department in Faculty of Medicine, The National University of Malaysia.

The data were analysed using the Statistical Package for the Social Sciences (SPSS) Version 19.0. A One-Way Repeated Measures ANOVA was conducted to compare mean scores in three mini CEXs (mini-CEX 1 and mini-CEX 2 and mini-CEX 3).

\section{Results and Discussion}

Table 1. Descriptive Statistics

\begin{tabular}{|c|c|c|c|}
\hline & Mean & Std. Deviation & $\mathrm{N}$ \\
\hline Mini CEX 1 & 5.35 & .84 & 232 \\
Mini CEX 2 & 5.80 & .82 & 232 \\
Mini CEX 3 & 5.79 & .78 & 232 \\
\hline
\end{tabular}


Table 2: Mauchly's Test of Sphericity

\begin{tabular}{|c|c|c|c|c|c|c|c|}
\hline $\begin{array}{c}\text { Within } \\
\text { Subjects } \\
\text { Effect }\end{array}$ & Mauchly's W & $\begin{array}{c}\text { Approx. } \\
\text { Chi-Square }\end{array}$ & df & Sig. & \multicolumn{3}{|c|}{ Epsilon $^{\text {b }}$} \\
\cline { 5 - 8 } & & & & $\begin{array}{c}\text { Greenhouse- } \\
\text { Geisser }\end{array}$ & Huynh-Feldt & Lower-bound \\
\hline Mini CEX & .990 & 2.304 & 2 & .316 & .990 & .999 & .500 \\
\hline
\end{tabular}

Table 3. Tests of Within-Subjects Effects

\begin{tabular}{|c|c|c|c|c|c|c|c|}
\hline \multicolumn{2}{|c|}{ Source } & $\begin{array}{c}\text { Type III Sum } \\
\text { of Squares }\end{array}$ & df & $\begin{array}{l}\text { Mean } \\
\text { Square }\end{array}$ & $\mathrm{F}$ & Sig. & $\begin{array}{c}\text { Partial Eta } \\
\text { Squared }\end{array}$ \\
\hline \multirow{4}{*}{ Mini CEX } & Sphericity Assumed & 30.196 & 2 & 15.098 & 34.357 & .000 & .129 \\
\hline & Greenhouse-Geisser & 30.196 & 1.980 & 15.248 & 34.357 & .000 & .129 \\
\hline & Huynh-Feldt & 30.196 & 1.997 & 15.118 & 34.357 & .000 & .129 \\
\hline & Lower-bound & 30.196 & 1.000 & 30.196 & 34.357 & .000 & .129 \\
\hline \multirow{4}{*}{ Error(Mini CEX) } & Sphericity Assumed & 203.024 & 462 & .439 & & & \\
\hline & Greenhouse-Geisser & 203.024 & 457.441 & .444 & & & \\
\hline & Huynh-Feldt & 203.024 & 461.377 & .440 & & & \\
\hline & Lower-bound & 203.024 & 231.000 & .879 & & & \\
\hline
\end{tabular}

Table 4. Pairwise comparisons

\begin{tabular}{|c|c|c|c|c|c|c|}
\hline \multirow[t]{2}{*}{ Mini CEX } & \multirow[t]{2}{*}{ Mini CEX } & \multirow[t]{2}{*}{$\begin{array}{c}\text { Mean } \\
\text { Difference }\end{array}$} & \multirow[t]{2}{*}{ Std. Error } & \multirow[t]{2}{*}{ Sig. ${ }^{b}$} & \multicolumn{2}{|c|}{$\begin{array}{c}\text { 95\% Confidence Interval for } \\
\text { Difference }^{\mathrm{b}}\end{array}$} \\
\hline & & & & & Lower Bound & Upper Bound \\
\hline \multirow{2}{*}{1} & 2 & $-.445^{*}$ & .059 & .000 & -.561 & -.330 \\
\hline & 3 & $-.438^{\star}$ & .064 & .000 & -.564 & -.313 \\
\hline \multirow{2}{*}{2} & 1 & $.445^{\star}$ & .059 & .000 & .330 & .561 \\
\hline & 3 & .007 & .062 & .911 & -.115 & .129 \\
\hline \multirow{2}{*}{3} & 1 & $.438^{*}$ & .064 & .000 & .313 & .564 \\
\hline & 2 & -.007 & .062 & .911 & -.129 & .115 \\
\hline
\end{tabular}

The mean score of the students' achievement was $5.35 \pm 0.84$ on the mini-CEX 1 ; $5.8 \pm 0.82$ on the mini-CEX 2; and $5.79 \pm 0.78$ on the mini-CEX 3 (Table 1). A nonsignificant result showed in the Mauchy's Test of Sphericity ( $>>0.05$ ) (Table 2). The ANOVA showed that the mean scores were significantly different, $F(2,462)=34.36$, $\mathrm{p}<0.0005$ ) (Table 3). Further analyses showed that there were significant improvement of the students' achievement in mini-CEX 2 or mini-CEX 3 compare to mini-CEX 1 $(\mathrm{p}<0.0005)$. However, result showed a non-significant improvement between miniCEX 2 and mini-CEX 3 (Table 4). 


\section{Discussion}

\section{Improvement in students' achievement in mini-CEX}

Compulsory feedback session is one of the crucial elements at the end of mini-CEX assessment. The students might have wrong interpretations to their performances without feedback. Feedback received at the end of mini-CEX 1 could be beneficial to the students in order to perform better in their respective mini-CEX. It was support by Sadler (2010) regarding the importance of feedback in formative assessment. During the feedback session, information about the discrepancies between the students' performances and the lecturers' expectations and a manner to lessen the discrepancies would be discussed. Feedback given by the assessors provide insights to the students on their clinical strengths and weaknesses (Burch et al. 2006). Giving feedback should be constructive in order to lead to a positive reaction from the students. Regular workshops as part of staff development activities were conducted to train the lecturers to improve their skills in giving feedback. They had been exposed on the theoretical aspect of giving feedback and participated in role-play activities. Based on these, the impact of training to the lecturers can be further improved by focusing more on their roles as examiners and evaluators. Lecturers also had been exposed on the strategies, types and techniques of giving feedback from the literature. Role-plays activities related the theories with the actual simulated scenarios followed by comment and discussion to improve the individual skills. However, the workshop could be improved by including students' perception on the content of the feedback during the training. Perhaps, direct student involvement during the role play may provide a better scenario.

In medical education, Pendleton's Rules which encouraging interactive feedback were used as conventional method of feedback (Chowdhury and Kalu 2004; Pendleton et al. 1984). Even though this study had shown a promising result in term of students' improvement, systematic review had found that there is no direct effect between feedback and work-based assessments (Saedon et al. 2012). There were few other factors that might be contributed to the result. Firstly, the element of teaching and learning in the family medicine posting such as lectures, seminars and clinical attachment during daily practice clinic with their respective supervisor may give a positive improvement to students' performance. Secondly, some group of students had already been exposed and trained in their previous posting before entering the family medicine posting. There were some possibilities that those student may get a similar cases during mini-CEX which they already learned from the previous postings.

\section{Authenticity and Reliability of the work-based assessment}

The results showed a non-significant improvement between mini-CEX 3 and mini-CEX 2. There are a few possibilities that may explain to the result. Firstly, the advantage of authentic work-based assessment had exposed the student into real clinical setting. Mini-CEX may produce high authenticity rate because the case assigned to the students are purely dependable on the patients who seek treatment at the community clinic on the examination day. However, students' result in each mini-CEX are varied despite of feedback intervention because of poor standardization on the case complexities. Feedback intervention given after each mini-CEX might be only can fully utilized by the student related to the specific case discussed. Those students who performed on task that was considered easy cases may performed better compared to when they got a moderate or difficult cases in another mini-CEX. Carr (2006) agreed that implementing 
mini-CEX requiring more planning and scheduling into either clinic to reduce significant effects on clinical service.

Secondly, the reliability of the mini-CEX assessment may influence the result. Including scores in mini-CEX may contribute to low reliability (Norcini et al. 2003). Reliability refers to the precision of measurement or the reproducibility of the scores obtained with the examination (Van der Vleuten 2000). There were few possible factors that may jeopardize the reliability in the work-based assessment. Firstly, clear and explicit scoring items in the checklist could avoid the examiners from making subjective decisions about the students' competencies. Without proper scoring checklist, it could increase the examiners' subjectivity towards the students. Development of objectives and structured checklist could minimize the subjectivity and enhance the inter-rater reliability among examiners (Newble 2004). Current checklist in mini-CEX only contained rating scale for the lecturers to choose which are excellent, good, satisfactory, borderline or fail for each parameters of clinical competencies. However, the lecturers still need to give scores on the students' performance for purpose of continuous assessment. Subjective judgments on rating scale may increase a variation of scores among the examiners. However, the subjectivity could be improve by introducing marking rubric in each rating scale.

Thirdly, all lecturers were involved in the postgraduate master student teaching at the community clinic. Ideally, level of expectations toward undergraduate students should be lower than postgraduate students on the similar cases. However, there was a possibility for some examiners to have high-level of expectation towards the undergraduate students. Different levels of expectation exposed the assessment to the poor inter-rater reliability (Besar et al. 2012). A borderline candidate could either pass or fail after being rated by two different examiners. Poor inter-rater reliability could be considered intrinsically unfair to the students (Bould et al. 2009). It may occur despite of having standardized and structured scoring checklist. Wilkinson et al. (2003) found that standardizing the examiners had more significant effect to improve inter-rater reliability compared with improving the task and scoring checklist. Kottner and Dassen (2008) defined inter-rater reliability as a specific aspect of reliability referring to the degree of measurement error due to bias caused by different raters or observers rating the same person or object. Good inter-rater reliability among examiners should be maintained to improve the reliability. Having a series of examiner training prior to assessment might overcome the problem. Research suggested that examiner training could improve the inter-rater reliability. Examiners training is an essential component to ensure the reliability (Khera et al. 2005). The objectives of the training include reviewing the assessment process, scoring checklist and align the examiners' expectations to improve the inter-rater reliability. 


\section{Conclusions}

We concluded that the element of feedback at the end of mini-CEX's in the formative assessment may contribute to the improving of the students' achievement. The authenticity of the mini-CEX assessment and the reliability of the mini-CEX scores might explained to the poor students' achievement. Further analyses are critical to explore the content of the feedback and its relation to the students' achievement.

\section{References}

Besar, M. N. A., Siraj, H. H., Manap, R. A., Mahdy, Z. A., Yaman, M. N., Kamarudin, M. A., and Mohamad, N. (2012). "Should a Single Clinician Examiner be used in Objective Structure Clinical Examination?" Procedia - Social and Behavioral Sciences, 60(0), 443-449.

Bould, M., Crabtree, N., and Naik, V. (2009). "Assessment of procedural skills in anaesthesia." British journal of anaesthesia, aep241.

Burch, V., Seggie, J., and Gary, N. (2006). "Formative assessment promotes learning in undergraduate clinical clerkships: original article." South African Medical Journal, 96(5), p. 430-433.

Carr, S. (2006). "The Foundation Programme assessment tools: an opportunity to enhance feedback to trainees?" Postgrad Med J, 82(971), 576-9.

Chowdhury, R. R., and Kalu, G. (2004). "Learning to give feedback in medical education." The Obstetrician \& Gynaecologist, 6(4), 243-247.

Daelmans, H., Hoogenboom, R., Donker, A., Scherpbier, A., Stehouwer, C., and Van Der Vleuten, C. (2004). "Effectiveness of clinical rotations as a learning environment for achieving competences." Medical teacher, 26(4), 305-312.

Ilgen, D., and Davis, C. (2000). "Bearing bad news: Reactions to negative performance feedback." Applied Psychology, 49(3), 550-565.

Khera, N., Davies, H., Lissauer, T., Skuse, D., Wakeford, R., and Stroobant, J. (2005). "How should paediatric examiners be trained?" Archives of disease in childhood, 90(1), 43-47.

Kluger, A. N., and DeNisi, A. (1996). "The Effects of Feedback Interventions on Performance: A Historical Review, a Meta-Analysis, and a Preliminary Feedback Intervention Theory.pdf." Psychological Bulletin119(2), 254-284.

Kottner, J., and Dassen, T. (2008). "Interpreting interrater reliability coefficients of the Braden scale: a discussion paper." International journal of nursing studies, 45(8), 1238-1246.

Newble, D. (2004). "Techniques for measuring clinical competence: objective structured clinical examinations." Medical education, 38(2), 199-203.

Norcini, J., and Burch, V. (2007). "Workplace-based assessment as an educational tool: AMEE Guide No. 31." Medical teacher, 29(9-10), 855-871.

Norcini, J. J., Blank, L. L., Duffy, F. D., and Fortna, G. S. (2003). "The mini-CEX: a method for assessing clinical skills." Annals of internal medicine, 138(6), 476481. 
Pendleton, D., Schofield, T., Tate, P., and Havelock, P. (1984). The consultation: an approach to learning and teaching: Oxford University Press Oxford.

Sadler, D. R. (1989). "Formative assessment and the design of instructional systems." Instructional science, 18(2), 119-144.

Sadler, D. R. (2010). "Beyond feedback: Developing student capability in complex appraisal." Assessment \& Evaluation in Higher Education, 35(5), 535-550.

Saedon, H., Salleh, S., Balakrishnan, A., Imray, C. H., and Saedon, M. (2012). "The role of feedback in improving the effectiveness of workplace based assessments: a systematic review." BMC medical education, 12(1), 25.

Van der Vleuten, C. (2000). "Validity of final examinations in undergraduate medical training." BMJ: British Medical Journal, 321(7270), 1217.

Wilkinson, T. J., Frampton, C. M., Thompson-Fawcett, M., and Egan, T. (2003). "Objectivity in objective structured clinical examinations: checklists are no substitute for examiner commitment." Academic Medicine, 78(2), 219-223. 


\title{
Introduction to the Pécs Model Innovation in teaching Medical History Taking
}

\author{
Á. Koppán*, K. Eklicsné Lepenye*, R. Halász*, J. Sebők**, G.A. Molnár** \\ * Department of Languages for Specific Purposes, University of Pécs, Medical School, Hungary** Second \\ Department of Medicine, University of Pécs, Medical School, Hungary
}

\begin{abstract}
Among clinical skills, doctor-patient communication is considered a high priority in establishing the proper diagnosis. Therefore, our team at the Department of Languages for Specific Purposes at the University of Pécs, Medical School (UPMS) has designed an educational model to improve these fundamental skills. Our primary objective is to share these innovative practices with others.

Peer-tutoring history taking courses are offered to international students assisted by Hungarian senior students, as well as digitally available educational materials. The latter is based on authentic doctor-patient conversations (video-recordings in Hungarian) while acquiring the patient's history. Following video recording, EU standardized texts from A1 to B2 levels are implemented including task-based case studies and check-lists to ensure the use of authentic communication.

The scene for pilot experimentation is a university course with blended-learning methods; the video-recorded conversations are used in class, followed by hospital-based practice to promote motivation and increase cultural awareness.

Aligned with the current general orientation of modern linguistics, we believe context-based language courses may better prepare physicians for interviewing their patients in the 21st century.
\end{abstract}

Key words: communication skills, clinical skills, context-based history taking, peer-tutoring, blended learning, medical training in international programs

\section{Introduction}

Early acquisition of clinical skills plays a significant role in medical training. These skills involve history-taking, physical examination, diagnostic imaging techniques and additional clinical investigations, effective doctor-patient and staff communication with particular emphasis on team work (Abdulmohsen, 2007). Among all the above, communication skills are found to be the pre-requisite for proper diagnosis and treatment, resulting in successful care with optimal time-management.

In our model the focus is on improving communication skills in international programs. The University of Pécs, Medical School similarly to a number of European universities provides medical training in English and German languages. Although all the core professional subjects may be studied extensively in these languages, the early encounters of medical students and patients can only take place in an authentic setting through the language of the host country, in our case, Hungarian. Thus, clinical skills acquisition becomes an interdisciplinary field integrating professional and language skills. Earlier it was considered the weakest point of medical training in foreign languages: acquisition of history taking skills through language and intercultural barriers was questionable. Application of our model guarantees the desired results. Our program has a two-fold objective: first, to enable students to bridge the gap between the two fields, and solve language-related communication problems, which represents an inevitable part of quality medical training, and secondly to ease the burden of overloaded doctors by preparing students for history taking. 


\section{Methods}

Originally, the design of the model was developed on language and professional requirements analysis (Koppán, Halász 2014; Eklicsné, Koppán, Németh 2015). Interestingly, the evaluation revealed international students acquire Hungarian Language skills primarily as a tool implemented when taking a patient's past medical history, performing a patient examination (within a Hungarian hospital) and additionally, to support on-going professional training. In collaboration with clinicians we explored the medical field's needs, followed by updating the educational material. Once the relevant data has been accumulated, we began searching for superior methods meeting or exceeding today's generation of learning styles and characteristics.

Our model is based on two main methods: peer-tutoring and blended-learning. The former is discussed below, the latter incorporates classroom and mobile learning (based on videorecorded conversations and related exercises in an online environment). The innovative measure may be found in teaching history taking through medical Hungarian to international students who - assisted by Hungarian senior students - acquire medical communication with real patients in an authentic hospital environment developing valuable interviewing skills. These skills are further improved by viewing and assessing video-recorded doctor-patient dialogues in the classroom. In all earnest, we believe the Pécs Model is superbly innovative, as peer-tutoring is a rarely applied model in Hungarian higher education, particularly because it combines language and professional skills, enhancing its development and ensuring authentic real-time scenarios featuring genuine participants (hospital staff and patients).

\section{Peer-tutoring}

Since the1980's peer assistance in acquisition of clinical skills has achieved immense recognition and widely accepted, e.g., in Germany (Krautter et al, 2014) the University of Heidelberg, the model is called PAL (peer assisted learning). The university's senior medical students assist their junior university students in the studies of history-taking.

The English word 'peer' - in Hungarian literature - is also interpreted as 'fellow-sufferer'(Rácz 2008), highlighting the shared or mutual status between partners similar in age, which is a determining factor in building trust and genuine reliability. Effectively the work accomplished by peers is built on agreement and motivation to achieve a common goal.

The phenomenon of shared status is described in Boud's reciprocal peer learning (2001) highlighting the mutual benefit from studying together.

Similar to the above notion, Nestel and Kidd (2003) claim that peer learning is a key factor in improving clinical skills when taking past medical history with a patient-centered approach.

Gwee (2003) argues that peer learning, especially in small groups, nurtures and facilitates the development of self-directed learning skills, including critical thinking and problem-solving skills; communication, interpersonal and teamwork skills; and improves peer-assessment and critical reflection.

\section{Mobile learning}

Currently a responsive interface is being developed at our department towards engaging the requirements of updating practice materials and the immediate availability of the material on tablets and smart phones. Our website is designed to enhance motivation. All materials available are contemporary and regularly updated. 
Our website provides learning opportunities from the first year of studying Hungarian. During the early phase the focus is on the language preparation for history taking: vocabulary expansion, practicing grammar and pronunciation. In the second year, the emphasis shifts to listening comprehension skills, situational awareness dialogue based on authentic doctorpatient dialogues and routine questions in the field of internal medicine become more emphasized.

Films provide the basis for educational materials including periodical examinations and testing: the purpose is to enable students to follow the examples and accomplish a history taking task at their particular level. This has been initiated during the first year with sustained attention and practice into the second year.

Video-recording has a designed system:

Films thematically follow the modules of our medical training with focus on internal medicine as a basic field, then further specialties. There is a collaboration of clinicians and language teachers; clinicians collect data of typical diseases in the field, then within each module our recordings are based on those typical diseases. The scenario is history taking (the doctor asks questions about the past medical and social conditions, and present illness of the patient followed by physical examination). Recordings are assessed and processed (formation of didactic patient's answers).

Level 1 - actors - wide spectrum of simplified responses

Level 2 - actors

Level 3 - original recording

Linguistic processing also includes patients' answers in reference to common misunderstanding. Doctors' questions are not modified; however, we apply a communicative approach. In the exercises designed for the films we focus on interviewing strategies, linguistic tools of politeness and emphasis, comprehension markers and the structure of the conversation (rigid structure, constant repetition, and establishing new subtopics) beside traditional language teaching vocabulary expansion and other exercises.

Following classroom activities, mobile learning tools convert the study material and are readily available for rehearsing for history taking within the sphere of peer learning.

Video-recording serves a double function. One is providing authentic models by the real doctor-patient conversations that enable development of clinical skills including interviewing techniques, patient examination, making diagnosis and writing case histories. The other is improving self-assessment skills and enhancing professional performance and delivery through reviewing the recorded doctor-patient dialogue and interviews. We have started to integrate this application of the videos into our curriculum as a test pilot program; however, due to constant updating and revising, an additional semester is required to ensure stable accessibility for the majority of our students.

Login interface for interviewing patient in the peer-tutoring /Tandem design is ensured for both international and Hungarian students.

\section{Training tutors}

It is of the utmost importance to motivate potential future tutors, senior Hungarian students, who already possess professional skills to acquire the necessary assisting behavior to comprehend how they can help their peers with the language and communication needs. It is also a learning process for them; since commenting and correcting one another's grammar and communication mistakes may appear to be harsh or negative criticism by its nature, but it should be understood the goal intends the complete opposite and as a result, is immensely beneficial to the participating and willing students. 
To determine a method and the proper opportunity towards effective interruption requires confidence, developed communication skills and empathy.

\section{Results and Discussion}

Currently, the innovative program demonstrates measurable success as a result of its popularity among students who wish to join this type of education in a growing number for its motivating power, and is also deemed effective by the University's senior leadership. The former communicative means of education is today replaced by the authentic doctor-patient dialogue and communication resulting in live interview with patients assigned to the clinical ward.

International and Hungarian students practice and develop medical language competencies while taking the patient's medical history together. The junior international student is assisted by not only a language but a professional tutor - a senior Hungarian student- who assists in structuring and sequencing pertinent medical questions to meet the professional protocol promoting assessment and detailing the final diagnosis.

To the senior Hungarian student tutoring conversations is considered to be invaluable both from a professional and communicative perspective: doctor-patient communication is taught in the first year of the medical training with little or no opportunity to evaluate patients, and the students are heavily involved towards absolving the core subjects, i.e., anatomy and physiology. Without successfully navigating these principle subjects, medical communication cannot possess a significant role.

Within the students' curriculum, clinical subjects are present from the third year similarly to the English and the German programs, providing the opportunity to actively engage the patients at bedside, and acquire essential skills of interviewing patients and performing physical examinations. Unfortunately, the first-year doctor-patient communication courses are largely forgotten over time; therefore, the fundamental conversational techniques should be acquired within the frames of the clinical subjects. The difficulty arises from the lack of time and opportunity for practicing the interviewing skills during clinical practices. Suitably, this is the ideal time towards developing deep interest in the medical profession, empathy toward the patients, and awareness of the patient-centered medicine.

Extracurricular activities - tutoring international students during bedside history taking enable the Hungarian medics to effectively prepare for their future career and become a good doctor. Soon enough, they realize the well-structured doctor-patient interview ideally ensures an appropriate diagnosis and adequate treatment. The previously mentioned peer-tutoring in history-taking groups provides an ideal opportunity for professional practice while internalizing the procedure of interviewing the patient. They must explain 'what, how and why in the specific measure we inquire in Hungarian' to the international students many times. Meanwhile, they develop and personalize their professional delivery of standard and routine questions paving the way to more effective and valued conversation.

The comparative analysis of the two languages is inevitable, as well as the exploration of differences and similarities between the cultures and history taking strategies of the medical students alike. Internalization of the above is of high importance for both the Hungarian and international students, hence more and more students start and accomplish their medical studies in Hungary, so the principles of doctor-patient communication are acquired at our university. This immense responsibility empowers us, colleagues of languages for specific purposes, to engage and prepare the students for history taking and language related physical 
examination, at the same time to increase awareness of doctor-patient interviews in their own languages and also Hungarian.

Beside oral communication, written skills are also improved, as case histories should be written by the students based on their notes taken at the clinic. Patient bedside interviewing is followed by an in-class processing where students are paired off to discuss and assess the information collected from the patients. Afterwards, there is a plenary format presentation session where they summarize the experience of the conversation, the patient's attitude, willingness to cooperate, interesting data and a possible diagnosis.

Reconstruction of the dialogues and case histories happens at home also in a written format in the target language (in Hungarian for the international students, in German or English for the Hungarian students), followed by correction of each-other's work, commenting mistakes via e-mail or social media. The final result is sent to the teacher, who forwards the collected case histories to the clinician for assessment. Thus, the course integrating peer-assisted learning contributes to practicing oral and written communication and professional competences.

\section{Conclusions}

We believe that the Pécs Model successfully contributes to previous teaching LSP (Language for Specific Purposes) approaches, which state first and foremost, general language is taught extensively and then followed by the specific language. Medical trainings need measureable results (being able to take medical history) in a limited time. Thus, following a brief general language course, the students are immersed into the LSP instruction, focusing on situational communication required by the professional settings and guidelines.

Our model is based on permanent needs analysis, aiming to explore all the components of LSP skills collected, and provides the basis for designing and implementing valued curricula. The pioneer German majors (colleagues of the Pécs Model) attend clinical courses combined with the international students in varied courses such as internal medicine, cardiology, dermatology and neurology to collect information of their professional needs. (In the following year vast amounts of data are collected and plans strategized for their future implementation).

The development of communication skills is a crucial area of focus for Clinical Skills Labs (CSLs). More and more universities establish CSLs for their substantial support of education. In fact, a better name for those laboratories would be clinical and communication skills centers or units, because the proper application of clinical skills requires the integration of technical clinical skills and those of communication (Kneebone et al, 2002).

A modern Skills Lab meeting the $21^{\text {st }}$ century requirements will soon open at the University of Pécs, Medical School. In the near future we hope to begin teaching techniques of historytaking in its communication skills lab. Ideally, it will provide the necessary environment for the innovative teaching-learning model integrating students of the three language programs at our respected university.

\section{References}

Abdulmohsen H. Al-Elq. (2007) Medicine and Clinical Skills Laboratories

In: J Family Community Med. May-Aug; 14(2): 59-63.

http://www.ncbi.nlm.nih.gov/pmc/articles/PMC3410147/ 
Boud, D. (2001) 'Introduction: Making the Move to Peer Learning'. In Boud, D., Cohen, Ruth \& Sampson, Jane (Ed.). Peer Learning in Higher Education: Learning From \& With Each Other. London: Kogan Page Ltd,1-17.

Gwee C.E.M. (2003) Peer Learning: Enhancing Student Learner Outcomes. CDTL 13.

Eklicsné L. K, Koppán Á, Németh T. (2015) How to involve medical history taking effectively in LSP teaching. Presentation given at the Language Centres in Higher Education: Sharing Innovations, Research, Methodology and Best Practices Conference in Brno, 15-17 January 2015, will be published in the CASALC Review.

Halász R, Koppán Á. (2014) A magyar orvosi kommunikatív szaknyelvi kompetenciafejlesztés lehetőségeinek vizsgálata a szaknyelvhasználati szükségletek és a tanulási szituáció feltérképezése alapján.In: Bocz, Zs. ( Ed.) (2014): PORTA LINGUA 2014 (pp.311-318)

Krautter M, Andreesen S, Köhl-Hackert N, Hoffmann K, Herzog W, Nikendei C. (2014) Cross-year peer tutoring on internal medicine wards: results of a qualitative focus group analysis. Advances in Medical Education and Practice. 5:323-330.

Kneebone R, Kidd J, Nestel D, Asvall S, Paraskeva P, Darzi A. (2002) An innovative model for teaching and learning clinical procedures. Medical Education. 36:628-634.

Rácz J.(szerk.) (2008) Az esélyteremtés útjai: kortárs és sorstárs segítéssel szerzett tapasztalataink. 12-108. Budapest, L’Harmattan Kiadó.

http://www.edutopia.org/pdfs/guides/edutopia-mobile-learning-guide.pdf 


\title{
Optimising Peer Marking with Explicit Training: from Superficial to Deep Learning
}

\author{
S.B. Caldwell, T.D. Gedeon \\ Research School of Computer Science \\ Australian National University
}

\begin{abstract}
We describe our use of formative assessment tasks measuring superficial learning as explicit training for peer assessment of a major summative assessment task (report writing), which requires deep learning. COMP1710 at the Australian National University is a first year Web Development and Design course done by over 100 students each year, by many Computing students in their first semester of their first year or at any time prior to graduation; the course also attracts some $25 \%$ of its cohort from other academic areas of the University. We found that formative assessment trained peer markers performing a surface learning task can produce peer marks consistent with our expert summative task marker. Weaker students only demonstrating superficial learning were able to reliably assess the reports of the better students capable of the deeper learning required to produce the reports. This significantly increases the usefulness of peer marking, and could have use in large online courses such as MOOCs.
\end{abstract}

Keywords: peer marking, formative assessment, summative assessment, desired mark

\section{Introduction}

As the landscape of education continues to be transformed via evolving pedagogies and technologies, finding ways to practically implement these as teaching enhancements has become a priority in our first year web development and design course. As a result, we are examining ways to combine formative and summative assessment to create multi-layered learning outcomes for students while creating efficiencies in marking for this well-attended course.

The contributions of the work reported in this paper include explicit training of peer assessors, use of superficial/formative assessment tasks for peer assessor training, peer assessment by comparative marking, and use of weaker students to reliably assess stronger students' work in a deep learning summative task.

\section{Theoretical Background}

Formative assessment is designed to facilitate learning and typically involves qualitative feedback rather than scores. Summative assessment is a snapshot of the learning at a particular time, and is usually the mechanism by which final results and grades are reported. However, it can be difficult to balance these two types of assessment. William (2000) indicates that "few teachers are able or willing to operate parallel assessment systems," and suggests formative assessments could only provide an 'envelope' of overall scores. Formative assessment with marks is only primarily formative but is not useful as a replacement for summative assessment (MacLean and McKeown, 2012), with formative assessment not predictive of final grade, but predictive of pass/fail.

There is a large body of work extant on peer assessment, thus we introduce this area only briefly, in particular mentioning work relevant to our study. The paper by Hamer et al. (2009) reports on the difference between student (peer assessment) marks and expert marks in a large programming course. They found "good correlations that 
improve with student ability and experience" (our emphasis added, see our results section). Kulkarni et al. (2015) used a "fortune cookie" approach to provide qualitative and personalised feedback. This was found to have no effect on the amount of feedback returned, however, they noted that multiple assignments assessed via peer assessments provided incremental improvements on the quality of assessments produced over time. Reilly et al. (2009) found that combining just 2 peer marks produced high reliability, which informed our grouping approach to peer evaluation.

\section{Methods - Assessment in COMP1710}

COMP1710 Web Development and Design is a course in the Research School of Computer Science at the Australian National University (ANU) delivered annually to over 100 students. Many Computing students take it in their first semester of their first year, or at any time prior to graduation, as there is not a strong prerequisites tail. The course also attracts some $25 \%$ of the cohort from other academic areas of the University. The authors are chief tutor and course co-ordinator, respectively.

Key to our approach is to separate the surface learning / competency parts of our course assessment from deeper learning assessment. We consider this to be essentially the same problem as separating the formative and summative marking we all do. Briefly, our solution to the surface / deep learning or formative / summative evaluation quandary is to explicitly separate the marks so that surface and formative marks can only be collected to achieve a Pass in the course, and higher grades require qualitatively different kinds of marks which add conventionally to the pass marks for students to achieve higher grades. Thus, by 'qualitatively different' we mean that the students have to perform qualitatively differently to earn such marks. While reporting on the overall outcomes will be done elsewhere, as far as this paper is concerned we note that the training in report assessment and the marks for doing that assessment are from the surface/formative category, while the report itself is from the deep/summative category.

\section{Formative - quiz on report writing}

The formative quiz on report writing discusses an online technical report with commentary, a more abstract discussion of the usual components of technical reports, the use of images and charts, mistakes to avoid, and two final short essay questions. Additional formative training was provided with the essay questions 9 (report structure) and 10 (experiment participation reflection), which required students to assign a mark out of 6 , then justify their mark with a short explanatory paragraph. Both questions 9 and 10 were marked twice. This required three marking sessions, as the second marking

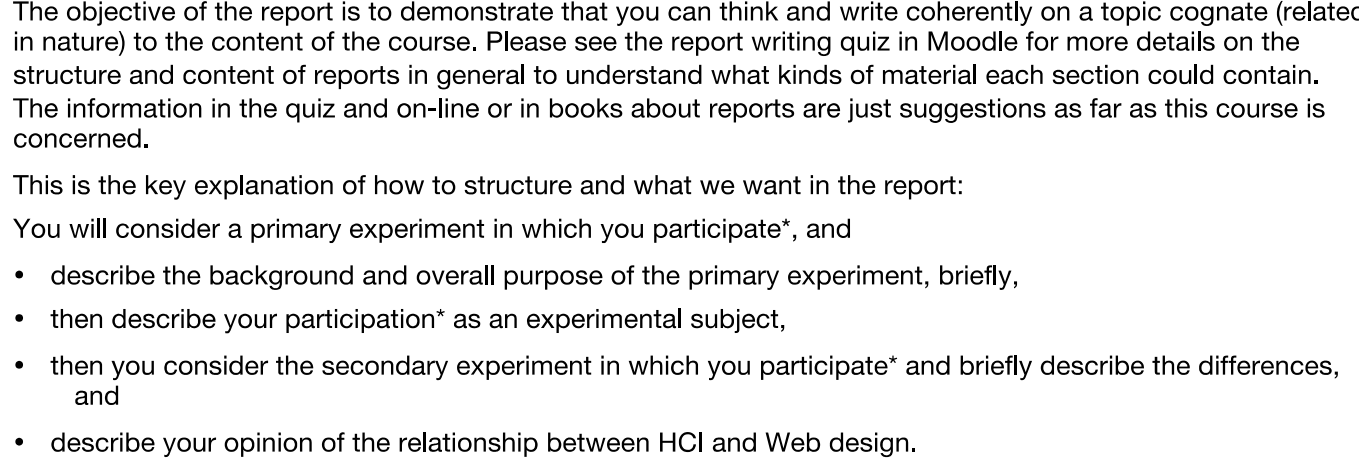

Figure 1. Report Specifications - Introduction 
of question 9 was done at the same time as the first marking of question 10 . The marking was all done by the course co-ordinator, and took substantial effort. The major reward was an unsolicited comment by email from the (independent) marker for the reports: "The quality of the reports is unrecognisably better than when I first marked these reports. Many came very close to completing what was required of them.”

\section{Summative - report specifications}

The report itself was primarily worth 'deep marks,' which would demonstrate understanding beyond a Pass level. Students wrote about their experiences when participating in real experiments as described in Figure 1.

Figure 2 demonstrates the link between the formative quiz and summative report tasks; question 9 of the quiz asks students to mark a report structure, and question 10 asks students to mark the reflection on experiment participation in sample reports, preparatory to students writing their own reports. The sample reports provided are similar in terms of overall topic, but with different experiments, thus ensuring that the samples are useful as examples of work but can not be directly copied.

\footnotetext{
Structure

Create an appropriate report structure. It should have a meaningful heading, your name and affiliation, an Abstract, an Introduction, a few sections listed below, Conclusion, and References. The Conclusion is a summary of what you've said in your report. Perhaps the experiment participation leads to a conclusion that strengthens or weakens your previous views of the relationship between $\mathrm{HCl}$ and Web design. There are no right answers or wrong answers in any part of the report, just well reasoned ones.

Experiences from participation in a primary experiment
}

This section describes the experience of participation, and relates it to the objectives of the experiment you took part in. It is meant to be a reflective section dealing with your individual reactions and is better if its not too theoretical, or too literal like a diary entry. It should be about your participation and reflect on the experience.

Figure 2. Target report sections related to Questions 9 and 10 of formative assessment

\section{Peer assessment - data and analyses}

Students participating in the peer evaluation were generally those who had not attained enough marks to achieve a Pass in the course, while students being evaluated were generally those who performed well in the course. Report peer evaluators had a mean total course score of 52.5 SD 13.4, while report writers had a mean total course score of 74.6 SD 9.6 (the mean total course score for all students was 61.2 SD 24.1).

The students doing peer evaluation are sent Excel spreadsheets with five anonymised embedded reports and both qualitative and quantitative evaluation tasks (Figure 3). Below each report is a set of sections with dropdown lists of alternative descriptions. Thus, for " 4.1 Structure”, the student chose the description shown as being the one most correct for that part of the evaluation, which in this case was worth 6 out of 6 . The student must then choose (again via dropdown lists) for each paper: best / good / middle / bad / worst and for these

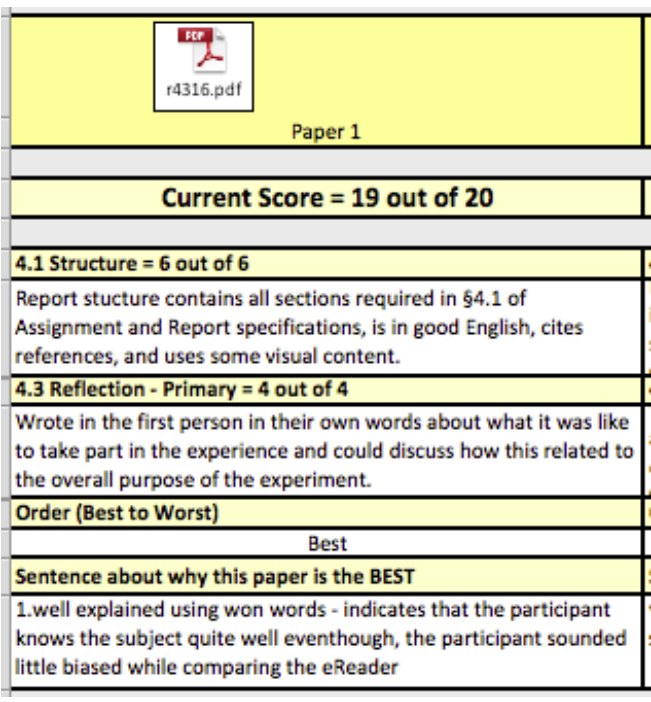

Figure 3. Peer marking spreadsheet 
reports write a sentence to explain why. The overall score at the top of "19 out of 20" is composed of these scores automatically.

Table 1. Sample results from 1 peer marker

\begin{tabular}{|l|r|r|r|r|r|r|}
\hline & 1st & 2nd & 3rd & 4th & 5th & sum \\
\cline { 5 - 8 } & r6994 & r1483 & r9549 & r3348 & r4195 & \\
\hline S rank & 1 & 5 & 4 & 2 & 3 & \\
\hline S mark & 17.5 & 11.5 & 7.5 & 16.5 & 12.5 & \\
\hline D rank & 1 & 4 & 5 & 2 & 3 & \\
\hline D mark & 15 & 7.5 & 6 & 14.25 & 12 & \\
\hline SqErr rank & 0 & 1 & 1 & 0 & 0 & 2 \\
\hline SqErr mark & 6.25 & 16 & 2.25 & 5.06 & 0.25 & 29.81 \\
\hline Total & 17.5 & 11.5 & 7.5 & 16.5 & 12.5 & \\
\hline Structure & 6 & 3 & 1.5 & 4.5 & 1.5 & \\
\hline Background & 3 & 3 & 1 & 4 & 4 \\
\hline Reflection & 4 & 2 & 2 & 4 & 4 \\
\hline Reflec-Diffs & 1.5 & 1.5 & 1 & 1 & 1 \\
\hline HCI-Design & 3 & 2 & 2 & 3 & 2 \\
\hline Ranking & Best & Worst & Bad & Good & Middle \\
\hline
\end{tabular}

The benchmark for our comparisons is the marks given by our expert marker. $\mathrm{He}$ is a senior colleague with significant relevant experience. He provides two guest lectures and does the marking of all of the reports, with no other engagement with the course. This is as close as seems possible to fully independent marking.

An example of our analysis is shown in Table 1. The bottom 7 rows show the numeric results from the Peer marking spreadsheet (Figure 3). The last row is the student-chosen rankings (converted to numeric form and shown as $S$ rank). Notice that the student-chosen Worst report is not necessarily the one with the lowest mark. In the table, the Total line is copied to the $S$ mark line. The two lines below ( $D$ rank/mark) should be read as "Desired mark" etc., being the mark from our expert marker. We then calculated the squared difference of the ranks, with the sum of these values shown in bold, right. The sum of squares eliminates negative values and penalises large differences, and is commonly used to compare information retrieval rankings. The values of 2, 29.81 can now be compared to the equivalent SqErr rank / mark values for all other students as two estimates of their reliability where that is a measure of similarity to the Desired marks and ranks.

These calculations allow us to derive three possible peer marking results for each report. Firstly, the average mark for each report (Ave_S), based on the students' marks. Second, we can pick the most reliable marks for any report by just picking the mark given by the most reliable student (by_rank) based on the similarity of their ranking of the 5 papers to the Desired ranking using the sum of the SqErr rank values as the

Table 2. Sample results by report

\begin{tabular}{|lrrrr|}
\hline ReportID & Ave S & by rank & by mark & D mark \\
\hline$\cdots$ & & & & \\
\hline r3348 & 17 & 16.5 & 16.5 & $\mathbf{1 4 . 3}$ \\
\hline r3406 & 13.2 & 17.5 & 17.5 & $\mathbf{1 3 . 5}$ \\
\hline r3626 & 10.5 & 10.5 & 10.5 & $\mathbf{1 2}$ \\
\hline r3790 & 18 & 19 & 15.5 & $\mathbf{1 5}$ \\
\hline r3841 & 16.5 & 16.5 & 16.5 & $\mathbf{1 3 . 5}$ \\
\hline r4195 & 12.6 & 15 & 12.5 & $\mathbf{1 2}$ \\
\hline$\cdots$ & & & & \\
\hline
\end{tabular}
reliability measure. Third, the same as the second but using the sum of the SqErr mark values (by_mark) as the reliability measure.

So for example the average mark for the first report shown in Table 2, r3348, is 17, but the by rank and by mark values are both 16.5, being the mark given by the student shown in Table 1 . That student also gave the by mark value for the last report in the table (r4195). This is possible because another student ranked their 5 reports in the same order as our expert marker, but gave 
more different numerical marks, hence was more reliable on one measure but not the other.

\section{Results and Discussion}

We received 155 peer marks in total for 53 reports, yielding a mean of 2.9 'marking events' per report (SD 1.1). We received a single mark for 6 reports, and six marks for just 1 report. For this dataset, we can compare Ave_S, by_rank, and by_mark for similarity to the estimator Desired values in a number of ways. We choose the simplest here, again using sum of squared differences, producing 3 numbers:

- D-to-Ave_S = 655.3 • D-to-by_rank = 806.7 • D-to-by_mark $=650.9$

The magnitudes of the numbers are not meaningful, and we just want to compare differences in magnitude. The results suggest that using selection by match of marks to the Desired mark produces results no different from simple averaging of marks, and that the use of the ordering of student marks as a selection means is not useful. This was contrary to our intuition.

Examining the statistical significance of peer evaluation results using a two-tailed t-test with Desired mark as estimator shows that all three results are highly statistically significant, using the $\mathrm{p}<0.05$ measure:

- $\mathrm{p}($ D-to-Ave_S $)=0.0009 \cdot \mathrm{p}($ D-to-by_rank $)=0.0006 \cdot \mathrm{p}($ D-to-by_mark $)=0.006$

Unfortunately, this means that none of these three results could be used to approximate the Desired marks. Instead of turning to more complex statistical measures such as the Pearson correlation coefficient, we performed a simple check of the averages of the Student and Desired marks and we discover that they differ by 2 marks out of 20: Student marks have a mean of 13.48 with standard deviation 3.3, while Desired marks have a mean of 11.53 with a standard deviation of 3.0.

To cope with the difference in mean, we applied the simplest measure, and one most often applied in our experience by examiners' meetings: subtraction. We subtracted two marks from each student mark and then we recalculated our measures:

- D-to-Ave_S = 455.1

- D-to-by_rank $=543.7$

- D-to-by_mark $=511.9$
- $\mathrm{p}\left(\mathrm{D}-\mathrm{to}-\mathrm{Ave} \_\mathrm{S}\right)=0.46$

- $\mathrm{p}(\mathrm{D}$-to-by_rank $)=0.36$

- $\mathrm{p}(\mathrm{D}$-to-by_mark $)=0.30$

These results show that the match to the Desired marks is better as the sum of squared

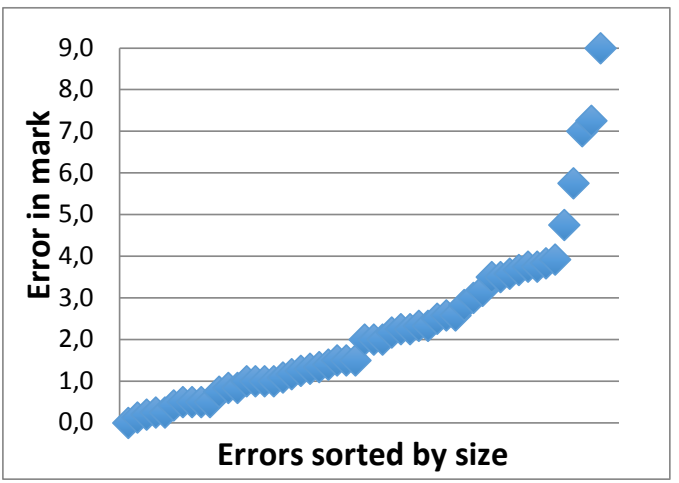

Figure 4. Distribution of Peer Marking 'errors’ error values are smaller, and the differences between the benefit of one over another in approximating the Desired marks is less. The $p$ values are interesting, as none of the columns is now statistically significantly different from the Desired column, which is what we want here. The average error for the best result (D-to-Ave_S) is 2.9 marks. In Figure 4 we can see that most of the differences between the peer review marks and the Desired marks ('errors'), are below 4 marks, with 5 outliers with errors of: 4.8, 5.8, 7.0, 7.3, and 9.0 marks. The other two 
distributions with sum of squares errors of 543.7 and 511.9 are similar with a few more outliers.

\section{Conclusions}

We have described an experiment involving 31 peer marking events comparing 5 reports at a time, with 53 reports marked in total. Similar to previous work in the literature (Kulkarni, 2015, Hamer, 2009), our work shows that we could reproduce the expert marking for this sample of 53 reports from formatively trained student peer evaluators, as we can produce (a number of) lists of marks which are not statistically significantly separable from the 'true' list of marks provided by our expert marker.

We have made 3 significant contributions. The first contribution is that the use of a surface learning task done as a formative task can perform the role of explicit training in the assessment task, and produces high quality results on the first peer assessment task, unlike previous work in the literature (Kulkarni, 2015) which has focused on repeated assessments (which was not possible in our course as only one report is written). The second contribution is the introduction of comparative assessment where a number of submissions are evaluated in parallel (five in our case). Finally, the third and perhaps most significant contribution is that we have achieved our results using the weakest students in our cohort marking the rest of the students including the best students, with a high level of accuracy. This use of a surface learning task to reliably predict the results of a deep learning task for better students is impressive. The implication of this is that our students in their surface task were able to correctly recognise the outputs of deep learning tasks from other students.

\section{Acknowledgements}

We sought and received approval from the ANU Human Research Ethics committee to undertake this work. We would also like to acknowledge the ANU Vice-Chancellor's Teaching Enhancement Grant that made this study possible.

\section{References}

Hamer, J., Purchase, H. C., Denny, P., \& Luxton-Reilly, A. (2009, August). Quality of peer assessment in CS1. In Proceedings of the fifth international workshop on Computing education research workshop (pp. 27-36). ACM.

Kulkarni, C., Wei, K. P., Le, H., Chia, D., Papadopoulos, K., Cheng, J., ... \& Klemmer, S. R. (2015). Peer and self assessment in massive online classes. In Design Thinking Research (pp. 131-168). Springer International Publishing.

Maclean, G. and McKeown, P. (2013): Comparing online quizzes and take-home assignments as formative assessments in a 100-level economics course, New Zealand Economic Papers, 47(3): 245-256.

Reilly, K., Finnerty, P. L., \& Terveen, L. (2009, May). Two peers are better than one: aggregating peer reviews for computing assignments is surprisingly accurate. In Proc. ACM 2009 Int. Conf. on Supporting group work (pp. 115-124). ACM.

William, D. (2000): Integrating formative and summative functions of assessment. In Working group, 10(November). 


\title{
Pre-service Secondary teachers’ learning styles
}

\author{
R. Sanz Ponce ${ }^{1}$, I. Hernando Mora ${ }^{2}$ \\ 1,2Universidad Católica de Valencia "San Vicente Mártir”
}

\begin{abstract}
Every student copes with his own learning in a particular way and teaching style can determine learning style. This research is developed at a Faculty of Education Sciences where pre-service teachers are being trained. The aim is to analyze the different students' learning styles in the Master for Secondary Teachers' Training. We have used the VARK Questionnaire that includes 4 different learning styles (or sensory modalities): visual, aural, read/write, and kinesthetic. Participants, who were graduated in different degrees, studied in 9 different specialities of the master at Catholic University of Valencia. Results indicated that girls were more likely to prefer a read/write learning style than boys. Furthermore, the most important learning style was aural one, irrespectively of specialities. We conclude that our results can be caused by Master classes, in which students listen to the teacher and teacher explains without a feed-back. Differences among these findings and other researches are discussed.
\end{abstract}

Keywords: Learning styles, teachers, VARK Questionnaire, Master for Secondary Teachers’ Training.

\section{Introduction}

Right to Education is not attending to school but learning (UNESCO, 2013). That means that there must be "learning" to consider the educational process as right (Piaget, 1974), to recognize the right to Education. That is why there are many researches who test teachers' practices and learning processes (Bain, 2006; Jarante y Medina, 2012; Escámez, 2013).

Every student copes with his own learning in a particular way. Knowledge about different learning styles can help to enhance achievement and motivation (Hervás, 2003; Martín y Rodríguez, 2003; Martínez-Fernández y García-Ravidá, 2012), to adapt teaching style in order to enhance educational process.

In this respect, a teacher must think about his own learning style and how this one determines his teaching style. The way in which a teacher learns determine the way in which he teaches. In addition, his styles affect the way in which their students learn (Martínez, 2007).

Learning styles are the strategies or methods which a person uses to learn. These strategies are often stable but they depend on context and activities, and can be raised and changed (Revilla, 1998; Vermunt, 1996). Cognitive, emotional, and physiological features affect the way in which a person responds to the learning (Keefe, 1988). Castro and Guzmán (2005) introduced sociological and psychological factors as features that determine the different styles. Other authors explain that learning styles are a set of variables, half way between intelligence and personality that affect the way of learning (Camarero, Martín y Herrero, 2000). Teachers must bear in mind all of these essential factors to adapt their teaching styles to their students' learning styles (Martínez Geijo, 2007).

The purpose of the present study was to test the students' learning styles in Secondary Teachers' Training Master. 


\section{Material and Methods}

The profile of student's learning preferences was assessed by VARK Questionnaire (Fleming \& Mills, 1992; Fleming, 2006). This Questionnaire provides 16 questions and 4 options for every question because of there are 4 VARK modalities: Visual, Aural, Read/Write and Kinesthetic (Fleming, 1995; Fleming y Baume, 2006). Besides there are multimodal (bi, tri and tetra-modal) learning models, each respondent can choose more than one answer for each of the questions.

Participants were students from Secondary Teachers' Learning Master of the Catholic University of Valencia who were graduated in different degrees (Table 1) at some universities of Valencia (Spain). A total of 9 classes (one class for every speciality) were invited to participate in the investigation. The final sample consisted of 262 students (88,2\% of the total population), $36,7 \%$ male and $63,3 \%$ female. The study was conducted between October and December of 2014.

The data were collected in 15 minutes sessions. An investigator administered the questionnaire to the students and gave instructions to fill out it.

Table 1: Percentage of participants

\begin{tabular}{|c|c|c|c|}
\hline Master for Secondary Teachers’ Training specialities & Enrolment & Participants & $\%$ \\
\hline Business and Economy & 26 & 25 & $96,1 \%$ \\
\hline English & 40 & 34 & $85 \%$ \\
\hline Biology and Geology & 31 & 30 & $96,8 \%$ \\
\hline Physical Education & 34 & 30 & $88.2 \%$ \\
\hline Geography and History & 36 & 25 & $69,4 \%$ \\
\hline Language and Literature & 43 & 40 & $93,0 \%$ \\
\hline Mathematics & 37 & 36 & $97,3 \%$ \\
\hline Technology & 33 & 31 & $94,0 \%$ \\
\hline Educational Guidance & 17 & 13 & $76,5 \%$ \\
\hline TOTAL & 297 & 262 & $88,2 \%$ \\
\hline
\end{tabular}

Frequency analysis, Chi-square tests, and Least Square Means were calculated with SPSS/PC. 


\section{Results and Discussion}

Figure 1 shows the frequency of different modalities. Chi-square analysis did not indicate significant differences between our distribution and a random distribution $(\mathrm{p}=$ 0,0527).

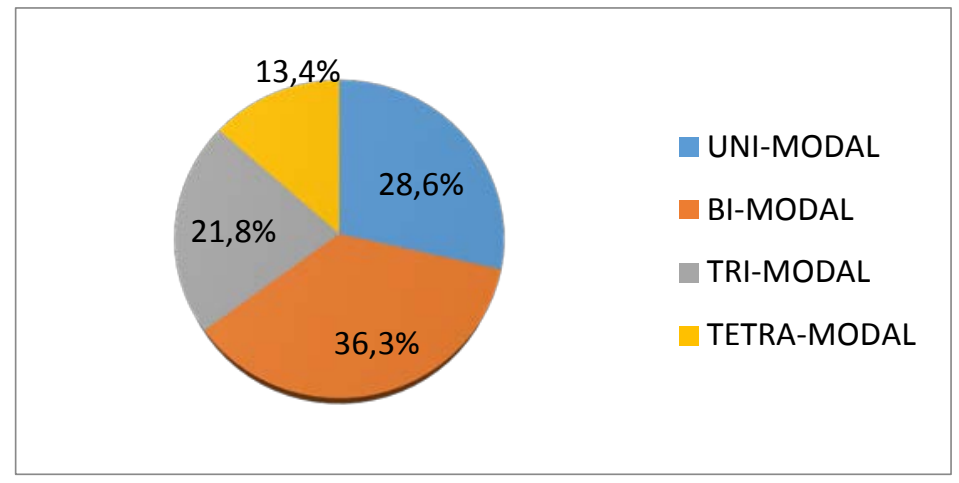

Figure 1. Students' distribution according to modalities.

Table 2 shows that the most frequent uni-modal learning style is the Aural one (58,6\%) and the most frequent bimodal learning style is the AK one.

Table 2. Frequency of different modalities.

\begin{tabular}{lccccccc} 
UNI-MODAL & \multicolumn{2}{c}{ BI-MODAL } & \multicolumn{2}{c}{ TRI-MODAL } & TETRA-IMODAL \\
\hline V weak & 2 & VA & 4 & VAR & 4 & VARK & 35 \\
V strong & 1 & VR & 4 & VAK & 11 & & \\
A weak & 20 & VK & 4 & VRK & 3 & \\
A strong & 24 & AR & 20 & ARK & 39 & \\
R weak & 5 & AK & 44 & & & \\
R strong & 2 & VK & 19 & & & \\
K weak & 11 & & & & & & \\
K strong & 10 & & & & & & \\
\hline TOTAL & 75 & & 95 & & & &
\end{tabular}

According to Horton, Wiederman y Saint (2012) most students have multi-modal styles, irrespective of sex. Wehrwein, Luján y DiCarlo (2006), instead, reported that most girls have uni-modal styles and most boys have multi-modal styles. Because of there are more multi-modal than uni-modal styles, students appear to be less likely to show an uni-modal style. We believe that it is more important to know what the most favourite learning styles of students are. 
Because of the preferences are weaker when combined we have calculated V, A, R, and $\mathrm{K}$ proportions. Each single answer counts as 1.0, each double answer counts as 0,5, each triple answer counts as 0,33 , and each quadruple answer counts as 0,25 . There is not a clearly predominant style: $16,6 \%$ of students are classified as Visual, $32,2 \%$ as Aural, 22,8 Read/Write and 28,4\% as Kinesthetic.

Table 3 gives the percentages of $\mathrm{V}, \mathrm{A}, \mathrm{R}$, and $\mathrm{K}$ profiles and the percentages of unimodal, bi-modal, tri-modal and tetra-modal preferences in every Master speciality.

Tabla 3. Percentages of every learning style and every modality

\begin{tabular}{lcccccccc} 
& \multicolumn{1}{c}{ LEARNING STYLES } & \multicolumn{1}{c}{ MODALITIES } \\
\cline { 2 - 9 } ESPECIALIDAD & $\mathrm{V}$ & $\mathrm{A}$ & $\mathrm{R}$ & $\mathrm{K}$ & $\begin{array}{c}\text { Uni- } \\
\text { modal }\end{array}$ & $\begin{array}{c}\text { Bi- } \\
\text { modal }\end{array}$ & $\begin{array}{c}\text { Tri- } \\
\text { modal }\end{array}$ & $\begin{array}{c}\text { Tetra- } \\
\text { modal }\end{array}$ \\
\hline Business and Economy & $16 \%$ & $36 \%$ & $22 \%$ & $26 \%$ & $24 \%$ & $44 \%$ & $24 \%$ & $8 \%$ \\
English & $16 \%$ & $34 \%$ & $23 \%$ & $27 \%$ & $19 \%$ & $36 \%$ & $26 \%$ & $19 \%$ \\
Biology and Geology & $18 \%$ & $32 \%$ & $21 \%$ & $29 \%$ & $43 \%$ & $24 \%$ & $24 \%$ & $9 \%$ \\
Physical Education & $17 \%$ & $32 \%$ & $24 \%$ & $27 \%$ & $45 \%$ & $31 \%$ & $24 \%$ & $0 \%$ \\
Geography and History & $16 \%$ & $31 \%$ & $22 \%$ & $31 \%$ & $32 \%$ & $20 \%$ & $28 \%$ & $20 \%$ \\
Language and Literature & $14 \%$ & $32 \%$ & $26 \%$ & $28 \%$ & $25 \%$ & $50 \%$ & $12 \%$ & $13 \%$ \\
Mathematics & $19 \%$ & $29 \%$ & $23 \%$ & $29 \%$ & $9 \%$ & $48 \%$ & $26 \%$ & $17 \%$ \\
Tecnology & $16 \%$ & $33 \%$ & $23 \%$ & $28 \%$ & $39 \%$ & $35 \%$ & $13 \%$ & $13 \%$ \\
Educational Guidance & $17 \%$ & $33 \%$ & $20 \%$ & $30 \%$ & $31 \%$ & $23 \%$ & $15 \%$ & $31 \%$ \\
\hline
\end{tabular}

The most frequent modalities are uni-modal and bi-modal ones. The most frequent style is the Aural one at all specialties. This learning style is maximum in Business and Economy (36\%). The least frequent style is the Visual one, whose maximum is $19 \%$ in Mathematics. Kinesthetic style is maximum in Geography and History (31\%). Read/Write style is maximum in Language and Literature speciality, in which Visual style is minimum. Despite that, we did not find significant differences among specialities. The most important one is the Aural style. Furthermore, all the participants are graduated. That means that they are, at least, twenty years old. If we take into account that master class is the most important teaching style in Spain for last few decades in almost any degree, we believe that this teaching style has could determine the students' learning style irrespectively of their initial learning style. According to Revilla (1998) and Vermunt (1996), their learning style has could be changed.

Results from the Least Square Means analysis exploring for possible sex differences, revealed that girls are more likely to prefer a Read/Write style than boys (24,1 and 21,6 per cent, respectively). Horton et al. (2012) reported similar results (28,9 and 25,3 per cent, respectively). Instead, Dobson (2009) found that boys tended to prefer a Read/Write learning more than girls.

There are no more significant differences in the rest of styles. 
Tabla 4. Ls means by sex

\begin{tabular}{lcccc} 
Learning style & Sex & LS Mean & Std Error & $\mathrm{p}$ \\
\hline \multirow{2}{*}{ Visual } & 0 & 16,3639 & 0,9567 & \\
& 1 & 16,6347 & 0,7292 & 0,8221 \\
& 0 & 32,7649 & 1,1958 & \\
Aural & 1 & 32,0072 & 0,9114 & 0,6147 \\
& 0 & 21,5649 & 1,0102 & \\
Read-Write & 1 & 24,0982 & 0,7699 & $0,0471^{*}$ \\
& 0 & 29,3165 & 1,0526 & \\
Kinestthetic & 1 & 27,2766 & 0,8022 & 0,1245 \\
& & &
\end{tabular}

Note. Sex 0 = male, Sex 1 = Female; LS mean = Least Square Means; Std Error = Standard Error; $\mathrm{p}=$ Probability of error; *Significant difference.

\section{Conclusions}

Martínez Geijo (2007) pointed out that teachers generally used the text book and the master class as the only teaching tools. This teaching style has determined the learning style of our students, who got used to learn in a very specific way for fair of fail. According to Rodríguez and Vázquez (2013), learning style of every teacher affects his teaching style which has an influence on his students learning style. Thus, our results can be caused by master classes, in which students listen to the teacher and teacher explains without a feed-back.

\section{References}

Bain, K. (2005). Lo que hacen los profesores de universidad. Valencia: Universidad de Valencia.

Camarero, F.; Martín, F. \& Herrero, J. (2000). Estilos y estrategias de aprendizaje en estudiantes universitarios. Psicothema, vol. 12, n 4, pp. 615-622.

Castro, S. \& Guzmán, B. (2005). Los estilos de aprendizaje en la enseñanza y el aprendizaje: una propuesta para su implementación. Revista de Investigación, 58, pp. 83-102.

Dobson, J. L. (2009) Learning style preferences and course performance in an undegraduate physiology class. Advances in Physiology Education, 33, 308-314.

Escámez, J. (2013). La excelencia en el profesorado universitario. Revista Española de Pedagogía, $n^{\circ}$ 254, pp. 11-27.

Fleming, N. D. (1995). I'm different; not dumb. Modes of presentation (VARK) in the tertiary classroom, in Zelmer, A. (ed.). Research and Development in Higher Education, Proceedings of the 1995 Annual Conference of the Higher Education 
and Research Development Society of Australasia (HERDSA), HERDSA, vol. 18, pp. 308-313.

Fleming, N. D. VARK. A guide to learning styles (on line). http.//www.vark-learn.com

Fleming, N. D. \& Baume, D. (2006). Learning Styles Again: VARKing up the right tree!, Educational Developments, SEDA, Issue 7.4, pp. 4-7.

Hervás, R. M. (2003). Estilos de enseñanza y de aprendizaje en escenarios educativos. Granada: Grupo Editorial Universitario.

Horton, D. M, Wiederman, S. D. y Saint, D. A. (2012). Assessment outcome is weakly correlated with lecture attendance: influence of learning style and use of alternative materials. Advances in Physiology, 36, 105-115.

Jarante, B. \& Medina, J. L. (2012). Saberes docentes y enseñanza universitaria. Estudios sobre Educación, vol. 22, pp. 179-198.

Keefe, J. W. (1988). Development of the NASSP learning style profile. In J. W. Keefe, (ed.): Profiling and utilizing learning style. Reston, Virgina: National Association of Secondary School Principals, pp, 1-21.

Martín, A. V. \& Rodríguez, Mª J. (2003). Estilos de aprendizaje y educación superior. Análisis discriminante en función del tipo de estudios. Enseñanza, 21, pp. 77-97.

Martínez Geijo, P. (2007) Estilos de aprendizaje. AAVV. Aprender y enseñar: Los estilos de aprendizaje y de enseñanza desde la práctica del aula (21-54). Bilbao: Mensajero.

Martínez-Fernández, J. R. \& García-Ravidá, L. (2012). Patrones de aprendizaje en estudiantes universitarios del Máster en Educación Secundaria: variables personales y contextuales relacionadas. Profesorado. Revista de Curriculum y formación del profesorado, vol. 16, nº 1, pp. 165-182.

Piaget, J. (1974). A dónde va la educación. Barcelona: Teide.

UNESCO (2013). Hacia un aprendizaje universal. Lo que cada niño debería aprender. Resumen ejecutivo, Informe $n^{\circ} 1$.

Revilla, D. (1998). Estilos de aprendizaje, in Temas de Educación. www.pucp.edu.pe/temas/estilos.html. (15 de septiembre del 2013).

Rodríguez, Ma . C. \& Vázquez, F. (2013). Fortalecer estilos de aprendizaje para aprender a aprender. Revista Estilos de Aprendizaje, nº 11, vol. 11, pp.19-37.

Vermunt, J. D. (1996). Metacognitive, cognitive and affective aspect of learning styles and strategies: A phenomenographic analysis. Higher Education, 31, pp. 25-50.

Wehrwein, E. A., Luján, H. L. \& DiCarlo S. E. (2006). Gender differences in learning style preferences among undergraduate physiology students. Advances in Physiology Education, 31, 153-157. 


\title{
Recent trends and status of women in Higher Education in India
}

\author{
Kapil M. Ingole*, Vicent Caballer**, Stephanie Galler*** \\ *MGM Institute of Health Sciences, India. \\ ${ }^{* *}$ Universitat Politècnica de València, Spain. \\ ****Birmingham City University, Creo, England
}

\begin{abstract}
The Indian education system is one of the oldest and largest in the world. Some progress has been made in the field of women's education. A recent trend shows that a huge number of female students are enrolling into higher education: $79.44 \%$ Undergraduate, $11.39 \%$ for Post graduate \& 0.72 $\%$ for Ph. D. The sex ratio in has increased; Gender Parity Index up to 0.88 in 2012 . Women's enrolment pattern has changed, currently it is much higher in Bachelor of Arts / Science / Commerce / Education than in non-technical / non-professional fields. A similar trend is being seen in Engineering Management and Technology in professional courses with less enrolment of women. This paper is an attempt to present the overall status of women in higher education.
\end{abstract}

Keywords: ASHE - Annual Status of Higher Education in States \& Union Territories, GER - Gross Enrolment Ratio, GPI - Gender Parity Index, MHRD - Ministry of Human Resource Development.

\section{Introduction}

\section{Historic background of Indian education System in India}

The Gurukul System of education was an ancient system of education during the Vedic period in which anyone who wished to study went to a teacher's Guru's home and requested to be taught. If accepted as a student by the Guru, the Guru taught everything the student wanted to learn, from Sanskrit to the Holy Scriptures, from Mathematics to Metaphysics (Kumar, 2014). During the Vedic period women had access to education in India, however, over time they lost this right to access education and academic exposure. The women had special customs, rituals and spirituality, with which men were not allowed to interfere. (Naik, 1978). This traditional system of education was in 1800 - 1900 replaced by the colonial system when the British ruled in India. After 1978 the colonial system was replaced by the National System of Education. The modern history of India, from 1857 to 1947, shows continuous efforts were made to educate the people enabling them to know their rights and duties towards their family, Society and Nation to enlarge and strengthen capabilities to fight ignorance, injustice, corruption, violence, disparity and communalism to fight for independence (Jitendra, April 2013) in the British period there was a revival of interest in women's education in India due to strong, British influence on the fundamentals of the Indian education system. During this period, various socio religious movements led by various social reformers in India who took various initiatives to make education available to the women (ASHE, www.aishe.gov.in, 2012). The women's right for education, which was lost after the Vedic period, was slowly recovered during this era. They were also ensured their participation in the social gatherings and events by introducing them into polity and administration at all levels during this period. (Naik, 1978) 
Women's education got a fillip after the country became independent in 1947, since then the government has taken various measures to provide education to all Indian women (Jitendra, April 2013). The Education Commission has stressed the need of women's education at all stages. To promote literacy in India, especially in rural areas and among the female population the government has done well in last decade as per Census 2011, 74.0\% of the population is literate comprising $65.5 \%$ females and $2.1 \%$ males. Among the States/Union Territories, the female literacy rate is the highest in Kerala at $92.0 \%$ the highest male literacy rate is observed in Lakshadweep at 96.1\%. (MHRD, 2013.) India with a population of more than 1.237 billion and $4.29 \%$ of GDP expenditure on education sector $79.44 \%$ under graduate. $11.39 \%$ for Post graduate and $0.72 \%$ for Ph.D.

The Radhakrishnan Commission (1948-49) in its reports has laid particular emphasis on women's education and has observed that Indian women can work like men in all spheres. Yet a large section of Indian society considers the home to be the only area for women's activities. Some people hold the view that unemployment will increase if women's education spreads. For the national development along with the women's education, the old values of society will have to be changed. It is also necessary to change the present system of women's education and make it more fruitful. In the past two decades, women's participation in primary, middle and secondary level has increased considerably. (IBEF, 2014) In the view of future perspective the education market in India, which is presently worth around Rs 5.9 trillion (US\$ 92.98 billion), is poised for some major growth in the years to come, as by 2020, India will have the world's largest tertiary-age population, and second largest graduate talent. Presently, higher education contributes 59.7 per cent of the market size, school education 38.1 per cent, pre-school segment 1.6 per cent, and technology and multi-media the remaining 0.6 per cent. The higher education sector in India is poised for an average growth of 18 per cent per year till 2020. (Pujar, Feb. 2014) The India's higher education system faces challenges on three fronts - expansion, equity and excellence (Jitendra, April 2013) which are well discussed in this paper. Indian education system ranks second in the world when comparing India, USA and China in terms of enrolment of students in higher educational institutions with Gross Enrolment Ratio GER 17.9\% in 2012 (Velkof, 1998).

In India lots of work is being carried out and most of the researchers have highlighted the various issues associated with education system and recommended various suggestions for improvement therein but very few attempts were made on women's status and their contribution in the Indian higher education system. The main objective of this study is to analyse the recent trends in higher education with pertaining to women's enrolment and their current status in higher education in India. 


\section{Methods}

This is a cross sectional, retrospective and descriptive type of research which is based on secondary data published in Research Articles, Journals, e-Journals, Report of state and central Governments as well as educational institutes. Various software such as Microsoft excel and word were used to represent and organise the data and with the statistical tools, techniques and graphical representation were use in order to organize, summarize the data for better understanding. The principle source of data are UGCs University Grant Commission report and ASHE - Annual Status of Higher Education in States and Union Territories -2012

\section{Results and Discussion}

Women's education in India has a major role in the social and economic development of the country. In recent years, India has progressed much in women's education to change the social face of country, despite there still being much to be done. The tremendous increase in the number of students and of the educational institutions has given rise to the term 'education explosion' in the country.

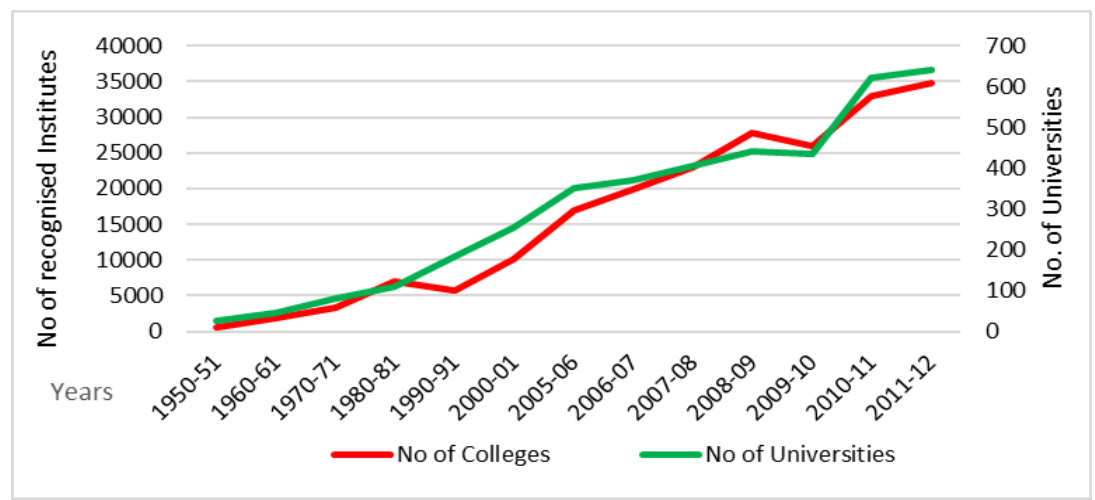

Figure 1 Number of Recognised Educational Institutions Data source: AISHE Portal (www.aishe.gov.in)

Fig1 shows the increase in recognised institutes and universities in India. With an increase in population the number of educational institutes, including colleges \& universities, have also increased, thus to fulfil the growing need for education which can be indicated by the overall enrolment.

There is no significant difference in the growth of enrolment rate between men and women in higher education since 1950. After 3 years of independence India had only 27 universities and 578 affiliated institutes, however, the population explosion has increased the demand of educational institutes which have increased, now numbering 254 universities and 10152 affiliated colleges by 2001. Currently there are 665 Universities, 35829 Graduate, PG, institutes with 29629022 students provides required knowledge, techniques, skills and information to $88 \%$ of students in regular mode. While $12 \%$ of the population is enrolled in a distance mode of education which includes one national \& thirteen state open universities which are providing the knowledge, techniques, skills required for continuation within their profession. 
The General courses (Arts, Commerce \& Education) account for 14.3 million and professional (Engineering, Medical, Management etc.) courses accounts for 7.1 million, general course having largest share of enrolment. Moreover, enrolment in professional courses has witnessed a higher growth in the last five years.

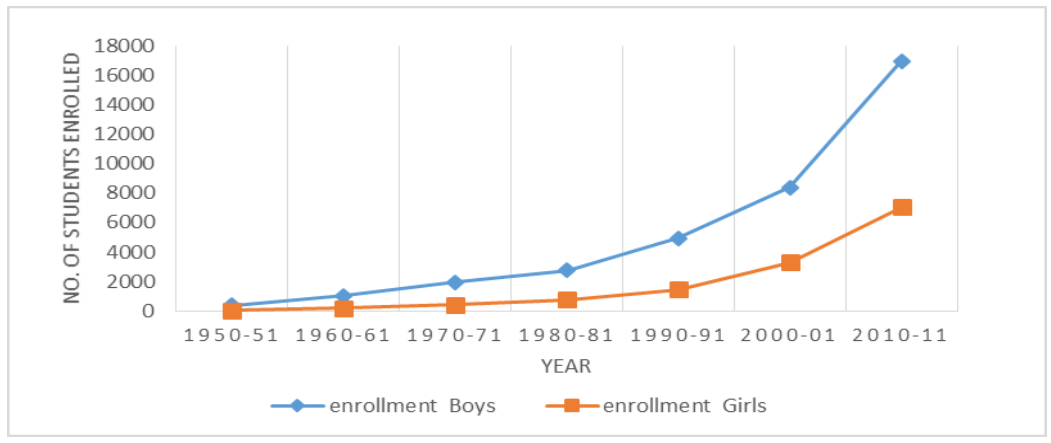

Figure 2: Growth of Students Enrolment ('000') in Higher Education Source: University Grant Commission report 2012

Fig 2 shows the total enrolment during 2012 among the various faculties, the maximum growth in enrolment being in the faculty of engineering (24.82\% increase), followed by commerce and management (5.46\%) and education (4.63\%). During 2011-12, the maximum enrolment of students have been in the faculty of arts (30.6\%), followed by engineering (24.3\%). Slightly above 3 percent of men and 1 percent of women attend college; women account for a third of the students at this level until 1993. This gender ratio is found in most fields of study, excluding firstly engineering and commerce, where women account for a much smaller proportion of the students; and secondly education, where women account for nearly half of all students

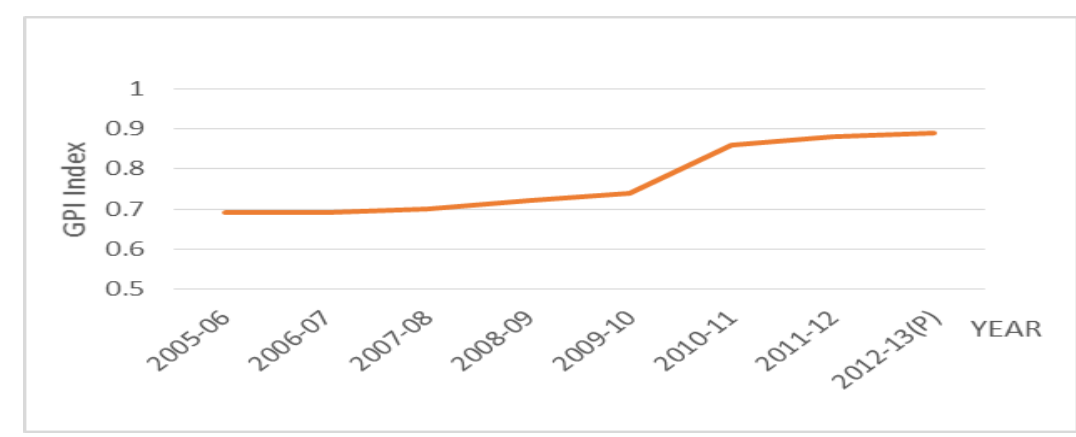

Figure 3: Gender Parity Index in Higher Education (18-23 Years) Source: MHRD Department of Education, Government of India

The Gender Parity Index (GPI) is a socioeconomic index usually designed to measure the relative access to education for males and females. In its simplest form, it is calculated as the quotient of the number of females by the number of males enrolled in a given stage of education. Gender equality has long been a major issue in Indian history since ancient times. Currently gender equality in education is one of the main 
priorities within every sector of Indian society, including education. The total number of girls enrolled per hundred boys was 13 in 1950, in 2012 this number increased to 81 resulting in an increase in the Gender Parity Index GPI of up to 0.89 in 2012 as shown in fig.3.

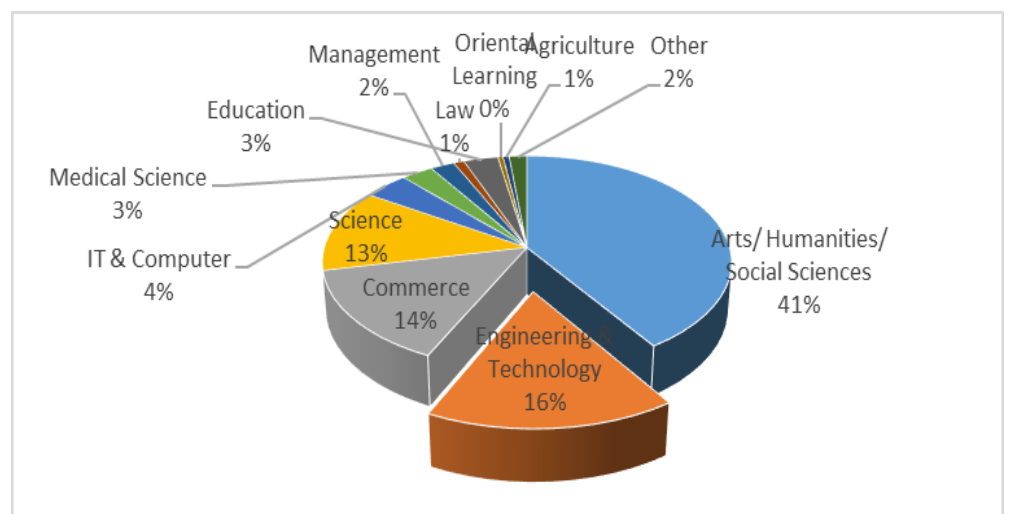

Figure 4 : Overall enrolment of students in different disciplines for UG programs.

Data source: AISHE Portal (www.aishe.gov.in)

Overall enrolment of students in different disciplines for UG programs. The Student enrolment is $79.44 \%$ undergraduate, amongst them $40.69 \%$ prefer to study Arts, Humanities and Social Science, 16 \% Engineering and Technology, 14 \% Commerce and 4\% IT \& Computer Science, while the most neglected fields of enrolment are Agriculture 0.55 and Law $0.95 \%$. At the master and Post Graduate level, only 11.39\% of enrolment for Post graduate and $0.72 \%$ for $\mathrm{Ph}$. D and additional research which are of similar enrolment numbers for both genders represented in fig.4.

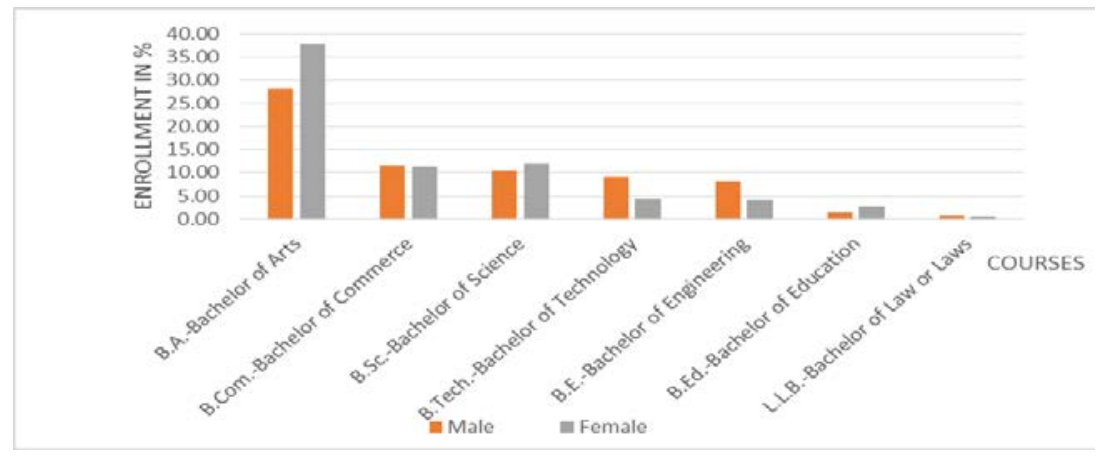

Figure 5 : Enrolment in different Programmes at graduation level (UG) Data source: AISHE Portal (www.aishe.gov.in)

At the graduation level certain programs, such as Bachlor of Arts and Bachlor of Science, women's enrolment is much higher than male's. Whereas in commerce \& MBBS. It's almost equal, notably in Bachlor of Engineering and Bachlor of Technology female enrolment is less when compared with male shown in Fig. 5 


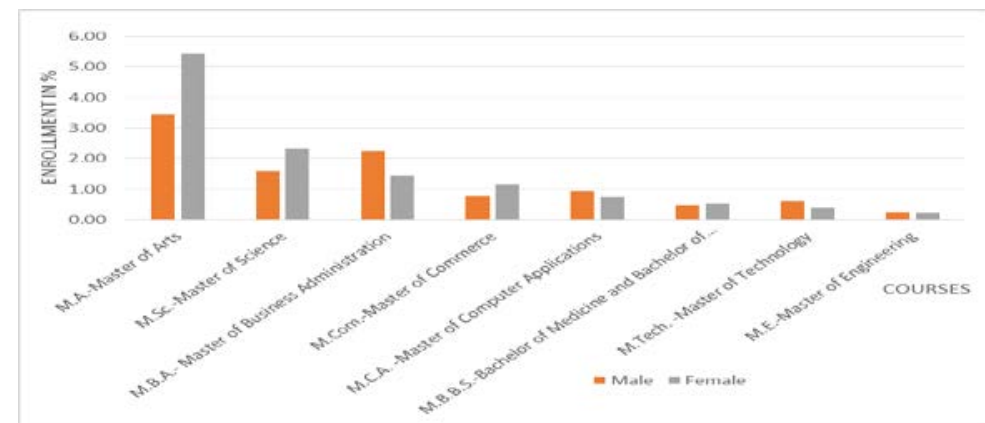

Figure 6: Enrolment in different Programmes at post graduate level

At the Post Graduate level there is a similar enrolment pattern being observed where in Master of Arts and Master of Science \& Master of Commerce women's enrolment is higher than men which is being almost equal at graduation level. Furthermore, a similar pattern is seen in Engineering, Technology and Management with fewer enrolment of women shown in Fig. 6.

In 2012 women's enrolment is higher in non-technical fields; According to MHRD in 1993 a very small percentage of the Indian population attends college, women account for a third of the students. This gender ratio is found in most fields of study excluding engineering and commerce, where female students are much fewer, and education, where nearly half are female students.

\section{Conclusions}

Indian education system is one of the largest in the world, having a network of more than 665 Universities, including one national \& thirteen state open universities. 35829 Graduate, PG, institutes in which general courses account for 14.3 million and professional courses accounts for 7.1 million; while more than 35 lakhs students enrolled in distance mode out of 2.96 million students in the country. Gender ratio in higher education has increased up to 80 girls per hundred boys resulting in an increase in GPI to 0.88 respectively. Over the last few years huge numbers of students are enrolling for higher education, a $1 / 4^{\text {th }}$ women and $2 / 3^{\text {rd }}$ male ratio was identified in the majority of the fields except engineering, where women's enrolment percentage was much lower. Women enrolled in education numbered almost half in comparison with men until 1992-93. However; at present women's enrolment is high in nonprofessional courses-Bachelor of Arts \& Science, almost equal in Bachelor of Commerce at graduation level, being higher at post-graduation Master of Commerce. Similar trends are being observed in Engineering Management and Technology as professional courses with fewer enrolments of women as compared with men resulted in different pattern.

In India very few efforts have been taken to explore the women's issues and status in higher education system further longitudinal researches are needed to explore for the improvement therein. 


\section{References}

ASHE. (2012). Annual Status of Higher Education in States and UTs, 2012. Retrieved from ASHE: http://www.aishe.gov.in

ASHE. (2012). http://www.aishe.gov.in Retrieved from ASHE.

Commission, U. G. ( Feb 2012 ). University Grant Commission (UGC) Report Feb 2012 . Delhi, India: University Grant Commission.

Commission, U. G. (2012). UGC Report .

Government of India, M. o. (2004). Selected Educational Statistics . Retrieved from http://mhrd.gov.in/highereducation

Gupta, N. (2003). Women's Education Through Ages,. New Delhi: Concept Publications Co.

IBEF. (2014, December ). Education Sector in India . Retrieved from India Brand Equity Foundation (IBEF): http://www.ibef.org/industry/education-sectorindia.aspx

India, G. o. (2011). Census report.

Jitendra, M. S. (April 2013). Status of Women Education in India. Educationia confab journal, 162 - 176.

Kumar. (2014, 12 7). The Education System in India. Retrieved from GNU Operating System: https://www.gnu.org/education/edu-system-india.html\#sasi

MHRD, G. o. ( 2013., October 26). Department of School Education and Literacy. Retrieved from "Sarva Shiksha Abhiyan".

Naik, j. P. (1978). Educational reform in India :a historical review. 1-2.

Pujar, U. (Feb. 2014). Trends in Growth of Higher Education in India . IOSR Journal of Economics and Finance, 01-04.

Velkoff, V. A. (October 1998). Women of the world. Womens Eduation in India. International Programs Center. 


\title{
'ROSE to DELAROSE' - Developing and transitioning a web- based pan European self-help programme for the management of work related stress.
}

\author{
J.S.G. Wells*, C. Ryan** \& M. Bergin*** \\ * Head of School of Health Sciences, Waterford Institute of Technology, Waterford, Ireland, \\ jswells@wit.ie \\ ** Research Assistant, School of Health Sciences, Waterford Institute of Technology, Waterford, \\ Ireland, cryan@wit.ie \\ *** Lecturer, Department of Nursing \& Healthcare, School of Health Sciences, Waterford \\ Institute of Technology, Waterford, Ireland, mbergin@wit.ie
}

\begin{abstract}
Work related stress is an increasingly common aspect of modern life and is identified as a considerable risk to employee mental well-being across Europe (Wells, 2011, EASHW, 2014). Numerous psychosocial web based interventions have been developed in response to this. However, targeted psycho-social interventions aimed at enhancing worker resilience and their management of work-related stress are needed if the issue is to be tackled effectively (Wells et al. 2011). This paper documents the development of two digital platform programmes, namely ROSE and DELAROSE, which deliver tailored interventions and act as valuable and accessible supports for workers in the health and social care sectors. The paper also describes the process of transitioning the ROSE into the educational DELAROSE programme in an effort to incentivise workers in these sectors to engage with the programme, and provide them with an accredited academic award from one of three Higher Education Institutions (HEI's) across Europe in recognition of their learning.
\end{abstract}

Keywords: Stress; Health \& Social Care Workers; Online Approaches

\section{Introduction}

The health and social care sector is ranked as one of the most stressful fields in which to work (Wells, 2011). Those working in this area have been found to experience the highest rates of work-related anxiety, stress and depression in any field, as reported by the UK Health and Safety Executive (2014). The highest rates of work-related stress are to be found amongst nurses, workers in caring personal services and welfare and housing associations. In Austria, approximately 65\% of the 350,000 employed in these sectors report at least one work related stress symptom. The European Agency for Safety and Health at Work (2009) found that 30\% of workers in education, health and welfare report feeling stressed at work.

\section{Managing Work Related Stress}

Identifying specific stressor issues and developing mind-body resilience is recognised as important in terms of prevention, self-management and empowerment of employees to work productively until their retirement age (Lazarus and Folkman, 1984; EASHW, 2014). Interventions that build upon and support individuals' resiliency within organisations are increasingly seen as an effective approach to the management and reduction of occupational stress (Ridge et al., 2011).

Interventions can be categorised into person-work interface directed (enhances the congruence between the person and the organisation e.g. role conflict-ambiguity) and organisationally directed so that enhanced employee well-being can be achieved, depending on the design of intervention (Ruotsalainen, 2008). 
MHealth for wellness focuses on providing immediate mobile access to support individuals in the work place for a range of health related problems and provision of health advice (European Commission, 2014). This paper will document the development and provision of a cost- effective and accessible web based programme for health and social care employees to manage their work-related stress - the European Commission funded DELAROSE (Delivering E-Learning Accreditation to Reduce Occupational Stress in Employment) and ROSE (Reducing Occupational Stress in Employment) projects.

\section{European Commission funded projects:}

In 2009, an international consortium, led by Waterford Institute of Technology, Ireland secured funding from the EU to develop an easy access psycho-social online self-help programme for health and social care workers to manage their work-related stress. The project was called Reducing Occupational Stress in Employment (ROSE), and it surveyed health and social care workers across five European countries. As well as measuring their levels of work-related stress, the project also examined what they felt they needed in terms of organisational policies and support in relation to reducing stress at work. Based on this survey work, expertise within the group and a review of the scientific literature, the ROSE online self -help programme was developed.

The ROSE project aimed to provide an online open access and relevant self-help combined person and work-directed stress management programme in order to improve the long-term retention within services of staff in rehabilitation and support services in health and social care.

An important consideration within the ROSE project was financial viability in relation to the 'reach' of the interventions across the sector. Thus ROSE had to be provided to the target group at minimal cost. Having secured EU development and innovation funding to support ROSE, a web based programme platform was used to develop and initially implement an online self-help intervention programme provided freely to the sector, hosted for minimal cost on the project co-ordinator's server.

In addition to this, the team observed that workers across Europe in this sector saw a lack of training and knowledge in managing challenging situations as a source of work stress. They also specified that they would like to receive some formal recognition in relation to their engagement with ROSE.

The team chose to use Moodle, an open source virtual learning environment (VLE) to deliver the ROSE programme. Preliminary feedback from the users indicated that the Moodle format was too plain and not graphical or interactive enough for potential users. This was an important consideration, since the attractiveness of the learning environment encourages engagement with the ROSE programme. Therefore, the ROSE team decided to utilise an 'off the shelf' software package, 'Articulate', to deliver the programme content.

Nimmo (2014) carried out a pilot study to determine the effectiveness of the ROSE program in a small sample of new graduate nurses in a small hospital in upstate New York. The study assessed whether the ROSE programme as an intervention assisted new graduates with their transition into a hospital setting by improving job satisfaction, decreasing stress, and increasing intent to stay. Also, the researcher attempted to determine if the ROSE program is transferrable across cultures, since it was developed in Ireland for a particular population of EU mental-health workers. 
This study highlighted that the ROSE program did indeed improve job satisfaction, decrease stress levels, and improve overall turnover rates in new graduate nurses and highlights that the ROSE program is indeed transferrable across cultures.

\section{Incentivising the use of ROSE through DELAROSE}

One of the findings arising from the ROSE programme was that workers wanted formal recognition of their learning once they had used ROSE. The team felt that extending ROSE into an accredited programme would incentivise workers to engage with the programme and show employers that they had acquired a skills and knowledge base in relation to their professional practice. Employers indicated that they would favour a formal course as a means of meeting health and safety metrics in the work environment.

These findings formed the basis for a further application to the EU for funding to establish ROSE as an accredited and sustainable programme for health and social care workers and to further strengthen programme content. The result became the DELAROSE project, which stands for 'Delivering E Learning Accreditation to Reduce Occupational Stress'. The programme is funded by the Education and Culture Directorate General, Leonardo Da Vinci fund for Lifelong Learning and is due to be completed at the end of October 2015.

Thus DELAROSE provides an opportunity for participants to receive accredited recognition for their learning from a Higher Education Institutions (HEIs). This could contribute to worker mobility while at the same time the programme would remain available for the purpose of personal support. The team have developed a two pronged strategy in this regard. The first is to embrace the concept of the MOOC (Massive Online Open Course) which still allows for free open access. Second is a registration process for those who wish to acquire credits through the ECVET (European Credit system for Vocational Education and Training) and ECTS credit systems.

Using the MOOC concept to deliver DELAROSE offers the opportunity for health and social care workers to fully engage with the programme as a means to manage their personal working environment to be less stressful and then decide post implementation whether they would like to receive credit for their achievements. This is important as there is considerable variability in the sector in terms of educational ability and qualifications and some workers may feel intimidated in having to 'sign up' for the programme from the start (Wells et al., 2011). The MOOC concept offers these workers the chance to use it and thereby build up their confidence towards registering for it. 


\section{DELAROSE Programme Content:}

Person Centred Management of Work-Related Stress:

1) Introduction to Stress

2) Prevention of Stress

3) Learning Ways of Coping with Stress

4) Changing How You Think About Things

5) Giving Feedback
Environment Centred Management of Work-Related Stress:

1) How the Organisation Contributes to Stress

2) Interpersonal Skills

3) Leadership and Motivation

4) Change Management

5) Organisational Policies

The DELAROSE online programme (www.delarose-project.eu) is provided in three languages (English, German and Italian). The content of the programme consists of units of learning divided under two thematic strands; a primary level intervention which consists of work-directed approaches to stress management, and a second strand which is person-directed and which focuses on the management of one's personal stress.

Expected outcomes from DELROSE include the development of a shared understanding of work-related stress in the sector across Europe and the transfer of skills and knowledge between Swiss and EU educational establishments in this field. It will also enhance European vocational education co-operation through utilising European Credit system for Vocational and Education and Training (ECVET) harmonised with the European Credit Transfer System (ECTS). Additionally, it will establish an ECVET and ECTS referenced online multi-lingual programme (English, Italian and German) in work-related stress management that will facilitate the mutual recognition of qualifications between institutions, and provide an access and progression route for workers within the sector.

\section{Conclusion}

Stress and particularly work related stress is now a feature of modern life and the human condition (Wells, 2011). There have been a number of broad based psychosocial web based interventions developed to deal with this and associated mental wellbeing issues, for example

'Hello Brain'; 'MOOD MAP'; 'PRISM' and 'Oiva'. However, sectoral targeted psycho- social interventions to assist workers with work related stress prevention and management are needed if the issue is to be effectively dealt with since particular working environments can create specific stressors not common in other sectors (Wells et al. 2011). Provision of a cost effective occupational health infrastructure that is readily accessible also provides small scale employers with a facility for the establishment of a resilience building work culture. Digital platforms delivering targeted simple programmes, such as ROSE and DELAROSE, can provide a valuable 
and accessible support for worker and employer that enhances the capability of both to manage work related stress.

\section{References}

European Agency for Safety and Health at Work, (2009). European Risk Observatory ReportOSH In figures: Stress At Work - Facts And figures, Luxembourg.

European Agency for Safety and Health at Work (2014). Priorities for Occupational Safety and Health Research 2013-2020 Brussels EASHW.

European Commission (2011). Commission Staff Working Paper Report on the implementation of the European social partners' Framework Agreement on Work-related Stress Brussels EC.

Lazarus, R.S. \& Folkman, S. (1984). Stress, Appraisal and Coping New York Springer.

Nimmo W. (2014). Stress among new graduate nurses. Is the Rose Program a successful intervention in a hospital setting? Unpublished $\mathrm{PhD}$, John Fischer College, Rochester, NY.

Ridge, M., Wells, J.S., Denny, M., Cunningham, J. \& Chalder, T. (2011). Developing a web based stress management intervention for occupational support workers Journal ofMental Health 20(22)185-197.

Ruotsalainen, J., Serra, C, Marine, A. \& Verbeek, J. (2008). Systematic review of interventions for reducing occupational stress in health care workers. Scandinavian Journal of Work, Environment and Health, 34(3)169-178.

Wells, J.S. (2011). Guest Editorial: The Impact of Stress Amongst Health Professionals Journal of Mental Health 20(22)111-114.

Wells, J.S.; Denny, M. \& Cunningham, J. (2011). Work related stress and European policy A comparative exploration of contextual stressors in the rehabilitation sector in five European countries Journal of Mental Health 20:22:165-173. 


\title{
Saving Elephants in Africa - Concept to Reality through Experiential Engineering Design
}

\author{
R.E. Gorga* and J.S. Jur* \\ * Department of Textile Engineering, Chemistry \& Science \\ North Carolina State University
}

\begin{abstract}
The purpose of this work is to provide undergraduate seniors in engineering 1) the opportunity to work on an industry/externally sponsored project and 2) provide an outside the classroom learning experience. Here we discuss each of these aspects as it relates to a single project, specifically working to save African elephants from unnecessary slaughter. The main results are that 1) industry sponsor commitment to the project is the number driver for overall success of the project and 2) an inthe-field educational experience is invaluable for the students to learn the real world pressures of time constraints and developing real-time contingency plans to successfully complete project goals. In conclusion, we discuss how an external sponsor, committed to interacting with the team and an "outside the classroom" learning experience coupled with good mentoring from the faculty provide an experience that closely parallels a real-life work experience for the students.
\end{abstract}

Keywords: Engineering Design; Undergraduate Education; Industry-Student Interaction; Project-based Learning; Outside-the-classroom learning

\section{Introduction}

Senior Design Capstone Course - The Senior Design capstone course serves as the final stage in the student's undergraduate degree to apply their skills to unique problems. Student entering this capstone course in the Department of Textile Engineering, Chemistry and Science (TECS) at North Carolina State University will have already gained valuable expertise in engineering fundamentals, information systems, medical textiles, product development, supply chain management, and consumer behaviour. The Senior Design capstone course provides students the opportunity to work with industry to creatively synthesize solutions to relevant problems, that is, the focus is on experiential learning as described by Kolb (1984). The students work on teams to solve technical problems, study commercialization processes, utilize project management tools, think globally, understand/develop intellectual property and apply patent mapping principles. Students in the TECS program are expected to graduate with the skills necessary to conceive (design and create), specify, implement, test, produce, and market complex engineering systems (see Fig. 1). Often, teaming with other department senior design course (such as this project outlined later in this paper) offers an experience that is similar to reality after college. These other senior design courses have parallel objectives to the TECS program.

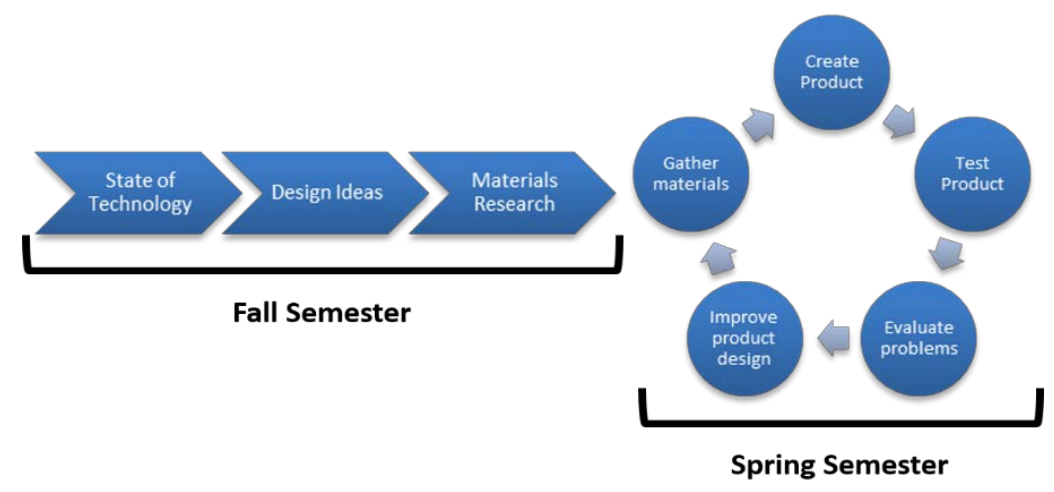

Figure 1. Overarching course paradigms for the fall and spring semesters. 
Industry Sponsors - Project stakeholders from industry sponsor and the faculty mentors (Drs. Jur and Gorga) guide the student team through the engineering design process to develop an innovative product that meets the criteria and constraints of the project definition. In the past two years, project sponsors have included: HanesBrand, Army Research Office, Nike, Johnson Controls, Limited Brands, Adidas, Hunter Safety Systems, Under Armour, Secant Medical, Porticos, and Firestone (see Fig. 2). Example final posters and student testimonials may be found online at: http://tx.ncsu.edu/tecs/acdemics/senior-design/.

Experience has shown that a project's success has very little to do with the project topic or the "name" of the company, but is strongly correlated to the commitment the sponsor has to interacting with the student team. If the sponsor has a strong commitment to communicating (providing feedback, answering questions, and generally being responsive to the team) the project has the highest probability for being successful. Therefore the faculty mentors have developed screening tools (to aid in sponsor selection) and provided guidelines and guidance to the sponsors (once selected) to help ensure a successful sponsor-team interaction.

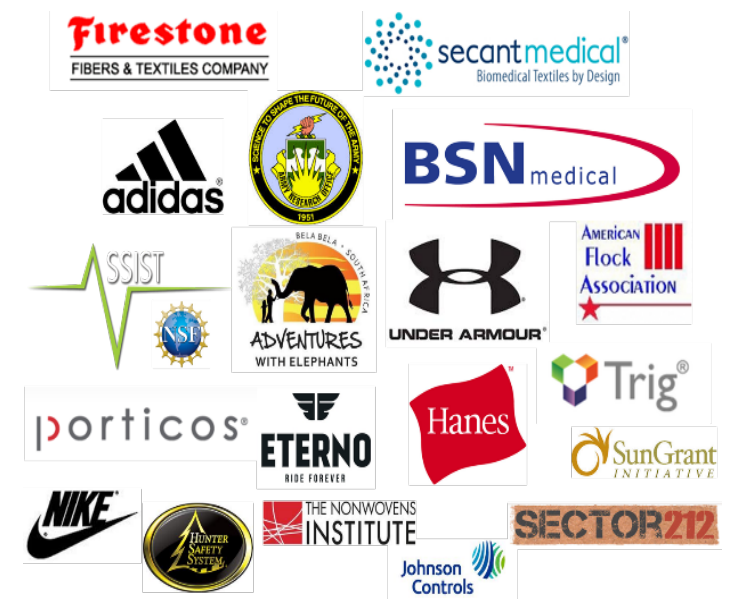

The most rewarding and educational aspect of the course for the student and sponsor is their mutual interaction. Expectations for the sponsor mentor include:

$>$ Regular meetings with team

$>$ Assist in defining project scope

$>$ Provide specific project feedback

$>$ Provide technical mentoring \& feedback on their deliverables

$>$ Provide coaching to help the student team reach the best solutions...it is important for the sponsor mentor not to tell the team exactly what to do!

Figure 2. Examples of industry sponsors over the last two academic years with an excerpt taken from our sponsorship solicitation (and the sponsor contract). In this period we have mentored 31 project teams, encompassing 98 undergraduate students in their last year of academic study.

\section{Teaching Pedagogy}

The teaching pedagogies employed in this particular project include both experiential learning (Kolb, 1984) and outside the classroom experiences, as discussed by Kuh (1994). This project is unique in that it incorporates both pedagogies. While every senior design project does focus on experiential learning, not everyone has as strong an outside the classroom component. However, our classroom is unique in that the focus is on a problem based learning platform (Savery and Duffy, 1994) and is therefore not a "traditional" classroom experience.

\section{Experiential Example: Collar for Elephant Monitoring and Feedback}

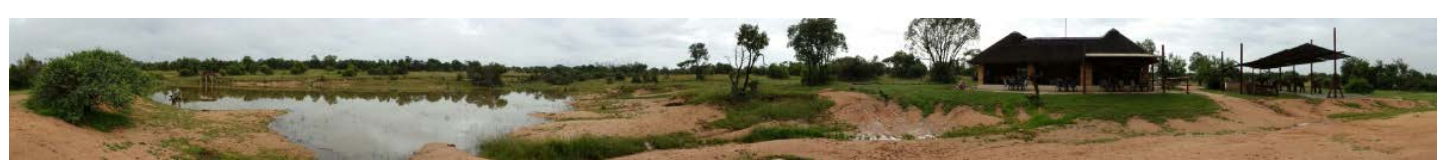

Figure 3. The "outside the classroom" classroom. This is the location where the collar was placed on the elephant, evaluated, and further iterations of redesign and testing occurred over the week long event. 
Background - The need for a keeping elephants out of villages is immediate. Elephants are getting killed and injured just because they go into areas in which they do not belong. Ensuring elephants stay out of villages keeps the villagers safe from their crops being destroyed, their houses getting damaged, and their water sources from being eliminated. The human-elephant conflict will only increase until preventative measures are made to allow humans and elephants to coexist without difficulty. The question posed by Sean Hensman (Director, Adventures with Elephants) was: "Can an innovative self-power collar be fabricated that provides non-harmful feedback to deter elephants from a designated area?" In response to this request, our team developed concepts for integrating nature-inspired feedback (sound and vibration) into the collar that allows for informed deterrence of the elephant into unwanted locations.

Existing technology for an elephant collars have the sole purpose of geotracking. Initial efforts by our team were to re-define an elephant collar with the following criteria and constraints:

1) The collar must be self-powered for extended useable lifetime of the animal in the wild. (The current battery life is short, often 1 month or less, resulting in the need to charge the battery which requires animal tranquilization.) A self-powering strategy is minimally invasive and the lifetime goal is 5-8 years.

2) Location tracking of the elephant must be included. The African landscape requires special protocols for communication between the collar and a base station.

3) Nature-inspired feedback mechanisms should be integrated into the collar. Protection of the elephant is paramount!

4) The collar must be 'elephant' and 'Africa' durable, as well as be of reduced burden as compared to the current collar structures, since the African environment is already tough enough on the elephant.

Testing - A major result of the senior design project was a field analysis (see Fig. 3) conducted at Adventures with Elephants in March of 2014. This field experience is in line with the importance of outside the classroom experiences, as described by Kuh (1994). Adventures with Elephants is a range, directed by Sean Hensman, that provides shelter for a group of five elephants that have previously faced life threatening circumstances. To support the facility, Adventures with Elephants provides positive human-elephant interactions that teaches humans about the elephants. More information can be found here: www.adventureswithelephants.co.za. The following field tests were performed using two collars and additional verification testing equipment.

1) The first collar, which was designed to primarily test packaging durability, was given a 24 hour stress by placing the collar on the bull elephant. From this test we observed behavior of the elephant's reaction to the collar and the elements that the collar would endure in a typical day. Figure 4 provides images of the application of the collar upon Chisuru and the durability testing.

2) The first collar, which was designed to primarily test packaging durability, was given a 24 hour stress by placing the collar on the bull elephant. From this test we observed behavior of the elephant's reaction to the collar and the elements that the collar would endure in a typical day. 


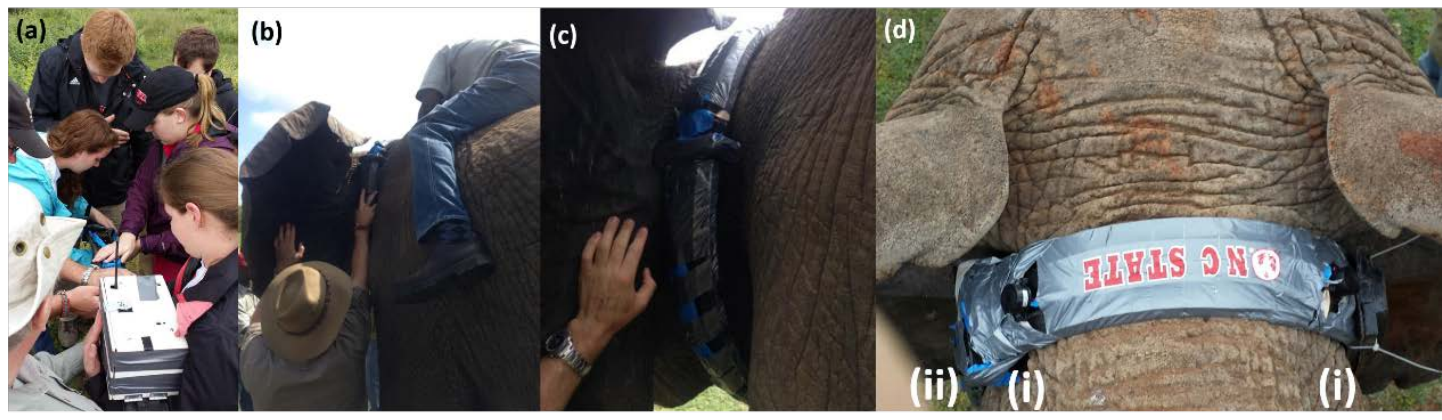

Figure 4. (a) Undergraduate student team performing one last verification test of the electronics. The electronics were held in a white box located at the bottom of the image. The antenna for remote control of the buzz and vibration can be observed sticking through the box. (b) Application of the collar onto Chisuru. (c) The collar in place. (d) Top view of the collar showing the locations of the speakers for the buzz feedback (i) located behind each ear and the motor used for vibration (ii) located on the side of the neck. The location of the motor can also be seen in (c).

3) A second collar, not constructed for durability testing, incorporated vibration and soundbased feedback mechanisms, as shown in Figure 4. The vibration feedback was design to the simulate ant or insect movement, while the sound (or buzz) was design to simulate bees. To test these feedback mechanisms, a remote activation of the collar was employed. The collar was again placed on the bull elephant and was subsequently allowed to go toward a field that contained a pile of apples. Perimeter zones designated at $\sim 50$ and $\sim 25$ meters away from apples were used for activation of the sound and vibration, respectively. A diagram and results of the initial experiment are shown in Figure 5. Our collar showed that upon activation of the vibration, Chisuru stopped abruptly (Fig. 5(c)), turned away from apple pile, and walked back to the rest of the pack. Moreover, Chisuru did not approach the area for a period of $30+$ days after our departure.

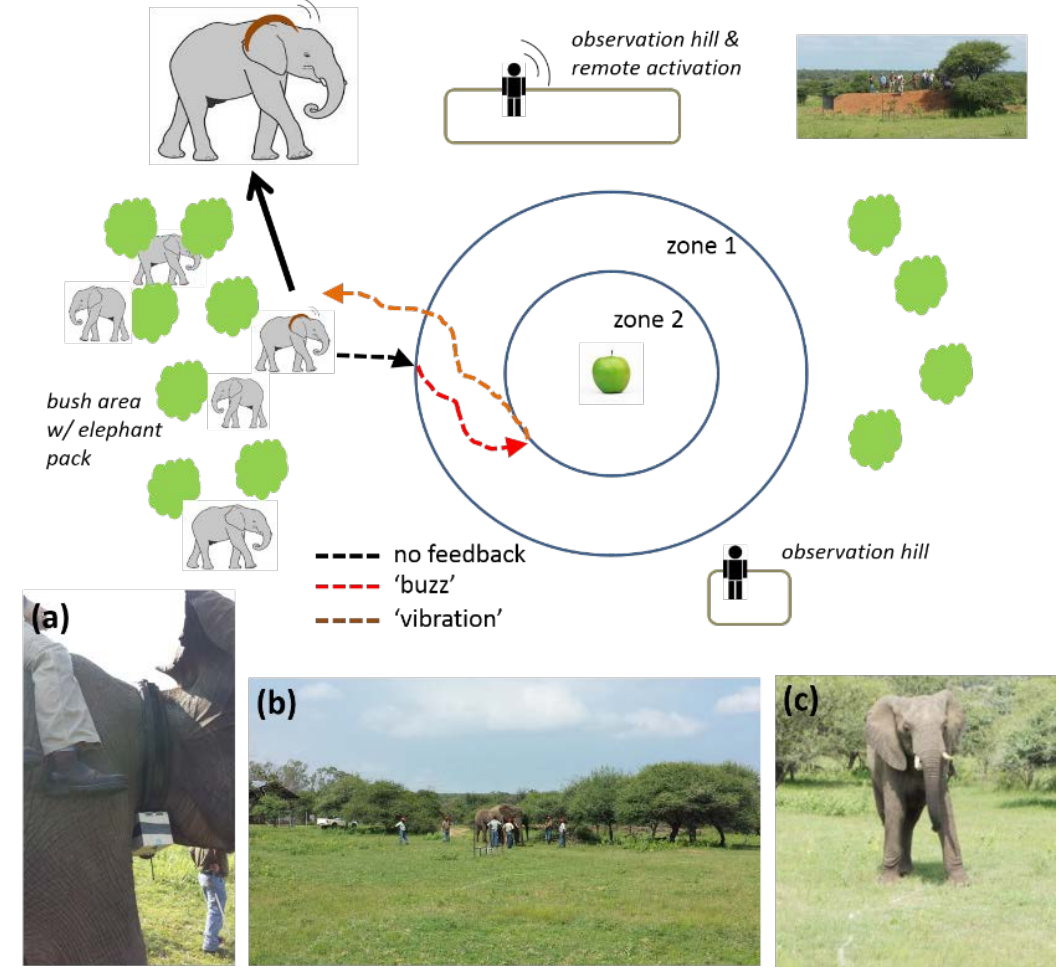

Figure 5. Diagram of the testing scenario used to verify the feedback hypothesis. When Chisuru heard the buzz sound, he stopped briefly before proceeding to the apples. When he felt the vibration, he stopped and returned to the pack in the bush adjacent to the field. The bottom panels show (a) Chisuru prior to the test, (b) the field test site, and (c) Chisuru's initial reaction when the vibration was initiated. 
4) The efficiency of the solar cells were evaluated at various conditions, including sunlight and time of day to determine a prospective power harvesting capability and number of solar cells required to support the collar.

5) Two prospective GPS devices were tested and verified for signal strength at 8+ strategic locations at the $25 \mathrm{~km}^{2}$ Adventures with Elephants range. This included evaluation of a tracking software tested on site.

Upon arrival back to NC State, the teams implemented solutions to the preceding design challenges in a new prototype iteration of the collar, with a focus on reduced weight and improved surface smoothness. In addition, a first draft of an electronics manual was written. This prototype, while not solving all of the challenges, provides a material roadmap for methods to improve the collar. These improvements are currently underway in a second year of the project.

\section{Senior Design Capstone Outcomes:}

\section{Industry and Education Relationship -}

$>$ Potential projects are pre-screened by the instructors prior to submission. Often, the project scope is too broad or is outside of the focus of the course. While open-ended questions are sought, parameters need to be set so that there is a tangible 'final product' at the end of the academic year.

Setting expectations for the industry sponsors and reiterating these expectations early in the project is essential to inspire and motivate the industry sponsor. These expectations include a single direct point of contact for the students and providing internal company resources to help ensure the students success.

$>$ While the project topic is provided by the industry sponsor, the details of the project (criteria and constraints) are developed by the students and mutually agreed upon with the sponsor to develop mutual expectations.

$>$ A team contract is developed and approved by the sponsor and faculty advisors, which includes how the teams will report to the sponsor (email, video conference, conference call) and how frequently (weekly, bi-weekly). The contract also identifies how the team will operate and deal with internal conflict.

> From the viewpoint of the sponsor, often the student team is an indirect employee of the company. This helps the students feel integrated into part of the company culture.

$>$ Intellectual property rights can be the biggest deterrent for a potential industry sponsor to work with a senior design program. At NC State, undergraduate students retain their individual rights outside of the university and may independently sign non-disclosure agreements with the sponsor. This provides an important lesson on how to protect individual rights and retain ownership of intellectual property. Further, many students file patent disclosures and learn how the patenting process works.

$>$ Year by year, we have grown in size and expertise. We encourage a donation of $\$ 10,000$ USD to sponsor a project, which is adjusted based on the scope of the project and the size of the company. We will typically lower the cost for smaller, in-state companies. This monetary investment by the sponsor provides a budgetary foundation for the students and teaches them to operate within a frame work with limited financial resources.

$>$ Two-directional feedback between the sponsor and the faculty mentors is critical for developing strategies in team and project issues. A mutual respect from all parties is necessary for this to be effective. 


\section{Experiences Outside the Classroom -}

One of the issues that is most apparent to the students is the real world time constraints of being in the field. The team only has a finite period of time to achieve its goals, with a very real (and physical) deadline.

Students also need to learn to deal with unforeseen issues and must learn to be adaptable in how to solve these problems and work with the resources available in the moment. Students learn how to develop "in the moment" contingency plans to move forward.

The faculty mentors need to set expectations high. Student teams will rise to the challenge!

Students experience working in a high stress environment (real life situations create different stressors than classroom stressors). This experience prepares them for stressors similar to what they will face in the workplace.

$>$ Global perspective and awareness is difficult to teach in the classroom, but can be easily communicated through an on-site experience. The students gained an appreciation for the gentle character, physical power, and high intelligence of the elephant and the endangerment they face through human conflict that other senior design projects would not have otherwise provided. This inspiration quickly spread across the university and beyond as the team was invited to speak to high school summer programs regarding their experience. A story on the project featured on NC State's website (https://news.ncsu.edu/2014/10/elephant-collar/).

\section{Conclusions}

The main results are that 1 ) industry sponsor commitment to the project is the number driver for overall success of the project and 2) an outside the classroom educational experience is invaluable for the students to learn the real world pressures of time constraints and developing real-time contingency plans to successfully complete project goals. In conclusion, we discuss how an external sponsor, committed to interacting with the team and an "in the field" learning experience coupled with good mentoring from the faculty provide an experience that closely parallels a real-life work experience for the students.

\section{References}

Kolb, D. A. (1984). Experiential learning: experience as the source of learning and development. Englewood Cliffs, NJ: Prentice Hall.

Kuh, G. D. (1994). Student Learning Outside the Classroom: Transcending Artificial Boundaries. ERIC Digest.

Savery, J. R., and Duffy, T. M. (1995). Problem based learning: An instructional model and its constructivist framework. Educational technology, 35(5), 31-38. 


\title{
Technical and Vocational Education in the Context of Reindustrialization. The Case of Romania
}

\author{
P. Dobrescu*, L. Radu* \\ *National University of Political Studies and Public Administration, Bucharest, Romania
}

\begin{abstract}
This paper aims to analyse the feasibility of a vocational and technical education campus in Central Romania (Braşov County). We discuss the necessity for such an initiative in the context of the EU reindustrialization strategies. There is a strong correlation and a causal relationship between economic growth, reindustrialization and employment (especially youth employment). In many EU countries, youth unemployment rate is increasing, despite the fact many organizations report that they lack properly trained workforce. Definitely, skills needed to enter the labour market are diversifying; some areas are oversaturated with overqualified specialists, while others remain weak in terms of welltrained workforce. This phenomenon signals the gap between the demand for skills, on the one hand, and the skills supply, on the other hand. This paper addresses this gap by proposing a comprehensive plan for reviving technical and vocational education in Central Romania, while taking a close look to educational (i.e. distribution of seats available at high schools, depending on the branch organization of the secondary education), economic (i.e. economic crises, industrialization of community building countries) and social (i.e. unemployment rate, social groups and structures) factors.
\end{abstract}

Keywords: technical and vocational education, reindustrialization, skills, unemployment

\section{Introduction}

The post crisis world has undergone structural changes. It has changed especially when referring to developed countries, which have been most affected by the economic earthquake that started in 2008. These countries have not reached the GDP levels or the development rate they had had before the crisis. Financial and economic tensions prevent many countries from attaining a real economic recovery, which translates into modest growth rates, which could hardly be situated between 1 and 2 percent. For instance, estimations on EU growth are around one percent. This is below of what Paul Krugman, winner of the Nobel Prize, calls technical recovery. Economic revival is only possible when actual growth exceeds two percent. USA is closer than the EU to this target.

The crisis, which has started as a financial crisis has gradually transformed into an economic crisis. The region that was most severely affected by the crisis in the developed world is Europe. According to The Economist, Europe's economic situation is "the main economic problem of the world." The Union still accounts for almost one fifth of the world's output; however, EU's growth trend is going downwards, one of the explanations being what the above cited magazine called "its self-destructive behaviour."

There is a whole debate about the factors that have led the European Union to be in such a distress. For this paper we only focus on two key explanations. The first one is that EU is an unfinished project, stuck between the sovereignty ideal, which emphasizes the state and its powers - on the one hand, and the federalist perspective, which, by contrast, emphasizes the importance of supranational structures - on the other one. EU is somehow caught between these two perspectives, which hinder effective strategic decision-making. According to David Marquand, "the new, continent-wide Union of the 2000s, with its twenty-seven member-states, its 500 million citizens, and its Europeanized currency and the Central Bank, was still trapped in the old halfway house between con-federalism and federalism. The foundations were patently shifting under 
the weight they now had to carry; there were cracks in the ceiling and loose slates in the roof" (2011, p. xi).

The second explanation is linked to the emergence of the so-called "financial periphery", involving a gap between Northern Europe and Southern Europe. This raises the question of economic and psychological fragmentation of the Union. Southern Member-States have accumulated more debt and saw looming unemployment rates, while needing considerable financial aid.

The economic strength of a state has two main sources: the workforce (population size) and the productivity rate. EU has an important vulnerability - as compared not only to emerging countries, but also to developed countries (e.g. USA): shrinking demography and accelerated aging.

\section{EU's Development Gaps and Reindustrialization}

Economic advancement and GDP growth are essential ingredients of development, though not the only ones. Development is an economic phenomenon as much as it is a social one, involving poverty, unemployment, and inequality reduction. Therefore, it should be conceived as a multidimensional process that implies the reorganisation and reorientation of the entire economic and social system. In addition to the improvement of income and productivity, development implies, typically, radical changes in the institutional, social and administrative structures. Development also implies changes in peoples' attitudes and, in many cases, even in their habits and beliefs - therefore, it implies cultural changes (Adelman, 1999). In EU, debates on development are strongly focused on reindustrialisation. Currently, industry sectors generate $16 \%$ of the EU's GDP. According to the 2020 Horizon Strategy, industry should account for $20 \%$ of the GDP. The four pillars taken into account at the level of reindustrialisation are: investments in innovation, better market conditions, access to capital, and skills improvement. Therefore, education should match the development needs.

The engine of development is knowledge, under its different forms - education, innovation, academic research and industrial research, personal improvement. We might rightfully state that knowledge is the engine of development - here, knowledge takes various shapes, such as education, academic and industry research, personal development - only to name a few. "Development requires closing the gap not only in “objects”, in human and physical capital, but also in knowledge. Knowledge and capital are in fact complements: improved knowledge enhances the return to capital, while additional capital provides the opportunity to make use of recently acquired knowledge. Incorporating knowledge into the development strategy requires creating capacities to absorb and adapt knowledge (through investments in human capital and in research institutions), investing in technologies to facilitate the dissemination of knowledge, and creating knowledge locally." (Stiglitz, 1998) Or, in the word of Th. Piketty (2014), "the main forces for convergence are the diffusion of knowledge and investment in training and skills." 


\section{Vocational and Technical Education in Romania}

\section{Background}

After a strong contraction in 2009, the Romanian economy has begun to recover; however, in Romania there are important disparities between the strongly urbanised areas - that have become growth poles - and rural and semi-urban areas - strongly affected by poverty. The most recent report of the European Commission regarding the economic and social cohesion reveals a deep gap between the Bucharest-Ilfov area (that has a GDP of $120 \%$ of the EU average) and the North-East region (that has a GDP of $24 \%$ of the EU average, being one of the poorest regions of the EU).

An important key to boosting development is reindustrialisation, a phenomenon that is starting to become more and more visible in several regions - including Central Romania. Brașov county is situated at the very centre of Romania, being subject to a steadily intensifying reindustrialisation process. Currently, the number of technical and professional education units in Brașov county $(49,4 \%)$ is below national average (54,5\%) and one of the lowest in Central Romania. In Brașov county, the number of students enrolled in highschools is constantly decreasing: in 2007 there were reported 20727 highschool students, as compared to only 17518 in 2014 (according to the data provided by the Ministry of National Education). While the decrease of the number of students in highschools is a consequence of the demographic decline, it is also an effect of the fact that preuniversity education is not properly fit to the local development trends. This is illustrated by the the increasing number of students who choose to attend technical and vocational schools.

\section{Objectives}

The educational campus in Brassov county has the general objective to create a pole of excellence for training and qualifying workforce for the most representative industry sectors in Central Romania.

The general objective will be made operational through several specific objectives, as follows: to build the infastructure of the vocational and technical campus; to recruit the teaching staff; to certify the training modules/qualifications; to organize internships/apprenticeships in various companies; to provide the specialists with career counseling services; to promote the educational campus and to position it as a regional pole of excelence in vocational and technical training.

\section{SWOT Analysis}

A SWOT analysis (Table 1) was prepared in order to identify the best options for creating the educational campus:

Table 1. SWOT Analysis for building a vocational and technical training campus in Brasov County

\begin{tabular}{|l|l|}
\hline \multicolumn{1}{|c|}{ Strengths } & \multicolumn{1}{c|}{$\begin{array}{c}\text { Weaknesses } \\
\text { - The industrial tradition of } \\
\text { Brașov County }\end{array}$} \\
- $\begin{array}{l}\text { High number of companies } \\
\text { (large companies and SMEs) }\end{array}$ & $\begin{array}{l}\text { Lack of experience in managing } \\
\text { a program of similar complexity, } \\
\text { with various activities } \\
\text { (construction and office }\end{array}$ \\
\hline
\end{tabular}




\begin{tabular}{|c|c|}
\hline $\begin{array}{l}\text { active in the industrial } \\
\text { production in Brașov county } \\
\text { - } \text { Interest of the Brașov County } \\
\text { Council for industrial } \\
\text { development } \\
\text { - } \quad \text { The attractiveness of county / } \\
\text { city of Braşov for potential } \\
\text { learners } \\
\text { - } \quad \text { Industrial parks and business } \\
\text { incubators } \\
\text { - Existing facilities which may be } \\
\text { subject to expansion and } \\
\text { modernization }\end{array}$ & $\begin{array}{l}\text { equipment, construction and } \\
\text { equipping workshops for } \\
\text { internship / apprenticeship } \\
\text { training, digital content for e- } \\
\text { learning, ongoing internship / } \\
\text { apprenticeship communication } \\
\text { and awareness) } \\
\text { - Limited financial resources in } \\
\text { public administration and } \\
\text { reduced availability of private } \\
\text { funding for such a long-term } \\
\text { investment }\end{array}$ \\
\hline $\begin{array}{l}\text { Opportunities } \\
\text { - } \\
\text { European policies, strategies and } \\
\text { qualified labour force, reducing } \\
\text { unemployment among young } \\
\text { people, supporting } \\
\text { disadvantaged groups etc. } \\
\text { - } \text { Harmonization of EU policies } \\
\text { and strategies and those existing } \\
\text { at a national level } \\
\text { The existence, in the Ministry of } \\
\text { National Education, of policies } \\
\text { to support vocational and } \\
\text { professional high schools } \\
\text { Structural Funds available for } \\
\text { this kind of program (creating / } \\
\text { upgrading educational } \\
\text { infrastructure, IT\&C } \\
\text { infrastructure and the creation of } \\
\text { digital content for e-learning, } \\
\text { training, internships and } \\
\text { apprenticeship, developing } \\
\text { infrastructure for SMEs to host } \\
\text { internships and apprenticeships); } \\
\text { Scalability: possibility of } \\
\text { extending the idea of creating a } \\
\text { vocational campus or steps to be } \\
\text { followed in other regions of the } \\
\text { country. }\end{array}$ & $\begin{array}{l}\text { Threats } \\
\text { - } \quad \text { Low popularity of vocational } \\
\text { and technical careers among } \\
\text { young people; } \\
\text { - } \quad \text { Workforce migration to more } \\
\text { developed countries (e.g. } \\
\text { Germany); } \\
\text { - The perception that the technical } \\
\text { education / vocational education } \\
\text { is a second-hand education } \\
\text { (perception among young } \\
\text { people, parents, employers); } \\
\text { - Few qualified trainers/teachers; } \\
\text { - Low involvement of companies } \\
\text { in the construction of the campus } \\
\text { workshops or hosting internships } \\
\text { / apprenticeships in their own } \\
\text { premises; } \\
\text { Co-funding and cash-flow for } \\
\text { EU-funded projects; } \\
\text { Excessive bureaucracy in the } \\
\text { implementation of publicly } \\
\text { funded projects; } \\
\text { Delays in the reimbursement of } \\
\text { expenses incurred in the project; } \\
\text { Social complexity of creating } \\
\text { campus vocational program } \\
\text { (different and interdependent } \\
\text { stakeholders - central and local } \\
\text { government, private } \\
\text { environment, schools, chamber } \\
\text { of commerce etc.) } \\
\text { Fluctuating regulatory } \\
\text { framework; } \\
\text { Identification of optimal legal } \\
\text { form of legal entity that will }\end{array}$ \\
\hline
\end{tabular}




\section{Key Phases}

The vocational and technical training campus is a complex program consisting of several projects - each with specific funding sources and timeframe for preparation and implementation. In what follows, we present both project ideas and potential funding sources for the construction and operation of the campus. It will be a complex program (Table 2) consisting of several integrated projects that can be financed from several sources of financing, such as:

Table 2. Program for building a vocational and technical training campus in Brasov County

\begin{tabular}{|c|c|}
\hline $\begin{array}{l}\text { Operational } \\
\text { Programme }\end{array}$ & Projects / specific actions \\
\hline \multirow{2}{*}{$\begin{array}{l}\text { Sectorial } \\
\text { Operational } \\
\text { Programme for } \\
\text { Economic } \\
\text { Competitiveness }\end{array}$} & $\begin{array}{l}\text { Building the IT campus infrastructure (computer labs, } \\
\text { networking, Internet connection) }\end{array}$ \\
\hline & $\begin{array}{l}\text { Creating the e-learning platform of the campus (acquisition and } \\
\text { tailoring of a professional platform for e-learning, development of } \\
\text { digital content, teacher training / platform users, the acquisition of } \\
\text { electronic resources for e-library) }\end{array}$ \\
\hline \multirow{3}{*}{$\begin{array}{l}\text { Sectorial } \\
\text { Operational } \\
\text { Programme } \\
\text { Human Capital }\end{array}$} & $\begin{array}{l}\text { Designing of the curricula and preparation of files for validation } \\
\text { of qualifications offered by the campus in accordance with the } \\
\text { National Qualifications Register (ANC) }\end{array}$ \\
\hline & $\begin{array}{l}\text { Realization of pilot training programs / qualifications for different } \\
\text { categories of the target group, especially for disadvantaged } \\
\text { groups (unemployed, especially young people looking for a job, } \\
\text { Roma people) }\end{array}$ \\
\hline & $\begin{array}{l}\text { Integration into the labour market: } \\
\text { - The development of apprenticeship programs. } \\
\text { - } \text { Counselling for socio-professional integration. } \\
\text { (teachers, trainers, administrative staff) } \\
\text { - Studies / analyses / forecasts made in Brașov county and } \\
\text { neighbouring counties on the evolution of the labour } \\
\text { market, the need for skills, training and retraining, skills } \\
\text { and emerging qualifications } \\
\text { - Funding internships and apprenticeships. }\end{array}$ \\
\hline $\begin{array}{l}\text { Regional } \\
\text { Operational } \\
\text { Programme }\end{array}$ & $\begin{array}{l}\text { Campus infrastructure - options: } \\
\text { - Identification of a vocational school that can be } \\
\text { rehabilitated / upgraded/redesigned. } \\
\text { - Building a greenfield campus, including workshops, } \\
\text { internships internship spaces and apprenticeship, } \\
\text { accommodation for students. }\end{array}$ \\
\hline
\end{tabular}


Partnering with SMEs relevant to the campus priorities.

Creating business incubators for graduates.

\section{Conclusions}

Romania has to enroll in the European race for competitiveness and reindustrialization. This requires two interrelated ingredients: a healthy industry and a properly trained workforce. According to the latest Country Report, "Romania has taken steps in addressing youth unemployment [...], but the high number of young people who are not in education, employment or training remains a challenge.” (2015, p. 61). Thus, one of Romania's priorities should be to create the proper grounds for educating a qualified work force fit for the needs of today's and tomorrow's society. This would translate not only into economic development, but also into social well-being. Our case study is intended to help accelerate such a positive evolution. Braşov County holds an important stake in the development of the Romanian industry and could constitute a good starting point for improving Romania's economic performance. It could also constitute a best practice for other emerging regions, which would be able to reach their full potential by expanding education opportunities and, consequently, providing feasible career paths for youth.

\section{References}

Adelman, I. (1999). Fallacies in Development Theory and Their Implications for Policy, CUDARE Working Paper Series nr. 887, University of California at Berkeley, Department of Agricultural and Resource Economics and Policy.

Marquand, D. (2011). The End of the West. The Once and Future Europe. UK: Princeton University Press.

European Commission. (2015). Country Report Romania 2015 Including an In-Depth Review on the prevention and correction of macroeconomic imbalances. Retrieved from http://ec.europa.eu/europe2020/pdf/csr2015/cr2015_romania_en.pdf on 2015 April 12.

European Commission. (2010). Europe 2020. Retrieved from http://eurlex.europa.eu/LexUriServ/LexUriServ.do?uri=COM:2010:2020:FIN:RO:PDF on 2015 April 21.

Piketty, T. (2014). Capital in the Twenty-First Century, Harvard: Harvard University Press.

Stiglitz, J. (1998). Towards a New Paradigm for Development: Strategies, Policies and Processes. Lecture given as the 1998 Prebisch Lecture at UNCTAD, Geneva, October 19. 


\title{
The surveys: nexus between industry and academia
}

\author{
J. Fernández, M. Cruells, N. Escaja, J.A. Garrido, J. Giménez, M. Llauradó, A. Roca, L. \\ Rodríguez, M.Ll. Sagristà, C. Navarro, J.O. Bernad, C. Escobar, N. López \\ Quality Committee, Faculty of Chemistry. Universitat de Barcelona. \\ C/ Martí i Franquès, 1. 08028 Barcelona. Spain. \\ Phone+34934021776. E-mail: javier.fernandez@ub.edu
}

\begin{abstract}
Analysis and improvement processes are key aspects in any quality management system and they have to be applied on the quality management systems that have all degrees currently taught at Spanish Universities. In this way, surveys can be an important tool. For this reason, the Faculty of Chemistry of the Universitat de Barcelona prepared a survey for chemical and pharmaceutical companies to identify the type of training that is required for students. The survey has questions related to the laboratory operations, chemical processes, calculation methods, management systems of quality, environment and safety, general management information, etc. The items are related to the formation given to the students in the Faculty. The scores obtained (minimum 1, maximum 4) are between 2 and 3 in all the items, both the required knowledge as to the skills demonstrated by students. This means a good agreement between the formation achieved by the students and the expectations of the industries. However, these results also show that the training of students can still be improved.
\end{abstract}

Keywords: Surveys; Skills; Quality management; Continuous improvement

\section{Introduction}

As is known, all spanish degrees should have implemented a quality management system (Real Decreto 1393/2007; Real Decreto 861/2010). Therefore, this is the case of the Faculty of Chemistry of the Universitat de Barcelona, which has implemented a quality management system (QMS) for the three degrees taught: Chemistry, Chemical Engineering and Materials Engineering.

Within any QMS, one of the basic tools are the processes of analysis and improvement (Companyó and Ríos, 2002), which are the key element to detect possible weaknesses in the system and, from there, the necessary corrections can be made to modify the defective items, into the process of continuous improvement. Corrective and preventive actions, audits, indicators and surveys are among the tools of analysis and improvement processes.

The Quality Committee of the Faculty of Chemistry is working for several years in the improvement of the quality of laboratories teaching in degrees developed in the Faculty. In their tasks the students have a high volume of purely experimental subjects or combined with theory. In this case one of the main tasks is to obtain the best training process in laboratories in the corresponding studies.

In this way and even before the implementation of new degrees, in 2007, taking advantage of the passage from the old to new degrees according to Bologna, the Quality Committee (QC) of the Faculty of Chemistry of the Universitat de Barcelona conducted a survey. This survey was sent to chemistry and pharmaceutical industries to know what the companies expect of new graduates. The survey was very successful and valuable conclusions were obtained for the development of students curricula in the new degrees (Companyó et al. 2008; Sainz et al. 2008). In relation to the work in the laboratory, the opinion of people from the companies was very varied regarding the utility that the work in laboratories can have in the development of the professional activity, and this opinion was related with the sector of activity typical of each company. Additionally, 
there was a high unanimity in relation to the need that the students have knowledge on management of the information and of the chemical documentation, management of the quality, environmental and safety, planning of the work and management of the time. The information facilitated by the companies through the survey was very useful in the design and application of the new degrees of the Faculty of Chemistry: Chemistry, Chemical Engineering and Engineering of Materials.

As an example, in the degree of Chemistry a course on Quality and Prevention has introduced, the subject of Chemical Documentation has promoted, and also has been included a specific section on safety, quality and environmental management in the presentation of any experimental subject. It has also incorporated a subject on Project Management to perform before or during the development of the degree final work. In surveys carried out to the students at the end of each stay in laboratories, in addition to matters related to the topic of the subject itself, other aspects of safety, environment and quality work performed are asked to them.

In the same way, and given the restructuring that seems looming again in degrees, from the QC, and seven years later (2014), it has been decided to prepare a new survey for companies to see again what the state of the art is regarding the knowledge and skills that should have future graduates in chemistry, chemical engineering and materials engineering. The survey has been passed to companies of different types in the chemical and pharmaceutical sector industry and, in this work, a summary of the main results obtained is shown.

\section{Results and Discussion}

\section{Results of the survey}

Survey was addressed to the following sector companies: Basic Chemistry, 30\%; Chemistry of Health, Animal and Vegetal, 33,3\%; Chemistry for Industry and Final Consumption, 36,7\%. Figure 1 shows the distribution of the companies classified with respect to the number of workers.

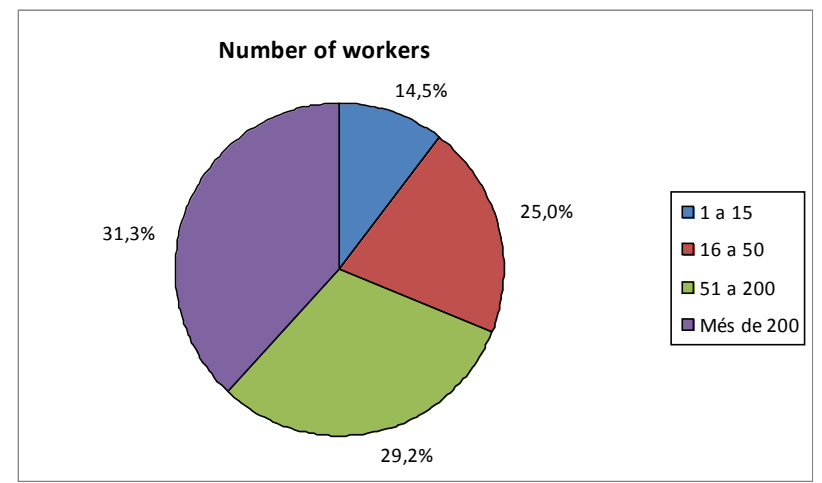

Figure 1. Percentage of companies, based on the number of workers.

Nine sections form the survey: 1) Laboratory operations (3 items). 2) Measurement and characterization techniques (10 items). 3) Chemical processes: pilot plant and industry (6 items). 4) Calculation methods and data processing (5 items). 5) Management of information and documentation (6 items). 6) Quality management (8 items). 7) 
Environmental management (5 items). 8) Safety and health (5 items). 9) Other (3 items): basic knowledge on economy, work planning, time management.

At the end of each section, the survey's respondents can evaluate the level of competences that graduates are on the subjects concerning this section.

Each question was evaluated between 1 and 4, with the following score: 1, not important; 2, unimportant; 3, important; 4, very important.

The average scores obtained in each item were the following:

- 1) Laboratory operations: 2.88

- 2) Measurement and characterization techniques: 2.33

- 3) Chemical processes: pilot plant and industry: 2.51

- 4) Calculation methods and data processing: 2.57

- 5) Management of information and documentation: 3.11

- 6) Quality management: 3.11

- 7) Environmental management: 2.53

- 8) Safety and health: 3.17

- Other (basic knowledge on economy, work planning, time management): 2.86.

As it can be observed, all the sections of the survey have been evaluated between 2 and 3. However, the aspects related to management (information, documentation, safety, quality, time, etc.) seem to be more important for industries.

An important data to be considered is the evaluation of the competences that graduates have in each section. This evaluation is made also by the industries. Results are shown in Figure 2. The sections appearing in the figure are the same indicated in the last paragraph. Results are all them between 2 and 3 showing that graduates can usually meet the expectations of companies.

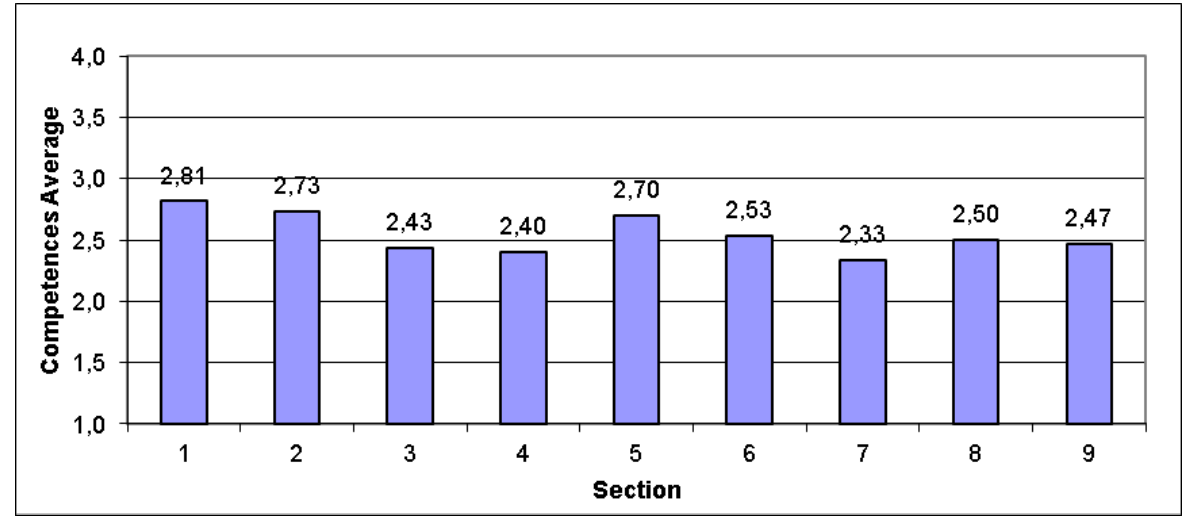

Figure 2. Competences showed by the graduates in each item.

\section{Some remarks}

It is not easy to make an overall assessment of the survey results, because companies answering the survey represent diverse activities, and therefore with very different interests. Moreover, the sections of the survey also covered quite different capacities 
on several levels. However, as commented before, the survey revealed that companies are very interested in that future professionals be fluent in skills related to management of information, quality management, environmental management, safety, work planning and time management. These results are not surprising, because all these issues are, today, of great interest to the industry and, most particularly, for the chemical industry.

For instance, concerning the results obtained in section 5 of the survey, sometimes it is not easy to find a structured documentation on a given subject. Hence companies valued to have people prepared in the management of information, who can go quickly and certainty to the most appropriate sources of information, finding the elements needed to develop the task has been entrusted to them.

Referring to the analysis of results and in the fields of chemistry, chemical engineering and materials engineering, companies need people with a critical view. Thus, they can well interpret the data from production or from the departments of research and development. This is a key step to decide on changes or improvements in production processes that lead to obtaining a higher quality product or raw material savings.

Currently, the quality management is a concern and a goal for companies. Thus, it is not surprising that items related to section 6 of the survey (quality management) are highly evaluated by the polled companies. Obviously, the implementation of a quality management system assures an improvement in production and guarantees the quality of the final product and, moreover, gives to the companies a distinctive and positive marketing element relative to industry peers. It is therefore clear that companies assess positively our students aware of these issues.

Section related to safety (section 8) is also very considered by industries. The reasons are obvious, because they are companies related to the chemical industry and, therefore, they use potentially dangerous substances and work in conditions that can also involve certain risks: high temperature, high pressure, etc. In addition, laws are very restrictive for this industry. In addition, safety is clearly also an issue for the future since it is expected that the regulations in this regard will be increasingly restrictive and, therefore, companies are increasingly forced into depth on these issues.

Finally, companies are very interested in work planning and time management (section 9 of the survey). These last two issues go well linked and are vital for good job performance. In addition, current degrees are focussed on the student's work. Thus, all the competences related to the improving of work planning and time use have to be strengthened.

\section{Improving our degrees from surveys results}

After the first survey (2007) when the new degrees were introduced in our Faculty, some actions were taken according to the companies answers. Thus a course on Quality and Prevention was introduced in the new degree on Chemistry. Concerning the degree on Chemical Engineering, the course related to industrial safety and health was maintained. In addition, in the courses on laboratory training, the aspects related to quality and safety were widely remarked.

It seems that these actions had a positive impact on the students training and, according to the companies' answers, the competences showed by the graduates are satisfactory, as shown in Figure 2. As commented before, the scores for all questions are between 2 and 3 . Thus, the task made seems to give positive results. 
However, we still have further to go in these aspects and more work is needed, including the awareness task of professors on the importance of these subjects. It has to be said that this is not an easy task and efforts have to be made in this way.

Obviously, all needs of the companies cannot be satisfied but these ones considered reasonably interesting for the students training have to be fulfilled as possible. As commented before, some subjects are considered as minor subjects for part of professors and this means an added obstacle

Looking to the future, the new Spanish legislation (Real Decreto 43/2015) opens the possibility to new degrees. Thus, it can be again other opportunity to introduce in a more large extension the items considered important by the industries, if possible.

In any case, this contact university - companies seems a very interesting way for the improvement of the students training and for the updating and adjustment of degrees to the necessities and requests of industries.

Summarizing, it should also be noted that the survey highlights the need for students to acquire skills and competences in the subjects mentioned above. Therefore, it stresses the idea that students have to acquire knowledge but they have also to be able to assimilate and apply. As it is well known, this has been a turning point in the degrees, which have to ensure that students acquire a range of skills and abilities necessary for further professional activity.

\section{Conclusions}

Surveys have proven to be a good tool for getting feedback from companies. From surveys, it is possible to know what is the knowledge, abilities, skills and competences that companies demand to the graduates. In our degrees these results are taken into account and applied in a continuous improvement of the degrees of Chemistry, Chemical Engineering and Materials Engineering.

\section{References}

Compañó, R. \& Ríos, A. (2002). Garantía de la calidad en los laboratorios analíticos. Madrid: Síntesis.

Companyó, R., Cruells, M., Garrido, J.A., Giménez, J., Granell, J., Llauradó, M., Mallol, J., Navarro, C., Pérez, I., Sainz, D., Urpí, F., Vallés, A., Bernad J.O. \& A. Prades, A. (2008). Las encuestas a las empresas: una fuente de información en el desarrollo de las competencias de los estudiantes. El cambio en la cultura docente universitaria - Contenidos de las conferencias y comunicaciones del V CIDUI, (formato electrónico). ISBN: 978-84-8458-286-1. Lleida.

Real Decreto 1393/2007, de 29 de octubre, por el que se establece la ordenación de las enseñanzas universitarias oficiales.

Real Decreto 861/2010, de 2 de julio, por el que se modifica el Real Decreto 1393/2007, de 29 de octubre, por el que se establece la ordenación de las enseñanzas universitarias oficiales.

Real Decreto 43/2015, de 2 de febrero, por el que se modifica el Real Decreto 1393/2007, de 29 de octubre, por el que se establece la ordenación de las 
enseñanzas universitarias oficiales, y el Real Decreto 99/2011, de 28 de enero, por el que se regulan las enseñanzas oficiales de doctorado.

Sainz, D., Companyó, R., Cruells, M., Garrido, J.A., Giménez, J., Granell, J., Llauradó, M., Mallol, J., Navarro, C., Pérez, I., Urpí F. \& Prades, A. (2008). La opinión de las empresas sobre la enseñanza práctica: una fuente de información en el desarrollo de las competencias de los estudiantes. Libro de Actas de la III Reunión de Innovación Docente en Química (INDOQUIM 2008). p. 181-182. ISBN: 97884-9828-204-7. D.L.: CA 203/08. Cádiz: Servicio de Publicaciones de la UCA. 


\title{
University volunteering. The UJI-Voluntària programme at the Universitat Jaume I
}

\author{
Lázaro Guillamón, C., García Renedo, M., \& Valero Valero, M. \\ Office for Development Cooperation and Solidarity (OCDS). \\ Universitat Jaume I (Castelló, Spain)
}

\begin{abstract}
Modern society encourages the development of values like solidarity, social commitment, altruistic actions and the establishment of social support networks. These values have been transferred to the university curriculum and students appear increasingly interested in carrying out volunteering activities. Specifically, the Universitat Jaume I in Castelló implements the UJI-Voluntària Programme, which has different areas of action aimed at offering members of the university community the chance to take an active part in achieving a fairer society and helping the people or groups in greatest need. We carried out a study for which we had a sample consisting of 62 students. We applied a Likert-type scale to analyse their satisfaction with the volunteering programme and their motivation for taking part in it. We found that the vast majority were women and second-year students. As for their motivation, the majority indicate their desire to help other people, followed by a desire to learn, and personal satisfaction. Finally, in relation to student satisfaction, the majority were satisfied with the running and development of the programme.
\end{abstract}

Keywords: Volunteering, university, motivation, programme, profile, solidarity

\section{Introduction}

Spanish universities are committed to transmitting values for the education of active, responsible citizens, committed to society. That makes volunteering a fundamental tool for bringing the university closer to society (Arias, 2008).

The aim of this paper is to present the way university volunteering is run at the Universitat Jaume I, via the UJI-Voluntària programme. In addition, the students' level of satisfaction with the programme will be presented, along with the profile of the gender and motivation for joining the programme of a typical volunteer.

\section{University volunteering}

Spanish universities began activities aimed at complying with their function as socially committed agents in society some years ago. As Arias (2008) pointed out: "A university can and must build attitudes, values and habits to be adopted as a way of life."

The Universities Act 6/2001, dated 21 December (BOE 24/12/2001), amended by Act 4/2007, dated 12 April, (BOE 13/04/2007), both in its preamble and its articles, establishes that "Universities will encourage the participation of members of the university community in international cooperation and solidarity activities and projects."

In order to unify and identify the lines of work carried out by universities concerning volunteering, the Conference of Rectors of Spanish Universities (CRUE) approved the document:

University: Social Commitment and Volunteering (2001). It describes the aims and lines of action by universities in support of volunteering activities. With the appearance of this document, universities were given a leading role in the promotion of volunteering and in putting strategies in place to allow them to contribute to building a fairer society through volunteering. 
We would like to make it clear, as Lázaro and Escribano (2009) have already highlighted, that universities are not Non-Governmental Organisations for Development (NGODs) or volunteer organisations. University volunteering has its own features which we will mention in the paper.

\section{The UJI-Voluntària programme at the Universitat Jaume I}

As a scientific and academic institution as well as a social agent, the Universitat Jaume I in Castelló is deeply interested in contributing to the development of the social sectors in greatest need and promoting committed, modern citizens. As part of assuming this responsibility, since 2010, the Universitat Jaume I has had the UJI-Voluntària programme. This programme is run by the Office for Cooperation for Development and Solidarity (OCDS) of the Office of the Vice-Rector for Internationalization, Cooperation and Multilingualism of the Universitat Jaume I. The programme is aimed at the whole university community (students, teaching and research staff and administrative and services staff). The aims pursued by the programme are:

- To involve the university community in social action activities.

- For the university to take part in achieving values that make society fairer.

- To highlight and teach the value of public participation.

- To stimulate reflection and critical thought about the problems affecting societies.

The following programmes are currently running:

- Helping students with special educational needs

- School support and integration

- Support for elderly and dependent people

- Volunteering at the Psychosocial Observatory of Resources in Disaster Situations (OPSIDE)

- Volunteering at the Permanent Observatory on Immigration (OPI-UJI)

- Volunteering in sport

- Environmental volunteering

- Showing the University programme

- Support to NGOs

- Language volunteering

- MENTOR programme

- Volunteering in Europe and other countries

- Volunteering for the prevention of violence

- Solidarity flats

- Ambassador programme

Each of these programmes includes different associations with which volunteers can volunteer.

\section{Operation of the programme}

To sign up and obtain information on the programme, the university community goes to the Office of Cooperation for Development and Solidarity (OCDS). The OCDS informs them about the existing programmes and they can consult a guide providing information including the description of all the programmes, the associations where they will do their volunteering and the activities they will carry out. If they are still interested, they fill in an application form. After this is analysed, and depending on their 
interests, the information is sent to the relevant association. The associations then contact the volunteers. When volunteers join, they sign an incorporation agreement and receive basic training (what it means to be a volunteer, rights, duties, etc.) given by the OCDS and specific training, which depends on the association. When the programme is complete, they are issued with certificates showing the hours they have worked and the equivalent credits for participation in solidarity activities. Before the certificate is presented, volunteers have to fill in an evaluation sheet.

\section{Volunteer satisfaction and profile}

In order to find out about the profile of the volunteers forming part of the UJIVoluntària programme and their level of satisfaction, we carried out a descriptive study, shown below.

\section{Sample}

The sample consists of 62 students on courses at the Universitat Jaume I in the academic year 2012-2013 who took part in the UJI-Voluntària Programme.

\section{Procedure}

At the end of the academic year, the students who took part in the programme filled in a questionnaire evaluating the experience. The questionnaire showed the students' personal details, their motivation for volunteering and their level of satisfaction with the programme. The evaluation scale was the Likert type (1 representing very unsatisfied and 5 completely satisfied).

\section{Data analysis}

The data was analysed descriptively using the SPSS (Statistical Package for Social Sciences) statistical program.

\section{Results}

Figure 1 shows results disaggregated by gender:

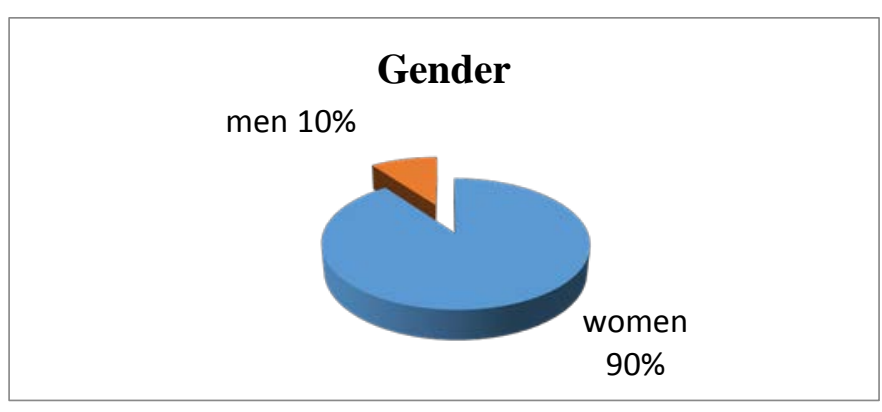

Figure 1. Gender of people participating in UJI-Voluntària

As shown in Figure 1, the vast majority of students who participate in UJI-Voluntària programme are women (90\%).

Figure 2 shows the specific academic year that is being attended by participant students. 


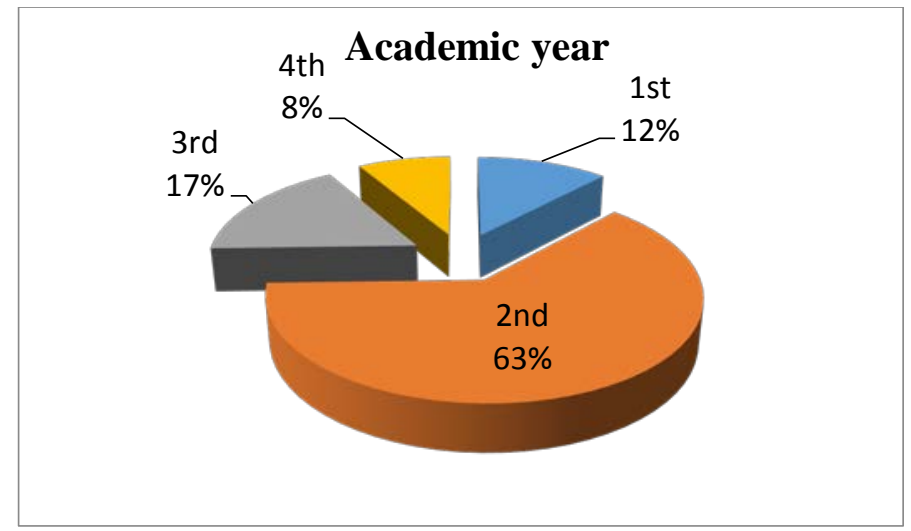

Figure 2. Students' academic year.

Most of the students who participated in UJI-Voluntària programme were attending 2nd year. Figure 3 shows the reasons that encourage students to undertake voluntary action.

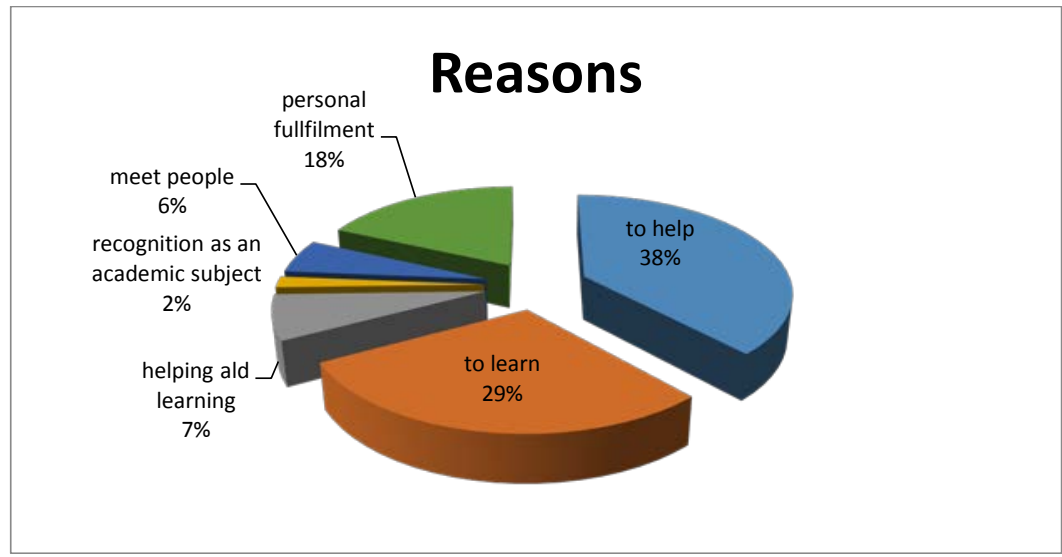

Figure 3. Students’ reasons to take part in UJI-Voluntària

With regard to the motivations/reasons the survey results stands out, as stated the study of Yubero and Larrañaga (2002), that the two main motivations/reasons that encourange students to take part of a university volunteer programme is helping and receive training, skills and abilities.

Finally, Figure 4 shows the assessment of UJI-Voluntària made by volunteers.

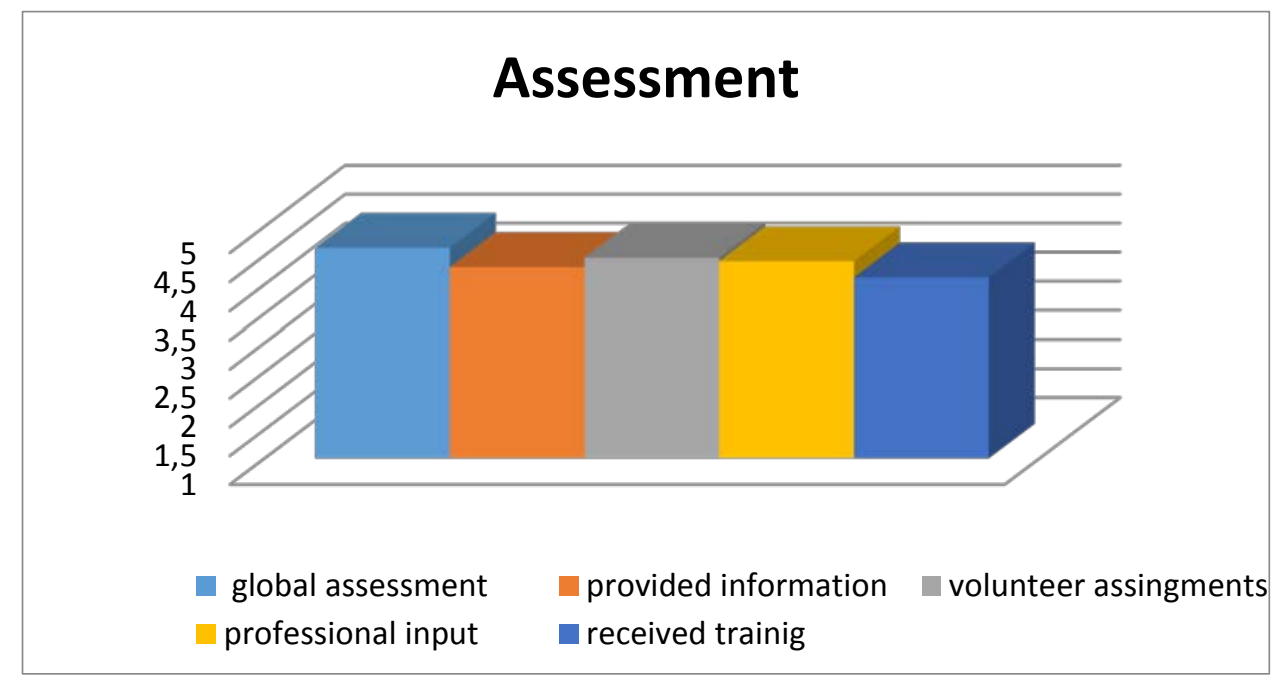

Figure 4. UJI-Voluntària assessment 
Broadly we found that students make a very positive assessment of the program. All ratings are above 4 . They are very satisfied with the training they have received, the information received, the contribution of the programme in the acquisition of professional knowledge and skills and the tasks that have been made as part of the volunteering program.

\section{Conclusions}

University volunteering is currently increasing and the sector is becoming stronger. At the Universitat Jaume I, as part of the UJI-Voluntària programme, we find that the profile of a typical volunteer corresponds to a female higher-level student.

The results of the study carried out on the motivation of students participating in UJIVoluntària show that the volunteers do provide disinterested help to other people, institutions and organizations because, although they can obtain optional credits for volunteering activity, the vast majority are largely motivated by a desire to help, followed by an interest in learning from the experience. This could result in better performance when students complete their studies and join the job market with a greater capacity for teamwork and cooperation.

At the same time, volunteering also allows students to confront and discover social problems different to their own, as well as other realities, other groups of the population and communities with diverse characteristics. This contributes towards the acceptance and development of tolerance towards other cultures, as well as the recognition of difference and personal dignity.

University volunteering contributes towards providing students with conflict resolution strategies and increased personal autonomy for solving problems.

As a result, students participating in voluntary activities also develop greater competence in social skills and they learn to take responsibility, putting other people's wishes and needs before their own, with which they acquire and maintain social commitment.

Ultimately, university volunteering brings the university as an institution closer to society and improves its involvement in the community. It also contributes to the complete education of people and promotes the awareness of participatory citizenship that will contribute to strengthening the social fabric through the transformative social action of university volunteers.

\section{References}

Arias, S (2008). Voluntariado Universitario. Guía para su gestión en las universidades madrileñas. Madrid: Dirección General de Voluntariado y Promoción Social.

CRUE (2000). Estrategia de Cooperación Universitaria al Desarrollo.

CRUE (2001). Universidad: Compromiso Social y Voluntariado.

CRUE (2006). Código de Conducta de las universidades españolas en materia de cooperación al desarrollo.

CRUE (2006). Protocolo de actuación de las universidades frente a situaciones de crisis humanitarias. 
Lázaro, C y Escribano, P (2009). Training for University Volunteers. A step foward in higher education for development. Proceedings of EDULARSN09 Conference. $6^{\text {th }}$ $8^{\text {th }}$ July, 2009. Bacelona: Spain.

Ley Orgánica 4/2007, de 12 de abril, por la que se modifica la Ley Orgánica 6/2001, de 21 de diciembre, de Universidades. (B.O.E. 13/04/2007)

Ley Orgánica 6/2001, de 21 de diciembre, de Universidades (BOE. 24/12/2001)

Ley 6/1996, de 15 de enero, de voluntariado. (BOE de 17/01/1996)

Real Decreto 1393/2007, de 29 de octubre, por el que se establece la ordenación de las enseñanzas universitarias oficiales. (BOE 30/10/2007).

Yubero, S y Llarrañaga, E. (2002). Concepción del voluntariado desde la perspectiva motivacional: conducta de ayuda \& altruismo. Pedagogía Social. Revista Interuniversitaria, 9, 27-39. 